Concordia University St. Paul DigitalCommons@CSP

$10-1-2021$

\title{
1. Northeast Insulae Project: Context and Analysis
}

Mark Schuler

Concordia University, St. Paul, mark.schuler@csp.edu

Follow this and additional works at: https://digitalcommons.csp.edu/nip-final

Part of the Ancient History, Greek and Roman through Late Antiquity Commons, Classical Archaeology and Art History Commons, Historic Preservation and Conservation Commons, and the History of Christianity Commons

\section{Recommended Citation}

Schuler, Mark, "1. Northeast Insulae Project: Context and Analysis" (2021). The Final Report. 1. https://digitalcommons.csp.edu/nip-final/1

This Book is brought to you for free and open access by the Northeast Insula Project at DigitalCommons@CSP. It has been accepted for inclusion in The Final Report by an authorized administrator of DigitalCommons@CSP. For more information, please contact digitalcommons@csp.edu. 


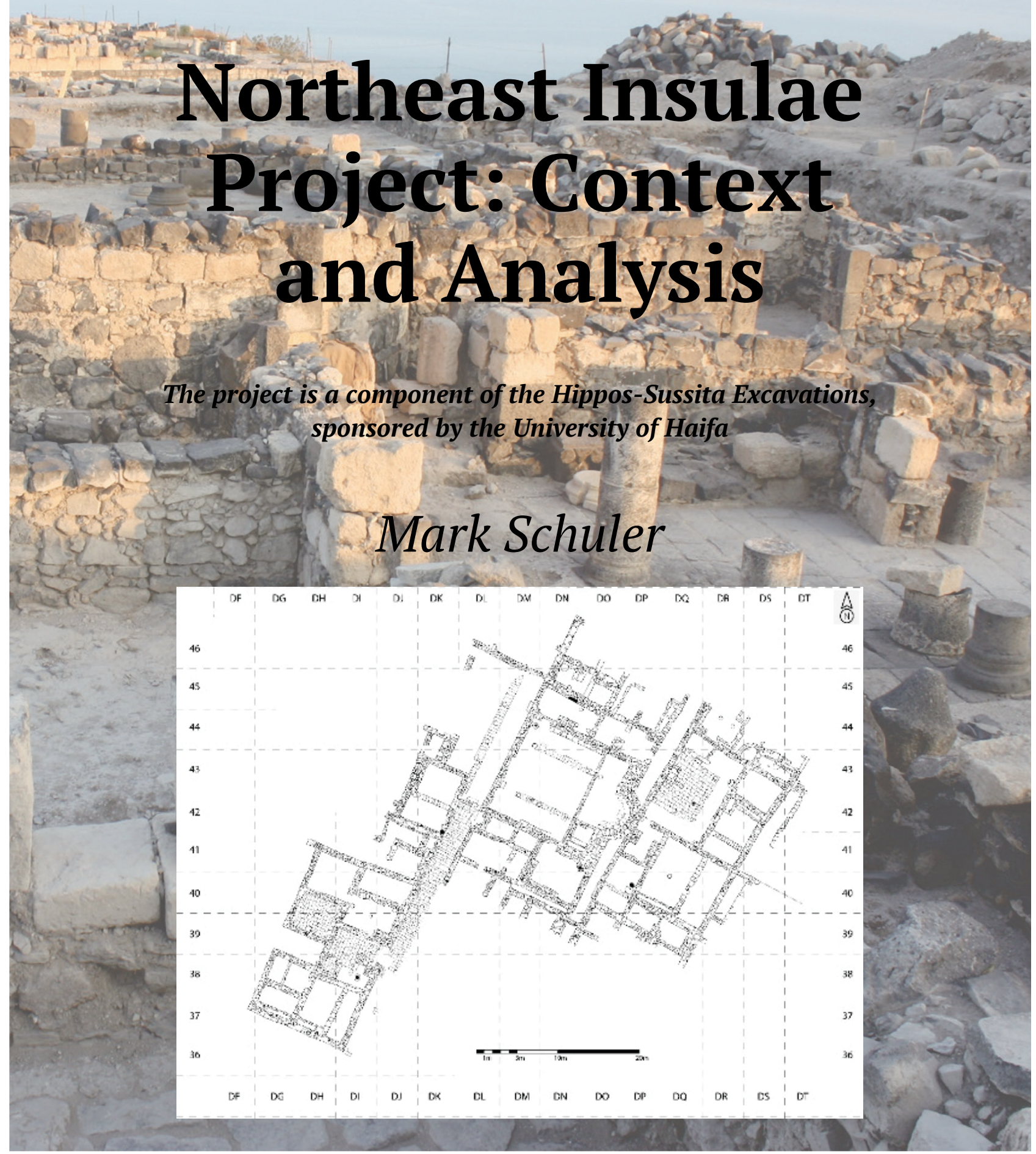



Northeast Insulae Project: Context and Analysis

C O P Y R I G H T

This work is licensed under a C C B Y-NC-ND 4.0 license.

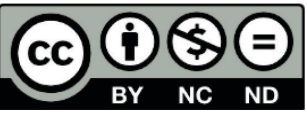

This license allows reusers to copy and distribute the material in any medium or format in unadapted form only, for noncommercial purposes only, and only so long as attribution is given to the creator.

https://creativecommons.org/licenses/by-nc-nd/4.0/

Requests for information should be addressed to:

Professor Mark Schuler

Concordia University

1282 Concordia Avenue

Saint Paul, MN 55104

\section{Published at:}

Concordia University, Saint Paul, Minnesota, USA

First Edition, 2021 



\section{TABLE OF CONTENTS}

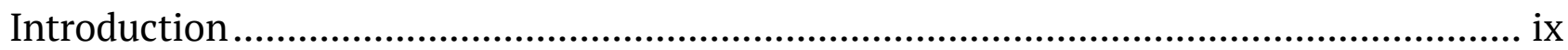

A word of thanks for volunteers ................................................................................... ix

A 16-year partnership ........................................................................................................

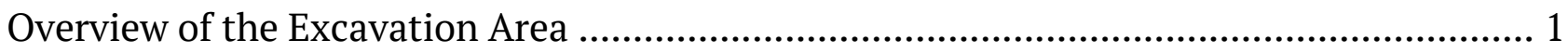

Late Antique Christianity at Hippos Palaistinēs ................................................................. 5

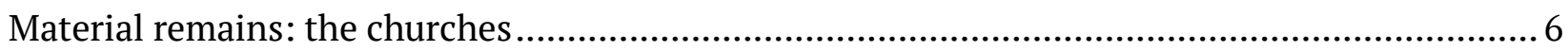

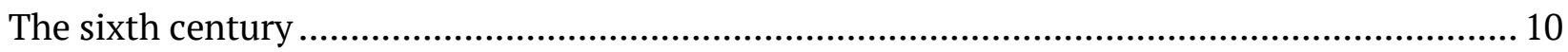

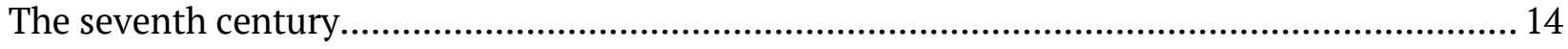

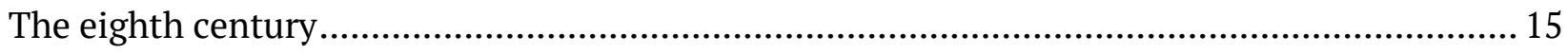

An Archaeological Description of the Northeast Insulae …............................................19

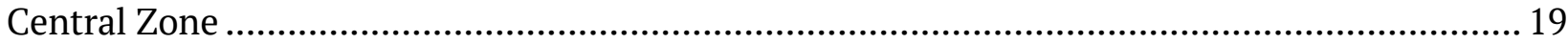

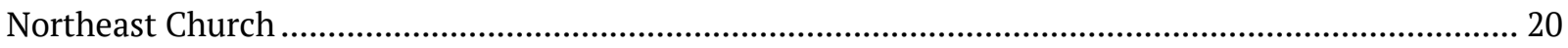

North of the domus ………………………………………………………………………... 42

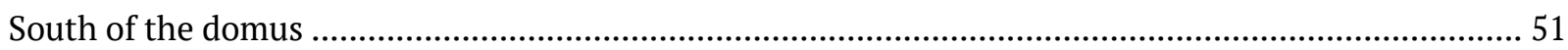

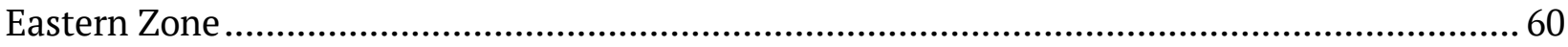

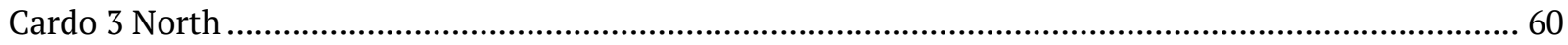

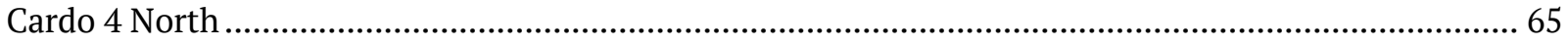

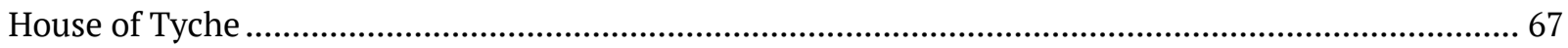

Structures built over the southern section of the House of Tyche........................................................ 102

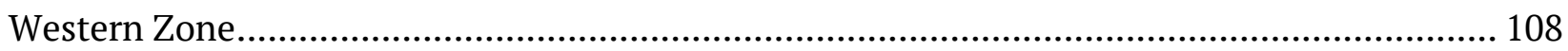

Via sacra and paved plaza ………………………………………………………………... 108

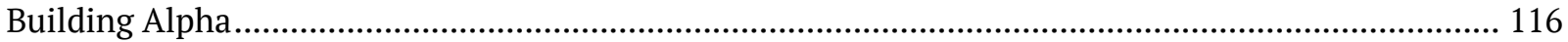

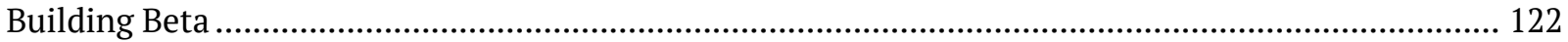

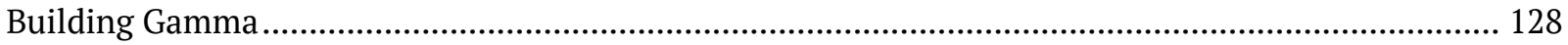

Remnants of Building Delta ......................................................................................................... 135

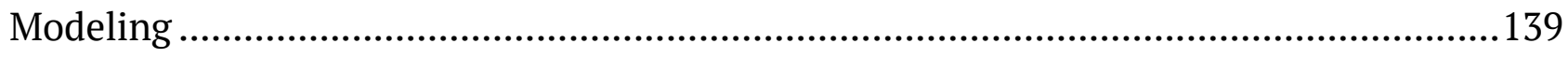

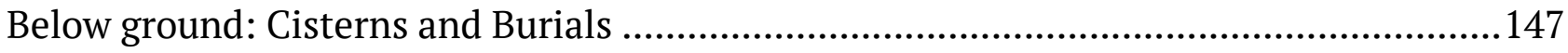

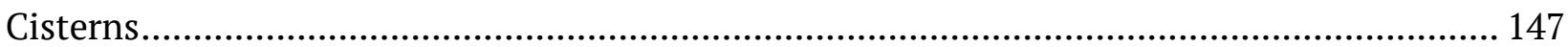

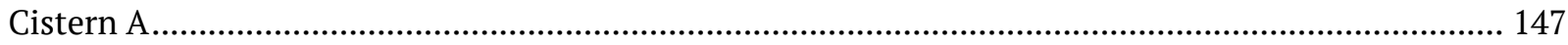

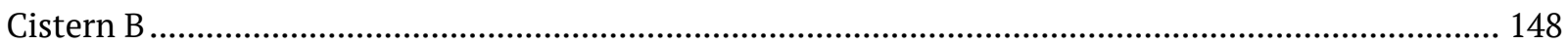

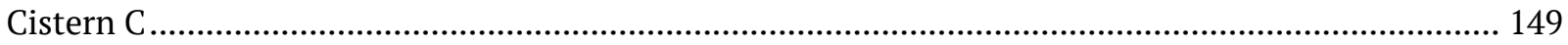

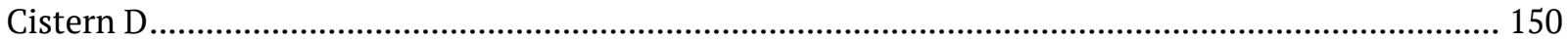

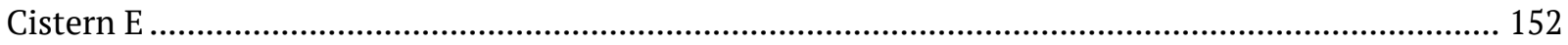

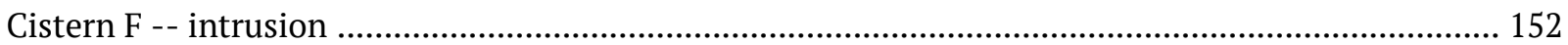

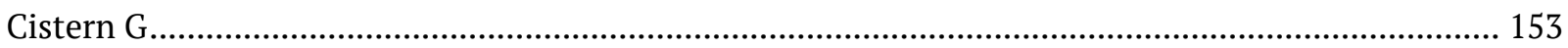

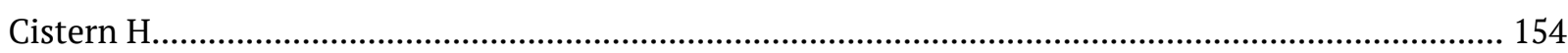

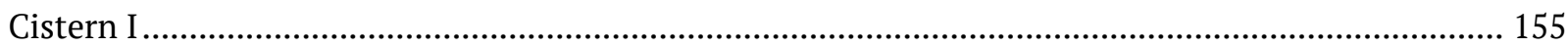

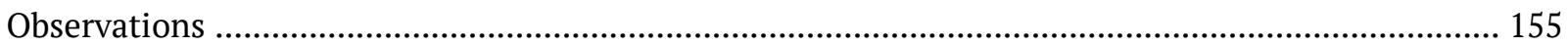




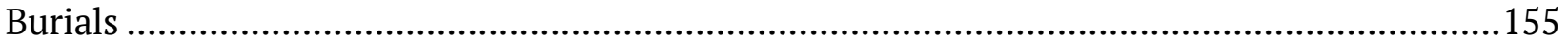

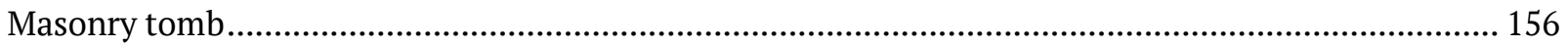

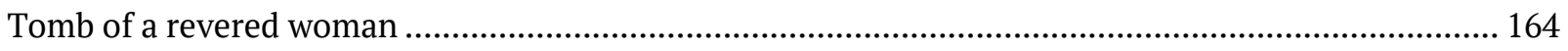

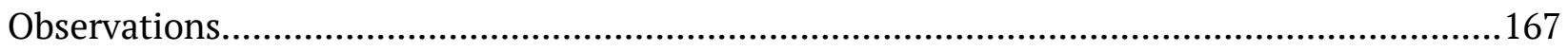

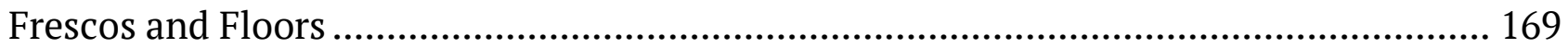

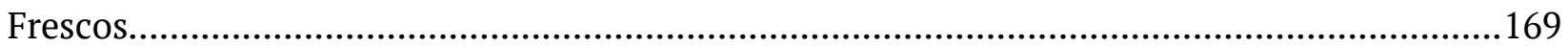

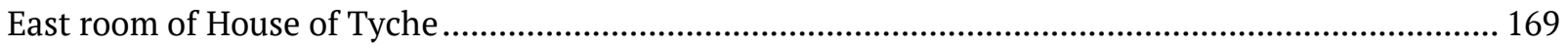

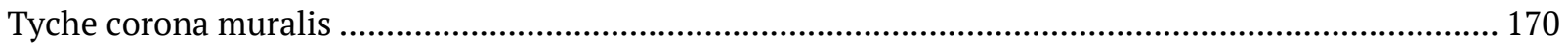

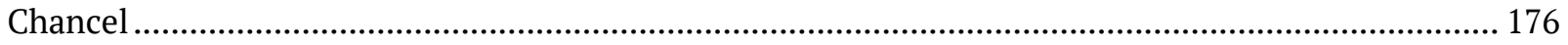

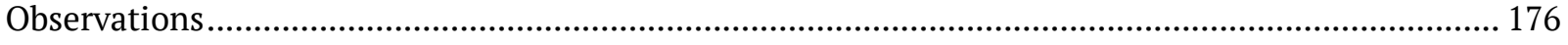

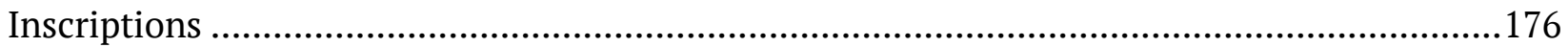

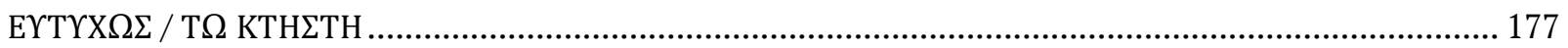

ЕІ

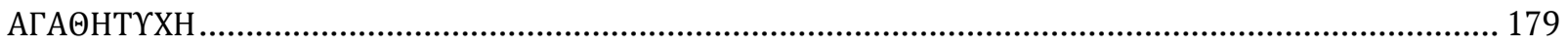

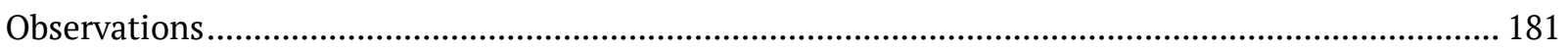

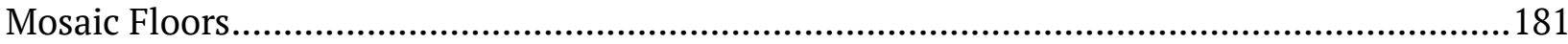

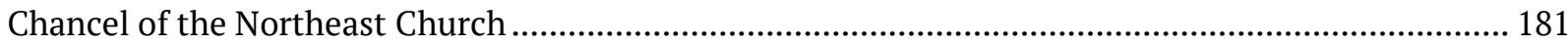

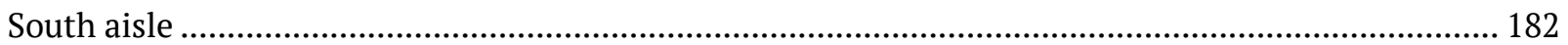

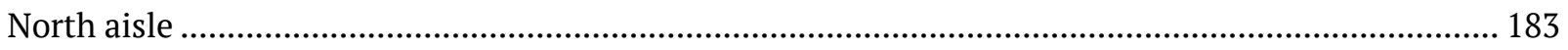

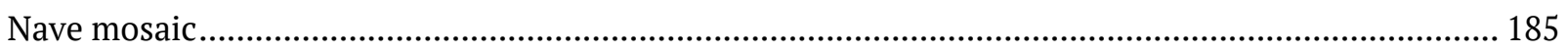

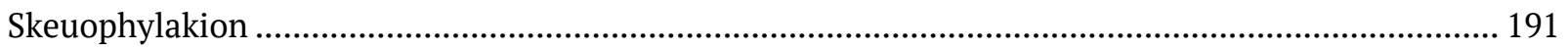

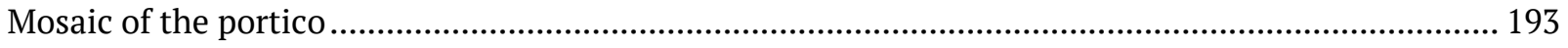

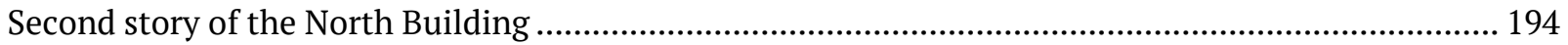

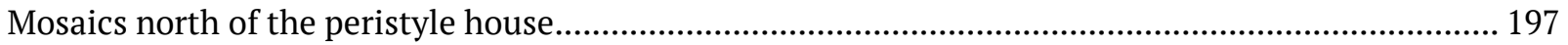

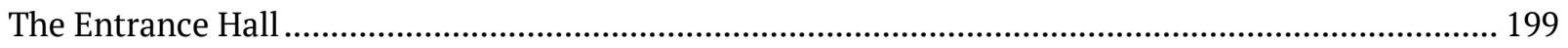

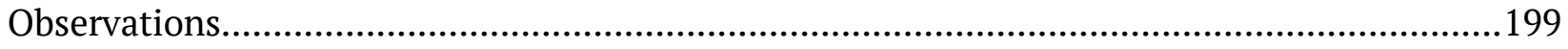

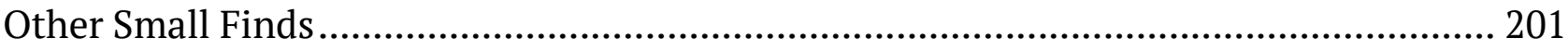

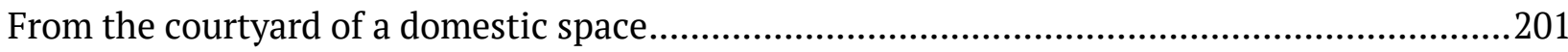

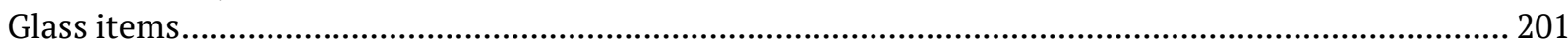

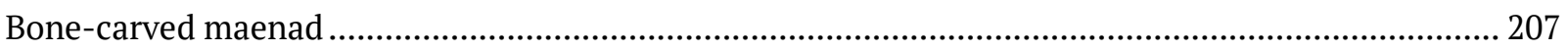

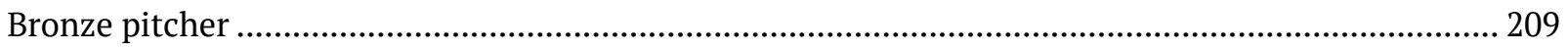

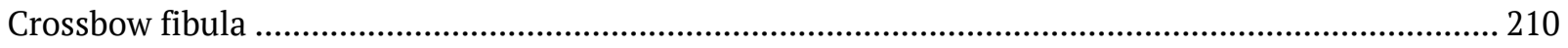

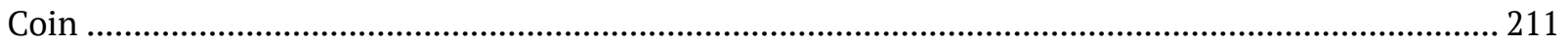

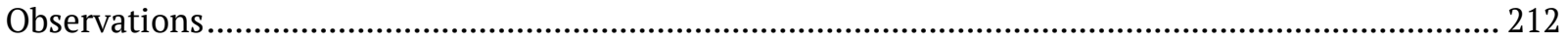

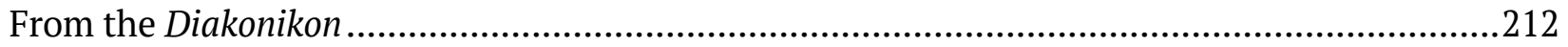

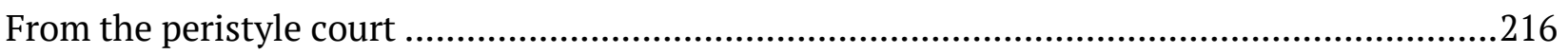

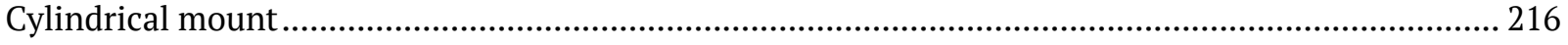

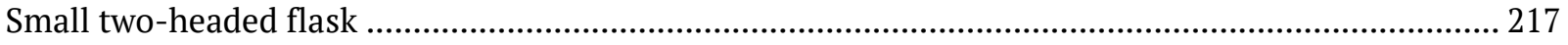

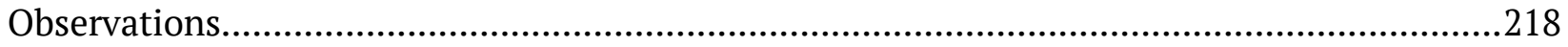

Flax Basins...................................................................................... 219

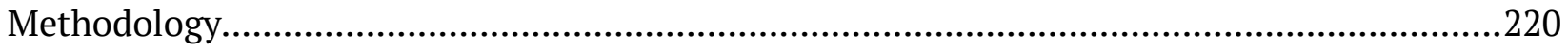




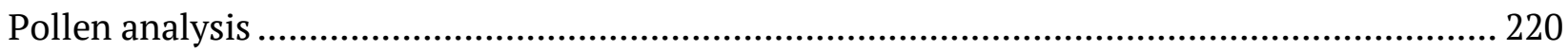

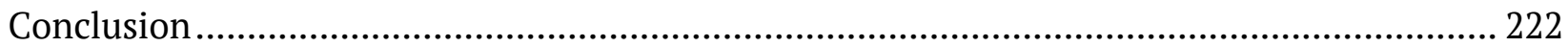

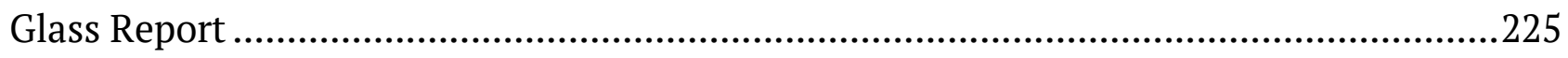

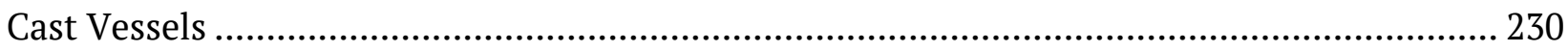

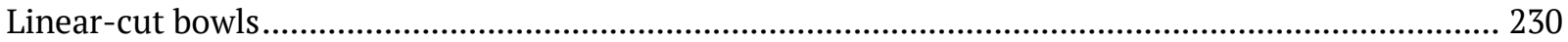

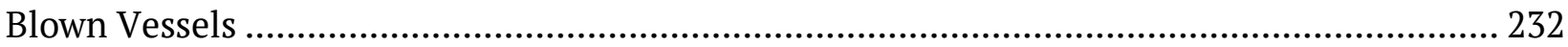

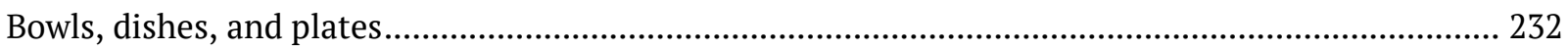

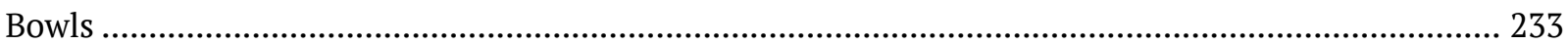

Ring-type bases from bowls or dishes ...................................................................................... 238

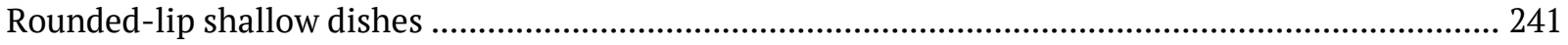

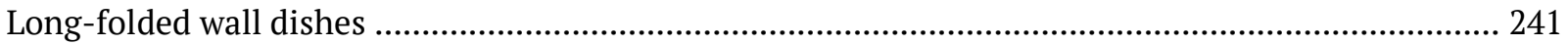

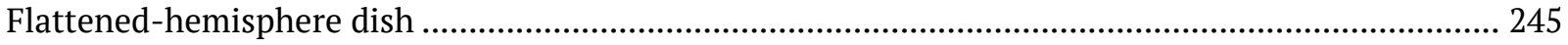

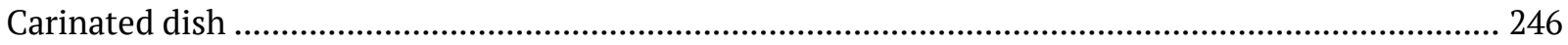

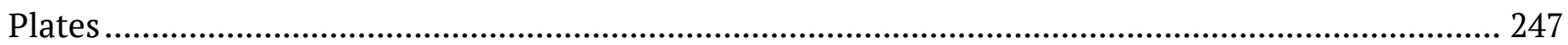

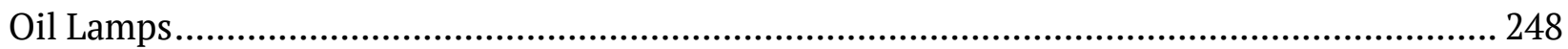

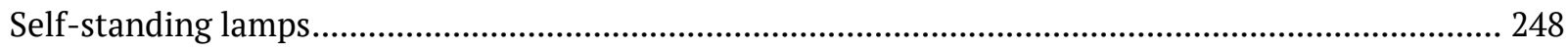

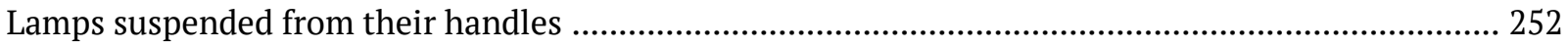

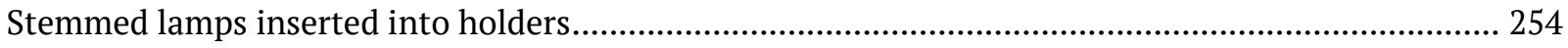

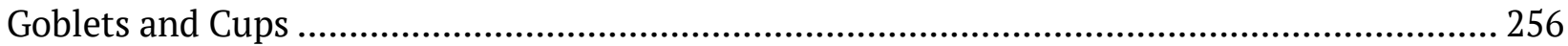

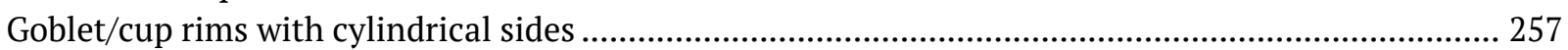

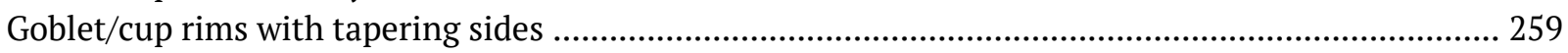

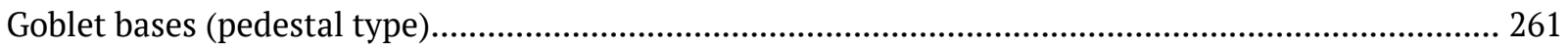

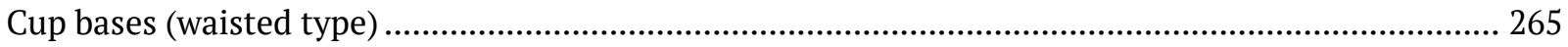

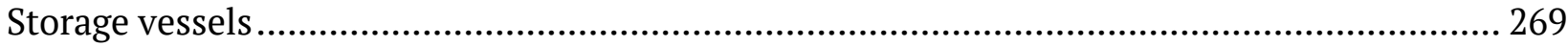

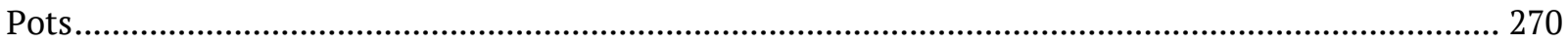

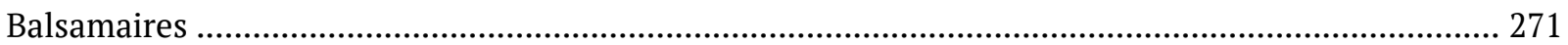

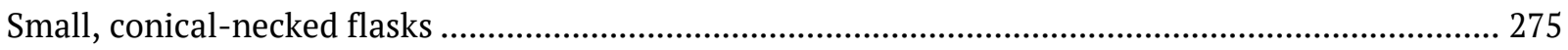

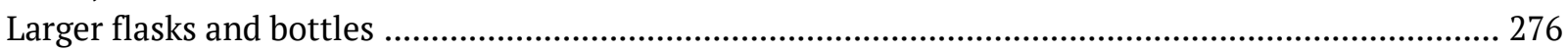

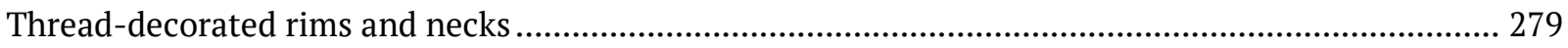

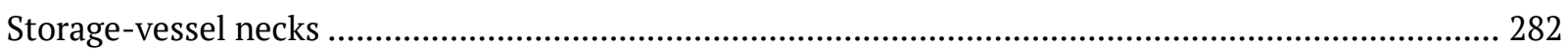

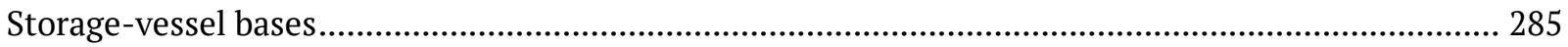

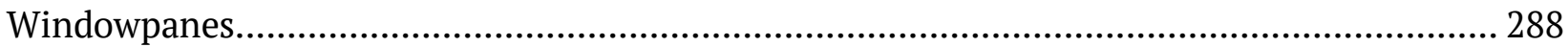

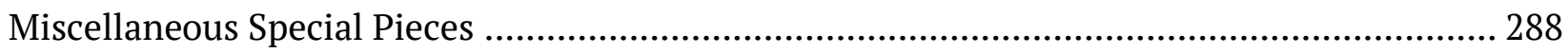

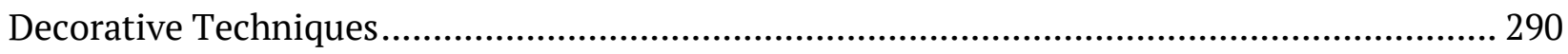

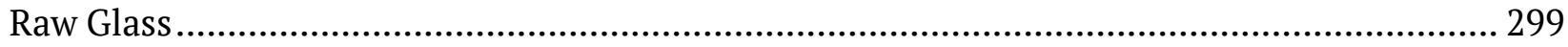

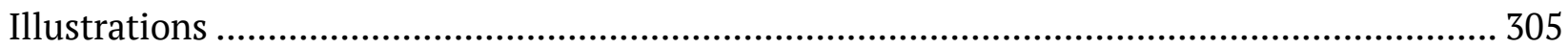

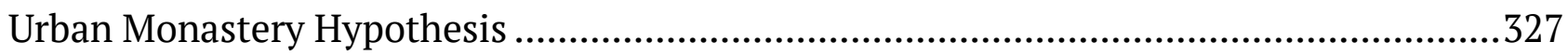

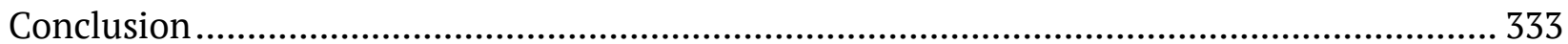

Materia Medica of monastic health care at Hippos Palaistinēs .......................................335

Part 1: Preliminary Pollen Analysis of Diakonikon Herbals ...................................................... 336 


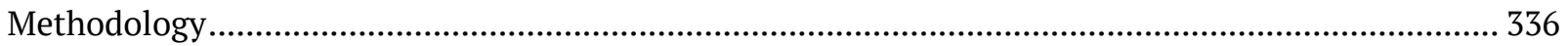

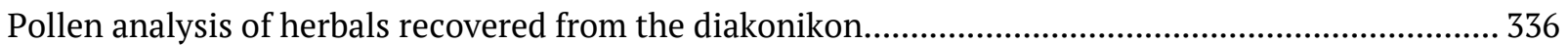

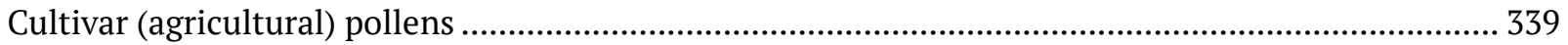

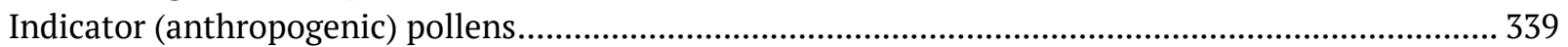

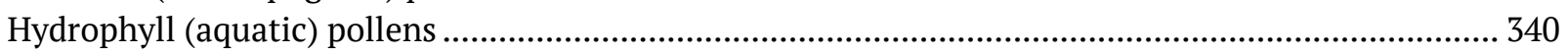

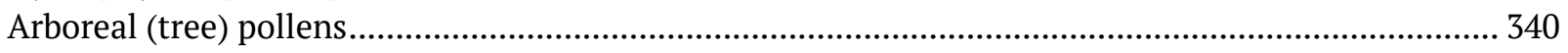

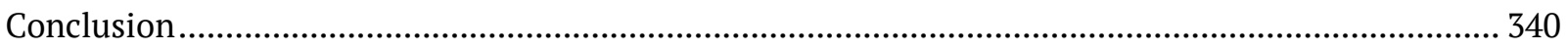

Part 2: the use of herbals in early Christian/monastic health care ......................................340

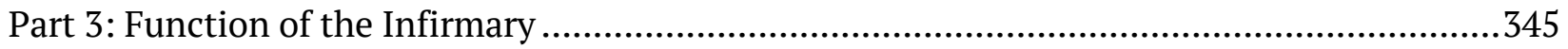

Diakonikon Pollen Counts in Percentages .....................................................................346

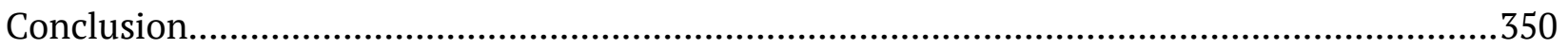

A Chronology of the Northeast Insulae ............................................................. 353

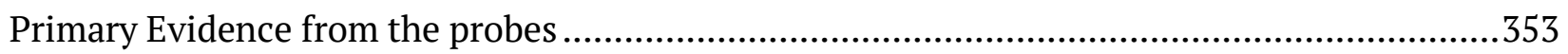

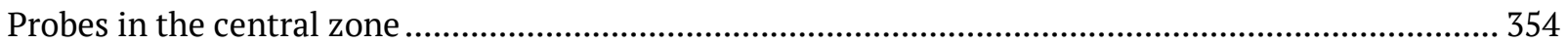

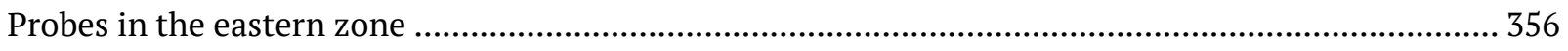

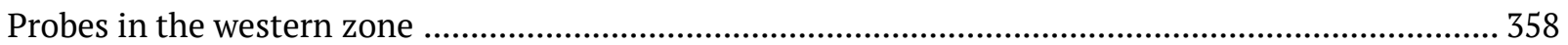

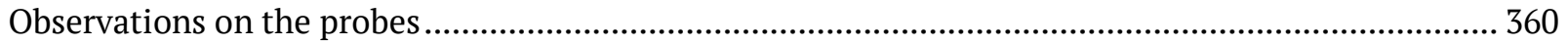

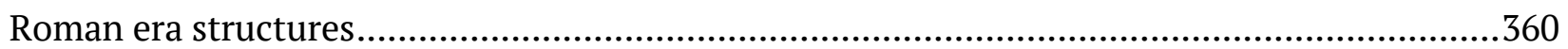

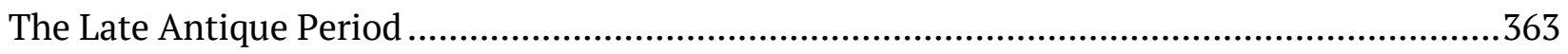

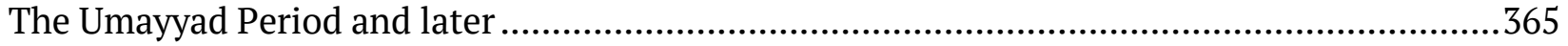

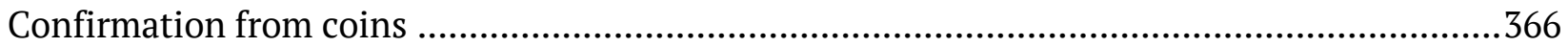

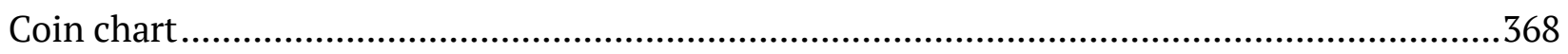

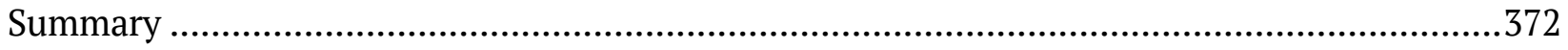

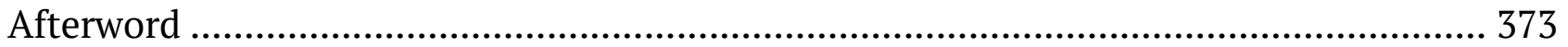

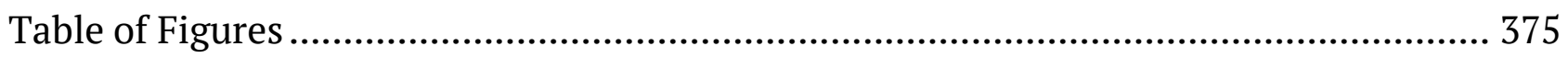

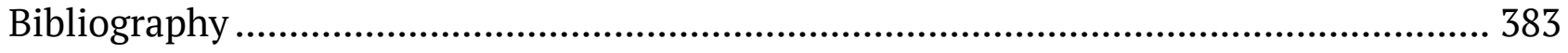




\section{INTRODUCTION}

The Department of Theology and Ministry at Concordia University, Saint Paul, participates in the Hippos Excavations of the Zinman Institute of Archaeology of the University of Haifa at the Hippos/Sussita National Park above the eastern shore of the Sea of Galilee at Ein Gev.

Since 2002 the Concordia Team has been excavating the Northeast Church, a mono-apsidal structure fifty meters east of the temple complex of the city and itself part of a larger configuration of rooms. Distinctive to the church are its burials in the chancel - one of which is a revered elderly woman. Beginning in 2010, the Concordia team has broadened its work to address the larger area north of the decumanus maximus and east of the Roman basilica within which the Northeast Church is located. This larger project bears the name Northeast Insulae Project.

The Concordia Team concluded its field excavations with the 2016 season. A study season was held in 2019.

This volume of the Final Report places the excavation of the northeast insulae into its historical and archaeological context and draws interpretive conclusions from the work done. Much of the material presented here is be repeated in a second volume which recounts the history of the project sequentially. But the focus in this volume is on interpretation of the material remains in their context.

\section{A word of thanks for volunteers}

No project such as this one would be possible without many volunteers. We list them here alphabetically as a way of thanking them for their work.

Irene Abrams
George Allen
Jackie Allen
Dr. Jay Anders
Katrianna Anderson
Brian Andrew
Dinah Appelbaum

Irene Abrams

George Allen

Jackie Allen

Katrianna Anderson

Dinah Appelbaum
Jim Appelbaum

Hannah Appelbaum

Aaron Astley

Elinor Bach

Emilie Bach

Gene Balding

Geoffrey Balke
Daniel Barr

Stephen Bartlett

Alex Bednar

Spencer Behmlander

Andrew Berson

Christopher Biernacki

Suzy Bishara 
Jonathon Bohlinger

Glenn Borchers

Amanda Bundy

+ Eric Cannedy

Ben Carnehl

Stefanie Carpus

Dr. Steve Chambers

Brenda Chambers

Jonathan Chambers

Adam Chandler

Eric Clausen

Laura Combrink

Tabitha Cook

Cody Cooper

William Craigin

Anna Dauffenbach

Cory Davis

Adam Debner

Dr. Michael Dorner

Kody Dougan

David Edwards

Nancy Endicott

Anna Fink

Kevin Fitzgerald

Matthew Foster

Dr. Arny Friend

Bill Fritsche

Rev. Bob Gehrke

Nikolai Gibbons

Jim Gimbel

Ezra Grabau

Shon Haastrup

Rachel Haberstock

Ryan Hatch

Bill Hayes

Rachel Hedberg

Danielle Heffern

Andrea Heiliger

Cameron Heiliger

Marc Hequet
Michelle Heumann

Matthew Hewitt

Elizabeth Hill

Dr. Robert Holst

Liz Horgan

Meg Horgan

Michelle Hugelen

Paul James

Colleen Janzen

Mark Kaetsu

Roger Keller

Felecia Kerntke

Lynn KhadijaSmith

John Klinkhammer

Dr. David Kluth

Ruth Knippelberg

Sarah Koscielniak

Christine Kreutz

James Laatsch

Karen Laatsch

Jacob LaCroix

Rebecca LaCroix

Lon Larson

Susan Leistico

Clinton Magnus

Joyce Magnus

Trevor Mankin

Gina Marchetti

Dr. Richard Marrs

Laura Marrs

Michael Marvosh

Michael Mayer

Max Mayrhofer

Connie McFadden

Eleanor McFadden

Christine Mennicke

Benjamin Meyer

Bill Meyer

Caleb Meyer

Jessica Meyer
Dr. Michael Middendorf

Jonathan Miller

Linda Miller

Jenn Mills

Quinn Moerike

Michael Montague

Ashley Moores

Jennifer Morey

Wayne Mory

Jake Mueller

Tamera Nelson

Kristina Neumann

Philip Nomura

Margaret Olsen

Dylan Olson

Meghan O'Neill

Stan Ostgren

Jan Pakan

John Pakan

Dam Park

Harrison Parker

Dr. Michael Patella OSB

Stephanie Pearce

Dr. Susan Pratt

Stephanie Randolph

Jason Ratke

Desiree Reding

Sarah Rice

President Tom Ries

Sam Rivera

Brian Roemen

Rachel Roeske

Carl Roessler

+ Rev. Jim Rogers

Erin Rudolph

Kathryn Schaefer

Darryl Schmidt

Robert Schrader

Dr. Rhoda Schuler

Tim Schumacher 


$\begin{array}{lll}\text { Laura Seefeld } & \text { Karina Sweeney } & \text { Daniel Walker } \\ \text { Jennifer Shack } & \text { Jessica Tewes } & \text { Heidi Weik } \\ \text { Fred Shade } & \text { Benjamin Thomas } & \text { Robert Weldon } \\ \text { Janet Shade } & \text { Pamela Thomas } & \text { Ian Wemyss } \\ \text { Anna Shaw } & \text { Wesley Thomas } & \text { Daniel Westberg } \\ \text { Lawson Short } & \text { Andrea Thomes } & \text { Harry Westberg } \\ \text { Darren Siegle } & \text { Erin Thompson } & \text { Jackie Wiebold } \\ \text { Carl Simmons } & \text { Nathan Thompson } & \text { Brennan Woell } \\ \text { Tina Simmons } & \text { Ted Thuening } & \text { Melissa Wolf } \\ \text { Kyle Sorkness } & \text { Kay Tidemann } & \text { Mark Wood } \\ \text { Peter Spartalis } & \text { Shawn Urban } & \text { Alexander Wright } \\ \text { Emily Stanzyk } & \text { Zachary Viggers } & \text { Caroline Zinz } \\ \text { Roland Starke } & \text { Andy Viken } & \\ \text { Micah Steinke } & \text { Jordan Voges } & \end{array}$

In addition, I wish to highlight key leaders from the team who helped over multiple seasons:

Darryl Schmidt

John Klinkhammer

Jim Appelbaum

Dr. Steve Chambers

Glenn Borchers

Dr. Arny Friend
Andrea Heiliger

Dr. Kristina Neumann

Nancy Endicott

+ Rev. Jim Rogers

Dr. Michael Dorner

Jackie Druckhammer

A rough summary of the contribution of these leaders and the volunteers who joined them would include:

- 16 years

- 183 individual diggers

- 284 trips to Israel

- 6300 cubic meters or roughly 22250 cubic feet of excavated soil/rock (very rough approximation)

- 66750 buckets of soil and rock moved

- 862 individually documented artifacts

- 969 pottery analysis baskets

- 335 loci (walls, floors, and distinct layers of soil in identifiable locales) 


\section{A 16-year partnership}

For sixteen years, Concordia University has been pleased to partner with the Zinman Institute of Archaeology at the University of Haifa on the Hippos Excavations. I am most thankful for the colleagues from Haifa, during the first eleven years with Prof. Arthur Segal and his associate, Michael Eisenberg, and more recently with Dr. Eisenberg and his team, including Arleta and Nofar.

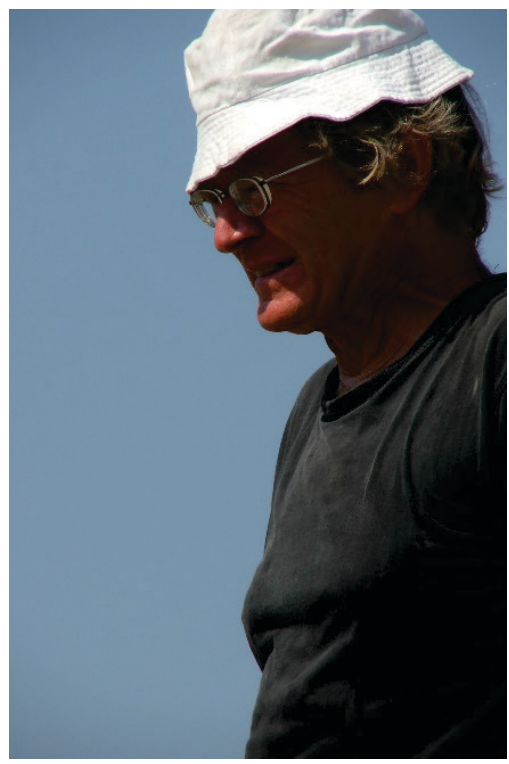

Figure 1 Arthur

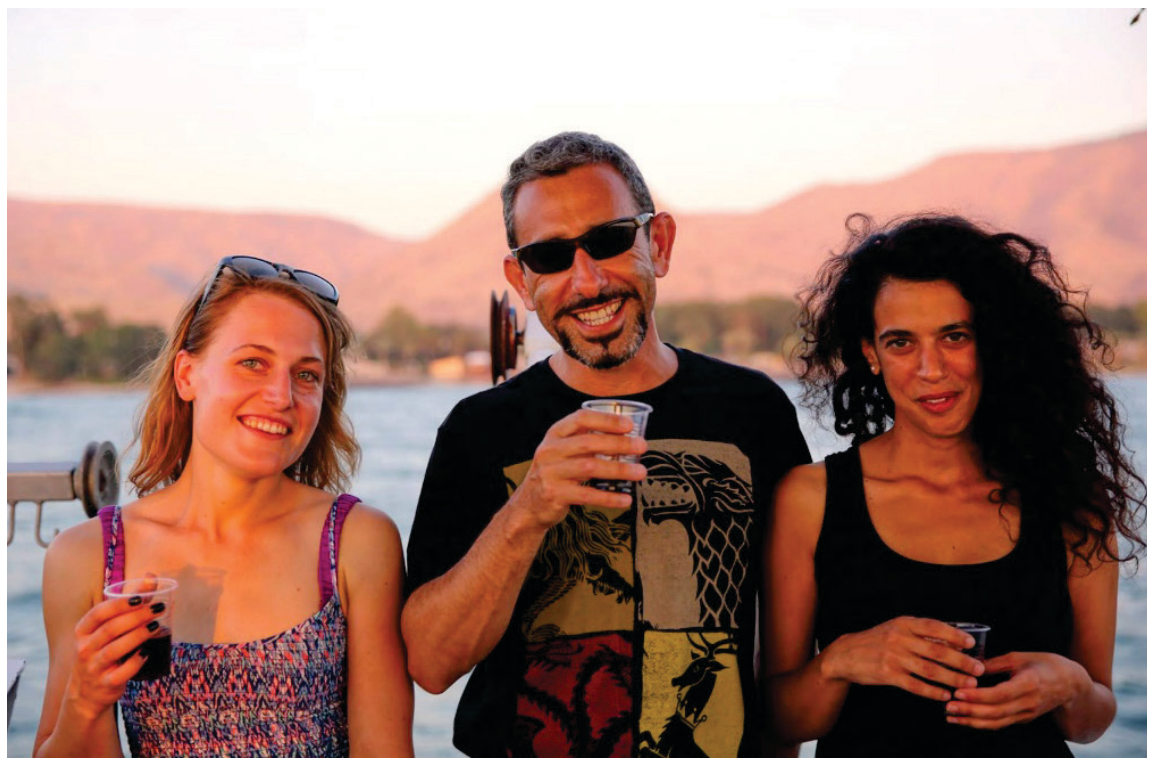

Figure 2 Arleta, Michael, and Nofar

These folks from Haifa have been gracious and supportive and demonstrate what is possible when institutions cooperate internationally.

I am proud to be part of this project and will miss interactions in the field with these colleagues.

Mark Schuler

Concordia University, Saint Paul

November 2021 




\section{A R K S C H U L E R \\ Northeast Insulae Project: Context and Analysis}





\section{1.}

\section{OVERVIEW OF THE EXCAVATION AREA}

$\Upsilon$ he northeast insulae are in a 50 x $60 \mathrm{~m}$ area to the east of the former Roman basilica
and north of the decumanus maximus.

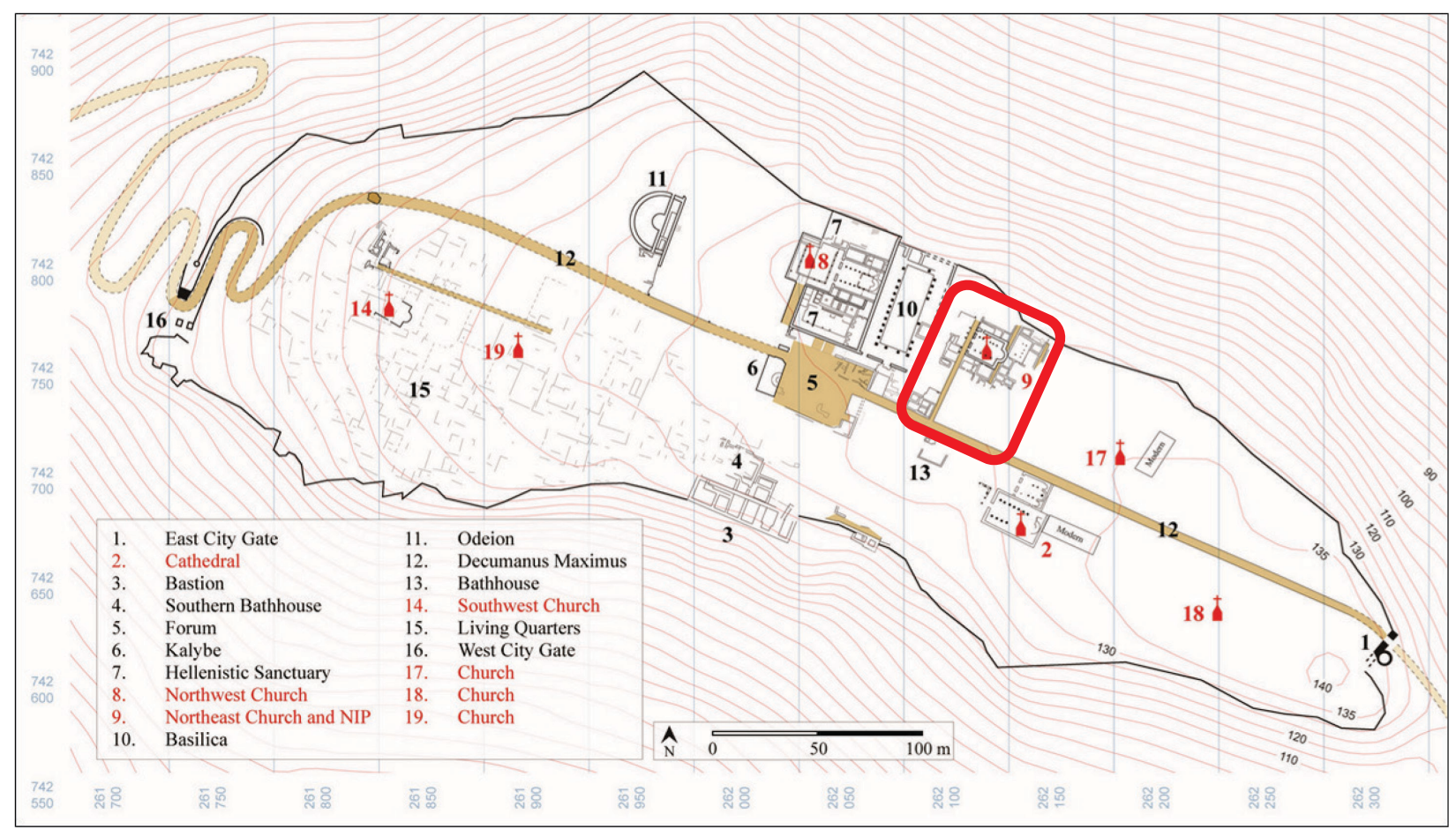

Figure 3 Churches of Hippos (Courtesy of the Hippos-Sussita Excavations. Used with permission.)

The insulae are bisected by three small cardines (Cardo 2, 3, and 4 North) which likely derive from the original Roman-era city plan. Cardo 2 North is the westerly street that functioned as a via sacra for the church, the portico of which continues its line. Cardo 3 North is the central street the line of which was interrupted by the construction of the apse of the church. Cardo 4 North is the eastern boundary of the project, lined on its west side by the east wall of the House of Tyche. These cardines provide a convenient way of delineating 
three excavation zones within the Northeast Insulae Project: the Western Zone, the Central Zone, and the Eastern Zone.

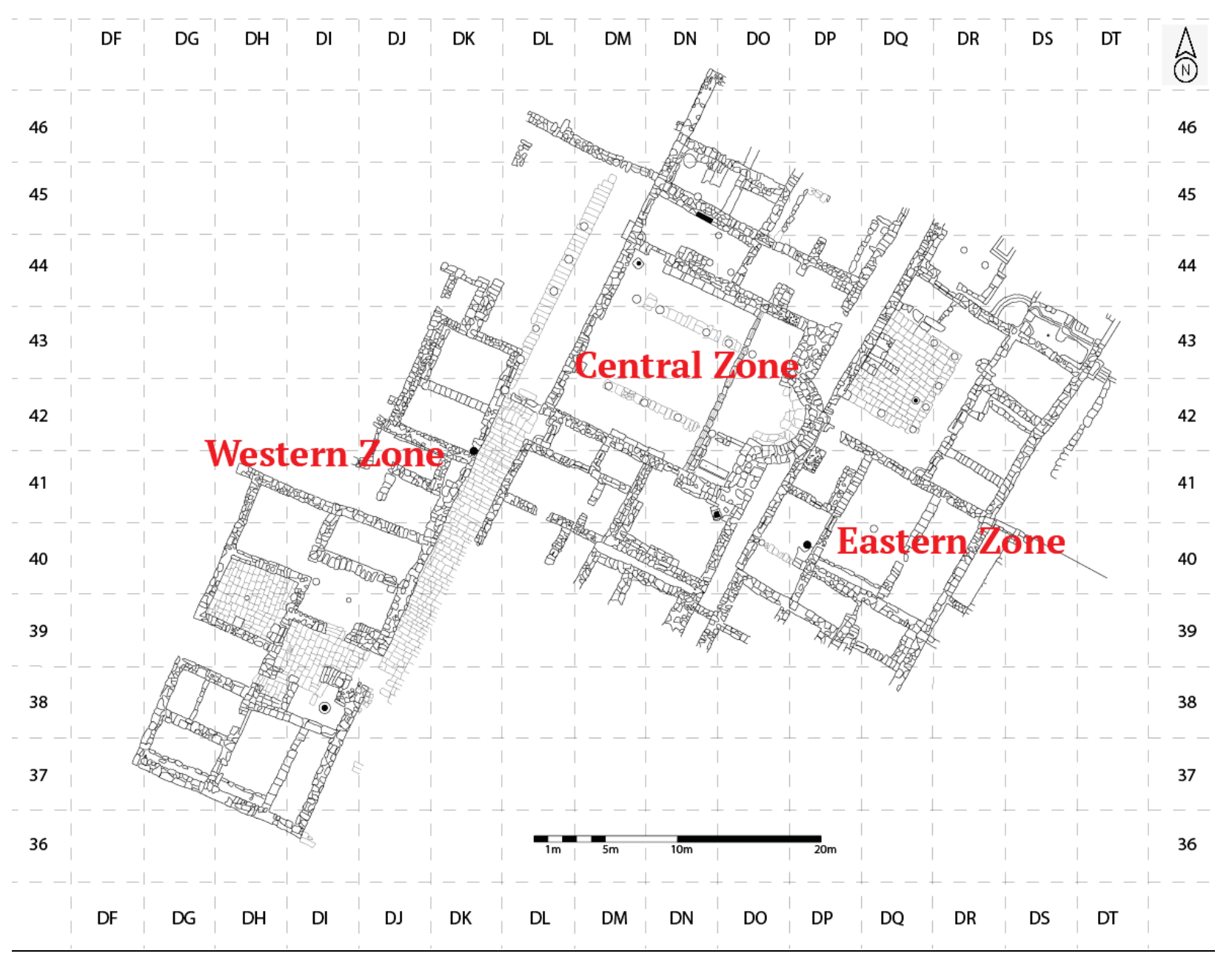

Figure 4 Zones in the project

The Eastern Zone is bounded to the east by Cardo 4 North and to the west Cardo 3 North. We have exposed a $30 \mathrm{~m}$ section of the line of this of Cardo 4 North and the entrance to the cardo at the decumanus. In the Eastern Zone are the peristyle house and what may be a Umayyad structure. The Central Zone is bounded to the east by Cardo 3 North and to the west by Cardo 2 North (via sacra). Cardo 3 North was exposed to its dirt surface over a similar distance. The Northeast Church is the most prominent feature of this zone. The Western Zone is bounded to the east by Cardo 2 North (via sacra), exposed over the entire distance to the southern gate of the church compound, and to the west by the Roman basilica. Within this zone seemingly are several buildings that we are labeling with Greek letters from south to north. Buildings Alpha, Beta, and Gamma are partially exposed. The foundation of a possible Building Delta was also identified. 
As will be discussed in a subsequent chapter, all zones reflect major occupation during two periods in the history of the site - the Roman Imperial period of the second to fourth centuries CE and the Late Antique (Byzantine) period of the sixth and seventh centuries CE. Some occupation continued into the Umayyad period of the first half of the eighth century, with minor evidence of agrarian usage over the centuries after the earthquake of $749 \mathrm{CE}$.

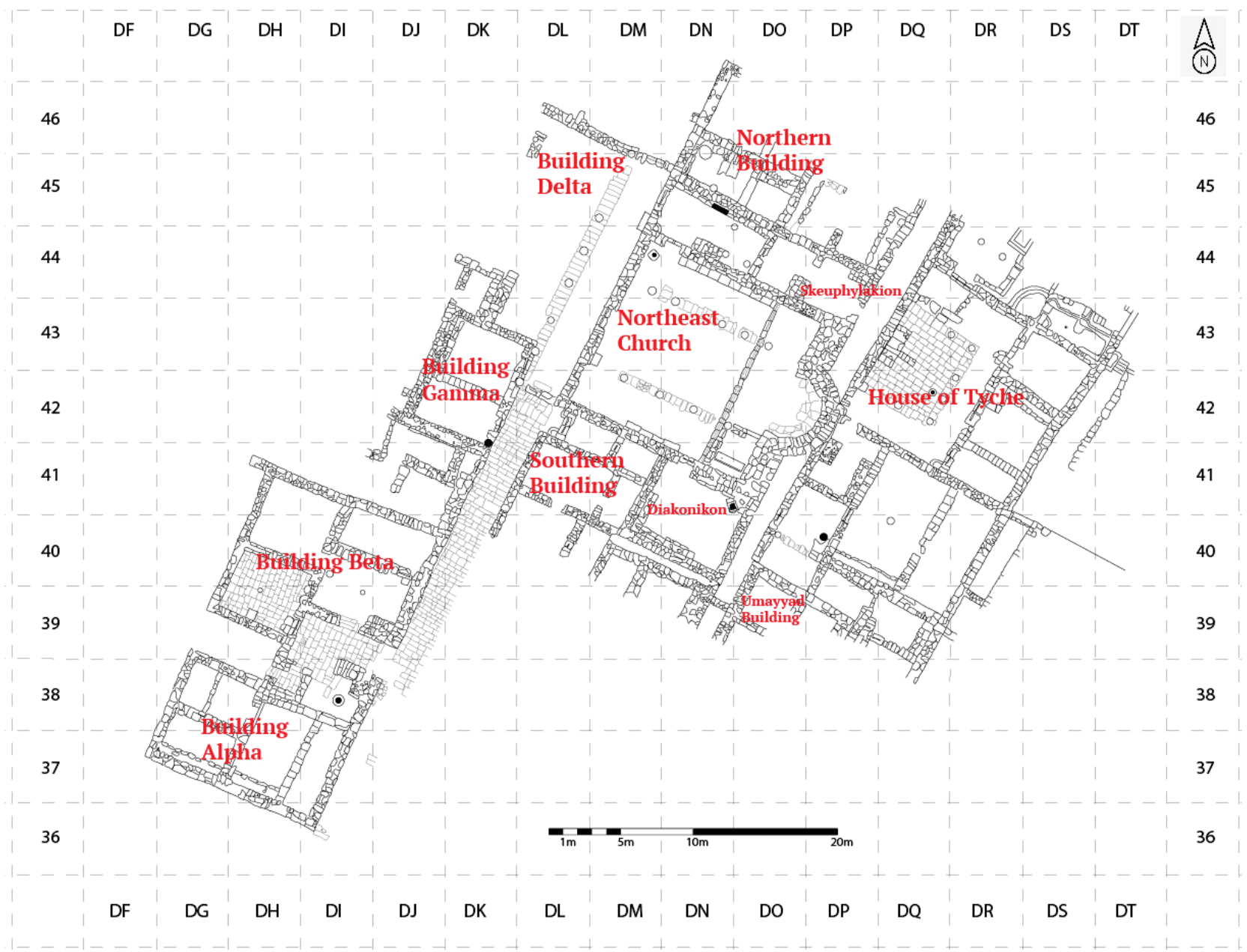

Figure 5 Buildings

A key tool in the later years of the excavation was the development of photogrammetry as a means of documentation. We are indebted to Dr. Michael Eisenberg and the photogrammetry lab of the Zinman Institute of Archaeology at the University of Haifa for the orthographic photos and DEM images of the Northeast Insulae Project. 

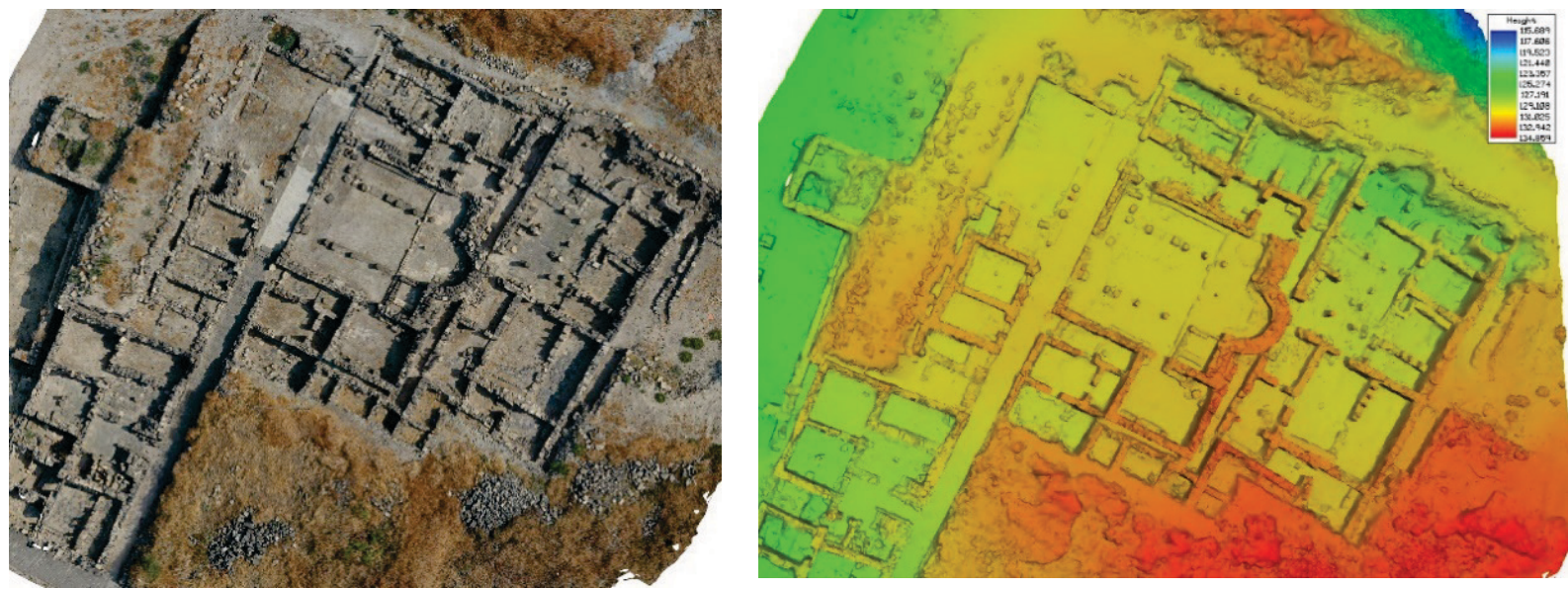

Figure 6 Ortho and DEM of NIP (Courtesy of the Hippos-Sussita Excavations. Used with permission.)

The model below overlays the geo-referenced grid system used in the excavation.

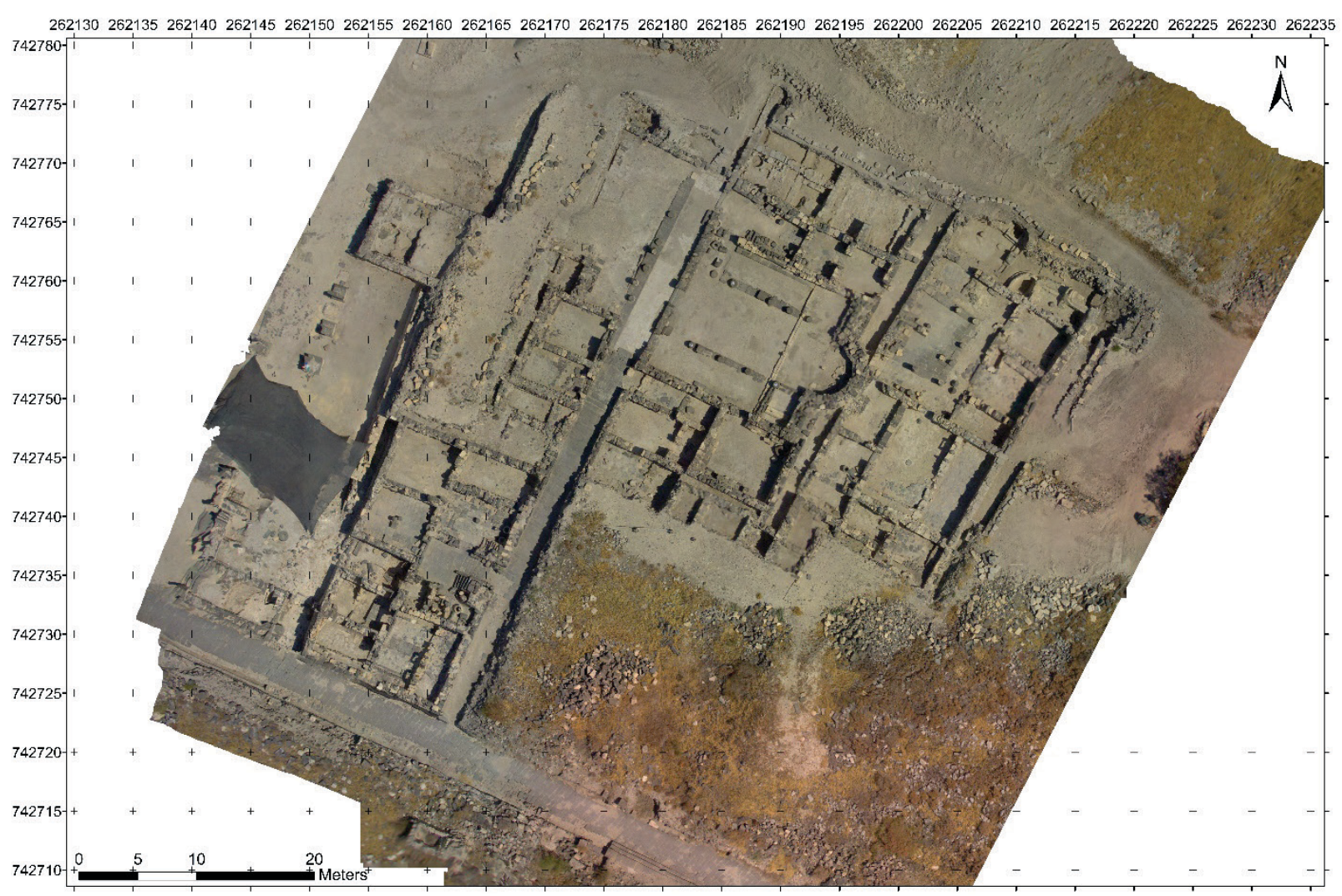

Figure 7 Orthographic of the insulae in 2016 (Courtesy of the Hippos-Sussita Excavations. Used with permission.) 


\title{
2.
}

\section{LATE ANTIQUE CHRISTIANITY AT HIPPOS PALAISTINĒS}

\begin{abstract}
lthough Antiochia Hippos reached its zenith in the Roman Imperial period, little of $A$ that period remains in the northeast insulae, having been surmounted by the Northeast Church and its surrounding complex. Before discussing the archaeological finds in detail, a larger view of Late Antique Christianity at Hippos Palaistinēs is presented in this chapter.
\end{abstract}

During the first centuries of its existence, earliest Christianity gradually separated from Judaism, especially after the revolts against Rome. Subsequently, Christianity remained a small and persecuted minority in the larger Roman Imperial world. With the co-opting of Christianity by Constantine to unite the peoples of the empire under his rule, Christianity was eventually legalized and swiftly came to hold a dominant position in the Roman world.

By the fifth and sixth centuries of the Common Era, there were both Jewish, Christian, and mixed communities around the Kinneret. Tiberias had become the great center of the Jewish learning and of Masoretic study of the text of the Hebrew Bible. Its rival, Antiochia Hippos, became a significant Christian center.

In the earliest literary reference to Christianity at Hippos, a bishop from Hippos is listed as

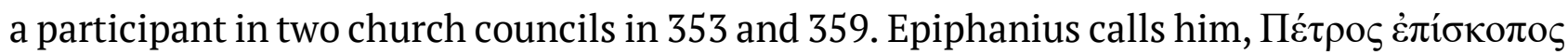

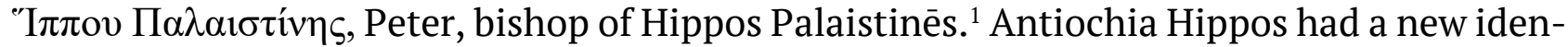
tity as Hippos Palaistinēs, born of its place in the Roman provincial system and of the rise of Christianity.

A great earthquake in $363 \mathrm{CE}$ devastated the Roman province of Palaistina. ${ }^{2}$ Coins at floor level under the destruction fill of the Roman basilica at Hippos date its destruction to this

\footnotetext{
${ }^{1}$ Epiphanius of Salamis, Panarion (Adversus Haereses), 73.26.

${ }^{2}$ Arthur Segal et al., Hippos-Sussita of the Decapolis: The First Twelve Seasons of Excavations (2000-2011) Vol 1 (Haifa, Israel: The Zinman Inst of Archaeology, 2013), 180; N Wechsler and Samuel Marco, "Historical Earthquakes in the North of Israel and Their Influence on Hippos-Sussita (Hebrew)," Michmanim 27 (2017): 35-46.
} 
event. ${ }^{3}$ It is safe to assume that significant features of Graeco-Roman Hippos were also laid waste. Hippos was typical of other cities during the lost fifth century CE. ${ }^{4}$ But from the ruins emerged a Christian community of which five churches have been excavated and the two others identified.

\section{Material remains: the churches}

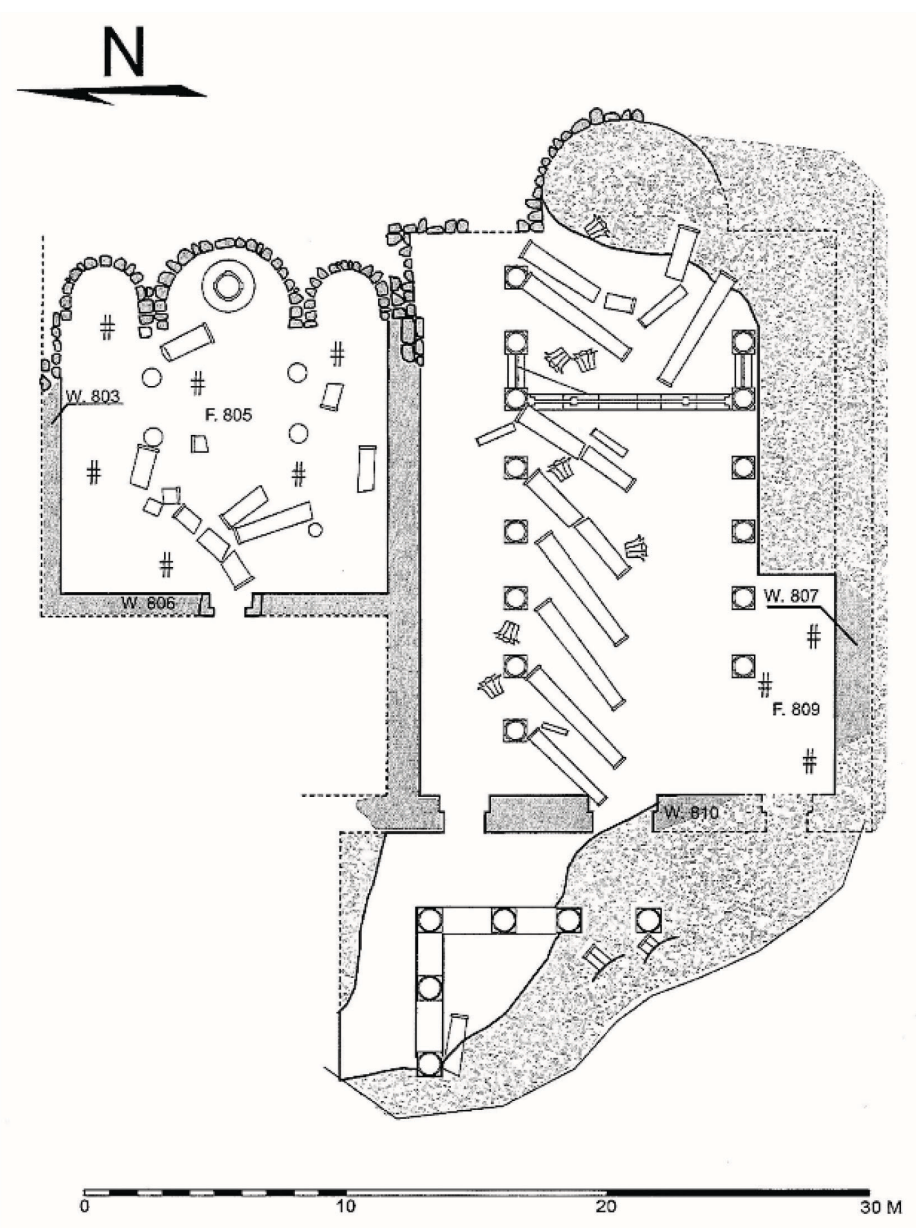

Figure 8 Plan of the "cathedral" 5

\footnotetext{
${ }^{3}$ Arthur Segal et al., Hippos-Sussita : Tenth Season of Excavations : July and September 2009 (Haifa, Israel: Zinman Institute of Archaeology, University of Haifa, 2009), 31.

${ }^{4}$ Zeev Safrai, The Missing Century: Palestine in the Fifth Century: Growth and Decline (Leuven: Peeters, 1998).

${ }^{5}$ Arthur Segal et al., Hippos-Sussita : Fourth Season of Excavations : June-July 2003 (Haifa: Zinman Institute of Archaeology, University of Haifa, 2003), Fig. 14.
} 
Excavations carried out between 1950 and 1955 by Epstein, Avi-Yonah, Shulman and Anati revealed two structures. ${ }^{6}$ The first is the so-called Cathedral.

The "cathedral" is a mono-apsidal church with an external apse and the most impressive of the church structures on the site. It domus is 20 by $40 \mathrm{~m}$. Two rows of nine columns averaging $5 \mathrm{~m}$ in height of differently colored marble and granite separated the nave from the aisles. The columns were found lying on the floor of the building in the same direction, having been thrown there during an earthquake. Close by were the pink and white Corinthian capitals that the columns had originally supported. The church has a chancel shaped like the Greek letter $\Pi$. To the immediate north is a tri-apsidal baptistry, unique in antiquity. Inscriptions in the floor of this baptistry dedicate it to Damian and Cosmos and provide a date for the final floor of $591 \mathrm{CE}$.

During the same excavations, a second church ${ }^{7}$ was identified and partially excavated north of the Decumanus Maximus. We are calling it the Eastern Church. When visiting the site, one can still see the apse at the head of the south aisle, although the rest of the excavation was reburied. Excavators exposed only the east end of this church. It is also mono-apsidal with an exterior apse. To its northeast is a paved area and another structure. The church seems to have a $\Pi$-shaped chancel. Excavation notes state that the apse of the south aisle is a secondary addition.

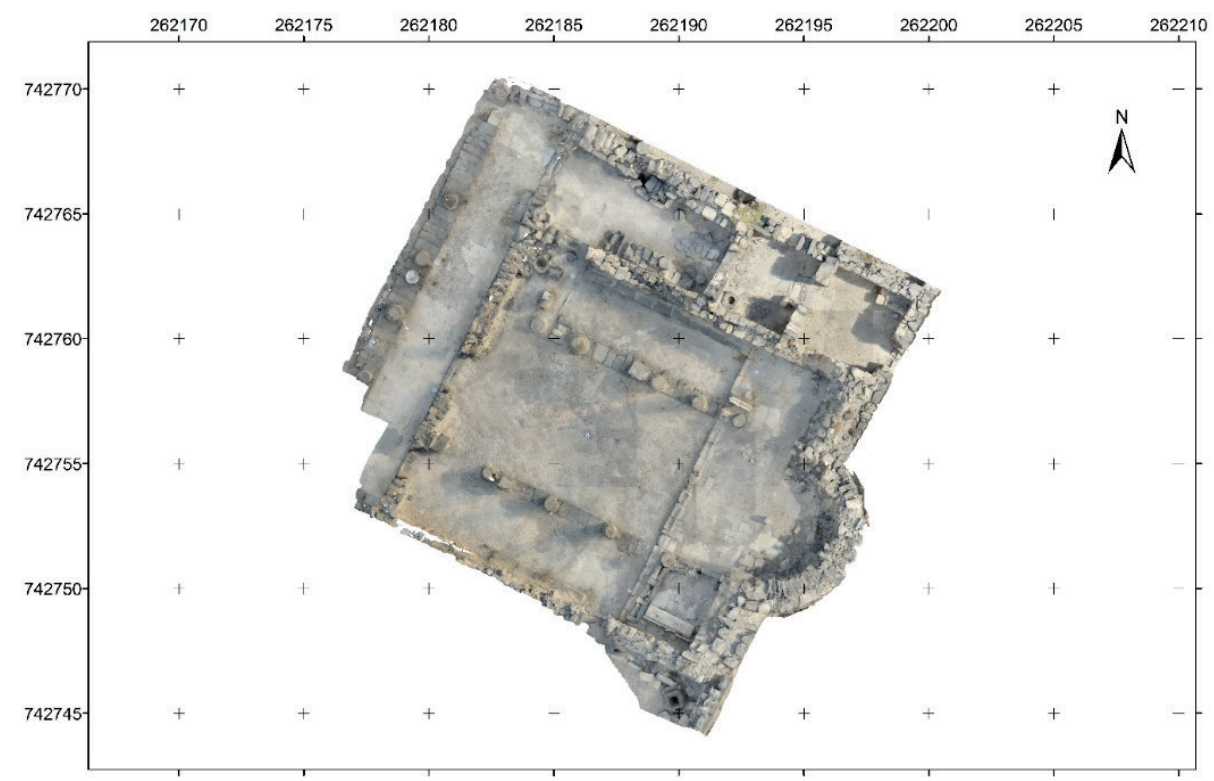

Figure 9 Northeast Church (Courtesy of the Hippos-Sussita Excavations. Used with permission.)

\footnotetext{
${ }^{6}$ Claire Epstein, "Hippos (Sussita)," in The New Encyclopedia of Archaeological Excavations in the Holy Land, ed. Ephraim Stern, Ayelet Leṿinzon-Gilbo'a, and J. Aviram, vol. 2 (Jerusalem : New York: Israel Exploration Society \& Carta ; Simon \& Schuster, 1993), 634-636.

${ }^{7}$ This excavation was never published. Our summary is based on copies of written materials and notes on file with the Israel Antiquities Authority.
} 
The Northeast Church and compound were excavated by Concordia University from 2002 to 2016. In the late fifth or more likely early sixth century, a religious compound was constructed in the ruins of a former domestic area. Central to the compound was a small monoapsidal church with a bar-shaped chancel and an exterior apse. It was a memorial chapel. At the east end of the south aisle partially exposed above the floor and marked with crosses was a prominent burial of a revered woman of significant age. Just north of the central axis of the chancel was a masonry tomb with a lead pipe to the burial below. Twelve distinct individuals were identified from the remains.

Significantly, the church seems to have been part of a larger compound. To the north was a building that had cooking and storage areas on a lower level and an upper level paved in mosaics. Doorways to the east provided access through a narrow entryway into the space previously occupied by a peristyle house of the Roman Imperial period. The original house was $22 \times 13$ m with a three-sided peristyle and a northern terrace. Reconstruction in the ruins of the house turned an eastern room into two spaces separated by a window wall. The southern half of the building likewise was subdivided by two window walls with a large central room, the ceiling of which was held up by a double arch. As we will argue later, this compound was likely an urban monastic complex.

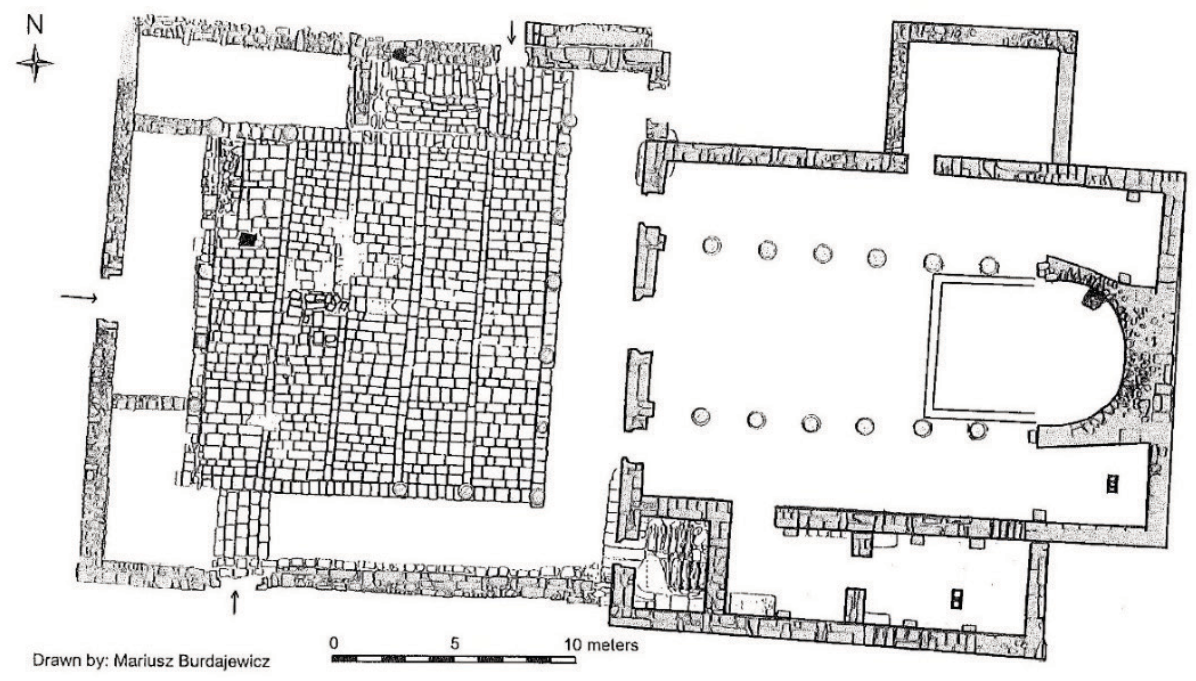

Figure 10 Phase 1 of the Northwest Church $^{8}$

The Northwest Church was excavated by Jolanta Mlynarczyk of the Polish Academy of Sciences and Marius Burdajewicz of the National Museum of Warsaw. ${ }^{9}$ The Northwest Church is situated inside the Hellenistic compound and supplants the previous temple on the site.

\footnotetext{
${ }^{8}$ Segal et al., Hippos-Sussita of the Decapolis: The First Twelve Seasons of Excavations (2000-2011) Vol 1, Fig. 262.

${ }^{9}$ Ibid., 194-217.
} 
In its original phase it was a mono-apsidal structure with an inscribed apse and a $\Pi$-shaped chancel.

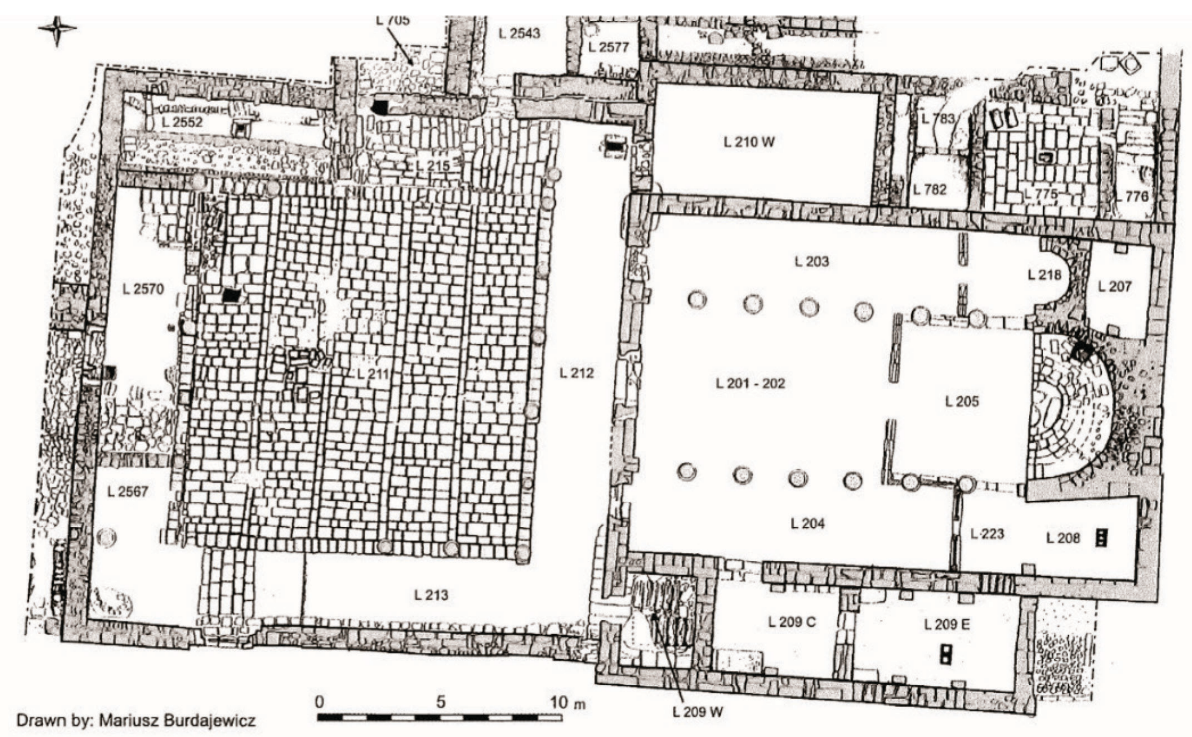

Figure 11 Phase 2 of the Northwest Church ${ }^{10}$

Its second phase from the sixth century added an apse in the north aisle and formalized the martyrion at the head of the south aisle. The chancel was expanded into a T-shape.

The Southwest Church (the Martyrion of Theodoros) was excavated by the University of Haifa in 2005 and 2007, and the domus was completed in 2019.

The structure has a single external apse. In the middle of the chancel a red limestone reliquary was found in situ fixed in the mosaic floor. The bases of a four-legged table surround the reliquary. The church sits within the residential quarter of the city and is surrounded by houses and streets. The construction of the church is dated to the second half of the fifth or the early sixth century. The main mosaic is from the first half of the sixth century and the structure was re-reordered in the second half of the sixth century. ${ }^{11}$

The mosaic floor of this church is the best preserved at Hippos. Its central inscription indicates the church is the Martyrion of Theodorus, likely Theodoros Tiron of Amaseia. The church was constructed by a bishop named Megas, unknown previously at Hippos. A second inscription honors a Father Theodorus (not of Amaseia) and a Father Petros who made a major albeit obscure contribution to the construction of the sanctuary. A third inscription notes the offering of Simonios, the priest, possibly referring to the reliquary or the mosaic in the chancel. ${ }^{12}$

\footnotetext{
${ }^{10}$ Ibid., Fig. 277.

${ }^{11}$ Gregor Staab and Michael Eisenberg, "Building Inscriptions from the Martyrion of Theodoros at the 'Burnt Church' in Hippos above the Sea of Galilee," Zeitschrift für Papyrologie und Epigraphik 2014 (2020): 203.

12 Ibid., 204-213.
} 


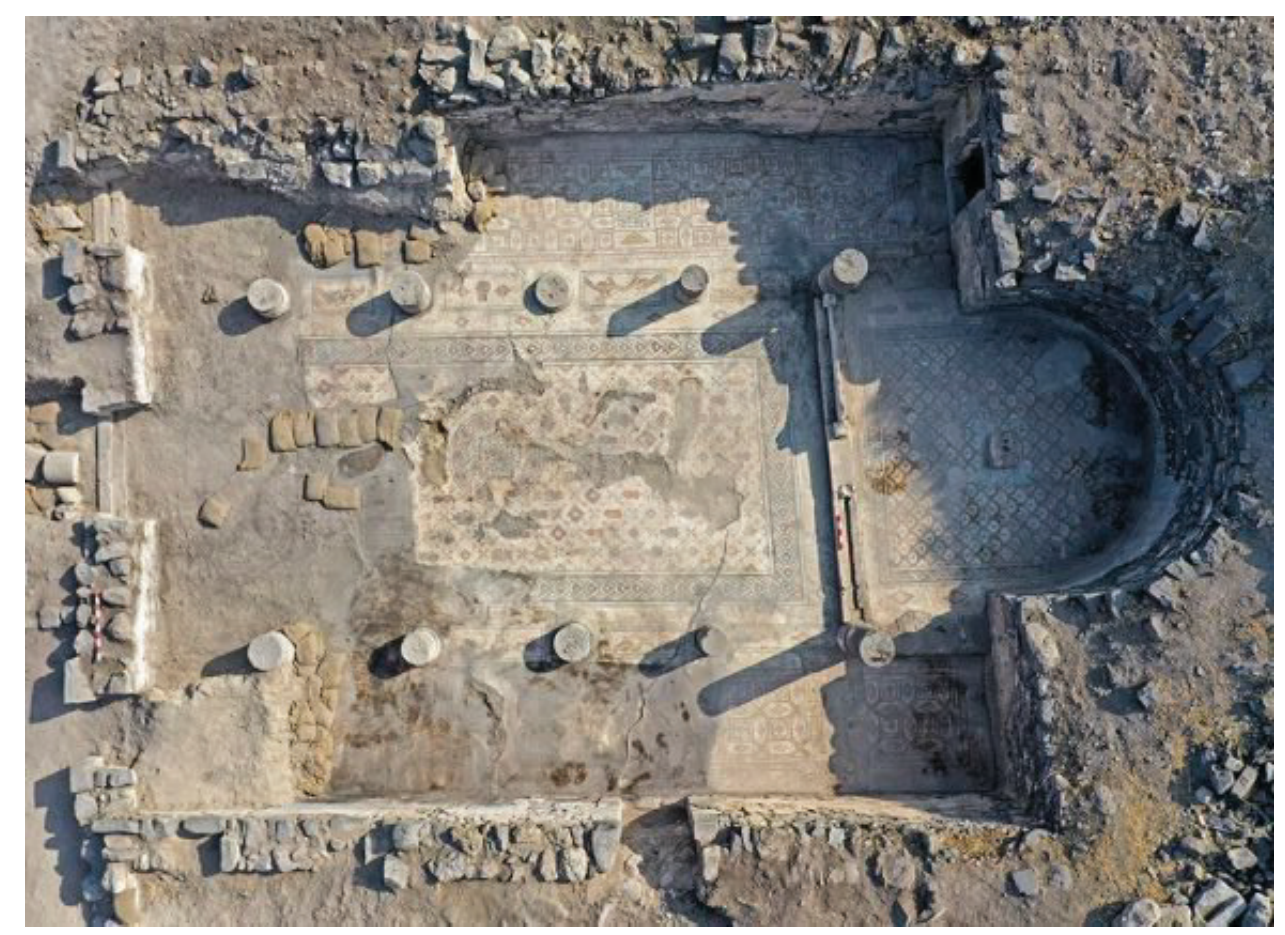

Figure 12 Southwest Church (Courtesy of the Hippos-Sussita Excavations. Used with permission.)

Surface features suggest the remains of two other churches. They await excavation.

The Christian community at Hippos Palaistinēs reached its zenith in the sixth century. But that same century witnessed changes and challenges, which would eventually be followed by decline and the near abandonment of the site by the middle of the eighth century.

\section{The sixth century}

The reign of Justinian (527-565 CE) impacted Hippos architecturally and theologically. Imperial resources supported the construction of churches both in Constantinople, across the empire, and in the Holy Land.${ }^{13}$ His claim to have outdone Solomon in the construction of Hagia Sophia ultimately understates the imperial influence, for most church structures even at Hippos have some major connection to this period.

Theologically, Justinian believed his empire was threatened by diverging religious currents, especially Monophysitism, which had a significant following in the eastern provinces of Egypt, Syria and Palaistina, and even at Hippos. ${ }^{14}$ Monophysite doctrine had been condemned by the Council of Chalcedon in 451 . But tolerant policies of Zeno and Anastasius I

\footnotetext{
${ }^{13}$ Robert G. Ousterhout, "Justinian's Building Program and Sixth-Century Developments," in Eastern Medieval Architecture: The Building Traditions of Byzantium and Neighboring Lands (New York: Oxford University Press, 2019), 219242.

${ }^{14}$ Jolanta Mlynarczyk, "Churches and Society in Byzantine and Umayyad-Period Hippos,” ARAM 23 (2011): 253.
} 
caused tension between the imperial court and the bishops of Rome. Justin I (518-527 CE) reversed this trend and reaffirmed Chalcedon, openly condemning the Monophysites. Justinian continued this policy and tried to impose religious unity on his subjects, although near the end of his life, Justinian became more inclined towards the Monophysite doctrine. ${ }^{15}$

Notably, two bishops from Hippos Palaistinēs were signatories to synods of Jerusalem in the first half of the sixth century: Bishop Conon in 518 CE and Bishop Theodorus in 536 CE. ${ }^{16}$ The synod of 518 was held under Patriarch John III. John was a Monophysite; however, after becoming patriarch of Jerusalem in 516, he became Orthodox and condemned the opponents of the Council of Chalcedon. The synod of 518, held the same year that Justin I began his rule, reiterated pro-Chalcedonian decrees. Present at the synod were 33 bishops along with Sabbas, a renowned Chalcedonian. The synod of 536, held during the early years of the reign of Justinian, was called by John's successor Peter. At the synod, Peter proclaimed his embrace of the Council of Chalcedon. Actions of the synod, which included forty-four bishops, reaffirmed anti-Monophysite decisions. ${ }^{17}$ The participation of two bishops from Hippos Palaistinēs in synods intentionally taking pro-Chalcedonian positions corresponds to a move toward more Roman liturgical practice, as is reflected archaeologically in sixth century modifications to churches in the city. These changes become clear when assessed using a classification system from Bernard Mulholland. ${ }^{18}$

Mulholland has reassessed forty-seven basilical churches, primarily from Israel and Jordan, to identify their historical and literary context. ${ }^{19}$ Using like-for-like analysis, he classifies sites according to their plans (monoapsidal, inscribed, or triapsidal) and the configuration of their sanctuaries (П-shaped or T-shaped).

From the data, he posits three major types. One has a protruding mono-apsidal plan with one or more entrances flanking the apse and a $\Pi$-shaped sanctuary that he labels "Constantinopolitan.” This type often has multiple entrances on both sides. A second type, the "Syrian," has an inscribed mono-apsidal plan with a $\Pi$-shaped sanctuary and rooms on either side of the apse. This type often has a parallel chapel or diakonikon accessible from

\footnotetext{
${ }^{15}$ John Meyendorff, Imperial Unity and Christian Divisions: The Church, 450-680 AD, Church history 2 (Crestwood, N.Y: St. Vladimir's Seminary Press, 1989), 207-250.

${ }^{16}$ Pius Bonifacius Gams, Series episcoporum Ecclesiae catholicae. (Graz: Akademische Druck- u. Verlagsanstalt, 1857), 454.

${ }_{17}$ Adrian Fortescue, "Jerusalem (A.D. 71-1099)," in The Catholic Encyclopedia, vol. 8 (New York: Robert Appleton Company, 1910), accessed July 9, 2021, https://www.newadvent.org/cathen/08355a.htm.

${ }^{18}$ Bernard Mulholland, The Early Byzantine Christian Church: An Archaeological Re-Assessment of Forty-Seven Early Byzantine Basilical Church Excavations Primarily in Israel and Jordan, and Their Historical and Liturgical Context, Byzantine and neohellenic studies Vol. 9 (Oxford; New York: Peter Lang, 2014).

${ }^{19}$ Mulholland's theoretical reconstruction is not without criticism. See Zbigniew Fiema, "The Early Byzantine Christian Church: An Archaeological Re-Assessment of Forty-Seven Early Byzantine Basilical Church Excavations Primarily in Israel and Jordan, and Their Historical and Liturgical Context," Bulletin of the American Schools of Oriental Research 376 (November 2016): 246-249.
} 
the southern aisle. A third type, the "Roman," is triapsidal or monoapsidal with a T-or barshaped sanctuary, side altars and evidence of multiple relics or reliquaries. ${ }^{20}$

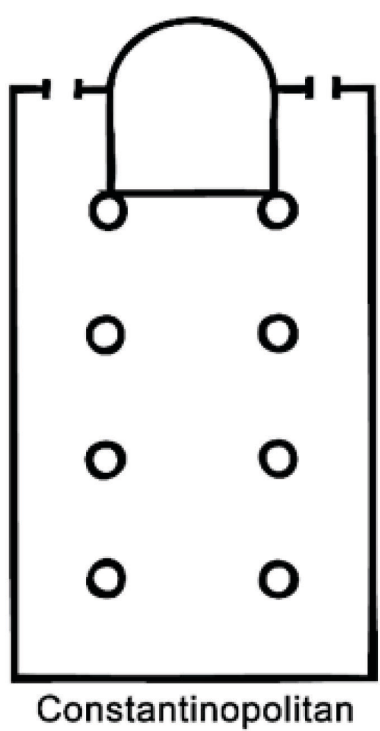

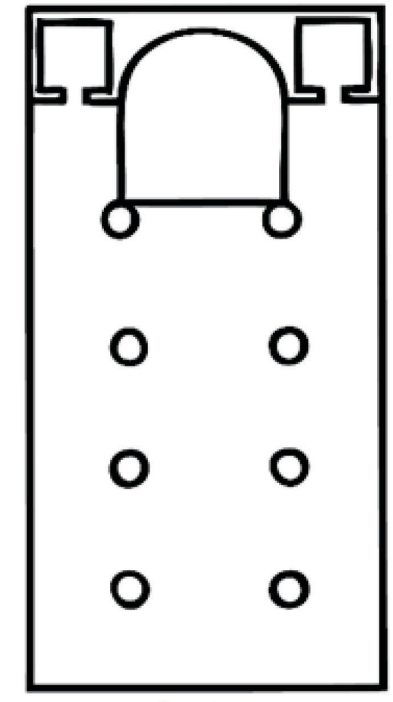

Syrian

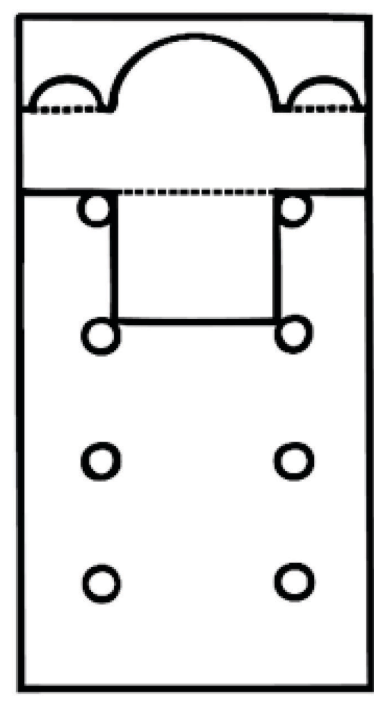

Roman

Figure 13 Schema from Mulholland ${ }^{21}$

Application of this classification system to the churches at Hippos Palaistinēs would identify the Southwest Church as Constantinopolitan. The "Cathedral" and the first phase of the East Church seem also to correspond to this type. The first phase of the Northwest Church is Syrian. The Northeast Church is Roman, especially since burials in the chancel are more characteristic of western and northern Africa. If the unexcavated church in the domestic quarter is tri-apsidal, it too would likely be Roman. Such a range of church types would suggest a diversity of theologian perspective in the city, as was the case in Palestine in the aftermath of the Council of Chalcedon in $451 \mathrm{CE}$.

However, numerous changes occurred in the sixth century. The East Church added an apse with an altar to the southern aisle in a second phase. The "Cathedral" added a triapsidal baptistery. The Southwest Church was reconfigured (a northerly door was closed and plastered over changing the direction of processions implied by the inscription in the north aisle). A three-line inscription was added to the mosaic in the chancel recording an offering by a priest named Simonios, referring possibly to the reliquary. ${ }^{22}$ Most significantly, the

\footnotetext{
20 The Council of Carthage in 401 made relics beneath altars compulsory in the West. Such positioning of relics became compulsory in the East in 787 at the Seventh Ecumenical Council at Nicea. Ann Marie Yasin, Saints and Church Spaces in the Late Antique Mediterranean: Architecture, Cult, and Community, Greek culture in the Roman world (Cambridge, UK ; New York: Cambridge Univ Press, 2009), 153-154.

${ }^{21}$ Mulholland, The Early Byzantine Christian Church, 45.

22 Adam Łajtar, "Mosaic Inscription from the South-West Church," in Hippos-Sussita : Eighth Season of Excavations : July 2007, ed. Arthur Segal (Haifa: Zinman Institute of Archaeology, University of Haifa, 2007), 57-59.
} 
Northwest Church added an apse and altar to the northern aisle and a martyrion chapel to the southern aisle forming a T-shaped chancel during the sixth century in its second major phase. ${ }^{23}$ The classification of the Northwest Church changes from Syrian to Roman. In fact, modifications at all four of these churches shift them toward a more Roman type. Assuming that the Northeast Church, the most Roman of the types, comes from this same period, some sort of theological/liturgical change seems to have come over Hippos Palaistinēs.

Mulholland finds similar modifications toward a Roman type within his catalogue in the sixth century. He states, "These modifications appear to coincide with the switch in religious favor from the Monophysite Antiochene or Syria Church to the Chalcedonian Roman Church during the sixth century that accompanied the accession of emperor Justin I and his nephew Justinian I." ${ }^{24} \mathrm{~A}$ second factor in church modification may have been the introduction of the Great Entrance rite to the liturgy in the second half of the sixth century, about the time of Justin II, which elevated the role of the rite of prothesis. ${ }^{25}$

Larger challenges of the sixth century also impacted Hippos. Inside the east gate of the city, a masonry tomb was discovered. Its location inside the city point to shrinkage of the parts of the classical city still occupied by domestic structures. Originally, a woman was buried in the tomb. At a later stage, likely the result of a plague or some other natural disaster, the tomb was opened, and other bodies were placed in it. At least twenty-seven separate skeletons have been identified, twenty of which were adults and seven of which were children. Small finds in the tomb date to the sixth century during which the empire was struck by the Justinianic plague (541-542). ${ }^{26}$

The plague may also help to an explain an unusual feature of the Northeast Church compound. To the south of the chancel and next to the tomb of a revered woman is an oversized diakonikon. Its roof was held up by two arches resting on pilasters. There are high benches on three sides of the room. Most unusual is the cistern in the northeast corner of the room. In that corner behind the cistern under a piece of a broken jar, we discovered a small hoard of gold jewelry including belt tabs and a healing amulet in a setting from the sixth century. Inscribed with the Greek word $\pi \varepsilon \dot{\pi} \pi \tau \varepsilon$, the amulet served stomachic purposes and supports the theory that a healing cult accompanied the tomb of a revered woman, in which the amulet was evidence for persistence of earlier practices. We will discuss this theory at length later in this report.

Intimated by the burial inside the east gate, the occupied portion of the city was shrinking in the sixth century. An additional indicator of this phenomenon is a family burial chapel

\footnotetext{
${ }^{23}$ Segal et al., Hippos-Sussita of the Decapolis: The First Twelve Seasons of Excavations (2000-2011) Vol 1, 198.

${ }^{24}$ Mulholland, The Early Byzantine Christian Church, 65.

${ }^{25}$ Robert F. Taft, The Great Entrance: A History of the Transfer of Gifts and Other Pre-Anaphoral Rites, 2nd ed., Orientalia Christiana analecta 200 (Roma: Pontificium Institutum Studiorum Orientalium, 1978).

${ }^{26}$ Arthur Segal et al., Hippos-Sussita : Eighth Season of Excavations : July 2007 (Haifa: Zinman Institute of Archaeology, University of Haifa, 2007), 98.
} 
excavated by the University of Haifa. In the corner of the ruins of the Roman Odeon, a small burial chapel was constructed. Its location near the city center suggests a dramatic shrinkage of the city. The chapel has a small nave carpeted in geometric mosaics and an even smaller chancel. They surround the opening to the tomb below. It is a masonry tomb like those in the Northeast Church and above the east gate. It held the remains of four individuals. $^{27}$

\section{The seventh century}

The decline that began in the sixth century continued and even accelerated in the seventh.

The first exemplar is the Southwest Church. A significant burn layer indicates that the structure was destroyed by fire and never rebuilt. Umayyad pottery is lacking in the ceramic profile, pointing to a late sixth or early seventh century destruction, after which the church was not rebuilt, and the location was abandoned.

A portion of the domestic quarter nearby displayed a paucity of ceramic finds near floor level and stone bowels and grinding mills were not in operational locations but pushed against the walls. This part of the city had been abandoned.

The seventh century marks the arrival of Islam in the land. Tiberias/Tabariya was "conquered by (the Arab commander) Shurahbil in the year 634/15 [CE/AH] by capitulation; one half of the houses and churches were to belong to the Muslims, the other half to the Christians. ${ }^{28}$ By 636 CE, Tabariya served as the regional capital.

While there is no evidence of such physical conquest at Hippos, the discovery of a Late Antique weight from the Northwest Church may nuance our understanding. The weight, with its high degree of craftsmanship and its elaborate inlay may have served as an official weight either of the church or even of the city. That the Golgotha cross on the weight was covered with a subtle mask "illustrates precisely where we can draw the line between the relative freedom of religion and tolerance that characterized Umayyad rule and the demands of official metrology." 29

Although crosses still adorned churches, in interpersonal interactions accommodations were necessary.

\footnotetext{
${ }^{27}$ Arthur Segal et al., Hippos-Sussita: Ninth Season of Excavations: June-July 2008 (Haifa: Zinman Institute of Archaeology, University of Haifa, 2008), 27-33.

${ }^{28}$ G. Le Strange, Palestine under the Moslems: A Description of Syria and the Holy Land from A.D. 650 to 1500, Khayats oriental reprints no. 14 (Beirut: Khayats, 1965), 340.

${ }^{29}$ Michael Eisenberg, Alexander Iermolin, and Sariel Shalev, "Archaeological and XRF Analysis of a Byzantine Weight from Hippos Sheds New Light on the Transition from Christian to the Islamic Rule," Israel Exploration Journal 68, no. 1 (2018): 95.
} 


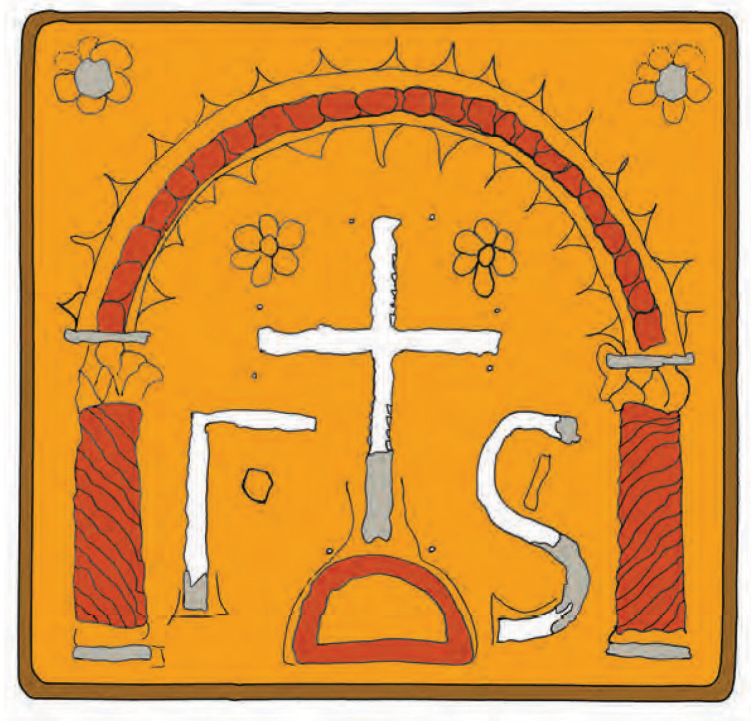

Figure 14 A drawing of the obverse of the weight ${ }^{30}$

[As] the weight may have been used in local and regional markets, and thus likely came into contact with representatives of the Umayyad administration from the nearby capital of Jund al-Urdunn (Tabariya), the need to hide symbols belonging to the previous rule and its religion on such artifacts should come as no surprise. ${ }^{31}$

Accommodation would soon be followed by additional decline in the occupation of the city and the practice of Christianity at Hippos Palaistinēs.

Nonetheless, near the center of the city the Northeast Church complex was still in use into the late seventh or early eighth centuries as was indicated by radiocarbon dating of the outer layer of plaster from the wall of the apse. ${ }^{32}$

\section{The eighth century}

Signs of decline are significant by the eighth century. During the reign of 'Abd al-Malik (685-705), known for his construction of the Dome of the Rock, a new road was constructed in the southern Golan to create a highway from Tiberias to Damascus. Although the identity of Hippos continues in literary references to a Susiya as a subdistrict of Jund al-Urdunn, the road bypassed Hippos. ${ }^{33}$ The city was no longer a significant site.

\footnotetext{
${ }^{30}$ Ibid., Fig. 8.

${ }^{31}$ Ibid., 95.

32 Arthur Segal et al., Hippos-Sussita : Seventh Season of Excavations : July 2006 (Haifa: Zinman Institute of Archaeology, University of Haifa, 2006), 84.

${ }^{33}$ Amikam Elad, "The Southern Golan in the Early Muslim Period: The Significance of Two Newly Discovered Milestones of Abd al-Malik," Der Islam; Zeitschrift für Geschichte und Kultur des islamischen Orients 76, no. 1 (1999): 64.
} 
Sometime during the late seventh or early eighth century, the Northeast Church complex seems to have been intentionally abandoned. We suspected such abandonment because throughout the project area only rarely did we find concentrations of ceramic shards at the floor level. Moreover, reliquaries were removed, a protective wall was constructed around the tomb of the elderly woman, and almost all the doorways to the various parts of a compound were intentionally sealed. Even Cardo 2 North, the via sacra to the site, was intentionally blocked about $18 \mathrm{~m}$ south of the south gate to the church compound. One door remained open to the church providing access to the south aisle. Such would allow continued veneration of tomb of the elderly woman.

An Arabic inscription has been found at Hippos. The inscription was great engraved on one of the columns that lined the ancient decumanus of the city. It was written after the column had already broken and fallen to the ground. There are seven lines to the inscription engraved in an angular, primitive, early eighth or even late seventh century, provincial script. Three words in lines one and two were destroyed later. They are the names of the person for whom the inscription was written and the name of the father as well as the word opening the invocation. The formula of this invocation resembles many other formulae of the same type which are common in graffiti or semi graffiti inscriptions from this period. Since the column was already broken when the inscription was made, it indicates that much of Hippos was already in ruins. ${ }^{34}$

Although Hippos was in serious decline, the practice of some Christianity seems to have survived until the earthquake of 749 . The so-called Cathedral was certainly destroyed by a major earthquake as is witnessed by the common position in which the columns were discovered. 749 is the most likely candidate.

Some ritual practice continued in the Northwest Church as well. For when the reliquaries in the martyrion chapel were unearthed in situ, having been sealed in place by the collapsing stone of the structure, the smaller reliquary sitting on top still had in its access hole a rod for the transference by touch of the sanctity of the relic to the petitioner. ${ }^{35}$

The terminus ad quem for occupation of Hippos is often given as the earthquake of 749 CE. As sites up and down the Jordan valley indicate, the quake was most destructive. Toppled columns of the forum are connected to this event. But Hippos was not thriving prior to the earthquake. By the mid-eighth century, most of the mountain top was abandoned.

There is little evidence of any occupation at the site following the earthquake of 749 . This site, with its concentration of churches, had been the largest Christian center around the

\footnotetext{
${ }^{34}$ Segal et al., Hippos-Sussita : Seventh Season of Excavations : July 2006, 43-46.

${ }^{35}$ Mlynarczyk, "Churches and Society in Byzantine and Umayyad-Period Hippos," 255. 
lake where Jesus was first active. But regional forces of urban decline and social change inevitably led to the end of the practice of Christianity at Hippos Palaistinēs. 
The Northeast Insulae Project

$-18-$ 


\section{3.}

\section{AN ARCHAEOLOGICAL DESCRIPTION OF THE NORTHEAST INSULAE}

$\boldsymbol{T}$ he excavation of the northeast insulae of Hippos of the Decapolis began with an explo1 ration of a building identifiable on the surface and labelled the Northeast Church. Work proceeded out from the church to expose major portions of the northeast insulae. A chronological description of the archaeological excavation of the northeast insulae is provided in a second volume of this report. It adds additional detail to this description which is abstracted here from that volume.

\section{Central Zone}

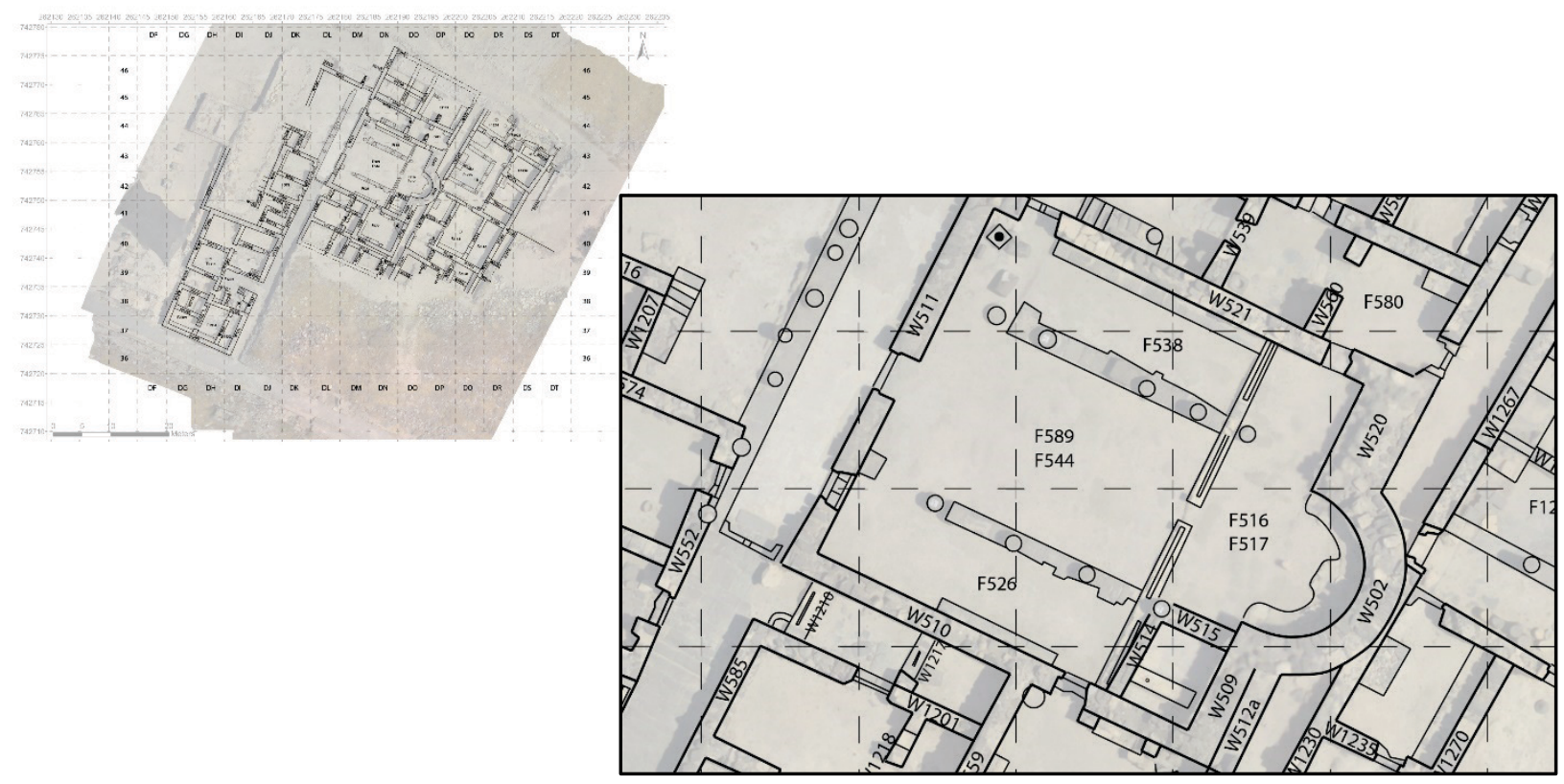

Figure 15 Northeast Church 


\section{Northeast Church}

The Northeast Church is a small structure $(12.5 \mathrm{x} 13 \mathrm{~m})$ with a single exterior apse. The aisles are separated from the nave by a row of columns. There were two entrances from the west and one from the north.

\section{Chancel}

The apse wall (W502) is intact to seven courses above the synthronon (1.57 m) with some declination of the north side. It is approximately $4.5 \mathrm{~m}$ wide and $3 \mathrm{~m}$ deep. Basalt stones with a rectangular, stipple face comprise the lower courses. Destruction fill suggests that upper courses were of limestone. The dome was surfaced on its interior with plaster. Pigmented plaster fragments (red, yellow, and orange) suggest a fresco covered the dome.

The chancel is clearly demarked from the rest of the domus by the base for a chancel screen that runs across nave and aisles in a north-to-south direction. Two chancel posts of divergent design were recovered from the destruction fill along with a fragment from the top of a third. There were three openings into the chancel from the west: one from the center of the nave, and one from each of the aisles next to their respective columns.

Two stone fragments of chancel screen panels were recovered from the destruction fill. Vine and cluster themes provide the background for the panel. The corner of the flared arm of a cross may be visible on one of the fragments.

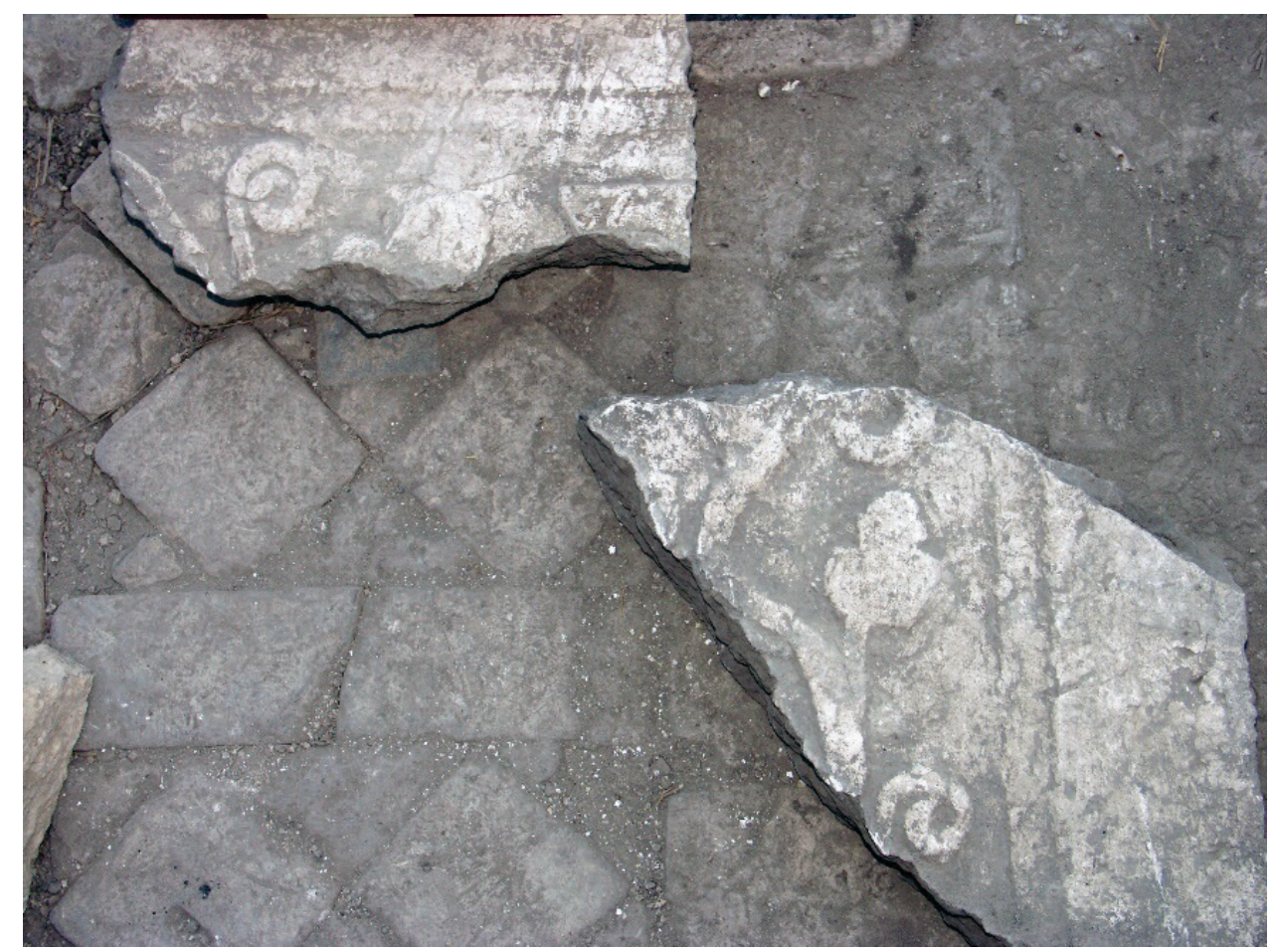

Figure 16 Chancel screen fragments 
Against the apse wall (W502) is a highly eroded synthronon of soft limestone covered by plaster. Its depth of 1.0-1.12 m would accommodate one row of presbyters. The central section of the synthronon protrudes an additional $10-15 \mathrm{~cm}$ into the apse and rises $26 \mathrm{~cm}$ above the rest of the synthronon. The remainder of the apse floor (F516) is covered with stone in opus sectile, portions of which are patterned.

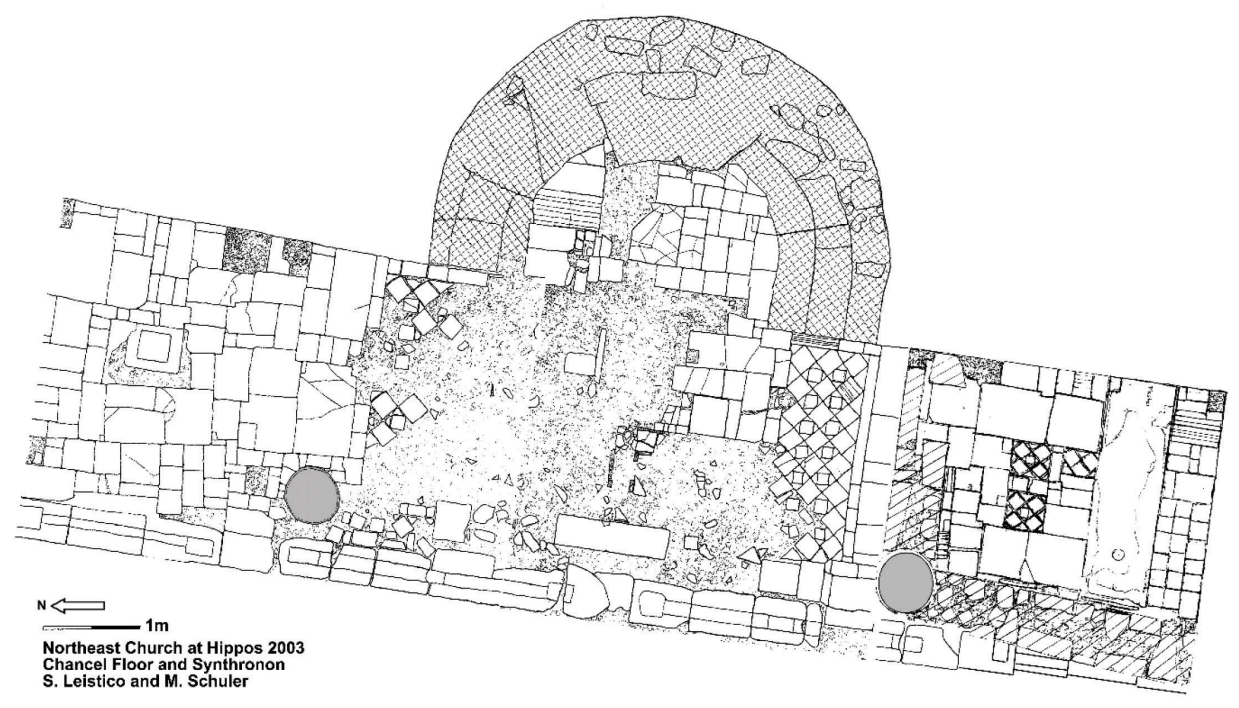

Figure 17 Plan of the chancel

A single panel of the chancel screen would have spanned the north-to-south dimension at the east end of the north aisle, allowing an entrance to the cancel from the west just north of the easterly column in the north run. Access to this same part of the cancel was also possible through a $1.06 \mathrm{~m}$ doorway in the north wall (W521), which closed from outside the domus. There are two voids in the floor. One is centrally located in the middle of the axis of the northerly chancel screen panel. In it was a loculus for a reliquary (31 x $31 \times 17 \mathrm{~cm}$ deep). Next to the east wall (W520) and slightly south of the central axis was a second void. It too seems to a loculus for a reliquary, but its dimensions are smaller $(20 \times 20 \mathrm{~cm})$ and its construction is poorer. Original wall plaster intact between the structure of this loculus and the wall confirms that F516 and both loculi are secondary to the original construction of the church.

Access to the central section of the chancel at the east end of the nave was gained through a central opening in the chancel screen. A $114 \times 30 \mathrm{~cm}$ stone in secondary use spans the entrance. Although most of the opus sectile floor (F516) had been destroyed, two bands ( $1 \mathrm{x}$ $2.2 \mathrm{~m}$ ) of square-in-square pattern are discernable on the north and south margins of the central section of the chancel.

Under the level of the destroyed floor is the plaster layer of the first floor (F517). Many loose tesserae were recovered from the fill. Cut into the plaster layer (and thus part of a secondary 
phase) was another loculus for a reliquary $(17 \times 26) .{ }^{36}$ Preserved partially, it sits on the central east/west axis of the church. Just to its south is another similarly sized loculus made of thin marble slabs. It had been plastered full.

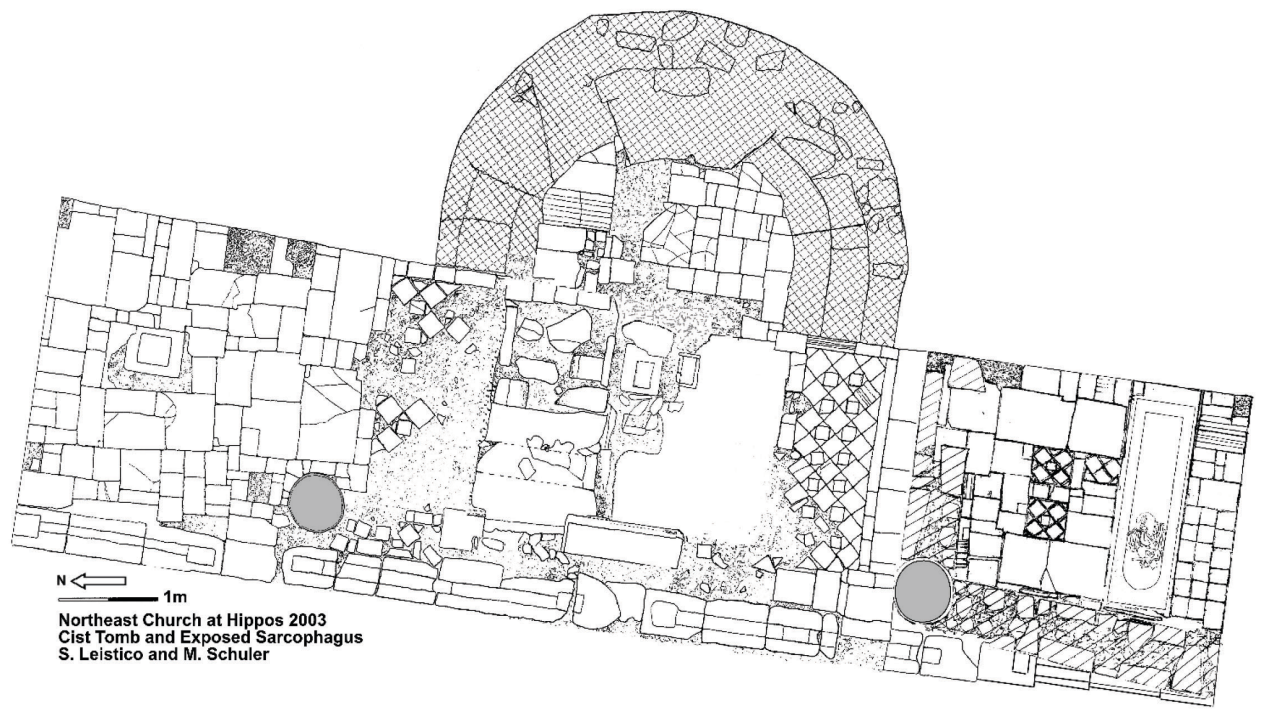

Figure 18 Chancel showing detail of the tombs

\section{Masonry tomb}

To the north of the central axis is a masonry tomb in an east-to-west orientation. Three basalt stones were in situ covering the western half of the tomb. The eastern cover stones (limestone) were broken. The sidewalls of the masonry tomb are basalt ashlars creating an opening $97 \times 216 \mathrm{~m} .{ }^{37}$ The chamber of the masonry tomb is constructed of four courses of ashlars. ${ }^{38}$ The interior opening of the chamber is $97 \mathrm{~cm}$ (north to south), $2.17 \mathrm{~m}$ (east to west), and $1.42 \mathrm{~m}$ deep.

\footnotetext{
${ }^{36}$ For an example of similar loculi, see Georges Tchalenko, E. Baccache, and Institut français d'archéologie du ProcheOrient, eds., Eglises de Village de La Syrie Du Nord, Bibliothèque archéologique et historique / Institut français d'archéologie du Proche-Orient t. 105 (Paris: Librairie orientaliste P. Geuthner, 1979), plate 153.

${ }^{37}$ Similar construction is visible in the tombs in the northwest corner of the Martyrion d'Antioche-Koussié. Jean Lassus, Sanctuaires Chrétiens de Syrie: Essai Sur La Genèse, La Forme et l'usage Liturgique Des Édifices Du Culte Chrétien En Syrie, Du IIIe Siècle à La Conquête Musulmane (Paris: P. Geuthner, 1947), plate xli.

${ }^{38}$ The bottom course is $37 \mathrm{~cm}$ high. The blocks from west to east are $38 \mathrm{~cm}, 34 \mathrm{~cm}, 56 \mathrm{~cm}, 38 \mathrm{~cm}, 49 \mathrm{~cm}$. The second course is $35 \mathrm{~cm}$ high. The blocks from west to east are $28 \mathrm{~cm}, 55 \mathrm{~cm}, 50 \mathrm{~cm}, 49 \mathrm{~cm}, 34 \mathrm{~cm}$. The third course is $40 \mathrm{~cm}$ high. The blocks from west to east are $40 \mathrm{~cm}, 68 \mathrm{~cm}, 37 \mathrm{~cm}, 71 \mathrm{~cm}$. The top course is $21 \mathrm{~cm}$ high. The blocks from west to east are $58 \mathrm{~cm}, 74 \mathrm{~cm}, 26 \mathrm{~cm}, 57 \mathrm{~cm}$.
} 


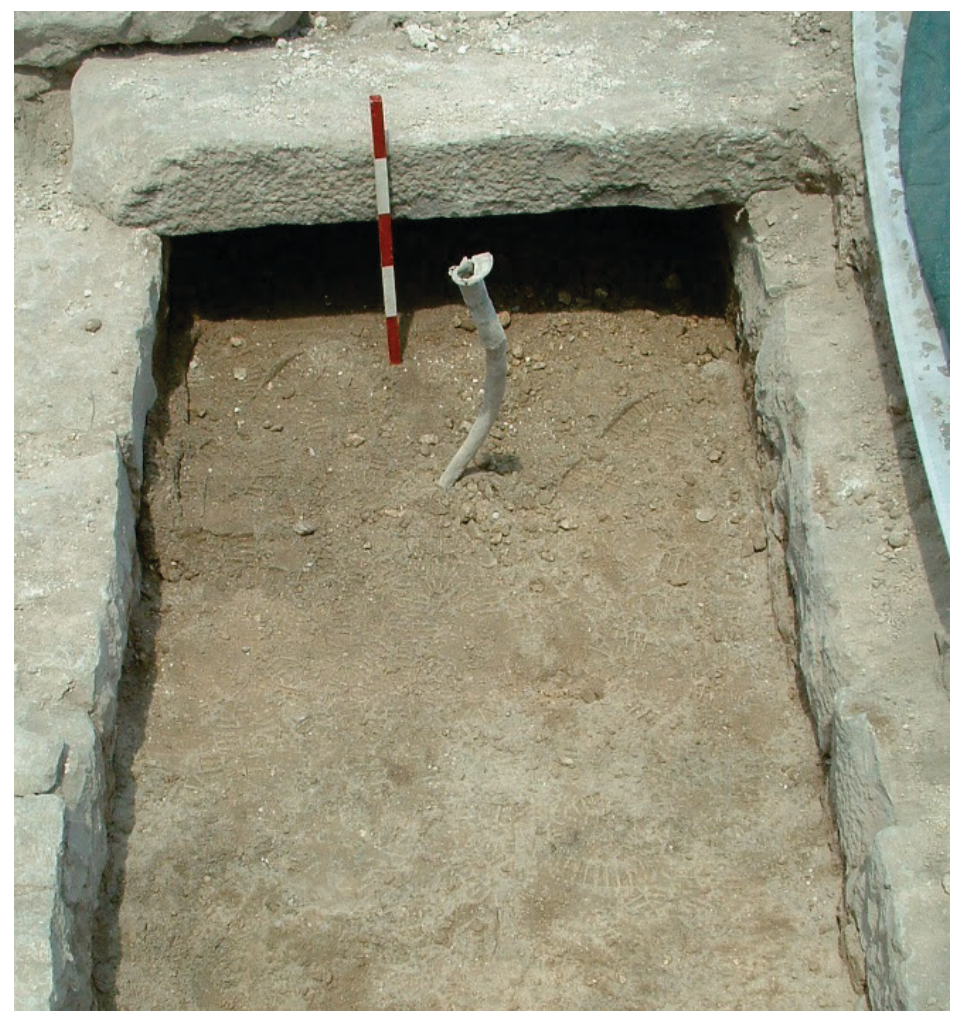

Figure 19 Lead pipe down to burial

Between the second and third covering stones, a lead pipe extended down into the tomb. The lead pipe is rolled, not melted. Its top was hammered into a funnel. The pipe is $72 \mathrm{~cm}$ long (partly broken at 16 and $35 \mathrm{~cm}$ from the top). The exterior diameter of the pipe is 2.44 $\mathrm{cm}$. The thickness of the lead is $3.7 \mathrm{~mm}$. The funnel end has a diameter of $4.58 \mathrm{~cm}$. A plaster mound held the funnel to the level of the opus sectile floor (F516).

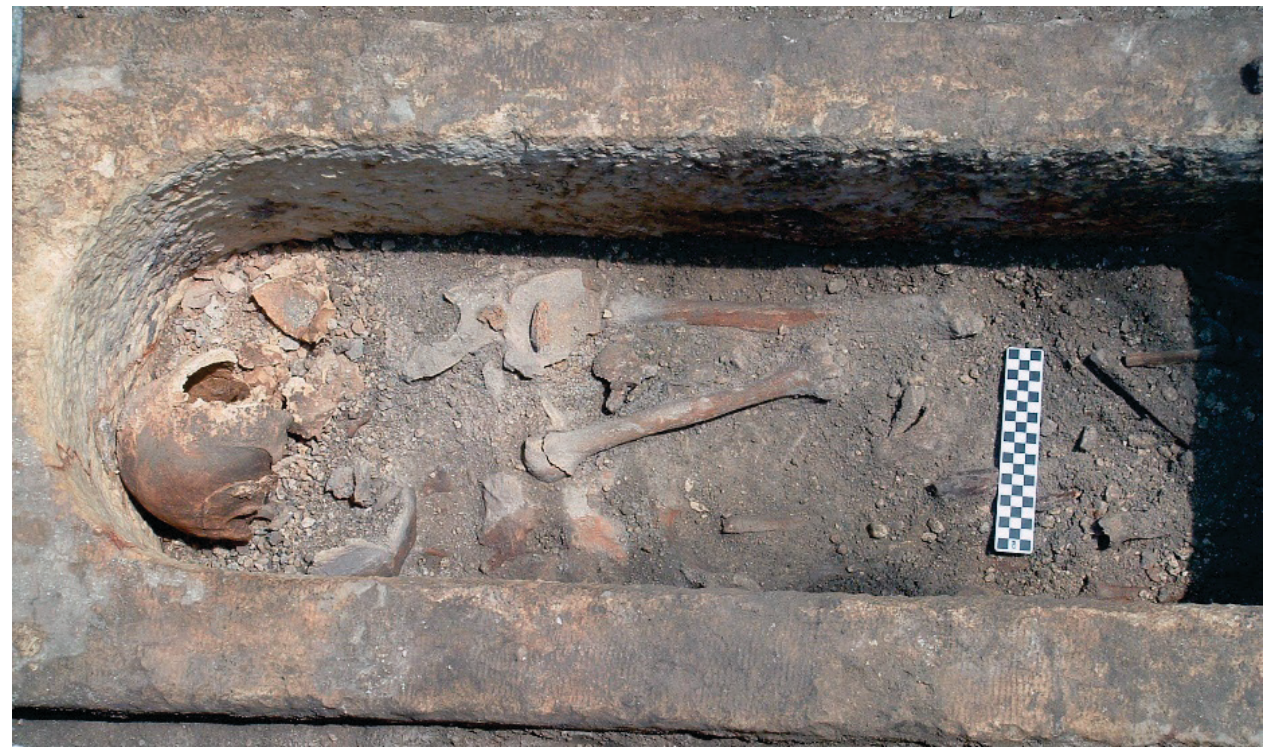

Figure 20 Remains in sarcophagus in masonry tomb 
At about $75 \mathrm{~cm}$ below the level of the opus sectile floor (F516) is the limestone box of a sarcophagus. The box measures $200 \times 60 \mathrm{~cm}$. Its walls are $11-12 \mathrm{~cm}$ in thickness and its internal depth is $30-34 \mathrm{~cm}$. The box of the sarcophagus was covered by six stones in secondary use that were $4-9 \mathrm{~cm}$ thick, two of which were marble. Between the second and third stones from the west, two triangular stones and plaster connected the lead pipe to the burial below. The burial was undisturbed.

Notably, the sarcophagus in the masonry tomb sits somewhat askew from level. Further excavation between the north side of the sarcophagus box and the north basalt wall of the masonry tomb showed that the sarcophagus box is perched on irregular stones 27 to $33 \mathrm{~cm}$ above the smooth limestone floor of the chamber of the masonry tomb. Recovered from the accessible fill at the bottom of the masonry tomb chamber were several nails and nail fragments.

The space between the bottom of the sarcophagus box and the floor of the masonry tomb $(27-33 \mathrm{~cm})$ is comparable to the depth of Late Antique lead coffins. ${ }^{39}$ The practice of stacking burials has a parallel in the tomb of Azonaine in the church of St. Theodore at 'Avdat, ${ }^{40}$ but the construction of the latter is finer.

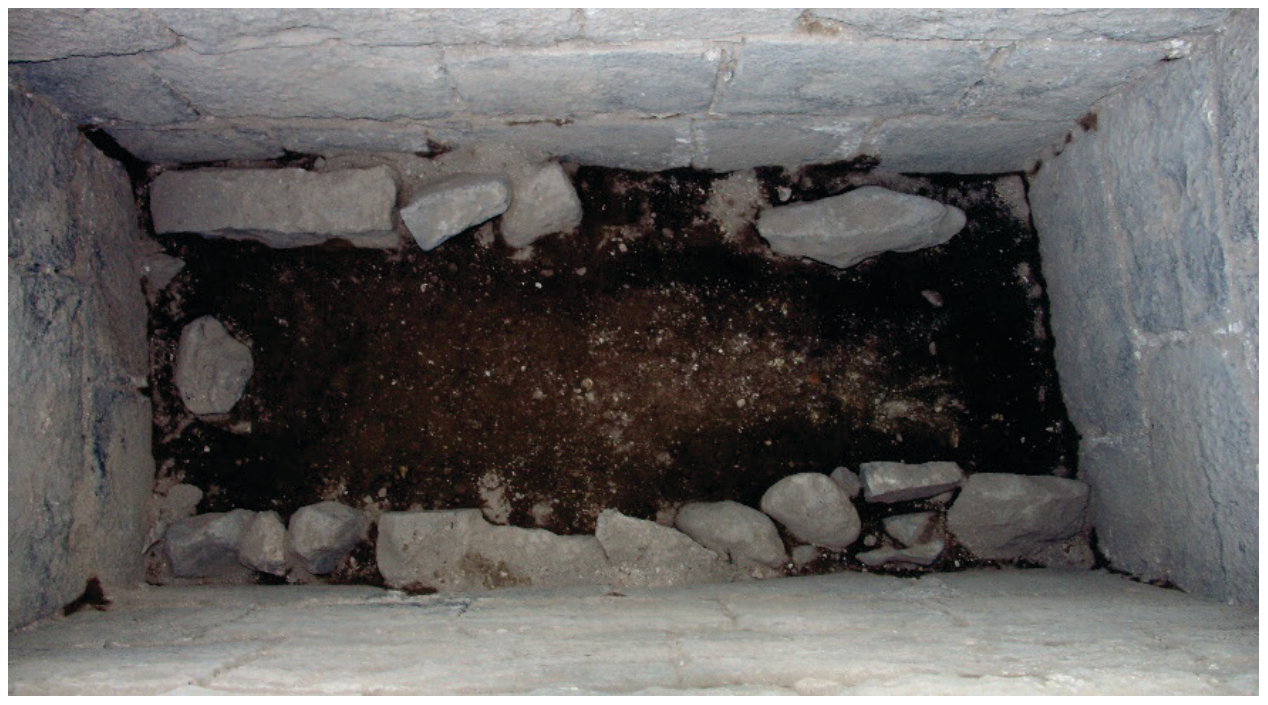

Figure 21 Masonry tomb

\footnotetext{
${ }^{39}$ A lead coffin with a depth of $31 \mathrm{~cm}$ is described by Levi Itshaq Rahmani, "A Christian Lead Coffin from Caesarea," Israel Exploration Journal 38, no. 4 (1988): 246; another lead coffin with a depth of $36 \mathrm{~cm}$ is noted by Levi Itshaq Rahmani, "A Lead Coffin from the Hefer Valley," Israel Exploration Journal, no. 24 (1974): 124-127; depths of 34 cm, $41 \mathrm{~cm}, 39 \mathrm{~cm}$ and $19 \mathrm{~cm}$ are cited by Levi Itshaq Rahmani, "Five Lead Coffins from Israel," Israel Exploration Journal 42, no. 1-2 (1992): 81-102.

${ }^{40}$ Avraham Negev, The Greek Inscriptions from the Negev, Studium Biblicum Franciscanum. Collectio minor N. 25 (Jerusalem: Franciscan Printing Press, 1981) fig. 33.
} 
Removal of the sarcophagus revealed that it had been placed on rough stones that lined the north, west, and south edges of the masonry chamber. Discoloration of the remaining soil (2.5 YR 5/1) indicated the outline of a decayed wooden box.

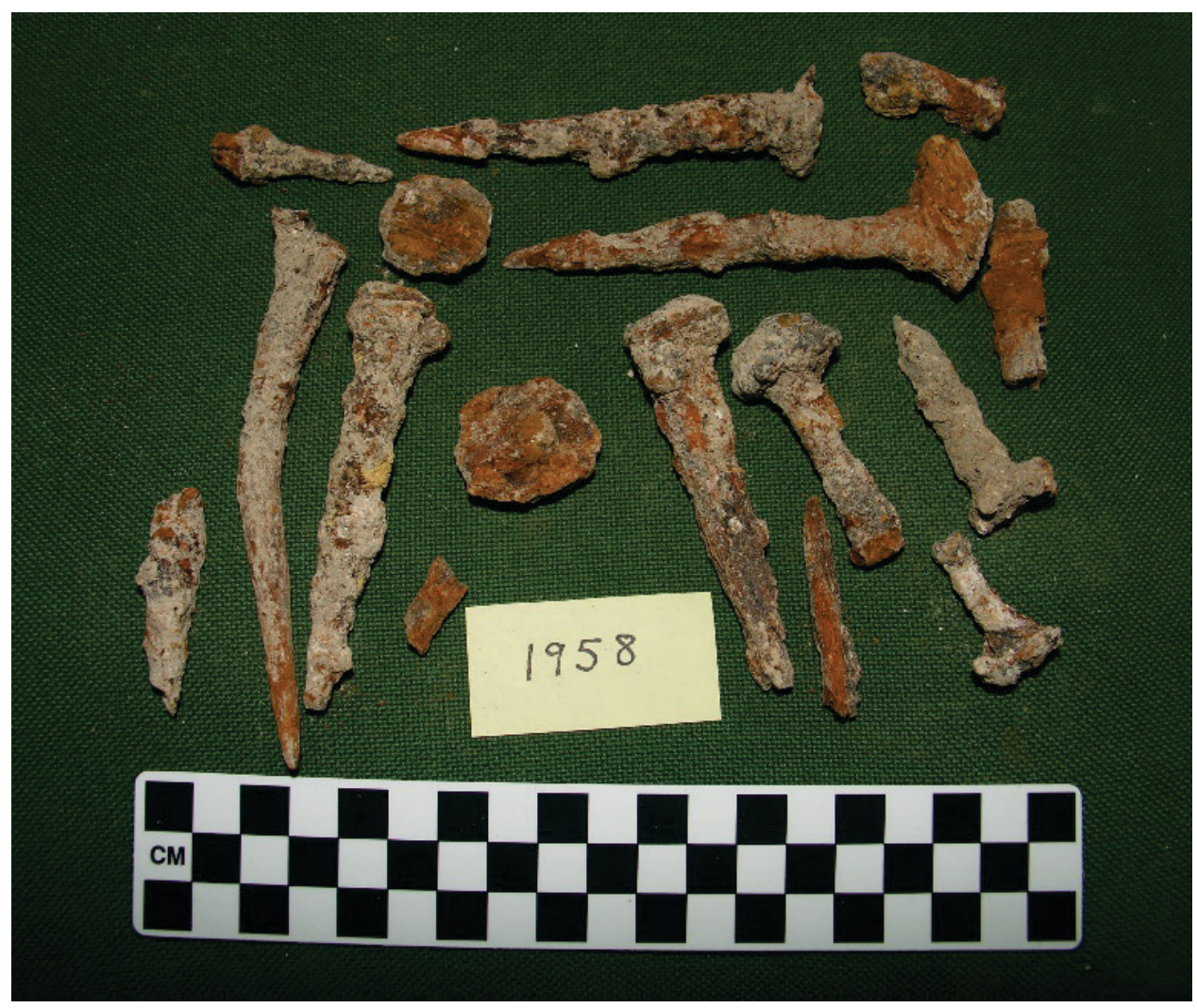

Figure 22 Nails from beneath the sarcophagus

Twenty-six fragments of iron nails are supportive of this proposal, as is a lead corner bracket $(7 \times 6 \mathrm{~cm})$ recovered from the fill. These are identical to those recovered at other Late Antique burial sites in the Hefer Valley and at Rammun and likely belonged to a wooden coffin. ${ }^{41}$

The remains of twelve individuals were recovered from the tomb, nine in the sarcophagus and three from the area below the sarcophagus. We recovered no major bones from the area below the sarcophagus, so we surmise that the burials were removed leaving only fragments. Nevertheless, those who inserted the sarcophagus on top of the remains of a coffin intentionally raised the sarcophagus above the coffin about $20-25 \mathrm{~cm}$. That which was below was too revered to be crushed or to be swept away. It is possible that the removal reflects the practice of extracting relics. ${ }^{42}$ But we also must consider the possibility that the bodies interred below were mostly exhumed and placed into the sarcophagus along with the other

\footnotetext{
${ }^{41}$ Rahmani, "A Lead Coffin from the Hefer Valley," 124; Hamdan Taha, "A Byzantine Tomb at the Village of Rammun," Liber Annuus 48 (1998): 342, plate 5.

${ }^{42}$ V. Saxer, "Cult of Martyrs, Saints, and Relics," ed. Angelo Di Berardino, Encyclopedia of the Early Church, Istituto patristico Augustinianum (New York: Oxford University Press, 1992), 533.
} 
burials. These burials in the sarcophagus were revered with oil/wine through a lead pipe and no provision was made for ongoing reverence of what was below.

Portions of the visible floor (F516) and the plaster layer of the first floor (F517) were removed in a $1.5 \times 2.5 \mathrm{~m}$ section north of the masonry tomb chamber. A vertical line of plaster of indeterminate function runs parallel to the long axis of the tomb about $1.5 \mathrm{~m}$ to the north between the first column base and the east wall (W520). The north wall of the masonry tomb is held in place by assorted stones in a dense mortar. A conical socket for a post is evident $1.2 \mathrm{~m}$ north of the masonry tomb opening and $1.5 \mathrm{~m}$ west of the synthronon under the plaster base (L550) of the first floor (F517). Also of note is a Late Antique ionic capital ${ }^{43}$ covered with intact plaster that serves as the foundation stone for the north corner of the apse wall. Only Roman/Late Antique pottery fragments were recovered under the sealed base of F517.

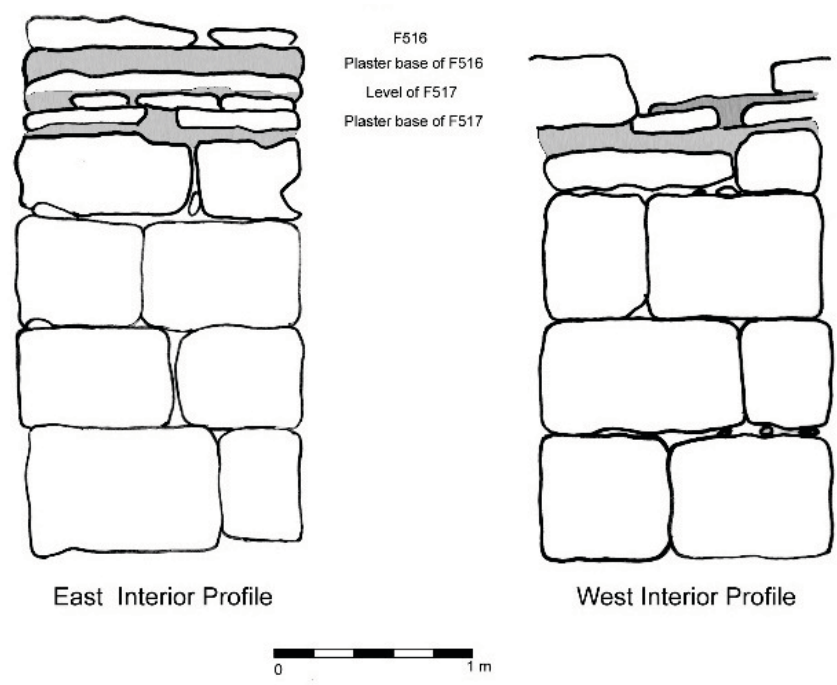

Figure 23 End profiles of the masonry tomb

Complete excavation of the chamber also allowed for clarification of its relationship to the Northeast Church complex. Cross sections and measurements ${ }^{44}$ show that the gap between

${ }^{43}$ See type 4 in Itamar Taxel, "Late Antique Ionic Column Capitals in the Countryside of Central Palestine between Provincial Trends and Classical Traditions," Studies in Late Antiquity 2, no. 1 (2018): 104-108.

${ }^{44}$ Elevations:

Plaster floor of the chamber east end

Plaster floor of the chamber west end

Bedrock lowest exposed level

Cross section examining floors on west end:

F516

Plaster layer of F517

Top course of masonry tomb

Cross section examining floors on east end:

F516

Plaster layer of F517

Top course of masonry tomb
129.227

129.151

129.053

130.854

130.650

130.521

130.941

130.760

130.596 
F516 and the plaster layer of F517 is $18-20 \mathrm{~cm}$. The gap between the plaster layer of F517 and the top course of masonry stones is $13-17 \mathrm{~cm}$. The plaster of F517 covers over the top course of the masonry tomb. The thickness of the covering stones is $18-20 \mathrm{~cm}$, the middle surviving stone of which has a piece of opus sectile paving adhering to its upper side. We therefore conclude that the masonry tomb was constructed prior to the laying of the original chancel floor (F517).

Subsequently, when the sarcophagus was inserted, a later opus sectile floor (F516) was placed over the top of the tomb, using some of the tiles to hold in place the lead pipe used to reverence the burials below.

\section{Tomb of a revered woman}

The floor at the east end of the south aisle in the chancel is opus sectile style in local stone with some marble pieces in secondary use. Two short, perpendicular walls are constructed on top of this floor. One wall (W515) runs from the east column in the south run to the east wall. The other (W514) runs from the same column to the south wall, skewing somewhat to the west over the top of the channel for the altar screen. W515 has a small doorway toward its east end. The design of what remains plus doorjambs recovered from the fill above suggests that the door was not used for regular access. These secondary walls and the room itself seem to serve a protective purpose for what is inside.

Inside the room created by W514 and W515 is a rectangular surface. It is $16.5 \mathrm{~cm}$ above the floor and $57 \mathrm{~cm}$ from the south wall (W510). The surface is monolithic limestone stone that had been plastered. It is $76 \mathrm{~cm}$ wide and $227 \mathrm{~cm}$ long. The sides of the raised surface are marble slabs $3 \mathrm{~cm}$ thick.

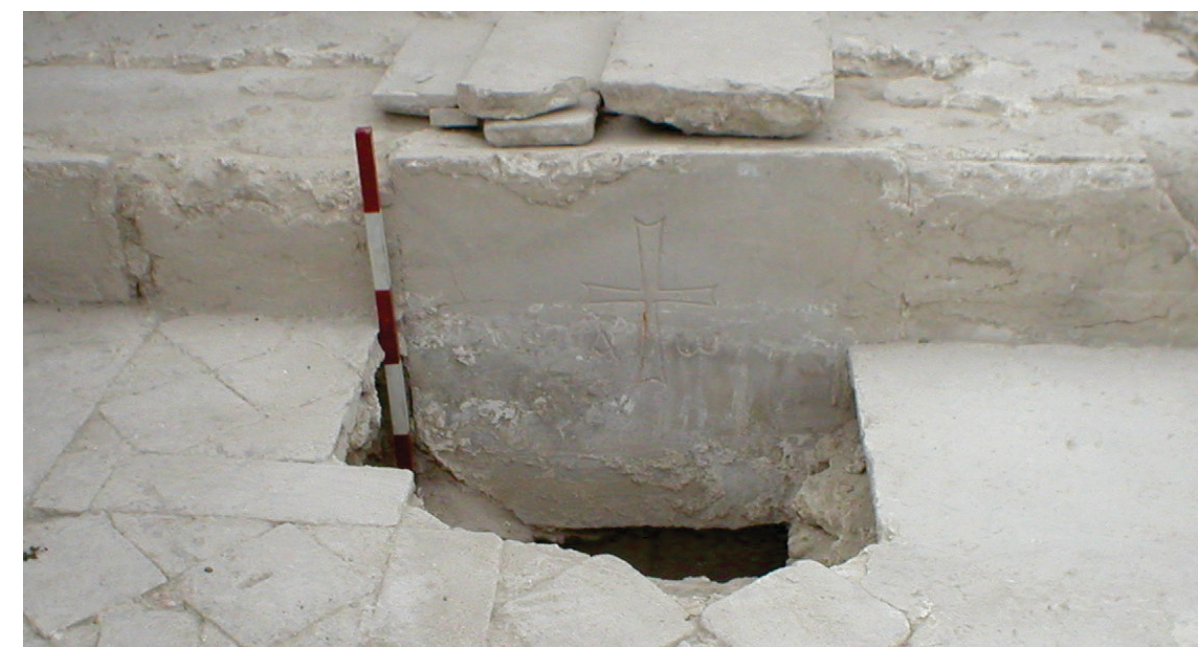

Figure 24 North facing of the tomb with cross

On the north side is an incised cross. The lower member of the cross with an alpha and omega were not visible until the floor was opened, and the plaster base of the original mosaic floor (F517) was exposed. 


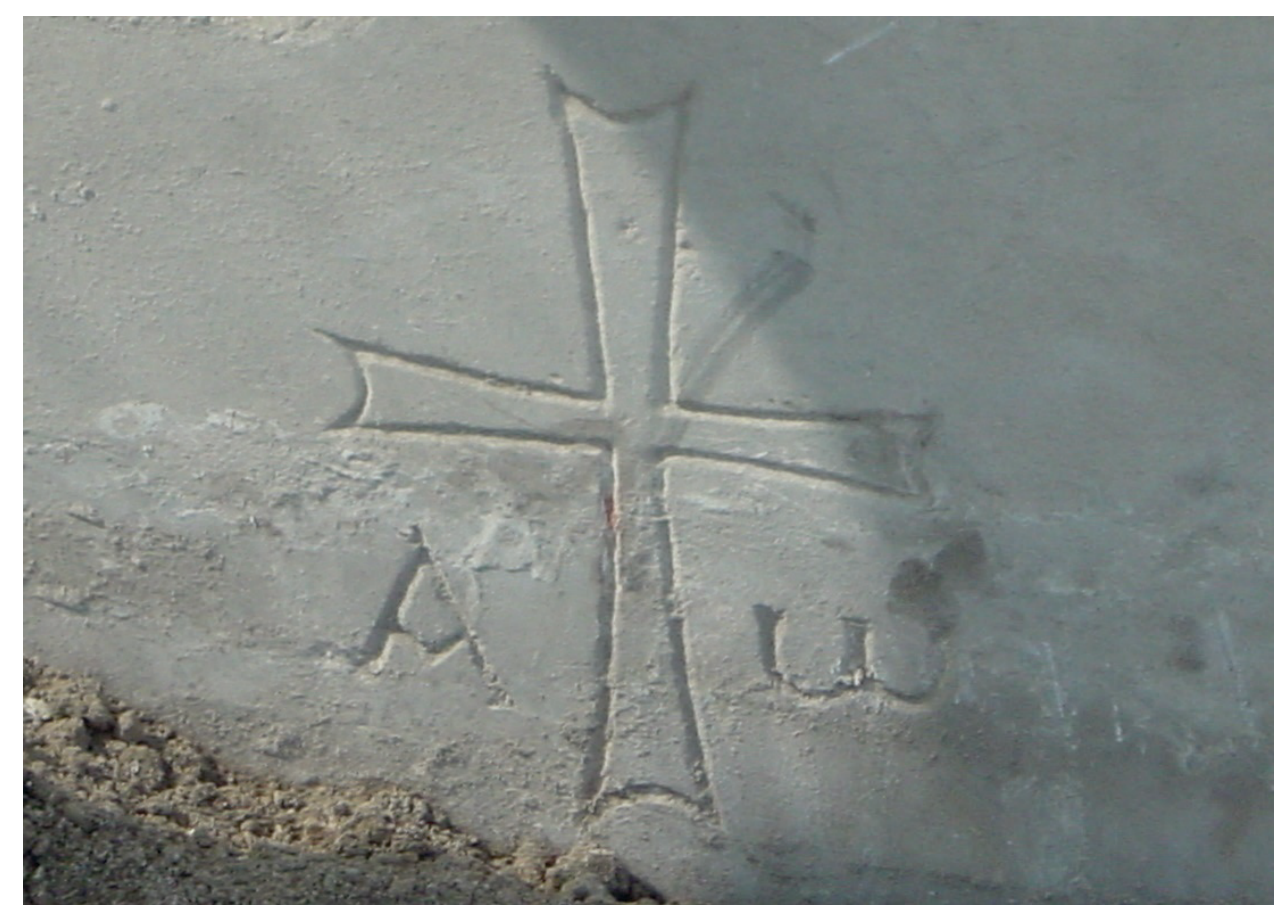

Figure 25 Closeup of the cross

On the top of the plastered lid of the tomb is a small basin and hole. Its center is $36 \mathrm{~cm}$ from the south edge and $53 \mathrm{~cm}$ from the west. The shallow basin is $9 \mathrm{~cm}$ in diameter with a $1 \mathrm{~cm}$ rim and a $1 \mathrm{~cm}$ hole. The hole was probed with a wire to the depth of $9 \mathrm{~cm}$.

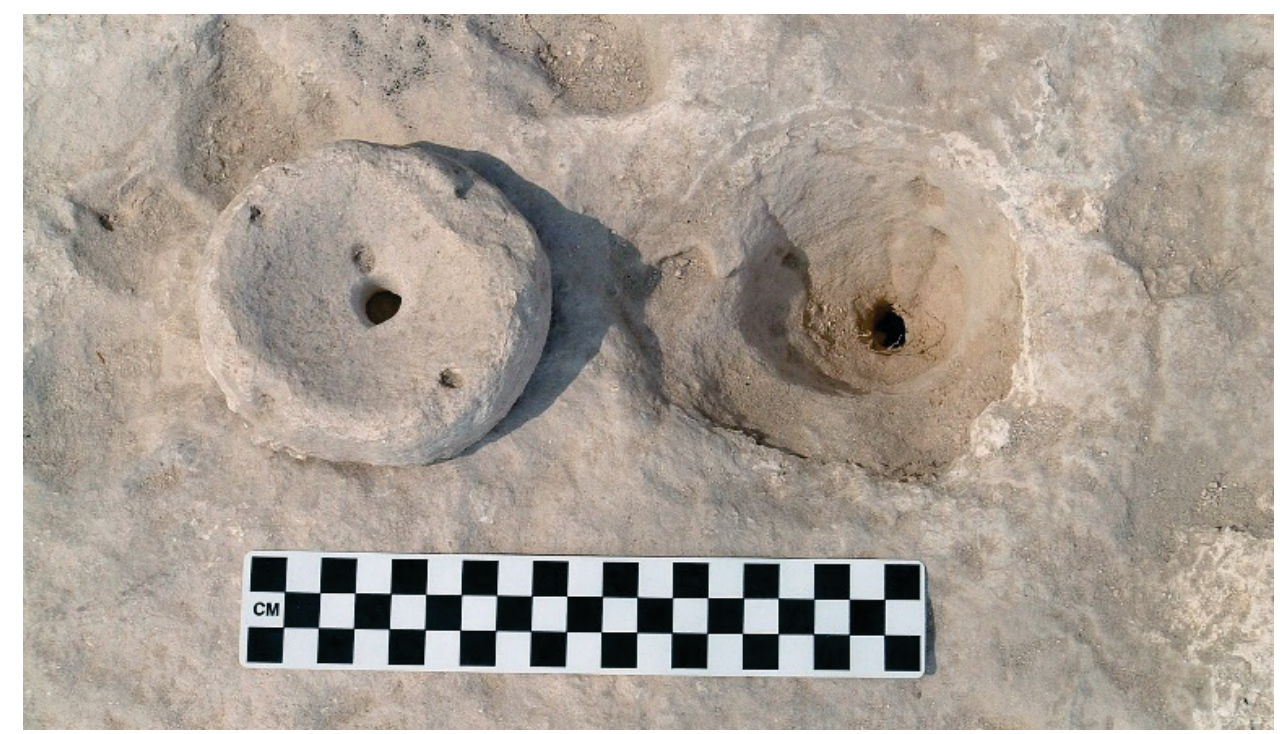

Figure 26 Basin and hole bored into the lid of the sarcophagus

On the west face of the tomb is a single piece of marble $3.5 \mathrm{~cm}$ thick and $65 \mathrm{~cm}$ wide. It was broken at the level of the top of the sarcophagus box, with the top pieces coarsely plastered 
back. An inscribed cross was discovered under the crude plaster. As with the cross inscription on the north face, the arms of the cross flare to points. Small disks or dots are inscribed just beyond each point. ${ }^{45}$

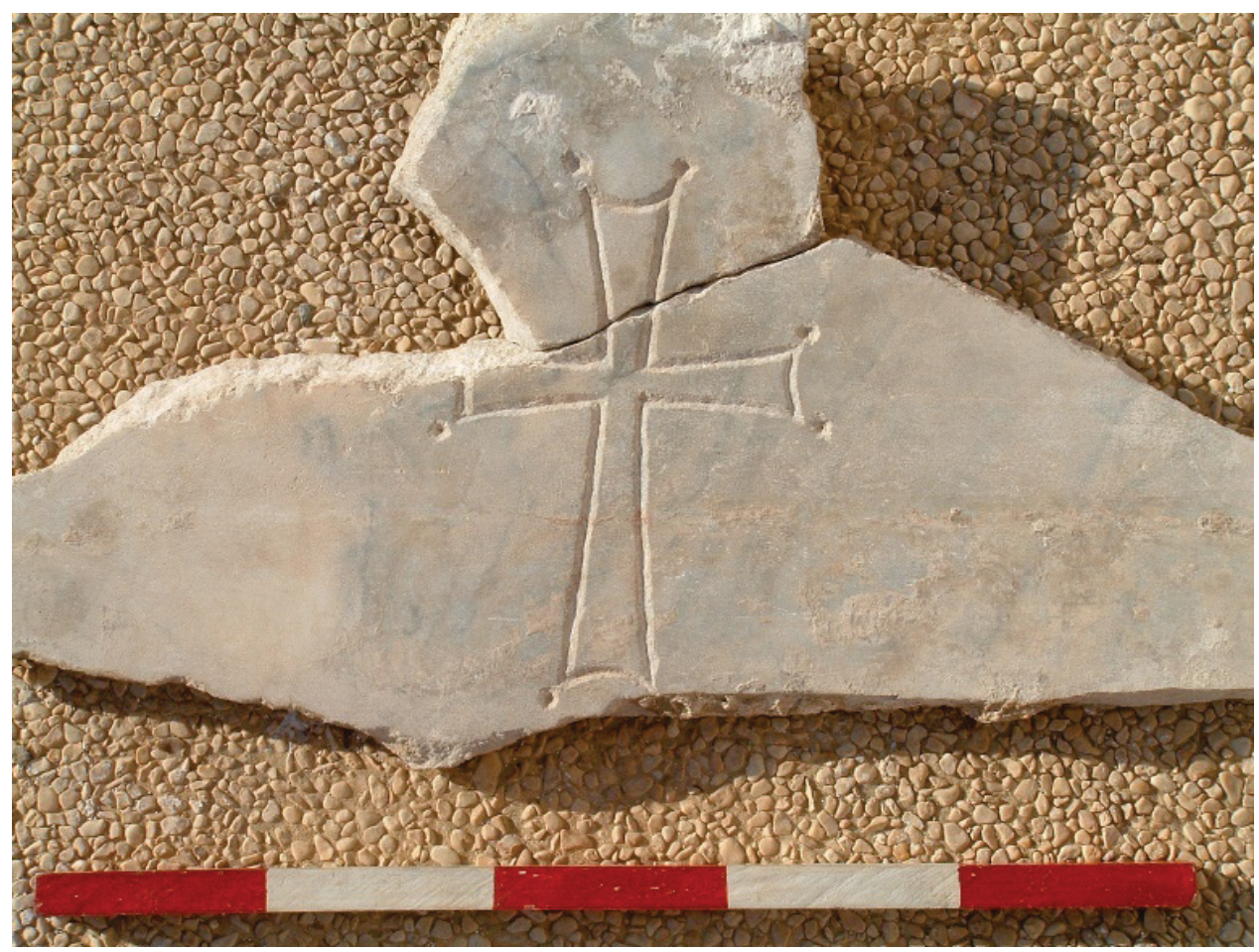

Figure 27 Cross on west face of south tomb

To allow access to the sarcophagus, the west wall (W514) was removed. The wall was sealed to the floor with plaster. The exposed channel in the base for the chancel screen was also filled with plaster. Portions of the opus sectile floor (F516) were removed to the north, west and south of the sarcophagus. Fill was cleared to the plaster base of F517. A 1 m section of mosaic tile from F517 was still intact next to the south wall (W510). Visible was the same black band that would characterize the border of the other mosaics in the church.

The box of the sarcophagus ${ }^{46}$ is a single piece of limestone. Its width varies from $61.5 \mathrm{~cm}$ at the west end to $64 \mathrm{~cm}$ at the east end. Its length is $2 \mathrm{~m}$ on center. The walls range between 10 and $12 \mathrm{~cm}$ thick. The interior is rounded at the west end, beginning $33 \mathrm{~cm}$ from the west. The interior depth slopes from 35 to $38 \mathrm{~cm}$ west to east. Carving stokes on the interior of the north side angle down from east to west at about 60 degrees. On the south side, there are some discernable stokes in a downward direction.

\footnotetext{
${ }^{45}$ This style of cross is frequently used for bronze processional crosses. John A. Cotsonis, Byzantine Figural Processional Crosses, Dumbarton Oaks Byzantine Collection publications no. 10 (Washington, D.C: Dumbarton Oaks Research Library and Collection, 1994), figs 8 and 9.

${ }^{46}$ The use of an exposed sarcophagus is without precedent in Byzantine churches in Palestine. For a discussion of the use of sarcophagoi in and near Byzantine churches of Syria, see Lassus, Sanctuaires Chrétiens de Syrie, 231-232.
} 
The lid is a monolithic piece of limestone $23 \mathrm{~cm}$ high x $197 \mathrm{~cm}$ long x $59 \mathrm{~cm}$ wide. Small stones and plaster on the edge of the box created a 2-3 cm gap at the west end. There was a rather large gap in the northwest corner between lid and box.

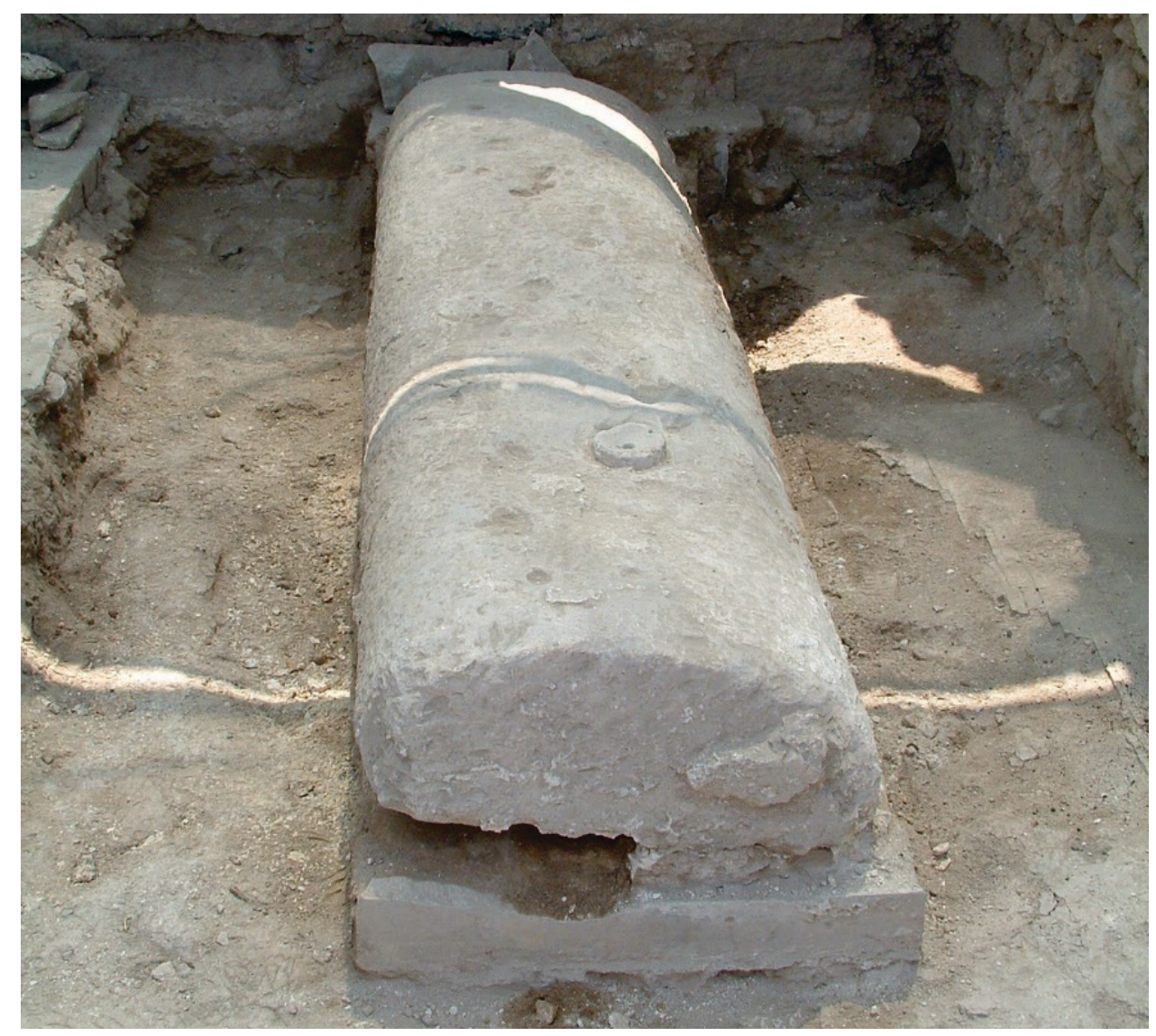

Figure 28 Sarcophagus and lid

The various layers of plaster and floor tiles, especially to the east of the sarcophagus, and well as the gaps and broken pieces, suggest several phases. The exposed sarcophagus is contemporaneous with the building of the church and the laying of F517, as its marble facing is set into the plaster of the floor. Subsequently, F516 was laid. Some plaster from W509 curves on top of the tile of this floor east of the tomb. In a third phase, the sarcophagus was opened by breaking the western marble face and its inscribed cross. Then the lid was pried up from the west. This action is suggested by a gap in northwest corner, the eastern facing being broken above the level of F516, and the breaking of two of the north facing pieces.

The lid was then lowered back into place. Plaster filled gaps left by broken pieces and leveled the top. A basin for holy oil was plastered over the hole bored into the lid. The shattered 
western inscription was put back and plastered over. Desecration seems to be a logical explanation for the third phase, the repair done by the poor survivors of whatever had happened. ${ }^{47}$ But, it is also possible that the damage was done while removing relics, a practice of eastern Christianity.

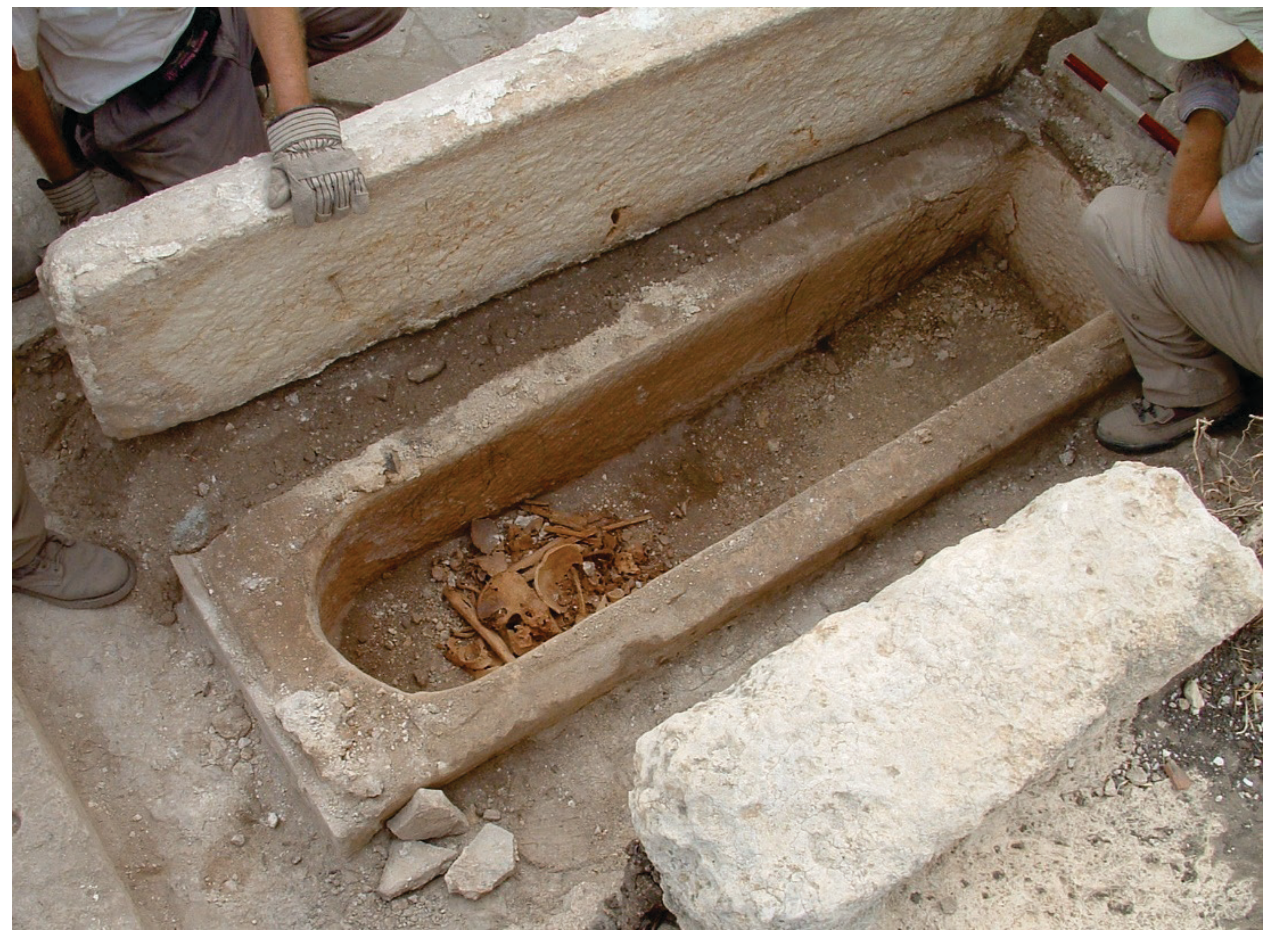

Figure 29 Opened sarcophagus

When the exposed sarcophagus was opened, it contained the bones of a single small woman of 60 plus years. ${ }^{48}$

The striking burial and saintly veneration of a woman in the chancel of this small Late Antique chapel in the heart of a Decapolis city raises questions of identity that are complicated by her anonymity. However, a plausible parallel is the Kyria Maria church at Scythopolis. The chapel was part of an urban monastic community (for recluses). There are tombs in the northeast and southeast corners of the chapel. A mosaic inscription over the tomb at the east end of the south aisle reserves the tomb for "Lady Mary who founded this church." 49

The burial in the Northeast Church at Hippos has the additional distinction of demarcating the tomb within the chancel, providing for on-going veneration, and according a degree of anonymity to the inhumation.

\footnotetext{
${ }^{47}$ A significant massacre took place at Kursi during the time of the Sassanid invasion in 613 CE. Kursi was within the territory of Hippos. Charles R. Page, "Kursi Excavations Resumed: Two New Seasons (2001, 2002)" (Presented at the Annual Meeting of the Society of Biblical Literature, Toronto, Canada, November 23, 2002).

${ }^{48}$ See chapter XXX for a full description of the burial.

${ }^{49}$ Gerald M. FitzGerald, A Sixth Century Monastery at Beth-Shan (Scythopolis) (Philadelphia: Published for the University museum by the University of Pennsylvania press, 1939), 27.
} 
After excavation of both tombs, we conclude that both the masonry tomb and the tomb of the elderly woman in the south section of the chancel are contemporaneous with F517. The church must have been built to house both tombs. Seemly over time the cult of the woman overshadowed the primacy of position of the masonry tomb.

\section{South aisle}

The south aisle of the church is about $13 \mathrm{~m}$ east to west and $2.75 \mathrm{~m}$ from the columns to south wall. At the west end is an entrance $90 \mathrm{~cm}$ wide. Its door would close from inside the domus. At the east end of the aisle just west of the base for the chancel screen is a second doorway to the south. It is $80 \mathrm{~cm}$ wide; its door would close from outside the domus.

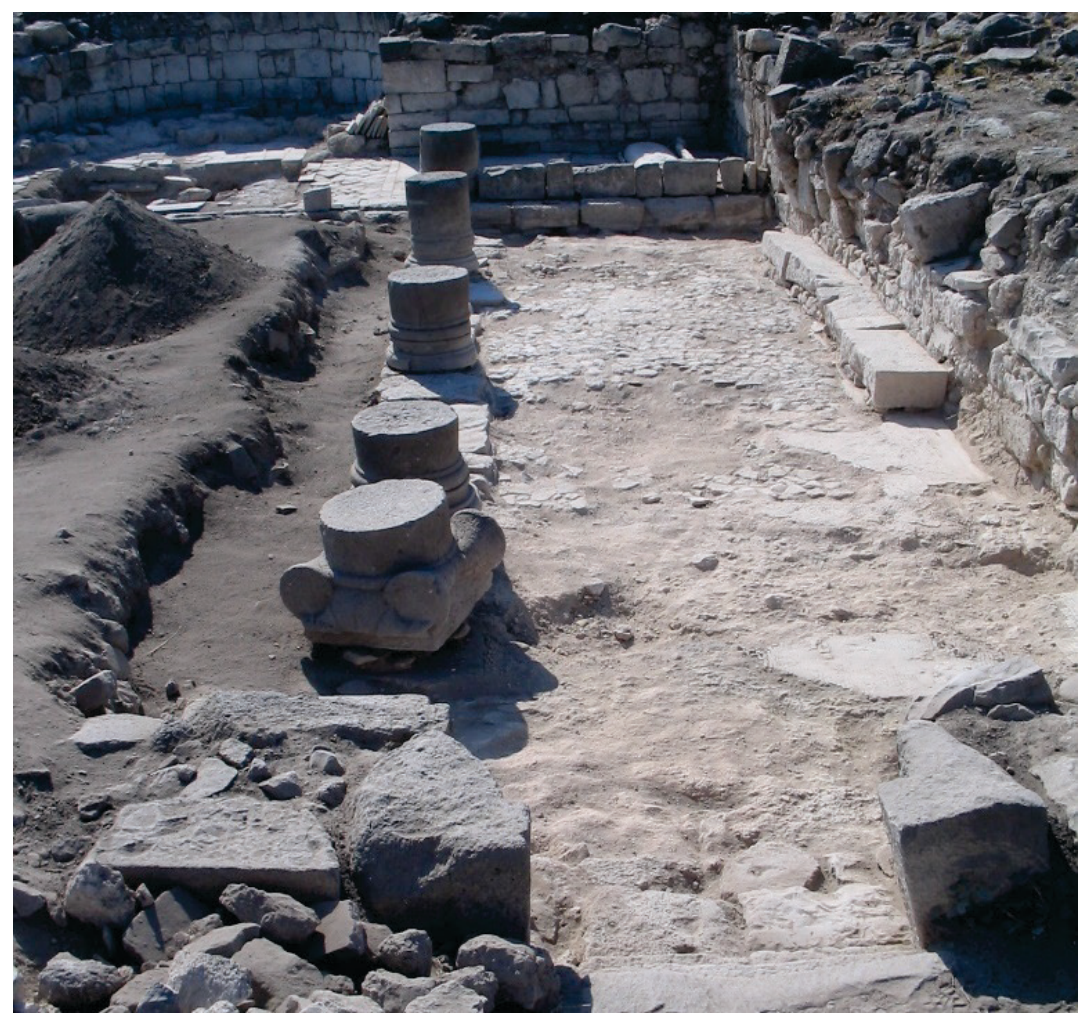

Figure 30 South aisle (looking east)

The south aisle is separated from the nave by a row of four column bases set on a stylobate. The stylobate (97-93 cm wide, comprised of diverse stones some in secondary use) runs west from the base of the chancel screen to the fourth column. The intercolumniation averages $2.1 \mathrm{~m}$. The shafts of the column bases are $52 \mathrm{~cm}$ in diameter with variant base profiles rising $30 \mathrm{~cm}$ and extending outward $10 \mathrm{~cm} .{ }^{50}$ Most of the floor for the south aisle (F526) was destroyed in antiquity. Only the pebble foundation and plaster remain in most places.

\footnotetext{
${ }^{50}$ Descriptions are like those published a more than a century ago. Gottlieb Schumacher, "Beschreibung Des Dscholan," Zeitschrift d. Deutschen Palastine-Veriens 9 (1886): 267-268: 331, figs. 106 and 107.
} 
Four meters from the west wall (W511) next to the south wall (W510) and running for 1.13 $\mathrm{m}$ to the west is a segment of the original mosaic floor with a guilloche border.

At the west end of the aisle, in the southwest corner, and in two fragmentary locations along the stylobate are segments of white mosaic tile of larger size $\left(1.5 \mathrm{~cm}^{2}\right.$ tesserae $)$. These seem to be a later repair.

Next to the south wall (W510) is a stone bench. It is $4.01 \mathrm{~m}$ long, 38 to $44 \mathrm{~cm}$ wide, and 26$30 \mathrm{~cm}$ high. It begins $47 \mathrm{~cm}$ west of the blocked south doorway and ends $4.2 \mathrm{~m}$ from the southwest corner. It is constructed of stones of various lengths $(60,40,100 \mathrm{~cm})$ and was plastered. Some remaining wall plaster curves onto the top of the bench. The bench is secondary to the original construction of the church as it sits on top of the original mosaic floor.

Benches are uncommon in the Late Antique churches of Palestine. Both the entrance hall and narthex of the church at the monastery of St. Martyrius at Macale Adummim have benches. In the narthex, the benches were part of a sixth CE renovation. ${ }^{51}$ Benches also are reported against the west wall in the church on the coast at Ostrakine ${ }^{52}$ and in one of the three rooms of the monastic oratory at Wadi Fraciyeh..$^{53}$ In trans-Jordanian regions, benches occur occasionally. H. C. Butler notes a bench on the north side of the nave between the second and third columns in the west church at Bākirhā. ${ }^{54}$ At Gerasa, benches occur in a southern side chapel at the church of St. Theodore, against the north wall of the Synagogue Church, and on the north, west, and southern walls of the nave of the Mortuary Church. ${ }^{55}$

In the destruction fill at the west end of the aisle, a basalt cross with base was discovered resting on its side on a thin layer of dirt above the floor. The cross is of Greek style with flared ends $(40 \mathrm{~cm}$ high $\mathrm{x} 37 \mathrm{~cm}$ wide $\mathrm{x} 23 \mathrm{~cm}$ deep). The cross sits on a base $(20 \mathrm{~cm}$ high $\mathrm{x}$ $23 \mathrm{~cm}$ wide $\mathrm{x} 56 \mathrm{~cm}$ deep). Cross and base are carved from one stone. Plaster on the edges of the base and numerous roof tiles in the fill suggest that the cross came from the peak of the western facade.

\footnotetext{
${ }^{51}$ Yitzhak Magen, "The Monastery of St Martyrius of Ma'ale Adummim," in Ancient Churches Revealed, ed. Yoram Tsafrir (Jerusalem: Israel Exploration Society, 1993), 178; Pachomian sources indicate that monks used three postures when praying the hours: standing, sitting, and prostration. Columba Stewart, Cassian the Monk, Oxford studies in historical theology (New York: Oxford University Press, 1998), 103.

${ }^{52}$ Eliezer Oren, "A Christian Settlement at Ostrakine in North Sinai," in Ancient Churches Revealed, ed. Yoram Tsafrir (Jerusalem: Israel Exploration Society, 1993), 307.

${ }^{53}$ Uzi Dahari and Yoram Tsafrir, "Remote Monasteries in Southern Sinai and Their Economic Base," in Anceint Churches Revealed (Jerusalem: Israel Exploration Society, 1993), 347.

${ }^{54}$ Howard Crosby Butler and E. Baldwin Smith, Early Churches in Syria (Princeton: Department of Art and Archaeology of Princeton University, 1929), 213.

${ }^{55}$ Carl H. Kraeling, Gerasa, City of the Decapolis (New Haven, Conn: American school of oriental research, 1938), plates xxxiii, xxxvi, lii.
} 


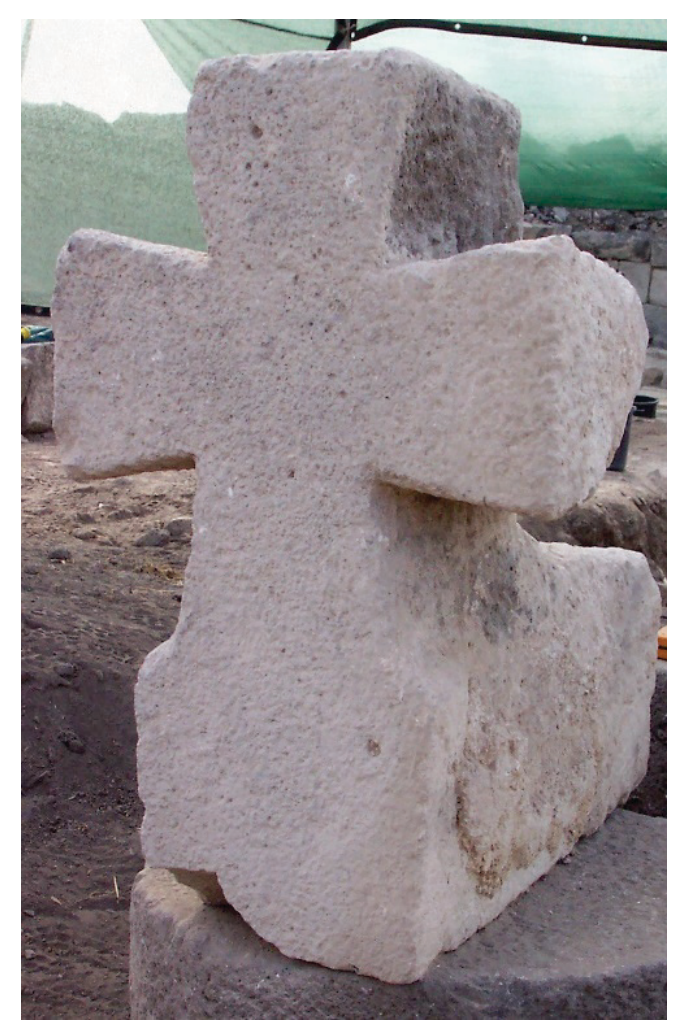

Figure 31 Basalt cross

The exposed southern wall (W510) is of poor quality. It is essentially two rows of mostly reused stones of diverse sizes approximately $80 \mathrm{~cm}$ thick. Ashlars are used in corners and to frame doorways. Walls were plastered on the inside.

North aisle

In the north aisle, the stylobate is of similar construction and dimension to that of the south aisle. However, the column bases and placement show a significant variance. Visible are five intact column bases. Again, the column shafts are $52 \mathrm{~cm}$ in diameter, but the base profiles vary dramatically in form and height.

The intercolumniation averages $1.1 \mathrm{~m}$, except between the third and fourth bases from the east where the intercolumniation is $2.7 \mathrm{~m}$. If a similar column base were placed in the middle of this gap, then all the intercolumniations would average $1.1 \mathrm{~m}$. In that case, there would be six bases for the north aisle and four for the south - a most unusual configuration for a Late Antique church. Of further note, the stylobate ends $7.2 \mathrm{~m}$ west of the base of the chancel screen, as it does in the south aisle. The westerly column base has a larger diameter and does not sit on the stylobate. It has a separate plaster foundation. 


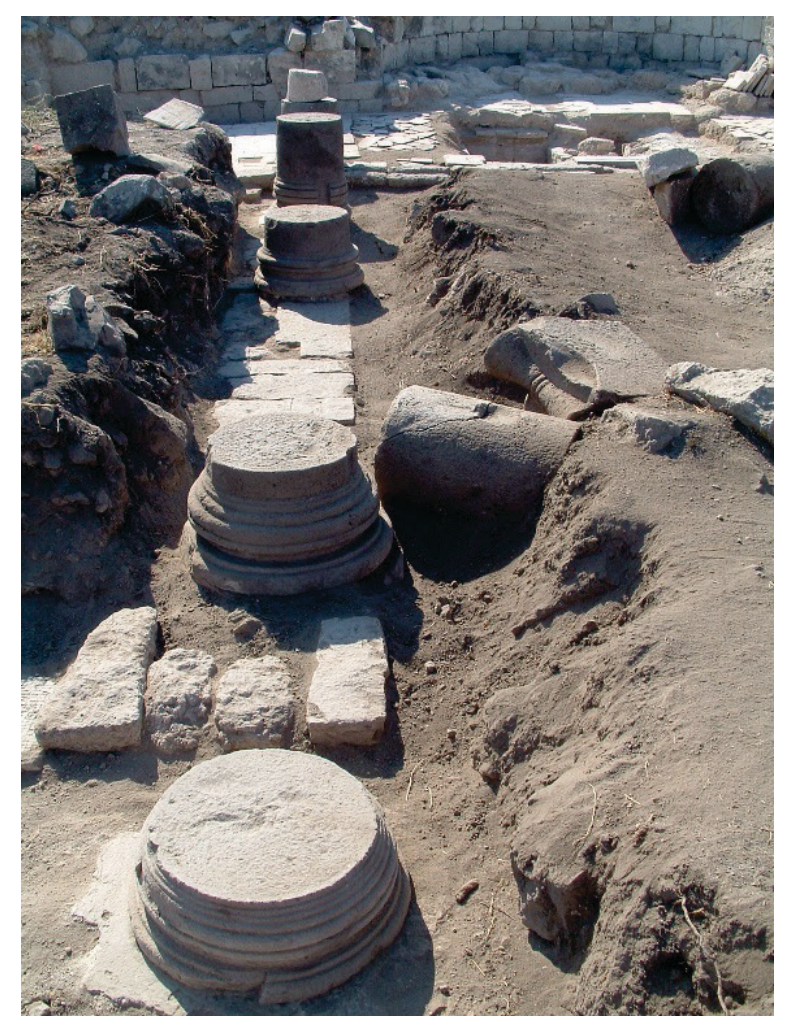

Figure 32 North stylobate and bases (looking east)

The walls comprising the northwest corner of the church (W511, W521) stand to the height of two poorly constructed runs.

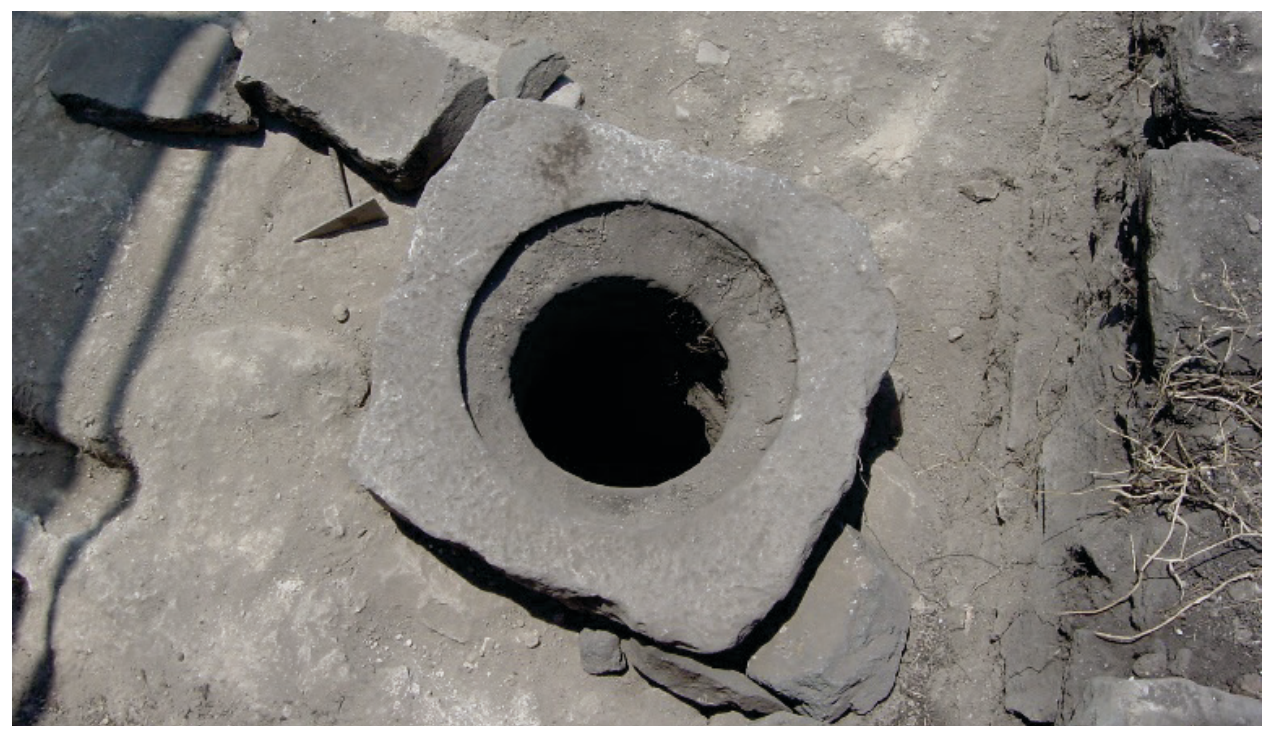

Figure 33 Aqueduct pipe segment over a cistern

There is no western door for the north aisle. Instead, in the northwest corner is a segment of an aqueduct pipe $(65 \times 60 \mathrm{~cm})$ serving as a cistern head for Cistern A. As the cistern extends under the walls in the northwest corner (W521 and W511) and required an unusual 
configuration of a northerly entrance instead of one from the west, the cistern predated the church. The pipe segment stands about $30 \mathrm{~cm}$ above the floor on a platform of paving stones $(1 \times 1.5 \mathrm{~m})$ like those in the peristyle court of the house to the east. The pipe has a $30 \mathrm{~cm}$ opening. Cisterns are commonly found in the atrium or narthex of a Late Antique church, not in the domus. ${ }^{56}$

Recovered from the destruction fill of the north aisle were several equally sized corbels. Along with others teetering from their position, the corbels had been reused to build the north wall (W521). Identical corbels were used to create a bench along the north wall 2.24 $\mathrm{m}$ from the base of the chancel screen to the ridge of stones in floor. That ridge of stones (3-4 cm wide x 5-7 cm high) runs south from the corner of the bench to the west end of the stylobate. To the west of the ridge is a mosaic floor of white $1.5 \mathrm{~cm}^{2}$ tesserae identical to the mosaic from the second phase in the south aisle. This mosaic surrounds the cistern and may have extended into the nave.

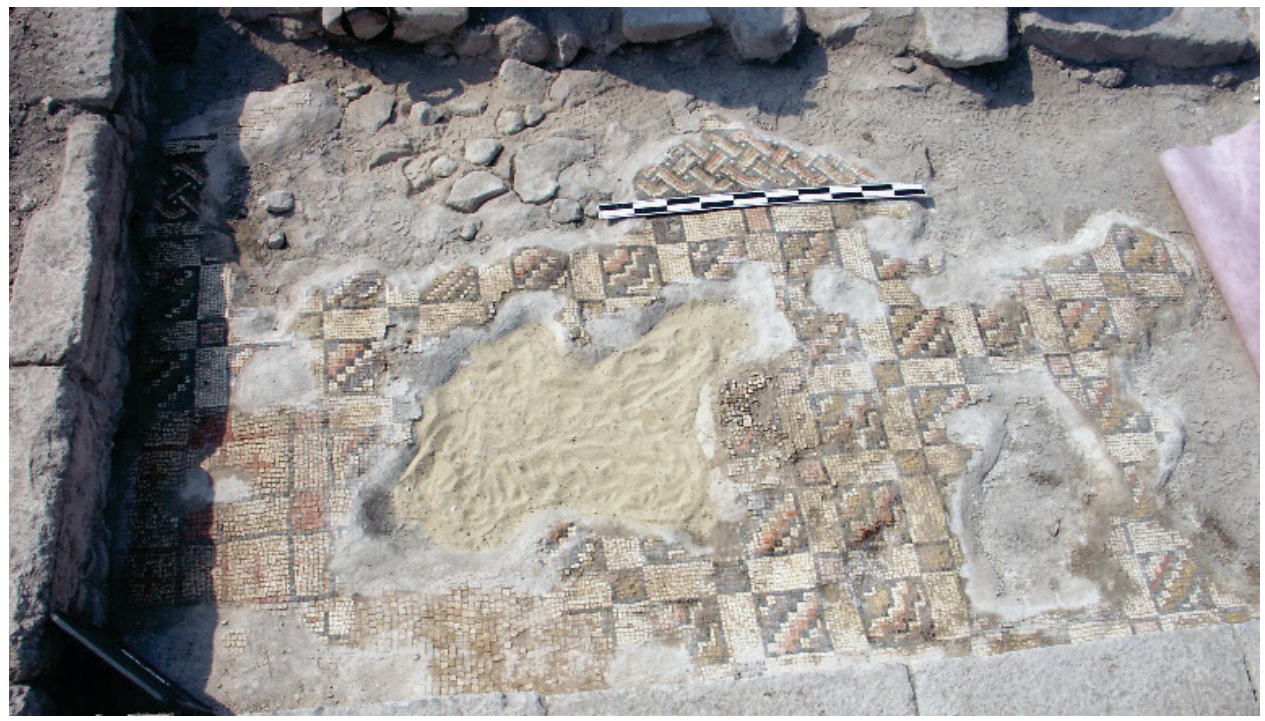

Figure 34 Mosaic from east end of the north aisle

The bench was plastered to the wall. This bench of corbels sits atop the original mosaic of the floor, suggesting that the corbels forming the bench and the corbels reused in the wall were installed as part of a major repair to the church.

\footnotetext{
${ }^{56} \mathrm{~A}$ precedent does exist in the cave church at Khirbet ed-Deir at the head of the south aisle. However, the location of the cistern in that monastery is most likely a consequence of topography. Yizhar Hirschfeld, The Early Byzantine Monastery at Khirbet Ed-Deir in the Judean Desert: The Excavations in 1981-1987, Qedem 38 (Jerusalem, Israel: Institute of Archaeology, the Hebrew University of Jerusalem, 1999), figs 37 and 43. Of minor note is a $42 \mathrm{~cm}$ sump in the southwest corner of the church at Khirbat al-Karak. Pinhas Delougaz and Richard C. Haines, A Byzantine Church at Khirbat AlKarak, University of Chicago. Oriental Institute Publications v. 85 (Chicago: University of Chicago Press, 1960), 14.
} 
This major repair, possibly after the earthquake of $551 \mathrm{CE},{ }^{57}$ may explain the unusual systyle intercolumnation in the north aisle. It does not balance the araeostyle intercolumnation in the south aisle because it is a repair, not the original.

In the northeast corner of the aisle next to the base of the chancel screen, a section of the mosaic floor is preserved. The original mosaic floor was decorated with several patterns. The bulk of the still visible pattern consists of $20 \mathrm{~cm}$ squares.

Nave

The nave of the church was excavated to the level of a fragmentary mosaic floor (F544). In several locals, it was clear that the original floor was overlaid by $3-4 \mathrm{~cm}$ of plaster and a second mosaic floor (F589). A section of the original mosaic (F544) is a carpet with a guilloche (Avi-Yonah pattern J3) ${ }^{58}$ like those in the south aisle of the Northwest Church and likely laid at the same time (late sixth century). Toward the western end of the nave, larger white tesserae might suggest a possible third layer, although there is a significant gap in continuity between the layers in the central part of the nave and those near the west wall.

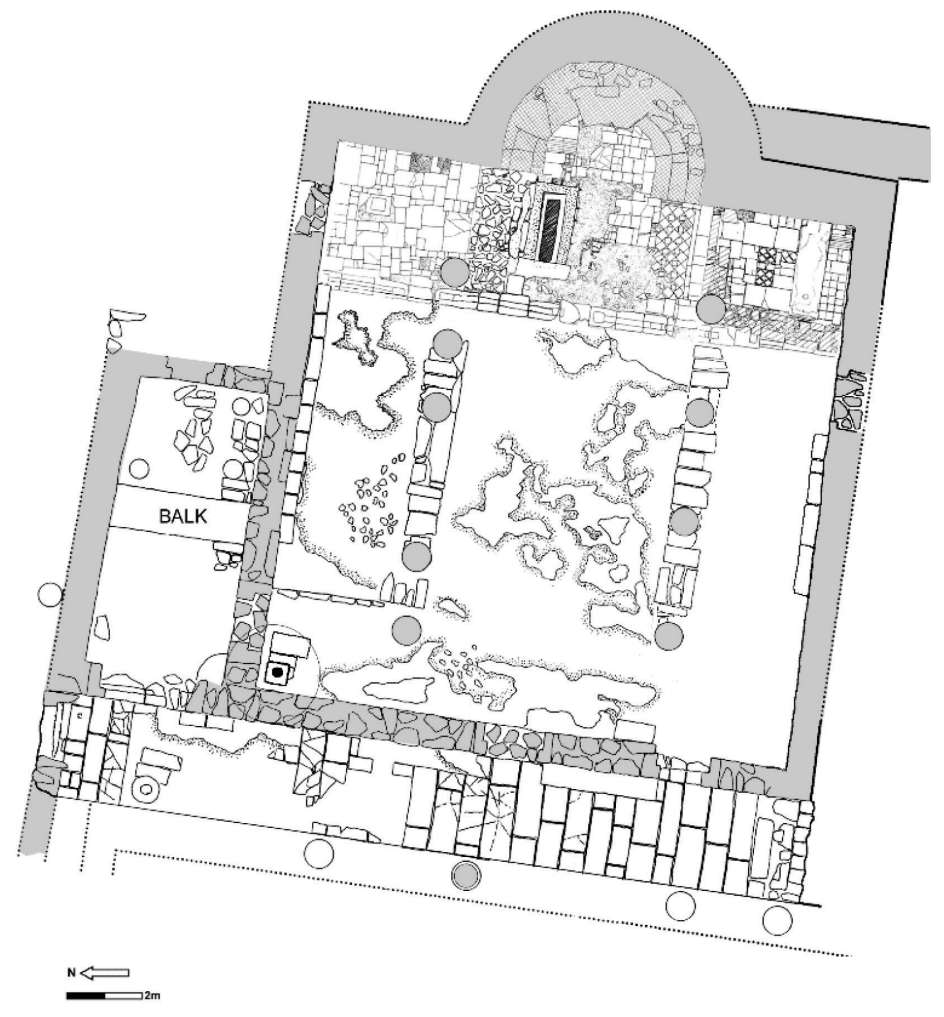

Figure 35 Nave and portico

\footnotetext{
${ }^{57}$ Kenneth W Russell, "The Earthquake Chronology of Palestine and Northwest Arabia from the 2nd through the Mid8th Century AD," Bulletin of the American Schools of Oriental Research 260, no. 1 (1985): 44-46.

${ }^{58}$ Michael Avi-Yonah, "Mosaic Pavements in Palestine," Quarterly of the Department of Antiquities of Palestine 2 (1932): 141.
} 
On the other hand, the white tesserae may be part of a carpet extending from the north aisle into the nave from the area of the north doorway (now blocked) and the cistern. The western doorway to the nave was blocked during the final phase of the church.

Two coins were recovered at floor level. One was next to the north stylobate and the westerly column base. It is a Roman provincial coin of Marcus Aurelius (165-166 CE) minted at Hippos. The second coin lay near the south stylobate and the second column from the west wall. It is an undated Umayyad coin of the mid-eighth century minted in Tabariya (Tiberias). Neither location was sealed. But the latter coin is consistent with the approximate terminus ante quem for usage of the Northeast Church.

\section{Window Glass}

Casting was the earliest method of making window glass. Molten glass was poured into a mould and tooled or rolled into a flat, rectangular sheet. A second method, which also resulted in a rectangular sheet of glass, entered use in the early fourth century. ${ }^{59} \mathrm{~A}$ glass cylinder was blown, cut open, and pressed onto a flat surface, resulting in a pane known as "muff" glass. The third kind of windowpane, crown glass, likely came into use in the East in the $4^{\text {th }}$ century..$^{60}$ This type of pane was made by blowing an open-ended sphere, folding its exposed edge to make a small tube, then rotating the mass until centrifugal force caused it to "flash" from a globe into a disk. This process gave crown-glass panes a reinforced rim, a circular shape, a thick and pontil-marked centre, and often a wavy, bowl-shaped profile.

Within this site, 238 fragments of window glass were recovered. Apart from several examples of muff- or cast-glass, all the window glass on this site that can be identified by type of manufacture comes from crown-type panes. Their diameters range between $200 \mathrm{~mm}$ and $380 \mathrm{~mm}$, although most of them are between 220 and $240 \mathrm{~mm}$. A few lack the hollow, folded rim that is otherwise a standard feature of the type. The massive rim of one contrasts with the delicate fragility of another, while the grooved double-hollow fold of a third is simply peculiar. Finally, the angular and rough worked edges of two circular fragments suggest that these pieces were cut from larger crown-type panes, as the literature reports. ${ }^{61}$

This corpus also provides decisive evidence that these fragments come from windowpanes, not bowls or plates. Of the various possibilities for suspension of these panes, the most workable is a system like the one used at a sixth-century monastery at Beth Shean and in the basilica of Moses on Mount Nebo. There, stacked-up tiles were bonded together with plaster to form small pillars within a wider stone archway, with multiple round panes set

\footnotetext{
${ }^{59}$ Carol Meyer, "Glass from the North Theater Byzantine Church, and Soundings at Jerash, Jordan, 1982-1983," Bulletin of the American Schools of Oriental Research. Supplementary Studies (1988): 195.

${ }^{60}$ Donald B Harden, "Roman Window-Panes from Jerash, and Later Parallels," Iraq 6, no. 1 (1939): 91.

${ }^{61}$ Meyer, "Glass from the North Theater Byzantine Church, and Soundings at Jerash, Jordan, 1982-1983," 209.
} 
into a further layer of plaster against and between these pillars. ${ }^{62}$ The presence of relatively large amounts of plaster on the periphery of six fragments, along with traces on others is suggestive. On several fragments, the plaster is both big enough and sufficiently intact to show that it was flattened and smoothed by compression between the pane and a parallel flat surface. Small traces of an earlier layer of plaster beneath and beyond the larger remnants on certain fragments might indicate that these panes were bonded into a frame more than once.

Over half of the window glass fragments (129 of 238 pieces) were recovered in eight squares. Four of these squares are immediately south of the nave's south wall (W510). The other four are immediately north of the nave's north wall. At the same time, very little window glass came to light within the nave itself.

Saller noted a similar pattern at Mt. Nebo, where very little window glass was found within the church itself but large amounts outside. ${ }^{63}$ At Khirbet al-Karak, the pattern was even closer to the one noted here, with "large heaps of broken glass" being found in the rooms just south of the church's south wall. ${ }^{64}$ Presumably this is because, there and here, most if not all the windows were in the churches' clerestory. Especially if these buildings suffered a collapse, it is likely that the walls-and glass-from their upper storeys would have been projected about as far away from the building as those walls were tall. This would explain the two large and very similar concentrations of window glass, with identical orientations with respect to this church building. Looking north to south, both concentrations lie outside the building, just north of the north wall and just south of the south wall. Looking east to west, both concentrations lie about five metres east of where they might have been expected, on the assumption that the windows were located along both sides of the nave. Together, these patterns suggest that the church might have collapsed in an easterly direction. ${ }^{65}$

\section{Portico}

The western portico of the church (F545) is $18.5 \mathrm{~m}$ in length. The floor consists of flagstone pieces uniformly $60 \mathrm{~cm}$ wide and of varying lengths. It is roughly $60 \%$ intact, the southern half being the best preserved. At the north end of the exposed floor is a cover for a reliquary in secondary use as a flagstone. It has an inscribed concavity and hole nearly identical in dimension to the receptacle on the exposed sarcophagus. The dimension of the stone would fit the reliquary loculus in the center of the chancel in the north aisle, the cover of which is missing.

\footnotetext{
${ }^{62}$ FitzGerald, A Sixth Century Monastery at Beth-Shan (Scythopolis), 3; Sylvester John Saller and Hilary Schneider, The Memorial of Moses on Mount Nebo (Jerusalem: Franciscan Press, 1941), 65.

${ }^{63}$ Saller and Schneider, The Memorial of Moses on Mount Nebo, 66.

${ }^{64}$ Delougaz and Haines, A Byzantine Church at Khirbat Al-Karak, 49.

${ }^{65}$ For more details and specific examples, see Stephen Chambers, "Window Glass Finds in the Northeast Church'," in Hippos-Sussita of the Decapolis: The First Twelve Seasons of Excavations (2000-2011) Vol 1, ed. Arthur Segal (Haifa, Israel: The Zinman Inst of Archaeology, 2013), 242-249.
} 
The western side of the portico is demarcated by a stylobate made of a single course of basalt stones $18 \mathrm{~m}$ from north to south and varying between 90 and $110 \mathrm{~cm}$ in width. The southwest corner of the domus aligned the southern end of the stylobate. Six of a presumed eight column bases are still in situ with an average intercolumniation of $1.96 \mathrm{~m} .{ }^{66}$

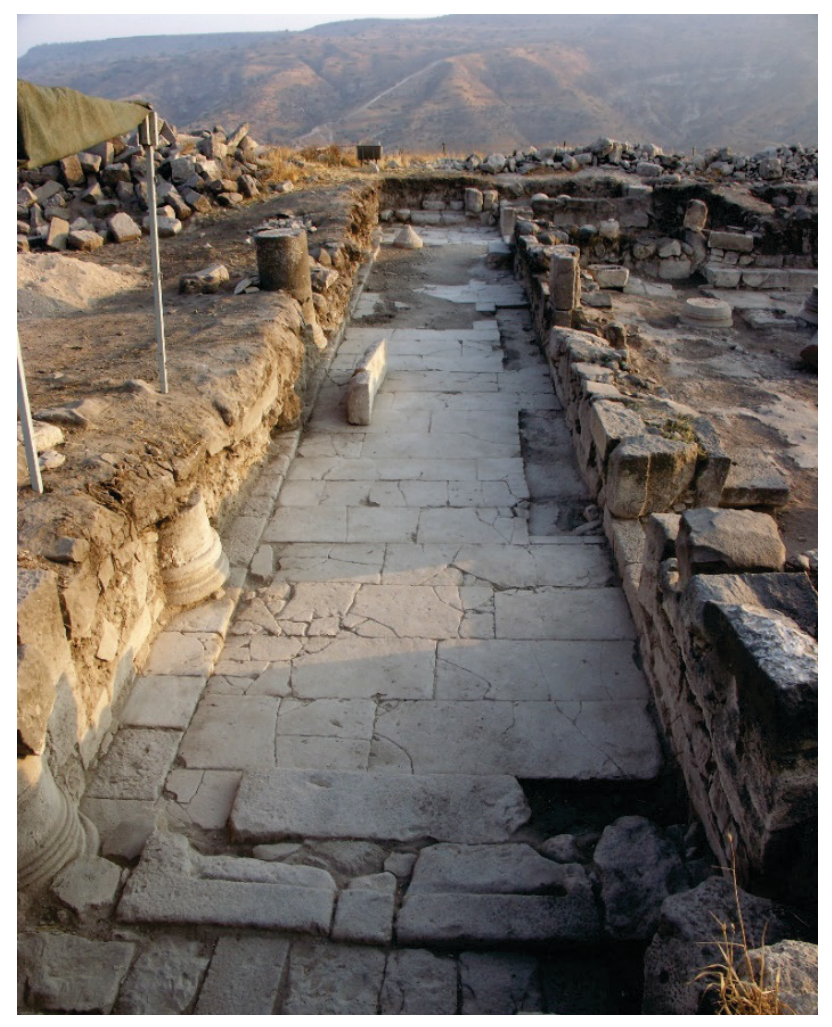

Figure 36 Portico (looking north)

The flagstone floor is interrupted by three lacunae next to the exterior west wall of the domus (W511). In each lacuna, remnants of an earlier mosaic floor (F546) is visible. In several spots, the plaster base of this floor (F546) curves up the side of W511, suggesting that the wall was plastered on its westerly face.

The lacunae mark the location of benches installed at the same time as the flagstone floor, as evidenced by a surviving section of the bench near the entrance of the north lateral chamber (compare the benches in the atrium of the Northwest church). As two lacunae are balanced on either side of the blocked western entrance to the nave, that blockage occurred sometime after the laying of the flagstone floor.

\footnotetext{
${ }^{66}$ Column diameters and intercolumniations are listed from south to north. Those measurements in parentheses represent missing column bases and assumed intercolumniations. $52 \mathrm{~cm}, 1.74 \mathrm{~m}, 54 \mathrm{~cm},(2.1 \mathrm{~m}, 53 \mathrm{~cm}, 2.1 \mathrm{~m}), 55 \mathrm{~cm}, 1.94 \mathrm{~m}, 53$ $\mathrm{cm}, 2.05 \mathrm{~m}, 52 \mathrm{~cm},(1.92 \mathrm{~m}, 53 \mathrm{~cm}, 1.92 \mathrm{~m}), 53 \mathrm{~cm}$.
} 
Fragments of the earlier mosaic paving survive to about $60 \mathrm{~cm}$ from W511 in places. The mosaic was geometric. The east border of the mosaic was Avi-Yonah pattern B9. ${ }^{67}$ After an additional six rows of white tesserae are a series of half circles. Further to the west, there is seemingly a third band of full circles. All the rest of the mosaic is missing, but its cobble base survives to the west as far as the stylobate.

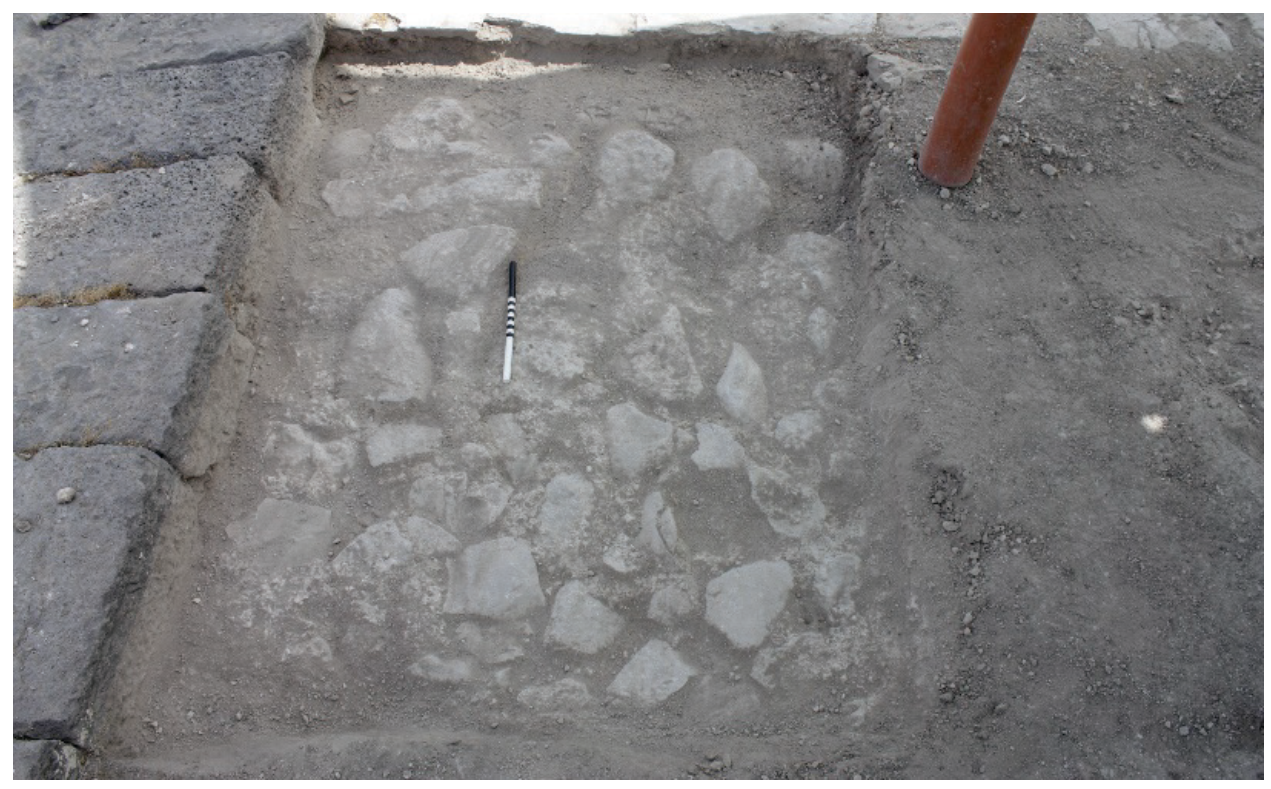

Figure 37 Cobble base for tesserae

At both ends of the exposed floor of the portico (F545), thresholds are installed that are contemporaneous with the flagstone floor (F545). The larger gate $(1.6 \mathrm{~m})$ to the south aligns with the southern wall of the domus (W510). However, it awkwardly abuts one of the column bases sitting on the stylobate of the portico - a secondary construction. To the south of the threshold is the via sacra.

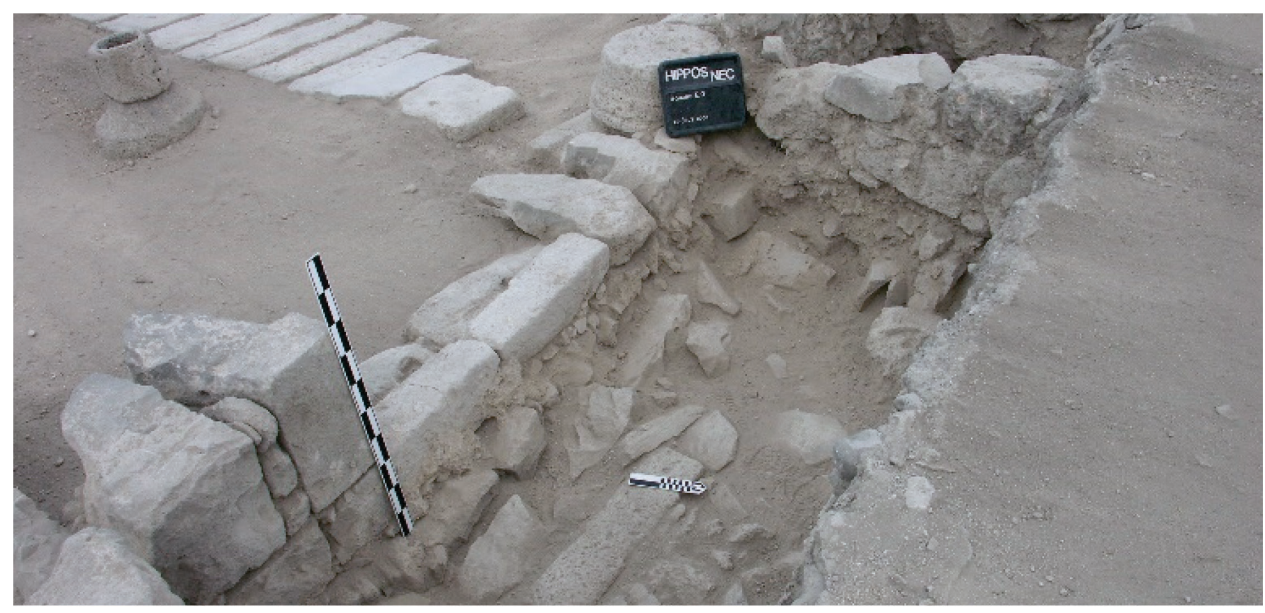

Figure 38 North gate (looking west)

\footnotetext{
${ }^{67}$ Avi-Yonah, "Mosaic Pavements in Palestine," 139.
} 
The north gate is approximately $1.4 \mathrm{~m}$ wide and was closed by two doors on pivots. About 1 meter was exposed to the north of the gate, but there was no evidence of a paved street as at the south gate. The west end of the gate was also bounded by a column base and a substantive Late Antique wall (W553) to the west ( $80 \mathrm{~cm}$ wide). That column base sits on the north end of the stylobate that forms the western border of the church's portico. To date, no indications of a presumed atrium have yet to be unearthed. To the north of this column base is a later wall of poor quality (W594) that floats above the level of the stylobate.

On the floor at the north end of the portico, part of a grain mill was recovered. It is the bellshaped bottom part (meta) ${ }^{68}$ The hour-shaped upper stone (catillus) is missing. The mill attests to later domestic use of the north lateral chamber and the portico.

\section{North of the domus}

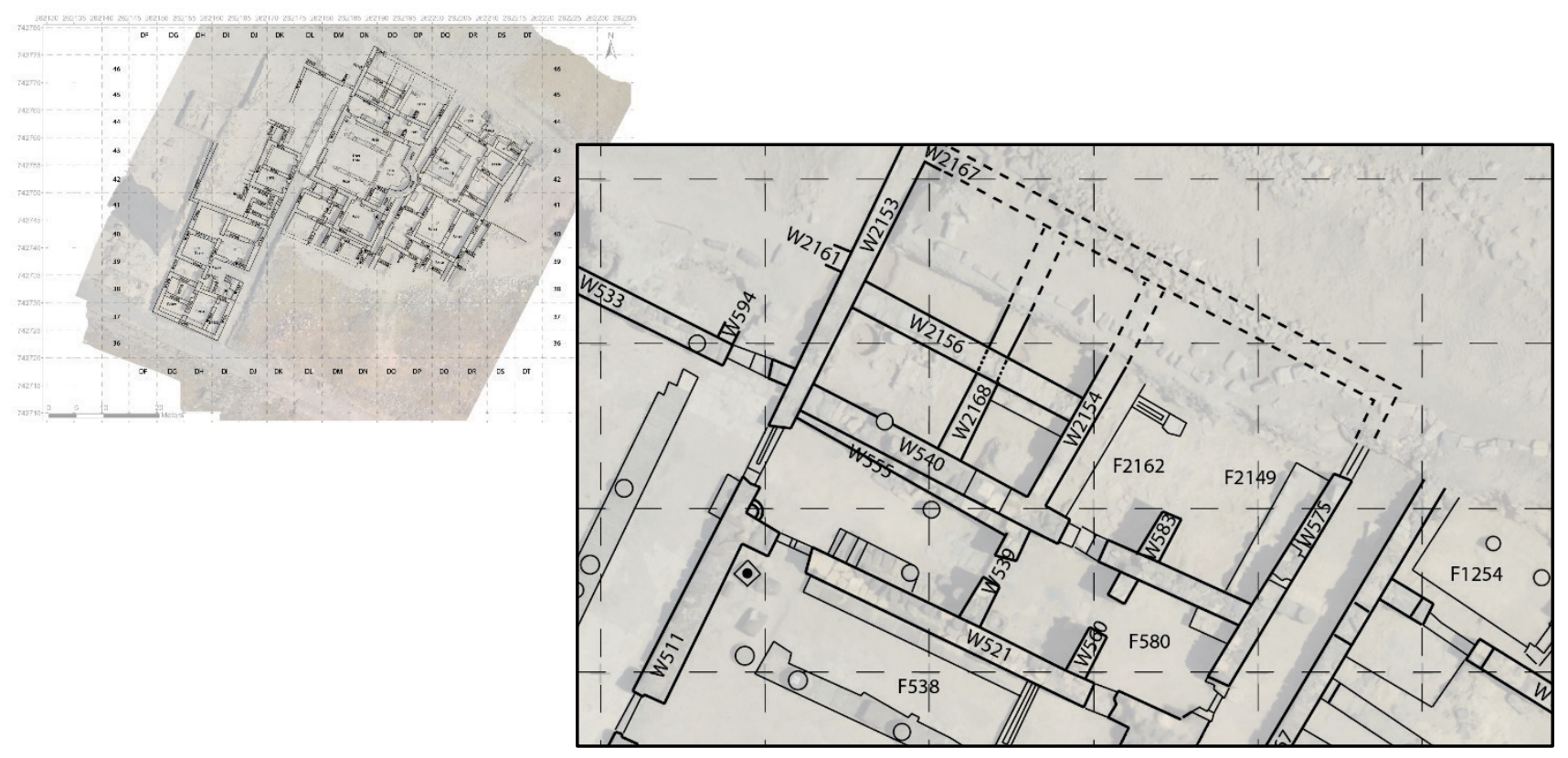

Northern chambers

Figure 39 North structures

Typically, the domus of a Late Antique church has three entrances from the west. In the Northeast Church, the expected northerly entrance from the west does not exist due to the location of the cistern. Instead, a wide entrance $(1.47 \mathrm{~m})$ to a long $(6.9 \mathrm{~m})$ lateral chamber provides access to the north aisle through a doorway $(98 \mathrm{~cm})$ in the north wall of the domus just east of the head of the cistern. In a later phase, this north doorway was blocked.

\footnotetext{
${ }^{68}$ L. A. Moritz, Grain-Mills and Flour in Classical Antiquity (Oxford: Clarendon Press, 1958), 74-90; for a relief demonstrating the usage of this animal-driven mill, see Paola Ciancio Rossetto, Il Sepolcro Del Fornaio Marco Virgilio Eurisace a Porta Maggiore, I Monumenti romani 5 (Roma: Istituto di studi romani, 1973).
} 
Structurally, the north lateral chamber and the room beyond it to the east are part of the original building and not annexes. The remaining exterior stones of the western wall (W511) span the joint of what would be the northwest exterior corner of the domus. The southwest interior corner of the lateral chamber has a plaster fixture that fed water into the cistern (drainage from the roof?). The north wall (W540) of the lateral chamber was the north wall of the entire structure. A doorway $(81 \mathrm{~cm})$ in the east wall (W539) of the lateral chamber that closes from the east provides access to a medial chamber. The doorway shows no sign of intentional blockage. The floor (F549) of the lateral chamber is hard plaster and packed earth.

Next to the north wall (W521) of the domus and just east of the north entrance is a small staircase climbing in an easterly direction. The remains of the staircase terminate at a column base squared off with ashlars $1.8 \mathrm{~m}$ from W539. The stairs would provide access to a small storage gallery ${ }^{69}$ over the north aisle made possible by the extra width of the church on the north side. Or it could provide access to the second story of the building to the north. In which case, the positioning of two more small column shafts in the east section of the chamber may have provided support for such a walkway. The stairs and the column that form their corner sit atop the hard dirt floor of the chamber. They seem to be a later addition to the chamber.

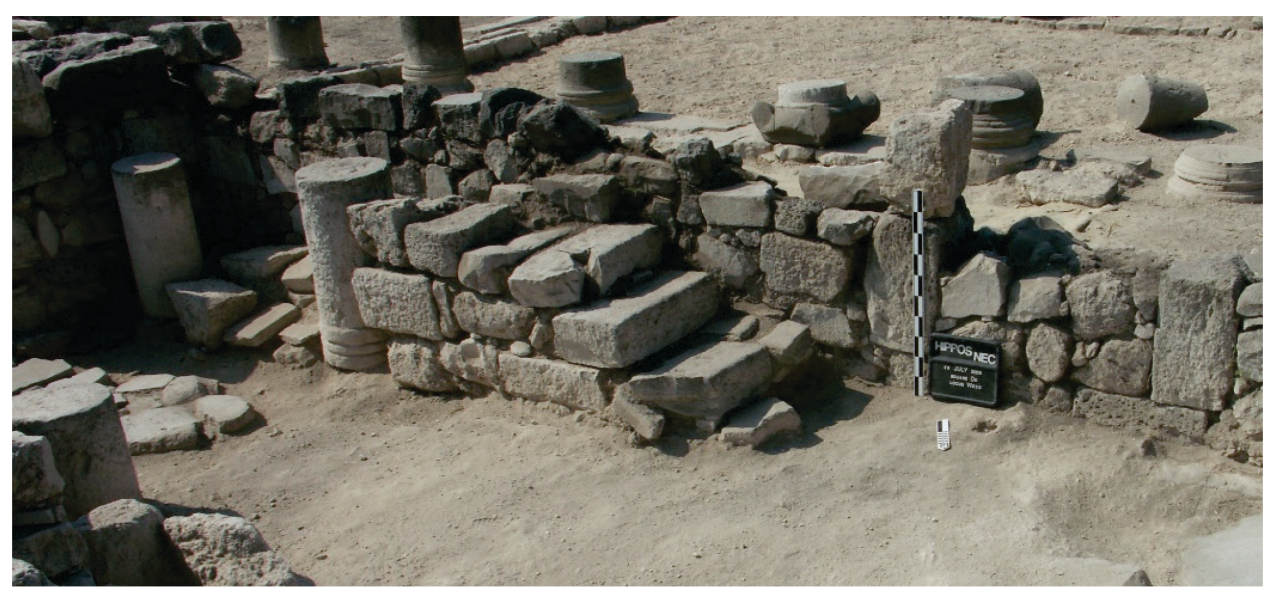

Figure 40 Stairs (looking south)

The opposite (north) wall of the chamber also displays a later alteration. What was thought to be an exceptionally wide wall is in fact two walls: a northerly wall (W540) of typical Late Antique width (72-75 cm) and an inner wall (W555) of poorer quality and narrower dimension $(44-47 \mathrm{~cm}) .2 .8 \mathrm{~m}$ east of W541 at floor level is a rectangular opening to a cistern ( $45 \mathrm{x}$

\footnotetext{
${ }^{69}$ Barbara Schellewald, "Zur Typologie, Entwicklung Und Funktion von Oberräumen in Syrien, Armenien Und Byzanz," Jahrbuch für Antike und Christentum 27 (1984): 216.
} 
$120 \mathrm{~cm}$ ) framed by ashlars (Cistern B). The opening abuts and runs parallel with W540. W555 apparently framed the opening to provide access to the cistern.

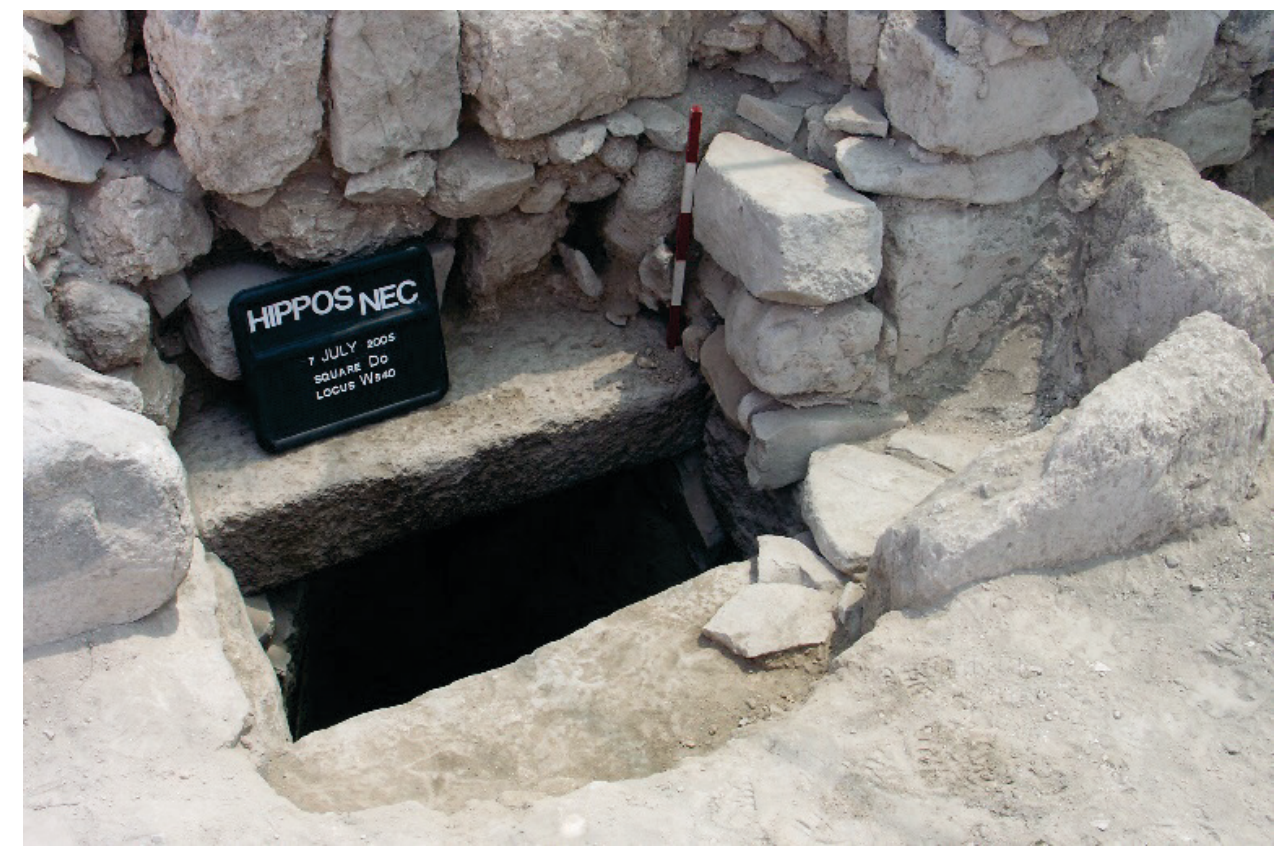

Figure 41 Cistern B (looking north)

To the east of the north lateral chamber is a square medial chamber (approx. $2.95 \mathrm{~m}$ ). Passageways from this chamber to the north (1.35 m wide) and to the east (1.15 m wide) lack door jambs. The medial chamber thus functions to separate these inner rooms from the more public space of the north lateral chamber and to provide free movement between them. W539 proceeds to the north of W540 on the west side of the north passageway. A parallel wall (W583) was discovered to the east of the same passageway.

During a later phase, a bench was installed in the southeast corner of the room next to the east wall (W560). The bench was $67 \times 150 \times 46 \mathrm{~cm}$ high. A small Corinthian capital was used as part of the fill of the bench. Below the bench and in the northeast corner of the medial chamber, small fragments of an earlier mosaic floor were detected. An intact oil lamp was also recovered from beneath the bench, sitting on a mosaic fragment.

In the southwest corner of the room, a segment of an aqueduct pipe was positioned on top of stones and earth and filled with ceramic and earth. It may have functioned as a crude chair or storage platform.

The western doorways to the north lateral chamber and to the medial chamber were never intentionally blocked as were so many of the other doorways in the church complex. These two rooms may have been used domestically after liturgical practice ceased in the Northeast Church. The use of two pieces of aqueduct pipe, one in the north medial chamber and one 
as a cistern head in the domus of the church (Cistern A), point to usage of the space into the eighth century CE. Large quantities of chopped animal bones and numerous shards of domestic cooking pots reinforce this hypothesis. Modifications to the north lateral chamber, noted above, may have come from this same period.

\section{Skeuophylakion}

A third side chamber is east of the medial chamber and of similar size to it ( $3.15 \mathrm{~m}$ east to west by $3.43 \mathrm{~m}$ north to south). In addition to the passageway in W560, there is an exterior doorway $(1.10 \mathrm{~m})$ in W575 that could be closed from inside the chamber. A third doorway provides direct access to the chancel and suggests that the room functioned as a preparatory space for clergy. We identify it as a skeuophylakion, while recognizing the tentative nature of using this label. ${ }^{70}$

The doorway to the chancel through W521 displays two phases. An original doorway (1.13 $\mathrm{m}$ ) with jambs provided a door that could be closed and locked from inside the skeuophylakion. Later that doorway was narrowed into a passageway $(81 \mathrm{~cm})$ without door jambs and with a higher threshold to accommodate the laying of the second floor (F516) in the chancel. In a third phase the passageway was intentionally blocked, as was the east door and the west passageway, thus sealing off the skeuophylakion.

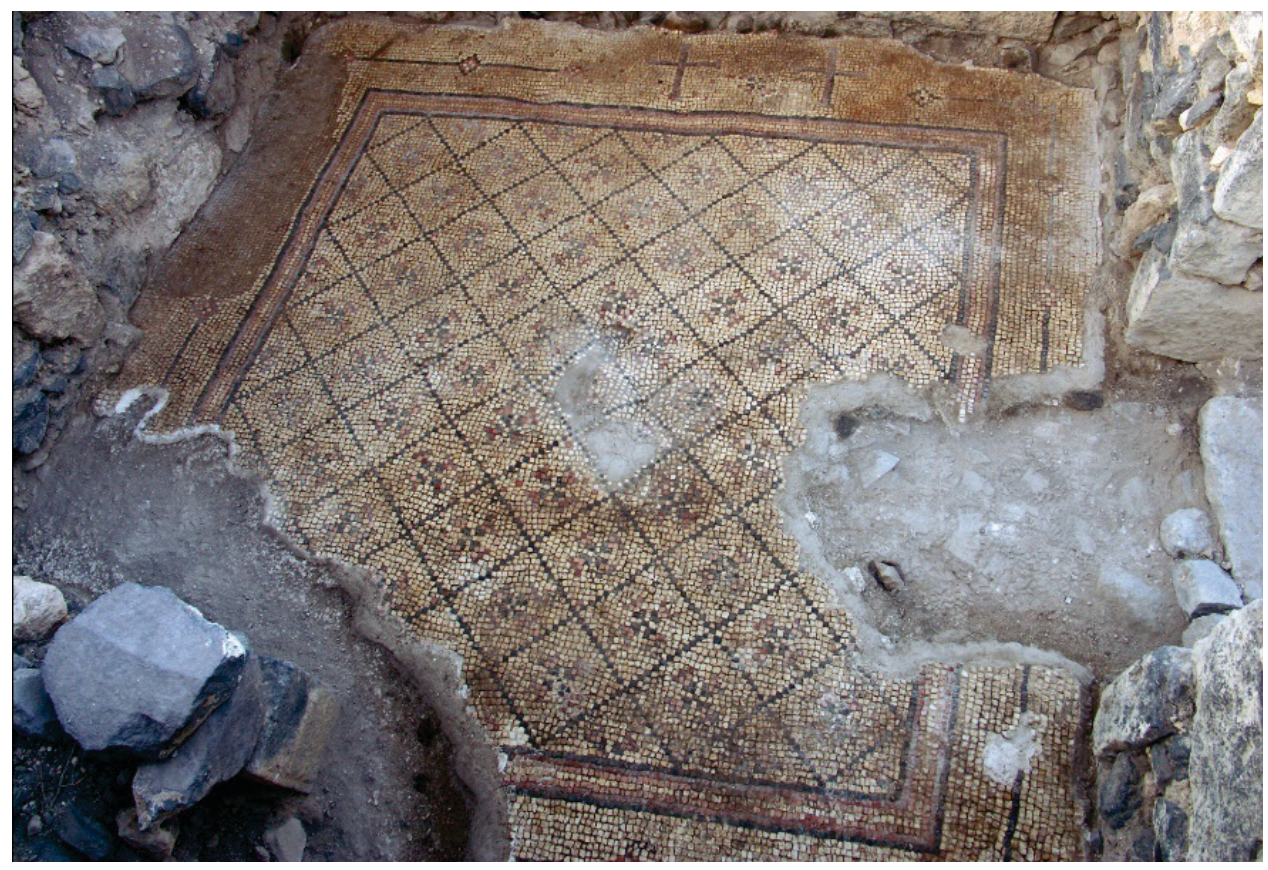

Figure 42 Skeuophylakion (looking east)

\footnotetext{
${ }^{70}$ Ecclesiastical sources from the 5th to the 7th centuries specifically name such side rooms as the diakonikon and the skeuophylakion. The term pastophoria is used in a collective sense. See Georges Descoeudres, Die Pastophorien Im SyroByzantinischen Osten: Eine Untersuchung Zu Architektur- Und Liturgiegeschichtlichen Problemen, Schriften zur Geistesgeschichte des östlichen Europa Bd. 16 (Wiesbaden: O. Harrassowitz, 1983) XVI.
} 
The fortuitous sealing of the skeuophylakion in antiquity preserved the mosaic floor of the room. The carpet is suited to the contours of the room. Next to W521 and east of the passageway to the chancel are two flared crosses some $35 \mathrm{~cm}$ in height. The central pattern of the carpet is filled with the same geometric motif that appears between the two large crosses.

In the northeast corner of the room against W540 is a bench that is $62 \times 132 \times 55 \mathrm{~cm}$ high. The mosaic floor is broken in front of the bench, making it unclear whether the bench sat on top of the floor. Also recovered from the fill in the room were several marble fragments that might have been parts of liturgical furnishings.

North Building

There are several indications in the Northeast Church that a building functioning as part of the compound sits immediately to the north. Previously, we noted the blocked passageway in the north medial chamber, two doorways in W575 and wall fragments proceeding north (now labelled W2153, W2154, and W583). There are also the remains of a staircase next to the south wall of the north lateral chamber that seemed to serve the building to the north, as there was no evidence of a balcony in the church.

We therefore opened a $5 \mathrm{~m}$ section paralleling W540. Work further to the north was restricted due to an access driveway along the north edge of the site. We subsequently did cut a trench into the driveway following W2161 to its north end where it formed a corner with W2167 proceeding to the east.

Assuming W2167 eventually connects to W575. We posit a Northern Building of two stories with an interior dimension of $7.6 \mathrm{~m}$ from north to south and $15 \mathrm{~m}$ from east to west on the south widening to approximately $15.75 \mathrm{~m}$ on the north (W575 and W2153 skew away from each other slightly). The building is subdivided into two sections by a central wall running north to south (W2154) and the westerly section is again subdivided by a wall running east to west (W2156).

We have exposed all the eastern section, except the northern third. The space is $8.8 \mathrm{~m}$ from east to west. $3.1 \mathrm{~m}$ west of W575 is a pilaster that protrudes $1.7 \mathrm{~m}$ into the room (W538). We presume it is matched by something similar next to the still buried W2167. An arch between the two pilasters would hold up the second story.

On the west side of W575 is a crude bench (75-115 cm deep south to north and approx. 40 $\mathrm{cm}$ high) that was installed in a second phase after the southern doorway in W575 was blocked. Most of the floor (F2149) is missing in the eastern section of this space. But near the still open doorway are several bricks (roughly $20 \times 20 \mathrm{~cm}$ ) remaining from the original flooring. 


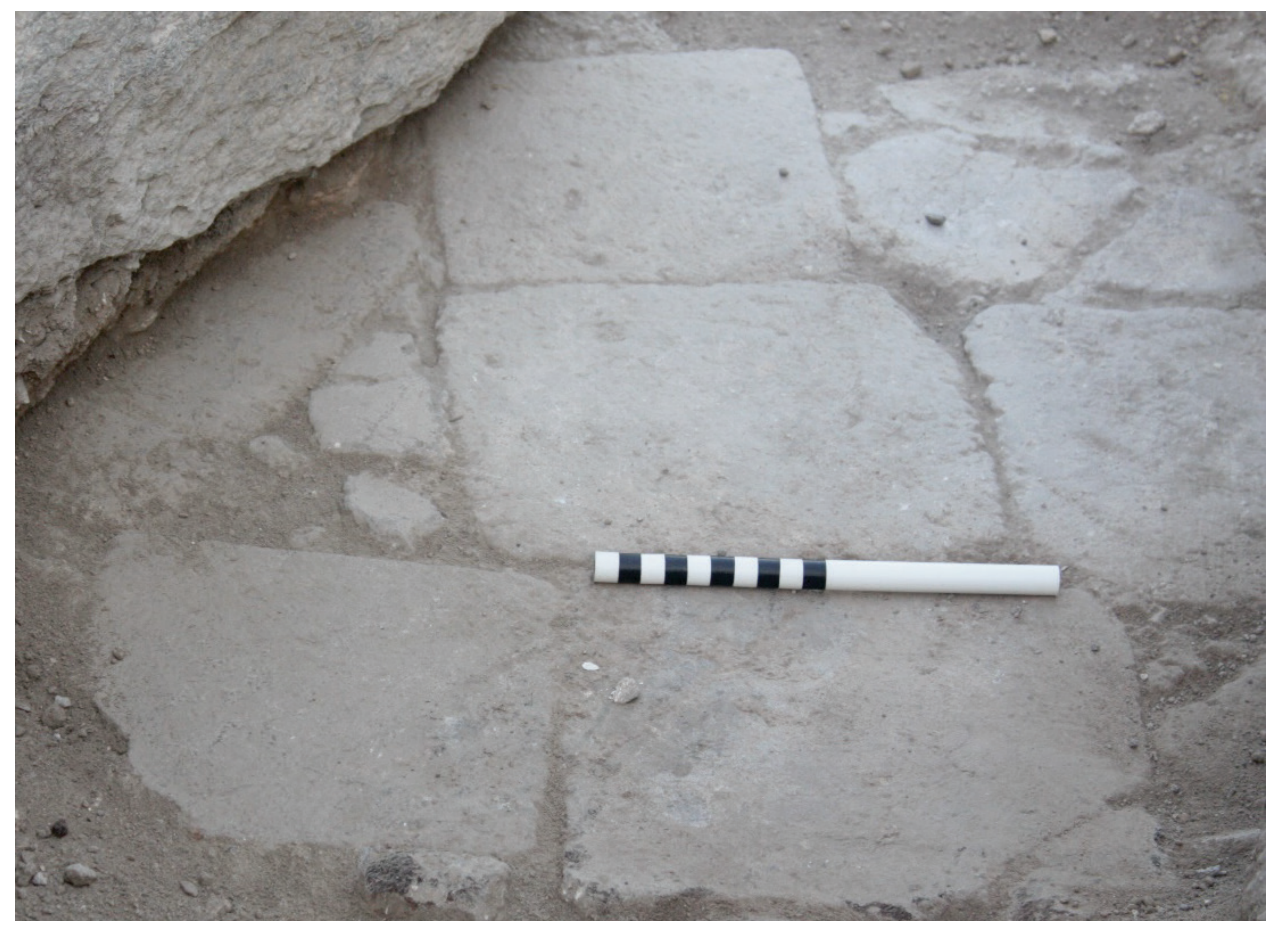

Figure 43 Remnant of brick flooring

$20 \mathrm{~cm}$ from the western line of the arch, the floor rises (F2162) about $10 \mathrm{~cm}$ and is paved with irregular flat stones to W2154. A low bench sits next to W2154 $(80 \mathrm{~cm}$ deep and $34 \mathrm{~cm}$ high).

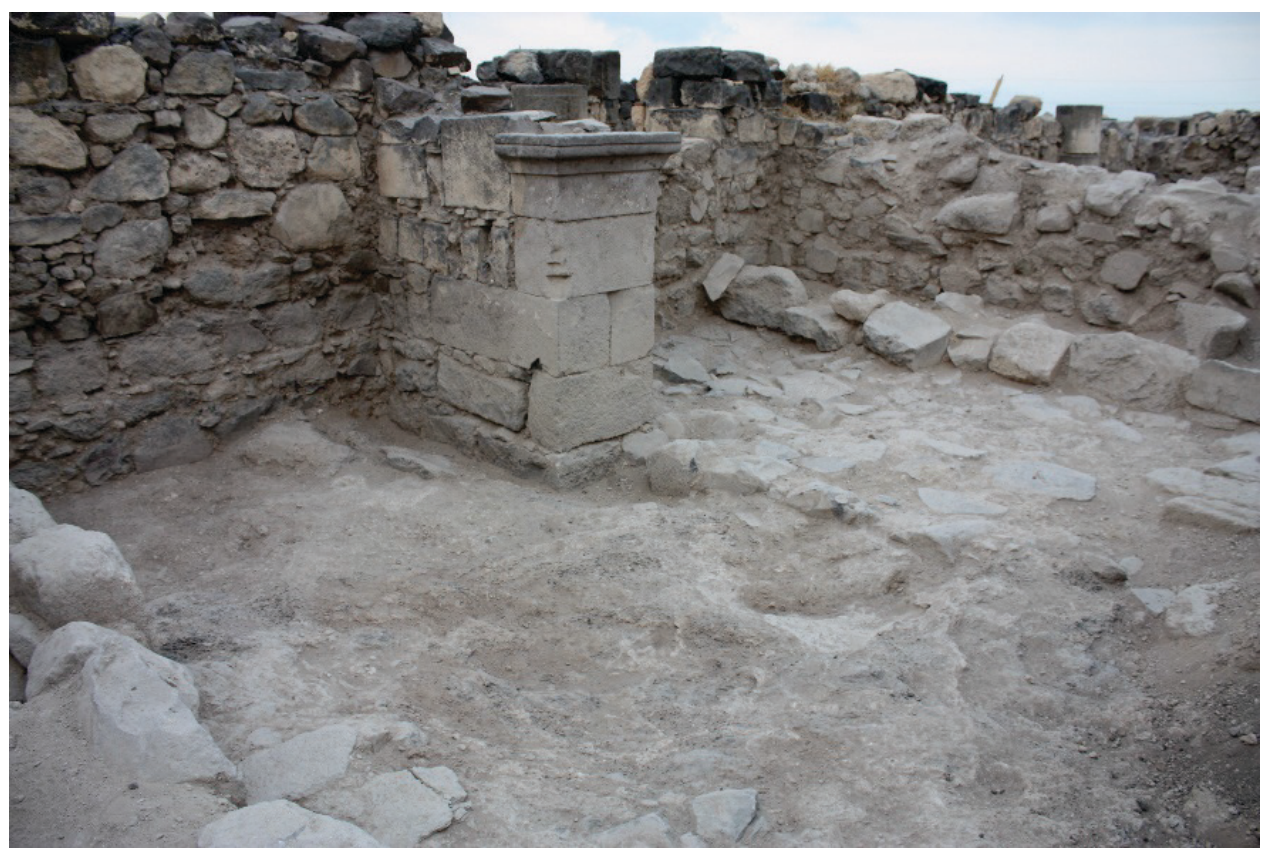

Figure 44 Eastern section (looking west)

$3.8 \mathrm{~m}$ north of W540 and parallel to it is the remains of a door threshold $(55 \times 103 \mathrm{~cm})$ from an earlier construction (W2163). The exterior of the threshold is to the north. Opposite it 
in W540 is the blocked passageway from the medial chamber. The threshold is of that doorway in in the medial chamber is $1.4 \mathrm{~m}$ above F2162 of the Northern Building.

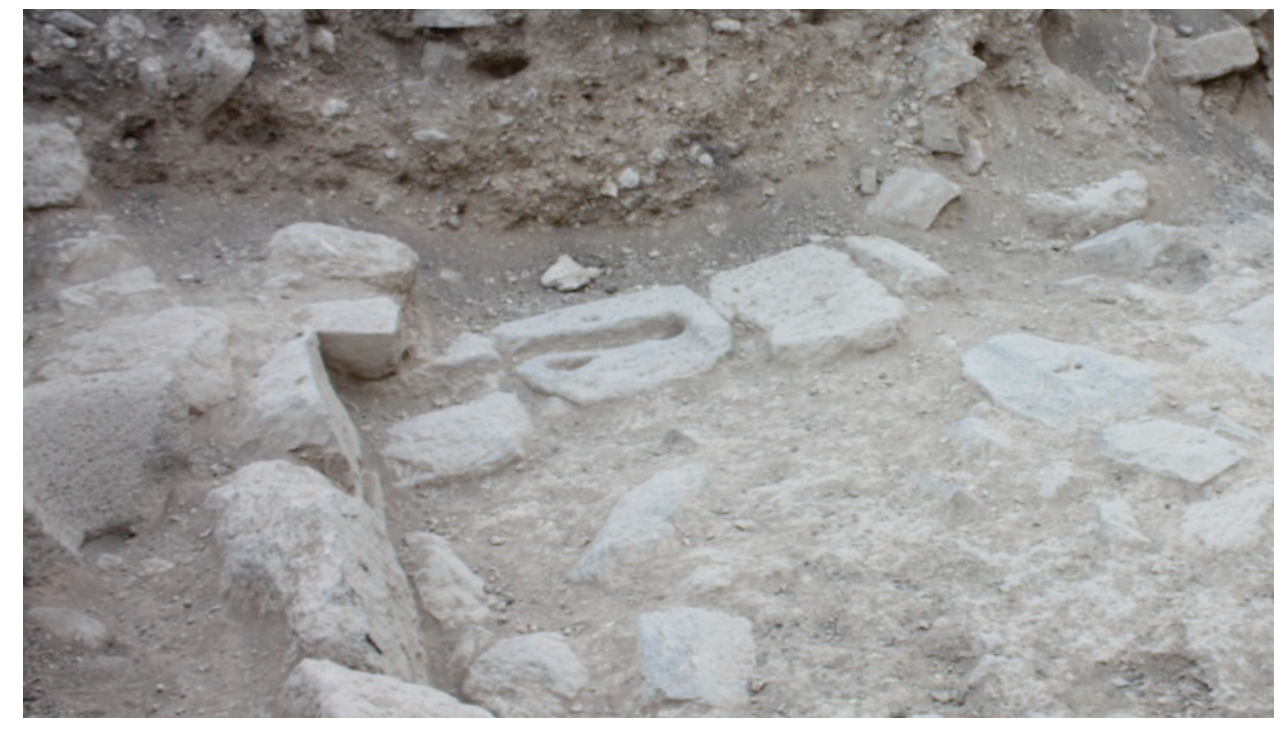

Figure 45 Threshold (looking north)

In the destruction fill beginning about $40 \mathrm{~cm}$ above the floor we recovered hundreds of individual tesserae, many small clusters, and several dozen fragments that showed evidence of geometric patterns. In addition, we found a few fragments that indicate an inscription was part of the mosaic from the second story.

Due to access limitations, we were only able to excavate a $1.5 \mathrm{~m}$ swath of the northwest quadrant to the north of W2156. There are no architectural features from the space and access to the quadrant was either from above or through a doorway hidden in the unexcavated area. We postulate that the area was used primarily for storage.

The layer of fill toward the bottom of the wall was particularly rich in larger animal bones, many chopped. Toward the bottom of the wall, we reached a layer of soil relatively lacking in small finds and containing some plaster. It was likely the floor.

We excavated below the level of the foundation trench of the wall to bedrock $(40-90 \mathrm{~cm})$. Sitting on bedrock under the wall was the foundation trench of an early wall (W2168), 4.3 $\mathrm{m}$ east of W2153. It runs under W2156, through the southwest quadrant, and under the north wall of the church building (W540).

The ceramic assemblage included storage jars and cooking pots (5-6 CE), and the notable find of a fully intact small storage jar. ${ }^{71}$

\footnotetext{
${ }^{71}$ Roni Ben-Arieh, "The Roman, Byzantine and Umayyad Pottery," in The Roman Baths of Hammat Gader, ed. Yizhar Hirschfeld (Jerusalem: Israel Exploration Society, 1997), plate XIII:9.
} 


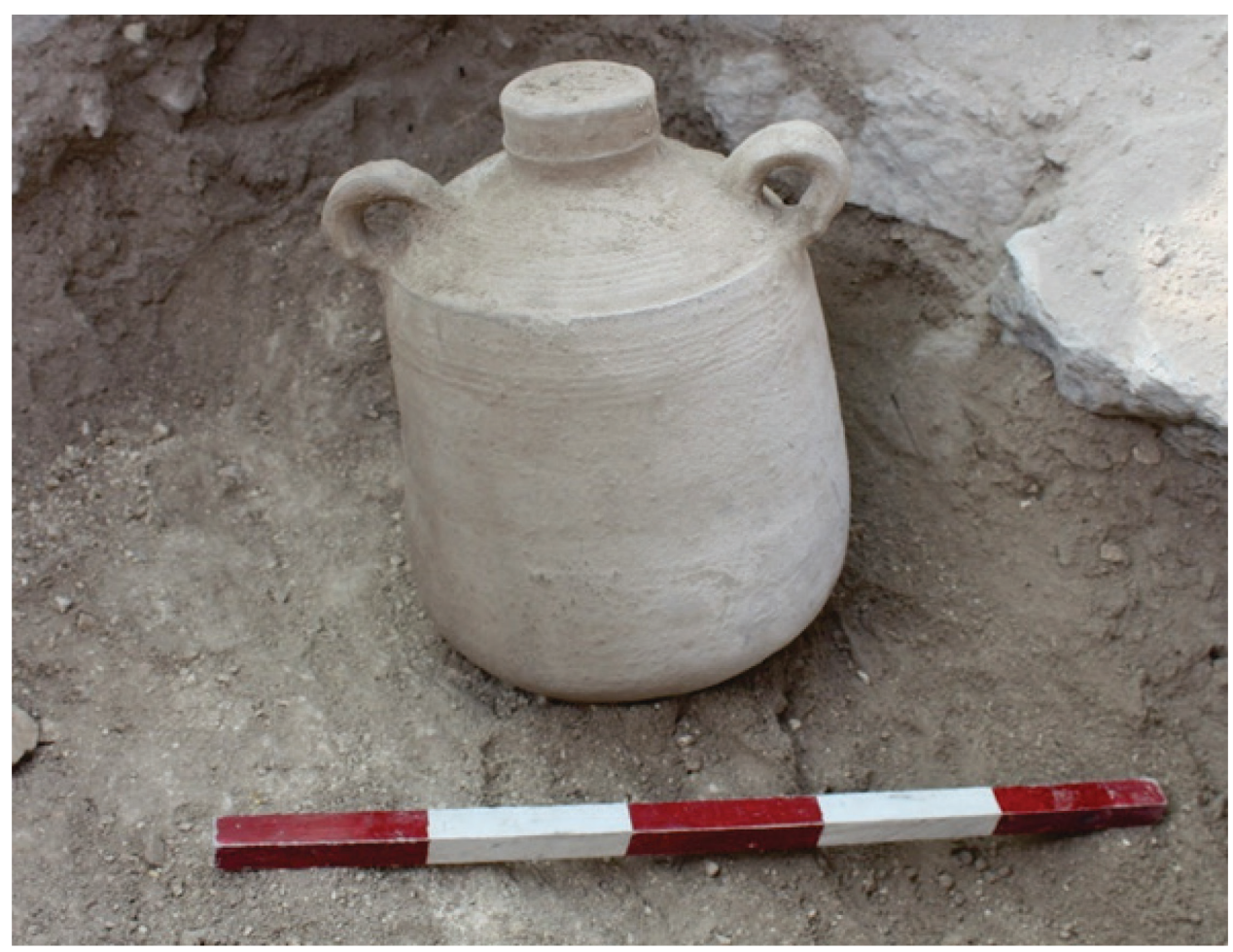

Figure 46 Buff ware storage jar (Late Antique/Umayyad)

While tracing W2153 to the north, we discovered the top of another wall perpendicular to and running to the west. This $70 \mathrm{~cm}$ wall is $4.1 \mathrm{~m}$ from the southwest corner of the Northern Building.

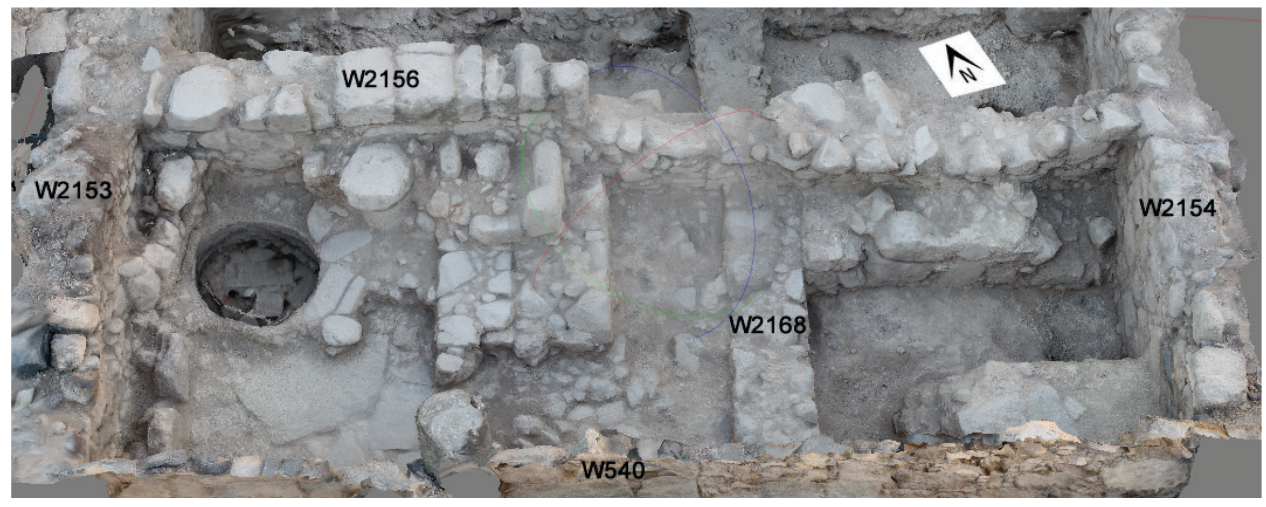

Figure 47 Southwest quadrant of the northern building

The southwest quadrant likely served as a food preparation area. On the east side of W2153 is a catch basin for water piped down from the roof. Although quite damaged, it seems to have held some water and channeled the excess south along and under W540 to the cistern under it. Next to it is a $90 \mathrm{~cm}$ taboun. The floor south of the taboun consists of flat stones. To the east of the taboun is a two-level platform/shelf the upper portion of which is composed of architectural fragments. The upper self is $65 \mathrm{~cm}$ deep. The lower section is $170 \mathrm{~cm}$ deep. 
To the east of this working area, the floor was a dense and hard-packed yellowish layer that overtopped the earlier W2168 and abutted the $60 \mathrm{~cm}$ bench on the south side of the eastern portion of W2156. We broke through and sifted that layer recovering two coins. Unfortunately, one could not be identified and the other seemed to be a Roman imperial coin of the late fourth century. We then dug an L-shaped trench to bedrock showing that W1268 and the easterly bench on the southern side of W2156 both sat on bedrock.

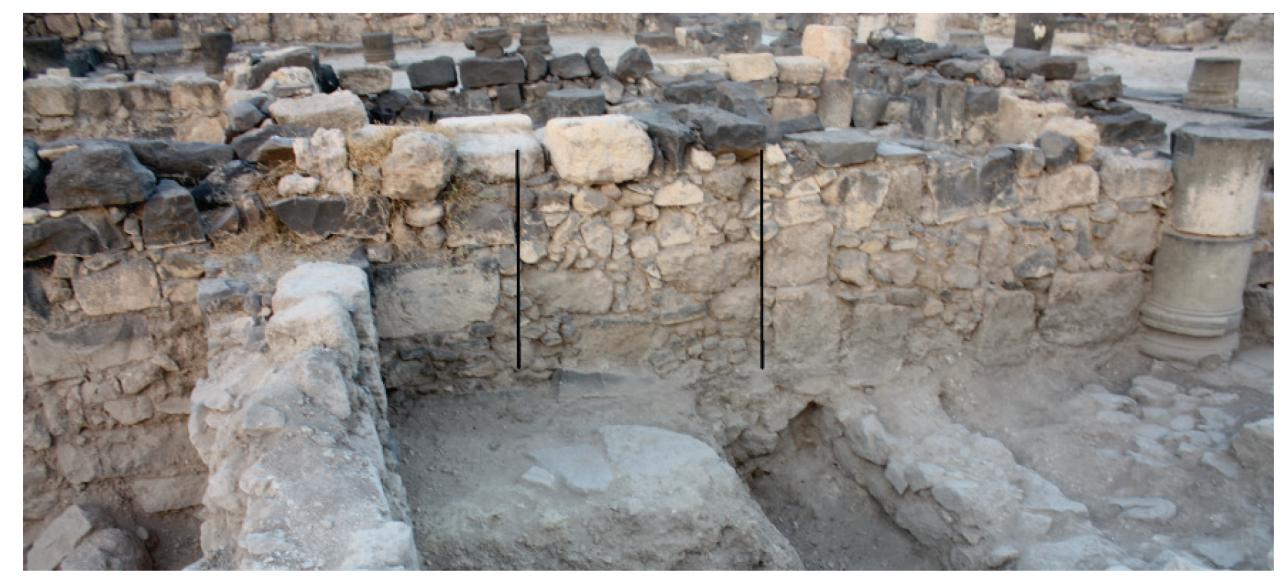

Figure 48 Blocked doorway from the Northern Building to the North Lateral Chamber (looking south)

Access to this working area was from the north lateral chamber. The doorway begins $60 \mathrm{~cm}$ from the corner and is $140 \mathrm{~cm}$ wide. This blockage in W540 along with the addition of a course of stones (W555) on the south face of W540 sealed off the Northern Building while allowing continued (domestic?) use of the north lateral and medial chambers after the complex and the domus were decommissioned.

The ceramic assemblage included many cooking pots and jars from the 5-7 CE and are consistent with the posited usage of the complex from the fifth to early seventh centuries.

The features of the Northern Building would seem supportive of a larger community complex. The lower floor provided for food preparation and storage. The upper floor was more decorative, although its function cannot be determined. 


\section{South of the domus}
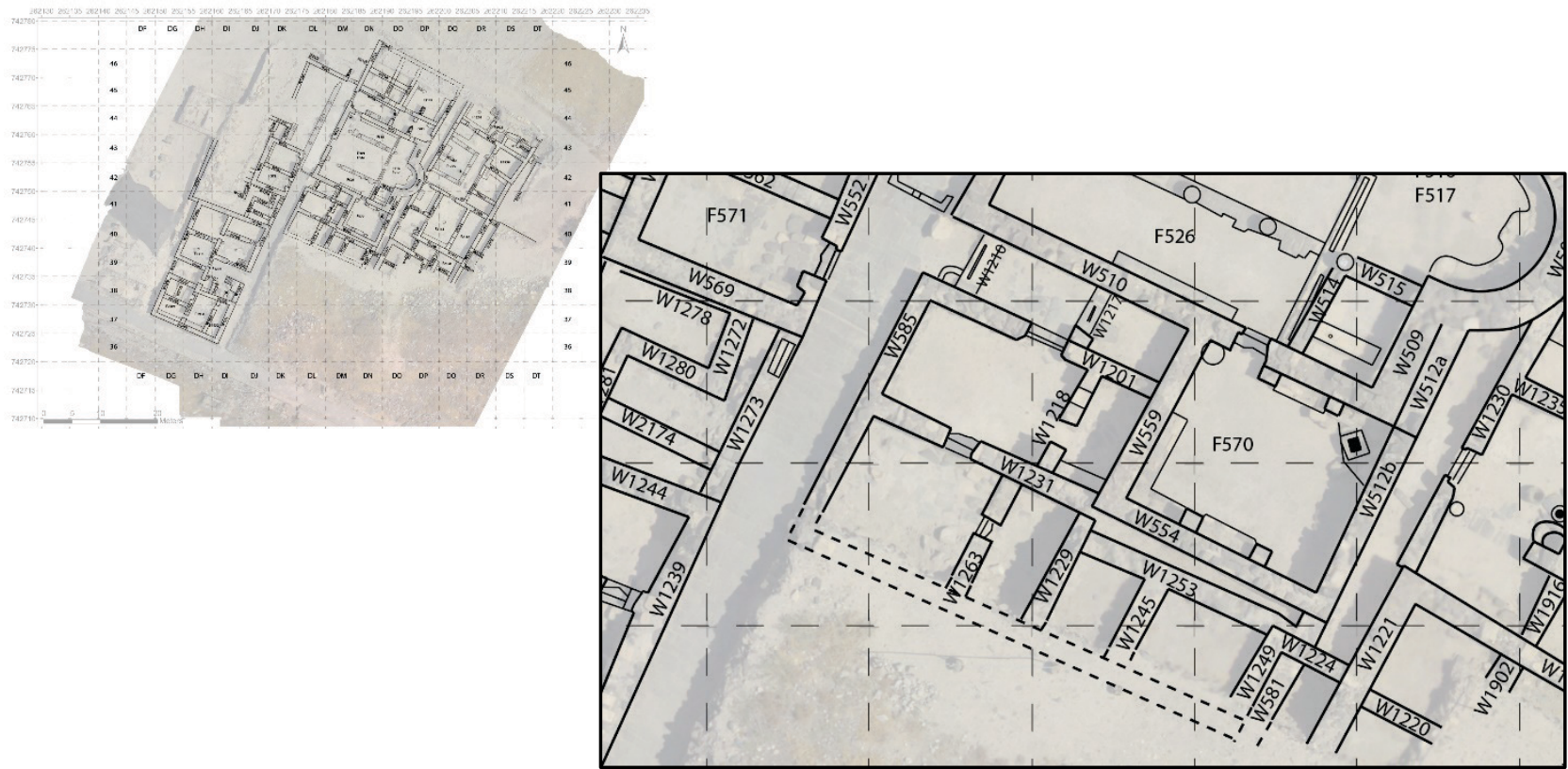

Figure 49 South structures

\section{Diakonikon}

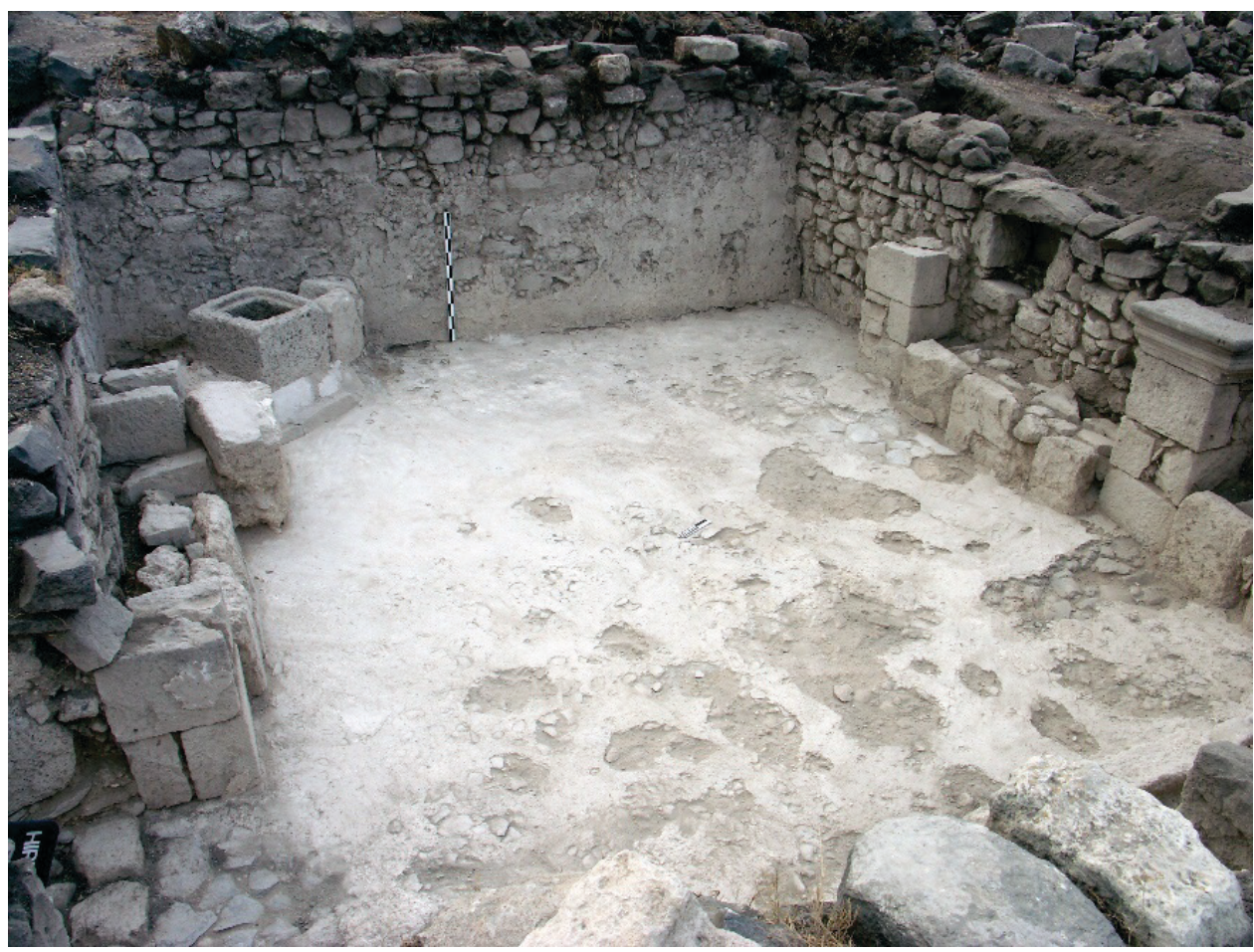

Figure 50 Diakonikon (looking southeast)

Immediately south of the chancel is a large barrel-vaulted room $(6.23 \mathrm{~m}$ from east to west and $5.63 \mathrm{~m}$ from north to south). Two pilasters for the ribbing of the barrel vaults are still 
in evidence next to the south (W554) and the north (W510) walls. A Roman-era pilaster base was inverted and reused as part of the westerly pilaster on the south side. The bases for the ribs are the typical 2.2-2.4 $\mathrm{m}$ apart. Some of the collapsed ribbing was recovered resting on about $25 \mathrm{~cm}$ of fine fill.

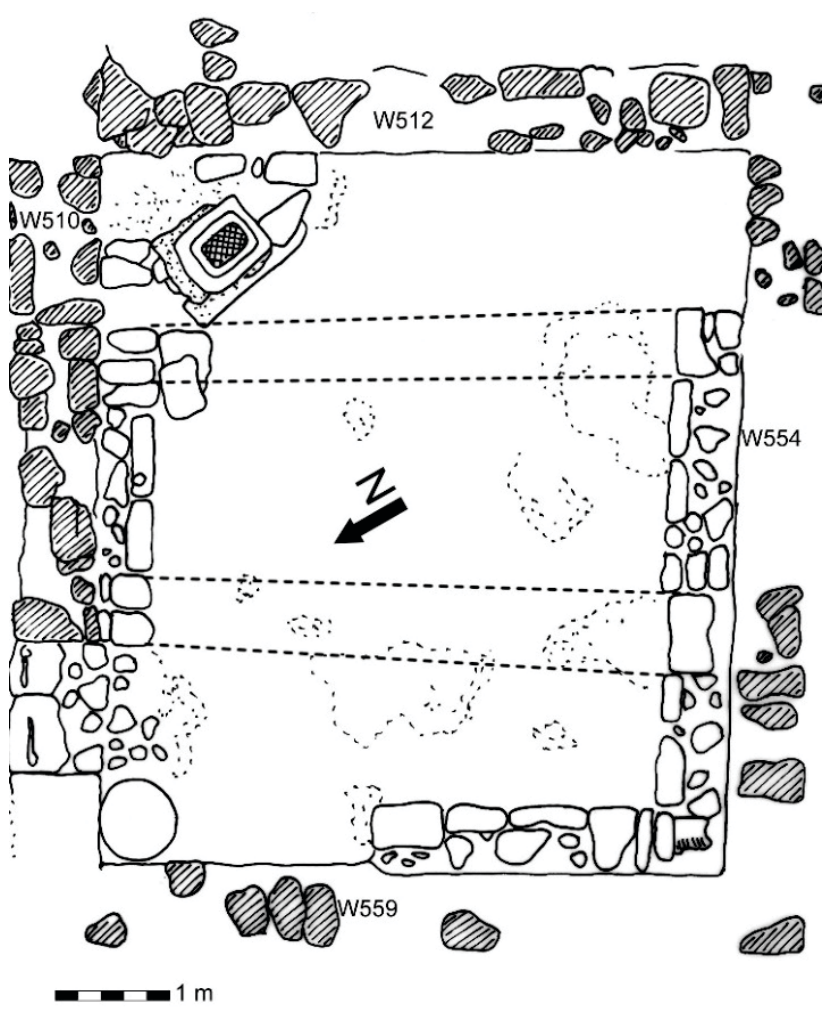

Figure 51 Top plan of the south vaulted chamber

Three high benches or platforms were discovered next to the south, west, and north walls of the vaulted chamber. The north bench fills the space between the pilasters ( $47 \mathrm{x} 171 \mathrm{x} 41$ $\mathrm{cm}$ high). A south bench (64 x $190 \times 41 \mathrm{~cm}$ high) fills the corresponding space. A third bench fills the corner from the westerly pilaster on the south wall to the corner and from the corner to the north for $3 \mathrm{~m}$ (west section is $63 \times 300 \times 34 \mathrm{~cm}$ high; south section is $62 \times 94 \times 36$ $\mathrm{cm}$ high). Lack of plaster between the stones of the bench and the pilasters may indicate that the benches were part of the original construction of the room. In the southwest corner of the room, a column base $(69 \mathrm{~cm}$ diameter, $20 \mathrm{~cm}$ high) sits inverted and may have functioned as a pedestal. The presence of these benches would suggest that the room functioned as a diakonikon.

On the south wall (W554) above the bench is a rectangular niche in the wall. The niche is $2.44 \mathrm{~m}$ west of W512 and $86 \mathrm{~cm}$ above the floor. It is $43 \mathrm{~cm}$ wide by $51 \mathrm{~cm}$ tall by $46 \mathrm{~cm}$ deep. Partially intact plaster in the bottom of the niche would reduce the interior height to $36 \mathrm{~cm}$. Nothing survives of the contents of the niche. 
The floor of the chamber is covered in hard plaster on top of a pebble base. In several locations the plaster is still visible curving up from the floor onto the walls, benches, and pilasters, especially on W512. Likewise, some plaster still clings to the joints between the benches and the walls. In its final phase, plaster covered walls, benches, pilasters, and the floor.

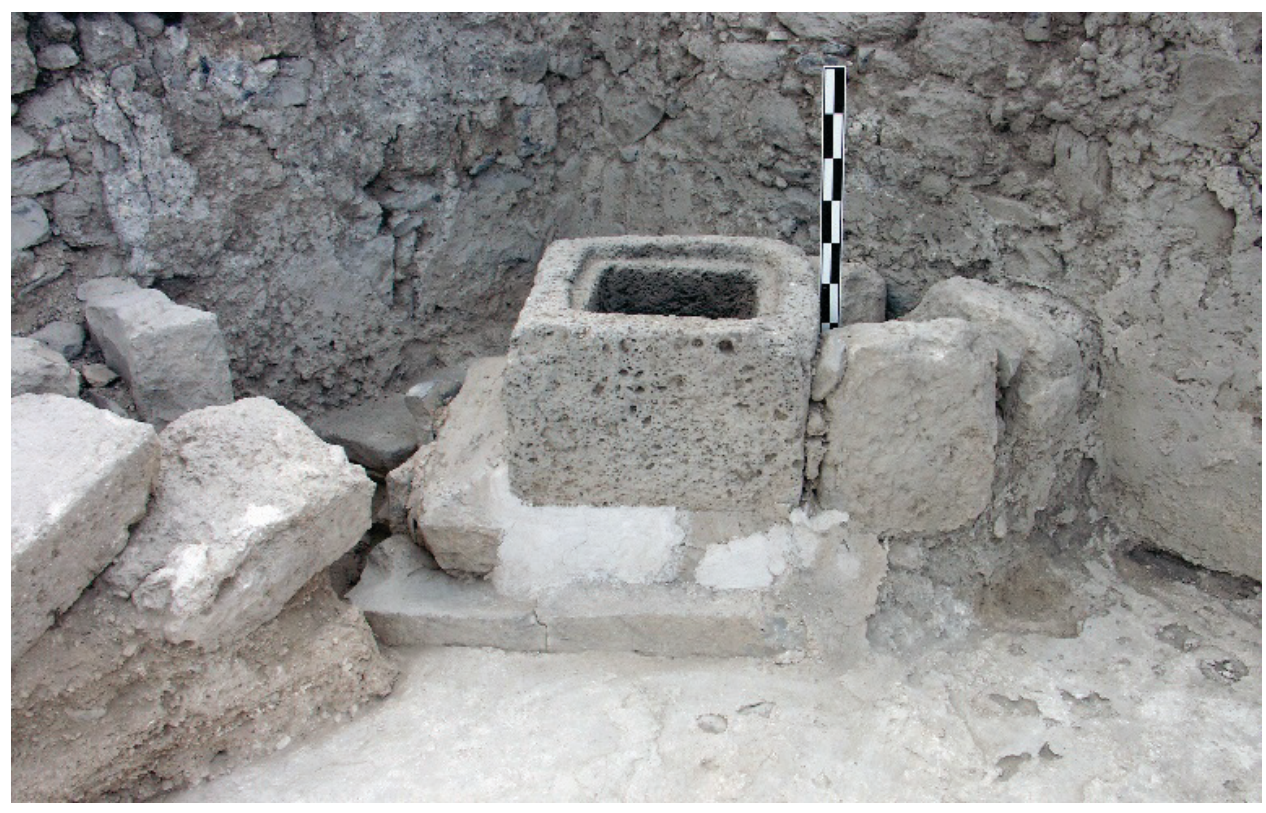

Figure 52 Cistern D (looking northeast)

In the northeast corner of the diakonikon is a well-preserved cistern head. The head is a finely worked square stone ( $66 \times 66 \times 49 \mathrm{~cm}$ high). The opening is 36 by $38 \mathrm{~cm}$ and space is provided for a $46 \times 48 \mathrm{~cm}$ lid, now lost. The front of the cistern (Cistern D) head faces the center of the room with one back corner $65 \mathrm{~cm}$ from W510 and the back other corner $37 \mathrm{~cm}$ from W512. The head sits on a platform, about $25 \mathrm{~cm}$ above the floor. Several stones are plastered to the southeast side of the head creating a catch basin that feeds the cistern. The cistern seems to be about three meters deep.

On the cistern platform in the northeast corner of the room, a small horde of gold jewelry was discovered hidden under a fragment of a ceramic jar. The horde included three belt elements and a magical healing amulet. The architecture of the room in proximity to a revered tomb coupled with the discovery of the amulet suggested that the space may have served as the site of a healing cult or an infirmary.

Subsequent extraction of the ancient pollen signature left within the diakonikon tells us that as many as fourteen ancient herbal plants were utilized for the purposes of healing within its confines. The pollen analysis of diakonikon herbals is an additional line of support for the thesis that the diakonikon of the Northeast Church at Hippos served as an infirmary as 
part a larger veneration of a revered woman at the site. ${ }^{72}$ The practice at the site is consistent with developing Christian approaches to healing in the Greek east in the sixth and seventh centuries, especially in view of the ongoing trauma of the plague of Justinian. In the infirmary at Hippos, faith and pharmacology brought some relief and hope in the context of the revered memory of a now unknown woman.

\section{South Building}

The antechamber to the South Building is $2 \times 5 \mathrm{~m}$ and provides access to the street from the other rooms. It consists of two sections separated by a wall (W1210; $60 \mathrm{~cm}$ wide) with the threshold of a small door locking from the inside. The outer section of the antechamber next to the street is $2 \times 1.2 \mathrm{~m}$. In the northeast corner of W510 and W1210 and in the southeast corner of W1210 and W1201 are two basins of hard plaster like the one in the north lateral chamber. As with the later example, these basins collected water from the roof and channeled it under the street to another channel running under the western edge of the street to Cistern C. The channels confirm the use of Cistern C during active phases of the Northeast Church complex. ${ }^{73}$

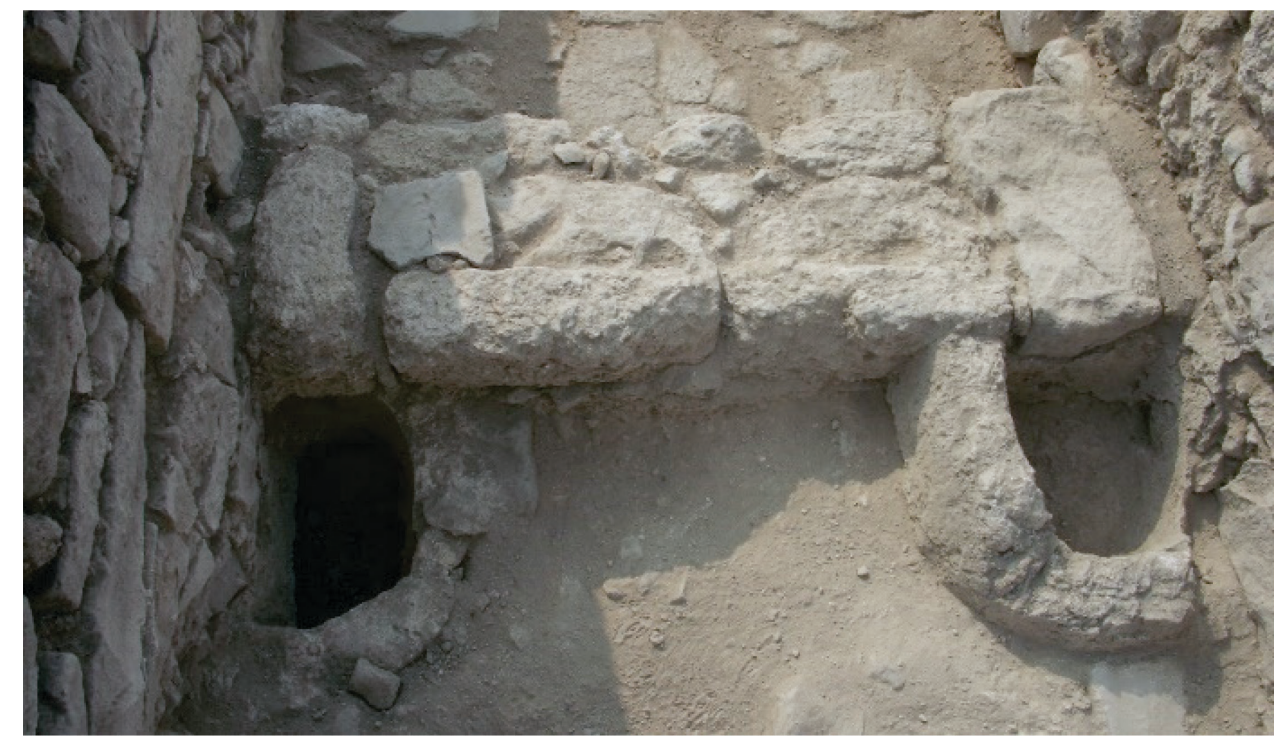

Figure 53 Catch basins

The inner section of the antechamber is $2 \times 3.3 \mathrm{~m}$ and has a stone surface (F1213) overlaying an earlier floor of soft ceramic tiles/bricks. At its east end is a threshold leading to an inner chamber ( 2 x $2.6 \mathrm{~m})$. A lacuna in W510 indicates that the wall (W1217) of which the threshold is a part was constructed at the same time as the south wall of the domus (W510). The

\footnotetext{
${ }^{72}$ Both amulet and herbals are discussed in greater detail later in this report.

${ }^{73}$ The drainage channel leading to cistern $\mathrm{C}$ on the surface of the street has no apparent function, although it terminates at the mouth of the cistern. While it may have provided a means of catching overflow and runoff from the street, it seems more likely that the pavers here were reused and the channel had an earlier use now unknown due to relocation.
} 
door for the inner chamber locked from the inside, suggesting that the chamber served as sleeping quarters for an individual.

In the southeast corner of the antechamber is a threshold providing access to a large hall. The hall is bounded on the north by W1201. W1201 runs from the street to W559 of the south vaulted chamber. Again, a lacuna in W559 indicates that W1201 and W559 were constructed at the same time. The lacunae in W559 and W510 are significant, for they confirm that these southerly chambers were part of the original construction of the church. From the beginning, the domus was part of a significantly larger complex.

The southerly wall (W1231) of the large hall abuts W559 to the east but is not a continuation of W554 as it is positioned about $10 \mathrm{~cm}$ to the south.

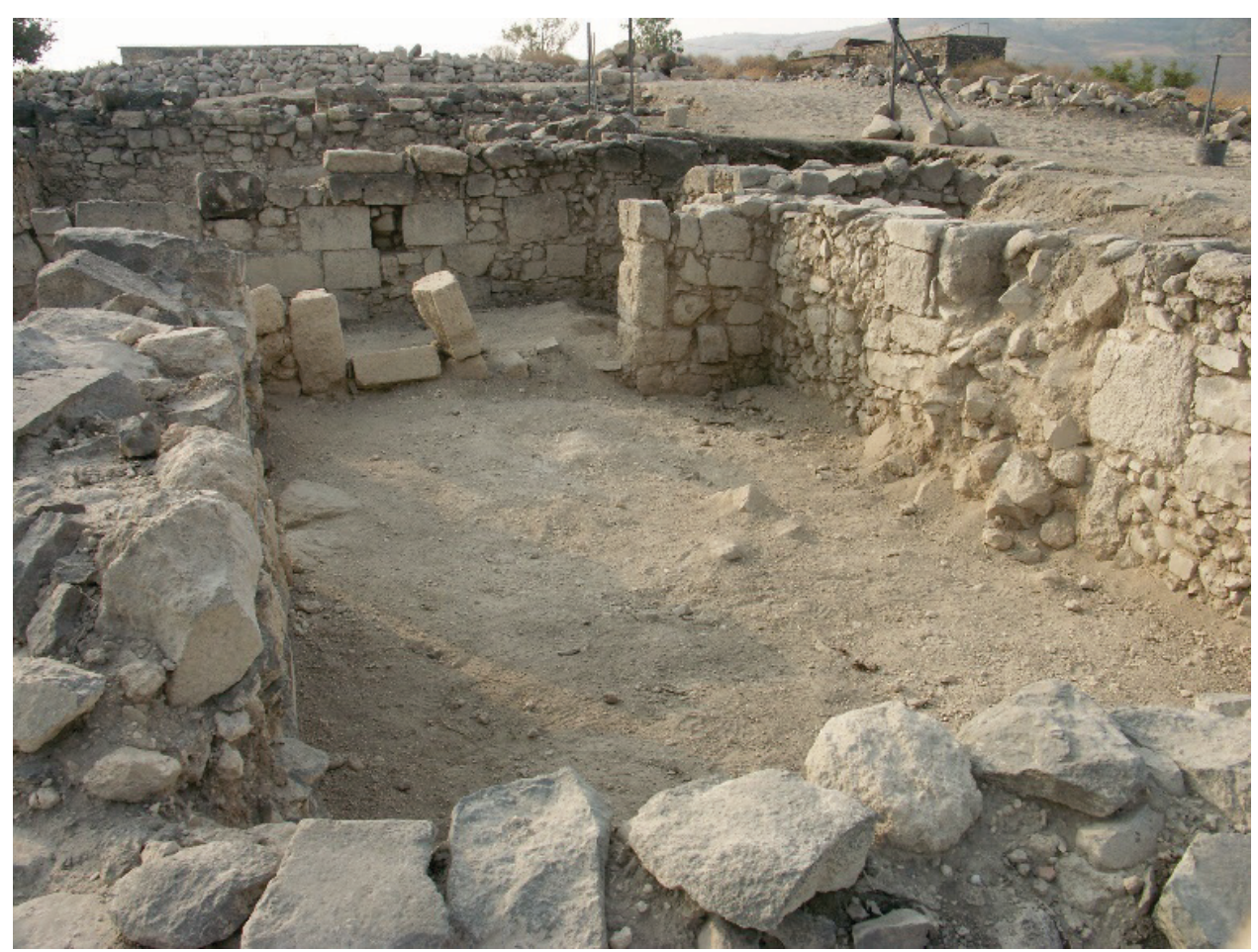

Figure 54 South hall (looking east)

The internal dimensions of the south hall are $3.23 \mathrm{~m}$ by $5.30 \mathrm{~m} .2 .6 \mathrm{~m}$ from the southwest corner of the hall is a $90 \mathrm{~cm}$ doorway to the south that closed from inside the room. The doorway was blocked. The floor is packed mud and plaster. Next to W1231 at approximately floor level was a substantial deposit of shards. No partial or complete vessels could be reconstructed. The bulk of the shards were cooking pots and casseroles of similar types, along with Late Roman, Cypriot, and ARS shards. No Umayyad shards were recovered.

A threshold in W1218 provides access to another inner chamber between W1218 and W559. The threshold is of poorer quality than those previously mentioned in this section. But this threshold also would hold a door that locks from inside the small chamber. The chamber is $1.5 \mathrm{~m}$ wide. It too seems to be a chamber that served as sleeping quarters for an individual. 
The discovery of such quarters may support that theory that the Northeast Church complex was an urban monastic compound. Rooms of similar small dimensions can be seen in the plans of the Kyria Maria Monastery at Scythopolis ${ }^{74}$ and in the plan of the Monastery of St. Martyrius..$^{75}$ Yizhar Hirschfeld points to an internal dimension of about $7 \mathrm{~m}^{2}$ for cells in the cenobia at Khirbet et-Tina and Khirbet ed-Deir. ${ }^{76}$

Similar deposits are at approximate floor levels in both small chambers. From the small chamber between W1201 and W510, many of the recovered potsherds were burnt, although no ash pits or cooking areas have been revealed. A blue loom weight was recovered from the fill.

A doorway exits the south hall through W1231.

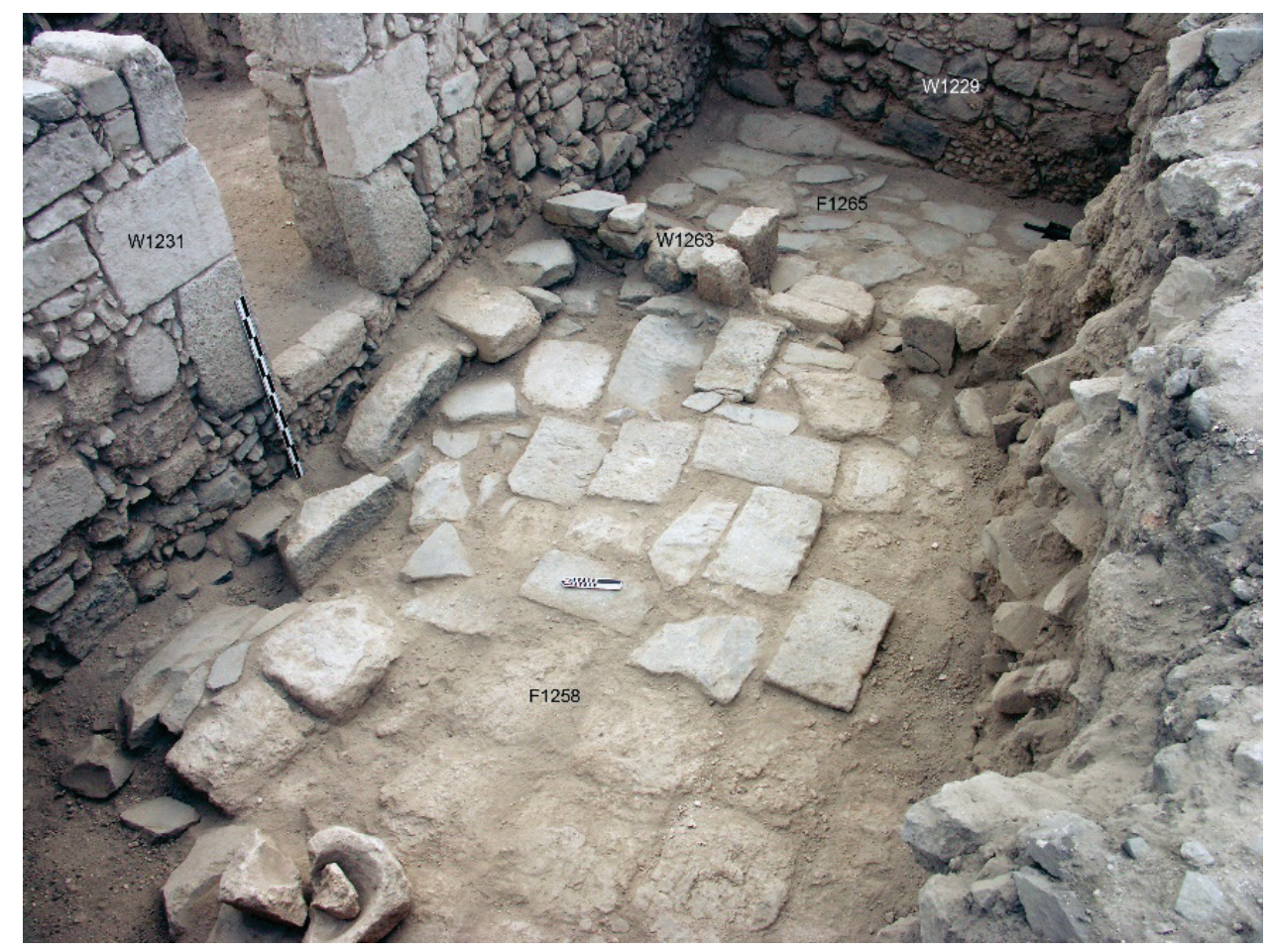

Figure 55 F1258 (looking northeast)

$53 \mathrm{~cm}$ below the threshold in W1231 is a surface (F1258) crudely paved with basalt and limestone. A small limestone feeding trough was in the fill near the floor. F1258 is $45 \mathrm{~cm}$ below the surface of Cardo 2 North, suggesting that the street comes from a later period. The easterly extent of the surface is marked by W1263 through which a doorway gives access to another similarly paved surface (F1265) about $10 \mathrm{~cm}$ lower. W1229 marks the eastern

\footnotetext{
${ }^{74}$ FitzGerald, A Sixth Century Monastery at Beth-Shan (Scythopolis), Plate 2.

${ }^{75}$ Magen, "The Monastery of St Martyrius of Ma'ale Adummim," 171.

${ }^{76}$ Yizhar Hirschfeld, The Judean Desert Monasteries in the Byzantine Period (New Haven: Yale University Press, 1992), 177.
} 
limit of this surface. At its northern end, the W1229 sits on bedrock that forms the northeast corner of F1265. W1229 survives to a height of more than $2 \mathrm{~m}$.

Large concentrations of pottery shards were recovered at the floor level next to W1231. Most were dated from the fourth and fifth centuries, with one shard perhaps datable into the early sixth century. Also recovered from the surface of this small room were two mortars, several pestles, and portable bronze brazier. Both mortars were of higher quality than typical pieces found in the destruction fill.

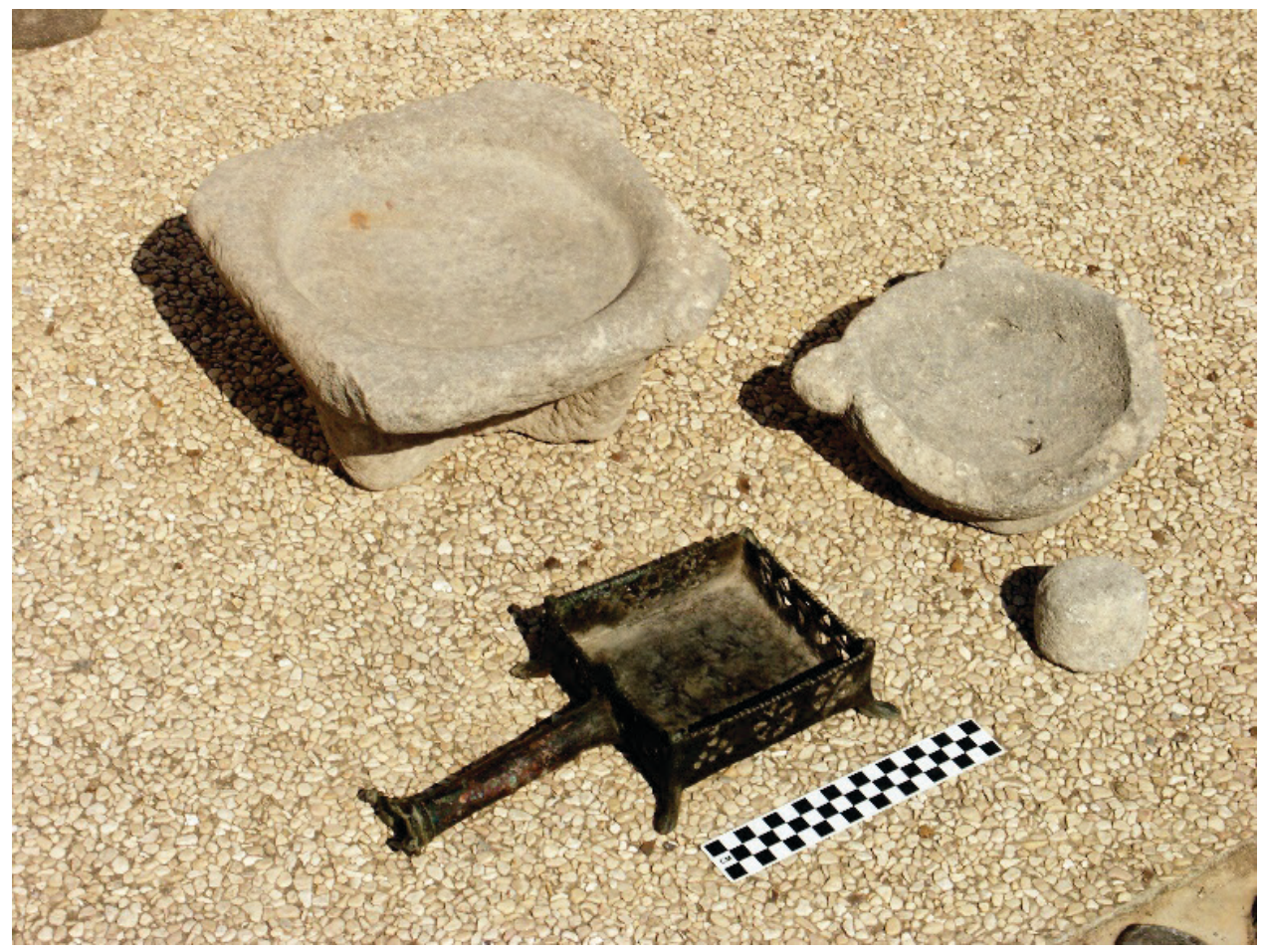

Figure 56 Mortars and brazier

The first is a ring-based mortar $21 \mathrm{~cm}$ in diameter. It stands $6.5 \mathrm{~cm}$ tall. It is carved from regular gray basalt. Two of its handles have been broken off. The ring base is $4 \mathrm{~cm}$ thick and $14 \mathrm{~cm}$ in diameter. The handles are about $5 \times 2.5 \mathrm{~cm}$ and $2 \mathrm{~cm}$ thick. The mortar lacks any decoration. A pestle was found $30 \mathrm{~cm}$ away.

The second is a tripodic mortar ${ }^{77}$ made from basalt with a finer grain. The mortar was carved from a cube of basalt $(28 \times 28 \times 28 \mathrm{~cm})$. In its finished form it is $34 \mathrm{~cm}$ is diameter and stands $28 \mathrm{~cm}$ tall. It has four handles that are $8 \mathrm{~cm}$ wide. These, and the lack of ash in the fill, rule out the use of this item as a votive stand. Its interior bowl has a ridge around the edge and is $22 \mathrm{~cm}$ in diameter. The ridge would help prevent the contents from scattering and so

\footnotetext{
${ }^{77}$ For the first appearance of three=legged mortars during the Bronze age, see William Foxwell Albright, The Excavation of Tell Beit Mirsim, vol. XVII, Annual of the American Schools of Oriental Research (New Haven: American Schools of Oriental Research, under the Jane Dows Nies Publication Fund, 1937), Plates 38-40; they became more prominent in the Iron Age, according to Harold Liebowitz, “A Unique Worked Stone Mortar from Tel Yin'am.," Levant 32 (2000): 129134.
} 
suggest it may have been used for grinding spices or another valuable commodity. However, no wear patterns are apparent. The bowl sits on three legs that are interconnected on the bottom forming a "Y" shape. A fourth leg joins the "Y" from the center of the bowl. The legs are 6-7 $\mathrm{cm}$ thick. Again, decoration is lacking.
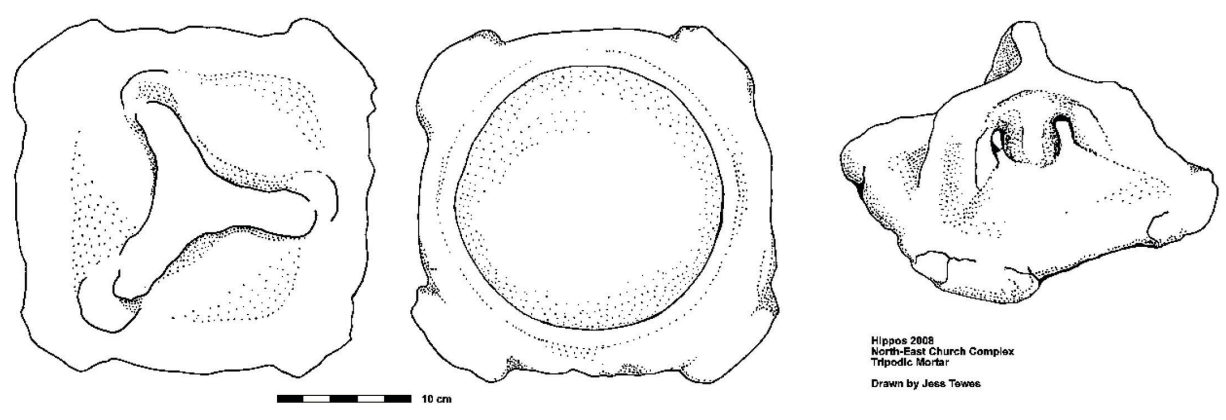

Figure 57 Tripodic mortar

A portable bronze brazier (foculus? ${ }^{78}$ ) was resting on the same floor.

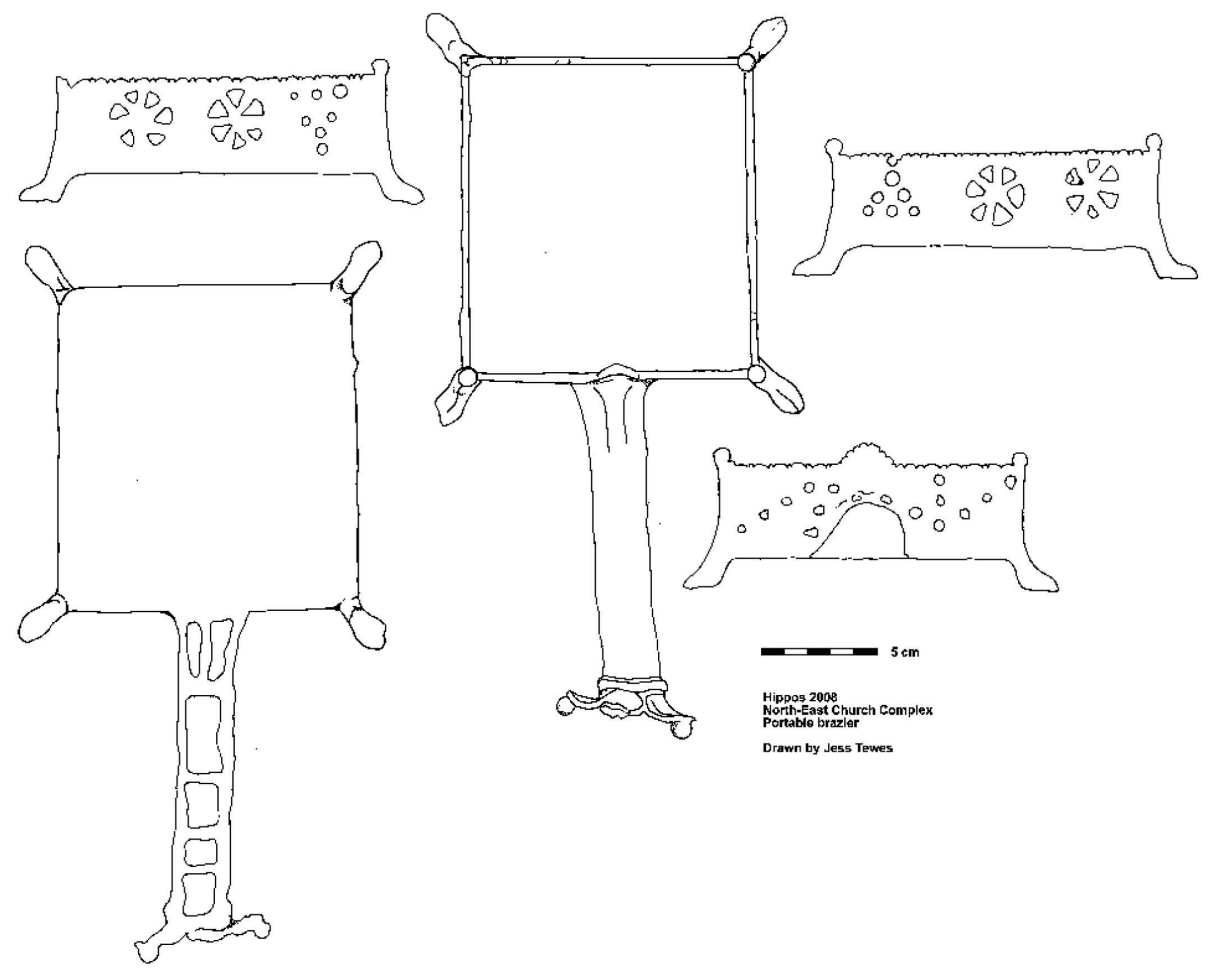

Figure 58 Brazier

The pan of the brazier is almost square $(13.3 \times 14.4 \mathrm{~cm})$ with a depth of $3.8 \mathrm{~cm}$. The pan stands on legs $(1.1 \mathrm{~cm}$ wide) that flair out from the corners adding about $1.5 \mathrm{~cm}$ to the ${ }^{78}$ Titus Maccius Plautus, Persa, 1.3.24; Titus Maccius Plautus, Captivi, 4.2.67; compare, Erich Pernice, Gefässe Und
Geräte Aus Bronze, Die hellenistische Kunst in Pompeji Bd. 4 (Berlin: W. de Gruyter, 1925), 5, Abb. 5. 
height. Each corner is topped with a bulb $(6 \times 7.9 \mathrm{~mm})$ although one is missing. The thickness of the metal is $3.7 \mathrm{~mm}$. A hollow handle protrudes $14.5 \mathrm{~cm}$ from one side. The handle is mostly open on the bottom (for heat dissipation) and has a damaged decorative end with bulbs $(6.2 \times 2.7 \mathrm{~cm})$. The sides are decorated with geometric openings to allow air for the coals. One pattern is six or seven circles forming a triangle. The other is exploded sixths of a pie. On the side facing the handle are a curving row of round circles. Opposite the handle are five pairs of crude triangles. Due to its size, its usage was probably culinary.

As these surfaces south of the hall are significantly below the level of the street and the threshold in W1231, we dug deeper into the mud floor of the south hall (F597).

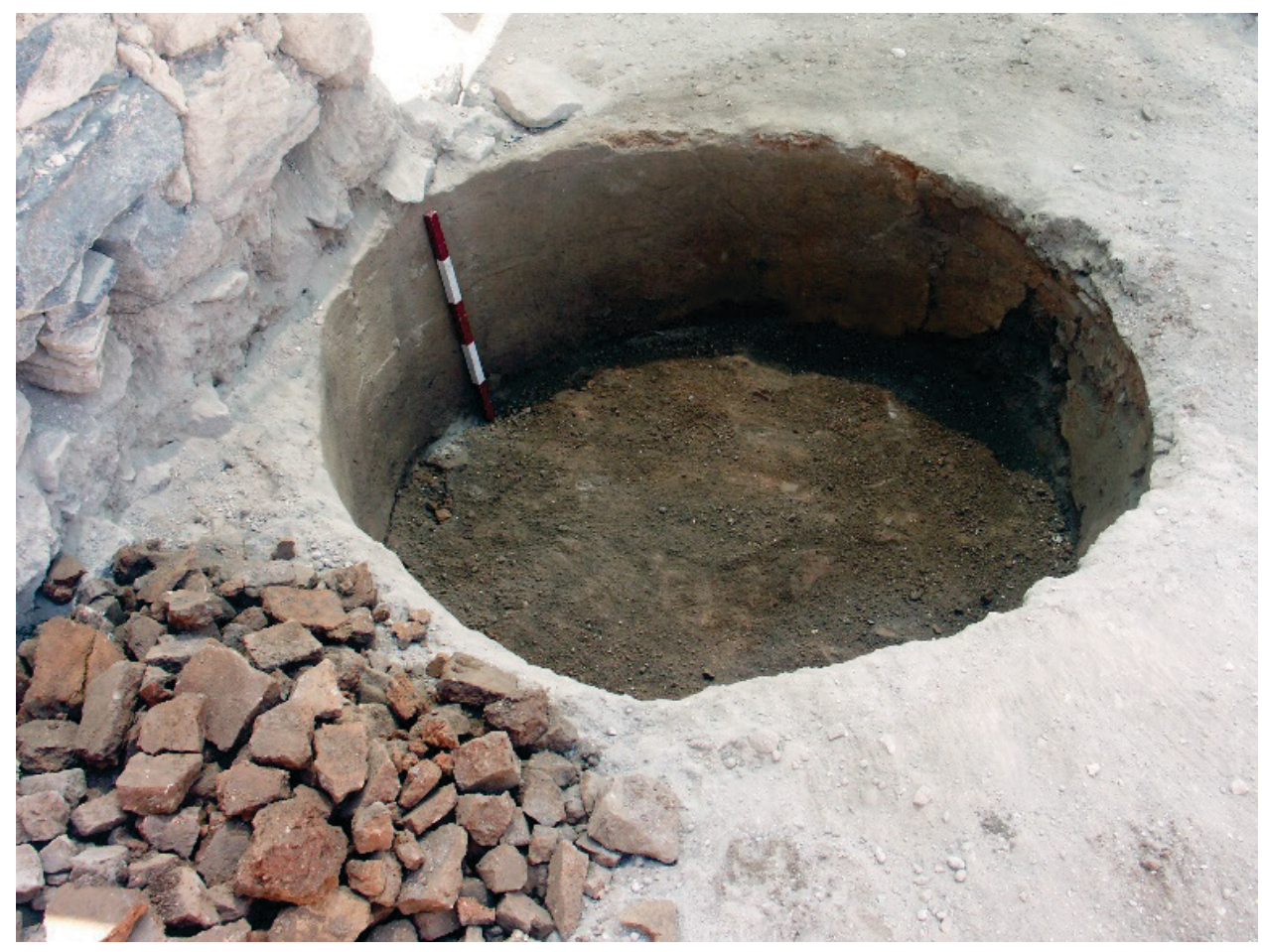

Figure 59 Oven

Next to W1201 and west of the doorway in that wall, the remains of a large round oven were discovered. Its inside diameter is $1.45 \mathrm{~m}$ and it was preserved to a height of about $50 \mathrm{~cm}$. The fill within it was mostly soft ceramic chunks from the top of the oven, although two nail fragments, a pestle, and a button were retrieved from the fill. The oven is similar in dimension to those from the "oven room" east of the Hellenistic Compound. ${ }^{79}$ However, the latest shards were from the fifth century. The surviving top edge of the oven is about $40 \mathrm{~cm}$ below the level of the street to the west.

\footnotetext{
${ }^{79}$ Segal et al., Hippos-Sussita : Eighth Season of Excavations : July 2007, 20-22.
} 


\section{Eastern Zone}
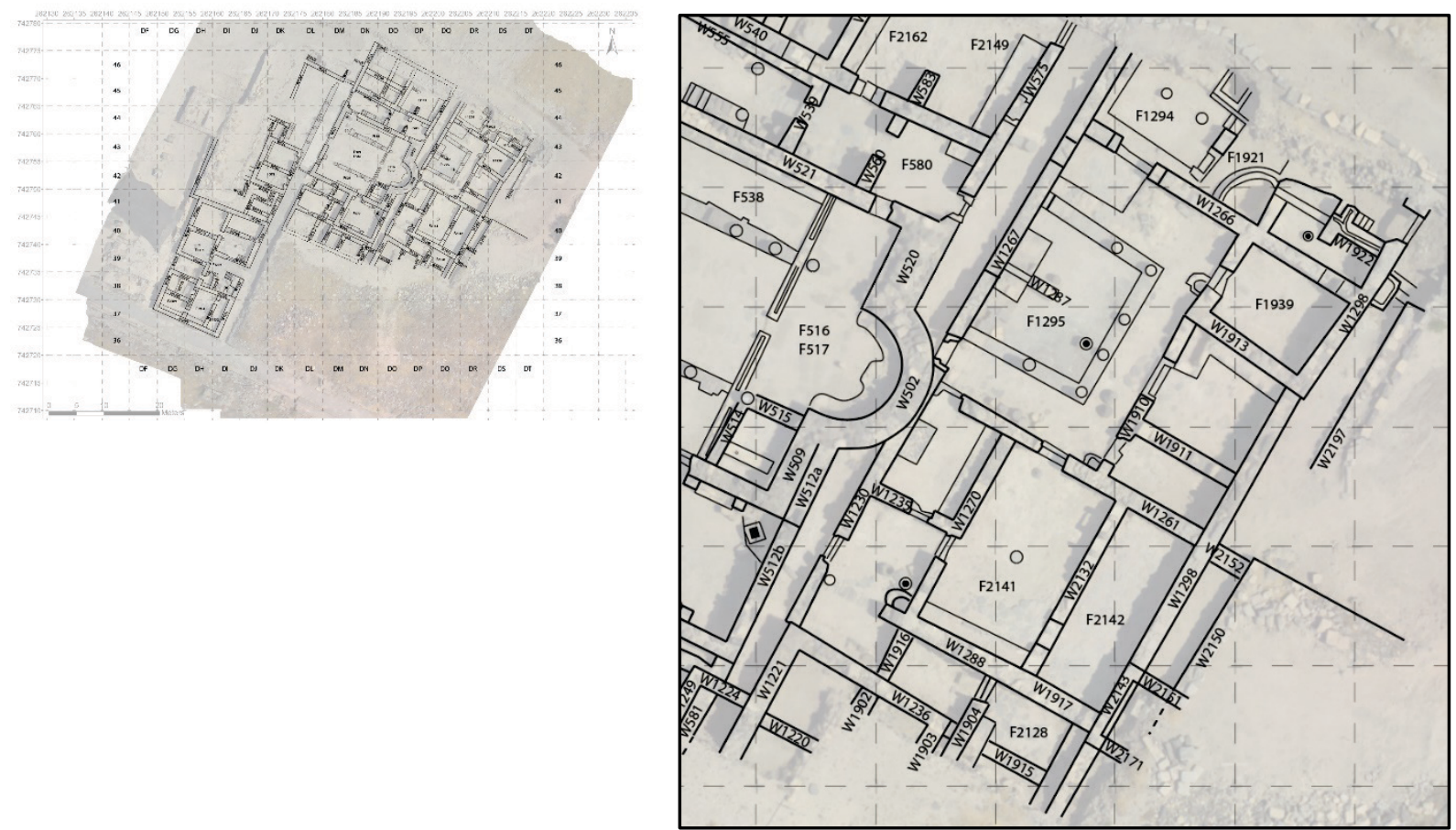

Figure 60 Eastern zone

\section{Cardo 3 North}

Cardo 3 North is a small street that runs parallel to the via sacra roughly $17 \mathrm{~m}$ to the east. The apse of the Northeast Church interrupts the line of the street. Structures were built along the east side the street incorporating elements of buildings from the Roman Imperial period. These large structures suggest that the Northeast Church is part of a much larger complex.

Roughly following the eastern side of Cardo 3 North is W1267 (72 cm wide). As it moves north from the apse, the wall skews slightly to the east from the line of W575 (approx. 15 $\mathrm{cm}$ over $10 \mathrm{~m}$ ). This wall is the western extent of a large structure to the east. As we will demonstrate below that structure was built at the same time as the Northeast Church using the ruins of and following most of the footprint of a Roman peristyle house that had previously occupied the site. That house filled the space between Cardo 3 North and Cardo 4 North immediately south of the north wall of the city. 


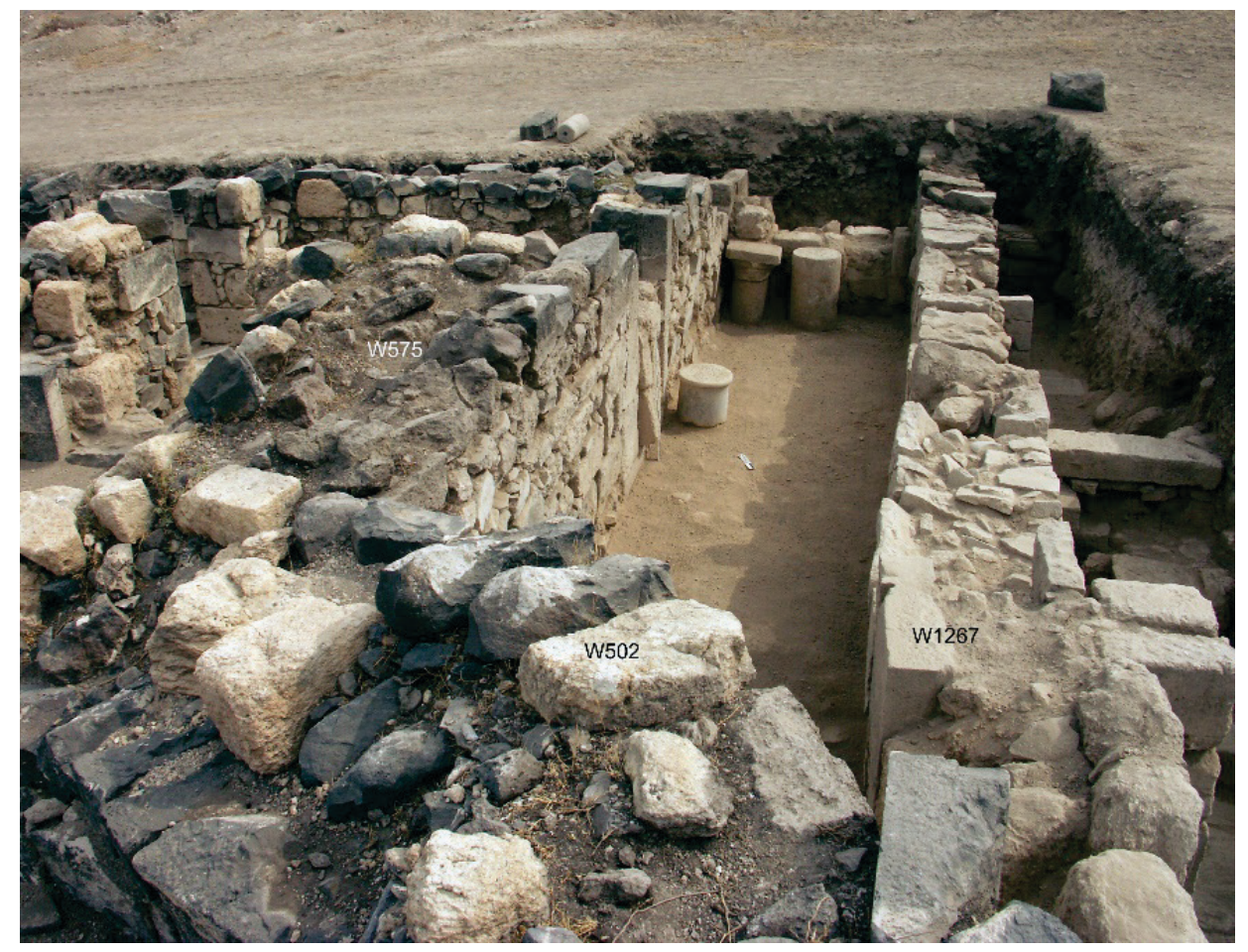

Figure 61 Street north of the apse

At the south end of W1267 is a large, blocked doorway $(1.55 \mathrm{~m})$, the southern jamb of which is incorporated into the exterior apse wall.

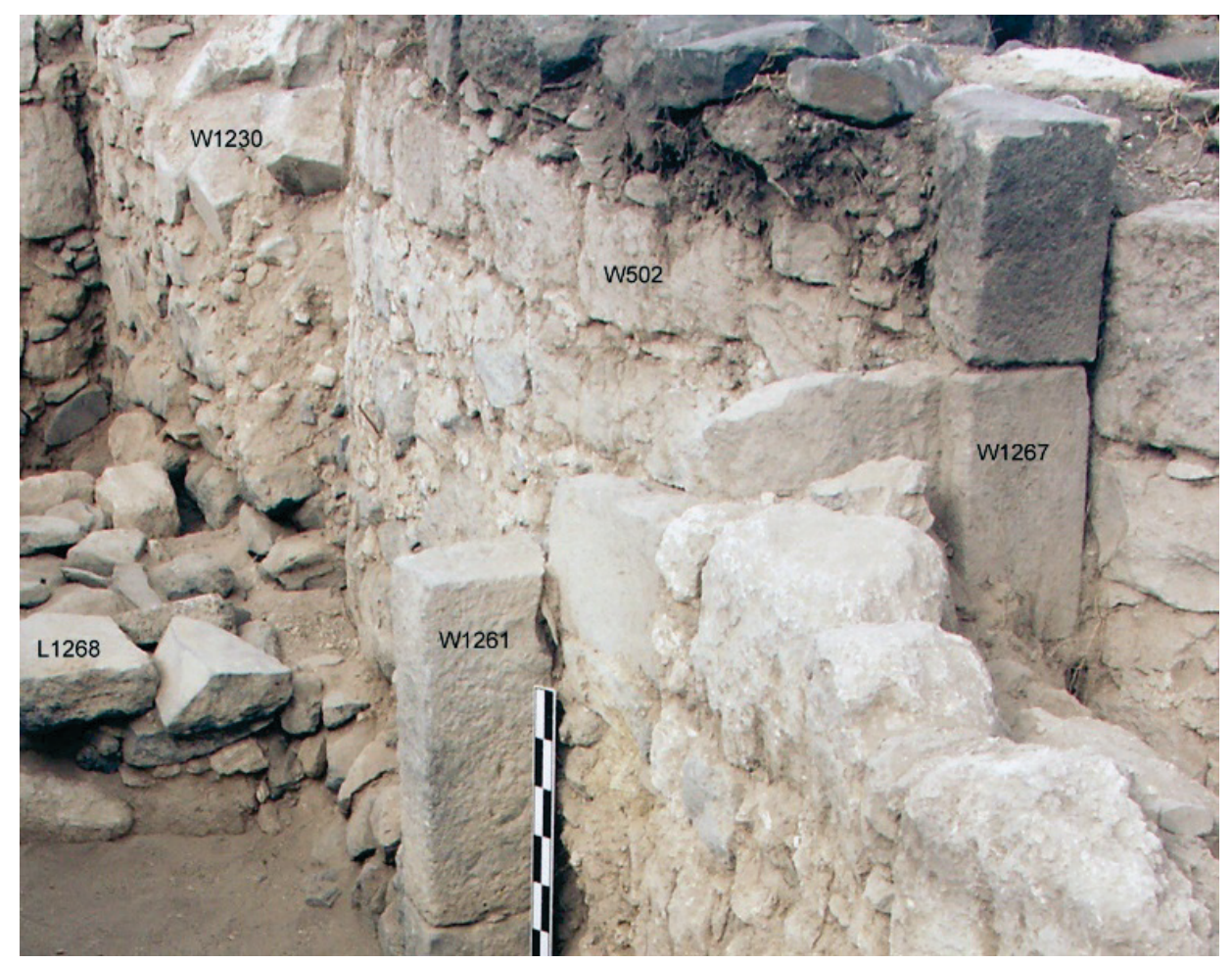

Figure 62 Doorframe incorporated into the wall of the apse (looking south) 
Therefore, we conclude that W1267 is an extension of W1230, both being constructed at the same time as the apse. These walls were parts of buildings to the east that were also incorporated into the church complex. Only the walls of the "Umayyad structure" southeast of the church are later (W1220, W1221, W1224, W1236, W1249).

The "alley" between W575 and W1267 allowed passage from the skeuophylakion or from areas to the north into the part of the complex to the east through the large doorway. While excavating this space between the two buildings, a large deposit of roof tiles, along with nails and several unidentified lead fragments,

W1267 forms a corner with W1266 but also continues further north. Plastering on the north side of W1266 and on the east side of W1267 indicates the interior corner of another space.

Similarly, W575 continues to the north, with a blocked doorway visible in the wall, beginning $2.10 \mathrm{~m}$ north of the skeuophylakion. The exterior of this doorway faces the alley which formerly was Cardo 3 North. The alley itself is intentionally blocked. The south face of the blockage has a smooth face. Next to the blockage, a column drum and a plain capital are placed on the surface of the alley; another column drum was placed just north of the blocked doorway to the skeuophylakion. As has been seen elsewhere in the complex, systematic blockage of doorways and passages indicates the formal decommissioning of most of the complex prior to the earthquake that destroyed the site.

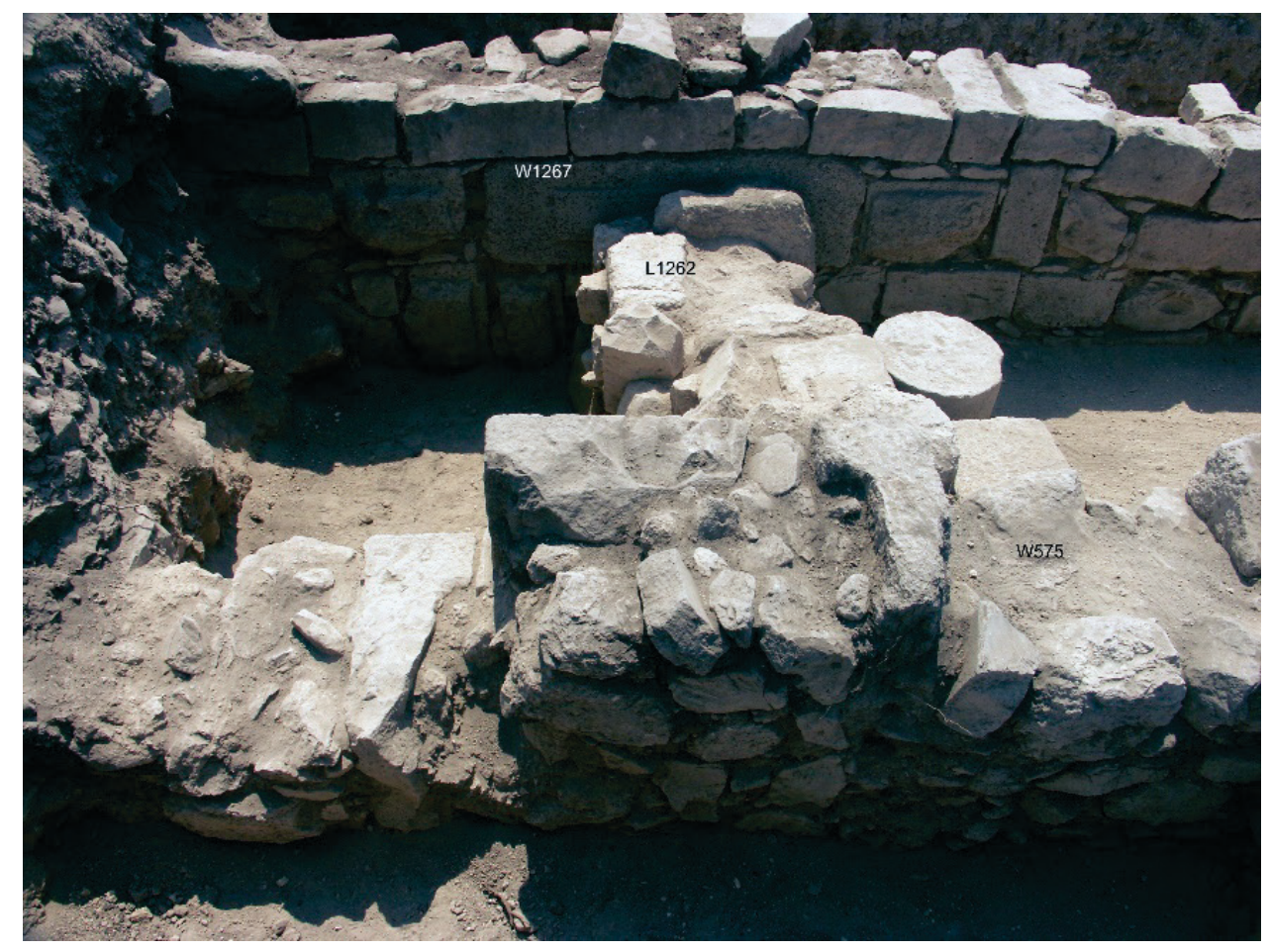

Figure 63 Blocked doorway (looking east) 


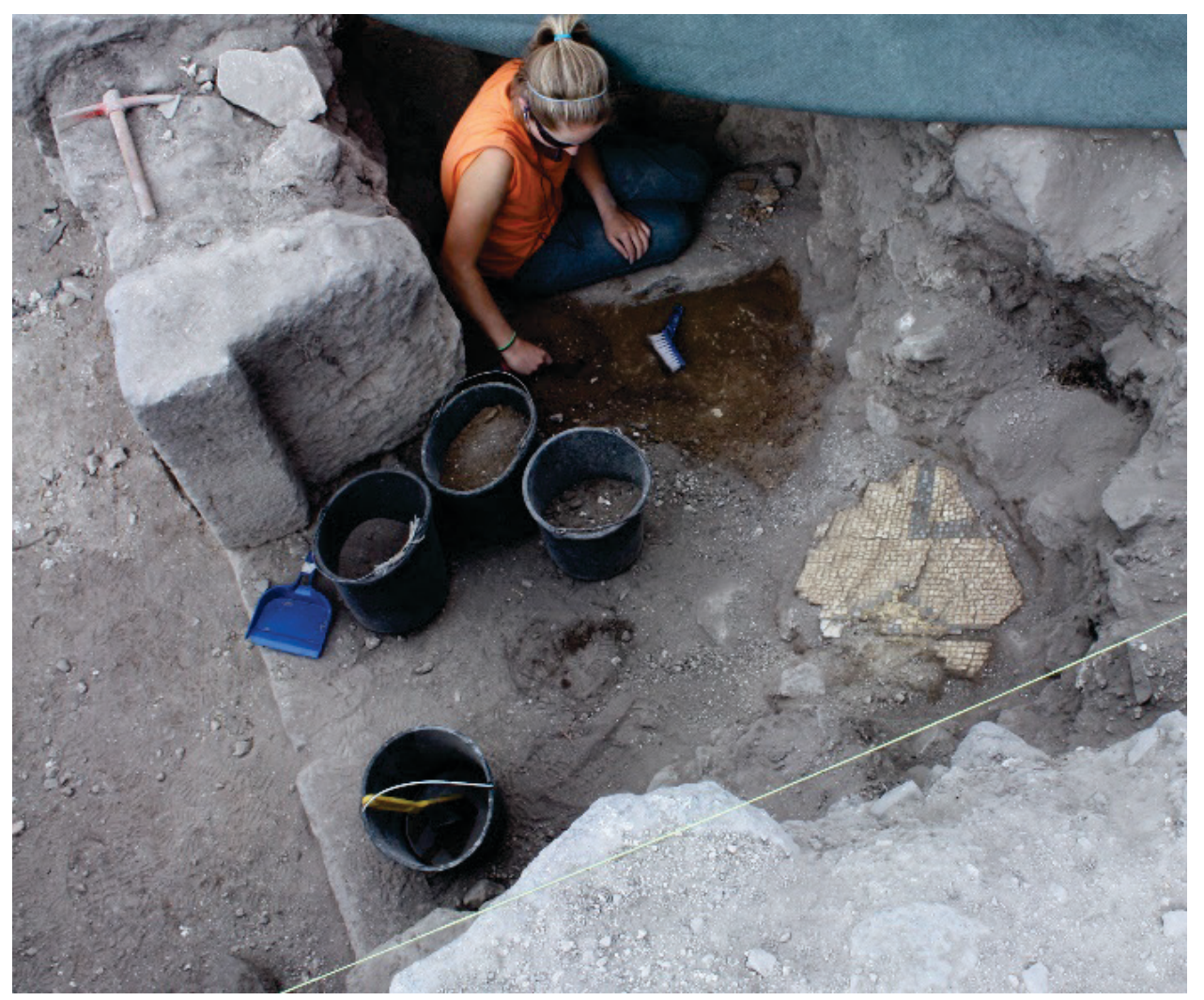

Figure 64 Doorway in W575 (looking south)

A second doorway with a threshold was discovered at the north end of W575, providing access to a room to the west. Unlike another door to the room located $2 \mathrm{~m}$ to the south, this door was not intentionally blocked. The blockage of the southern doorway and the blockage of the street were apparently sufficient to close off this section of the compound.

A significant collection of some twelve nails was recovered from the threshold of the unblocked door in W575. Intentional bending in a number of these nails suggests a door thickness of $9-11 \mathrm{~cm}$. The nails are $10-16 \mathrm{~cm}$ in length.

To the west of the doorway, a large section of mosaic $(44 \times 70 \mathrm{~cm})$ was discovered well above floor level in the northwest corner of the square. The fragment was tilting at an angle. Smaller fragments were discovered upside down. These pieces are likely also part of a floor from an upper story that has collapsed down from above. With another fragment of collapsed mosaic floor discovered just north of W540, we now have a second piece of evidence indicating that the structure north of the domus had at least two stories.

A $4.4 \mathrm{~m}$ probe was opened in the north end of Cardo 3 North. The purpose of this probe was to explore earlier phases of the small cardo and to search for a threshold of a doorway presumed to be below the intact lintel stone in W1267.

We reached bedrock $80 \mathrm{~cm}$ below the surface and noted the bedrock dropping off rapidly to the north. The presumed entrance in W1267 turned out to be the reuse of the lintel stone 
and part of the door frame from another structure as wall stones in the west wall of the house. Limestone blocks below the surface of the cardo sat directly on bedrock.

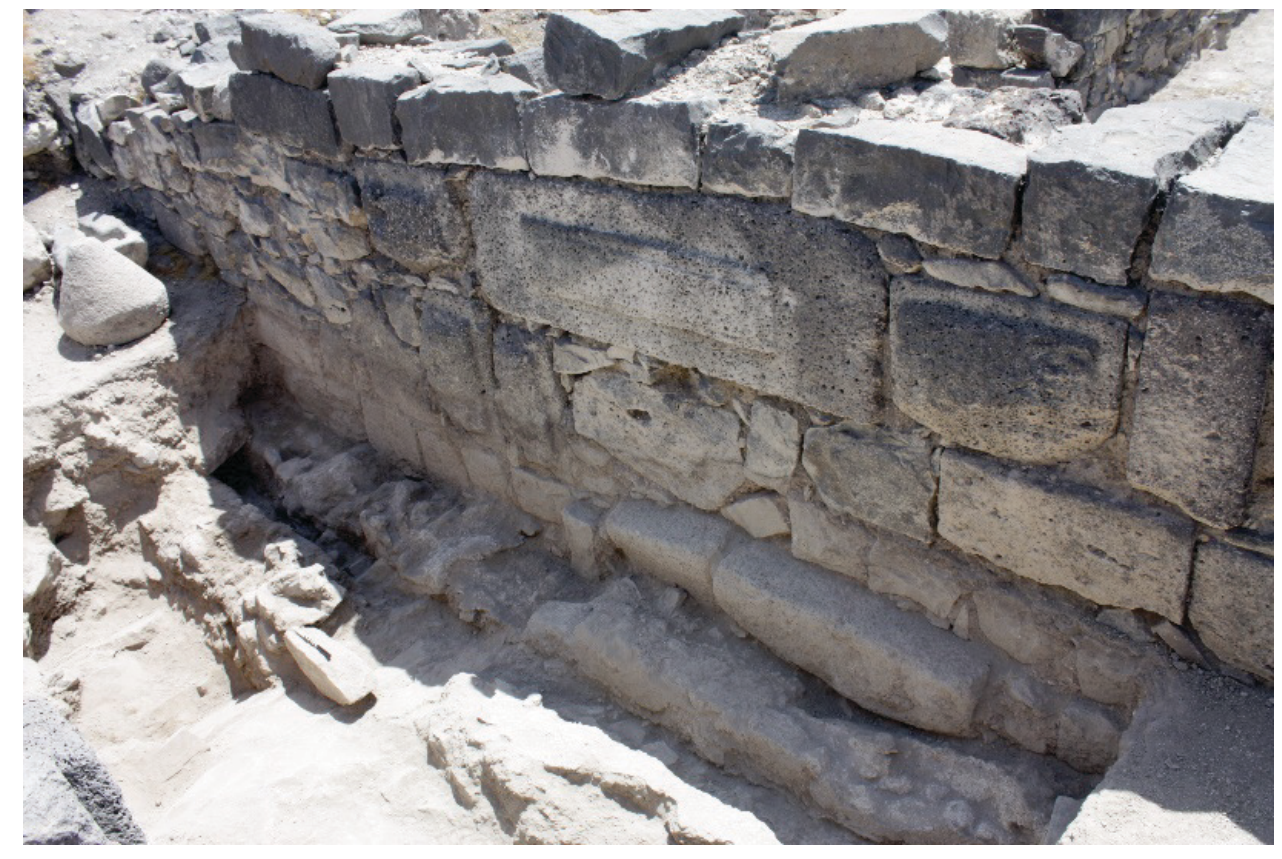

Figure 65 Lintel stone in secondary use (looking northeast)

In the probe, we exposed a plastered drainage channel covered with crude stones $45 \mathrm{~cm}$ from the west wall of the house and running parallel with it. The drain is $24 \mathrm{~cm}$ wide at the south end of the probe and widens about $40 \mathrm{~cm}$ at the north end. The source of the drain is unknown. The bottom of the drain is $60 \mathrm{~cm}$ below the surface at the south end of the probe and $79 \mathrm{~cm}$ below the surface at the north end.

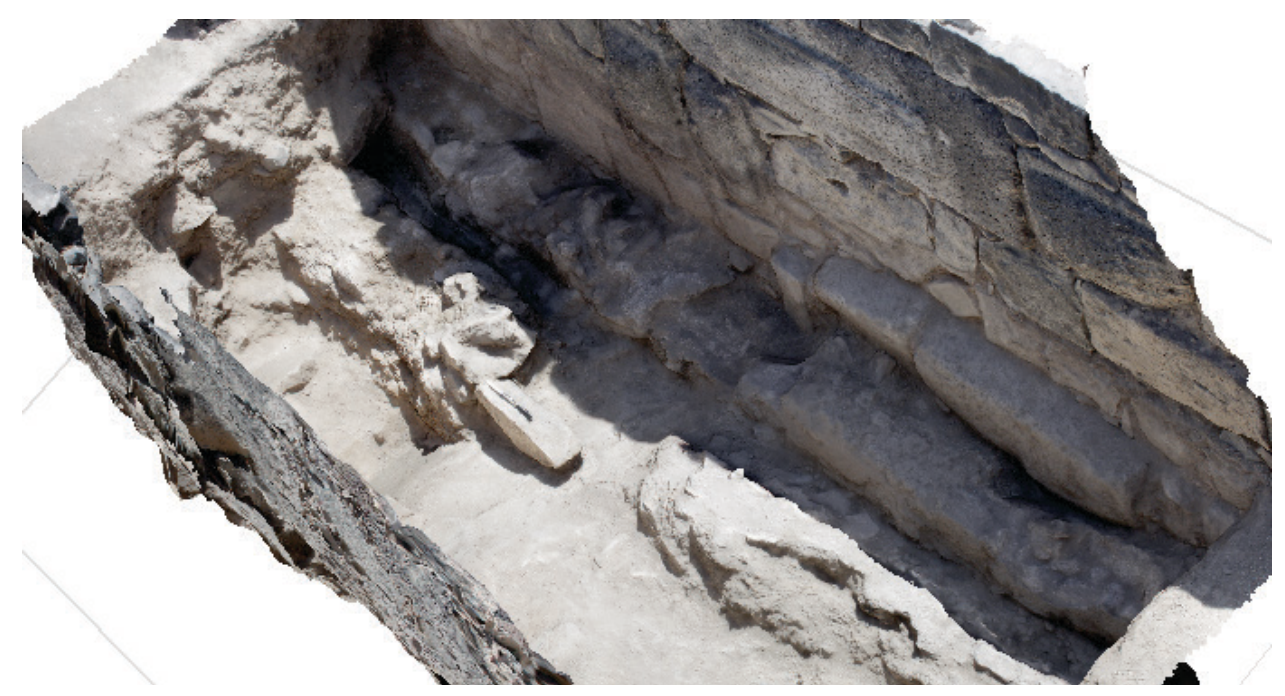

Figure 66 Photogrammetry of the drainage channel 
Field readings of pottery identified Late Antique fragments in the drain including a fragment of a sixth century oil lamp. The fill at the level of bedrock was exclusively Roman including a fragment of an early Roman oil lamp. We surmise that the foundations set on bedrock date from Roman Imperial times with the drain having been added in the Late Antique period.

\section{Cardo 4 North}

To the east of the peristyle house, we exposed the line of another alley (Cardo 4 North).

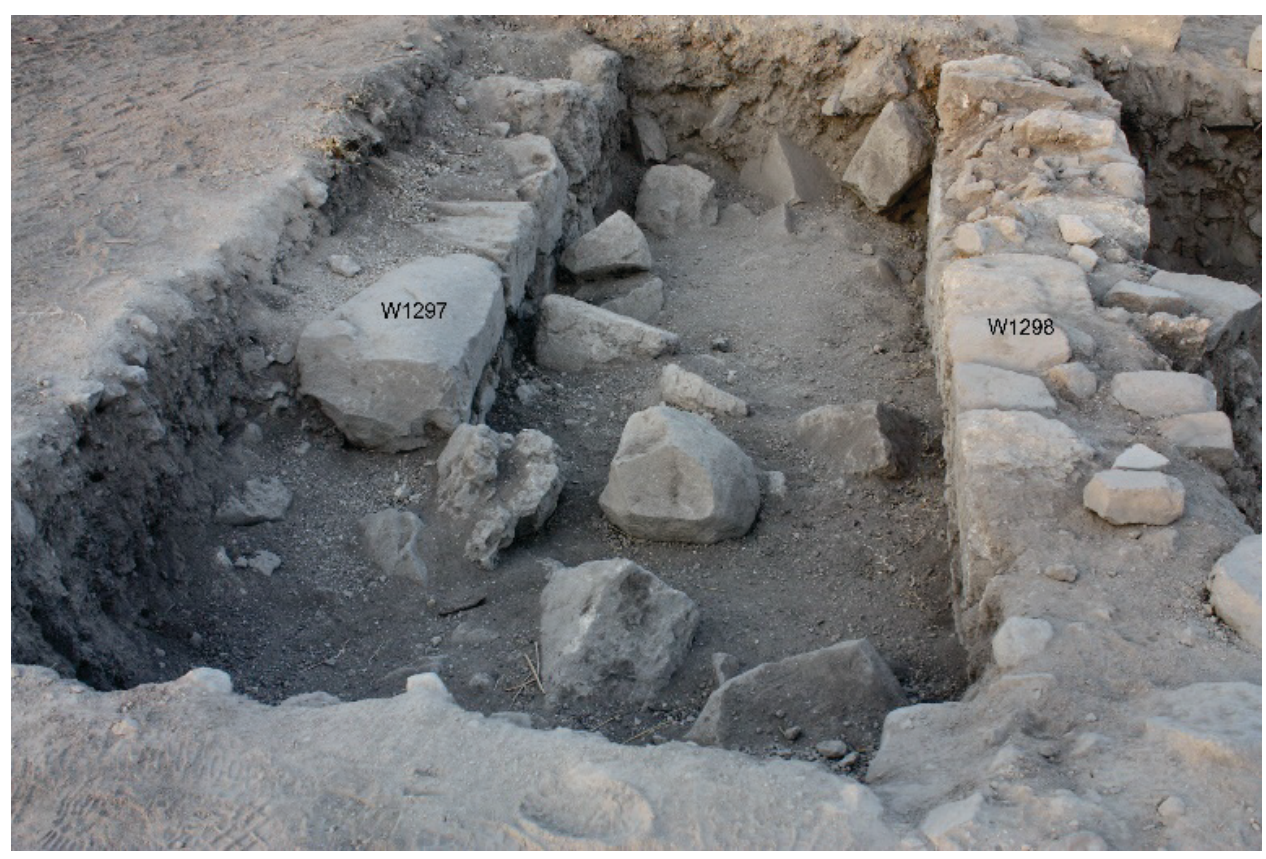

Figure 67 Cardo 4 North (looking south)

In the $5 \mathrm{~m}$ section exposed, the alley varies in width from 1.55 to $1.32 \mathrm{~m}$. At the decumanus, the center-to-center measurement from Cardo 3 North to this new Cardo 4 North is 16.65 $\mathrm{m}$. The center-to-center measurement for these cardines at the north end of the excavation area is $16.9 \mathrm{~m}$.

The easterly north-to-south wall of the alley is W1297. We exposed it to the level of the top of the second course. This wall is constructed mostly of limestone ashlars and may make a corner (or doorway) $3.4 \mathrm{~m}$ from the south end of the portion exposed.

The westerly wall of Cardo 4 North is the W1298. It is $90 \mathrm{~cm}$ wide. This wall also is constructed of ashlars. W1298 was exposed to a depth of about $50 \mathrm{~cm}$ on its eastern face, slightly exposing the second course of stones. Fragments of painted plaster are still visible on the western face of W1298. Some fragments have dark red paint and other have yellow. At the northerly end of W1298, we exposed a formal entrance to the compound between the two cardines through a doorway with its lintel stone still intact. 


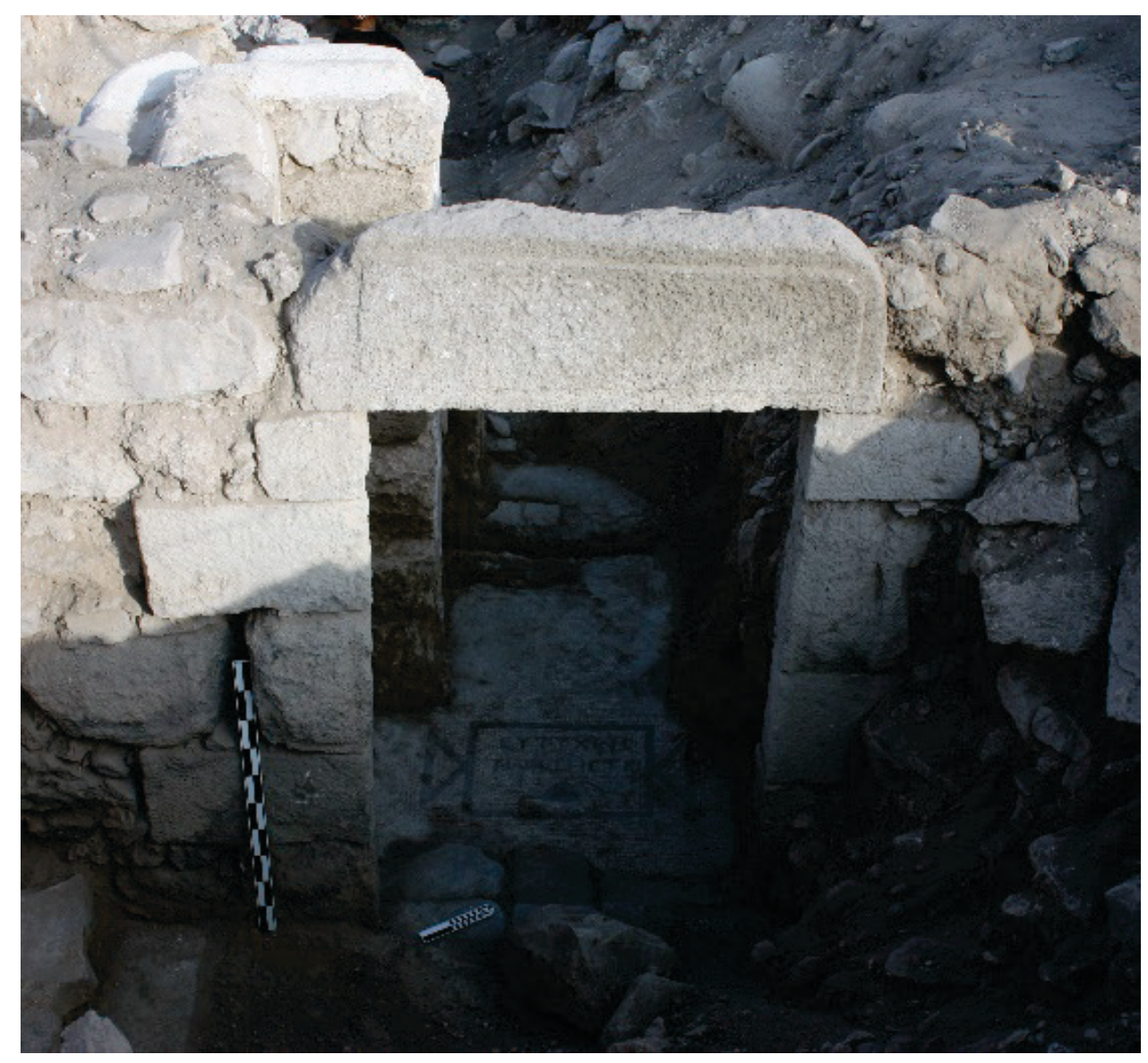

Figure 68 East entrance (looking west)

W1298 continues to the south and shows an offset of $15 \mathrm{~cm}$ to the west at the south line of W1913, $9.5 \mathrm{~m}$ from north side of entrance doorway. The wall continues to the south, forming the eastern boundary of the structure. The corner of an unidentified building to the southeast continues the easterly line of Cardo 4 North.

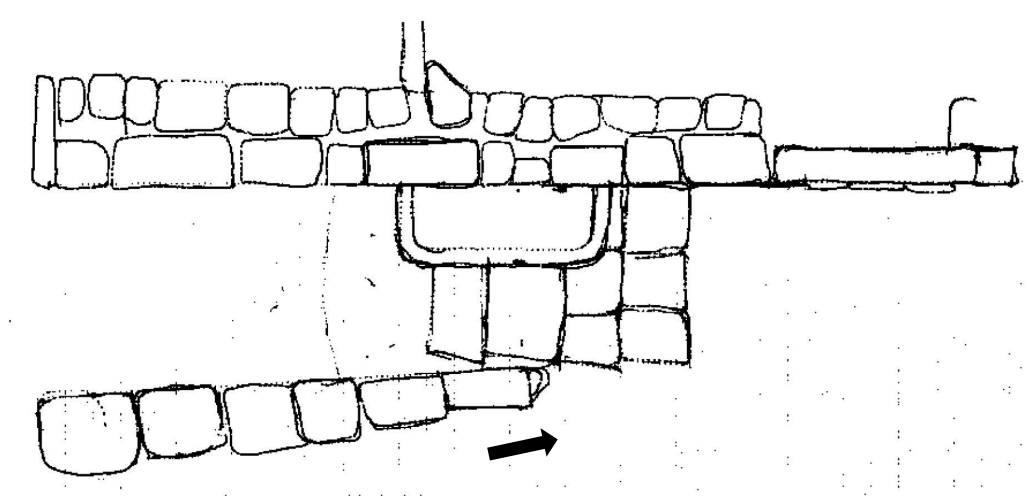

Figure 69 North section of Cardo 4 North 
A catch basin was excavated next to W1298. It is elongated north to south (114 x $41.5 \mathrm{~cm}$ interior, $150 \times 49 \mathrm{~cm}$ exterior, depth $14 \mathrm{~cm}$ south to $21 \mathrm{~cm}$ north). It provides water to the water pipe and channel feeding the pool of the fountain to be discussed below.

There is a series of steps in the cardo over which the catch basin was constructed leading down to the entrance as the bedrock drops off from and elevation of 130.70. The top step has a width $49 \mathrm{~cm}$, a height $22 \mathrm{~cm}$, at elevation 130.55 . The second step tread is $43 \mathrm{~cm}$ deep, with a width of $53 \mathrm{~cm}$, a height of $27 \mathrm{~cm}$, at elevation 130.35. The third step is constructed of three stones with a tread of $38 \mathrm{~cm}$, a width of $124 \mathrm{~cm}$, a height of $30 \mathrm{~cm}$, at elevation 130.08. The fourth step consists of two stones with a tread of $36 \mathrm{~cm}$, a width of $121 \mathrm{~cm}$, a height of $23 \mathrm{~cm}$, at elevation 129.77. The fifth step is made of two stones with a tread of 32 $\mathrm{cm}$, a width of $121 \mathrm{~cm}$, at elevation 129.53 .

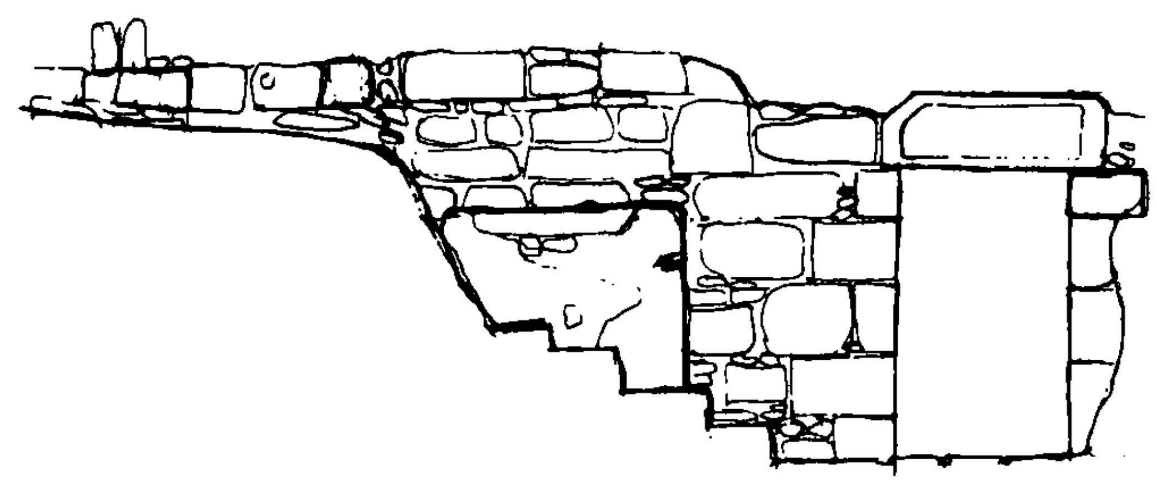

Figure 70 Cross section of stairs and east entrance

\section{House of Tyche}

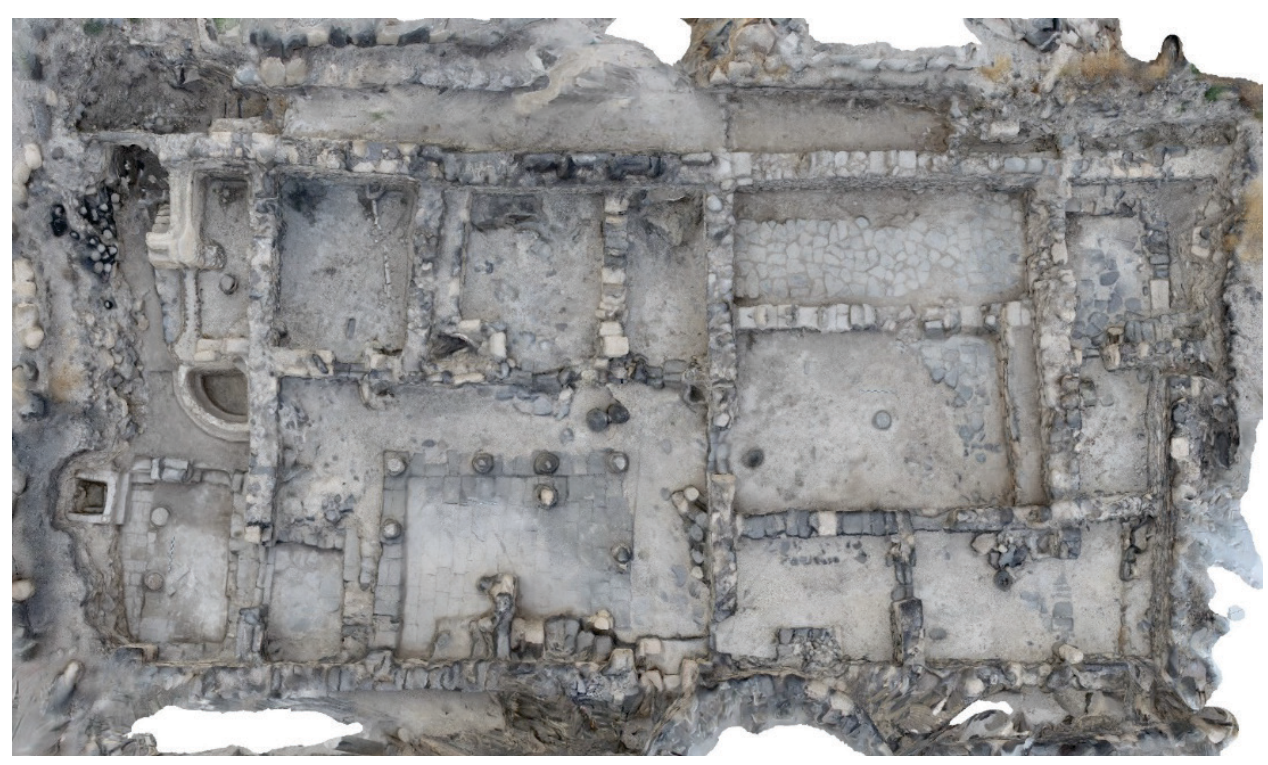

Figure 71 Photogrammetric model of the eastern zone 
Excavation to the east, south, and north of the apse exposed rooms, a peristyle court, and an outdoor complex with water features. It is a Roman peristyle house that was destroyed and partially reconstituted as part of an urban monastic complex supporting the Northeast Church. We call it the House of Tyche because of a fresco of the goddess discovered next to its fountain.

The peristyle court
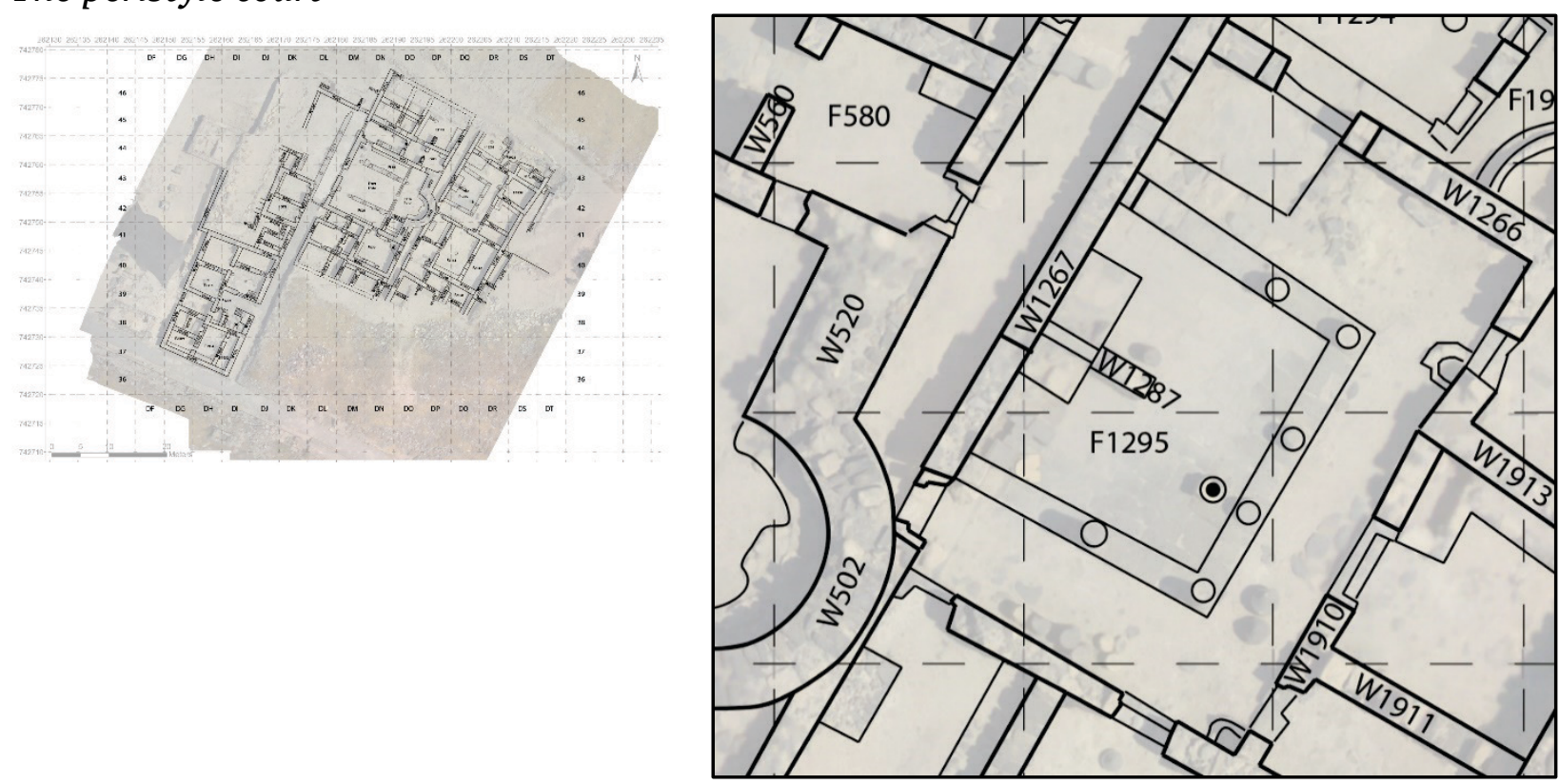

Figure 72 Plan of peristyle court

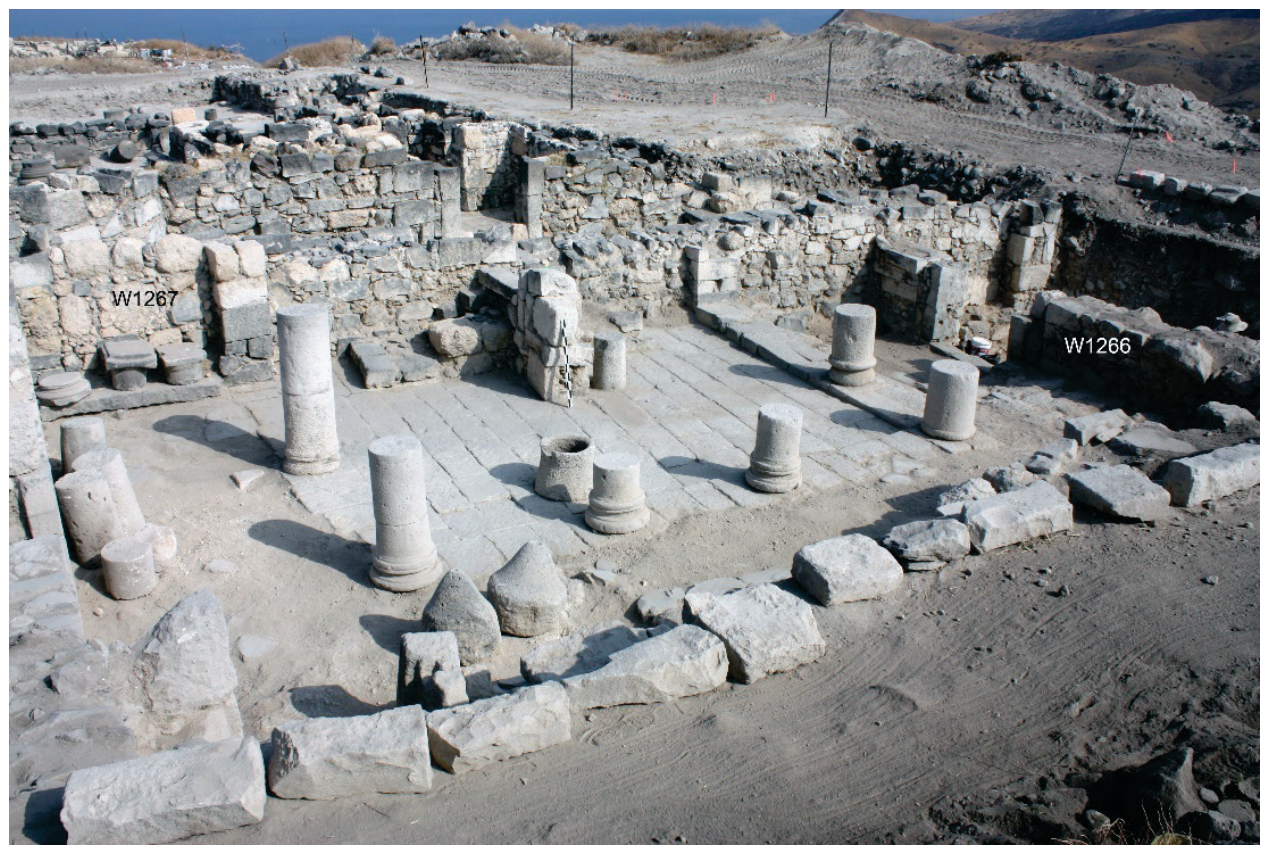

Figure 73 Peristyle court (looking northwest) 
Central to the identification of these structures as a Roman peristyle house is the central courtyard. The peristyle court is bounded to the south by W1261, to the east by W1910, to the north by W1266 and to the west by W1267. As is indicated by the columns and change in flooring from stone to hard plaster, it had porticos on three sides (south, east, and north).

There is a major entrance in W1267 open into the south portico from the west. It is the only entrance to the courtyard from outside the house, the door of which closed from inside the courtyard. That entrance was intentionally blocked, perhaps at the same time as the other blockages in the Northeast Church complex to the west. ${ }^{80}$

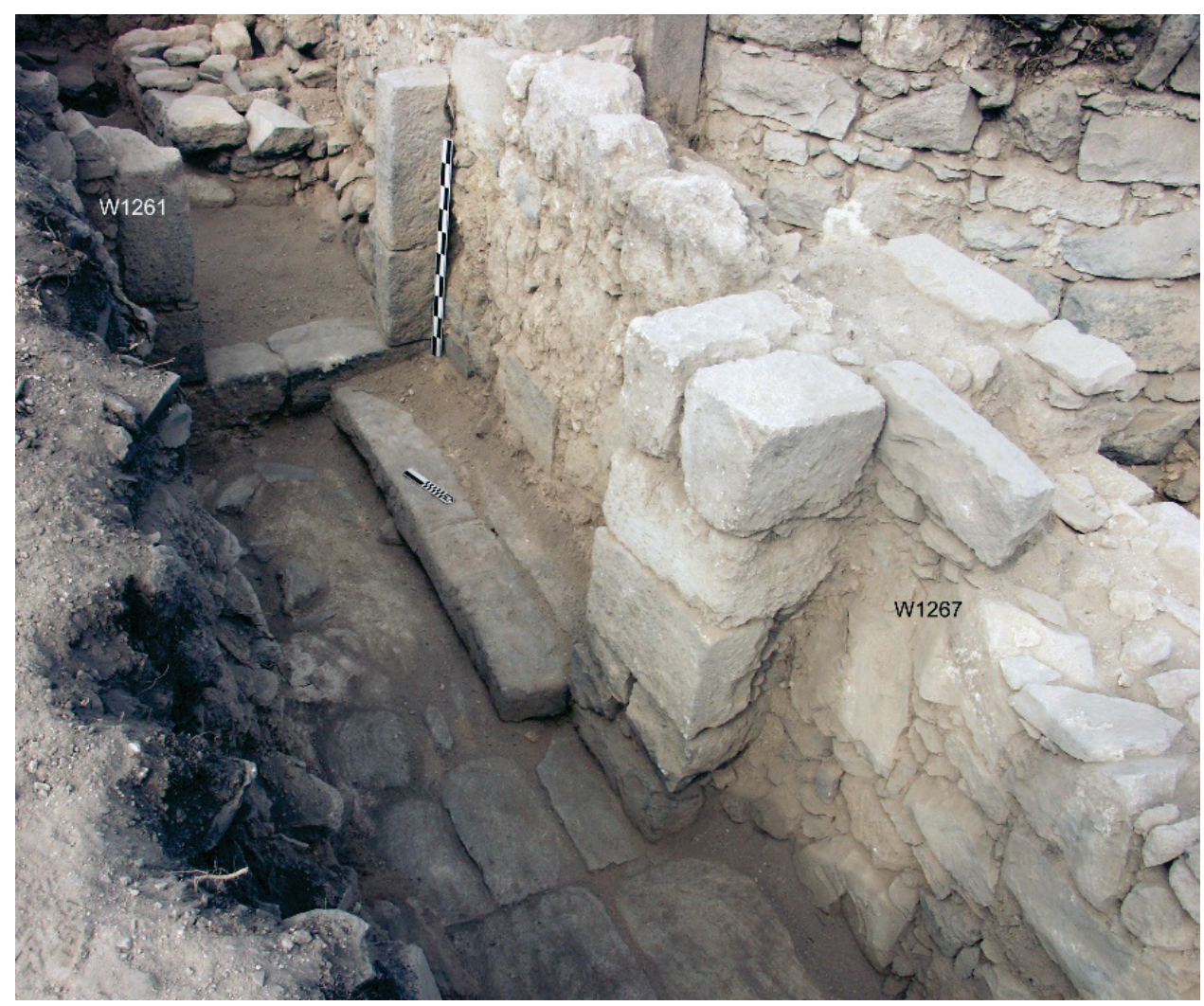

Figure 74 Pilaster and blocked doorway (looking south)

There are two entrances to the south portico through W1261. The western entrance in W1261 has a $1 \mathrm{~m}$ doorway, the exterior of which faces north. The eastern entrance is 5.05 $\mathrm{m}$ from W1267. The doorway is $1.07 \mathrm{~m}$ wide. The door would have been $1.22 \mathrm{~m}$ wide and would also close from the south.

${ }^{80}$ Segal et al., Hippos-Sussita: Ninth Season of Excavations: June-July 2008, 45. 


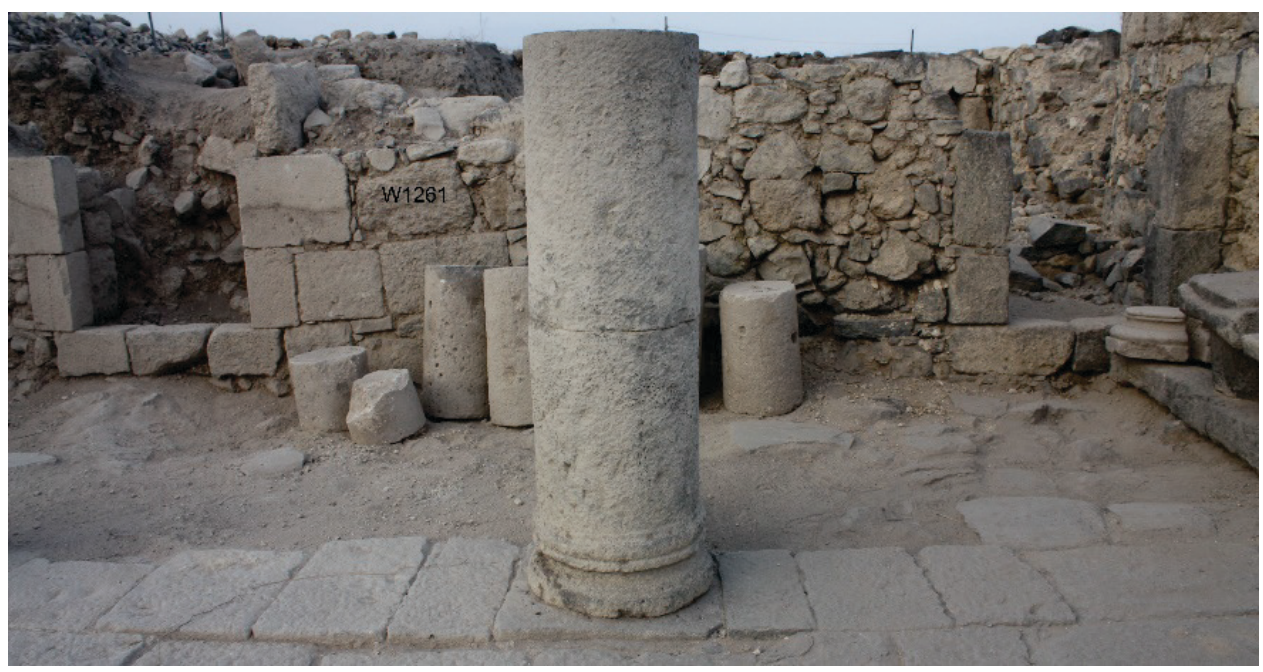

Figure 75 Entrances to the south portico (looking south)

$1.35 \mathrm{~m}$ to the east there is a catch basin in the northwest interior corner of the junction of W1261 with W1910. Many pipe fragments were found in and around the basin, and plaster on W1261 hints at a route down from the roof. W1261 continues to the east as does W1910 to the south.

There are three entrances to the peristyle court from the east through W1910. The exterior of each of the doorways faced the west.

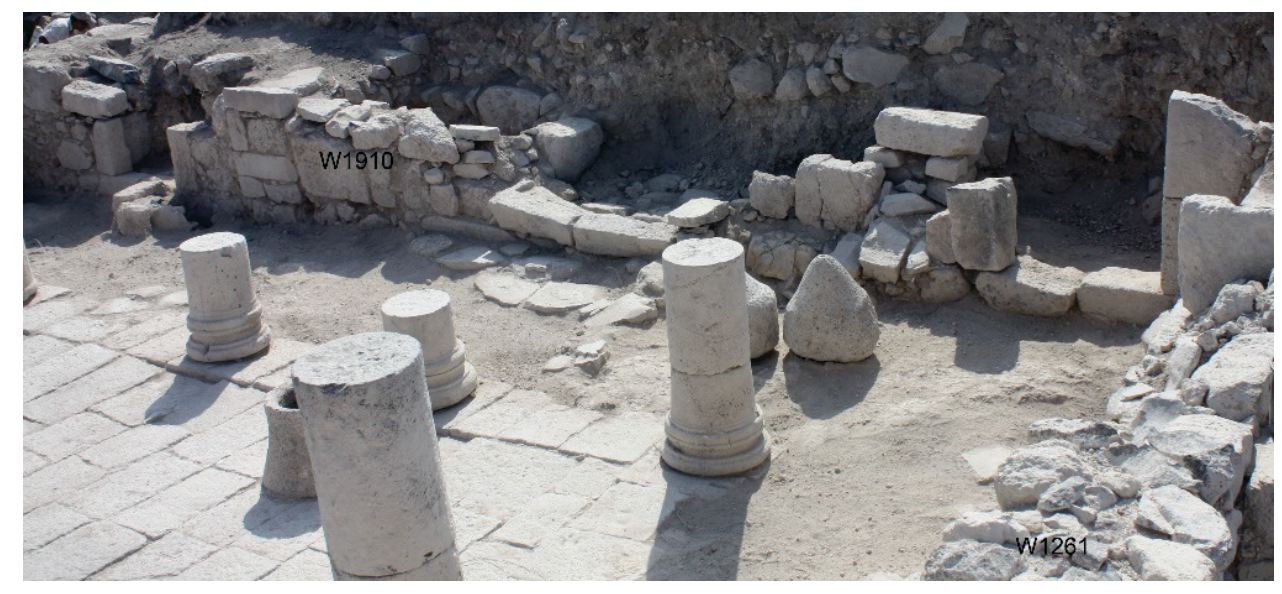

Figure 76 Entrances to the east portico (looking east)

At the east end of the southern portico there is a doorway $67 \mathrm{~cm}$ from W1261. The doorway is $1.00 \mathrm{~m}$ wide and was closed by a $1.10 \mathrm{~m}$ door. To the north and $1.6 \mathrm{~m}$ from W1261 is W1911. It is crudely built and goes east from W1910. The room contained by W1261, W1910, and W1911 has a mud/plaster floor.

$3.90 \mathrm{~m}$ north of W1261 is a second threshold in W1910. The doorway is $1.70 \mathrm{~m}$ in width. Most of W1910 is gone in this area except for the base course. There are large flat stones to 
the west of the threshold in the east portico suggesting significant traffic through this doorway.

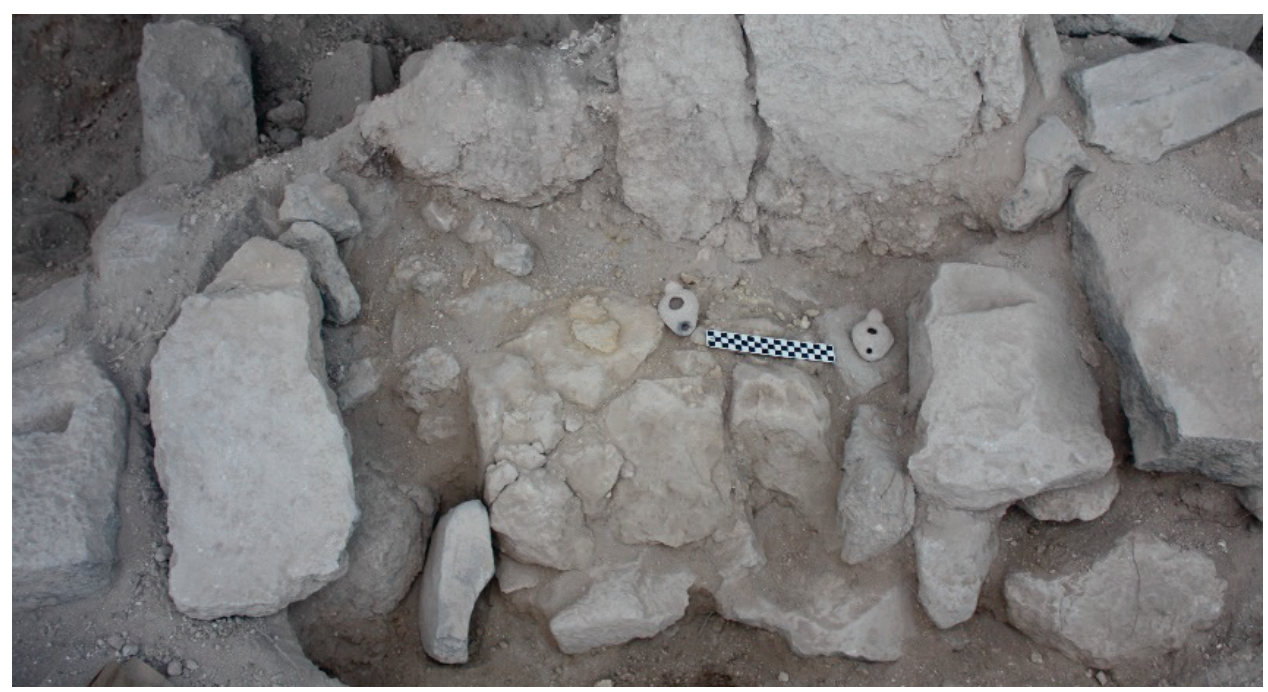

Figure 77 Shelf with lamps (looking east)

Between W1911 and the south side of this threshold, a west-facing shelf was revealed in W1910. Little survives of this poorly constructed space, but two intact oil lamps were discovered sitting on it and another was found in the threshold to the north. In Roman times, the lararium could at times be in the peristyle court.

8.20 m north of W1261, W1913 proceeds to the east. The function of the space between W1913 and the threshold to the south is uncertain, although portions of three partially restorable amphora were recovered from the fill. Fragments of one contained tituli dipinti. The markings are likely commercial symbols illegible to the modern reader.

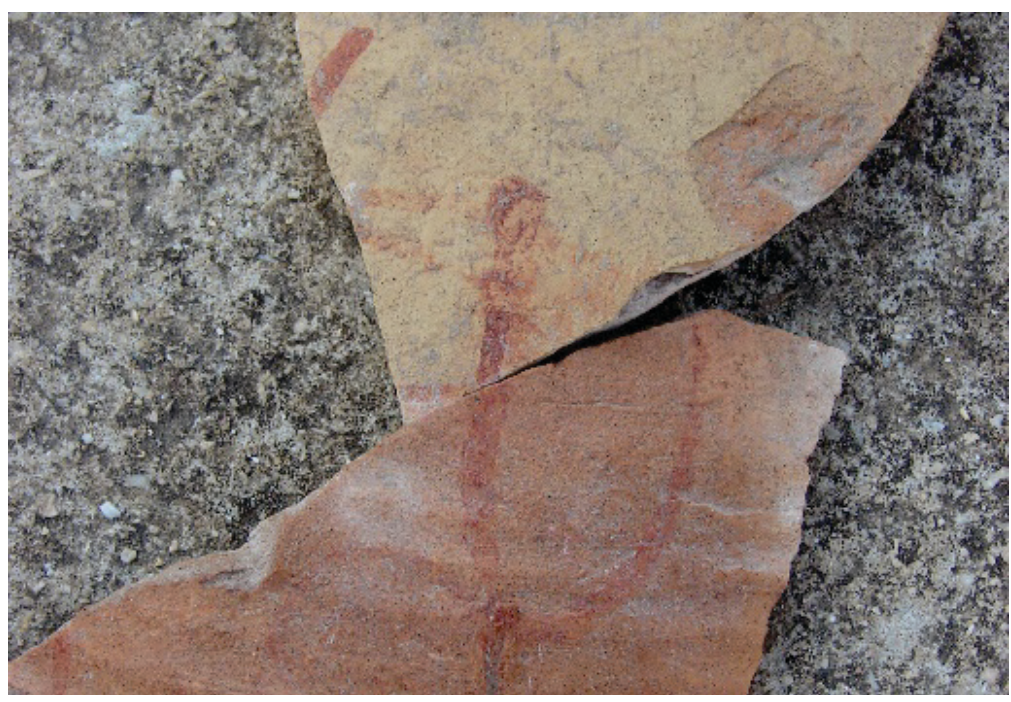

Figure 78 Dipinti 
An extension to W1910 fills the gap between W1913 and W1266. In this section of the wall at the east end of the north portico is the third doorway. It is $72 \mathrm{~cm}$ wide and was closed by a $96 \mathrm{~cm}$ door. To the east of the threshold is evidence of a later plaster floor at the height of the top of the threshold. The exterior of the doorway is again to the west. There is a catch basin in the portico that partially overlaps the south part of the threshold.

The surface of the porticos is a combination of flat stones, mud, and plaster. The north portico slopes downward somewhat from W1910 toward the steps that lead from the north stylobate of the courtyard to the large western doorway in W1266. A crude line of stones set on their points functions to separate the floor from the staircase.

The courtyard itself is paved with rectangular basalt pavers. The pavers are laid out in rows with the longer dimension oriented east to west. A slightly raised stylobate surrounds the courtyard on three sides.

The southern stylobate runs parallel to W1261 about $2 \mathrm{~m}$ away. The north stylobate is 2.72 $\mathrm{m}$ from W1266. As with the south stylobate, its pilaster and column(s) may have held up a roof for a portico, although the dimension is significantly wider.

There are pilasters at the west ends of the north and south stylobates. Two pilasters are visible on the east side of the wall. The southerly one is next to the doorway. The pilaster is $57 \mathrm{~cm}$ wide and protrudes into the room $36 \mathrm{~cm}$. Its construction is like the wall. The northerly pilaster is $3.8 \mathrm{~m}$ from W1266. It is $70 \mathrm{~cm}$ wide and protrudes into the room about 35 $\mathrm{cm}$. However, this pilaster is constructed of finely cut ashlars, four courses of which remain. The pilaster sits on a high-quality stone surface, although pavers north and south of the pilaster have been robbed out. It also intrudes into the wall to an unknown depth. The quality of the pilaster suggests that it comes from an earlier structure on the east side of Cardo 3 North and was incorporated into W1267.

At the west end of the courtyard next to W1267 are the remains of a staircase around which the pavers are laid. It is slightly off center to the south. If we assume that the stairs ascended toward the south and that the basalt paver in the middle of the staircase was one of the steps ( $1.07 \mathrm{~m}$ above the courtyard), the staircase would reach a height of $2 \mathrm{~m}$ at the southern end of the staircase. We therefore surmise that it led to an exedra that covered the space between the south stylobate and W1261. The pilaster and column(s) of the south stylobate supported the exedra. Assuming this reconstruction, the structures to the south would have been of at least two stories. 


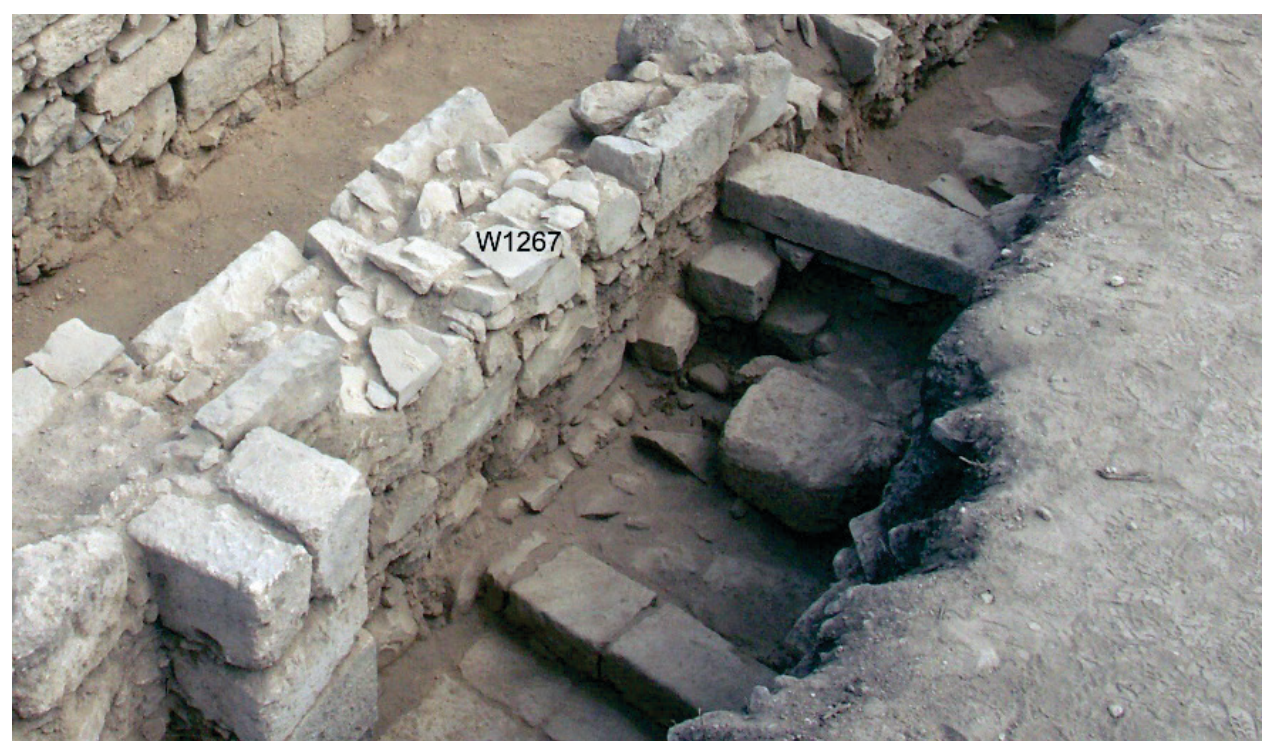

Figure 79 Remains of stairs (looking north)

At the east ends of these stylobates there are column bases. Both stylobates have one intervening column base. On the south stylobate, the corner column is $42 \mathrm{~cm}$ in diameter. The intercolumniation with the central column is $2.04 \mathrm{~m}$. Between the central column and the pilaster the distance is $1.65 \mathrm{~m}$. On the north stylobate, the corner column is $44 \mathrm{~cm}$ in diameter. The intercolumniation with the central column is $1.16 \mathrm{~m}$. Between the central column and the pilaster the distance is $3.12 \mathrm{~m}$. The central column on the north stylobate is offset to the east. On the east stylobate, there are two additional column bases between the corners.

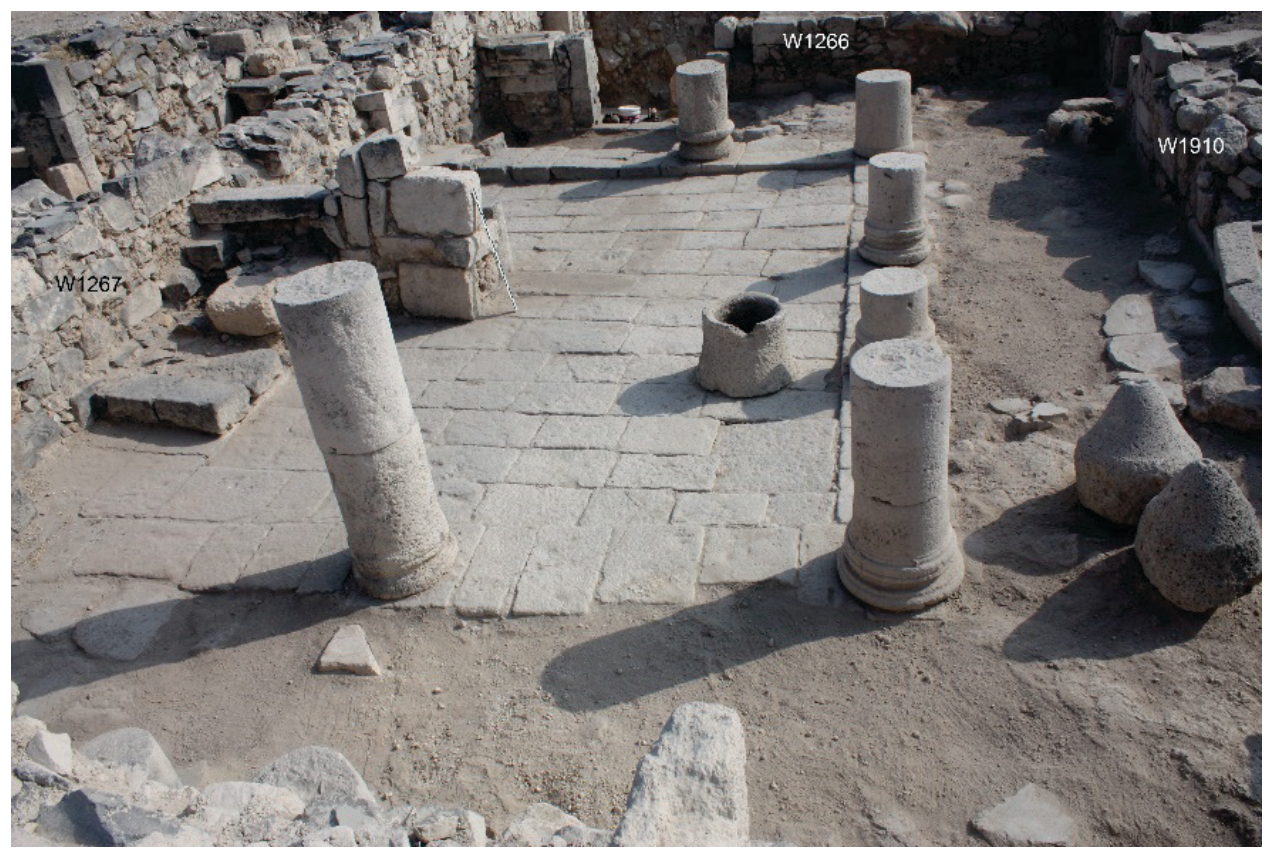

Figure 80 Three-sided peristyle (looking north) 
The intercolumniation between the column base at the south end and the next column to the north is $1.61 \mathrm{~m}$. That next column is $40 \mathrm{~cm}$ in diameter. The third column from the south on the stylobate was tipped. Since the intercolumniation between the second and fourth columns is $3.55 \mathrm{~m}$, the remaining intercolumniations would be $1.57 \mathrm{~m}$. We reset the column base on the stylobate in that approximate location.

Cistern $\mathrm{H}$ was discovered in the paved plaza. Its head is a column drum that has been hollowed out. The inner diameter of the head is $37 \mathrm{~cm}$ with the wall about $6 \mathrm{~cm}$ thick. The drum was originally about $50 \mathrm{~cm}$ in diameter. The cistern is located $1.2 \mathrm{~m}$ from the north edge of the south stylobate and $4.2 \mathrm{~m}$ from W1267. Both catch basins previously identified likely drain into this cistern.

The elevation drops $1 \mathrm{~m}$ from the north stylobate to the threshold in W1266. That change in elevation is navigated by two stairs down and a surface paved with irregular large flat stones (F1293) that slopes the rest of the way to the threshold. At the west end of the paved surface, an open drainage channel (dimensions $40 \mathrm{~cm} \times 30 \mathrm{~cm}$ ) runs from under the north stylobate through W1266. The channel is open and is plastered. A row of limestone blocks was plastered to the surface to the east of the channel, perhaps to contain overflow from the channel.

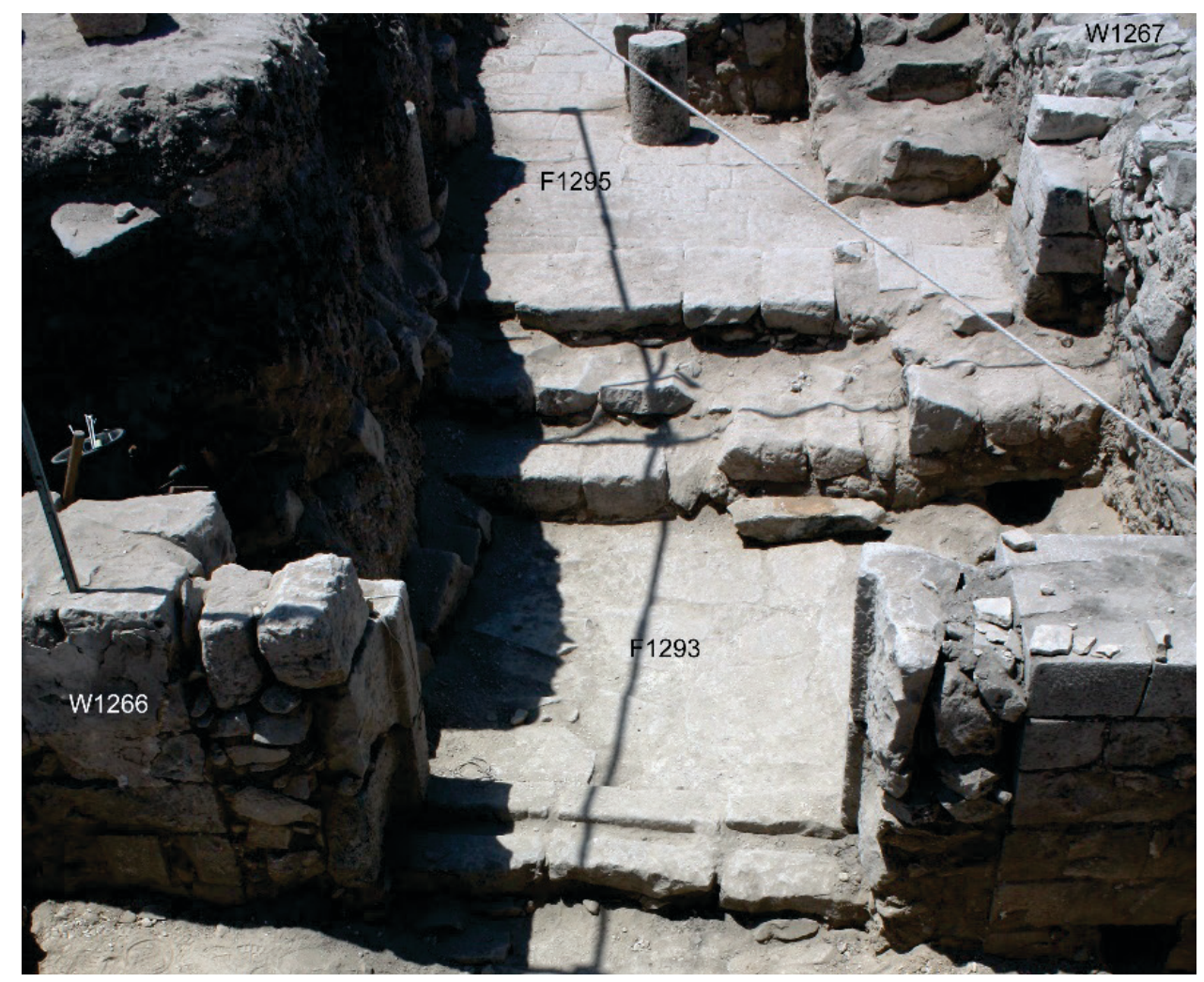

Figure 81 Stairs up to paved courtyard from the north (looking south) 
The west section of W1266 is finely built opus quadratum $1.08 \mathrm{~m}$ in length and penetrating into W1267. An open doorway of $2.32 \mathrm{~m}$ in the wall was later closed by a door frame for a $1.72 \mathrm{~m}$ door of two sections. The eastern section is wider $(1.08 \mathrm{~m})$ than the western section $(64 \mathrm{~cm})$. Notably, the exterior of the door faced the peristyle court, not the exterior.

A typical array of architectural and domestic small finds occurs in the destruction fill of the peristyle court. Several column drums of diameters from $32-47 \mathrm{~cm}$ were retrieved in addition to the three marble Corinthian capitals. Some fifty pieces of marble cornice (roughly $10.5 \mathrm{~m}$ in combined length) were recovered, the majority of which were found in the south portico. Widths and ornamentation patterns varied with most displaying one to three rounded or v-shaped grooves and occasionally one rib. Some twenty nail fragments were retrieved, many of which were bent. Fragments of wall plaster with some hints of color may point to decorative paintings, especially on the western wall of the peristyle court. Also recovered was a portion of a floor/decorative stone tile with a flared-arm cross. A fragmentary metal cross medallion may have been part of a polycandelon like one found in $2007 .{ }^{81}$

Typical of a space with significant domestic usage, we recovered two substantive lower or cone portions of hourglass grinding mills, other fragmentary grinding bowls and mortaria, two knives (16.5 and $17.5 \mathrm{~cm}$ ), a cylindrical mount of carved bone, and a small two-headed flask.

A peristyle court is a strong indication that the structure was an urban house the ruins of which were used in the Late Antique period without the subdivision of space typical of that period.

"The peristyle house has a long tradition in the East going back at least to the fourth century B.C.E.”82 Despite Roman influence, peristyle houses at Pergamon, Delos, and Ephesus remain essentially Greek-Hellenistic and lack the atriums seen in Italy. ${ }^{83}$ In the remaining unexcavated space of this house at Hippos we would be surprised to find an atrium. So, although Romanization can be seen at Hippos, in this house Hellenization seems to prevail.

"The known distribution of the peristyle house in Palestine is quite limited." ${ }^{44}$ Hirschfeld lists four sites from the late Roman and early Late Antique periods (Umm el-Jimal, Sepphoris, Aphek and Jerusalem). ${ }^{85}$ At least two others have been subsequently published from

\footnotetext{
${ }^{81}$ Segal et al., Hippos-Sussita : Eighth Season of Excavations : July 2007, 85 and fig. 129.

${ }^{82}$ Monika Trümper, "Material and Social Environment of Graeco-Roman Houses in the East: The Case of Hellenistic Delos," in Early Christian Families in Context: An Interdisciplinary Dialogue, ed. David L. Balch and Carolyn Osiek (Grand Rapids, Mich: W.B. Eerdmans Pub. Co, 2003), 37.

83 Ibid., 41 .

${ }^{84}$ Yizhar Hirschfeld, The Palestinian Dwelling in the Roman-Byzantine Period, Collectio minor n. 34 (Jerusalem: Franciscan Printing Press ; Israel Exploration Society, 1995), 86.

${ }^{85}$ Ibid.
} 
Sepphoris ${ }^{86}$ and 'Ein ez-Zeituna. ${ }^{87} \mathrm{~A}$ three-sided peristyle is particularly characteristic of the evolution of the peristyle house in Roman North Africa, ${ }^{88}$ although both the House of the Tragic Poet ${ }^{89}$ and the House of Sallust ${ }^{90}$ at Pompeii have three-sided peristyle courts. Ellis has argued that the latest peristyle houses were constructed in the mid-sixth century. ${ }^{91}$ The construction of the church to the west in the early sixth century and its connection to this structure suggest a third/fourth century CE date for the house and a sixth century date for construction in its ruins.

\section{Terrace area north of the house}

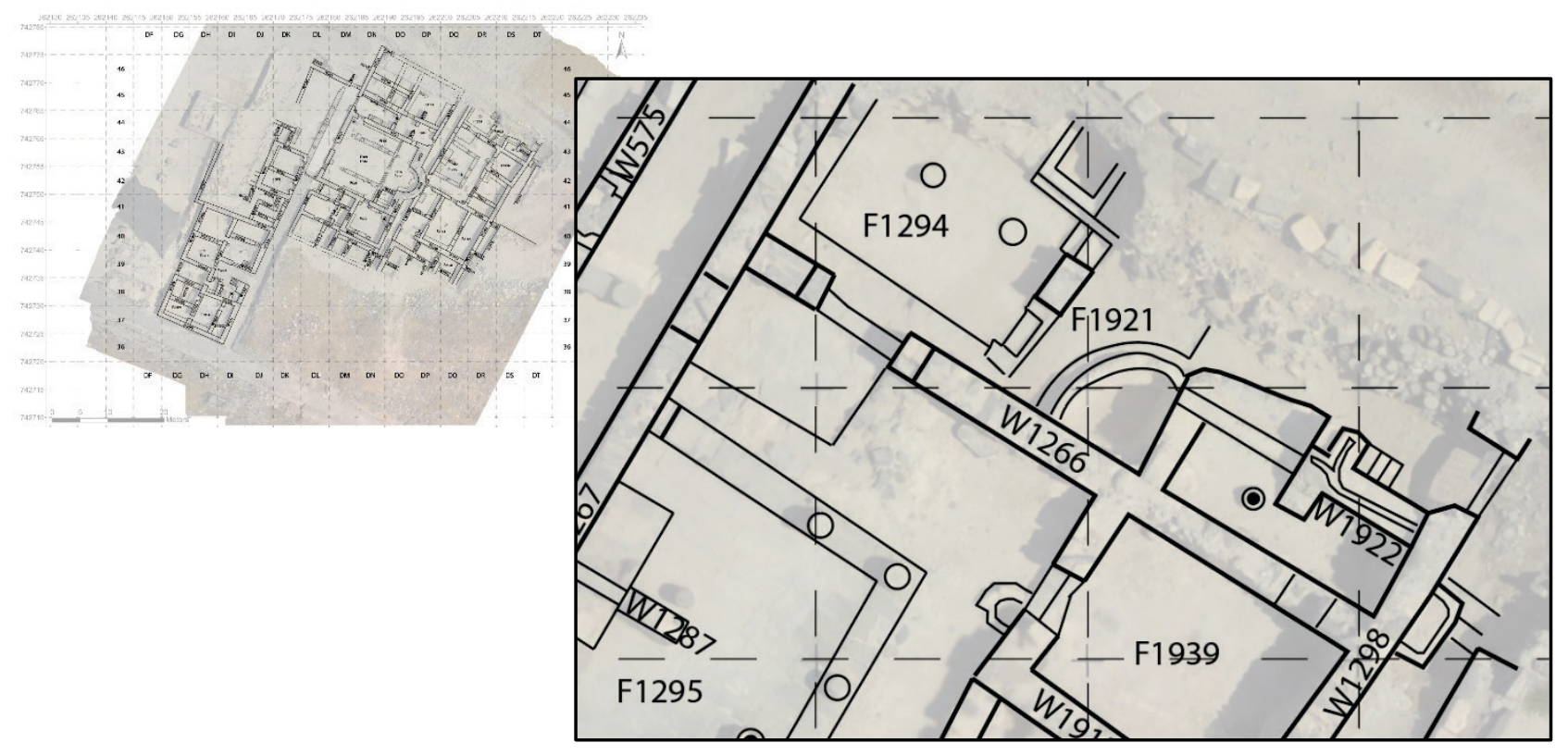

Figure 82 Terrace area north of the house

$2.8 \mathrm{~m}$ north of the north stylobate is W1266. Two steps down from the threshold in that wall is the southeast corner of a paved space. The first step is $25 \mathrm{~cm}$ down with a tread depth of $54 \mathrm{~cm}$. The second step is $17 \mathrm{~cm}$ down and $28 \mathrm{~cm}$ deep.

\footnotetext{
${ }^{86}$ Ofer Sion and 'Abd al-Salam Sa'id, "A Mansion House from the Late Byzantine-Umayyad Period in Beth SheanScythopolis.," Liber Annuus 52 (2002): 353-366.

${ }^{87}$ David Milson, "Design Analysis of the Peristyle Building from 'Ein Ez-Zeituna," Atiqot 51 (2006): 71-75.

${ }^{88}$ Yvon Thébert, "Private Life and Domestic Architecture in Roman Africa," in A History of Private Life, vol. 1: From pagan Rome to Byzantium (Cambridge: Harvard University Press, 1987), 357-364.

${ }^{89}$ In this case the peristyle court is against the outside wall of the house. Bettina Bergmann, "The Roman House as Memory Theater: The House of the Tragic Poet in Pompeii," The Art Bulletin 76, no. 2 (June 1, 1994): 225-256.

${ }^{90}$ Paul Zanker, Pompeii: Public and Private Life, Revealing antiquity 11 (Cambridge, Mass: Harvard University Press, 1998), 43.

${ }^{91}$ Simon P Ellis, “The End of the Roman House,” American Journal of Archaeology 92 (1988): 565.
} 


\section{Opus Sectile portico}

The steps reach a floor (F1294). The floor is opus sectile. There is an $11 \mathrm{~cm}$ border next to the steps made of re-used local stones and marble. The floor consists of $21.5 \mathrm{~cm}$ squares in black and white set on their points (diamonds).

There is a plastered bench about $50 \mathrm{~cm}$ deep and $55 \mathrm{~cm}$ tall bordering the west and the south part of the room. Two larger stone slabs on the floor (F1294) next to the opus sectile (on the west) suggest that water at one time flowed from the channel over the bench and onto the floor. The channel was later plastered shut. The western bench runs from the southwest corner to the pilaster in W1267. A column base sits east of the pilaster. A second column base sits further to the east having an approximate column diameter of $40 \mathrm{~cm}$. The opus sectile floor is $1.5 \mathrm{~m}$ below the paved courtyard to the south, likely due to the topography of the hill.

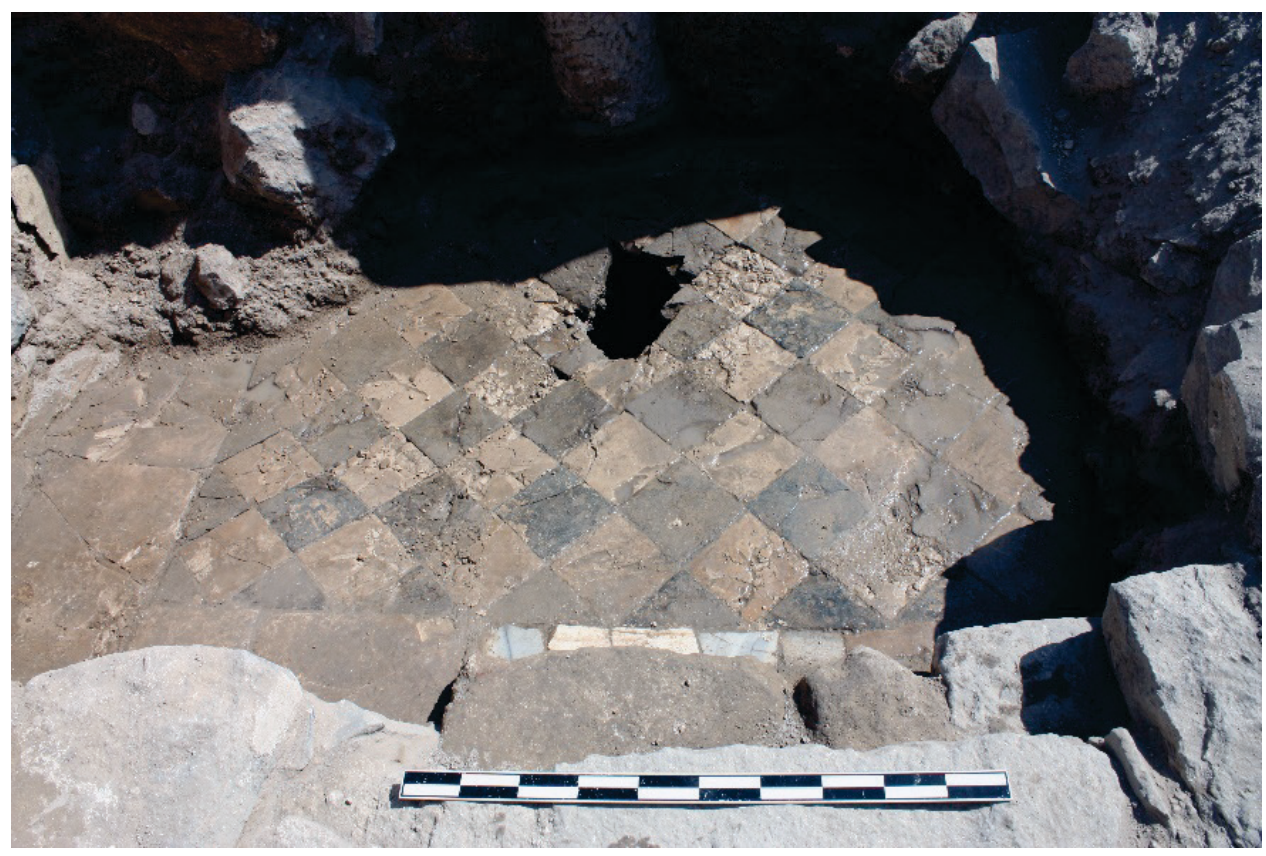

Figure 83 Opus sectile floor (looking north)

Further to the east are the remains of a masonry podium $1.10 \mathrm{~m}$ north to south and $60 \mathrm{~cm}$ east to west. Only some of its base blocks survive to a height of about $90 \mathrm{~cm}$. The podium has two stairs on either side that rise $30 \mathrm{~cm}$ to the east.

From W1267 to the stairs is $4.8 \mathrm{~m}$. The intercolumniation from the west pilaster to the west column is $1.45 \mathrm{~m}$; the intercolumniation between the two columns is also $1.45 \mathrm{~m}$. From the east column to the stairs is $1.1 \mathrm{~m}$. This colonnade likely supported a roof over the opus sectile floor forming a small portico.

Supporting the two columns and continuing to the north is a stone pavement (not opus sectile). There is no discernable stylobate. South of the columns, the opus sectile is missing east of the second column. 


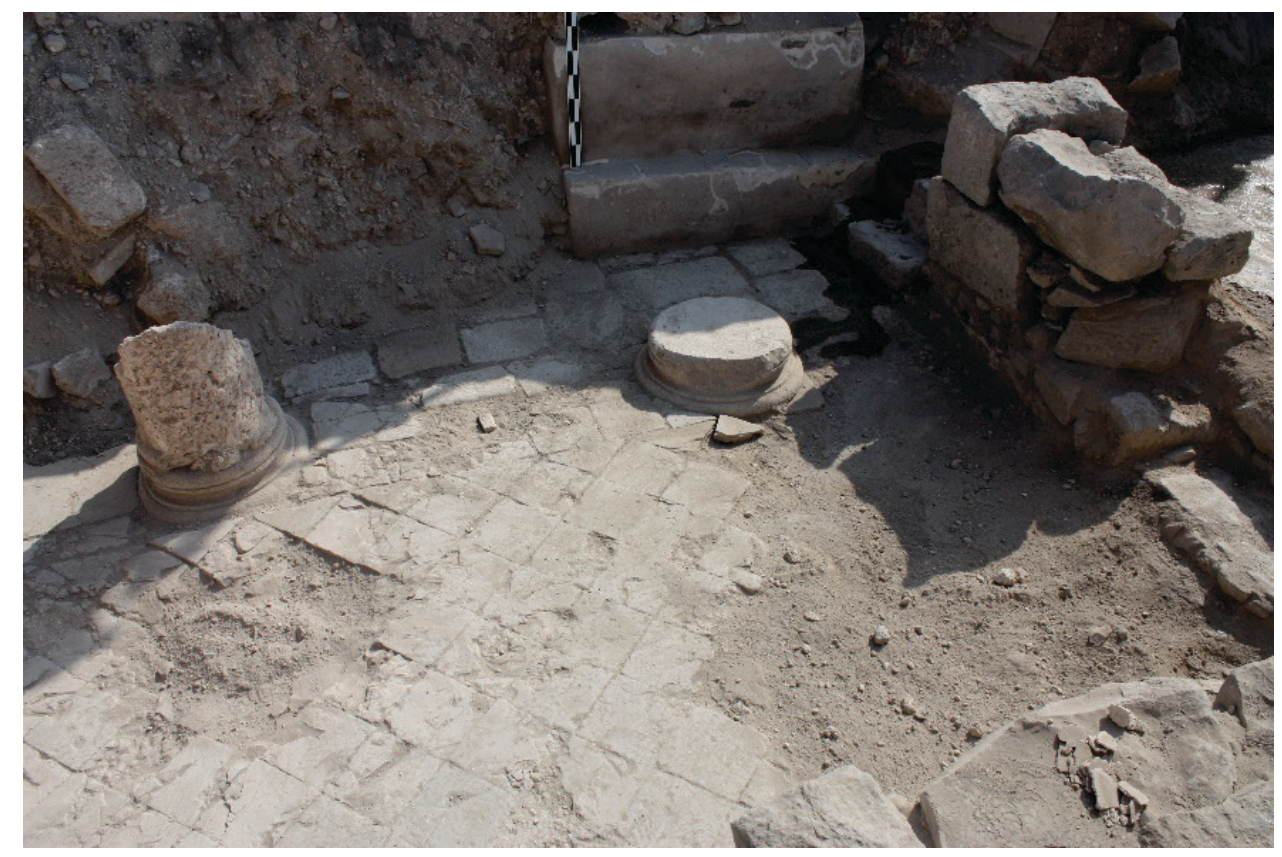

Figure 84 Portico with opus sectile floor (looking north)

The opus sectile was likely arrayed only south of the two columns, providing a decorative entrance to the terrace space north of W1266. In the southeast corner of this entrance space a small patch of industrial sized tesserae was discovered at a level $2 \mathrm{~cm}$ below that of the opus sectile floor. It was likely an earlier floor replaced by the opus sectile floor.

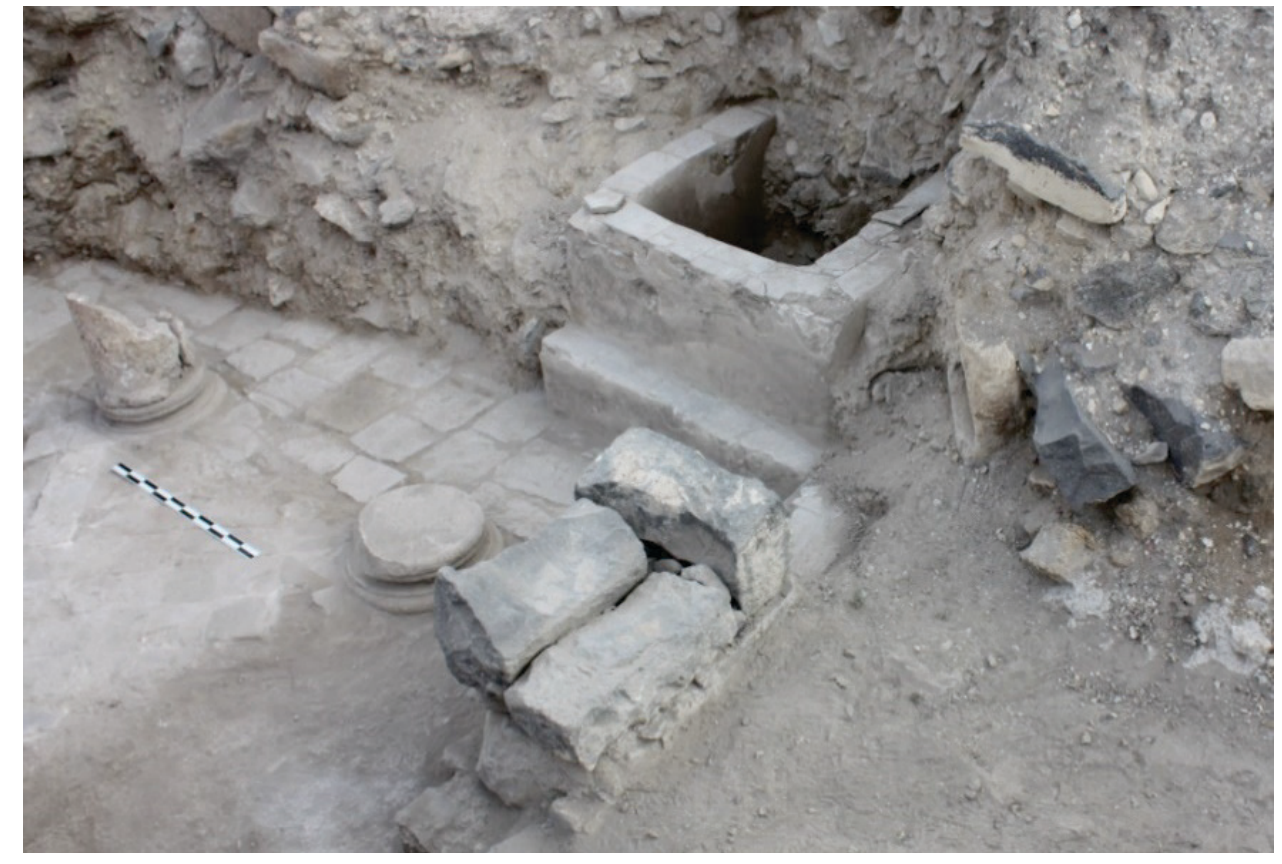

Figure 85 Water feature (looking north) 
There is a plastered pool in the north balk extending west of first northerly stair. The first ledge is $33 \mathrm{~cm}$ above the floor and is $16 \mathrm{~cm}$ wide. The top of the water feature is $54 \mathrm{~cm}$ above the ledge. The feature is $143 \mathrm{~cm}$ wide from east to west. The interior measurement is $97 \mathrm{~cm}$. The top ledge is surfaced with reused marble slabs $20-30 \mathrm{~cm}$ wide, some of which are decorated with ficus leaves. Inside the feature there is a ledge on the south and west sides of the feature $93 \mathrm{~cm}$ below the top ledge, with the bottom of the feature another $19 \mathrm{~cm}$ below. We sifted material from the water feature, recovering only small ceramic fragments. As will be discussed later in this report, pollen samples extracted from the plaster of other water features in the terrace suggest that this pool was also used for growing flax.

For parallels to this portico and water feature, we note that in North Africa, many courts "were filled with basins and pools." ${ }^{22}$ In the House of Europa at Cuicul the peristylum has three complex basins. Four basins flank the porticos in the House of Castorius. At Bulla Regis in the House of the Fisherman, the peristyle court is given entirely over to water..$^{93}$ Basins could be decorated with marine motifs and, at times, fish were raised in such pools. ${ }^{94}$

\section{Fountain and pool}

The two steps east of the opus sectile floor lead to another level including a mosaic floor and a fountain with a pool.

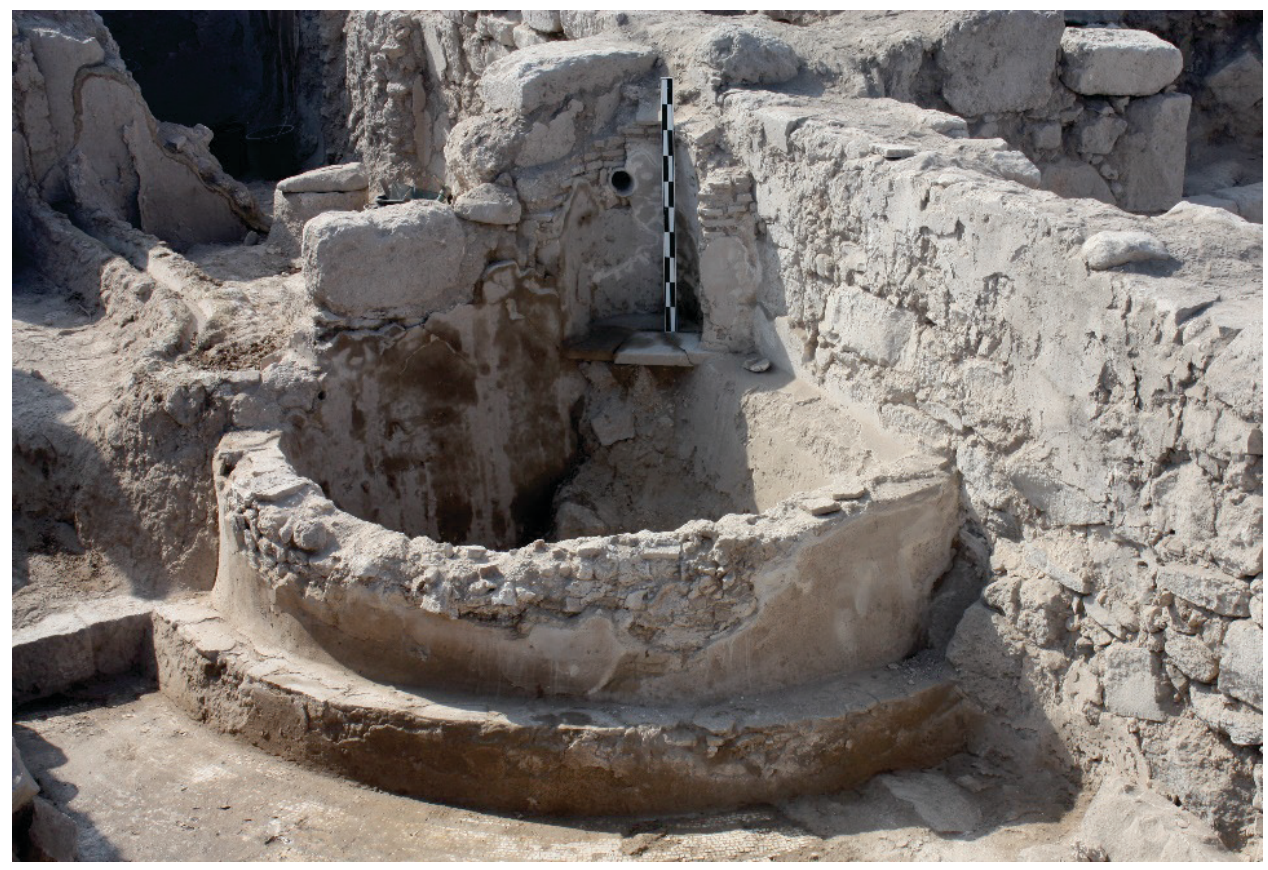

Figure 86 Single-niche fountain and pool (looking east)

The area extends $2.84 \mathrm{~m}$ to the east to a single step which aligns roughly with the line of W1910. A single-niche fountain sits in the southeast interior corner formed by W1266 and

\footnotetext{
92 Thébert, "Private Life and Domestic Architecture in Roman Africa," 362.

${ }^{93}$ Ibid.

${ }^{94}$ Ibid., 367.
} 
a $1.44 \mathrm{~m}$ wall segment that roughly extends the line of W1910 north of W1266 with an offset of $40 \mathrm{~cm}$ to the east.

The fountain portion of the structure is semicircular. Its niche is $55 \mathrm{~cm}$ across with a depth of $33 \mathrm{~cm}$. The structure is composed of reused roof tiles and floor pieces that have been plastered. At about 11 o'clock is a ceramic pipe that provides water for the fountain. The pipe has a $9 \mathrm{~cm}$ interior diameter and an $11 \mathrm{~cm}$ exterior diameter and passes through the wall to the east to a catch basin on the opposite side. The center of the pipe feeding the fountain is $36 \mathrm{~cm}$ from the top of the fountain. A decorative spout is missing. The fountain has a stone base $96 \mathrm{~cm}$ from the top. The base stone (marble) is broken in three parts and is $4.5 \mathrm{~cm}$ thick. The pool is $110 \mathrm{~cm}$ deep with an interior shelf $78 \mathrm{~cm}$ below the top of the pool. The pool is $144 \times 141 \mathrm{~cm}$ at the top and $110 \times 109 \mathrm{~cm}$ at the bottom. The measurement from the bottom curve to corner $114 \mathrm{~cm}$. The interior shelf is $32 \mathrm{~cm}$ above the bottom. From the top of the marble slab onto which the water splashed from the fountain to the bottom of the pool is $115 \mathrm{~cm}$. The base of the pool is limestone slabs. There is a $54 \times 73 \mathrm{~cm}$ slab in the corner of the pool. Other slabs seem to go under the pool walls. A $4.5 \mathrm{~cm}$ pipe was discovered in fountain in southwest corner on west side. Whether it served as a drain or as a means of keeping a level with the cistern in the peristyle court is uncertain.

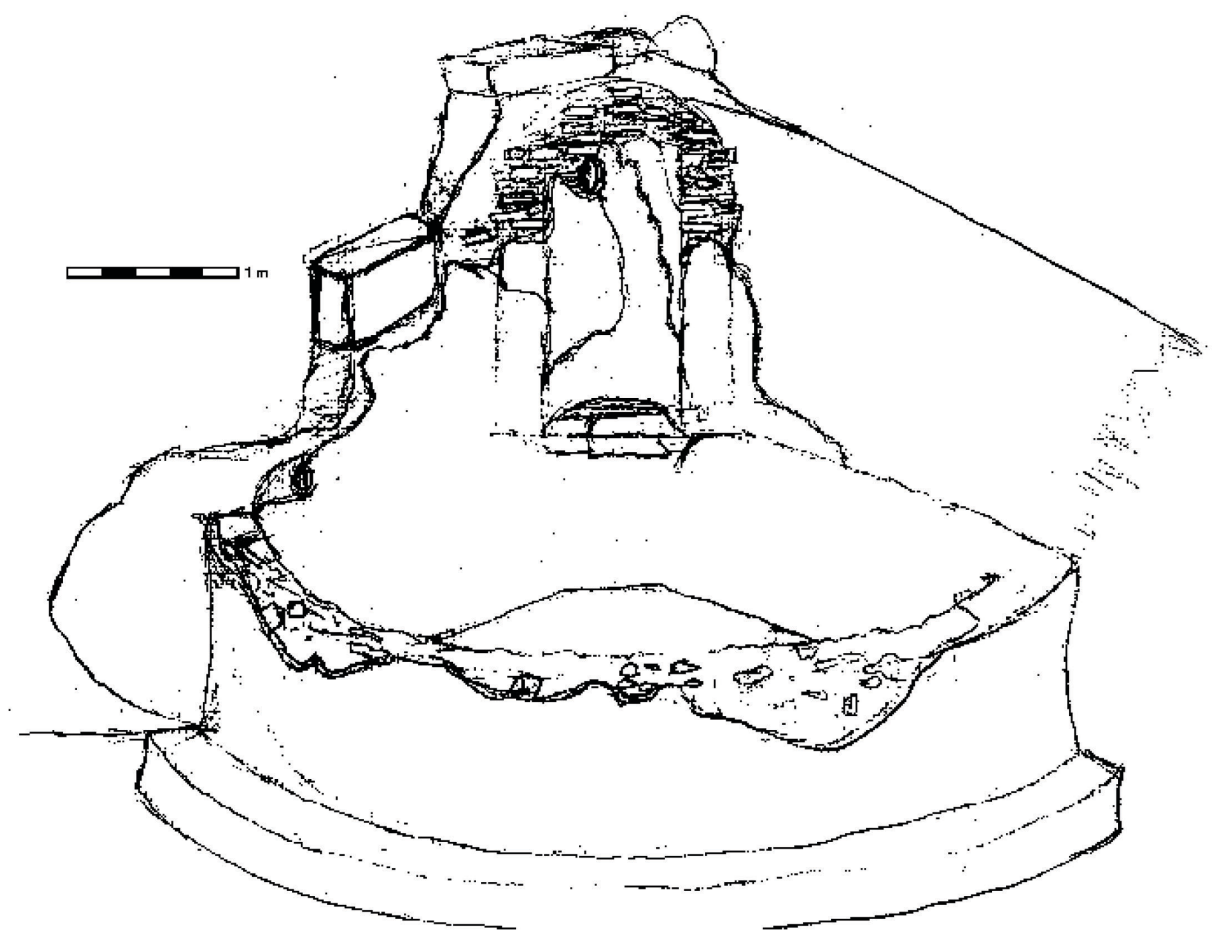

Figure 87 Drawing of fountain and pool

The water to feed the fountain apparently came from the roof of the complex. A pipe brought the water down from the roof, as plaster evidence on W1266 indicates, to a shallow 
basin that then channeled the water through the extension of W1910 to the fountain. The water from the fountain flowed into a pool.

The pool has a second source of water. Over the top of a short east-to-west wall (W1922) is an open water channel. It originates in a pipe in W1298 about $30 \mathrm{~cm}$ south W1922. The pipe has an internal diameter of $9 \mathrm{~cm}$ and runs straight for at least $26 \mathrm{~cm}$ inside of W1298. The pipe is fed by a catch basin on the east side of W1298.

From the pipe the water flows into a channel about $15 \mathrm{~cm}$ wide and $12 \mathrm{~cm}$ deep. The water flows north along the side of W1298 briefly and then flows west down the centerline of W1922. At the west end of W1922, some of the water is channeled down the west side. Part of the channel turns to the north. The terminus of this northerly section is uncertain as the plaster breaks down.

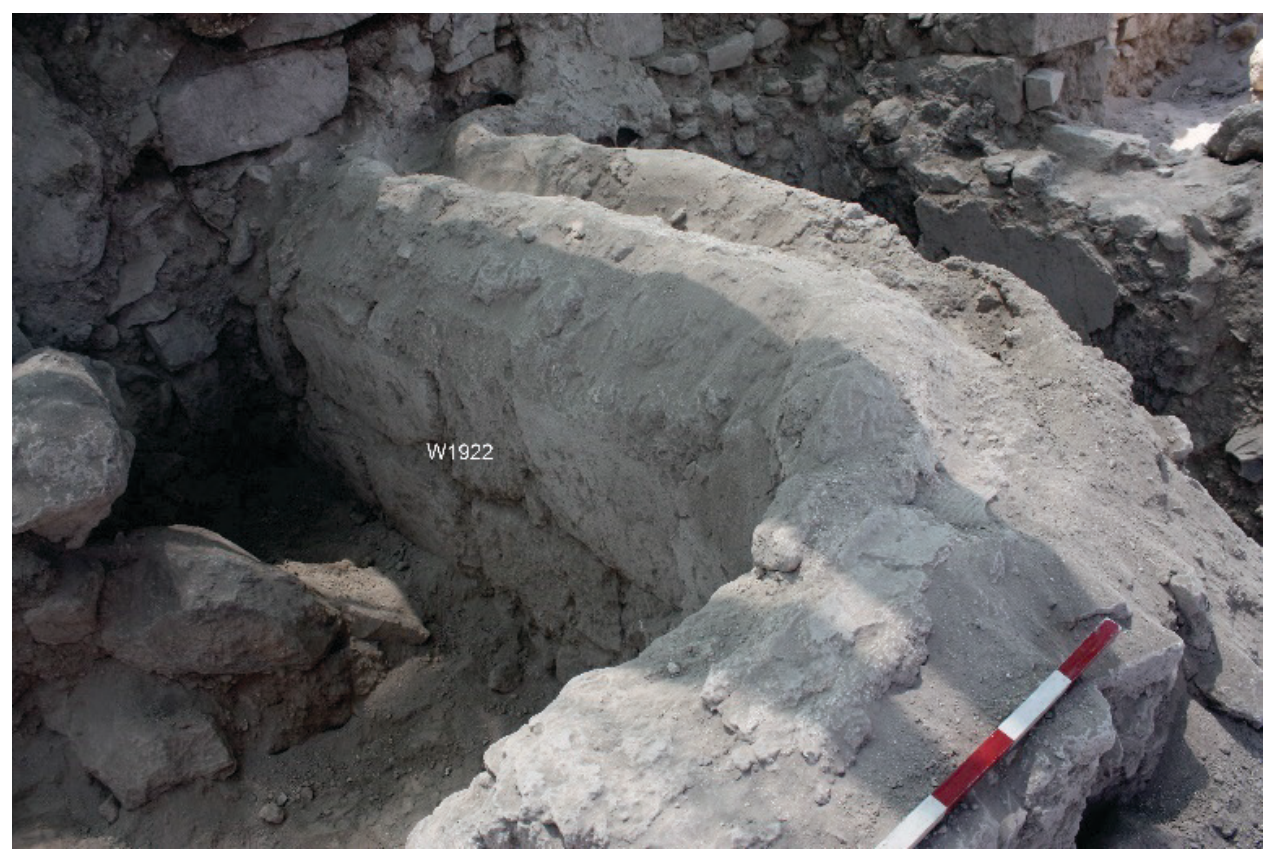

Figure 88 Upper portion of the secondary channel (looking southeast)

At the base of the west end of W1922 and 1.65m from W1266 the channel continues, running parallel with W1266. The channel is $9 \mathrm{~cm}$ wide and $6 \mathrm{~cm}$ deep. It curves away in a north westerly direction when it approaches the extension of W1910. The channel then curves back to the southwest in the form of a question mark. The water then flows through the wall of the pool into the basin through a $3.5 \mathrm{~cm}$ ceramic pipe. This lower channel sits on a low wall.

As will be suggested in a later chapter, pollen from the plaster of the pool indicates that the pool was used for processing flax. Due to the fountain and the decorative floor next to the 
pool, it is possible that the fountain and pool were originally decorative and were repurposed later when this channel was added along with the cistern and water feature to the east.

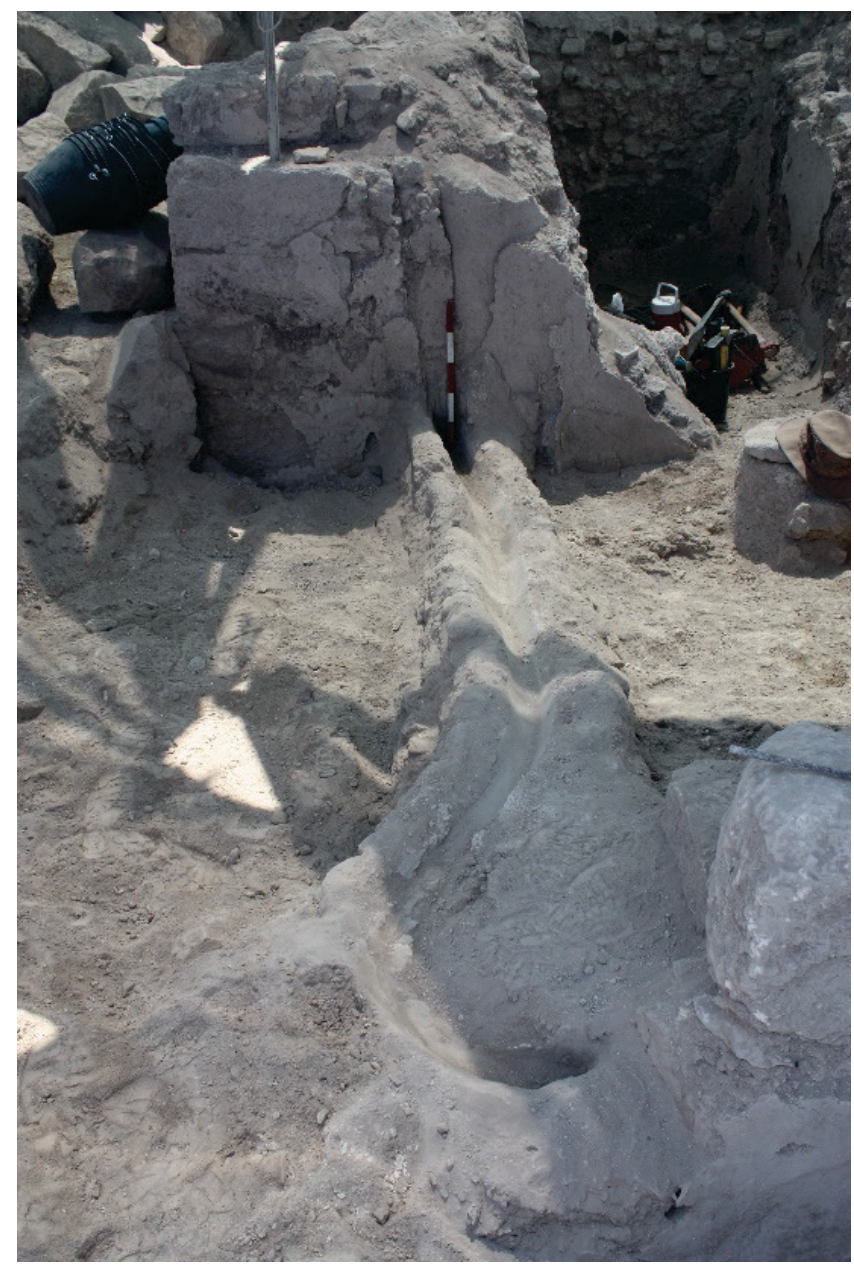

Figure 89 Lower portion of the secondary channel (looking east)

While removing destruction fill from north of the fountain pool, we removed a $2.91 \mathrm{~m}$ monolithic column from the square and balk. Its base and top are like parts of a column previously removed in an earlier season from this same general area. After lifting out the column, underneath it we recovered a limestone block $(24 \times 38 \times 22 \mathrm{~cm})$ to which plaster holding a partial face of a woman was attached. It is a fragmentary fresco of a Tyche corona muralis.

Based on the discovery of the fresco of Tyche, we now call the area east of the church the "House of Tyche."

Below the Tyche was a mosaic floor that proceeds north from the fountain and pool. 


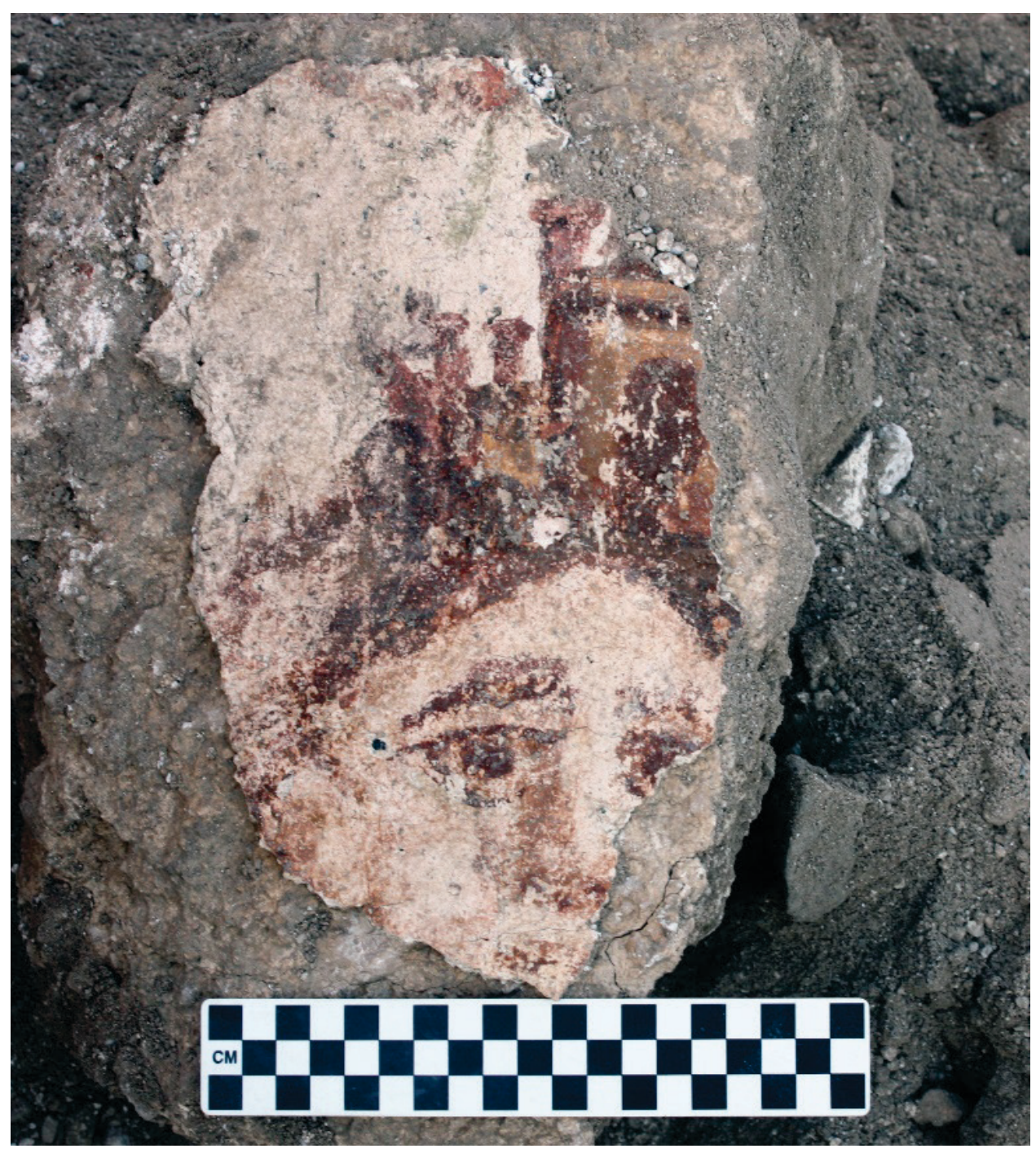

Figure 90 Fresco of Tyche at discovery

\section{Upper pool}

W1266 is the north wall of the peristyle house. It proceeds $3.94 \mathrm{~m}$ to the east to W1910 east of the fountain and then another $5.36 \mathrm{~m}$ to W1298. $72 \mathrm{~cm}$ from W1298 is a $98 \mathrm{~cm}$ doorway in W1266 that was subsequently blocked. $1.48 \mathrm{~m}$ north of W1266 is W1922 which proceeds west from W1298 for $2.55 \mathrm{~m}$ where it terminates at a broken vertical column. During the Late Antique period, a third pool was constructed in this space between W1922 and the blocked doorway of W1266. The pool begins approximately $80 \mathrm{~cm}$ below the surviving top of W1298. The walls (W1266, W1298, and W1922) were surfaced with smaller stones and plaster $20 \mathrm{~cm}$ thick. On the north side of W1266, there are at least two layers of plaster. The outer layer is $6 \mathrm{~cm}$ thick. North to south, the pool is $1.4 \mathrm{~m}$. East to west, the pool is approximately $1.55 \mathrm{~m}$, as the west wall of the pool was destroyed by a column shaft that fell against it. 


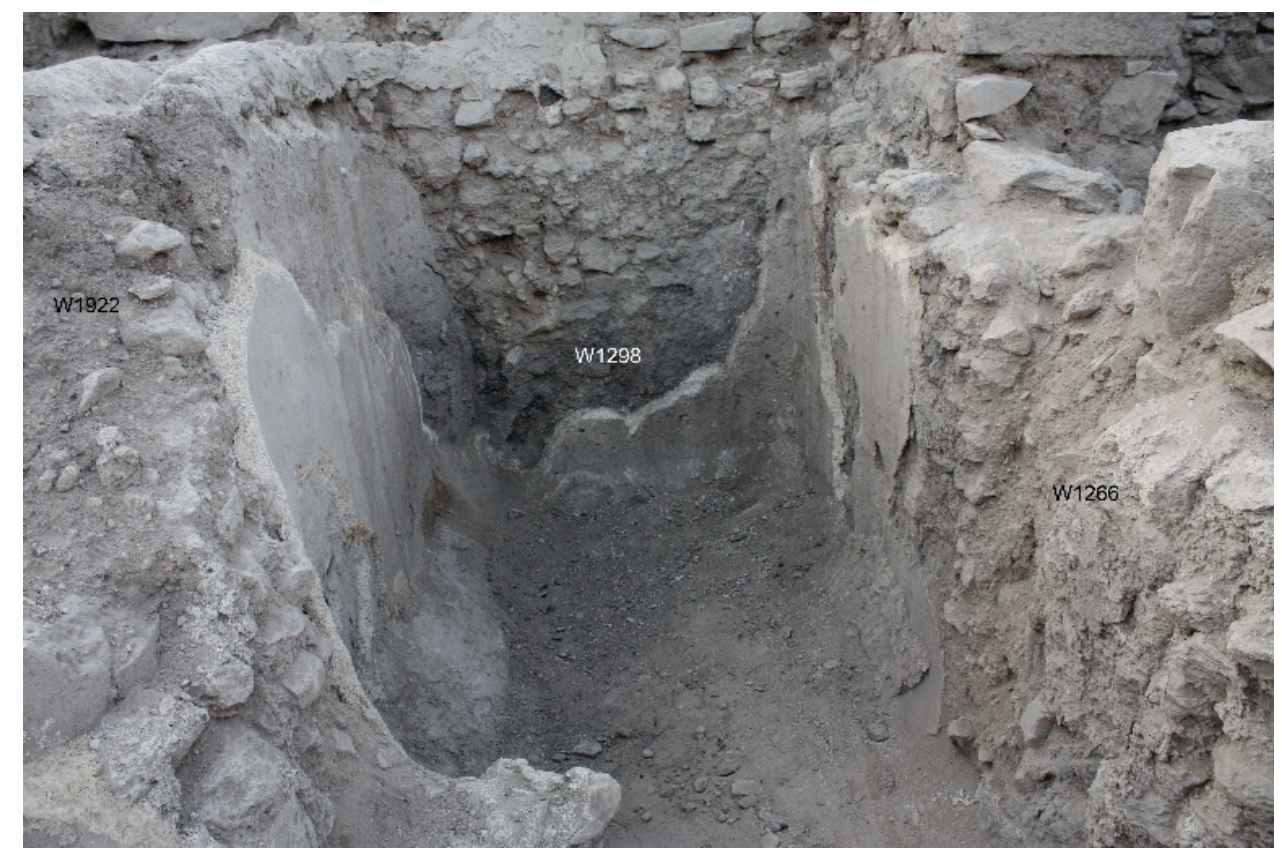

Figure 91 Upper pool (looking east)

The pool is about $1.65 \mathrm{~m}$ deep. An hour-glass mill sat on the floor of the pool. It is $45 \mathrm{~cm}$ in external diameter and $24 \mathrm{~cm}$ internally slanting to that diameter over $15 \mathrm{~cm}$. From the sifted fill at the bottom of the vat a dozen olive pits were retrieved.

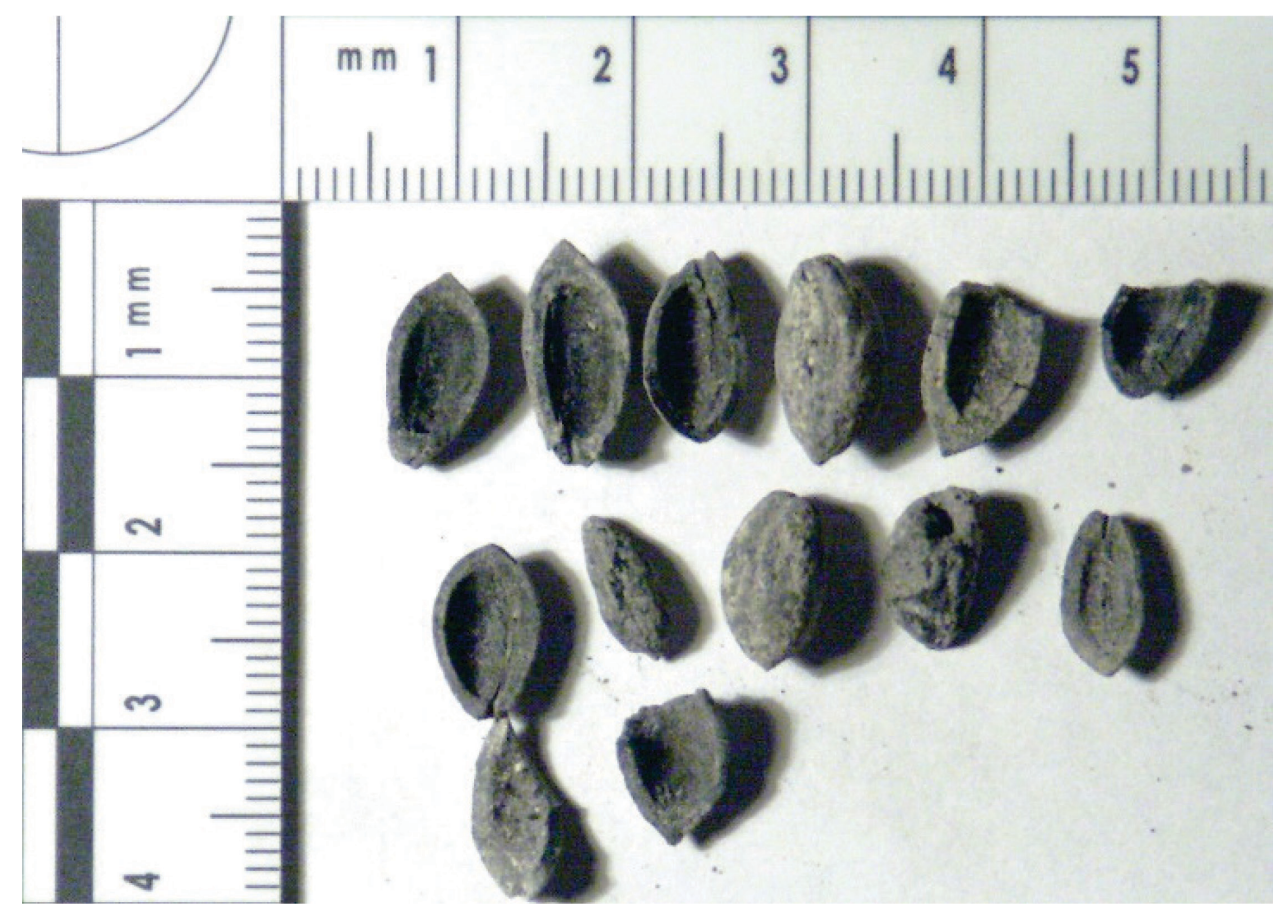

Figure 92 Olive pits 
$20 \mathrm{~cm}$ west of the west wall of the pool is the neck for Cistern I. The neck of the cistern consists of two hour-glass mill stones. We surmise that the hour-glass mill found in the upper pool was used secondarily as the head for the cistern. When an earthquake toppled a column, that falling column broke the west side of the pool and pushed/toppled the mill into the vat, where it was recovered. Cistern I would provide a water source for the various water features of the terrace north of the house during the dry season. As will be presented below, this pool, which at times stored olives, was also used for flax processing.

Formal entrance from the east

A formal entrance to the terrace from the east is provided to the north in W1298, the lintel stone of which is still intact. The opening of the doorway is $1.16 \mathrm{~m}$ wide and $1.95 \mathrm{~m}$ tall. The top of the threshold is at 129.39 , which is $26 \mathrm{~cm}$ above the level of the step next to the fountain (129.13). The lintel stone is $49 \mathrm{~cm}$ tall, $22 \mathrm{~cm}$ thick, and $1.51 \mathrm{~m}$ in length. An inscription in tabula ansata was discovered just inside the threshold facing those entering through the threshold. The Greek is EYTYX $\Omega \Sigma$ / T $\Omega$ KTH $\Sigma T H$.

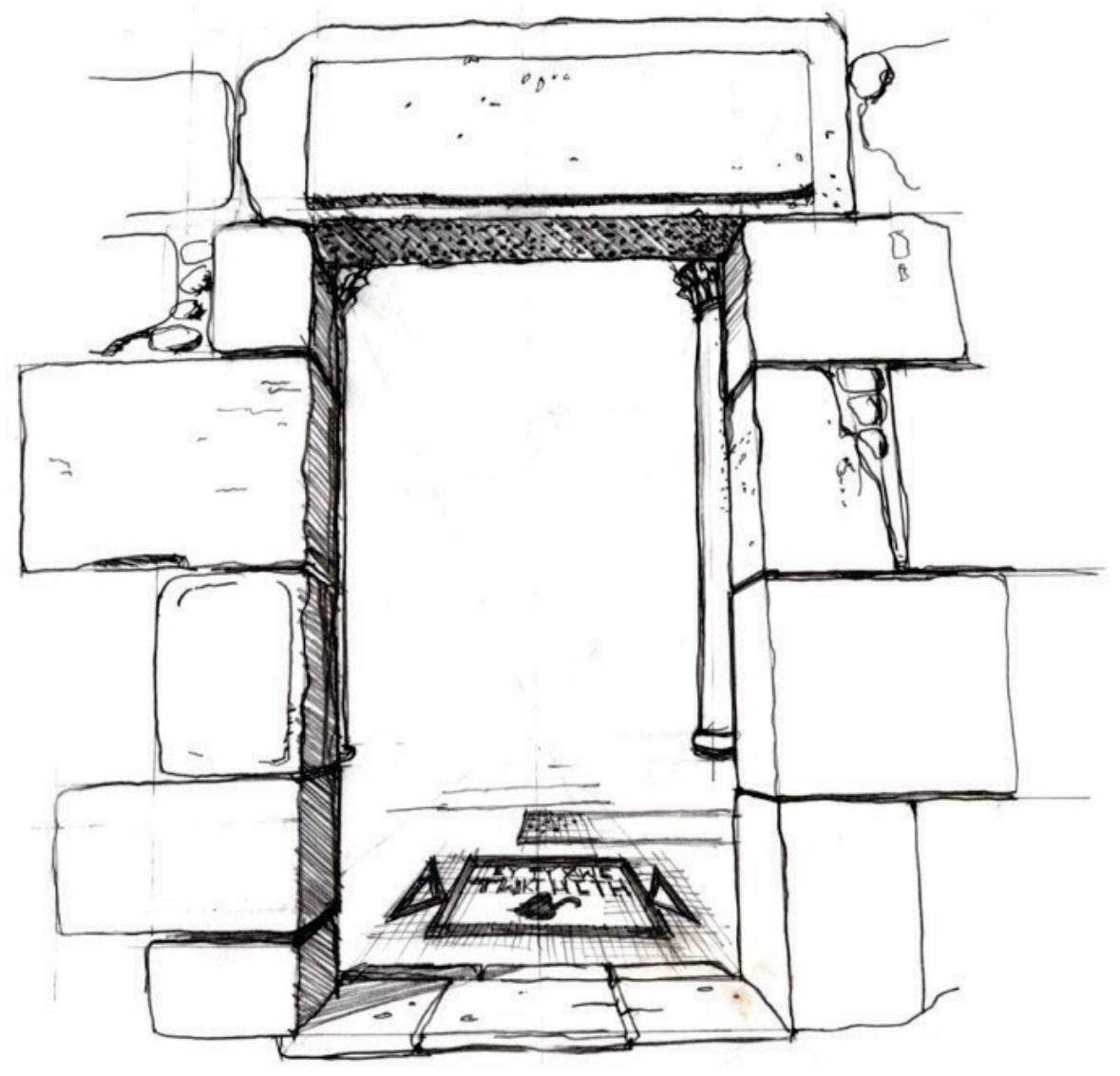

Figure 93 East entrance with inscription

Inside the entrance to the garden on the left (south) is the W1922. On its north side is a small staircase rising to the west. W1922 fills the gap between W1298 and a broken column 
fragment still in situ and serving as the western extent of W1922. A similar broken column is in situ $1.95 \mathrm{~m}$ to the north in the balk and is equidistant from W1298. W1922 and its staircase are a later addition, as is the catch basin in Cardo 4 North and watercourse that flows over W1922 to pool of the pool of the fountain. The column at the west end of W1922 and the column in the balk likely provided a portico for the entrance mosaic. As two small Corinthian capitals were recovered from the destruction fill, we presume these columns were so capped. The blocked doorway in W1266, which is $72 \mathrm{~cm}$ from W1298, suggests that the space south of W1266 was an entrance hall to the house.

Thus, the terrace to the north of W1266 has at least three entrances: a doorway to the north of and below the peristyle court that was later narrowed and fitted with two doors, a doorway at the east end of the same wall from the private area to the south, and a formal entrance from the alley to the east and north of W1922.

In summary, the space to the north of W1266 has three discernable areas. The lowest area is in the west, consisting of an entrance paved in opus sectile with a stone floor to the north bounded by two columns and a small above-ground pool. An intermediate area is two steps up to the east with a fountain and pool in the southeast corner and a geometric mosaic floor proceeding north. A third area is one step further up to the east. It has entrances from the house and from the alley. In a second phase, a channel was added from a catch basin in Cardo 4 North as an additional source of water for the fountain pool. During this phase, the upper pool and Cistern I were also constructed.

The various water features north of W1266, especially the two lower features, suggest that the area may an elaborate garden (hortus) in the Roman Imperial period. Row houses at Pompeii devote significant space to gardens. ${ }^{95}$ The House of the Small Fountain at Pompeii places the single-niche fountain in a garden. ${ }^{96}$ The House of the Moralist has an extensive garden in the form of a sacred grove..$^{97}$ Osiek and Balch point to several homes at Pompeii where the owners "placed priority on horticulture and outdoor living, being willing to live rather modestly indoors." " Examples include the Houses of Diomedes and Epidius Rufus, the House of the Faun, of which the rear third of the property is taken up by a huge peristyle garden, and the House of D. Octavius Quarto of Loreius Tiburtinus, of which two-thirds of the property is occupied by a garden. ${ }^{99}$ However, by the Late Antique period, when the ruins of the House of Tyche were repurposed in support of the Northeast Church complex, these

\footnotetext{
95 Trümper, "Material and Social Environment of Graeco-Roman Houses in the East: The Case of Hellenistic Delos," 34 35 .

${ }^{96}$ Zanker, Pompeii, plate 12.

${ }^{97}$ Ibid., $163-165$.

${ }^{98}$ Carolyn Osiek and David L. Balch, Families in the New Testament World: Households and House Churches, 1st ed., The family, religion, and culture (Louisville, Ky: Westminster John Knox Press, 1997), 15.

${ }_{99}$ Ibid., 227, no. 27; Lawrence Richardson, Pompeii: An Architectural History (Baltimore: Johns Hopkins University Press, 1988), 329-343.
} 
features took on a more industrial purpose, as would other parts of the House of Tyche. Flax production is the suggested purpose.

\section{Entrance hall}

A small room ( $3.70 \mathrm{~m}$ north to south and $4.69 \mathrm{~m}$ east to west) occupies the northeast corner of the House of Tyche. It is bounded to the east by W1298, to the south by W1913, to the west by W1910 and to the north by W1266. There is a blocked doorway in the north wall ( $1.03 \mathrm{~m}$ wide). In the west wall is a doorway $89 \mathrm{~cm}$ in width the exterior of which faces the peristyle court. Interestingly, the pottery profile during the excavation of this area was inverted, with significant deposits of late Roman overlaying the typical Late Antique profiles. We speculate that this inversion was caused by the construction of the upper pool and perhaps Cistern I to the north of W1266.
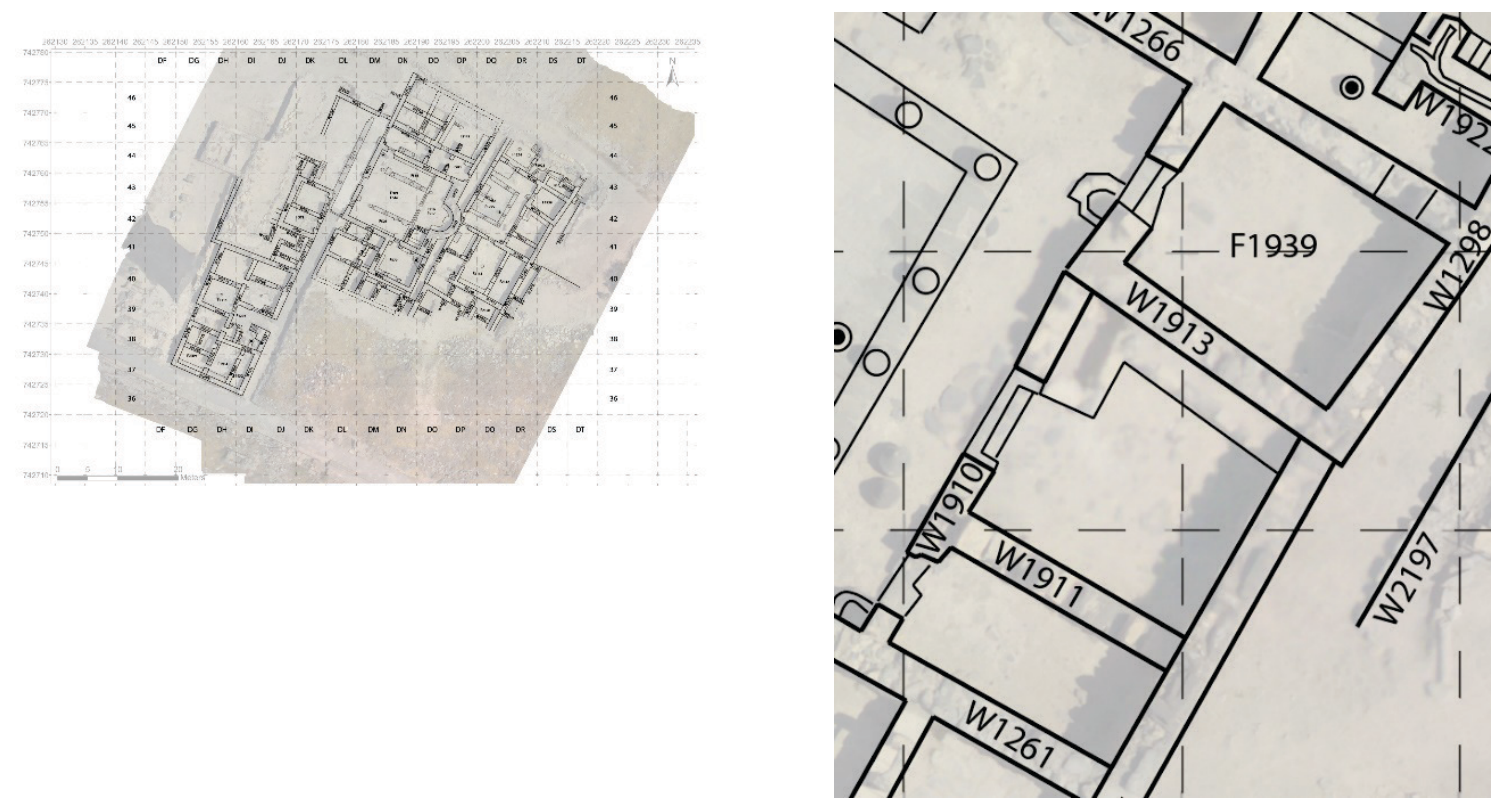

Figure 94 Entrance hall and east room

When approaching the floor, three layers were identified. An upper plaster floor is visible in the southern half of the threshold and in the SW corner (elevation 130.14). The original floor is a mosaic carpet and located at elevation 129.85. Between these two is a layer of mud/plaster.

There is a pear-shaped catch basin $(24 \times 30 \mathrm{~cm})$ next to the east wall $110 \mathrm{~cm}$ from the southeast corner of the room. There was a fixture next to the north wall. Only the stone base remains, $110 \mathrm{~cm}$ wide and $50 \mathrm{~cm}$ from the west wall. Workers identified a thin line of plaster, indicating that the fixture on the north wall had a comparable feature on the south. The features are $78 \mathrm{~cm}$ apart offset to the north.

Two ceramic tiles/pipes cross room on top of mosaic floor $(12 \mathrm{~cm}$ in diameter). One comes through the blocked doorway in W1266 (the bottom elevation of the pipe at the blocked 
door is 129.92 , the bottom elevation in the center of room is 129.90). Its continuance to the north of the blocked doorway is untraceable as the upper pool destroyed it. We speculate it was originally connected to the catch basin by the north stairs in Cardo 4 North, the water of which was later redirected to the pool associated with the fountain. The other pipe comes from a catch basin next to the east wall. Both direct water to the southwest corner of the room. In the southwest corner is a small sedimentation? pool. It collects water from the two pipes crossing above the remains of the mosaic floor and from the external catch basin west of W1910. A third pipe also enters this area from a lower level. Its origin is unknown. Water from all these sources then flows under W1910 presumably into the Cistern H under the peristyle court. There pipes come from a later phase in the House of Tyche when this portion of the house was converted for more utilitarian usage.

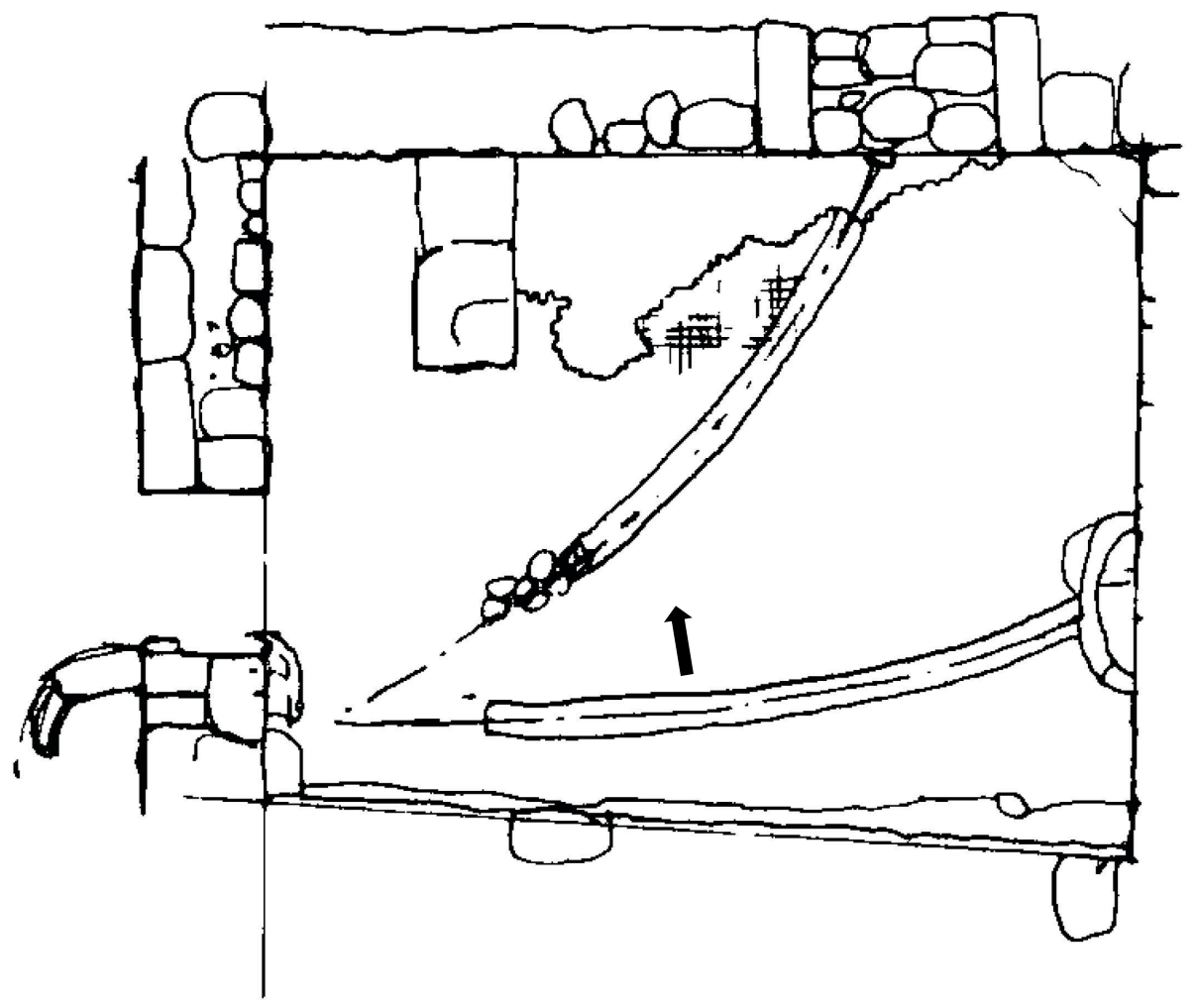

Figure 95 Pipes crossing the entrance hall

The original mosaic carpet (F1939) is intact in many places. Geometric patterns are visible in blue and white. The mosaic was seemingly cut about halfway across the room leaving most of the north side intact. An inscription was discovered just south of the blocked en-

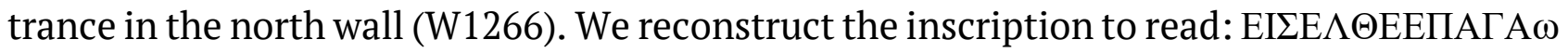
"enter for good."

In a lacuna in the mosaic (F1939), conservators identified a pot buried into the floor. Someone had cut the mosaic to insert the pot. The pot is Kfar Hananya form $\mathrm{C}$. The pot was 
located $1.17 \mathrm{~m}$ from W1266, $3.24 \mathrm{~m}$ from W1298, and $5.7 \mathrm{~cm}$ below top of mosaic. The interior mouth diameter of pot is $11 \mathrm{~cm}$. The pot contained a layer of soil like that above it with tesserae and some plaster. At $6 \mathrm{~cm}$ down a more ashen soil occurred with greater sand content. A harder sloping layer appears at a depth of $10.5 \mathrm{~cm}$ into the pot. The soil is quite ashen. At $13.9 \mathrm{~cm}$ below the top of the pot a nail and a chunk of burnt wood were recovered. At $14 \mathrm{~cm}$ more glass, bone, and perhaps some seeds were found. Subsequently, the lacuna cleaned to a depth of $20 \mathrm{~cm}$ high and $30 \mathrm{~cm}$ low. The dimensions of the lacuna are $40 \mathrm{~cm}$ (north to south) and $42 \mathrm{~cm}$ (east to west). The hole is oblong to the northeast with a diagonal of $48 \mathrm{~cm}$. If the pot was used to hide anything valuable, those contents are now missing.

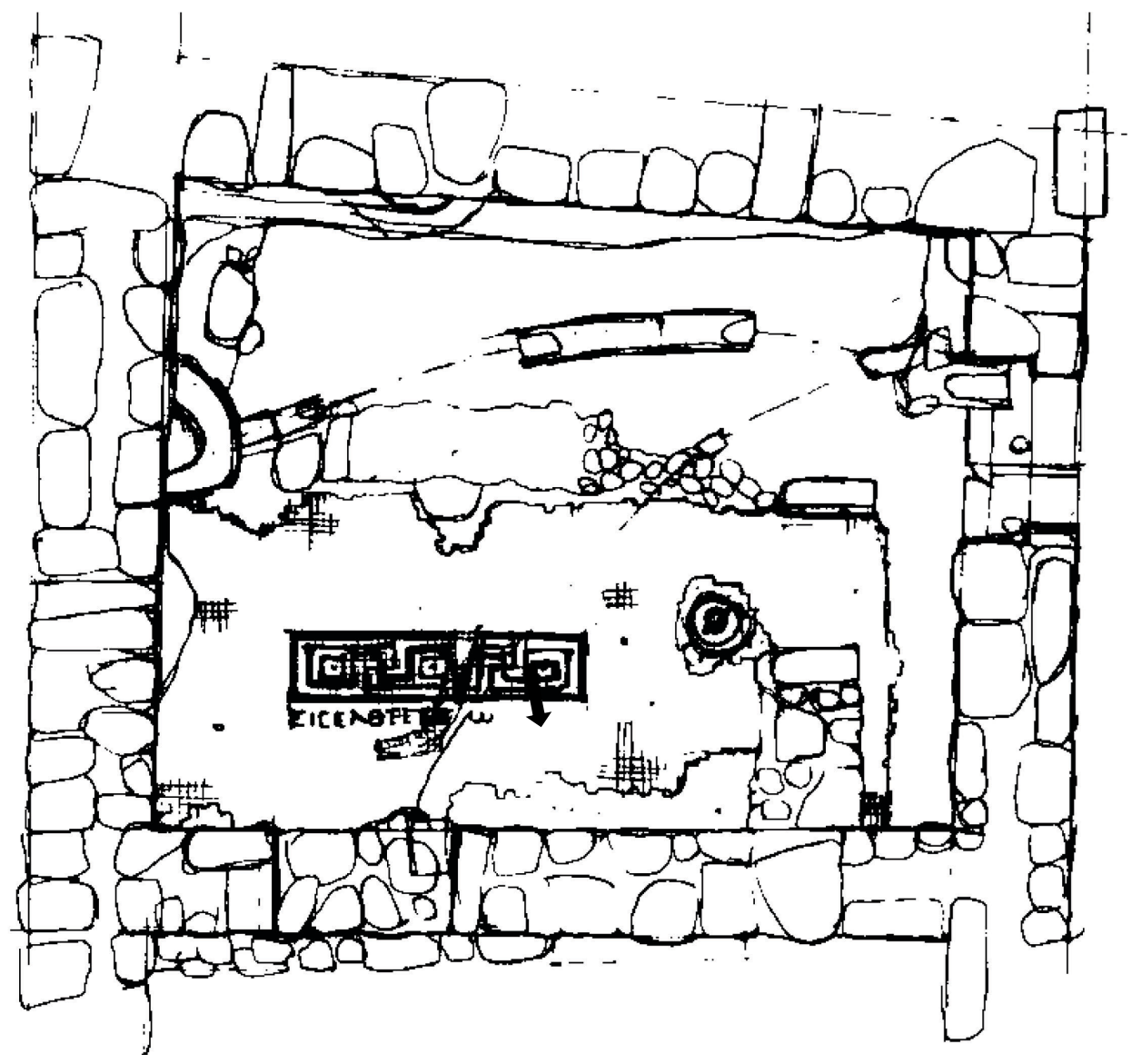

Figure 96 Top plan of the entrance hall with inscription

Two coins were recovered on or near the mosaic floor having been sealed by the fill and floor above. One had a diameter of $2.5 \mathrm{~cm}$. It was heavily effaced. Likely it is a Roman provincial coin of the third century. A second coin was recovered near the west entrance to the room. It is a coin from $382 \mathrm{CE}$ of Gratian, Valentinian II and Theodosius I (bust right on the obverse, on the reverse within a wreath: VOT/X/ MVLT/ XX. The coins are consistent with the house being abandoned in the decades after the earthquake of 363. 
Eastern room of the House of Tyche

Directly east of the peristyle court and sharing a common southern wall is a room of approximately $8 \times 6$ that was subdivided by a window wall in a later phase.

The east interior length is $6.94 \mathrm{~m}$; the south interior width is $4.33 \mathrm{~m}$; the west interior wall is $7.45 \mathrm{~m}$; and the north interior dimension is $4.53 \mathrm{~m}$. The south section of the room is 2.03 $\mathrm{m}$ wide on the east end and $2.17 \mathrm{~m}$ wide on the west end. From the north side of the window wall to the south edge of the shelf is 3.57 at the east end and 3.81 at the west end. The gaps between the three uprights of the window wall are $74 \mathrm{~cm}$ from the east wall to the first upright, $81 \mathrm{~cm}$ between the first and second uprights, and $78 \mathrm{~cm}$ between the second upright and the westerly most surviving upright.

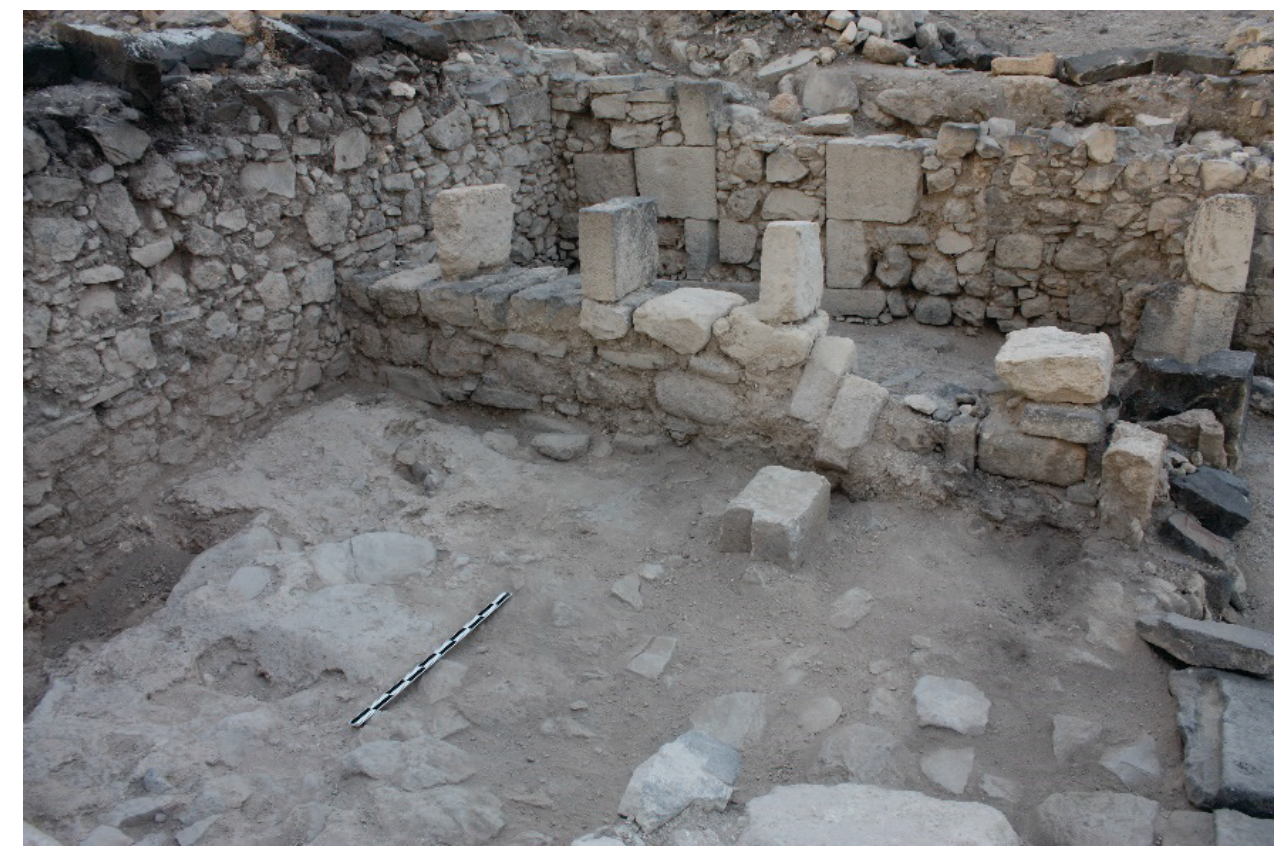

Figure 97 Window wall in the east room (looking south)

Window walls have been found at several ancient sites and seem to have served at least a couple different purposes. At Chorazim, where this structure was first discovered, the window wall divided a large multipurpose room from a smaller storage or service area. This same plan was found in three apartments that were all part of a large complex at Tel elJoukhadar, as well as in two village homes in Qatzrin. ${ }^{100} \mathrm{~A}$ similar design was found in an ancient house at Horvat Kanaf. ${ }^{101}$

\footnotetext{
${ }^{100}$ Ann E. Killebrew, Billy J. Grantham, and Steven Fine, “A' Talmudic' House at Qasrin: On the Use of Domestic Space and Daily Life during the Byzantine Period," Near Eastern Archaeology 66, no. 1-2 (March 2003): 59-72.

${ }^{101}$ Stephen J. Pfann et al., "Surveys and Excavations at the Nazareth Village Farm (1997-2002): Final Report," Bulletin of the Anglo-Israel Archaeological Society 25 (2007): 19-21.
} 
The window wall apparently allowed for light and air to flow easily through both rooms. Archaeologists at Qatzrin speculate that the large room was where most family activity took place, including eating. They also believe that a sleeping loft, reached by a wooden ladder, was located above the smaller room. ${ }^{102}$ At Capernaum, the smaller room functioned as an animal stable with each window acting as a separate stall to which the animals were tied. On cold nights warmth from the animals spread to the sleeping loft directly above. ${ }^{103}$

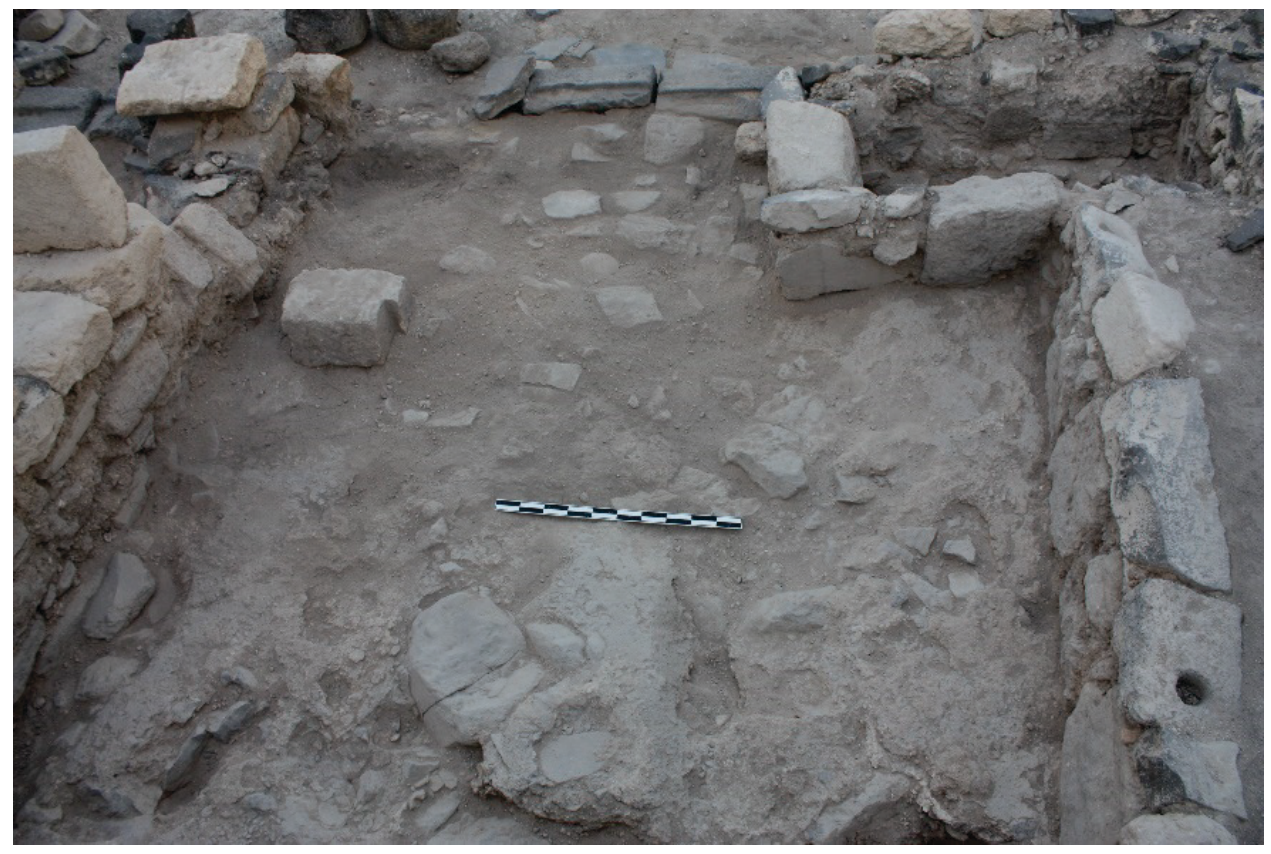

Figure 98 Bench and fixture in eastern room (looking west)

The fixture in the northwest corner of the eastern room is $1.98 \mathrm{~m}$ on east, $2.09 \mathrm{~m}$ on the west, 1.2 on the south, and 1.19 on the north. There is a shelf next to the north wall of the space. The dimensions of the shelf are $3.40 \mathrm{~m}$ east to west. Its width varies from $67 \mathrm{~cm}$ on the west to $70 \mathrm{~cm}$ on the east. Its height is $65 \mathrm{~cm}$ on the east and $57 \mathrm{~cm}$ on the west.

A blocked doorway was identified in W1261. Doorway is $92 \mathrm{~cm}$ wide; the west edge of the door is $2.80 \mathrm{~m}$ from the west face of W1910. The exterior of the door is to the north.

Along with the typical destruction fill, significant quantities of molded plaster were recovered, especially as we approached the floor. One collection of 9 pieces of molded and painted plaster is typical. The two most prominent pieces have a double bevel near the top, followed by a longer inward bevel and one more outward bevel. One smaller piece may be the same double bevel as the top of the two prominent pieces. Other pieces in the collection

\footnotetext{
${ }^{102}$ Ann E Killebrew and Steven Fine, "Qatzrin: Reconstructing Village Life in Talmudic Times," Biblical Archaeology Review 17, no. 3 (May 1991): 44-56.

${ }^{103}$ Lawrence E Stager, "The Archaeology of the Family in Ancient Israel," Bulletin of the American Schools of Oriental Research 260 (1985): 12-17.
} 
appear to be painted, some with a dark color (either blue or black) or with a red color. Likewise, several pieces of painted fresco were recovered from the fill.

As we approached the floor, we began to recover large quantities of tesserae. Most tesserae in the fill are individual of the $1 \mathrm{~cm}^{3}$ or slightly larger size and white in color. There are also a good number of smaller tesserae. Occasional clumps of tesserae were recovered. One clump of tesserae indicated a merging of two flows of white tesserae. There is a single border of black tesserae. To the border cling a red, yellow, and red tesserae. The colors coordinate with the fresco fragment found in the room.

Portions of a plaster floor (F2119) (or a sublevel to a mosaic floor) survive. However, we never found any tesserae intact in the plaster. The floor survives best next to the northerly shelf and in northeast and southeast corners. In the middle and toward the west, less of the floor survives. The plaster shows indications of going up the front of the shelf. So, during at least one plastering, the shelf was also plastered. The fixture in the northwest corner of the room sits on the plaster. The window wall is imbedded into the plaster. We did open a $1 \times 2 \mathrm{~m}$ probe in the northeast corner of the room (L2123), but we shortly reached bedrock. There were almost no remains in the plaster. Elsewhere in the room, no plaster remained on top of the bedrock. The ceramic assemblages near the floor level were mostly from the sixth and seventh centuries. Nothing distinctly Umayyad was found.

In its final phases, this eastern room of the House of Tyche underwent the typical subdivision and domestication of larger structures in the time of the Late Antique to Umayyad transition. Its original function in the House of Tyche may have been as a triclinium. But all evidence of that function, besides the shape of the room, has vanished.

\section{Southern Room complex}

The Late Antique remains in the House of Tyche have so far reused or rebuilt walls and floors from a Roman-era peristyle house and reflect its floorplan. However, rebuilding in the southern half of the house departs from the original floorplan. A large and arched central room is connected by window walls ${ }^{104}$ on the east and the west to additional spaces: a paved storage room to the east and two rooms to the west.

\footnotetext{
${ }^{104}$ Katharina Galor, "Domestic Architecture in Roman and Byzantine Galilee and Golan," Near Eastern Archaeology 66, no. 1-2 (March 2003): 48-52.
} 


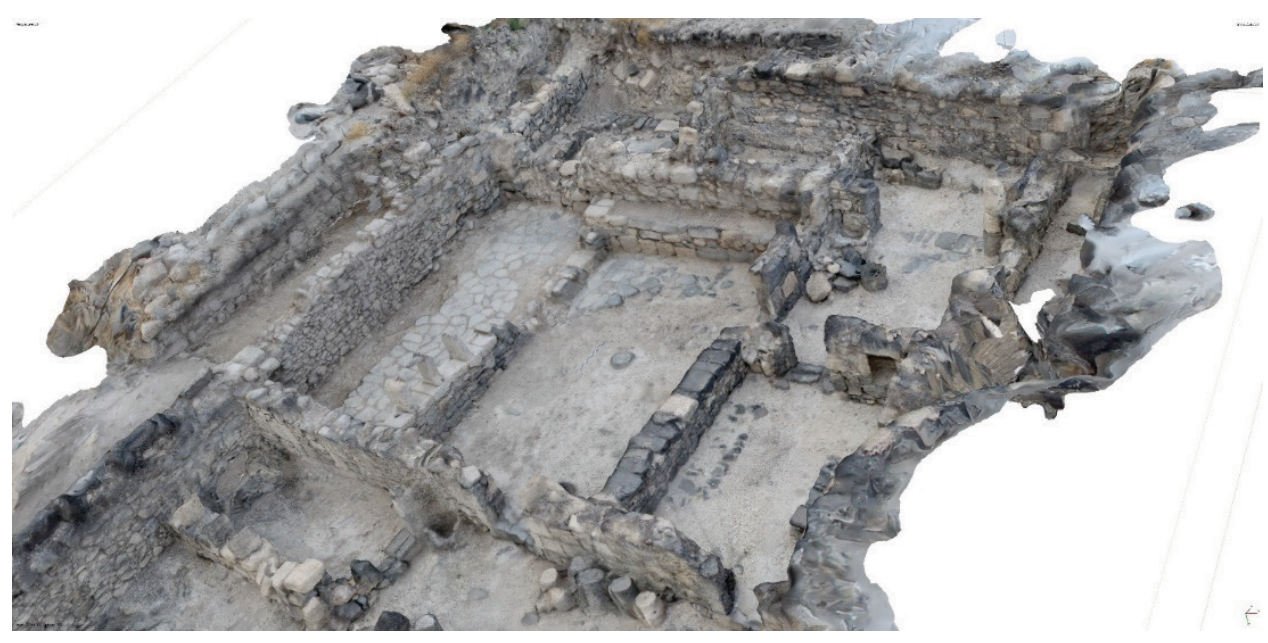

Figure 99 Southern room complex (looking south)

Whereas the south room on the west side includes the southwest corner of the original house, the central and eastern rooms are $2.9 \mathrm{~m}$ from the original southern wall of the house.

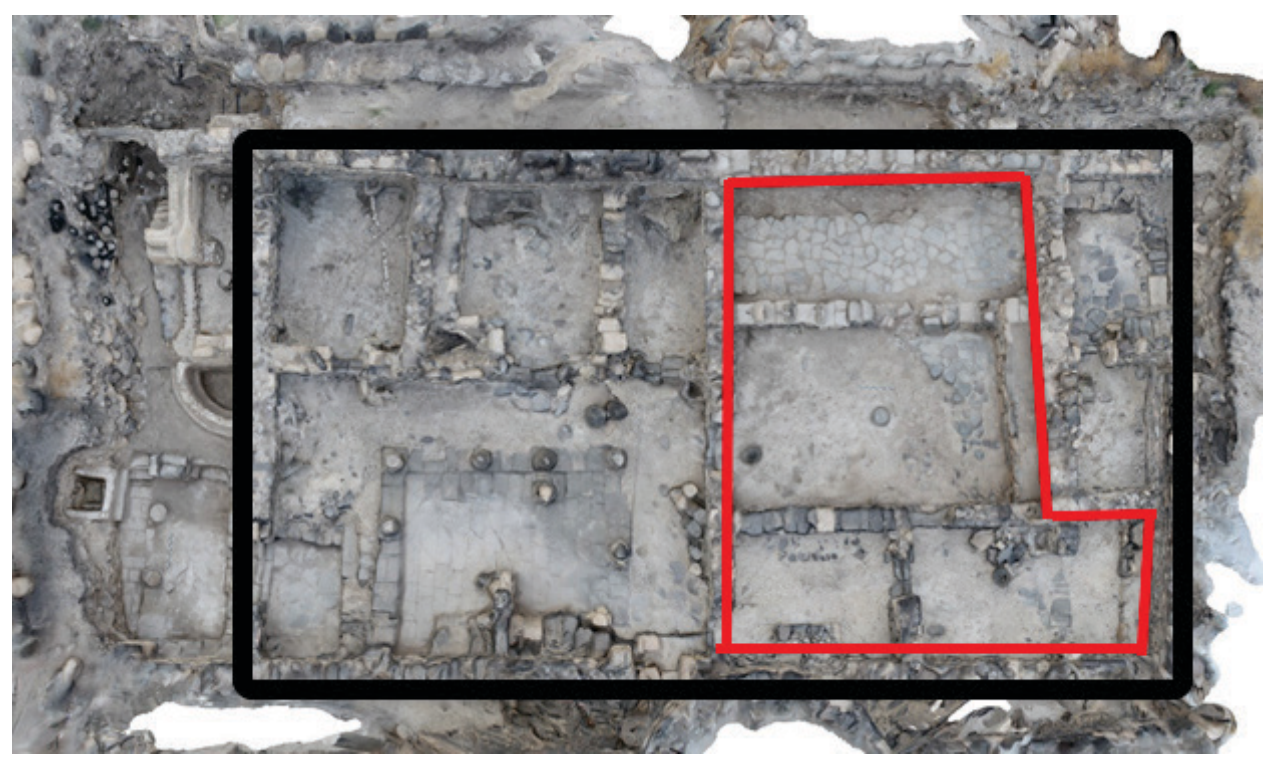

Figure 100 Extent of the southern room complex

Other structures now fill the gap. But they are not part of the Late Antique structure that occupies most of the footprint of the original house. 

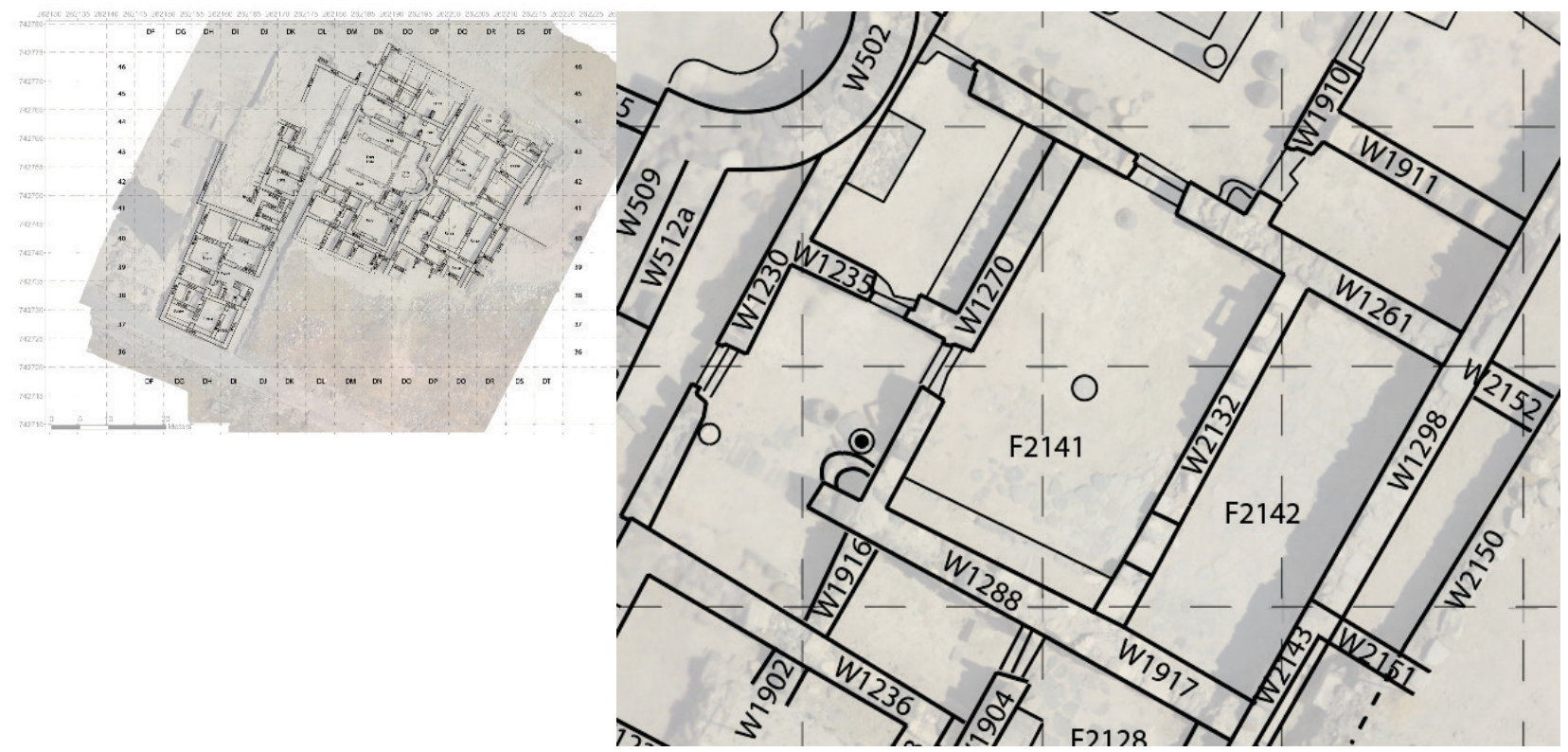

Figure 101 Southern rom complex

Work east and southeast of the apse revealed a $70 \mathrm{~cm}$ wall (W1270) roughly parallel to W1230 between W1261 on the north and W1236 on the south. W1270 is the eastern side of two rooms: a larger room with a cistern to the south and a smaller space to the north with a niche next to the apse of the church.

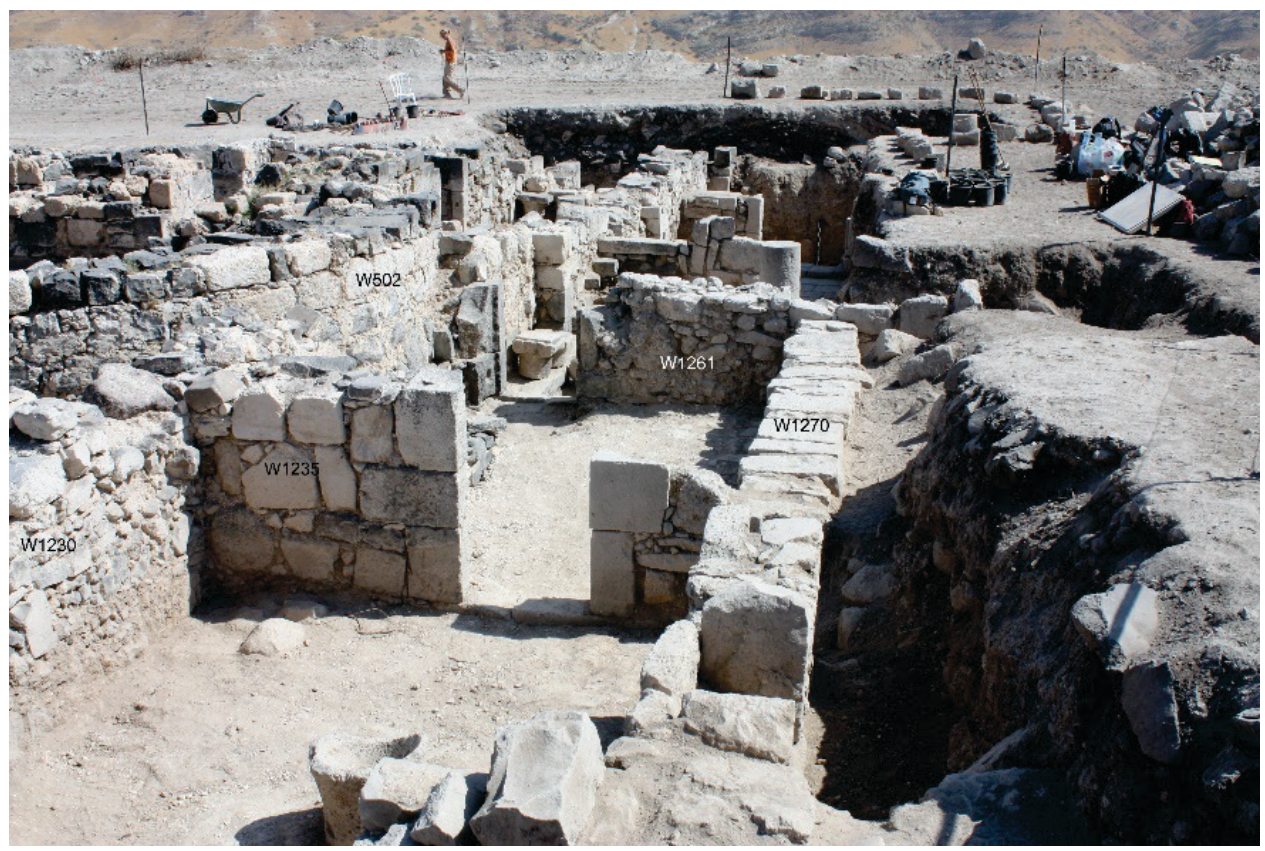

Figure 102 East of the apse (looking north) 


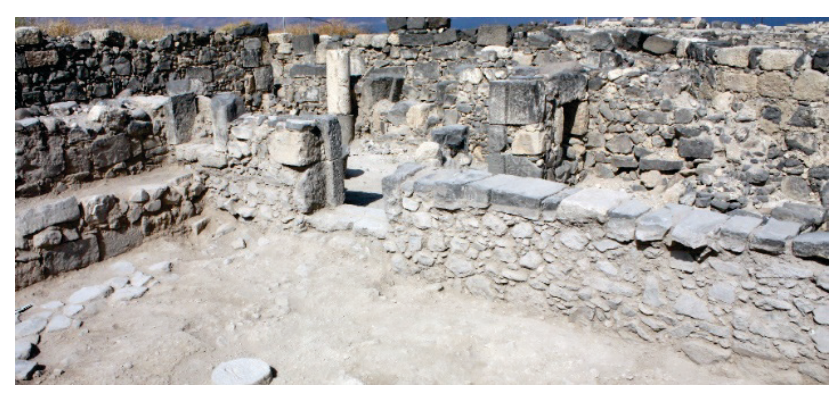

Figure 103 West window wall

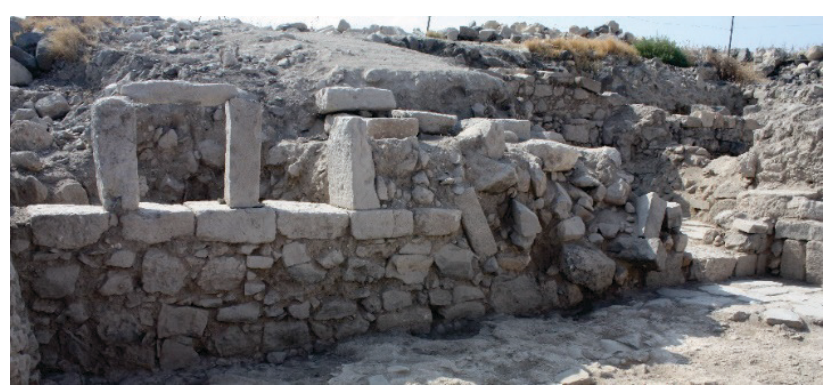

Figure 104 East window wall

The west window wall (W1270) has a doorway to the west with its exterior to the west. The base for the windows survives. But only two uprights are in situ at the south end. The east window wall (W2132) is intact at its north end. The uprights are approximately $77 \mathrm{~cm}$ tall. The first upright is $61 \mathrm{~cm}$ from W2161. The upright is $24 \mathrm{~cm}$ in width. The second upright is $54 \mathrm{~cm}$ to the south and is $24 \mathrm{~cm}$ in width. The third upright is $73 \mathrm{~cm}$ to the south and is $18 \mathrm{~cm}$ in width. However, after about $3 \mathrm{~m}$, the wall seems to have exploded (earthquake damage?). One of the vertical pieces of the window wall has slid down two courses. Another vertical piece lies horizontal on the current surface of the fill. Most of the middle section of the window wall has been destroyed with even the base course showing some shifting. There is a doorway toward the south end of W2132. The doorway is $97 \mathrm{~cm}$ in width, and it begins $1.34 \mathrm{~m}$ from W1917. The bottom course (all that survives) seems to indicate that the doorway was blocked intentionally in antiquity. The presence of this doorway explains the many limestone doorjambs in the destruction fill.

\section{Central room with double arch}

Next to the southern wall of the room (W1288) is a high $(70 \mathrm{~cm})$ and wide $(70 \mathrm{~cm})$ bench. A light roof roller sits on its surface, possibly having fallen when the roof collapsed. The floor of the central room (F2141) is a mud/plaster combination on top of flat stones or cobbles. Some of the plaster floor remains against the western wall (W1270).

We discovered a column base/drum protruding from the plaster floor of the central room at 130.50. The column in the center of the room is $48 \mathrm{~cm}$ in diameter. It is $3.87 \mathrm{~m}$ from W1261 and $3.78 \mathrm{~m}$ from W1288. It is $2.27 \mathrm{~m}$ from W2132 and $2.21 \mathrm{~m}$ from W1270.

We opened the floor to the south of the protruding column and found that it was a base (not a drum). A $15 \mathrm{~cm}$ shaft protruded above the floor. The upper torus is $6 \mathrm{~cm}$, the scotia is 5 $\mathrm{cm}$, and the lower torus is $9 \mathrm{~cm}$. The column base is not from previous construction but was brought to the room from elsewhere as it sits on and is held in place by crude stones. 


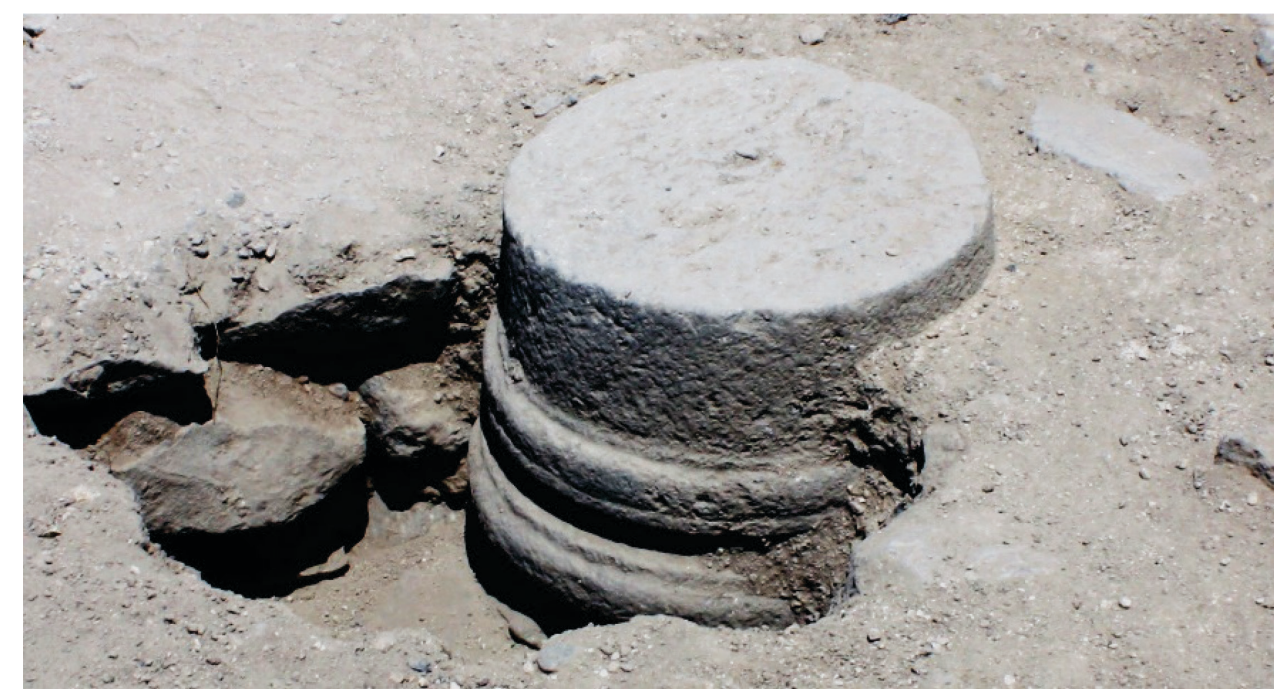

Figure 105 Protruding column base

The survival of the floor is inconsistent, with gaps and holes. In the southeast corner of the room, flat stones form a flagstone surface near the doorway to the eastern space. Some flat stones continue across the southern end near the bench.

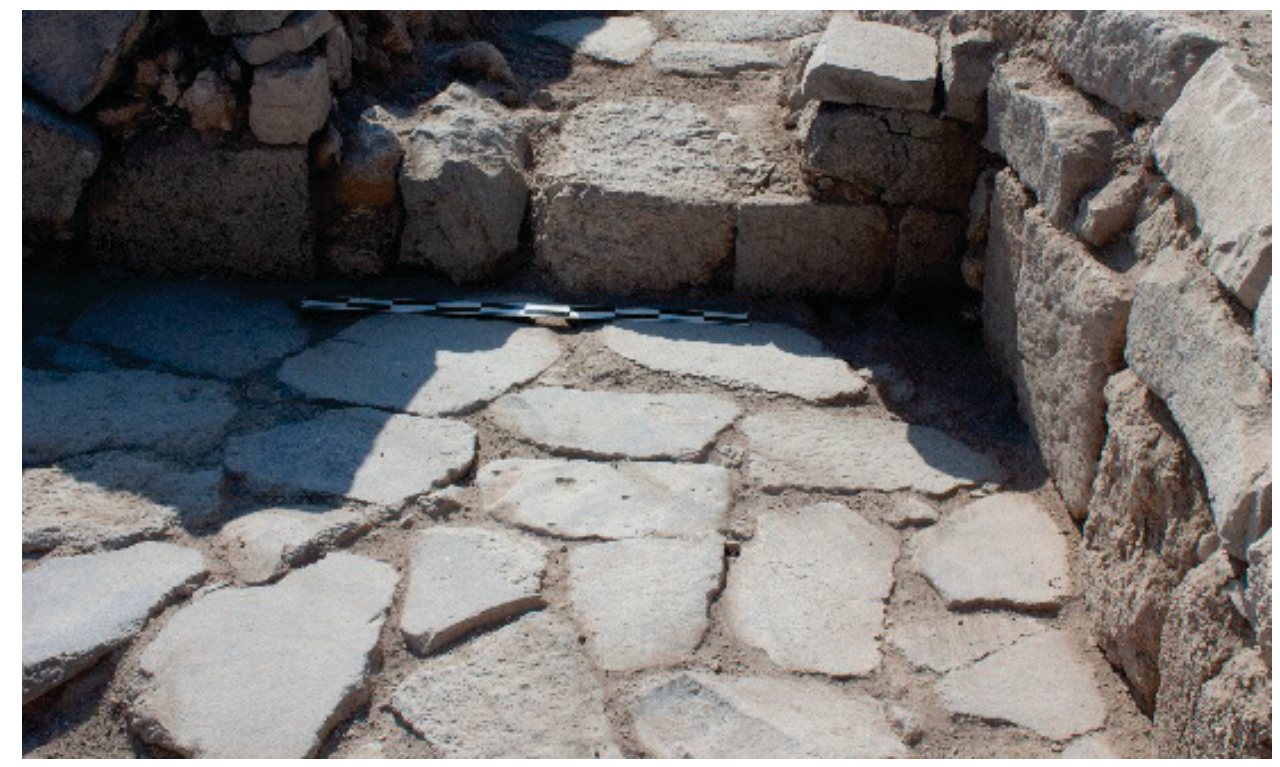

Figure 106 Flagstone floors (looking east)

Destruction fill suggests that an arch spanned from wall to column to wall. 


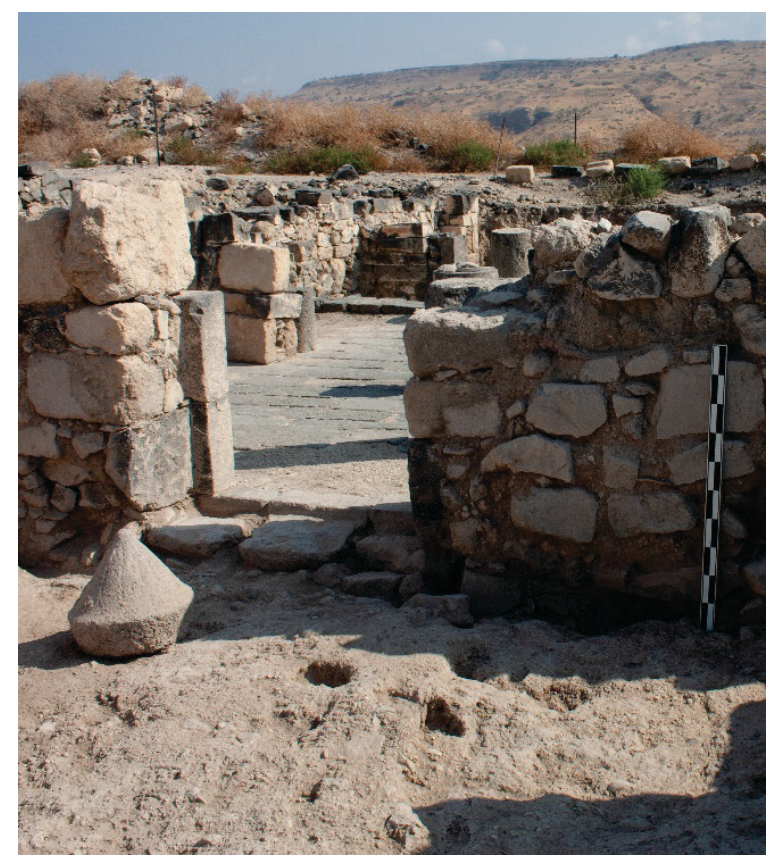

Figure 107 North "pilaster"

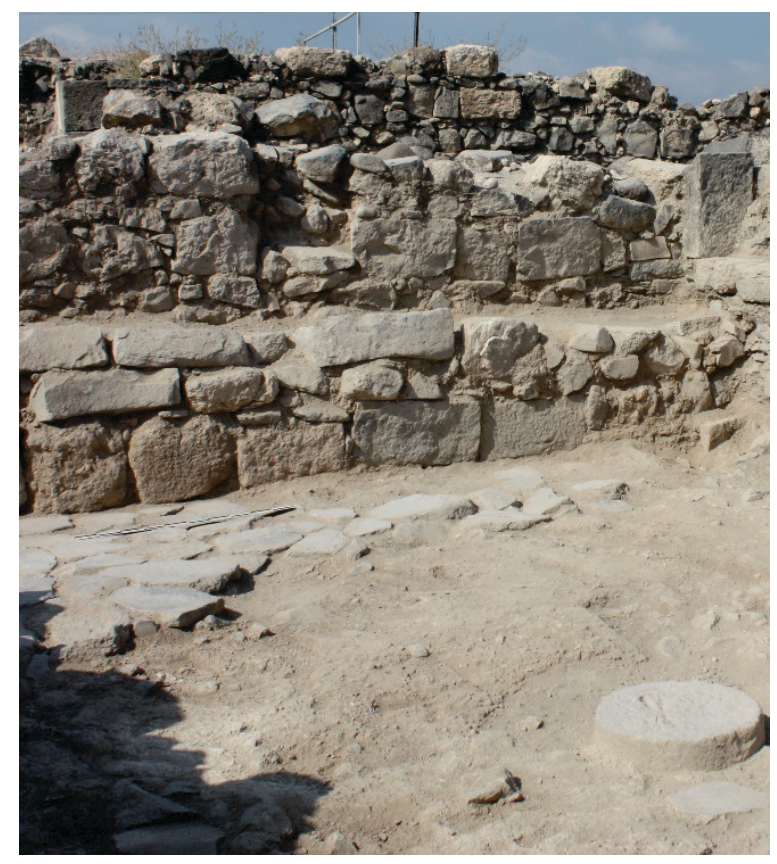

Figure 108 South notch

As it would be easier to cover the 2.2+ m gap with branches and mud than a gap of around $3.8 \mathrm{~m}$, we surmised that the arches went from north to south (from W1261 to the column base to W1288). Examination of the walls indicated a crude pilaster in W1261 just to the east of the doorway and there seems to be a notch in W1288 to receive the arch. The pilaster and notch are on a straight line with the column base.

\section{Ceramics and other small finds}

A heavy concentration of pottery shards was recovered from the middle portion of the central room near the column base about $15 \mathrm{~cm}$ above the floor. Most were Baysan jars (some restorable) and cooking pots. The collection included a restorable Late Antique funnel (larger than the Umayyad funnels found south of the Northwest Church in the wine vat area in previous seasons). Our field reading did not identify any distinctively Umayyad pottery in the collection.

An intact ceramic unguentarium (sixth century?) was retrieved next to the floor just to the right (east) of the north doorway. It is $20 \mathrm{~cm}$ in length.

Close by, two oil lamps were recovered intact from a small crevice next to the north doorway in W1261 on the right side. They were $6 \mathrm{~cm}$ in width, $9 \mathrm{~cm}$ in length, and $3 \mathrm{~cm}$ high. Field reading is Late Antique. One has beads around the filling hole. The other has a herringbone pattern on the shoulder and a round decoration between the nozzle and the fill hole. Further investigation suggests that these are so-called "North Jordan" lamps type, dated (mainly on stylistic criteria) to the late fifth and the sixth centuries CE. Their manufacturing 
center might have been Beit Ras (Capitolias of the Decapolis) where hundreds of them were found. ${ }^{105}$

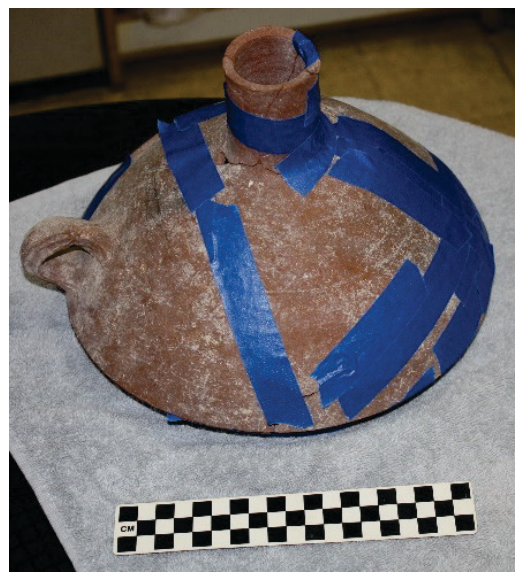

Figure 109: Byz funnel

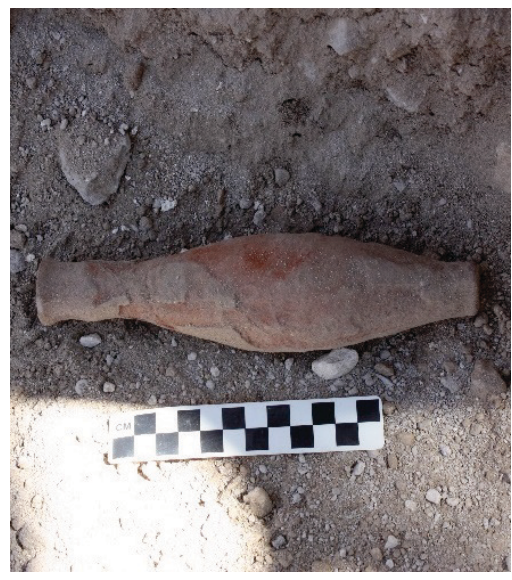

Figure 110: Unguentarium

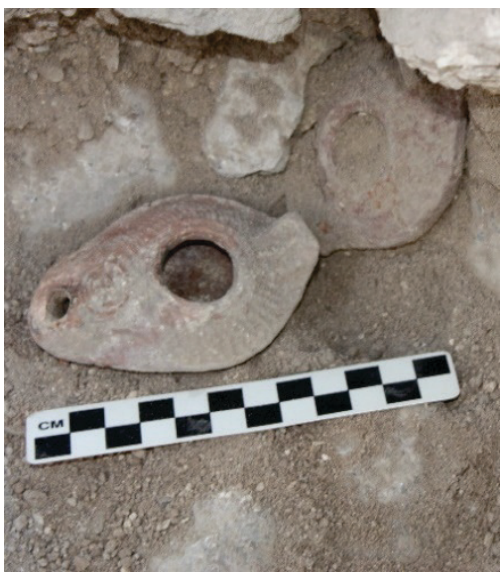

Figure 111: North Jordan lamps

Lastly, in the central room, an anta for an hourglass grinding mill sits inside the northerly door. It is like the two that sit outside the room in the peristyle court.

\section{Eastern storage room}

To the east of W2132, we excavated a second room that likely served a storage function. The storage room has an interior dimension of roughly $8 \times 3.1 \mathrm{~m} .{ }^{106}$

W1298 is the east boundary of the room. We discovered that the original W1298 (about 70 $\mathrm{cm}$ wide) has sitting on top of it a later wall (W2143, about $50 \mathrm{~cm}$ wide) that seems to be the west wall of a much later building set atop the ruins of the House of Tyche. W1298 survives to an elevation of about 132.35 . Approximately $70 \mathrm{~cm}$ of W1243 sits above. About $2.55 \mathrm{~m}$ of W1243 is visible. We also cleared about a meter of Cardo 4N east of W1298. In so doing, we identified the western wall of a building to the east (W2150) along with a small perpendicular wall blocking the cardo between W1298 and W2150 on the line of W1261. They are likely part of a much later agrarian complex build over the ruins of the site.

\footnotetext{
${ }^{105}$ K. da Costa, "Economic Cycles in the Byzantine Levant: the Evidence from Lamps at Pella in Jordan." Levant 42 (2010): 70-87.

${ }^{106}$ The interior lengths of the walls are:

$\mathrm{W} 1917$ is $3.02 \mathrm{~m}$

W2132 is $7.97 \mathrm{~m}$

W1298 is $8.06 \mathrm{~m}$

W2161 is $3.20 \mathrm{~m}$
} 


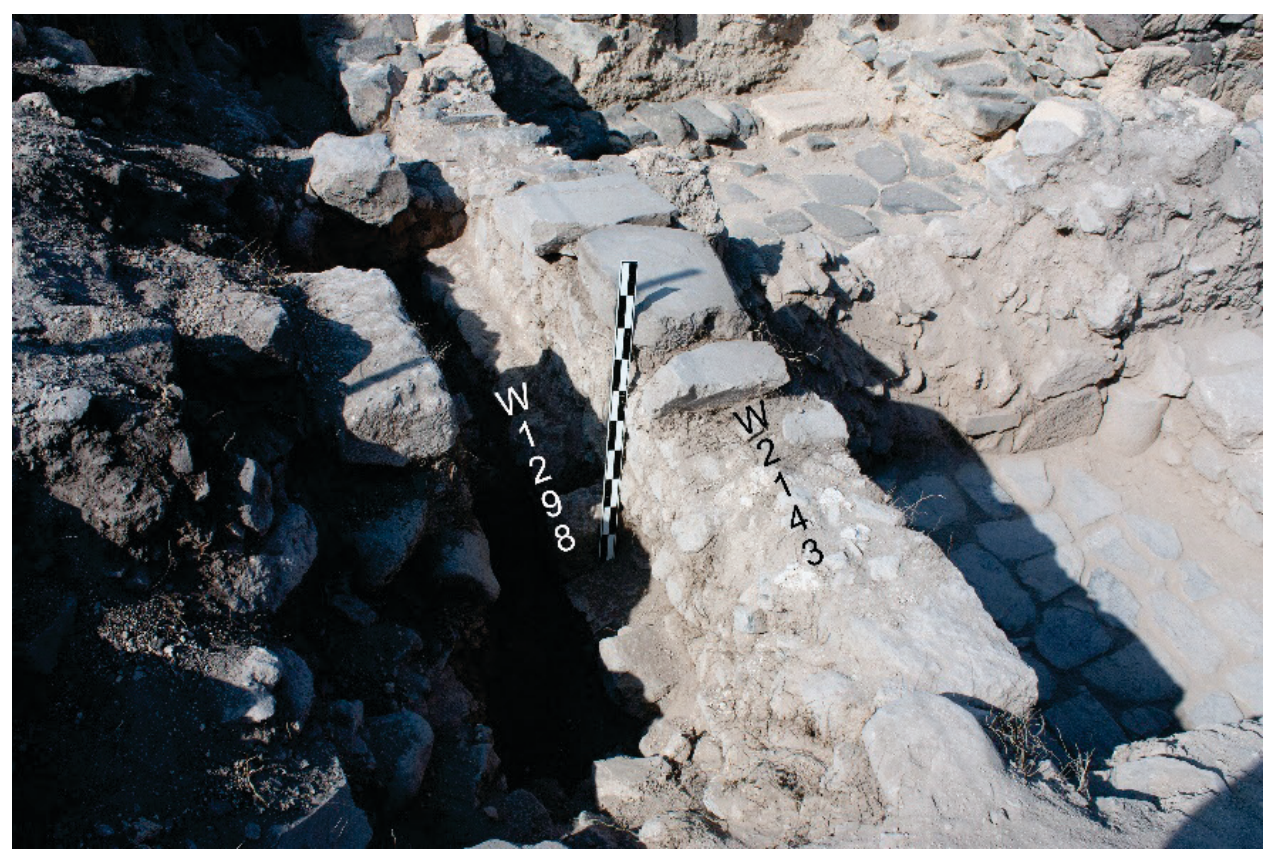

Figure 112 W2143 sitting on W1298 (looking south)

W1917 is the south wall of the eastern room and is of poor construction. It is a conglomeration of reused stones and architectural items (small column drums, the diameter of one is $56 \mathrm{~cm}$ and of another is $40 \mathrm{~cm}$ ). In the southeast corner, part of W1298 abuts W1917 and part penetrates it.

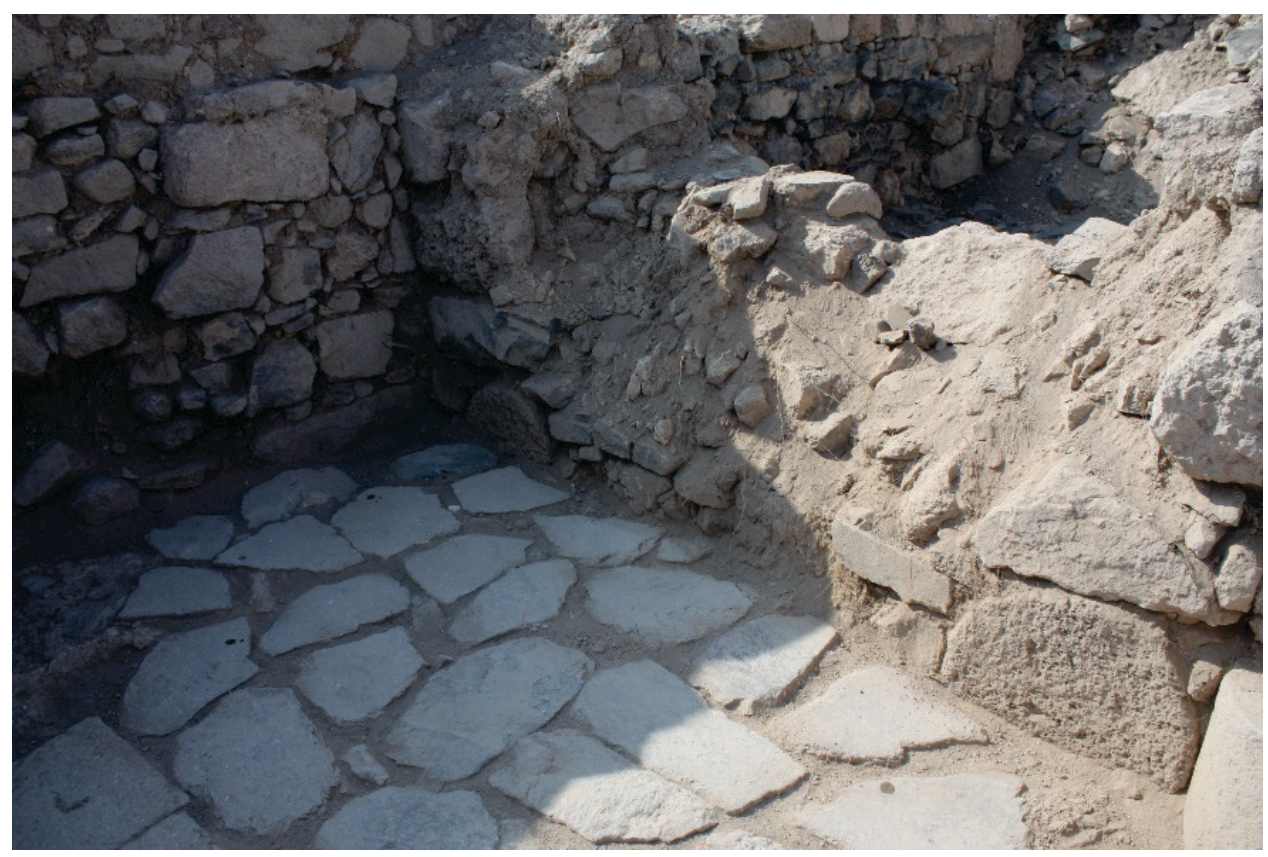

Figure 113 W1917 collapsing (looking southeast)

W2161 is the north wall of the eastern room. It was modified from its earlier use by the blockage of a substantive doorway to the spaces to the north. As this blockage was smooth 
on both faces, the blockage was functional for the final phase and not part of decommissioning the structure.

In this eastern room, a deposit of glass in layers was discovered next to W1298 about $1.2 \mathrm{~m}$ from W1917 at an elevation of 131.39. The layer was very fragile and shattered. After gentle exposure, it appeared to be a crushed bowel (three sections alternating concave and convex).

The floor of the storage areas is paved with irregular flat stones that fit together loosely. The paving is most consistent and tightly fitting in the center of the room and toward the southwest doorway, reinforcing the idea that the room was used for storage. Large quantities of Baysan jar fragments confirm the hypothesis. An almost complete oil lamp was recovered on the floor near the middle of W2132. It is parallel to a type reported from Bet Shean from 5-6 CE and almost early 7 CE. ${ }^{107}$

\section{Cistern room}

Just as the eastern storage room was separated from the central room by a window wall, so to the west two rooms are separated from the central room by a second parallel window wall. The southerly of the two rooms is the cistern room.

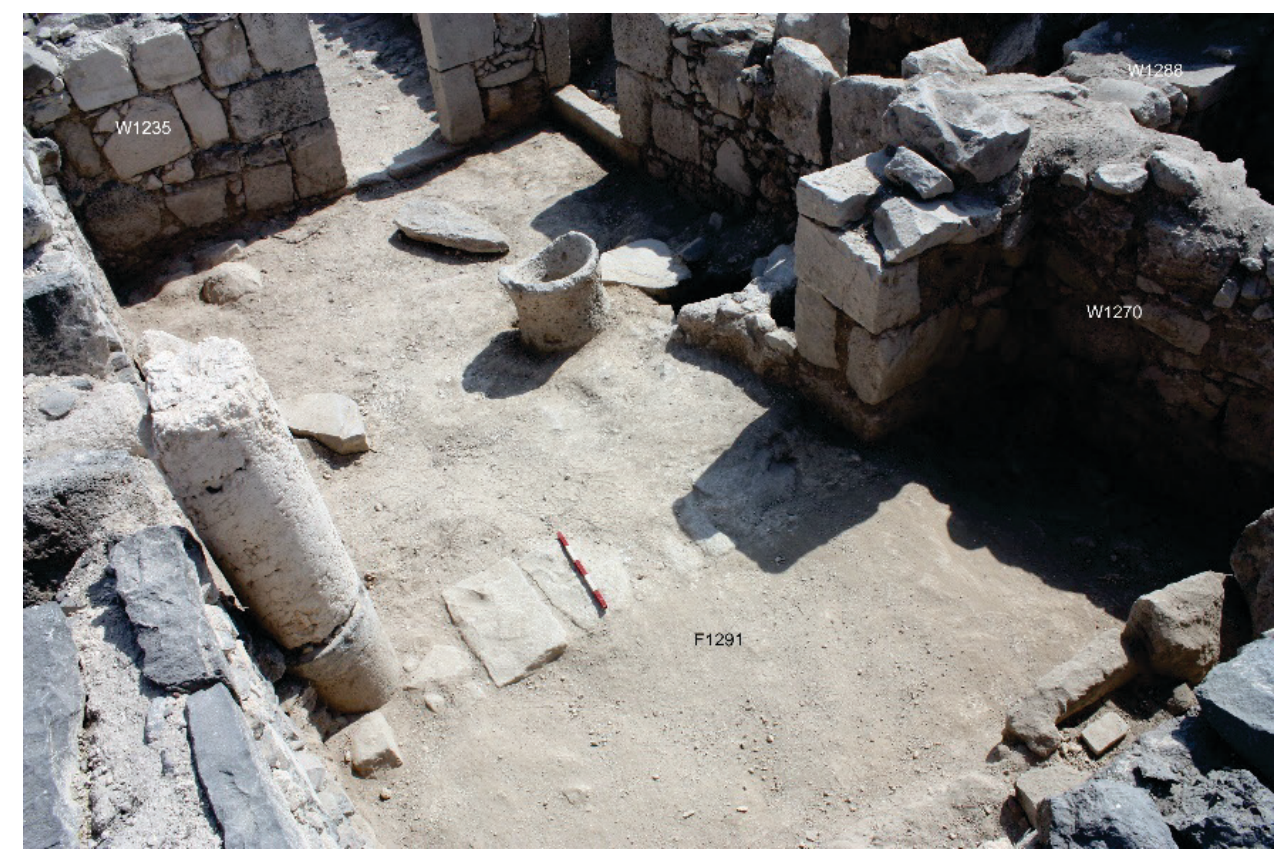

Figure 114 Cistern room (looking north)

The room is $6.75 \mathrm{~m} \times 3.68 \mathrm{~m}$ and is subdivided into two sections by a crude stylobate with a pilaster to the east and a column to the west next to W1230. The room has an exterior door

\footnotetext{
${ }^{107}$ Hadad 2002, p.65 Type 25 (n.281).
} 
facing the street. There are two additional doors to the cistern room from a room to the north and from the central room. The exteriors of both doors faced the cistern room.

In the southern section of the room, a crude bench about $40 \mathrm{~cm}$ tall runs the width of the room next to W1236. On hard-packed floor (F1291) of this part of the room was a heavy deposit of Late Antique common-ware sherds including pieces of the shoulder of a late Roman amphora (form LRA1) with Greek writing (dipinti). ${ }^{108}$ As the northwest corner of W1236 $6^{109}$ is slightly offset to the east from the line of W1230, W1230 marks the southerly extent of the House of Tyche east of the domus of the Northeast Church on the east side of Cardo 3 North.

In the northern section of the room, the floor was degraded and removed to the level of its stone base. In the southeast of this section next to the pilaster is Cistern G.

\section{Niche room}

To the north of the room with the cistern is a small room $(3.5 \mathrm{~m} \mathrm{x} 4.2 \mathrm{~m})$. The room abuts the apse of the church and has a platform (likely for sleeping) next to the apse.

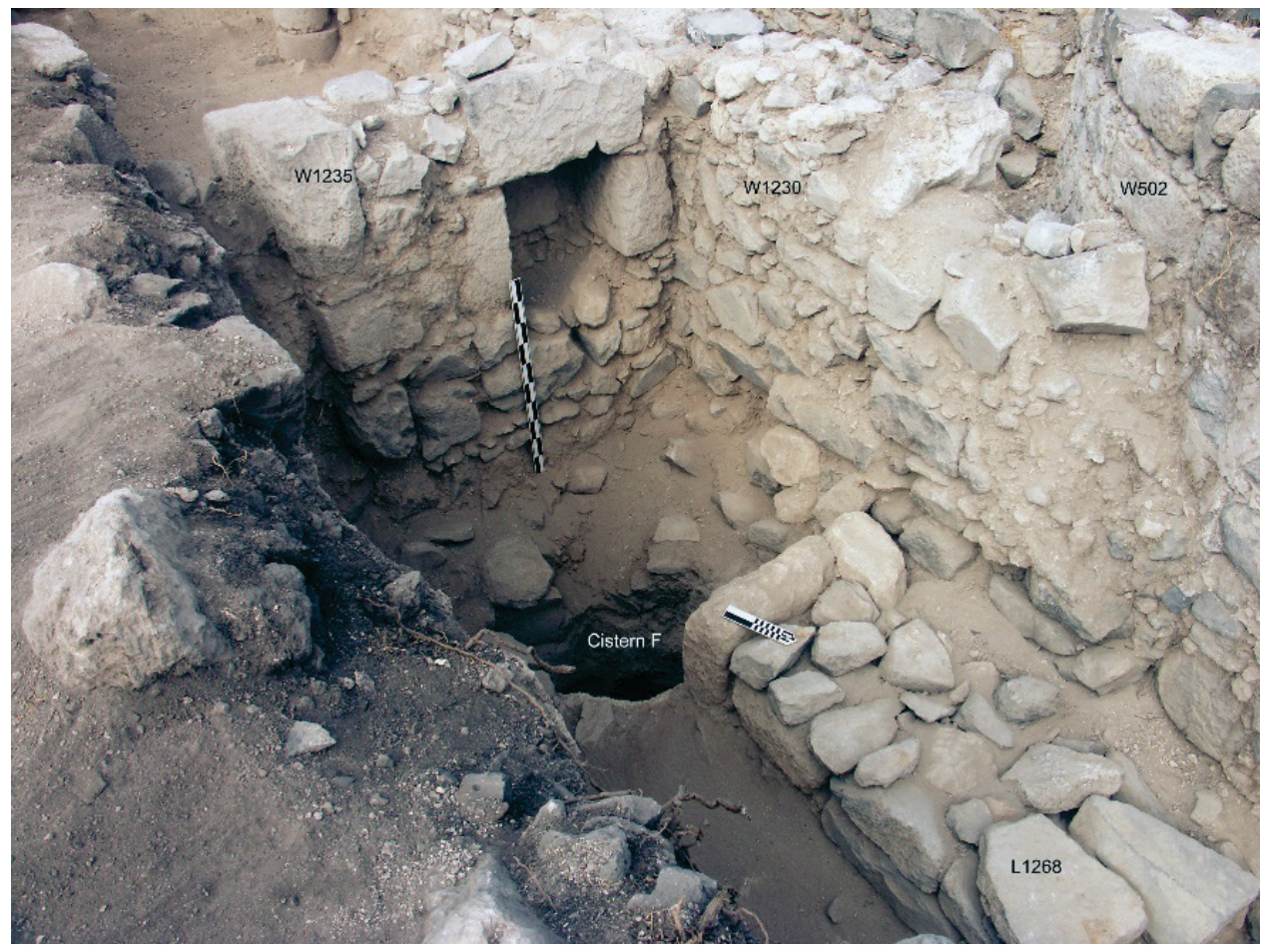

Figure 115 Niche and Cistern F (looking south)

\footnotetext{
${ }^{108}$ Kristina Neumann, "The Dipinti of the North-East Church Complex," in Hippos-Sussita : Tenth Season of Excavations : July and September 2009, ed. Arthur Segal (Haifa, Israel: Zinman Institute of Archaeology, University of Haifa, 2009), 80-83.

${ }^{109}$ W1236 is the northerly wall of a later structure tentatively identified as an Umayyad farmhouse in Segal et al., HipposSussita : Eighth Season of Excavations : July 2007, 87.
} 
There is a niche in the south wall. Doors allow exiting the room to the north or to the south. Both doors were locked from inside the room. The floor of the room (F1284) is mud/plaster on cobbles and slopes to the north. The first course of a bench survives at floor level next to the east wall. The southern threshold is at elevation 130.77 . The northern threshold is at 130.41 .

The function of the room is uncertain. It could be a dwelling or monastic cell for a member of the community. Or, as the diakonikon could have served as an infirmary for the public, this room could have served the health care needs of the monastic community.

Below the level of the floor in this room is the remnant of a small cistern (Cistern F).

\section{Structures built over the southern section of the House of Tyche}

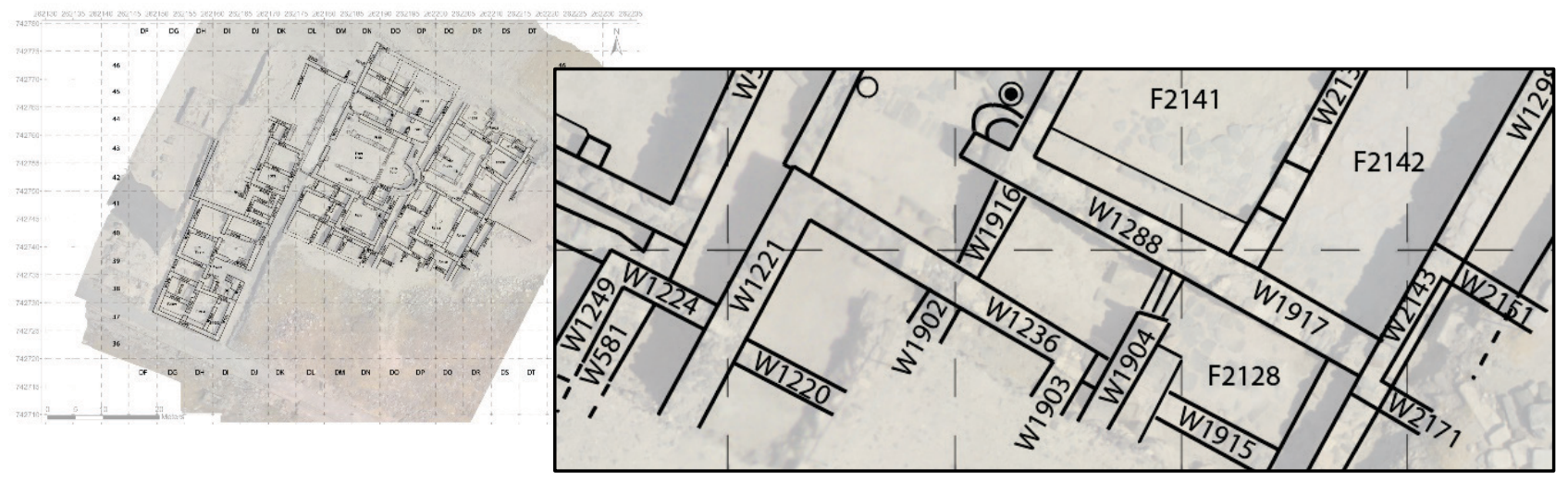

Figure 116 Additional structures

A single-room domestic residence

East of the cistern room and south of W1288 is a small room. This room has an interior dimension of $2.20 \mathrm{~m}$ from north to south and $3.30 \mathrm{~m}$ from east to west. It is bounded on the north by W1288, on the east by W1904, and on the south by W1915. On the west is W1916, a poorly built wall that spanned the gap between W1288 and W1915. W1236 of a later building was constructed over the line of W1915 and destroyed most of the south end of W1916. W1904 has a $77.5 \mathrm{~cm}$ doorway closed by a $90 \mathrm{~cm}$ door from inside the room. The doorway is $30 \mathrm{~cm}$ from W1288. The floor is packed earth with some plaster mixed in. Several nail fragments were discovered near floor level in the room. Stones protruding from the surviving top of the south face of W1288 at the east end of the room may hint at a low roof or platform, although this ledge is located problematically just inside the doorway. 


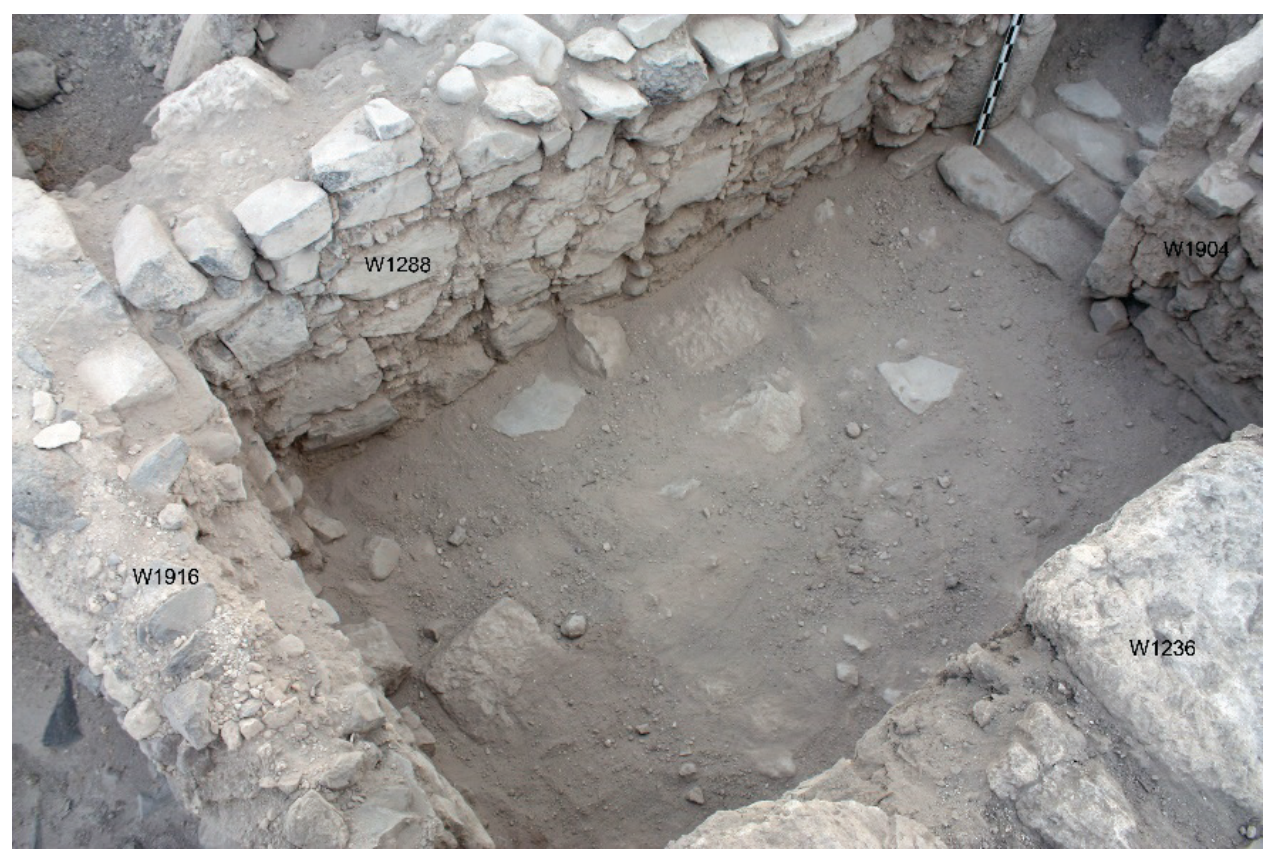

Figure 117 Domestic space (looking northeast)

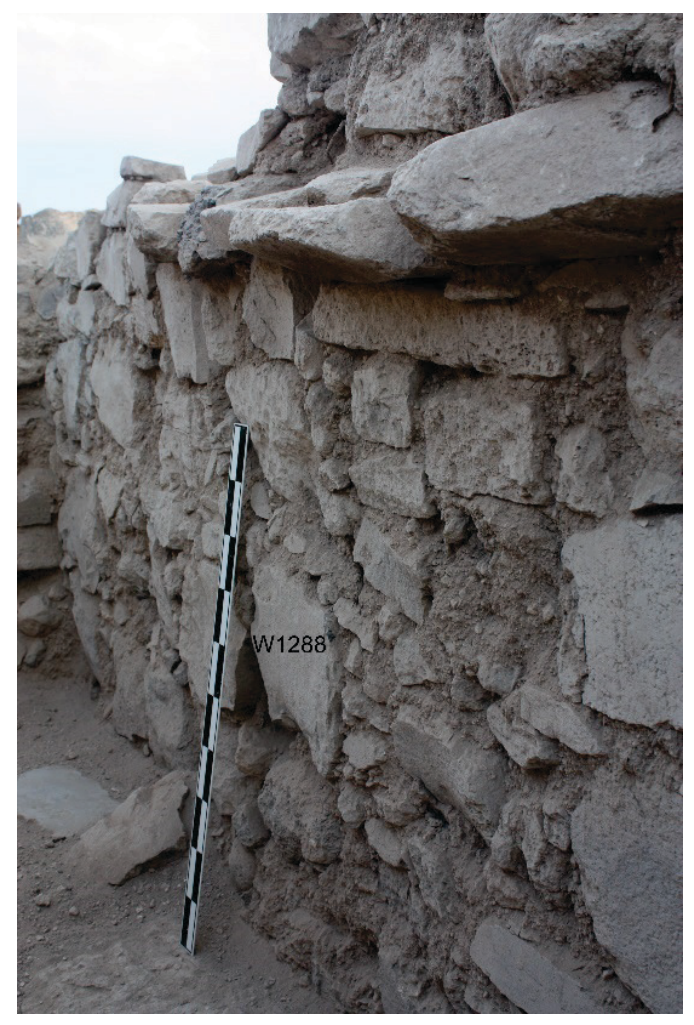

Figure 118 Supporting protrusions/corbels (looking west)

The function of this domestic space may be hinted at by the small finds discovered in and near the room at floor level. In the room there were some large pieces of Baysan jars, some cooking ware dating from 350-600 CE, and a partially restorable amphora. A coin and a fibula were also retrieved from the floor. $16 \mathrm{~cm}$ east of the entrance to the room and $17 \mathrm{~cm}$ 
south of W1917 we recovered a horde of pottery, glass, bronze, and bone on the crudely paved surface of a courtyard. The pieces of this horde were hidden behind a broken but restorable storage jar.

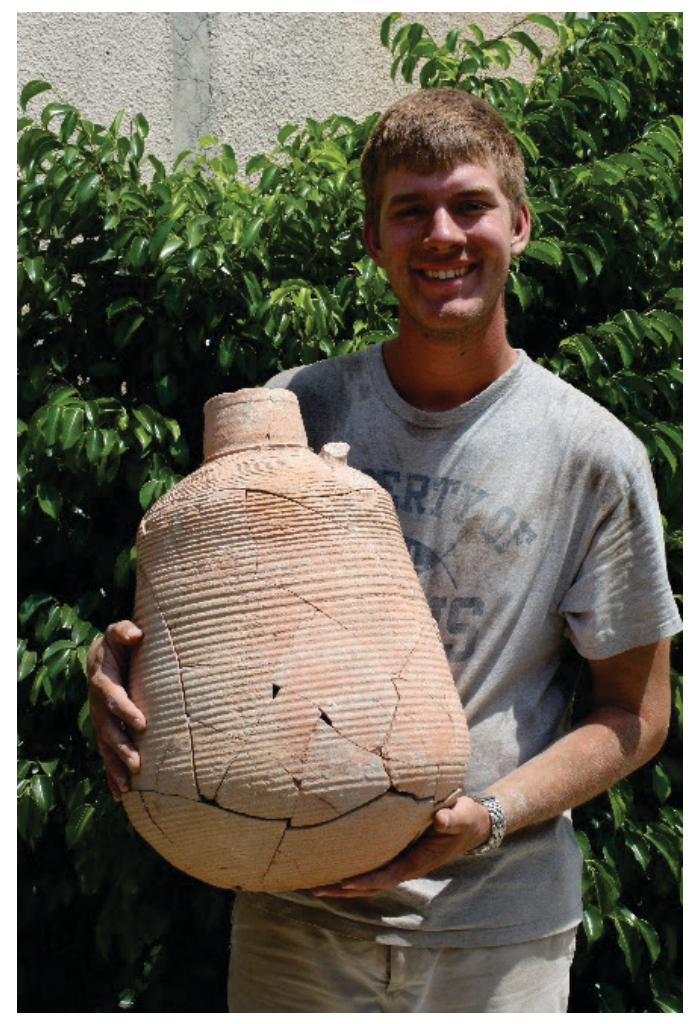

Figure 119 Storage jar

The horde included two bottles, a glass lamp or beaker, a figure carved of bone (dancing maenad), a scarab, a glass ring, and a bronze pitcher with an iron handle (see below for a more detailed discussion). The finds are luxury items of a domestic sort.

\section{Courtyard of a small residence}

East of the small residence is a crudely paved courtyard. W1915 continues to the east of W1904 and another wall (W1917) also continues east of W1915 roughly on the line of W1288 but slanting slightly to the south.

The northern wall is of poor quality and comes from a later time than the House of Tyche, as it blocks access to the rest of the house. Only the foundation course of the south wall (W1915) of the peristyle house remains. A threshold is in situ in the wall, indicating that there was a door from the house to the south. The threshold is $53 \mathrm{~cm}$ wide and begins 2.58 $\mathrm{m}$ from W1298. $83 \mathrm{~cm}$ of the threshold is visible. The rest is covered by a plastered basin. 


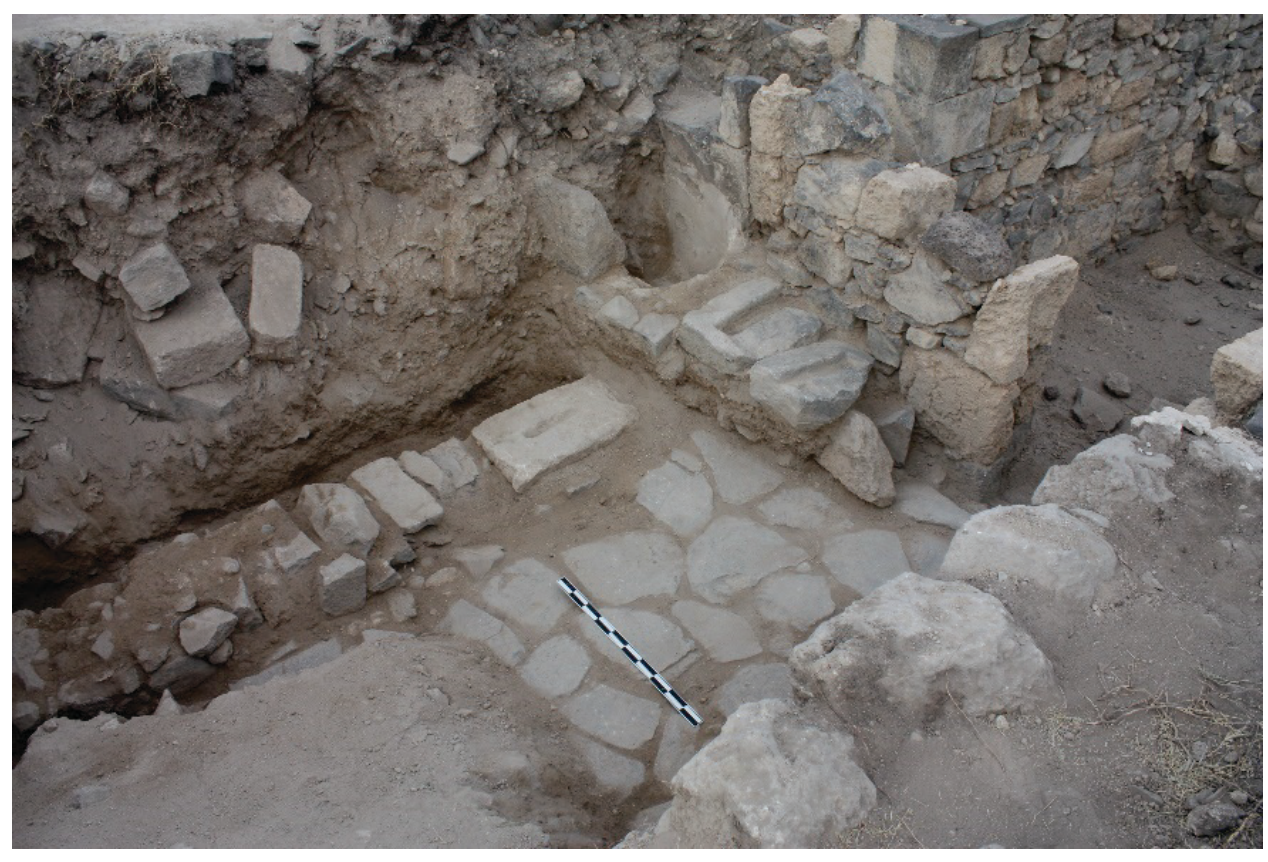

Figure 120 Southeast room (looking southwest)

A plastered basin sits in the southwest corner of the area overlaying W1915. The basin curves to a flat bottom and continues to the south into the balk. The basin is preserved to a depth of $90 \mathrm{~cm}$ next to the wall (W1904). It is $41 \mathrm{~cm}$ east to west and more than $65 \mathrm{~cm}$ north to south. It is preserved to a height of $26 \mathrm{~cm}$ to the north. Two fragments of a threshold are placed, seemingly intentionally, against the north side of the basin. A double headed ax $(16.0 \times 21.0 \times 2.5 \mathrm{~cm})$ missing one of the heads was recovered near the basin along with a large gastropod likely from the Red Sea and indicating importation.
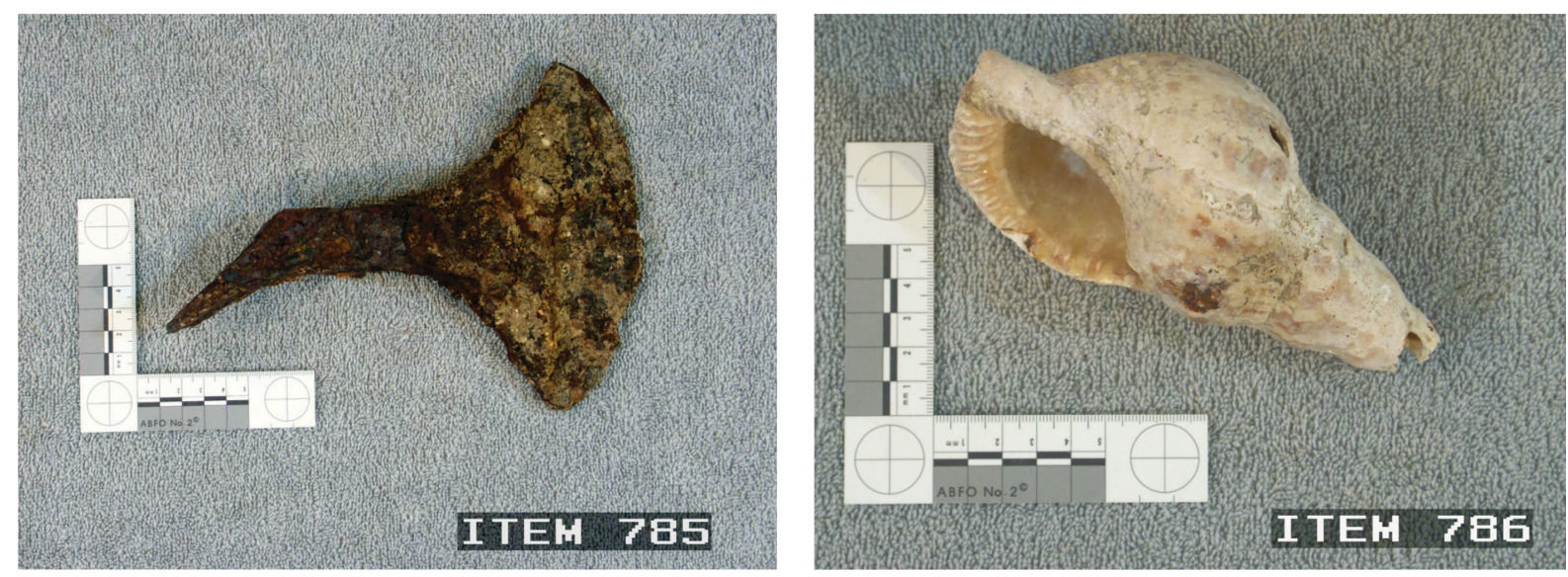

Figure 121 Items from southeast corner of House of Tyche

The entire space is roughly paved with flat basalt pieces, but at an elevation higher than the threshold in W1904. The paving seems to come from the same phase as W1917. There is a bench next to the east wall (W1298). 


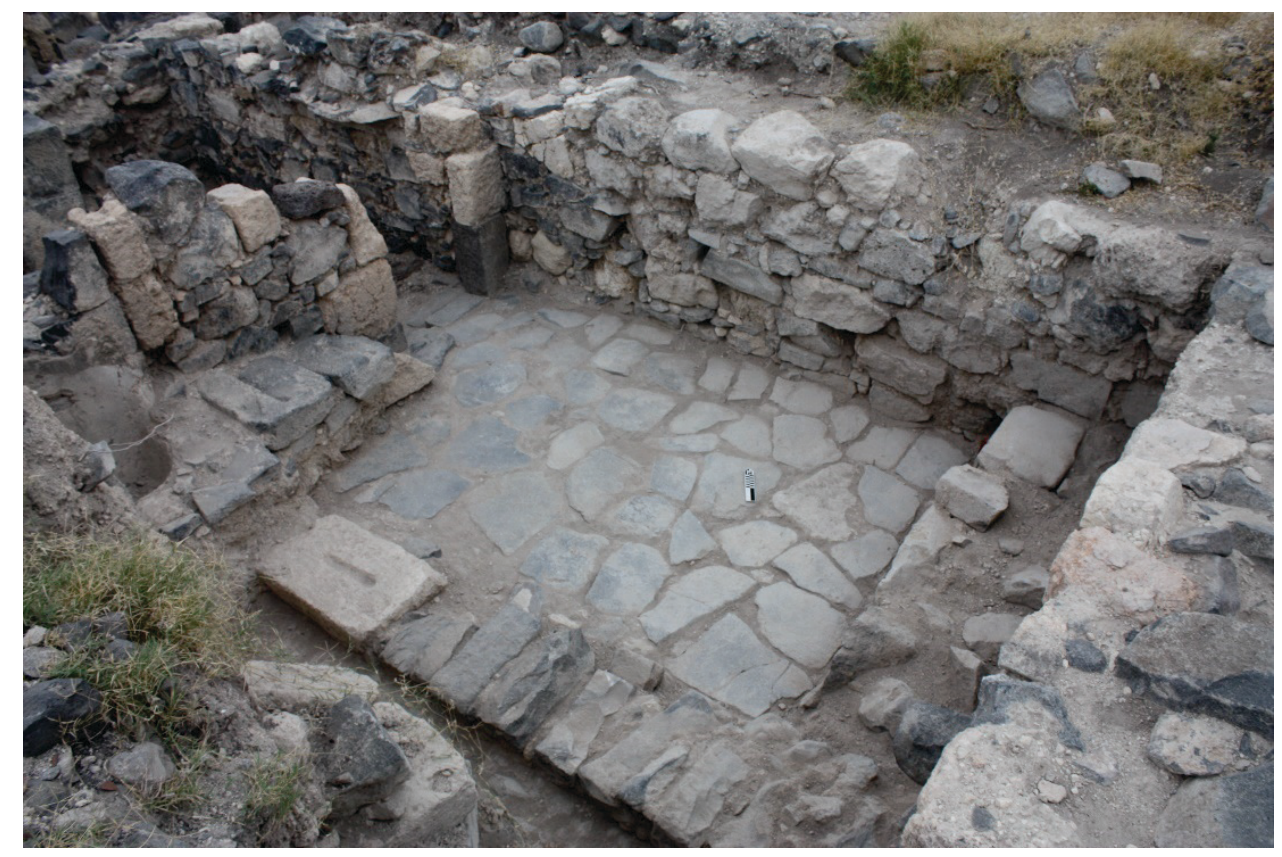

Figure 122 Southwest corner and bench (looking northwest)

The ceramic assemblage is the courtyard dated from the sixth century to the eighth century $\mathrm{CE}$. The deposits were heavy, mostly medium sized fragments of cooking vessels and Baysan jars with a large quantity of handles, several Phocaean Red Slip wares and an African Red Slip rim. Indicative wares included Phocaean Red Slip form 10A from late sixth - early seventh CE and form 10C from early seventh CE, a late BYZ - UMM casserole, Phocaean Red Slip form 3F from sixth CE, an oil lamp made of buff material from fourth - sixth CE. We recovered two restorable Baysan jars next to the north wall. Against the base of the bench next to the north wall of the courtyard, we recovered a small amphora $(9 \times 25 \mathrm{~cm})$ nearly intact.

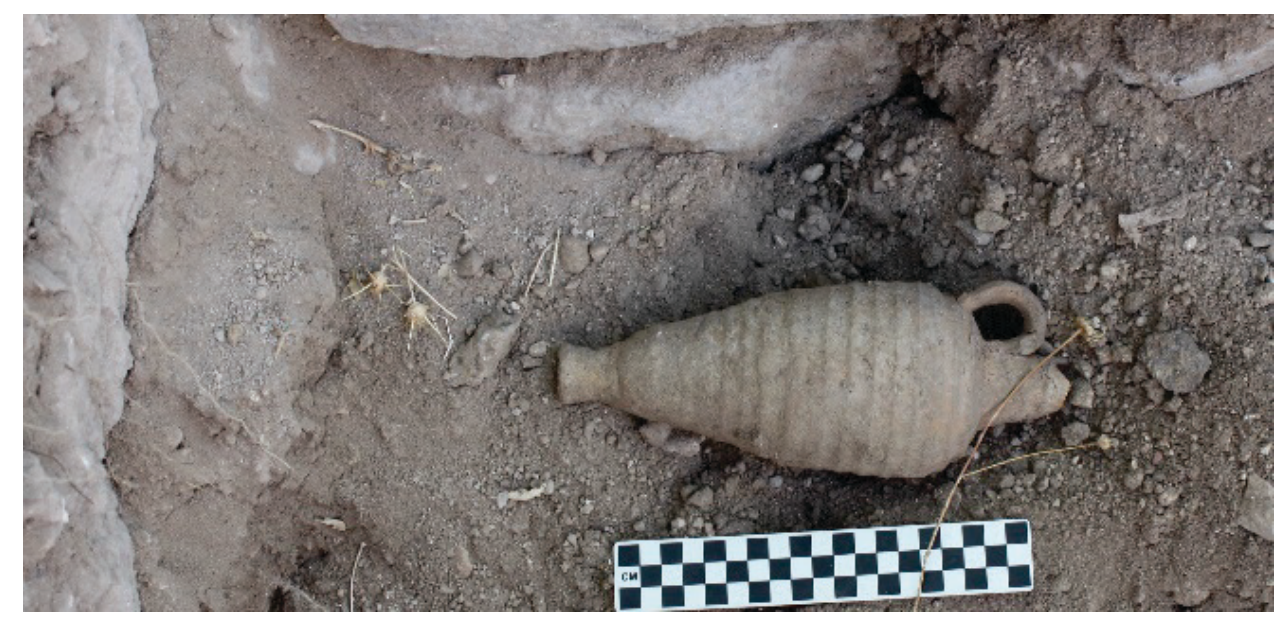

Figure 123 Small amphora 
The domestic space and the crude courtyard with a bench were not part of the original House of Tyche but were built into and over the ruins of its southeast corner of the house.

This space has three phases: the original late Roman House of Tyche abandoned in the late fourth century, a small domestic structure of one room and a courtyard and a bench to the east from the Late Antique period, and a later structure (Umayyad or possibly post-749) built on top of the ruins.

\section{Umayyad building}

Surviving to a much greater height and built over the foundation and surviving courses of the southern wall of the House of Tyche is a later building that has not been fully excavated. The building sits atop the southeastern corner of W1230. Its northwesterly corner is the junction of W1221 and W1236. The northeast corner of this later building is $40 \mathrm{~cm}$ west of W1904 and is formed by the intersection of W1903 and W1236. 2.5 m west of W1903 is another wall of the later building (W1902). It follows roughly the same line as W1270 and W1916. The building also has at least two rooms for the portion exposed to date is bisected by W1220. Perpendicular to W1221 is W1224. It proceeds to the west and forms a corner with W1229. The similar elevations of these and other floating walls around the church complex suggest poor village or agrarian usage of the area after the decline of the Northeast Church complex. A pottery reading of the material from inside the later structure shows Umayyad shards. The latest pottery from the fill in the earlier building and the last levels of Cardo 3 North is Late Antique. Consequently, we identify the building created by W1221 and W1236 as a Umayyad structure (farmhouse?) and suggest that the many poorly constructed floating walls around the Northeast Church may be part of its agricultural complex built employing the ruins of the site after its abandonment until (and perhaps after) the earthquake of 749 CE.

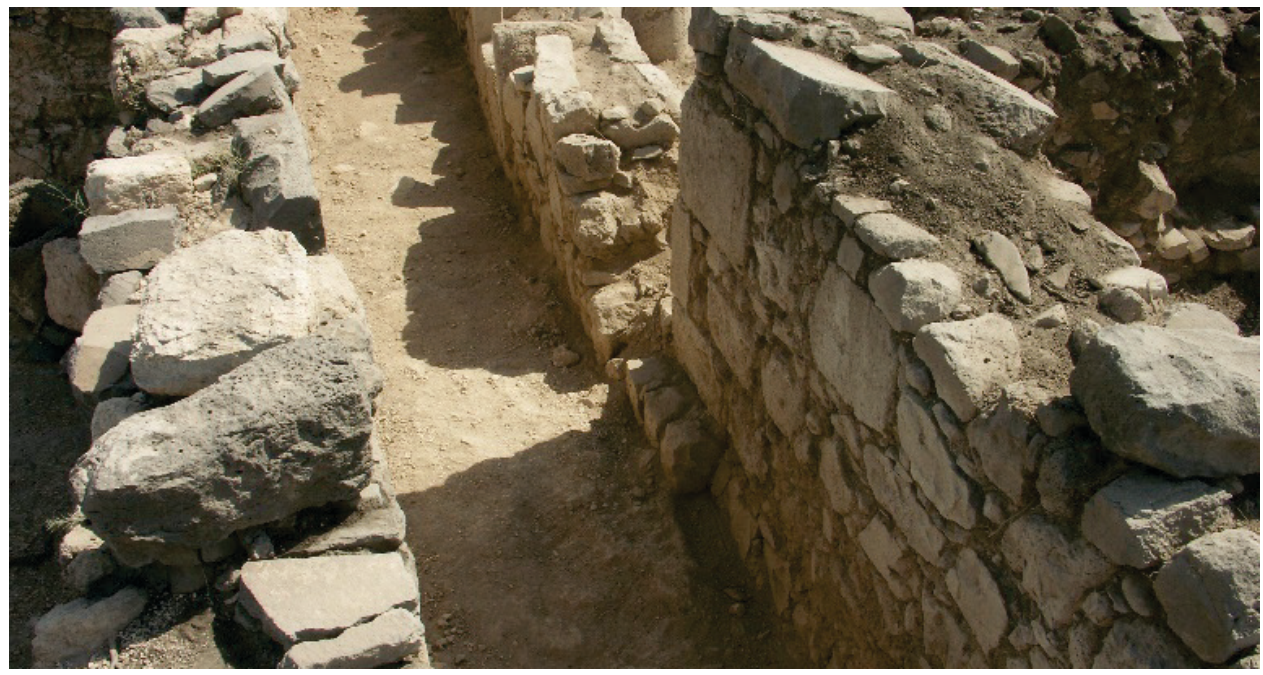

Figure 124 Umayyad structure on the corner of W1230 (looking north) 


\section{Western Zone}
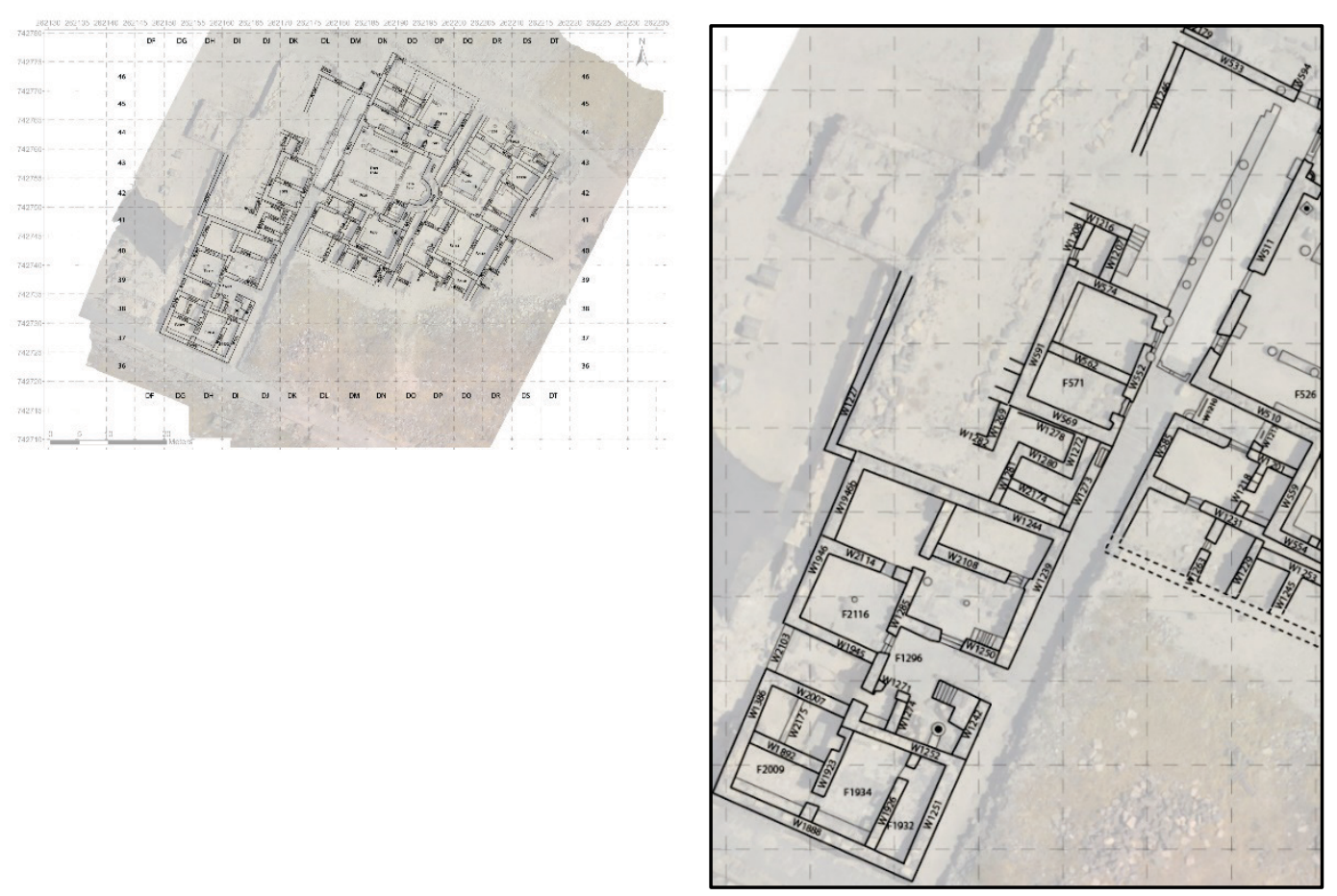

Figure 125 Structures in the western zone

\section{Via sacra and paved plaza}

A paved street proceeds south from the southern gate of the church complex to the decumanus maximus. Designated as Cardo 2 North on the master site plan, this street may have functioned as a via sacra for visitors to the venerated tombs in the Northeast Church complex. ${ }^{110}$ Its full length of $34.3 \mathrm{~m}$ slopes down $2.17 \mathrm{~m}$ from the main gate of the church to the decumanus maximus (elevation 130.83 to 128.66), a slope of about $8 \mathrm{~cm}$ per meter.

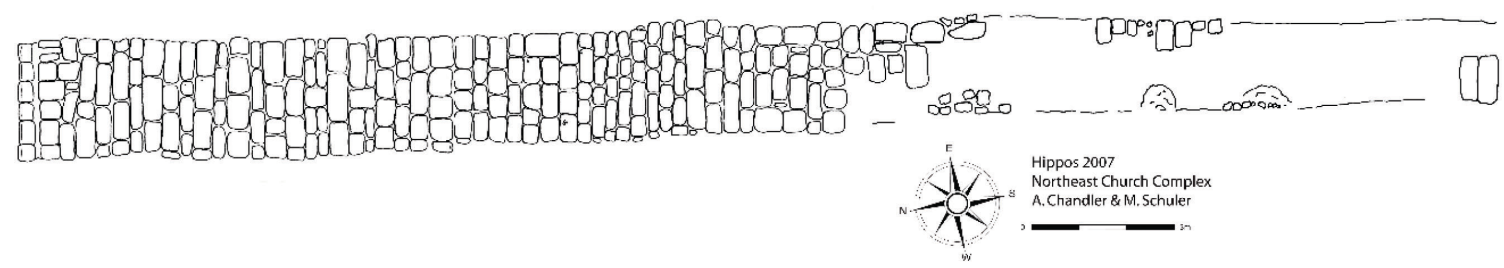

Figure 126 Drawing of Cardo $2 \mathrm{~N}$

\footnotetext{
${ }^{110}$ In a Roman context, one would expect a via sacra to follow a route through the necropolis to a central shrine. The practice continued in Christianity. For example, the tomb of St. Crispine of Thebeste is approached by a via sacra entered through triumphal arches. Jürgen Christern and Eckhart Müller, Das frühchristliche Pilgerheiligtum von Tebessa: Architektur u. Ornamentik e. spätantiken Bauhütte in Nordafrika (Wiesbaden: Steiner, 1976).
} 
The street narrows over its length from an approximate width of $2.4 \mathrm{~m}$ at the gate of the church to approximately $1.75 \mathrm{~m}$ at the junction with the decumanus maximus. ${ }^{111}$

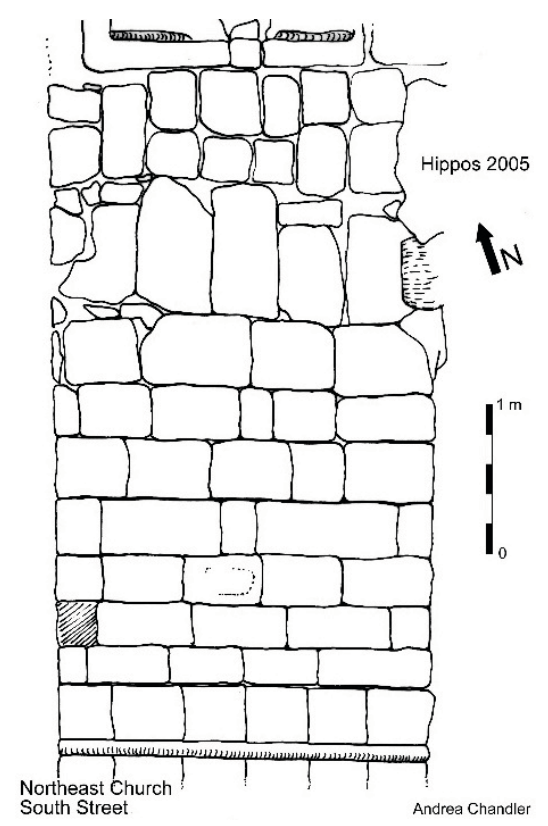

Figure 127 Street south of the portico

The initial courses of basalt pavers south of the southern gate of the church are irregular, either suggesting that the street was repaired or more likely the later insertion of the threshold into a pre-existing pavement. Subsequently the courses average 40 to $50 \mathrm{~cm}$ in width.

As pavers abut the walls of buildings on both sides of the street, the pavers may have been laid after the walls were constructed.

$3.95 \mathrm{~m}$ south of the threshold, the paving of the street changes. A $1.0 \mathrm{~m}$ wide section of paving has a rounded channel cut in it that flows from east to west. The channel is $11 \mathrm{~cm}$ wide and $5 \mathrm{~cm}$ deep. It flows from under the unidentified building to W552 and proceeds under that wall for $24 \mathrm{~cm}$. The channel empties into a cistern (Cistern C). The oval opening of the cistern is $44 \mathrm{~cm}$ east to west and $57 \mathrm{~cm}$ north to south. There is no surviving head for the cistern.

${ }^{111}$ A street of this size might be more properly called a semita or an angipontus. Daniel Sperber, The City in Roman Palestine (New York: Oxford University Press, 1998), 103. 


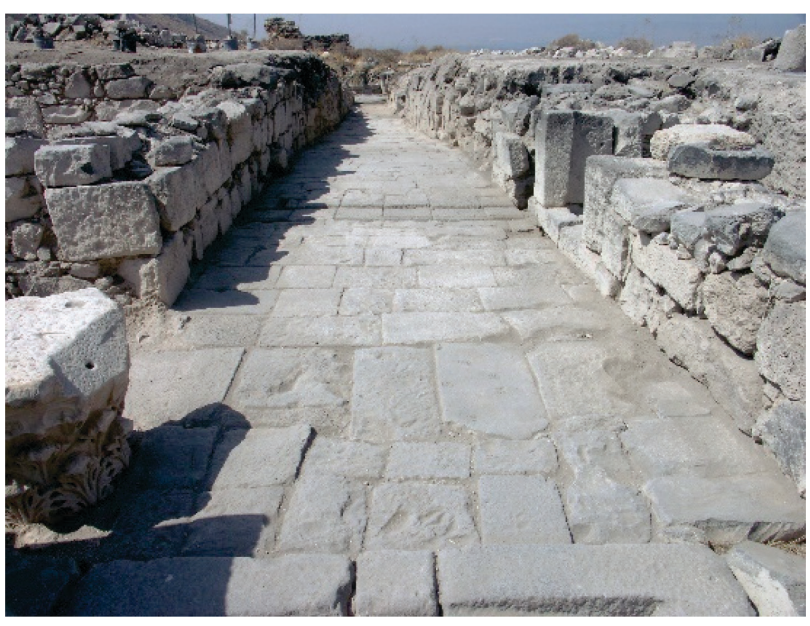

Figure 128 Cardo 2N (looking south)

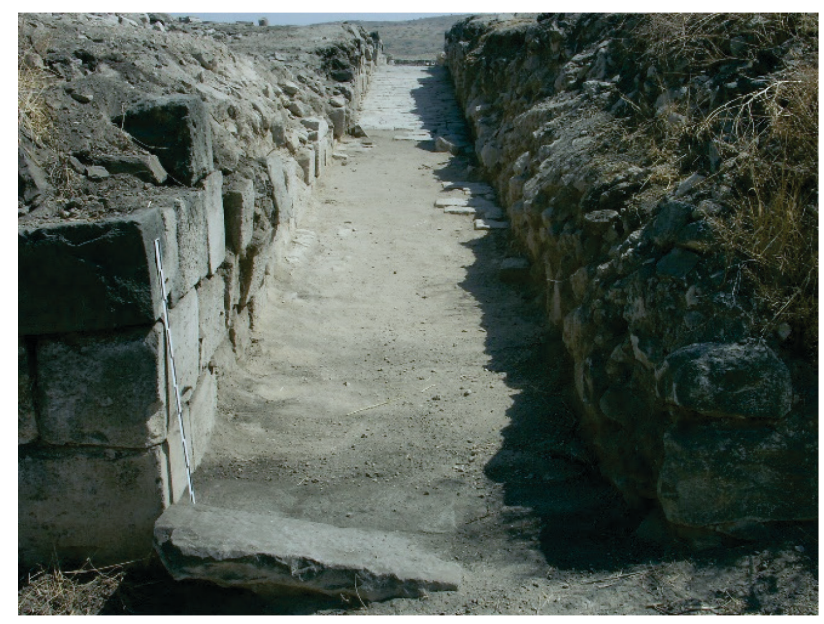

Figure 129 Entrance to Cardo 2N (looking north)

$18.65 \mathrm{~m}$ south of the south gate of the church, several large blocks sat on about $20 \mathrm{~cm}$ of packed soil on a perpendicular line bisecting the street. Their alignment suggests a crude wall blocking the roadway. Of significance is the intact nature of the street north of the "blockage" and its poor condition (most pavers robbed out) south of the blockage. The blockage came quite late in the occupation of Hippos relatively speaking. The blockage suggests a significant shrinkage in the size of the town, and yet may attest to a memory of the sacred nature of the Northeast Church complex that necessitated some protection.

About 11 meters south of the church gate, the east side of the street is no longer bordered by ashlars. Crude stone walls and destruction tumble form a boundary to the decumanus maximus. On the northeast corner of the junction with the decumanus maximus, there seems to be a building wall of $4.9 \mathrm{~m}$. But the construction is quite crude.

On the west side of the street are two block buildings (Alpha and Beta). The northern building (Beta) has a westerly face of 10.9 meters that is preserved to a height of four to five courses in places. It is located $9.75 \mathrm{~m}$ from the gate of the church complex.

The southern building (Alpha) sits on the northwest corner of the junction of Cardo 2 North and the decumanus maximus. $12.9 \mathrm{~m}$ to the west of the cardo is the southwest corner of the building. The south wall is constructed of ashlars that are three to five courses high, as the decumanus slopes down to the west. The easterly face of the building is $11.9 \mathrm{~m}$. 


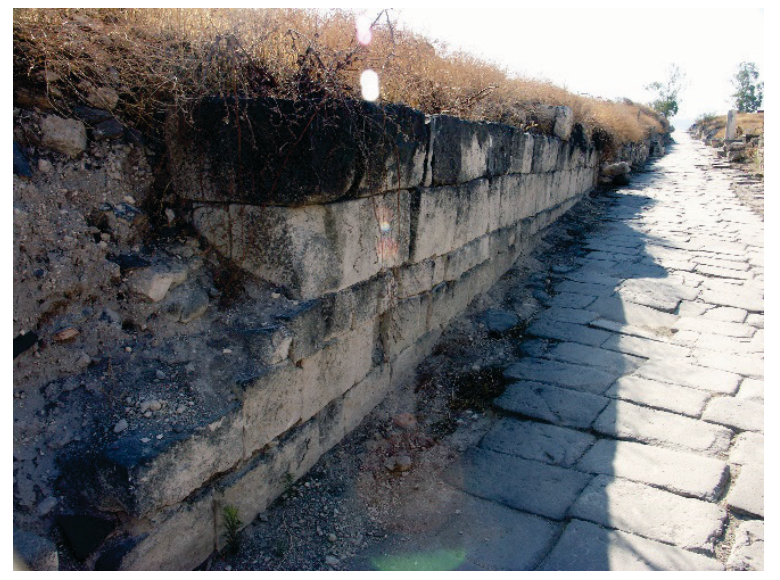

Figure 130 South face of Building Alpha (looking east)

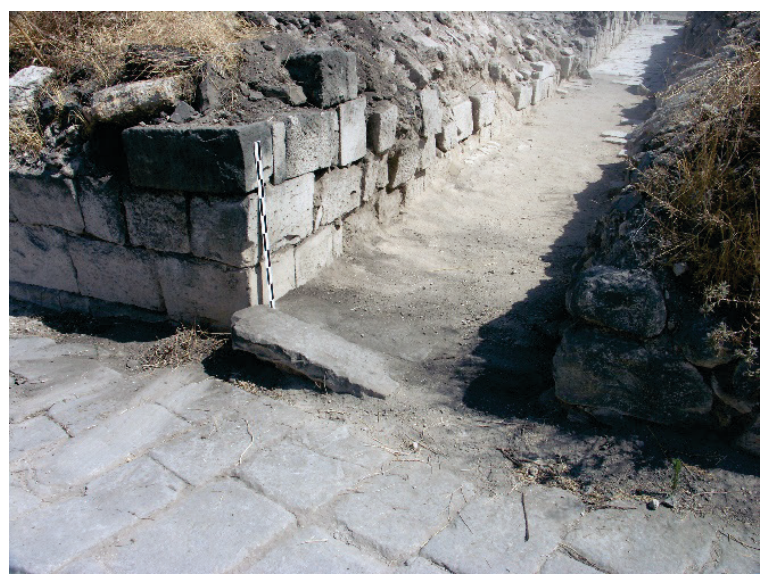

Figure 131 East face of Building Alpha (looking north)

Between the two buildings was a gap of $1.75 \mathrm{~m}$.

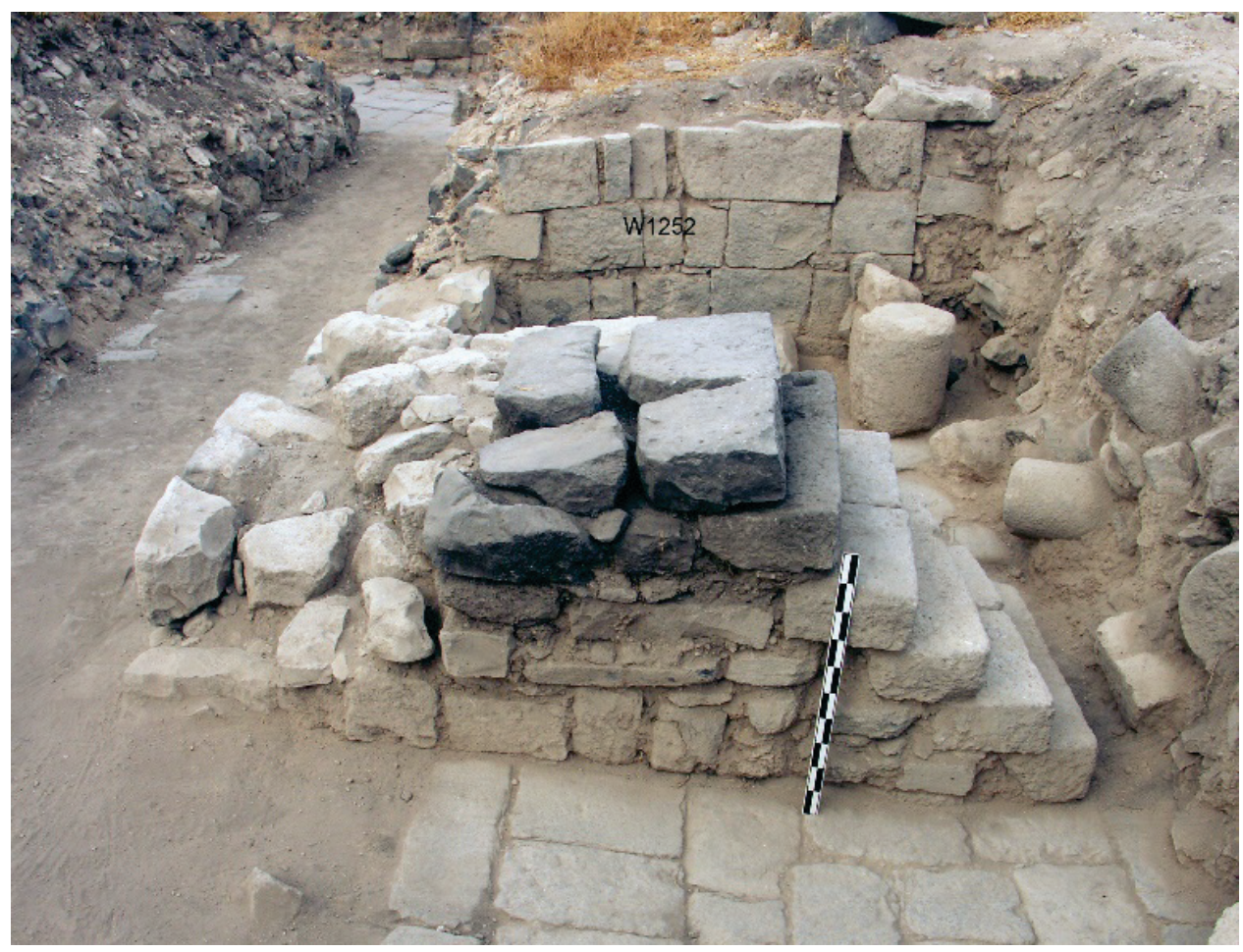

Figure 132 Stairs on paved surface (looking south)

In that gap is a paved surface upon which an L-shaped staircase had been built giving access to a second level of the southerly block building. The surface is paved with ashlars like those of Cardo 2 North. The paved surface spans the distance between the two block buildings (almost $6 \mathrm{~m}$ ).

A staircase sits atop the paved surface. Its northerly face is $2.1 \mathrm{~m}$ south of W1250. The staircase is $1.15 \mathrm{~m}$ wide and rises to the east. Six stairs remain in situ. The treads range from 18- 
$24 \mathrm{~cm}$ in depth ( $21.8 \mathrm{~cm}$ average) and $20-27 \mathrm{~cm}$ in height (24.2 $\mathrm{cm}$ average). The steps begin $3.42 \mathrm{~m}$ from Cardo 2 North.

To the east of the staircase is solid base $(1.9 \mathrm{~m} \mathrm{x} 2.3 \mathrm{~m})$ that marks the northeast corner of W1251. The staircase intrudes into the base about $50 \mathrm{~cm}$. We speculate that about four more stairs completed the staircase to a height of more than two meters. One who climbed the staircase would then turn south at the base and walk over the structures below to the second story or to the roof of the southerly block building (Alpha). Perhaps there was an exedra ${ }^{112}$ on the north side of W1252. A column drum and base sit in the corner of the "L" formed by the staircase. The moldings of the base are covered by the paving. Several basalt beams and column drums recovered from the fill may have been part of the exedra. ${ }^{113}$ Alternatively, the staircase could continue to climb to the south to a significantly greater height.

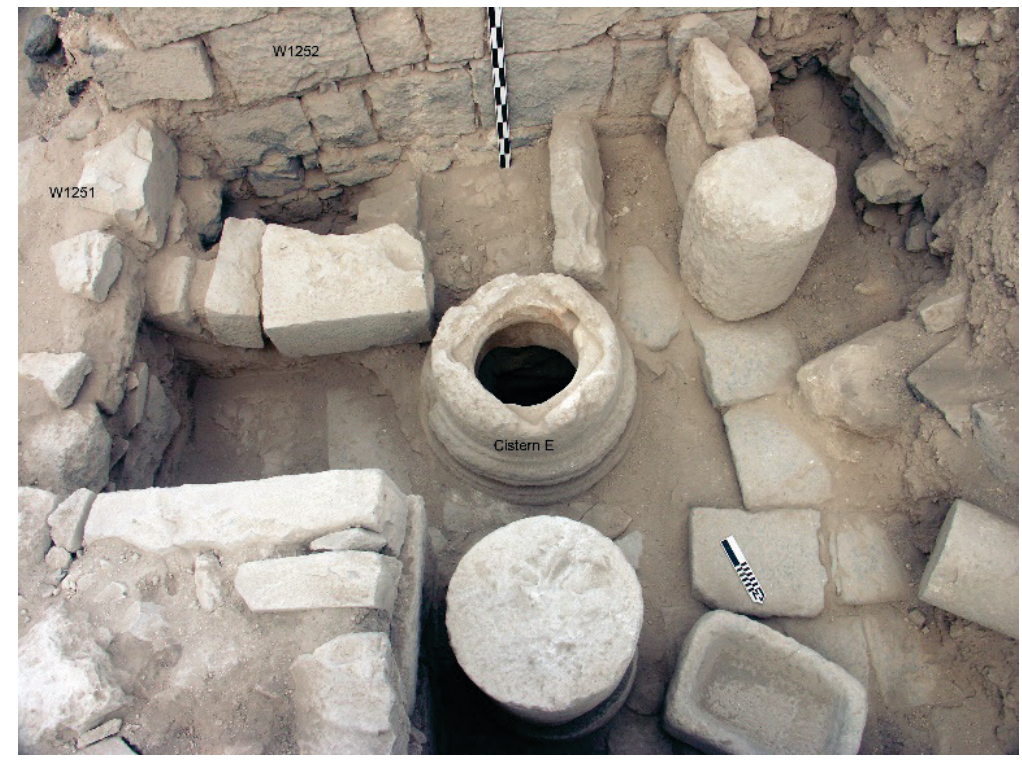

Figure 133 Cistern E

$1.5 \mathrm{~m}$ south of the staircase is a Cistern E. A plastered channel and plastering on the north face of W1252 indicates that water from the roof of the southerly block building was routed to this cistern. The cistern is capped with limestone column base modified to serve as a cistern head by carving out its center. Several nails, a feeding trough, a grinding mill, and various column fragments were recovered in the fill around the cistern.

\footnotetext{
${ }^{112}$ Hirschfeld, The Palestinian Dwelling in the Roman-Byzantine Period, 265.

${ }^{113}$ For a sample of such an exedra in a monastic complex, see Izchak Magen and Rina Talgam, "The Monastery of Martyrius at Maale Adummim (Khirbet El-Murassas) and Its Mosaics.," in Christian Archaeology in the Holy Land, ed. G.C. Bottini (Jerusalem: Franciscan Printing Press, 1990), 95, Fig 5.
} 


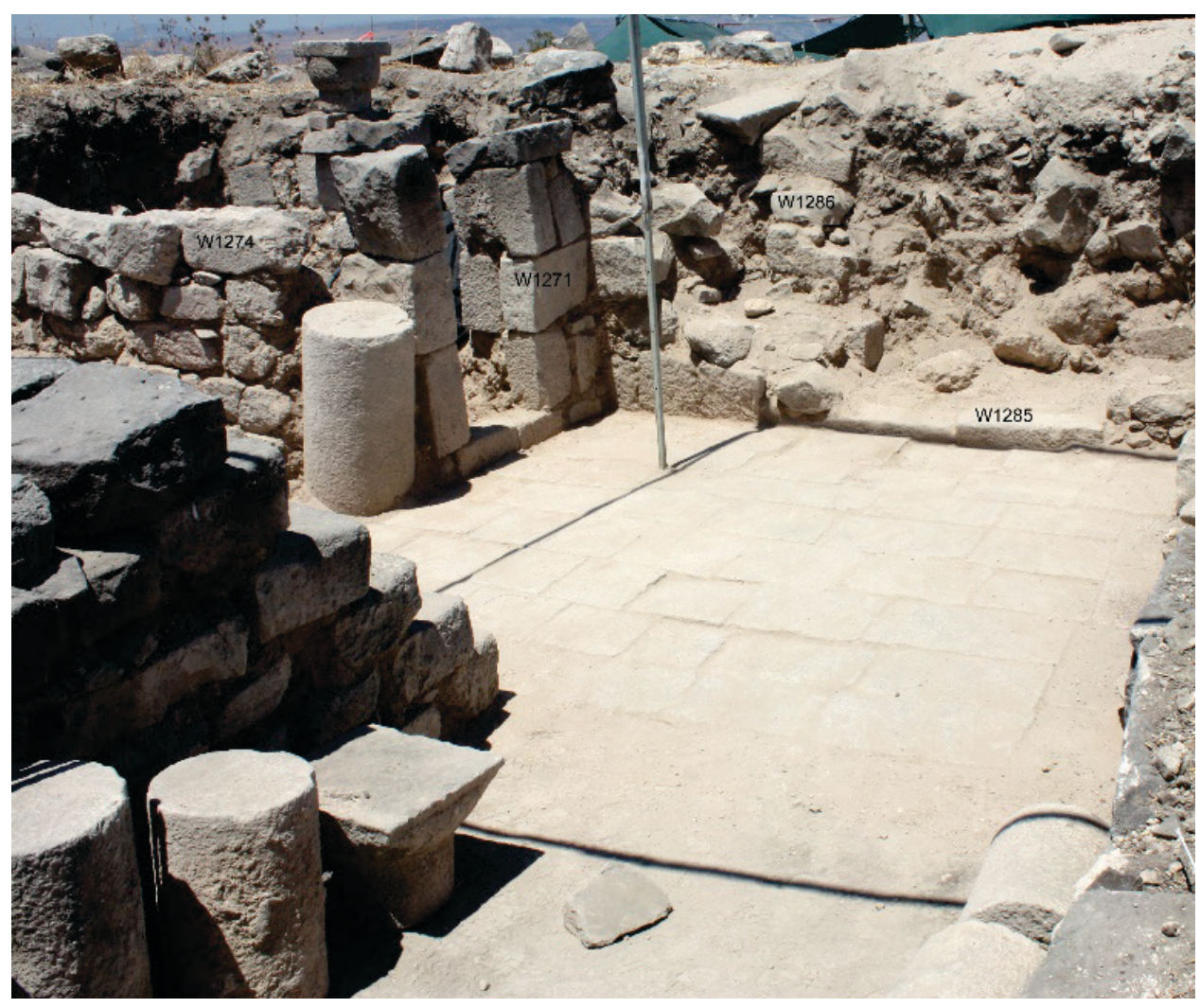

Figure 134 Paved plaza west of Cardo 2 North (looking southwest)

The paved plaza is bounded on the west by a wall (W1285) of which only the foundation course remains. Set in the wall is a threshold providing access to the west. The exterior of the doorway faced east toward the plaza. A perpendicular wall (W1286, $60 \mathrm{~cm}$ wide) proceeds west of W1285 from a point south of the threshold. One course of the north wall of the plaza (W1250) is visible in most places. Numerous architectural fragments were recovered from the destruction fill in the plaza, including three small diameter drums, a plain capital, and a roof roller.

The plaza itself is constructed of paved ashlars like those used in Cardo 2 North and extends 6.68 meters to the west of the cardo. The plaza slopes slightly to the east (about $5 \mathrm{~cm}$ ) and is essentially intact except for some pavers robbed out of a $1 \mathrm{~m}$ section next to the cardo. We presume it was constructed at the same time as the cardo. In the second row of pavers east of W1285 is an inscription. It is roughly centered on the plaza but off center to the

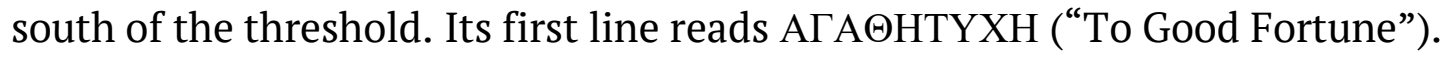

This inscription is in secondary use and was originally part of an honorific inscription for Tarius Titianus, governor of Syria Palestinae. ${ }^{114}$

\footnotetext{
${ }^{114}$ Segal et al., Hippos-Sussita of the Decapolis: The First Twelve Seasons of Excavations (2000-2011) Vol 1, 251.
} 


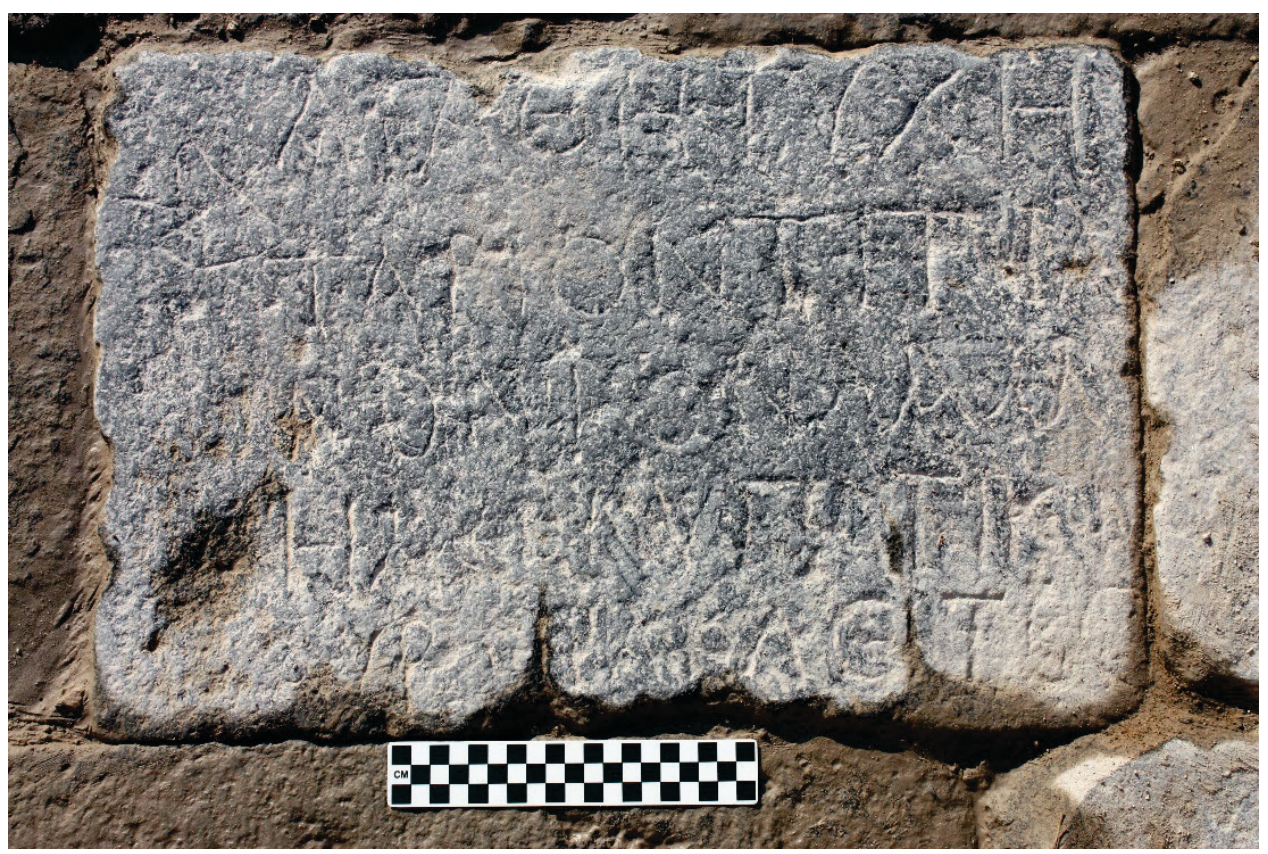

Figure 135 Inscription "good fortune"

In the southwest corner of the plaza is a crudely build small room with interior dimensions of $1.6 \mathrm{~m} \mathrm{x} 2 \mathrm{~m}$. It is bounded to the south by W1252, although this wall shows major reconstruction, as its current form lacks any indication of a western door jamb to match the eastern jamb. A column with two remaining drums forms the northeast corner of the room, from which W1274 proceeds to the south and W1271 to the west. This column aligns with the column next to the staircase, supporting the theory that there was an exedra on the north side of W1252. The doorway has a $64 \mathrm{~cm}$ opening and $71 \mathrm{~cm}$ door that closed from inside the room. The construction is quite poor. The paving of plaza was removed to set the threshold and walls of the small room. On the south side of the room is a sleeping platform (or bench) spanning the room's width. At the west end, the platform is $60 \mathrm{~cm}$ wide; at the east end it is $75 \mathrm{~cm}$ wide. Several nails, small column drums, and a small mill were recovered from the fill. The construction of this room is characteristic of the Late Antique custom of creating low-status structures by subdividing disused spaces. ${ }^{115}$

To the south of the paved plaza just described is a block building (Alpha) with an eastern face (W1251) of $7.9 \mathrm{~m}$. To the north of the paved plaza are two block buildings. The east wall (W1239) of the first building (Beta) is $7.95 \mathrm{~m}$. The second building (Gamma) consists of two rooms bounded on the east by W552, on the north by W574, on the west by W591,

\footnotetext{
${ }^{115}$ Gilbert Dagron, "The Urban Economy, Seventh-Twelfth Centuries," in The Economic History of Byzantium: From the Seventh through the Fifteenth Century, ed. A. E. Laiou (Washington, D.C.: Dumbarton Oaks Research Library and Collection, 2002), 393-461; Ellis, "The End of the Roman House"; Helen Saradi, "Privatization and Subdivision of Urban Properties in the Early Byzantine Centuries: Social and Cultural Implications," The Bulletin of the American Society of Papyrologists 35, no. 1/2 (1998): 17-43.
} 
and on the east by W569. The eastern W552 is $8.9 \mathrm{~m}$ in length. The space between these two block buildings is $5.8 \mathrm{~m}$. The width of the paved plaza is $5.9 \mathrm{~m}$. Thus, the west side of Cardo 2 North seems to consist of block buildings with eastern faces of eight to nine meters and with spaces between those buildings of about six meters.
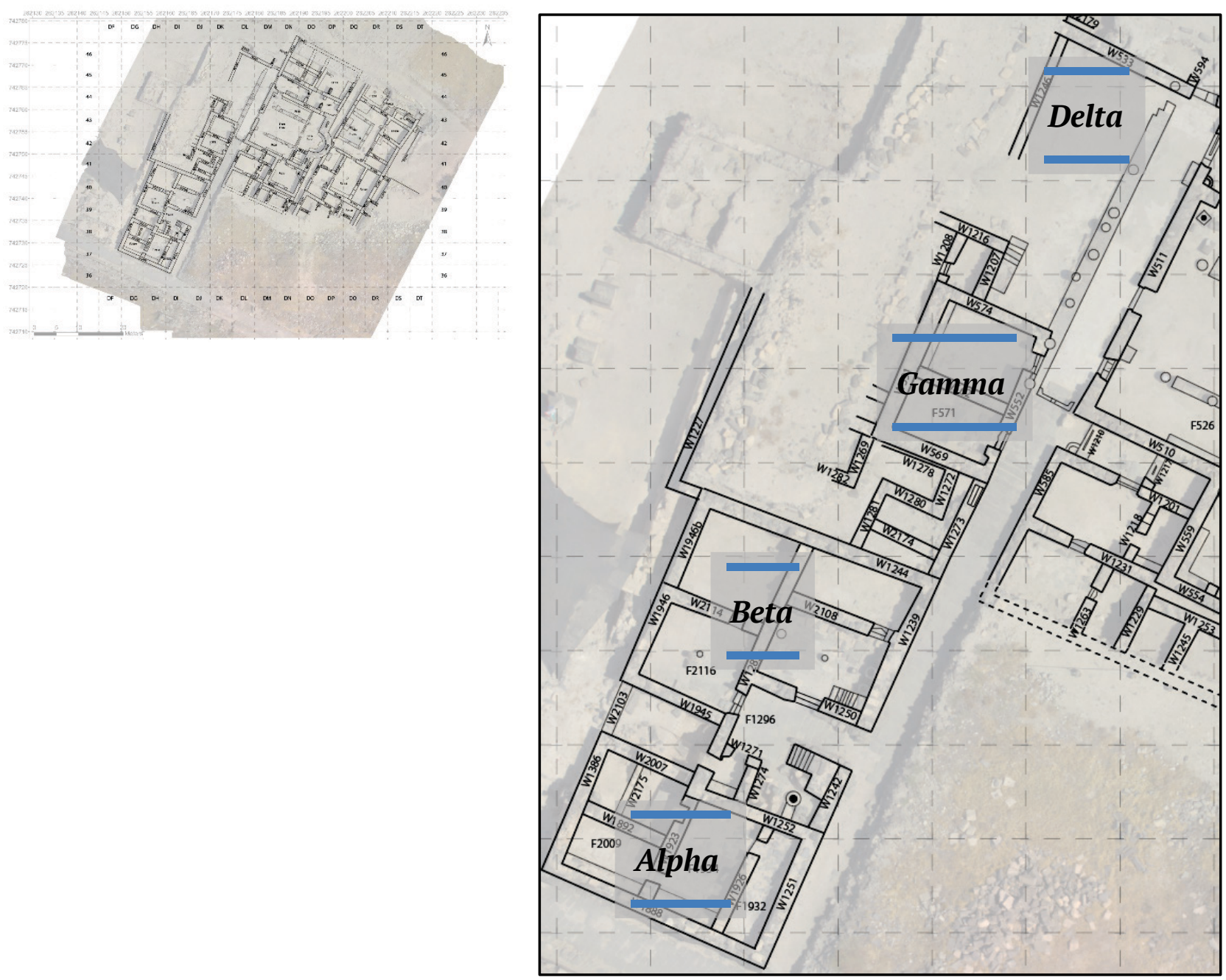

Figure 136 Four buildings 


\section{Building Alpha}
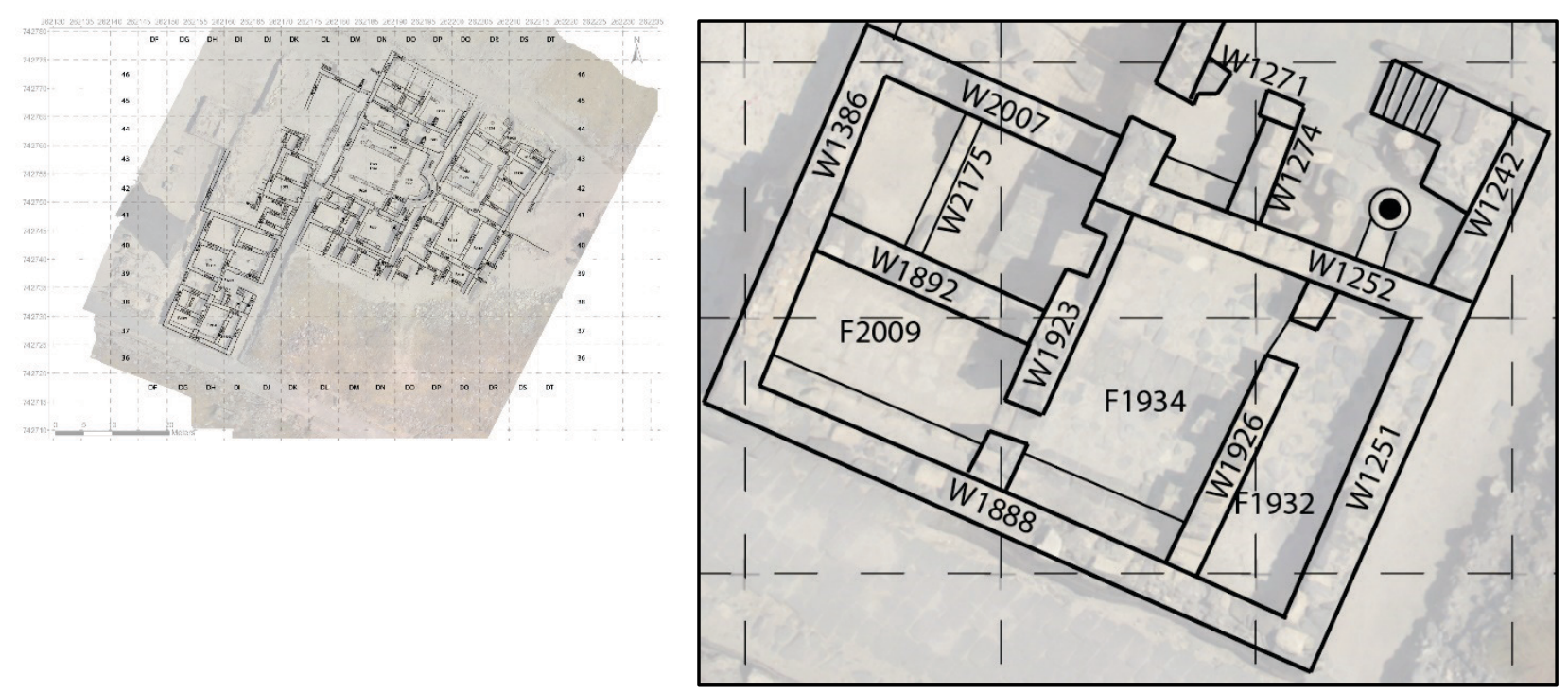

Figure 137 Building Alpha

Building Alpha consists of four rooms: a storage room to the east separated from the central room by window wall; a central room with a bench against the south wall, a southwesterly room with a southerly bench and two niches on the north wall and a northwesterly room likewise with two niches in the north wall. The only known access to the building is via an L-shaped staircase from the plaza to the north. There are no doorways providing access from the outside to the surviving rooms.

\section{Eastern storage room}

The easterly storage room is $6.34 \mathrm{~m}$ north to south and $2.0 \mathrm{~m}$ east to west. It is bounded to the east by window wall (W1926), as uprights of stone appear at regular intervals (compare window-wall houses at Qazrin, Capernaum, and Chorazin ${ }^{116}$ ). A few of the toping stones remain. There is a $73 \mathrm{~cm}$ doorway from this storage room the exterior of which faces the central room. The doorway is $65 \mathrm{~cm}$ from W1252.

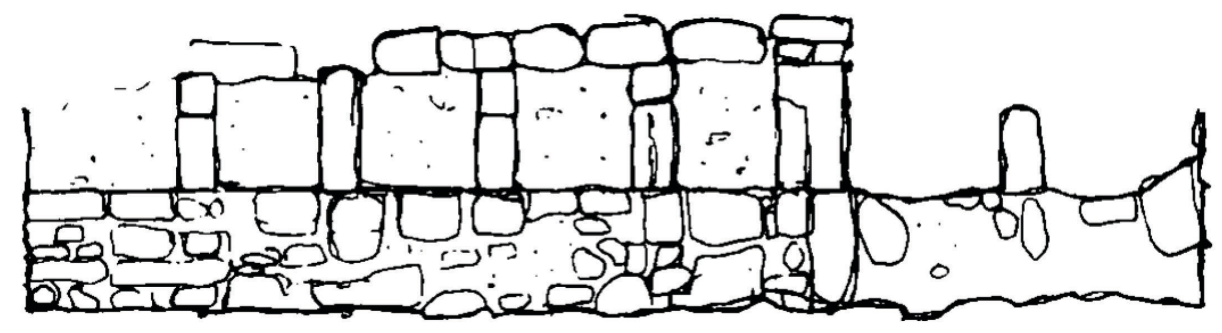

Figure 138 East face of window wall (1926)

\footnotetext{
${ }^{116}$ Galor, "Domestic Architecture in Roman and Byzantine Galilee and Golan," 48-52.
} 
The floor is extremely crude (F1929) of randomly distributed flat stones. Our hypothesis is that this area served as a storage room, as was supported by high concentration of Baysan jar fragments.

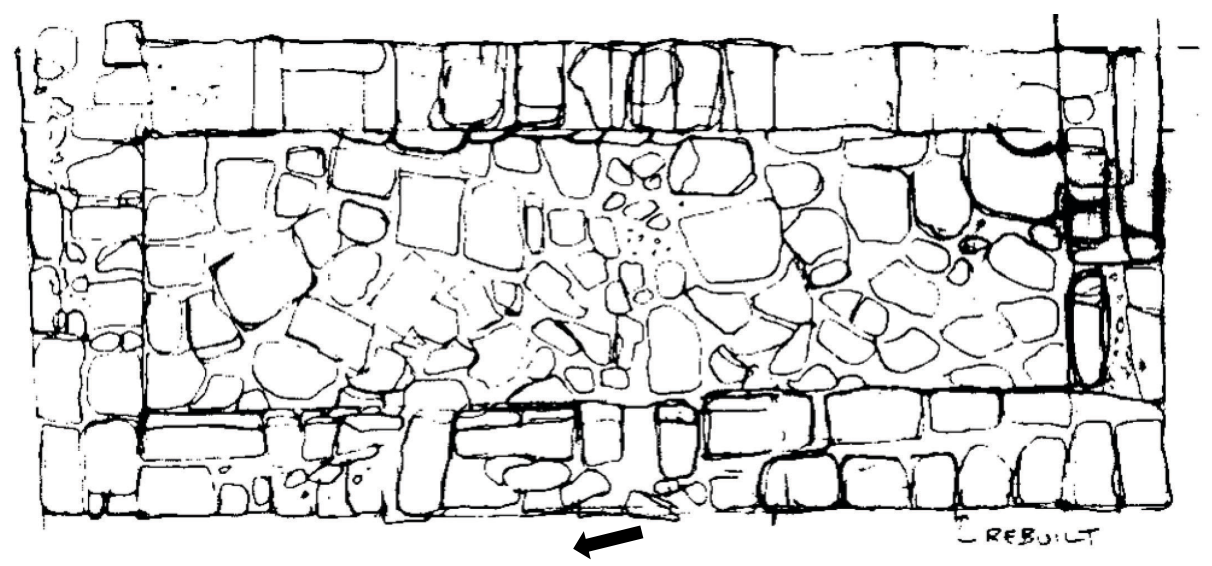

Figure 139 Top plan of the storage room

A five-meter section of W1251 was reconstructed to a height of two courses from its junction with W1252 to the south.

Central room with bench

The central room is $6.13 \mathrm{~m}$ from north to south and $3.46 \mathrm{~m}$ from east to west. There is a bench against the south wall (W1888). The bench is $84 \mathrm{~cm}$ wide and $61 \mathrm{~cm}$ tall. It proceeds east from W1923 for $2.59 \mathrm{~m}$. On either end of W1923 there is a doorway. The southern doorway has a width of $76 \mathrm{~cm}$. The northern doorway has its lintel stone in situ. The width of the northern doorway is $78 \mathrm{~cm}$ and its height is $1.61 \mathrm{~m}$. The lintel stone is $20 \mathrm{~cm}$ thick, $43 \mathrm{~cm}$ tall, and $1.92 \mathrm{~m}$ long.

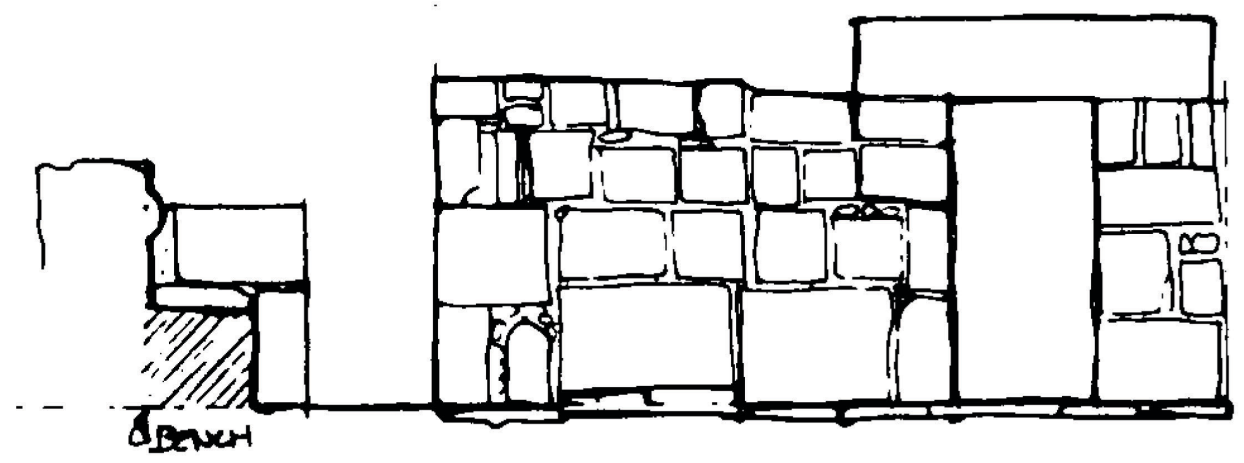

Figure 140 East face of W1923

The stone floor (F1934) consists of irregular flagstones and is somewhat uneven. Numerous nail fragments, hooks, pins, grinding stones and Baysan jar shards were recovered near the floor. 


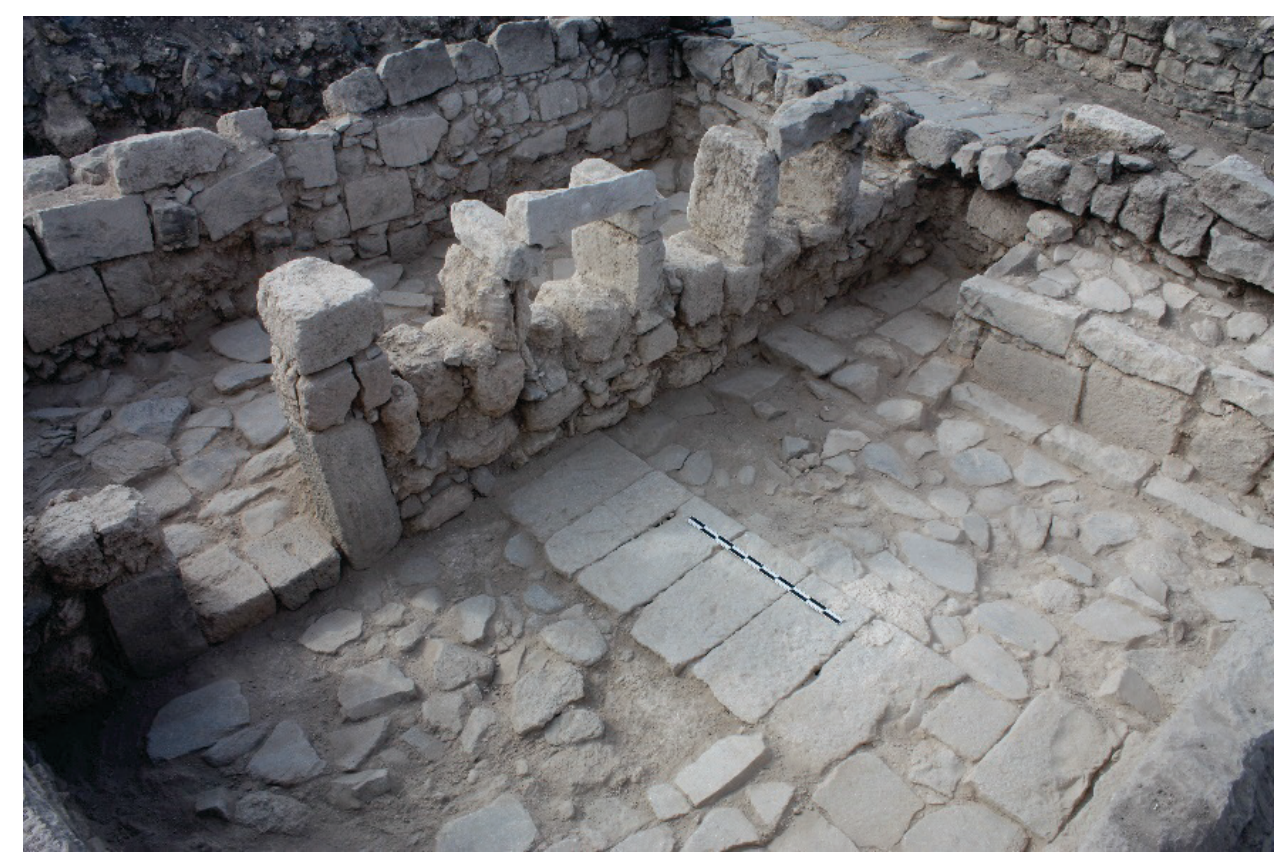

Figure 141 East and central rooms (looking southeast)

Southwest room with niches and bench

The western section of the southwest room was previously excavated. ${ }^{117}$ The 2011 season exposed the rest of the room. The room is $4.69 \mathrm{~m}$ from east to west and $2.91 \mathrm{~m}$ from north to south. A bench lines the south wall (W1888) for the length of the room. There are two niches in the north wall (W1982) of the room. The west niche is $1.91 \mathrm{~m}$ from W1386. It is 60 $\mathrm{cm}$ wide and $50 \mathrm{~cm}$ deep. Its base is $87 \mathrm{~cm}$ above the floor. The east niche is $65 \mathrm{~cm}$ wide and $56 \mathrm{~cm}$ deep. It is located $32 \mathrm{~cm}$ from W1923 and its base is also $87 \mathrm{~cm}$ above the floor.

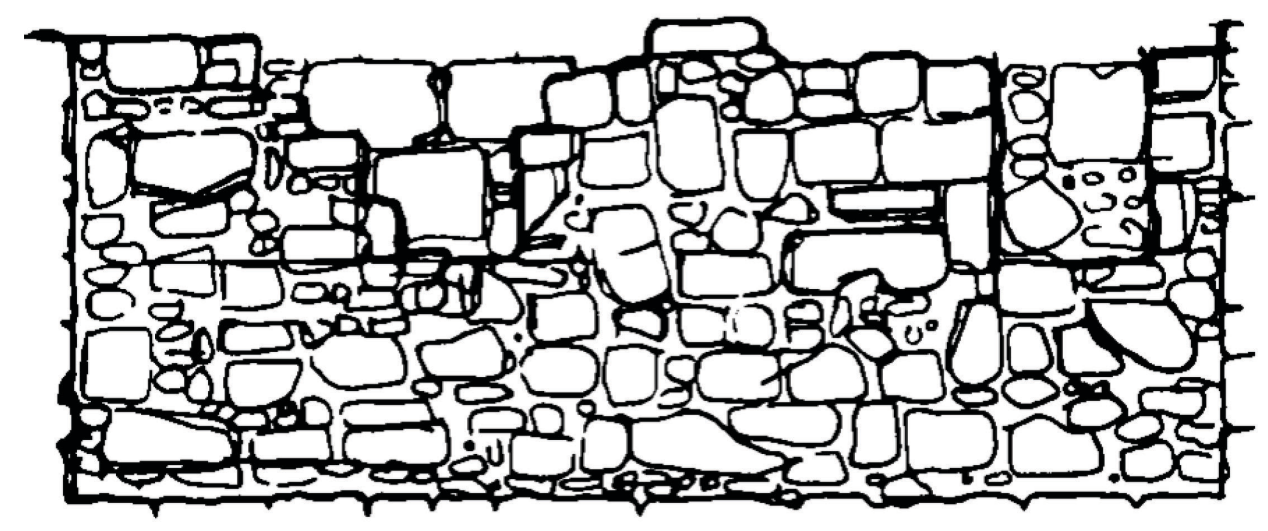

Figure 142. South face of W1892 with niches

\footnotetext{
117 Arthur Segal, Mark Schuler, and Michael Eisenberg, Hippos-Sussita : eleventh season of excavations : July 2010 (Haifa: University of Haifa, 2010), 27-28.
} 
The floor (F2009) consists of tightly placed rectangular stones of irregular sizes. A watering bowl sits in the northeast corner the room. The bowl has an internal diameter of $41.5 \mathrm{~cm}$ and an internal depth of $15-18 \mathrm{~cm}$. It was seemingly made by modifying an anta of an hourglass mill. Numerous nail fragments and a hook lock were found near the doorway.

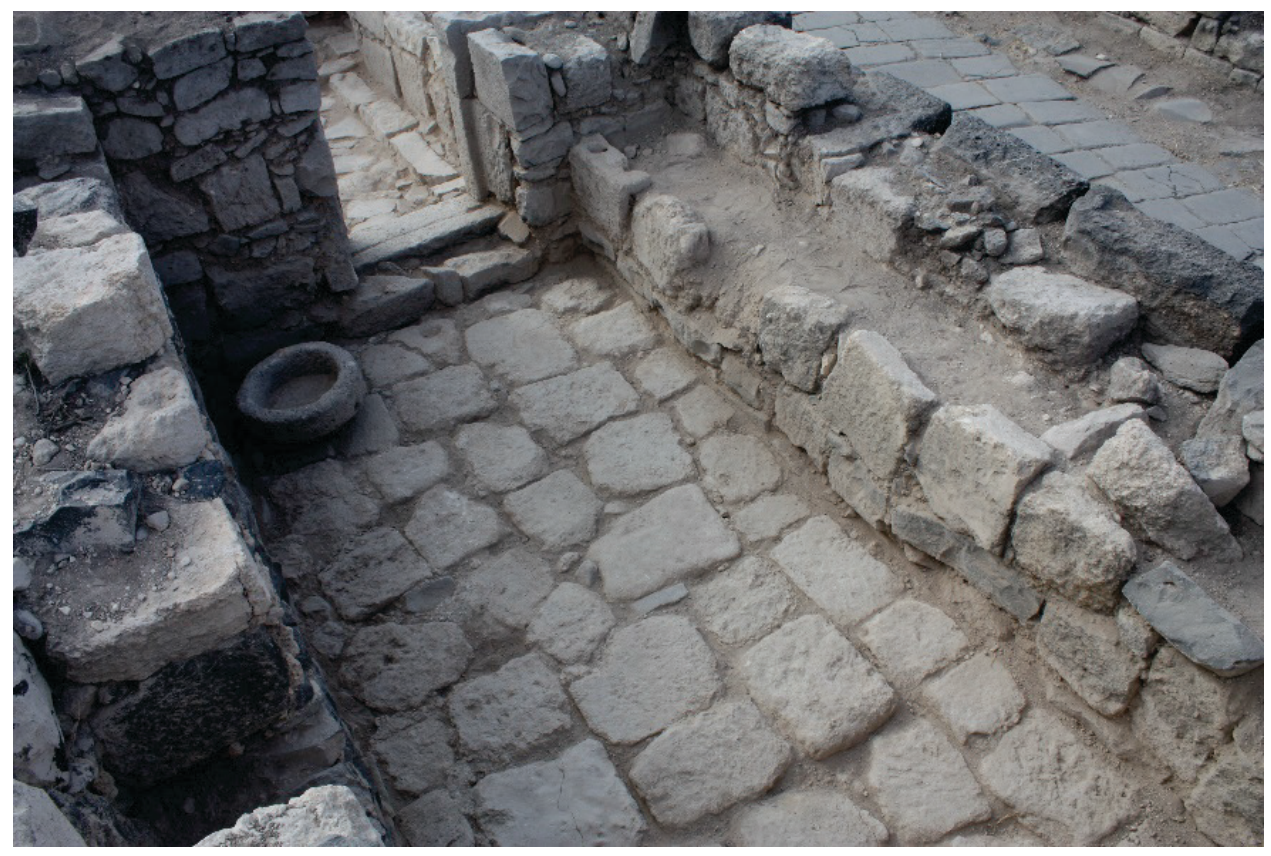

Figure 143 Southwest room (looking southeast)

One stone of the bench near the same doorway had a hole drilled in it, perhaps for tying an animal.

In its final phase, the room seems to have functioned as a place for storing animals due to the presence of a watering bowl and an animal tie up on the east side of the room. However, the door frame was designed to close and lock the door from inside the room. Such would not be the case for an animal pen.

Northwest room with niches and dividing wall

The northeast room of Building Alpha is $4.69 \mathrm{~m}$ from east to west on its south wall (W1892) and $4.76 \mathrm{~m}$ on its north wall (W2007). It is $2.84 \mathrm{~m}$ from north to south. As with the southwest room, there are two niches in the north wall. The west niche is $1.0 \mathrm{~m}$ from the west wall (W1388). It is $72 \mathrm{~cm}$ wide and $54 \mathrm{~cm}$ deep. The east niche is $34 \mathrm{~cm}$ from W1923. It is $57 \mathrm{~cm}$ wide and $61 \mathrm{~cm}$ deep. The niche contained two nearly complete pots dated to the late seventh or early eighth centuries. In front of the western niche in W2007 and west of W2002, there seems to be a low bench (dimensions $155 \mathrm{~cm} \times 46 \mathrm{~cm}$ deep $\times 24 \mathrm{~cm}$ high). The top of the bench is $81 \mathrm{~cm}$ below the top of W2007. 


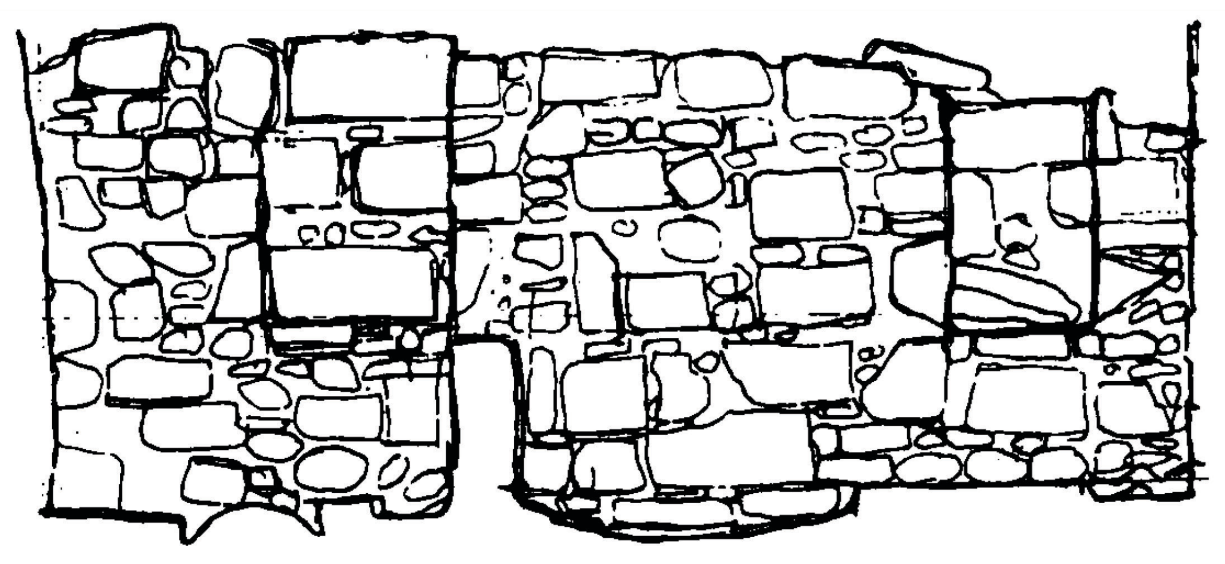

Figure 144 South face of W2007 with niches

The northwest room is subdivided by a limestone wall constructed of a single row of blocks set on end (W2002). There is a slight easterly curve in the wall, and it is clearly a later addition. Its function is uncertain. The rest of the floor is compressed earth.

Of note, Building Alpha has no external entrance to the occupational level represented by the current remains. The most plausible location for a staircase to the level from above is the space between the north-to-south stylobate and W2002. Many limestone blocks were recovered from the area tipped to the east. But there were no clear remains of a staircase.

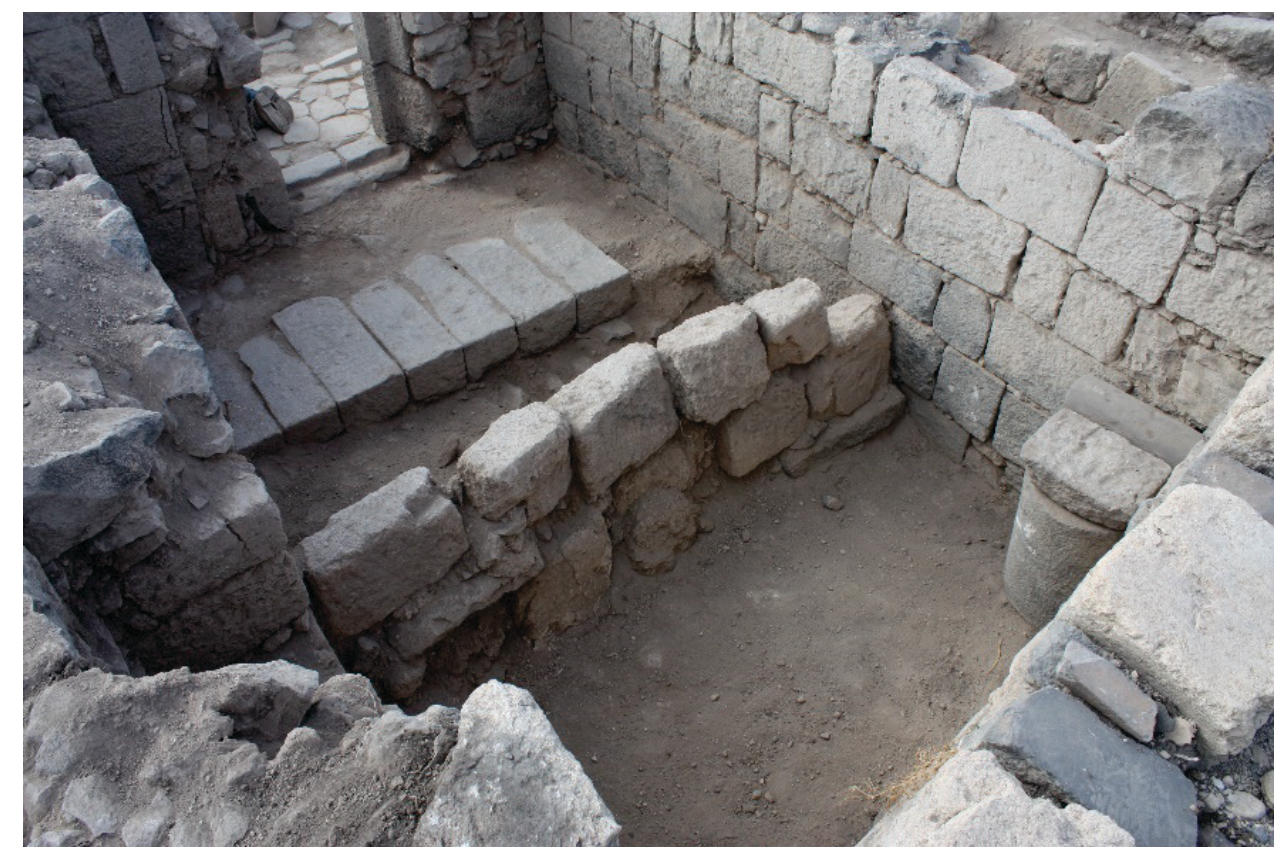

Figure 145 Northwest room (looking southeast) 


\section{Stylobates}

Evident in the floor of the central and northwest rooms are remains of the corner of a stylobate that preceded the building. In the central room, the stylobate is on a line with W1892. The stylobate is $89 \mathrm{~cm}$ wide, the southern edge of which is $2.29 \mathrm{~m}$ from W1952. In the northwest room is a perpendicular portion of the same stylobate (similar dimensions). The stylobate runs north to south and continues under W2007. Its western line is $1.44 \mathrm{~m}$ from W1923. This stylobate likely formed a corner with the east-to-west stylobate in the central room. The outward face of the stylobate is to the west and is 4.12 from the line of the east face of the wall of the Roman basilica. The stylobate is $33 \mathrm{~cm}$ thick and sits on a foundation base. Possibly, during the Roman Imperial period a substantive public building stood on this location north of the decumanus.

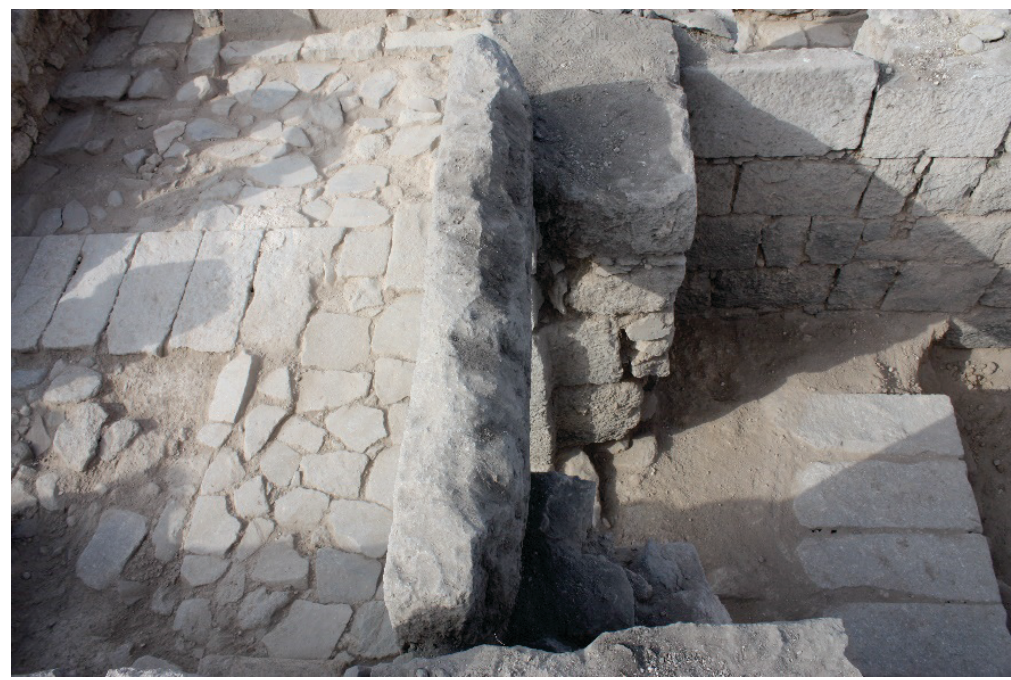

Figure 146 Stylobates in floor of the Building Alpha (looking south)

Between the Buildings Alpha and Beta

The south room of Building Beta is set $2.75 \mathrm{~m}$ to the north of Building Alpha. To access the area between them, we removed W1286, a floating wall with three courses surviving. It likely comes from some pastoral occupation of the site in more recent times.

The gap between the buildings was blocked on the west end by a simple wall (W2103) thrown up between the buildings after the original construction. Likewise, the gap was blocked on the east end by a small room with a bench/bed set onto the pavers of the plaza. Originally, it was possible to pass between the buildings. There seemed to be the remains of a staircase next to the north wall of the Building Alpha, indicated by one surviving basalt beam positioned perpendicular to the wall. The rest of the staircase was robbed out. The staircase would have provided a second entrance to Building Alpha, perhaps from the west.

We dug a $1.5 \times 2.75 \mathrm{~m}$ probe in the east end of the gap to a level of cobbles, identified as the base for the stylobate previously seen as running to the north in Building Alpha. The stylobate is clearly visible in W2007 but has been robbed out to the north. There is no evidence 
of the stylobate in situ in south wall (W1945) of Beta Building, although at least two stones of similar shape were used in the wall as well as multiples in the south wall (W2108) of the northeast room. Two feeding troughs were discovered at the level of the cobbles.

\section{Other observations}

The surviving portions of Building Alpha likely served a storage function for whatever floor(s) stood above. The heavy basalt ashlars of the exterior walls suggest something substantive stood above as do the presence of one and possibly two staircases. The building seems to have been in use up to the last days of Hippos, having replaced an earlier Roman structure intimated by the remains of two stylobates. Its function was likely utilitarian or even industrial in view of its plain construction and surrounding installations. Building Beta was built after removal of the stylobate for the purpose of getting building stones for constructing the building. We infer that Building Beta was constructed after Building Alpha.

\section{Building Beta}
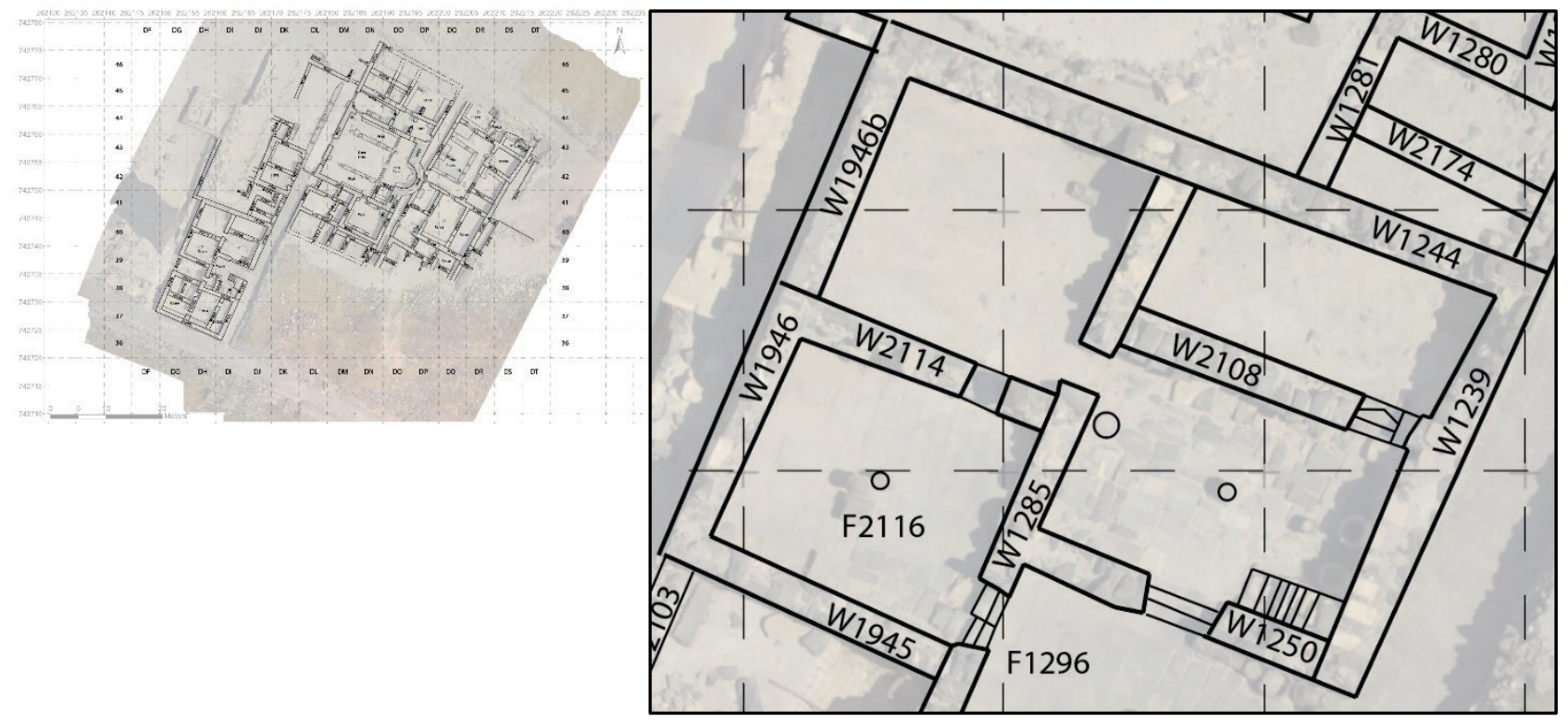

Figure 147 Building Beta

Building Beta has a westerly face of 10.9 meters that is preserved to a height of four to five courses in places. It is located $9.75 \mathrm{~m}$ from the gate of the church complex. Building Beta is an L-shaped structure the wraps around the northwest corner of the paved plaza. 


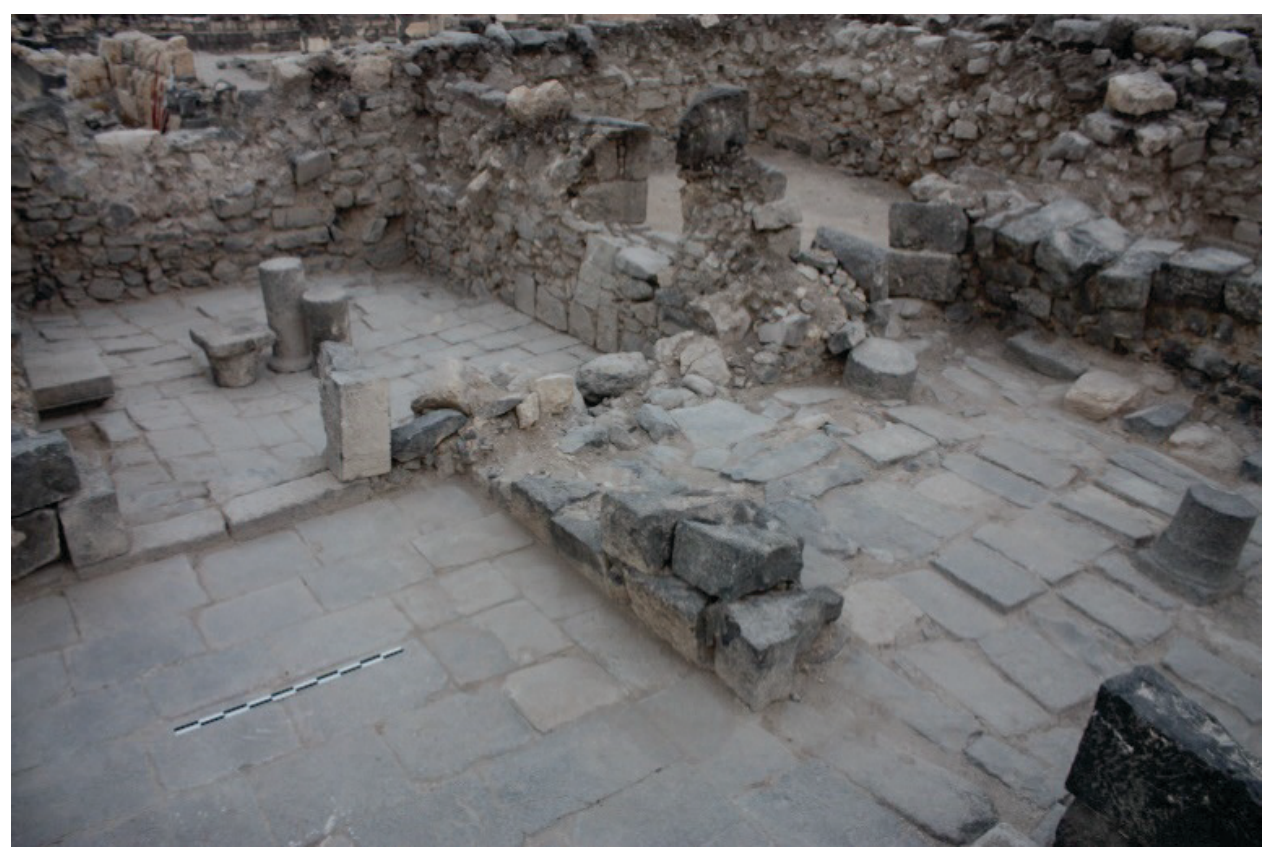

Figure 148 Beta Building (looking northwest)

Southern room of Building Beta

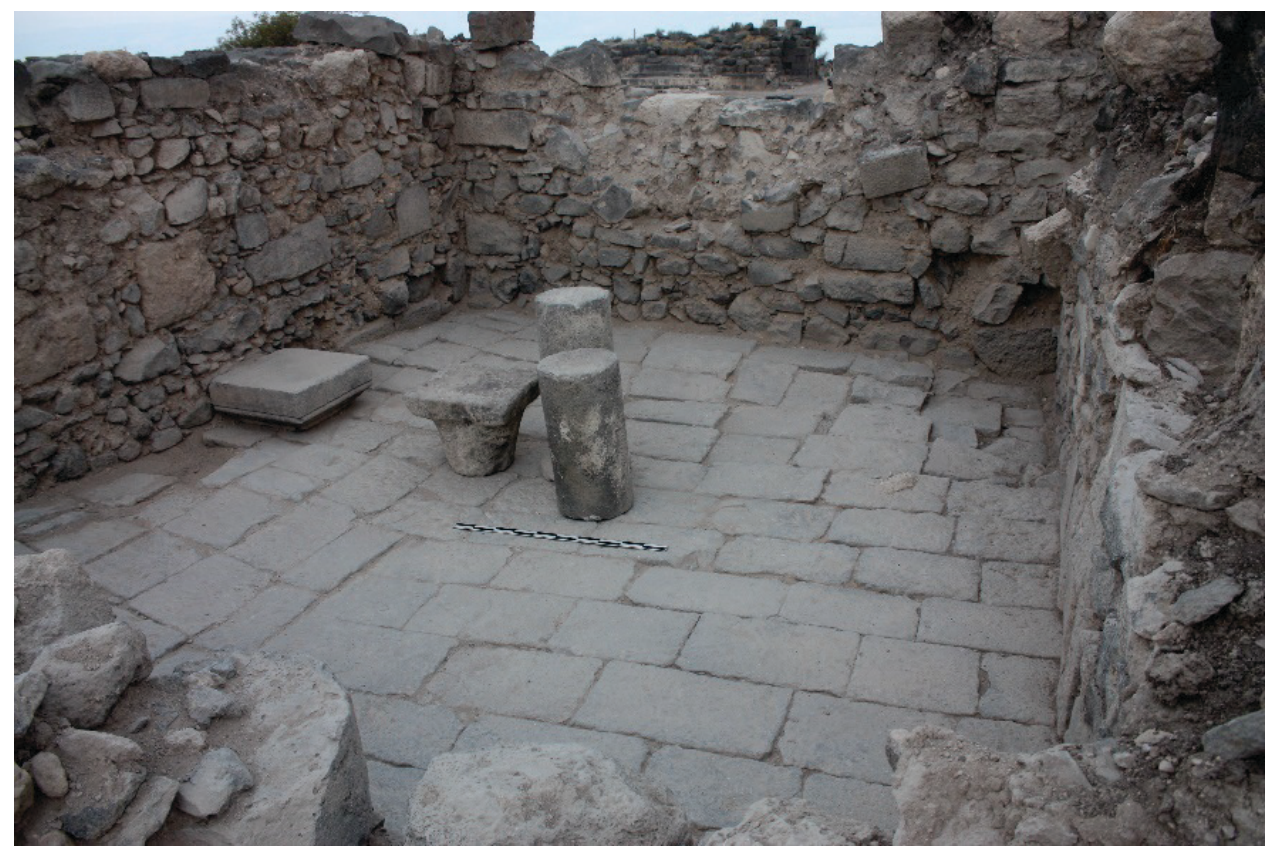

Figure 149 Southern room (looking west)

The southern room of Building Beta has an interior dimension is about $4.5 \times 5 \mathrm{~m}$. The west interior face is $4.28 \mathrm{~m}$, the east face is $4.55 \mathrm{~m}$, the north face is $4.98 \mathrm{~m}$, and the south face is $5.14 \mathrm{~m} .5 .62 \mathrm{~m}$ from the southwest exterior corner is a seam in the west wall. The seam aligns with the north face of the north wall of the room (W2114). W2114 has a north-facing 
doorway $87 \mathrm{~cm}$ from its east end. The doorway is $95 \mathrm{~cm}$ wide and is blocked. The threshold is $65 \mathrm{~cm}$ above the floor. There is a $1.20 \mathrm{~m}$ doorway to the east that provides access to the paved plaza.

The floor of the southern room sits one half meter below the paved plaza to the east and is itself paved with basalt pavers of similar size and orientation. The pavers abut the east, west, and south walls. But the north wall sits on top of the pavers, suggesting that that the space was originally an outdoor plaza. A roof was added to the room in this later phase.

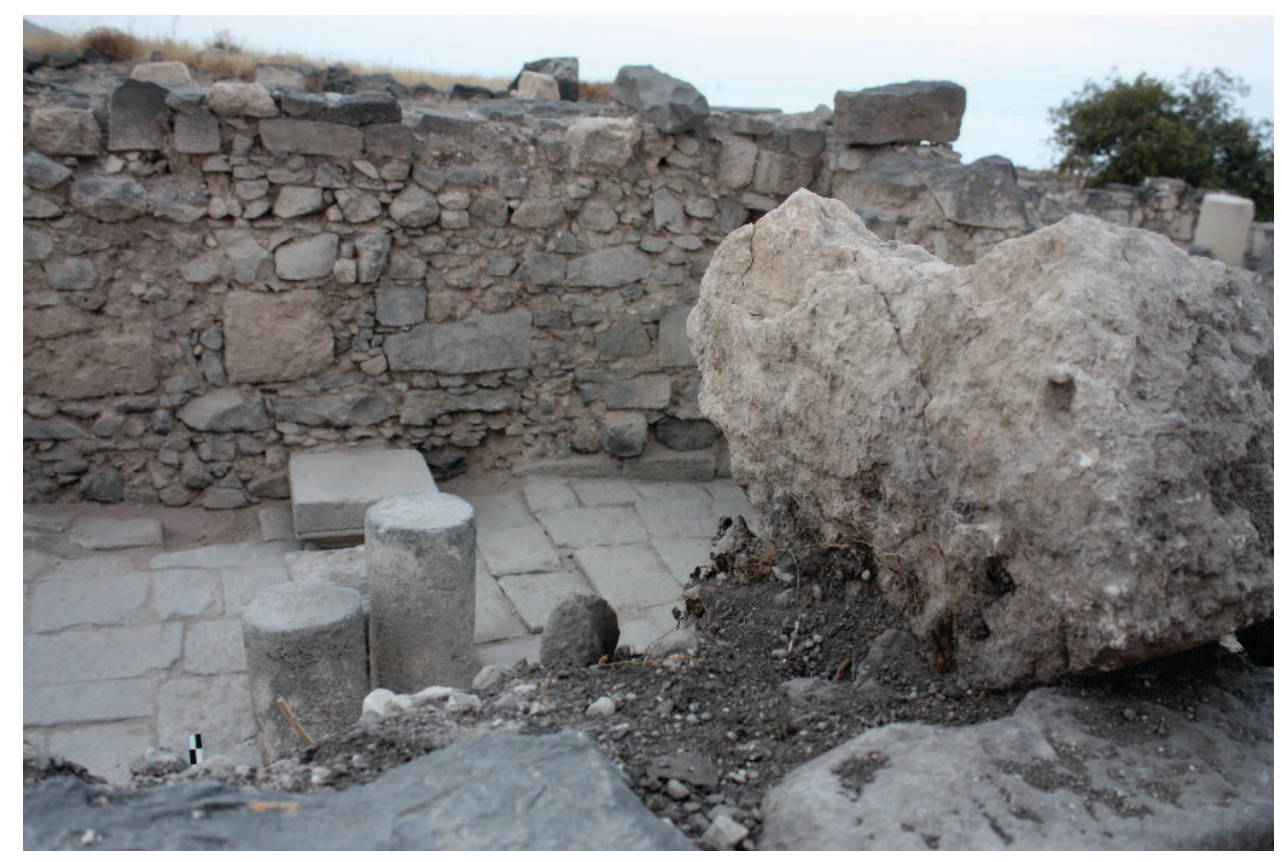

Figure 150 Arching of southern room (looking south)

The roof was held up by a double arch. The arch spanned from an inverted base $(63 \times 64.5$ $\mathrm{cm})$ next to the south wall that functioned as a pilaster to a central column base $(36 \mathrm{~cm}$ diameter) sitting on top of the paved plaza to a y-shaped limestone block on the top of W2114 that aligns with the central column and the southern inverted base. Several fragments of the arch were recovered in the fill, as was a small roof roller. We presume that the arch continued to the north over the northwest room.

In the southwest corner of the room sitting on the floor was a $75 \times 173 \mathrm{~cm}$ marble panel. It was broken and undecorated on either side. We revealed two limestone column drums and a broken spiral-fluted column in the northwest corner of the room. The fluted column has a square bottom measures $22 \times 21 \times 6 \mathrm{~cm}$. The square portion has 3 horizontal bands with a total measurement is $10 \mathrm{~cm}$ (top band is $3 \mathrm{~cm}$, middle band is $3 \mathrm{~cm}$, and bottom band is 4 $\mathrm{cm}$ ). The upper portion of the fragment has carved spirals $51 \mathrm{~cm}$ long, $16 \mathrm{~cm}$ wide at top, and $17 \mathrm{~cm}$ at bottom. We speculate that these fragments supported the marble panel and functioned as a table. 


\section{Northwest room of Building Beta}

The northwest room $(4.75 \times 5 \mathrm{~m})$ in Building Beta is more poorly constructed and was abutted to the south room perhaps secondarily. The west interior face is $4.77 \mathrm{~m}$; the east interior face is $4.72 \mathrm{~m}$. The north interior face is $4.99 \mathrm{~m}$ and the south is $5.04 \mathrm{~m}$. The exterior faces are basalt ashlars with crude and sometimes undefined interior faces.

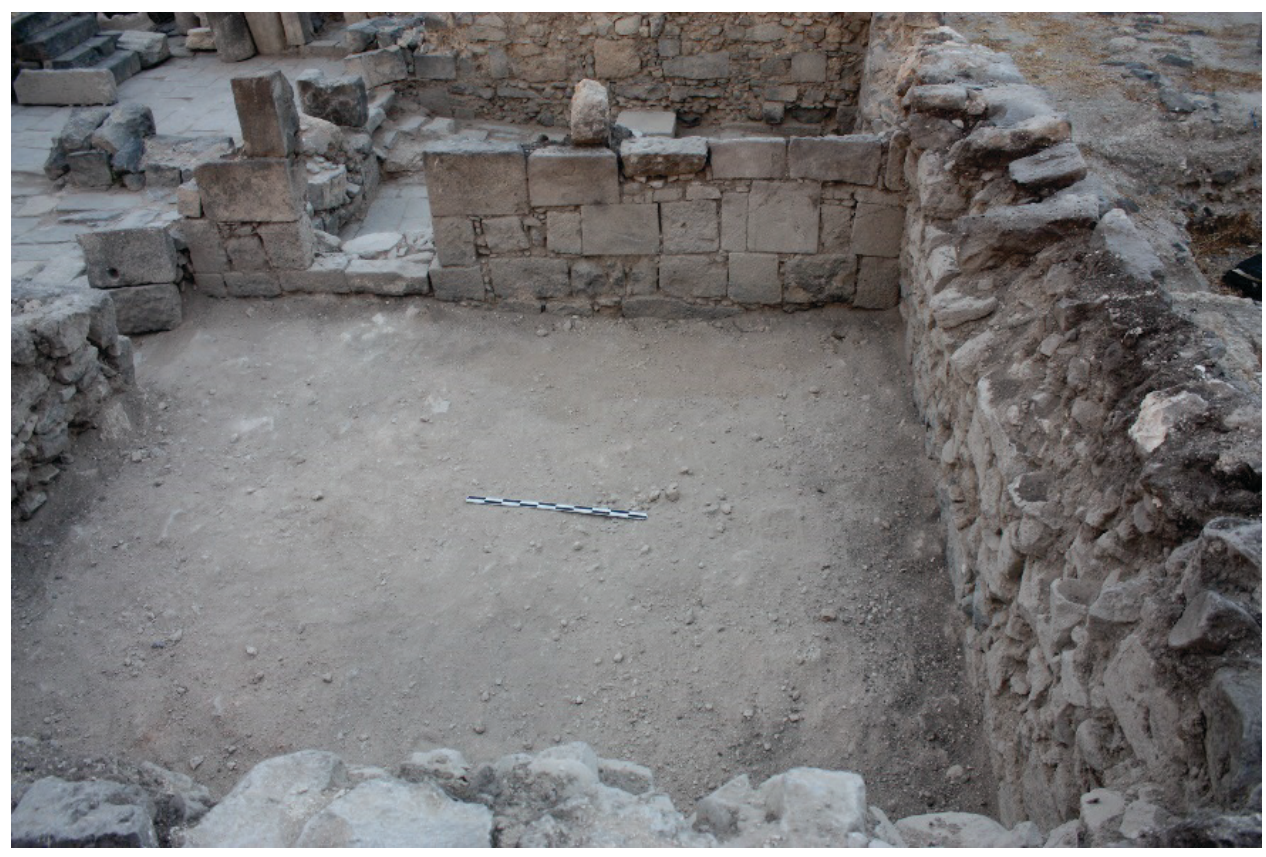

Figure 151 Northwest room (looking south)

There was a small doorway $(93 \mathrm{~cm})$ without a door jamb from the southeast corner of the room into a courtyard to the east. The floor is compressed earth and was identified by the foundation trench for the south wall (W2114). A coin retrieved at floor level was from the reign of Theodosius I (393-395 CE). The meager pottery assemblage was from the seventh and eighth $\mathrm{CE}$.

\section{Northeast room of Building Beta}

The northeast room $(6 \times 2.75 \mathrm{~m})$ is of similar construction. The interior face of the north wall is $6.34 \mathrm{~m}$, of the south wall is $6.08 \mathrm{~m}$, of the west wall is $2.81 \mathrm{~m}$, and of the east wall is $2.75 \mathrm{~m}$. The room has a single doorway $(1.11 \mathrm{~m}$, door is $1.22 \mathrm{~m})$ in its southeast corner that gives access to and interior courtyard to the south. The exterior of the door is to the south.

The floor is of pressed earth and is at a similar elevation to the floor in the northwest room. Besides a concentration of pottery shards and small bones at the middle of the south wall, no other distinguishing factors identify the room. The ceramic assemblage consists mostly of medium-sized shards of jars and cooking vessels. Indicative wares include: Umayyad casseroles and Umayyad grey Baysan jars. 


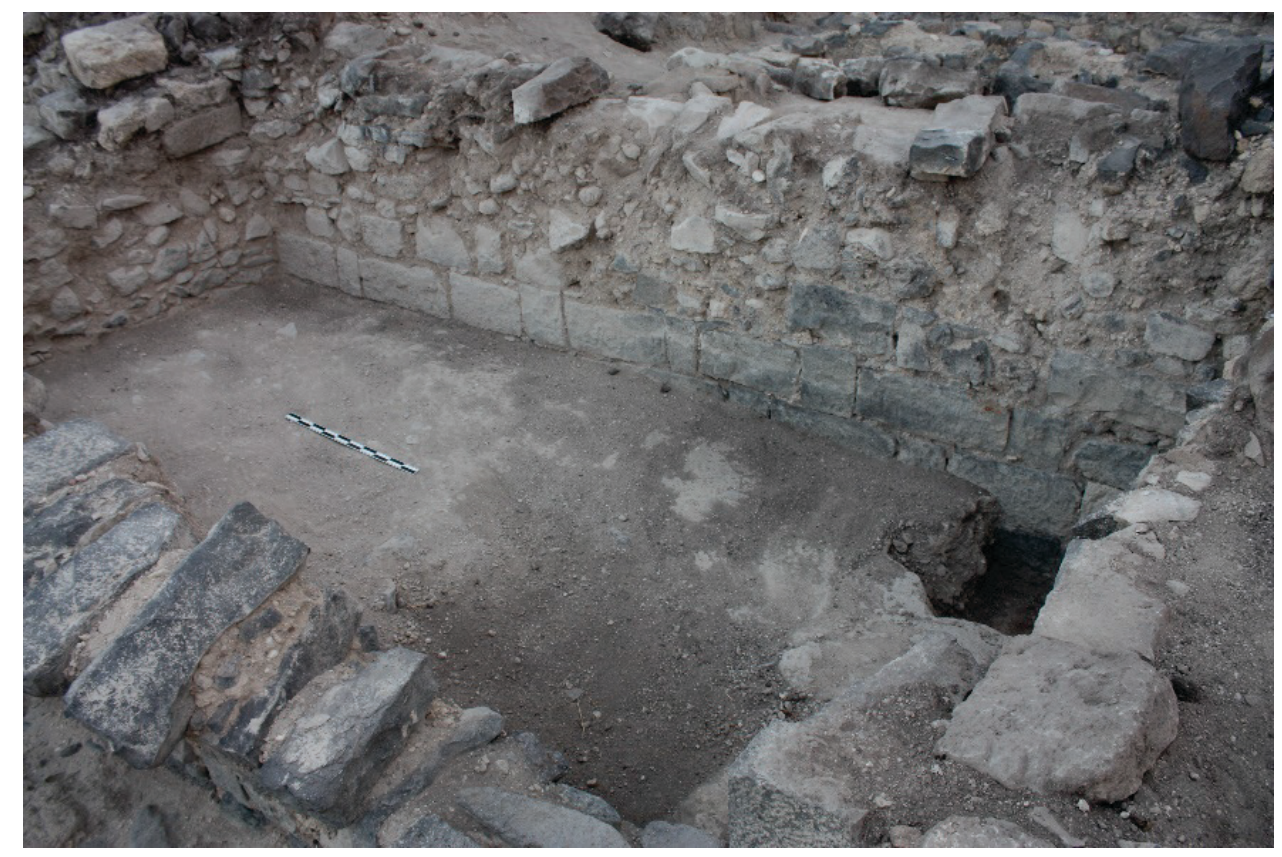

Figure 152 Northeast room and probe (looking northwest)

Interior courtyard of Building Beta

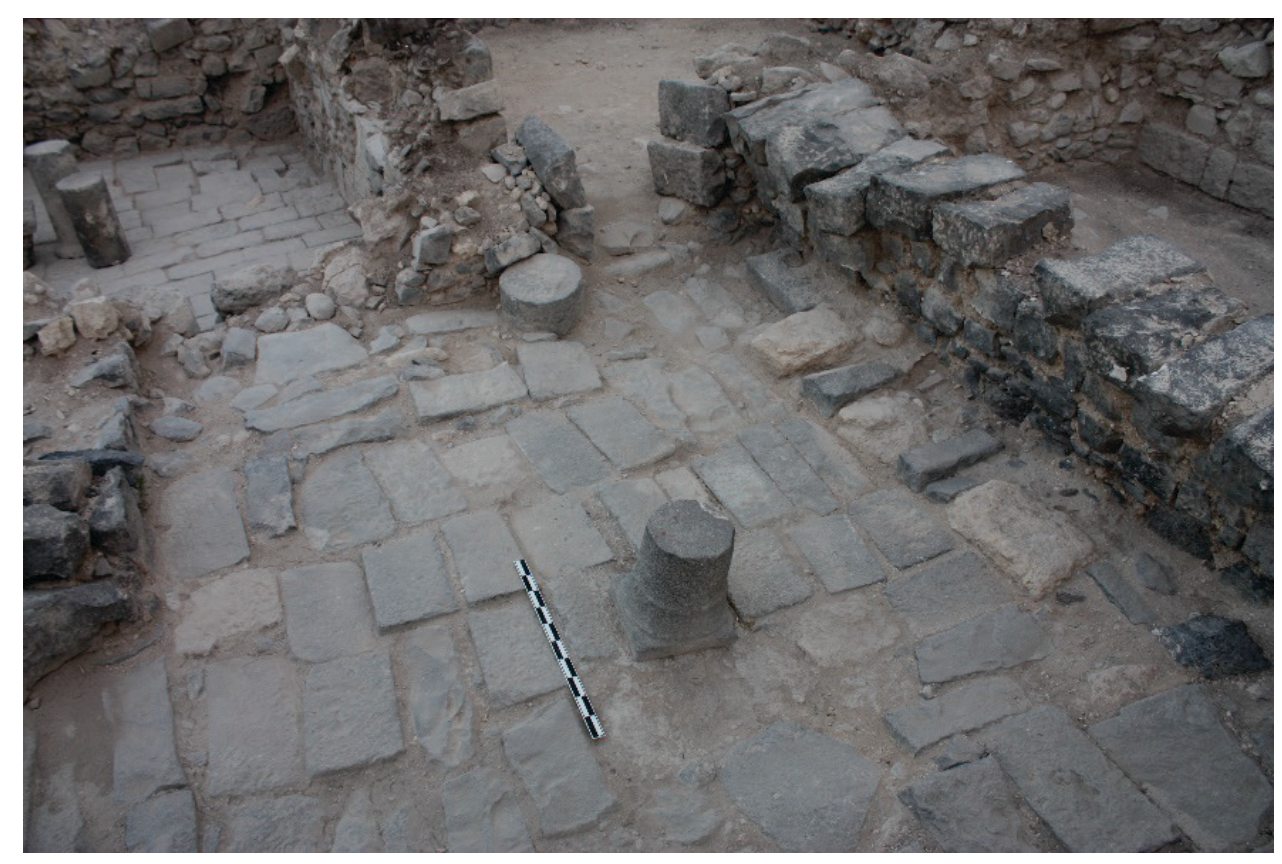

Figure 153 Courtyard (looking west)

Directly south is a crudely paved interior courtyard. Most pavers are rectangular in basalt. Some are basalt building stones. In the eastern part of the square, some of the floor is plaster/mud over cobbles. 
In the center of the courtyard is a column base upon which there was a drum tilted to the north in the destruction fill. The presence of this column suggests that the courtyard may have been partially roofed. The pavers against the north wall are raised about $15 \mathrm{~cm}$ and may have functioned as a low bench.

A wall (W1250) separates the courtyard from the paved plaza to the south. There is a doorway in W1250 located $4.98 \mathrm{~m}$ from the southeast exterior corner of the building. The exterior of the door is to the south. The opening is $1.28 \mathrm{~m}$; the door was $1.38 \mathrm{~m}$ wide.

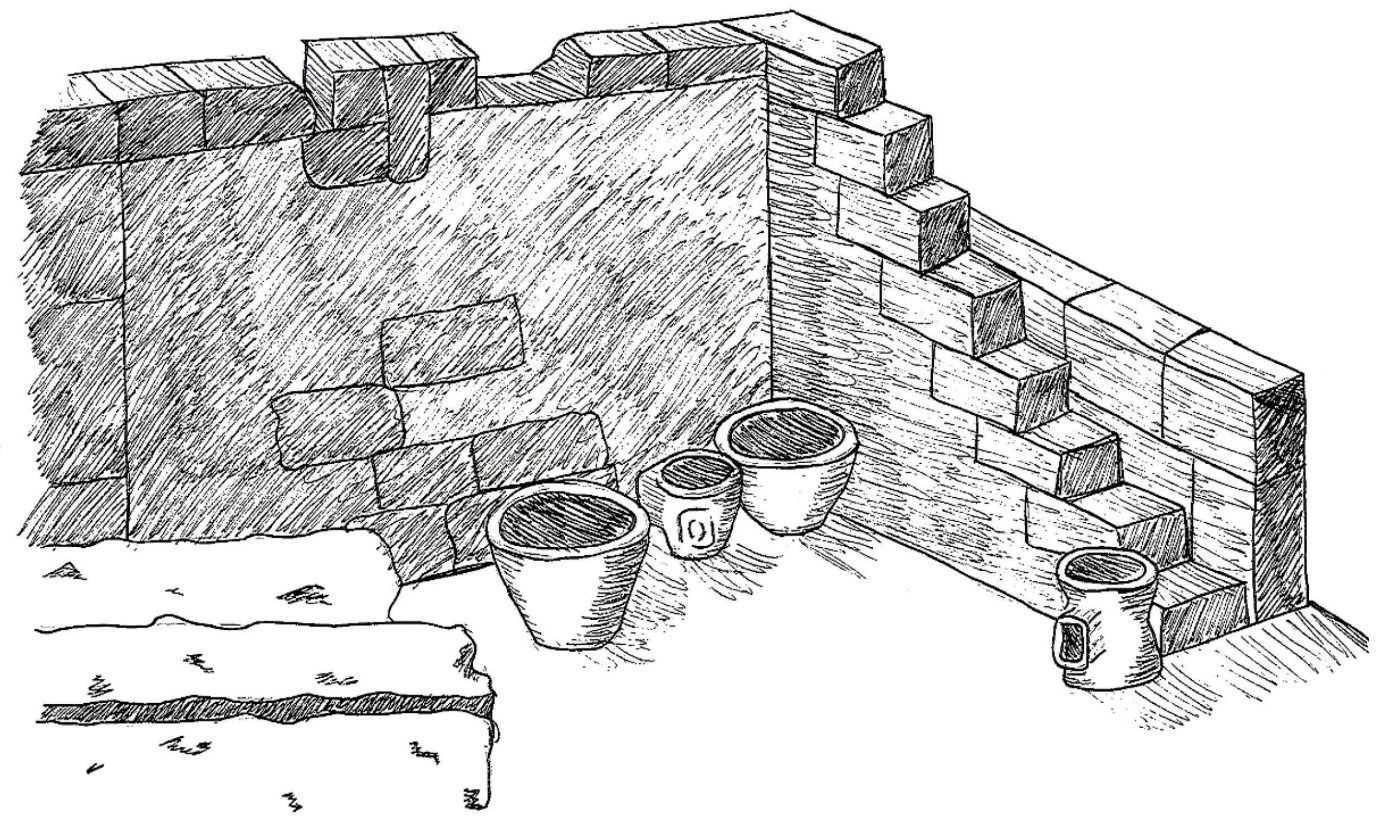

Figure 154 Staircase in the interior courtyard of Building Beta

In the southeast corner is a makeshift limestone staircase which rises to the east toward W1239. It led to the roof or a second story. Eight stairs remain. The treads are $15-22 \mathrm{~cm}$; the stairs rise 22-24 cm. Elevations of the steps are: 128.766 (bottom step); 129.041 (step 2); 129.214 (step 3); 129.451 (step 4); 129.636 (step 5); 129.881 (step 6); 130.095 (step 7); 130.272 (step 8).

Two basalt bowls were found in the southeast corner of the room next to the west wall. Between was a small crude grinder with a handle. All three were sitting on the floor. At the base of the stairs is an hour-glass mill with two rectangular notches on the sides across from each other for handles.

Other observations

Remarkable in the excavation of the rooms of Building Beta was the relative paucity of ceramic finds. No restorable vessels were found. The heavy stone bowls were pushed against a wall and doorways were intentionally blocked. A similar situation was discovered a domestic area and street in the western part of Hippos. It seems that Building Beta was abandoned prior to the earthquake of $749 \mathrm{CE}$. The westerly structures not only illustrate the 
extreme poverty of the Umayyad period, but they also mark a trend notable throughout the excavation area of the Project. This quadrant of Hippos, located as close as it may be to the center of the city, was essentially abandoned well before the earthquake. Such would likely be true of much of the rest of the city. The glories of Antiochia Hippos were in the distant past.

\section{Building Gamma}

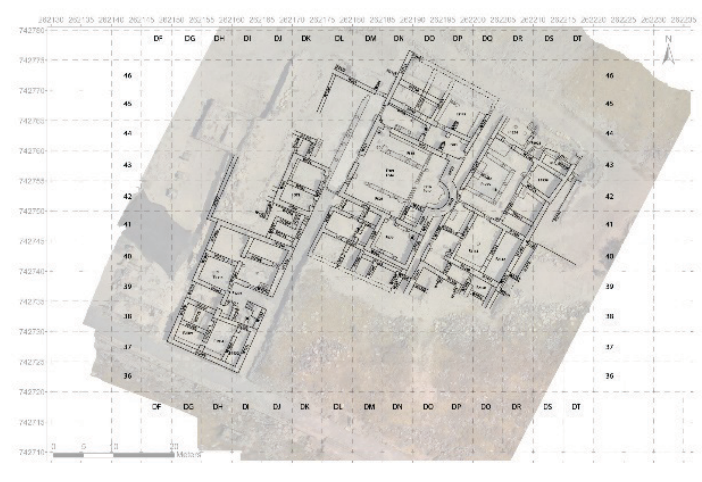

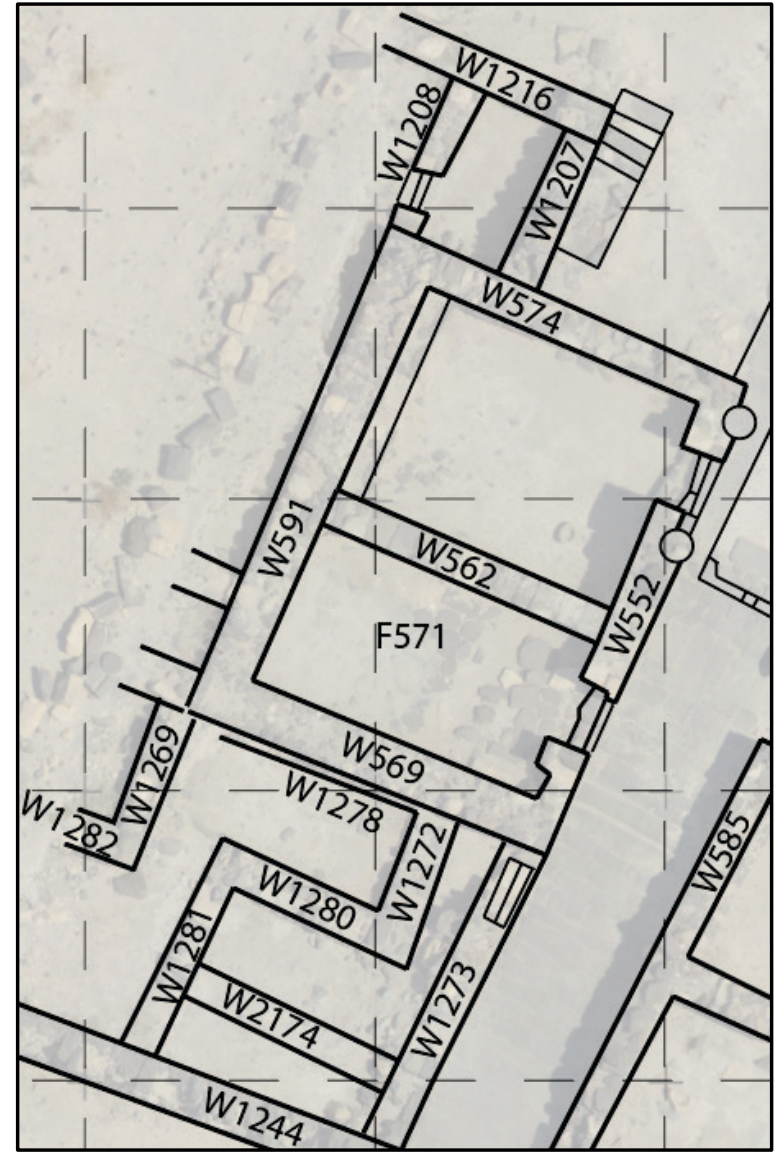

Figure 155 Building Gamma

To the west of the street and on the line of the stylobate of the portico of the church runs W552. A doorway in the wall provides access to the southerly of two rooms. The door closed and locked from inside the room. The room is $2.5 \mathrm{~m}$ wide (north to south) and is bounded on the south by W569 and to the north by W562. The top surviving course of W562 is constructed with pavers, one of which displays the mason marks alpha and eta. This flat surface suggested that W562 is a window wall. ${ }^{118}$

${ }^{118}$ Galor, "Domestic Architecture in Roman and Byzantine Galilee and Golan," 48-52. 


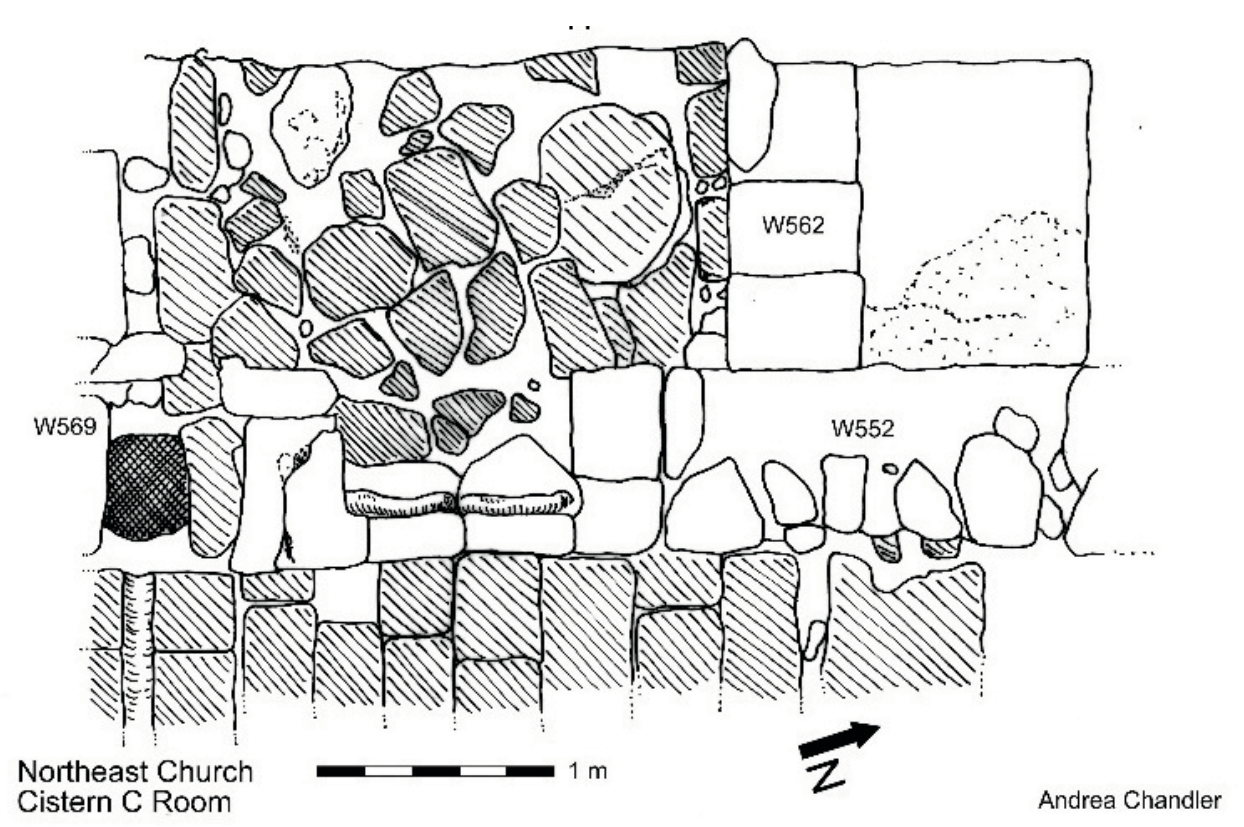

Figure 156 West of street and Cistern C

To the north is a second similarly sized room bounded to the north by W574. The doorway for this room is inside the threshold to the portico and is constructed between the first two column bases on the stylobate. The threshold is placed on top of the stylobate enabling a door to be locked from inside the room. Several nails were recovered from the fill. Significantly, this room did not have evidence of any stone floor as in the southerly room outside the main gate. Hard packed earth provided the floor. A common wall (W591) serves as the westerly demarcation for both rooms, yielding in internal east-to-west dimension of $5.2 \mathrm{~m}$.

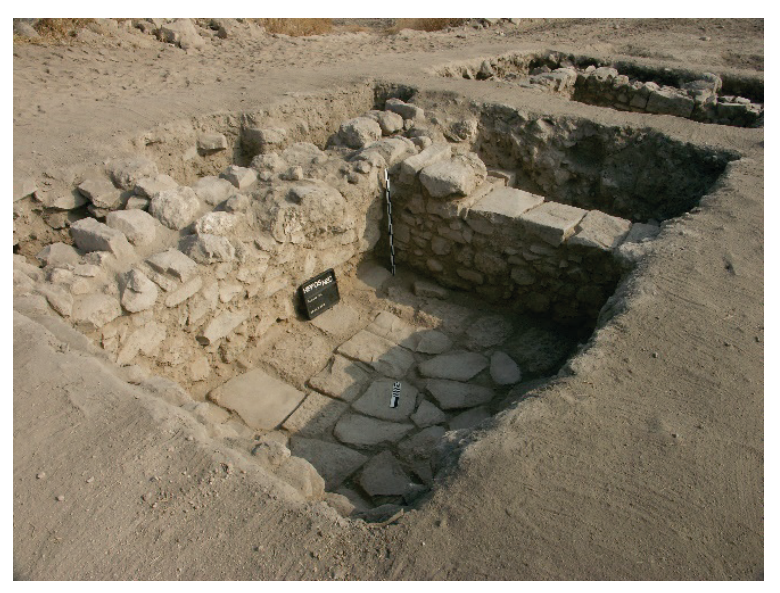

Figure 157 Cistern room (looking northwest)

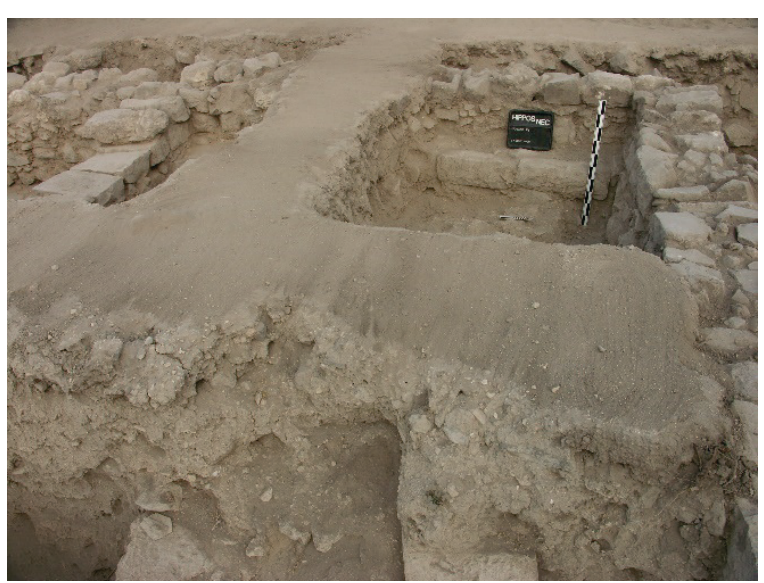

Figure 158 Incubatio with bench (looking west)

W562 and W591 allow us to conclude that the southerly room is part of the Northeast Church complex and not merely abutting it. The southerly room had a $20-25 \mathrm{~cm}$ plaster floor (F568) overlaying a stone floor (F571) of basalt and limestone pieces. The chamber 
inside the gate had a similar plaster floor but in poorer condition. Of note is a bench along the western wall of this larger room ( $40 \mathrm{~cm}$ wide and $25 \mathrm{~cm}$ tall).

The Northeast Church complex has benches of similar proportions in many its rooms. In the domus benches line both aisles. The south vaulted chamber has benches on three walls. Small benches have been found in the north medial chamber and in the skeuophylakion. Lacunae for several benches can be seen along the east edge of the portico on the west side of W511. We suspect that the benches may be indicative of the memorial nature of the complex. The entrance hall for the church (L200) of the Monastery of St. Martyrius at Ma'ale Adummim has benches on three sides. At the center of the hall is a tombstone with the inscription, "Tomb of Paul, the priest and archimandrite." ${ }^{119}$ Likewise, the mortuary church at Jerash has benches on three sides. ${ }^{120}$

We further suggest that the large room inside the south gate had a particular function. We note, in addition to its size, that this room stands opposite the only entrance to the church kept open after other usage ceased. This entrance provided access to the tomb of the elderly woman, whose ongoing veneration has been previously discussed. We have posited that the large diakonikon with its cistern may have been part of a healing cult centered at the tomb of the woman. We therefore speculate that this western chamber served as a place for incubatio - prayer, fasting and even deprivation of sleep prior to participation in healing rites. ${ }^{121}$

The chambers west of the street and the portico are reminiscent of later chambers built around portions of the atrium at such sites as the north church at Shivta. ${ }^{122}$ These chambers come from a later phase in the history of the Northeast Church. Likewise, the large cistern (Cistern C) was no longer in use, as the drainage system to it was covered (W585) and the head was replaced by a wall (W552). The stone floor (F571) may be a remnant of the paving around the cistern.

A least one wall has been identified going west from W591. A large pot $(45-50 \mathrm{~cm})$ containing several cooking pots and eggshells was retrieved from the area west of W591. To the north of the putative incubation chamber is a north-to-south wall (W1207) tied in to W574. It is the eastern wall of a small chamber $(1.6 \times 2.2 \mathrm{~m})$ with a threshold facing west. The door closed from inside this cell and provided access to a hard-packed surface where a hand mill

\footnotetext{
${ }^{119}$ Magen, "The Monastery of St Martyrius of Ma'ale Adummim,” 178.

${ }^{120}$ Butler and Smith, Early Churches in Syria, 213.

${ }^{121}$ For a parallel example of a place of incubation, see the discussion of the basilica at Dor along with pertinent citations from Greek and early Christian healing sources in Claudine Dauphin, "On the Pilgrim's Way to the Holy City of Jerusalem. The Basilica of Dor in Israel," in Archaeology and Biblical Interpretation, ed. John R Bartlett (New York: Routledge, 1997), 159-160.

122 Shlomo Margalit, "The North Church of Shivta: The Discovery of the First Church," Palestine Exploration Quarterly 119 (1987): 107.
} 
was recovered. To the east of W1207 a limestone block that may have been part of a protruding shelf was recovered from the fill. The shelf was inscribed with a flared cross (17 x $17 \mathrm{~cm})$.

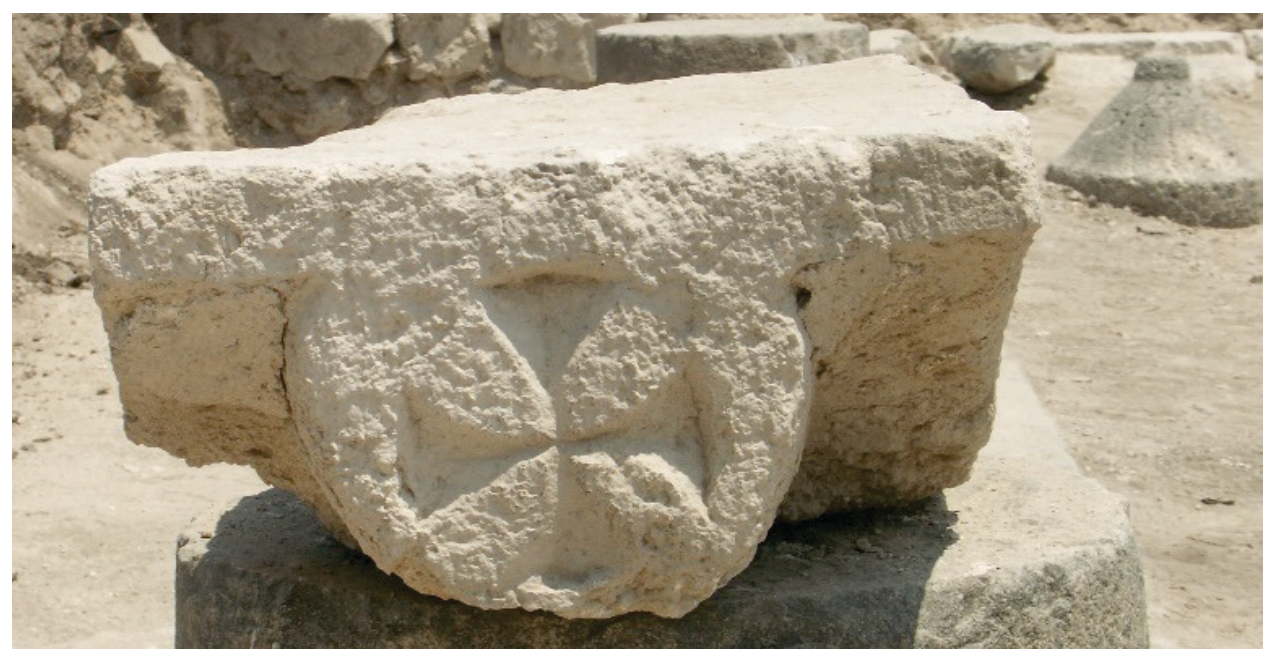

Figure 159 Shelf with cross

West of the stylobate, we excavated to the level of the mud and plaster surface. W553 continues to the west. To the north is a perpendicular wall (W1232) the base of which floats about $25 \mathrm{~cm}$ above the stylobate. W594 floats at a similar height.

Two coins were in the fill to the south of the wall. One is from $263 \mathrm{CE}$, a Roman imperial coin of Gallienus. The other coin was too worn for identification. In addition, the fill was disturbed and contained modern intrusions, including burlap and a $2.86 \mathrm{~m}$ iron rake frame. The mud and plaster surface continues to the south to W1216 and suggesting the area was some sort of courtyard.

Two column drums were in the fill. The position of their fall suggests that they came from a missing column base on the stylobate. Both are $52 \mathrm{~cm}$ in diameter. The lower one is $90 \mathrm{~cm}$ in length; the upper one is $58 \mathrm{~cm}$.

Numerous metals were recovered from this location, including a nail bent $8 \mathrm{~cm}$ length and another unidentifiable coin. Many loose tesserae were recovered including some elongated pieces of limestone from which small cubes were being broken off or cut. ${ }^{123}$

From the level of this courtyard, we recovered part of a copper chain of a polycandelon. The medallion had four l-shaped slots cut in it forming a cross.

\footnotetext{
${ }^{123}$ Ruth Ovadiah and Asher Ovadiah, Mosaic Pavements in Israel: Hellenistic, Roman, and Early Byzantine, Bibliotheca archaeologica 6 (Roma: "L’Erma” di Bretschneider, 1987), 146-150.
} 


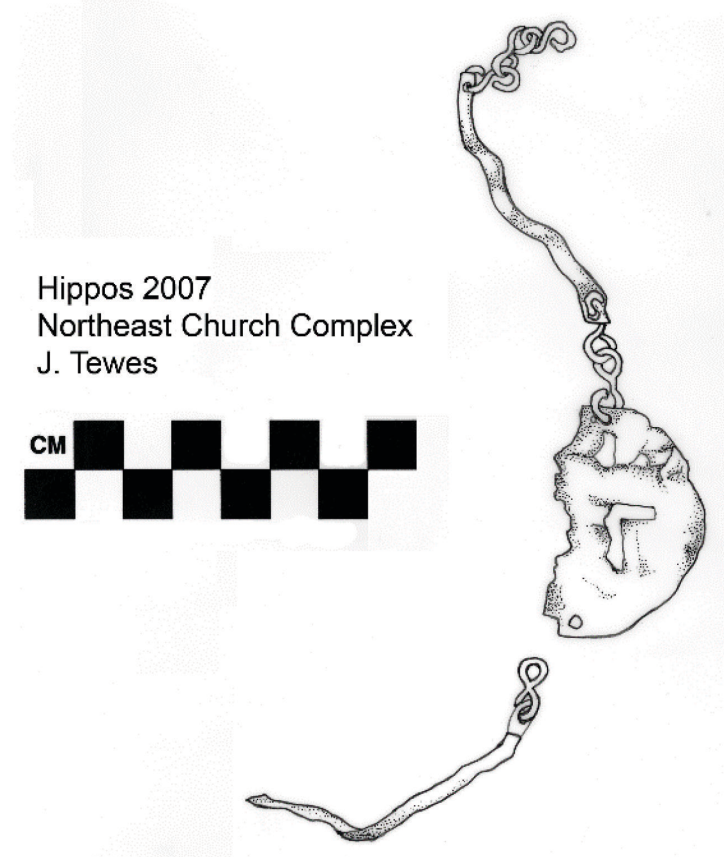

Figure 160 Polycandelon fragment

There is a staircase rising from the north on the east side of the room formed by W1216, W1207, W574, and W1208.

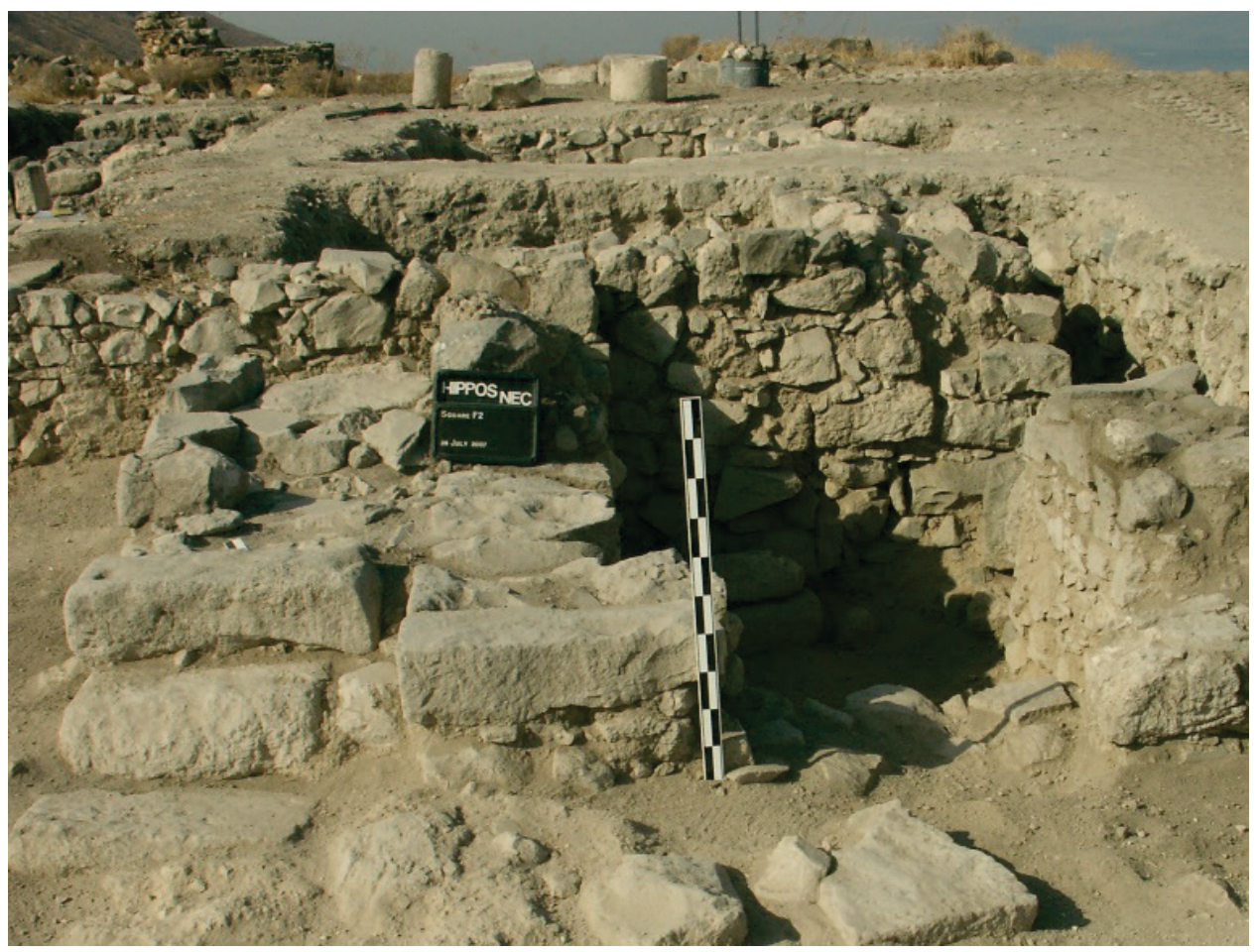

Figure 161 Stairs west of portico (looking south) 
Three steps are in situ. The average tread depth is $28 \mathrm{~cm}$, and the average rise is $24 \mathrm{~cm}$. Since $2.9 \mathrm{~m}$ of steps have been robbed out, the staircase could have contained an addition ten stairs, rising to about $2.9 \mathrm{~m}$ above the first step and $3.4 \mathrm{~m}$ above the threshold of the small room. Such a height suggests that the stair gave access to a second story or roof over the large room to the south.

South of Building Gamma, we excavated between W569 and W1244 to test the hypothesis that this space was a plaza like the paved plaza between Building Alpha and Building Beta previously described.

To the west we identified a thick (1.2 m) wall (W1269) abutting W569 and proceeding south for $2.2 \mathrm{~m}$ where it formed a corner with W1282 to the west. The bases of both walls float at an elevation of 130.40 , approximately $30 \mathrm{~m}$ above the floor level of the putative plaza. The level of these walls is like the wall previously removed that floated above the line of the stylobate of the portico of the church and likely comes from agrarian usage of the site significantly after the earthquake.
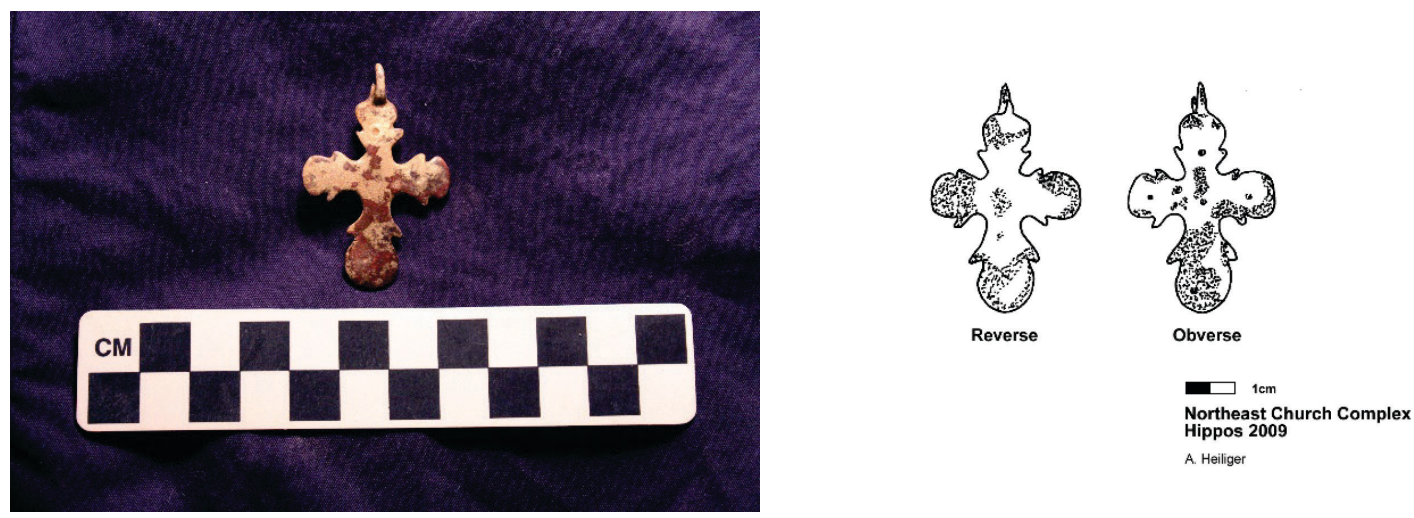

Figure 162 Cross pendant

To the west of the wall at its base level a small cross pendant was discovered. The pendant is simply made of a bronze alloy. It is $3.1 \mathrm{~cm} \mathrm{x} 4.1 \mathrm{~cm}$ with a $7 \mathrm{~mm}$ eyelet (broken) at the top. The design is Type III in Pitarakis' typology, ${ }^{124}$ flared cross arms that are extended by disks protruding from the arms. On the obverse are five punched dots seemingly surrounded by circles, one on each of the cardinal points and one at the intersection of the arms, the clearest example being on the upper arm. As there are only five, they likely refer to the wounds of Christ (head, hands, feet and side). However, some Late Antique crosses are covered with such punched dots that have been interpreted as protective "evil eye" dots. ${ }^{125}$ The reverse is plain. The discovery of such a cross at this level may attest to the persistence of

\footnotetext{
${ }^{124}$ Brigitte Pitarakis, Les Croix-Reliquaires Pectorales Byzantines En Bronze, Bibliothèque des cahiers archéologiques 16 (Paris: Picard, 2006), 30, 32; catalog numbers 102-106, 196, 213, 232, 234, 588.

${ }^{125}$ Ibid., 131, fig. 81, nos. 1 and 2.
} 
some Christian piety after the destruction of Hippos in 749 C.E. The cross type was particularly popular in the ninth and tenth centuries. ${ }^{126}$

Just to the west of Cardo 2 North, we have tentatively identified a wall (W1273) blocking access to the space. Its construction is very poor, essentially stones and some architectural fragments piled up in a line with only some pieces of the lowest course indicating the line of the wall.

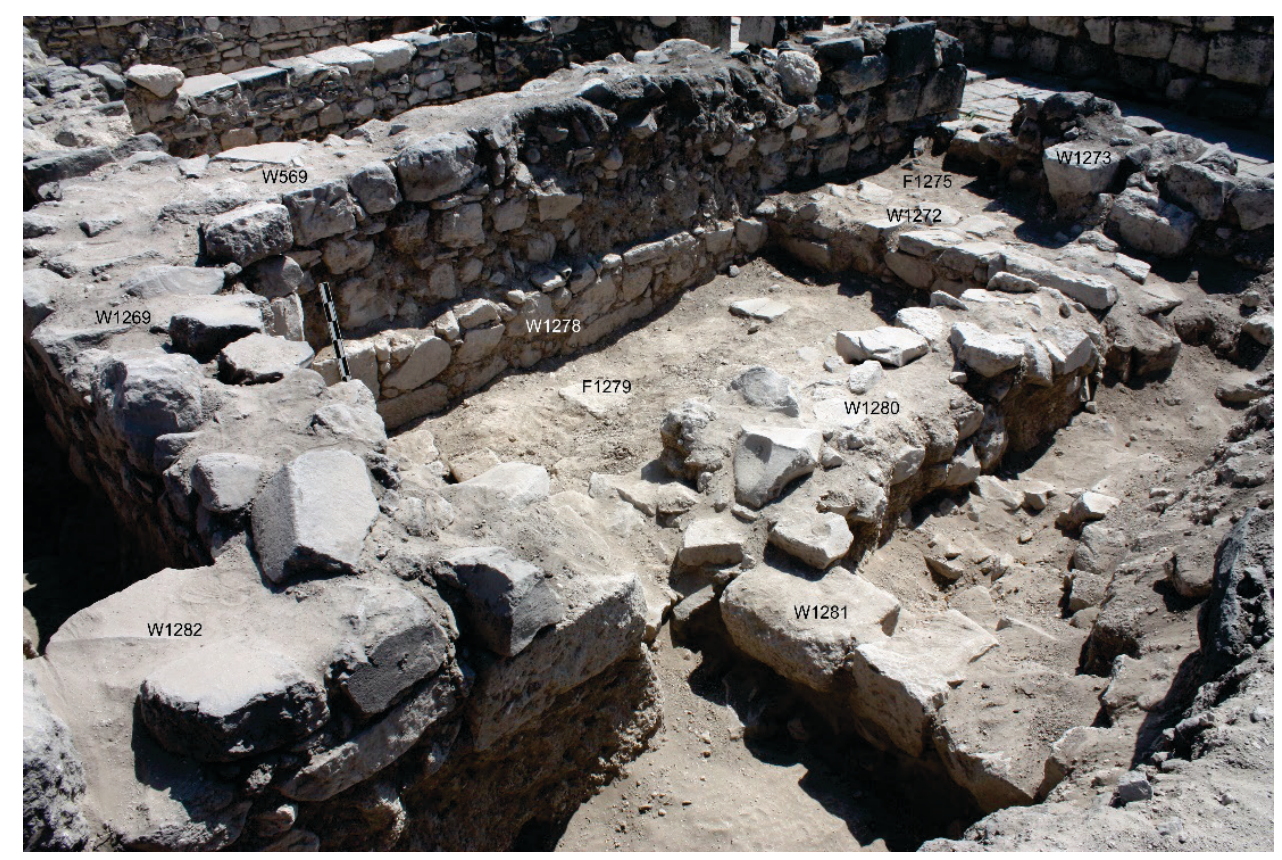

Figure 163 South of Building Gamma west of Cardo 2 North (looking northeast)

The remaining walls identified on the plan (W1272, W1278, W1280, W1281) survive only to the level of the base of W569 which sits on top of W1278. They attest to earlier structures on the site. However, there is no evidence that the space was paved. Rather, in similar fashion to the space west of the church's portico (F1214), the space had a mud surface mixed with some plaster (F1275).

We propose the following detailed sequence of construction, although we cannot state any firm dates for the phases. Earliest seem to be walls on north (W1278, under W569) and on the east (W1272, $1.60 \mathrm{~m}$ from the street). Contemporaneous to these walls is a lower surface/floor (elevation 129.70). Next were constructed the east-to-west wall in the south portion of the space (W1281) and a second wall (W1282) proceeding to the south from W1281. The bottoms of both walls are roughly level with the lower surface. Subsequently, W1278, W1272, W1280, W1281, and W1282 were taken down leaving a course of two. A packed surface was laid at a level over the top of the reduced walls creating a plaza of sorts (elevation

${ }^{126}$ Ibid., 30. 
130.10). The base of W569 is at this level. Later, a blocking wall closed the area (W1273). The floating walls (W1269 and W1282) were built on about $30 \mathrm{~cm}$ of destruction fill and at significantly later time.

\section{Remnants of Building Delta}
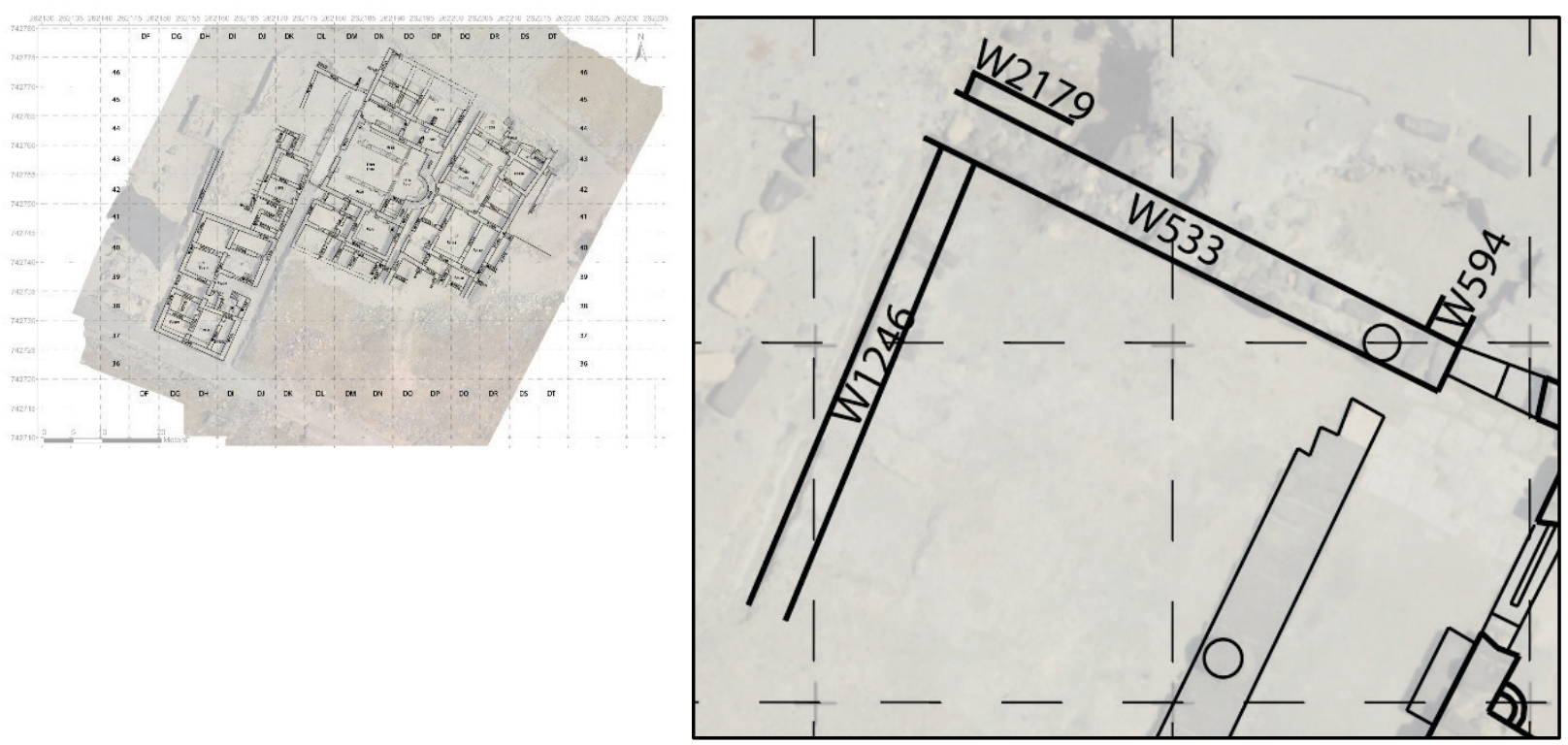

Figure 164 Building Delta

A $1 \mathrm{~m}$ trench was opened perpendicular to and west of the stylobate for the portico west of the church. The top 35-50 cm of the trench were the mud/plaster layer identified as F1214.

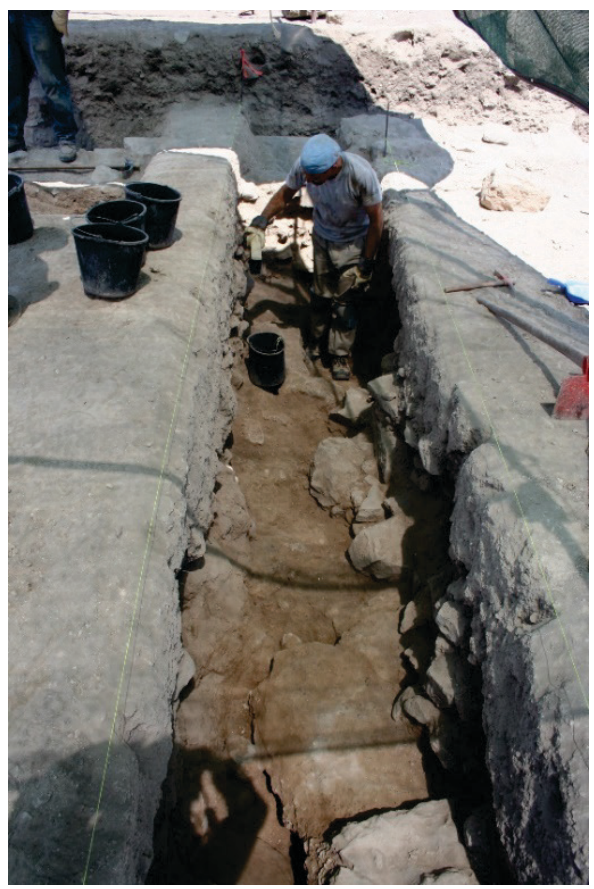

Figure 165 Probe perpendicular to the stylobate (looking west) 
A level of cobbles appeared about $50 \mathrm{~cm}$ below the top of the floor (F1214). Below the cobbles, the soil (L1248) was softer and contained heavy destruction fill.

At about $1.1 \mathrm{~m}$ below the surface of F1214, bedrock was exposed through the length of the trench. To the east, the builders cut a foundation trench in the marl, filled it with stones and then laid a single course of stones as a foundation for the stylobate. To the west, the builders erected the wall (W1246) directly on the hard limestone. Trenching on its western line reveals that its external surface is to the west and that it proceeds to the north under W553. The wall is $70 \mathrm{~cm}$ wide.

Two trenches were dug north of W553 in line with W1246 and with the stylobate. An eastto-west wall (W2179) was identified forming a corner with W1246 and seemingly forming a corner on the east in line with the stylobate. In the westerly probe, bedrock was reached.

Two courses of stone sit on the cut bedrock on a layer of shards and small stones. The fanning of the tumble to the northwest suggests a collapse of earlier (and higher) parts of the wall in an earthquake. W1246 and W2179, both under W553, are likely the surviving foundation courses of a Building Deltat that antedated the stylobate and sat on the western side of Cardo 2 North.

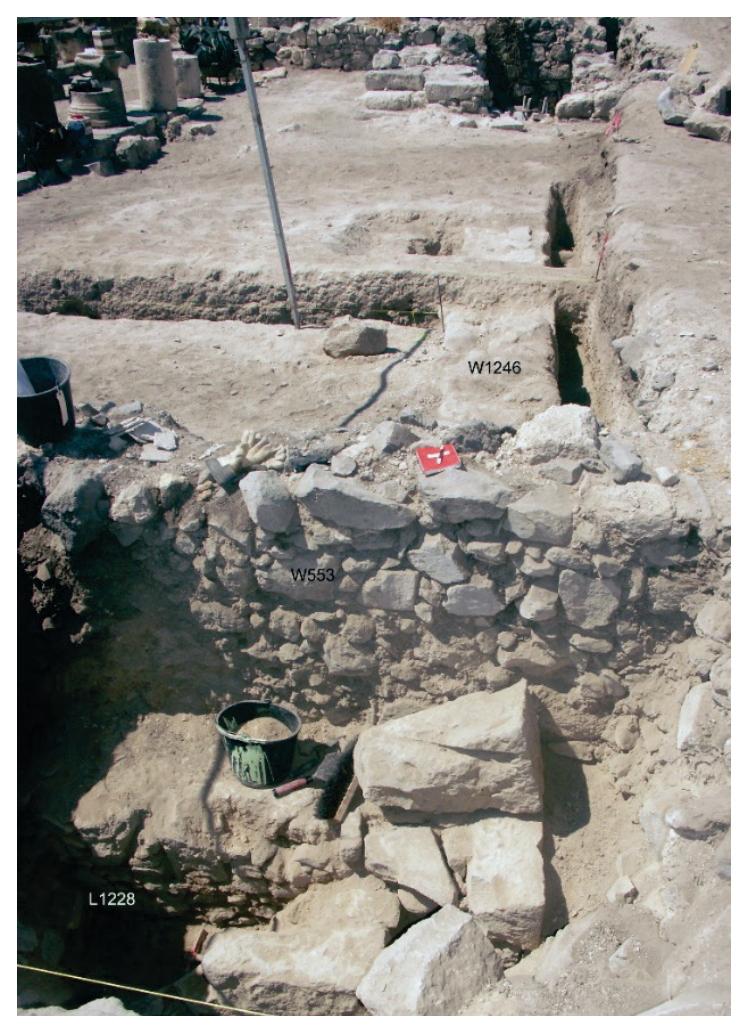

Figure 166 Probe north of W553 (looking south) 
The pottery collection from these probes is helpful in dating construction. Shards sealed in the plaster floor are late fifth to mid-sixth century material, including Phocaean Red Slip form 3C (ca. 460-490 CE) and Phocaean Red Slip form 3H (ca. mid-sixth century). From beneath the floor came common wares of the third to fourth century. From the base of the foundation trench came common wares of the fifth century and an African Red Slip Ware form 91 flanged bowl, probably variant B and dated to 450-530 CE. We conclude that Building Delta was constructed in the fifth century to be replaced by the church complex (or at least F1214) in the late fifth or early sixth centuries. 
The Northeast Insulae Project 


\section{4.}

\section{MODELING}

$\mathrm{T}$

oward the end of the 2009 season, a survey of the Northeast Church complex was conducted by Wayne L. Mory, PLS, and Mark Wood, PLS, of American Surveying \& Engineering, P.C., a privately held, multi-disciplined surveying and engineering firm with offices in Chicago, Dixon and Aurora, Illinois.

Their work product used LiDAR methodology. LiDAR, which stands for Light Detection and Ranging, is a remote-sensing method that uses light in the form of a pulsed laser to measure ranges (variable distances) to an object. These light pulses generate precise, three-dimensional information about the object. Data was collected using a Leica ScanStation provided by Mabat 3D Technologies, Ltd., from Tirat-Carmel.

The survey of the Northeast Church complex consisted of thirteen scan worlds that were registered into a point cloud- a measurable mirror image of reality that can be surveyed virtually.

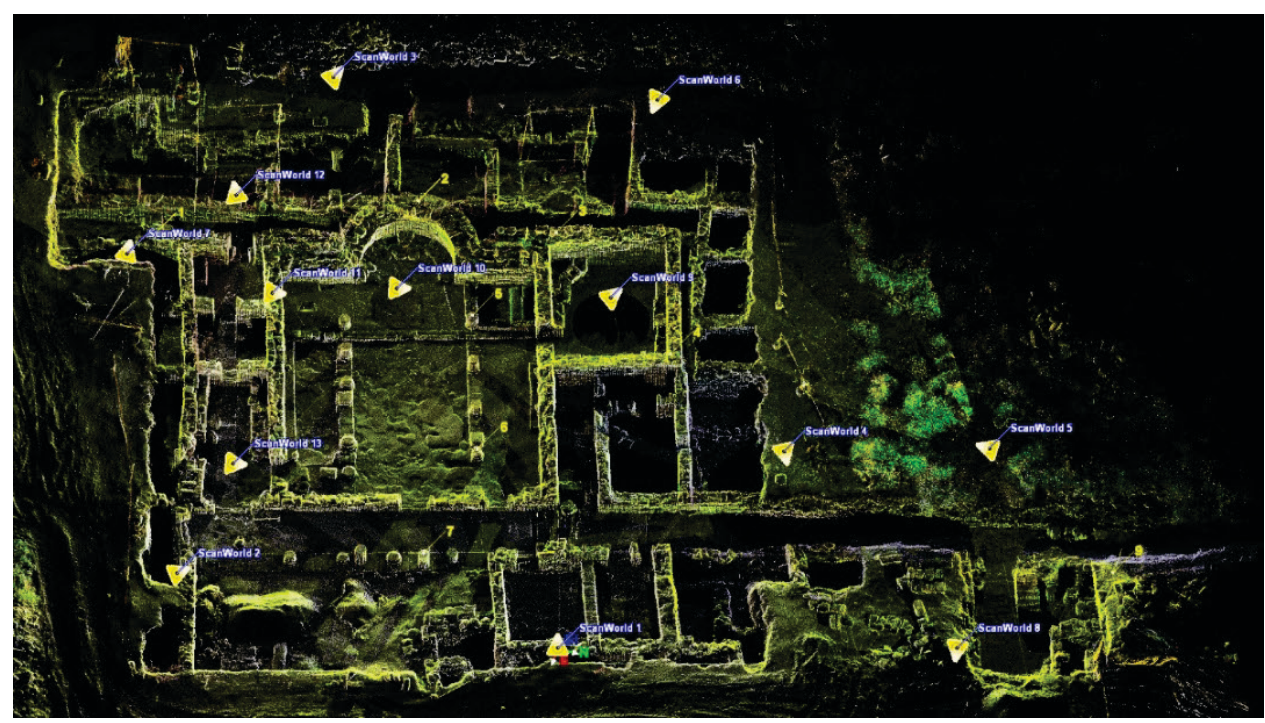

Figure 167 Point cloud 
Point clouds may be rendered with photography or may be used as the basis for highly accurate 3D modeling. The point cloud also serves as a permanent and detailed record of the architectural remains of the Northeast Insulae Project.

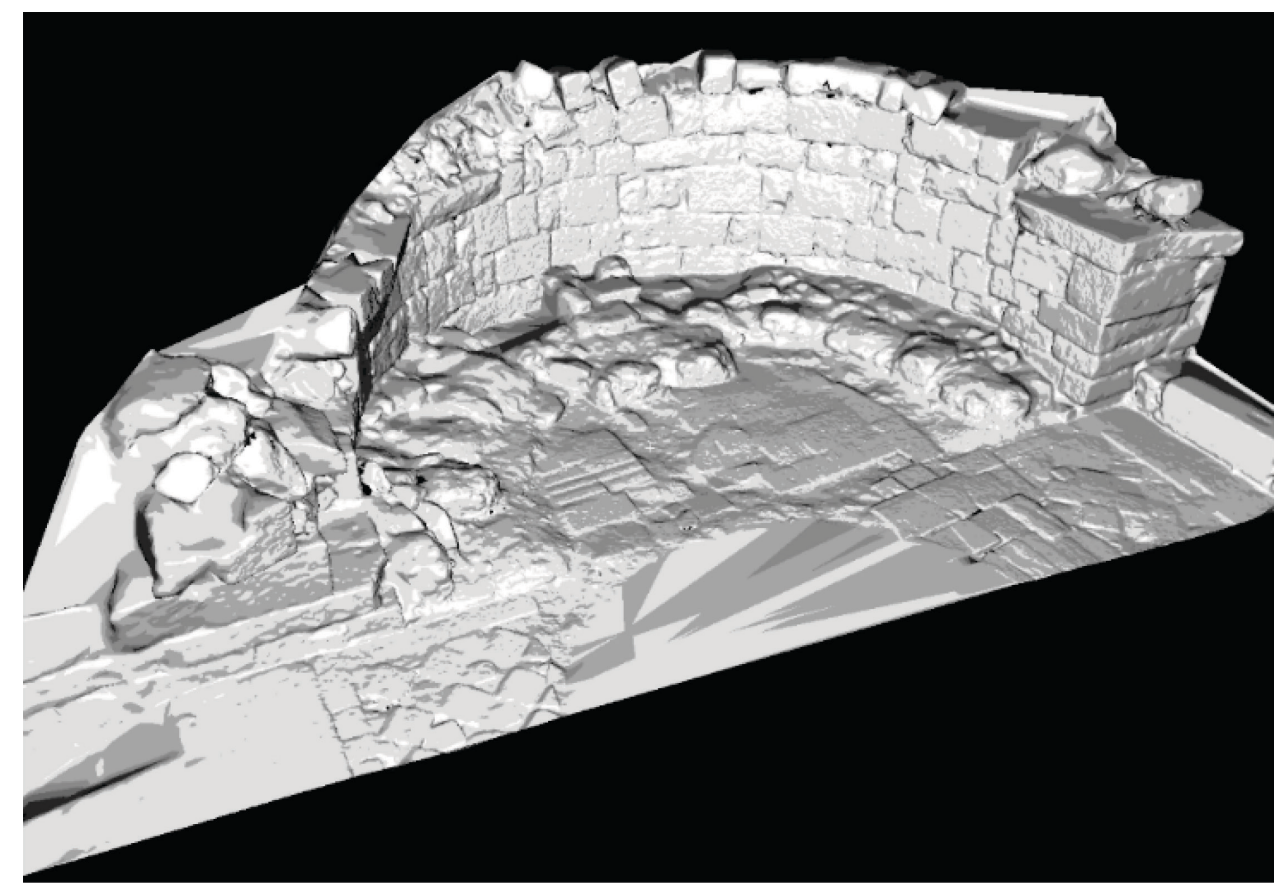

Figure 168 3D model of apse

3D models can also be produced using a second technology: photogrammetry. Photogrammetry is the science and technology of obtaining reliable information about physical objects and the environment through the process of recording, measuring, and interpreting photographic images. It extracts three-dimensional measurements from two-dimensional data (i.e., images); for example, the distance between two points that lie on a plane parallel to the photographic image plane can be determined by measuring their distance on the image.

In 2015, photogrammetry using a camera suspended from a $4 \mathrm{~m}$ pole produced a 3D model and orthographic photo of the Northeast Church.

In 2016, a drone was used to produce a 3D model and orthographic image of the entire Northeast Insulae Project via photogrammetry.

Both models are courtesy of the Hippos Excavations and of the Photogrammetry Lab of the Zinman Institute of Archaeology at the University of Haifa. 


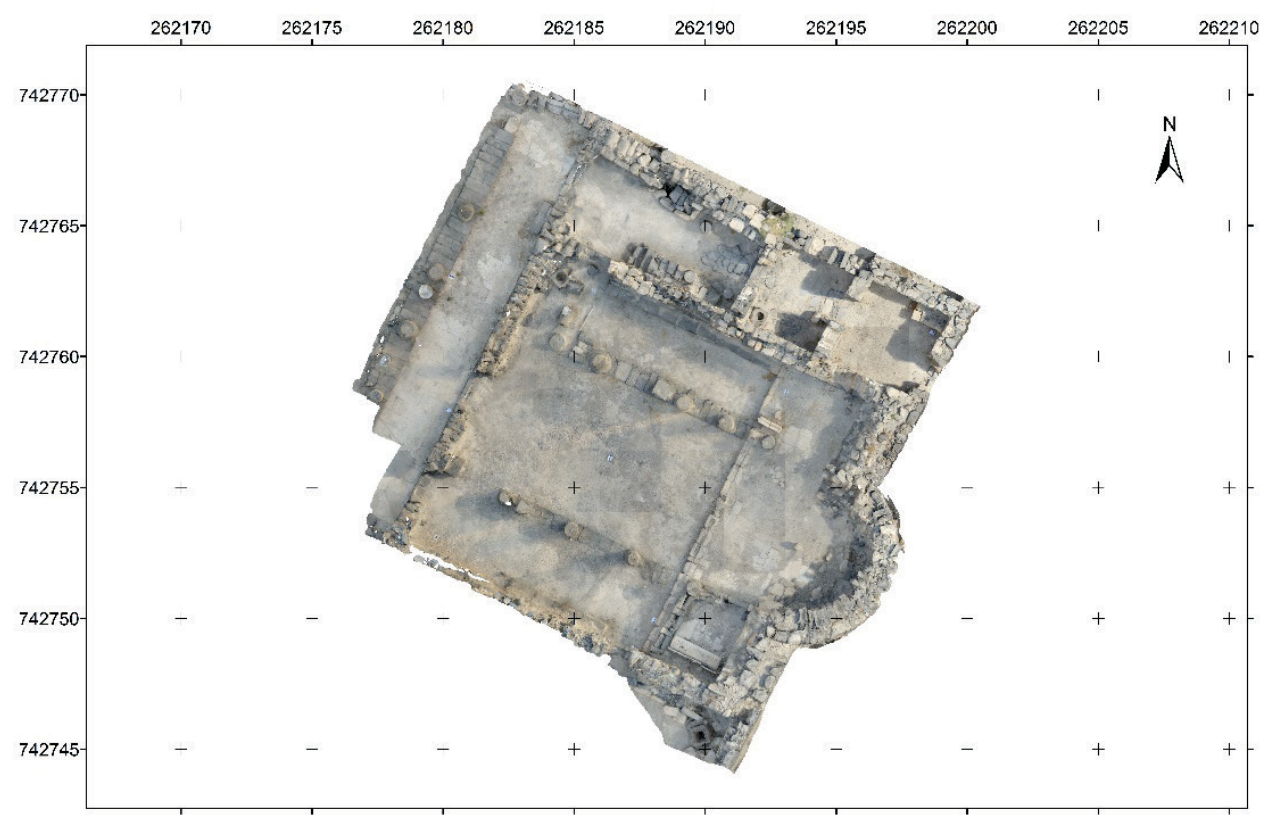

Figure 169 Photogrammetric Model of the Northeast Church (Courtesy of the Hippos-Sussita Excavations. Used with permission.)

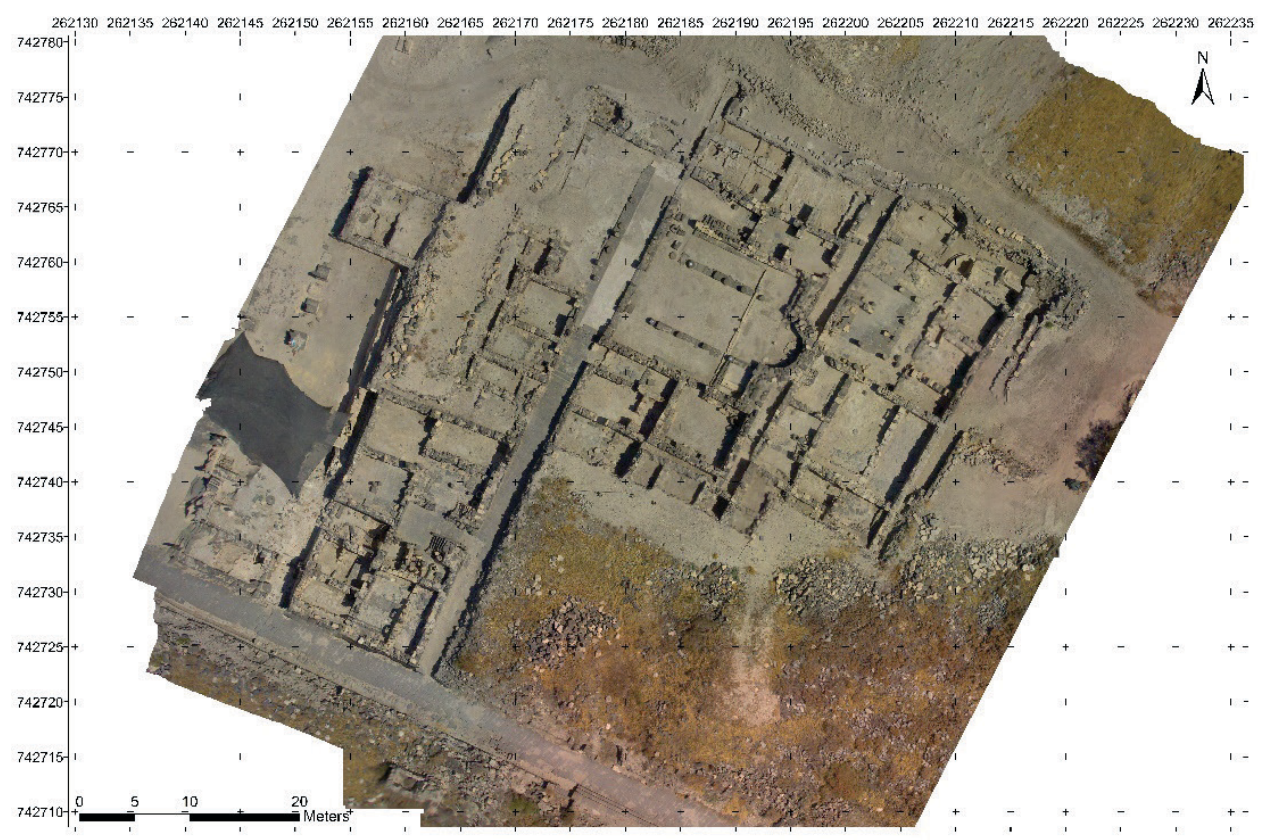

Figure 170 Photogrammetic model of the northeast insulae (Courtesy of the Hippos-Sussita Excavations. Used with permission.)

In 2019, after conclusion of all fieldwork, a second scanning project was undertaken using LiDAR methodology. Again, due to the generosity of Wayne Mory, PLS, the team brought to the site a Leica BLK360 digital scanner for documentation purposes. 181 scans were made of various subsections of the site, of which 141 were merged into the final digital model using Autodesk Recap Pro, Leica Register 360 and Nubigon Pro. The first finalized iteration 
includes the entire point cloud and shows the northeast insulae in the context of surrounding features.

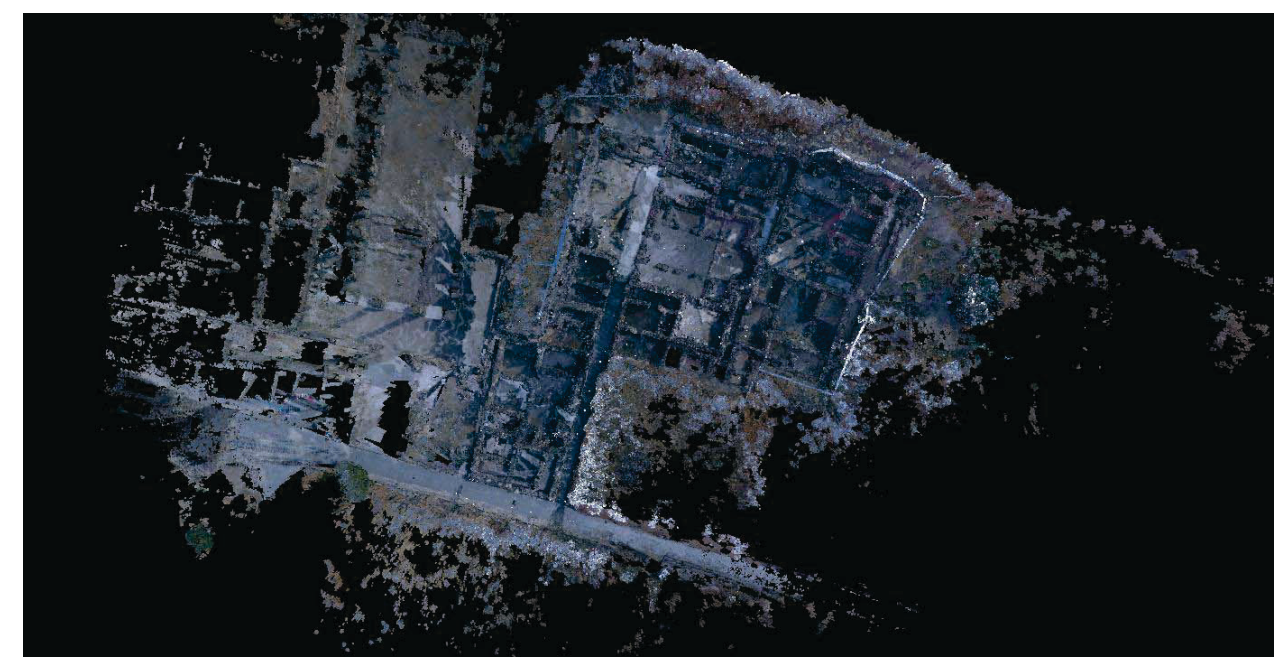

Figure 171 NIP with basilica to the west

After cropping and cleaning, the point cloud shows only the northeast insulae.

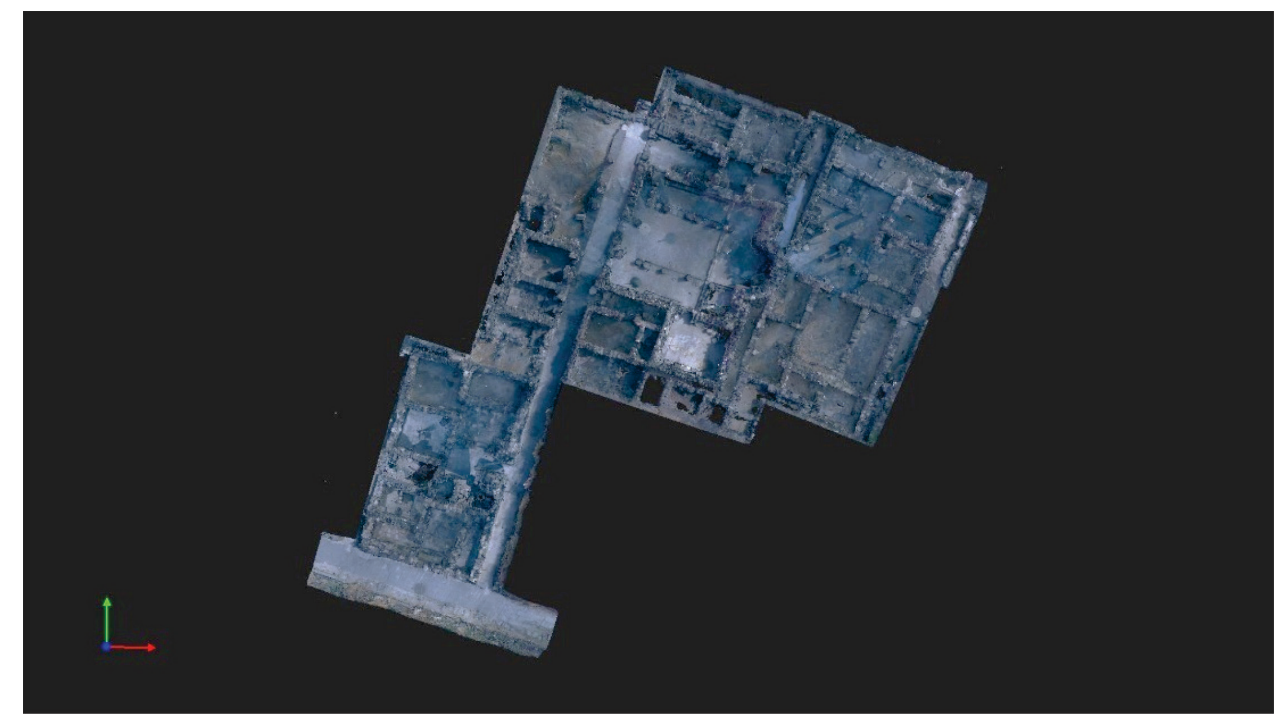

Figure 172 Northeast Insulae Project 


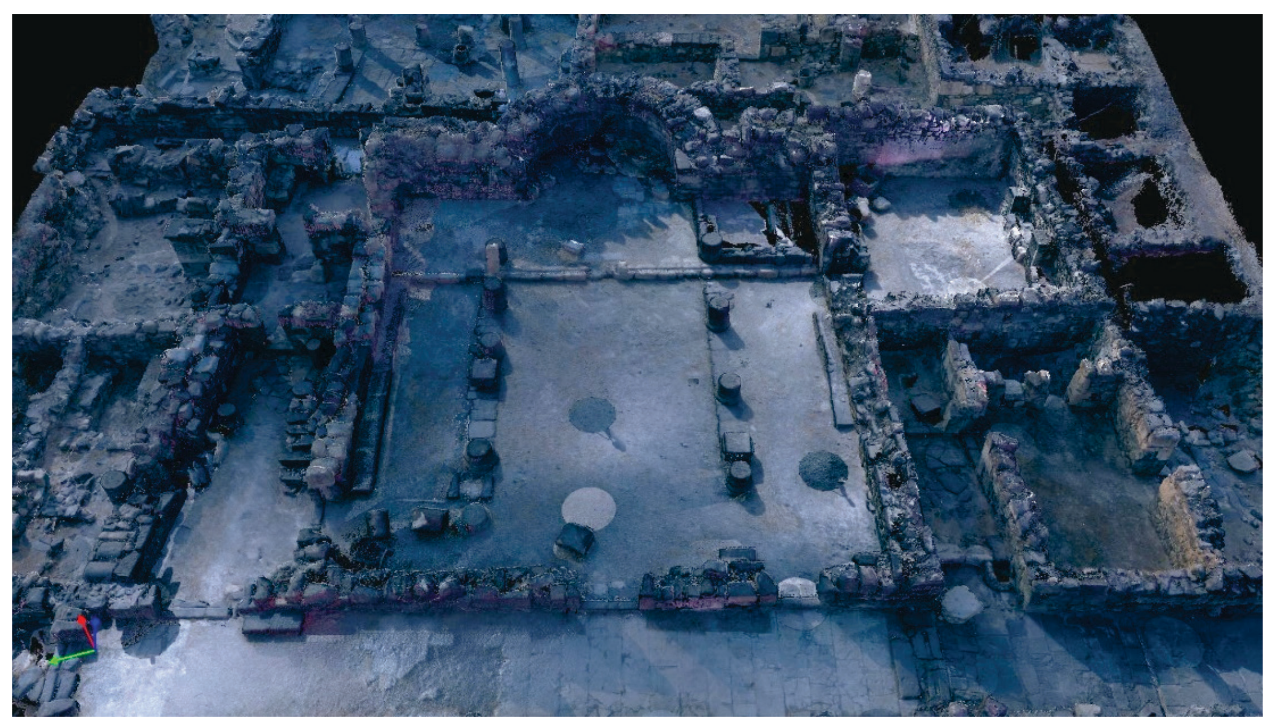

Figure 173 Northeast Church

Even fine details are viewable.

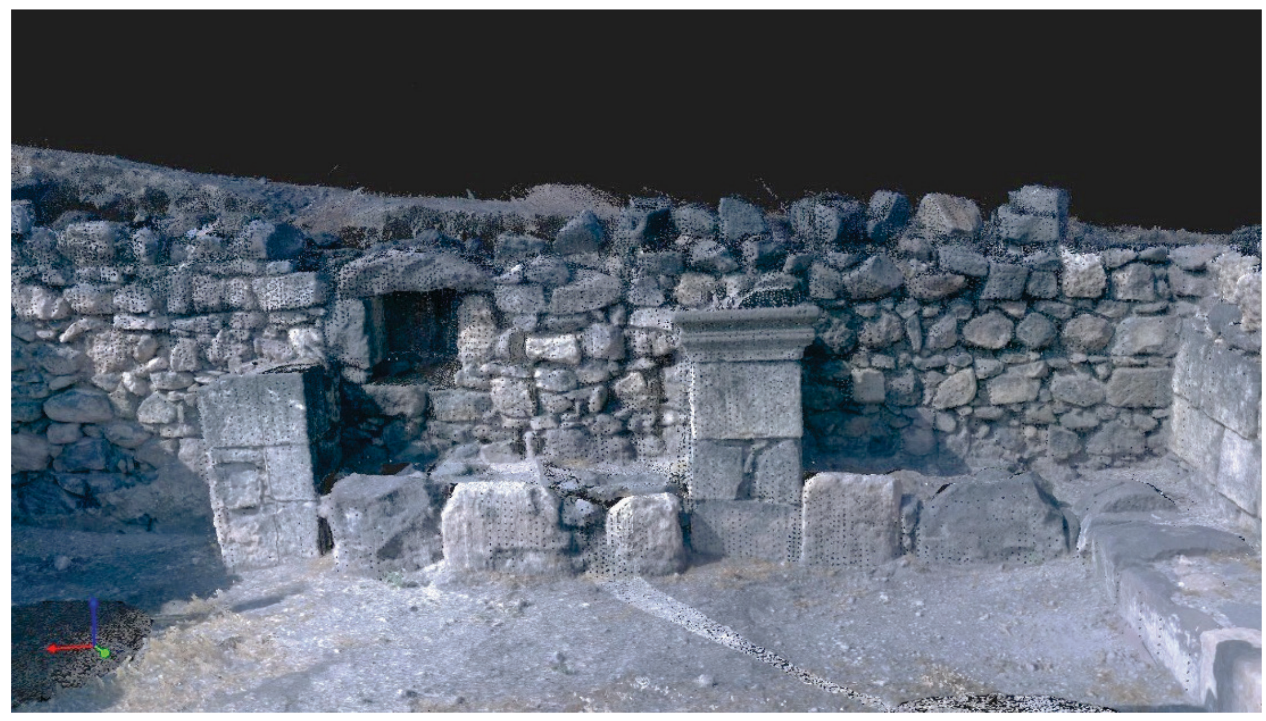

Figure 174 South wall and niche from the diakonikon

Whereas LiDAR produced a model that is quite precise and detailed and moves more easily into CAD software, photogrammetry produces a model that is more visually appealing, even if slightly less precise. Here are two examples, the first produced with LiDAR and the second produced with photogrammetry. 


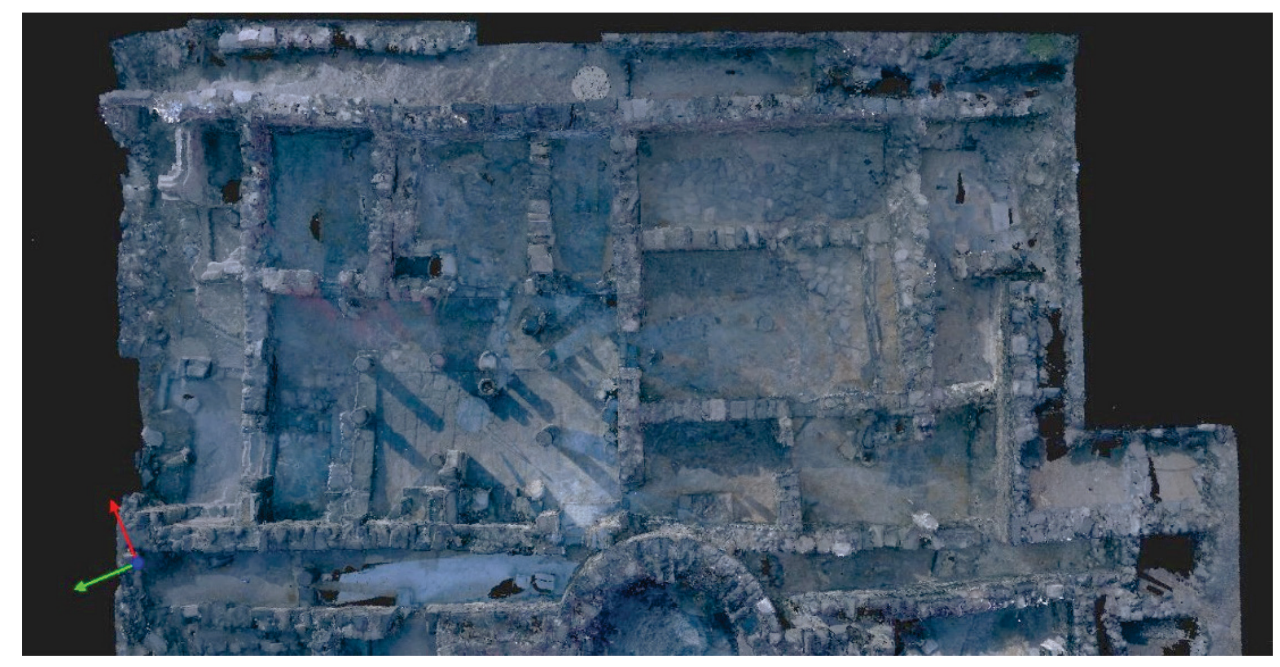

Figure 175 LiDAR of the House of Tyche

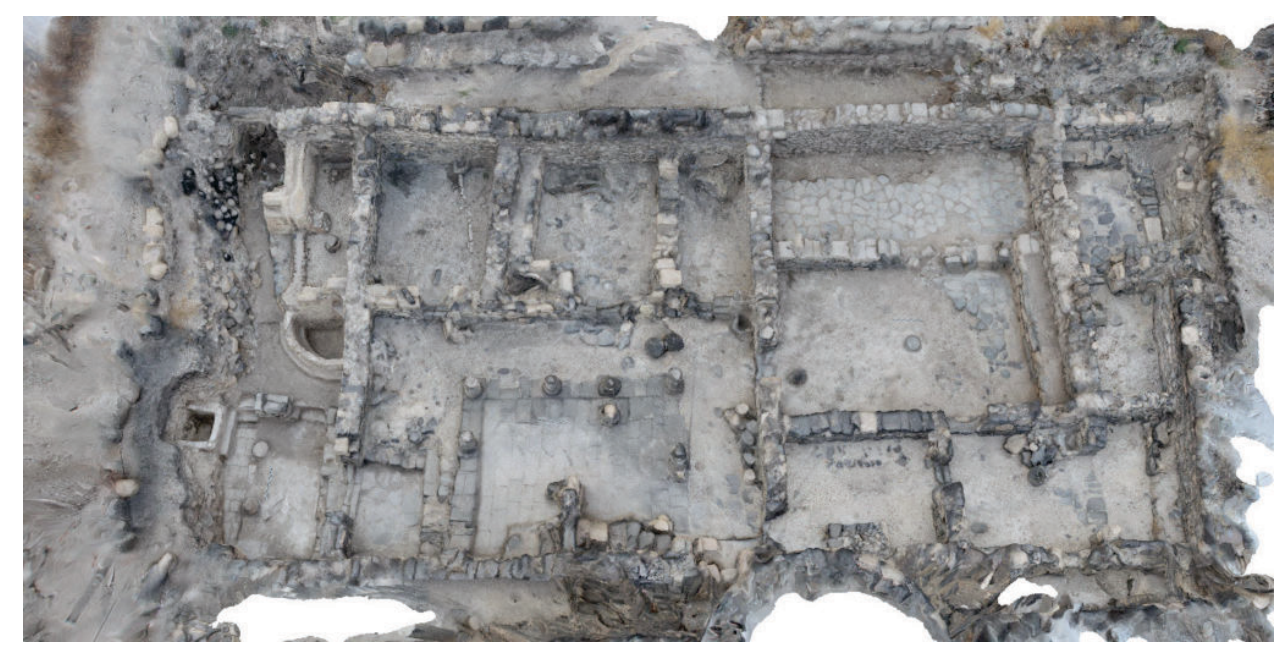

Figure 176 Photogrammetry of the House of Tyche

One can orbit and zoom in the model to get at details of the excavation.

A decimated version may be viewed on Sketchfab.com and the full model may be accessed at OpenHeritage3D.org. ${ }^{127}$

The registration report attests to the precision of the LiDAR model.

${ }^{127}$ Links to the models are available through the excavation website (https://www.northeastinsulaeproject.org). 
Cyclone REGISTER 360

Registration Report

Northeast Insulae Project at the Hippos Excavations

Sep 2, 2021

Certified by:

Mark Schuler, ThD

Professor of Theology, Greek and Archaeology

Concordia University, Saint Paul

https://nip.hippos.markschuler.com

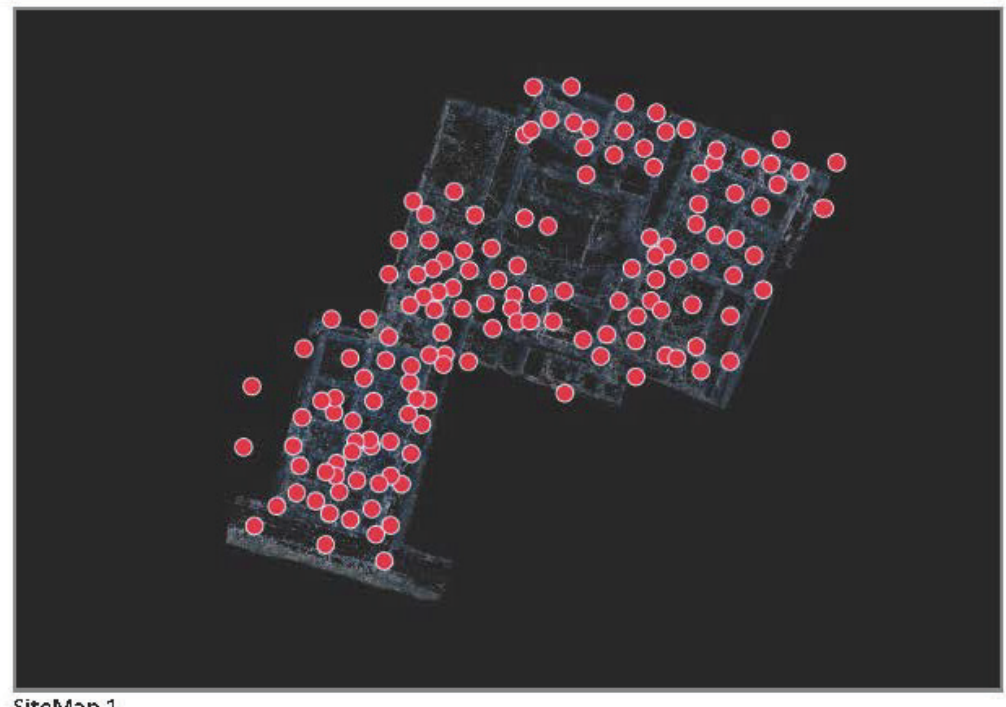

SiteMap 1

Overall Quality

Error Results for Bundle 1

$\begin{array}{ll}\text { Setup Count: } & 145 \\ \text { Link Count: } & 381 \\ \text { Strength: } & 68 \% \\ \text { Overlap: } & 48 \%\end{array}$

\begin{tabular}{|c|c|}
\hline \multicolumn{3}{|c|}{ Bundle Error } \\
$0.014 \mathrm{~m}$ & $\checkmark$ \\
\hline \multicolumn{3}{|c|}{ Overlap } & Strength \\
$48 \% \quad \checkmark$ & $68 \% \quad \checkmark$ \\
\hline
\end{tabular}


The Northeast Insulae Project 


\section{5. \\ BELOW GROUND: CISTERNS AND BURIALS}

$\boldsymbol{T}$ he architectural and materials remains of a site are the basis for its story. Remains be1 low the surface, specifically cisterns and tombs, are also essential to the telling, even if their appearance is not obvious.

\section{Cisterns}

The primary water source for Hippos was a $52 \mathrm{~km}$ water system consisting of three aqueducts that brought water from the Golan through an inverted siphon across the saddle to a reservoir under forum of the city. Plasters from the system are dated by Carbon 14 from 50 BCE to $240 \mathrm{CE} .{ }^{128}$ Although parts of the system continued to function until the earthquake of 749 , by the Late Antique period cistern construction proliferated across the mountain and may have served as the primary water source for most purposes. Nine cisterns have been identified from the northeast insulae.

\section{Cistern A}

Cistern A is in the northwest corner of the domus. The head for this cistern is a piece of aqueduct pipe possibly from one of the aqueducts of the city and attesting to their deterioration. The cistern is roughly bell-shaped. It is fed by a basin that channels water through W521 and then into the cistern. At least two layers of plaster were visible in the throat area

\footnotetext{
${ }^{128}$ Zeev Meshel et al., The Water-Supply System of Susita (Tel Aviv: Tel Aviv Univ. Pr., 1998), 69-72.
} 
of the cistern. The top layer of plaster was pinkish in color. Based on the profile, we estimate the volume of the cistern to be fifteen cubic meters.

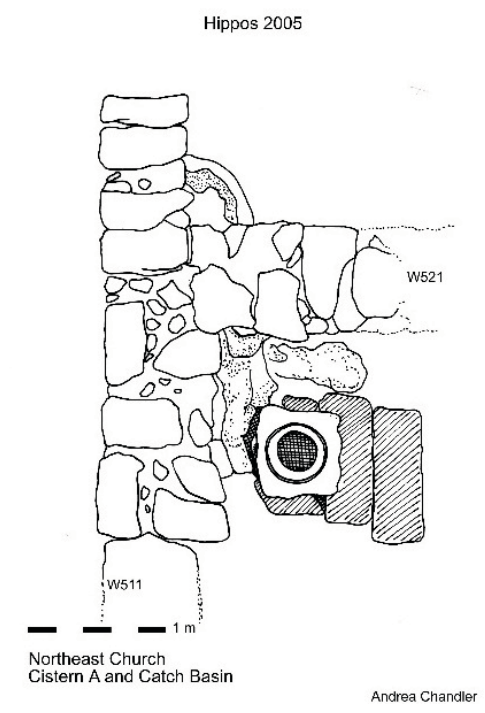

Figure 177 Head and catch basin

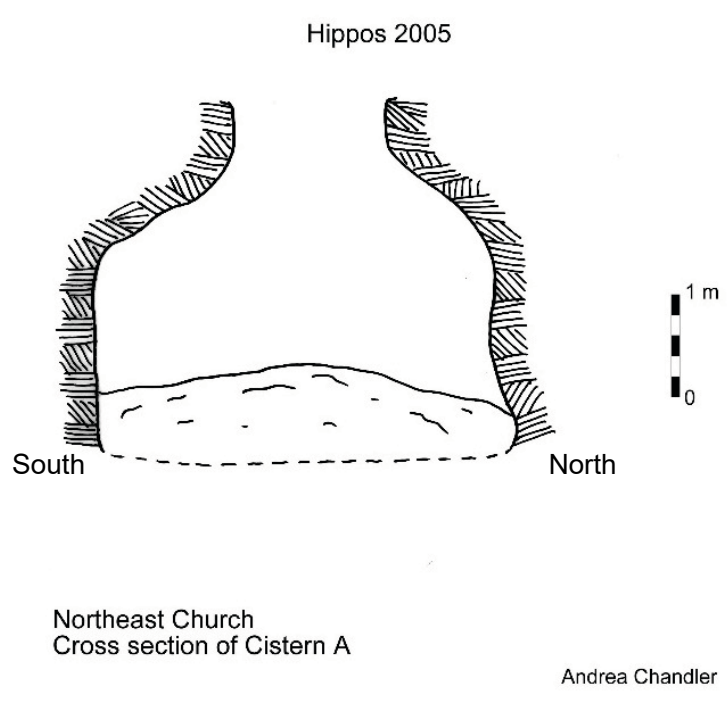

Figure 178 Cross section of Cistern A

The pavers next to the cistern head and the irregular entrance configuration to the north aisle (from the north instead of from the west) suggest that this cistern was part of an earlier structure. We posit it was part of the peristyle court of domestic compound that previously occupied the site.

\section{Cistern B}

Cistern B is located on the north side of the north lateral chamber. Cistern B is also roughly bell-shaped. The cistern is fed by a basin to its south and east. The basin is plastered into W555, which framed the cistern opening. The wall is a later addition appended to the south side of W540. It may have been part of a repair or part of the blockage of a doorway into the North Building from the east part of the north lateral chamber. It likely comes from a later period of the compound's usage.

As is indicated by both the floor profile and the cross section, the cistern is irregularly carved. In one place it shows a square corner. Elsewhere stone nodules protrude, especially from the ceiling. One possibility is that the cistern made partial use of a pre-exiting fissure in the rock (lava tube?). Plaster recovered from the cistern is grayish in color. We estimate the volume of Cistern B to be just under thirteen cubic meters. 


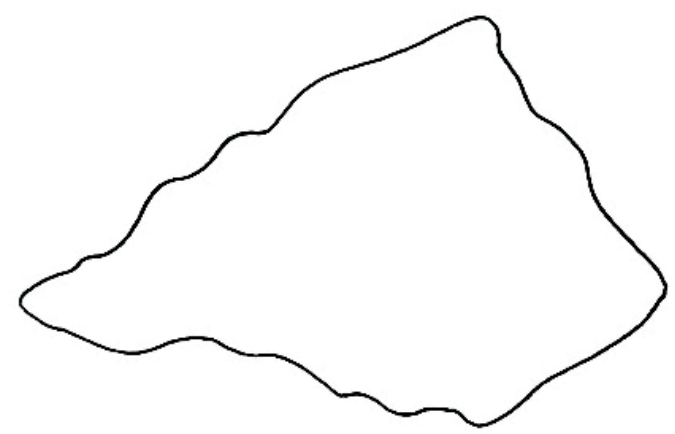

South

North

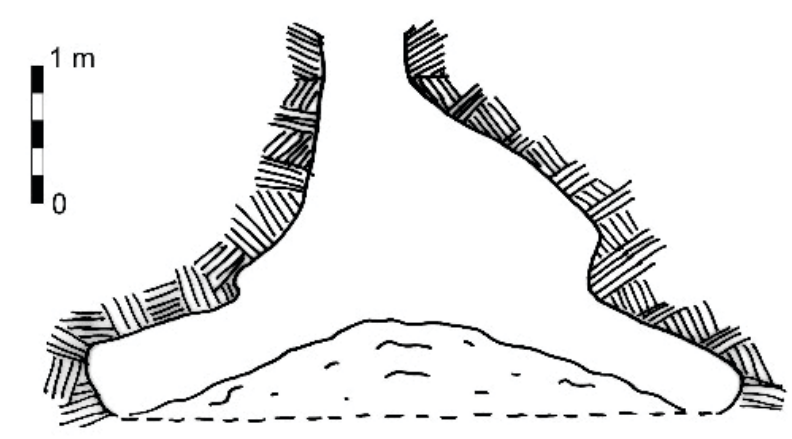

Northeast Church

Cross Section of Cistern B

Andrea Chandler

Figure 179 Cistern B

\section{Cistern C}

Cistern $\mathrm{C}$ is located $4.25 \mathrm{~m}$ south of the entrance to the portico of the church and on the west side of the Cardo 2 North. It is on a line with the stylobate of the portico.

Cistern $\mathrm{C}$ was fed by a channel that crosses the street from east to west. The cistern has an oval horizontal profile $(2.2 \times 4.7 \mathrm{~m})$ and is bell-shaped. It is approximately three meters deeper than the other cisterns and has an estimated volume of almost twenty-nine cubic meters.

The larger size and the location of the neck outside of the gate of the church compound may point to public usage or that Cistern $\mathrm{C}$ may have pre-existed the construction of the Northeast Church complex.

Recovered plaster is grayish in color. 


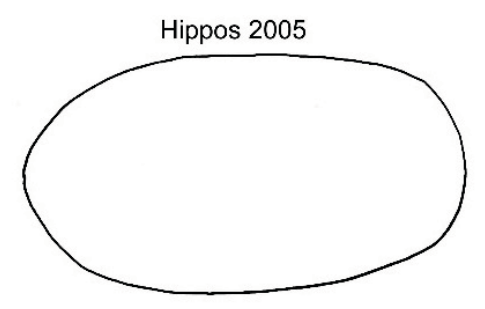

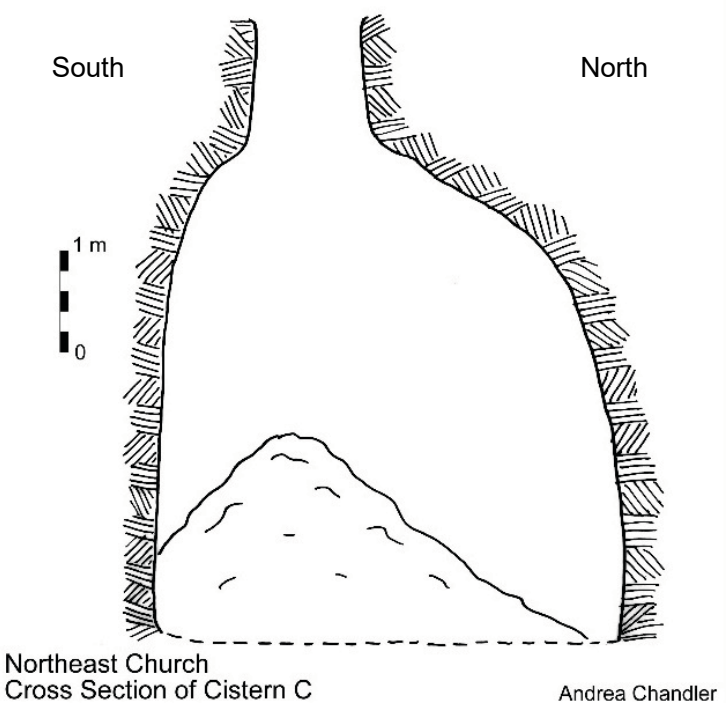

Figure 180 Profile of Cistern C

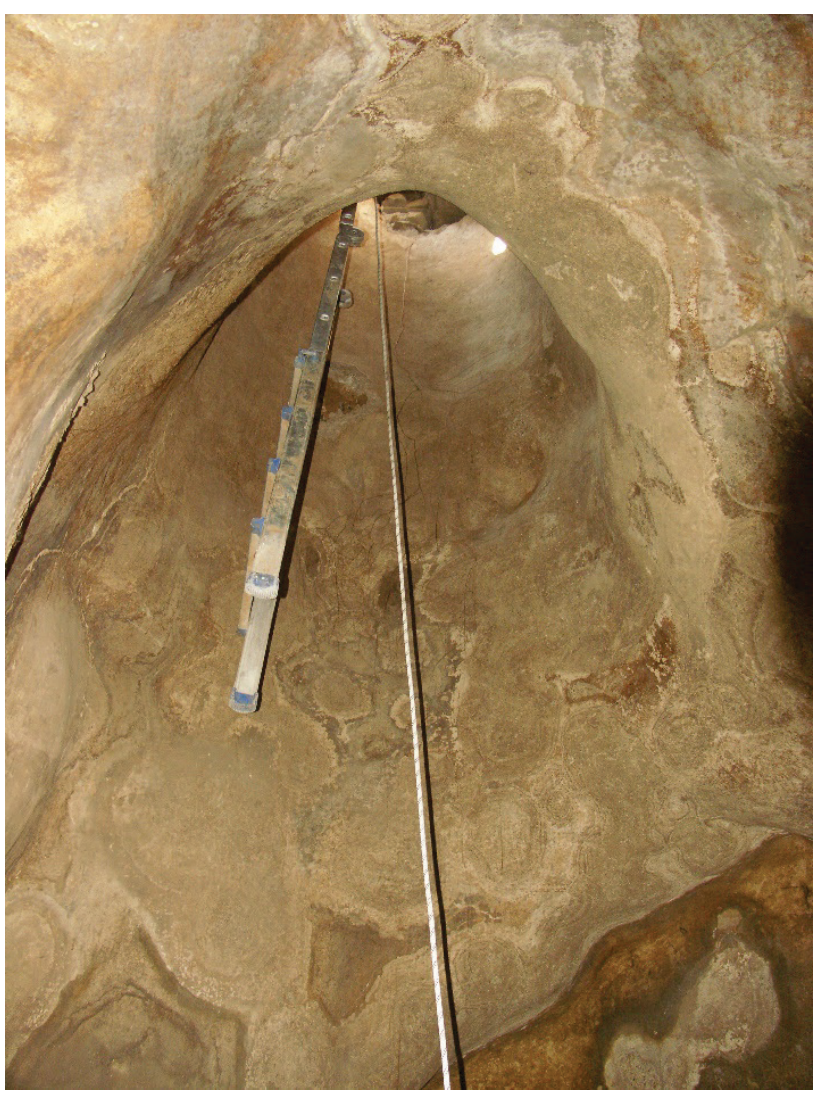

Figure 181 Cistern C

\section{Cistern D}

Cistern D is in the northeast corner of the south vaulted chamber. It's unusual location inside the diakonikon is noteworthy.

Cistern D was constructed by digging a pit down and slightly into the bedrock. Crudely worked stone blocks were stacked in layers to construct the cavity and neck of the cistern. The cistern was then sealed with two layers of plaster, the second perhaps being applied later. The initial layer was hard grayish plaster with fine agate particles (1-2 mm; medium sand No. 10-40). The secondary layer was softer and lighter with larger agate (4-7 mm; fine gravel).

We excavated this cistern in its entirety. The topmost part of the fill contained many large pieces of crumbling limestone and basalt. The thinner pieces of basalt (under $10 \mathrm{~cm}$ ) may be from the broken cistern cover, as the 2005 excavation found no lid. A large concentration of bones was uncovered in the southeast section of the floor. Several pieces of skull, a canine molar and numerous ribs and leg bones were among the pieces removed. Considering the size and shape of the bones, they may come from a dog or jackal. Other pieces of animal 
bones were found in the upper fill, including a large tooth (bovine?), several rat or small mammal skulls and some vertebrae (possibly goat or sheep).

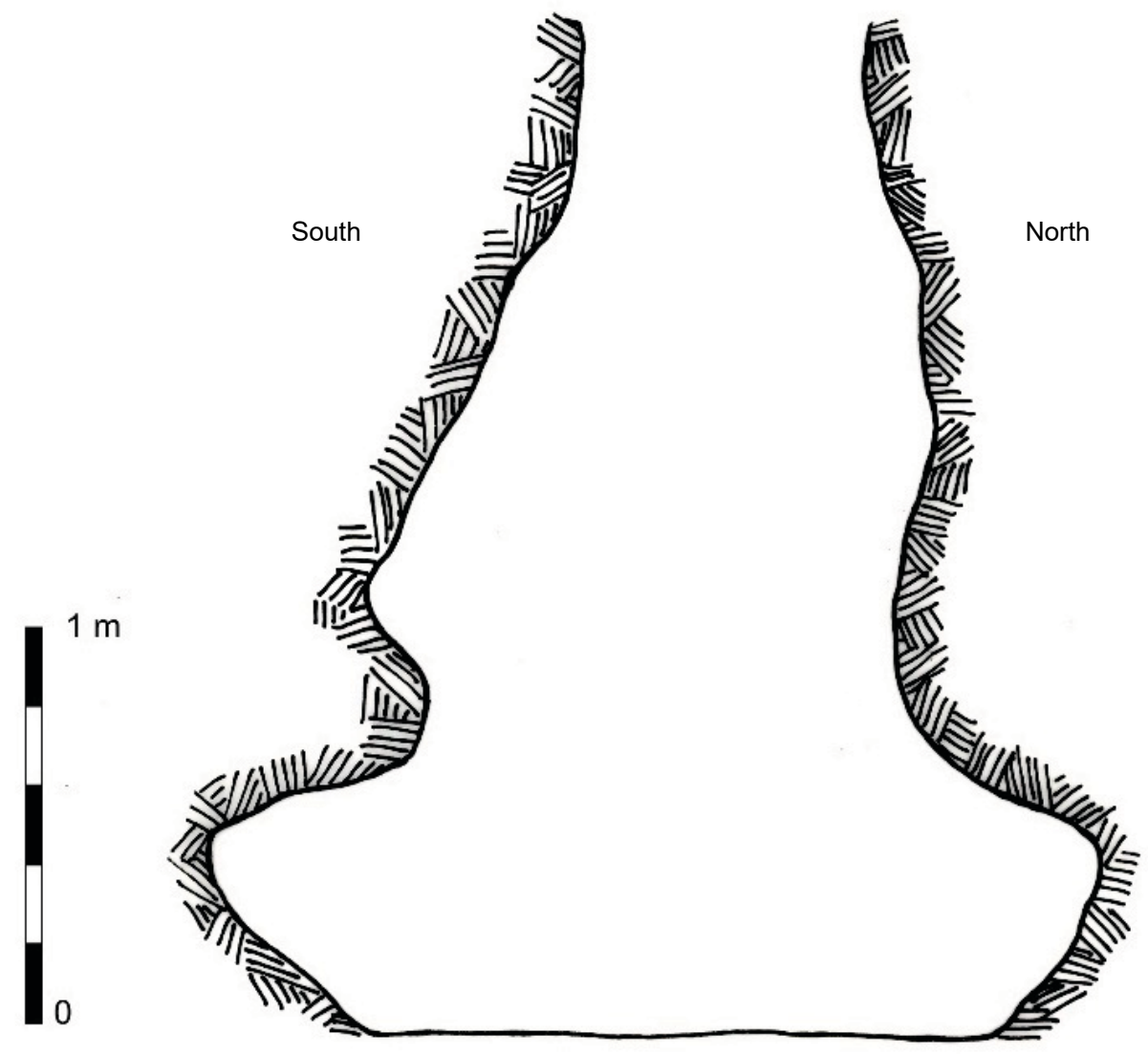

Figure 182 Cistern D

Numerous pieces of a roof tile were removed from the southwest section of the cistern. Several large pieces and numerous small pieces of pottery were also taken from the floor. A field reading placed these as Late Antique/Umayyad. As the excavation of the cistern continued downward, the soil became finer. Fewer pieces of pottery were unearthed, but more pieces of tesserae (some in clusters) were found. The number of bones also decreased, although many tiny bones from a rat or mouse were still brought up. In this middle layer, a heavily oxidized, circular coin was discovered (elevation $128.46 \mathrm{~m}$ ). Unfortunately, the coin could not be identified.

Several two-to-three-inch narrow pieces of rusted metal were removed from a lower fill layer. At elevation $128.44 \mathrm{~m}$, a layer of highly compact, grayish silt was found, likely formed during the cistern's use as a collector of water in Late Antique times. The silt layer was no more than 20-25 cm thick.

Cistern $\mathrm{D}$ is the smallest of the four cisterns discussed so far, measuring approximately 4.77 cubic meters. 


\section{Cistern $E$}

Located to the south of the basalt staircase that gave access to the second story of Building Alpha, this cistern was surveyed using a laser measuring device set perpendicular to a rod. Measurements were taken every twenty centimeters in four directions from the central rod to produce an east/west profile and a north/south profile. Cistern $\mathrm{E}$ is about $4.5 \mathrm{~m}$ deep, and the bell has a diameter of 3-4 $\mathrm{m}$. The volume is about 14 cubic meters.
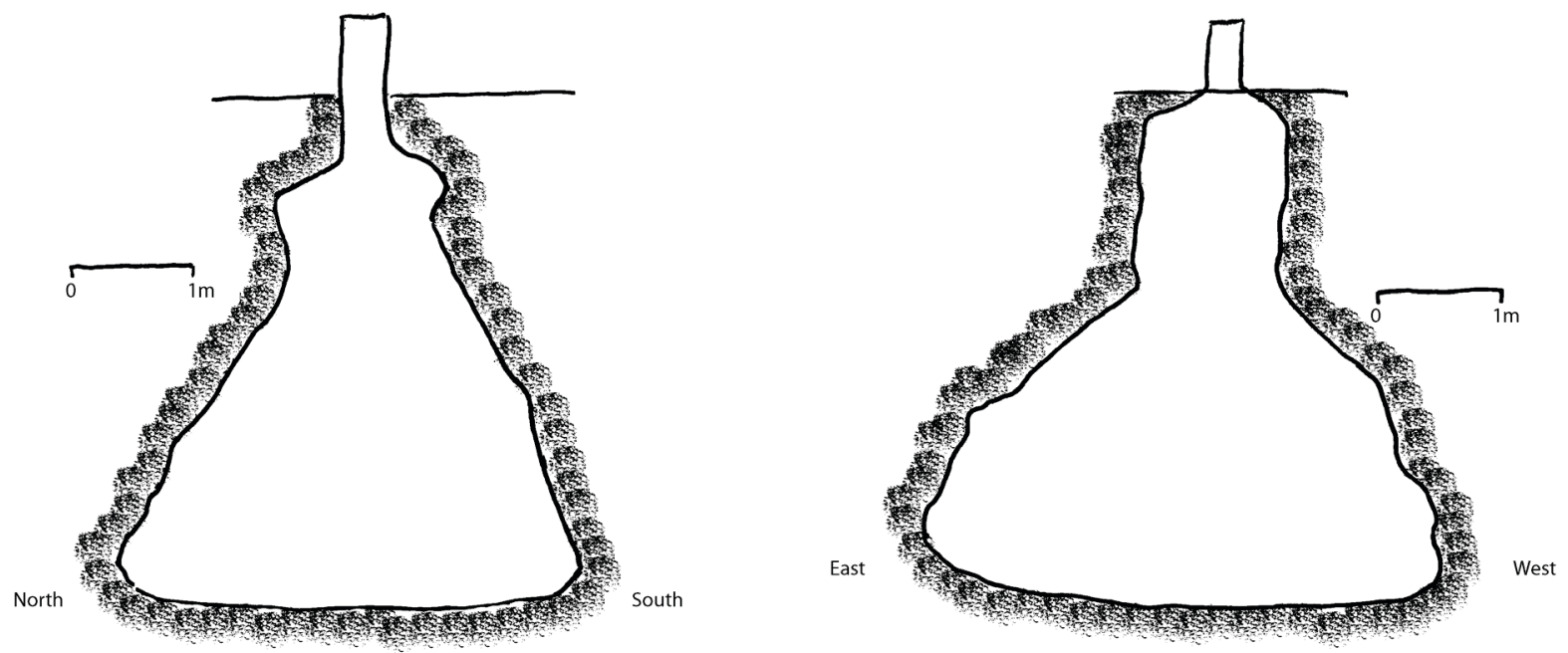

Figure 183 Profiles of Cistern E

\section{Cistern F -- intrusion}

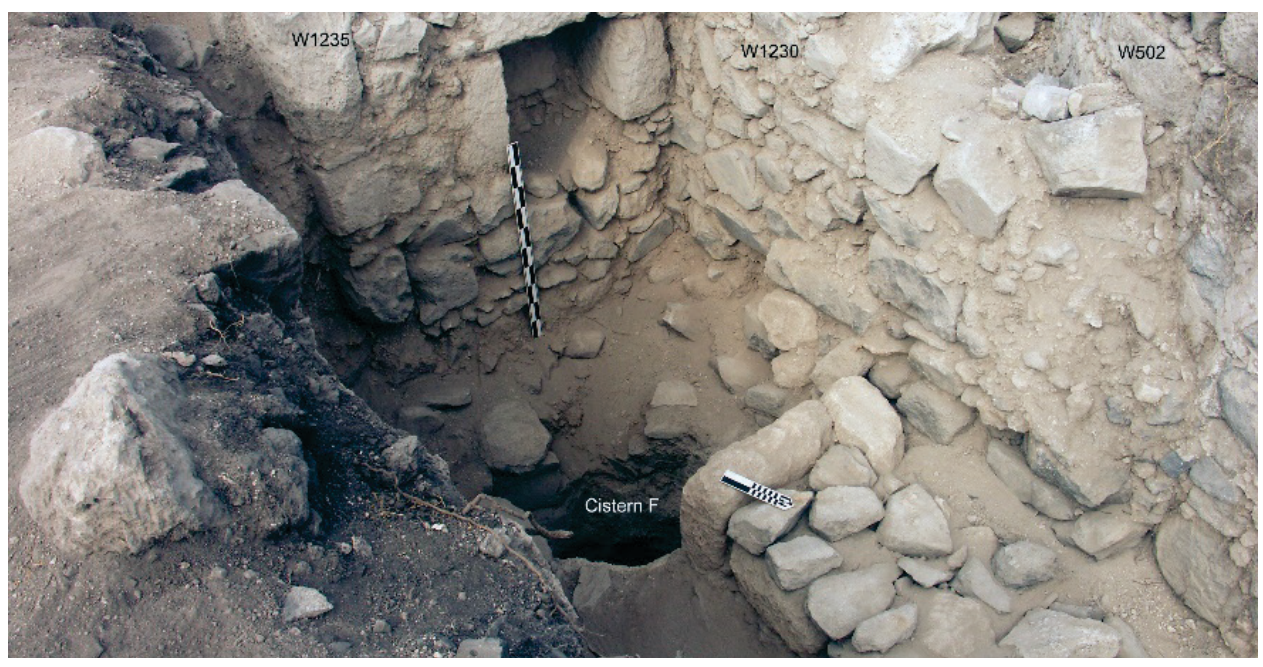

Figure 184 Cistern F (looking south)

Below the level of the floor of a small room adjacent to the east wall of the apse is the remnant of a small cistern. The head and neck are missing, leaving only the bell. The opening of the cistern is $1.2 \mathrm{~m}$ and its remaining depth is $1.55 \mathrm{~m}$. The bell held a volume of about 
$2.75 \mathrm{~m}^{3}$. The plaster of the cistern is grey in color. This cistern likely was inserted into the ruins of the church after the church was abandoned and destroyed. It comes from a later period when occupants of the site were agrarian.

\section{Cistern G}

The head of the cistern seems to be a column drum (approximately $52 \mathrm{~cm}$ in diameter), the center of which is carved out. The drum is $48 \mathrm{~cm}$ tall. At its widest, the area carved out is 47 $\mathrm{cm}$, and it narrows to a width of $27 \mathrm{~cm}$.

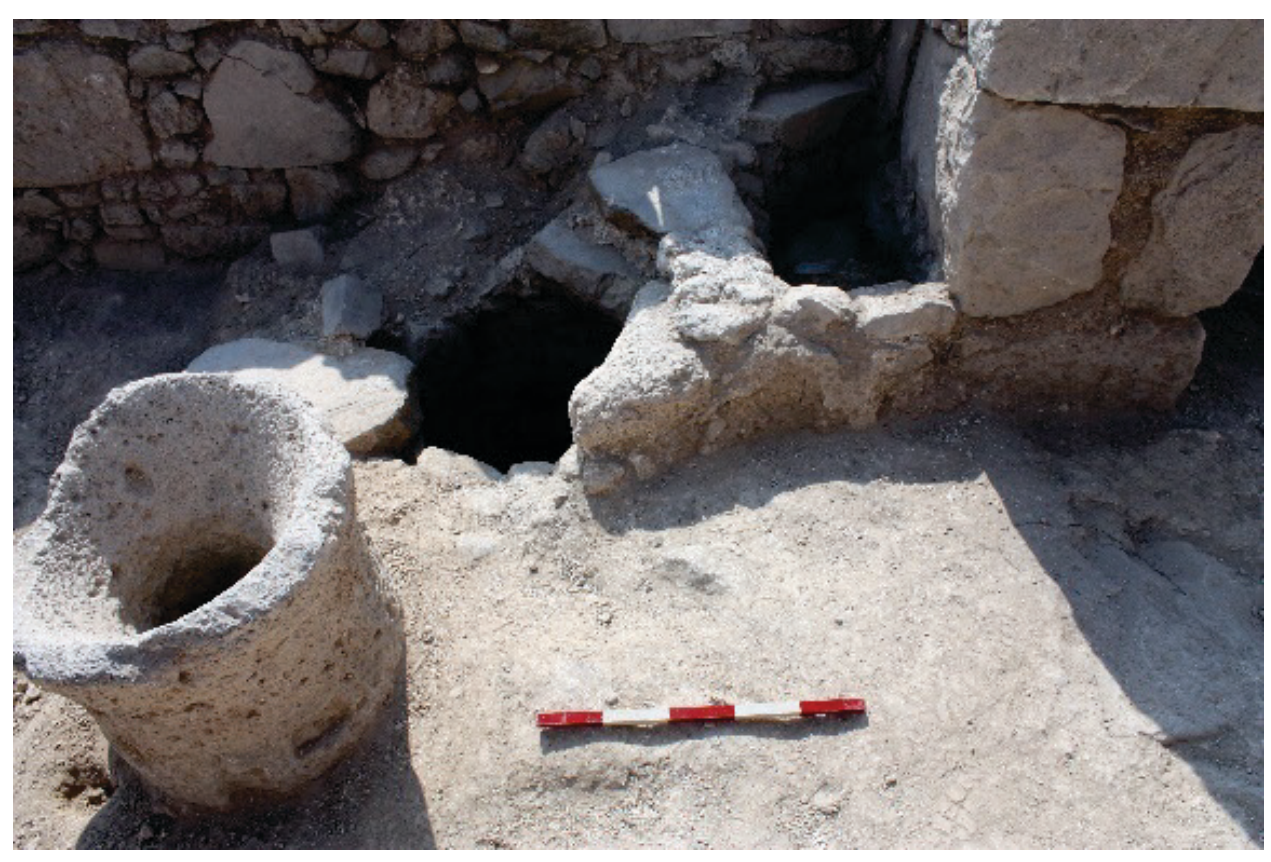

Figure 185 Head, Cistern G, and catch basin (looking east)

The diameter of opening to the cistern is $50 \mathrm{~cm}$. The neck is about $68 \mathrm{~cm}$ in diameter. The cistern is about $4.5 \mathrm{~m}$ deep and oblong to the north. The cistern bell is some $4 \mathrm{~m}$ north to south and $2.5 \mathrm{~m}$ east to west. Its volume is about 26.5 cubic meters. It is similar in construction to other cisterns (bell dug, lined with stones, and plastered). It appears as if a column drum was used by the builders as one of the framing stones. The plaster is grayish and delicate. Plastering on the north face of the pilaster, a drainage hole to the north of the cistern opening and numerous drain tiles in the fill identify how the cistern was filled. 


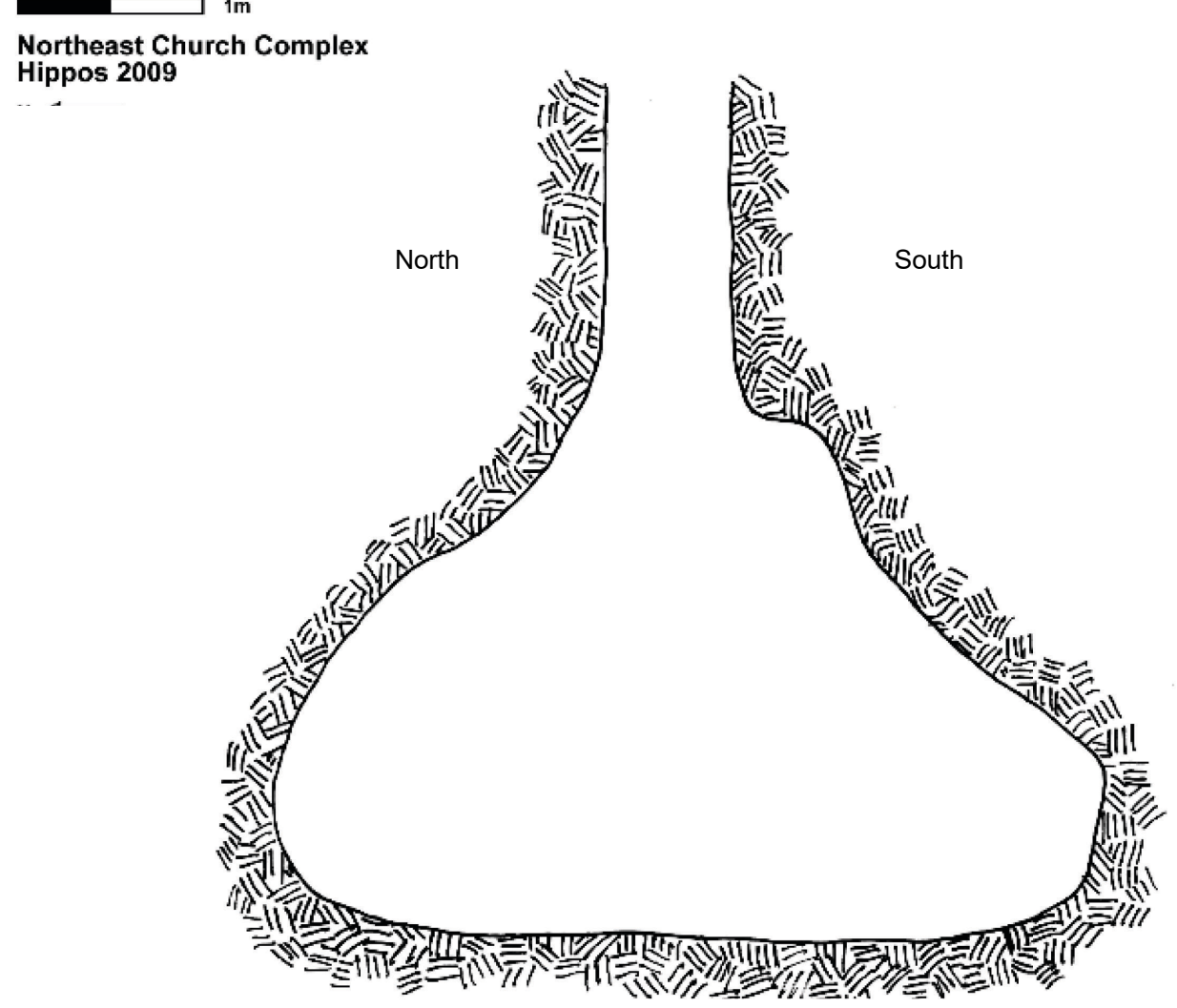

Figure 186 Cistern G

\section{Cistern $\mathrm{H}$}

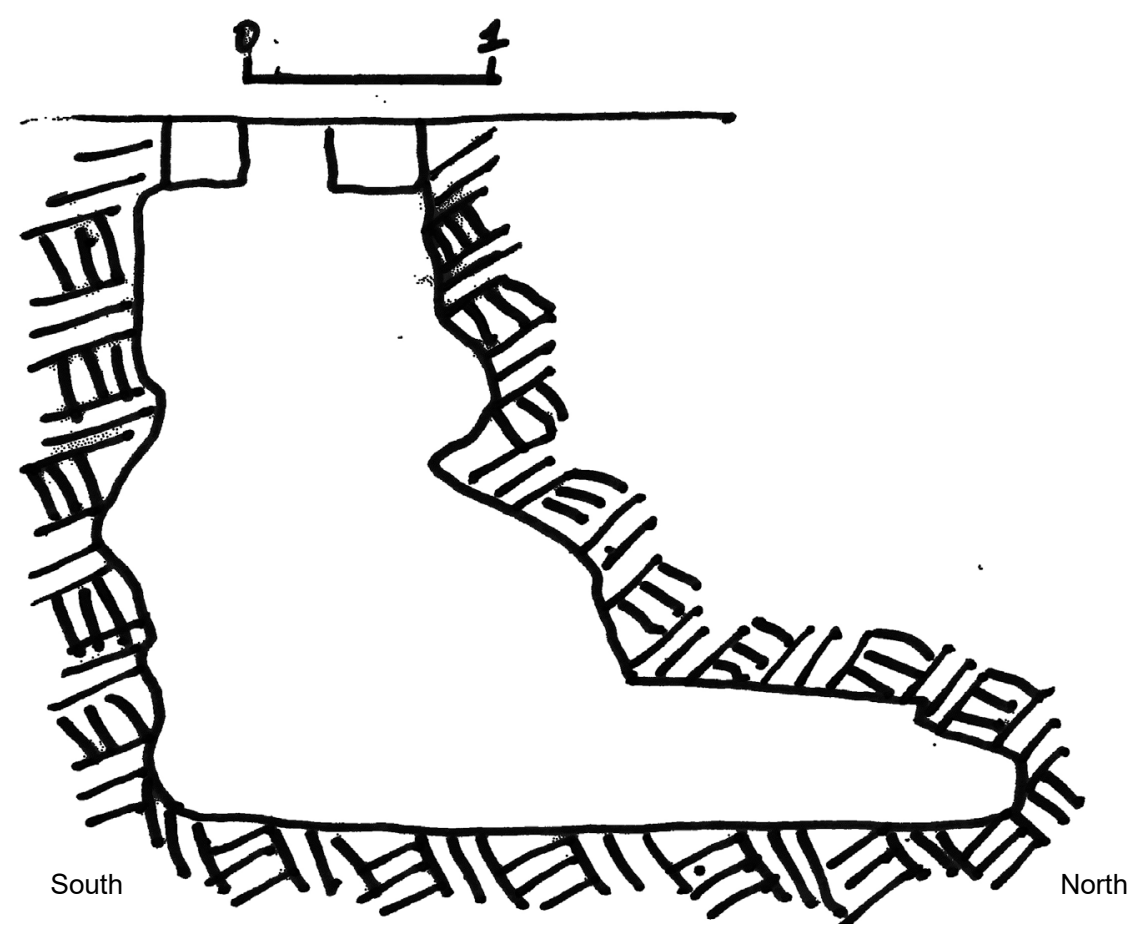


Figure 187 Profile of Cistern H under the peristyle court

Cistern $\mathrm{H}$ is below the peristyle court. Two basalt beams are used, one the east and one on the west, to form the opening and to hold up the paving. We identified a ceramic pipe that brought water from the north to the cistern, likely from the catch basins from the entrance hall. The cistern is bell shaped, with at least two layers of grayish plaster. It is about $3.2 \mathrm{~m}$ deep with a neck of $34 \mathrm{~cm}$. Its volume is approximately $10.25 \mathrm{~m}^{3}$.

\section{Cistern I}

$20 \mathrm{~cm}$ west of the upper pool and just north of the entrance hall of the House of Tyche is the neck for Cistern I. The neck is an hour-glass mill stone and survives to a height of 28 $\mathrm{cm}$ above the floor of the vat. A tape measure showed a depth of at least $4.5 \mathrm{~m}$. The neck of the cistern consists of two additional hour-glass mill stones. Due to the narrowness of the opening carved in the mill stone, it was not possible to enter this cistern.

As it would impede use of the north doorway to the entrance hall, this cistern comes from a later phase in the occupation of the space. We suggest it was added as an additional source for water for the pools to the west, especially during the dry season.

\section{Observations}

Of the cisterns in use in the Late Antique period (A, B, C, D, E, G, H, and I), cisterns A, C, and $\mathrm{H}$ may also have been in use already in the Roman Imperial period. Cistern $\mathrm{F}$ is from later agrarian usage of the ruins. The seven primary cisterns range in size from 4.7 cubic meters to 29 cubic meters. Their average size is 16 cubic meters. By comparison, the average size of the cisterns at Shivta is 46 cubic meters, at Sepphoris the average is 47 cubic meters and, and the cisterns of Hurvat Zikhrin average 46 cubic meters. ${ }^{129}$ Although its cisterns are smaller than other sites on average, the northeast insulae had substantive water sources independent of the water system of the city.

The cisterns of the northeast insulae could hold as much as 29,000 gallons, sufficient to provide drinking water for some 150-160 persons per year. They could certainly support the communal life of 30-50 persons.

\section{Burials}

As we have noted earlier, the church in the center of the northeast insulae was built to house two memorials: a masonry tomb in the center of the chancel and the tomb of a revered woman at the head of the south aisle also in the chancel and partially exposed above

${ }^{129}$ Tsvika Tsuk, "The Water Supply System of Shivta in the Byzantine Period," Cura Aquarum in Israel (2002): 73. 
its floor. These anonymous inhumations are central to understanding the urban monastic community built in the northeast insulae in the Late Antique period.

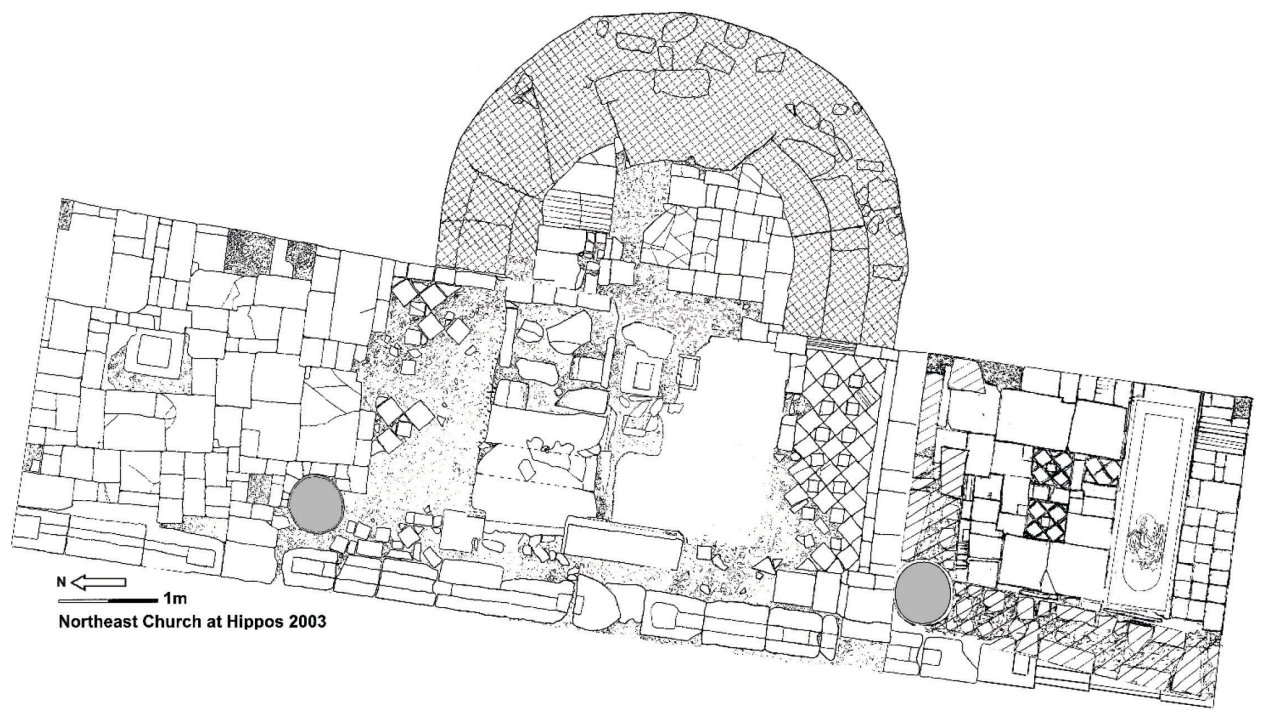

Figure 188 Chancel showing the location of the tombs

\section{Masonry tomb}

To the north of the central axis of the chancel is a masonry tomb in an east/west orientation. The burial in the tomb was undisturbed. A good portion of the box was filled with dirt.

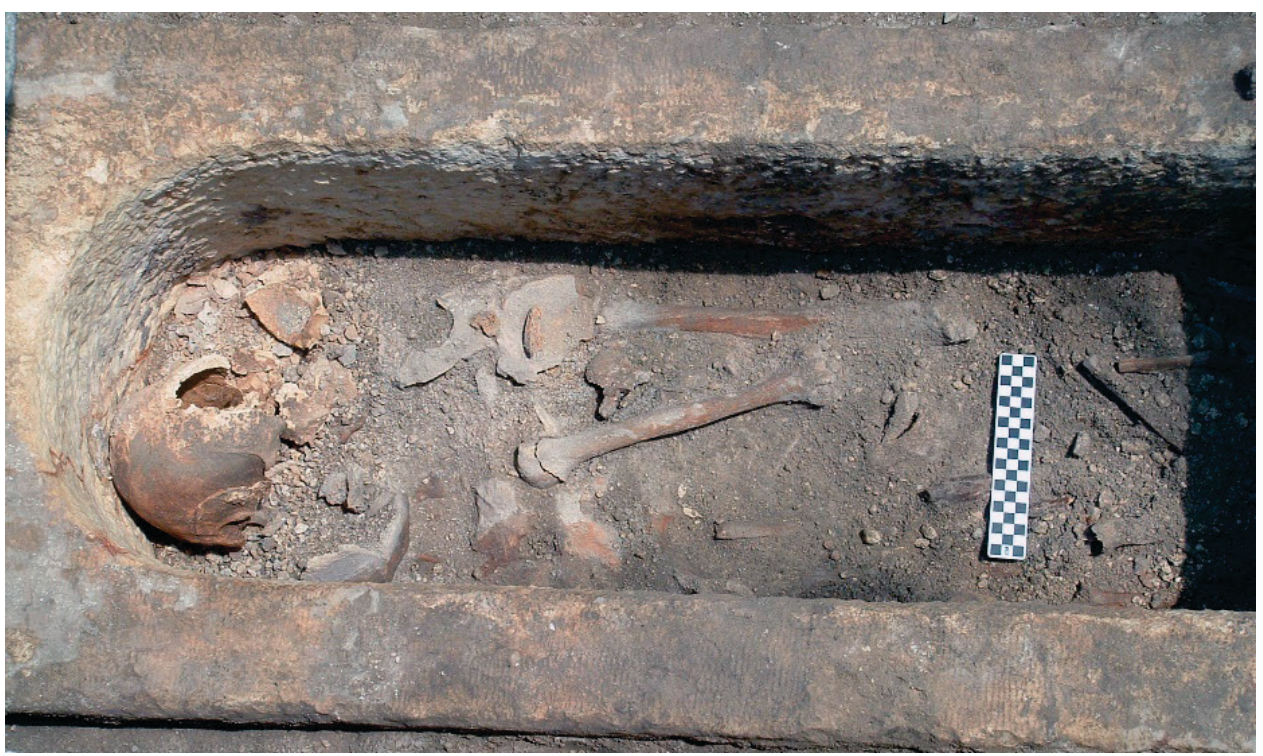

Figure 189 Remains in sarcophagus in masonry tomb

It is likely that both the sidewalls of the masonry tomb and the covering stones of the box of the sarcophagus were plastered, as a few small pieces of plaster were still adhering. One 
larger piece of painted plaster (in several sections) was recovered above the stones covering the sarcophagus. It showed a dark band, a yellow background and the four fingers of a near life-sized left hand (outlined in red) on a parallel line to and below the dark band. The hand was likely part of a fresco in the area above the sarcophagus but below the original covering stones. By way of comparison, outstretched hands feature prominently in depictions of saints and in frescoes from Christian catacombs. ${ }^{130}$

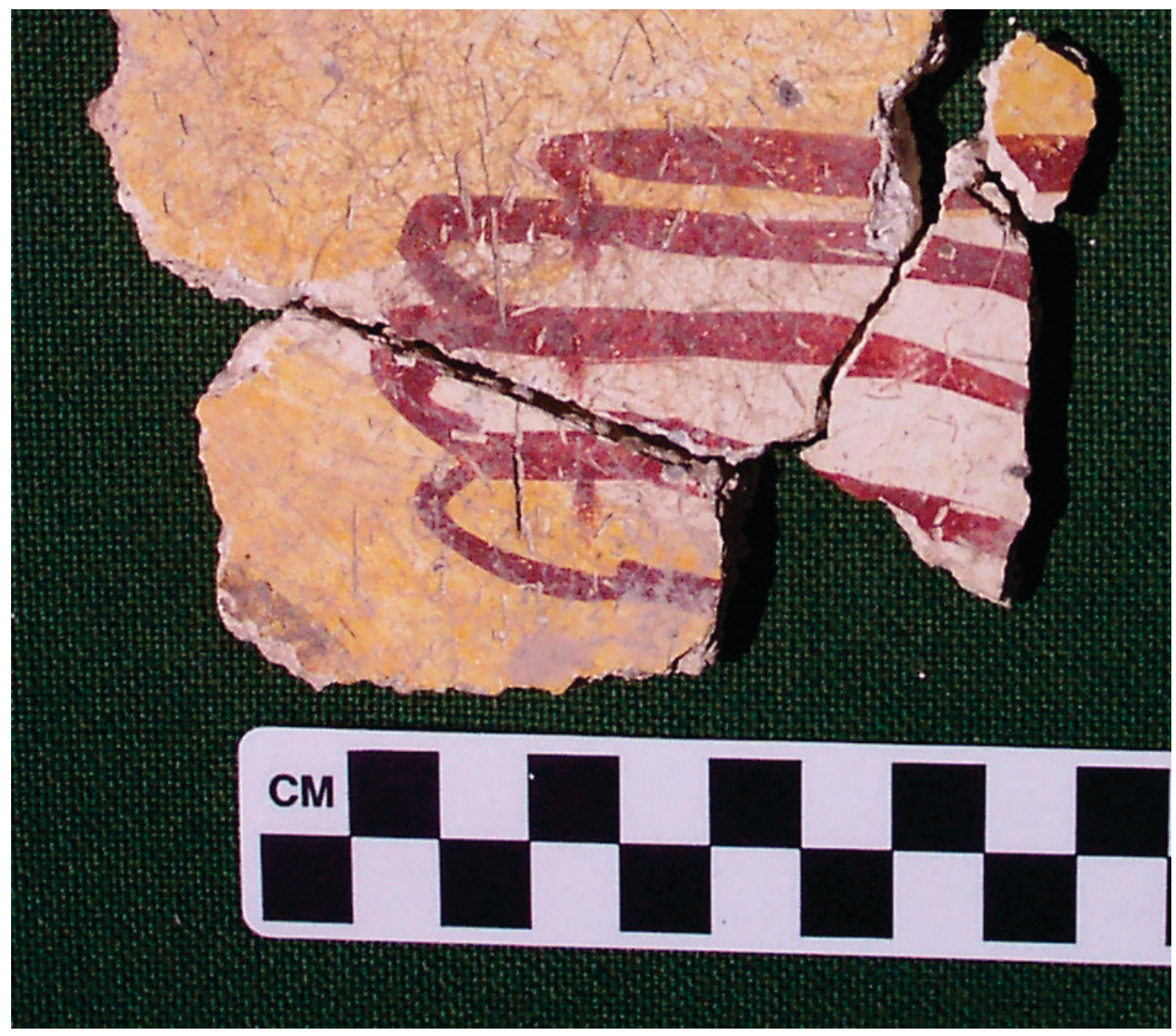

Figure 190 Fresco of hand from masonry tomb

Excavation of the interior of the sarcophagus revealed the disturbed remains of multiple individuals that had been interred sequentially over time. With each inhumation previous skeletal remains were pushed aside, and some bones were inverted. Skulls were crushed. The pattern is like so-called "family tombs" at Beth Yerakh, Rekhovot-in-the-Negev, Khirbet Karkur, `Avdat, and Nesanna. ${ }^{131}$

\footnotetext{
${ }^{130}$ André Grabar, Martyrium: Recherches Sur Le Culte Des Reliques et l'artchrétien Antique, vol. 2 (London: Variorum Reprints, 1972), plates xxix - xxxii.

${ }^{131}$ In discussing the multiple burial phenomenon, Haim Goldfus writes: "In many churches - evidently private foundations, whether of a single family or several families - the tombs were used as a family burial receptacle. The 'family' could have consisted of members of consecutive generations or of several members of the same generation, as we have observed in churches of the Negev region such as Rehovot-in-the-Negev, Nessana, and 'Avdat." In monasteries, "This 'family' was not necessarily based on blood ties but rather on ecclesiastical kinship or monastic brotherhood." Haim
} 


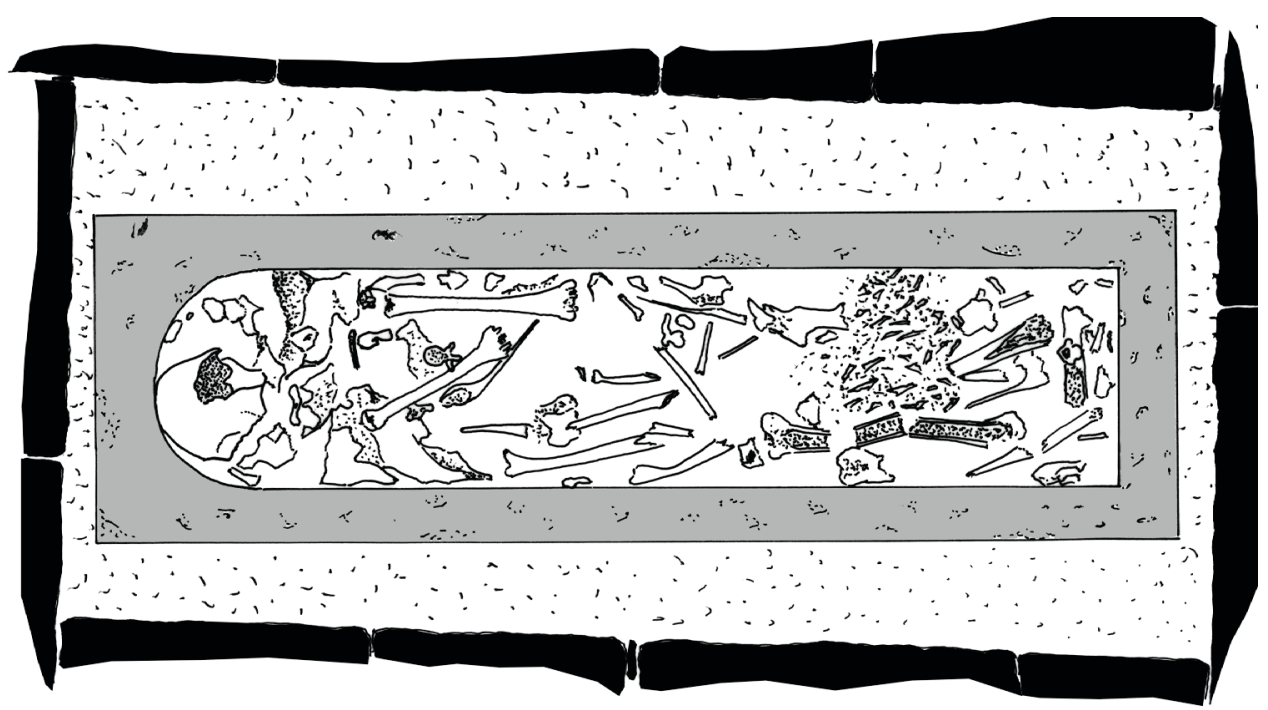

Figure 191 Remains in the masonry tomb

Field analysis of the skeletal remains suggests that the most recent burial was a young individual, since the squamosal suture between the temporal and parietal bones of the skull was not fully fused. ${ }^{132}$ Using the field measurements of the subpubic angle and the siatic notch, the most recent burial seems to belong to a male. ${ }^{133}$ The siatic notch of any earlier burial may be indicative of a female.

Only fragmentary pottery sherds and a few loose mosaic tesserae were recovered from the earth that had washed in around the bones along with several fragments of green Late Antique glass. Numerous rodent bones were intermingled, especially at the head and foot of the box.

Notably, the sarcophagus in the masonry tomb sits somewhat askew from level. We did remove the sarcophagus to excavate the rest of the chamber.

Numerous bone fragments were recovered in the area beside and under the sarcophagus. In the collection are three lunate bones of which there are only two in a human body. The bones also seem to represent both an adult and a juvenile. A large metatarsal bone likely belongs to a male. We have remains from an adult male and a juvenile of indeterminate sex.

We recovered no major bones, so we surmise that the earlier burials were removed leaving only fragments and the above listed items. Nevertheless, those who inserted the sarcophagus on top of the remains of a coffin intentionally raised the sarcophagus above the coffin

Goldfus, "Tombs and Burials in Churches and Monasteries of Byzantine Palestine (324--628 AD)" (Ph.D. dissertation, Princeton University, 1997), 240.

${ }^{132}$ William M. Bass, Human Osteology: A Laboratory and Field Manual, 4th ed., Special publication no. 2 of the Missouri Archaeological Society (Columbia, Mo: Missouri Archaeological Society, 1995), 12, 39.

${ }^{133}$ Ibid., 209, 213. 
about $20-25 \mathrm{~cm}$. That which was below was too revered to be crushed or to be swept away. It is possible that the removal reflects the practice of extracting relics, also posited for the tomb of the elderly women. But we also must consider the possibility that the bodies interred below were mostly exhumed and placed into the sarcophagus along with the last burial. These final burials in the sarcophagus were revered with oil/wine through a lead pipe and no provision was made for ongoing reverence of what was below.

Anthropological work on the human remains from the tomb was concluded in 2007 by Esti Deuisch of the Hebrew University, Jerusalem. Her report reads in part:

\section{Methods}

The bones and teeth were cleaned, measured, photographed (Plates 1 and 2) and examined for gross pathology. The age estimation of the infant was based on dental development. ${ }^{134}$ The age estimates for the adult individuals were based on the final stages of the skeletal maturation, ${ }^{135}$ the stage of the cranial suture closure, and the degree of the dental. ${ }^{136}$ The gender was determined morphologically. ${ }^{137}$ The metric analysis of the skeletal remains was based on the Standards for Data Collection from Human Skeletal Remains. ${ }^{138}$ The pathological examination and analysis was made according to White and Folkens and Lovell. ${ }^{139}$

\section{Description of the remains}

The human remains were found in two main areas: the first area (Locus 537) housed the remains of at least nine individuals, while the second area (Loci 543 and 590) yielded three individuals (see table 1). The skeletal remains were fragmentary and incomplete. All the individuals found at these areas were adults, except one infant age $0-1$ years which was found in locus 537 and was represented only by teeth and pelvis fragments.

As can be seen in table 1, the age estimation of most individuals was partial, mainly due to the fragmentary state of the remains. As for the gender, Locus 537 yielded the

\footnotetext{
134 David Whittaker, “Ageing from the Dentition," in Human Osteology in Archaeology and Forensic Science, ed. M. Cox and S. Mays (London: Greenwich Medical Media, 2000), 83-99.

${ }^{135}$ Which includes the fusion stage of the Ilaic crest, the ventral rings of the vertebrae, and limb bones.

${ }^{136}$ M. Cox, "Aging Adults from the Skeleton," in Human Osteology in Archaeology and Forensic Science, ed. M. Cox and S. Mays (London: Greenwich Medical Media, 2000), 61-82; Mehmet Yasar Iscan and Susan R Loth, "Osteological Manifestations of Age in the Adult," in Reconstruction of Life from the Skeleton, ed. M. Yaşar İşcan and Kenneth A. R. Kennedy (New York: Wiley-Liss, 1989), 23-40.

137 S. Mays and M. Cox, "Sex Determination in Skeletal Remains," in Human Osteology in Archaeology and Forensic Science, ed. S. Mays and M. Cox (London: Greenwich Medical Media, 2000), 117-130.

138 Jonathan Haas et al., eds., Standards for Data Collection from Human Skeletal Remains: Proceedings of a Seminar at the Field Museum of Natural History, Organized by Jonathan Haas, Arkansas Archeological Survey research series no. 44 (Fayetteville, Ark: Arkansas Archeological Survey, 1994).

139 T. D. White and Pieter A. Folkens, Human Osteology (San Diego: Academic Press, 1991); Nancy C Lovell, "Paleopathological Description and Diagnosis," in Biological Anthropology of the Human Skeleton, ed. S. R. Saunders and M. A. Katzenberg (New York: Wiley-Liss, 2000), 217-248.
} 
remains of at least three men, three women and one infant and three adults whom gender was undetermined (see table 1).

\section{Discussion}

The number of individuals reported here is far too small for any estimates of paleodemography or rigorous evaluation of mortuary practices. As mentioned, the disarticulated remains of at least 12 individuals were found in two areas. The inventory of the human remains is provided in table 1.

\begin{tabular}{|c|c|c|c|c|}
\hline Ind' & Locus & Basket & age & sex \\
\hline 1 & 537 & 1911,1933 & Adult & Female \\
\hline 2 & 537 & 1911,1933 & older adult & Male \\
\hline 3 & 537 & 1933 & Adult & Female \\
\hline 4 & 537 & 1930 & Adult & \\
\hline 5 & 537 & 1903 & Adult & Male \\
\hline 6 & 537 & 1914 & $55+$ & \\
\hline 7 & 537 & 1914 & $0-1$ & \\
\hline 8 & 537 & 1923 & Adult & Male \\
\hline 9 & 537 & 1923 & Adult & Female \\
\hline \hline 10 & 543 & 2039 & Adult & \\
\hline 11 & 590 & 2047 & Young Adult & \\
\hline 12 & 590 & 2051 & Adult & \\
\hline
\end{tabular}

Table 1: Inventory of the human remains

Morphometrical Analysis

The morphometrical analysis included the cranial and post-cranial measurements of only three adult individuals whose remains were found in Locus 537, since the individuals buried in Loci 543 and 590 were represented only by tarsals, vertebra and one left patella. The details of these measurements are provided in table 2 (for the cranial measurements), table 3 (for the mandible measurements) and table 4 (for the post cranial measurements). Stature could only be calculated for three of the nine adults found in Locus 537 . The stature was calculated for individual $2(168 \mathrm{~cm})$, individual $3(153 \mathrm{~cm})$ and individual $4(175 \mathrm{~cm}) .{ }^{140}$

\begin{tabular}{|c|c|c|}
\hline Measurement & ind' 1(older adult male) & ind' 2 (adult female) \\
\hline Cranial Length & & 178 \\
\hline
\end{tabular}

\footnotetext{
${ }^{140}$ W. M. Bass, Human Osteology: A Laboratory and Field Manual, third edition (Columbia, MO: Missouri Archaeological Society, 1987) 22-23.
} 


\begin{tabular}{|c|c|c|}
\hline Cranial Breadth & 140.3 \\
\hline Nasal Height & 52 & 48.2 \\
\hline Nasal Breadth & 26 & 22 \\
\hline $\begin{array}{c}\text { Minimum Frontal } \\
\text { Width }\end{array}$ & 99.3 & 96 \\
\hline Basion-Bregma & & 126 \\
\hline Basion-Nasion & & 93.7 \\
\hline Porion-Bregma & 109 \\
\hline $\begin{array}{c}\text { Foramen Magnum } \\
\text { length }\end{array}$ & 109.2 & 32.5 \\
\hline $\begin{array}{c}\text { Foramen Magnum } \\
\text { breadth }\end{array}$ & & 29 \\
\hline $\begin{array}{c}\text { Mastoid Process } \\
\text { breadth }\end{array}$ & & 106.1 \\
\hline
\end{tabular}

Table 2: Cranial Measurements

\begin{tabular}{|c|c|c|c|c|c|c|c|c|}
\hline Ind & Age & Sex & $\begin{array}{c}\text { Mandible } \\
\text { length }\end{array}$ & $\begin{array}{c}\text { Ramus } \\
\text { breadth }\end{array}$ & $\begin{array}{c}\text { Ramus } \\
\text { height }\end{array}$ & $\begin{array}{c}\text { Mandible } \\
\text { height }\end{array}$ & $\begin{array}{c}\text { Height at } \\
\text { M1-M2 }\end{array}$ & $\begin{array}{c}\text { Chin } \\
\text { height }\end{array}$ \\
\hline 8 & Adult & Male & 96 & 37.5 & 66 & 63.5 & 29.5 & 32.9 \\
\hline 2 & $\begin{array}{c}\text { older } \\
\text { adult }\end{array}$ & Male & 89.1 & 33 & 61 & & & \\
\hline 9 & Adult & Female & 101.1 & 36.1 & 53 & 70 & 27 & 28 \\
\hline
\end{tabular}

Table 3: Mandible Measurements

\begin{tabular}{|c|c|c|c|c|c|c|}
\hline \multicolumn{2}{|c|}{ Femur } & & & & & \\
\hline Ind & Age & Sex & Max Length & Phy Length & Min Circ. & $\begin{array}{c}\text { Max. Diam. } \\
\text { Head }\end{array}$ \\
\hline 2 & $\begin{array}{c}\text { Older } \\
\text { adult }\end{array}$ & Male & 449 & & 91.8 & 43.7 \\
\hline 4 & Adult & Male? & & & 92.3 & 44 \\
\hline 3 & Adult & Female & 402 & 396.8 & 87 & 42.3 \\
\hline \multicolumn{2}{|c|}{ Tibia } & & & & & \\
\hline ind & Age & Sex & Max Length & Min Circ. & & \\
\hline 2 & $\begin{array}{c}\text { Older } \\
\text { adult }\end{array}$ & Male & 362 & 88 & & \\
\hline 3 & Adult & Female & 328 & 78 & & \\
\hline \multicolumn{2}{|c|}{ Humerus } & & & & Max. Diam. & \\
\hline \multicolumn{2}{|c|}{ ind } & Age & Sex & Max Length & Min Circ. & \\
\hline
\end{tabular}




\begin{tabular}{|c|c|c|c|c|c|c|}
\hline 2 & $\begin{array}{c}\text { Older } \\
\text { adult }\end{array}$ & Male & 341 & 60 & 46 & \\
\hline 4 & Adult & Male? & 339 & 58.7 & 46.4 & \\
\hline 3 & Adult & Female & 281 & 59.8 & 38.7 & \\
\hline \multicolumn{2}{|c|}{ Radius } & & & & & Min Circ. \\
\hline ind & Age & Sex & Max Length & Phy Length & $\begin{array}{c}\text { Max. Diam. } \\
\text { Head }\end{array}$ \\
\hline 2 & $\begin{array}{c}\text { older } \\
\text { adult }\end{array}$ & Male & & & 44.8 & 23 \\
\hline 3 & Adult & Female & 215.2 & 208 & 39 & 20.1 \\
\hline
\end{tabular}

Table 4: Post-cranial Measurements

\section{Summary}

The Northeast church complex at Hippos (Sussita) housed the remains of at least 12 individuals in two areas (Locus 537 and Loci 590, 543). All the individuals found at these areas were adults, except one infant age 0-1 years which was represented only by teeth and pelvis fragments. The number of individuals reported here is far too small for any estimates of paleodemography or rigorous evaluation of mortuary practices; therefore, the data shown here can be combined in future research, when the sample size will enable it.

Earlier in this report we suggested that the church was part of a larger urban monastic complex and that the tombs in its chancel were places of veneration and invention of relics. This anthropological report on the human remains from the masonry tomb adds supporting evidence to these hypotheses. All the skeletons are disarticulated with some individuals represented by only a few pieces. Even assuming significant decomposition over the centuries due to the low and wet location of the tomb in the ruins of the complex, the partial skeletal remains suggest that relics were extracted from the masonry tomb. The tomb was originally plastered and painted with at least one human figure ${ }^{141}$ and held a coffin. ${ }^{142} \mathrm{~A}$ sarcophagus was crudely placed on stones to hold it above the level of the coffin. The sarcophagus was covered with assorted slabs in secondary use. The diminishing quality of the burials over time supports the hypothesis of relic extraction, as the sale of relics could fund a declining community and complex. Relics were important to the Christians at Hippos, for even after the Northeast Church was abandoned, the veneration of relics continued in the Northwest church until the destruction of the city. ${ }^{143}$

\footnotetext{
${ }^{141}$ Segal et al., Hippos-Sussita : Fourth Season of Excavations : June-July 2003, 45.

${ }^{142}$ Segal et al., Hippos-Sussita : Fifth Season of Excavations : September-October 2004, 85.

${ }^{143}$ Segal et al., Hippos-Sussita : Fourth Season of Excavations : June-July 2003, 26.
} 
The presence of both males, females, and a child furthers the hypothesis that the church was part of an urban monastery. The 15,000 bones in repository 6 of the St. Stephens monastery in Jerusalem contained both males and females ${ }^{144}$ of which about a third were subadult. ${ }^{145}$ At the Kyria Maria monastery at Bet Shean, the skeletal remains in the sarcophagus from Room E belonged to two males, a female, and one child. ${ }^{146}$
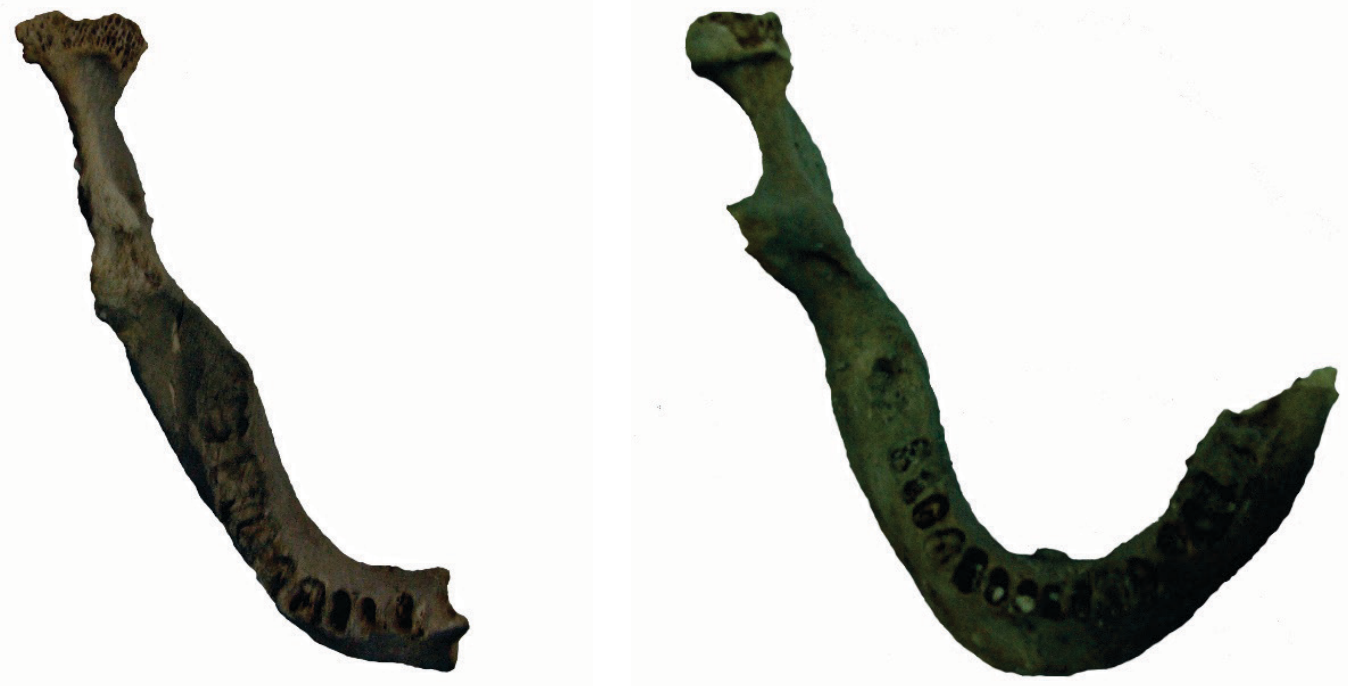

Figure 192 Large jaws

The stature of two of the individuals may also be of note: a male at $168 \mathrm{~cm}$ and an undetermined adult at $175 \mathrm{~cm}$. These seem tall for the typical averages from other Late Antique sites: $162 \mathrm{~cm}$ at Kursi, ${ }^{147} 163 \mathrm{~cm}$ at Ein Gedi and Lavav, ${ }^{148} 166.5$ at St. Stephen's, ${ }^{149} 167 \mathrm{~cm}$ at Khan el-Ahmar, ${ }^{150}$ and $170 \mathrm{~cm}$ at Rehovot-in-the-Negev. ${ }^{151}$ The variance may not be terribly significant since Lawrence Angel reports an average stature for males in the eastern Mediterranean during this period as $169.3 \mathrm{~cm} .{ }^{152}$ An interesting literary note comes from D. Chitty about a group of monks called the Tall Brothers who led the Origenist movement in

\footnotetext{
${ }^{144}$ Susan Guise Sheridan, "Sex Determination," Byzantine St. Stephens: A Biocultural Reconstruction of Urban Monastic Life, accessed June 7, 2021, https://www3.nd.edu/ stephens/sex.html.

${ }^{145}$ Susan Guise Sheridan, "Biocultural Reconstruction of Byzantine St. Stephen's," ASOR Newsletter 50.1 (2000): 14.

${ }^{146}$ Eliot Braun, "Soundings under a Sixth Century Monastery at Beth Shean.," Atiqot 17 (1985): 203. The author notes that the sarcophagus comes from an earlier period and may have been reused by the monastery, although an internment pre-dating the monastery is also possible.

${ }^{147}$ Baruch Arensburg, "A Short Review of Paleopathology in the Middle East.," Mitekufat Haeven 18 (1985): 21-30.

148 Baruch Arensburg, "The People in the Land of Israel from the Epipaleolithic to Present Times" (Ph.D., Tel Aviv University, 1973), 22.

${ }^{149}$ Susan Guise Sheridan, "Statue Reconstruction," Byzantine St. Stephens: A Biocultural Reconstruction of Urban Monastic Life, accessed June 7, 2021, https://www3.nd.edu/ stephens/sex.html.

${ }^{150}$ Israel Hershkovitz, “The Human Remains from the Byzantine Monastery at Khan El-Ahmar.," Liber Annuus 43 (1994): 374.

${ }^{151}$ Israel Hershkovitz, "Skeletal Remains from the Northern Church," Qedem (1988): 203.

152 J. Lawrence Angel, "Health as a Crucial Factor in the Changes from Hunting to Developed Farming in the Eastern Mediterranean," in Paleopathology at the Origins of Agriculture, ed. M. Cohen and G. Armelagos (Orlando, FL: Academic Press, 1984), 51-74.
} 
Egypt at the end of the fourth century CE. They fled Nitria when Origenism was condemned in synod in $400 \mathrm{CE}$ and about 300 monks went with them, many to Jerusalem and others on to Scythopolis. ${ }^{153}$ Although this story is from about 100 years before the founding of the urban monastic complex at Hippos, it is plausible that individuals of such stature were part of the Origenist movement in the north of Palaestina, some descendants of which found their way to Hippos.

\section{Tomb of a revered woman}

Inside the room created by W514 and W515 is a partially exposed sarcophagus.

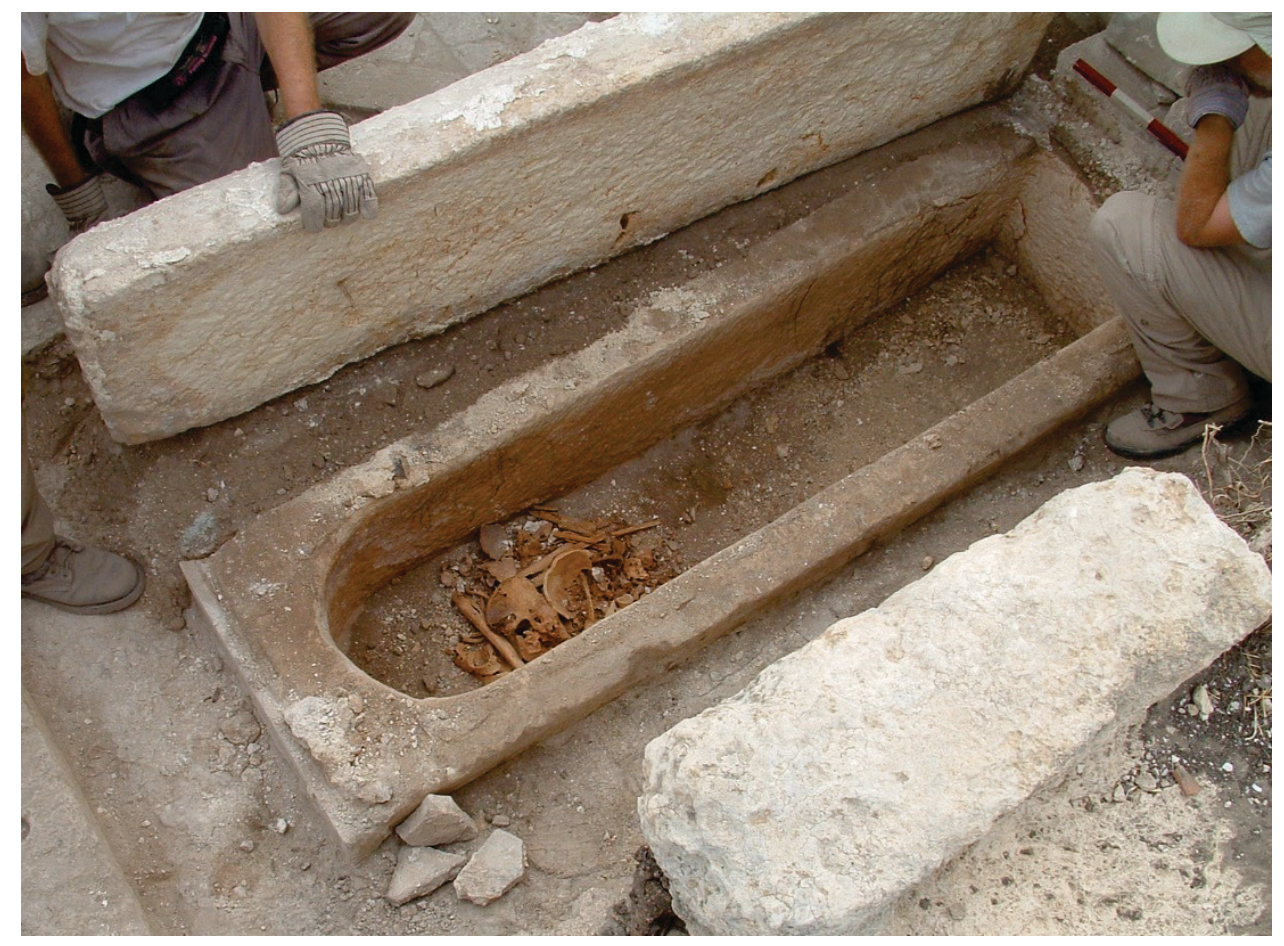

Figure 193 Opened sarcophagus

When the exposed sarcophagus was opened, it contained the bones of a single small woman of advanced years. The bones were gathered under the anointing hole, long bones placed in a frame around fragments of the skull, pelvis and other smaller bones. A small quantity of earth was also recovered from the box of the sarcophagus (remains of decomposition). In the earth at the east end of the box were some fifteen metatarsals and phalanges of the foot. Four white tesserae were also recovered. While the sarcophagus was originally used for burial, after it was opened, the remaining bones were arranged under the location of the

\footnotetext{
${ }^{153}$ Derwas J. Chitty, The Desert a City: An Introduction to the Study of Egyptian and Palestian Monasticism under the Christian Empire (Crestwood, NY: St. Vladimir's Seminary Press, 1995), 58.
} 
anointing hole, except for the bones from the feet that were missed in the decompositional remains.

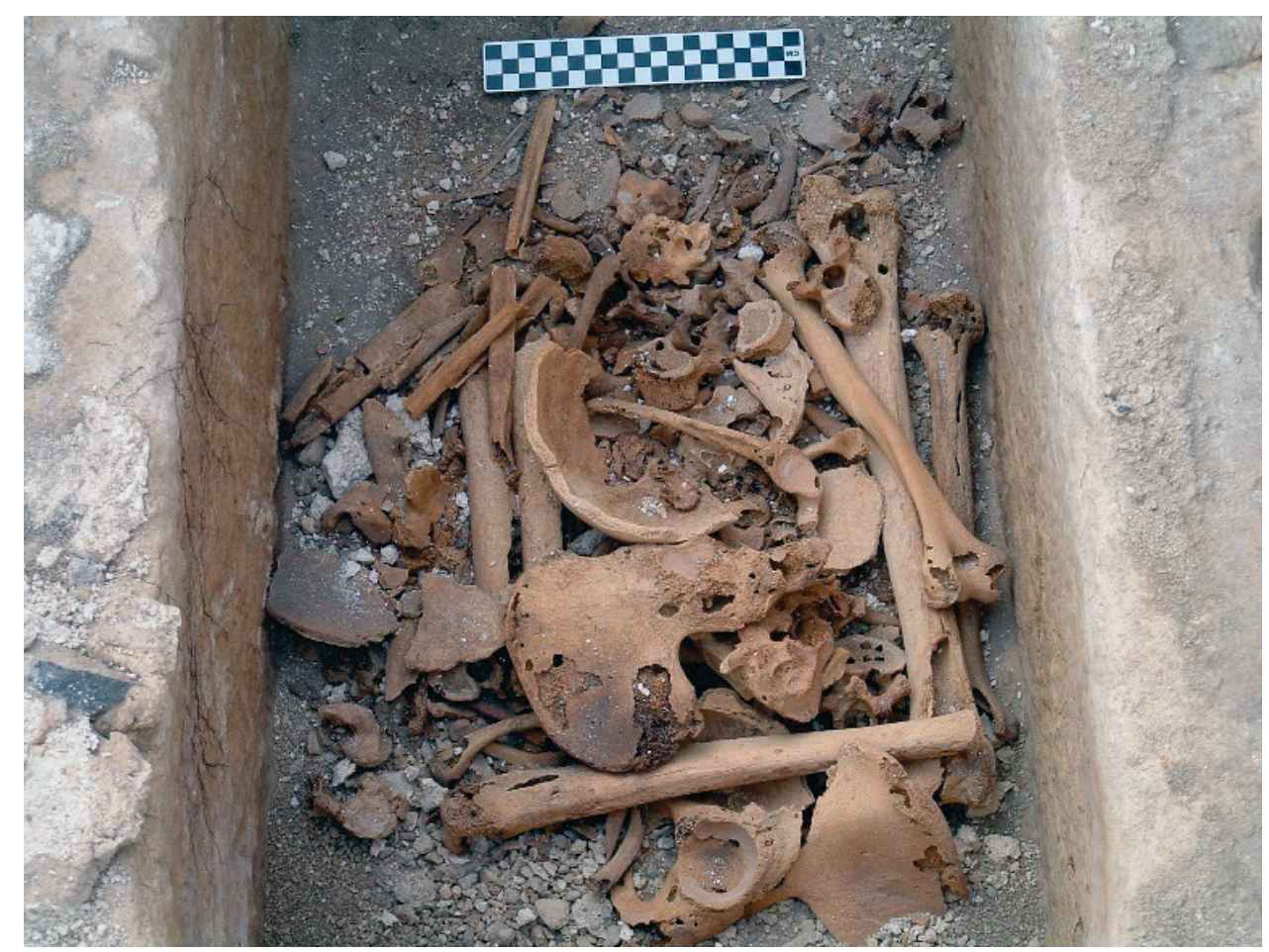

Figure 194 Gathered remains

Vered Eshed and Israel Hershkovits of the Department of Anatomy and Anthropology, Sackler Faculty of Medicine, Tel Aviv University, Tel Aviv, Israel, prepared an anthropological report that reads in part:

\section{Anthropological consideration}

The human remains were concentrated on the western part of the sarcophagus, except for seventeen metatarsals and phalanges of the foot recovered from the east end. The bones were not in their anatomical positions, indicating either secondary burial or interference of the original burial. The bones were not piled randomly, but rather were organized in a peculiar manner. The long bones were prearranged in the shape of a table -- the legs (two humeri and one femur on one side and a femur, tibia and fibula on the other) along the long axis of the sarcophagus and the plate (tibia) along the short axis. The other bones were placed within the inner space of the table, including the skull (now fragmented) that was placed on top of the postcranial bones (in the center). The os coxae and sacrum were placed under the skull. Underneath them were the rest of the postcranial bones. The bones were in a very fragmentary condition. Due to post-depositional processes much of the mineral content of the bones was lost, making the bones light and fragile. Large areas of the bones manifest a 'worm-eaten' appearance. The inventory included most of the cranial and post cranial bones. 


\section{Methodological consideration}

Sex determination was based on the following methods: cranial and long bones morphology, ${ }^{154}$ vertical diameter of the femoral and humerus heads, ${ }^{155}$ and os coxae morphology. ${ }^{156}$ Scoring techniques are described by Buikstra and Ubelaker. ${ }^{157}$

Age determination was determined using the following criteria: morphology of the auricular surface of the ilium, ${ }^{158}$ morphology of the pubic symphysis, ${ }^{159}$ morphology of the sternal end of the ribs, ${ }^{160}$ cranial suture closure (based on combined methods described in Buikstra and Ubelaker, ${ }^{161}$ and the presence of osteophytes and arthritic lesions on the vertebral body. A final estimated age for this skeleton was computed by averaging the data obtained from the above methods.

What do the bones tell us about the deceased in the sarcophagus?

All bone parameters indicated that the skeleton probably belonged to a woman of low stature $(152 \mathrm{~cm})$ and advanced age ( $>50$ years). As mentioned before, all bones were very light and porous, raising the suspicion that this woman suffered from an advanced condition of osteoporosis, i.e., a reduction of total one mass per unit volume. ${ }^{162}$ Women normally suffer a substantial acceleration of this phenomenon during the post-menopausal state. The osseous changes seen in the vertebrae (osteophytes and Schmorl's nodes) are also indicative of the advanced age of this individual. The cause of death could not be ascertained for this individual. No specific pathology was noticed.

This burial in the Northeast Church at Hippos is significant. The prominence and reverence accorded this woman seems to be more that that accorded to a patron. She was certainly honored for her role in the community and for her perceived sanctity, both of which influenced her ongoing veneration. As the burial is associated with a healing site, she may also have been approached for help by the sick while still alive.

\footnotetext{
${ }^{154}$ Bass, Human Osteology; Haas et al., Standards for Data Collection from Human Skeletal Remains.

155 Bass, Human Osteology.

${ }^{156}$ George R Milner, Determination of Skeletal Age and Sex: A Manual Prepared for the Dickson Mounds Reburial Team (Lewiston, Illinois: Dickson Mound Museum, 1992); Bass, Human Osteology; Terrell W. Phenice, "A Newly Developed Visual Method of Sexing the Os Pubis," American journal of physical anthropology 30, no. 2 (1969): $297-301$.

${ }^{157}$ Haas et al., Standards for Data Collection from Human Skeletal Remains.

${ }^{158}$ C Owen Lovejoy et al., "Chronological Metamorphosis of the Auricular Surface of the Ilium: A New Method for the Determination of Adult Skeletal Age at Death," American journal of physical anthropology 68, no. 1 (1985): 15-28.

159 Sheilagh Brooks and Judy M Suchey, "Skeletal Age Determination Based on the Os Pubis: A Comparison of the Acsádi-Nemeskéri and Suchey-Brooks Methods," Human evolution 5, no. 3 (1990): 227-238.

${ }^{160}$ Susan Loth, "Morphological Assessment of Age in the Adult: The Thoracic Region," in Age Markers in the Human Skeleton, ed. M. Y. Iscan (Springfield, IL: Charles C. Thomas, 1989), 105-136.

${ }^{161}$ Haas et al., Standards for Data Collection from Human Skeletal Remains.

162 Arthur C. Aufderheide, Conrado Rodriguez-Martin, and Odin Langsjoen, The Cambridge Encyclopedia of Human Paleopathology (Cambridge, UK; New York, NY, USA: Cambridge University Press, 1998).
} 
Secondly, most Byzantine churches and monasteries with burials are "located outside, or on the fringes of the inhabited area of the city... close to or in the midst of cemeteries.”163 The Northeast Church is in the city center.

The burial is even more unusual, if Haim Goldfus' research is confirmed:

Proportionally, the total number of tombs - especially inside the space of the prayer hall, in the Galilee and the Northern Coasts sites, as well as in the site of other regions - is by far lower than in most sites of the Negev region. ${ }^{164}$

The tomb of a revered woman is significant for its location in the chancel and its partial exposure above the floor. Inhumations in a chancel do occur on occasion in the Decapolis region; but they do not seem to occur west of the Jordan River.

The exposed burial in the Northeast Church at Hippos has the additional distinction of healing cult seemingly connected to the tomb associated with the nearby diakonikon become an infirmary.

Even after the church compound went out of use and was closed off, access remained open to the south aisle of the church and this locally important site of veneration.

Although the anonymity of the remains hides full understanding, there are glimpses here of something quite sacred inside a poor and non-descript compound.

\section{Observations}

That which is hidden does provide perspective on a community and its life. The cisterns assert the capability of the community living in the compound to sustain their activities. The burials within the chancel of the church attest to the belief of the community that their sacred dead are not dead in an absolute sense. Rather than defiling, the dead make holy and are revered in the hope of the petitioner to be made whole as well.

This small and relatively poor compound did host a community that offered the city a place of hope and healing and did so while maintaining a vibrant memory of and reverence for leaders who established and preserved this place and role.

163 Goldfus, "Tombs and Burials in Churches and Monasteries of Byzantine Palestine (324--628 AD)," 238.

164 Ibid., 249. 
The Northeast Insulae Project 


\section{6.}

\section{FRESCOS AND FLOORS}

$\mathbf{R}$ emnants of decoration appear in the archaeological record. In the case of the northeast $\mathbf{R}$ insulae these are quite fragmentary. Still, through frescos, inscriptions, and floors one can get a sense of the inside of some of the archaeological remains and, for the Late Antique period, some of the theology embraced by the community on the site.

\section{Frescos}

\section{East room of House of Tyche}

Several pieces of painted fresco were recovered from the fill in the east room. They seem to portray portions of a disk or medallion with a gold center crossed by red lines (a sun disk?).

During the Roman Imperial period, the First Pompeian Style of painting (beginning in the fourth century BCE) introduced colors such as red, yellow, black, green, and purple into wall paintings. These colors continued to be popular for the next several centuries, and well into the Late Antique period. ${ }^{165}$ Late Antique art was primarily religious art, most often depicting religious figures, such as Jesus, Mary, or the apostles. ${ }^{166}$ However, figures of animals and birds were also common, especially in Syria, Palestine, and Transjordan. These figures were usually isolated and set against a geometric background. Scenes of months, seasons, and the sun and moon were also popular in wall paintings. ${ }^{167}$

\footnotetext{
${ }^{165}$ Roger Ling, Roman Painting (Cambridge [England]; New York: Cambridge University Press, 1991), 13-25.

${ }^{166}$ Irmgard Hutter, Early Christian and Byzantine, The Universe history of art and architecture (New York: Universe Books, 1988), 64-71.

${ }^{167}$ John Beckwith, Early Christian and Byzantine Art, The Pelican history of art (Harmondsworth: Penguin, 1970), 67.
} 


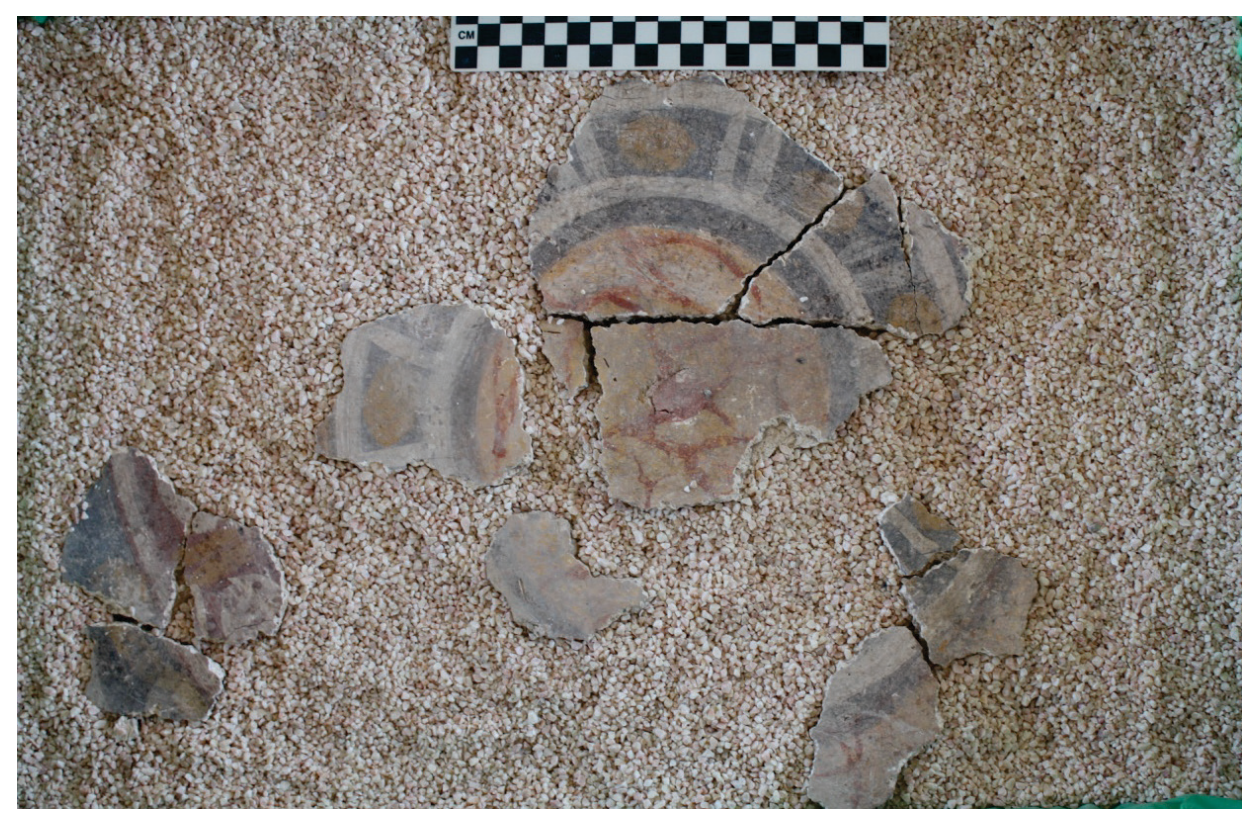

Figure 195 Fresco

\section{Tyche corona muralis}

A fragment of a fresco of the Roman goddess Tyche was recovered from the destruction fill next to the fountain by the north wall of the peristyle house. It preserves the upper right portion of the face and the crown.

The left cheek and half of the left eye are missing, as is everything below the upper lip. The wide eyes look off to the left. Such a glance may be imitative of the oft-copied Tyche of Antioch by Eutychides of Sikyon.

The right eyebrow is prominent. The dark brown hair is pulled back toward the ears, perhaps with plaited braids. Fortifications of a city form the crown. The main gate consists of a Roman arch, as can be seen typically in detail of fortifications from Trajan's Column. The tops of the towers appear bulbous - a most unusual configuration. We wonder if what look like towers might instead be columns with capitals. The two possible columns next to the gate have identical elevations and the one closest to the gate has a square top (viewed from an angle). As mural crowns could reflect actual circumstances of the city to which the Tyche belonged, these standing columns might point to a time when some decline had already come to Hippos.

Detailed photos of the find were examined by Keith Williams, Professor of Art, at Concordia University. In private correspondence, he writes: 
The fresco of the head and crown of the goddess Tyche from the Hippos archeological site has many aesthetic characteristics that are worth noting. These may help us suggest dating based on stylistic analysis. Some of these observations include:

The red iron oxide pigment that remains after these years gives us a Tyche that is nearly life-sized. It is three quarters view of the head. It is painted with observational realism and idealism, showing little stylization of proportions or flattening of the shape of the head. The sense of observational perspective of the structures on the crown, although not in strict western perspective, does show the orthogonal lines that are associated with an attempt to give the illusion of depth.

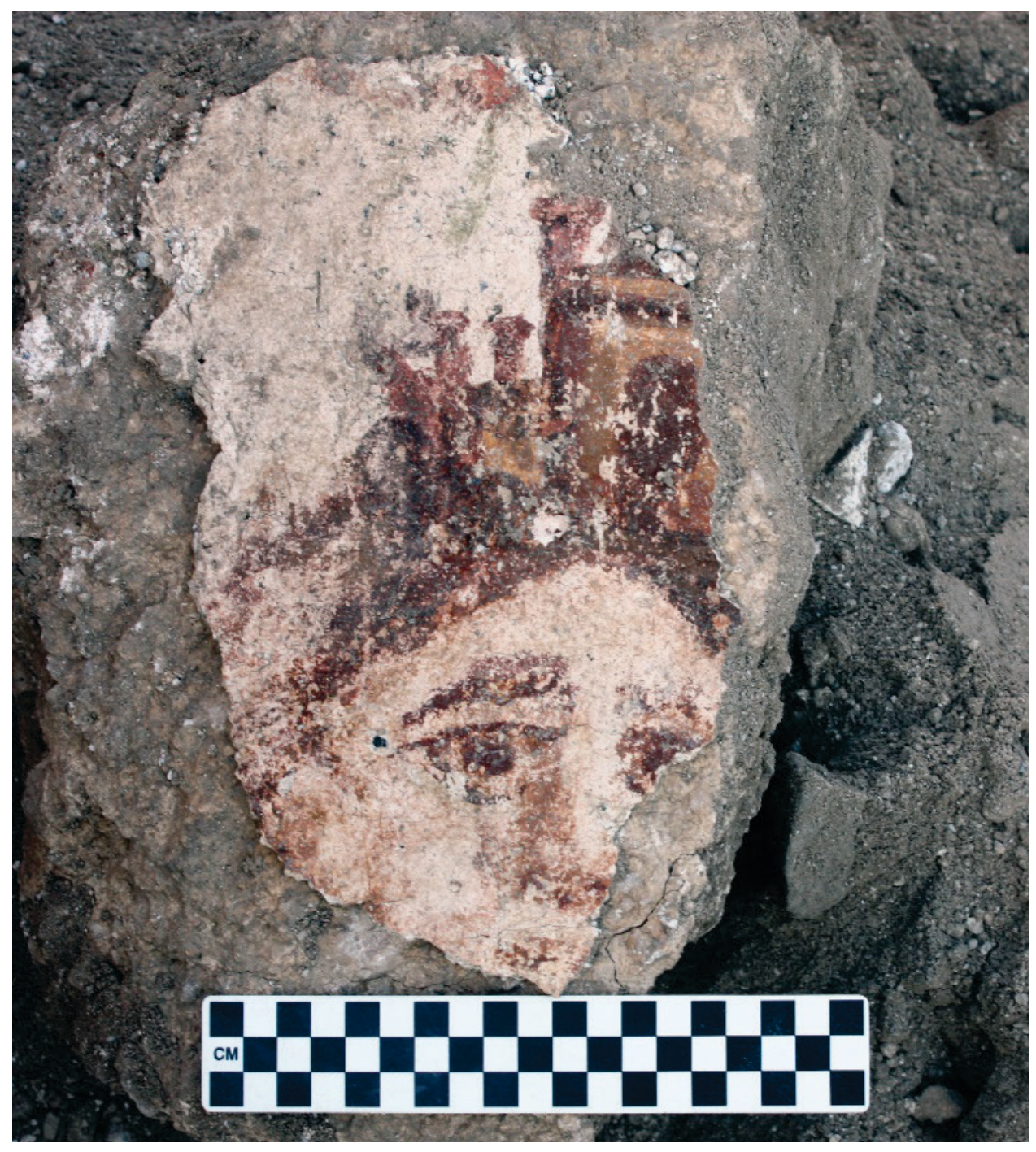

Figure 196 Fresco of Tyche at discovery

These observations, from the size of the image to its observational realism, make the style of the fresco very similar to the third Roman style of villa painting frozen at Pompeii and Herculaneum--the Architectural Style. This style was common 
throughout the Roman Empire, but often was practiced in different areas at different times based on remoteness and acceptability within the cultural context.

The context of the Middle East saw a strong disposition toward stylization prior to Roman influence and was an early area in returning to stylization in aesthetics as the Roman Empire gave way to the Late Antique. Jewish frescos remained stylized throughout the Roman occupation. Early Christian and Late Antique images began to lose their classical Roman observational realism as early as the fourth and fifth centuries.

With these things broadly stated, and due to the remoteness and eastern location of the site, aesthetic observations suggest that this artifact is probably rather early in its date. That this image would have been painted near the end of the activity at Hippos is unlikely. It is more likely that the image was painted in the third or fourth centuries and perhaps repurposed in its meaning and use as the site became Christianized. ${ }^{168}$

"Cities throughout the ancient world employed the image of the statue as ... the archetypal representation of a city's protector." 169 Tyche also played an important role in the self-identification of Hippos. Four of the eleven city-coin types from Hippos enumerated by Spijkerman involve a representation of Tyche, two of which make specific connection by including a horse or a little horse. ${ }^{170}$ An inscription was uncovered on the paved plaza west of Cardo 2 North beginning with the words АГА $\Theta \mathrm{H}$ ТYХН. ${ }^{171}$ But Tyche's importance extended far beyond Hippos.

"La référence à la Tychè était universelle dans les cités du Proche-Orient romain." ${ }^{172}$ Chance or fortune (tyche) was an element of life in Greek culture. Since fortune could be unpredictable and fate seemingly evil, cults devoted to Good Fortune (АГА $\Theta \mathrm{H}$ TYXH) developed. Tyche came to personify the fortune of a city or an individual. ${ }^{173}$ As Greek colonists in the wake of Alexander settled in the east, "Tyche appeared in many guises, absorbing traits of

\footnotetext{
${ }^{168}$ Keith Williams, September 2, 2021.

${ }^{169}$ Pieter BFJ Broucke, "Tyche and the Fortune of Cities in the Greek and Roman World," in An Obsession with Fortune: Tyche in Greek and Roman Art, ed. Susan Matheson (New Haven, Conn.: Yale University Art Gallery, 1994), 39-40.

${ }^{170}$ Augustus Spijkerman, The Coins of the Decapolis and Provincia Arabia, Studii biblici franciscani collectio maior 25 (Jerusalem : Franciscan Printing Press, 1978), 169.

${ }^{171}$ Segal et al., Hippos-Sussita : Tenth Season of Excavations : July and September 2009, 74-79.

172 Nicole Belayche, "Tychè et la 'Tychè' dans les cités de la Palestine romaine," Syria; revue d'art oriental et d'archéologie 80 (2003): 112.

173 Susan Matheson, "The Goddess Tyche," in An Obsession with Fortune: Tyche in Greek and Roman Art, ed. Susan B. Matheson and J. J. Pollitt, Yale University Art Gallery Bulletin 1994 (New Haven, Conn: Yale University Art Gallery, 1994), 19.
} 
other divinities in some cases, becoming simply an aspect of a stronger divinity in others." ${ }^{174}$ A head of a Tyche was discovered in the southern temple at Petra. ${ }^{175}$ The Tyche of Dura-Europas sits next to the Tyche of Palmyra in a fresco from Dura. ${ }^{176}$ In a limestone cult relief from Dura, the Tyche crowned by Seleukos Nikator is a bearded male. ${ }^{177}$ At Caesarea, one statue of Tyche depicts her as an Amazon while also invoking images of Poseidon, Demeter and the cult of Roma and the emperor; another statue seems to equate Tyche with Fortuna. ${ }^{178}$ In Spijkerman's catalogue, almost every city has one or more coins types with Tyche. In view of social conditions and the uncertainties of life at the eastern fringe of the Roman Empire, "Fortune became an obsession." 179

"The idea of Tyche as a city goddess and her visual representation in this role developed for the most part in the ancient Near East." ${ }^{180}$ The origins of the idea are quite ancient. As Greek towns developed into $\pi$ ó $\lambda \varepsilon 1 \zeta$, each city united individuals, a governing system, and a set of religious beliefs into a cohesive whole that was more than just a physical entity. In uncertain times, each city, "hoping for a favorable destiny, came to rely on its Tyche, its protecting goddess." ${ }^{181}$ As new Greek cities were founded in the east after the conquests of Alexander, "Tyche assumed a propagandistic role," 182 uniting disparate peoples especially in view of the vulnerabilities of life on the frontier. Broucke summarizes:

[Tyche's] prominence as a civic deity in these later phases of Antiquity resulted from the fact that populations of these cities were characterized by cultural diversity. Tyche as the city goddess, then, functioned as the point around which all citizens could rally; despite their different cultural backgrounds and religious beliefs, all had an interest in the communal fate of the city. As such, Tyche, the great protector of cities in Antiquity, belonged both to the realm of secular rite and to the religious sphere. ${ }^{183}$

The fragmentary fresco from Hippos was recovered on top of a Late Antique mosaic floor, having been knocked down by a column collapsing during an earthquake likely late in the major occupational phase of the site. This Tyche becomes another example of the persistence of Tyche into and beyond the time of Christianity's intentional destruction of pagan worship and its images. Evidence for such persistence is widespread.

\footnotetext{
174 Ibid., 23.

175 Joseph J. Basile, “A Head of the Goddess Tyche from Petra, Jordan. The Seventh Season,” Annual of the Department of Antiquities of Jordan 41 (1997): 255-266.

${ }^{176}$ Broucke, "Tyche and the Fortune of Cities in the Greek and Roman World," 41.

${ }^{177}$ Matheson, "The Goddess Tyche," 27-28.

178 Rivka Gersht, "The Tyche of Caesarea Maritima," Palestine Exploration Quarterly 116, no. 2 (1984): 110-114.

179 J. J. Pollitt, "An Obsession with Fortune," in An Obsession with Fortune: Tyche in Greek and Roman Art, ed. Susan B. Matheson and J. J. Pollitt, Yale University Art Gallery Bulletin 1994 (New Haven, Conn: Yale University Art Gallery, 1994), 14.

${ }^{180}$ Basile, "A Head of the Goddess Tyche from Petra, Jordan. The Seventh Season,” 259.

${ }^{181}$ Broucke, "Tyche and the Fortune of Cities in the Greek and Roman World," 37.

182 Ibid., 38.

183 Ibid., 44.
} 
When Constantine made Byzantium the new Rome as Constantinople, this Christian city held a temple for Tyche with a statue of the Fortuna of Rome. ${ }^{184}$ Various Tychai also appear on fourth-century coins of the city. When Julian visited Antioch in 361/2, few pagan temples remained. Nonetheless, he could still sacrifice to the city's Tyche. ${ }^{185}$ In the early fourth century, Fortune is a topic for speculative discussion by Nemesius of Emesa. ${ }^{186}$ In the fifth century, the "Tyche of Antioch is attested as late as the reign of Theodosius II (A.D. 408450)." ${ }^{187}$

Closer to Hippos, at Scythopolis on the west side of Palladius street is the Sigma Plaza, which according to a mosaic inscription was built in the beginning of the sixth century. The mosaic floor of one of the twelve rooms around it has a round frame with a portrait of Tyche. ${ }^{188}$ The Tyche of Madaba appears on a mosaic floor in the Hall of Hippolytus, an early sixth century mansion, later leveled to make room for the Church of the Virgin. ${ }^{189}$ In the Church of St. Bacchus at Horbat Tinshemet is a marble medallion of Tyche that is $67 \mathrm{~cm}$ in diameter. The frame of the medallion contains two inscriptions beginning and ending with crosses. "The lower inscription reads, 'In the month of Xanticus Year 654.' The year mentioned in the inscription probably follows the Pompeian indiction, so that the date corresponds to 582 CE." ${ }^{190}$ These examples demonstrate that Tyche persists well into the period of the occupation of the northeast insulae at Hippos.

The sixth-century chronicler Malalas provides some nuance to the persistence of Tyche into the Late Antique period. Having noted the sacrifice of the virgin Aimathe by Seleukos to Tyche at the founding of Antioch and the sacrifice of the virgin Kalliope by Trajan to Tyche at the reconstruction of Antioch following the earthquake of 115 C.E., Malalas emphasizes that Constantine made a Tyche for Constantinople with a "bloodless sacrifice to God" rather than a human sacrifice. ${ }^{191}$ "In both pagan and Christian hands, therefore, Tyche exercised a very real protective function over a city. In Malalas's Chronicle, the triumph of Chris-

\footnotetext{
${ }^{184}$ John Ferguson, The Religions of the Roman Empire, Aspects of Greek and Roman life (Ithaca, N.Y: Cornell University Press, 1970), 87.

${ }^{185}$ Ibid., 86-87.

${ }^{186}$ Nemesius of Emesa, De Natura Hominis, PG 40, cols. 761b-764a; cited in Glenn Chestnut, "The Pagan Background," in The Christian and Judaic Invention of History, ed. Jacob Neusner, Studies in religion / American Academy of Religion no. 55 (Atlanta, Ga: Scholars Press, 1990), 34.

${ }^{187}$ Broucke, "Tyche and the Fortune of Cities in the Greek and Roman World," 46.

${ }^{188}$ Rachel Bar-Nathan and Gabriel Mazor, "City Center (South) and Tel Iztabba Area Excavations of the Antiquities Authority Expedition.," Excavations and Surveys in Israel 11 (1993): 42-44.

${ }^{189}$ Michele Piccirillo and Eugenio Alliata, eds., The Madaba Map Centenary, 1897-1997: Travelling through the Byzantine Umayyad Period, Collectio maior 40 (Jerusalem: Studium Biblicum Franciscanum, 1999), 246-248.

${ }^{190}$ Uzi Dahari, "The Church of St. Bacchus near Horvat Tinshemet.," Christ Is Here! (2012): 105-124.

${ }^{191}$ Mark Stansbury-O’Donnell, "Reflections of the Tyche of Antioch in Literary Sources and on Coins," in An Obsession with Fortune: Tyche in Greek and Roman Art, ed. Susan B. Matheson and J. J. Pollitt, Yale University Art Gallery Bulletin 1994 (New Haven, Conn: Yale University Art Gallery, 1994), 52-53.
} 
tianity expresses itself not through the repudiation of the idea of the personification of fortune, but through differences in ritual." 192 "The risk to the city of ignoring its Tyche appeared to have been too great, even for Christians." 193

But more than "differences in ritual" may be involved in the persistence of Tyche into the Late Antique period. Tsafrir posits a distinction between the classical heritage of an aesthetic object and cultic connotations surrounding that object. The former persists into the late fourth and fifth centuries, even as the later are forbidden and forgotten. Cult centers were closed, but in non-cultic and private locales, the classical heritage continued.

The classical tradition (which cannot be differentiated from its polytheistic origin) remained alive. The population, at least the elite classes, tried to preserve this classical heritage and there were many ways to do so: maintaining the theatre and other spectacles, studying classical Greek literature and philosophy, and keeping alive artistic motifs." ${ }^{194}$

To discover a fresco of Tyche surviving in the terrace of a compound built into the ruins of a peristyle house ought not surprise us.

In a related way, the aesthetic object -- in this case Tyche figures -- may lack significant religious connotations in the Late Antique period. Pollitt writes of them serving "the same function that flags and state seals do in our own time." ${ }^{195}$ Having noted the scarcity of actual places of worship of Tyche in Palestine, Belayche concludes:

En tant que patronne tutélaire en laquelle on plaçait une confiance permanente, sa seule évocation iconographique, omniprésente en public comme en privé, suffisait ... Donc en Palestine, la figure de Fortune semble avoir servi prioritairement de support pour exprimer la participation à un univers gréco-romain reconnaissable à des codes sémantiques. C'est pourquoi nous allons la rencontrer aussi dans des cités à direction juive où, comme dans la majeure partie des cités, elle était convoquée sans être divinisée. ${ }^{196}$

Tyche functions as a language or a code. Tyche is not systematically the divine personification of a city. Rather, Tyche in Palestine appears mostly as an artistic expression of the reality of the city, both institutional and cultural. The Tyche expresses loyalty to the empire and civic pride. ${ }^{197}$ By way of analogy, the discovery of an image of a "blue devil" in RaleighDurham, North Carolina, would not convey religious overtones, but rather identity with and

\footnotetext{
192 Ibid., 53.

${ }^{193}$ Matheson, "The Goddess Tyche," 25-26.

${ }^{194}$ Yoram Tsafrir, "The Classical Heritage in Late Antique Palestine: The Fate of Freestanding Sculptures," in The Sculptural Environment of the Roman Near East, ed. Yaron Z. Eliav, Elise A. Friedland, and Sharon Herbert (Lueven: Peeters, 2008), 212.

${ }^{195}$ Pollitt, "An Obsession with Fortune," 15.

${ }^{196}$ Belayche, "Tychè et la 'Tychè' dans les cités de la Palestine romaine," 125.

${ }^{197}$ Ibid., 126.
} 
civic pride in the sports program of Duke University. Interestingly, a mosaic sidewalk in front of the entrance of a shop southeast of the ancient city center at Scythopolis has a carefully executed Greek inscription which reads, "To the victory of Tyche of the Blues." The "Blues" were one of two circus factions known from the Late Antique period. ${ }^{198}$

\section{Chancel}

Throughout the excavation of the chancel, especially at the head of the north aisle, numerous fragments of plaster were recovered. At higher levels most were white. Lower in the square, colors, lines, and patterns were observed. The dominant color is red although some yellows are also visible. From basket 1831, it is possible to reconstruct a broad red band (6$7 \mathrm{~cm}$ wide) that is bordered by one to three very narrow stripes $(1-2 \mathrm{~mm})$. On the opposite side of the narrow stripes, the background color is yellow. From basket 1833 comes a fragment with a white background, a yellow band $(4 \mathrm{~mm})$, and a red blotch that may be grapes. From the same basket comes a fragment with a yellow background, a brown band (4 mm) and a small red blotch. A small fragment from basket 1835 may capture the edge of a round red object.

\section{Observations}

As the Sea of Galilee is in a temperate climate zone, the intact survival of frescos is rare. So, the Tyche is a notable find. Its sense of realism attested to the high culture of the Roman Imperial period. Other frescos are quite fragmentary but do suggest the use of such for decorative purposes in domestic and liturgical contexts.

\section{Inscriptions}

Three intact inscriptions and one set of fragmentary remains were unearthed during the excavation. Two inscriptions are in mosaic and come from the Roman Imperial period of the peristyle house. One inscription is incised into a stone surface reused as a paving stone in a Late Antique plaza. The fragmentary remains come from a collapsed floor in the North Building of the Late Antique urban monastic compound. As they are so broken to make a reading impossible, these fragments are discussed later in this chapter with the rest of the collapsed mosaic floor.

${ }^{198}$ Danny Syon, “Bet She'an,” Hadashot Arkheologiyot: Excavations and Surveys in Israel 116 (2004): 10, fig. 3. 


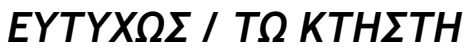

An inscription in tabula ansata was discovered inside the threshold of the entrance from Cardo 4 North to the terrace area north of the peristyle house from its Roman Imperial period. The small cardo has steps down at this point due to the topographic drop off prior to the north wall of the city. The inscription faces those entering through the threshold.

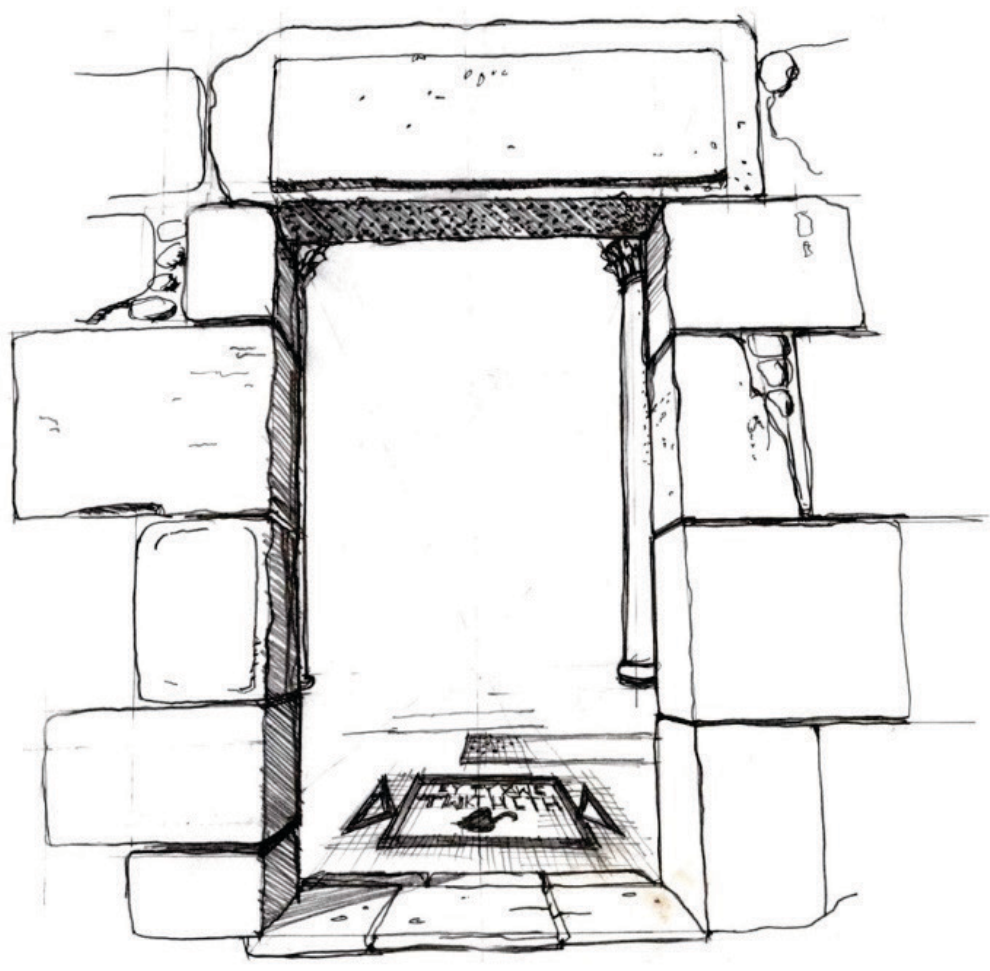

Figure 197 East entrance with inscription

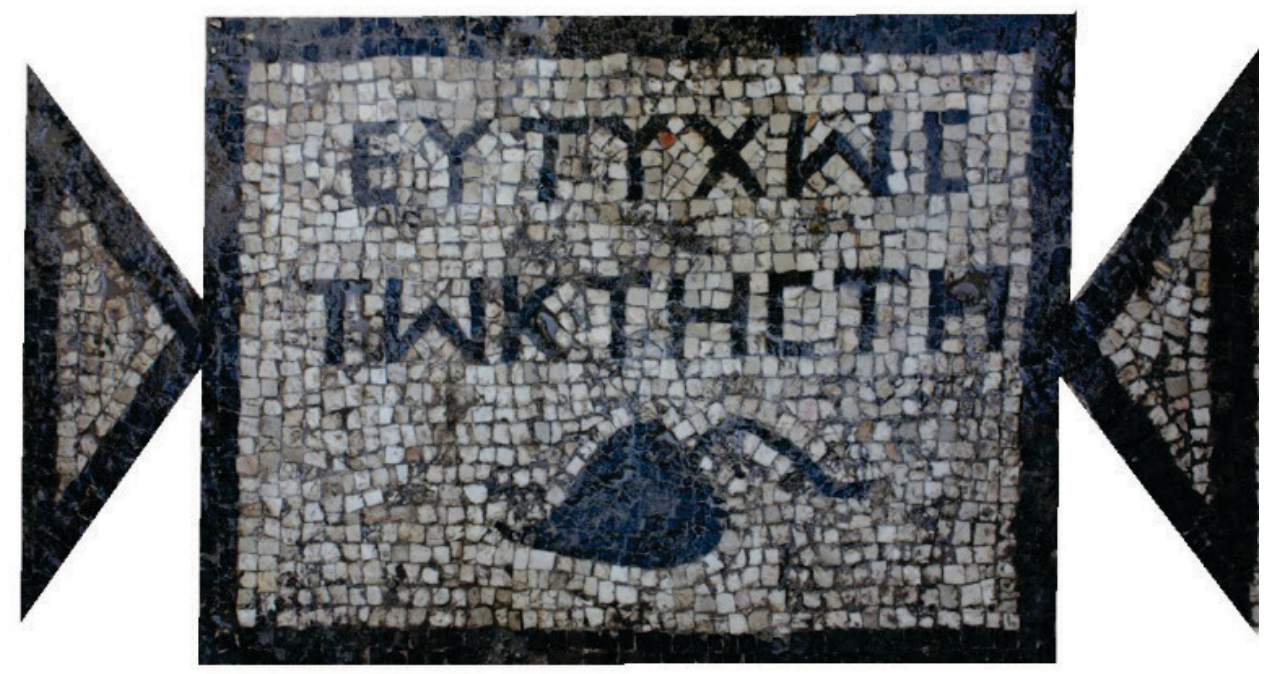

Figure 198 Entrance inscription 
The Greek is EYTYX $\Omega \Sigma / T \Omega \mathrm{KTH} \Sigma \mathrm{TH}$. The omegas are lower case formed large with the middle part of the letter in the form of a chevron. The inscription is $97.5 \mathrm{~cm}$ wide counting the dovetail handles with the main frame $67 \mathrm{~cm}$ wide. It is $51 \mathrm{~cm}$ tall. The letters are 6-6.5 $\mathrm{cm}$ tall. The ivy leaf is $11 \times 17 \mathrm{~cm}$. There are 41 tesserae $/ \mathrm{dm}^{2}$. The inscription contains a

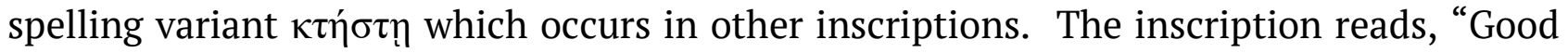
fortune to the builder." The builder was probably also the owner. The inscription has parallels at Tell el-Farama ${ }^{199}$ and Shiqmona near Haifa, ${ }^{200}$ with the same variant.

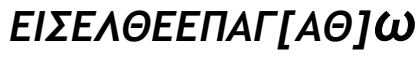

An inscription greeting visitors to the peristyle house of the Roman Imperial period was discovered south of the blocked entrance in the north wall (W1266) in a surviving section of the original mosaic floor (F1939) of the room. That doorway would have provided entrance from the terrace into the northeast room of the peristyle house.

The inscription is almost intact. A repair band goes between the second box and the second swastika above it and takes out the alpha and part of the theta in the inscription. The repair is $10-16 \mathrm{~cm}$ wide. It starts $10 \mathrm{~cm}$ below the lambda of the inscription and curves to about 26 $\mathrm{cm}$ above the inscription.

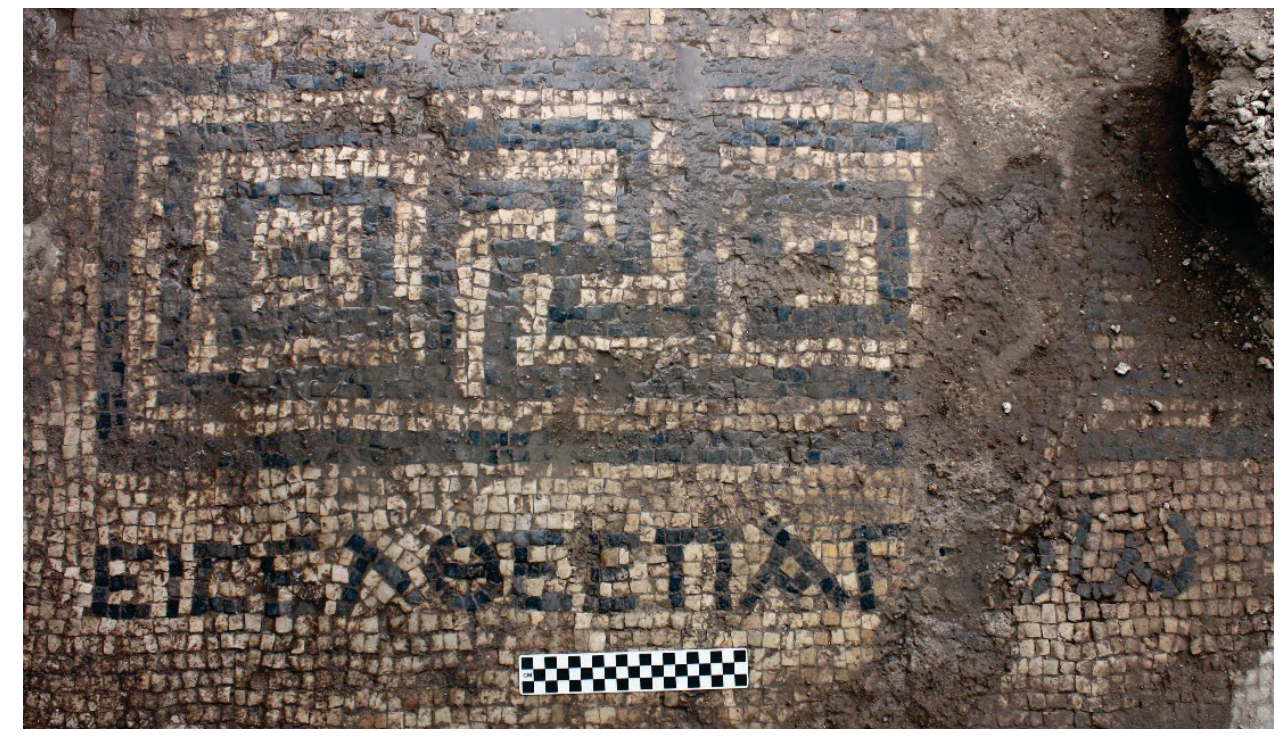

Figure 199 Inscription of welcome

In the inscription itself, the repair removed the third to last letter and part of the second to

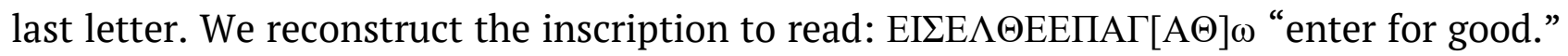

\footnotetext{
199 Supplementum Epigraphicum Graecum (Alphen aan den Rijn, the Netherlands: Sijthoff \& Noordhoff, 1923ff), 37:1639.

${ }^{200}$ Ibid., 37:1487. 
The inscription is $96 \mathrm{~cm}$ in length. The letters are $5.5-6.5 \mathrm{~cm}$ tall. The inscription was to be read by persons entering through the now blocked doorway from the courtyard/garden. The inscription is centered on the doorway. We therefore identify the northeast hall as an entrance foyer for the house. The inscription from the entrance hall has parallels at Pompeiopolis ${ }^{201}$ and Krokodeilon Polis near Caesarea. ${ }^{202}$ Greetings of this sort occur in entrances to buildings both public and private in the Roman Imperial and Late Antique periods.

\section{AГAӨHTYXH}

An inscription was identified on the paved plaza between Building Alpha and Building Beta west of Cardo 2 North. The inscription is the second row of pavers east of W1285. It is roughly centered on the plaza but off center to the south of the threshold. The stone is in

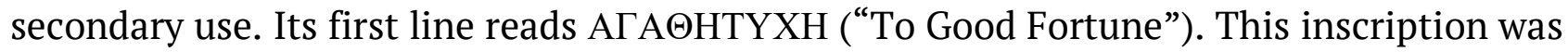
originally part of an honorific inscription for Tarius Titianus, governor of Syria Palestinae. ${ }^{203}$

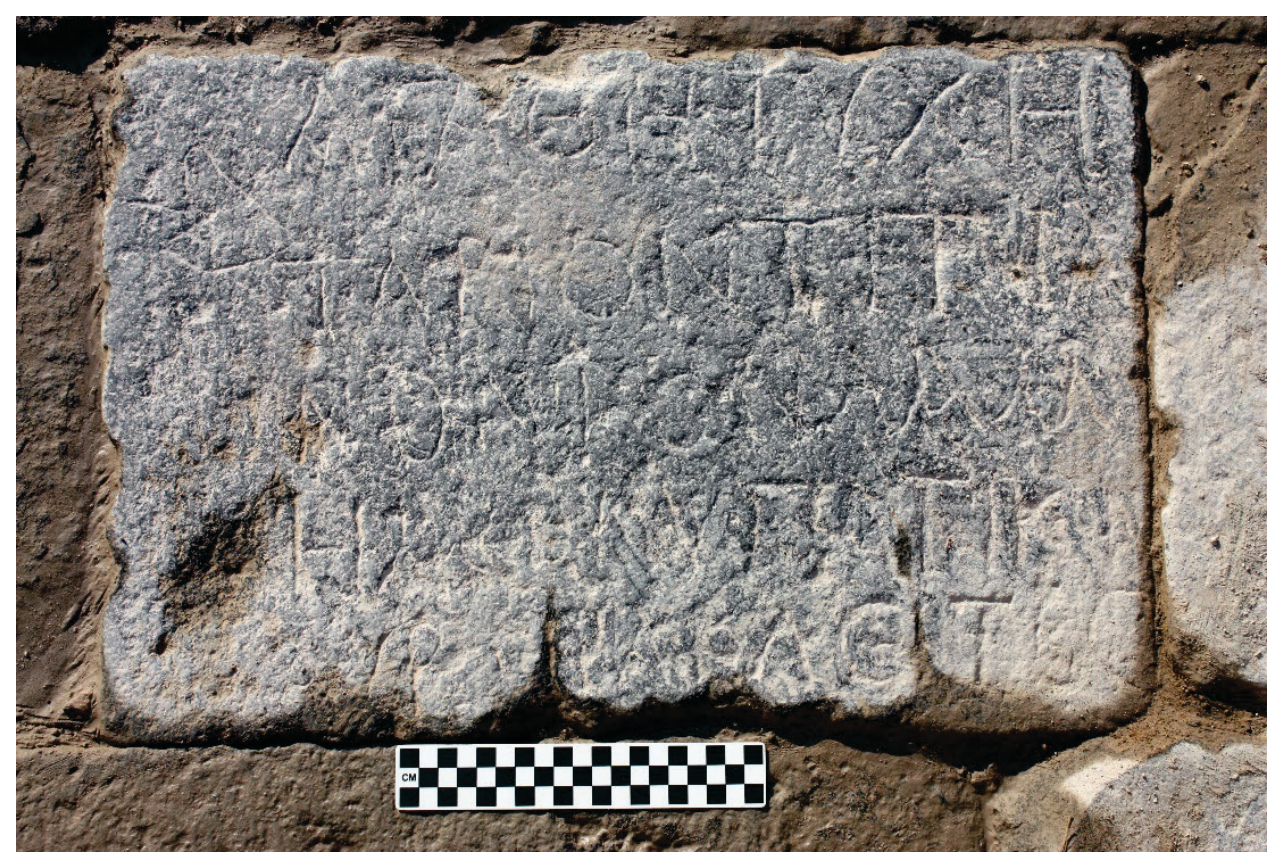

Figure 200 Inscription "good fortune"

The five lines are:

A $\gamma \alpha \theta \eta ̣$ Túxn

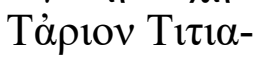
vòv $\tau$ òv $\lambda \alpha \mu[\tau \rho o ́ \tau \alpha \tau i o v]$

\footnotetext{
${ }^{201}$ Ibid., 40:1177.

${ }^{202}$ Ibid., 56: 1891.

${ }^{203}$ Adam Lajtar, "Greek Inscriptions," in Hippos-Sussita of the Decapolis: The First Twelve Seasons of Excavations (2000-2011) Vol 1, ed. Arthur Segal (Haifa, Israel: The Zinman Inst of Archaeology, 2013), 251-253.
} 


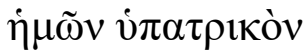

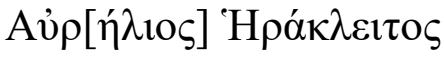

To the Good Fortune. Aurelius Heraclitus [honors] Tarius Titianus, our illustrious governor...

Titianus governed Syria Palaestinae in the second decade of the third century CE. ${ }^{204}$

Subsequently, while removing initial layers of destruction fill from Building Alpha, we recovered a fragment of a Greek inscription. The stone is basalt with an inscription face that is $29 \times 36 \mathrm{~cm}$. There is a large crude hedera inscribed horizontally in the lower right corner.

The stone is horizontally $29 \mathrm{~cm}$ at top and $30 \mathrm{~cm}$ at bottom. Vertically it is $36 \mathrm{~cm}$ on the right edge and $36.5 \mathrm{~cm}$ on the left edge. At its longest, the stone is $57 \mathrm{~cm}$. Most of the letters are about $5 \mathrm{~cm}$ in height. The shortest letter is the delta in the last line. It is $4 \mathrm{~cm}$ tall. The tallest letter is the sigma in the last line. It measures $6 \mathrm{~cm}$ tall.

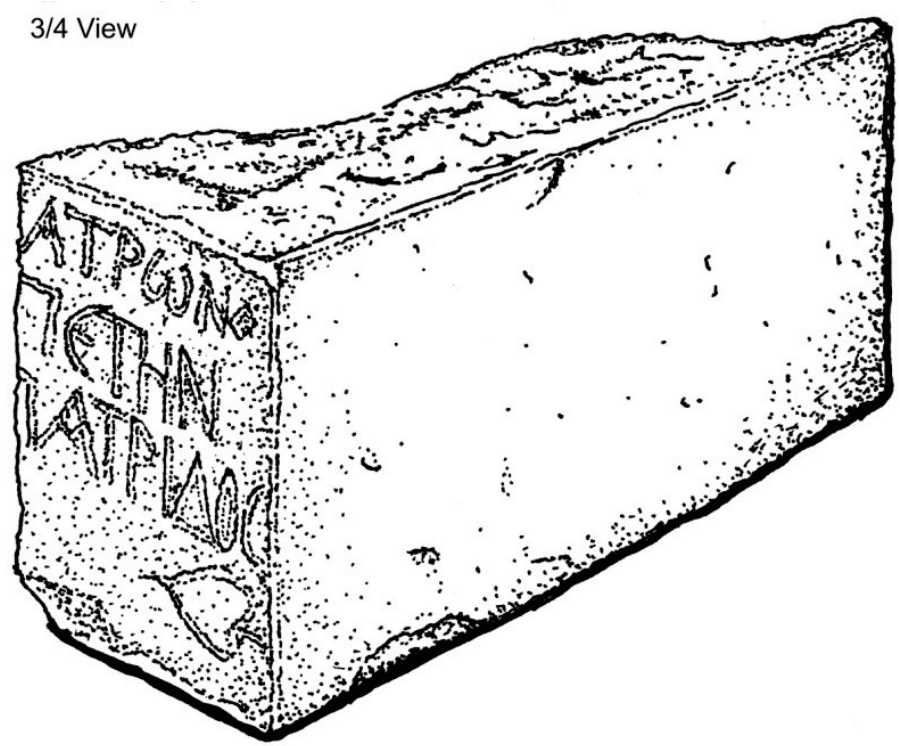

Figure 201 Portion of Tarius Titianus inscription

This fragment is part of the inscription noted above. In combination with a third fragment discovered between Building Alpha and the Roman basilica, the complete text of the honorific can be reconstructed. Titianus is honored as "patron and euergetes of the fatherland."

\footnotetext{
${ }^{204}$ Adam Łajtar, "Two Honorific Monuments for Governors of Syria Palaestinae in Hippos," Palamedes: A Journal of Ancient History 5 (2010): 177-186.
} 


\section{Observations}

These three inscriptions recovered in the northeast insulae accentuate honor and hospitality in the Roman Imperial period. In the Greek east, such benefactions put emphasis on the "virtue, generosity, and public giving" of those honored, even if that perspective was idealized in anticipation. ${ }^{205}$ Likewise, hospitality was a prized and praised practice in the Roman world, even if descriptions could be exaggerated:

Throughout the City the front gates of the houses were thrown open and all sorts of things placed for general use in the open courts, all comers, whether acquaintances or strangers, being brought in to share the hospitality. ${ }^{206}$

It is consistent with such practice for a wealthy homeowner to accentuate in inscriptions both benefaction and welcome when guests arrive, even as city leaders might honor a regional governor with expansive language.

\section{Mosaic Floors}

Mosaic floors display the skill of the artisans at work and, to a degree, the theology of the community/donor funding the carpet. The domus of the Northeast Church yielded fragments of mosaic decoration, as did the skeuophylakion, the portico of the church, and several spaces both outside and within the peristyle house.

\section{Chancel of the Northeast Church}

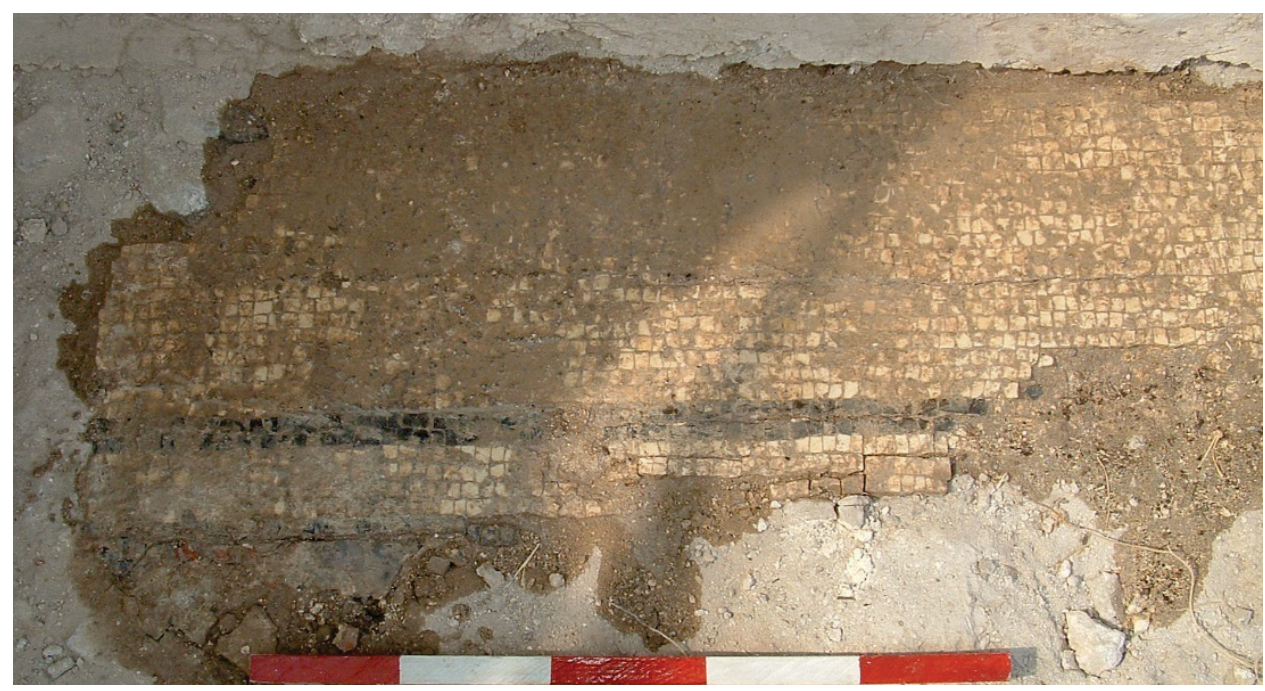

Figure 202 Fragment of F517 next to the south wall of the chancel

\footnotetext{
${ }^{205}$ Marc Domingo Gygax and Arjan Zuiderhoek, Benefactors and the Polis: The Public Gift in the Greek Cities from the Homeric World to Late Antiquity (Cambridge University Press, 2021), 216-217.

${ }^{206}$ Livy, "History of Rome," 5.13.
} 
In the process of excavating the two burial sites in the church, we discovered evidence of the plaster base of an earlier floor beneath the surviving opus sectile floor (F516). North, west, and south of the sarcophagus we cleared to the plaster base of this earlier floor (F517). A $1 \mathrm{~m}$ section of mosaic tile from F517 was still intact next to the south wall (W510) of the chancel. Visible was the same black band that would characterize the border of the other mosaics in the church.

\section{South aisle}

In the south aisle of the church under and west of the benches along the south wall is a continuous fragment of the mosaic carpet for the aisle.

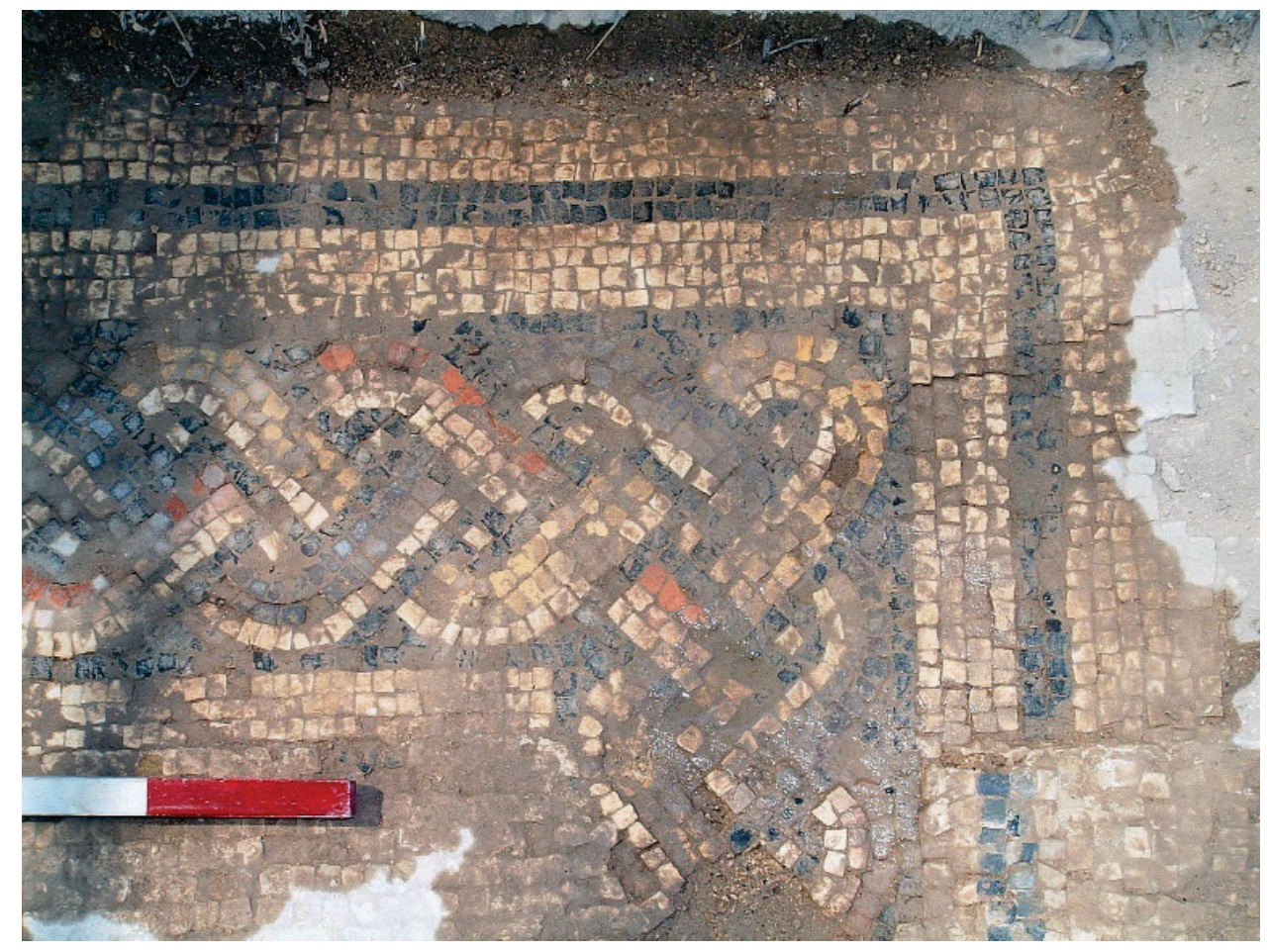

Figure 203 Guilloche Mosaic

The background field is white. There is a black band of two tesserae, a white band of four tesserae, and black band of one tessera, and then a simple guilloche pattern (Avi-Yonah pattern B2) ${ }^{207}$ in black, white, red, and yellow (approximately $1 \mathrm{~cm}^{2}$ tesserae). At about three meters from the west wall (W511) the border turns to the north briefly. The border also runs to the east beneath a bench for four meters. West of this border is an $80 \times 60 \mathrm{~cm}$ segment of tesserae in a circular pattern (portions of four circles). At the west end of the aisle, in the

207 Avi-Yonah, "Mosaic Pavements in Palestine," 139. 
southwest corner, and in two fragmentary locations along the stylobate are segments of white mosaic tile of larger size $\left(1.5 \mathrm{~cm}^{2}\right.$ tesserae). These seem to be a later repair.

\section{North aisle}

In the northeast corner of the north aisle next to the base of the chancel screen, a section of the original mosaic floor is preserved. Toward the east end next to the bench is a repair done with larger tesserae in no discernable pattern, probably from the same incident that required structural repair to the church. The poverty of the community in the late sixth century is reflected in the repairs which neither preserved the symmetry of the church nor the pattern of the mosaic.

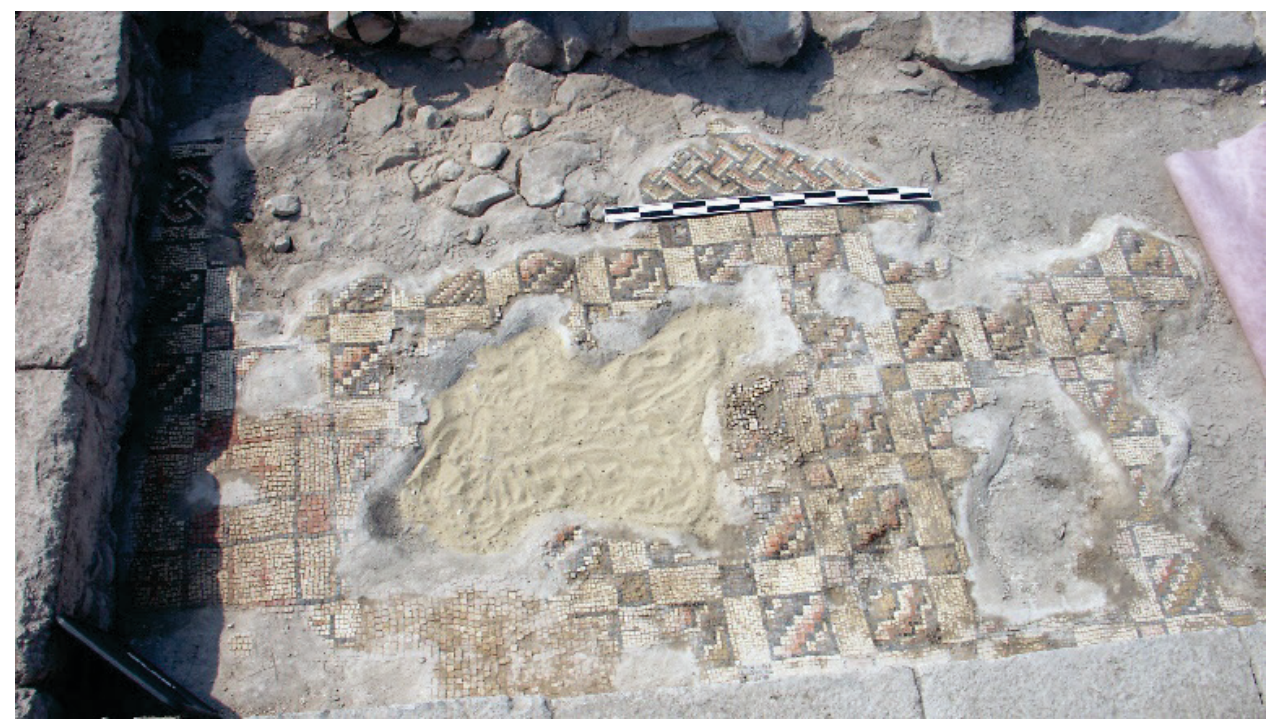

Figure 204 Mosaic from east end of the north aisle (looking south)

The original mosaic floor was decorated with several patterns. Running parallel to the stylobate is a three-strand guilloche (Avi-Yonah pattern B2). ${ }^{208}$ The guilloche matches the pattern discovered in the south aisle and is separated from the stylobate by roughly the same distance as the guilloche from the south aisle is offset from the south wall. The gap was likely filled by the same banding of white and black stripes.

The bulk of the still visible pattern consists of $20 \mathrm{~cm}$ squares framed by a single row of black tesserae. On each of the four corners is an $8 \mathrm{~cm}$ framed square. The field of the small squares is a solid color (red, brown, yellow, black, pink). The field of the large square is filled by diagonal lines in five or six colors constructed of 2 x 2 blocks of tesserae. Minor variations

${ }^{208}$ Ibid., 139. 
to the diagonal patterns can be seen. The rectangles between the corners are white. ${ }^{209}$ The pattern was likely replicated down the aisle to the west.

Next to the base of the chancel screen in the center of the aisle are four $20 \mathrm{~cm}$ squares. The squares are framed mostly in red tesserae and are separated by $8 \mathrm{~cm}$ rectangles and squares. The central $8 \mathrm{~cm}$ square is framed in black and has a red field. Black framing continues to the west. The $20 \mathrm{~cm}$ squares have white field. In the middle of each field is an equal-armed cross ( $5 \times 5$ tesserae).

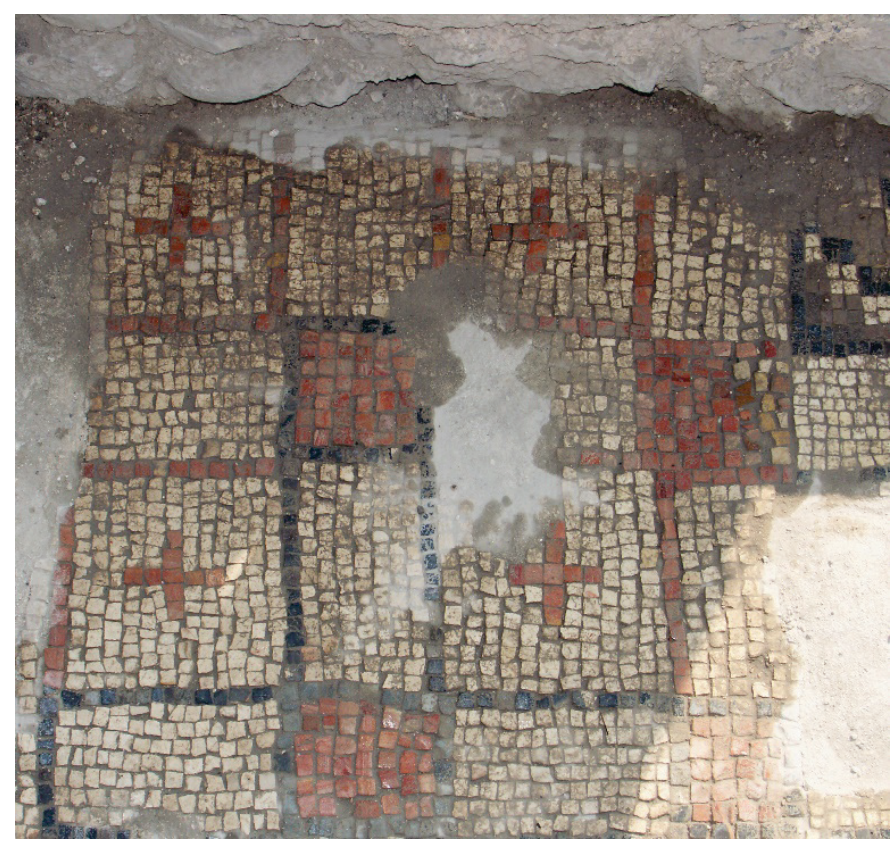

Figure 205 Crosses from the east end of the north aisle

Crosses in mosaic floors are important due to the prohibition against their use after $427 \mathrm{CE}$ by the Theodosian code. ${ }^{210}$ However, crosses continue to appear on Mosaic floors into the sixth century. ${ }^{211}$ Ernst Kitzinger, in discussing the plain red crosses in the floor of the Martyrion of St. Babylas at Antioch, proposes,

In early Christian times crosses placed more or less conspicuously on or near entrances served primarily an apotropaic function. They denied access to the powers of

\footnotetext{
${ }^{209}$ General parallels can be found at Mt. Nebo and Jerash. Michele Piccirillo, Patricia Maynor Bikai, and Thomas A. Dailey, The Mosaics of Jordan, American Center of Oriental Research publications no. 1 (Amman, Jordan: American Center of Oriental Research, 1993), figs.188, 521.

${ }^{210}$ Nimini locere signum salvatoris Christi vel in silice vel in marmore aut sculpere aut pingere. "Codex Theodosianus," 1.8.0.

${ }^{211}$ The prohibition was reaffirmed in the Code of Justinian and was even included in the canons of the Council of Trullo in 692 CE. Giovan Domenico Mansi et al., Sacrorum conciliorum nova et amplissima collectio: in qua praeter ea quae Phil. Labbeus et Gabr. Cossartius ... et novissime Nicolaus Coleti in lucem edidere ea omnia insuper suis in locis optime disposita exhibentur, Edito novissima ab eodem patre Mansi ... curata; accedunt etiam notae, et dissertationes quamplurimae quae in ceteris editionibus desiderantur. (Paris: H. Welter, 1901) vol. 11, col. 975, no. 73.
} 
evil.... Two kinds of buildings were in need of particular attention - the house and the tomb. Since the Martyrion of St. Babylas was both a tomb and a church our mosaic crosses fit into this picture very well. ${ }^{212}$

The Northeast Church likewise is a tomb and a church. The appearance of crosses, while suggesting an earlier foundation than the late sixth century, is also in continuity with the apotropaic practice of other churches in the lower Galilee. "The placement of crosses near entrances to the church and sanctuary continues in the mosaics of this region." ${ }^{213}$ Evil must be kept at bay.

\section{Nave mosaic}

An initial cleaning of sample sections of the nave mosaic revealed a variety of decorations and styles that clustered in two types. Some were quite decorative and elaborate, such as Avi-Yonah pattern B8 in red bordered by a guilloche, Avi-Yonah pattern J3, ${ }^{214}$ and a sauvastika (a counter-clockwise swastika) in black. Other portions were simple and geometric, such as a border of crosslets on the east and south sides of the nave.

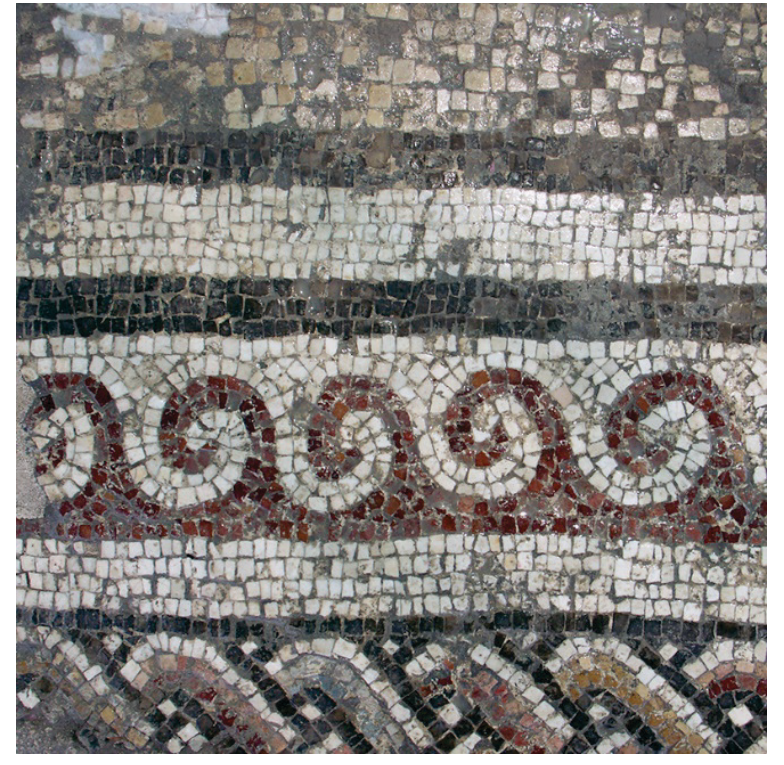

Figure 206 Pattern B8

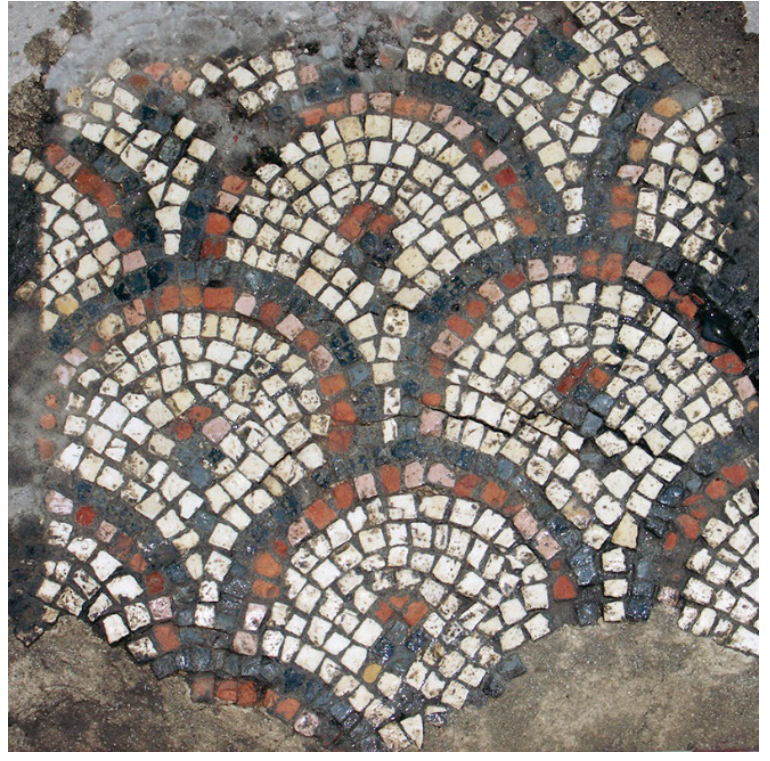

Figure 207 Pattern J3

\footnotetext{
212 Ernst Kitzinger, "The Threshold of the Holy Shrine: Observations on the Floor Mosaics at Antioch and Bethlehem," in Kyriakon: Festschrift Johannes Quasten, ed. Patrick Granfield and Josef A. Jungmann, vol. 2 (Münster/Westf: Aschendorff, 1970), 640.

${ }^{213}$ Karen Christina Britt, "Mosaics in the Byzantine Churches of Palestine: Innovation or Replication?" (Ph.D., Indiana University, 2003), 249. Britt cites examples from Kursi, Tabgha, Nazareth, and elsewhere.

${ }^{214}$ Avi-Yonah, "Mosaic Pavements in Palestine," 138, 141.
} 


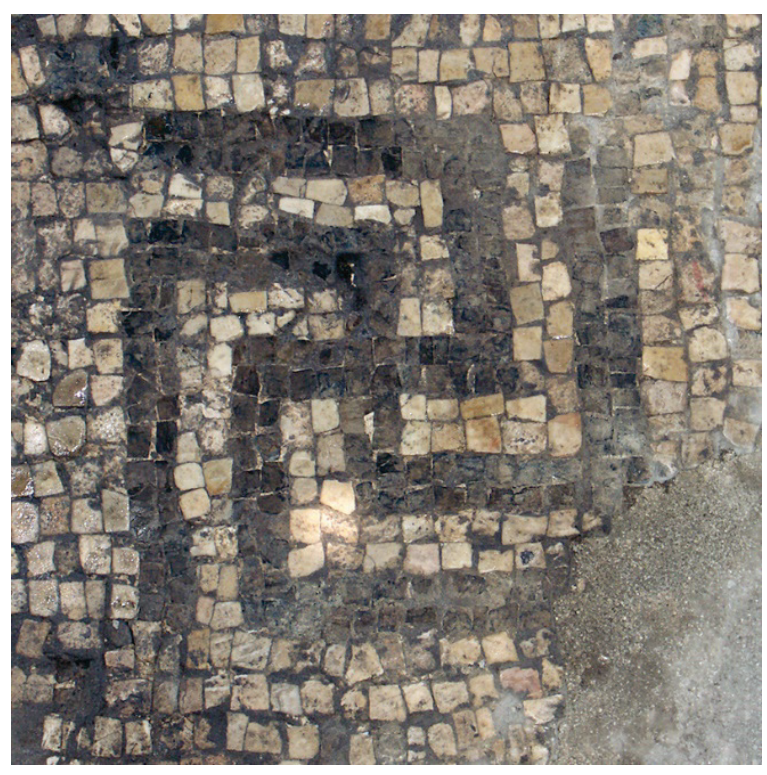

Figure 208 Sauvastika

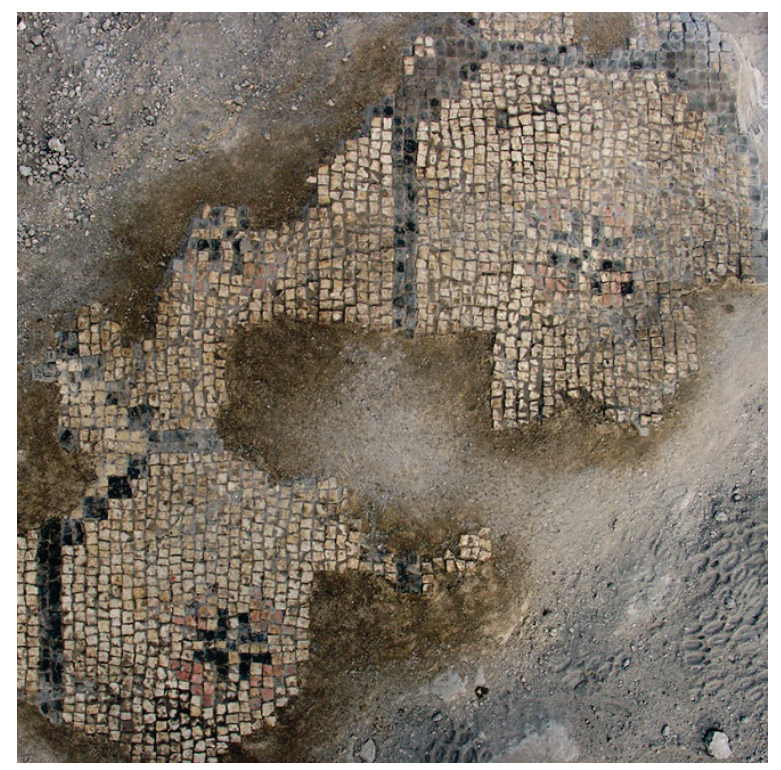

Figure 209 Crosslets

We concluded that the nave had two floors: a later upper floor (F589) and an earlier more elaborate lower floor (F544).

\section{Upper floor (F589)}

Only small fragments of the upper floor (F589) remain. It seems to have been entirely geometric in design.

At the east end along the chancel screen base and next to the southern stylobate was a border of crosswise arrangements (Avi-Yonah patterns F4 and F9215) framed by a white field
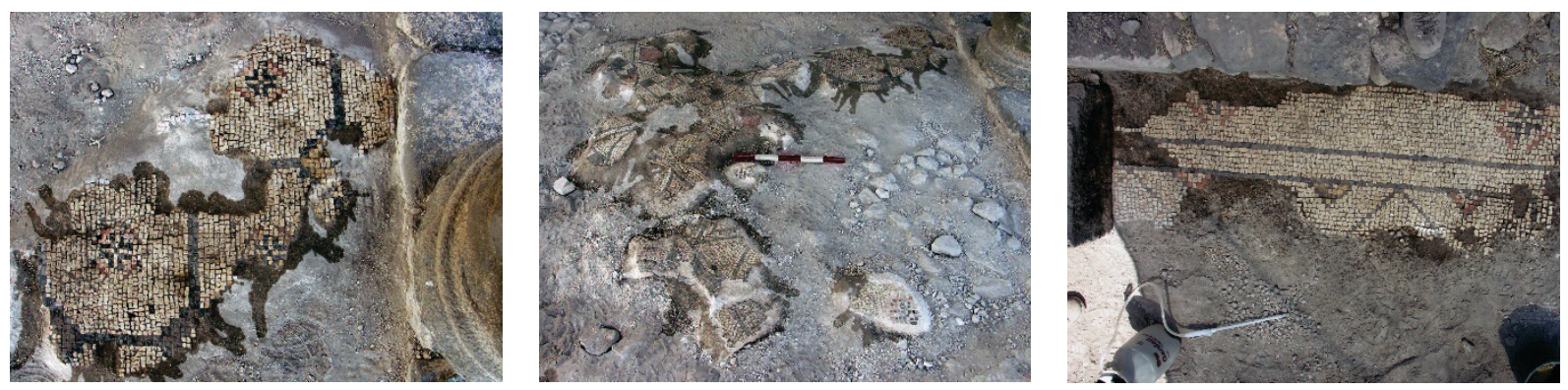

Figure 210 F589 samples

with random tesserae in orange and yellow and by a black square border two tesserae wide with decorative corners.

${ }^{215}$ Ibid., 139. 

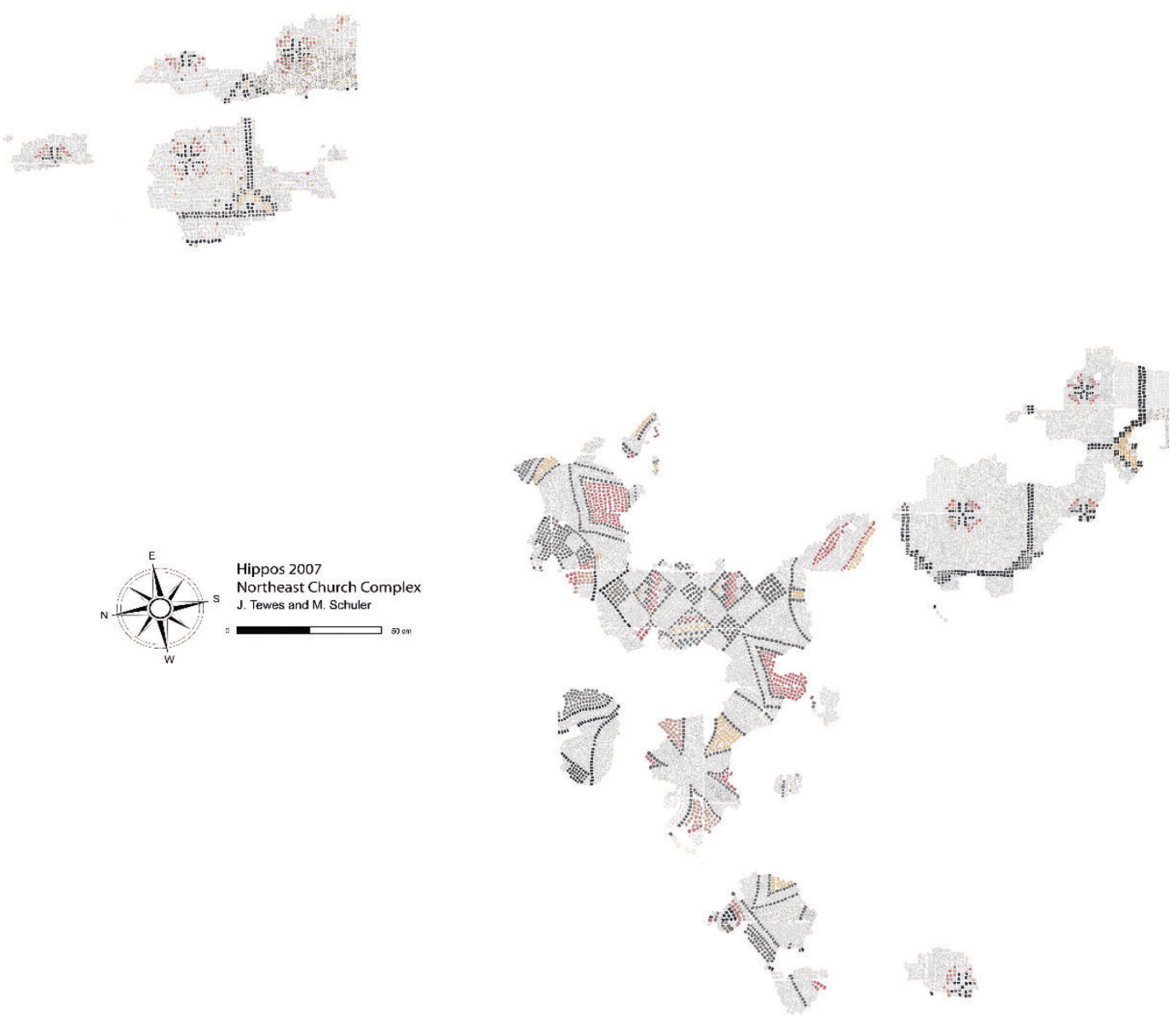

Figure 211 F589 of nave

Other major portions of the eastern part were covered with geometric patterns. The squarein-square pattern is like the one previously observed in the north aisle of the Northeast Church and in intercolumnar panel 2 at Kursi. ${ }^{216}$ Western portions of the nave were apparently covered with Avi-Yonah pattern $\mathrm{J}^{217}$ beginning at about $6.8 \mathrm{~m}$ west of the base of the chancel screen. A white field some 14 tesserae in width abutted W510 . The field is interspersed with randomly placed colored tesserae. A border of two bands of single rows of black tesserae separated by five rows of white tesserae initiate a field of diamond geometrics bordered by black tesserae. Portions of this F589 were lifted to reveal the lower F544.

The late sixth-century date of the mosaics at Kursi suggests a similar date for the geometric floor of the Northeast Church complex. According to Karen Britt, geometric compositions and uniform carpet patterns are part of a "stylistic shift in the pavements of the fifth and sixth centuries. The compositional arrangement of fifth century mosaics displays a degree of spontaneity and liveliness that gave way to predictability and repetitiveness during the

${ }^{216}$ Vassilios Tzafaris, E. Kessin, and D. Urman, "The Excavations of Kursi-Gergesa," Antiqot 16 (1983): I-X, Plate 8.5.

217 Avi-Yonah, "Mosaic Pavements in Palestine," 141. 
sixth century." ${ }^{218}$ The geometric patterns of F589 covered over the complexity and beauty of the earlier F544.

\section{Lower floor (F544)}

Only fragments of the western five meters of the lower floor (F544) remain. A complex series of borders surround two rows of six overlapping medallions on the east, south, and west. The outermost border is a band of three black tesserae. Inside is a double band of swastikas, the arms of which are composed of a double row of black tesserae. Fourteen such swastikas would have spanned the width of the nave. A double row of eight swastikas separates the easterly and westerly bands. The swastikas alternate between left- and rightfacing, some of which are more complex than others. Lacunae make it difficult to determine a precise pattern of alternation between the four forms (right-facing, left-facing, right-facing complex, and left-facing complex). The corners of each swastika and the outer borders are linked by diagonals composed of $2 \times 2$ clusters of black tesserae.

In the center of the hexagonal spaces created by the diagonals and the edges of the swastikas are crosswise arrangements in Avi-Yonah pattern F2. ${ }^{219}$ This border is somewhat reminiscent of the field of the south aisle at Shavei Zion which was dated by Avi-Yonah to the beginning of the fifth century. ${ }^{220}$

Inside the band of mosaics are three plain bands: the first consisting of three black tesserae, the second of five white tesserae, and the third of three black tesserae. Moving inward, the next band is Avi-Yonah B8 in red, separated by a bank of four white tesserae from a guilloche (Avi-Yonah B4) with alternating strands of five tesserae. ${ }^{221}$ One strand is black, white, pink, red, black; the other is black, white, yellow, orange, black. A single row of white tesserae separates the guilloche from a band of red triangles (Avi-Yonah A6222). Two rows of white tesserae and two rows of black tesserae complete the border.

In the main section of the floor, only fragments of up to twelve medallions remain. Each medallion was surrounded by a border of eleven tesserae. The borders overlap neighboring medallions. Some borders were a spectrum of colors (black to blues to whites to pinks to reds to black). Others are a background spectrum (black to pink to red to pink to black)

\footnotetext{
218 Britt, "Mosaics in the Byzantine Churches of Palestine," 251.

219 Avi-Yonah, "Mosaic Pavements in Palestine," 139.

${ }^{220}$ Moshe W. Prausnitz and Michael Avi-Yonah, Excavations at Shavei Zion: The Early Christian Church; Report of the Excavations Carried out by the Israel Department of Antiquities and Museums (in Cooperation with the Hebrew University of Jerusalem), Monografie di archeologia e d'arte 2 (Roma: Centro per le antichita e la storia dell'arte del Vicino Oriente, 1967), 51-53; see also the Portico of the Rivers in the House of Porticos in Doro Levi, Antioch Mosaic Pavements (Roma: L'Erma di Bretschneider, 1971) vol. 2, plate 98c.

221 Avi-Yonah, "Mosaic Pavements in Palestine," 138.

222 Ibid.
} 
overlain by alternating half circles (white to gray to blue to white). Still others show gold and brown fish on a field of red.
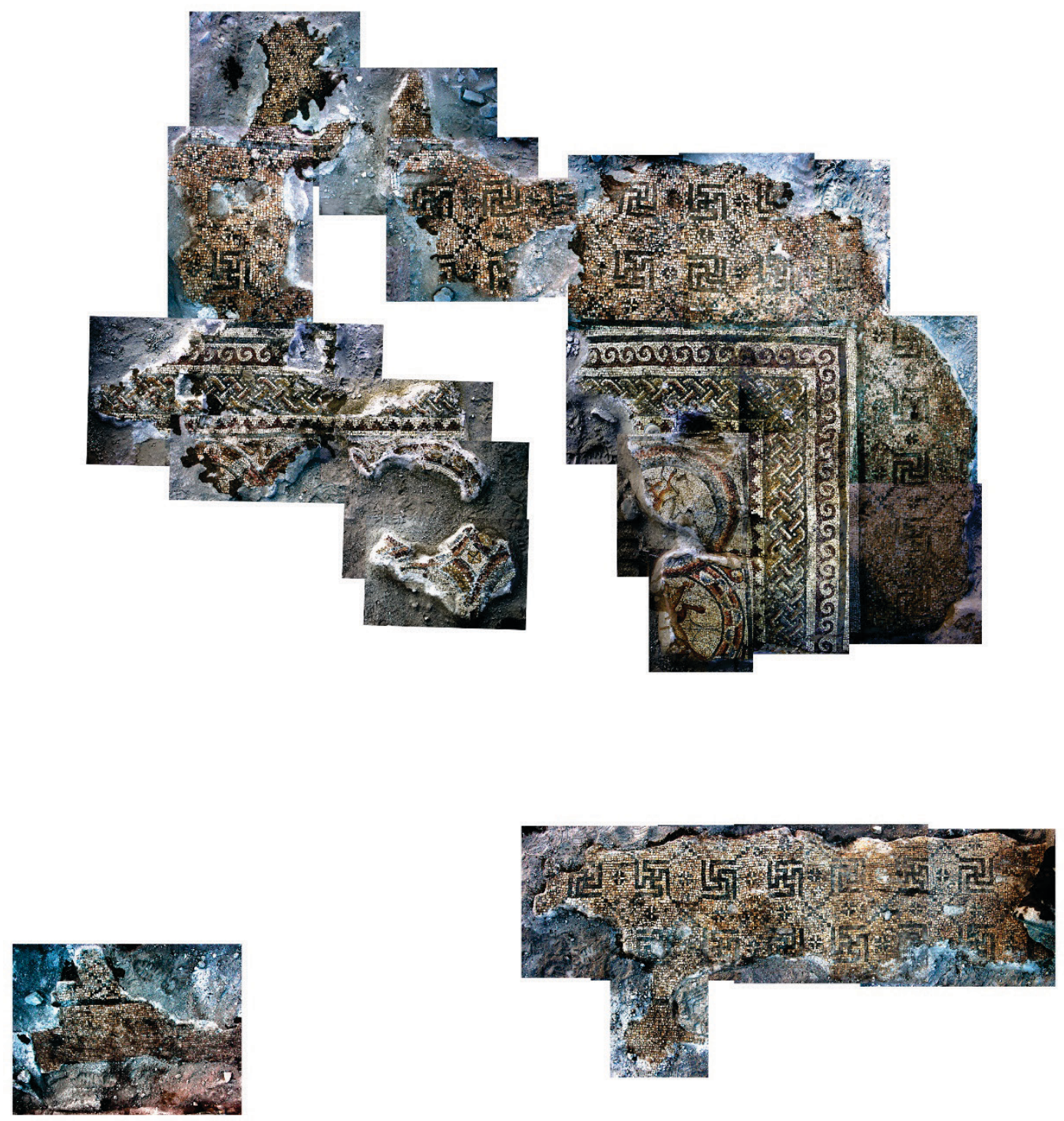

Figure 212 Composite of F544

The spaces between the medallions and the external border are filled with birds. Visible between easterly medallions are a duck with raised wings and a walking bird. Between the two southerly medallions, a head of another duck may be detected. 

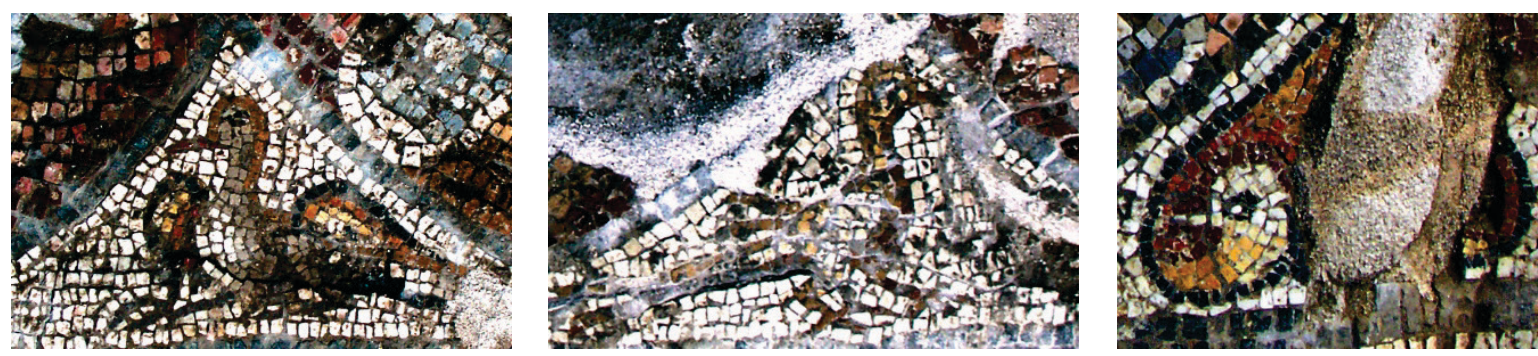

Figure 213 Birds from F544

These birds are strikingly like the birds adorning the floor of the Kyria Maria memorial chapel in a monastery at Scythopolis. ${ }^{223}$ Karen Britt writes that the birds confirm the commemorative function of the space and "should be interpreted as the blessed who take flight to heaven." 224

In the center of the mosaic, the fragmentary borders of four medallions overlap leaving a field of thirteen by nineteen white tesserae bounded by a row of single black tesserae. In the center of the field is a crosswise arrangement (Avi-Yonah F11225). The cross is a single row of black tesserae with a white center. Each corner arrangement begins with a white tessera and proceeds outward through yellow to brown. We presume similar crosswise arrangements between other overlapping medallions. The two southerly medallions are partially intact.

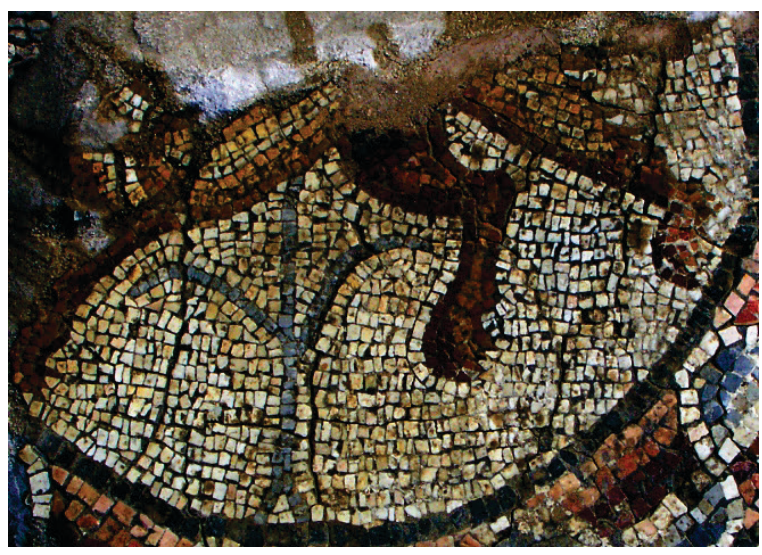

Figure 214 Lion (?)

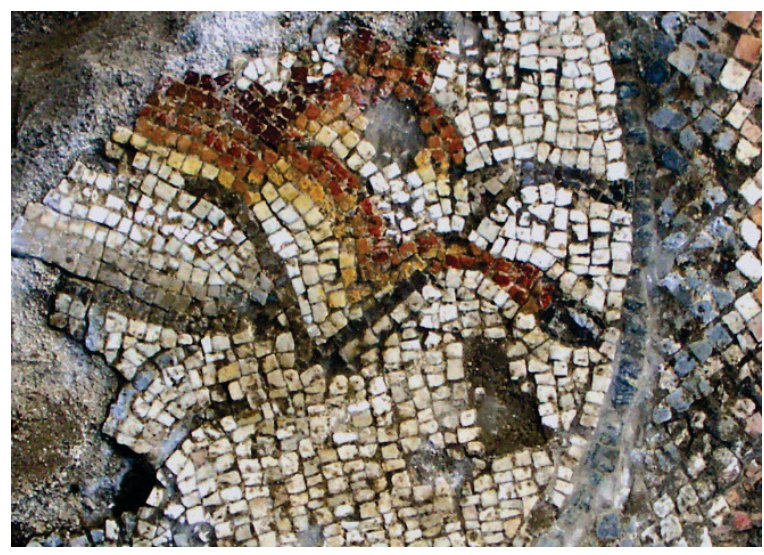

Figure 215 Gazelle (?)

The westerly medallion seems to be a feline creature, perhaps a young lion, as suggested by the claws in the feet. In the background of the medallion is a palm tree with three branches. The easterly animal has small hoofs. It may be a gazelle. In the background is a palm tree

\footnotetext{
${ }^{223}$ FitzGerald, A Sixth Century Monastery at Beth-Shan (Scythopolis)], Plate XIV.

224 Britt, "Mosaics in the Byzantine Churches of Palestine," 315.

225 Avi-Yonah, "Mosaic Pavements in Palestine," 139.
} 
of five or more branches. Likely, the other medallions displayed similar animals. Some calendric function may be implied by the presence of twelve medallions.

While the cleaning of F544 did not reveal inscriptional insight into the church's function, the beauty of the remaining fragments is significant and suggestive of a fifth century date for the floor.

The upper floor (F589) has a density of 72 tesserae/dm². Although the lower floor (F544) shows a density of 62 tesserae $/ \mathrm{dm}^{2}$ in the field with the swastikas, the density increases to 115 tesserae $/ \mathrm{dm}^{2}$ in the decorative banding to 196 tesserae $/ \mathrm{dm}^{2}$ in the medallions and in the spaces between the medallions that are decorated with crosses and birds. Claudette Dauphin distinguishes three types of Late Antique floors: course pavements (20-60 tesserae $/ \mathrm{dm}^{2}$ ), intermediated pavements (60-110 tesserae/dm ${ }^{2}$ ), and fine pavements (more than 110 tesserae $/ \mathrm{dm}^{2}$ ), with some pavements displaying of mixture of intermediate and fine carpets. ${ }^{226}$ Most of the fifth and sixth century pavements of the Middle East show an intermediate or mixed density. ${ }^{227}$ The mosaics of the nave of the Northeast Church are consistent with this observation.

\section{Skeuophylakion}

The fortuitous sealing of the skeuophylakion in antiquity preserved the mosaic floor of the room. The edges of the mosaic tiles are about $1.7 \mathrm{~cm}$ with an average of 38 cubes per square decimeter. The carpet is suited to the contours of the room. It consists of an outer area paved with mostly white tesserae, a seven-tesserae border, and a simple geometric pattern (Ovadiah Type $\mathrm{A}^{228}$ ) filled with a geometric motif.

The outer area is interrupted with a medial line of single black tesserae. About every $40 \mathrm{~cm}$ the line expands to a Avi-Yonah type E diamond (7 x 7) bordered in black. In the center of the diamond is a white Avi-Yonah type $\mathrm{D}$ crosslet surrounded by pink tesserae with a single black tessera in the center. ${ }^{229}$ The medial line and diamonds are interrupted in front of the exterior doorway in W575.

Next to W521 and north of the passageway to the chancel are two flared crosses some 35 $\mathrm{cm}$ in height. The width of the arms of each cross is two tesserae, flaring at the end to four tesserae. The upper and left rows and the flairs are red; the lower and right rows are black. Between the two large crosses is a black crosswise arrangement ( 5 by 5) with an Avi-Yonah F3 pattern of three peach tesserae and three red tesserae in each corner. ${ }^{230}$ As with the

\footnotetext{
${ }^{226}$ Claudine Dauphin, “Carpets of Stone: The Graeco-Roman Legacy in the Levant," Classics Ireland 4 (1997): 23.

${ }^{227}$ Britt, "Mosaics in the Byzantine Churches of Palestine," 143.

${ }^{228}$ Ovadiah and Ovadiah, Mosaic Pavements in Israel, 166.

${ }^{229}$ Avi-Yonah, "Mosaic Pavements in Palestine," 138.

${ }^{230}$ Ibid., 139.
} 
crosses at the east end of the north aisle, these crosses served an apotropaic function in protection of the chancel and the revered burials there.

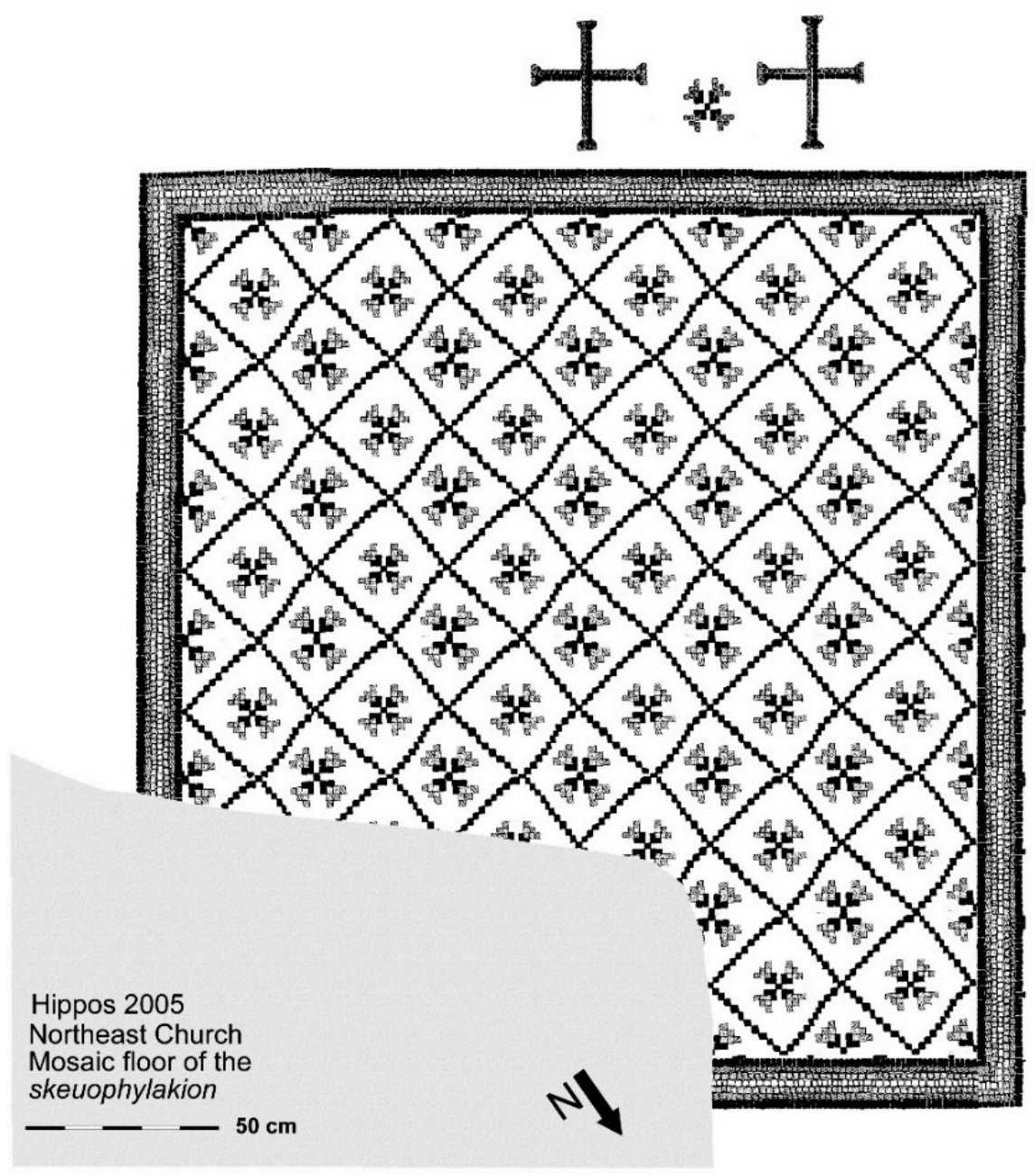

Figure 216 Mosaic from the skeuophylakion

Between the outer area and the main geometric pattern is a border of seven tesserae. From outside to inside, single rows of tesserae are black, red, peach, white, peach, red, and black.

The central Ovadiah Type A geometric pattern of the carpet is filled with the same geometric motif that appears between the two large crosses: a black crosswise arrangement ( 5 by 5) with an Avi-Yonah F3 pattern of three peach tesserae and three red tesserae in each corner. The geometric pattern replicates itself six times in each direction, filling the floor of the room. 


\section{Mosaic of the portico}

The western portico of the Northeast Church is paved with flagstones. However, there are three lacunae on the exterior side of the west wall of the church where benches had previously been located. From these lacunae and from areas where the flagstone has been robbed out, we revealed fragments of the earlier mosaic paving surviving to about $60 \mathrm{~cm}$ from the wall in places. The mosaic was geometric. The east border of the mosaic was Avi-Yonah pattern B9. ${ }^{231}$

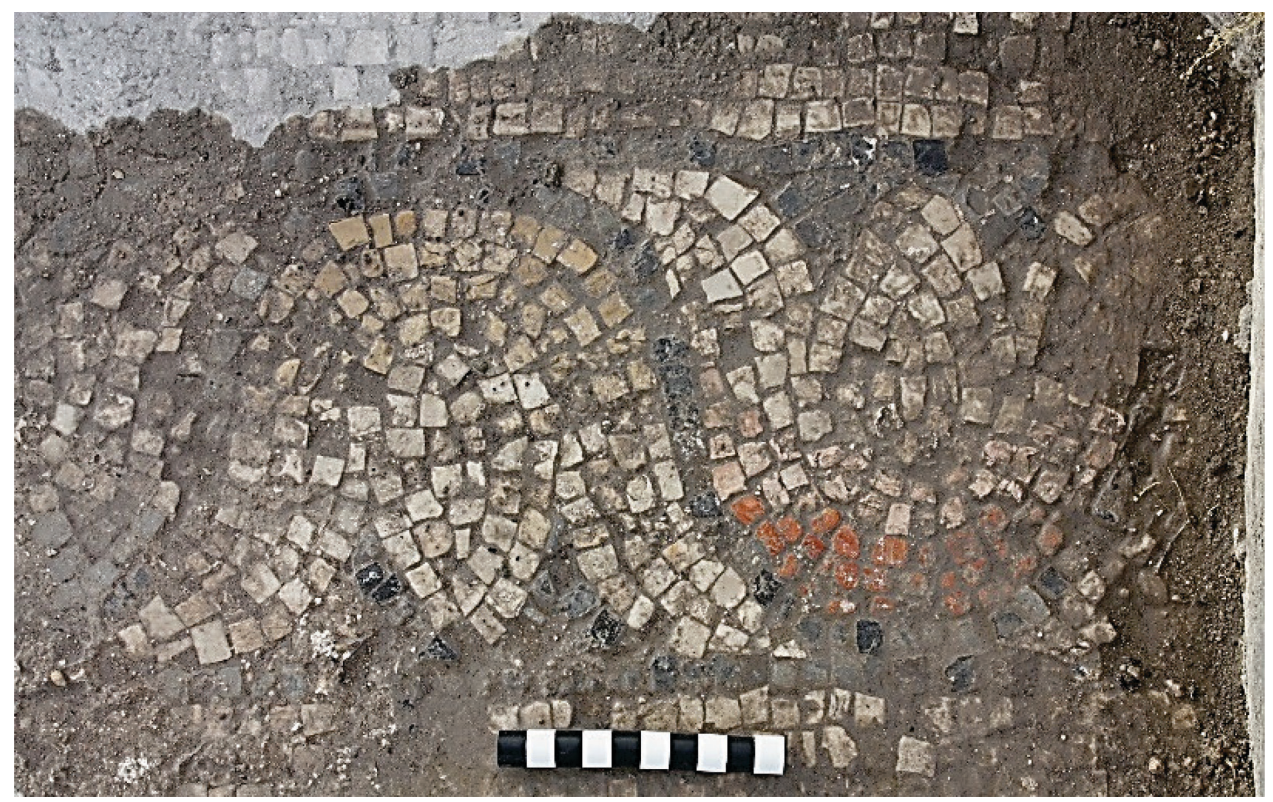

Figure 217 Avi Yonah pattern B9

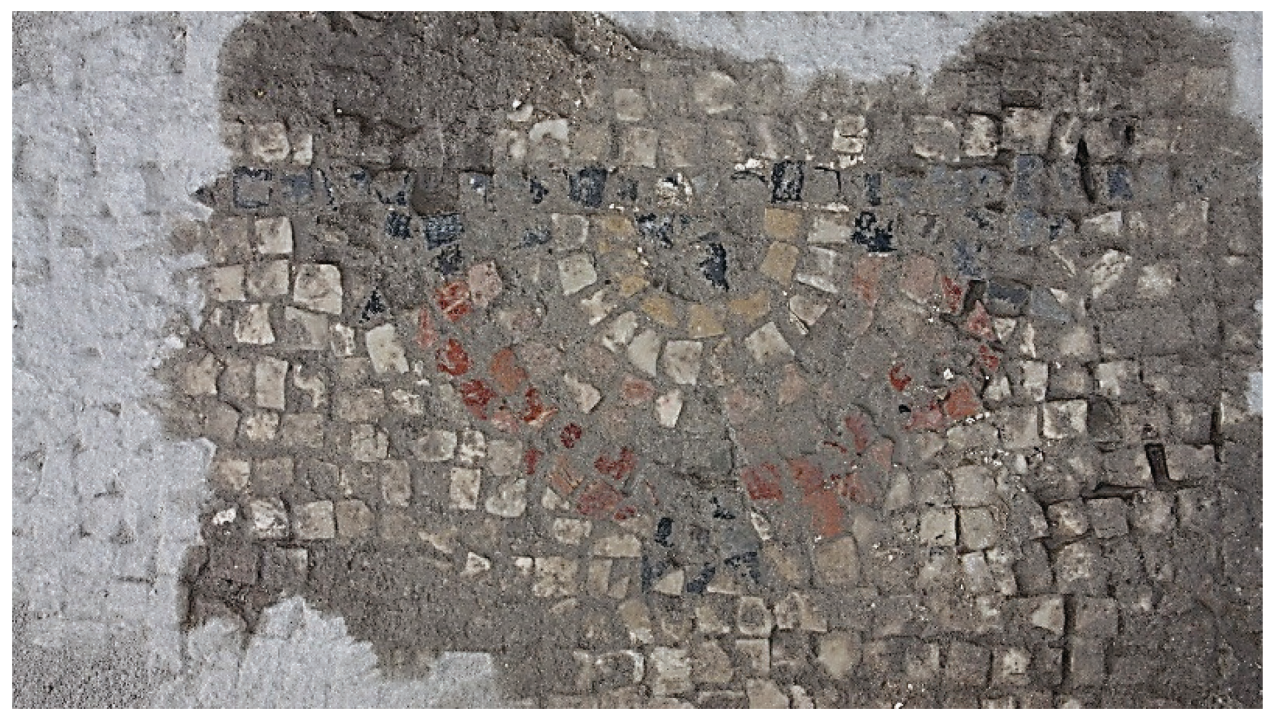

Figure 218 Second band of half circles

${ }^{231}$ Ibid., 139. 
An additional six rows of white tesserae intervene before a series of half circles consisting of two half circles of red tesserae, three half circles of white, one half circle of yellow, and a central cluster of black tesserae. The half circle is capped by a row of black tesserae and seems to rest on a small stand of three black half tesserae. These half circles form a parallel band to the inverted tulips of the first band, recurring every $54 \mathrm{~cm}$ on center.

Further to the west, after eight rows of white tesserae, there is seemingly a third band of geometric figures, although only one sample survives. This geometric figure is a full circle, with a similar sequence of tesserae circles: two red, three white, one yellow and a black center. On the four compass points are black inserts that extend beyond the circle in a form like the base of the previous half circles.

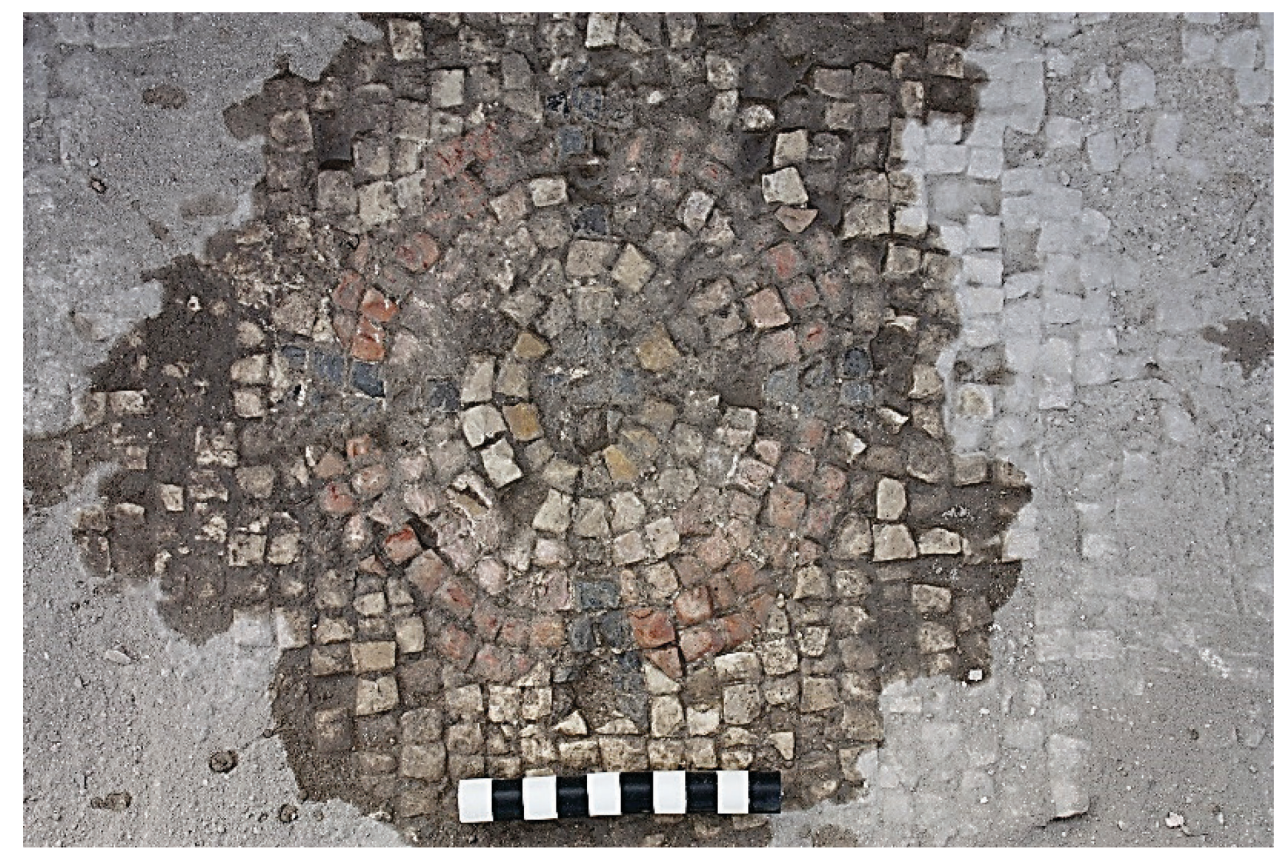

Figure 219 Third band of full circles

On the western side of the portico, we opened a probe. We discovered no additional surviving mosaic carpet. But there was a cobble base, affirming that the portico had been surfaced with tesserae prior to the installation of the surviving flagstone surface.

The tesserae surface of the portico is most like the later F589 in the nave. For these stylistic reasons, it probably comes from the later part of the sixth century. The probe to bedrock revealed no addition surface below these cobbles.

\section{Second story of the North Building}

While excavating an entrance to the North Build from Cardo 3 North, a section of mosaic $(44 \times 70 \mathrm{~cm})$ was discovered well above floor level in the northwest corner of the square. 
The fragment was tilting at an angle. Smaller fragments were discovered upside down. These pieces are likely part of a floor from an upper story that has collapsed down from above.

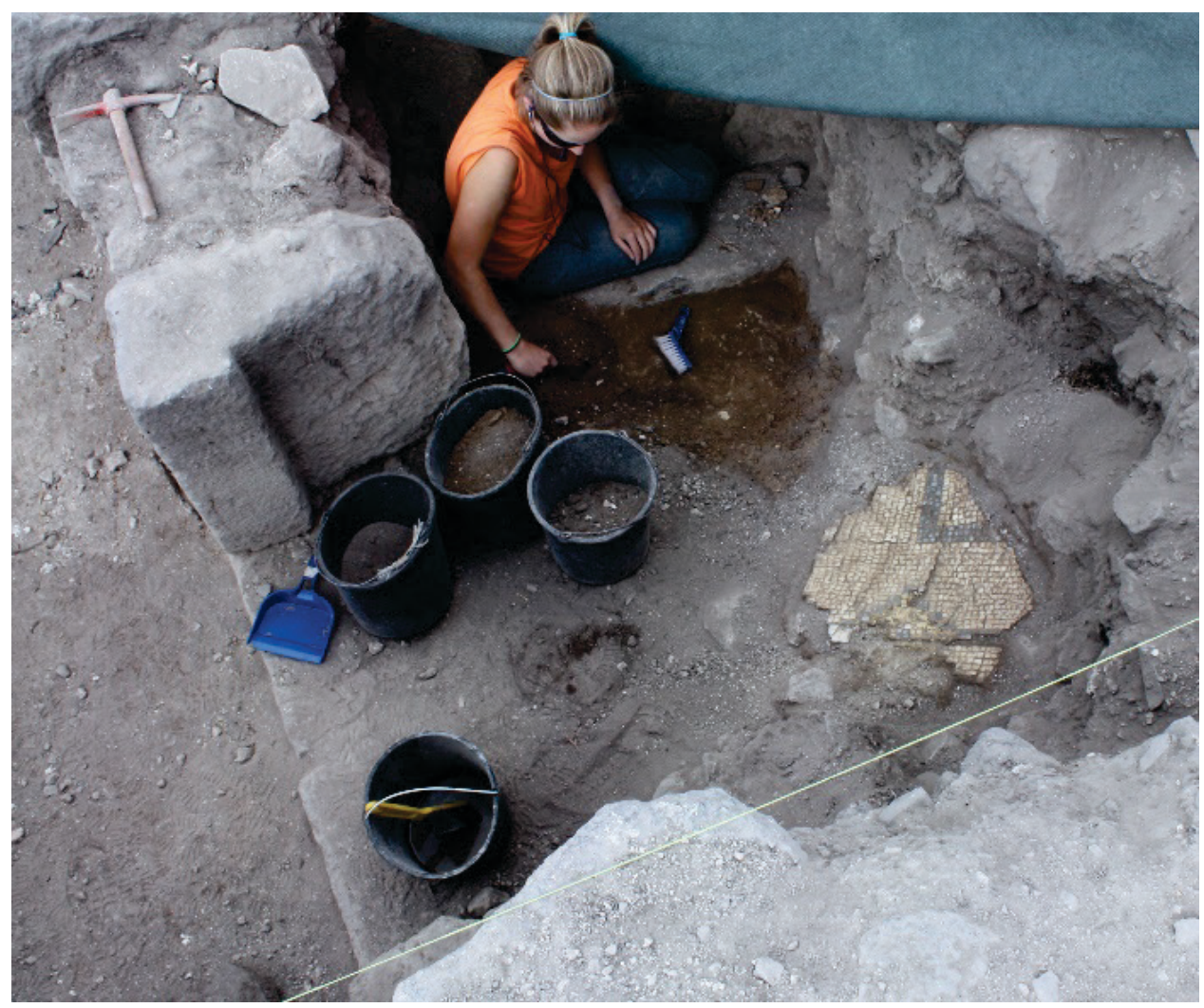

Figure 220 Doorway in W575 (looking south)

Earlier in 2008 we had discovered a similar but smaller piece in the destruction fill on the north side W540. ${ }^{232}$ As a result, we have two pieces of evidence indicating that the structure north of the church had at least two stories.

As we excavated the east room of the North Building beginning about $40 \mathrm{~cm}$ above the floor we recovered hundreds of individual tesserae, many small clusters, and several dozen fragments that showed evidence of geometric patterns.

${ }^{232}$ Segal et al., Hippos-Sussita: Ninth Season of Excavations: June-July 2008, 48. 

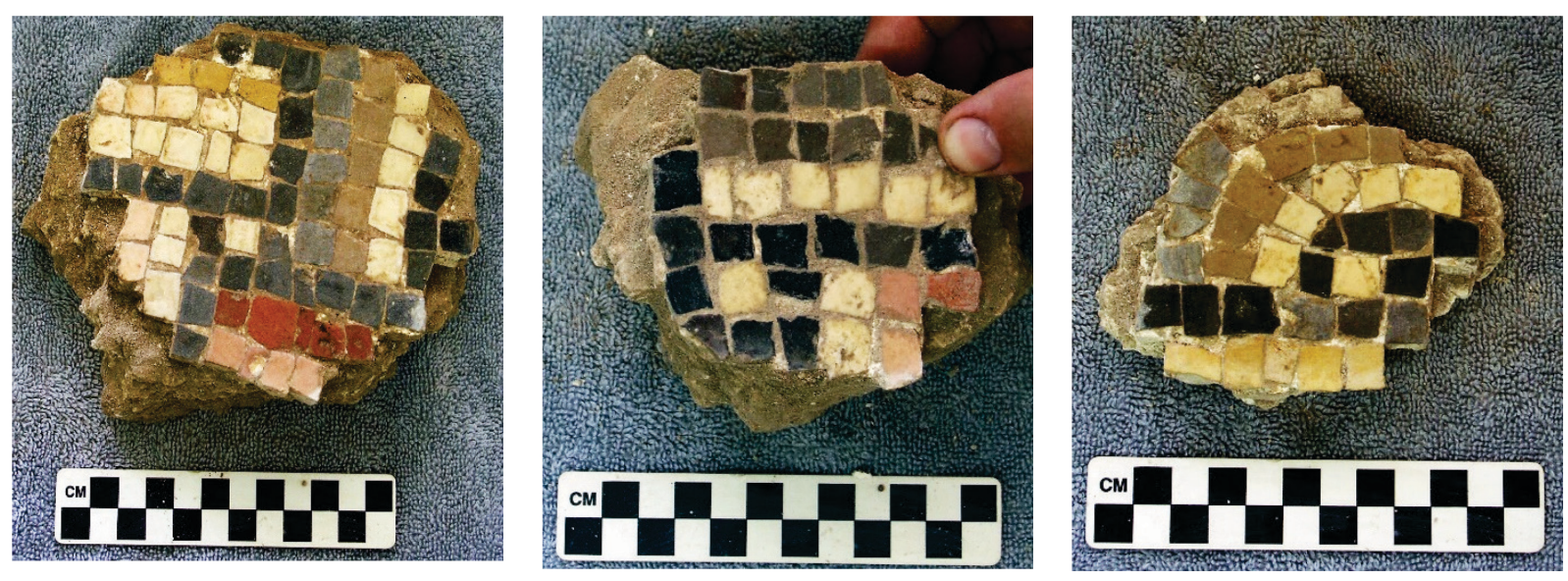

Figure 221 Geometric samples

The top two examples on the right in the figure above are reminiscent of the same guilloche pattern discovered in the first layer of the mosaic floor of the domus, an example of which is provided in the figure below.

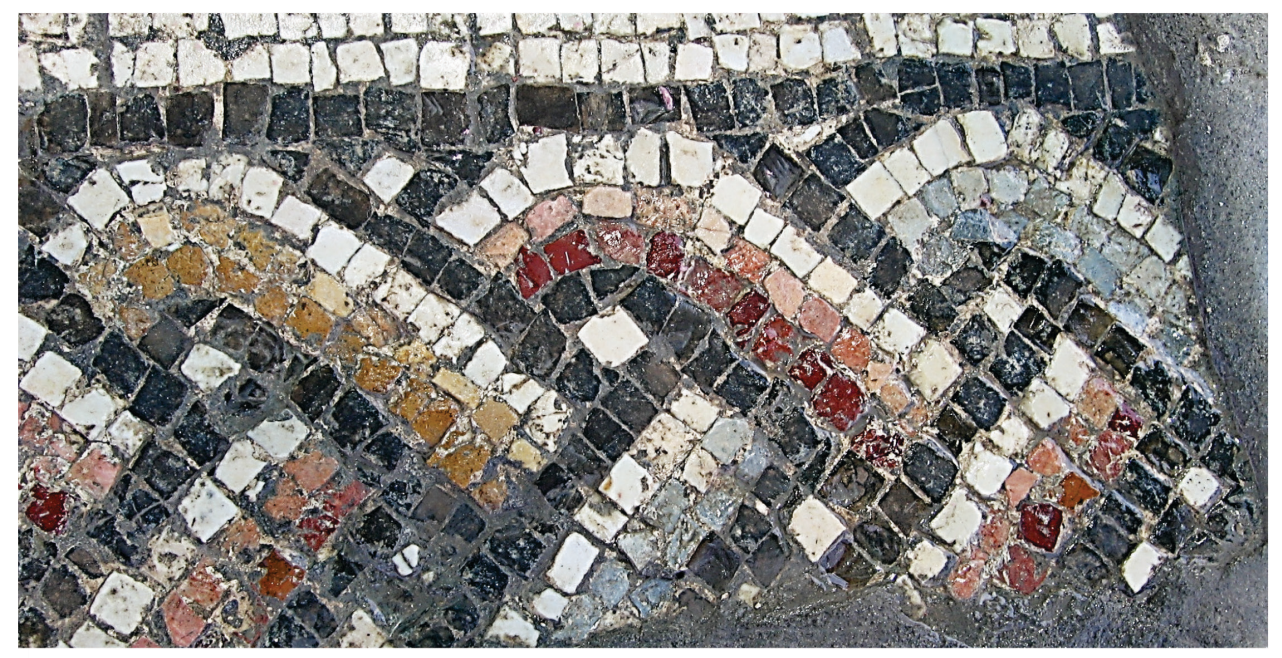

Figure 222 Guilloche from floor the church aisles

In addition to a decorative band of guilloche, we found a few fragments that indicate an inscription was part of the mosaic from the second story. 

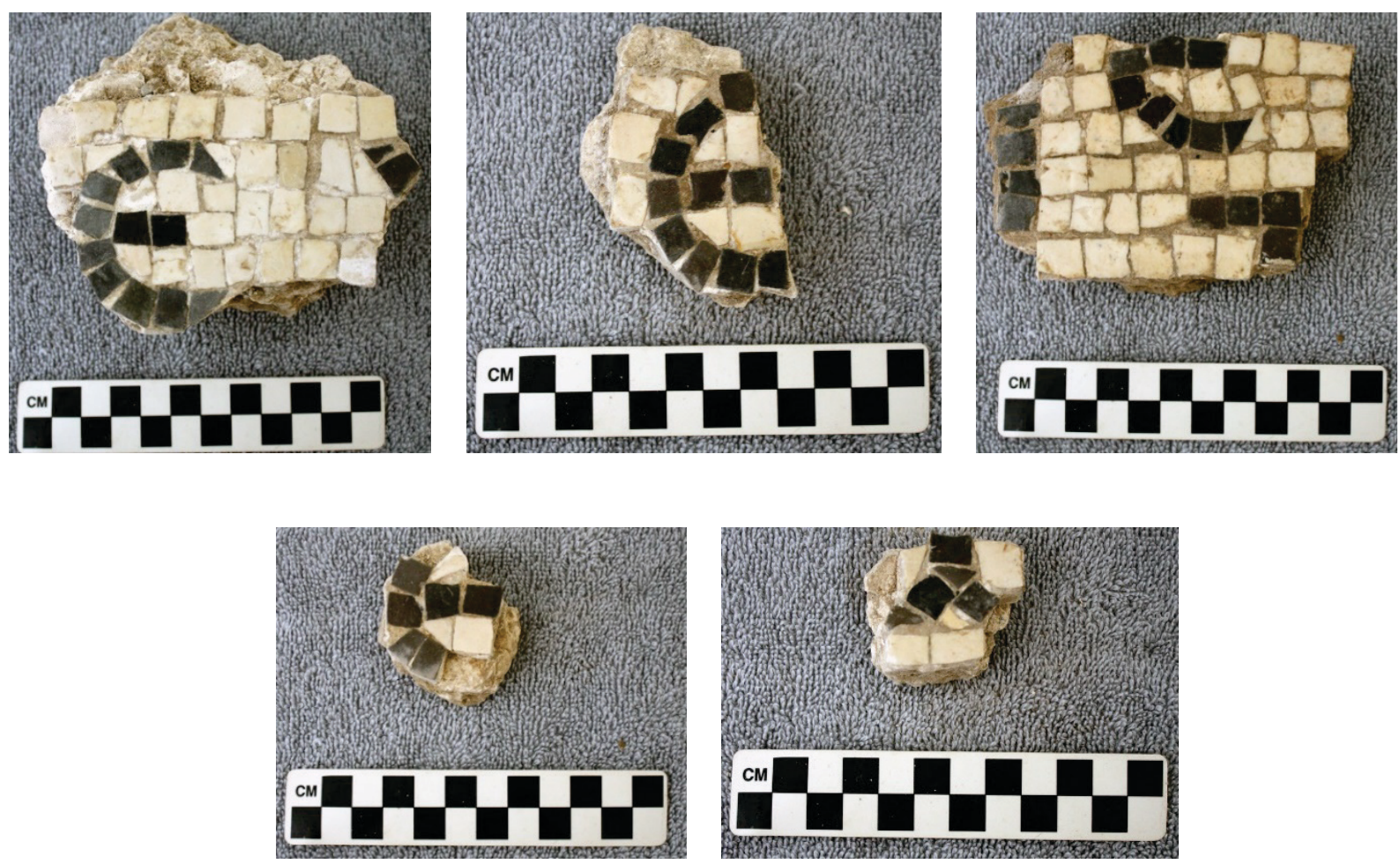

Figure 223 Fragments of an inscription

The letters identified include an epsilon followed by a space and then a new word perhaps beginning with a lambda, a theta, an epsilon beginning a line with a tau beginning the next line, a second theta, and the bottom of an omega or the top of an upsilon. Of the letters, our epigrapher, Adam Łajtar, wrote, "Unfortunately the fragments are too small to say something certain about the content of the inscription. What seems important to me is that the letters are of two different heights. If so, we probably are dealing with some abbreviated words. Smaller letters were shifted to mark abbreviations." 233

We surmise, based on this evidence, that the North Building had a large room with a mosaic floor on its second story -- a story held up by a heavy arch sitting on pilasters. A guilloche border was part of the decoration of the floor. The floor also had an inscription in two or more lines with letters of two different heights. The similarities of these fragments to the earlier floor in the domus would date the inscription and the building to the late fifth or earth sixth century.

\section{Mosaics north of the peristyle house}

Full understanding of the mosaic carpets north of the peristyle house is limited by the presence of an access road. Only segments near the fountain and the entrance from Cardo 4

\footnotetext{
${ }^{233}$ Adam Łajtar, "Mosaic Fragments from the Northern Building," July 9, 2016.
} 
North could be uncovered. The carpet next to the east entrance is a white field with the inscription in tabula ansata discussed earlier in this chapter. It sits at an elevation of 129.17.

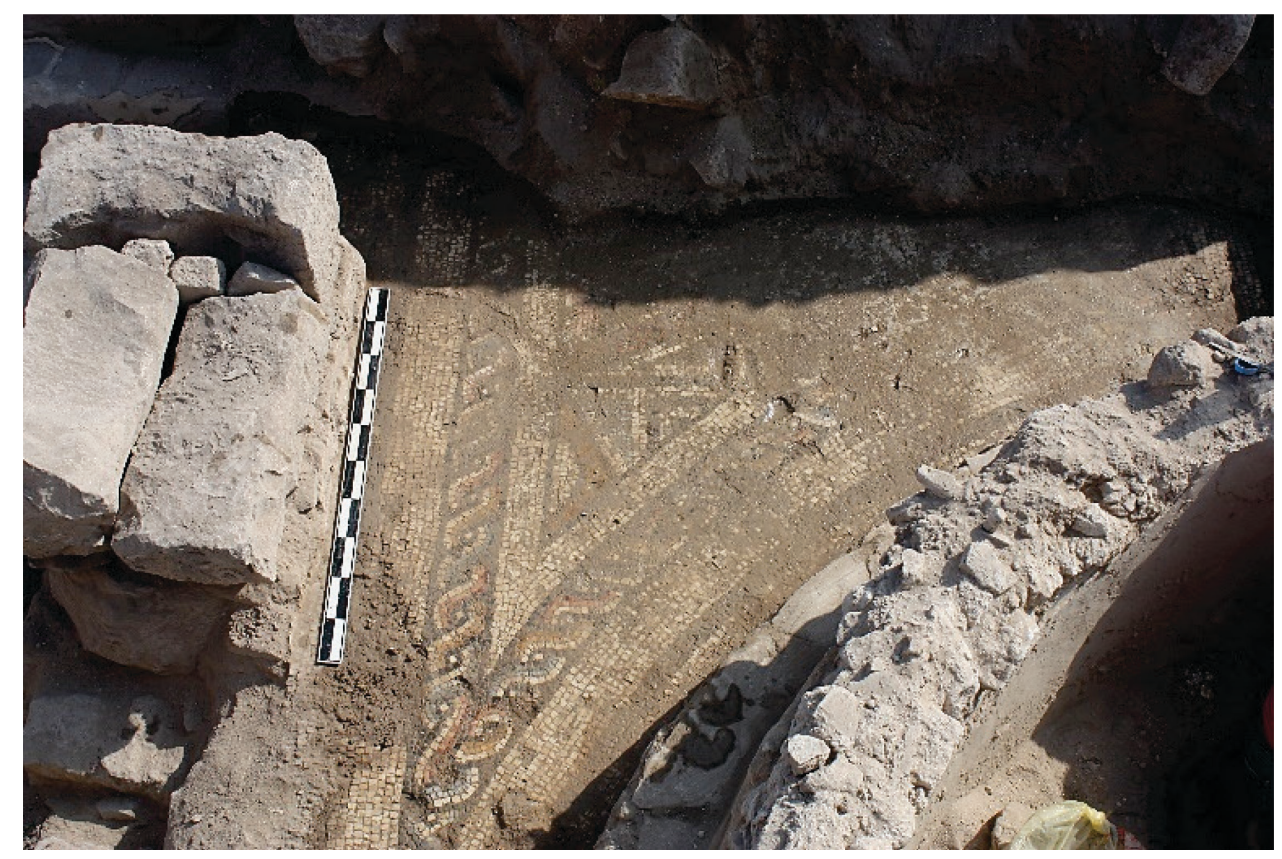

Figure 224 Mosaic floor next to the fountain (looking north)

The mosaic north of the fountain pool is about $30 \mathrm{~cm}$ lower (128.87). The relationship and extent of these two mosaics is uncertain, although at the east edge of the fountain there is a step down to the mosaic north of the fountain. Both mosaics were covered by roofs, explaining the presence of columns and drums in the destruction fill.

The mosaic by the fountain proceeds north from the fountain and pool. Pieces of marble in secondary use form a western border for the floor at the top of the two stairs. The design of the floor is geometric and like other Late Antique floors at Hippos. The concentration of tesserae is 34 per $\mathrm{dm}^{2}$. A black border of three cubes parallels the curve of the wall of the pool demonstrating contemporaneous construction. From the west, the floor begins with a black band of three tesserae, then a white band of eight tesserae. Then a guilloche $(19 \mathrm{~cm}$ wide) runs north to south. It consists of two five-tesserae bands (black, white, double blue, black; and black, white, double orange, black). An identical pattern follows the curve of the pool (black band, white band, guilloche). The two guilloche bands are woven together when they meet in the southern part of the floor. Inside each guilloche is a band of five white tesserae. Between the guilloche bands are triangular geometric patterns that continue under the balk to the north. Based on similarity to other mosaics at the site, the carpet would be dated to the sixth century and would have been installed when the monastic compound was constructed. 


\section{The Entrance Hall}

Inside the northeast room of the peristyle house, the northern have of the room preserves a mosaic carpet likely from the Roman Imperial period. A geometric band crosses the room from east to west just toward its north end south of an inscription discussed above. The band is $174 \times 36 \mathrm{~cm}$. It is a meander pattern of four concentric box groups alternating with three left-facing swastikas, in contrast to the swastikas in the earlier nave floor which have diagonal connections.

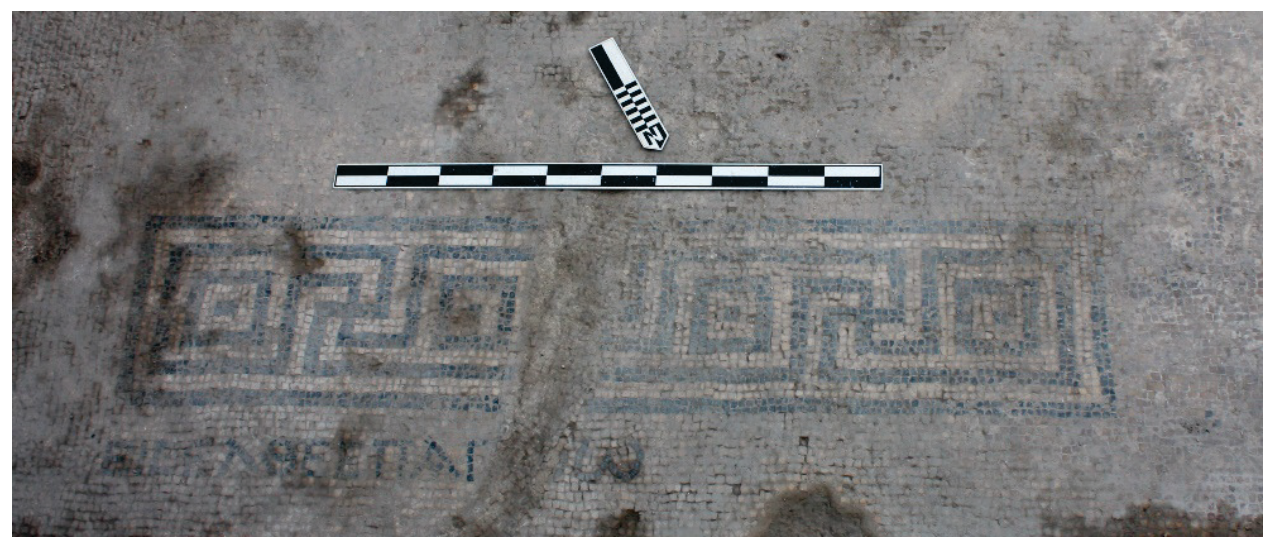

Figure 225 Decoration with inscription in the entrance hall

Meander patterns involving various forms of the swastika are common from the Roman through the Late Antique periods. They are symbols of auspiciousness and good fortune (Tyche).

\section{Observations}

Although the mosaic carpets of the northeast insulae are heavily damaged, the surviving segments hint at the decorative beauty of the site both in the Roman Imperial and the Late Antique periods. One can also detect in them a shift from present good fortune, welcome, and benefaction toward a future hope beyond present trials (e.g., swastika to birds). Whether one considers the art or the ideas behind the art, these carpets give identity and perspective to those who commissioned and walked on them.

For the most part, the remains of the northeast insulae are unremarkable. The architecture is simple and small in scale. Walls are constructed mostly with reused materials. Most floors are packed earth or crude flagstones. But in fragments of frescoes, a few inscriptions, and remnants of mosaic floors one gets a sense of some internal beauty of the structures and of the perspectives of those who built them. The northeast insulae would come to be a monastic memorial site in the Late Antique period to which locals came in hopes of healing. Its simplicity, anonymity, and abandonment suggest its influence remained local at best, despite some decoration. 
The Northeast Insulae Project 


\title{
7.
}

\section{OTHER SMALL FINDS}

\begin{abstract}
s we have noted earlier, the northeast insulae were closed and abandoned well before 1 the earthquake of $749 \mathrm{CE}$, after which Hippos as a city ceased to exist. In addition to blocked doorways, the primary evidence for such closure is the lack of small finds: crushed pottery and broken objects. For the most part we found few items at or near floor levels that could be reconstructed. Larger and heavy items such as stone bowels and conical millstones are pushed to the side of rooms or left in courtyards. But there were a few locations in which we found small hordes of items worthy of note.
\end{abstract}

\section{From the courtyard of a domestic space}

A single-room domestic space and a courtyard were built over the southern end of the ruins of the House of Tyche to the south of the Late Antique Southern Room complex. As previously noted, we recovered from the courtyard a small amphora, a broken ax head, and a gastropod. Next to the north wall of the courtyard, we recovered a horde of items in glass, bone, and metal.

\section{Glass items}

This section on glass finds was authored by Stephen Chambers, Our Saviour Lutheran Church, Parksville, $B C$

\section{Conical lamp or beaker}

Three fragments from the same straight-sided conical vessel were recovered near one another. Their fabric is light aqua ${ }^{234}$ in color, and ranges for the most part between 1.1 and 1.3

\footnotetext{
${ }^{234}$ A descriptive range of colors is provided by Robert H. Brill, "Scientific Investigations of the Jalame Glass and Related Finds," in Excavations at Jalame, Site of a Glass Factory in Late Roman Palestine, ed. Gladys Davidson Weinberg (Columbia, MO: University of Missouri Press, 1988), 269; this particular color corresponds to Saldern's "fabric 1" in Axel
} 
$\mathrm{mm}$ in thickness. ${ }^{235}$ All three fragments exhibit a uniform-and unusual-degree of slope, ${ }^{236}$ showing that the vessel from which they came was evenly conical in shape all the way from the bottom to the out-flaring rim.
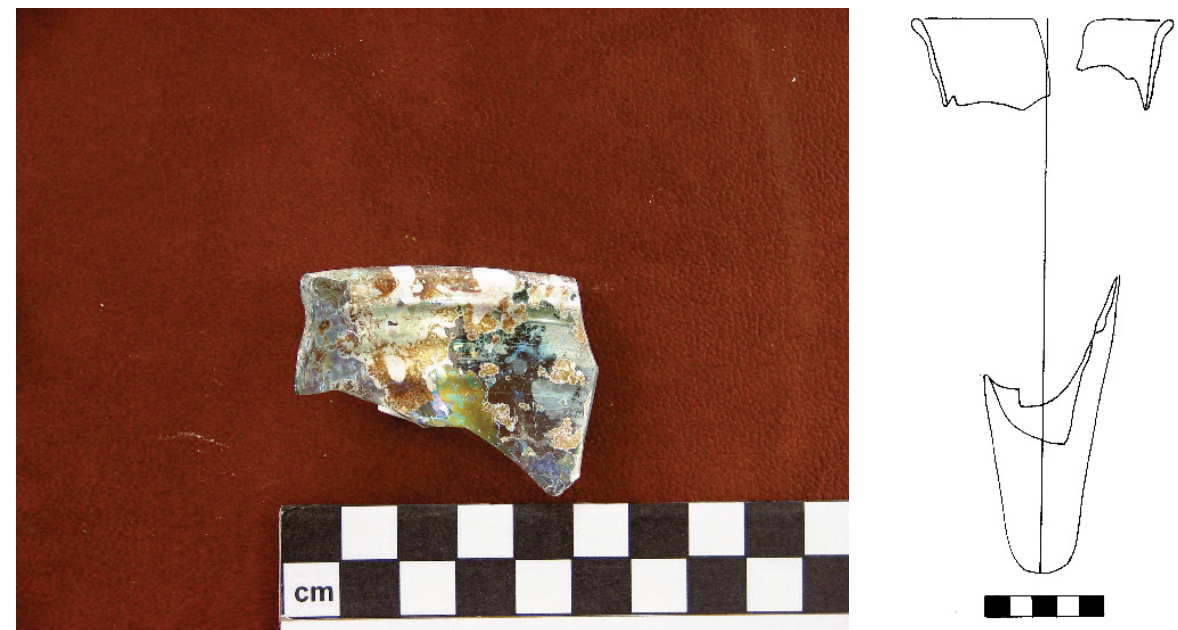

Figure 226 Lamp/beaker fragments

The two rim fragments have the same calculated diameter $(110 \mathrm{~mm})$. This, together with the diameter of the base fragment and the slope of all three fragments, produces a calculated height for the complete vessel of approximately $235 \mathrm{~mm}$. Both in height and in rim diameter, this vessel is considerably larger than most other straight-sided conical vessels that have been published to date. ${ }^{237}$

von Saldern, Ancient and Byzantine Glass from Sardis, Monograph - Archaeological Exploration of Sardis ; 6 (Cambridge, Mass: Harvard University Press, 1980), 36.

${ }^{235}$ Part of one fragment expands to $2.1 \mathrm{~mm}$ in thickness, a common variation arising from the manufacturing process.

${ }^{236}$ Slope $=$ rise $/$ run $=210 / 65[\mathrm{~mm}]=3.23$. Conical vessels from other excavations almost always reflect much lower slope-values (that is, their profile is a wider "V"). A good example is the corpus reported by Véronique Arveiller-Dulong and Jacques Arveiller. The five vessels for which slope can be calculated all have values between 1.7 and 2.4. Véronique Arveiller-Dulong and Jacques Arveiller, Le Verre d'époque Romaine Au Musée Archéologique de Strasbourg, Notes et documents des musées de France 10 (Paris: Ministère de la culture, Editions de la Réunion des musées nationaux, 1985), 146.

${ }^{237}$ For example, Dussart's Type B.VI.1111b has a (calculated) height of $171 \mathrm{~mm}$, in Odile Dussart, Le verre en Jordanie et en Syrie du Sud, Bibliothèque archéologique et historique t. 152 (Beyrouth: Institut français d'archéologie du ProcheOrient, 1998); Arveiller-Dulong reports on five intact conical vessels ranging between 94 and $140 \mathrm{~mm}$ in height in Le Verre d'époque Romaine Au Musée Archéologique de Strasbourg, 146; another study, covering several variations of conical beakers, reports heights ranging between 115 and $150 \mathrm{~mm}$ in C. Isings, Roman Glass from Dated Finds, Archaeologica traiectina 2 (Groningen: J. B. Wolters, 1957), 126-131, nos. 106a-d; the rim diameter of most other straight-sided conical vessels ranges from ca. 60-95 mm, including those in the prototypical study by Grace M Crowfoot and Donald B Harden, "Early Byzantine and Later Glass Lamps," The Journal of Egyptian Archaeology 17, no. 1 (1931): 196-208, 196208, especially plate XXVIII, nos. 1-3; see also John W. Hayes, Roman and Pre-Roman Glass in the Royal Ontario Museum: A Catalogue (Toronto: Royal Ontario Museum, 1975), nos. 365, 366, 380, 477; Saldern, Ancient and Byzantine Glass from Sardis, nos. 288, 289; Einat Cohen, "Roman, Byzantine and Umayyad Glass," in The Roman Baths of Hammat Gader, ed. Yizhar Hirschfeld (Jerusalem: Israel Exploration Society, 1997), 406; larger rim-diameters include Dussart's B.VI.1111b and Arveiller-Dulong's nos. 323 and 327, all three of which have exactly the same rim diameter (104 mm) 
The base bears a small pontil mark, approximately $12 \mathrm{~mm}$ in diameter. Together with the fire polishing of the two rim fragments, this shows that the vessel was first formed on a blowpipe, then transferred to a pontil for further working of its upper edge. This relatively refined manufacturing technique resulted in a conical vessel of higher quality than those that have been found in many other excavations. ${ }^{238}$

Studies suggest that pontil-made conical vessels with a fire-polished rim developed from the simpler form with a cracked-off rim that had become popular throughout the Roman Empire in the fourth century. ${ }^{239}$ Thus, this vessel could perhaps be dated to the fifth or sixth century. ${ }^{240}$

Whether this vessel functioned as a lamp or a beaker cannot be easily determined. Conical glass lamps are verbally described by Paulus Silentianus in his account of the dedication of the Hagia Sophia in $563 \mathrm{CE},{ }^{241}$ and graphically portrayed both on a tombstone in Rome and in a fourth-century mosaic in the synagogue at Hammat Tiberias. ${ }^{242}$ On the other hand, an engraving on a large glass plate from the Beth Shearim catacomb, showing a conical vessel together with a jug and a pitcher, suggests use as a drinking-cup. ${ }^{243} \mathrm{~A}$ wooden tripod found near a conical vessel at Karanis in Egypt could support either use. ${ }^{244}$ This vessel's smoothly fire-polished rim, unlike a cracked-off rim, would also be suitable for either purpose.

as this vessel, plus four vessels discussed in Gladys Davidson Weinberg and Sidney M. Goldstein, "The Glass Vessels," in Excavations at Jalame, Site of a Glass Factory in Late Roman Palestine, ed. Gladys Davidson Weinberg (Columbia, MO: University of Missouri Press, 1988), 38-102, 91, nos. 404, 405, 406, 408, 410. All 8 of these larger vessels, however, exhibit a smaller slope-value (i.e., they are shorter for their width; their profile is a wider "V").

${ }^{238}$ Conical vessels that lack this pontil mark always feature a rougher, cracked-off rim. Their manufacture is described and illustrated by Weinberg and Goldstein, "The Glass Vessels," 87-89; this simpler type was common in both East and West; they were known already to Crowfoot and Harden "Early Byzantine and Later Glass Lamps," 200; Isings discusses them Roman Glass from Dated Finds, 127; see also Dussart, Le verre en Jordanie et en Syrie du Sud, groups BVI.1111 a1 and BVI.1111 a2; Hayes, Roman and Pre-Roman Glass in the Royal Ontario Museum, nos. 380, 476, 477; Cohen, "Roman, Byzantine and Umayyad Glass"; Arveiller-Dulong and Arveiller, Le Verre d'époque Romaine Au Musée Archéologique de Strasbourg, nos. 321-329.

239 Weinberg and Goldstein, "The Glass Vessels," 87-89; Crowfoot and Harden, "Early Byzantine and Later Glass Lamps," 198; Isings, Roman Glass from Dated Finds, 127, 130-131; Cohen, "Roman, Byzantine and Umayyad Glass," 408.

${ }^{240}$ In Baur's study of glass from Jerash, many conical lamps (= his Type E, including no. 13, which is morphologically like this one) are dated 5th to 7th century. Paul Victor Christopher Baur, "Glassware," in Gerasa, City of the Decapolis, ed. Carl H. Kraeling (New Haven, Conn.: American Schools of Oriental Research, 1938), 523524; note also the strikingly similar vessel shown in Axel von Saldern, Ancient Glass in the Museum of Fine Arts, Boston (Greenwich, Conn: New York Graphic Society, 1968), no. 61, which is unprovenanced but dated by the author to "late 4th - early 5th century."

${ }^{241}$ Crowfoot and Harden, "Early Byzantine and Later Glass Lamps," 200, n. 4; Saldern, Ancient and Byzantine Glass from Sardis, 50; Cohen, "Roman, Byzantine and Umayyad Glass," 408.

${ }^{242}$ For discussion and bibliography of these images, see Weinberg and Goldstein, "The Glass Vessels," 90, nos. 206, 208.

${ }^{243}$ Nahman Avigad, Beth She'arim: Report On The Excavations During 1953-1958. Vol III: Catacombs 12-23, ed. Benjamin Mazar (New Brunswick, N.J: Rutgers University Press on behalf of the Israel Exploration Society and the Institute of Archaeology, Hebrew University, 1973), 210 fig. 100; the grouping of this vessel with a jug and a pitcher suggests, however, that Avigad is wrong in calling it a lamp (p. 211), for a different section of the same plate portrays a hanging lamp of a different shape; see Weinberg and Goldstein, "The Glass Vessels," 90, no. 212.

${ }^{244}$ Weinberg and Goldstein, "The Glass Vessels," 89-90 and 322, plates 4-17. 


\section{Mold-blown bottle}

This vessel's fabric is aqua in color and relatively thick (approximately $2.5 \mathrm{~mm}$ at the neck).
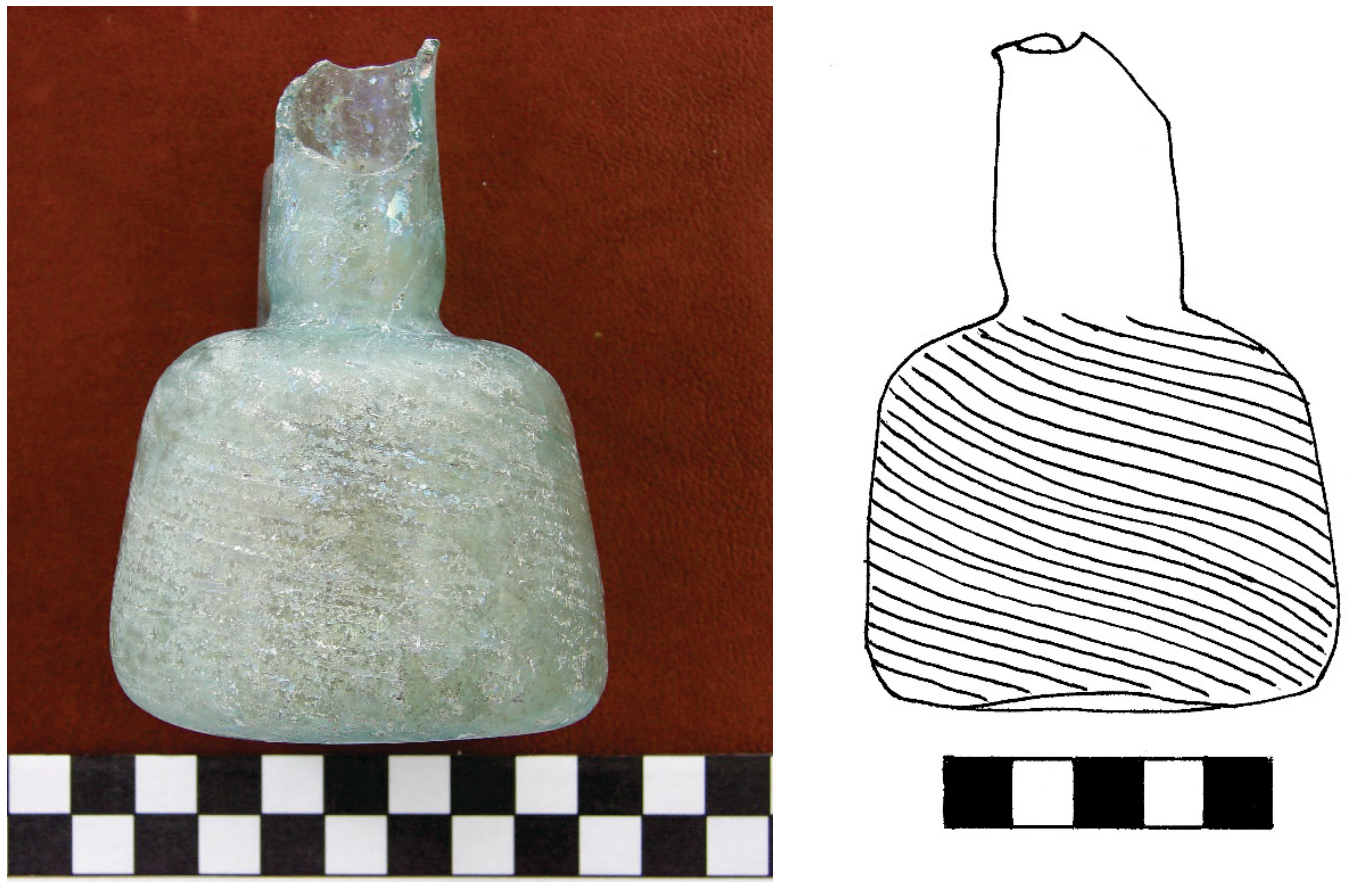

Figure 227 Ribbed bottle

Most of its surface is dulled by weathering, although a high gloss remains on two vertical sections of its straight-sided, piriform body. ${ }^{245}$ The vessel stands quite squarely on its slightly concave (approximately $1.5 \mathrm{~mm}$ ) base, which features a wide, smoothed-off, slightly off-center pontil mark approximately $33 \mathrm{~mm}$ in diameter. The preserved portion of its cylindrical neck is slightly constricted where it joins the body. ${ }^{246} \mathrm{~A}$ small out-turn at the very top of the neck, right where it is broken off, suggests that it might have had a funnelled mouth.

Its most prominent feature is a set of diagonal shallow ribs on its body. Sixteen parallel lines, each approximately $3 \mathrm{~mm}$ wide and approximately $1.5 \mathrm{~mm}$ deep, encircle the body. This pattern was probably created in two stages: first by inflating a paraison in a ribbed mold, then rotating (and possibly further expanding) the vessel after removing it from the

\footnotetext{
${ }^{245}$ Piriform: a globular body having its greatest diameter at the base, in distinction from oval (greatest diameter at center) and ovoid (greatest diameter at shoulder). Saldern, Ancient and Byzantine Glass from Sardis, 3.

${ }^{246}$ This style of neck resembles Isings' no. 103, although she notes that "a more or less outsplayed rim is very rare." Roman Glass from Dated Finds, 121.
} 
mold, to create the spiralling effect. ${ }^{247}$ The degree of rotation was about $350^{\circ}$ and carefully performed, resulting in a pleasingly even pattern.

Similar decorations are common on vessels of approximately the same size and shape: that is, bottles with relatively slender necks and bases between $70-90 \mathrm{~mm}$ in diameter. One group of smaller bottles with similar decoration, and another group of substantially bigger ones, have also been reported. ${ }^{248}$ Although the shape of the bodies of such bottles varies considerably, this example appears to be one of a very few piriform bottles to have been mold-decorated. ${ }^{249}$ The necks of comparably decorated bottles also vary greatly. Some are either significantly wider than this one or conical in shape. ${ }^{250}$ Some have a pronounced flare toward the top, resulting in a funnel-mouth-a feature which may have been present here too, judging by a slight out-turn of the neck right at the point of its fracture. ${ }^{251}$

Mold-decorated bottles of this general type are often associated with manufacturing dates in the late third and early fourth centuries, although many of these assignments seem to have been made on stylistic grounds rather than archaeological context. ${ }^{252}$ Examples that can be more securely dated include one at El Bassa stemming from the late fourth century and one at Sardis from the sixth or early seventh century. ${ }^{253}$ The latter resembles the present bottle in the size, although not so much the shape, of its body; sadly, its neck is completely missing. A closer morphological parallel apparently came from a tomb in western Galilee but lacks firm dating. ${ }^{254}$

\footnotetext{
${ }^{247}$ Saldern, Ancient and Byzantine Glass from Sardis, 89; Hayes presents a parallel vessel that has vertical ribs, probably indicating a bottle that was not rotated upon extraction from the mold Roman and Pre-Roman Glass in the Royal Ontario Museum, 93, no. 311.

${ }^{248}$ Dussart portrays four bigger and more elaborate mold-decorated bottles of varying shapes Le verre en Jordanie et en Syrie du Sud, B.X.1111.b.1, B.X.42; B.X.631, B.XIV.4, B.XIV.131; Cohen reports six much smaller ones "Roman, Byzantine and Umayyad Glass," Type 7.15-20.

${ }^{249}$ Most mold-decorated bases are oval or ovoid. Examples: Hayes, Roman and Pre-Roman Glass in the Royal Ontario Museum, nos. 282, 306; Saldern, Ancient and Byzantine Glass from Sardis, no. 647; Dussart, Le verre en Jordanie et en Syrie du Sud, B.X.1111a.1; Cohen shows one mold-decorated piriform bottle from Hammat Gader "Roman, Byzantine and Umayyad Glass" Type 7.21, although its base is much more globular than this one.

${ }^{250}$ Wider or conical necks: Hayes, Roman and Pre-Roman Glass in the Royal Ontario Museum, nos. 300, 327; Dussart, Le verre en Jordanie et en Syrie du Sud, B.X.1111.a.2. As noted above, this bottle too might have had a conical (funnelshaped) mouth.

${ }^{251}$ Bottles with funnel-shaped mouths have been published by Hayes, Roman and Pre-Roman Glass in the Royal Ontario Museum, nos. 282, 306, 311, 327; Cohen, "Roman, Byzantine and Umayyad Glass," Type 7.21; Dussart, Le verre en Jordanie et en Syrie du Sud, B.XIV.4.

${ }^{252}$ The problem is noted by Weinberg and Goldstein, "The Glass Vessels," 79; Hayes very consistently reports dates in this range for the numerous vessels of this type in the Royal Ontario Museum-most of which resemble this flask fairly closely Roman and Pre-Roman Glass in the Royal Ontario Museum, 78, no. 282; 82, no. 306; 91, no. 300; 95, no. 327.

${ }^{253}$ I have not been able to see the discussion of the piece from El Bassa noted in Weinberg and Goldstein, "The Glass Vessels," 79 no.156; for the other, see Saldern, Ancient and Byzantine Glass from Sardis, 87; note the many similarly decorated - though considerably larger-items recorded by Dussart and sourced from tombs at Mahayy that are provisionally dated to the late 3rd/early 4th CE Dussart, Le verre en Jordanie et en Syrie du Sud, B.X.1111.b.1, B.X.42, B.X.631, B.XIV.131, B.XIV.4.

${ }^{254}$ Donald B Harden, "Tomb-Groups of Glass of Roman Date from Syria and Palestine," Iraq 11, no. 2 (1949): 154 item W.1.
} 
No special function is assigned to this type of vessel, beyond the general observation that most glass bottles of this size in the late Roman and Late Antique eras probably saw use in the kitchen or dining-room, often as wine-flasks. ${ }^{255}$ Its decoration does not seem to be associated with a particular use, but simply suggests that it was a relatively expensive vessel.

Small bottle
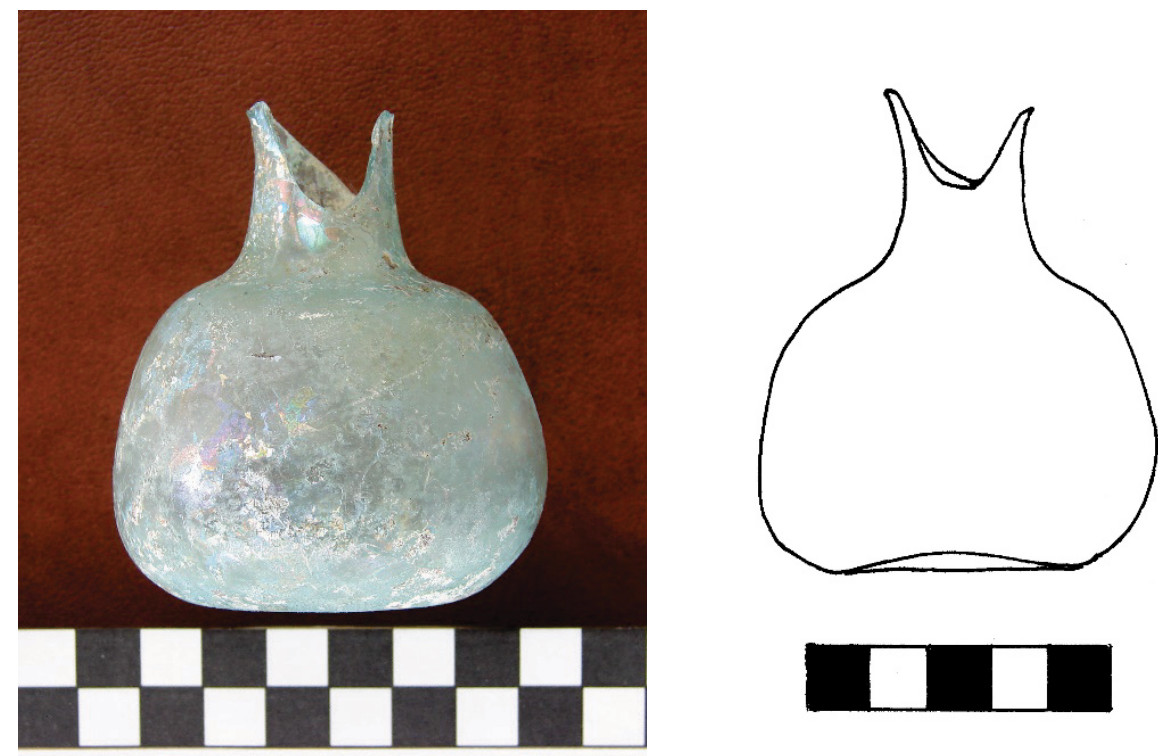

Figure 228 Small bottle

This bottle is aqua in color but made of thin fabric (approximately $1.2 \mathrm{~mm}$ in thickness). Like the spiral-decorated bottle described above, it has a slightly piriform body, although this one is more globular than straight-sided. Its bottom lacks a pontil mark and is slightly concave (approximately $2.5 \mathrm{~mm}$ ).

The preserved section of its cylindrical neck flares outward more abruptly on one side than the other. Because both flaring sections are broken off just at the point they begin to turn outward, and because the intervening sections are not preserved to this same height, it is hard to say whether this was an intentional feature associated with a particular use. On balance, and especially because this bottle's bottom has no pontil mark, it is probably more likely that this side-to-side variation was an accidental result of the manufacturing process. ${ }^{256}$

Small bottles with globular bodies and tubular necks (flaring or cylindrical) were used throughout the Roman and Late Antique periods from the first through eighth centuries.

\footnotetext{
255 Isings, Roman Glass from Dated Finds, 122.

${ }^{256}$ Without the vessel having been transferred from the blowing-rod to a pontil, it is hard to imagine how such a specialized rim-contour could have been created.
} 
They seem to have been especially popular during the late third and fourth centuries. Several close morphological parallels have been dated to this period. ${ }^{257}$ On the other hand, two bottles found in fifth/sixth century tombs at Khirbat al-Karnak, which is not far from this site, also closely resemble this bottle. ${ }^{258}$ Accordingly, it could reasonably be dated anywhere between the third and seventh centuries.

\section{Bone-carved maenad}

A significant find from the hoard is a maenad carved from bone. Maenads are women inspired to ritual frenzy by Dionysus. Maenadism was integrated into city life and involved inseparable social and religious aspects. The piece is $10.05 \times 3.22 \mathrm{~cm}$ with a thickness of 7 $-7.5 \mathrm{~mm}$. The piece was likely carved from the tibia of a large animal. After removal of the cancellous material, a slightly convex shaped remained, the outside edges of which were smoothed, suggesting that the item decorated a piece of furniture or perhaps a box..$^{259}$

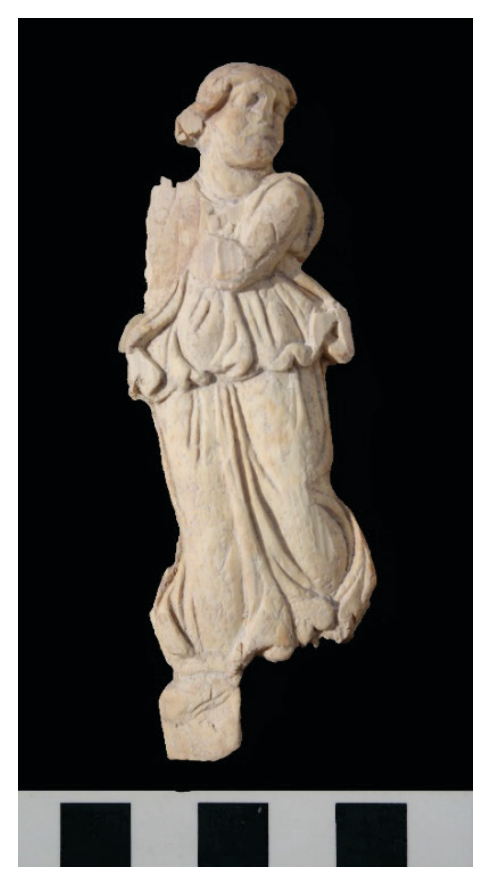

Figure 229 Maenad

\footnotetext{
${ }^{257}$ Hayes, Roman and Pre-Roman Glass in the Royal Ontario Museum, 94, no. 320; Dussart, Le verre en Jordanie et en Syrie du Sud, B.X.611 (noting parallels at Hanita and Peqin); Arveiller-Dulong and Arveiller, Le Verre d'époque Romaine Au Musée Archéologique de Strasbourg, nos. 279-297; Isings goes so far as to say, regarding her Type 104 (which this bottle closely resembles), "It is mainly a 4th century type" in Roman Glass from Dated Finds; both she and ArveillerDulong deal primarily with examples from the West, not the East. Hayes' and Dussart's examples are more relevant in this respect - as is the close parallel from a 3rd century grave in Sa-maria reported in John Winter Crowfoot, Grace Mary Crowfoot, and Kathleen M. Kenyon, The Objects from Samaria, Samaria-Sebaste; reports of the work of the Joint expedition in 1931-1933 and of the British expedition in 1935; no. 3 (London: Palestine Exploration Fund, 1957), 410, item C665.

${ }^{258}$ Delougaz and Haines, A Byzantine Church at Khirbat Al-Karak, 28-29, 49, and plate 50, nos. 6 and 15.

${ }^{259}$ Haim Goldfus and Kimberly Diane Bowes, "New Late Roman Bone Carvings from Halusa and the Problem of Regional Bone Carving Workshops in Palestine.," Israel Exploration Journal 50, no. 3-4 (2000): 190.
} 
The maenad is carved in medium relief with some vertical tool markings visible and no evident polishing. It is damaged around the edges and quite worn. The maenad stood on a block pedestal, three quarters of which is broken away. Tool markings on the surface of the remaining flat section of the pedestal may be defacing what is there, although some of the tool markings seem to follow the flow of the garment. The right arm was raised and is missing. The left arm crossed the body. It is broken above the elbow as it bends up to the figure's right. Both arms could have been holding a vessel. A portion of the hair by the right ear is missing, as is the nose. Both breaks are quite smooth and may be intentional. Nose-cutting was a practice used both by Jews and Christians as a way of desecrating pagan statues, especially in the seventh century. But the practice was also used to punish women for alleged adultery. ${ }^{260}$

The head is oversized $(1.63 \times 1.58 \mathrm{~cm})$. The eyes are large and lack detail. Both are "characteristic features of Oriental art." ${ }^{261}$ The hairstyle is difficult to determine as the object is quite worn. But the style seems simple, with the hair parted down the middle and the front sections braided to below the ears.

The maenad is fully dressed. ${ }^{262}$ She wears a Doric chiton in the form of a sleeveless dress. The overfold, called an apotygma, displays heavy folding and the motions of a dance. There are significant wear patterns on the outer edges of the overfold. The chiton is likely belted with a zoster under the breast ("high-girdled"). The garment flows to ankle level with both knees of the maenad flexed slightly inward, again to indicate motion. The feet are missing.

Articles by Rosenthal and by Goldfus and Bowes both question previous identification of such bone carvings as Alexandrian imports. Instead, they posit that "the carvings were made locally"263 and that "Palestine indeed supported some type of bone-carving industry." 264 Precise dating of bone carvings is difficult, especially in view of variations in form. "There is no evidence for an evolution from more 'naturalistic' to more 'abstract' pieces.

\footnotetext{
${ }^{260}$ Frank Richard Trombly, "Destruction of Pagan Statuary and Christianization (Fourth-Sixth Century C.E.)," in The Sculptural Environment of the Roman Near East: Reflections on Culture, Ideology, and Power, ed. Yaron Z. Eliav, Elise A. Friedland, and Sharon Herbert, Interdisciplinary studies in ancient culture and religion 9 (Leuven; Dudley, MA: Peeters, 2008), 156-157.

${ }^{261}$ Renate Rosenthal-Heginbottom, "Late Roman and Byzantine Bone Carvings from Palestine.," Israel Exploration Journal 26 (1976): 97.

${ }^{262}$ Maenads are at times a partially nude, see Marvin C. Ross and Kurt Weitzmann, Catalogue of the Byzantine and Early Mediaeval Antiquities in the Dumbarton Oaks Collection, vol. 2, Dumbarton Oaks catalogues (Washington DC: Dumbarton Oaks Research Library and Collection, 1962), 24-25, plate XII; Anthony Cutler, The Craft of Ivory: Sources, Techniques, and Uses in TheMediterranean World, A.D. 200-1400, Publications / Dumbarton Oaks, Byzantine Collection no. 8 (Washington, D.C.: Dumbarton Oaks, Research Library and Collection, 1985), 19, figs. 22-23; other bone figures are often nude as in Goldfus and Bowes, "New Late Roman Bone Carvings from Halusa and the Problem of Regional Bone Carving Workshops in Palestine.," 190, 193, 196, 200-201; Rosenthal-Heginbottom, "Late Roman and Byzantine Bone Carvings from Palestine.," plate 22, cp. plate 23.

${ }^{263}$ Rosenthal-Heginbottom, "Late Roman and Byzantine Bone Carvings from Palestine.," 103.

${ }^{264}$ Goldfus and Bowes, "New Late Roman Bone Carvings from Halusa and the Problem of Regional Bone Carving Workshops in Palestine.," 198.
} 
Those pieces from reliable stratigraphic contexts indicate that both the finely modeled pieces and the schematic renderings appear together among late fourth-sixth century finds." 265 This conclusion accords with the identified stratigraphic context of the hoard found just outside the single room domestic space.

\section{Bronze pitcher}

In addition, the horde contained a bronze pitcher. The pitcher is $21 \mathrm{~cm}$ tall made from a soft copper or bronze 1.8-2.0 mm thick. The pitcher consists of two pieces. The bottom piece of the body is $3 \mathrm{~cm}$ tall and $18 \mathrm{~cm}$ wide. The base is concave with a $10 \mathrm{~cm}$ basal rim. The body fits inside the base which was hammered to it and presumably soldered. The workmanship is basic and without decoration. The body rises cylindrically with a slight inward contraction to a shoulder that bends into a neck that gradually narrows from $5.5 \mathrm{~cm}$ to $3.7 \mathrm{~cm}$. The typical round mouth of such pitchers ${ }^{266}$ is pinched to form a spout $4 \mathrm{~cm}$ long and $2 \mathrm{~cm}$ wide.

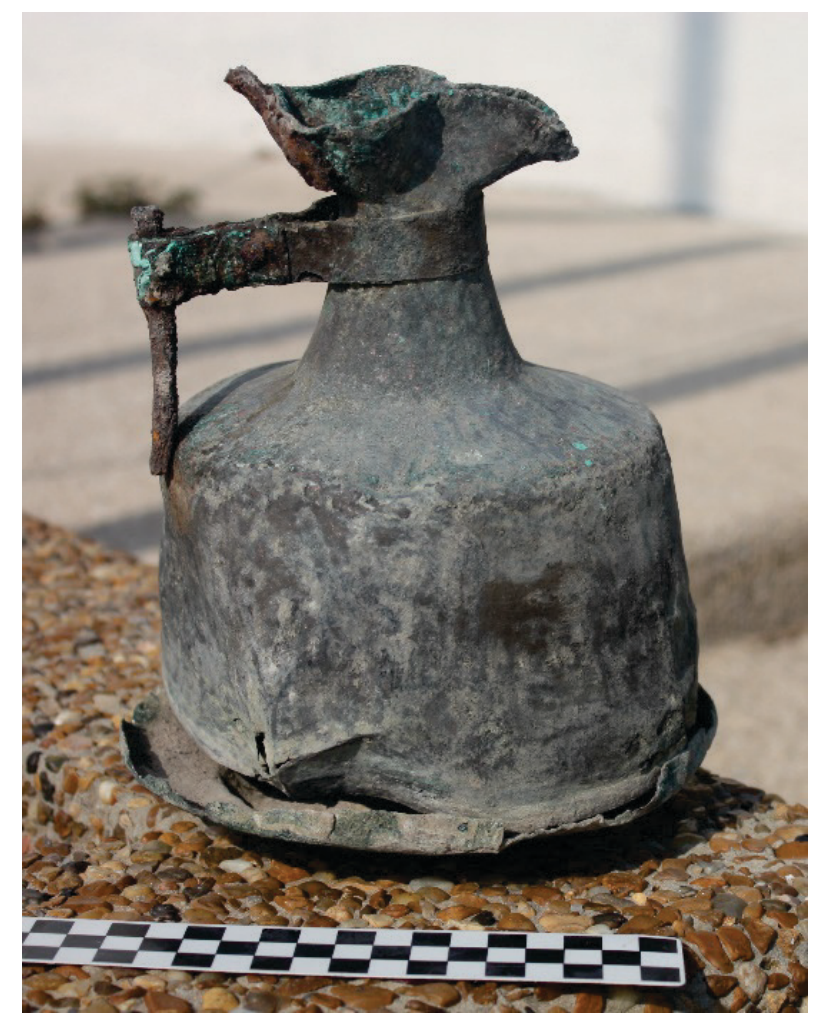

Figure 230 Pitcher

The opposite side of the mouth is flattened so that the upper part of an iron handle might be attached with two pins. The rod of the iron handle (found broken) proceeded upward

\footnotetext{
${ }^{265}$ Ibid., 201-202.

${ }^{266}$ George Fletcher Bass and Frederick H. Van Doorninck, Yassl Ada, 1st ed., The Nautical archaeology series no. 1 (College Station: Published with the cooperation of the Institute of Nautical Archaeology by Texas A\&M University Press, 1982), 270-271, MF5; Frederick O Waagé, "Bronze Objects from Old Corinth, Greece," American Journal of Archaeology 39, no. 1 (1935): 89, fig. 9; GRH Wright, "Some Byzantine Bronze Objects from Beycesultan," Anatolian Studies 50 (2000): 166, fig. 12a.
} 
from the attachment at the mouth and then curved sharply downward to the shoulder of the vessel. In this part of the handle the rod is flattened to $7 \mathrm{~mm} \times 1.01 \mathrm{~cm}$. A bronze or copper strap of $1.5 \mathrm{~cm}$ width encircles the neck and the handle and is bonded together by two pins. If this pitcher handled hot liquids, the heat would transfer quickly to the handle. We wonder if some now-lost handle surrounded the metal.

\section{Crossbow fibula}

A crossbow fibula consists of a transverse bar (the crossbar), a bow, a pin, and a catch or foot. ${ }^{267}$ The fibula from the horde is $7.83 \mathrm{~cm}$ from the top finial to the bottom of the catch with a $4.56 \mathrm{~cm}$ crossbar also capped with finials.

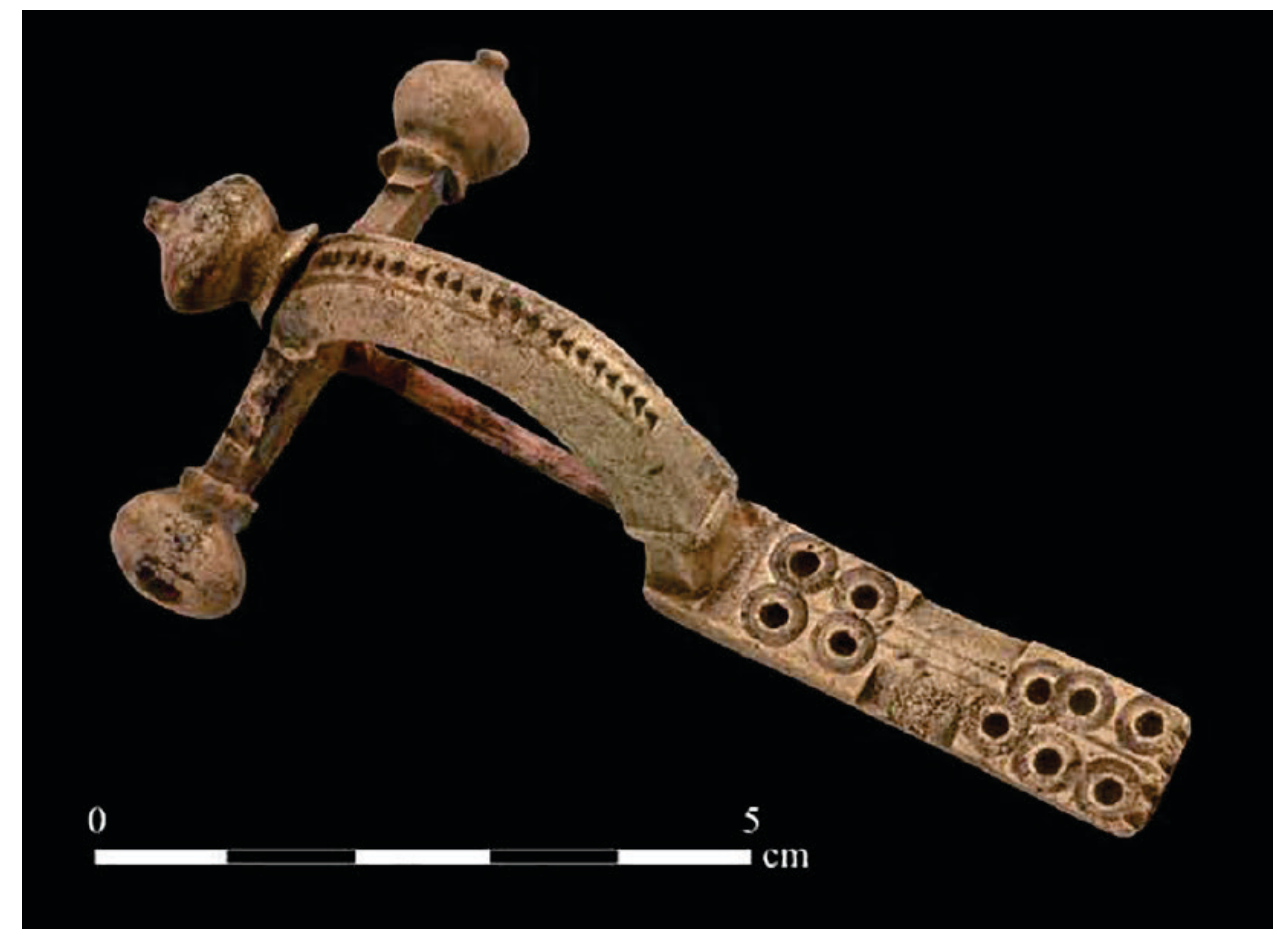

Figure 231 Crossbow fibula

The shaft of the crossbar is relatively square in cross section $(3.7 \mathrm{~mm})$. Each finial is bulbous $(1.04 \mathrm{~cm})$ with a small knob at the top and flaring to a ring at the base. The bow is moderately arched, $3.6 \mathrm{~cm}$ long and $2.3 \mathrm{~cm}$ high. The bow is triangular in cross section with a rounded front surface $(7.8 \mathrm{~mm} \times 4.3 \mathrm{~mm})$. Two decorative bands (rope-like?) run down the length of the exterior of the bow. The pin is $5.87 \mathrm{~cm}$ in length and $2.7 \mathrm{~mm}$ in diameter. It is permanently hinged to the crossbar and secured in an open slot in the catch. The catch is $3.76 \mathrm{~cm}$ long and $9.8 \mathrm{~mm}$ thick. Its front surface is flat and decorated with two rows of

\footnotetext{
${ }^{267}$ Pete Dandridge, "Idiomatic and Mainstream: The Technical Vocabulary of a Late Roman Crossbow Fibula," Metropolitan Museum Journal 35 (2000): 72, fig. 3.
} 
punched eyelets. Next to the bow there are four eyelets. An intervening bar $(1 \mathrm{~cm})$ is followed by six more eyelets. Alignment of the eyelets is imprecise. Overlaps suggest that the eyelets were punched left to right and then from the bow to the tip of the catch. Symbolism is uncertain, but such punched dots may be "evil eye" dots. ${ }^{268}$

A fibula is a practical item used by both men and women to fasten clothing. But the crossbow fibula "was exclusively a male ornament, created to hold in place the heavy woolen cloak or cape that was the outer garment of a Roman soldier." 269 Although the first and second centuries C.E. saw a large number of shapes and types, "in the early decades of the third century, the crossbow fibula became the dominant type." ${ }^{270}$ Crossbow fibulae made of precious metals could be worn by officers and came to take on an official nature. The length of the catch and the hinging of the pin to the crossbar suggest that this crossbow fibula is of a style from the early stage of the development of this ornament, namely $240-276$ CE. ${ }^{271}$ However, transition among styles is fluid with fourth century examples betraying "a Byzantine spirit, and later ones ... sometimes so deeply embedded in classical traditions that they suggest an earlier origin." ${ }^{772}$ In addition, crossbow fibulae also appear in non-military contexts and Christian contexts. For example, the Late Antique mosaics in Basilica of San Vitale, Ravenna, depict the Emperor Justinian flanked by three attendants with crossbow fibulae and another has Empress Theodora attended by a chaplain wearing a crossbow fibula. We are left with ambiguity. The crossbow fibula discovered in the horde certainly belonged to a male. Whether he was a soldier or a church leader is uncertain. But the Late Antique context might suggest the latter. If so, this small domestic space and courtyard may relate to the monastic compound, or to other nearby ecclesial compounds, such as the church directly to the east.

\section{Coin}

The final item in the hoard was a worn coin of Diocletian, minted at Antioch (293-295). On the obverse is a radiate, draped, and cuirassed bust of Diocletian facing right. On the reverse, Diocletian, standing right, holds scepter and receives Victory on globe from Jupiter, who is standing on the left and holding scepter. The inscription reads: CONCORDIA MILITVM ("concord to the military"). Three other nearly identical coins were found that season in other parts of the Hippos excavation.

\footnotetext{
${ }^{268}$ Segal et al., Hippos-Sussita : Tenth Season of Excavations : July and September 2009, 66.

${ }^{269}$ Barbara Deppert-Lippitz, "A Late Antique Crossbow Fibula in the Metropolitan Museum of Art," Metropolitan Museum Journal 35 (2000): 41-42.

270 Ibid., 42.

${ }^{271}$ For more detailed discussion of dating, see E. Toth, "Zur Datierung Der Zwiebelknopffibeln," Folia Archaeologica 31 (1980): 146-154; and P. M. Prottel, “Zur Chronologie Der Zwiebelknopffibeln," Jahrbuch des Römisch-Germanischen Zentralmuseums Mainz 35, no. 1 (1988): 347-372.

272 Deppert-Lippitz, “A Late Antique Crossbow Fibula in the Metropolitan Museum of Art,” 67.
} 


\section{Observations}

This horde is quite eclectic. As it was recovered from a space with a ceramic profile from the sixth to the eighth century, the retention of valued items from an earlier time (the coin, the fibula, and the maenad) suggests they were of some financial or social value to the owner. Together with the glass bottles they form a collection of minor luxury items. Their preservation together points to a complex cultural history, only some of which can be inferred with confidence.

\section{From the Diakonikon}

A second horde of small finds comes from the diakonikon. This oversized space adjacent to the tomb of a revered woman served her memorial cult and functioned as a monastic infirmary/healing site. The horde is part of the argumentation for that proposal.

On the cistern platform in the northeast corner of the room, a small horde of gold jewelry was hidden under a fragment of a ceramic jar. The horde included three belt elements and a magical healing amulet. ${ }^{273}$

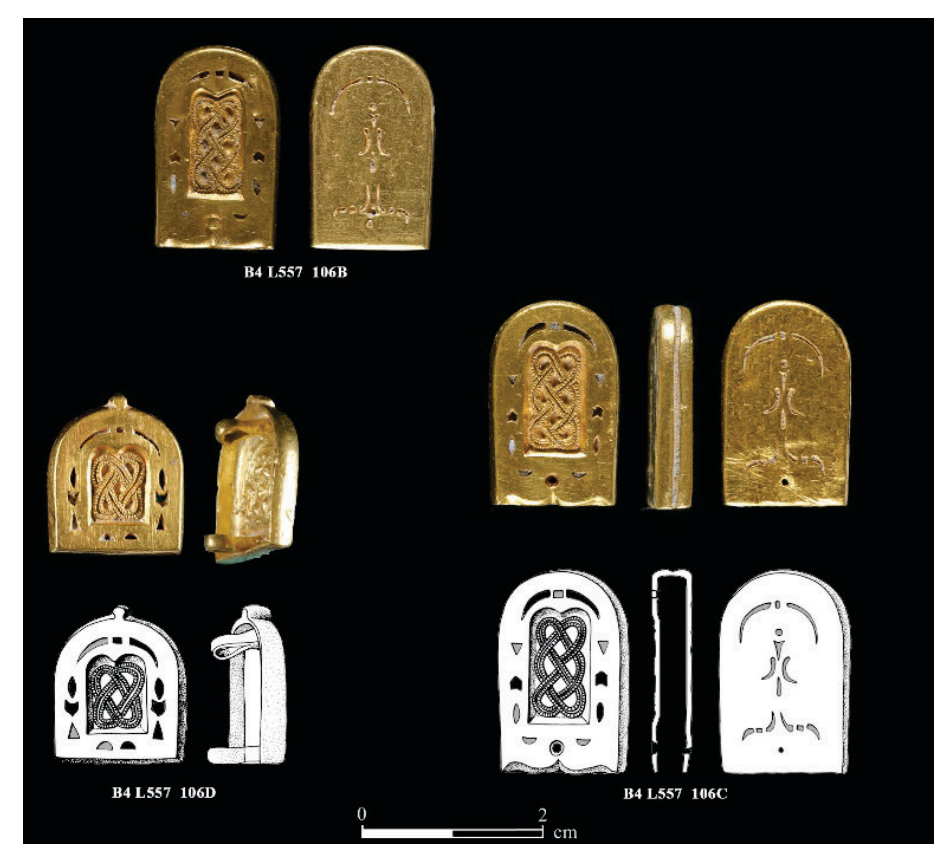

Figure 232 Belt elements (Courtesy of the Hippos-Sussita Excavations. Used with permission.)

The belt elements consist of two nearly identical pieces $1.43 \times 2.23 \mathrm{~cm}$. They are made of two pieces of metal $0.7 \mathrm{~mm}$ thick with edges bent over and pressed together making a total

\footnotetext{
${ }^{273}$ This report is indebted to Adam Łajtar of the University of Warsaw and Jeffrey Spier of the Kimbell Museum in Fort Worth for their assistance in identifying the finds and in supplying supporting bibliography.
} 
thickness of $4.5 \mathrm{~mm}$. On the obverse is an outer decorative border of quarter moons, arrows, triangles, and scrolling with an entwined pattern in the center. The reverse has a lightly punched pattern. One of the two pieces has a protruding nodule on the obverse that is part of a $4.7 \mathrm{~mm}$ small pin through the tab (creating a catch?). The third belt element is $1.48 \mathrm{x}$ $1.61 \mathrm{~cm}$. It is made of one piece of metal $1 \mathrm{~mm}$ thick with bent edges yielding a total thickness $2.9 \mathrm{~mm}$. Its obverse is of similar pattern to the other two pieces. On the reverse are two eye hooks.

The belt elements are like a set of eleven pieces purchased in Constantinople but said to come from Syria and currently in the Dumbarton Oaks collection. ${ }^{274}$ A gold buckle (probably from Italy) with a similar entwined pattern is in Berlin. ${ }^{275}$ Similar belt elements have been discovered in widely scattered locations: Langobard Italy, along the Danube, Antioch and Cairo. The belt elements from Antioch were discovered with a silver candlestick with early seventh-century control stamps. ${ }^{276} \mathrm{~A}$ dating to the late sixth or early seventh century seems plausible.

Recovered from the top layer of destruction fill in the cistern was a gold belt element likely from the same horde. However, its shape and patterning are distinctly different.

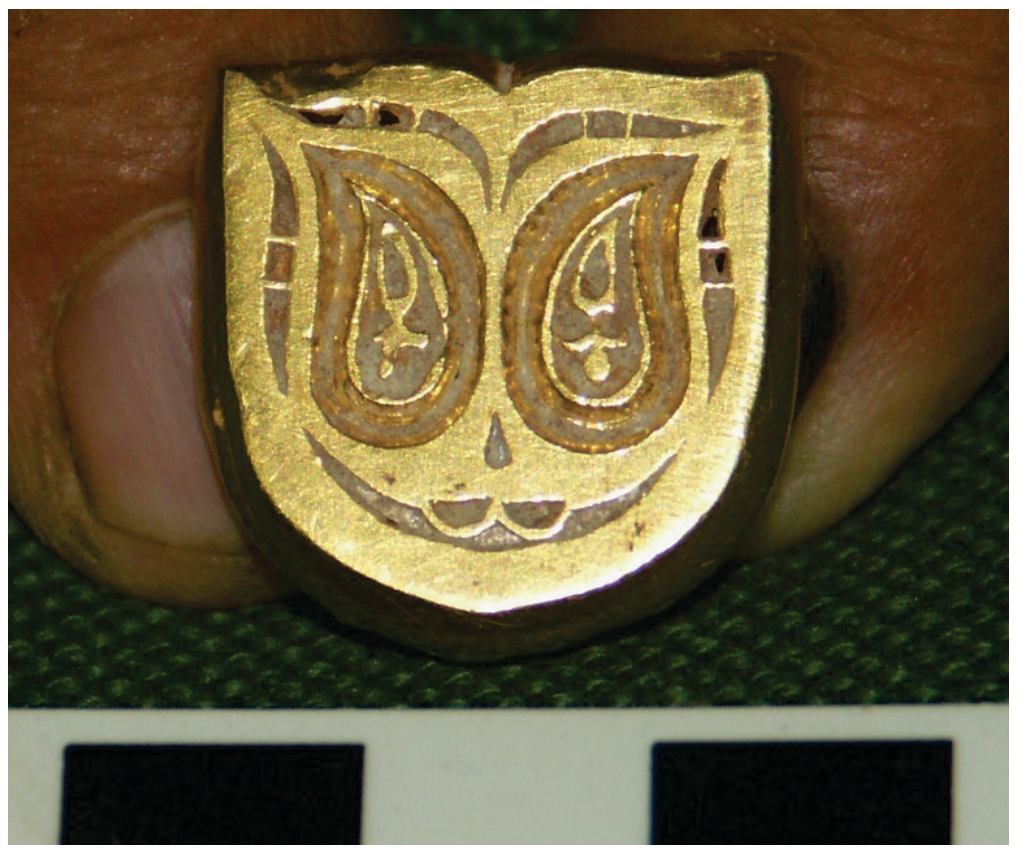

Figure 233 Belt tab

\footnotetext{
${ }^{274}$ Ross and Weitzmann, Catalogue of the Byzantine and Early Mediaeval Antiquities in the Dumbarton Oaks Collection, vol. 2, p. , no. 42.

275 Jeffrey Spier, "Belt Tabs and Healing Amulet," July 18, 2005.

${ }^{276}$ Marvin C Ross, “A Small Byzantine Treasure Found at Antioch-on-the-Orontes," Archaeology 5, no. 1 (1952): 3032.
} 
The shape of the obverse is like a tulip flower $(2.12 \times 2.21 \mathrm{~cm})$. The metal is $1 \mathrm{~mm}$ thick. The bent edges yield a thickness of $3.6 \mathrm{~mm}$. The obverse has an outer decorative border interspersed with squares and half-moons. Tiny jewels seem to be impressed into the border. Within the border are outlines of two tears with their upper points turned outwards. Inside each tear are stylistic representations of a young plant coming forth from a bulb. On the reverse are two eyehooks protruding $1.1 \mathrm{~cm}$ from the metal. A small repair to one of the tear drops is also visible, marked with a cruciform jeweler's stamp. A dating to the late sixth or early seventh century seems plausible. ${ }^{277}$

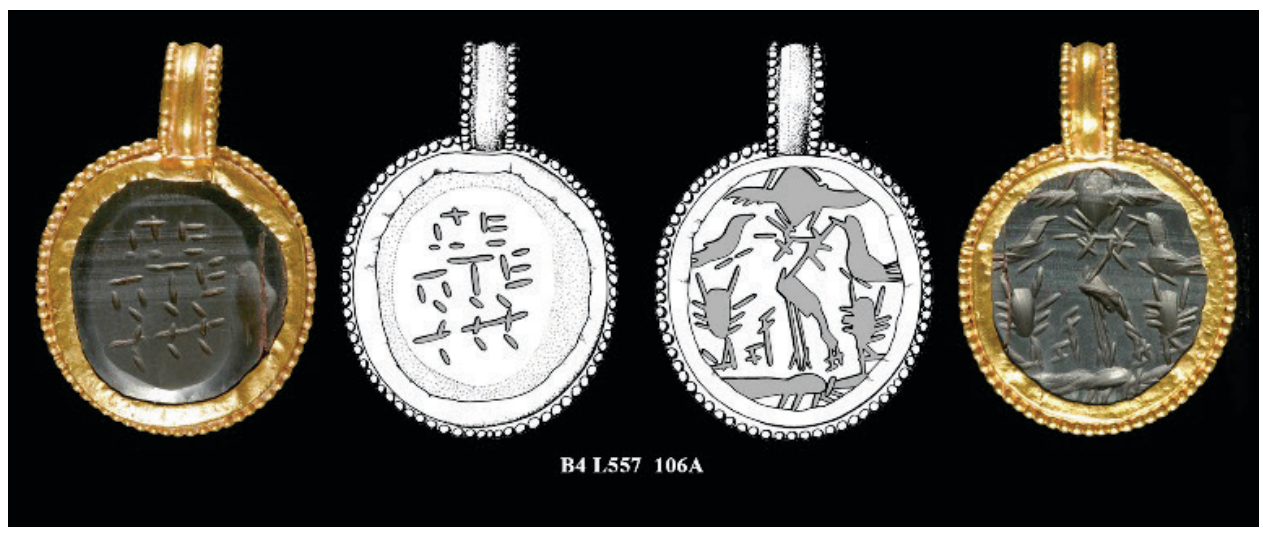

Figure 234 Healing amulet (Courtesy of the Hippos-Sussita Excavations. Used with permission.)

Most significantly, the horde included a healing amulet. The amulet is fitted into a gold Late Antique setting. The complete piece has a horizontal dimension of $2.23 \mathrm{~cm}$ and a vertical dimension of $2.37 \mathrm{~cm}$. Its thickness is $2.2 \mathrm{~mm}$. The hanging ring at the top of the amulet has a $9.2 \mathrm{~mm}$ outside diameter. The ring has a smooth inner ridge; both outer ridges are nodules $0.9 \mathrm{~mm}$ thick with 23 nodules around the ring. The amulet stone is held in a gold fitting hammered around the stone. The outer ridge consists of similar nodules - 64 around the ring. The setting is from the sixth or early seventh centuries.

The amulet itself is a well attested type. ${ }^{278}$ The amulet is likely made of haematite (an iron oxide), a material used for similar magical amulets. On the obverse is a long-legged bird, likely a crane (phoenix?), with rays (seven?) around the head. The bird stands on a crocodile. Above it is a winged scarab. On either side in descending order are a bird, a scorpion (the tail of which is partially hidden by the setting), and a stylized snake. The working of the animals is somewhat primitive, and the identification is partially based on clearer parallels. The reverse reads, in Greek over two lines, $\pi \varepsilon ́ \pi \tau \varepsilon$, meaning "digest." Its primary purpose is

\footnotetext{
${ }^{277}$ Segal et al., Hippos-Sussita : Fifth Season of Excavations : September-October 2004, 69-70.

${ }^{278}$ Campbell Bonner lists seventy-one medical amulets. Many are stomachic (77-107) with numbers 102-105 being the closest parallels. Campbell Bonner, Studies in Magical Amulets: Chiefly Graeco-Egyptian, University of Michigan studies Humanistic series, (Ann Arbor London: University of Michigan Press; Geoffrey Cumberlege, Oxford University Press, 1950); see also, Simone Michel et al., Die Magischen Gemmen Im Britischen Museum, 2 vols. (London: British Museum Press, 2001), no. 401.
} 
stomachic, although an effective amuletic design might be appealed to for broader purposes. Below the Greek lettering is the Chnoubis symbol, a stylized coiled snake with a lion's head likely referred to by Galen. ${ }^{279}$ Of such amulets, Campbell Bonner writes, "There is reason to think that all came from Syria, through the subjects are Egyptian." ${ }^{280}$ As to dating, Jeff Spier writes: "Most of these amulets are second-third century in date, although I feel that this variety is slightly later, probably fourth century (as Michel also suggests) or even later, but not as late as the sixth century. Old magical amulets were occasionally reused in later times." 281

To find such an amulet in an ecclesiastical context is noteworthy. While early Christian writers inveighed against the practice of magic, ${ }^{282}$ James Russell's survey of the archaeological evidence from the Late Antique period led him to conclude, "Underlying this devotion to the new faith, however, there clearly remained a deeply engrained attachment to practices inherited from some timeless past involving various forms of magic." ${ }^{283}$ Chrysostom may condemn amulets, ${ }^{284}$ but Alexander of Tralles, a practicing physician of the sixth century, condones the therapeutic use of amulets. ${ }^{285}$ Whoever hid this horde in the diakonikon of the Northeast Church complex likely believed in the power of the amulet as much as in the power of the church.

The discovery of a healing charm in the diakonikon indirectly raises the question of the function of the room in which the horde was hidden. The room is oversized in comparison to the small size of the church. It is wrapped around the corner of the church that houses the tomb of a revered woman. Its only entrance is immediately adjacent to the tomb. The cistern in its northeast corner is in direct proximity to the tomb, prominently placed in the room, and at the same time is an unprecedented feature of a diakonikon. Might the room have served some sort of cultic function in the veneration of the sacred woman? Might the waters of the cistern have been drawn for healing purposes? ${ }^{286}$ Might one who treasured an

\footnotetext{
${ }^{279}$ Galen, "De Simplicium Medicamentorum Temperamentis et Facultatibus," 10.19.

${ }^{280}$ Bonner, Studies in Magical Amulets: Chiefly Graeco-Egyptian, 60.

${ }^{281}$ Spier, "Belt Tabs and Healing Amulet."

${ }^{282}$ For the views of the ante-Nicene fathers on magic, see Francis CR Thee, Julius Africanus and the Early Christian View of Magic, vol. 19 (Mohr Siebeck, 1984), 316-448; for Origen, Chrysostom, and Augustine, conmsult Norbert Brox, "Magie Und Aberglaube an Den Anfängen Des Christentums," Trierer Theologische Zeitschrift 83 (1974): 157-180.

283 James Russell, "Archaeological Context of Magic," in Byzantine Magic: [Papers... Originally Delivered at a Colloquium... at Dumbarton Oaks Feb. 27-28, 1993], ed. Henry Maguire (Dumbarton Oaks Res. Library and Collection, 1995), 37.

${ }^{284}$ John Chrysostom, In Epistulam I Ad Corinthios, PG 61, col. 38; John Chrysostom, In Epistulam I Ad Timotheum, PG 62 , col. 552.

${ }^{285}$ Theodor Puschmann, Alexander von Tralles: Originaltext Und Übersetzung Nebst Einer Einleitenden Abhandlung: Ein Beitrag Zur Geschichte Der Medicin; Zwei Bände, vol. 2 (Braumüller, 1879), 375, 475.

286 "In late antiquity Christians in search of miraculous healing began to visit the shrines of saints, usually their tombs or another place where their relics were preserved. Examples are Abu Mina in Egypt, dedicated to the martyr St. Menas and functioning by the late fourth century; Sts. Abbakyros and John at Menouthis in Egypt, which flourished between the fifth and seventh centuries; the shrine of St. Thekla in Anatolian Seleukeia (Meriamlik), which is attested between the fourth and sixth centuries; the pilgrimage complex of Qal'at Sem'an near Antioch, at the column of St. Symeon the Stylite the Elder, which was particularly active in the late fifth and sixth centuries; and the shrine of his later homonym, Symeon the
} 
amulet also seek the solace of sacred waters? ${ }^{287}$ We propose affirmative answers to these questions.

\section{From the peristyle court}

The peristyle court of the structure to the east of the church was central to the house of Tyche and was reused in a support function for the Late Antique monastic complex. Conical mills were left on its surface and two knives $(15-20 \mathrm{~cm}$ in length) were found in the destruction fill. While not part of a horde, two small items are worthy of note, as they attest to life in the House of Tyche.

\section{Cylindrical mount}

A hollow cylindrical object fashioned of bone (tibia of a medium sized animal?) was recovered from the peristyle court.

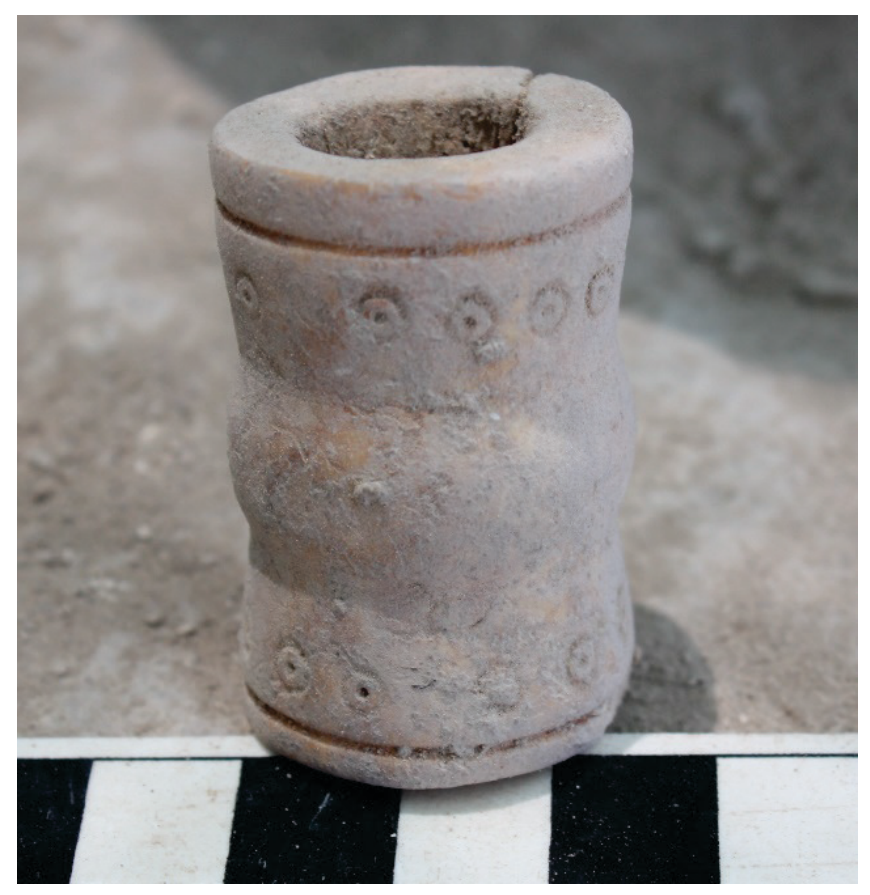

Figure 235 Cylindrical mount

Stylite the Younger, at the Wondrous Mountain (6th-7th century). These shrines are known through their extensive archaeological remains, through accounts of the posthumous miracles performed by the saints, and through pilgrimage artifacts or 'souvenirs,' such as ampullae, designed as containers for holy oil or water, and clay tokens made from the dust of a holy site." Alice-Mary Talbot, "Pilgrimage to Healing Shrines: The Evidence of Miracle Accounts," Dumbarton Oaks Papers 56 (2002): 154.

${ }^{287}$ Alexander of Tralles advocated the use of any means in the interests of the sick. Puschmann, Alexander von Tralles, 319,475 . 
The object is $3.98 \mathrm{~cm}$ tall, $2.54 \mathrm{~cm}$ in diameter with an interior hole of $1.4 \mathrm{~cm}$. The surface is smoothed but not polished. Two shallow grooves divide the length of the cylinder into three bands. The middle band ( $9.8 \mathrm{~mm}$ wide) is plain. The top and bottom bands are decorated with a sharper groove around the outside of the cylinder $2.5 \mathrm{~mm}$ from each end and by a row of eyelets. One band has twelve eyelets; the other band has thirteen.

Rosenthal suggests that "hollow bones with carving" were "used as handles." 288 According to St. Clair, "surviving evidence documents the use of cylindrical and ring-shaped mounts primarily on furniture legs, which were assembled around an iron rod. Cylindrical members turned from a single length of hollowed bone ... [were] then drilled through to receive the rod. They vary considerably in size and are both undecorated and decorated." 289

\section{Small two-headed flask}

Next to the south-east column base of the peristyle court, a small two-headed flask was recovered, sitting on the stylobate. The glass is $2 \mathrm{~mm}$ thick and light greenish grey (GLEY 1 $7 / 5 \mathrm{GY})$. The fabric is translucent with some granularity and small bubbles. The glass is weathered and somewhat calcified.

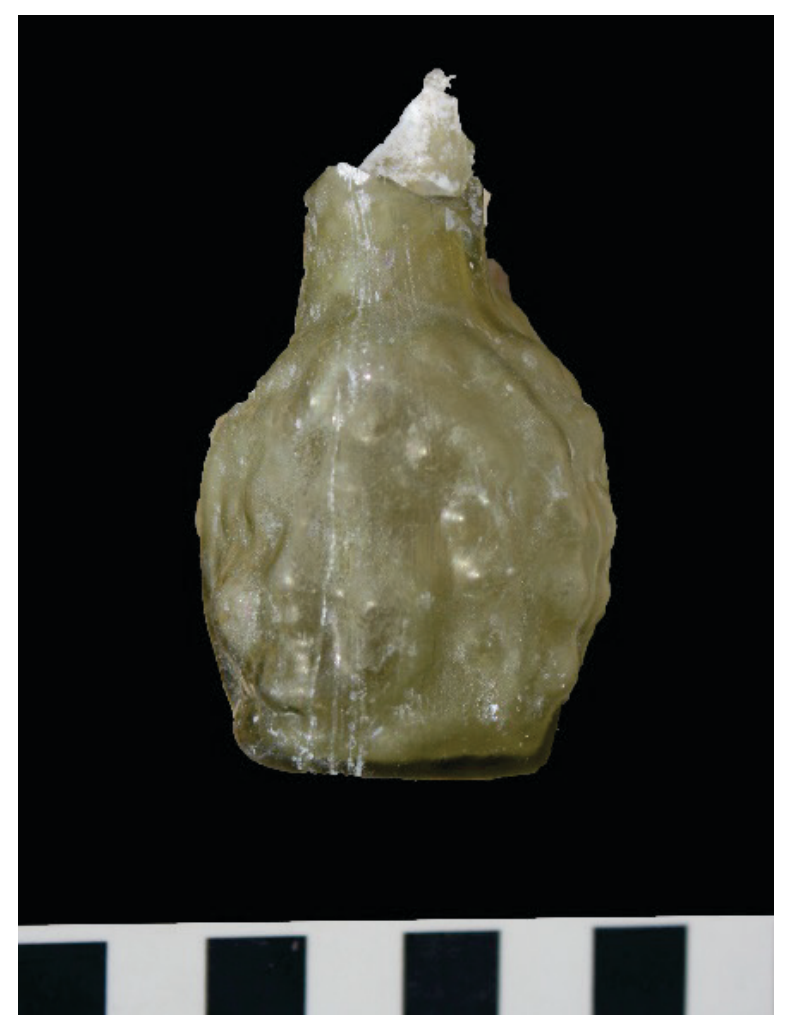

Figure 236 Two-headed ("Janus") flask

\footnotetext{
${ }^{288}$ Rosenthal-Heginbottom, "Late Roman and Byzantine Bone Carvings from Palestine.," 101.

${ }^{289}$ Archer St. Clair, Carving as Craft: Palatine East and the Greco-Roman Bone and Ivory Carving Tradition (Baltimore: Johns Hopkins University Press, 2003), 69.
} 
The body is $4.5 \mathrm{~cm}$ tall and approximately $4 \mathrm{~cm}$ in diameter. The body was blown in a twopart mold with two heads set back-to-back. Seam lines are visible. Two rows of globules indicate long hair on the nearly identical figures. The faces are nondescript with large noses and chubby cheeks. The base is flat and shows some imprecision in the alignment of the two molds.

The neck is cylindrical $(1.5 \mathrm{~cm})$ although the misalignment makes the neck appear in cross section more like a Cassini oval than a circle. The neck of the flask is broken about a centimeter above the body.

The flask is a common type with nearly identical examples in the Museum of Bosra, ${ }^{290}$ the Museum of Fine Arts in Boston, ${ }^{291}$ and the Royal Ontario Museum. ${ }^{292}$ Hayes dates the flask he is documenting to the "late third-fourth century A.D." ${ }^{293}$ Von Saldern dates his example to "about second century A.D." ${ }^{294}$ Earlier examples of mold-blown flasks with human heads come from Pompeii and Dura-Europas. ${ }^{295}$ Barag claims that the manufacture of vases with two masks probably began in the late Flavian period or slightly later. They were common in the West and East until the end of Roman Imperial period. However, Foy believes, "ces pieces n' apparaissent pas avant le début du V ${ }^{\mathrm{e}} \mathrm{s} .{ }^{296}$ All such dates are prior to the last active period of the house, making the find likely residual from the earlier House of Tyche.

\section{Observations}

Despite the paucity of small finds, these small collections along with the coins and the analysis of ceramic finds help to date and provide descriptive function to the spaces excavated in the northeast insulae. The domestic horde gives insight into the eclectic items deemed of value to an occupant and hint at a surviving valuation of the Graeco-Roman heritage of the site. The horde from the diakonikon was the impetus for further steady and a contributor to the hypothesis that the monastic community provided an infirmary/hospital for the larger community. The small pieces from the peristyle court provide a furtive view of life in the House of Tyche in the Roman Imperial period. But of all the finds, the amulet was most significant in driving new understanding.

\footnotetext{
290 Dussart, Le verre en Jordanie et en Syrie du Sud, BXIII.31.

${ }^{291}$ Saldern, Ancient Glass in the Museum of Fine Arts, Boston, fig. 37.

292 Hayes, Roman and Pre-Roman Glass in the Royal Ontario Museum, 50, no. 94.

293 Ibid.

${ }^{294}$ Saldern, Ancient Glass in the Museum of Fine Arts, Boston, fig. 37.

295 Isings, Roman Glass from Dated Finds, 93.

${ }^{296}$ Quoted in Dussart, Le verre en Jordanie et en Syrie du Sud, 176.
} 


\section{8.}

\section{FLAX BASINS}

W orth of the House of Tyche, three plastered pools were revealed. One is an "upper 1 pool" next to the east wall of the house. A second is a quarter circle (the "lower pool") positioned next to the north wall of the house and feed by a fountain. A third pool sits opposite it to the west and is partially buried in the balk. These last two pools are of similar construction.

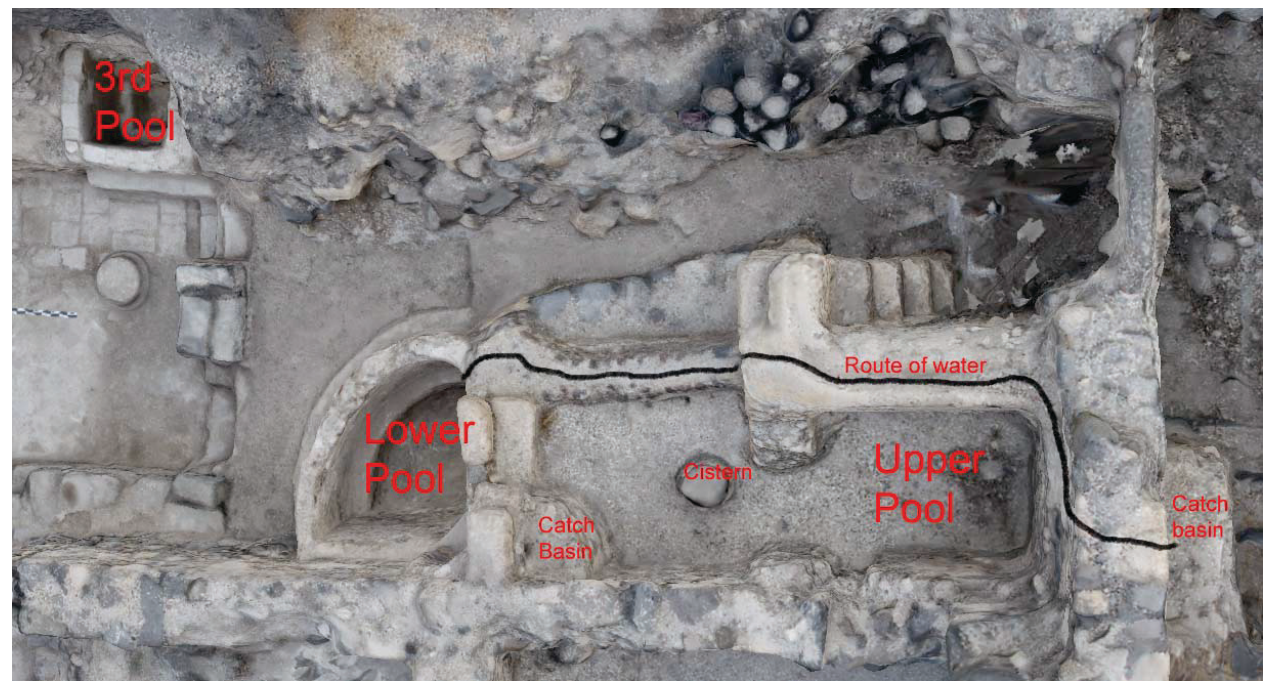

Figure 237 Water features from the terrace

Insight into the functions of these features is provided through the analysis of fossil pollen samples retrieved from the surface of their plasters.

Chapter co-authored with Patrick Scott Geyer, University of San Diego and the Zinman Institute of Archaeology, University of Haifa. 


\section{Methodology 297}

A total of four samples from level depths of between two and five centimeters were taken as cores from two distinct loci within the plaster walls midway from the top of the two pools north of the peristyle house. One sample was taken from the northern wall of the upper pool (sample 55), while and additional sample was taken from the opposing southern wall, again midway from the top of the pool (sample 56). In the case of the quarter-circle lower pool, one sample was taken from the eastern wall (sample 57) and one sample from the southern wall (sample 58) well within the levels that would have contained water. The results of these extractions are presented in the table below.

To identify the pollen present, pollen is separated or loosened from the sediment matrix to which it has bonded over time. The plaster samples were exposed to strong solutions of sodium hydroxide and tri-sodium phosphate. In a final step, the pollen was floated free from the plaster matrix by placing it in a solution of Zinc Chloride with a specific gravity of 2.0 .

After the pollen was extracted, it was placed in a glycerol medium and mounted on slides. Individual grains were identified and then counted. Statistically standard 200-grain counts were performed for each of the samples. Identification of individual grains was based upon laboratory reference collections from the Laboratory of Palynology at the Zinman Institute of Archaeology and a digital image collection of the co-author, Patrick Scott-Geyer.

\section{Pollen analysis}

The plant species represented by the pollen recovered from these pools are broken down into the following four categories: cultivar (agricultural or economic species), arboreal (tree species), indicator (disturbance or anthropogenic species) and lacustrine-hydrophyll (species from either lake or stream habitats).

Three cultivar pollens present strong signatures within the confines of these water installations: cereals, grape and most importantly flax. Cereal (grain) and grape (Vitis sp.) make up two of the three main staples of the eastern Mediterranean diet of grain, grape and olive. However, why are they presenting themselves in a water installation? Grain pollen presents itself in markedly higher concentrations in the plasters of the upper pool. Nearly double that of the concentrations of the lower pool. Sample 56, which was taken from the south

\footnotetext{
${ }^{297}$ For a full discussion of the methodology, see Patrick Scott Geyer et al., "Pollen Analysis," in Gamla III Part 2, vol. 59, The Shmarya Gutmann excavations 1976-1989, finds and studies: part 2 (Israel Antiquities Authority, 2016), 351362, accessed April 13, 2021, http://www.jstor.org/stable/j.ctt1m3p1w7.22; and James Schoenwetter and Patrick ScottGeyer, "Implications of Archaeological Palynology, at Bethsaida, Israel," Journal of field archaeology 27, no. 1 (2000): $63-73$.
} 
wall of the upper pool, registers 22 pollen (11\%), while sample 58 taken from the south wall of the lower pool registers 16 pollen (8\%); a decrease of $3 \%$.

This data suggests a contamination from an outside contemporary source. Likely, there was a threshing floor bordering the Northeast Church Complex. Looking at the grain levels in the two remaining samples, we find sample 55, taken from the north wall of the upper pool contains 34 cereal pollen (17\%), the highest amount of grain, while sample 57 from the east wall of the lower pool contains 12 grain pollen, the lowest amount of grain. This repeats, but more strongly, the pattern of concentration of the southern wall samples. If there was a threshing floor adjacent to this installation, then it would, based on the pollen grain concentrations in the pools, be situated at a higher elevation southwest of the installation. This is the general direction of the threshing floor situated in the previously studied industrial complex near the forum. ${ }^{298}$

The remaining highly concentrated cultivar species is flax (Linum sp.). Flax pollen is far too concentrated in the plasters of both the upper pool and the lower pool to be explained away as contamination. In most of the four samples taken from these water installations flax pollen exceeds fifty percent of the pollen count, the only exception being sample 58 (33\%), which was taken from the lower pool. However, this leads one to a comparison of the lower pool with the upper pool. Like the case of grain pollen, flax pollen is more concentrated in the upper pool than in the lower pool. The concentration of both upper pool samples registers higher than those of the lower pool. Upper pool sample 55 registers at $114(57 \%)$ and sample 56 registers at 148 (74\%), the highest individual species count for all four samples. While lower pool sample 57 registers at 110 (55\%) and sample 58 registers at 66 (33\%), both samples are clearly lower than the upper pool amounts and like what we saw in the grain pollen depositions.

We believe this can be explained by the way flax is processed. In the first stage, flax is softened, by being soaked in water over a prolonged period. This would have taken place in the upper pool. Then, again in water, its fibers are separated by hand. This would have been done in the lower pool. Normally, most of the pollen remaining upon the flax stems would have been washed away in the bath of the upper pool, working its way, over time, into its porous plaster lining. When the flax fibers were transferred to the lower pool for further processing, they would thus have been devoid of most of their pollens. We would then expect the pollen counts for flax to be even lower than what we see. However, in this case, flax is not being processed adjacent to an abundant natural water source, such as the Jordan River or Sea of Galilee, thus water conservation is necessary. The water soaking the flax in the upper pool is apparently being recycled into the water used to ret the flax in the lower

\footnotetext{
${ }^{298}$ Patrick Scott Geyer, "Pollen Analysis of the Hippos-Sussita Industrial Complex," in Hippos-Sussita : eleventh season of excavations, July 2010, ed. Arthur Segal (Haifa: University of Haifa, 2010), 83-88.
} 
pool, which accounts for the amounts of flax being lower there, but still being both strong and high concentrations.

Within the Arboreal pollens we have the expected background environmental pollens of oak and walnut, which have the strongest presence, as well as single instances acacia, cypress, and pine. Overall, the presence of tree pollens is minimal and probably is indicative of wind born contamination from the surrounding slopes.

In the Indicator category we see strong Cheno am, Liguliflorae and Tubuliflorae weed types. Both Liguliflorae and Tubuliflorae are significant indicators for both meadows and footpaths. Flax would have been grown in open spaced, treeless, meadow-like areas. Also, species types inhabiting and taking advantage of natural environments disturbed by human pathways would make sense in a primary agricultural setting such as Hippos. However, the presence of Cheno am, which is only strongly indicative of foot paths tips the balance and suggests the latter source of these three indicator types. As the flax was brought in from the fields, the humans carrying it as well as the flax bundles they carried picked up these weed pollens along the way.

One other indicator pollen bears special mention. Dipsacus sp., commonly called fullers brush, with its hard barb like flower, was used to comb or ret the flax stems. Thus, its presence in the vicinity of the installation is a further indication of flax processing being done there.

Lacustrine-hydrophyll species, as would be expected in water installations, are strongly present. The three main water dwelling species, Papyrus sp., Salix sp. (willow) and Scirpus sp. (reed) are present in meaningful concentrations, as they were in the wine presses and grape vats of the industrial complex near the forum. ${ }^{299}$

\section{Conclusion}

The main revelation brought about by this sampling of the plasters of the upper pool and lower pool of the "fountain" of the peristyle house is the very strong presence of flax pollen. The historical evidence for a flax or linen industry in the Sea of Galilee region during this period and place have already been established by both written ${ }^{300}$ as well as archaeological evidence. ${ }^{301}$ What's different here is that it is occurring within the walls of a city-state. This seems to be typical of Hippos. Wine presses at the site are an example of this anomaly. In most cases, wine presses are located outside the walls of both villages and cities. This is the case in nearby Gamla, for example. Similarly, as mentioned above, flax basins are usually

\footnotetext{
${ }^{299}$ Ibid., 85.

${ }^{300}$ Zeev Safrai, The Economy of Roman Palestine (London ; New York: Routledge, 1994), 195.

${ }^{301}$ Schoenwetter and Scott-Geyer, "Implications of Archaeological Palynology, at Bethsaida, Israel."
} 
erected in the countryside, close at hand to ready natural water sources. However, in this case we have another exception with flax pools being erected within an urban area, utilizing the more limited sources of water derived from man-made and more limited water sources.

While what is presented here is a reconstruction, having considered both the archaeology and the ecofacts involved, we believe that the pollen recovered from the plaster walls makes for a strong argument that these water installations were either primarily or secondarily used for flax processing.

As mentioned above, the Sea of Galilee region during this period was well known for its flax industry, as Safrei states in witness to this phenomenon, "Thus an Amora states: Bar Hedaya said- 'I saw myself how the Sea of Tiberias was encircled with washbasins of flaxen clothes on the intermediate days of the festival (hol hamoed)' (BT Moed Qatan 18b)." 302 Safrei goes on to state,

Flax was more profitable than any other grain...1.2-1.8 times the profit of a dunam of wheat. This is also not taking into account the price of tow, which is unknown. Once the flax was turned into rope, the profit skyrockets to 62.4-93.6 times the profit of wheat. ${ }^{303}$

Thus, it is little wonder that the Greeks and subsequently the early Christians of Hippos would avail themselves of this valuable crop -- a crop that once processed had a market value of nearly one hundred times that of grain. The two flax pools of the Northeast Church complex and the fossil pollen within their plasters are historical evidence of this.

Table: Villa Urbana “Fountain” Pollen Counts

\begin{tabular}{|l|l|l|l|l|l|}
\hline $\begin{array}{l}\text { Sample \# } \\
\text { Type/species }\end{array}$ & $\begin{array}{l}\text { Hippos } \\
\# 55\end{array}$ & Hippos \#56 & $\begin{array}{l}\text { Hippos } \\
\# 57\end{array}$ & $\begin{array}{l}\text { Hippos } \\
\# 58\end{array}$ & $\begin{array}{l}\text { Surface } \\
\text { control }\end{array}$ \\
\hline Sample area: & Reservoir & Reservoir & Basin & Basin & \\
\hline Cultivar (crop): & & & & & \\
\hline Ephedra (herb) & & & & 4 & 1 \\
\hline Cerealis (grain) & 34 & 22 & 12 & 16 & \\
\hline Olea (olive) & & & & & 2 \\
\hline Allium (onion/garlic/leek) & & 2 & 2 & 4 & 4 \\
\hline Amygadalus (almond) & & 2 & & & \\
\hline Ficus (fig) & & & & & \\
\hline Linum (flax) & 114 & 148 & 110 & 66 & \\
\hline Vitis (grape) & & & 8 & 22 & \\
\hline Arboreal (tree): & & & & & 6 \\
\hline Acacia & & & & 8 & 9 \\
\hline Quercus (oak) & & 2 & & 4 & \\
\hline Cupressus & & & & 6 & \\
\hline
\end{tabular}

${ }^{302}$ Safrai, The Economy of Roman Palestine, 157.

${ }^{303}$ Ibid., 159-160. 


\begin{tabular}{|l|l|l|l|l|l|}
\hline Juglans (walnut) & & 2 & 2 & 2 & \\
\hline Pistacia & & & & & 21 \\
\hline Pinus (pine) & & & 2 & & 1 \\
\hline Indicator: & & & & & \\
\hline Cheno am & 12 & & 2 & 6 & \\
\hline Echinops & & 2 & 12 & 12 & \\
\hline Cylamen & & & & 4 & 9 \\
\hline Dipsacus & & 6 & 2 & & \\
\hline Liguliflorae & & 2 & 2 & 6 & \\
\hline Poacea (grass) & 2 & & & & 63 \\
\hline Tubuliflorae & 18 & & 14 & 2 & \\
\hline Umbelliflorae & & 2 & & & 3 \\
\hline Lacustrine/hydrophill: & & & & & \\
\hline Papyrus & 2 & 6 & 6 & 10 & \\
\hline Salix & & & 12 & 2 & 1 \\
\hline Scirpus & 18 & 4 & 12 & 20 & 18 \\
\hline Typha & & & & 2 & \\
\hline Ulmus & & & 2 & 4 & \\
\hline TOTALS & 200 & 200 & 200 & 200 & 200 \\
\hline Lycopodium (exotic marker)* & & & & & \\
\hline
\end{tabular}

* The absence of Lycopodium markers indicates high pollen concentrations (>180,000 per cubic centimeter). 


\section{9.}

\section{GLASS REPORT}

Chapter authored by Stephen Chambers, Our Saviour Lutheran Church, Parksville, BC

S everal thousand fragments of glass were recovered from the Northeast Insulae Project $\mathcal{S}$ (NIP) between 2002 and 2016. Their fragmentary character is illustrated by the fact that only one vessel is preserved to its entire height (No. 85). Because the excavation site was covered with destruction fill, these fragments could not be securely dated based on stratigraphy. For the same reason, few fragments could be tightly linked to the loci in which they were found. Their small size and light weight meant that they could be-and, judging by the diversity of pieces found in most locations, were-transported from locus to locus as the site was gradually filled and levelled over time. This is a common problem in poorly stratified sites. ${ }^{304}$ It is illustrated here by the fact that three vessels (Nos. 16, 33, and 201 in the listings below) are represented by pairs of matching fragments found between 20 and 35 meters apart from each other, separated by numerous walls. In two of these cases, the halves of these matching pairs were found quite close to each other. That is, Nos. 33A and 201A were relatively close to each other, as also were Nos. 33B and 201B. In addition, within each pair, its two parts were found in locations that were oriented NNE/SSW of each other, which corresponds closely to the slope of the ground in this area. In the case of No. 33, its A and B parts were located about $25 \mathrm{~m}$ apart from each other in DK 42 and DH 39. Similarly, the A and B parts of No. 201 were separated by about $35 \mathrm{~m}$, in DK 43 and DG 39. This does not prove, but strongly suggests, that forces such as wind, water, and gravity played a significant role in determining the final location of at least some of the smaller and lighter weight finds from the NIP.

\footnotetext{
304 Ayala Lester, "Islamic Glass Finds," in The Roman Baths of Hammat Gader: Final Report, ed. Yizhar Hirschfeld (Jerusalem: Israel Exploration Society, 1997), 432-441; Rachel Pollak, "The Glass," in Tel Tanninim: Excavations at Krokodeilon Polis, 1996-1999, ed. R. Raphael Stieglitz and Ya'el D Arnon (Boston MA: American Schools of Oriental Research, 2006), 155-192.
} 


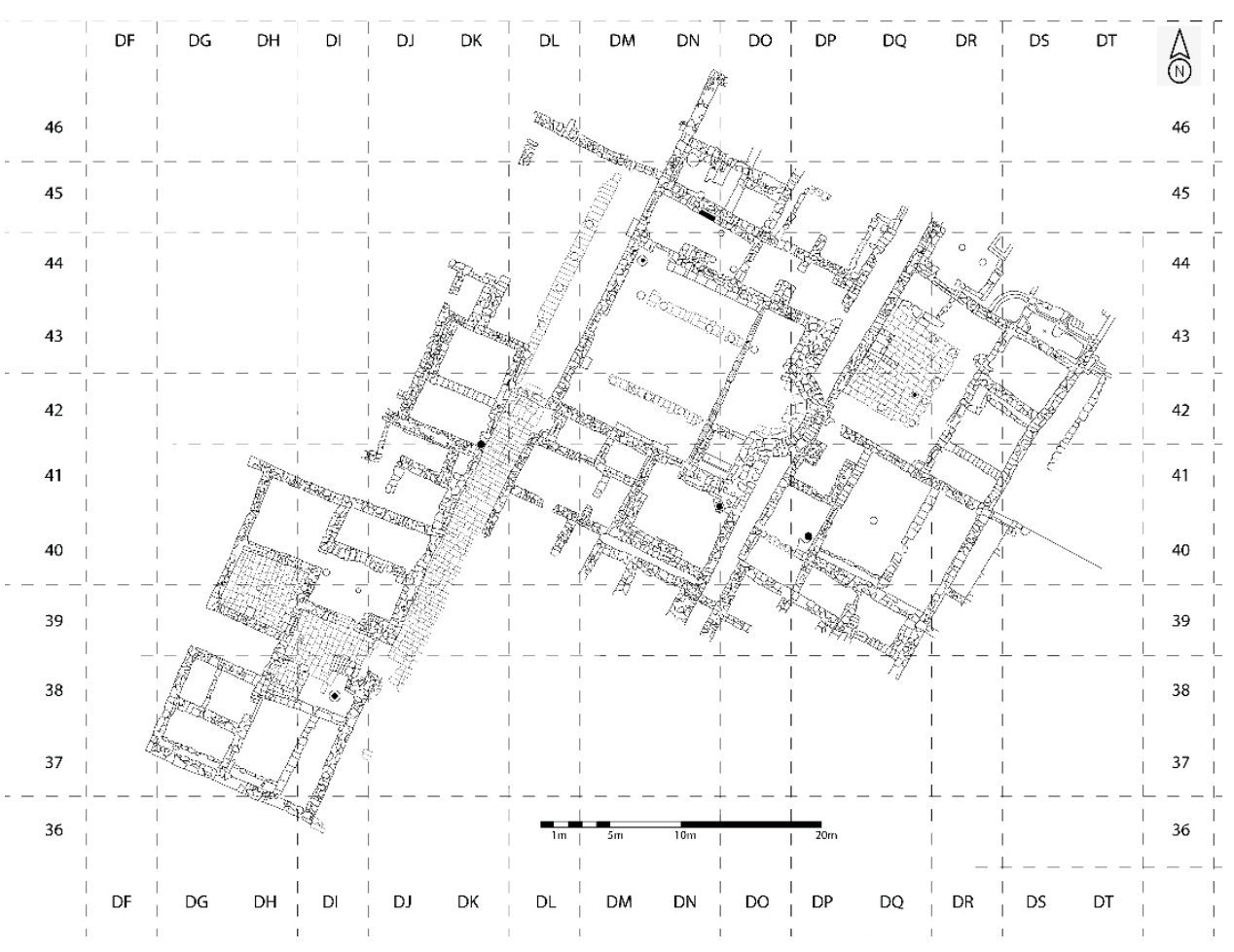

Figure 238 Grid with labels for squares

Altogether, thirty vessels are conclusively represented by more than one fragment each. Among these, fourteen vessels include three or more pieces. It should be noted, however, that this analysis almost certainly underestimates the true extent of commonality among the thousands of fragments collected. The problem, of course, is the difficulty of proving that fragments come from the same vessel, not only among indeterminate fragments but even between diagnostic fragments that were found in the same locus. For example, a cuprim and a suitably sized base that seem to have been made from the same fabric and were found in the same place could have originally come from the same vessel, even in the absence of any firm evidence that this was the case. The same is true of fragments of the same morphological type (for example, goblet rims with cylindrical sides) that were found together and have similar fabrics and profiles but once again lack definite signs of physical contiguity. In addition, in places where multiple sets of rims and bases were found together, it seems highly unlikely that every such fragment represents a different vessel. However, the absence of demonstrable contiguity makes it risky to claim that any two (or more) fragments did indeed come from the same vessel. For this reason, the following discussion claims common origin only for fragments that can be unambiguously physically fitted together or-in a few cases-exhibit sufficiently distinctive decorative and/or morphological features to make their relationship obvious. 
In the initial phase of this study, 1680 fragments were identified by their morphology as belonging to six broad types of vessels. Because specialists have, over time, created divergent sets of categories for studying glass corpora such as this, the present study follows the approach used in Rachel Pollak's work on the similarly fragmentary corpus at Tel Tanninim, which is in turn based on several other studies, especially Odile Dussart's typology of Byzantine-Umayyad glass from Jordan and southern Syria. ${ }^{305}$ The six categories are:

\begin{tabular}{|l|l|l|l|}
\hline Category & Name & Number of fragments & \% of total corpus \\
\hline 1 & Bowls, dishes, plates & 187 & $11.1 \%$ \\
\hline 2 & Oil lamps & 197 & $11.7 \%$ \\
\hline 3 & Goblets, cups & 447 & $26.6 \%$ \\
\hline 4 & Storage vessels & 473 & $28.2 \%$ \\
\hline 5 & Miscellaneous & 77 & $4.6 \%$ \\
\hline 6 & Windowpanes & 299 & $17.8 \%$ \\
\hline Total & & 1680 & $100.0 \%$ \\
\hline
\end{tabular}

The last of these categories, windowpanes, not only includes many fragments but is also the least-considered category in many studies. For this reason, windowpane fragments from NIP receive only passing comment below and are treated more fully elsewhere..$^{306}$

The five remaining categories fall into two main groups according to their method of manufacture. Among these 1680 fragments, only nine were cast. This is a much smaller proportion $(0.54 \%)$ than that reported by Dussart (3\%) in her similar-sized study of 1868 Roman, Byzantine, and Islamic vessels from Jordan. ${ }^{307}$ Because of their rarity, these fragments will be presented first, as a group. Eleven fragments of the remaining corpus were mould-blown $(0.65 \%)$. All the other fragments - that is, 1660 of the 1680 identifiable pieces from this site-were free-blown. Decoration, while infrequent overall (156 of 1680 pieces, 9.3\%), consists of the following: cuttings (7 fragments); moulded decoration (52 pieces); thread-decoration (97 fragments).

Most of these fragments came from everyday glass items that are routinely found in households. None are unique to churches. On the other hand, the design and size of the lamps, as well as their number, might be said to be characteristic of church use. The same is true

\footnotetext{
305 Dussart, Le verre en Jordanie et en Syrie du Sud.

${ }^{306}$ Chambers, "Window Glass Finds in the Northeast Church '."

${ }^{307}$ Dussart, Le verre en Jordanie et en Syrie du Sud, 49.
} 
of the windowpanes, which seem to be rarely found in domestic contexts before the ninth century. ${ }^{308}$

The discussion below focuses on 269 representative fragments from these five categories, or $16.0 \%$ of the NIP's total of 1680 identifiable pieces. The criteria for selection varied from category to category. Some of the rarer types of storage vessels, such as pots and balsamaires, are treated in their entirety. Vessel types that are much more common, such as goblets and cups, are represented by the best-preserved and most interesting examples.

Within the five main categories, there are twenty-six different groups, mostly based on morphological distinctions that have been drawn from Pollak's and Dussart's typologies. Each group is treated in turn, with general comments followed by a chart containing detailed information about each example within that group, including its find-spot and possible dating. More detailed information can be obtained from the studies mentioned in these charts. In general, Dussart is invaluable for its completeness and Pollak for its synthesizing, summarizing approach. Please note that drawings of each fragment are presented in a separate illustration.

Of the 933 fragments whose colour can be firmly determined, most (618 pieces, or $66.2 \%$ of the total) are of clear, bluish-green glass (von Saldern's fabric 1$)$. Some $(265 ; 28.2 \%)$ are pale green (fabric 2). A small number $(18 ; 1.9 \%)$ are almost clear, with a very slight green or yellow tint (fabric 5). The number of fragments of other colours is tiny: darker green (fabric $3)$ : eleven pieces ( $1.2 \%$ ); bottle-green (fabric 4$)$ : one piece ( $0.1 \%)$; light blue (fabric 6): two pieces $(0.2 \%)$; brown (fabric 7$)$ : two pieces $(0.2 \%)$; other (fabric 8$)$ : eleven pieces $(1.2 \%)$.

These sources are referenced by page number in the charts:

Baur, P. V. C. "Other Glass Vessels.” Pages 513-46 in C. H. Kraeling, Gerasa: City of the Decapolis. New Haven, Conn.: American Schools of Oriental Research, 1938.

Cohen, Einat. "Roman, Byzantine and Umayyad Glass.” Pages 396-431 in The Roman Baths at Hammat Gader: Final Report. Edited by Yizhar Hirschfeld. Jerusalem: The Israel Exploration Society, 1997.

Crowfoot, Grace M., and D. B. Harden. “Early Byzantine and Later Glass Lamps.” The Journal of Egyptian Archaeology 17 (1931):196-208.

Crowfoot, G. M. “Glass.” Pages 403-22 in The Objects from Samaria. Edited by J. W. Crowfoot, G. M. Crowfoot, and Kathleen M. Kenyon. London: Palestine Exploration Fund, 1957.

${ }^{308}$ Saldern, Ancient and Byzantine Glass from Sardis, 91-93. 
Delougaz, Pinhas, and Richard C. Haines. A Byzantine Church at Khirbat Al-Karak. Chicago: University of Chicago Press, 1960.

Dussart, Odile. Le Verre En Jordanie Et En Syrie Du Sud. Beyrouth [Beirut]: Institut Français d'Archéologie Du Proche-Orient, 1998.

Gorin-Rosen, Yael. "Glass Vessels from Area A." Jewish Quarter Excavations in the Old City of Jerusalem. Volume II: The Finds from Areas $A, W$, and $X$-2. Jerusalem: Israel Exploration Society, 2003.

Hayes, John W. Roman and Pre-Roman Glass in The Royal Ontario Museum: A Catalogue. Toronto: Royal Ontario Museum, 1975.

Isings, Clasina. Roman Glass from Dated Finds. Groningen: J. B. Wolters, 1957.

Jackson-Tal, Ruth E. "The Late Hellenistic Glass Industry in Syro-Palestine: A Reappraisal.” Journal of Glass Studies 46 (2004):11-32.

Lester, Ayala. "Islamic Glass Finds.” Pages 432-41 in The Roman Baths at Hammat Gader: Final Report. Edited by Yizhar Hirschfeld. Jerusalem: Israel Exploration Society, 1997.

. “The Glass.” Pages 167-220 in Excavations at Tiberias, 1973-1974: The Early Islamic Periods. Edited by David Stacey. Jerusalem: Israel Antiquities Authority, 2004.

Meyer, Carol. "Glass From the North Theater Byzantine Church, and Soundings at Jerash, Jordan, 1982-1983. Pages 175-222 in Preliminary Reports of ASOR-Sponsored Excavations, 1982-1985. Edited by W. E. Rast. BASOR Supplement 25. Baltimore: Johns Hopkins University, 1988.

Pollak, Rachel. “The Glass.” Pages 155-92 in Tel Tanninim: Excavations at Krokodeilon Polis 1996-1999. Edited by Robert R. Stieglitz. Boston, Mass.: American Schools of Oriental Research, 2006.

Saldern, Axel von. Ancient Glass in the Museum of Fine Arts, Boston. Boston: Museum of Fine Arts, 1968.

. Ancient and Byzantine Glass from Sardis. Cambridge, Mass.: Harvard University Press, 1980.

Saller, Sylvester J. The Memorial of Moses on Mount Nebo. Jerusalem: Franciscan Press, 1941.

Weinberg, Gladys Davidson. “Hellenistic Glass From Tel Anafa in Upper Galilee.” Journal of Glass Studies 12 (1970):17-27.

. “Notes on Glass From Upper Galilee.” Journal of Glass Studies 15 (1973):35-51. 
. Excavations at Jalame: Site of a Glass Factory in Late Roman Palestine. Columbia, Mo.: University of Missouri Press, 1988.

\section{Cast Vessels}

\section{Linear-cut bowls}

Nos. 1-8 represent two varieties of monochrome cast-or, more accurately, mouldpressed-bowls that are known since Hellenistic times. Although some evidence suggests that such bowls continued to be produced into the Umayyad era, most examples from SyroPalestine date from the second and first centuries BCE. They probably served as drinking vessels. ${ }^{309}$

Although its diameter is relatively small, No. 2 is a good example of Dussart's Type AII.3, "flared hemispherical," having short sides compared to its width. By contrast, the other pieces in this group are quite deep (Dussart's Type AII.4), with walls of varying slope. Both varieties are well-known and are strongly associated with the Hellenistic and Roman eras, in other words second century BCE through second century CE. With one exception, the decoration on all these pieces is typical of the type, namely single grooves, or sets of two or three grooves, parallel to the rim and a short distance below it. ${ }^{310}$ The exception is No. 1, which differs in having four such grooves on the interior plus one additional groove on the exterior. This exuberance, while not unique, ${ }^{311}$ is unusual, and required a high degree of skill to accomplish. ${ }^{312}$

(Note also that No. 225 below is likely also a fragment from a different type of cast bowl, a discovery that was not made until very late in the preparation of this report.)

Group 1: Cast Vessels (8 pieces: see drawings in Illustration 1)

\begin{tabular}{|c|c|c|c|c|}
\hline No. & Loc. & Basket & Description & Parallels \\
\hline 1 & 1223 & 2271.1 & $\begin{array}{l}\text { Bowl with plain rim and deep, slightly in- } \\
\text { sloping wall (Dussart Type AII.4). Rim di- } \\
\text { ameter } 200 \mathrm{~mm} \text {; } 3 \% \text { of rim circumference } \\
\text { extant. Wall thickness } 6 \mathrm{~mm} \text {; preserved } \\
\text { height } 32 \mathrm{~mm} \text {. Four horizontal incised } \\
\text { grooves on inner surface, } 5,8,15 \text {, and } 26\end{array}$ & $\begin{array}{l}\text { Isings } 44 \text { (form 29), first century; } \\
\text { Weinberg 1970:18, second-first } \\
\text { century BCE; von Saldern } \\
\text { 1980:7-8, 13, first century BCE- } \\
\text { early second century; Meyer 185, } \\
\text { Hellenistic; Dussart } 53 \text { (Type }\end{array}$ \\
\hline
\end{tabular}

\footnotetext{
${ }^{309}$ Ruth E Jackson-Tal, “The Late Hellenistic Glass Industry in Syro-Palestine: A Reappraisal,” Journal of Glass Studies 46 (2004): 17, 27.

${ }^{310}$ Saldern, Ancient and Byzantine Glass from Sardis, 7.

${ }^{311}$ Jackson-Tal, "The Late Hellenistic Glass Industry in Syro-Palestine: A Reappraisal," 19.

${ }^{312}$ Gladys Davidson Weinberg, "Hellenistic Glass from Tel Anafa in Upper Galilee," Journal of Glass Studies 12 (1970): 23.
} 


\begin{tabular}{|c|c|c|c|c|}
\hline & & & $\begin{array}{l}\mathrm{mm} \text { from top. One horizontal incised } \\
\text { groove on outer surface, } 6 \mathrm{~mm} \text { from top. } \\
\text { Evidence of wheel polishing on inner \& } \\
\text { outer walls. Very pale green fabric (von } \\
\text { Saldern \#2). }\end{array}$ & $\begin{array}{l}\text { AII.4), first century BCE-eighth } \\
\text { century; Jackson-Tal 27, third } \\
\text { century BCE-first century CE; } \\
\text { Pollak } 159 \text {, second century BCE } \\
\text { onward. }\end{array}$ \\
\hline 2 & 1237 & 2014.5 & $\begin{array}{l}\text { Bowl with plain rim and shallow, in-slop- } \\
\text { ing wall (Dussart Type AII.3). Rim diame- } \\
\text { ter } 120 \mathrm{~mm} \text {; } 5 \% \text { of rim circumference ex- } \\
\text { tant. Wall thickness } 7 \mathrm{~mm} \text {; preserved } \\
\text { height } 26 \mathrm{~mm} \text {. Two horizontal incised } \\
\text { grooves on inner surface, } 11 \text { and } 15 \mathrm{~mm} \\
\text { from top. Evidence of wheel polishing on } \\
\text { outer wall. Bright green fabric (von } \\
\text { Saldern \#4). }\end{array}$ & $\begin{array}{l}\text { Isings } 36 \text { (form 18), first century; } \\
\text { Weinberg 1970:18, second-first } \\
\text { century BCE; von Saldern } \\
\text { 1980:7-8, 13, first century BCE- } \\
\text { early second century; Meyer 185, } \\
\text { Hellenistic; Dussart 52-53 (Type } \\
\text { AII.3), first century BCE-eighth } \\
\text { century; Jackson-Tal 27, third } \\
\text { century BCE-first century CE; } \\
\text { Pollak 159, second century BCE } \\
\text { onward. }\end{array}$ \\
\hline 3 & 2115 & 3146.1 & $\begin{array}{l}\text { Bowl with plain rim, flaring in-sloping } \\
\text { wall (Dussart Type AII.4). Rim diameter } \\
180 \mathrm{~mm} \text {; } 2 \% \text { of rim circumference extant. } \\
\text { Wall thickness } 3 \mathrm{~mm} \text {; preserved height } 15 \\
\text { mm. One horizontal incised groove on in- } \\
\text { ner surface, } 7 \mathrm{~mm} \text { from top. Light aqua } \\
\text { fabric (von Saldern \#1). }\end{array}$ & See No. 1. \\
\hline 4 & 505 & 1900.1 & $\begin{array}{l}\text { Bowl with plain rim, deep in-sloping wall } \\
\text { (Dussart Type AII.4). Rim diameter } 160 \\
\mathrm{~mm} \text {; } 11 \% \text { of rim circumference extant. } \\
\text { Wall thickness } 3.5-5.5 \mathrm{~mm} \text {; preserved } \\
\text { height } 40 \mathrm{~mm} \text {. Two horizontal incised } \\
\text { grooves on inner surface, } 6 \text { and } 10 \mathrm{~mm} \\
\text { from top. Evidence of wheel-polishing on } \\
\text { inner wall. Olive green fabric (von Saldern } \\
\# 3 \text { ). }\end{array}$ & See No. 1. \\
\hline 5 & 2127 & 3181.1 & $\begin{array}{l}\text { Bowl with plain rim, deep in-sloping wall } \\
\text { (Dussart Type AII.4). Rim diameter } 160 \\
\text { mm; } 12 \% \text { of rim circumference extant. } \\
\text { Wall thickness } 6.6 \mathrm{~mm} \text {; preserved height } \\
28 \mathrm{~mm} \text {. Three horizontal incised grooves } \\
\text { on inner surface, } 10,16 \text {, and } 22 \mathrm{~mm} \text { from } \\
\text { top. Heavily corroded. Pale green fabric } \\
\text { (von Saldern \#2). }\end{array}$ & See No. 1. \\
\hline 6 & 1906 & 2347.1 & $\begin{array}{l}\text { Bowl with plain rim and deep, slightly in- } \\
\text { sloping wall (Dussart Type AII.4). Rim di- } \\
\text { ameter } 150 \mathrm{~mm} \text {; } 7 \% \text { of rim circumference } \\
\text { extant. Wall thickness } 6 \mathrm{~mm} \text {; preserved } \\
\text { height } 24 \mathrm{~mm} \text {. Three horizontal incised }\end{array}$ & See No. 1. \\
\hline
\end{tabular}




\begin{tabular}{|l|l|l|l|l|}
\hline & & & $\begin{array}{l}\text { grooves on inner surface, 11, 14, and 17 } \\
\text { mm from top. Heavily corroded. Pale } \\
\text { green fabric (von Saldern \#2). }\end{array}$ & \\
\hline 7 & 548 & 2167.1 & $\begin{array}{l}\text { Bowl with plain rim and deep, slightly in- } \\
\text { sloping wall (Dussart Type AII.4). Rim di- } \\
\text { ameter 120 mm; 6\% of rim circumference } \\
\text { extant. Wall thickness 4 mm; preserved } \\
\text { height 30 mm. Two horizontal incised } \\
\text { grooves on inner surface, 7 and 9.5 mm } \\
\text { from top. Pale green fabric (von Saldern } \\
\text { \#2). }\end{array}$ & See No. \\
\hline 8 & 1237 & 3142.1 & $\begin{array}{l}\text { Bowl with plain rim and deep, slightly in- } \\
\text { sloping wall (Dussart Type AII.4). Rim di- } \\
\text { ameter 100 mm; 11\% of rim circumference } \\
\text { extant. Wall thickness 5 mm; preserved } \\
\text { height 16 mm. One horizontal incised } \\
\text { groove on inner surface, 8 mm from top. } \\
\text { Heavily corroded. Bright green fabric (von } \\
\text { Saldern \#4). }\end{array}$ & See No. 1. \\
\hline
\end{tabular}

\section{Blown Vessels}

\section{Bowls, dishes, and plates}

In some ways, the distinctions between these three vessel types are fluid. Broadly speaking, the ratio of height to depth is the key variable separating bowls, on the one hand, from dishes and plates, on the other. Vessels that are relatively deep for their width are usually classified as bowls. Those that are shallower tend to be called dishes (if they stand on a smaller, central footed base) or plates (if they lack such a base and stand, instead, on their own).

The assembly of vessels that represent all these types on this site is relatively small. For this reason, this study discusses them in groups that are based on clusters of key features.

Bowls are the most numerous of these three vessel types, and fall into two main groups: large-diameter specimens that have out-folded rims, and medium-diameter examples with rounded rims. Especially within the latter cluster, several sub-groups are also distinguished. By contrast, most of the dishes are of the same style, namely those with long-folded walls. Only a few other styles are represented. Plates are very rare, numbering only a single example. In addition to these well-defined pieces, a small group of base rings is also described. It is impossible to know whether these came from bowls or plates. 


\section{Bowls}

Many of the bowls found on this site feature a distinctive out-and-down fold that creates a tubular rim. There is a strong correlation between these vessels' large diameter-usually $200 \mathrm{~mm}$ or more-and this type of construction, which makes sense due to the structural advantages inherent in this double-thick, tubular rim. Only a few of the bowls in this group are smaller than $200 \mathrm{~mm}$ in diameter. Rims of similar construction but folded inward rather than outward are relatively rare, both here (Nos. 17, 18, and 19) and elsewhere. ${ }^{313}$ As noted in the following chart, the first five examples in this group are light aqua in colour; the other four are pale green.

Similar out-folded rims are common on cups/goblets and windowpanes. The two features that set bowl rims apart are their diameter, which is significantly larger than that of a cup/goblet, and their profile, which results in a deeper vessel body than that of a windowpane, which is always much flatter.

Most of these out-folded rims flare outward beyond the wall of the bowl (Dussart's BI.1211). Example no. 16 extends this basic form into a beautiful compound structure with a double fold that creates a curving "bead" feature that, even more interestingly, terminates in a protruding serrated flange (Dussart's BI.1312). It should be noted that this distinctive piece is one of three vessels in this assembly (the others are Nos. 33 and 201) that are represented by two fragments that were found at a considerable distance from each other, one piece in square D4 and the other in ZZ4. No. 15 exhibits a "re-entrant" lip that turns sharply inward at the end of that outward flare (Dussart's BI.413), while No. 9 is basically cylindrical, following the same upward slope as the wall (Dussart's BI.1121). There are also two examples of incomplete folds, namely rims in which the fold extends outward but lacks the usual downward and inward extension that typically creates a hollow tube (Nos. 13, 14).

The second group of bowls has rounded-off rims. Just as folded rims are usually correlated with diameters of more than $200 \mathrm{~mm}$, rounded rims are usually found on vessels between 110 and $160 \mathrm{~mm}$ in diameter. Only one bowl in this group has a diameter larger than 160 $\mathrm{mm}$. While roughly cracked-off rims on vessels of various shapes are discussed separately below in the discussion of oil lamps, it should be noted that No. 23 is identical to many such lamps in most respects apart from the fact that its rim was not left in a crude, unfinished state, but flame polished. This seems to be a unique combination, namely rim polishing on a type of vessel that typically features cracked-rims (see the discussion and numerous examples in Dussart, regarding her type BI.221). ${ }^{314}$

Perhaps because bowls with rounded rims are smaller in diameter, they are proportionately deeper than those with folded rims. In the group presented below, only two of nine examples (Nos. 20, 23) are categorized by Dussart as "shallow" (her BI.221 and BI.23); the others

\footnotetext{
${ }^{313}$ Weinberg and Goldstein, "The Glass Vessels," 41.

${ }^{314}$ Dussart, Le verre en Jordanie et en Syrie du Sud, 61-62.
} 
are "deep." Even so, these deep bowls present three distinct profiles. Nos. 25 and 26 have walls that are basically vertical, terminating in this rounded lip (Dussart's BI.4211); Nos. 27 and 28 have walls and lips that flare outward (Dussart's BI.4221); No. 29 has dramatically “spread" lips (Dussart's BI.4231).

Group 2: Bowls with folded rims (11 pieces: see drawings in Illustration 2)

\begin{tabular}{|c|c|c|c|c|}
\hline No. & Loc. & Basket & Description & Parallels \\
\hline 9 & 1907 & 2451.1 & $\begin{array}{l}\text { Out-folded vertical rim of large bowl, with } \\
11 \mathrm{~mm} \text { of straight, cylindrical wall extant } \\
\text { below the rim. Rim fold } 11 \mathrm{~mm} \text { high x } 5 \\
\text { mm wide. Rim diameter } 260 \mathrm{~mm} ; 8 \% \text { of } \\
\text { rim circumference extant. Light aqua fab- } \\
\text { ric (von Saldern \#1). }\end{array}$ & $\begin{array}{l}\text { Dussart } 64 \text { (Type BI.1121a), } \\
\text { fourth-fifth century; Meyer 189, } \\
\text { early Byzantine; Weinberg } \\
\text { 1988:64, early fifth century. }\end{array}$ \\
\hline 10 & 2166 & 3475.1 & $\begin{array}{l}\text { Out-folded vertical rim of large bowl, with } \\
12 \mathrm{~mm} \text { of straight, cylindrical wall extant } \\
\text { below the rim. Rim fold } 11 \mathrm{~mm} \text { high x } 2.5 \\
\text { mm wide, fused to wall (no hollow). Rim } \\
\text { diameter } 260 \mathrm{~mm} ; 8 \% \text { of rim circumfer- } \\
\text { ence extant. Light aqua fabric (von Saldern } \\
\text { \#1). }\end{array}$ & $\begin{array}{l}\text { Dussart } 64 \text { (Type BI.1121a), } \\
\text { fourth-fifth century; Meyer 189, } \\
\text { early Byzantine; Weinberg } \\
\text { 1988:64, early fifth century. }\end{array}$ \\
\hline 11 & 536 & 1910.5 & $\begin{array}{l}\text { Out-folded slightly sloping rim of large } \\
\text { bowl, with } 14 \mathrm{~mm} \text { of straight, slightly in- } \\
\text { sloping wall extant below the rim. Rim- } \\
\text { fold } 10.5 \mathrm{~mm} \text { high x } 5 \mathrm{~mm} \text { wide. Rim diam- } \\
\text { eter } 160 \mathrm{~mm} \text {; } 28 \% \text { of rim circumference } \\
\text { extant. Light aqua fabric (von Saldern \#1). }\end{array}$ & $\begin{array}{l}\text { Dussart } 64 \text { (Type BI.4122), late } \\
\text { fourth to early eighth century. }\end{array}$ \\
\hline 12 & 1931 & $\begin{array}{l}2443.1 \\
2443.2 \\
2446.3\end{array}$ & $\begin{array}{l}\text { Out-folded flaring rim of large bowl, with } \\
15 \mathrm{~mm} \text { of straight, slightly in-sloping wall } \\
\text { extant below the rim. Rim fold } 9 \mathrm{~mm} \text { high } \\
\text { x } 4.5 \mathrm{~mm} \text { wide. Rim diameter } 260 \mathrm{~mm} \text {; } 25 \% \\
\text { of rim circumference extant in three frag- } \\
\text { ments (non-contiguous). Light aqua fabric } \\
\text { (von Saldern \#1). }\end{array}$ & $\begin{array}{l}\text { Dussart } 57 \text { (Type BI.1211), late } \\
\text { fourth to early sixth century; } \\
\text { Hayes 119, fourth century; Meyer } \\
\text { 216, late Byzantine-Umayyad; } \\
\text { Weinberg 1988:43, late fourth } \\
\text { century. }\end{array}$ \\
\hline 13 & 1226 & 2337.2 & $\begin{array}{l}\text { Out-turned flaring rim of large bowl, with } \\
23 \mathrm{~mm} \text { of sloping, in-turning wall extant } \\
\text { below the rim. Rim-fold quite dramatic but } \\
\text { only partial, not complete, } 4 \mathrm{~mm} \text { high x } 6 \\
\text { mm wide. Rim diameter } 300 \mathrm{~mm} ; 10 \% \text { of } \\
\text { rim circumference extant. Light aqua fab- } \\
\text { ric (von Saldern } \# 1 \text { ). }\end{array}$ & See No. 12. \\
\hline
\end{tabular}




\begin{tabular}{|c|c|c|c|c|}
\hline 14 & 1226 & 2351.3 & $\begin{array}{l}\text { Out-turned flaring rim of large bowl, with } \\
25 \mathrm{~mm} \text { of sloping, in-turning wall extant } \\
\text { below the rim. Rim fold only partial, not } \\
\text { complete, } 5 \mathrm{~mm} \text { high x } 4 \mathrm{~mm} \text { wide. Rim di- } \\
\text { ameter } 260 \mathrm{~mm} \text {; } 6 \% \text { of rim circumference } \\
\text { extant. Light aqua fabric (von Saldern \#1). }\end{array}$ & See No. 12. \\
\hline 15 & 567 & 2022.1 & $\begin{array}{l}\text { Out-folded, sharply flaring then unusually } \\
\text { in-turning rim of large bowl, with } 14 \mathrm{~mm} \\
\text { of sloping, in-turning wall extant below } \\
\text { the rim. Rim fold } 7 \mathrm{~mm} \text { high x } 5 \mathrm{~mm} \text { wide, } \\
\text { with a small round hollow in the fold. Rim } \\
\text { diameter } 220 \mathrm{~mm} \text {; } 4 \% \text { of rim circumfer- } \\
\text { ence extant. Light aqua fabric (von Saldern } \\
\text { \#1). }\end{array}$ & $\begin{array}{l}\text { See No. 12, but regarding the in- } \\
\text { turned rim compare Dussart } 65 \\
\text { (BI.413), fourth-eighth century; } \\
\text { Weinberg 1988:43, late fourth } \\
\text { century. }\end{array}$ \\
\hline $\begin{array}{l}16 \mathrm{~A} \\
16 \mathrm{~B}\end{array}$ & $\begin{array}{l}1265 \\
1289\end{array}$ & $\begin{array}{l}5497.1 \\
2293.1\end{array}$ & $\begin{array}{l}\text { Out-folded, doubly folded rim of medium- } \\
\text { sized bowl, with } 10 \mathrm{~mm} \text { of sharply down- } \\
\text { sloping wall extant below the rim. Rim fold } \\
\text { varies; } 11 \mathrm{~mm} \text { high x } 11 \mathrm{~mm} \text { wide ( } 5497.1 \text { ) } \\
\text { vs. } 7 \mathrm{~mm} \text { high x } 7 \mathrm{~mm} \text { wide (2293.1), with a } \\
\text { horizontal separation between upper and } \\
\text { lower halves, projecting outward beyond } \\
\text { the rim to create a serrated flange with its } \\
\text { points ca. } 35 \mathrm{~mm} \text { apart, } 12 \mathrm{~mm} \text { beyond the } \\
\text { fold. Rim-fold diameter } 110 \mathrm{~mm} \text {; } 42 \% \text { of } \\
\text { circumference extant (in two fragments } \\
\text { found in widely separated areas-see dis- } \\
\text { cussion above in text). Pale green fabric } \\
\text { (von Saldern \#2). }\end{array}$ & $\begin{array}{l}\text { Weinberg 1988:53-54, late fourth } \\
\text { century; Dussart } 59 \text { (Type } \\
\text { BI.1312), late first century-fourth } \\
\text { century. }\end{array}$ \\
\hline 17 & 1215 & 2156.1 & $\begin{array}{l}\text { In-folded flaring rim of large bowl, with } 3 \\
\text { mm of sloping wall extant below the rim. } \\
\text { Rim fold } 13 \mathrm{~mm} \text { high x } 9.5 \mathrm{~mm} \text { wide, with a } \\
\text { large tubular hollow in the fold. Rim diam- } \\
\text { eter } 180 \mathrm{~mm} \text {; } 11 \% \text { of rim circumference } \\
\text { extant. Pale green fabric (von Saldern } \# 2 \text { ). }\end{array}$ & $\begin{array}{l}\text { Dussart } 67 \text { (BI.4213.b1), fourth- } \\
\text { sixth century, with a smaller par- } \\
\text { allel from Jerash (Meyer 198, late } \\
\text { Byzantine). }\end{array}$ \\
\hline 18 & 1940 & 2459.5 & $\begin{array}{l}\text { In-folded flaring rim of large bowl, with } 23 \\
\text { mm of sloping, in-turning wall extant be- } \\
\text { low the rim. Rim fold } 3 \mathrm{~mm} \text { high } \times 3 \mathrm{~mm} \\
\text { wide, with a small hollow in the fold. Rim } \\
\text { diameter } 195 \mathrm{~mm} \text {; } 4 \% \text { of rim circumfer- } \\
\text { ence extant. Pale green fabric (von Saldern } \\
\text { \#2). }\end{array}$ & See No. 17. \\
\hline 19 & 2147 & $\begin{array}{l}3447.2 \\
3450.1\end{array}$ & $\begin{array}{l}\text { In-folded rim of small bowl; none of wall } \\
\text { extant. Rim-fold } 10.5 \mathrm{~mm} \text { high x } 6.5 \mathrm{~mm} \\
\text { wide, with a large hollow in the fold. Rim }\end{array}$ & $\begin{array}{l}\text { Dussart } 70 \text { (BI.5132), third cen- } \\
\text { tury - Umayyad. }\end{array}$ \\
\hline
\end{tabular}




\begin{tabular}{|l|l|l|l|}
\hline & $\begin{array}{l}\text { diameter } 75 \mathrm{~mm} ; 100 \% \text { of rim circumfer- } \\
\text { ence extant in two pieces, broken in antiq- } \\
\text { uity. Pale green fabric (von Saldern \#2). }\end{array}$ & \\
\hline
\end{tabular}

Group 3: Bowls with rounded rims (10 pieces: see drawings in Illustration 3)

\begin{tabular}{|c|c|c|c|c|}
\hline No. & Loc. & Basket & Description & Parallels \\
\hline 20 & 2125 & $\begin{array}{l}3168.3 \\
3168.4\end{array}$ & $\begin{array}{l}\text { Out-turned, slightly thickened, rounded } \\
\text { rim, with } 49 \mathrm{~mm} \text { of in-curving wall extant } \\
\text { below the rim. Hemispherical profile to } \\
\text { body. Rim-thickening } 5 \mathrm{~mm} \text { high x } 3 \mathrm{~mm} \\
\text { wide. Rim diameter } 120 \mathrm{~mm} \text {; } 39 \% \text { of rim } \\
\text { circumference extant in two fragments } \\
\text { (non-contiguous). Light aqua fabric (von } \\
\text { Saldern's \#1). }\end{array}$ & $\begin{array}{l}\text { Dussart } 62 \text { (BI.23), mostly late } \\
\text { first-second century; one exam- } \\
\text { ple sixth century. }\end{array}$ \\
\hline 21 & 2135 & $\begin{array}{l}3444.6 \\
3444.7\end{array}$ & $\begin{array}{l}\text { Out-flaring, slightly thickened rim with } 34 \\
\text { mm of curving wall extant below the rim. } \\
\text { Body of vessel has hemispherical profile. } \\
\text { Rim-thickening } 2.3 \mathrm{~mm} \text {. Rim diameter } 140 \\
\mathrm{~mm} \text {; } 18 \% \text { extant in two fragments non- } \\
\text { contiguous). Decorated with a row of } \\
\text { wheel-cut "dots," } 18 \mathrm{~mm} \text { below the rim } \\
\text { and ca. } 8 \mathrm{~mm} \text { apart, plus two wheel-cut } \\
\text { parallel lines, } 20 \text { and } 22 \mathrm{~mm} \text { below the rim, } \\
\text { plus further geometric pattern below these } \\
\text { lines. Light aqua fabric (von Saldern } \# 1 \text { ). }\end{array}$ & $\begin{array}{l}\text { Dussart } 62 \text { (BI.23: fourth-early } \\
\text { sixth century. }\end{array}$ \\
\hline 22 & 2125 & $\begin{array}{l}3168.1 \\
3168.2\end{array}$ & $\begin{array}{l}\text { Slightly in-turned, cracked-off rim with } 52 \\
\text { mm of curving wall extant below the rim. } \\
\text { Body of vessel has hemispherical profile. } \\
\text { Rim flares out, then in, to create everted } \\
\text { ("reverse convex") profile. Rim diameter } \\
180 \mathrm{~mm} \text {; } 34 \% \text { of circumference extant in } 2 \\
\text { pieces (non-contiguous). Light aqua fabric } \\
\text { (von Saldern \#1). }\end{array}$ & $\begin{array}{l}\text { Dussart } 61 \text { (BI.221), mostly late } \\
\text { fourth-early sixth century, but } \\
\text { continuing into Umayyad era; } \\
\text { Meyer 189, 197, Byzantine- } \\
\text { Umayyad. }\end{array}$ \\
\hline 23 & 2136 & $\begin{array}{r}3408.1 \\
3408.2 \\
3408.3\end{array}$ & $\begin{array}{l}\text { Out-flaring, slightly thickened rim with } 63 \\
\text { mm of curving wall extant below the rim. } \\
\text { Body of vessel has hemispherical profile. } \\
\text { Rim flares out, then back in, to create } \\
\text { everted ("reverse convex") profile. Rim di- } \\
\text { ameter } 160 \mathrm{~mm} \text {; } 41 \% \text { of rim circumference } \\
\text { extant in three fragments (non-contigu- } \\
\text { ous). Pale green fabric (von Saldern \#2). }\end{array}$ & $\begin{array}{l}\text { Dussart } 61 \text { (BI.221), mostly late } \\
\text { fourth-early sixth century, but } \\
\text { continuing into Umayyad era; } \\
\text { Meyer 189, 197, Byzantine- } \\
\text { Umayyad. }\end{array}$ \\
\hline
\end{tabular}




\begin{tabular}{|c|c|c|c|c|}
\hline 24 & 2135 & $\begin{array}{l}3444.5 \\
3444.12 \\
3444.13\end{array}$ & $\begin{array}{l}\text { Out-turned, slightly thickened, rounded } \\
\text { rim, with } 40 \mathrm{~mm} \text { of in-curving wall extant } \\
\text { below the rim. Hemispherical, flared pro- } \\
\text { file to body. Rim-thickening } 2 \mathrm{~mm} \text { wide. } \\
\text { Rim diameter } 120 \mathrm{~mm} \text {; } 65 \% \text { of rim circum- } \\
\text { ference extant in } 3 \text { pieces (non-contigu- } \\
\text { ous). Pale green fabric (von Saldern \#2). }\end{array}$ & $\begin{array}{l}\text { Dussart } 61 \text { (BI.221), mostly late } \\
\text { fourth-early sixth century, but } \\
\text { continuing into Umayyad era; } \\
\text { Meyer 189, 197, Byzantine- } \\
\text { Umayyad. }\end{array}$ \\
\hline 25 & 1238 & 3131.7 & $\begin{array}{l}\text { Vertical, very slightly thickened, rounded } \\
\text { rim, with } 14 \text { mm of slightly tapering wall } \\
\text { extant below the rim. Body of vessel has } \\
\text { tapered profile (Dussart BI. } 4 \text { = "tron- } \\
\text { conique"). Rim-thickening } 6 \mathrm{~mm} \text { high x } 2 \\
\text { mm wide. Rim diameter } 200 \mathrm{~mm} \text {; } 3 \% \text { of } \\
\text { rim circumference extant. Almost colour- } \\
\text { less fabric (von Saldern \#5). }\end{array}$ & $\begin{array}{l}\text { Dussart } 65 \text { (BI.4211), mostly } \\
\text { third-fourth century, but known } \\
\text { from first century through Umay- } \\
\text { yad period; Crowfoot } 410 \text {, third } \\
\text { century. }\end{array}$ \\
\hline 26 & 1929 & 2432.2 & $\begin{array}{l}\text { Vertical, very slightly thickened, rounded } \\
\text { rim, with } 19 \mathrm{~mm} \text { of slightly tapering wall } \\
\text { extant below the rim. Body of vessel has } \\
\text { tapered profile (Dussart BI.4 = "tron- } \\
\text { conique"). Rim-thickening } 7 \mathrm{~mm} \text { high x } 3 \\
\text { mm wide. Rim diameter } 160 \mathrm{~mm} \text {; } 5 \% \text { of } \\
\text { rim circumference extant. Pale green fabric } \\
\text { (von Saldern \#2). }\end{array}$ & See No. 25. \\
\hline 27 & 564 & 1989.2 & $\begin{array}{l}\text { Moderately out-flaring, noticeably thick- } \\
\text { ened rim with triangular cross-section; } 20 \\
\text { mm of tapering wall extant below the rim. } \\
\text { Body of vessel has tapered profile (Dussart } \\
\text { BI.4 = "tronconique"). Rim-thickening } 6 \\
\text { mm high x } 4 \text { mm wide. Rim diameter } 120 \\
\text { mm; } 7 \% \text { of rim circumference extant. Light } \\
\text { aqua fabric (von Saldern \#1). }\end{array}$ & $\begin{array}{l}\text { Dussart } 68 \text { (BI.4221), late fourth- } \\
\text { early sixth century; Hayes } 80 \text {, late } \\
\text { third-early fourth century; ibid., } \\
\text { p.120, fourth-fifth century. }\end{array}$ \\
\hline 28 & 1914 & 2365.8 & $\begin{array}{l}\text { Sharply out-flaring, thickened and elabo- } \\
\text { rately contoured rim with } 18 \mathrm{~mm} \text { of taper- } \\
\text { ing wall extant below the rim. Body of ves- } \\
\text { sel has tapered profile (Dussart BI. } 4 \text { = } \\
\text { "tronconique"). Slight rim-thickening, } 2.5 \\
\text { mm wide. Rim diameter } 110 \mathrm{~mm} \text {; } 15 \% \text { of } \\
\text { rim circumference extant in two fragments } \\
\text { (non-contiguous). Light aqua fabric (von } \\
\text { Saldern \#1). }\end{array}$ & See No. 27s. \\
\hline 29 & 1931 & $\begin{array}{l}2446.1 \\
2446.2 \\
2443.6\end{array}$ & $\begin{array}{l}\text { Widely out-flaring, thickened rim with } 14 \\
\text { mm of tapering wall extant below the rim. } \\
\text { Body of vessel has tapered profile (Dussart } \\
\text { BI.4 = "tronconique"). Rim thickened in } \\
\text { three small parallel ridges, } 5 \mathrm{~mm} \text { apart. }\end{array}$ & $\begin{array}{l}\text { Dussart } 69 \text { (BI.4231), first century } \\
\text { BCE-first century CE. No other } \\
\text { good parallels. }\end{array}$ \\
\hline
\end{tabular}




\begin{tabular}{|l|l|l|l|}
\hline & 2443.7 & $\begin{array}{l}\text { Rim diameter 160 mm; 19\% of rim circum- } \\
\text { ference extant in four fragments (non-con- } \\
\text { tiguous). Rich blue fabric (like von Saldern } \\
\# 6) .\end{array}$ \\
\hline
\end{tabular}

\section{Ring-type bases from bowls or dishes}

Ring-type bases were made in two ways. Some were folded from the material of the paraison itself to form a hollow tube. Others were formed from a separate piece of glass into a solid wall-like ring which was then fused to a vessel's base. This type seems to be rare on most sites. ${ }^{315}$ Both types do, however, appear on bowls and dishes of various sizes, depths, and profiles. ${ }^{316}$ The literature does not usually draw distinctions between these types of base rings in establishing its various typologies.

Tubular base rings consist of a folded section that is hollow in cross-section and slopes outward from the bottom of the vessel to form a concave base. Every dimension varies greatly: the diameter, proportions, and angle of the folded tube, and the diameter and height of the base ${ }^{317}$ The form is widely known, dating from at least the second to the sixth century. Within this corpus there are six examples of tubular base rings (Nos. 30-35). Four of them feature tall bases of contrasting diameters (large diameter, Nos. 30-32; small diameter, No. 33). The other two have very short bases, of medium-sized (No. 34) and small (No. 35) diameters. Apart from its interesting morphological features, it should be noted that No. 33 is one of the three vessels in this assemblage (the others are Nos. 16 and 201) that is represented by two fragments found at a significant distance from each other.

Solid ring-type bases also range widely in the height, thickness, and angle of the ring in relation to the vessel bottom. One of these examples is especially robust (No. 36), three are medium-sized (Nos. 37-39), and one is relatively small (No. 40).

Group 4: Bowls with ring-type bases (11 pieces: see drawings in Illustrations 4 and 5)

\begin{tabular}{|l|l|l|l|l|}
\hline No. & Loc. & Basket & Description & Parallels \\
\hline 30 & 2135 & 3444.1 & $\begin{array}{l}\text { Large, folded base ring, both layers folded } \\
\text { from the vessel's body and descending to- } \\
\text { gether from its bottom to form a tubular } \\
\text { base ring 14 mm high, diameter 140 mm; } \\
100 \% \text { of circumference extant in eight } \\
\text { fragments. Body of vessel (17 mm extant) } \\
\text { extends horizontally from the base (170 }\end{array}$ & Dussart BII.111. \\
\hline
\end{tabular}

\footnotetext{
${ }^{315}$ Weinberg and Goldstein, "The Glass Vessels," 58; Pollak, "The Glass," 166.

${ }^{316}$ Dussart, Le verre en Jordanie et en Syrie du Sud, 57.

317 Saldern, Ancient and Byzantine Glass from Sardis, 63.
} 


\begin{tabular}{|c|c|c|c|c|}
\hline & & & $\begin{array}{l}\text { mm min. circumference). Pale green fabric } \\
\text { (von Saldern \#2). }\end{array}$ & \\
\hline 31 & 1226 & $\begin{array}{l}3428.1 \\
3428.2\end{array}$ & $\begin{array}{l}\text { Large, folded base ring, both layers folded } \\
\text { from the vessel's body and descending to- } \\
\text { gether from its bottom to form a tubular } \\
\text { base ring } 17 \mathrm{~mm} \text { high, diameter } 110 \mathrm{~mm} \text {; } \\
73 \% \text { of circumference extant in two frag- } \\
\text { ments (broken in antiquity). Noticeable } \\
\text { deformation in roundness of } 3428.2 \text {. Body } \\
\text { of vessel ( } 20 \mathrm{~mm} \text { extant) extends horizon- } \\
\text { tally from the base ( } 150 \mathrm{~mm} \text { min. circum- } \\
\text { ference). Pale green fabric (von Saldern } \\
\text { \#2). }\end{array}$ & Dussart BII.111. \\
\hline 32 & 1226 & 2344.1 & $\begin{array}{l}\text { Large, folded base ring, both layers folded } \\
\text { from the vessel's body and descending to- } \\
\text { gether from its bottom to form a vertical } \\
\text { section ca. } 15 \mathrm{~mm} \text { high, diameter } 150 \mathrm{~mm} \text {, } \\
11 \% \text { of circumference extant. These layers } \\
\text { then separate to form a tubular base ring, } \\
\text { at least } 10 \mathrm{~mm} \text { high x } 8 \mathrm{~mm} \text { wide. Body } \\
\text { profile unknown. Light aqua fabric (von } \\
\text { Saldern \#1). }\end{array}$ & $\begin{array}{l}\text { Unusual type; rough parallels but } \\
\text { different size and/or profile in } \\
\text { Dussart } 1998 \text { (Types BI.1211, } \\
\text { BII.111, BIII.1). }\end{array}$ \\
\hline $\begin{array}{l}33 \mathrm{~A} \\
33 \mathrm{~B}\end{array}$ & $\begin{array}{l}567 \\
2115\end{array}$ & $\begin{array}{l}1998 \\
3145.1\end{array}$ & $\begin{array}{l}\text { Large, folded base ring, both layers folded } \\
\text { from the vessel's body and descending to- } \\
\text { gether from its bottom to form a tubular } \\
\text { base ring } 17 \mathrm{~mm} \text { high, diameter } 70 \mathrm{~mm} \text {; } \\
92 \% \text { of circumference extant in two con- } \\
\text { tiguous fragments (broken in antiquity). } \\
\text { Body of vessel ( } 3 \mathrm{~mm} \text { extant) flares out } \\
\text { horizontally from the base. Rough pontil } \\
\text { mark, } 13 \mathrm{~mm} \text { diameter Pale green fabric } \\
\text { (von Saldern \#2). }\end{array}$ & $\begin{array}{l}\text { Von Saldern 1980:63, third-sixth } \\
\text { century; Meyer 1987:193, late } \\
\text { third-early seventh century; } \\
\text { Weinberg 1988:42, third-fourth } \\
\text { century; Dussart } 57 \text { (Type } \\
\text { BI.1211), third-fourth century; } \\
\text { Pollak 166, third-sixth century. }\end{array}$ \\
\hline 34 & 1296 & 2375.1 & $\begin{array}{l}\text { Small, folded base ring, both layers folded } \\
\text { from the vessel's body, immediately below } \\
\text { its flat bottom. Base ring height } 5 \mathrm{~mm} \text {, di- } \\
\text { ameter } 75 \mathrm{~mm} \text { ( } 18 \% \text { of circumference ex- } \\
\text { tant), with small hollow section. Body pro- } \\
\text { file unknown. Colour of fabric indetermi- } \\
\text { nate due to very heavy corrosion. }\end{array}$ & See No. 33. \\
\hline 35 & 1276 & 2305.2 & $\begin{array}{l}\text { Small, folded base ring, both layers folded } \\
\text { from the vessel's body, immediately below } \\
\text { is concave bottom. Folded layers fused to- } \\
\text { gether (no hollow section). Base ring } \\
\text { height } 3 \mathrm{~mm} \text {; diameter } 55 \mathrm{~mm} \text {; } 16 \% \text { of cir- } \\
\text { cumference extant. Body tapers outward; }\end{array}$ & See No. 33. \\
\hline
\end{tabular}




\begin{tabular}{|c|c|c|c|c|}
\hline & & & $\begin{array}{l}15 \mathrm{~mm} \text { of height extant. Almost colour- } \\
\text { less fabric (von Saldern } \# 5 \text { ). }\end{array}$ & \\
\hline 36 & 1930 & 2438.1 & $\begin{array}{l}\text { Large solid-wall base ring with cylindrical } \\
\text { profile (vertical, no slope), fused to bot- } \\
\text { tom of vessel. Bottom extends horizon- } \\
\text { tally at least } 12 \mathrm{~mm} \text { beyond outer edge of } \\
\text { base ring. Base ring height } 21 \mathrm{~mm} \text {; thick- } \\
\text { ness } 6 \mathrm{~mm} \text {; diameter } 160 \mathrm{~mm} ; 12 \% \text { of base } \\
\text { circumference extant. Pale green fabric } \\
\text { (von Saldern \#2). }\end{array}$ & $\begin{array}{l}\text { See Dussart } 68 \text { (Type BI.4222.b1), } \\
\text { third-fourth century. }\end{array}$ \\
\hline 37 & 1226 & 2258.3 & $\begin{array}{l}\text { Large solid-wall base ring with tapering } \\
\text { profile (smaller diameter at top), fused to } \\
\text { bottom of vessel. Bottom (16 mm extant) } \\
\text { slopes gently out and up. Base ring height } \\
14 \mathrm{~mm} \text {; thickness } 4 \mathrm{~mm} \text {; diameter } 90 \mathrm{~mm} \text {; } \\
21 \% \text { of base circumference extant. Light } \\
\text { aqua fabric (von Saldern \#1). }\end{array}$ & See No. 36. \\
\hline 38 & 1226 & 2435.2 & $\begin{array}{l}\text { Large solid-wall base ring with tapering } \\
\text { profile (smaller diameter at top), presum- } \\
\text { ably fused to bottom of vessel. Top of base } \\
\text { ring, and body of vessel, missing. Base } \\
\text { ring height at least } 147 \mathrm{~mm} \text {; thickness } 5.5 \\
\text { mm; diameter } 70 \mathrm{~mm} ; 13 \% \text { of base cir- } \\
\text { cumference extant. Light aqua fabric (von } \\
\text { Saldern \#1). }\end{array}$ & See No. 36. \\
\hline 39 & 2166 & 3475.4 & $\begin{array}{l}\text { Solid-wall base ring with tapering profile } \\
\text { (smaller diameter at top), fused to bottom } \\
\text { of vessel. Bottom has concave profile, } \\
\text { then slopes out and up. Base ring height } \\
\text { >11 mm; thickness } 3 \mathrm{~mm} \text {; diameter at top } \\
36 \mathrm{~mm} \text {; } 100 \% \text { of base circumference ex- } \\
\text { tant. Crudely made, with } 2 \text { layers of glass } \\
\text { in base ring, and vessel-bottom neither } \\
\text { centred nor level; ca. } 20 \text { diagonal tooling- } \\
\text { marks. Pontil mark. Light aqua fabric (von } \\
\text { Saldern \#1). }\end{array}$ & See No. 36. \\
\hline 40 & 1928 & 2448.15 & $\begin{array}{l}\text { Relatively small solid-wall base ring with } \\
\text { tapering profile (smaller diameter at top), } \\
\text { fused to bottom of vessel. Bottom has } \\
\text { concave profile, then slopes out and up. } \\
\text { Base ring height }>6 \mathrm{~mm} \text {; thickness } 3 \mathrm{~mm} \text {; } \\
\text { diameter at top } 31 \mathrm{~mm} \text {; } 77 \% \text { of base cir- } \\
\text { cumference extant. Massive, odd pontil } \\
\text { mark, } 15 \mathrm{~mm} \text { diameter x } 8 \mathrm{~mm} \text { high, of }\end{array}$ & See No. 36. \\
\hline
\end{tabular}




\begin{tabular}{|l|l|l|l|}
\hline & & $\begin{array}{l}\text { different-coloured fabric. Vessel is light } \\
\text { aqua fabric (von Saldern \#1); pontil frag- } \\
\text { ment is olive green (von Saldern \#3). }\end{array}$ & \\
\hline
\end{tabular}

\section{Rounded-lip shallow dishes}

These large shallow bowls with sloping walls and rounded rims seem to have originated in the Roman period (first-second century) but are most abundant and securely datable to the third-fourth centuries. In Dussart's landmark study, about one quarter of the handful of examples known, originated in the Galilee. ${ }^{318}$

A single fragment of this vessel type came to light on this site.

Group 5: Rounded-lip, shallow dishes (1 piece: see drawing in Illustration 5)

\begin{tabular}{|l|l|l|l|l|}
\hline No. & Loc. & Basket & Description & Parallels \\
\hline 41 & 2127 & 3178.1 & $\begin{array}{l}\text { Large shallow dish with uniformly curved } \\
\text { wall ending in rounded lip with no flare. } \\
\text { Rim diameter 270 mm; 12\% of rim circum- } \\
\text { ference extant. Wall ca. 35 mm high. Ap- } \\
\text { prox. 27 mm of horizontal dimension ex- } \\
\text { tant, from outer wall to inner edge of frag- } \\
\text { ment. Light aqua fabric (von Saldern \#1). }\end{array}$ & $\begin{array}{l}\text { Hayes 103, fourth century; } \\
\text { Dussart 73 (Type BII.111), third- } \\
\text { fourth century. }\end{array}$ \\
& & & & \\
\hline
\end{tabular}

\section{Long-folded wall dishes}

This type of dish has a distinctive type of construction that is also known as "broad collar," 319 "folded collar," 320 "looped rim and base," 321 or "collar rim." 322 Its rim was folded out and down to form either a flange or a tube, which was then pressed against the bottom edge of the vessel's vertical wall to form a decorative ring. These dishes vary greatly in diameter, wall height (relative to their diameter), and wall slope. Most of these examples probably stood on a central pedestal-foot, although many of these are missing because of these examples' fragmentary condition. Because of this separate foot, the ring at the bottom of the wall would have been purely decorative.

These dishes are found elsewhere but are especially associated with the Roman East. They are relatively uncommon: the glass factory at Jalame yielded three examples, ${ }^{323}$ while Dussart notes just nine published examples from Jordan plus four others, unpublished (all

\footnotetext{
${ }^{318}$ Dussart, Le verre en Jordanie et en Syrie du Sud, 74.

${ }^{319}$ Isings, Roman Glass from Dated Finds, 148.

${ }^{320}$ Weinberg and Goldstein, "The Glass Vessels," 47.

${ }^{321}$ Meyer, "Glass from the North Theater Byzantine Church, and Soundings at Jerash, Jordan, 1982-1983,” 191.

322 Pollak, "The Glass," 158.

${ }^{323}$ Weinberg and Goldstein, "The Glass Vessels," 47-49.
} 
of which comprise her type BII.3). Most are dated mid-fourth / early-fifth century, although a few survived-or were manufactured?-as late as the Umayyad period..$^{324}$

Readily identifiable fragments of twenty-two of these dishes were found in the NIP. Seventeen are included in this survey. As a group they fall into Dussart's category BII.311.

Although most of these examples have relatively vertical, straight-sided walls, the walls of others are significantly sloped (Nos. $42,44,45$ ). There are notable differences in the proportions of the top and bottom sections of the folds that form these walls: in Nos. 47 and 49 they are roughly the same size and shape; in Nos. 45 and 54 the top fold is somewhat bigger and differently shaped than the bottom fold. In Nos. 49 and 54, the upper fold is somewhat smaller than the bottom fold; Nos. 46, 50, 51, and 52 have no hollow in the bottom fold. The outer walls of Nos. 54 and 55 feature an especially attractive recess between the top and bottom hollow sections created by the folds. By contrast, Nos. 43 and 47 have such short walls that the two hollow sections are immediately adjacent to each other. The proportions of the gracefully curving walls of Nos. $42,44,45$, 47, and 48 are strikingly beautiful. The fine craftsmanship of this entire group may suggest that they are, indeed, products of the fourth century.

Group 6: Long-folded wall dishes (17 pieces: see drawings in Illustrations 5 and 6)

\begin{tabular}{|l|l|l|l|l|}
\hline No. & Loc. & Basket & Description & Parallels \\
\hline 42 & 564 & 2201.1 & $\begin{array}{l}\text { Dish with very short, out-sloping, curved } \\
\text { wall. Relatively large, elongated hollow } \\
\text { sections in folds, both at rim and at base- } \\
\text { tube. Elegantly proportioned folds. Rim } \\
\text { diameter 300 mm; 8.5\% rim circumference } \\
\text { extant. Wall height 10 mm; vessel height } \\
\text { 16 mm, incl. folded base tube. Light aqua } \\
\text { fabric (von Saldern \#1) }\end{array}$ & $\begin{array}{l}\text { Dussart 74 (Type BII.311. fourth- } \\
\text { eighth century; Isings 148 (form } \\
\text { 118), fourth century; Meyer } \\
\text { Weinberg 1988:46-47, fourth } \\
\text { century; Dussart 75, fourth-fifth } \\
\text { century, or perhaps as late as } \\
\text { eighth century; Pollak 158, } \\
\text { mainly fourth-fifth century }\end{array}$ \\
\hline 43 & 2135 & 3449.2 & $\begin{array}{l}\text { Dish with short, relatively vertical wall } \\
\text { and complex, multi-layered folded decora- } \\
\text { tive "ring" at turn from wall into base. } \\
\text { Ring diameter 300 mm; 4\% circumference } \\
\text { extant. Pale green fabric (von Saldern \#2). }\end{array}$ & See No. 42. \\
\hline 44 & 2133 & 3419.1 & $\begin{array}{l}\text { Dish with relatively tall, out-sloping, rela- } \\
\text { tively straight wall. Fairly tall hollow sec- } \\
\text { tion in fold at rim; very small hollow at } \\
\text { base-tube. Beautifully made, well-propor- } \\
\text { tioned example. Rim diameter 280 mm; }\end{array}$ & See No. 42. \\
\hline
\end{tabular}

${ }^{324}$ Dussart, Le verre en Jordanie et en Syrie du Sud, 75. 


\begin{tabular}{|c|c|c|c|c|}
\hline & & & $\begin{array}{l}6 \% \text { of rim circumference extant. Wall } \\
\text { height } 35 \mathrm{~mm} \text {; vessel height ca. } 30 \mathrm{~mm} \text {, } \\
\text { incl. folded base tube. Pale green fabric } \\
\text { (von Saldern \#2). }\end{array}$ & \\
\hline 45 & 1226 & $\begin{array}{l}5410 \\
5412.1\end{array}$ & $\begin{array}{l}\text { Dish with relatively tall, out-sloping, } \\
\text { curved wall. Fairly tall hollow section in } \\
\text { fold at rim; very small hollow in fold at } \\
\text { base-tube. Beautifully made, well-propor- } \\
\text { tioned folds. Rim diameter } 260 \mathrm{~mm} ; 18 \% \\
\text { of rim circumference extant (2 fragments). } \\
\text { Wall height } 22 \mathrm{~mm} \text {; vessel height } 28 \mathrm{~mm} \text {, } \\
\text { incl. folded base tube. Light aqua fabric } \\
\text { (von Saldern \#1). }\end{array}$ & See No. 42 . \\
\hline 46 & $\begin{array}{l}1226 \\
1226 \\
2133\end{array}$ & $\begin{array}{l}3430.1 \\
3432.1 \\
3441.2 \\
3441.3 \\
3443.1 \\
3444.2 \\
3444.3 \\
3444.4\end{array}$ & $\begin{array}{l}\text { Dish with relatively tall, out-sloping, } \\
\text { slightly curved wall. Fairly tall hollow sec- } \\
\text { tion in fold at rim; no hollow in fold at } \\
\text { base tube. Nicely made, graceful folds. } \\
\text { Rim diameter } 260 \mathrm{~mm} \text {; } 55 \% \text { of rim circum- } \\
\text { ference extant in eight pieces (broken in } \\
\text { antiquity). Wall height varies between } \\
34.5-35.5 \mathrm{~mm} \text {. Ca. } 17 \mathrm{~mm} \text { of bottom sur- } \\
\text { face extant. Pale green fabric (von Saldern } \\
\# 2 \text { ). }\end{array}$ & See No. 42 . \\
\hline 47 & 1214 & 5427.3 & $\begin{array}{l}\text { Dish with very short, out-sloping, curved } \\
\text { wall. Tall hollow, flattened section in fold } \\
\text { at rim; small hollow in fold at base-tube. } \\
\text { Well-made, nicely proportioned vessel. } \\
\text { Rim diameter } 250 \mathrm{~mm} \text {; } 4 \% \text { of rim circum- } \\
\text { ference extant. Wall height } 8 \mathrm{~mm} \text {; vessel } \\
\text { height } 11 \mathrm{~mm} \text {, incl. folded base-tube. } \\
\text { Light aqua fabric (von Saldern \#1). }\end{array}$ & See No. 42. \\
\hline 48 & $\begin{array}{r}2133 \\
1226 \\
2133\end{array}$ & $\begin{array}{l}3420.1 \\
3430.2 \\
3443.2\end{array}$ & $\begin{array}{l}\text { Dish with relatively tall, out-sloping, } \\
\text { curved wall. Fairly tall hollow section in } \\
\text { fold at rim; very small hollow in fold at } \\
\text { base-tube. Nicely made, graceful folds. } \\
\text { Rim diameter } 230 \mathrm{~mm} \text {; } 24 \% \text { of rim circum- } \\
\text { ference extant in three pieces (broken in } \\
\text { antiquity). Wall height varies between } 29 \text { - } \\
33 \mathrm{~mm} \text {. Ca. } 5 \mathrm{~mm} \text { of bottom surface ex- } \\
\text { tant. Pale green fabric (von Saldern \#2). }\end{array}$ & See No. 42 . \\
\hline 49 & 2165 & 3474.1 & $\begin{array}{l}\text { Dish with short, out-sloping, curved wall. } \\
\text { Mid-sized hollow section in fold at rim; }\end{array}$ & See No. 42 . \\
\hline
\end{tabular}




\begin{tabular}{|c|c|c|c|c|}
\hline & & & $\begin{array}{l}\text { larger hollow in fold at the base tube. Rim } \\
\text { diameter } 190 \mathrm{~mm} ; 7 \% \text { of rim circumfer- } \\
\text { ence extant. Wall height } 13 \mathrm{~mm} .7 \mathrm{~mm} \text { of } \\
\text { bottom surface extant. Light aqua fabric } \\
\text { (von Saldern \#1). }\end{array}$ & \\
\hline 50 & 579 & 2013.1 & $\begin{array}{l}\text { Dish with short, relatively vertical wall. } \\
\text { Small hollow section in fold at rim; no } \\
\text { hollow in fold at base-flange. Both folds } \\
\text { about the same diameter. Rim diameter } \\
180 \mathrm{~mm} ; 4 \% \text { of rim circumference extant. } \\
\text { Wall height } 10 \mathrm{~mm} \text {; vessel height } 14 \mathrm{~mm} \text {, } \\
\text { incl. folded base flange. Very pale green } \\
\text { fabric (von Saldern \#2). }\end{array}$ & See No. 42 . \\
\hline 51 & 1905 & 2342.1 & $\begin{array}{l}\text { Dish with medium tall, out-sloping, } \\
\text { curved wall. Fairly tall hollow section in } \\
\text { fold at rim; no hollow in fold at the base } \\
\text { tube. Beautifully made. Rim diameter } 170 \\
\text { mm; } 13 \% \text { of rim circumference extant. } \\
\text { Wall height } 19 \mathrm{~mm} \text {. Ca. } 2 \text { mm of bottom } \\
\text { surface extant. Pale green fabric (von } \\
\text { Saldern \#2). }\end{array}$ & See No. 42 . \\
\hline 52 & 2160 & 3469.1 & $\begin{array}{l}\text { Dish with short, out-sloping, relatively } \\
\text { straight wall. Fairly tall hollow section in } \\
\text { fold at rim; no hollow in fold at the base } \\
\text { tube. Rim diameter } 140 \mathrm{~mm} \text {; } 14 \% \text { of rim } \\
\text { circumference extant. Wall height } 13 \mathrm{~mm} \text {; } \\
\text { vessel height } 16 \mathrm{~mm} \text {, incl. folded base } \\
\text { tube. None of bottom surface extant. Light } \\
\text { aqua fabric (von Saldern \#1). }\end{array}$ & See No. 42 . \\
\hline 53 & 1226 & 2344.3 & $\begin{array}{l}\text { Dish with short, almost vertical wall. Rela- } \\
\text { tively tall hollow sections in fold at rim; } \\
\text { very small hollow in fold at the base tube. } \\
\text { Rim diameter } 130 \mathrm{~mm} \text {; } \% \text { of rim circum- } \\
\text { ference extant. Wall height } 13 \mathrm{~mm} \text {; vessel } \\
\text { height } 17 \mathrm{~mm} \text {, incl. folded base tube. Pale } \\
\text { green fabric (von Saldern \#2). }\end{array}$ & See No. 42 . \\
\hline 54 & 557 & 2087.2 & $\begin{array}{l}\text { Dish with short, almost vertical wall. } \\
\text { Small hollow sections in fold at rim and at } \\
\text { the base tube. Base fold much bigger than } \\
\text { rim fold. Rim diameter } 120 \mathrm{~mm} \text {; } 10 \% \text { of } \\
\text { rim circumference extant. Wall height } 12 \\
\mathrm{~mm} \text {; vessel height } 17 \mathrm{~mm} \text {, incl. folded }\end{array}$ & See No. 42 . \\
\hline
\end{tabular}




\begin{tabular}{|c|c|c|c|c|}
\hline & & & $\begin{array}{l}\text { base tube. Pale green fabric (von Saldern } \\
\# 2 \text { ). }\end{array}$ & \\
\hline 55 & 1214 & 5427.1 & $\begin{array}{l}\text { Dish with short, almost vertical wall. } \\
\text { Fairly big hollow sections in fold at rim } \\
\text { and at base tube. Beautifully made, well- } \\
\text { proportioned folds. Rim diameter } 110 \mathrm{~mm} \text {; } \\
15 \% \text { of rim circumference extant. Wall } \\
\text { height } 12 \mathrm{~mm} \text {; vessel height } 17 \mathrm{~mm} \text {, incl. } \\
\text { folded base tube. Ca. } 4 \mathrm{~mm} \text { of bottom sur- } \\
\text { face extant. Pale green fabric (von Saldern } \\
\# 2 \text { ). }\end{array}$ & See No. 42 . \\
\hline 56 & 1226 & 2337.1 & $\begin{array}{l}\text { Dish with short, out-sloping, relatively } \\
\text { straight wall. Moderately sized hollow sec- } \\
\text { tions in folds at rim and base tube. Rim di- } \\
\text { ameter } 110 \mathrm{~mm} \text {; } 11 \% \text { of rim circumference } \\
\text { extant. Wall height } 10 \mathrm{~mm} \text {; vessel height } \\
14 \mathrm{~mm} \text {, incl. folded base tube. Ca. } 10 \mathrm{~mm} \\
\text { of bottom surface extant, including unu- } \\
\text { sual up-then-down contour. Pale green } \\
\text { fabric (von Saldern } \# 2 \text { ). }\end{array}$ & See No. 42 . \\
\hline 57 & 1226 & 2344.2 & $\begin{array}{l}\text { Dish with short, out-sloping, curved wall. } \\
\text { Small hollow sections in folds at rim and } \\
\text { base tube. Rim diameter } 100 \mathrm{~mm} ; 10 \% \text { of } \\
\text { rim circumference extant. Wall height } 7 \\
\text { mm; vessel height } 11 \mathrm{~mm} \text {, incl. folded } \\
\text { base tube. Ca. } 3 \mathrm{~mm} \text { of bottom surface ex- } \\
\text { tant. Pale green fabric (von Saldern \#2). }\end{array}$ & See No. 42 . \\
\hline 58 & 2160 & 3469.2 & $\begin{array}{l}\text { Dish with short, out-sloping, relatively } \\
\text { straight wall. Small hollow sections in } \\
\text { folds at rim and base tube. Rim diameter } \\
110 \mathrm{~mm} ; 14 \% \text { of rim circumference extant. } \\
\text { Wall height } 9 \mathrm{~mm} \text {; vessel height } 12 \mathrm{~mm} \text {, } \\
\text { incl. folded base tube. } 5 \mathrm{~mm} \text { of bottom } \\
\text { surface extant. Light aqua fabric (von } \\
\text { Saldern \#2). }\end{array}$ & See No. 42 . \\
\hline
\end{tabular}

\section{Flattened-hemisphere dish}

Such dishes are very similar to the long-folded wall dishes discussed above. However, instead of having a vertical sidewall that turns upward quite sharply from the vessel's bottom, the bottom and wall of these dishes form a more continuous unit. Rather than terminating in a ring that emphasizes the sharp turn between the wall and the bottom, the downward and outward fold in the rim simply ends at the point where the sidewall gradually becomes the bottom. Thus, as the name suggests, their profile is that of a flattened hemisphere. 
This type of vessel is represented here by two fragments of a single dish, broken in antiquity. It is a very rare type, known to Dussart only by a single example from the temple of Zeus at Jerash (sixth-seventh century). Because, however, its construction is so like that of longfolded wall dishes, it may also have originated somewhat earlier, as they did (fourth-fifth century).

Group 7: Flattened-hemisphere dish (1 piece: see drawing in Illustration 7)

\begin{tabular}{|l|l|l|l|l|}
\hline No. & Loc. & Basket & Description & Parallels \\
\hline 59 & 567 & 2045.1 & $\begin{array}{l}\text { Out-folded diagonally sloping rim, with 8 } \\
\text { mm of in-sloping wall extant below the } \\
\text { rim. Rim fold 11 mm high x 4 mm wide, } \\
\text { with a distinctive angle in the fold. Rim di- } \\
\text { ameter 220 mm; 20\% of rim circumference } \\
\text { extant. Light aqua fabric (von Saldern \#1). }\end{array}$ & $\begin{array}{l}\text { Von Saldern 1980:81, fifth-sev- } \\
\text { enth century; Meyer 1987:189, } \\
\text { early Byzantine; Dussart 75 (Type } \\
\text { BII.312), sixth-seventh century; } \\
\text { Pollak 156-57, second-ninth cen- } \\
\text { tury. }\end{array}$ \\
\hline
\end{tabular}

\section{Carinated dish}

This type of dish is distinguished by its wide, out-turned, and almost horizontal rim. These rims, on most examples from other sites, are folded to form a tube that adds strength to the vessel. Occasionally, although, as on the sole example from this site, this fold is incomplete, creating a small down-turning ridge along the outer edge of the rim.

The example described here is also unusual in its enormous size. (The necessity of using a different scale to accommodate its size is why it is drawn out of sequence.) Dussart reports examples from Jerash, Amman, Umm Qais, and elsewhere that range between 180 and 240 $\mathrm{mm}$ in rim diameter, but this piece's diameter of $420 \mathrm{~mm}$ puts it in a class by itself $-40 \mathrm{~mm}$ bigger than the largest windowpane on the site. ${ }^{325}$

Group 8: Carinated dish (1 piece: see drawing in Illustration 7)

\begin{tabular}{|c|c|c|c|c|}
\hline No. & Loc. & Basket & Description & Parallels \\
\hline 60 & 547 & 1961.1 & $\begin{array}{l}\text { Broad, flat rim with highly detailed con- } \\
\text { tour, culminating in small, down-turned } \\
\text { ridge, } 4 \mathrm{~mm} \text { high x } 5 \mathrm{~mm} \text { wide. Rim diam- } \\
\text { eter } 420 \mathrm{~mm} \text {; } 3 \% \text { of rim circumference ex- } \\
\text { tant. Pale green fabric (von Saldern \#2). }\end{array}$ & $\begin{array}{l}\text { Dussart } 76 \text { (Type BII.4), sixth- } \\
\text { seventh century; Isings } 39 \text { (Form } \\
\text { 22), first century; Meyer } \\
\text { 1987:198, Roman? (although re- } \\
\text { covered from late Byzantine } \\
\text { level); Lester 2004:168, Abbasid? }\end{array}$ \\
\hline
\end{tabular}

${ }^{325}$ Chambers, "Window Glass Finds in the Northeast Church"," 244. 


\section{Plates}

Plates are distinguished from dishes by their flatter profile, having shorter walls relative to their width. They also typically lack the central base-foot that characterizes dishes. Folded rims are also rare.

Only three fragments of plates have been identified on this site, two from the same square and locus and the other one nearby. Parallels to the first example come from Bosra, Jerash, and a Byzantine church at Khirbet al-Kerak. The second fragment is from a plate that was much bigger than a similar piece found at Jerash and dated to the late sixth century. However, the scarcity of other analogous pieces reduces the heuristic value of this observation considerably. The third example is even more unusual, having a very low sidewall and a matching folded base ring immediately below the bottom surface.

Group 9: Plates (3 pieces: see drawings in Illustration 7)

\begin{tabular}{|l|l|l|l|l|}
\hline No. & Loc. & Basket & Description & Parallels \\
\hline 61 & 1948 & 2483.8 & $\begin{array}{l}\text { Partial base and lower wall of large plate, } \\
\text { including sharp "turn" between wall and } \\
\text { concave base of vessel. Base ca. 10 mm } \\
\text { concave. Body diameter 140 mm; 12\% of } \\
\text { circumference extant; cylindrical profile. } \\
\text { Preserved height 14 mm. Light aqua fabric } \\
\text { (von Saldern \#1) }\end{array}$ & $\begin{array}{l}\text { Delougaz and Haines 59, Byzan- } \\
\text { tine; Weinberg 1988:52, late } \\
\text { fourth century; Dussart 78 (Type } \\
\text { BV.111), first century - Umayyad } \\
\text { era. }\end{array}$ \\
\hline 62 & 1948 & 2488.3 & $\begin{array}{l}\text { Short vertical wall and rounded rim of me- } \\
\text { dium-diameter plate, including sharp } \\
\text { "turn" between wall and flat bottom of } \\
\text { vessel. Rim diameter 150 mm; 5.5\% of rim } \\
\text { circumference extant. Wall ca. 8 mm tall. } \\
\text { Bottom extant for 8 mm inboard of the } \\
\text { wall. Almost colourless, clear fabric (von } \\
\text { Saldern \#5). }\end{array}$ & $\begin{array}{l}\text { Dussart 75 (Type BV.322), late } \\
\text { sixth century. }\end{array}$ \\
\hline 63 & 2101 & 3154.1 & $\begin{array}{l}\text { Double-folded rim of large plate, with up- } \\
\text { per fold flaring outward to form short side- } \\
\text { wall and lower fold tucking in to form dec- } \\
\text { orative ring. Rim diameter 140 mm; 12\% of } \\
\text { circumference extant. Bottom surface per- } \\
\text { fectly flat; 11 mm extant. Almost colour- } \\
\text { less fabric (von Saldern \#5). }\end{array}$ & $\begin{array}{l}\text { Very unusual; no parallels } \\
\text { known. }\end{array}$ \\
\hline
\end{tabular}




\section{Oil Lamps}

The literature employs a wide variety of classifications of lamp types. ${ }^{326}$ There are three basic types, corresponding to three methods of use: (1) lamps that basically stand on their own, whether they are conical or rounded in the body; (2) relatively wide-mouthed, bowlshaped lamps with attached handles from which the vessel was suspended by chains; and (3) smaller, cup-shaped lamps with narrow stems, either solid or hollow, which protruded downward through holes in metal frames and enabled the angle of the lamp's body to be adjusted. Although attempts have been made to establish a chronology among these forms, they seem to have co-existed throughout the Byzantine and Umayyad periods (fourtheighth centuries), with self-standing lamps perhaps originating a little earlier and handled lamps persisting a little longer.

\section{Self-standing lamps}

This seems to be the earliest type of glass oil lamp, originating perhaps in the third century. ${ }^{327}$ However, it is often difficult to identify with certainty because it lacks both of the easily recognizable features (handles and stems) of other types. Even so, there are two distinctive morphological features that make their identification possible.

Some vessels that stood on their own had conical bodies and simple, medium-width bases. Three of these bases are part of this collection. The tall, tapering and relatively narrow bodies that perched atop these bases set these vessels apart from bowls, pots, and goblets. Although they are described as "self-standing" lamps, it is possible that at least some of them might have been fitted into tripod- or ring-type holders that supported their mid-section. ${ }^{328}$ Some conical lamps, particularly in the fourth century, were decorated with fused-on blobs of blue glass; No. 65 is a good example.

Other lamps that stood on their own share a high degree of morphological overlap with certain types of bowls and pots, except for their distinctively unpolished cracked-off rims. In fact, according to many specialists, these vessels could be called either lamps or bowls, given that both classes of vessel feature rim-diameters between 110 and $200 \mathrm{~mm}$, an everted (that is, reverse-convex) upper profile, and a rounded or hemispherical mid-profile.

\footnotetext{
${ }^{326}$ Crowfoot and Harden, "Early Byzantine and Later Glass Lamps"; Saldern, Ancient and Byzantine Glass from Sardis; Dussart, Le verre en Jordanie et en Syrie du Sud; Pollak, "The Glass."

${ }^{327}$ Crowfoot and Harden, "Early Byzantine and Later Glass Lamps," 201; Dussart, Le verre en Jordanie et en Syrie du Sud, 79.

${ }^{328}$ Weinberg and Goldstein, "The Glass Vessels," 89-90.
} 
Dussart, for example, notes that her types BI.221 (bowls) and BVI.1112b (lamps) are identical in all four of these features. ${ }^{329}$ Likewise, a similar morphological overlap is obvious in the case of No. 70, which resembles a common type of pot (Dussart's BVII.221).

However, the distinguishing feature within this group is the presence of an unpolished, cracked-off rims. The absence of wheel or flame polishing reflects the fact that such vessels-unlike goblets or most bowls-were not used for drinking or pouring. ${ }^{330}$ The rough edge remaining after the cracking process was not a functional problem on a lamp. In fact, as No. 72 demonstrates, the apparent crudeness of this type of rim did not preclude a vessel's body being decorated with fine wheel-cut lines.

Were it not for these cracked-off rims, all thirteen of the fragments identified in this section as lamps could just as easily be categorized as bowls or pots. The size of Nos. 73-74 and, to some extent, No. 75, would certainly support such an identification (again compare Dussart's BI.211 [bowls] and BVI.1111 and BVI.1112 [lamps]). Or, on different grounds, No. 75 could be equally well discussed based on its shape as a cup-type lamp to be inserted in a holder (see below). For that matter, No. 76 could easily be classified as a dish, apart from its very large rim-diameter of $260 \mathrm{~mm}$. Nonetheless, the decision to discuss all these fragments as self-standing lamps reflects a desire to treat all pieces with cracked-off rims in one place instead of dispersing them into different categories.

Among these cracked-off rims, three examples (Nos. 73-75) are simple upward extensions of the vessel wall (Dussart's Type BVI.1111.a1). The others flare sharply outward before resuming a more cylindrical profile immediately below the crack (Dussart's Type BVI.1112). This everted or reverse-convex contour is a common lamp-profile both here on this site and elsewhere (also compare No. 82 in the next section). No. 69 is notable for the unusual thickness of its wall.

Group 10: Self-standing lamps (13 pieces: see drawings in Illustrations 7 and 8)

\begin{tabular}{|c|c|c|c|c|}
\hline No. & Loc. & Basket & Description & Parallels \\
\hline 64 & 1906 & $\begin{array}{l}\text { Item } \\
469\end{array}$ & $\begin{array}{l}\text { Partial bottom section of conical lamp, } \\
\text { plus two sections of rim. Rim diameter } 110 \\
\text { mm; } 37 \% \text { of rim circumference extant in } \\
\text { two non-contiguous fragments (broken in } \\
\text { antiquity); preserved height } 35 \mathrm{~mm} \text {. Base } \\
\text { diameter } 24 \mathrm{~mm} \text {; preserved height } 120 \\
\text { mm. Wall } 1.2 \mathrm{~mm} \text { thick; mould-decorated } \\
\text { with shallow spiralling ridges / grooves ca. } \\
5 \mathrm{~mm} \text { apart. Base } 5.5 \mathrm{~mm} \text { thick. Slight } \\
\text { pontil mark. } 100 \% \text { of body circumference } \\
\text { extant in lower sections. Calculated height }\end{array}$ & $\begin{array}{l}\text { Von Saldern } 1968 \text { no. 61, fourth- } \\
\text { fifth century; Hayes 104, fourth } \\
\text { century; Weinberg 1988:87-94, } \\
\text { late-fourth century; Dussart 79 } \\
\text { (decoration: BVI.1111a2, fourth } \\
\text { century; shape: BVI.1111b, fifth- } \\
\text { seventh century). }\end{array}$ \\
\hline
\end{tabular}

${ }^{329}$ Dussart, Le verre en Jordanie et en Syrie du Sud, 81.

${ }^{330}$ Cohen, "Roman, Byzantine and Umayyad Glass," 408. 


\begin{tabular}{|c|c|c|c|c|}
\hline & & & $\begin{array}{l}\text { of vessel } 235 \mathrm{~mm} \text {. Light aqua fabric (von } \\
\text { Saldern \#1). }\end{array}$ & \\
\hline 65 & 1226 & 5490.1 & $\begin{array}{l}\text { Partial bottom section of conical lamp; } \\
\text { base diameter } 32 \mathrm{~mm} \text {; preserved height } 54 \\
\mathrm{~mm} \text {; wall } 0.9 \mathrm{~mm} \text { thick; base } 3 \mathrm{~mm} \text { thick. } \\
\text { No pontil mark. One fused-on, oval, blue- } \\
\text { glass blob, } 13 \text { x } 6 \mathrm{~mm}, 30 \mathrm{~mm} \text { from bot- } \\
\text { tom, protruding slightly into interior of } \\
\text { body. } 55 \% \text { of body circumference extant. } \\
\text { Almost colourless fabric (von Saldern \#5). }\end{array}$ & See No. 64 . \\
\hline 66 & 1907 & 2451.3 & $\begin{array}{l}\text { Complete bottom section of conical lamp; } \\
\text { base diameter } 25 \mathrm{~mm} \text {; preserved height } 32 \\
\mathrm{~mm} \text {; wall } 4 \mathrm{~mm} \text { thick; base } 6 \mathrm{~mm} \text { thick. } \\
\text { Very large pontil mark, covering almost } \\
\text { the entire base. Colour indiscernible due } \\
\text { to very heavy corrosion. }\end{array}$ & See No. 64 . \\
\hline 67 & 1219 & 2316.3 & $\begin{array}{l}\text { Partial bottom section of conical lamp; } \\
\text { base diameter } 32 \mathrm{~mm} \text {; preserved height } 23 \\
\text { mm; wall } 4 \mathrm{~mm} \text { thick; base } 5 \mathrm{~mm} \text { thick. } \\
\text { Pontil mark covering most of base. } 58 \% \text { of } \\
\text { body circumference extant. Light aqua } \\
\text { fabric (von Saldern } \# 1 \text { ). }\end{array}$ & See No. 64 . \\
\hline 68 & 564 & 2201.4 & $\begin{array}{l}\text { Cracked-off rim of bowl-shaped lamp. Rim } \\
\text { diameter } 140 \mathrm{~mm} \text {; } 11 \% \text { of rim circumfer- } \\
\text { ence extant. Preserved height } 27 \mathrm{~mm} \text {. } \\
\text { Typically everted (reverse-convex) profile } \\
\text { to upper body; hemispherical mid-body } \\
\text { section obvious. Wall thickness approx. } \\
0.9 \mathrm{~mm} \text { at rim. Light aqua fabric (von } \\
\text { Saldern \#1). }\end{array}$ & $\begin{array}{l}\text { Dussart 80-81 (BVI.1112.b1), } \\
\text { fourth-early sixth century. }\end{array}$ \\
\hline 69 & 2155 & 3454.1 & $\begin{array}{l}\text { Cracked-off rim of bowl-shaped lamp. Rim } \\
\text { diameter } 130 \mathrm{~mm} \text {; } 8 \% \text { of rim circumfer- } \\
\text { ence extant. Preserved height } 25 \mathrm{~mm} \text {. } \\
\text { Typically everted (reverse-convex) profile } \\
\text { to upper body; hemispherical mid-body } \\
\text { section obvious. Wall thickness approx. } \\
3.5 \mathrm{~mm} \text { in body. Light aqua fabric (von } \\
\text { Saldern \#1). }\end{array}$ & See No. 68. \\
\hline 70 & 536 & 1910.1 & $\begin{array}{l}\text { Cracked-off rim of pot-shaped lamp. Rim } \\
\text { diameter } 120 \mathrm{~mm} ; 14 \% \text { of rim circumfer- } \\
\text { ence extant. Preserved height } 18 \mathrm{~mm} \text {. A } \\
\text { short neck and spherical body are typical } \\
\text { of a pot (e.g., Dussart BVII.212), but large }\end{array}$ & $\begin{array}{l}\text { Pollak 170, fourth-seventh cen- } \\
\text { tury. }\end{array}$ \\
\hline
\end{tabular}




\begin{tabular}{|c|c|c|c|c|}
\hline & & & $\begin{array}{l}\text { diameter and everted profile just below } \\
\text { cracked-off rim suggests a lamp. Wall } \\
\text { thickness approx. } 1 \mathrm{~mm} \text { at rim. Light aqua } \\
\text { fabric (von Saldern \#1). }\end{array}$ & \\
\hline 71 & 1226 & 2362.3 & $\begin{array}{l}\text { Cracked-off rim of bowl-shaped lamp. Rim } \\
\text { diameter } 110 \mathrm{~mm} \text {; } 10 \% \text { of rim circumfer- } \\
\text { ence extant. Preserved height } 24 \mathrm{~mm} \text {. } \\
\text { Wall thickness approx. } 1.0 \mathrm{~mm} \text { at rim. } \\
\text { Several small oval bubbles in the top } 5 \mathrm{~mm} \\
\text { of the wall, just below the rim. Pale green } \\
\text { fabric (von Saldern } \# 2 \text { ). }\end{array}$ & See No. 68. \\
\hline 72 & 2135 & 3449.1 & $\begin{array}{l}\text { Cracked-off rim of bowl-shaped lamp. Rim } \\
\text { diameter } 80 \mathrm{~mm} \text {; } 8 \% \text { of rim circumference } \\
\text { extant. Preserved height } 20 \mathrm{~mm} \text {. Wall } \\
\text { thickness approx. } 1.5 \mathrm{~mm} \text { at rim. Two par- } \\
\text { allel wheel-cut lines just below out-flaring } \\
\text { rim, } 2 \mathrm{~mm} \text { apart. Light aqua fabric (von } \\
\text { Saldern \#1). }\end{array}$ & $\begin{array}{l}\text { Dussart } 80 \text { (BVI.1112a22), fourth } \\
\text { century? }\end{array}$ \\
\hline 73 & 1206 & $\begin{array}{l}2099.17 \\
2099.18 \\
2099.19 \\
2099.20\end{array}$ & $\begin{array}{l}\text { Four fragments of cracked-off rim of a } \\
\text { large, spherical-body lamp. Rim diameter } \\
220 \mathrm{~mm} \text {; } 34 \% \text { of rim circumference extant } \\
\text { in four fragments (not contiguous). Very } \\
\text { thin wall ( } 0.8 \mathrm{~mm} \text { ), gradually curving in- } \\
\text { ward below rim. Pale green fabric (von } \\
\text { Saldern \#2). }\end{array}$ & $\begin{array}{l}\text { Crowfoot and Harden } 201 \\
\text { (“Group 1”), fourth-sixth cen- } \\
\text { tury; Isings } 113 \text { (Form 96a), } \\
\text { third-fourth century; von } \\
\text { Saldern 1980:52, early Byzan- } \\
\text { tine; Weinberg 1988:94-96, } \\
\text { fourth century; Dussart 78-79 } \\
\text { (Type BVI.1111a1), third-early } \\
\text { sixth century. }\end{array}$ \\
\hline 74 & 1226 & 3430.3 & $\begin{array}{l}\text { Cracked-off rim of a large, spherical-body } \\
\text { lamp. Rim diameter } 220 \mathrm{~mm} \text {; } 6 \% \text { of rim } \\
\text { circumference extant. Wall thickness } 1.5 \\
\text { mm, gradually curving inward below rim. } \\
\text { Preserved height } 25 \mathrm{~mm} \text {. Light aqua fabric } \\
\text { (von Saldern \#1). }\end{array}$ & See No. 73. \\
\hline 75 & 504 & 1830.1 & $\begin{array}{l}\text { Vertical cracked-off rim of medium-sized, } \\
\text { hemispherical-body lamp. Rim diameter } \\
140 \mathrm{~mm} ; 10 \% \text { of rim circumference extant. } \\
\text { Wall thickness } 2 \mathrm{~mm} \text {. Preserved height } 31 \\
\text { mm. Almost colourless fabric (von Saldern } \\
\text { \#5). }\end{array}$ & See No. 73. \\
\hline 76 & 1226 & 2349.1 & $\begin{array}{l}\text { Tall, out-folded, vertical rim, with } 6 \mathrm{~mm} \\
\text { of sharply in-sloping wall extant below } \\
\text { the rim. Rim-fold } 25 \mathrm{~mm} \text { high x } 3 \mathrm{~mm} \\
\text { wide. Rim diameter } 260 \mathrm{~mm} ; 6 \% \text { of rim } \\
\text { circumference extant. Overall preserved }\end{array}$ & $\begin{array}{l}\text { Dussart } 81 \text { (BVI.1222), late sixth } \\
\text { c? }\end{array}$ \\
\hline
\end{tabular}




\begin{tabular}{|l|l|l|l|}
\hline & & $\begin{array}{l}\text { height } 29 \mathrm{~mm} . \text { Light aqua fabric (von } \\
\text { Saldern \#1). }\end{array}$ & \\
\hline
\end{tabular}

\section{Lamps suspended from their handles}

Handles are associated exclusively with bowl-type lamps, that is, lamps with relatively wide mouths and short bodies. Out-folded tubular rims are common (the cracked-off rim of No. 79 is a notable exception). For stability, at least three handles are found on each lamp, which would have been suspended by a chain attached to each handle.

Most handles are open in form, attached to the body at or near its rim and then again partway down its body. The lower attachment-point is usually a large blob; the upper is typically smaller. Between these points, some handles are largely vertical in orientation (see No. 80) while others are noticeably diagonal as they proceed upward (No. 78). Most handles are simple in form, whether they are slender in their dimensions (No. 81) or stout (No. 82). A few are more elaborate, such as the extremely unusual No. 83, which extended upward from the rim before (perhaps?) angling down and out once again toward the body. This lamp is also distinctive in having a bluish-green handle on a darker-green body. The numerous and relatively well-preserved remains of No. 79 are also unusual in having handles that were thickest at the top, not the bottom, ending in fancy "tails" that reached down the side of the vessel for some distance. This lamp's simple, cracked-off rim contrasts sharply with these elaborate handles. Its round shape, too, with a larger diameter in the body than at the rim, is quite unusual (compare Dussart BVI.1241, 1242), compared to most lamps' tapering profile.

Closed handles are comparatively rare; they are attached to the body of the lamp for their entire height. One of the three handles of No. 79 is closed. The thick, ribbon-type handle No. 82 seems to have had a tail as well.

Group 11: Lamps suspended from their handles (7 pieces: see drawings in Illustration 9)

\begin{tabular}{|l|l|l|l|l|}
\hline No. & Loc. & Basket & Description & Parallels \\
\hline 77 & 2112 & 2499.1 & $\begin{array}{l}\text { Medium sized closed handle, slanted to } \\
\text { right, width varying from 7-18 mm, at- } \\
\text { tached to generous fragment (40 x 33 mm) } \\
\text { of large lamp with spherical body of ap- } \\
\text { prox. 350 mm diameter Rim profile un- } \\
\text { known. Light aqua fabric (von Saldern \#1). }\end{array}$ & $\begin{array}{l}\text { Crowfoot and Harden 1931:205 } \\
\text { (“Group 3”), sixth-seventh cen- } \\
\text { tury onward; von Saldern } \\
\text { 1980:45-47 (“Type 2”), fifth-sev- } \\
\text { enth century; Meyer 1987:205, } \\
\text { late Byzantine-Umayyad; } \\
\text { Dussart 79-81 (Type BVI.1221), } \\
\text { fourth-eighth century; Pollak } \\
\text { 169, fifth-twelfth century }\end{array}$ \\
\hline
\end{tabular}




\begin{tabular}{|c|c|c|c|c|}
\hline 78 & 567 & 2052.10 & $\begin{array}{l}\text { Large, open handle, slanted to left, taper- } \\
\text { ing from } 16 \times 20 \mathrm{~mm} \text { oblong blob at bot- } \\
\text { tom to } 8 \times 15 \mathrm{~mm} \text { at top. Handle } \\
\text { "perched" on top of out-folded, tubular } \\
\text { rim, ca. } 260 \mathrm{~mm} \text { diameter Wall flares } \\
\text { sharply inward below rim, then more gen- } \\
\text { tly inward. Light aqua fabric (von Saldern } \\
\text { \#1). }\end{array}$ & $\begin{array}{l}\text { Body of lamp: Dussart } 85 \\
\text { (BVI.1222), date indeterminate. }\end{array}$ \\
\hline 79 & 1226 & 5460 & $\begin{array}{l}\text { Fragments of large lamp with cracked-off, } \\
\text { out-flaring rim and three handles. Han- } \\
\text { dles attached with large blob at top, ex- } \\
\text { tending out and down, with long tails (up } \\
\text { to } 50 \mathrm{~mm} \text { ). Three handles completely pre- } \\
\text { served (two open, one closed). Rim diame- } \\
\text { ter } 240 \mathrm{~mm} \text {; } 6 \% \text { of rim circumference ex- } \\
\text { tant. Body is spherical and at least } 260 \\
\text { mm in diameter Pale green fabric (von } \\
\text { Saldern \#2). } 31 \text { frags in all, incl. } 3 \text { diagnos- } \\
\text { tics, each } 2 \text { pcs. }\end{array}$ & $\begin{array}{l}\text { Dussart } 85 \text { (Type BVI.1241 or } \\
\text { 1242), Byzantine-Umayyad, alt- } \\
\text { hough note significantly larger } \\
\text { diameter of this example. }\end{array}$ \\
\hline 80 & 2113 & 3136.1 & $\begin{array}{l}\text { Small, open handle, slightly twisting in } \\
\text { orientation, tapering from } 14 \times 20 \mathrm{~mm} \text { ob- } \\
\text { long blob at bottom to } 8 \times 10 \mathrm{~mm} \text { blob on } \\
\text { outer surface of tubular rim, ca. } 220 \mathrm{~mm} \\
\text { diameter Wall flares sharply inward below } \\
\text { rim, suggesting hemispherical body pro- } \\
\text { file. Pale green fabric (body) (von Saldern } \\
\# 2 \text { ); light aqua fabric (handle) (von } \\
\text { Saldern \#1). }\end{array}$ & See No. 77. \\
\hline 81 & 547 & 1961.5 & $\begin{array}{l}\text { Small, narrow, open handle, slightly twist- } \\
\text { ing in orientation, tapering from } 7 \text { x } 11 \\
\text { mm oblong blob at bottom to } 5 \times 10 \mathrm{~mm} \text { at } \\
\text { top. Handle "perched" on top of out- } \\
\text { folded, tubular rim. Rim diameter } 100 \\
\mathrm{~mm} \text {; } 9 \% \text { of rim circumference extant. Wall } \\
\text { curves gently inward below rim. Light } \\
\text { aqua fabric (von Saldern } \# 1 \text { ). }\end{array}$ & See No. 77. \\
\hline 82 & 548 & 1981.3 & $\begin{array}{l}\text { Large, closed, ribbon-type handle, at- } \\
\text { tached at its bottom, looping up, then ex- } \\
\text { tending down, ending with a tail. Pre- } \\
\text { served height } 42 \mathrm{~mm} \text {; } 10-17 \mathrm{~mm} \text { wide x } 4- \\
7 \mathrm{~mm} \text { thick. Pale green. }\end{array}$ & See No. 77. \\
\hline 83 & 1226 & 2248.1 & $\begin{array}{l}\text { Relatively large, open handle, slightly } \\
\text { twisting in orientation, extending verti- } \\
\text { cally upward from out-folded, tubular rim; }\end{array}$ & $\begin{array}{l}\text { Upward reach of handle from rim } \\
\text { is extremely unusual. }\end{array}$ \\
\hline
\end{tabular}




\begin{tabular}{|l|l|l|l|}
\hline & & $\begin{array}{l}\text { handle } 11 \mathrm{~mm} \text { wide x } 5 \mathrm{~mm} \text { thick. Pre- } \\
\text { served height of handle } 18 \mathrm{~mm} . \text { Rim diam- } \\
\text { eter } 80 \mathrm{~mm} \text {; } 9 \% \text { of rim circumference ex- } \\
\text { tant. Wall curves inward below rim. Pale } \\
\text { green fabric (body) (von Saldern \#2); light } \\
\text { aqua fabric (handle) (von Saldern \#1). }\end{array}$ & \\
\hline
\end{tabular}

\section{Stemmed lamps inserted into holders}

Lamps with stems feature cup-shaped, relatively short bodies with curving sides. No. 85 is an excellent example of the shape, presenting a complete profile from top to bottom. The rims of these lamps are often cracked-off, either flame polished (No. 84) or unpolished (No. 75 , above).

Three types of stems were used to steady this type of lamp and adjust its angle as it sat within one of two types of metal support. Two bronze candelabra, each of which held multiple lamps and are thus called polycandela, came to light in Hippos' Northwest Church. ${ }^{331}$ Metal holders that were attached to a building's walls and held a single lamp each are known from other sites.

The most common stem-type for lamps used in such holders is hollow and basically cylindrical. It is widely found throughout the Byzantine and Umayyad eras. The length, width, and taper of these stems vary considerably. Among the following examples, note the range of proportions from short and stubby to tall and graceful. Solid, straight stems are relatively rare, here and elsewhere; 332 among these examples, see only No. 92. They were probably concurrent with the tubular type. ${ }^{333}$ Solid, beaded stems seem to be a later development, popular during the Umayyad era. ${ }^{334}$ Nos. 93 and 94 are the best examples in this corpus.

Group 12: Stemmed lamps inserted into holders (11 pieces: see drawings in Illustration 10)

\begin{tabular}{|c|c|c|c|c|}
\hline No. & Loc. & Basket & Description & Parallels \\
\hline 84 & 1206 & 2099.1 & $\begin{array}{l}\text { Fire-polished rim of cup-type lamp. Iden- } \\
\text { tical profile to No. } 85 \text { but slightly larger. } \\
\text { Rim diameter } 85 \mathrm{~mm} \text {; } 39 \% \text { of rim circum- } \\
\text { ference extant. Wall thickness } 0.6-1.0\end{array}$ & $\begin{array}{l}\text { Crowfoot and Harden } 205 \\
\text { (“Group 2”), sixth-seventh cen- } \\
\text { tury onward; von Saldern } \\
\text { 1980:49, fourth-twelfth century; } \\
\text { Meyer 1987:205, Umayyad or } \\
\text { later; Dussart 86-88 (Type }\end{array}$ \\
\hline
\end{tabular}

\footnotetext{
${ }^{331}$ Mariusz Burdajewicz, "Glass Finds from the North-West Church Complex," in Hippos-Sussita : Seventh Season of Excavations : July 2006, ed. Arthur Segal et al. (Haifa: Zinman Institute of Archaeology, University of Haifa, 2006 ), 132.

332 Crowfoot and Harden, "Early Byzantine and Later Glass Lamps," 203.

${ }^{333}$ Dussart, Le verre en Jordanie et en Syrie du Sud, 88.

${ }^{334}$ Crowfoot and Harden, "Early Byzantine and Later Glass Lamps," 203; Meyer, "Glass from the North Theater Byzantine Church, and Soundings at Jerash, Jordan, 1982-1983," 205.
} 


\begin{tabular}{|c|c|c|c|c|}
\hline & & & $\begin{array}{l}\text { mm. Preserved height } 45 \mathrm{~mm} \text {. Light aqua } \\
\text { fabric (von Saldern \#1). }\end{array}$ & $\begin{array}{l}\text { BVI.211), fourth-eighth century; } \\
\text { Pollak 166, fifth-sixteenth cen- } \\
\text { tury.k }\end{array}$ \\
\hline 85 & 1930 & 2445.1 & $\begin{array}{l}\text { Mostly complete cup-type lamp. Overall } \\
\text { height } 90 \mathrm{~mm} \text {. Fire-polished rim, diameter } \\
75 \mathrm{~mm} \text {; } 26 \% \text { of rim circumference extant. } \\
\text { Rim flares ca. } 4 \text { mm outward in uppermost } \\
5 \mathrm{~mm} \text { of body. Cylindrical profile below } \\
\text { this flare, until sharply curve into flat bot- } \\
\text { tom section. Wall thickness } 1.5 \mathrm{~mm} \text { at rim, } \\
1 \mathrm{~mm} \text { in body. Hollow stem } 48 \mathrm{~mm} \text { high x } \\
23 \mathrm{~mm} \text { wide. Prominent narrowing of up- } \\
\text { per stem from } 23-20 \mathrm{~mm} \text { just before out- } \\
\text { turn into body. Large pontil mark. Light } \\
\text { aqua fabric (von Saldern } \# 1 \text { ). }\end{array}$ & See No. 84 . \\
\hline 86 & 1928 & 2448.9 & $\begin{array}{l}\text { Fairly complete hollow lamp stem with } \\
\text { generous part of cup-type body extant. } \\
\text { Body diameter ca. } 80 \mathrm{~mm} \text {. } 48 \mathrm{~mm} \text { of stem } \\
\text { height extant; graceful taper down from } \\
22-14 \mathrm{~mm} \text {. Body } 1 \mathrm{~mm} \text { thick; stem } 1.5 \mathrm{~mm} \\
\text { thick. }\end{array}$ & See No. 84 . \\
\hline 87 & 567 & 2056.1 & $\begin{array}{l}\text { Complete hollow lamp stem; stem height } \\
74 \mathrm{~mm} \text {, tapering from } 27 \text { to } 16 \mathrm{~mm} \text {; hol- } \\
\text { low to within } 4 \mathrm{~mm} \text { of bottom. Stem wall } \\
1.5 \mathrm{~mm} \text { thick. Pontil mark. Base nearly } \\
\text { horizontal. Pale green fabric (von Saldern } \\
\# 2 \text { ). }\end{array}$ & See No. 84 . \\
\hline 88 & 1226 & 2351.1 & $\begin{array}{l}\text { Complete hollow lamp stem; stem height } \\
62 \mathrm{~mm} \text {, tapering from } 23 \text { to } 18 \mathrm{~mm} \text {; hol- } \\
\text { low to within } 4 \mathrm{~mm} \text { of bottom. Sloping } \\
\text { bottom. Stem wall } 1.5 \mathrm{~mm} \text { thick. Pontil } \\
\text { mark. Base nearly horizontal. Light aqua } \\
\text { fabric (von Saldern \#1). }\end{array}$ & See No. 84 . \\
\hline 89 & 1226 & 2329.1 & $\begin{array}{l}\text { Complete hollow lamp stem; stem height } \\
48 \mathrm{~mm} \text {, tapering from } 19 \text { to } 17 \mathrm{~mm} \text { just } \\
\text { before out-turn into body; hollow to } \\
\text { within } 5 \mathrm{~mm} \text { of bottom. Sloping bottom. } \\
\text { Stem wall } 1.5 \mathrm{~mm} \text { thick. Off-centre pontil } \\
\text { mark. Base not horizontal. Light aqua fab- } \\
\text { ric (von Saldern \#1). }\end{array}$ & See No. 84 . \\
\hline 90 & 1276 & 2289.1 & $\begin{array}{l}\text { Complete hollow lamp stem; stem height } \\
37 \mathrm{~mm} \text {, tapering from } 19 \text { to } 17 \mathrm{~mm} \text { just } \\
\text { before out-turn into body; hollow to } \\
\text { within } 6 \mathrm{~mm} \text { of bottom. Bottom nearly } \\
\text { horizontal. Wall ca. } 1 \mathrm{~mm} \text { thick. No pontil }\end{array}$ & See No. 84 . \\
\hline
\end{tabular}




\begin{tabular}{|l|l|l|l|l|}
\hline & & & $\begin{array}{l}\text { mark. Base horizontal. Pale green fabric } \\
\text { (von Saldern \#2). }\end{array}$ & \\
\hline 91 & 563 & 2128.2 & $\begin{array}{l}\text { Complete hollow lamp-stem; stem height } \\
82 \mathrm{~mm} \text {, diameter tapering down from 19 } \\
\text { to 8 mm; hollow to within 14 mm of bot- } \\
\text { tom. Stem wall 3 mm thick. No pontil } \\
\text { mark. Narrow base, diagonally slanted. } \\
\text { Pale green fabric (von Saldern \#2). }\end{array}$ & See No. 84. \\
\hline 92 & 557 & 1987 & $\begin{array}{l}\text { Complete solid lamp stem; stem height 57 } \\
\text { mm, diameter 10 mm; depression in top of } \\
\text { stem, 12 mm deep. Small pontil mark, plus } \\
\text { "squaring-off" of bottom of stem with } \\
\text { pincers, 6 mm in height, immediately } \\
\text { above base. Bottom of body nearly hori- } \\
\text { zontal. Light aqua fabric (von Saldern \#1). }\end{array}$ & $\begin{array}{l}\text { Crowfoot and Harden 199 (“Type } \\
\text { antine-Umayyad; Dussart 88 } \\
\text { (BVI.212), Umayyad era. Pollak } \\
\text { 166, fifth century-Umayyad. }\end{array}$ \\
\hline 93 & 1226 & 2362.1 & $\begin{array}{l}\text { Bottom section of multi-beaded solid } \\
\text { lamp-stem; preserved height 39 mm, in- } \\
\text { cluding 3 beads. Bead diameter uniform, } \\
\text { 19-21 mm. Light aqua fabric (von Saldern } \\
\text { \#1). }\end{array}$ & $\begin{array}{l}\text { Dussart 88 (BVI.23), seventh cen- } \\
\text { tury onward; Bauer 519, seventh- } \\
\text { eighth century; Saller 317, sixth- } \\
\text { seventh century. }\end{array}$ \\
\hline 94 & 563 & 2128.1 & $\begin{array}{l}\text { Bottom section of multi-beaded solid } \\
\text { lamp-stem; preserved height 23 mm, in- } \\
\text { cluding 2 beads. Upper bead 16 mm diam- } \\
\text { eter; lower bead 12 mm diameter pontil } \\
\text { mark. Four round depressions on narrow } \\
\text { part of the stem between beads (tool } \\
\text { marks?). Light aqua fabric (von Saldern } \\
\text { \#1). }\end{array}$ & See No. 93. \\
\hline
\end{tabular}

\section{Goblets and Cups}

As vessels used for drinking, the fragments in this classification are characterized by three features: (1) rim-diameters of 70-100 mm; (2) non-folded rims, flame polished to produce a thickened, rounded edge; and (3) straight, not curving, sides, either cylindrical or tapering. The bases of such vessels fall into two groups: pedestal-bases, in which case such vessels are called goblets (Dussart's Type BVIII), or wineglass-type bases with very narrow waists that terminate in a wider, disc-type foot, in which case they are called cups (Dussart's Type BIX). In the case of fragments that terminate above the vessel's base, it is therefore impossible to determine whether a given fragment is from a goblet or a cup. Functionally, however, there are not known to be any significant differences between the uses to which 
these various vessel types were put, beyond basic considerations of size and capacity (volume). Differences of form appear to be primarily, if not exclusively, aesthetic. Especially when they are found in churches, any or all the following forms may have served as oil lamps rather than drinking vessels. ${ }^{335}$

The fragments discussed below have been divided by these stylistic criteria into four groups, each with further sub-groups. There are two groups of rim-fragments, subdivided according to whether they come from vessels with cylindrical or tapering sides (Dussart's Types BVIII.1 and BVIII.2, respectively). Both types are common here and elsewhere. In addition, there are two types of base fragments, also subdivided according to their shape. The group of pedestal bases (that is, goblet-bases) includes two sub-varieties: solid and folded (Dussart's Types BVIII.121 and BVIII.2112). The group of waisted bases (that is, cup bases) also includes two sub-varieties: cylindrical stems plus folded, tubular rims, and solid stems plus plain rims (Dussart's Types BIX.1 and BIX.2).

\section{Goblet/cup rims with cylindrical sides}

This type is common on this site and elsewhere, but difficult to date because the form is both simple (lacking distinguishing marks) and long-lived (persisting from before the Common Era through the Islamic era).

Most examples are simple, with relatively thin, straight walls and flame polished, slightly thickened rims. The simplest type of rim (No. 97) is simply an extension of the vessel wall (Dussart's type BVIII.111). More typically, flame polishing has produced some thickening of the rim (Nos. 95-96, 98-99; Dussart's type BVIII.112). Often, the rim exhibits a degree of flaring. Sometimes the flare is inward (Nos. 100 and 101, Dussart BVIII.15), sometimes inthen-out (No. 102, Dussart BVIII.1221a), and occasionally out-and-down (Dussart type BVIII.1222), either diagonally (No. 103) or almost horizontally (No. 104).

Several examples are decorated with applied threads. In the case of No. 98, this was somewhat crudely done, with the thread varying greatly in diameter and mostly perching atop the vessel wall. On No. 99, the thread was more carefully applied, fusing with the wall so that it penetrates the wall, and being of a strikingly beautiful colour to boot.

Group 13: Goblet/cup rims with cylindrical sides (10 pieces: see drawings in Illustration 11)

\begin{tabular}{|l|l|l|l|l|}
\hline No. & Loc. & Basket & Description & Parallels \\
\hline 95 & 1948 & 2493.10 & $\begin{array}{l}\text { Flame polished, slightly thickened rim of } \\
\text { cylindrical goblet. Rim continuous with } \\
\text { the vessel wall, diameter 90 mm; 15\% of } \\
\text { rim circumference extant. Rim 1.5 mm }\end{array}$ & $\begin{array}{l}\text { Dussart 96 (Type BVIII.112), } \\
\text { early Roman-Umayyad but espe- } \\
\text { cially Byzantine. }\end{array}$ \\
\hline
\end{tabular}

${ }^{335}$ Crowfoot and Harden, "Early Byzantine and Later Glass Lamps," 200; Dussart, Le verre en Jordanie et en Syrie du Sud, 120. 


\begin{tabular}{|c|c|c|c|c|}
\hline & & & $\begin{array}{l}\text { thick; wall } 1 \mathrm{~mm} \text { thick. Preserved height } \\
18 \mathrm{~mm} \text {. Light aqua fabric (von Saldern \#1), } \\
\text { with numerous elongated bubbles parallel } \\
\text { and close to the rim. }\end{array}$ & \\
\hline 96 & 1931 & $\begin{array}{l}2443.21 \\
2443.22\end{array}$ & $\begin{array}{l}\text { Flame polished, thickened rim of cylindri- } \\
\text { cal goblet. Rim continuous with the vessel } \\
\text { wall, diameter } 70 \mathrm{~mm} \text {; } 33 \% \text { of rim circum- } \\
\text { ference extant in two contiguous frag- } \\
\text { ments (broken in antiquity). Rim } 2 \mathrm{~mm} \\
\text { thick; wall } 1 \mathrm{~mm} \text { thick. Preserved height } \\
29 \mathrm{~mm} \text {. Light aqua fabric (von Saldern \#1). }\end{array}$ & See No. 95. \\
\hline 97 & 1938 & 2449.1 & $\begin{array}{l}\text { Flame polished rim of cylindrical goblet. } \\
\text { Rim continuous with the vessel wall, di- } \\
\text { ameter } 70 \mathrm{~mm} \text {; } 28 \% \text { of rim circumference } \\
\text { extant. Rim and wall } 2 \mathrm{~mm} \text { thick. Pre- } \\
\text { served height } 28 \mathrm{~mm} \text {. Seven thin threads } \\
\text { applied to wall, } 16-27 \mathrm{~mm} \text { below rim. Pale } \\
\text { green fabric (von Saldern \#2). }\end{array}$ & $\begin{array}{l}\text { Dussart 95-96 (Type BVIII.111), } \\
\text { Byzantine-Umayyad. }\end{array}$ \\
\hline 98 & 563 & 2133.5 & $\begin{array}{l}\text { Flame polished, slightly thickened rim of } \\
\text { cylindrical goblet. Rim continuous with } \\
\text { the vessel wall. Rim diameter } 70 \mathrm{~mm} ; 19 \% \\
\text { of rim circumference extant. Rim } 2.5 \mathrm{~mm} \\
\text { thick; wall } 1.5 \mathrm{~mm} \text { thick. Preserved height } \\
36 \mathrm{~mm} \text {. One rather crude thread applied to } \\
\text { wall, } 31 \mathrm{~mm} \text { below rim. Light aqua fabric } \\
\text { (von Saldern \#1). }\end{array}$ & See No. 95. \\
\hline 99 & 1931 & 2443.42 & $\begin{array}{l}\text { Flame polished, thickened rim of cylindri- } \\
\text { cal goblet. Rim continuous with the vessel } \\
\text { wall. Rim diameter } 70 \mathrm{~mm} \text {; } 9 \% \text { of rim cir- } \\
\text { cumference extant. Rim } 2.5 \mathrm{~mm} \text { thick; } \\
\text { wall } 1 \mathrm{~mm} \text { thick. Preserved height } 24 \mathrm{~mm} \text {. } \\
\text { Two blue threads applied to (and fused } \\
\text { with) wall, at rim and } 8 \mathrm{~mm} \text { below rim. Al- } \\
\text { most colorless fabric (von Saldern } \# 5 \text { ). }\end{array}$ & See No. 95. \\
\hline 100 & 1931 & $\begin{array}{l}2443.29 \\
2443.31\end{array}$ & $\begin{array}{l}\text { Flame polished, thickened rim of cylindri- } \\
\text { cal goblet. Rim flares out from vessel wall, } \\
\text { then turns slightly in at top. Rim diameter } \\
80 \mathrm{~mm} \text {; } 20 \% \text { of rim circumference extant } \\
\text { in two fragments (not contiguous). Rim } 3 \\
\text { mm thick; wall } 1 \mathrm{~mm} \text { thick. Preserved } \\
\text { height } 20 \mathrm{~mm} \text {. Light aqua fabric (von } \\
\text { Saldern \#1). }\end{array}$ & $\begin{array}{l}\text { Dussart 104-106 (Type BVIII.15), } \\
\text { Byzantine-Umayyad. }\end{array}$ \\
\hline
\end{tabular}




\begin{tabular}{|l|l|l|l|l|}
\hline 101 & 547 & 1913.1 & $\begin{array}{l}\text { Flame polished, thickened rim of cylindri- } \\
\text { cal goblet. Rim turns in, markedly, at top. } \\
\text { Rim diameter 75 mm; 28\% of rim circum- } \\
\text { ference extant. Rim 2.5 mm thick; wall 1 } \\
\text { mm thick. Preserved height 14 mm. Light } \\
\text { aqua fabric (von Saldern \#1). }\end{array}$ & See No. 100. \\
\hline 102 & 1226 & 2365.10 & $\begin{array}{l}\text { Flame polished, thickened rim of cylindri- } \\
\text { cal goblet. Rim flares out slightly at top. } \\
\text { Rim diameter 90 mm; 18\% of rim circum- } \\
\text { ference extant. Rim 2 mm thick; wall 1 } \\
\text { mm thick. Preserved height 33 mm. Pale } \\
\text { green fabric (von Saldern \#2). }\end{array}$ & $\begin{array}{l}\text { Dussart 98-101 (Type } \\
\text { BVIII.1221a), first century BCE- } \\
\text { Umayyad, concentrated in fifth- } \\
\text { sixth century. }\end{array}$ \\
\hline 103 & 557 & 2083.1 & $\begin{array}{l}\text { Flame polished, thickened rim of cylindri- } \\
\text { cal goblet. Rim flares out sharply at top. } \\
\text { Rim diameter 70 mm; 28\% of rim circum- } \\
\text { ference extant. Rim 2 mm thick; wall 1 } \\
\text { mm thick. Preserved height 15 mm. Light } \\
\text { aqua fabric (von Saldern \#1). }\end{array}$ & $\begin{array}{l}\text { Dussart 101-103 (Type } \\
\text { BVIII.1222), first century BCE- } \\
\text { Umayyad, especially Byzantine- } \\
\text { Umayyad; Hayes 64, second- } \\
\text { third century. }\end{array}$ \\
\hline 104 & 2136 & 3407.9 & $\begin{array}{l}\text { Flame polished, thickened rim of cylindri- } \\
\text { cal goblet. Rim flares out sharply-almost } \\
\text { horizontally-at top. Rim diameter 70 } \\
\text { mm; 27\% of rim circumference extant. } \\
\text { Rim 2 mm thick; wall 1 mm thick. Pre- } \\
\text { served height 20 mm. Light aqua fabric } \\
\text { (von Saldern \#1). }\end{array}$ & See No. 103. \\
\hline
\end{tabular}

\section{Goblet/cup rims with tapering sides}

This was a very common vessel type, surviving in large numbers on this site and elsewhere and known from the first century BCE through the Umayyad era. It is especially common in Byzantine times. ${ }^{336}$

The straight rim of No. 105, which is merely a flame polished extension of the vessel wall, is the simplest form (compare Nos. 108-112). Nos. 106 and 107 have an unusual, slightly incurving profile. Nos. 113-114 illustrate a variant, sharply out-flaring rim type; No. 113's is diagonal while that of No. 114 is nearly horizontal (compare Nos. 100-104 for a similar set of variations within the cylindrical type of goblet).

Unusually, the interior and exterior walls of two examples show clear evidence of wheel polishing (Nos. 113 and 114).

${ }^{336}$ Dussart, Le verre en Jordanie et en Syrie du Sud, 110. 
Group 14: Goblet/cup rims with tapering sides (10 pieces: see drawings in Illustration 11 and 12)

\begin{tabular}{|c|c|c|c|c|}
\hline No. & Loc. & Basket & Description & Parallels \\
\hline 105 & 1206 & 2099.3 & $\begin{array}{l}\text { Flame polished, thickened rim of taper- } \\
\text { ing-sided goblet. Rim continuous with the } \\
\text { vessel wall. Rim diameter } 95 \mathrm{~mm} ; 22 \% \text { of } \\
\text { rim circumference extant. Rim } 2.5 \mathrm{~mm} \\
\text { thick; wall } 1 \mathrm{~mm} \text { thick. Preserved height } \\
22 \mathrm{~mm} \text {. Light aqua fabric (von Saldern \#1). }\end{array}$ & $\begin{array}{l}\text { Dussart 107-110 (Type } \\
\text { BVIII.2113), early Roman } \\
\text { through Umayyad; widespread in } \\
\text { Byzantine. }\end{array}$ \\
\hline 106 & 1931 & $\begin{array}{l}2443.39 \\
2443.40\end{array}$ & $\begin{array}{l}\text { Flame polished, thickened rim of taper- } \\
\text { ing-sided goblet. Rim flares outward, then } \\
\text { slightly inward at top. Rim diameter } 90 \\
\text { mm; } 29 \% \text { of rim circumference extant in } \\
\text { two contiguous fragments (broken in an- } \\
\text { tiquity). Rim } 3 \mathrm{~mm} \text { thick; wall } 1 \mathrm{~mm} \text { thick. } \\
\text { Preserved height } 29 \mathrm{~mm} \text {. Pale green fabric } \\
\text { (von Saldern \#2). }\end{array}$ & $\begin{array}{l}\text { See No. } 105 \text { but note that this } \\
\text { rim profile resembles Dussart's } \\
\text { Type BVIII.1222 (similar dating). }\end{array}$ \\
\hline 107 & 548 & 2167.2 & $\begin{array}{l}\text { Flame polished, thickened rim of taper- } \\
\text { ing-sided goblet. Rim flares outward, then } \\
\text { slightly inward at top. Rim diameter } 85 \\
\text { mm; } 18 \% \text { of rim circumference extant. } \\
\text { Rim } 3 \text { mm thick; wall } 1 \text { mm thick. Pre- } \\
\text { served height } 30 \mathrm{~mm} \text {. Almost colorless } \\
\text { fabric (von Saldern \#5). }\end{array}$ & See No. 106. \\
\hline 108 & 2136 & 3407.3 & $\begin{array}{l}\text { Flame polished, slightly thickened rim of } \\
\text { tapering-sided goblet. Rim continuous } \\
\text { with the vessel wall. Rim diameter } 60 \mathrm{~mm} \text {; } \\
32 \% \text { of rim circumference extant. Rim } 2 \\
\text { mm thick; wall } 1.5 \mathrm{~mm} \text { thick. Preserved } \\
\text { height } 58 \mathrm{~mm} \text {. Light aqua fabric (von } \\
\text { Saldern \#1). }\end{array}$ & See No. 105. \\
\hline 109 & 1931 & 2443.34 & $\begin{array}{l}\text { Flame polished, slightly thickened rim of } \\
\text { tapering-sided goblet. Rim continuous } \\
\text { with the vessel wall. Rim diameter } 90 \mathrm{~mm} \text {; } \\
14 \% \text { of rim circumference extant. Rim } 2.5 \\
\text { mm thick; wall } 1.5 \mathrm{~mm} \text { thick. Preserved } \\
\text { height } 48 \mathrm{~mm} \text {. Light aqua fabric (von } \\
\text { Saldern \#1). }\end{array}$ & See No. 105. \\
\hline 110 & 1226 & 2325.1 & $\begin{array}{l}\text { Flame polished, slightly thickened rim of } \\
\text { tapering-sided goblet. Rim continuous } \\
\text { with the vessel wall. Rim diameter } 90 \mathrm{~mm} \text {; } \\
22 \% \text { of rim circumference extant. Rim } 1.5\end{array}$ & See No. 105. \\
\hline
\end{tabular}




\begin{tabular}{|c|c|c|c|c|}
\hline & & & $\begin{array}{l}\mathrm{mm} \text { thick; wall } 1 \mathrm{~mm} \text { thick. Preserved } \\
\text { height } 14 \mathrm{~mm} \text {. Light aqua fabric (von } \\
\text { Saldern \#1). }\end{array}$ & \\
\hline 111 & 1931 & $\begin{array}{l}2443.32 \\
2433.33\end{array}$ & $\begin{array}{l}\text { Flame polished, slightly thickened rim of } \\
\text { tapering-sided goblet. Rim continuous } \\
\text { with the vessel wall. Rim diameter } 85 \mathrm{~mm} \text {; } \\
32 \% \text { of rim circumference extant in two } \\
\text { contiguous fragments (broken in antiq- } \\
\text { uity). Rim } 2 \mathrm{~mm} \text { thick; wall } 1.5 \mathrm{~mm} \text { thick. } \\
\text { Preserved height } 44 \mathrm{~mm} \text {. Light aqua fabric } \\
\text { (von Saldern \#1). }\end{array}$ & See No. 105. \\
\hline 112 & 557 & 2112 & $\begin{array}{l}\text { Flame polished, slightly thickened rim of } \\
\text { tapering-sided goblet. Rim continuous } \\
\text { with the vessel wall. Rim diameter } 70 \mathrm{~mm} \text {; } \\
26 \% \text { of rim circumference extant. Rim } 2.5 \\
\text { mm thick; wall } 12 \mathrm{~mm} \text { thick. Preserved } \\
\text { height } 62 \mathrm{~mm} \text {. Pale green fabric (von } \\
\text { Saldern \#2). }\end{array}$ & See No. 105. \\
\hline 113 & 1226 & $\begin{array}{l}5460.39 \\
5460.40\end{array}$ & $\begin{array}{l}\text { Flame polished, slightly thickened rim of } \\
\text { tapering-sided goblet. Rim sharply flaring, } \\
\text { almost horizontal. Numerous horizontal } \\
\text { wheel-polishing lines on interior and ex- } \\
\text { terior. Rim diameter } 70 \mathrm{~mm} ; 21 \% \text { of rim } \\
\text { circumference extant. Rim } 2.5 \mathrm{~mm} \text { thick; } \\
\text { wall } 1.0 \mathrm{~mm} \text { thick. Preserved height } 41 \\
\text { mm. Light aqua fabric (von Saldern } \# 1 \text { ). }\end{array}$ & $\begin{array}{l}\text { Dussart 111-112 (Type } \\
\text { BVIII.2123), early Roman-Umay- } \\
\text { yad, especially late fourth-early } \\
\text { sixth century. }\end{array}$ \\
\hline 114 & 1248 & 5438.2 & $\begin{array}{l}\text { Flame polished, slightly thickened rim of } \\
\text { tapering-sided goblet. Rim flares outward. } \\
\text { Two horizontal wheel-polishing lines on } \\
\text { interior. Rim diameter } 70 \mathrm{~mm} ; 21 \% \text { of rim } \\
\text { circumference extant. Rim } 2.5 \mathrm{~mm} \text { thick; } \\
\text { wall } 1.0 \mathrm{~mm} \text { thick. Preserved height } 23 \\
\text { mm. Pale green fabric (von Saldern } \# 2 \text { ). }\end{array}$ & See No. 113. \\
\hline
\end{tabular}

\section{Goblet bases (pedestal type)}

These bases feature two divergent profiles. The first sub-type is characteristic of the Byzantine era in the Syro-Palestinian region, ${ }^{337}$ although many examples stem from Jordan as well, mostly from the same time-period (her Type BVIII.121). ${ }^{338}$ This kind of base is solid, usually with a slight narrowing to form a thick "neck" before the body flares outward and

\footnotetext{
${ }^{337}$ Weinberg and Goldstein, "The Glass Vessels," 60.

${ }^{338}$ Dussart, Le verre en Jordanie et en Syrie du Sud, 96-98.
} 
upward, often quite vertically. Such vessels typically have a prominent dome on the interior of their bottom surface.

The first two fragments (Nos. 115 and 116) are typical examples of this type, as are Nos. 119 and 120. By contrast, No. 116 is rather small, No. 117 is rather large, and No. 118 rather asymmetrical. No. 121 is unusual in lacking a narrowed neck; instead, the base flares sharply outward into the body. Perhaps it served as a "self-standing" lamp. Another distinctive variation is No. 122, which has a distorted, irregular base and a relatively tall and narrow neck. Because of these features, this example seems to bridge the gap between goblets and cups.

The second sub-type (Dussart's BVIII.2112) has a folded base that was formed by means of a sharp outward fold that was then further folded inward to create a tube-like rim. Less common overall, it is represented here by six examples (Nos. 123-128). This type of base may have given rise to the waisted cup ("wineglass" type) in the late fourth century. Certainly, the two types of vessels have similar bases.

The diameter and shape of these vessels' bodies could vary considerably (compare Nos. 127 and 128). The former is notable for having a narrow cylindrical body atop a relatively wide base; the body of the latter seems to have been round. The tapering sides of Nos. 123 and 124 are perhaps more typical.

Some bases are mostly flat (Nos. 123 and 126); others rise to form a prominent hollow (Nos. 124 and 125). The last example (No. 128) has an unusually high dome within its base and, like Nos. 122 and 127, features a very well-defined neck between its body and base.

Group 15: Goblet bases (pedestal type) (14 pieces: see drawings in Illustration 12)

\begin{tabular}{|c|c|c|c|c|}
\hline No. & Loc. & Basket & Description & Parallels \\
\hline 115 & 1930 & 2442.1 & $\begin{array}{l}\text { Intact solid pedestal-foot of goblet. Promi- } \\
\text { nent convex “dome" on top surface of } \\
\text { base, protruding into body. Base diameter } \\
45 \mathrm{~mm} \text {, narrowing to } 31 \mathrm{~mm} \text {; body flaring } \\
\text { outward and upward into cylindrical body } \\
\text { (diameter ca. } 48 \mathrm{~mm} \text { ). Preserved height } 22 \\
\text { mm. Slight pontil mark. Pale green fabric } \\
\text { (von Saldern \#2). }\end{array}$ & $\begin{array}{l}\text { Von Saldern 1980:64, fifth-sixth } \\
\text { century; Meyer 1987:193, third- } \\
\text { seventh century; Weinberg } \\
\text { 1988:60, third-fifth century; } \\
\text { Dussart 96-98 (Type BVIII.121), } \\
\text { first century BCE-eighth century } \\
\text { (though most = fifth-sixth cen- } \\
\text { tury). }\end{array}$ \\
\hline 116 & 567 & 2056.2 & $\begin{array}{l}\text { Intact solid pedestal-foot of goblet. Promi- } \\
\text { nent convex "dome" on top surface of } \\
\text { base, protruding into body. Base diameter } \\
43 \mathrm{~mm} \text {, narrowing to } 38 \mathrm{~mm} \text {; body gently } \\
\text { flaring outward into cylindrical body (di- } \\
\text { ameter ca. } 50 \mathrm{~mm} \text { ). Preserved height } 22\end{array}$ & See No. 115. \\
\hline
\end{tabular}




\begin{tabular}{|c|c|c|c|c|}
\hline & & & $\begin{array}{l}\text { mm. Rough pontil mark. Light aqua fabric } \\
\text { (von Saldern \#1). }\end{array}$ & \\
\hline 117 & 1215 & 2164.3 & $\begin{array}{l}\text { Intact solid pedestal-foot of goblet. Care- } \\
\text { fully made, with regular and pleasing con- } \\
\text { tours. Prominent convex “dome” on top } \\
\text { surface of base, protruding into body. Base } \\
\text { diameter } 37 \mathrm{~mm} \text {, narrowing to } 32 \mathrm{~mm} \text {; } \\
\text { body slightly flaring outward into cylindri- } \\
\text { cal body (diameter ca. } 36 \mathrm{~mm} \text { ). Preserved } \\
\text { height } 17 \mathrm{~mm} \text {. Coarse pontil mark. Pale } \\
\text { green fabric (von Saldern \#2). }\end{array}$ & See No. 115. \\
\hline 118 & 2101 & 3152.1 & $\begin{array}{l}\text { Solid pedestal-foot of goblet. Slight } \\
\text { "dome" on top surface of base, but signifi- } \\
\text { cant concavity beneath it. Base diameter } \\
55 \mathrm{~mm} \text {, narrowing to ca. } 35 \mathrm{~mm} \text { before } \\
\text { out-and-up turn to body. } 45 \% \text { of base cir- } \\
\text { cumference preserved. Preserved height } 11 \\
\text { mm. Slight pontil mark. Pale green fabric } \\
\text { (von Saldern \#2). }\end{array}$ & See No. 115. \\
\hline 119 & 1296 & 2379.1 & $\begin{array}{l}\text { Intact solid pedestal-foot of goblet. Care- } \\
\text { lessly made, with body of vessel poorly } \\
\text { centred on base. Slight "dome" on top sur- } \\
\text { face of base, and slight concavity beneath } \\
\text { it. Base diameter } 50 \mathrm{~mm} \text {, narrowing to } 44 \\
\text { mm. Body profile unknown. Preserved } \\
\text { height } 16 \mathrm{~mm} \text {. Slight pontil mark. Pale } \\
\text { green fabric (von Saldern \#2). }\end{array}$ & See No. 115. \\
\hline 120 & 2145 & 3444.9 & $\begin{array}{l}\text { Intact solid pedestal-foot of goblet. Slight } \\
\text { "dome" on top surface of base, and slight } \\
\text { concavity beneath it. Base diameter } 50 \\
\text { mm, narrowing to } 44 \mathrm{~mm} \text {, sharply flaring } \\
\text { out and up into body of at least } 70 \mathrm{~mm} \text { di- } \\
\text { ameter Preserved height } 17 \mathrm{~mm} \text {. Pontil } \\
\text { mark. Pale green fabric (von Saldern } \# 2 \text { ). }\end{array}$ & See No. 115. \\
\hline 121 & 567 & 2014.3 & $\begin{array}{l}\text { Intact solid pedestal-foot of goblet (or } \\
\text { lamp?). Slight "dome” on top surface of } \\
\text { base, and slight concavity beneath it. Base } \\
\text { diameter } 36 \mathrm{~mm} \text {; no narrowing, but } \\
\text { sharply flaring out and up into body of at } \\
\text { least } 55 \mathrm{~mm} \text { diameter Preserved height } 17 \\
\text { mm. Tidy pontil mark. Pale green fabric } \\
\text { (von Saldern \#2). }\end{array}$ & $\begin{array}{l}\text { See No. } 115 \text {. The shortness and } \\
\text { flatness of this base suggest that } \\
\text { it might have served as a self- } \\
\text { standing oil-lamp. }\end{array}$ \\
\hline 122 & 567 & 2052.6 & $\begin{array}{l}\text { Intact solid pedestal-foot of goblet. Very } \\
\text { slight "dome" on top surface of base. } \\
\text { Poorly made, highly irregular concave }\end{array}$ & $\begin{array}{l}\text { See No. } 115 . \text { Note the similar } \\
\text { waist-profile of No. } 128 .\end{array}$ \\
\hline
\end{tabular}




\begin{tabular}{|c|c|c|c|c|}
\hline & & & $\begin{array}{l}\text { base, } 4.0 \mathrm{~mm} \text { thick and ca. } 42 \mathrm{~mm} \text { diame- } \\
\text { ter, narrowing in diameter to } 21 \mathrm{~mm} \text {; sides } \\
\text { flaring sharply out and up into body of at } \\
\text { least } 65 \mathrm{~mm} \text { diameter Preserved height } 29 \\
\mathrm{~mm} \text {. Slight pontil mark. Light aqua fabric } \\
\text { (von Saldern \#1). }\end{array}$ & \\
\hline 123 & 2136 & 3407.12 & $\begin{array}{l}\text { Intact folded pedestal-foot of goblet. } \\
\text { Pushed-in base rises } 11 \mathrm{~mm} \text {, creating con- } \\
\text { vex "dome” in bottom of body. Visible hol- } \\
\text { low in tube at rim of base. Base diameter } \\
48 \mathrm{~mm} \text {, narrowing to } 35 \mathrm{~mm} \text { before body } \\
\text { tapers gently outward and upward. Pre- } \\
\text { served height } 46 \mathrm{~mm} \text {. Coarse pontil mark. } \\
\text { Light aqua fabric (von Saldern \#1). }\end{array}$ & $\begin{array}{l}\text { Von Saldern 1980:22, second- } \\
\text { third century; Meyer 1987:187, } \\
\text { first to seventh century; Wein- } \\
\text { berg 1988:62, third to mid-fourth } \\
\text { century; Dussart } 107 \text { (Type } \\
\text { BVIII.2112), late fourth-early } \\
\text { sixth century, some as late as } \\
\text { Umayyad period. }\end{array}$ \\
\hline 124 & 2133 & 3420.3 & $\begin{array}{l}\text { Folded pedestal-foot of goblet. Pushed-in } \\
\text { base rises } 10 \mathrm{~mm} \text {, creating convex "dome” } \\
\text { in bottom of body. No hollow in tube at rim } \\
\text { of base. Base diameter } 48 \mathrm{~mm} \text {, narrowing } \\
\text { to } 46 \mathrm{~mm} \text { before body tapers gently out- } \\
\text { ward and upward. Preserved height } 26 \mathrm{~mm} \text {. } \\
\text { Slight pontil mark. Pale green fabric (von } \\
\text { Saldern \#2). }\end{array}$ & See No. 123. \\
\hline 125 & 1226 & 2240 & $\begin{array}{l}\text { Intact folded pedestal-foot of goblet. } \\
\text { Pushed-in base rises } 9 \mathrm{~mm} \text {, creating con- } \\
\text { vex-but offset-“dome” in bottom of } \\
\text { body. Flat, wide hollow in tube at rim of } \\
\text { base. Base diameter } 46 \mathrm{~mm} \text {, } 70 \% \text { of rim cir- } \\
\text { cumference extant. Base narrows to } 34 \mathrm{~mm} \\
\text { before flaring outward and upward into cy- } \\
\text { lindrical body (diameter ca. } 48 \mathrm{~mm} \text { ). Pre- } \\
\text { served height } 15 \mathrm{~mm} \text {. Slight pontil mark. } \\
\text { Light aqua fabric (von Saldern } \# 1 \text { ). }\end{array}$ & See No. 123. \\
\hline 126 & 2135 & 3444.10 & $\begin{array}{l}\text { Intact folded pedestal-foot of goblet. } \\
\text { Pushed-in base rises irregularly up to } 4 \\
\mathrm{~mm} \text {, creating "dome” in bottom of body. } \\
\text { Small, round hollow in tube at rim of base. } \\
\text { Base slightly oval, max. diameter } 29 \mathrm{~mm} \text {, } \\
100 \% \text { of rim circumference extant. Base } \\
\text { narrows to } 25 \mathrm{~mm} \text { before flaring outward. } \\
\text { Body profile unknown. Preserved height } 7 \\
\text { mm. Slight pontil mark. Light aqua fabric } \\
\text { (von Saldern \#1). }\end{array}$ & See No. 123. \\
\hline
\end{tabular}




\begin{tabular}{|l|l|l|l|l|}
\hline 127 & 1226 & 2344.16 & $\begin{array}{l}\text { Intact folded pedestal-foot of goblet. } \\
\text { Pushed-in base rises 12 mm, creating con- } \\
\text { vex “dome” in bottom of body. Prominent } \\
\text { tube-shape at rim of asymmetrically } \\
\text { domed base. Base diameter 48 mm, nar- } \\
\text { rowing to 14 mm before flaring sharply } \\
\text { outward then upward into cylindrical body } \\
\text { (diameter ca. 34 mm). Preserved height 29 } \\
\text { mm. Slight pontil mark. Light aqua fabric } \\
\text { (von Saldern \#1) }\end{array}$ & See No. 123. \\
\hline 128 & 1226 & 2344.14 & $\begin{array}{l}\text { Folded pedestal-foot of goblet. Very wide, } \\
\text { pushed-in base rises at least 10 mm. No } \\
\text { "dome” on top surface of base. Base diam- } \\
\text { eter at least 45 mm, narrowing to 32 mm } \\
\text { before flaring outward then upward into } \\
\text { body (diameter at least } 60 \text { mm). Preserved } \\
\text { height 24 mm. Slight pontil mark. Pale } \\
\text { green fabric (von Saldern \#2). }\end{array}$ & See No. 123. Note the similar \\
waist-profile of No. 122. & \\
\hline
\end{tabular}

\section{Cup bases (waisted type)}

Unfortunately, the bodies of goblets and cups are more fragile than their bases, with the result that "ces vases... sont essentiallement connus par des fragments de pieds." 339 Certainly here in the NIP, base fragments are very common, both in residential contexts and in the Northeast Church, where they presumably represent vessels that served as lamps.

Nos. 129-134 represent the first sub-group, the "folded-foot" type. These have a cylindrical waist that arises from a circular base with a folded, tubular rim (Dussart's Type BIX.1). Some of these bases are quite conical (Nos. 131 and 132); others relatively flat (No. 133). On most examples, the waist portion is hollow for a significant part of its height (an exception is No. 133). Although this style of cup is known from Roman times, most Near Eastern examples are late Byzantine (fifth-seventh century) or Islamic (Umayyad-Abbasid, eighth-thirteenth century). ${ }^{340}$

Nos. 135-140 illustrate the other sub-group, the "plain-foot” type (Dussart's BIX.2). These have a solid stem that typically includes a thick, spherical bulge. The base is usually a simple, flat disc with unadorned edges. Similar cups are known as early as the second century, but they are most common in the late Byzantine and especially the Umayyad period, by which point they significantly out-number the folded-foot type. ${ }^{341}$

\footnotetext{
${ }^{339}$ Ibid., 120.

${ }^{340}$ Meyer, "Glass from the North Theater Byzantine Church, and Soundings at Jerash, Jordan, 1982-1983,” 199.

${ }^{341}$ Dussart, Le verre en Jordanie et en Syrie du Sud, 124.
} 
Among the fragments presented here, crude workmanship is evident in examples of both sub-types: No. 134 (cylindrical stem, folded base rim); Nos. 135 and 140 (solid stems, disc bases). Disc bases are seldom uniformly round, and the bodies of such cups are sometimes canted askew (compare the two halves of the drawings of Nos. 138 and 139). On the other hand, greater care is clear in other examples of both types: No. 133 (cylindrical stem, folded base rim); No. 135 and 139 (solid stems, disc bases). This suggests that both types co-existed through different time-periods, although the more technically advanced folded-foot type tends to be dominant somewhat earlier and the simpler flat-foot type somewhat later. ${ }^{342}$

Contrasting shapes are represented especially by Nos. 129 and 133 (massive vs. delicate), and Nos. 133 and 138 (tapering vs. cylindrical body). Several examples show clear evidence of twisting, perhaps as a decorative technique (Nos. 131, 135, 138, 140). Tooling is also visible on numerous pieces (Nos. 135-140), mostly on the base but sometimes also at the top of the waist (Nos. 136, 137). In some cases, this tooling may have been decorative, not merely functional. ${ }^{343}$ Contrast the diagonal, parallel, regularly spaced slashes on the base of No. 139 with the cruder ones on No. 140. In the latter case, this tooling probably reflects the obvious joining of two different paraisons (masses of molten glass) to form its stem and its base. Equally curiously, the pontil mark on No. 134 shows traces of a different-coloured glass, while that on No. 135 still has a small part of a cracked-off glass tube attached.

Group 16: Cup bases (waisted type) (12 pieces: see drawings in Illustrations 12 and 13)

\begin{tabular}{|l|l|l|l|l|}
\hline No. & Loc. & Basket & Description & Parallels \\
\hline 129 & 1205 & 2168.1 & $\begin{array}{l}\text { Cylindrical hollow stem and folded base } \\
\text { rim of very big waisted cup. Folded base } \\
\text { rises 15 mm, 4-8 mm thick, with 90 mm } \\
\text { diameter; 43\% of rim circumference ex- } \\
\text { tant. Tubular base rim 6 mm high x 10 mm } \\
\text { wide. Preserved height 24 mm. Pontil } \\
\text { mark 12 mm wide. Waist diameter 28 mm } \\
\text { (fabric itself not preserved). Pale green } \\
\text { fabric (von Saldern \#2) }\end{array}$ & $\begin{array}{l}\text { Isings 139 (Form 111), fourth } \\
\text { century onward; Von Saldern } \\
\text { 1980:58, sixth-seventh century; } \\
\text { Meyer 1987:199, late Byzantine/ } \\
\text { Umayyad; Dussart 121 (Type } \\
\text { BIX.1), first-thirteenth century, } \\
\text { but mostly fifth-eighth century; } \\
\text { Pollak 171, fifth-seventh cen- } \\
\text { tury. }\end{array}$ \\
\hline 130 & 2118 & 3165.4 & $\begin{array}{l}\text { Cylindrical hollow stem and thick folded } \\
\text { base rim of very big waisted cup. Folded } \\
\text { base rises 15 mm, 8 mm thick, with 60 mm } \\
\text { diameter; 53\% of rim circumference ex- } \\
\text { tant. Tubular base rim 6 mm high x 10 mm }\end{array}$ & See No. 129. \\
\hline
\end{tabular}

\footnotetext{
${ }^{342}$ Meyer, "Glass from the North Theater Byzantine Church, and Soundings at Jerash, Jordan, 1982-1983," 199.

${ }^{343}$ Ibid., 201.
} 


\begin{tabular}{|c|c|c|c|c|}
\hline & & & $\begin{array}{l}\text { wide. Pontil mark } 17 \mathrm{~mm} \text { wide. Waist di- } \\
\text { ameter } 20 \mathrm{~mm} \text { (fabric itself not preserved). } \\
\text { Pale green fabric (von Saldern } \# 2 \text { ). }\end{array}$ & \\
\hline 131 & 587 & 2040.1 & $\begin{array}{l}\text { Well-made, cylindrical hollow stem and } \\
\text { folded base rim of waisted cup. Folded } \\
\text { base rises } 11 \mathrm{~mm} \text {, with } 48 \mathrm{~mm} \text { diameter; } \\
100 \% \text { of rim circumference extant. Tubu- } \\
\text { lar rim } 5 \mathrm{~mm} \text { high x } 6 \mathrm{~mm} \text { wide. Preserved } \\
\text { height } 33 \mathrm{~mm} \text {. Pontil mark } 14 \mathrm{~mm} \text { wide. } \\
\text { Waist diameter } 17 \mathrm{~mm} \text { high x } 17 \mathrm{~mm} \text { wide; } \\
\text { height } 12 \mathrm{~mm} \text {. Decorative twisting, both } \\
\text { in base and in waist. Slight irregularities } \\
\text { in folded base rim. Light aqua fabric (von } \\
\text { Saldern \#1). }\end{array}$ & See No. 129. \\
\hline 132 & 1226 & 2322.9 & $\begin{array}{l}\text { Delicate cylindrical hollow stem and } \\
\text { folded base rim of waisted cup. Folded } \\
\text { base rises } 13 \mathrm{~mm} \text {, with } 45 \mathrm{~mm} \text { diameter; } \\
100 \% \text { of rim circumference extant. Tubu- } \\
\text { lar rim } 3 \mathrm{~mm} \text { high x } 2 \mathrm{~mm} \text { wide. Preserved } \\
\text { height } 37 \mathrm{~mm} \text {. Pontil mark } 12 \mathrm{~mm} \text { wide. } \\
\text { Waist diameter } 7.5-8.5 \mathrm{~mm} \text {; height } 10 \\
\text { mm. Pale green fabric (von Saldern \#2). }\end{array}$ & See No. 129. \\
\hline 133 & 1206 & 2160.1 & $\begin{array}{l}\text { Delicate, well-proportioned cylindrical } \\
\text { solid stem and folded base rim of waisted } \\
\text { cup. Folded base rises } 2.0 \mathrm{~mm} \text {, with } 40 \mathrm{~mm} \\
\text { diameter; } 38 \% \text { of rim circumference ex- } \\
\text { tant. Tubular rim diameter } 4 \mathrm{~mm} \text {. Pre- } \\
\text { served height } 27 \mathrm{~mm} \text {. Pontil mark } 10 \mathrm{~mm} \\
\text { wide. Waist diameter } 9 \mathrm{~mm} \text {; height } 11 \\
\mathrm{~mm} \text {. Body at least } 42 \mathrm{~mm} \text { wide, curving up } \\
\text { and out. Pale green fabric (von Saldern } \\
\# 2) \text {. }\end{array}$ & See No. 129. \\
\hline 134 & 567 & 2063.1 & $\begin{array}{l}\text { Cylindrical hollow stem and folded base } \\
\text { rim of waisted cup. Folded base rises } 4 \\
\text { mm, with } 39 \text { mm diameter; } 100 \% \text { pre- } \\
\text { served. Tubular rim diameter } 4-6 \mathrm{~mm} \text {. } \\
\text { Preserved height } 24 \text { mm. Pontil mark } 13 \\
\text { mm wide, with traces of green glass at- } \\
\text { tached. Waist diameter } 11 \mathrm{~mm} \text {; height } 14 \\
\text { mm. Light aqua fabric (von Saldern } \# 1 \text { ). }\end{array}$ & See No. 129. \\
\hline 135 & 1948 & 2478.1 & $\begin{array}{l}\text { Well-proportioned disc-type base, solid } \\
\text { stem, lower body of waisted cup. Base } \\
\text { rises } 10 \mathrm{~mm} \text {, with ca. } 43 \mathrm{~mm} \text { diameter (ir- } \\
\text { regular); } 100 \% \text { preserved. } 6 \text { parallel diago- } \\
\text { nal slashes in upper surface of base, in a }\end{array}$ & $\begin{array}{l}\text { Isings } 139 \text { (Form 111), fourth } \\
\text { century onward; Von Saldern } \\
\text { 1980:55, fifth-seventh century; } \\
\text { Dussart 121-124 (Type BIX.2), }\end{array}$ \\
\hline
\end{tabular}




\begin{tabular}{|c|c|c|c|c|}
\hline & & & $\begin{array}{l}\text { tight group. Small, off-centre pontil mark } \\
\text { with fragment of cracked-off hollow tube } \\
\text { attached ( } 2 \mathrm{~mm} \text { tall x } 9 \mathrm{~mm} \text { wide). Waist } \\
\text { bulges from } 14-16 \mathrm{~mm} \text { diameter; } 15 \mathrm{~mm} \\
\text { high. Body diameter } 50 \mathrm{~mm} \text {; flat bottom } \\
\text { with tapering sides. Preserved height } \\
\text { (body) } 30 \mathrm{~mm} \text {; overall } 54 \mathrm{~mm} \text {. Pale aqua } \\
\text { fabric (von Saldern \#1). }\end{array}$ & $\begin{array}{l}\text { second century onward, but es- } \\
\text { pecially common in Byzantine- } \\
\text { Umayyad eras. }\end{array}$ \\
\hline 136 & 1948 & 2483.1 & $\begin{array}{l}\text { Disc-type base, solid stem, lower body of } \\
\text { waisted cup. Base rises } 8 \mathrm{~mm} \text {, with } 42-44 \\
\text { mm diameter (irregular); } 100 \% \text { preserved. } \\
\text { Twisting lines in upper surface of base, ir- } \\
\text { regularly distributed. Small pontil mark. } \\
\text { Waist bulges from } 13-15 \mathrm{~mm} \text { diameter; } 15 \\
\text { mm high. Two pincer marks at top of } \\
\text { waist. Body diameter } 40 \mathrm{~mm} \text {; "flat" bot- } \\
\text { tom with very noticeable slope; tapering } \\
\text { sides. Preserved height (body) } 25 \mathrm{~mm} \text {; } \\
\text { overall } 49 \mathrm{~mm} \text {. Pale aqua fabric (von } \\
\text { Saldern \#1). }\end{array}$ & See No. 135. \\
\hline 137 & 1948 & 2483.2 & $\begin{array}{l}\text { Disc-type base, solid stem, lower body of } \\
\text { waisted cup. Base rises } 6 \mathrm{~mm} \text {, with } 43-45 \\
\text { mm diameter (irregular); } 100 \% \text { preserved. } \\
\text { Pronounced “step” in upper surface of } \\
\text { base. Small pontil mark. Waist bulges } \\
\text { from } 13-16 \mathrm{~mm} \text { diameter; } 16 \mathrm{~mm} \text { high. Six } \\
\text { pincer marks at top of waist. Body diame- } \\
\text { ter } 56 \mathrm{~mm} \text {; flat bottom with tapering } \\
\text { sides. Preserved height (body) } 7 \mathrm{~mm} \text {; over- } \\
\text { all } 30 \mathrm{~mm} \text {. Pale green fabric (von Saldern } \\
\# 2 \text {. }\end{array}$ & See No. 135. \\
\hline 138 & 1929 & 2432.1 & $\begin{array}{l}\text { Disc-type base, solid stem, lower body of } \\
\text { waisted cup. Base rises } 10 \mathrm{~mm} \text {, with } 44-49 \\
\text { mm diameter (irregular); } 100 \% \text { preserved. } \\
\text { Twisting lines in upper surface of base, ir- } \\
\text { regularly distributed. Small pontil mark. } \\
\text { Waist bulges from } 12-14 \mathrm{~mm} \text { diameter; } 15 \\
\text { mm high. Body diameter } 50 \mathrm{~mm} \text {; "flat" } \\
\text { bottom with very noticeable slope; cylin- } \\
\text { drical sides. Preserved height (body) } 8 \\
\text { mm; overall } 33 \mathrm{~mm} \text {. Light aqua fabric (von } \\
\text { Saldern \#1). }\end{array}$ & See No. 135. \\
\hline 139 & 567 & 2014.1 & $\begin{array}{l}\text { Disc-type base, solid stem, bottom of } \\
\text { waisted cup. Base rises } 3 \mathrm{~mm} \text {, with } 41-42\end{array}$ & See No. 135. \\
\hline
\end{tabular}




\begin{tabular}{|l|l|l|l|l|}
\hline & & $\begin{array}{l}\text { mm diameter (irregular); 100\% preserved. } \\
\text { Faint pontil mark. Twelve parallel regu- } \\
\text { larly spaced diagonal slashes in upper sur- } \\
\text { face of base. Waist bulges from 8-11 mm } \\
\text { diameter; 16 mm high. Body ca. 46 mm di- } \\
\text { ameter; flat bottom with sharp turn to } \\
\text { vertical wall. Preserved height (body) } 3 \\
\text { mm; overall 29 mm. Light aqua fabric (von } \\
\text { Saldern \#1). }\end{array}$ & \\
\hline 140 & 563 & 2043.2 & $\begin{array}{l}\text { Poorly made, disc-type base and solid } \\
\text { stem of waisted cup. Base rises 3 mm, 45- } \\
\text { 47 mm diameter (very irregular); 78\% of } \\
\text { rim circumference extant. Pontil mark 13 } \\
\text { mm diameter. Ca. twelve irregular diago- } \\
\text { nal slashes in upper surface of base, with } \\
\text { obvious joining of two paraisons. Waist } \\
\text { bulges from 12-16 mm diameter; 17 mm } \\
\text { high. Olive green fabric (von Saldern \#3). }\end{array}$ & See No. 135. \\
\hline
\end{tabular}

\section{Storage vessels}

The division points between the three sections of the following discussion are simple. The first section includes rim fragments, sorted by vessel type. Five groups are discernible: (1) squat, short-necked pots; (2) small delicate containers known as balsamaires; (3) small conical-necked bottles; (4) larger bottles with in-folded rims; and (5) assorted rims and necks decorated with threads. The second section comprises the neck sections of several vessels, ranging from small to large, further illustrating the diversity of bottles and flasks in this corpus. Finally, a selection of bottle bases represents another selection of vessels. Even though these categories are neither technically rigorous nor mutually exclusive, they are an efficient way of surveying the breadth and depth of the collection of fragments found on this site from storage vessels of many types. ${ }^{344}$

Because these fragments were subjected to an array of mechanical and hydraulic forces over a long period of time while the NIP site gradually filled with debris, there is a certain amount of "predictable unpredictability" in their survival. Because they were often decorated by folding or thickening, and because their basic morphology as small tubes is relatively strong, the rims of bottles and flasks tend to remain intact and are accordingly overrepresented in this assortment of fragments. By contrast, because they are bigger and less likely to be reinforced, the necks of most bottles and flasks are quite fragile and less likely to survive. In addition, bottle necks are not often useful as diagnostic pieces unless they are attached to a rim or a shoulder; this factor too contributes to their under representation in

\footnotetext{
${ }^{344}$ Note the similar methodology of Pollak, “The Glass,” 175-187.
} 
this study. Finally, much the same is true of the bases of most pots, bottles, and flasks, which seldom retain enough of their sidewall to enable a detailed description of the vessels from which they came. Both their rarity and their relative formlessness reduce their usefulness, and thus also their representation in this study.

\section{Pots}

The nine pieces below are the only identifiable pot fragments in this corpus. Their identification as such rests mostly upon the presence of a very short neck. Rim fragments from pots with longer necks (Dussart's Types BVII.24-29) are difficult to distinguish from fragments of goblets and bottles or flasks. Similarly, the rims of pots with no neck (Dussart's Type BVII.1) may look very much like fragments from bowls. Therefore, it is not surprising that most of the fragments presented here are quite small and fall into only a few categories. The first two have no neck at all. The next four have a very short neck that quickly flares out into a rounded body. The final three are notable for their distinctive but somewhat parallel pairs of features: two have very beautiful out-folded and in-turning rims (Nos. 147 and, especially, 148), the other has an in-folded and out-flaring rim (No. 149).

Group 17: Pots (9 pieces: see drawings in Illustration 13)

\begin{tabular}{|l|l|l|l|l|}
\hline No. & Loc. & Basket & Description & Parallels \\
\hline 141 & 1226 & 2322.1 & $\begin{array}{l}\text { In-folded, in-turning rim of spherical-bod- } \\
\text { ied pot. Rim diameter 80 mm; 19\% of rim } \\
\text { circumference extant. Rim 7.5 mm tall x 4 } \\
\text { mm thick; noticeable hollow at top of tube. } \\
\text { Body 1 mm thick. Preserved height 13 mm. } \\
\text { Light aqua fabric (von Saldern \#1). }\end{array}$ & $\begin{array}{l}\text { Dussart 89 (BVII.121), perhaps } \\
\text { late fourth / early sixth? (a rare } \\
\text { type). }\end{array}$ \\
\hline 142 & 1226 & 2322.2 & $\begin{array}{l}\text { Out-folded, in-turning rim of spherical- } \\
\text { bodied pot. Rim diameter 110 mm; 7\% of } \\
\text { rim circumference extant. Rim 5 mm tall x } \\
4 \text { mm thick. Body 1 mm thick. Preserved } \\
\text { height 11 mm. Light aqua fabric (von } \\
\text { Saldern \#1). }\end{array}$ & $\begin{array}{l}\text { Dussart 89 (BVII.122), late Byzan- } \\
\text { tine-Umayyad. }\end{array}$ \\
\hline 143 & 1226 & 2362.2 & $\begin{array}{l}\text { Flame polished, rounded, out-flaring rim } \\
\text { of spherical-bodied pot. Rim diameter 110 } \\
\text { mm; 12\% of rim circumference extant. Rim } \\
\text { 3.5 mm thick; body 2 mm thick. Preserved } \\
\text { height 3 mm. Light aqua fabric (von } \\
\text { Saldern \#1). }\end{array}$ & $\begin{array}{l}\text { Von Saldern 1980:80, late fourth- } \\
\text { early fifth century; Meyer } \\
\text { 1987:211, Umayyad?; Dussart 90 } \\
\text { (Type BVII.221), fourth c-Umay- } \\
\text { yad; Lester 2004:175, third-elev- } \\
\text { enth century. }\end{array}$ \\
\hline 144 & 2115 & 3146.3 & $\begin{array}{l}\text { Flame polished, rounded, out-flaring rim } \\
\text { of spherical-bodied pot. Rim diameter 90 } \\
\text { mm; 8\% of rim circumference extant. Rim }\end{array}$ & See No. 143. \\
\hline
\end{tabular}




\begin{tabular}{|c|c|c|c|c|}
\hline & & & $\begin{array}{l}2.5 \mathrm{~mm} \text { thick; body } 1 \mathrm{~mm} \text { thick. Preserved } \\
\text { height } 19 \mathrm{~mm} \text {. Pale green fabric (von } \\
\text { Saldern \#2). }\end{array}$ & \\
\hline 145 & 1290 & 2301.2 & $\begin{array}{l}\text { Flame polished, rounded, out-flaring rim } \\
\text { of spherical-bodied pot. Rim diameter } 70 \\
\mathrm{~mm} \text {; } 22 \% \text { of rim circumference extant. Rim } \\
2.5 \mathrm{~mm} \text { thick; body } 1.0 \mathrm{~mm} \text { thick. Pre- } \\
\text { served height } 30 \mathrm{~mm} \text {. Evidence of wheel } \\
\text { polishing on external walls. Light aqua fab- } \\
\text { ric (von Saldern \#1). }\end{array}$ & See No. 143. \\
\hline 146 & 2136 & 3407.8 & $\begin{array}{l}\text { Flame polished, rounded, out-flaring rim } \\
\text { of spherical-bodied pot. Rim diameter } 65 \\
\mathrm{~mm} ; 32 \% \text { of rim circumference extant. Rim } \\
2 \mathrm{~mm} \text { thick; body } 1 \mathrm{~mm} \text { thick. Preserved } \\
\text { height } 24 \mathrm{~mm} \text {. Pale aqua fabric (von } \\
\text { Saldern \#1). }\end{array}$ & See No. 143. \\
\hline 147 & 1226 & 2337.3 & $\begin{array}{l}\text { Out-folded, in-turning rim of spherical- } \\
\text { bodied pot with complex fold in rim. Rim } \\
\text { diameter } 80 \mathrm{~mm} \text {; } 12 \% \text { of rim circumference } \\
\text { extant. Rim } 7.5 \mathrm{~mm} \text { tall x } 4 \mathrm{~mm} \text { thick; body } \\
1 \mathrm{~mm} \text { thick. Preserved height } 16 \mathrm{~mm} \text {. Col- } \\
\text { our of fabric not discernible (fabric is heav- } \\
\text { ily corroded). }\end{array}$ & $\begin{array}{l}\text { Dussart } 92 \text { (BVII.2431), fourth- } \\
\text { fifth century. }\end{array}$ \\
\hline 148 & 1226 & 2351.2 & $\begin{array}{l}\text { Out-folded, in-turning, up-reaching rim of } \\
\text { spherical-bodied pot with very complex } \\
\text { triple fold in rim (out-in-up). Rim diameter } \\
50 \mathrm{~mm} .32 \% \text { of rim circumference extant. } \\
1.5 \mathrm{~mm} \text { thick. Preserved height } 14 \mathrm{~mm} \text {. Al- } \\
\text { most colourless fabric (von Saldern \#5). }\end{array}$ & $\begin{array}{l}\text { Dussart (Type BVII.2431), late } \\
\text { fourth-fifth c (but a very rare } \\
\text { type). }\end{array}$ \\
\hline 149 & 2136 & 3407.4 & $\begin{array}{l}\text { In-folded, out-flaring rim of spherical- } \\
\text { bodied pot. Rim diameter } 90 \mathrm{~mm} \text {; } 47 \% \text { of } \\
\text { rim circumference extant. Rim } 5 \mathrm{~mm} \text { tall x } \\
13 \mathrm{~mm} \text { wide, with tubular structure. Body } 1 \\
\text { mm thick. Preserved height } 23 \mathrm{~mm} \text {. Light } \\
\text { aqua fabric (von Saldern } \# 1 \text { ). }\end{array}$ & $\begin{array}{l}\text { Dussart } 94 \text { (BVII.2712), late } \\
\text { third-early fourth century. }\end{array}$ \\
\hline
\end{tabular}

\section{Balsamaires}

These delicate bottles were used for storing valuable liquids such as oils, perfumes, and ointments. ${ }^{345}$ They are also called ampullae, unguent flasks, or "kohl jars" because of their

\footnotetext{
${ }^{345}$ Cohen, "Roman, Byzantine and Umayyad Glass," 419.
} 
typical use as storage for that kind of eye cosmetic. Many examples on other sites come from tombs. ${ }^{346}$

Because they were manufactured in a wide variety of forms, with varying features, from the first century BCE through the Islamic era, classifying and dating pieces is difficult. ${ }^{347}$ Illustrating this difficulty are No. 150, which finds no good parallel in Dussart's catalogue, and Nos. 155 and 157, each of which have only one. However, simpler and better-made examples such as No. 151 are a little more likely to be early, while more flamboyant and careless ones like Nos. 157 and 158 are a little more likely to be late. Among these examples, No. 165 and 166 are the easiest to date since double-balsamaires seem to be unique to Palestine and Jordan from the fourth to the sixth century. ${ }^{348}$

In terms of their overall morphology, most balsamaires in this collection are the single type, consisting of one tube. Only two fragments among the 18 balsamaires found on this NIP site (all of which are included here) are of the double-tube type (Nos. 165 and 166). Especially where the vessels' rims are quite stout (for example, No. 151), a stopper might have been used.

Group 18: Balsamaires (18 pieces: see drawings in Illustration 14)

\begin{tabular}{|l|l|l|l|l|}
\hline No. & Loc. & Basket & Description & Parallels \\
\hline 150 & 567 & 1994.1 & $\begin{array}{l}\text { Partial rim, complete neck, and partial } \\
\text { shoulder of balsamaire. Flared, funnel- } \\
\text { neck rim, 36 mm diameter Neck 12-14 mm } \\
\text { diameter, 60 mm high. Shoulder flares } \\
\text { quite sharply out-and-down, but profile } \\
\text { unknown. Preserved height 71 mm. Dark } \\
\text { yellow-green fabric (not in von Saldern's } \\
\text { typology). }\end{array}$ & $\begin{array}{l}\text { Dussart 164 (Type BXIII.1121d, } \\
\text { but this has a much longer neck), } \\
\text { third-sixth century; Dussart 166- } \\
67 \text { (Type BXIII.1221, but this } \\
\text { lacks a constricted neck), fourth } \\
\text { century or later. }\end{array}$ \\
\hline 151 & 505 & 1917.1 & $\begin{array}{l}\text { Complete rim and partial neck of small } \\
\text { balsamaire. Horizontal, folded rim, 20 mm } \\
\text { diameter and 3 mm thick. Rim opening of } \\
\text { 7 mm intrudes into neck diameter of 10 } \\
\text { mm, creating a restriction. Neck tapers, } \\
9.0-13 \text { mm; at least 20 mm high. Pre- } \\
\text { served height 23 mm. Light aqua fabric } \\
\text { (von Saldern \#1). }\end{array}$ & $\begin{array}{l}\text { Meyer 1987:198, Roman or early } \\
\text { Byzantine; Dussart 168 (Type } \\
\text { Dussart 171 (Type BXIII.191), } \\
\text { third-eighth century. }\end{array}$ \\
\hline
\end{tabular}

\footnotetext{
${ }^{346}$ See the list in Dussart, Le verre en Jordanie et en Syrie du Sud, 165.

347 Saldern, Ancient and Byzantine Glass from Sardis, 77; Meyer, "Glass from the North Theater Byzantine Church, and Soundings at Jerash, Jordan, 1982-1983,” 187, 198, 212.

${ }^{348}$ Meyer, "Glass from the North Theater Byzantine Church, and Soundings at Jerash, Jordan, 1982-1983," 194; Weinberg and Goldstein, "The Glass Vessels," 75; Dussart, Le verre en Jordanie et en Syrie du Sud, 174.
} 


\begin{tabular}{|c|c|c|c|c|}
\hline 152 & 1228 & 2448.0 & $\begin{array}{l}\text { Complete rim and partial neck of small } \\
\text { balsamaire. Out-flaring, in-folded rim, } 23 \\
\mathrm{~mm} \text { diameter and } 2 \mathrm{~mm} \text { thick. Cylindrical } \\
\text { neck, } 10 \mathrm{~mm} \text { diameter Preserved height } 16 \\
\mathrm{~mm} \text {. Light aqua fabric (von Saldern \#1). }\end{array}$ & $\begin{array}{l}\text { See No. } 151 \text { or Dussart } 165 \text { (Type } \\
\text { BXIII.1211a), first-fifth century } \\
\text { (insufficient evidence to make a } \\
\text { firm determination). }\end{array}$ \\
\hline 153 & 1226 & 2338.3 & $\begin{array}{l}\text { Partial rim and neck of balsamaire. Hori- } \\
\text { zontal, folded rim, } 35 \mathrm{~mm} \text { diameter and } 3 \\
\mathrm{~mm} \text { thick. } 35 \% \text { of rim circumference ex- } \\
\text { tant. Rim opening } 23 \mathrm{~mm} \text {. Cylindrical } \\
\text { neck, } 16 \mathrm{~mm} \text { diameter Preserved height } 11 \\
\mathrm{~mm} \text {. Light aqua fabric (von Saldern \#1). }\end{array}$ & See No. 152. \\
\hline 154 & 548 & 2068.6 & $\begin{array}{l}\text { Partial rim and neck of balsamaire. Thick- } \\
\text { ened, in-turned rim, } 22 \mathrm{~mm} \text { diameter Rim } \\
2.5 \mathrm{~mm} \text { thick; neck } 1.0-1.5 \mathrm{~mm} \text { thick } \\
\text { (somewhat irregular). Neck seems to be } \\
\text { slightly tapered. Preserved height } 18 \mathrm{~mm} \text {. } \\
\text { Light aqua fabric (von Saldern \#1). }\end{array}$ & $\begin{array}{l}\text { Weinberg 1988:73, first-fourth } \\
\text { century; Dussart } 168 \text { (Type } \\
\text { BXIII.1321), first century or later, } \\
\text { or Dussart 171-172 (Type } \\
\text { BXIII.1931b1), fourth century- } \\
\text { Umayyad. }\end{array}$ \\
\hline 155 & 2143 & 2244.2 & $\begin{array}{l}\text { Complete rim and neck, and partial shoul- } \\
\text { der, of very small balsamaire. Irregularly } \\
\text { thickened rim, } 10-13 \mathrm{~mm} \text { diameter Neck } \\
17 \mathrm{~mm} \text { high, widening upward; outer di- } \\
\text { ameter } 10-13 \mathrm{~mm} \text {, inner diameter } 7.0-10 \\
\text { mm. Shoulder flares sharply out-and- } \\
\text { down; body profile unknown. Composite, } \\
\text { opaque fabric, mostly dark brown with nu- } \\
\text { merous white flecks. }\end{array}$ & $\begin{array}{l}\text { Dussart } 171 \text { (Type BXIII.1931a), } \\
\text { early eighth century (but a very } \\
\text { rare type) or Dussart } 171 \text { (Type } \\
\text { BXIII.191), third-eighth century. }\end{array}$ \\
\hline 156 & 1205 & 2168.3 & $\begin{array}{l}\text { Partial neck of mould-blown balsamaire, } \\
19 \mathrm{~mm} \text { diameter, } 1 \mathrm{~mm} \text { thick. Flaring at } \\
\text { one end (shoulder? rim?). Small, regularly } \\
\text { shaped and spaced diagonal lines, } 1.0 \mathrm{~mm} \\
\text { wide x } 0.5 \mathrm{~mm} \text { (?) deep, covering the fab- } \\
\text { ric. Preserved height } 35 \mathrm{~mm} \text {. Light aqua } \\
\text { fabric (von Saldern } \# 1 \text { ). }\end{array}$ & No close parallels known. \\
\hline 157 & 557 & 2073.2 & $\begin{array}{l}\text { Decorative "ring" encircling the neck ( } 17 \\
\text { mm outer diameter, } 15 \mathrm{~mm} \text { inner diame- } \\
\text { ter) of a balsamaire. Ring consists of a ta- } \\
\text { pering coil, } 2.0-7.0 \mathrm{~mm} \text { wide, encircling } \\
\text { the neck } 1.4 \text { times. Preserved height } 18 \\
\text { mm. Colour of fabric not known due to } \\
\text { heavy corrosion. }\end{array}$ & $\begin{array}{l}\text { Dussart } 157 \text { (Type BX.7), sixth c- } \\
\text { Umayyad (but a very rare type). }\end{array}$ \\
\hline 158 & 548 & 2141.1 & $\begin{array}{l}\text { Partial neck of handled balsamaire, with } \\
\text { four fine threads ( } 0.3 \mathrm{~mm} \text { diameter) ap- } \\
\text { plied 3-5 mm apart and covered with the } \\
\text { L-shaped "tail" of a relatively large, rib- } \\
\text { bon-type handle. Neck } 20 \text { mm diameter, }\end{array}$ & $\begin{array}{l}\text { Dussart } 170 \text { (Type BXIII.1811), } \\
\text { Byzantine. }\end{array}$ \\
\hline
\end{tabular}




\begin{tabular}{|c|c|c|c|c|}
\hline & & & $\begin{array}{l}\text { 1.5-2.5 mm thick. Preserved height } 33 \\
\text { mm. Light aqua fabric (von Saldern } \# 1 \text { ). }\end{array}$ & \\
\hline 159 & 1929 & 2432.6 & $\begin{array}{l}\text { Partial base of ovoid-bodied balsamaire. } \\
\text { Base } 2.5 \mathrm{~mm} \text { thick. Body diameter } 55 \mathrm{~mm} \text {; } \\
1 \mathrm{~mm} \text { thick. } 16 \% \text { of circumference extant. } \\
\text { Preserved height } 16 \mathrm{~mm} \text {. Light aqua fabric } \\
\text { (von Saldern \#1). }\end{array}$ & $\begin{array}{l}\text { Dussart 167-168 (Type } \\
\text { BXIII.1312a), first-fifth century. }\end{array}$ \\
\hline 160 & 1938 & 2467.1 & $\begin{array}{l}\text { Partial base of cylindrical-bodied balsa- } \\
\text { maire. Slight concavity in base (1.0 mm?). } \\
\text { No pontil mark. Base } 2.5 \mathrm{~mm} \text { thick. Body } \\
\text { diameter } 30 \mathrm{~mm} \text {; ca. } 0.5 \mathrm{~mm} \text { thick. Pre- } \\
\text { served height } 10 \mathrm{~mm} \text {. Light aqua fabric } \\
\text { (von Saldern \#1). }\end{array}$ & $\begin{array}{l}\text { Dussart } 168 \text { (Type BXIII.1321, } \\
\text { but body-shape might be wrong), } \\
\text { first century or later, or Dussart } \\
167 \text { (Type BXIII.123, but a very } \\
\text { rare type), possibly Roman? }\end{array}$ \\
\hline 161 & 1248 & 5438.4 & $\begin{array}{l}\text { Partial base of small balsamaire, with } \\
\text { small bit of vertical, cylindrical wall. Slight } \\
\text { concavity in base (1.0 mm?). No pontil } \\
\text { mark. Base } 2.5 \mathrm{~mm} \text { thick. Body diameter } \\
\text { ca. } 30 \mathrm{~mm} \text {; ca. } 1.5 \mathrm{~mm} \text { thick. Preserved } \\
\text { height } 9 \mathrm{~mm} \text {. Almost colourless fabric } \\
\text { (von Saldern \#5). }\end{array}$ & See No. 160. \\
\hline 162 & 1226 & 2238.4 & $\begin{array}{l}\text { Partial lower section of cylindrical body, } \\
\text { and a trace of the base, of mould-blown } \\
\text { balsamaire. Base } 2.5 \mathrm{~mm} \text { thick, profile un- } \\
\text { known. Body } 48 \mathrm{~mm} \text { diameter, } 1 \mathrm{~mm} \\
\text { thick, decorated with parallel horizontal } \\
\text { rows of round "dimples," } 3 \mathrm{~mm} \text { wide and } 6 \\
\text { mm apart. } 40 \% \text { of circumference extant. } \\
\text { Preserved height } 32 \mathrm{~mm} \text {. Pale green fabric } \\
\text { (von Saldern \#2). }\end{array}$ & $\begin{array}{l}\text { Hayes } 49 \text { (although not a very } \\
\text { close parallel), third century; } \\
\text { Dussart } 177 \text { (Type BXIII.32), } \\
\text { first-third century. }\end{array}$ \\
\hline 163 & 548 & 2121.3 & $\begin{array}{l}\text { Partial lower section of cylindrical body } \\
\text { and base of mould-blown balsamaire. Base } \\
\text { quite concave ( } 7 \mathrm{~mm} \text { "dome"), } 1.5-2.5 \mathrm{~mm} \\
\text { thick. Pontil mark } 8 \mathrm{~mm} \text { diameter Body } 40 \\
\text { mm diameter, } 1 \mathrm{~mm} \text { thick, decorated with } \\
\text { vertically oriented "scallops," ca. } 4 \mathrm{~mm} \\
\text { wide, beginning ca. } 5 \mathrm{~mm} \text { from the bot- } \\
\text { tom. } 42 \% \text { of circumference extant. Pre- } \\
\text { served height } 12 \mathrm{~mm} \text {. Light aqua fabric } \\
\text { (von Saldern \#1). }\end{array}$ & $\begin{array}{l}\text { Dussart } 160 \text { (Type BXI.3211a), } \\
\text { third-sixth century? }\end{array}$ \\
\hline 164 & 2113 & 3141.1 & $\begin{array}{l}\text { Complete base of balsamaire, with added } \\
\text { base layer in different fabric. Base quite } \\
\text { concave ( } 5 \mathrm{~mm} \text { "dome"), } 1 \mathrm{~mm} \text { thick. Pon- } \\
\text { til mark } 13 \mathrm{~mm} \text { diameter Base layer } 28 \mathrm{~mm}\end{array}$ & No parallels for added base-layer. \\
\hline
\end{tabular}




\begin{tabular}{|l|l|l|l|l|}
\hline & & & $\begin{array}{l}\text { diameter (irregular shape), ca. 2 mm thick, } \\
\text { dark brown fabric (not in von Saldern's ty- } \\
\text { pology). Body profile unknown; ca. 45 mm } \\
\text { diameter, 1 mm thick, pale green fabric } \\
\text { (von Saldern \#2). Preserved height 15 mm. }\end{array}$ & \\
\hline 165 & 1940 & 2462.1 & $\begin{array}{l}\text { Top section of double balsamaire. Each } \\
\text { tube ca. 26 mm diameter, with out-flaring, } \\
\text { in-turning rim, 4 mm fold diameter Pre- } \\
\text { served height 29 mm. No evidence of } \\
\text { thread-decoration or handles. Pale green } \\
\text { fabric (von Saldern \#2). }\end{array}$ & $\begin{array}{l}\text { Dussart 173 (Type BXIII.211), } \\
\text { fourth-sixth century, although } \\
\text { this un-decorated, non-handled } \\
\text { type is quite rare. }\end{array}$ \\
\hline 166 & 1219 & 2137.3 & $\begin{array}{l}\text { Bottom section of double balsamaire. Each } \\
\text { tube ca. 16 mm diameter; deep “groove” } \\
\text { between them, with shared wall ca. 2 mm } \\
\text { thick. Preserved height 25 mm. Light aqua } \\
\text { fabric (von Saldern \#1). }\end{array}$ & $\begin{array}{l}\text { Dussart 174 (Type BXIII.2211), } \\
\text { fourth-sixth century. }\end{array}$ \\
\hline 167 & 2155 & 3471.1 & $\begin{array}{l}\text { Bottom section of double balsamaire. } \\
\text { Tube ca. 14 mm diameter; wall thickness 4 } \\
\text { mm. Overall profile unknown. Preserved } \\
\text { height 15 mm. Light aqua fabric (von } \\
\text { Saldern \#1). }\end{array}$ & $\begin{array}{l}\text { Dussart 174 (Type BXIII.2211), } \\
\text { fourth-sixth century. }\end{array}$ \\
\hline
\end{tabular}

\section{Small, conical-necked flasks}

Although they were especially popular in the Byzantine era, ${ }^{349}$ conical-necked flasks were widely used over long periods of time. Distinctions in use seem to have been made based on the width of the vessel's neck. Other details, such as the angle of the neck's flaring (a slight angle = "conical" neck, a sharp angle = "funnel" neck) and the type of rim (rounded or in-folded) seem to reflect aesthetic considerations more than differences in use. Nor are they particularly helpful in establishing a vessel's dating. Dussart, for example, groups together vessels with conical and funnel necks and suggests the same dating for both rounded and in-folded rims (Type BX.3242a). ${ }^{350}$ More recently, Pollak cites many studies that differ greatly in their dating. ${ }^{351}$ Because all but the first of these representative fragments consists of the rim only, further judgements regarding either the date or the usage of any of them are impossible.

\footnotetext{
349 Pollak, "The Glass," 177.

${ }^{350}$ Dussart, Le verre en Jordanie et en Syrie du Sud, 149.

${ }^{351}$ Pollak, "The Glass," 177-180.
} 
Group 19: Small, conical-necked flasks (5 pieces: see drawings in Illustration 15)

\begin{tabular}{|c|c|c|c|c|}
\hline No. & Loc. & Basket & Description & Parallels \\
\hline 168 & 1290 & 2301.3 & $\begin{array}{l}\text { Partial rim of funnel-necked flask with in- } \\
\text { folded rim, with small part of neck. Rim di- } \\
\text { ameter } 60 \mathrm{~mm} .11 \% \text { of rim circumference } \\
\text { extant. Neck } 2 \mathrm{~mm} \text { thick; diameter ca. } 32 \\
\text { mm(?). Preserved height } 26 \mathrm{~mm} \text {. Light } \\
\text { aqua fabric (von Saldern \#1). }\end{array}$ & $\begin{array}{l}\text { Dussart 146-149 (Type } \\
\text { BX.3242a), late Roman-Abbasid } \\
\text { (third-thirteenth century), alt- } \\
\text { hough many are fourth-eighth } \\
\text { century. }\end{array}$ \\
\hline 169 & 1928 & 2404.1 & $\begin{array}{l}\text { Partial rim of funnel-necked flask with in- } \\
\text { folded rim. Rim diameter } 55 \mathrm{~mm} .33 \% \text { of } \\
\text { rim circumference extant. Neck } 1 \mathrm{~mm} \\
\text { thick; diameter no greater than } 20 \mathrm{~mm} \text {. } \\
\text { Preserved height } 29 \mathrm{~mm} \text {. Light aqua fabric } \\
\text { (von Saldern \#1). }\end{array}$ & See No. 169. \\
\hline 170 & 2008 & 2428.1 & $\begin{array}{l}\text { Partial rim of funnel-necked flask with } \\
\text { flame polished rim. Rim diameter } 55 \mathrm{~mm} \text {. } \\
21 \% \text { of rim circumference extant. } 1 \mathrm{~mm} \\
\text { thick. Preserved height } 23 \mathrm{~mm} \text {. Many hori- } \\
\text { zontally elongated bubbles in fabric just } \\
\text { below rim. Pale green fabric (von Saldern } \\
\text { \#1). }\end{array}$ & $\begin{array}{l}\text { Dussart 132-135 (Type } \\
\text { BX.1125a1), Byzantine-Umayyad, } \\
\text { or perhaps Dussart 144-145 (Type } \\
\text { BX.3241a), Roman-Abbasid eras, } \\
\text { but especially Byzantine-Umay- } \\
\text { yad. }\end{array}$ \\
\hline 171 & 1205 & 2107 & $\begin{array}{l}\text { Partial rim of conical-necked flask with } \\
\text { flame polished rim. Rim diameter } 45 \mathrm{~mm} \text {. } \\
31 \% \text { of rim circumference extant. } 2 \mathrm{~mm} \\
\text { thick. Preserved height } 19 \mathrm{~mm} \text {. Yellowish } \\
\text { brown fabric (not in von Saldern's typol- } \\
\text { ogy). }\end{array}$ & See No. 170. \\
\hline 172 & 548 & 2169.1 & $\begin{array}{l}\text { Partial rim of conical-necked flask with in- } \\
\text { folded rim. Rim diameter } 36 \mathrm{~mm} .37 \% \text { of } \\
\text { rim circumference extant. } 1 \mathrm{~mm} \text { thick. Pre- } \\
\text { served height } 30 \mathrm{~mm} \text {. Light aqua fabric } \\
\text { (von Saldern \#1). }\end{array}$ & $\begin{array}{l}\text { Dussart 128-31 (Type } \\
\text { BX.1113a1), Byzantine-early } \\
\text { Umayyad (to mid-eighth cen- } \\
\text { tury). }\end{array}$ \\
\hline
\end{tabular}

\section{Larger flasks and bottles}

Flasks have longer necks in proportion to the height of their bodies; bottles are relatively short-necked. Flasks outnumber bottles, generally and within this site. Representative examples of both types are discussed here together.

Most of these vessels have necks with a larger diameter at the top than the bottom, likely for ease of pouring (an exception is No. 177). Two-thirds of them also have in-folded rims, 
presumably to lend greater strength to the vessel. Apart from these two significant factors, there are many variations in their design, especially regarding the slope of the rim and neck. These range from gently tapering necks (the first four examples, in larger and smaller versions) to a conical-necked example (No. 177) to two significantly funnel-necked vessels (Nos. 178 and 179). All these styles were common throughout the Byzantine and early Islamic periods, ${ }^{352}$ although some are also known from the late Roman era. ${ }^{353}$

The four bottles (Nos. 180-183) have a completely different profile, with much shorter necks and even stouter rims than the flasks. Even though Nos. 180 and 181 resemble each other closely, parallels from beyond this site are few.

The care with which No. 179 was made may point to a date earlier rather than later within this timeframe. Its extremely large size is unusual, both generally and within this assemblage.

Group 20: Larger flasks and bottles (11 pieces: see drawings in Illustration 15)

\begin{tabular}{|l|l|l|l|l|}
\hline No. & Loc. & Basket & Description & Parallels \\
\hline 173 & 547 & 1918.2 & $\begin{array}{l}\text { Partial rim of large-mouth, tapering- } \\
\text { necked flask with infolded rim. Rim diam- } \\
\text { eter 100 mm. 5\% of rim circumference ex- } \\
\text { tant. Rim-fold 5 mm tall x 3 mm wide. } \\
\text { Neck 2 mm thick. Preserved height 62 } \\
\text { mm. Light aqua fabric (von Saldern \#1). }\end{array}$ & $\begin{array}{l}\text { Dussart 137-138 (BX.1132b1), } \\
\text { Byzantine-Umayyad. }\end{array}$ \\
\hline 174 & 1942 & 2464.3 & $\begin{array}{l}\text { Partial rim of large-mouth, tapering- } \\
\text { necked, thread-decorated flask with in- } \\
\text { folded rim. Rim diameter 90 mm. 8\% of } \\
\text { rim circumference extant. Rim fold 5 mm } \\
\text { tall x 3 mm wide. Neck 1 mm thick. 5 thin } \\
\text { parallel blue threads decorating neck, ca. } \\
\text { 2 mm apart, starting ca. 27 mm below } \\
\text { rim. 1 thick blue thread, 2-4 mm thick, 23 } \\
\text { mm below rim. Preserved height 34 mm. } \\
\text { Light aqua fabric (von Saldern \#1). }\end{array}$ & $\begin{array}{l}\text { BX.1132b2), likely Byzantine- } \\
\text { Umayyad, or perhaps Type } \\
\text { usual type). }\end{array}$ \\
\hline 175 & 1243 & 5429.2 & $\begin{array}{l}\text { Partial rim of medium-mouth, tapering- } \\
\text { necked flask with infolded rim. Rim diam- } \\
\text { eter 60 mm. 18\% of rim circumference ex- } \\
\text { tant. Rim-fold 6 mm tall x 4 mm wide. } \\
\text { Neck 1 mm thick. Preserved height 57 } \\
\text { mm. Light aqua fabric (von Saldern \#1). }\end{array}$ & $\begin{array}{l}\text { Meyer 1987:202, late Byzan- } \\
\text { tine/early Umayyad; Dussart } \\
\text { 135-136 (Type BX.1125b1), Byz- } \\
\text { antine. }\end{array}$ \\
\hline
\end{tabular}

${ }^{352}$ Meyer, "Glass from the North Theater Byzantine Church, and Soundings at Jerash, Jordan, 1982-1983," 202-203.

${ }^{353}$ Pollak, "The Glass," 180-181. 


\begin{tabular}{|c|c|c|c|c|}
\hline 176 & 1948 & 2483.15 & $\begin{array}{l}\text { Partial rim of medium-mouth, tapering- } \\
\text { necked flask with flame polished, } \\
\text { rounded rim. Rim diameter } 65 \mathrm{~mm} .13 \% \\
\text { of rim circumference extant. Rim thick- } \\
\text { ness } 2 \mathrm{~mm} \text {; neck } 1.5 \mathrm{~mm} \text {. Preserved } \\
\text { height } 35 \mathrm{~mm} \text {. Light aqua fabric (von } \\
\text { Saldern \#1). }\end{array}$ & $\begin{array}{l}\text { Dussart 132-135 (BX.1125a1), } \\
\text { Byzantine-Umayyad. }\end{array}$ \\
\hline 177 & 1931 & 2446.4 & $\begin{array}{l}\text { Partial rim of conical necked (inward flar- } \\
\text { ing) flask with flame polished, rounded } \\
\text { rim. Rim diameter } 50 \mathrm{~mm} \text {. } 26 \% \text { of rim cir- } \\
\text { cumference extant. Rim thickness } 1.5 \\
\mathrm{~mm} \text {; neck } 1 \mathrm{~mm} \text {. Neck diameter larger at } \\
\text { bottom than at top. Preserved height } 26 \\
\mathrm{~mm} \text {. Pale green fabric (von Saldern \#2). }\end{array}$ & $\begin{array}{l}\text { Dussart } 141 \text { (BX.2211), indeter- } \\
\text { minate (unusual type). }\end{array}$ \\
\hline 178 & 2136 & 3407.2 & $\begin{array}{l}\text { Partial rim of funnel-necked (outward } \\
\text { flaring) flask with flame polished, } \\
\text { rounded rim. Rim diameter } 60 \mathrm{~mm} .37 \% \\
\text { of rim circumference extant. Rim thick- } \\
\text { ness } 2 \mathrm{~mm} \text {; neck } 1.5 \mathrm{~mm} \text {. Preserved } \\
\text { height } 35 \mathrm{~mm} \text {. Light aqua fabric (von } \\
\text { Saldern \#1). }\end{array}$ & $\begin{array}{l}\text { Dussart 144-145 (Type } \\
\text { BX.3241a), Byzantine-Abbasid } \\
\text { eras. }\end{array}$ \\
\hline 179 & 563 & $\begin{array}{l}2105.1 \\
2105.2 \\
2105.3 \\
2105.4 \\
2105.5 \\
2105.8 \\
2105.9 \\
2105.10\end{array}$ & $\begin{array}{l}\text { Eight fragments of a big, funnel-necked } \\
\text { (outward flaring) flask. Infolded rim di- } \\
\text { ameter } 90 \mathrm{~mm} \text {; } 78 \% \text { of rim circumference } \\
\text { extant in three fragments broken in an- } \\
\text { tiquity (two of them contiguous). Rim } \\
\text { fold } 6 \mathrm{~mm} \text { high x } 4 \mathrm{~mm} \text { wide. Neck diam- } \\
\text { eter } 38-46 \mathrm{~mm}, 85 \mathrm{~mm} \text { tall, narrowing } \\
\text { upward; shoulder flares moderately } \\
\text { downward; body profile unknown. Pale } \\
\text { green fabric (von Saldern } \# 2 \text { ). }\end{array}$ & $\begin{array}{l}\text { Meyer 1987:202, late Byzan- } \\
\text { tine/early Umayyad; Dussart } 142 \\
\text { (Type BX.3211a), third century? } \\
\text { or perhaps late Byzantine? (cf. } \\
\text { BX.3211b). }\end{array}$ \\
\hline 180 & 563 & 2094.1 & $\begin{array}{l}\text { Complete out-turned, in-folded rim, } \\
\text { short neck, and part of shoulder of bottle. } \\
\text { Rounded, out-turned, in-folded rim, } 45 \\
\text { mm diameter, } 5 \mathrm{~mm} \text { high x } 8 \text { mm wide, } \\
\text { extending } 7 \text { mm outward past neck. Neck } \\
36 \mathrm{~mm} \text { diameter x } 15 \mathrm{~mm} \text { high. Shoulder } \\
\text { turns quickly out and down, details un- } \\
\text { known. Preserved height } 24 \text { mm. Colour } \\
\text { unknown due to heavy corrosion. }\end{array}$ & $\begin{array}{l}\text { Isings } 120 \text { (Form 102a), second- } \\
\text { fourth century; Hayes 66, mid- } \\
\text { second to mid-third century; } \\
\text { Dussart } 160 \text { (Type BXI.3113), } \\
\text { first-fourth century. }\end{array}$ \\
\hline
\end{tabular}




\begin{tabular}{|c|c|c|c|c|}
\hline 181 & 1893 & 2454.1 & $\begin{array}{l}\text { Partial out-turned, in-folded rim, and } \\
\text { part of neck of bottle. Rounded, out- } \\
\text { turned, in-and-down folded rim, } 53 \mathrm{~mm} \\
\text { diameter, } 8 \mathrm{~mm} \text { high x } 15 \mathrm{~mm} \text { wide, ex- } \\
\text { tending } 7 \mathrm{~mm} \text { outward past neck and } 14 \\
\text { mm downward into neck. Neck } 38 \mathrm{~mm} \text { di- } \\
\text { ameter; height unknown. Preserved } \\
\text { height } 19 \mathrm{~mm} \text {. Colour unknown due to } \\
\text { heavy corrosion. }\end{array}$ & See No. 180. \\
\hline 182 & 2136 & 3407.1 & $\begin{array}{l}\text { Partial out-turned, in-folded rim, and } \\
\text { part of neck of large bottle. Rounded, } \\
\text { out-turned, in-and-down folded rim, } 75 \\
\text { mm diameter, } 8 \mathrm{~mm} \text { high x } 9 \mathrm{~mm} \text { wide, } \\
\text { extending } 7 \mathrm{~mm} \text { outward past neck and } \\
22 \mathrm{~mm} \text { downward into neck. Neck } 75 \mathrm{~mm} \\
\text { diameter; height unknown. Very sharp } \\
\text { out-turn into shoulder; profile unknown. } \\
\text { Preserved height } 24 \mathrm{~mm} \text {. Light aqua fab- } \\
\text { ric (von Saldern \#1). }\end{array}$ & $\begin{array}{l}\text { See above, or perhaps Dussart } \\
161 \text { (Type BXII.1), fourth-eighth } \\
\text { century. } \\
\text { OR: it is possible that this is a } \\
\text { base ring for a bowl (Dussart's } \\
\text { Type BI.1211), plate (BII.111), or } \\
\text { cup (BIII.1) (see Nos. 30-33). }\end{array}$ \\
\hline 183 & 1948 & 2483.6 & $\begin{array}{l}\text { Complete out-turned, in-folded rim and } \\
\text { partial short neck of bottle. Rounded, } \\
\text { out-turned, in-folded rim, } 5-8 \mathrm{~mm} \text { high x } \\
\text { 4-5 mm thick (very irregular). Neck } 33 \\
\text { mm diameter Preserved height } 18 \mathrm{~mm} \text {. } \\
\text { Light aqua fabric (von Saldern \#1). }\end{array}$ & See above. \\
\hline
\end{tabular}

\section{Thread-decorated rims and necks}

This corpus includes 107 examples of thread decoration among its 1680 identifiable fragments. In terms of morphology, these fragments do not comprise a separate classification. The vessels from which they come share their primary characteristics of function and shape with identical undecorated examples. However, they are presented here as a group because most of the vessels from this site that are adorned with thread-decorations are morphologically similar (medium-sized cylindrical- or tapering-necked flasks) and because this style of decoration is a special, if not unique, characteristic of the Byzantine period. ${ }^{354}$

The patterns which thread-decorating followed and the care with which the threads were applied varies considerably from piece to piece. The second example (No. 185) is unusual in having just one thick thread girdling its sides. The next two pieces are more typical, No. 186 having one thick thread at the top of the group, followed by several thinner strands, while No. 187 and No. 184 have a very large number of parallel, similar threads.

\footnotetext{
${ }^{354}$ Meyer, "Glass from the North Theater Byzantine Church, and Soundings at Jerash, Jordan, 1982-1983," 207; Dussart, Le verre en Jordanie et en Syrie du Sud; Pollak, "The Glass," 184.
} 
Most of the thread-decorated fragments on this site seem to have come from taperingnecked vessels of medium size (ca. 50-100 mm in diameter). Based on their profile alone, it would be very difficult to say whether most of these were cups or flasks. An exception is the first example, No. 184, which is a flask because of an out-turn into the vessel's shoulder. More broadly, it is possible that the presence of thread-decoration signifies that such vessels were used for storage, not drinking-and thus flasks, not cups. ${ }^{355}$ On the other hand, it is clear that cups and lamps, as well as storage vessels, were sometimes decorated with similar threads. ${ }^{356}$ It is hard to be dogmatic about such a distinction when working with nothing more than fragments (again, No. 184 being the only clear exception within this set of samples).

The first three examples in this cluster, and five of the eight in total, are therefore likely from tapering-necked flasks (more likely) or cups (less likely). The middle examples, Nos. 187-189, are from flasks with particularly interesting shapes. While No. 188 is from a flask with a cylindrical neck (Dussart's Type BX.5332), Nos. 187 and 189 are from flasks with a very distinctive "convex-cylindrical” profile (Dussart’s Type BX.4422).

Several examples in this group are interesting in that their threads are of a significantly different colour than the fabric of the vessels themselves. ${ }^{357}$ The threads on No. 189 are a striking reddish-brown; on No. 190 they are olive green.

Group 21: Thread-decorated rims and necks (8 pieces: see drawings in Illustration 16)

\begin{tabular}{|l|l|l|l|l|}
\hline No. & Loc. & Basket & Description & Parallels \\
\hline 184 & 2133 & 3441.9 & $\begin{array}{l}\text { Complete rim of medium-mouth, taper- } \\
\text { ing-necked, thread-decorated flask with } \\
\text { flame polished, rounded rim. Rim diame- } \\
\text { ter 65 mm. Rim thickness 2.3 mm; neck } \\
1.5 \mathrm{~mm} \text {. Neck narrows to 38 mm diameter } \\
\text { before slight out-turn to shoulder. Ten } \\
\text { thin threads, body colour, horizontally } \\
\text { around neck, 31 mm below rim. Preserved } \\
\text { height 115 mm; slight out-turn into } \\
\text { shoulder, right at bottom. Pale green fab- } \\
\text { ric (von Saldern \#2). }\end{array}$ & $\begin{array}{l}\text { Dussart 135 (Type BX.1125a2), } \\
\text { Byzantine-Umayyad. }\end{array}$ \\
\hline 185 & 2136 & 3408.1 & $\begin{array}{l}\text { Partial rim of medium-mouth, tapering- } \\
\text { necked, thread-decorated flask (or cup?) } \\
\text { with flame polished, rounded rim. Rim di- } \\
\text { ameter 65 mm. 40\% of rim circumference }\end{array}$ & $\begin{array}{l}\text { Dussart 135 (Type BX.1125a2-if } \\
\text { flask), Byzantine-Umayyad or } \\
\text { BIX.32 (if cup), fourth century - }\end{array}$ \\
\hline
\end{tabular}

\footnotetext{
${ }^{355}$ Weinberg and Goldstein, "The Glass Vessels," 71.

${ }^{356}$ Dussart, Le verre en Jordanie et en Syrie du Sud, 80, 127, 140.

357 Weinberg and Goldstein, "The Glass Vessels," 71.
} 


\begin{tabular}{|c|c|c|c|c|}
\hline & & & $\begin{array}{l}\text { extant. Rim thickness } 3 \mathrm{~mm} \text {; neck } 1.5 \mathrm{~mm} \text {. } \\
\text { One large thread, body colour, } 2 \mathrm{~mm} \text { wide, } \\
\text { horizontally around body, } 28 \mathrm{~mm} \text { below } \\
\text { rim. Preserved height } 54 \mathrm{~mm} \text {. Pale green } \\
\text { fabric (von Saldern \#2). }\end{array}$ & $\begin{array}{l}\text { Umayyad, but especially Byzan- } \\
\text { tine. }\end{array}$ \\
\hline 186 & 1928 & 2448.1 & $\begin{array}{l}\text { Partial rim of medium-mouth, tapering- } \\
\text { necked, thread-decorated flask (or cup?) } \\
\text { with flame polished, rounded rim. Rim di- } \\
\text { ameter } 60 \mathrm{~mm} .17 \% \text { of rim circumference } \\
\text { extant. Rim thickness } 1.5 \mathrm{~mm} \text {; neck } 1 \mathrm{~mm} \text {. } \\
1 \text { medium thread, } 1 \mathrm{~mm} \text { wide, horizontally } \\
\text { around body, } 33 \mathrm{~mm} \text { below rim. } 5 \text { smaller } \\
\text { threads, parallel, about } 2 \mathrm{~mm} \text { apart, below } \\
\text { this. All threads body colour. Preserved } \\
\text { height } 44 \mathrm{~mm} \text {. Light aqua fabric (von } \\
\text { Saldern \#1). }\end{array}$ & See above. \\
\hline 187 & 563 & 2050.8 & $\begin{array}{l}\text { Partial neck of convex-cylindrical-necked, } \\
\text { thread-decorated flask. Rim type un- } \\
\text { known. Neck diameter } 50 \mathrm{~mm} \text {; } 31 \% \text { of cir- } \\
\text { cumference extant. } 8 \text { threads of progres- } \\
\text { sively narrower diameter, in } 32 \mathrm{~mm} \text { of } \\
\text { neck height, beginning } 15 \mathrm{~mm} \text { above the } \\
\text { flare into the convex part of the neck. All } \\
\text { threads body colour. Preserved height } 60 \\
\text { mm. Light aqua fabric (von Saldern } \# 1 \text { ). }\end{array}$ & $\begin{array}{l}\text { Cohen 433, Umayyad; Dussart } \\
150 \text { (Type BX.4422), eighth cen- } \\
\text { tury? }\end{array}$ \\
\hline 188 & 1226 & 3190.3 & $\begin{array}{l}\text { Partial neck and shoulder of medium-di- } \\
\text { ameter, cylindrical-necked, spherical-bod- } \\
\text { ied, thread-decorated flask. Rim type un- } \\
\text { known. Neck diameter } 35 \mathrm{~mm} \text {; } 48 \% \text { of cir- } \\
\text { cumference extant. Two thin body colour } \\
\text { threads, parallel, about } 1 \mathrm{~mm} \text { apart, } 33 \\
\text { mm above out turn to shoulder. Preserved } \\
\text { height } 54 \mathrm{~mm} \text {. Light aqua fabric (von } \\
\text { Saldern \#1). }\end{array}$ & $\begin{array}{l}\text { Dussart } 154 \text { (Type BX.5322), per- } \\
\text { haps Roman but more likely Byz- } \\
\text { antine. }\end{array}$ \\
\hline 189 & 1929 & 2425.2 & $\begin{array}{l}\text { Partial neck of convex-cylindrical-necked, } \\
\text { thread-decorated flask. Rim type un- } \\
\text { known. Neck diameter } 35 \mathrm{~mm} \text {; } 30 \% \text { of cir- } \\
\text { cumference extant. Two thick threads, one } \\
\text { medium thread, five thin threads, in } 16 \\
\text { mm of neck-height, beginning } 10 \mathrm{~mm} \\
\text { above the flare into the convex part of the } \\
\text { neck. All threads reddish-brown colour. } \\
\text { Preserved height } 34 \mathrm{~mm} \text {. Almost colour- } \\
\text { less fabric (von Saldern \#5). }\end{array}$ & $\begin{array}{l}\text { Cohen 433, Umayyad; Dussart } \\
150 \text { (Type BX.4422), eighth cen- } \\
\text { tury? }\end{array}$ \\
\hline
\end{tabular}




\begin{tabular}{|c|c|c|c|c|}
\hline 190 & 1948 & 2493.3 & $\begin{array}{l}\text { Partial rim of medium-mouth, tapering- } \\
\text { necked, thread-decorated flask (or cup?) } \\
\text { with flame polished, rounded rim. Rim di- } \\
\text { ameter } 55 \mathrm{~mm} \text {. } 17 \% \text { of rim circumference } \\
\text { extant. Rim thickness } 2 \mathrm{~mm} \text {; neck } 1 \mathrm{~mm} \text {. } \\
\text { One thick thread, olive-green colour (von } \\
\text { Saldern \#3), } 1 \mathrm{~mm} \text { wide, horizontally } \\
\text { around body, } 21 \mathrm{~mm} \text { below rim. Preserved } \\
\text { height } 32 \mathrm{~mm} \text {. Almost colourless fabric } \\
\text { (von Saldern \#5). }\end{array}$ & $\begin{array}{l}\text { Dussart } 127 \text { (Type BIX.32), } \\
\text { fourth century - Umayyad, but } \\
\text { especially Byzantine. }\end{array}$ \\
\hline 191 & 1243 & 2264.2 & $\begin{array}{l}\text { Partial rim of medium-mouth, tapering- } \\
\text { necked, thread-decorated flask with flame } \\
\text { polished, rounded rim. Rim diameter } 40 \\
\text { mm. } 27 \% \text { of rim circumference extant. } \\
\text { Rim thickness } 1.5 \mathrm{~mm} \text {; neck } 1 \mathrm{~mm} \text {. One } \\
\text { thick thread, light blue colour (von } \\
\text { Saldern \#6), } 1 \mathrm{~mm} \text { wide, horizontally } \\
\text { around body, } 17 \mathrm{~mm} \text { below rim, with two } \\
\text { thin threads, parallel, below it. Preserved } \\
\text { height } 25 \mathrm{~mm} \text {. Light aqua fabric (von } \\
\text { Saldern \#1). }\end{array}$ & $\begin{array}{l}\text { Weinberg 1988:71, fourth-fifth } \\
\text { century; Dussart } 131 \text { (Type } \\
\text { BX.1113a2), fourth-seventh cen- } \\
\text { tury. }\end{array}$ \\
\hline
\end{tabular}

\section{Storage-vessel necks}

As mentioned above, the common feature shared by the pieces in this group is that they are relatively well-preserved bottle necks. Their diversity in other respects is a good illustration of the range of sizes and forms that comprise this type of vessel. The first five fragments are from relatively small flasks, all of them having notably out-flaring funnel necks. The sixth, No. 197, is notable for its asymmetrically flaring rim (or shoulder?), which suggests it might have served as a pitcher with a pouring lip. No. 199 is one of two neck fragments from the same locus that bears signs of having been rather crudely cut off, perhaps after suffering damage (compare No. 235). No. 201 features beautiful mould-blown decoration, while No. 202 has a convex-cylindrical profile. It is also worth noting that No. 201 is one of three matching pairs of fragments within this corpus (the others are Nos. 16 and 33). One of its pieces came to light in square F3 and the other in DI39.

\section{Group 22: Storage-vessel necks (13 pieces: see drawings in Illustration 17)}

\begin{tabular}{|l|l|l|l|l|}
\hline No. & Loc. & Basket & Description & Parallels \\
\hline 192 & 1226 & 2362.5 & $\begin{array}{l}\text { Complete conical neck of small flask. Fun- } \\
\text { nel-shaped rim, sharply flaring }>9 \text { mm be- } \\
\text { yond neck. Neck diameter } 17 \mathrm{~mm} \text {; cylindri- } \\
\text { cal profile; height } 25 \mathrm{~mm} ; \mathrm{mm} \text { thick. }\end{array}$ & $\begin{array}{l}\text { Dussart } 143 \text { (Type BX.3245a), } \\
\text { Byzantine to mid-eighth cen- } \\
\text { tury. }\end{array}$ \\
\hline
\end{tabular}




\begin{tabular}{|c|c|c|c|c|}
\hline & & & $\begin{array}{l}\text { Shoulder turns sharply down, body profile } \\
\text { unknown. Preserved height } 43 \mathrm{~mm} \text {. Pale } \\
\text { green fabric (von Saldern } \# 2 \text { ). }\end{array}$ & \\
\hline 193 & 557 & 2074.1 & $\begin{array}{l}\text { Complete conical neck of small flask. Fun- } \\
\text { nel-shaped rim, gently flaring }>7 \mathrm{~mm} \text { be- } \\
\text { yond neck. Neck diameter tapers from 19- } \\
26 \mathrm{~mm} \text {, larger diameter at bottom; height } \\
27 \mathrm{~mm} \text {; } 1 \mathrm{~mm} \text { thick. Shoulder slopes grad- } \\
\text { ually down; body profile unknown. Pre- } \\
\text { served height } 52 \mathrm{~mm} \text {. Light aqua fabric } \\
\text { (von Saldern \#1). }\end{array}$ & See No. 192. \\
\hline 194 & 2136 & 3407.16 & $\begin{array}{l}\text { Complete conical neck of small flask. Fun- } \\
\text { nel-shaped rim, flaring }>4 \text { mm beyond } \\
\text { neck. Neck diameter tapers from } 17-20 \\
\text { mm, larger diameter at bottom; height } 63 \\
\text { mm; } 1 \text { mm thick. Shoulder slopes gradually } \\
\text { down; body profile unknown. Preserved } \\
\text { height } 85 \mathrm{~mm} \text {. Light aqua fabric (von } \\
\text { Saldern \#1). }\end{array}$ & See No. 192. \\
\hline 195 & 1931 & 2443.10 & $\begin{array}{l}\text { Complete cylindrical neck and partial body } \\
\text { of small flask. Funnel-shaped rim, gently } \\
\text { flaring }>4 \mathrm{~mm} \text { beyond neck. Neck diameter } \\
\text { ca. } 18 \mathrm{~mm} \text {, cylindrical profile with small ir- } \\
\text { regular "indentation" on one side (tong- } \\
\text { mark?); height } 32 \mathrm{~mm} \text {; } 1 \mathrm{~mm} \text { thick. Shoul- } \\
\text { der curves down into spherical body. Body } \\
\text { diameter } 75 \mathrm{~mm} \text {; height ca. } 60 \mathrm{~mm} \text { ? Pre- } \\
\text { served height } 72 \mathrm{~mm} \text {. Light aqua fabric } \\
\text { (von Saldern \#1). }\end{array}$ & $\begin{array}{l}\text { Dussart } 154 \text { (Type BX.5331), late } \\
\text { third-mid eighth century. }\end{array}$ \\
\hline 196 & 1276 & 2305.1 & $\begin{array}{l}\text { Complete concave neck of small flask. } \\
\text { Funnel-shaped rim, gently flaring }>3 \mathrm{~mm} \\
\text { beyond neck. Neck diameter } 17-20 \mathrm{~mm} \text {, } \\
\text { concave profile; height } 35 \mathrm{~mm} .1 \mathrm{~mm} \\
\text { thick. Shoulder slopes gradually down; } \\
\text { body profile unknown. Preserved height } 51 \\
\text { mm. Light aqua fabric (von Saldern \#1). }\end{array}$ & $\begin{array}{l}\text { Dussart } 157 \text { (Type BX.6431), } \\
\text { likely Byzantine. }\end{array}$ \\
\hline 197 & 1257 & 2256.4 & $\begin{array}{l}\text { Complete lower cylindrical neck of flask. } \\
\text { Rim profile unknown. Neck flares from } \\
\text { constricted base, then narrows (29-32 mm } \\
\text { diameter) as it rises. Asymmetrical shoul- } \\
\text { der-profile, very sharply down-turning on } \\
\text { two opposing sides ("front" and "back"?) } \\
\text { while projecting horizontally on a third } \\
\text { side, suggests that the body was flattened } \\
\text { and rectangular (like a hip flask?). } 2 \mathrm{~mm}\end{array}$ & $\begin{array}{l}\text { Neck resembles Dussart } 151 \\
\text { (Type BX.511), second-fourth } \\
\text { century. Body profile is unique. }\end{array}$ \\
\hline
\end{tabular}




\begin{tabular}{|c|c|c|c|c|}
\hline & & & $\begin{array}{l}\text { thick. Preserved height } 72 \mathrm{~mm} \text {. Light aqua } \\
\text { fabric (von Saldern } \# 1 \text { ). }\end{array}$ & \\
\hline 198 & 2136 & 3407.19 & $\begin{array}{l}\text { Partial lower conical neck of flask. Rim } \\
\text { profile unknown. Neck flares from con- } \\
\text { stricted base, then widens ( } 45-52 \mathrm{~mm} \text { di- } \\
\text { ameter) as it rises. Neck } 1 \mathrm{~mm} \text { thick. } \\
\text { Shoulder turns sharply into spherical body; } \\
23 \mathrm{~mm} \text { of body-width extant. Preserved } \\
\text { height } 41 \mathrm{~mm} \text {. Light aqua fabric (von } \\
\text { Saldern \#1). }\end{array}$ & $\begin{array}{l}\text { Dussart } 151 \text { (Type BX.514), un- } \\
\text { certain date. }\end{array}$ \\
\hline 199 & 2136 & 3407.17 & $\begin{array}{l}\text { Partial neck of medium-sized flask. Rim } \\
\text { profile unknown. Neck diameter } 50 \mathrm{~mm} \text {; } \\
77 \% \text { of circumference extant. Neck height } \\
>30 \mathrm{~mm} \text {. Abrasion marks and straight sur- } \\
\text { face, ca. } 30^{\circ} \text { to neck profile, suggest neck } \\
\text { was cut off after manufacture (damage?). } \\
\text { Preserved height } 36 \mathrm{~mm} \text {. Light aqua fabric } \\
\text { (von Saldern \#1). }\end{array}$ & $\begin{array}{l}\text { Re. cutting-off: see No. } 235 \\
\text { (note: same locus). }\end{array}$ \\
\hline 200 & 2135 & 3444.14 & $\begin{array}{l}\text { Partial cylindrical neck of flask. Rim profile } \\
\text { unknown. Neck diameter } 38 \mathrm{~mm} \text {; } 55 \% \text { of } \\
\text { circumference extant. Neck } 55 \mathrm{~mm} \text { tall; } 1.5 \\
\text { mm thick. Shoulder slopes gently down- } \\
\text { ward; body profile unknown. Preserved } \\
\text { height } 40 \mathrm{~mm} \text {. Pale green fabric (von } \\
\text { Saldern \#2). }\end{array}$ & $\begin{array}{l}\text { Neck resembles Dussart } 155 \\
\text { (Type BX.5332), first century? }\end{array}$ \\
\hline $\begin{array}{l}201 \mathrm{~A} \\
201 \mathrm{~B}\end{array}$ & $\begin{array}{l}1206 \\
2107\end{array}$ & $\begin{array}{l}2099.6 \\
3120.1\end{array}$ & $\begin{array}{l}\text { Partial cylindrical neck of flask. Rim profile } \\
\text { unknown. Neck diameter } 36 \mathrm{~mm} \text {; } 65 \% \text { of } \\
\text { circumference extant in two fragments } \\
\text { (contiguous; broken in antiquity). Neck } 75 \\
\text { mm tall; } 1.5 \mathrm{~mm} \text { thick. Shoulder slopes } \\
\text { gently downward; body profile unknown. } \\
\text { Decorated with vertical, parallel, evenly } \\
\text { spaced, mould-blown "stripes," ca. } 3.0 \mathrm{~mm} \\
\text { wide. Preserved height } 86 \mathrm{~mm} \text {. Light aqua } \\
\text { fabric (von Saldern \#1). }\end{array}$ & $\begin{array}{l}\text { Neck resembles Dussart } 155 \\
\text { (Type BX.5332), first century? } \\
\text { But the neck-decoration is } \\
\text { unique. }\end{array}$ \\
\hline 202 & 1206 & 2099.16 & $\begin{array}{l}\text { Partial funnel-topped neck of large flask. } \\
\text { Rim profile unknown. Cylindrical neck, di- } \\
\text { ameter } 42 \mathrm{~mm},>14 \mathrm{~mm} \text { tall, flares upward } \\
\text { into funnel, >60 mm diameter, >40 mm } \\
\text { tall. Neck } 1 \mathrm{~mm} \text { thick. Preserved height } 58 \\
\mathrm{~mm} \text {. Pale green fabric (von Saldern } \# 2 \text { ). }\end{array}$ & $\begin{array}{l}\text { Meyer 1987:202, late Byzantine- } \\
\text { Umayyad; Dussart } 149 \text { (Type } \\
\text { BX.3245a), early eighth century. }\end{array}$ \\
\hline
\end{tabular}




\begin{tabular}{|l|l|l|l|l|}
\hline 203 & 1243 & 3147.1 & $\begin{array}{l}\text { Partial lower neck and shoulder of large } \\
\text { flask. Rim profile unknown. Neck diameter } \\
55 \mathrm{~mm} \text {;0\% of circumference extant; } \\
\text { height unknown. Very sharp out-turn into } \\
\text { horizontal-profile shoulder; sharp down- } \\
\text { turn into almost-vertical body, diameter } \\
\text { ca. } 120 \mathrm{~mm} \text {. } 1 \mathrm{~mm} \text { thick. Preserved height } \\
13 \mathrm{~mm} \text {. Light aqua fabric (von Saldern \#1). }\end{array}$ & $\begin{array}{l}\text { Shoulder resembles Dussart 142 } \\
\text { (Type BX.313), fourth century. }\end{array}$ \\
\hline 204 & 1296 & 2370.3 & $\begin{array}{l}\text { Partial lower cylindrical neck and shoulder } \\
\text { of large flask. Rim profile unknown. Neck } \\
\text { diameter 46 mm; 57\% of circumference ex- } \\
\text { tant; }>14 \text { mm tall. Gentle out-turn into } \\
\text { spherical body, diameter >140 mm. 1 mm } \\
\text { thick. Preserved height 37 mm. Light aqua } \\
\text { fabric (von Saldern \#1). }\end{array}$ & $\begin{array}{l}\text { von Saldern 1980:87, sixth-early } \\
\text { (Type BX.52), sixth-seventh cen- } \\
\text { tury. }\end{array}$ \\
\hline
\end{tabular}

\section{Storage-vessel bases}

As with the preceding group of necks, so with these bases there is a considerable degree of diversity among the twelve representative fragments. They may, however, be placed into two broad groups according to their size and profile. The first four examples are from small, cylindrical bottles, very similar to one another in most respects; No. 205 is an especially good example. The other eight are more spherical, or perhaps piriform (pear-shaped), and considerably larger, although only Nos. 213 and 216 retain enough of their lower walls to provide a good understanding of their shape. The profiles of most of the other spherical vessels are difficult to ascertain. None can be dated with precision, although the distinctive profile of No. 208 has relatively early parallels.

Other physical characteristics vary significantly within this cluster. Only one cylindrical vessel and one spherical vessel are made from pale green fabric; all the others are light aqua. Pontil marks appear on all the cylindrical vessels but only two of the spherical vessels (Nos. 212 and 214). The fabric is significantly thinner on all the vessels lacking pontil marks. The mould-blown ribs on No. 211 are quite striking.

Group 23: Storage-vessel bases (12 pieces: see drawings in Illustration 18)

\begin{tabular}{|l|l|l|l|l|}
\hline No. & Loc. & Basket & Description & Parallels \\
\hline 205 & 2125 & 3168.8 & $\begin{array}{l}\text { Complete base of cylindrical bottle, with } \\
\text { significant portion of body. diameter 55 } \\
\text { mm. Pushed-in base with conical “dome” 7 } \\
\text { mm high. Very sharp turn from base into } \\
\text { wall; slight concavity immediately above }\end{array}$ & $\begin{array}{l}\text { Isings 120 (Form 102a), second- } \\
\text { fourth century; Hayes 66, mid- } \\
\text { second to mid-third century; } \\
\text { Dussart 160 (Type BXI.3113), } \\
\text { first-fourth century. }\end{array}$ \\
\hline
\end{tabular}




\begin{tabular}{|c|c|c|c|c|}
\hline & & & $\begin{array}{l}\text { (diameter reduces from } 55 \text { to } 50 \mathrm{~mm} \text { ). Pon- } \\
\text { til mark, } 15 \mathrm{~mm} \text { diameter Preserved height } \\
75 \mathrm{~mm} \text {. Light aqua fabric (von Saldern } \# 1 \text { ). }\end{array}$ & \\
\hline 206 & 2125 & 3168.13 & $\begin{array}{l}\text { Complete base of cylindrical bottle, with } \\
\text { small portion of body. diameter } 55 \mathrm{~mm} \text {. } \\
\text { Pushed-in base with conical "dome” } 7 \mathrm{~mm} \\
\text { high. Very sharp turn from base into wall; } \\
\text { slight concavity immediately above. Pontil } \\
\text { mark, } 15 \mathrm{~mm} \text { diameter Preserved height } 15 \\
\text { mm. Light aqua fabric (von Saldern \#1). }\end{array}$ & $\begin{array}{l}\text { See No. } 205 \text { (virtually identical in } \\
\text { all respects, including find-spot). }\end{array}$ \\
\hline 207 & 557 & 2087.1 & $\begin{array}{l}\text { Complete base of cylindrical bottle, with } \\
\text { small portion of body. diameter } 55 \mathrm{~mm} \text {. } \\
\text { Pushed-in base with conical “dome” } 5.0 \\
\text { mm high. Sharp turn from base into wall. } \\
\text { Pontil mark, } 9 \text { mm diameter. Preserved } \\
\text { height } 15 \mathrm{~mm} \text {. Pale green fabric (von } \\
\text { Saldern \#2). }\end{array}$ & $\begin{array}{l}\text { See No. 205, although colour and } \\
\text { somewhat coarser fabric may } \\
\text { point to a later date. }\end{array}$ \\
\hline 208 & 563 & 2081.3 & $\begin{array}{l}\text { Complete base of piriform bottle, with } \\
\text { small portion of body. diameter } 50 \mathrm{~mm} \text {. } \\
\text { Pushed-in base with conical "dome" } 9 \mathrm{~mm} \\
\text { high. Sharp turn from base into wall. Pontil } \\
\text { mark, } 8 \mathrm{~mm} \text { diameter. Preserved height } 16 \\
\text { mm. Light aqua fabric (von Saldern \#1). }\end{array}$ & See No. 205. \\
\hline 209 & 1205 & 2182 & $\begin{array}{l}\text { Partial base of large bottle. Base signifi- } \\
\text { cantly concave ( } 11 \mathrm{~mm} \text { deep). Sharp turn } \\
\text { from base into body of at least } 130 \mathrm{~mm} \text { di- } \\
\text { ameter; } 62 \% \text { of circumference extant. Body } \\
\text { profile unknown. No pontil mark. Pre- } \\
\text { served height } 14 \mathrm{~mm} \text {. Light aqua fabric } \\
\text { (von Saldern } \# 1 \text { ). }\end{array}$ & Indeterminate. \\
\hline 210 & 1206 & 2099.5 & $\begin{array}{l}\text { Partial base of large spherical or piriform } \\
\text { bottle. Pushed-in base with conical "dome” } \\
11 \mathrm{~mm} \text { high; } 22 \% \text { of circumference extant. } \\
\text { Body diameter }>130 \mathrm{~mm} \text {; exact body pro- } \\
\text { file unknown. Preserved height } 12 \mathrm{~mm} \text {. } \\
\text { Light aqua fabric (von Saldern \#1). }\end{array}$ & Indeterminate. \\
\hline 211 & 1243 & 5437 & $\begin{array}{l}\text { Part of mould-decorated lower wall of large } \\
\text { spherical or piriform bottle, with parts of } \\
\text { its base. Significantly concave base; } 21 \% \text { of } \\
\text { circumference extant. Sharp turn into body } \\
\text { with diameter of ca. } 100 \mathrm{~mm} \text {. Body profile } \\
\text { unknown. Moulded, shallow, vertical ribs } \\
\text { ca. } 4 \mathrm{~mm} \text { wide, } 8 \mathrm{~mm} \text { apart, begin } 27 \mathrm{~mm}\end{array}$ & $\begin{array}{l}\text { Dussart } 158 \text { (Type BX } 812 \text { or } 82 \text { ), } \\
\text { late sixth century. }\end{array}$ \\
\hline
\end{tabular}




\begin{tabular}{|c|c|c|c|c|}
\hline & & & $\begin{array}{l}\text { above the base. A round "dent" deforms } \\
\text { the wall, } 20 \mathrm{~mm} \text { above the base. Preserved } \\
\text { height } 41 \mathrm{~mm} \text {. Light aqua fabric (von } \\
\text { Saldern } \# 1 \text { ). }\end{array}$ & \\
\hline 212 & 2125 & 3168.11 & $\begin{array}{l}\text { Complete base of large spherical or pi- } \\
\text { riform bottle. Pushed-in base with conical } \\
\text { "dome" } 5 \mathrm{~mm} \text { high. Body diameter }>100 \\
\mathrm{~mm} ; 2 \mathrm{~mm} \text { thick; exact body profile un- } \\
\text { known. Preserved height } 23 \mathrm{~mm} \text {. Pontil } \\
\text { mark, } 17 \mathrm{~mm} \text { diameter. Light aqua fabric } \\
\text { (von Saldern \#1). }\end{array}$ & Indeterminate. \\
\hline 213 & 2113 & 3139.1 & $\begin{array}{l}\text { Partial base of spherical or piriform bottle, } \\
\text { with portion of body. Pushed-in base with } \\
\text { conical "dome" } 6 \mathrm{~mm} \text { high; } 65 \% \text { of circum- } \\
\text { ference extant. Up-turn into body with di- } \\
\text { ameter of ca. } 80 \mathrm{~mm} \text {. Exact body profile } \\
\text { unknown. No pontil mark. Preserved } \\
\text { height } 24 \mathrm{~mm} \text {. Light aqua fabric (von } \\
\text { Saldern \#1). }\end{array}$ & Indeterminate. \\
\hline 214 & 1226 & 3171.2 & $\begin{array}{l}\text { Complete base of large spherical or pi- } \\
\text { riform bottle. Pushed-in base with conical } \\
\text { "dome" } 3 \mathrm{~mm} \text { high. Body diameter ca. } 80 \\
\text { mm; } 1 \mathrm{~mm} \text { thick; exact body profile un- } \\
\text { known. Preserved height } 19 \mathrm{~mm} \text {. Pontil } \\
\text { mark, } 8 \mathrm{~mm} \text { diameter. Light aqua fabric } \\
\text { (von Saldern \#1). }\end{array}$ & Indeterminate. \\
\hline 215 & 1948 & 2483.7 & $\begin{array}{l}\text { Partial base of spherical or piriform bottle, } \\
\text { with significant portion of body. Pushed-in } \\
\text { base with conical "dome" } 9 \text { mm high; } 55 \% \\
\text { of circumference extant. Up-turn into body } \\
\text { with diameter of ca. } 60 \mathrm{~mm} \text {. Exact body } \\
\text { profile unknown. No pontil mark. Pre- } \\
\text { served height } 22 \mathrm{~mm} \text {. Pale green fabric } \\
\text { (von Saldern \#2). }\end{array}$ & Indeterminate. \\
\hline 216 & 563 & 2043.1 & $\begin{array}{l}\text { Partial base of spherical or piriform bottle, } \\
\text { with portion of body. Pushed-in base with } \\
\text { conical "dome” } 6 \mathrm{~mm} \text { high; } 67 \% \text { of circum- } \\
\text { ference extant. Up-turn into body with di- } \\
\text { ameter of ca. } 80 \mathrm{~mm} \text {. Exact body profile } \\
\text { unknown. No pontil mark. Preserved } \\
\text { height } 28 \mathrm{~mm} \text {. Light aqua fabric (von } \\
\text { Saldern \#1). }\end{array}$ & Indeterminate. \\
\hline
\end{tabular}




\section{Windowpanes}

Whether because of its relative uniformity, its low status as a building material rather than a (semi-?) artistic product, or for other reasons, window glass is somewhat neglected in the literature. At Sardis, window sherds from an estimated 1,000 panes surpassed, in weight if not in number, the total amount of fragments of glass vessels. ${ }^{358}$ Meyer's important survey of glass from the 1982-83 Jerash expeditions notes that window glass was "among the most numerous identifiable pieces recovered,” yet discusses only twelve pieces. ${ }^{359}$

Within this site, 299 fragments of window-glass were recovered. Twenty-four representative pieces from this assemblage have been discussed in an earlier publication. ${ }^{360}$

\section{Miscellaneous Special Pieces}

Bracelets were not common at Byzantine sites but multiplied in the fifth and sixth centuries, remaining popular through the Umayyad and Abbasid eras. ${ }^{361}$ Still, they are relatively rare. The simplicity of their design makes their dating elusive, apart from the kind of precise stratigraphic data which are for the most part lacking on this site.

Five of the seven bracelets in this corpus are of an indeterminate dark colour. Due to heavy corrosion, it is difficult to say whether it is dark green, dark brown, or (in the case of No. 222) perhaps even black. The other two fragments are medium blue (Nos. 217, 218) and pale green (No. 223). In design, No. 217 is simple and round in cross-section. Three fragments are oval in profile, although with differences among them: No. 219 is plain and unadorned; No. 220 has a regular series of perpendicular grooves impressed upon its outward surface; No. 221 has similar grooves set at a diagonal angle; and No. 222 features a noticeably flat surface on its inward face, at an unusual angle oblique to the wearer's wrist. No. 222 also widens in diameter from 3-8 mm. Lastly, No. 223 is completely covered with a braided design, possibly reflecting the technique used in its fabrication.

Glass beads are known as early as the Roman period (Meyer 1987:186), and while it is possible that No. 224 is a bead, its lack of decoration and perforation make this unlikely. ${ }^{362}$ Because it is completely plain, flat on one side and domed on the other, it is more likely a

\footnotetext{
358 Saldern, Ancient and Byzantine Glass from Sardis, 3, 91.

${ }^{359}$ Meyer, "Glass from the North Theater Byzantine Church, and Soundings at Jerash, Jordan, 1982-1983," $194-195,207$.

${ }^{360}$ Chambers, "Window Glass Finds in the Northeast Church '."

${ }^{361}$ Meyer, "Glass from the North Theater Byzantine Church, and Soundings at Jerash, Jordan, 1982-1983,” $195,216$.

362 Lester, "Islamic Glass Finds," 209.
} 
counter or game-piece. Such pieces are reported from the Hellenistic period onward. ${ }^{363} \mathrm{An}$ other possibility is that it is a ring-stone, which are known primarily from the Roman and Early Byzantine periods. ${ }^{364}$

In addition, it should be noted that several groups of coloured-glass tesserae were found on this site, but not considered here in this study. Compared to the very large number of stone tesserae, this number is surprisingly low, perhaps reflecting the fact that glass tesserae were normally used only in wall mosaics, which are typically Early Byzantine in date. ${ }^{365}$ The colours of these tesserae are blue, dark blue, dark brown, pale green, medium green with a few streaks of medium-blue, dark green, light yellow, and medium yellow.

Group 24: Special pieces (8 pieces: see drawings in Illustration 18)

\begin{tabular}{|l|l|l|l|l|}
\hline No. & Loc. & Basket & Description & Parallels \\
\hline 217 & 1277 & 2256.2 & $\begin{array}{l}\text { Piece of round-section bracelet, 60 mm in- } \\
\text { ner diameter, 10\% of circumference extant, } \\
\text { 4 mm thickness. Light blue fabric (von } \\
\text { Saldern \#6). }\end{array}$ & $\begin{array}{l}\text { Von Saldern 1980:34, 91, Byzan- } \\
\text { tine; Meyer 1987:195, 216, Early } \\
\text { Byzantine or later; Lester } \\
\text { 2004:210, fourth century or later? }\end{array}$ \\
\hline 218 & 2135 & 3449.4 & $\begin{array}{l}\text { Piece of round-section bracelet(?), 35 mm } \\
\text { inner diameter, 28\% of circumference ex- } \\
\text { tant, 5-6 mm thickness. Light blue fabric } \\
\text { (von Saldern \#6). }\end{array}$ & See No. 217. \\
\hline 219 & 1226 & 2271.3 & $\begin{array}{l}\text { Piece of flattened oval-section bracelet, 40 } \\
\text { mm inner diameter, 13\% of circumference } \\
\text { extant, 4.5 mm thick x 9.5 mm wide. } \\
\text { Opaque brown fabric. }\end{array}$ & See No. 217. \\
\hline 220 & 1226 & 2271.2 & $\begin{array}{l}\text { Piece of flattened oval-section bracelet, 46 } \\
\text { mm inner diameter, 22\% of circumference } \\
\text { extant, 4.0 mm thick x 8.5 mm wide. Some- } \\
\text { what irregular tooled grooves impressed in } \\
\text { outer surface, spanning the width. Opaque } \\
\text { brown fabric. }\end{array}$ & See No. 217. \\
\hline 221 & 1276 & 2298.3 & $\begin{array}{l}\text { Piece of flattened oval-section bracelet, 60 } \\
\text { mm inner diameter, 8\% of circumference } \\
\text { extant, 7.5 mm wide. Moulded (?) diagonal } \\
\text { grooves impressed in outer surface, creat- } \\
\text { ing a braided pattern. Opaque brown fab- } \\
\text { ric. }\end{array}$ & See No. 217. \\
\hline
\end{tabular}

\footnotetext{
${ }^{363}$ Weinberg, "Hellenistic Glass from Tel Anafa in Upper Galilee," 27.

364 Saldern, Ancient and Byzantine Glass from Sardis, 104-105; Yael Gorin-Rosen, "Glass Vessels from Area A," in Jewish Quarter Excavations in the Old City of Jerusalem Conducted by Nahman Avigad 1969-1982, Volume II The Finds from Areas $A, W$, and $X$-2, ed. Hillel Geva (Jerusalem: Israel Exploration Society, 2003), 388.

${ }^{365}$ Saldern, Ancient and Byzantine Glass from Sardis, 92.
} 


\begin{tabular}{|l|l|l|l|l|}
\hline 222 & 1277 & 2260.1 & $\begin{array}{l}\text { Large piece of bracelet, } 70 \mathrm{~mm} \text { inner diam- } \\
\text { eter, 38\% of circumference extant. Profile } \\
\text { varies from 3.0 x 4.5 mm to 4.5 x 8.0 mm. } \\
\text { Flattened surface of bracelet at oblique an- } \\
\text { gle to wearer's wrist. Opaque brown fabric. }\end{array}$ & See No. 217. \\
\hline 223 & 1237 & 2222 & $\begin{array}{l}\text { Piece of bracelet, 90 mm inner diameter, } \\
\text { 18\% of circumference extant, } 6.0 \text { mm wide. } \\
\text { Attractive braided-rope design on all sur- } \\
\text { faces. Pale green fabric (von Saldern's \#2). }\end{array}$ & See No. 217. \\
\hline 224 & 1289 & 2293.5 & $\begin{array}{l}\text { Mostly intact, hemispherical game-piece or } \\
\text { ring-stone, 15 mm diameter x 6 mm high; } \\
\text { ca 65\% of diameter extant. Opaque brown } \\
\text { fabric. }\end{array}$ & $\begin{array}{l}\text { Von Saldern 1980:104, Roman- } \\
\text { Early Byzantine; Gorin-Rosen } \\
\text { 388, Late Hellenistic-Early Ro- } \\
\text { man; Meyer 1987:195, Early Byz- } \\
\text { antine or later. }\end{array}$ \\
\hline
\end{tabular}

\section{Decorative Techniques}

The first group of fragments in this section comes from vessels that have decorative design elements built or tooled into their fundamental structure, including ribs, scallops, and spouts. Such features became an intrinsic part of the vessel while the glassworker was forming it.

The most elaborate technique of this type is a characteristically Islamic style of decoration, "marvering," in which multicoloured threads are wound around a vessel which is, in turn, dragged in a distinctive way on a hard surface (a "marver") while the threads are still plastic. ${ }^{366}$ This produces a scalloped or U-shaped pattern known as "feather and loop." ${ }^{67}$ No. 226 is an excellent example, apparently from the footed base of a relatively large vessel. On this fragment the marvered threads are white, iridescent silver-blue, and a composite redand-black thread which, when flattened, gave a very thin black outline to its red core. Close parallels are rare. ${ }^{368}$ Even more interestingly, on the lower left of this fragment, the redand-black threads are jumbled and/or missing and the area is filled with a mix of white and silver-blue. Because the entire area is uniformly smooth, this is probably the result of damage (and repair) during the manufacturing process.

Tooling is evident on another fragment, No. 225, which probably came from a large cast bowl. A parallel series of deep, vertical ribs were scribed into its shoulder, likely after the

\footnotetext{
${ }^{366}$ Meyer, "Glass from the North Theater Byzantine Church, and Soundings at Jerash, Jordan, 1982-1983," 213.

${ }^{367}$ Saldern, Ancient Glass in the Museum of Fine Arts, Boston, no. 62.

${ }^{368}$ Saldern, Ancient Glass in the Museum of Fine Arts, Boston no.62, dated seventh-eighth c.; Saldern, Ancient and Byzantine Glass from Sardis, 102 tenth-twelfth c.; Meyer, "Glass from the North Theater Byzantine Church, and Soundings at Jerash, Jordan, 1982-1983," 213 Umayyad.
} 
bowl itself was formed but while the glass was still soft. ${ }^{369}$ These ribs are closely spaced and span the radius of the shoulder of the bowl. Although these details are markedly different from the more common kind of ribbing that is moulded when the vessel itself is formed, which typically results in shallower, more widely spaced ribs, this example fits within the range of known examples from the Hellenistic era. ${ }^{370}$ Thus, while its decorative elements warrant its placement here in this discussion, its method of manufacture-and date-make it more closely analogous to the other cast bowls presented as Nos. 1-9 above.

Another feature that was worked into the basic shape of the vessel is a spout, which is represented here by three probable examples (Nos. 226-229). In each case, a small section of a vessel's rim appears to have been pulled or pinched outward to facilitate pouring. Unfortunately, all these examples are ambiguous in form and isolated from the rest of the vessel of which they were once a part. Therefore, their identification as spouts remains tentative. (Another explanation is that they are simply deformations, whether at the time of manufacture or through the subsequent application of a very large amount of heat.)

Group 25: Decorative elements as part of a vessel's structure (5 pieces: see drawings in Illustration 19)

\begin{tabular}{|c|c|c|c|c|}
\hline No. & Loc. & Basket & Description & Parallels \\
\hline 225 & 1226 & 2131.1 & $\begin{array}{l}\text { Bowl with vertical, closely spaced ribs on } \\
\text { upper part of wall. diameter ca. } 240 \mathrm{~mm} \text {; } \\
\text { wall thickness } 2.8 \mathrm{~mm} \text {. Ribs ca. } 21 \mathrm{~mm} \text { tall } \\
\text { x } 3 \mathrm{~mm} \text { wide x } 2 \mathrm{~mm} \text { deep. Preserved } \\
\text { height } 22 \mathrm{~mm} \text {. Light aqua fabric (von } \\
\text { Saldern \#1). }\end{array}$ & $\begin{array}{l}\text { Isings } 21 \text { (form 3c), first century } \\
\text { CE; Weinberg 1973:39, first cen- } \\
\text { tury BCE - first century CE; Jack- } \\
\text { son-Tal 19-20, third-first century } \\
\text { BCE. }\end{array}$ \\
\hline 226 & 1276 & 2249.2 & $\begin{array}{l}\text { Partial finely decorated foot-ring of } \\
\text { bowl/goblet; height of foot } 15 \mathrm{~mm} \text {; rim of } \\
\text { foot } 52 \mathrm{~mm} \text { diameter, } 42 \% \text { of rim circum- } \\
\text { ference preserved, rim-thickness } 4.5-7.0 \\
\text { mm. White, silver (?), and black-and-red } \\
\text { threads marvered into its surface; ca. } 20 \\
\text { threads per column; width of scalloped (U- } \\
\text { shaped) sections } 7.0-10.0 \mathrm{~mm} \text {. Threads } \\
\text { missing and/or jumbled on lower left side } \\
\text { of fragment, and area filled in with "regu- } \\
\text { lar" glass, then polished: possibly due to } \\
\text { damage during manufacture? Preserved } \\
\text { height } 18 \mathrm{~mm} \text {. }\end{array}$ & $\begin{array}{l}\text { Saller 321, sixth c or later; Von } \\
\text { Saldern } 1968 \text { (no. 62), early Is- } \\
\text { lamic; Von Saldern 1980:102, } \\
\text { tenth-twelfth century; Meyer } \\
\text { 1987:213, Umayyad; Lester } \\
\text { 2004:208, Umayyad-Abbasid. }\end{array}$ \\
\hline 227 & 1931 & 2443.43 & $\begin{array}{l}\text { Partial pouring-spout from large-mouthed } \\
\text { pitcher with flaring neck. Flame polished, } \\
\text { thickened rim, diameter unknown due to }\end{array}$ & $\begin{array}{l}\text { Dussart } 177 \text { (Type BXIV.121), } \\
\text { second-fourth century. }\end{array}$ \\
\hline
\end{tabular}

${ }^{369}$ Gladys Davidson Weinberg, "Notes on Glass from Upper Galilee," Journal of Glass Studies 15 (1973): 37.

${ }^{370}$ Ibid., 40. 


\begin{tabular}{|l|l|l|l|l|}
\hline & & & $\begin{array}{l}\text { contour of spout. Radius of spout ca. 30 } \\
\text { mm. Preserved height 14 mm. Pale green } \\
\text { fabric (von Saldern \#2). }\end{array}$ & \\
\hline 228 & 2126 & 3173.3 & $\begin{array}{l}\text { Partial pouring-spout from large-mouthed } \\
\text { pitcher with flaring neck. Flame polished } \\
\text { rim, diameter unknown due to contour of } \\
\text { spout. Radius of spout ca. 15 mm. Pre- } \\
\text { served height 15 mm. Light aqua fabric } \\
\text { (von Saldern \#1). }\end{array}$ & See No. 228. \\
\hline 229 & 1948 & 2478.8 & $\begin{array}{l}\text { Partial pouring-spout or other rim-section } \\
\text { of large-mouthed pitcher. Flame polished } \\
\text { thickened rim, diameter unknown due to } \\
\text { contour of fragment but perhaps 120 mm. } \\
\text { Preserved height 21 mm. Pale green fabric } \\
\text { (von Saldern \#2). }\end{array}$ & See No. \\
\hline
\end{tabular}

The second group comes from mould-decorated vessels. Here, a pattern was created on the outer surface of a vessel as glass was blown into a mould. There are 52 such fragments in this corpus, six of which have already been mentioned (Nos. 64, 156, 162, 163, 201, and 211). Mould-decoration is rare before the Byzantine period. At that point it became and remained popular for centuries. Consequently, most mould-blown vessels are dated to the Islamic and medieval eras, when patterns could become quite complex. ${ }^{371}$ Most mould-decorated fragments, both generally and on this site, come from flasks, although some are from bottles. At least one (No. 235) appears to come from a large flask but also, strangely, features a cut-off rim. Perhaps this was a later modification to the vessel's original profile after its rim or upper neck became damaged. (For a similar cut on another vessel's neck, see No. 199. Both fragments were found in the same locus.)

Most of the moulded patterns in this corpus are simple linear fluting, namely, parallel lines or grooves. This type of pattern seems to have been popular in part because it could be easily applied to many shapes and sizes of vessels, namely by blowing the paraison (molten glass) into a mould decorated with an internal pattern, then removing it and continuing to blow the vessel into the desired contour. As the glass stretched during the second blowing, the pattern became amplified and sometimes also distorted, as four fragments from this site illustrate (Nos. 233, 236, and 239, along with No. 201, which was presented earlier). Several of these pieces, plus No. 232, have their moulded lines running diagonally rather

${ }^{371}$ Gladys R Davidson, “A Mediaeval Glass-Factory at Corinth,” American Journal of Archaeology 44, no. 3 (1940): 311 , 315, 321; Lester, "Islamic Glass Finds,” 201-204. 
than vertically, an effect that was probably achieved by rotating the paraison in the mould. ${ }^{372}$

A few fragments seem to have been inflated to full size before being removed from their moulds. The evidence for this is the precision, definition, and depth of their moulded features. In the case of No. 231, parallel ribs cover the vessel's neck and shoulder. Similar ribs on Nos. 237 and 238 are equally well defined but come from the spherical part of their vessel's bodies. On both fragments, the ribbing protrudes not only on the outside but also on the inside of the vessel's wall, presumably because of its very thin fabric. Indeed, there seems to be an inverse relationship between a vessel's thickness and the extent to which its moulded features are perceptible on its inside surface. On No. 230, for instance, the ribbing is very elaborate, running in two directions to form rectangles, each of which sports a raised dot in the centre. Yet because the vessel's wall is quite thick, the traces of this pattern on its inner surface are almost undetectable.

Many of the other mould-decorated fragments in this corpus are too small or indistinct for their patterns to be clearly discernible.

Group 26: Moulded decoration (10 pieces: see drawings in Illustration 19)

\begin{tabular}{|l|l|l|l|l|}
\hline No. & Loc. & Basket & Description & Parallels \\
\hline 230 & 2109 & 3109.1 & $\begin{array}{l}\text { Mould-decorated fragment from body and } \\
\text { shoulder of spherical (or perhaps piriform) } \\
\text { flask. Body diameter ca. 50 mm. Moulded } \\
\text { grid-lines ca. 2.5 mm wide form rectangles } \\
\text { ca. 20 x 25 mm; portions of 6 are visible. } \\
\text { Raised round dot, 7 mm diameter, in the } \\
\text { middle of each rectangle; 3 are visible. } \\
\text { Overall dimensions ca. 50 x 35 mm. Pale } \\
\text { green fabric (von Saldern \#2). }\end{array}$ & No close parallels. \\
\hline 231 & 1214 & 5427.9 & $\begin{array}{l}\text { Mould-decorated fragment from neck and } \\
\text { shoulder of spherical flask. Body diameter } \\
\text { ca. 50 mm. Two well-defined, sharply } \\
\text { moulded lines ca. 2 mm wide run in paral- } \\
\text { lel across the fragment, down the neck } \\
\text { and onto the body. Overall dimensions ca. } \\
\text { 27x25 mm. Pale green fabric (von Saldern } \\
\text { \#2). }\end{array}$ & Indeterminate. \\
\hline 232 & 547 & 1918.8 & $\begin{array}{l}\text { Mould-decorated fragment of cylindrical } \\
\text { neck of flask. Neck diameter 40 mm; 15\% } \\
\text { of circumference extant. Small, moulded } \\
\text { lines ca. 2 mm wide run diagonally across }\end{array}$ & Indeterminate. \\
\hline
\end{tabular}

${ }^{372}$ Dussart, Le verre en Jordanie et en Syrie du Sud, 94. 


\begin{tabular}{|c|c|c|c|c|}
\hline & & & $\begin{array}{l}\text { the fabric. Preserved height } 38 \mathrm{~mm} \text {. Light } \\
\text { aqua fabric (von Saldern \#1). }\end{array}$ & \\
\hline 233 & 563 & 2105.7 & $\begin{array}{l}\text { Mould-decorated fragment of large cylin- } \\
\text { drical bottle. Body diameter ca. } 80 \mathrm{~mm} \text {; } \\
\text { 37\% of circumference extant. Body height } \\
>80 \mathrm{~mm} \text {. Slight in-turn toward shoulder. } \\
\text { Shallow moulded ribs ca. } 3-5 \mathrm{~mm} \text { wide run } \\
\text { diagonally across the body, becoming less } \\
\text { distinct as they extend upward. Preserved } \\
\text { height } 83 \mathrm{~mm} \text {. Pale green fabric (von } \\
\text { Saldern \#2). }\end{array}$ & $\begin{array}{l}\text { Dussart } 159 \text { (Type BXI.231, incl. } \\
\text { moulded decoration), late third } \\
\text { century. }\end{array}$ \\
\hline 234 & 2133 & 3441.10 & $\begin{array}{l}\text { Mould-decorated base of large piriform } \\
\text { flask. Body diameter } 150 \mathrm{~mm} \text {; } 15 \% \text { of cir- } \\
\text { cumference extant. Body height }>60 \mathrm{~mm} \text {. } \\
\text { Shallow, vertical moulded ribs ca. } 10 \mathrm{~mm} \\
\text { apart. Prominently domed base. Pale } \\
\text { green fabric (von Saldern \#2). }\end{array}$ & $\begin{array}{l}\text { Dussart BX.812 (flask with inde- } \\
\text { terminate neck and moulded } \\
\text { decoration). }\end{array}$ \\
\hline 235 & 2136 & 3407.27 & $\begin{array}{l}\text { Mould-decorated fragment of large globu- } \\
\text { lar (piriform?) vessel with crudely cut-off } \\
\text { rim. Rim diameter } 50 \mathrm{~mm} \text {; } 15 \% \text { of circum- } \\
\text { ference extant. Faintly moulded lines ca. } 3 \\
\text { mm apart run diagonally. Overall dimen- } \\
\text { sions ca. } 45 \times 20 \mathrm{~mm} \text {. Light aqua fabric } \\
\text { (von Saldern \#1). }\end{array}$ & $\begin{array}{l}\text { Re. cutting-off: see No. } 199 \\
\text { (note: same locus). }\end{array}$ \\
\hline 236 & 2124 & 3167.2 & $\begin{array}{l}\text { Mould-decorated fragment from body and } \\
\text { shoulder of spherical flask. Body diameter } \\
\text { ca. } 65 \mathrm{~mm} \text {; ca. } 18 \% \text { of circumference ex- } \\
\text { tant. Faint moulded lines ca. } 3 \mathrm{~mm} \text { wide } \\
\text { radiate vertically across the fragment: } \\
\text { down the neck and onto the body. Pre- } \\
\text { served height } 28 \mathrm{~mm} \text {. Pale green fabric } \\
\text { (von Saldern \#2). }\end{array}$ & Indeterminate. \\
\hline 237 & 1226 & 3430.4 & $\begin{array}{l}\text { Part of thread-decorated spherical body of } \\
\text { large bottle. Body diameter } 250 \mathrm{~mm} \text {; } 8 \% \text { of } \\
\text { circumference extant (x } 52 \mathrm{~mm} \text { height); } \\
\text { wall thickness } 1.2 \mathrm{~mm} \text {. Two threads radi- } \\
\text { ate vertically along curve of body. Threads } \\
3 \mathrm{~mm} \text { wide, well integrated into fabric of } \\
\text { body. Pale green fabric (von Saldern \#2). }\end{array}$ & $\begin{array}{l}\text { Dussart } 94 \text { (Type BVII.261, } 2621 \\
\text { are rough parallels), fourth-fifth } \\
\text { century. }\end{array}$ \\
\hline 238 & 547 & $\begin{array}{l}\text { 1918.6, } \\
7\end{array}$ & $\begin{array}{l}\text { Mould-decorated fragment from body of } \\
\text { large spherical flask. Body diameter ca. } \\
100 \mathrm{~mm} \text {. Five moulded lines ca. } 3 \mathrm{~mm} \\
\text { wide radiate across the fragment, } 7-10\end{array}$ & Indeterminate. \\
\hline
\end{tabular}




\begin{tabular}{|l|l|l|l|l|}
\hline & & & $\begin{array}{l}\text { mm apart. Overall dimensions ca. 46 x 40 } \\
\text { mm. Pale green fabric (von Saldern \#2). }\end{array}$ & \\
\hline 239 & 2136 & 3407.26 & $\begin{array}{l}\text { Mould-decorated fragment of large globu- } \\
\text { lar (piriform?) vessel. Faintly moulded } \\
\text { lines ca. 5 mm apart. Overall dimensions } \\
\text { ca. } 45 \times 35 \mathrm{~mm} \text {. Light aqua fabric (von } \\
\text { Saldern \#1). }\end{array}$ & Indeterminate. \\
\hline
\end{tabular}

The third group of decorated fragments presented below is characterized by elements that were applied to a vessel within the manufacturing process after its basic structure had already been formed.

Some of these elements are "trails": that is, elongated segments of varying thickness that were applied to the outside of a vessel's body, usually in a horizontal direction. Some trails retain a simple linear orientation; the best example here is the massive No. 242. Other trails zigzag up and down to create a fancy ruffle pattern. In fact, as several fragments in this cluster show, such ruffles were not always strictly horizontal but sometimes wandered up and down a vessel's wall (note especially No. 243). Parallels for these ruffled trails come mostly from bottles with long necks that can be dated from the sixth century or later; the form was most common in the Byzantine and Umayyad periods. ${ }^{373}$

A second sub-group consists of handles, which resemble trails and ruffles in their basic morphology but stand proud of the vessel's body so they can be more easily grasped. Their design varies greatly. Handles attached to pitchers are often hollow tubes, generally symmetrical in design and carefully attached to the side and rim of their host vessels (No. 246). Handles attached to other vessel types (notably lamps) are usually solid, and as a group demonstrate a lively exuberance both in their shape and in the carefree way in which they were globbed onto vessels' walls.

Another type of decoration in this group is represented by a particularly elaborate example of thread-decorating, similar in technique to the simple examples discussed above but entirely different in its design objective. This fragment, No. 251, is from a small bottle with threads not wound horizontally around a vessel neck but radiating from the pontil mark at the centre of its base, forming a star-like pattern. These threads are also somewhat unusual (though Nos. 189 and 190 are similar in this respect) in being of a different colour (blue) from the body of the vessel (pale green). The quality of workmanship does not seem to match the high calibre of the design.

${ }^{373}$ Meyer, "Glass from the North Theater Byzantine Church, and Soundings at Jerash, Jordan, 1982-1983,” 206-207. 
It should be remembered that No. 65 (discussed above) is decorated with a fused-on blue blob, which is a style of decoration notably used in the fourth century, ${ }^{374}$ especially on conical lamps with cracked-off rims, but also occasionally found on other vessel types between the Roman and medieval eras. ${ }^{375}$

Finally, quite a few of the 125 small fragments of a very thick-walled vessel of indeterminate shape, bear both moulded and incised decorations. Among the seven diagnostic pieces presented here (Nos. 252-258), the moulded elements (Nos. 253-256) are lozenge-shaped while the wheel-cut elements (Nos. 254, 256-258) include parallel and perpendicular lines. Interestingly, the largest piece of this thoroughly shattered vessel (No. 252) bears no decoration at all. (Note: It is possible that this vessel is not glass at all, but rather carved from rock crystal. See table below.)

Group 27: Applied decoration (19 pieces: see drawings in Illustration 20)

\begin{tabular}{|l|l|l|l|l|}
\hline No. & Loc. & Basket & Description & Parallels \\
\hline 240 & 2118 & 3160.1 & $\begin{array}{l}\text { Part of cylindrical body of medium-sized } \\
\text { vessel with large ruffle attached. Body di- } \\
\text { ameter 80 mm; 19\% of circumference ex- } \\
\text { tant. Ruffle is round in cross section, 9 } \\
\text { mm diameter, and "pinched" at intervals } \\
\text { to create zigzag, up-and-down pattern } \\
\text { that wanders up and down the vessel wall. } \\
\text { Preserved height 32 mm. Pale green fabric } \\
\text { and decorations (von Saldern \#2). }\end{array}$ & $\begin{array}{l}\text { Bauer 534-35, fourth-sixth cen- } \\
\text { tury; Crowfoot 418, sixth cen- } \\
\text { tury; Meyer 1987:206-7, seventh } \\
\text { century onward; Lester 2004:186, } \\
\text { eighth-eleventh century. }\end{array}$ \\
\hline 241 & 1237 & 2470.5 & $\begin{array}{l}\text { Part of cylindrical body of medium-sized } \\
\text { vessel with small linear trail. Body diame- } \\
\text { ter 70 mm; 15\% of circumference extant. } \\
\text { Trail is round in cross section, 5.5 mm di- } \\
\text { ameter, and sharply “pinched" to create } \\
\text { narrow waist at one point. One thick } \\
\text { thread decoration (2 mm thick) is sand- } \\
\text { wiched between this trail and the vessel } \\
\text { wall. Preserved height 19 mm. Light aqua } \\
\text { fabric (von Saldern \#1) with light blue dec- } \\
\text { orations (von Saldern \#6). }\end{array}$ & Indeterminate. \\
\hline 242 & 1296 & 2370.2 & $\begin{array}{l}\text { Part of cylindrical body of medium-sized } \\
\text { vessel with massive linear trail. Body di- } \\
\text { ameter 70 mm; 16\% of circumference ex- } \\
\text { tant. Trail is oblong in cross section, 14 }\end{array}$ & Indeterminate. \\
\hline
\end{tabular}

\footnotetext{
${ }^{374}$ Weinberg and Goldstein, "The Glass Vessels," 87-94.

${ }^{375}$ Meyer, "Glass from the North Theater Byzantine Church, and Soundings at Jerash, Jordan, 1982-1983," 198.
} 


\begin{tabular}{|c|c|c|c|c|}
\hline & & & $\begin{array}{l}\mathrm{mm} \text { high } \times 7.5 \mathrm{~mm} \text { wide, and runs hori- } \\
\text { zontally around the neck. Preserved } \\
\text { height } 14 \mathrm{~mm} \text {. Light aqua fabric and deco- } \\
\text { ration (von Saldern \#1). }\end{array}$ & \\
\hline 243 & 2113 & 3134.1 & $\begin{array}{l}\text { Part of conical body of medium-sized ves- } \\
\text { sel with large ruffle attached. Body diame- } \\
\text { ter } 65 \mathrm{~mm} \text {; } 41 \% \text { of circumference extant. } \\
\text { Ruffle is round in cross section, } 8 \mathrm{~mm} \text { di- } \\
\text { ameter, and "pinched" at irregular inter- } \\
\text { vals to create zigzag, up-and-down pat- } \\
\text { tern that wanders up and down the vessel } \\
\text { wall. Preserved height } 33 \mathrm{~mm} \text {. Light aqua } \\
\text { fabric and decorations (von Saldern \#1). }\end{array}$ & See No. 240. \\
\hline 244 & 563 & 2148.1 & $\begin{array}{l}\text { Part of cylindrical body of medium-sized } \\
\text { vessel with large ruffle attached. Body di- } \\
\text { ameter } 50 \mathrm{~mm} \text {; } 19 \% \text { of circumference ex- } \\
\text { tant. Ruffle is round in cross section, } 6 \\
\text { mm diameter, and "pinched" at intervals } \\
\text { to create zigzag, up-and-down pattern } \\
\text { that wanders up and down the vessel wall. } \\
\text { Preserved height } 18 \mathrm{~mm} \text {. Light aqua fabric } \\
\text { and decorations (von Saldern } \# 1 \text { ). }\end{array}$ & See No. 240. \\
\hline 245 & 2157 & 3464.3 & $\begin{array}{l}\text { Part of spherical body of large vessel with } \\
\text { ruffle attached. Body diameter } 140 \mathrm{~mm} \text {; } \\
9 \% \text { of circumference extant. Ruffle is } 34 \\
\text { mm long, bulging out from body in mid- } \\
\text { dle; two very distinctive flat, semicircular } \\
\text { "disks" at either end, ca. } 15 \mathrm{~mm} \text { diameter, } \\
\text { evidently made by tong flattening of a } \\
\text { small blob. Light aqua fabric (von Saldern } \\
\text { \#1). }\end{array}$ & See No. 240. \\
\hline 246 & 1948 & 2488.6 & $\begin{array}{l}\text { Complete hollow handle from large } \\
\text { pitcher. Body diameter ca. } 80 \mathrm{~mm} \text {; spheri- } \\
\text { cal profile; height from shoulder attach- } \\
\text { ment point of handle to rim ca. } 65 \mathrm{~mm} \text {. } \\
\text { Handle has "C"-shape profile, flattened in } \\
\text { middle section to } 6 \mathrm{~mm} \text { thick x } 11 \mathrm{~mm} \\
\text { wide, with up-folded flourish at top before } \\
\text { attachment to rim. One small, errant } \\
\text { thread decoration meanders down the top } \\
\text { half of the handle. Preserved height } 85 \\
\text { mm. Yellow-brown fabric (not in von } \\
\text { Saldern's typology). }\end{array}$ & $\begin{array}{l}\text { Possible analogue: Dussart } 177 \\
\text { (Type BXIV.121), middle-second } \\
\text { to fourth century. }\end{array}$ \\
\hline 247 & 2147 & 3447.4 & $\begin{array}{l}\text { Almost complete solid handle from large } \\
\text { pitcher (or lamp?). Body diameter ca. } 150\end{array}$ & $\begin{array}{l}\text { Indeterminate. Note similarity of } \\
\text { dimensions to No. } 248 .\end{array}$ \\
\hline
\end{tabular}




\begin{tabular}{|c|c|c|c|c|}
\hline & & & $\begin{array}{l}\mathrm{mm} \text {; spherical profile; height from middle } \\
\text { of shoulder attachment-point of handle to } \\
\text { rim ca. } 51 \mathrm{~mm} \text {. Handle made from round } \\
\text { section, evenly tapering, curving sharply } \\
\text { inward at top toward rim. Preserved } \\
\text { height } 52 \mathrm{~mm} \text {. Pale green fabric (von } \\
\text { Saldern \#2). }\end{array}$ & \\
\hline 248 & 2126 & 3173.1 & $\begin{array}{l}\text { Almost complete solid handle from large } \\
\text { pitcher (or lamp?). Body diameter ca. } 150 \\
\text { mm; spherical profile; height from middle } \\
\text { of shoulder attachment point of handle to } \\
\text { rim ca. } 49 \mathrm{~mm} \text {. Handle made from round } \\
\text { section, } 14 \mathrm{~mm} \text { diameter, flattened to cre- } \\
\text { ate a flat band, } 11 \mathrm{~mm} \text { wide, on its outer } \\
\text { surface, curving sharply inward at top to- } \\
\text { ward rim. Preserved height } 59 \mathrm{~mm} \text {. Pale } \\
\text { green fabric (von Saldern } \# 2 \text { ). }\end{array}$ & $\begin{array}{l}\text { Indeterminate. Note similarity of } \\
\text { dimensions to No. } 247 \text {. }\end{array}$ \\
\hline 249 & 1940 & 2459.7 & $\begin{array}{l}\text { Lower portion of hollow handle from large } \\
\text { vessel. Body diameter ca. } 60 \mathrm{~mm} \text {; profile } \\
\text { unknown. Handle diameter } 9 \mathrm{~mm} \text {, straight } \\
\text { profile. Preserved height } 31 \mathrm{~mm} \text {. Light } \\
\text { aqua fabric (von Saldern \#1). }\end{array}$ & Indeterminate. \\
\hline 250 & 2136 & 3408.9 & $\begin{array}{l}\text { Partial solid handle from large lamp. Body } \\
\text { diameter ca. } 100 \mathrm{~mm} \text {; spherical profile. } \\
\text { Handle flattened to create an oblong cross } \\
\text { section; } 4 \mathrm{~mm} \text { thick x } 8 \mathrm{~mm} \text { wide. Bottom } \\
\text { of attachment-point pinched then pulled } \\
\text { to create a small flat flourish. Preserved } \\
\text { height } 28 \mathrm{~mm} \text {. Body is light aqua fabric } \\
\text { (von Saldern \#1) with light blue handle } \\
\text { (von Saldern \#6). }\end{array}$ & $\begin{array}{l}\text { Dussart } 85 \text { (Type BVI.123), Byz- } \\
\text { antine-Umayyad. }\end{array}$ \\
\hline 251 & 2112 & 2290.3 & $\begin{array}{l}\text { Partial thread decorated base of small } \\
\text { spherical or piriform flask or bottle. Body } \\
\text { diameter ca. } 55 \mathrm{~mm} \text {; exact profile un- } \\
\text { known. Five pairs of blue threads radiate } \\
\text { outward and upward in star shape, from } \\
\text { pontil mark at centre. Threads } 1.5-2 \mathrm{~mm} \\
\text { thick. Preserved height } 12 \mathrm{~mm} \text {. Body is } \\
\text { pale green fabric (von Saldern \#2) with } \\
\text { light blue threads (von Saldern \#6). }\end{array}$ & $\begin{array}{l}\text { Dussart } 94 \text { (Type BVII.261, } 2621 \\
\text { are rough parallels), fourth-fifth } \\
\text { century; cp. Dussart } 159 \text { (Type } \\
\text { BXI.232), late third century; Da- } \\
\text { vidson 1940:321, eleventh cen- } \\
\text { tury. }\end{array}$ \\
\hline $\begin{array}{l}252 \\
253\end{array}$ & 2133 & $\begin{array}{l}3419.2 \\
3419.7\end{array}$ & $\begin{array}{l}\text { Seven diagnostic fragments (of } 125 \text { total) } \\
\text { of a vessel of unknown shape. Body } \\
\text { (neck?) tapers from } 45 \text { to } 35 \mathrm{~mm} \text { inner di- }\end{array}$ & $\begin{array}{l}\text { Lester 2004:11 (a single fragment } \\
\text { of a carved rock-crystal vessel } \\
\text { from Tiberias). }\end{array}$ \\
\hline
\end{tabular}




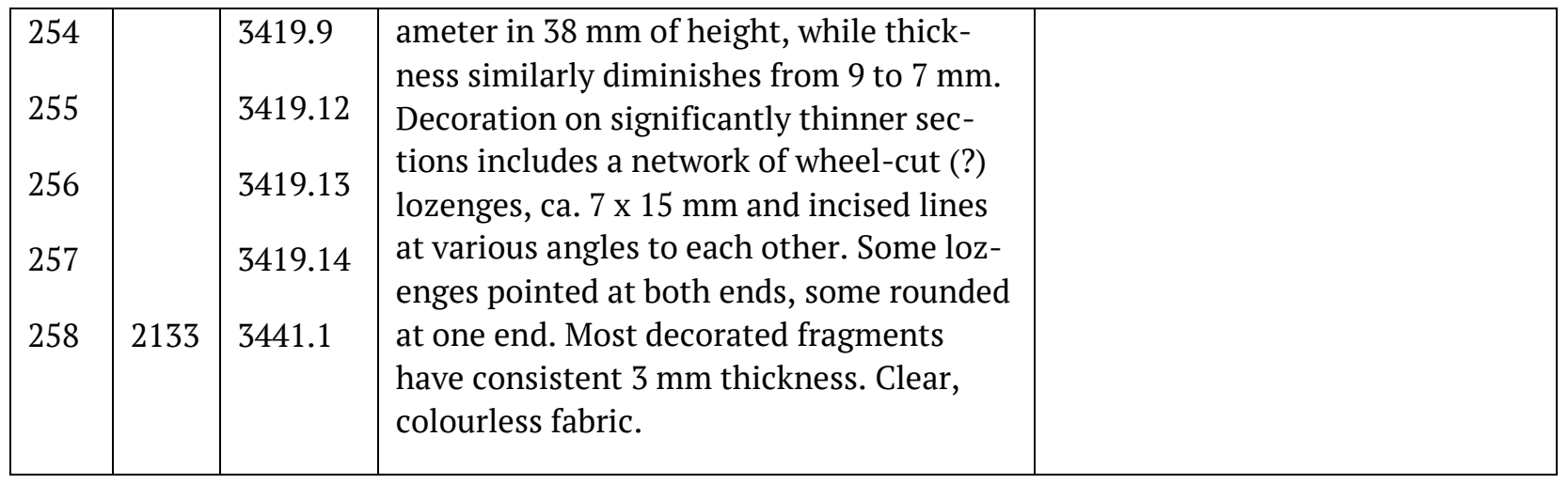

\section{Raw Glass}

In addition to the fragments of finished vessels discussed above, the NIP also recovered eleven chunks of raw glass. All of them were found in the same room, close to the floor.

All these chunks are fragmentary, with most of their vertical faces being sharply broken in antiquity. In a few cases, what are now separate chunks obviously once fitted together (Nos. 259-260, probably also 261-262, and perhaps also Nos. 267-270). Interestingly, most of these chunks include at least one edge indicating that the shape of the larger piece from which they came was round, and large (ranging from ca. 200 to ca. $350 \mathrm{~mm}$ in diameter). All the chunks that come from round masses are thinner at the outer edge (the "rim" of the round) than the inner edge (toward the centre of the mass). The thickness of the outer edge ranges from 13 to $26 \mathrm{~mm}$; the inner edge, from 17 to $35 \mathrm{~mm}$. In several cases (Nos. 259, 260, 261) the outer edge bears a series of shallow, sharply cut slash-marks, roughly perpendicular to the edge itself. The purpose of this tooling is unclear but may be related to the way these round masses were formed. The bottom surface of most chunks suggests that hot glass-malleable but not entirely molten-was poured onto a hard surface then pressed down in a way that flattened the numerous air-bubbles within it. In the case of No. 259, the pouring action seems to have been quick and jerky, resulting in an irregular pattern on the bottom surface, with highly distinct "ropy" textures overlapping and intersecting with each other in unpredictable ways, especially toward the outer edges of the mass. By contrast, No. 267 seems to have been poured in a smoother, more spiral manner, resulting in a relatively regular pattern of arcing textures on both the top and bottom surfaces of the chunk.

Most of these chunks are made of a relatively uniform light aqua fabric, although several different shades of that colour occur. Two shades of medium blue are each represented by one chunk (Nos. 265, 266), again with only a little variegation of colour throughout each piece. By contrast, the fabric of Nos. 267-269 is a poorly mixed blend of light aqua and olive green. Furthermore, these same three chunks include many small white particles whichjudging by their shape and relatively complete integration into the body of these chunksappear to be yet another colour of inmixed glass. At the same time, their porosity suggests 
that they may have been small remnants of a previous batch of raw glass that had been worked in the same furnace.

Several chunks have inclusions of one kind or another-that is, distinct pieces of solid material that became embedded in their fabric during the process of forming these masses of raw glass. One of the vertical edges of No. 259 exhibits a jagged piece of grey-brown granular material (dirt? ash?). A vertical edge of No. 264 exposes a more regularly shaped piece of porous material (brick? coarse ceramic?). Three chunks have embedded pieces of differently coloured glass that was obviously solid at the time this mass was being created, as indicated by the sharp demarcation between the inclusion and the body of the chunk. In No. 263, the embedded piece (lozenge-shaped) is right at the bottom of the chunk and very dark in colour. In No. 267, the intruding piece of glass is irregularly shaped and seems to have been lightly pressed into the top surface of the chunk. By contrast, the more smoothly rounded piece of white glass in the top surface of No. 260 is fully integrated into the fabric of the chunk. So is the more angular piece of black glass embedded in the bottom surface of the same chunk.

It is likely that this collection of chunks was gathered as potential raw material for a workshop engaged in secondary glass production: that is, glass working rather than glassmaking. Primary glass production is known with certainty to have taken place at only one location in Palestine during the Byzantine era: namely, Apollonia-Arsuf. ${ }^{376}$ Additional primary-production furnaces at Beth She'arim in the Jezreel Valley and at Beth Eli'ezer on the Sharon plain appear to date from the Umayyad era. ${ }^{377}$ However, the product of such furnaces was not relatively small disks such as these chunks found in the NIP, but enormous slabs that were usually hammered apart into variously sized irregular lumps after the whole mass finally cooled. ${ }^{378}$ Disks like the ones presented in this study were formed in secondary furnaces, some of which are known to have existed in proximity to primary furnaces. However, because their feedstock was not coastal sand and natron, but a mixture of already-formed glass lumps and broken vessels destined for recycling, secondary glass workshops could be established in less-specialized locations than primary furnaces, and are known to have existed throughout Byzantine Palestine, including at Tiberias. ${ }^{379}$ Typically, such workshops are identified by the presence of bricks from the furnace structure, the lumpy products of primary glass production, working debris from the vessel-making process (including moil,

\footnotetext{
${ }^{376}$ Ian C Freestone, Ruth E Jackson-Tal, and Oren Tal, "Raw Glass and the Production of Glass Vessels at Late Byzantine Apollonia-Arsuf, Israel," Journal of glass studies 50 (2008): 79.

377 Oren Tal, Ruth E Jackson-Tal, and Ian C Freestone, "New Evidence of the Production of Raw Glass at Late Byzantine Apollonia-Arsuf, Israel," Journal of Glass Studies 46 (2004): 59.

${ }^{378}$ Ibid., 57.

${ }^{379}$ Ayala Lester, "The Glass," in Excavations at Tiberias, 1973-1974: The Early Islamic Periods, ed. David Allen Stacey (Jerusalem: Israel Antiquities Authority, 2004), 216.
} 
waste, and broken, distorted, and misshapen vessels), and sometimes also finished products. ${ }^{380}$

Although no secondary glass workshops have so far been identified at Hippos, the combination of elements this industry would require are present in the city's immediate hinterland: an elevated location near to, but separate from, a sizeable population centre; frequent steady winds on a predictable axis; and a ready supply of fuel. It is possible, therefore, that this collection of eleven chunks of raw glass was intended to become feedstock for a secondary glass workshop somewhere in the nearby area. The same theory would also account for the presence in this otherwise quite nondescript room in the House of Tyche of a sizeable number of fragments of large glass vessels, including relatively early-style bowls and plates. The whole assemblage-the largest number of glass fragments within the House of Tyche, and the fourth-largest collection within the entire NIP-could plausibly have been gathered in this room pending an opportunity to forward it to a vessel-production workshop somewhere in the vicinity.

Group 28: Raw glass (11 pieces: see drawings in Illustrations 21 and 22)

\begin{tabular}{|l|l|l|l|l|}
\hline No. & Loc. & Basket & Description & Parallels \\
\hline 259 & 2133 & 3443.7 & $\begin{array}{l}\text { Large chunk, } 130 \mathrm{~mm} \text { x 75 mm x 22 mm } \\
\text { thick at rim edge, 35 mm thick at inner } \\
\text { edge. Rim diameter ca. 340 mm; 10\% of } \\
\text { circumference extant. Outer edge ("rim") } \\
\text { tooled, evidently to smooth the surface. 6 } \\
\text { parallel slashes along rim edge, roughly } \\
\text { perpendicular to edge. Centre section has } \\
\text { rough, ropy texture, concave bottom sur- } \\
\text { face. One chunk of grey-brown dirt (or } \\
\text { ash?), with granular texture and poorly de- } \\
\text { fined, irregular edges, visible along broken } \\
\text { edge, embedded in fabric, ca. 11 mm x 3.5 } \\
\text { mm. Light aqua fabric (von Saldern \#1). }\end{array}$ & See No. 260 (contiguous). \\
\hline 260 & 2135 & 3449.5 & $\begin{array}{l}\text { Oblong chunk, 75 mm x 55 mm x 22 mm } \\
\text { thick at rim edge, 32 mm thick at inner } \\
\text { edge. Contiguous with No. 259, although } \\
\text { smaller rim diameter (ca. 300 mm); 6\% of } \\
\text { circumference extant. Outer edge ("rim") } \\
\text { tooled as No. 259, including 3 slashes } \\
\text { along rim edge. Light aqua fabric (von } \\
\text { Saldern \#1). }\end{array}$ & See No. 259 (contiguous). \\
\hline
\end{tabular}

380 Oren Tal, Ruth E Jackson-Tal, and Ian C Freestone, "Glass from a Late Byzantine Secondary Workshop at Ramla (South), Israel,” Journal of Glass Studies 50 (2008): 93-94. 


\begin{tabular}{|c|c|c|c|c|}
\hline 261 & 2135 & 3444.18 & $\begin{array}{l}\text { Long thin chunk, } 87 \mathrm{~mm} \times 20 \mathrm{~mm} \times 13 \mathrm{~mm} \\
\text { thick at rim, } 17 \mathrm{~mm} \text { thick at inner edge. } \\
\text { Rim diameter ca. } 220 \mathrm{~mm} \text {; } 13 \% \text { of circum- } \\
\text { ference extant. No tooling on outer edge, } \\
\text { but possibly one slash along rim edge, } \\
\text { roughly perpendicular to edge. Centre sec- } \\
\text { tion has rough, ropy texture, unevenly } \\
\text { wavy bottom surface. Numerous large bub- } \\
\text { bles. Light aqua fabric (von Saldern \#1). }\end{array}$ & $\begin{array}{l}\text { Possibly from same object as Nos. } \\
\text { 259, 260, } 262 \text { (though note lesser } \\
\text { thickness). }\end{array}$ \\
\hline 262 & 2133 & 3443.5 & $\begin{array}{l}\text { Oblong chunk, } 60 \mathrm{~mm} \times 35 \mathrm{~mm} \times 26 \mathrm{~mm} \\
\text { thick at rim-edge, } 31 \mathrm{~mm} \text { thick at inner } \\
\text { edge. Rim diameter ca. } 340 \mathrm{~mm} \text {; } 8 \% \text { of cir- } \\
\text { cumference extant. Outer edge ("rim") } \\
\text { tooled as No. } 259 \text {, but no slashes. Centre } \\
\text { section has rough, ropy texture, concave } \\
\text { bottom surface. Light aqua fabric (von } \\
\text { Saldern \#1). }\end{array}$ & $\begin{array}{l}\text { Likely from same object as Nos. } \\
259,260,261 .\end{array}$ \\
\hline 263 & 2135 & 3444.25 & $\begin{array}{l}\text { Oblong chunk, } 42 \mathrm{~mm} \times 32 \mathrm{~mm} \times 15 \mathrm{~mm} \\
\text { thick. Numerous small bubbles. One loz- } \\
\text { enge-shaped chunk of dark-coloured glass, } \\
\text { with porous texture and smooth edges, vis- } \\
\text { ible along broken edge of chunk, embedded } \\
\text { in fabric, ca. } 9.5 \mathrm{~mm} \text { long x } 4 \mathrm{~mm} \text { diameter } \\
\text { Light aqua fabric (von Saldern \#1). }\end{array}$ & \\
\hline 264 & 2133 & 3443.6 & $\begin{array}{l}\text { Irregular chunk, } 72 \mathrm{~mm} \times 24 \mathrm{~mm} \times 22 \mathrm{~mm} \\
\text { thick at rim edge, } 31 \mathrm{~mm} \text { thick at inner } \\
\text { edge. Rim diameter ca. } 340 \mathrm{~mm} \text {; } 2 \% \text { of cir- } \\
\text { cumference extant. Numerous bubbles. } \\
\text { One oblong chunk of orange-brown, po- } \\
\text { rous, composite material (coarse ceramic? } \\
\text { mudbrick?), with fine porous texture and } \\
\text { well-defined edges visible along broken } \\
\text { edge, embedded in fabric, ca. } 5 \mathrm{~mm} \times 3 \\
\text { mm. Light aqua fabric (von Saldern \#1). }\end{array}$ & \\
\hline 265 & 2135 & 3444.22 & $\begin{array}{l}\text { Long thin chunk, } 68 \mathrm{~mm} \times 23 \mathrm{~mm} \times 15 \mathrm{~mm} \\
\text { thick at rim, } 17 \mathrm{~mm} \text { thick at inner edge. } \\
\text { Rim diameter ca. } 200 \mathrm{~mm} \text {; } 5 \% \text { of circum- } \\
\text { ference extant. Outer edge ("rim") tooled, } \\
\text { evidently to smooth the surface. Unevenly } \\
\text { wavy bottom surface. Numerous bubbles, } \\
\text { some quite large. Medium blue fabric (von } \\
\text { Saldern \#6). }\end{array}$ & \\
\hline
\end{tabular}




\begin{tabular}{|c|c|c|c|c|}
\hline 266 & 2135 & 3444.23 & $\begin{array}{l}\text { Oblong chunk, } 34 \mathrm{~mm} \times 31 \mathrm{~mm} \times 18 \mathrm{~mm} \\
\text { thick. Numerous bubbles, some quite large. } \\
\text { Medium blue fabric (von Saldern \#6). }\end{array}$ & \\
\hline 267 & 2133 & 3441.13 & $\begin{array}{l}\text { Large chunk, } 89 \mathrm{~mm} \times 100 \mathrm{~mm} \times 20 \mathrm{~mm} \\
\text { thick at rim edge, } 26 \mathrm{~mm} \text { thick at inner } \\
\text { edge. Rim diameter ca. } 350 \mathrm{~mm} \text {; } 7 \% \text { of cir- } \\
\text { cumference extant. No appreciable tooling } \\
\text { on outer edge. Ropy texture on top and } \\
\text { bottom surfaces; perpendicular to rim on } \\
\text { top, parallel to it on bottom. Numerous } \\
\text { small, embedded chunks of fine-textured, } \\
\text { porous, opaque white material, throughout } \\
\text { (glass?); shapes vary from small round bits } \\
\text { to long thread-like structures. One embed- } \\
\text { ded chunk of medium-blue glass on top } \\
\text { surface; irregular shape with jagged edges } \\
\text { (and itself containing irregular, multi-col- } \\
\text { oured inclusions), poorly integrated into } \\
\text { fabric. Fabric is mostly light aqua (von } \\
\text { Saldern \#1) but with extensive swirling / } \\
\text { mixing of olive-green fabric (von Saldern } \\
\text { \#3). }\end{array}$ & See Nos. 268 and 269. \\
\hline 268 & 2133 & 3441.14 & $\begin{array}{l}\text { Rectangular chunk, } 84 \mathrm{~mm} \times 29 \mathrm{~mm} \times 20 \\
\text { mm thick at rim edge, } 35 \mathrm{~mm} \text { thick at inner } \\
\text { edge. Rim diameter uncertain. No appre- } \\
\text { ciable tooling on outer edge. Ropy texture } \\
\text { on top surface, perpendicular to rim. Bot- } \\
\text { tom surface rough. Numerous small, em- } \\
\text { bedded chunks of fine-textured, porous, } \\
\text { opaque white material, throughout } \\
\text { (glass?); some are rice-grain shaped, some } \\
\text { are longer and more thread-like. Fabric is } \\
\text { mostly light aqua (von Saldern \#1) but with } \\
\text { extensive swirling / mixing of olive-green } \\
\text { fabric (von Saldern \#3). }\end{array}$ & See Nos. 267 and 269. \\
\hline 269 & 2135 & 3444.21 & $\begin{array}{l}\text { Oblong chunk, } 70 \mathrm{~mm} \times 32 \mathrm{~mm} \times 23 \mathrm{~mm} \\
\text { thick. Ropy texture on top surface. Bottom } \\
\text { surface rough. One oblong chunk of white } \\
\text { glass, with coarse porous texture and well- } \\
\text { defined edges, embedded in upper surface, } \\
\text { ca. } 6 \mathrm{~mm} \times 4 \mathrm{~mm} \text {. One oval chunk of black } \\
\text { glass, with medium porous texture and } \\
\text { well-defined edges, embedded in broken } \\
\text { edge, ca. } 10 \mathrm{~mm} \times 6 \mathrm{~mm} \text {. Additional small, } \\
\text { embedded chunks of fine-textured, opaque } \\
\text { white material, throughout, as in Nos. } 268 \text {, } \\
269 \text {. Fabric is mostly light aqua (von }\end{array}$ & See Nos. 267 and 268. \\
\hline
\end{tabular}


The Northeast Insulae Project

\begin{tabular}{|l|l|l|l|}
\hline & & $\begin{array}{l}\text { Saldern \#1) but with some swirling / mix- } \\
\text { ing of olive-green fabric (von Saldern \#3). }\end{array}$ & \\
\hline
\end{tabular}




\section{Illustrations}

Illustration 1
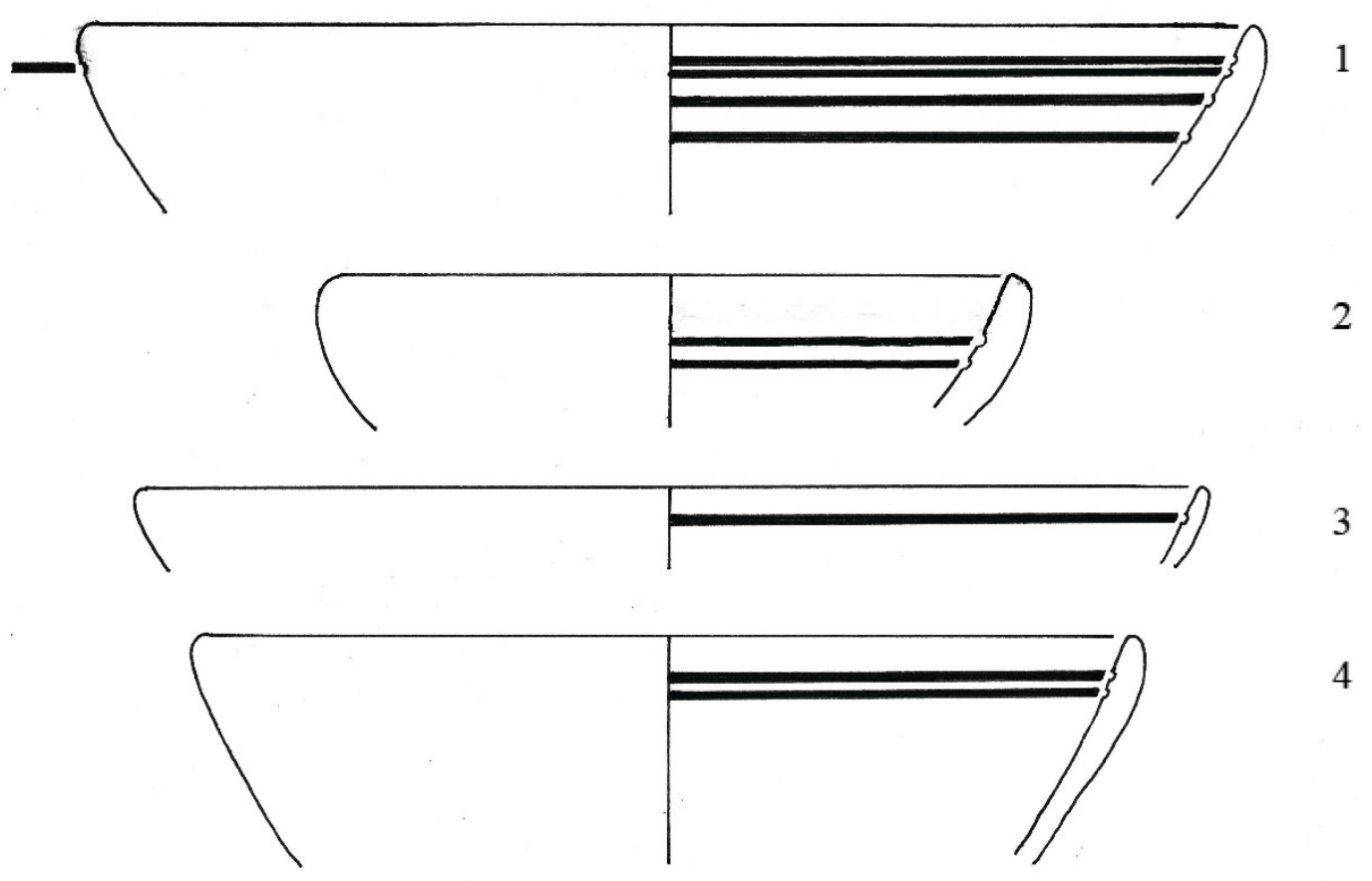

(
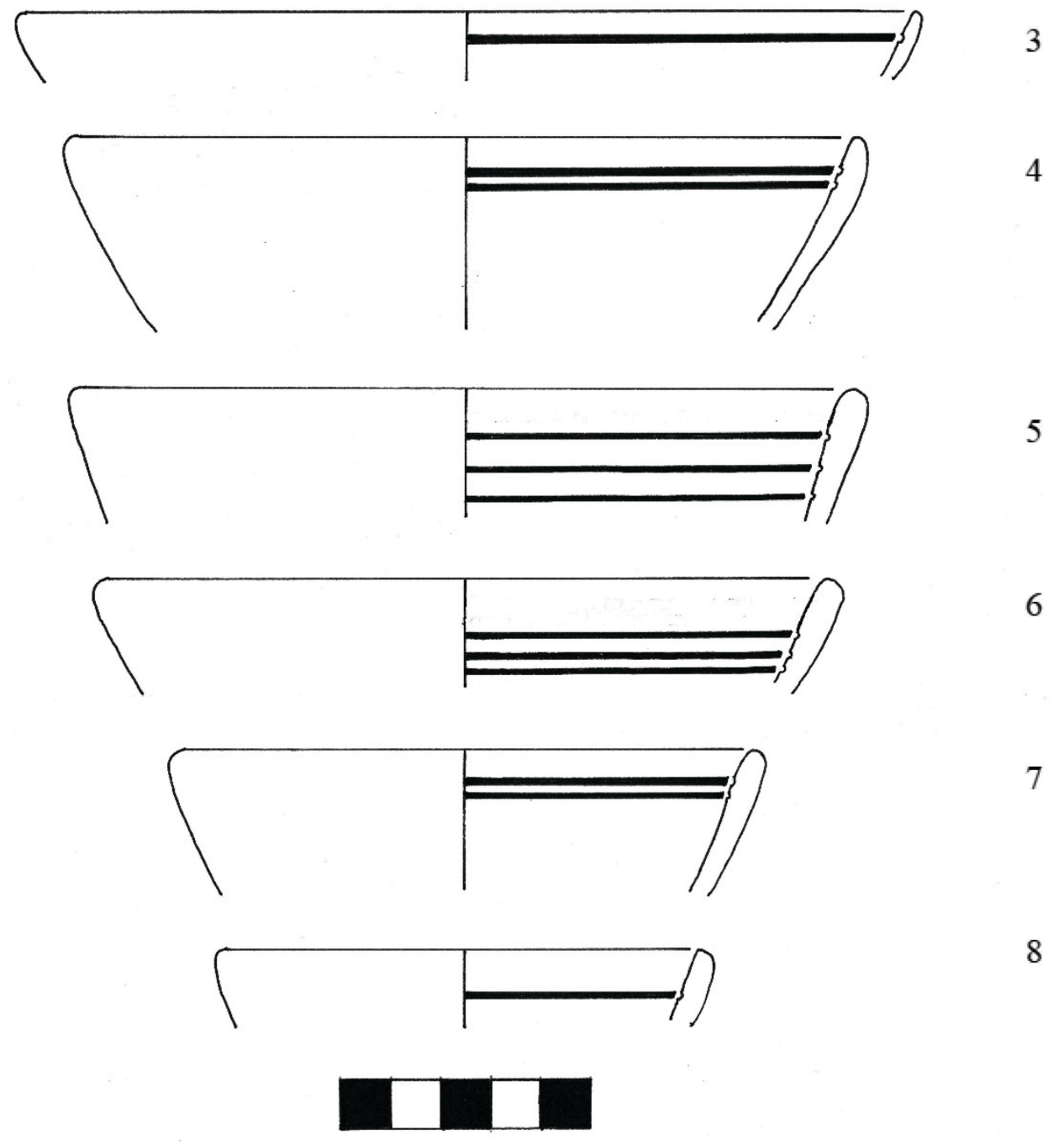
The Northeast Insulae Project

Illustration 2
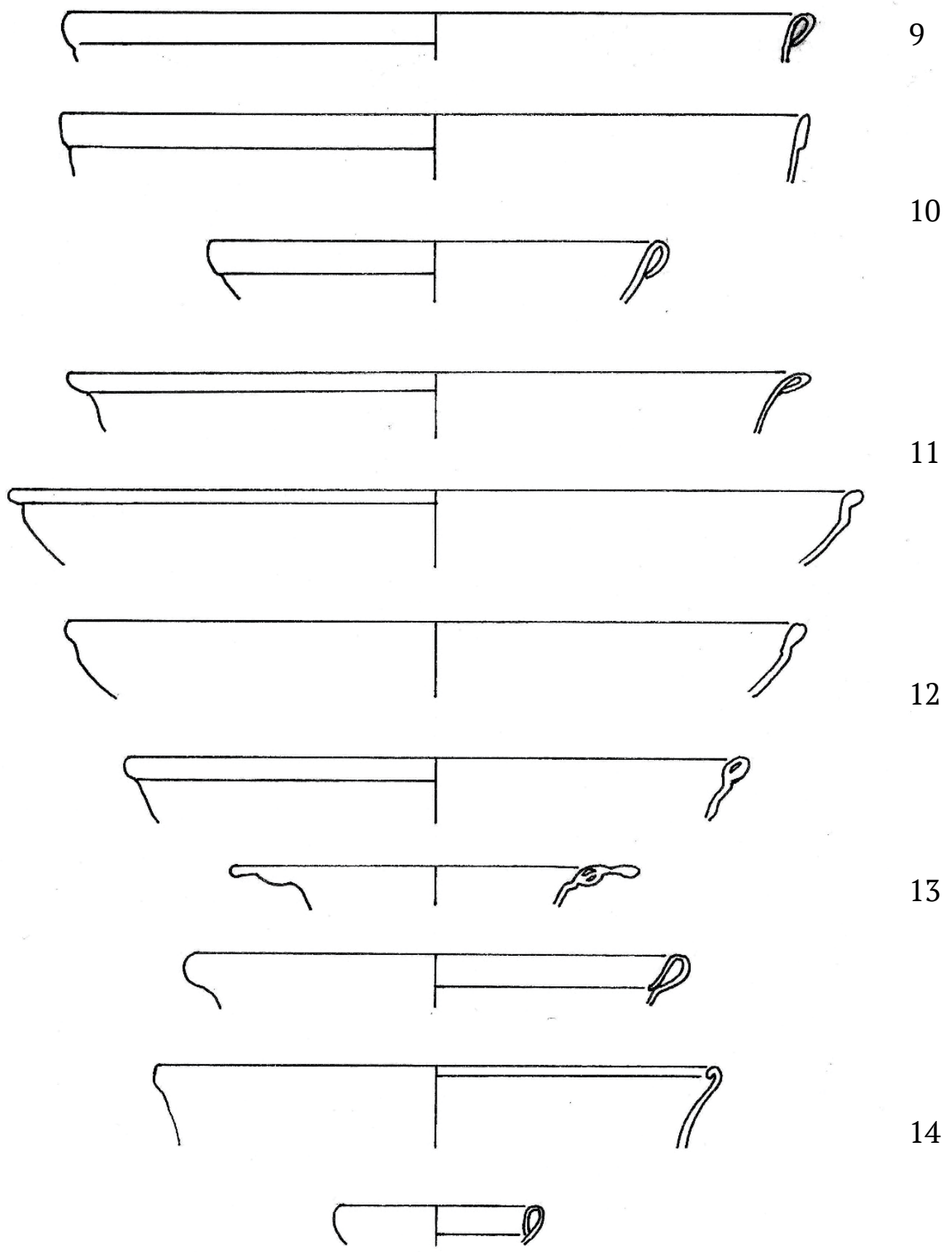

प⿴囗十口卄10 


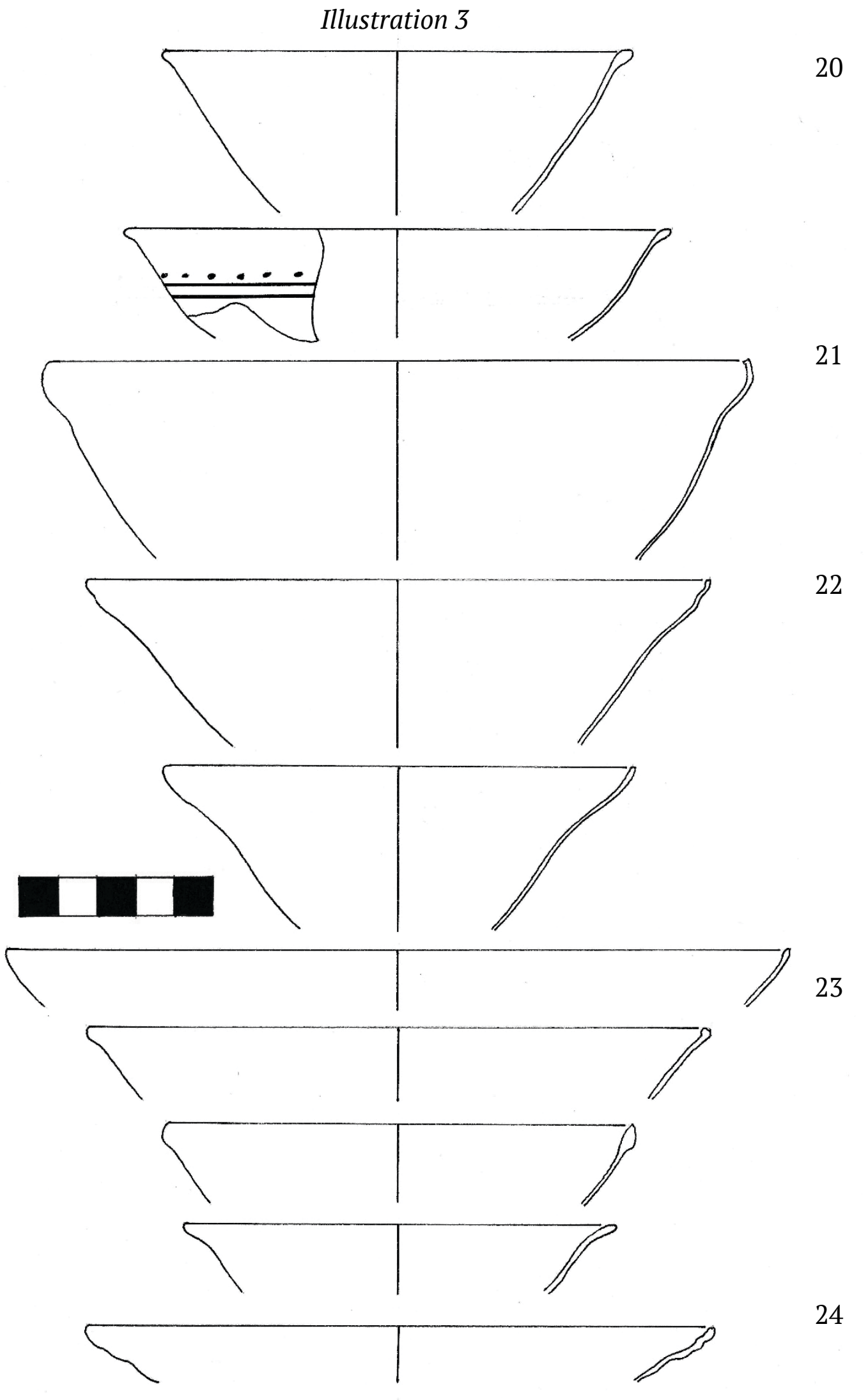




\section{Illustration 4}

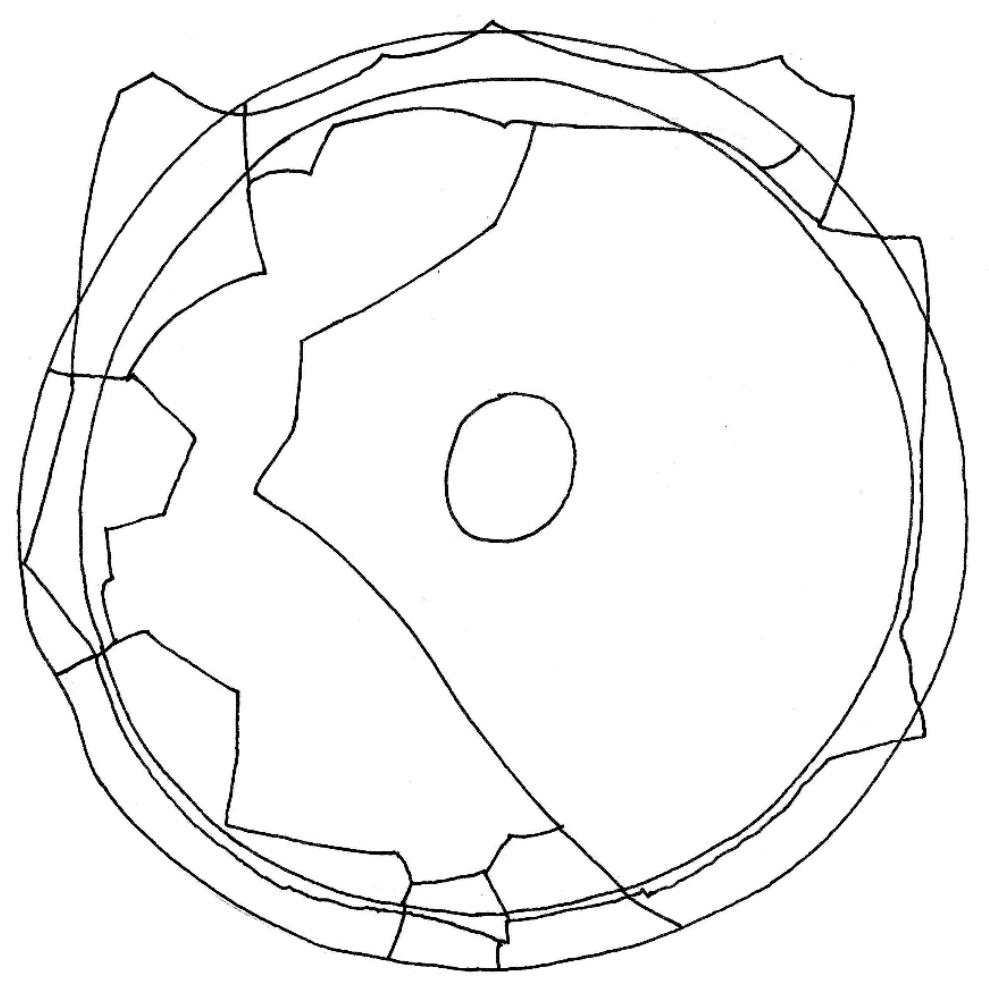

30 a

(top)
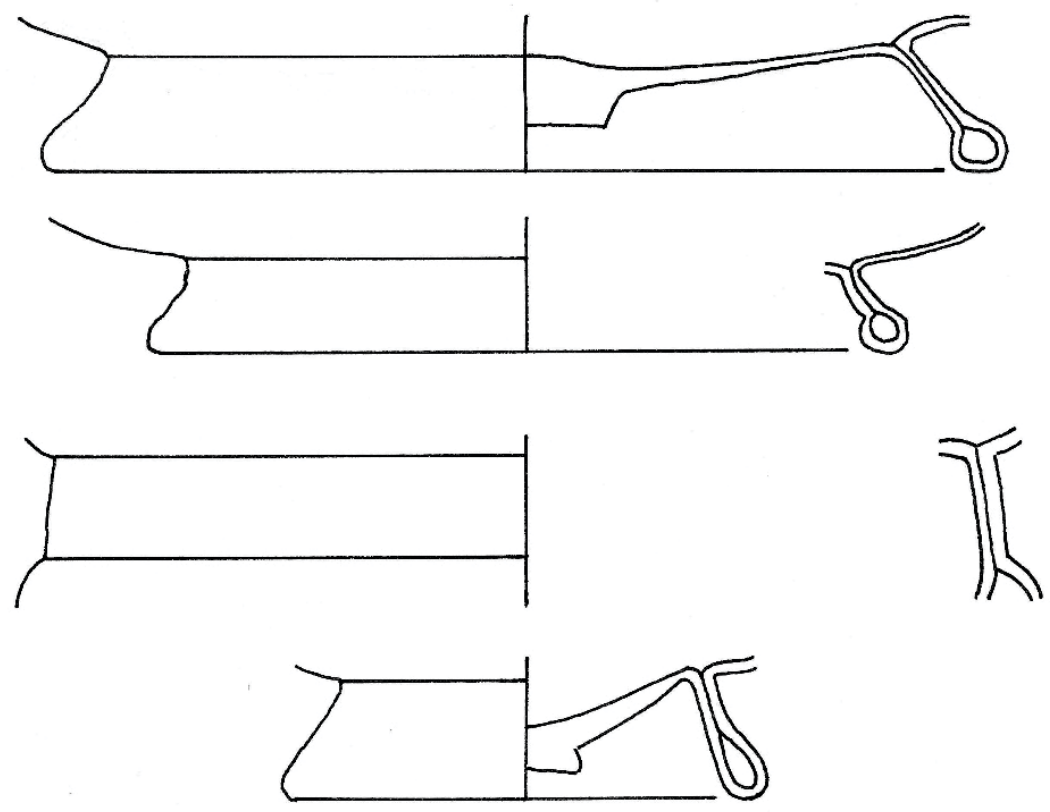

$30 \mathrm{~b}$

(base)
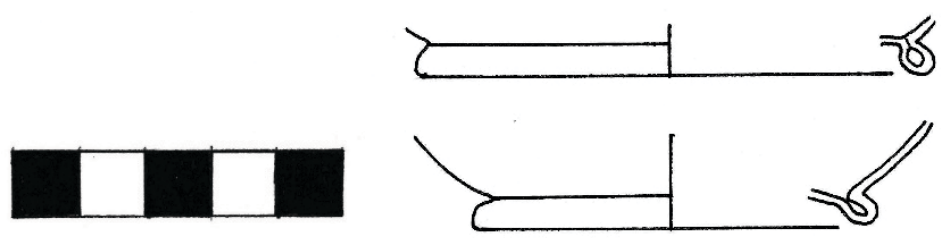


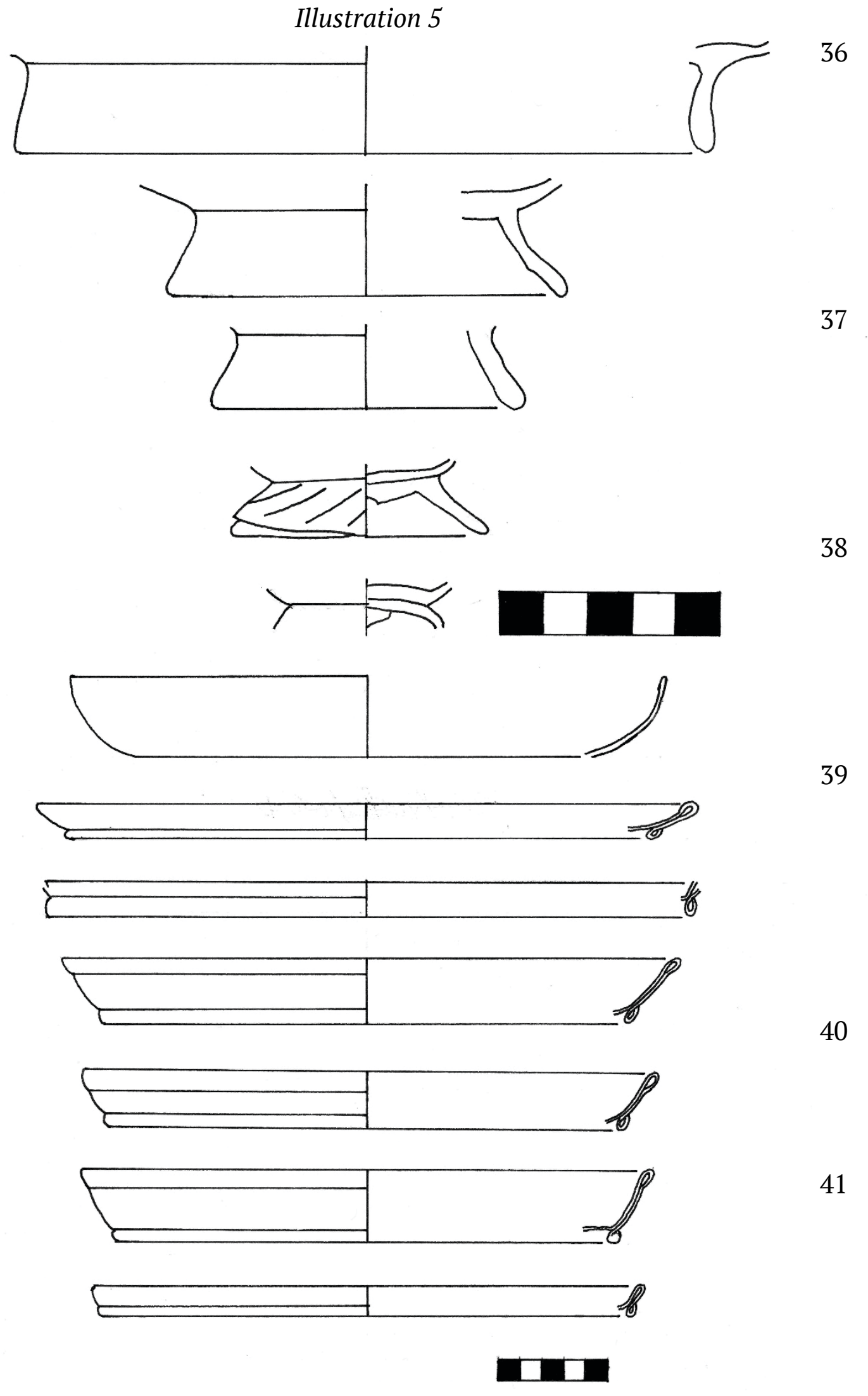




\section{Illustration 6}
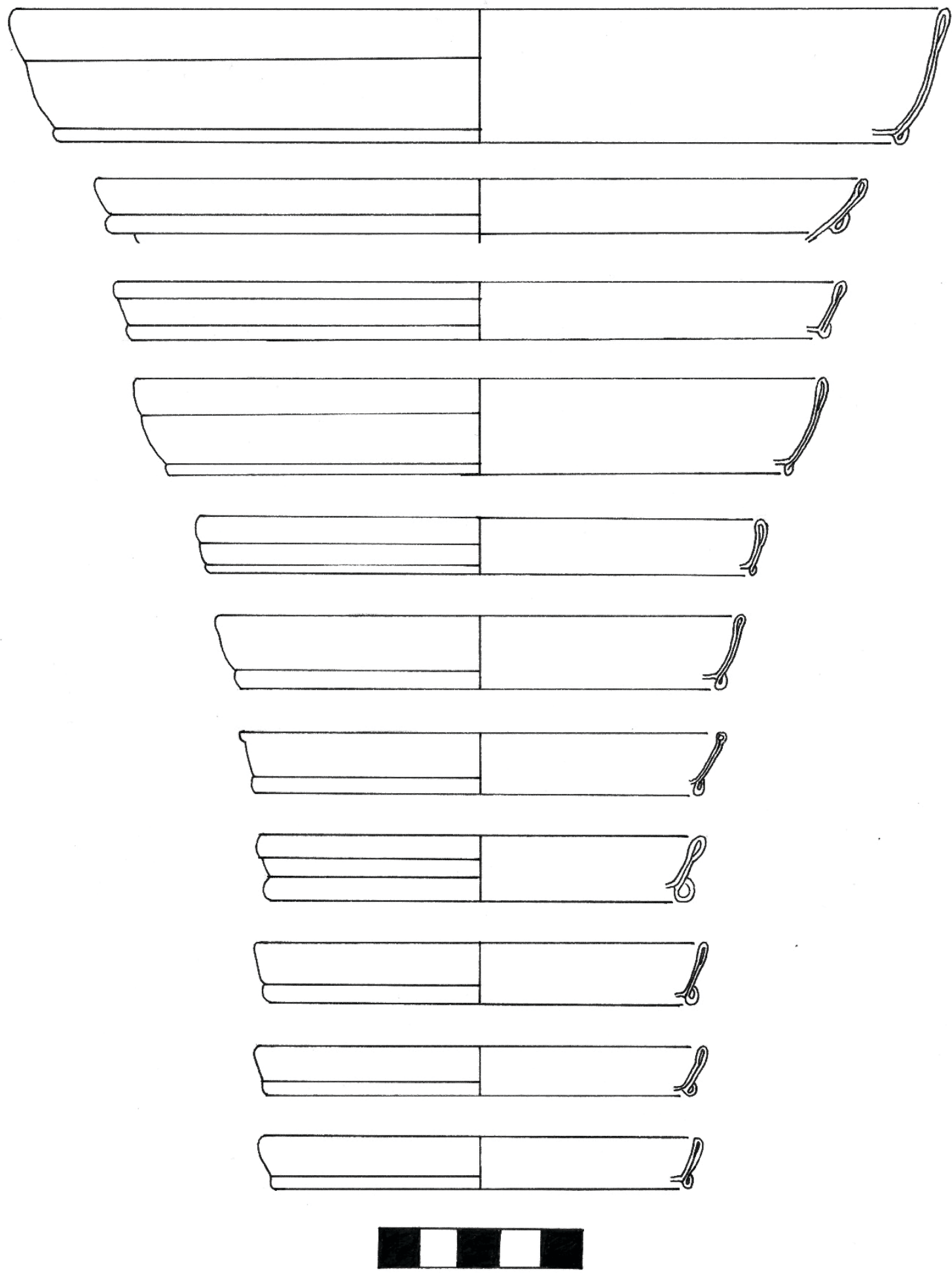


\section{Illustration 7}
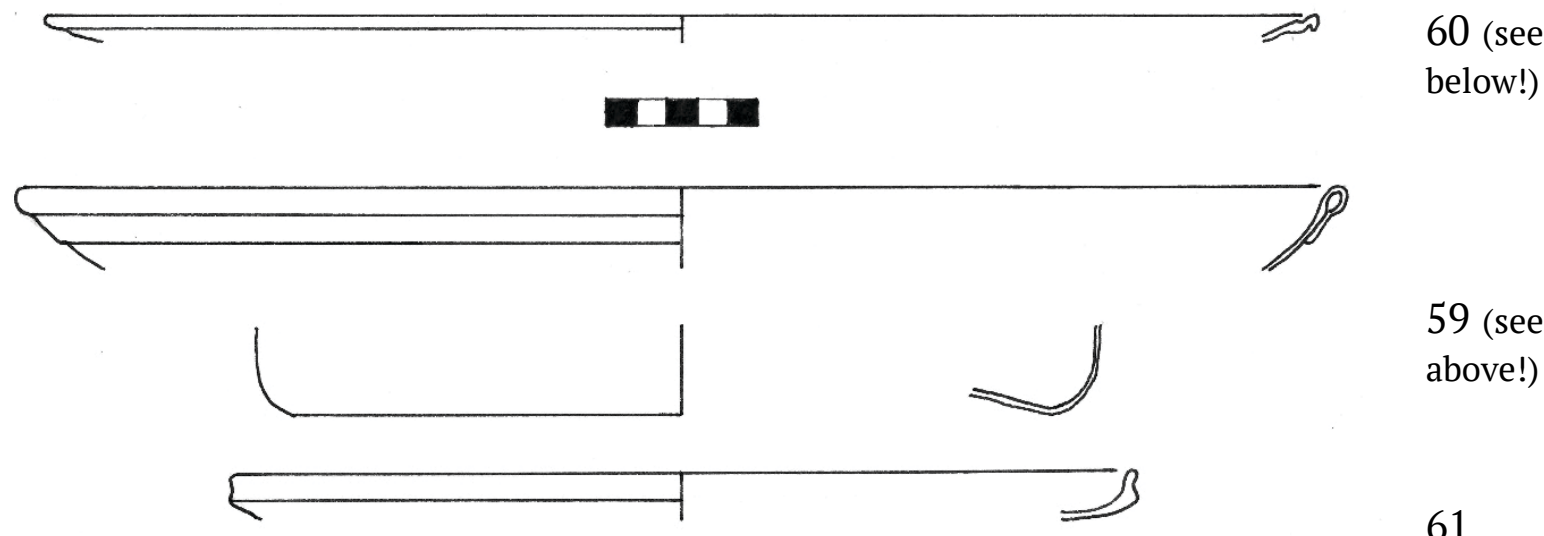

59 (see above!)

61
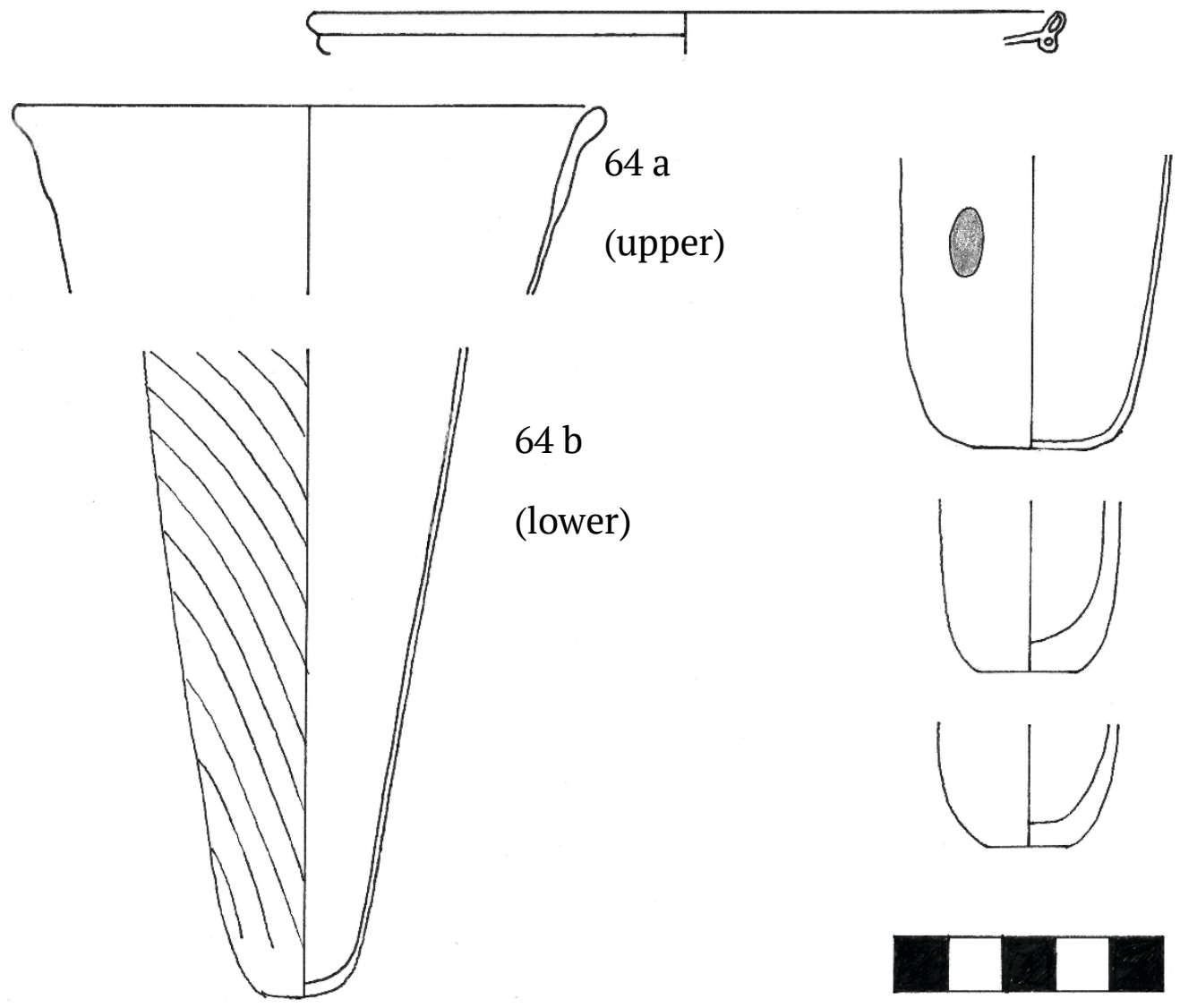

62

63

65 
The Northeast Insulae Project

\section{Illustration 8}
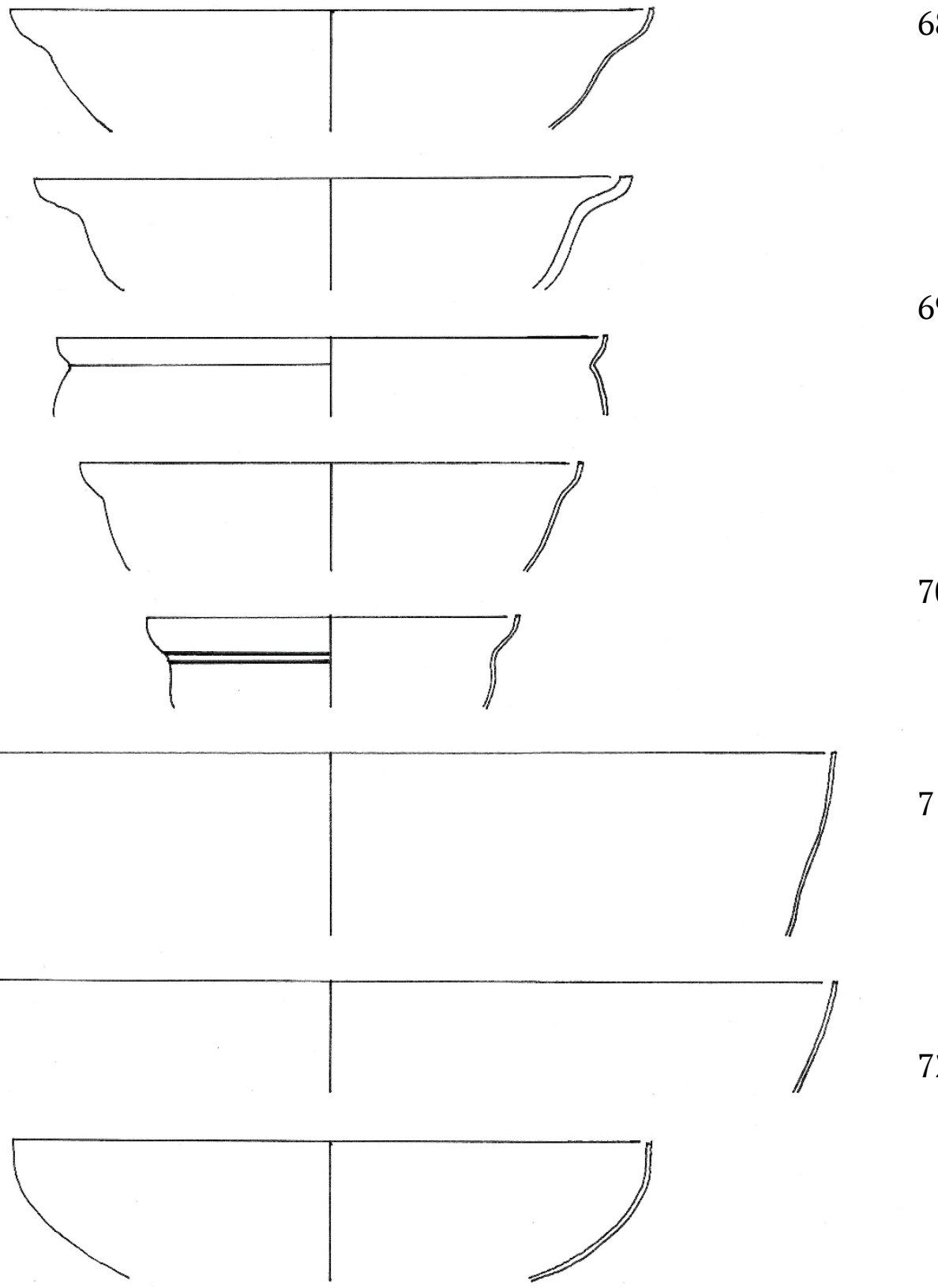

72
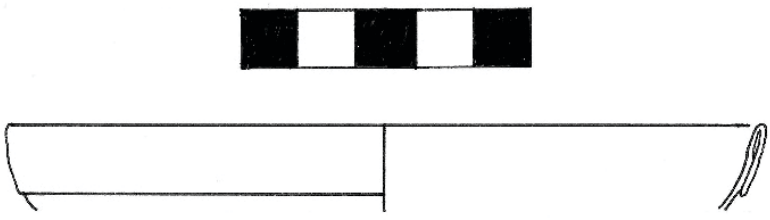

$\square \square$ 


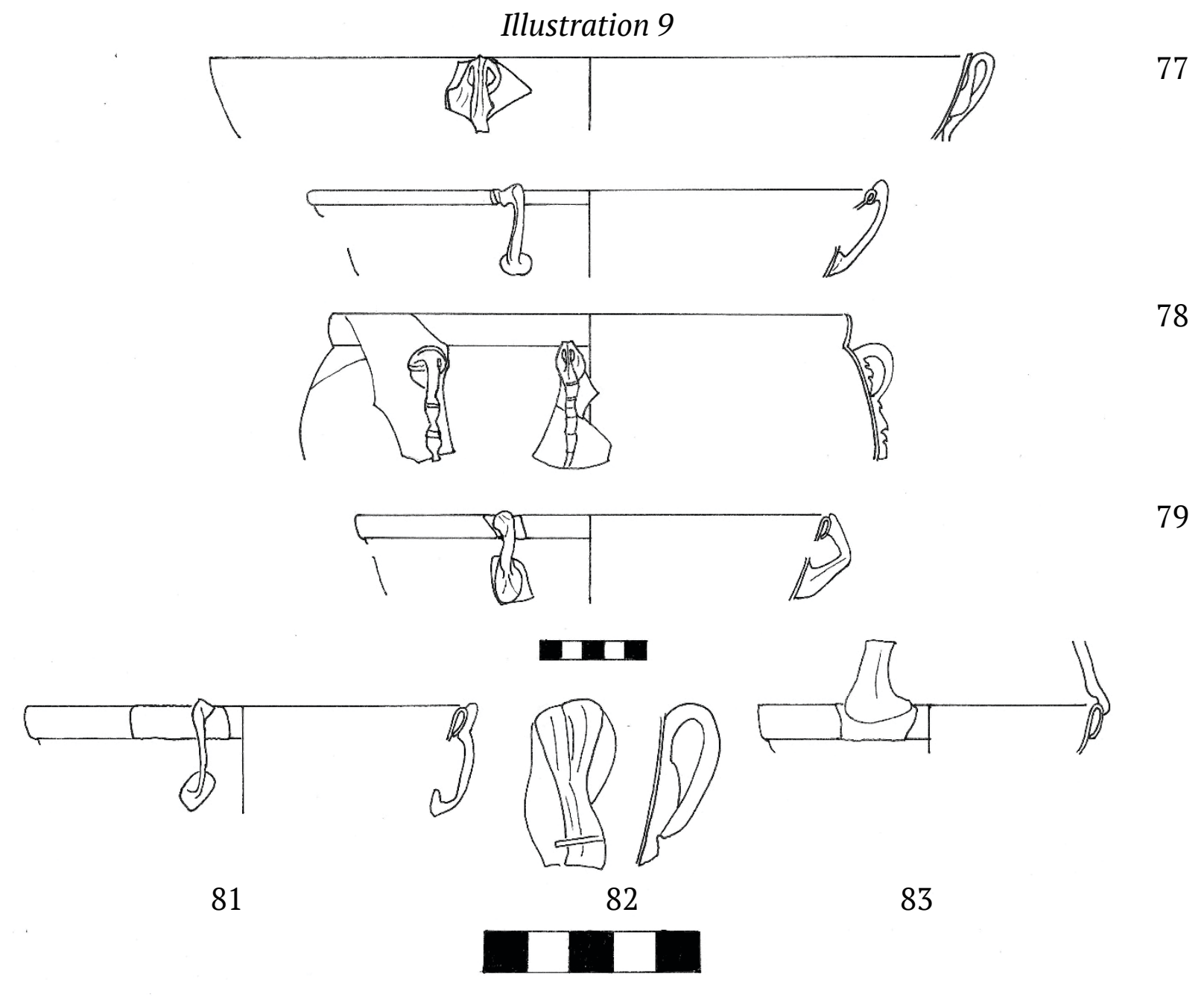




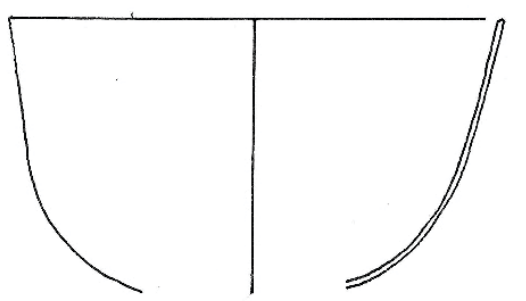

84
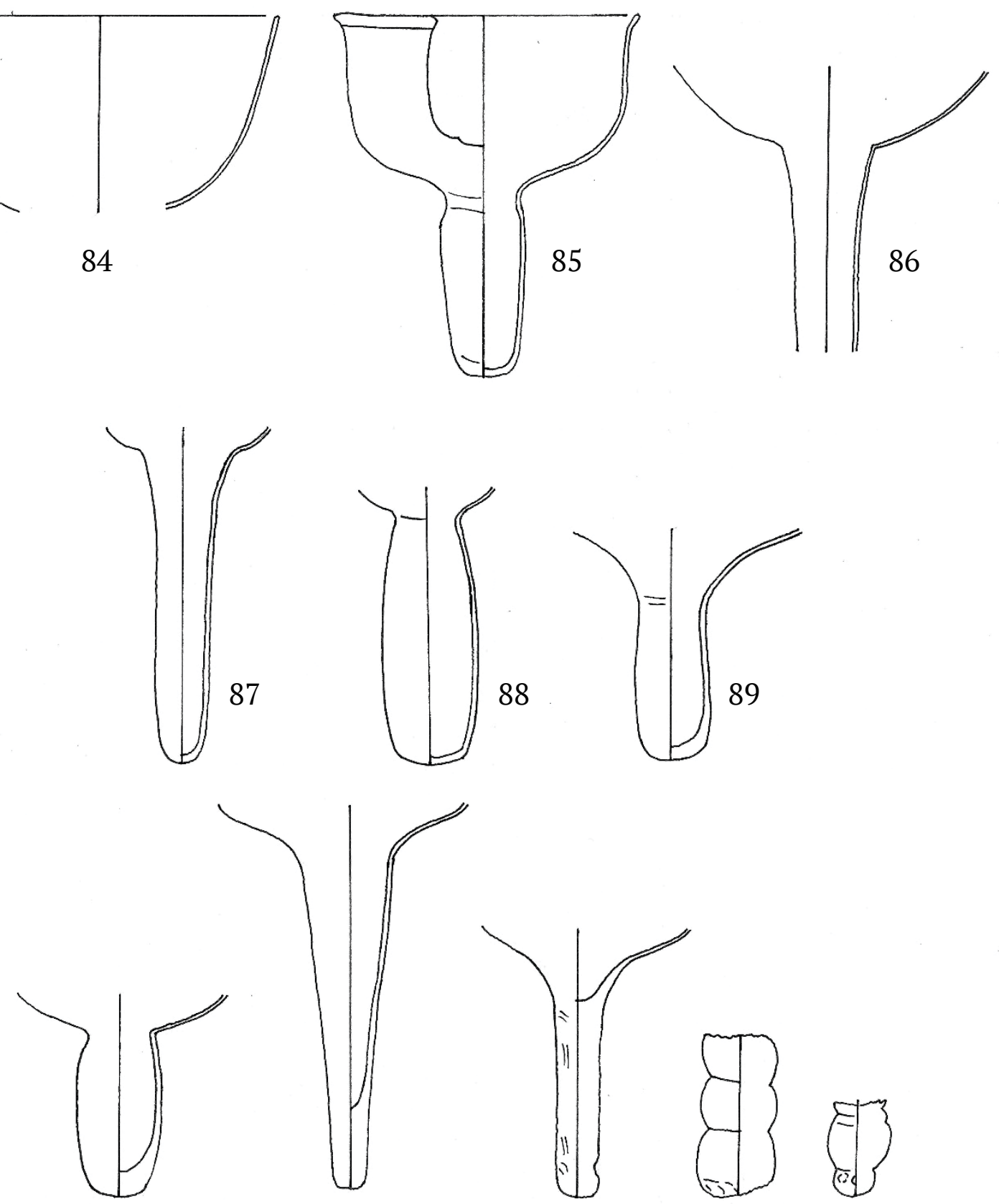

90

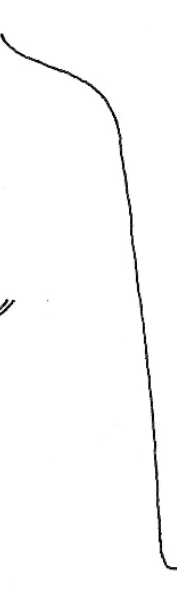

91
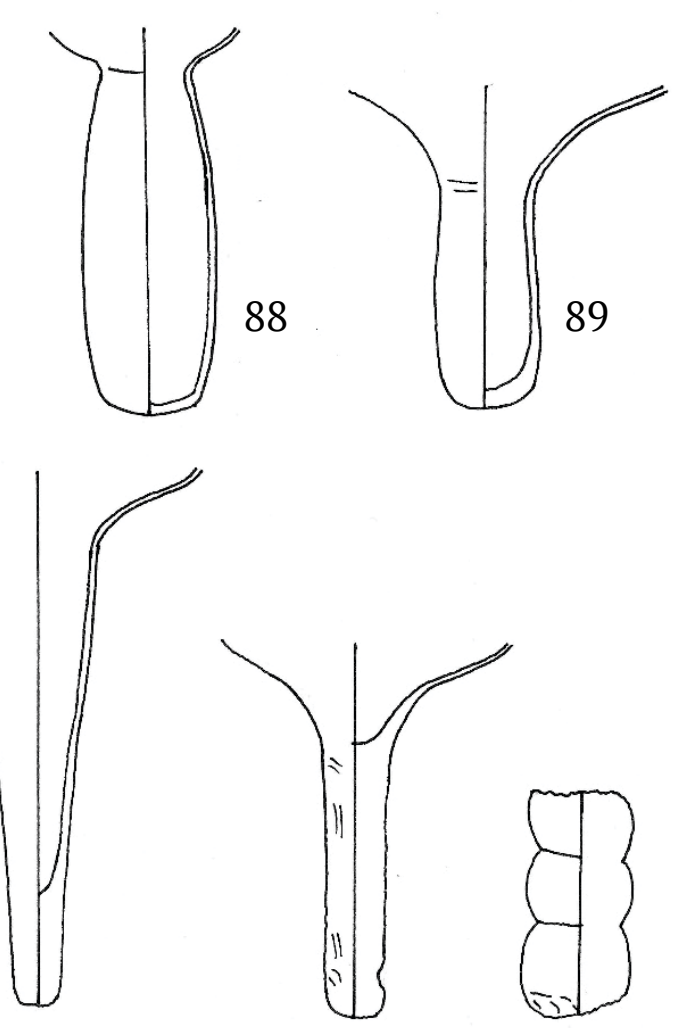

E

92

93

94

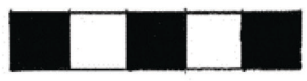


Illustration 11
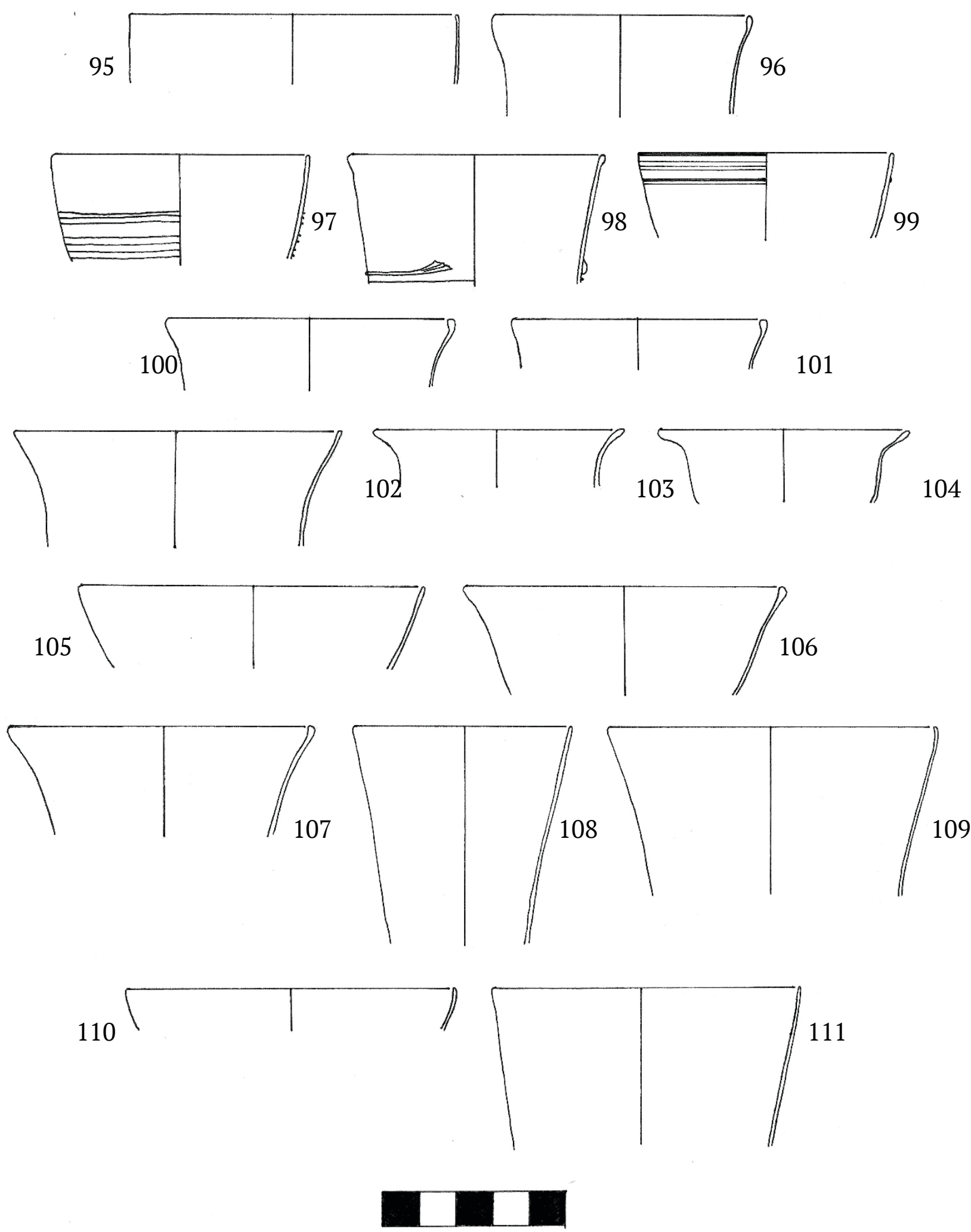


\section{Illustration 12}

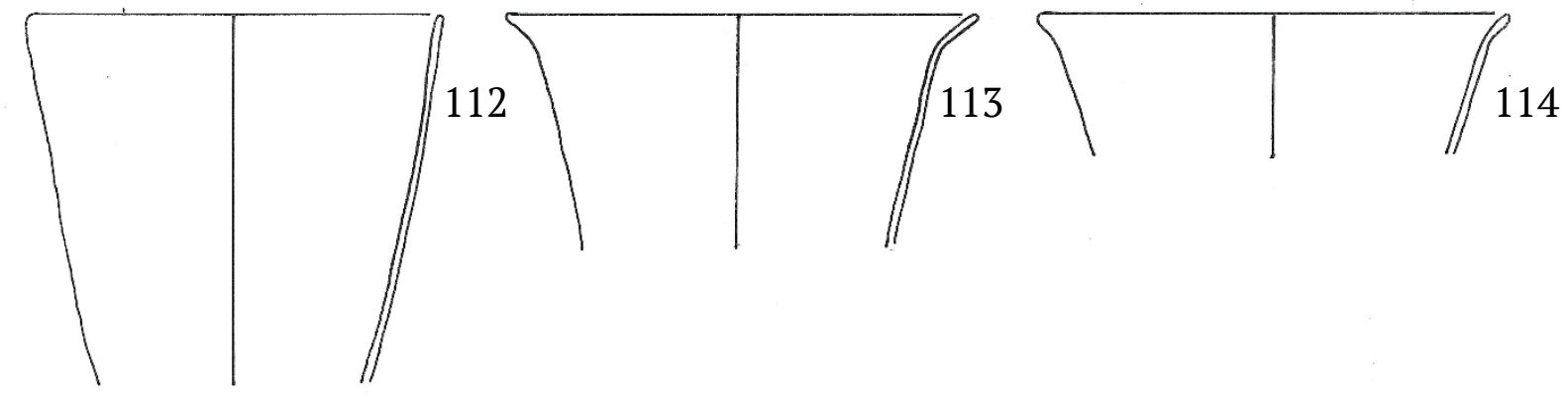

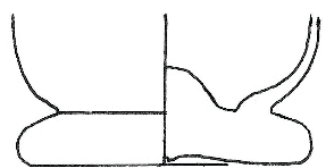

115

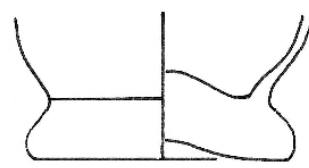

116

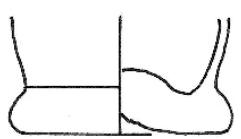

117
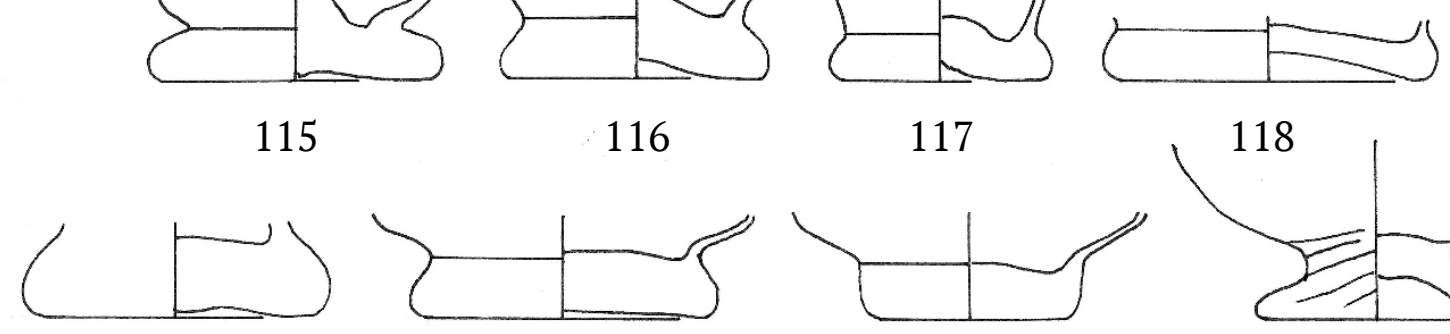

119

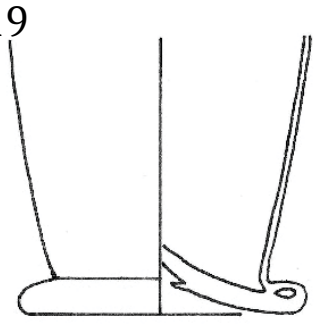

120

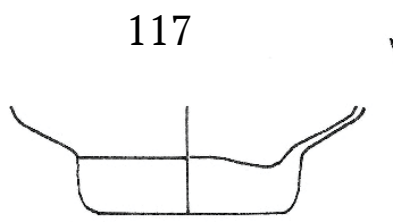

121

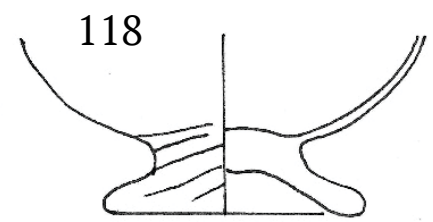

122

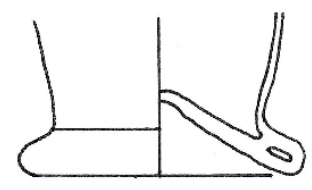

123
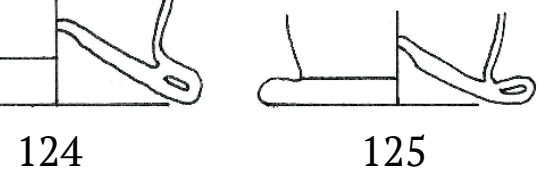

125
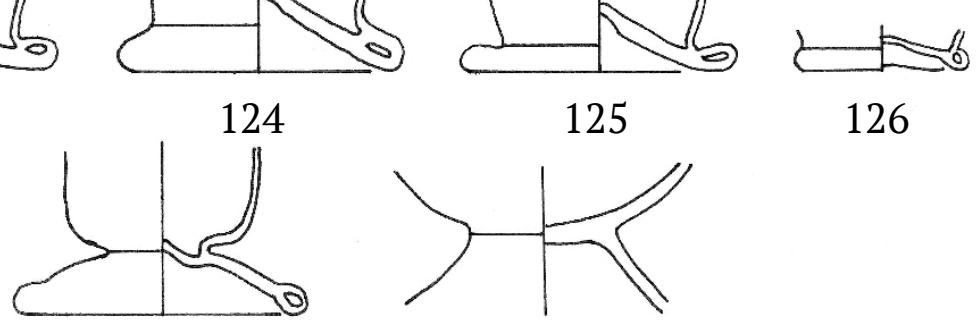

127

128

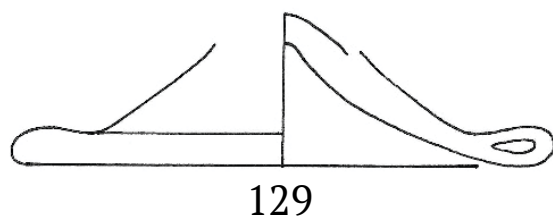

129

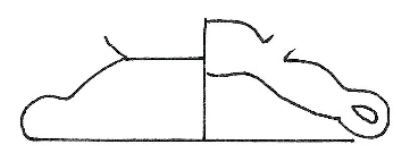

130

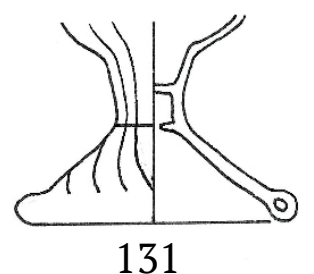




\section{Illustration 13}

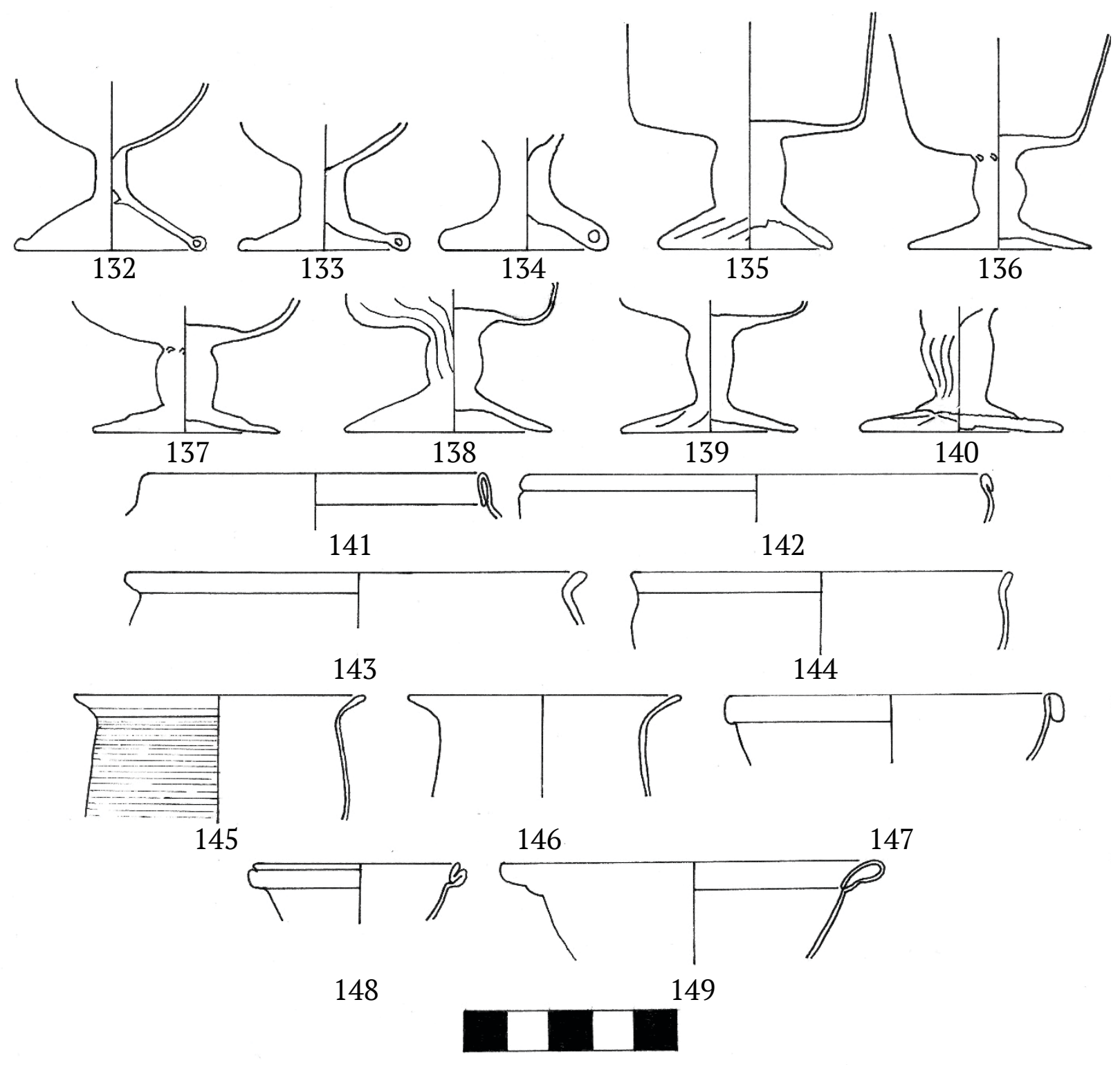


The Northeast Insulae Project

\section{Illustration 14}

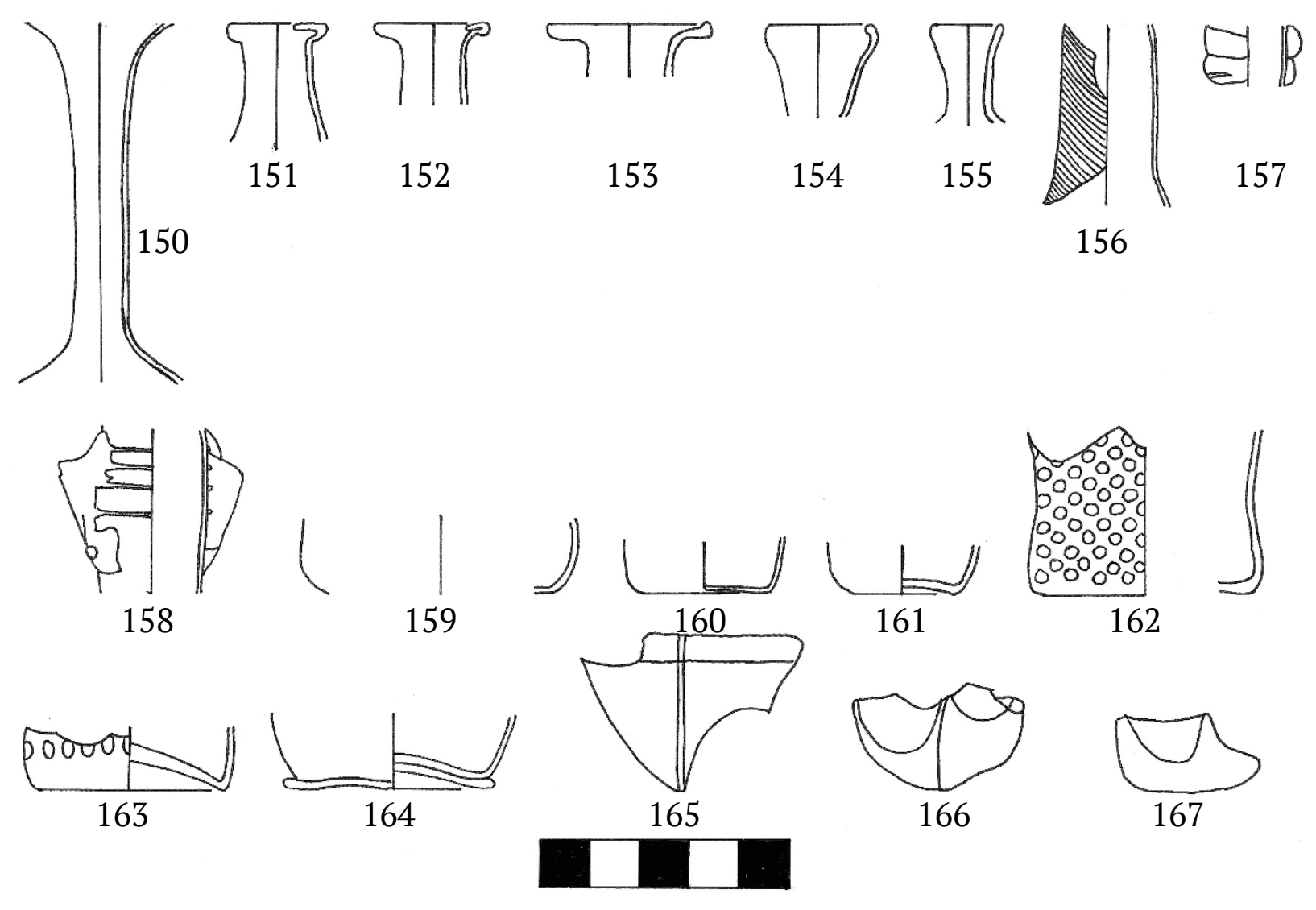




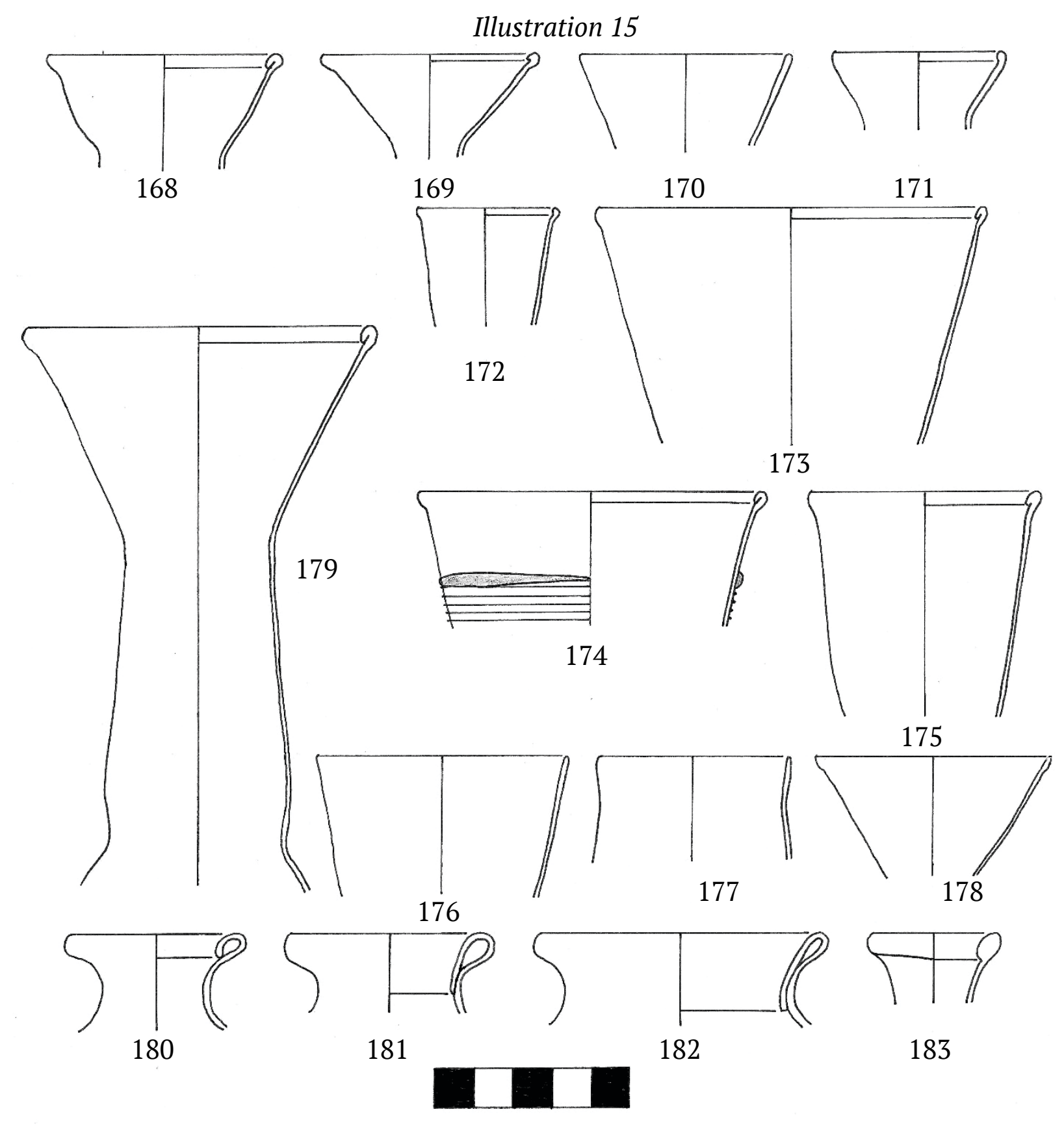


Illustration 16

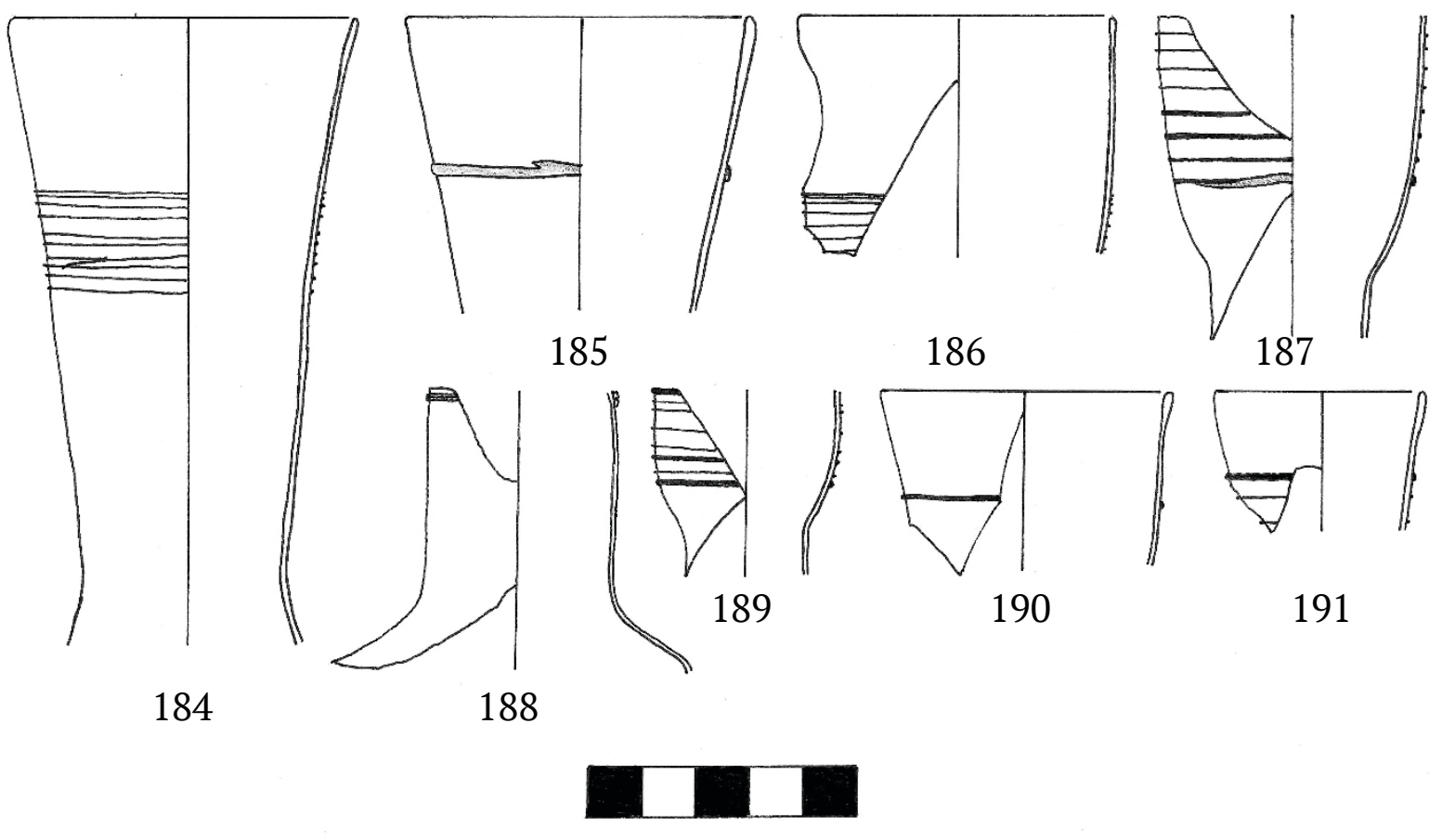




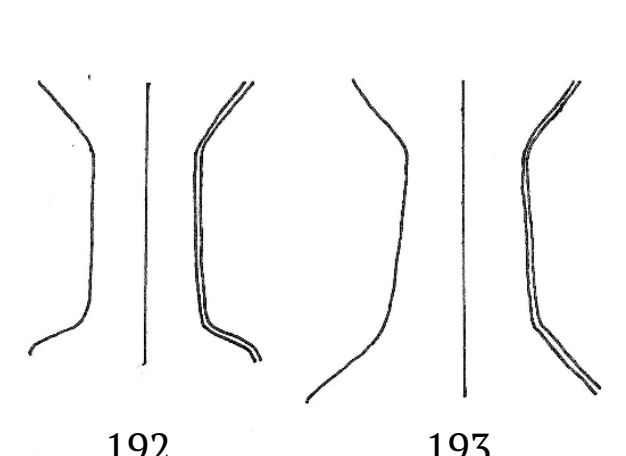

Illustration 17

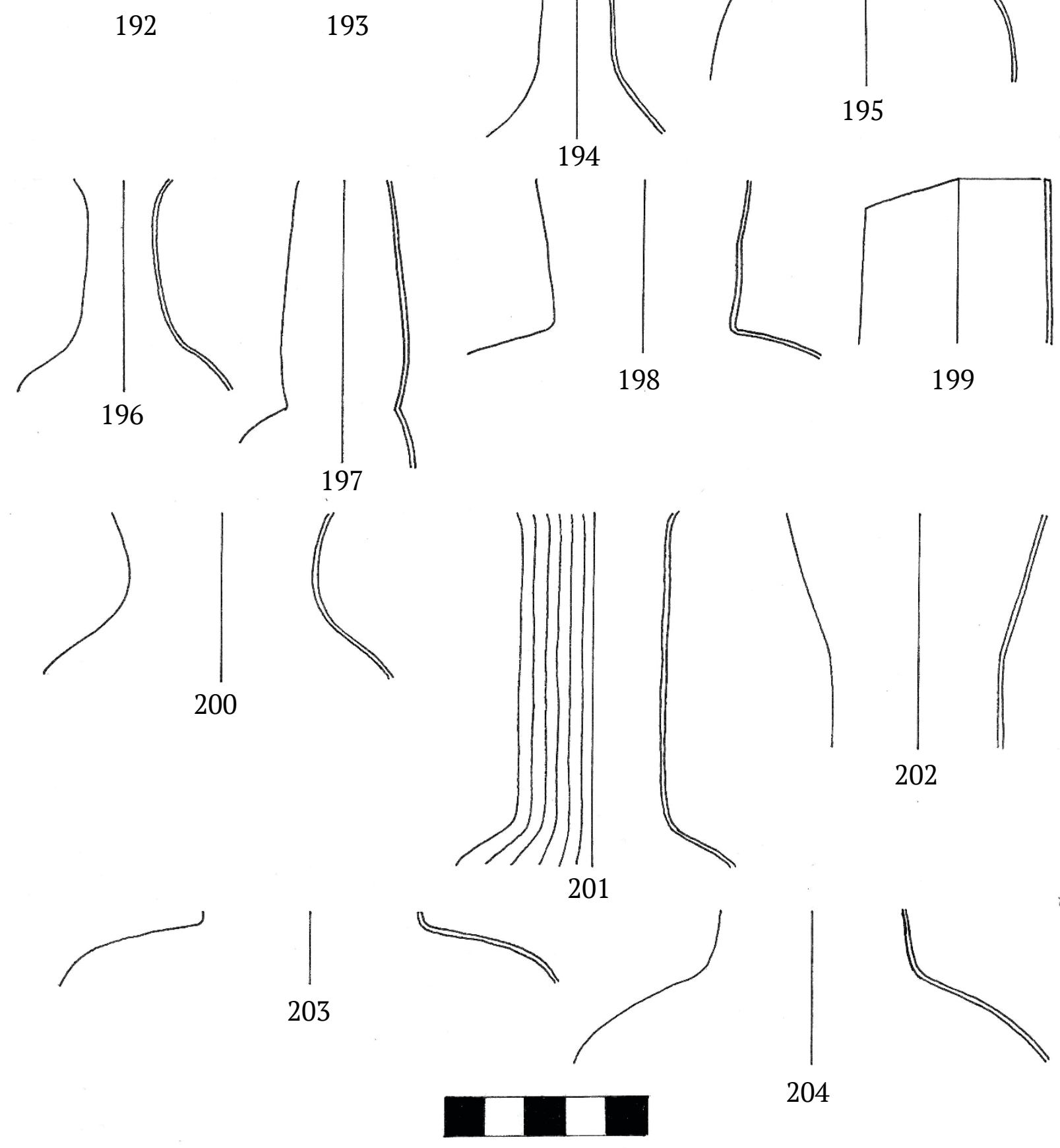




\section{Illustration 18}
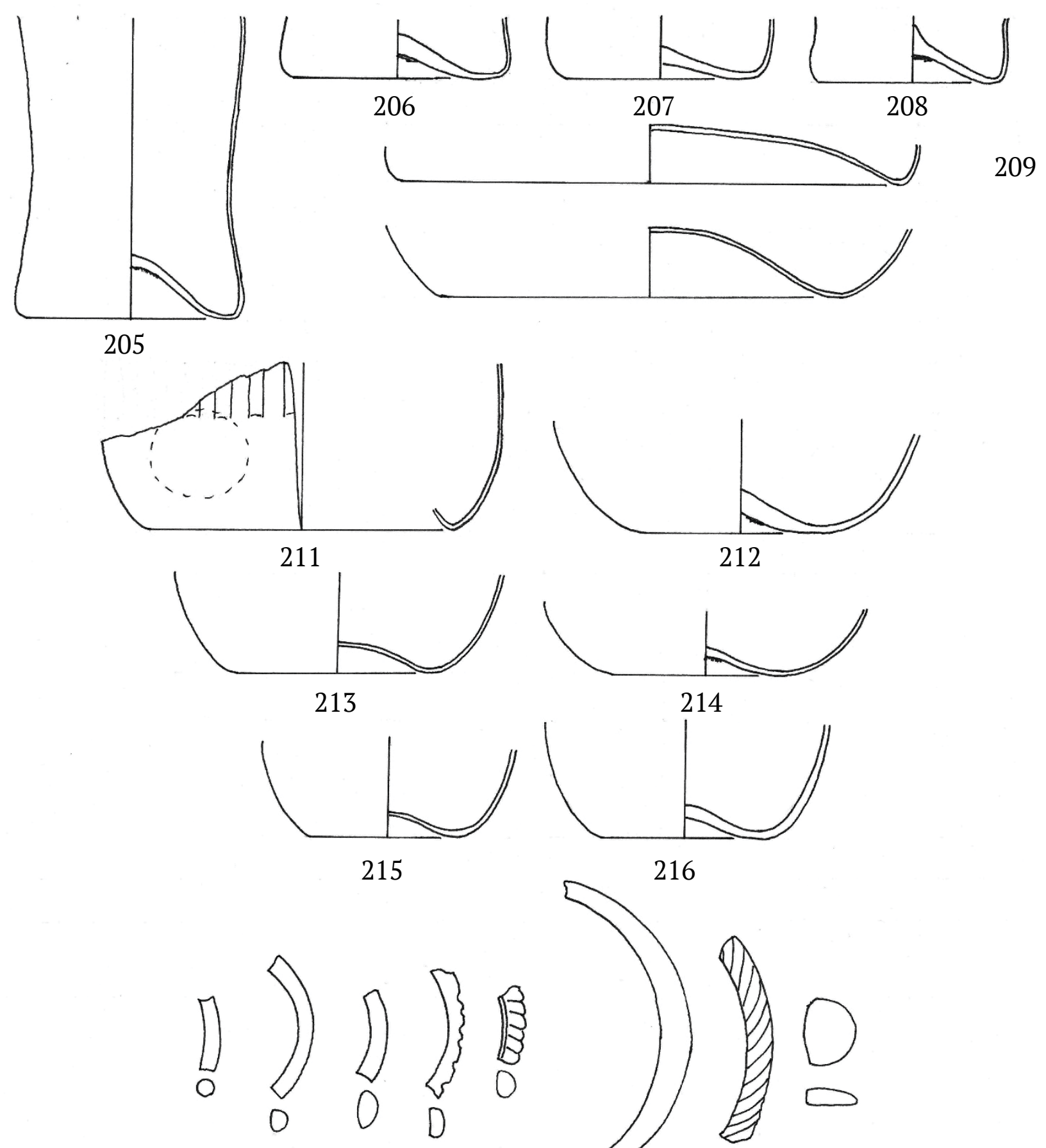

$\begin{array}{lllll}217 & 218 & 219 & 220 & 221\end{array}$
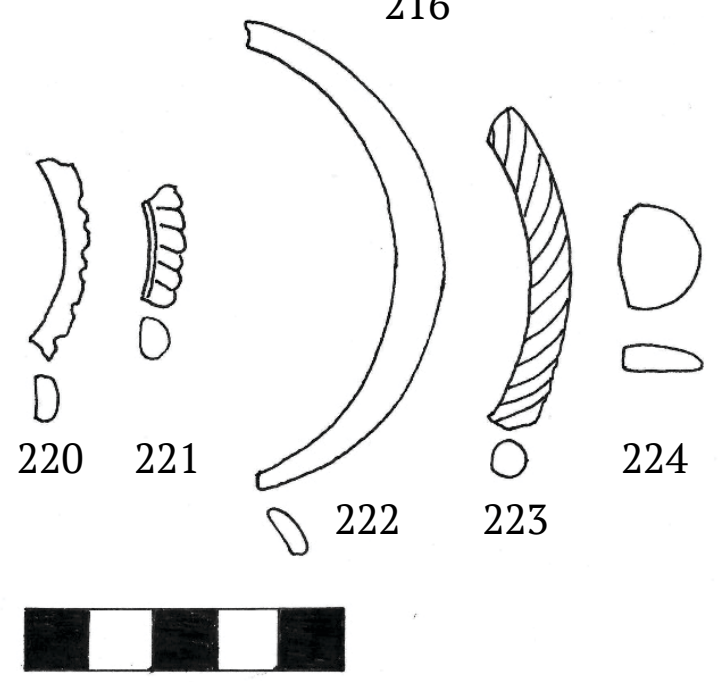


\section{Illustration 19}

V
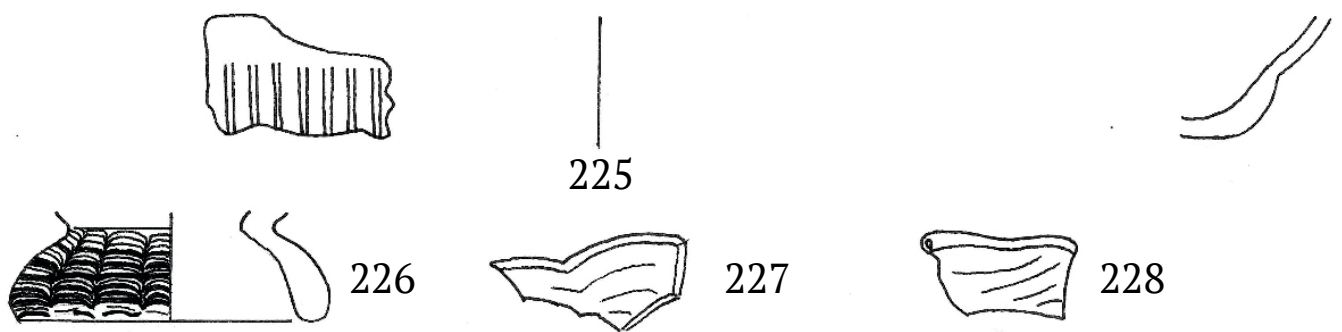

225

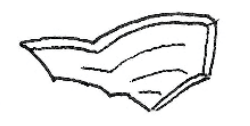

227
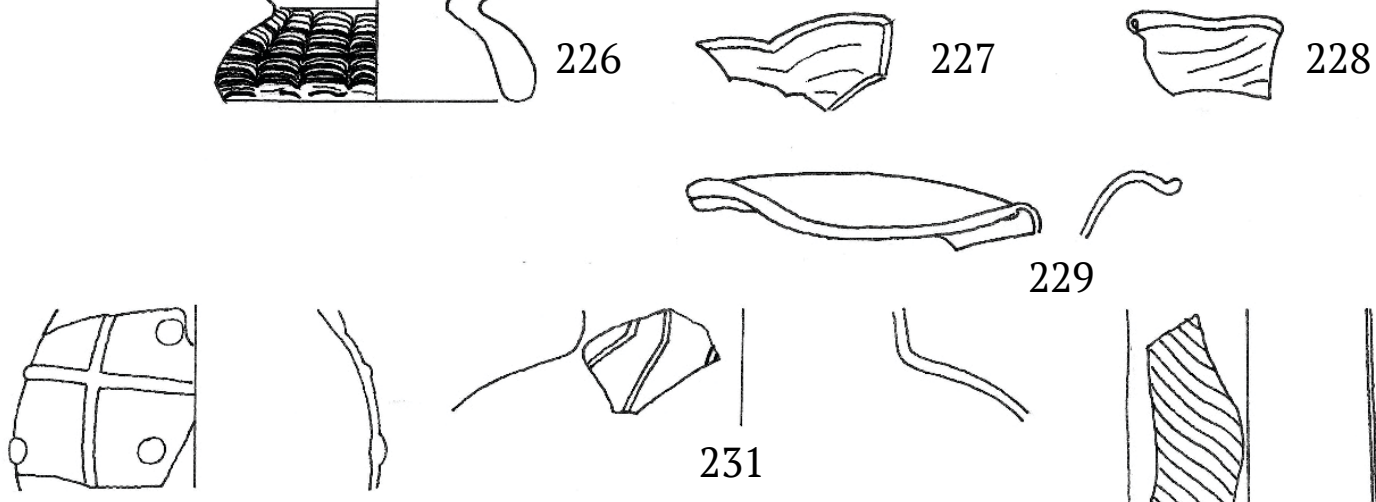

231
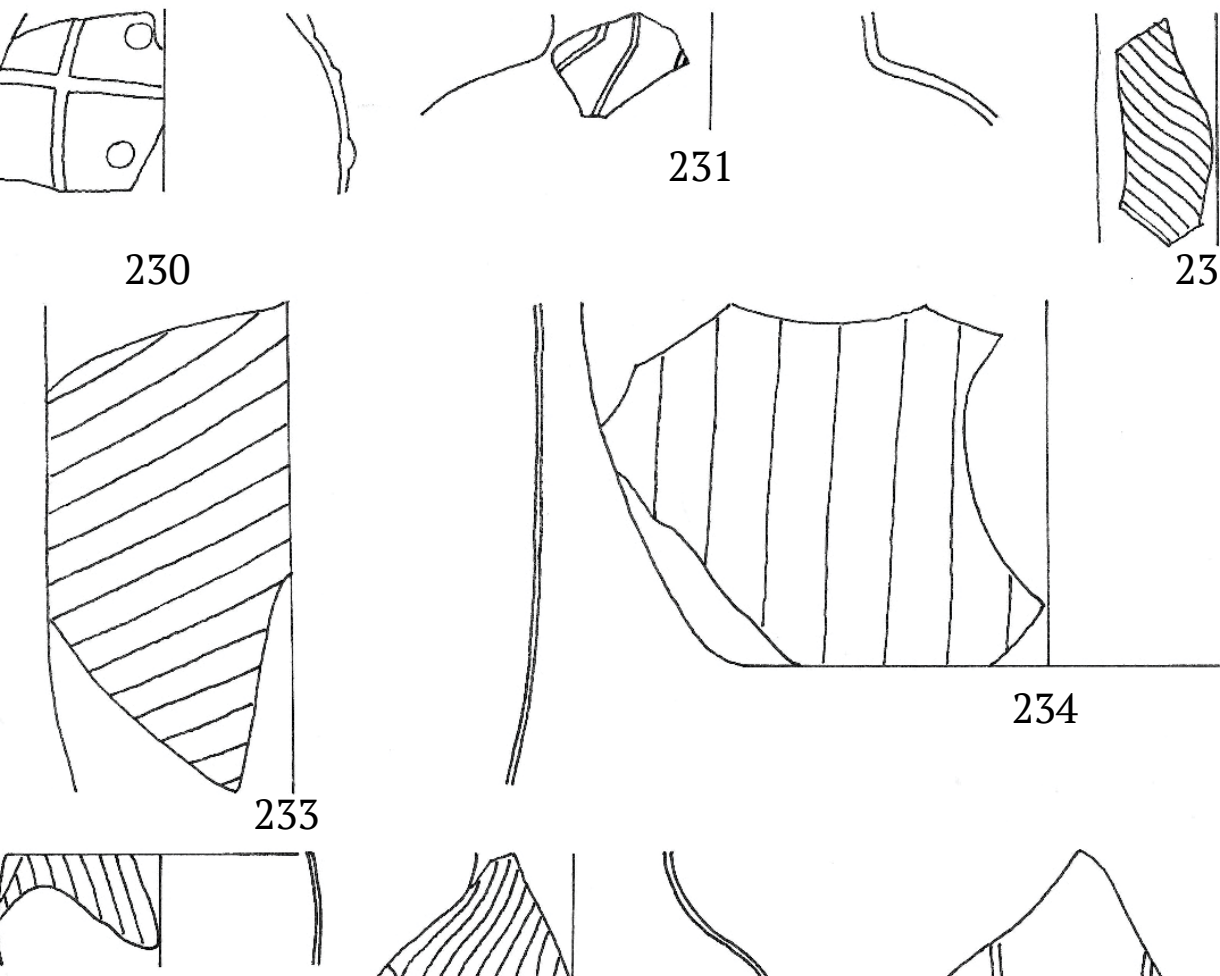

235
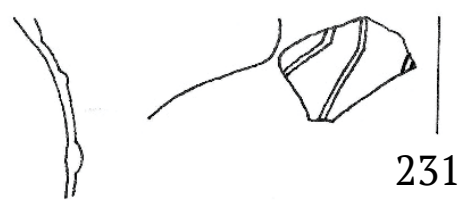

232
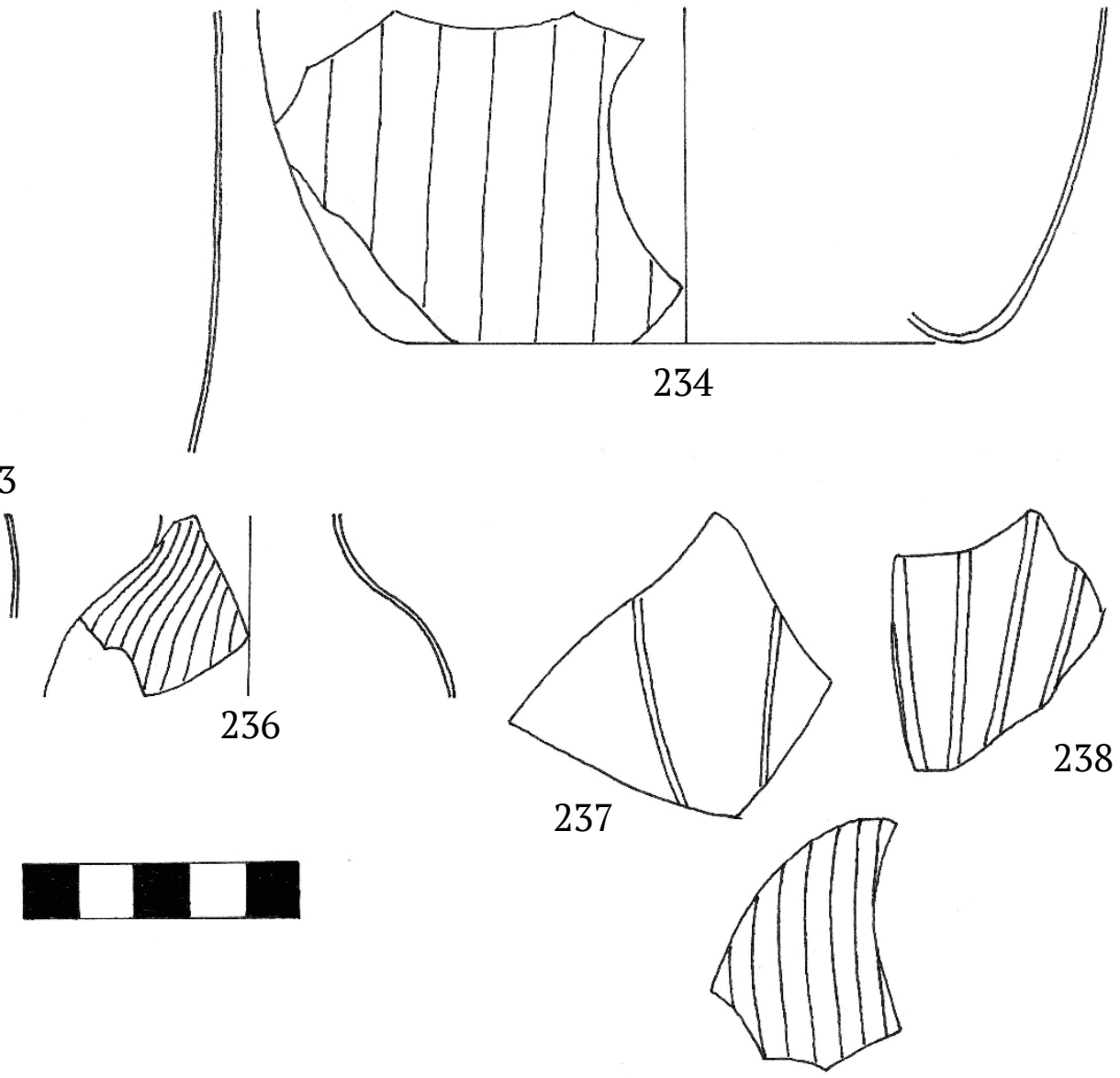

239 


\section{Illustration 20}
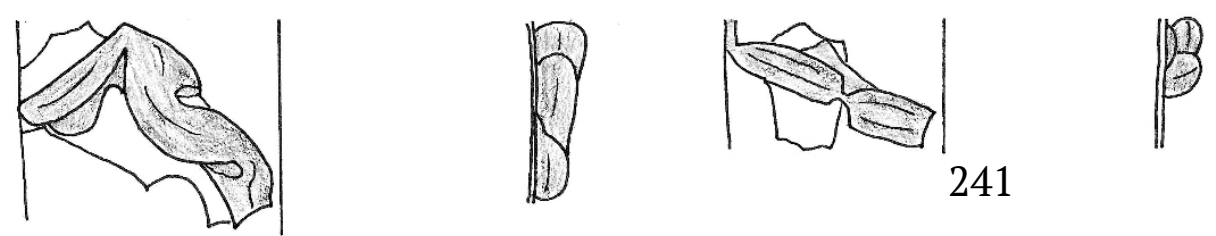

241

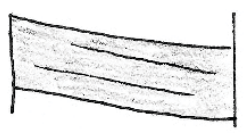

240

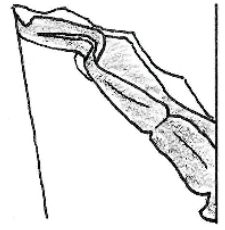

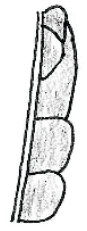

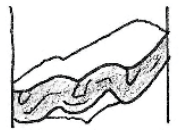

2

242
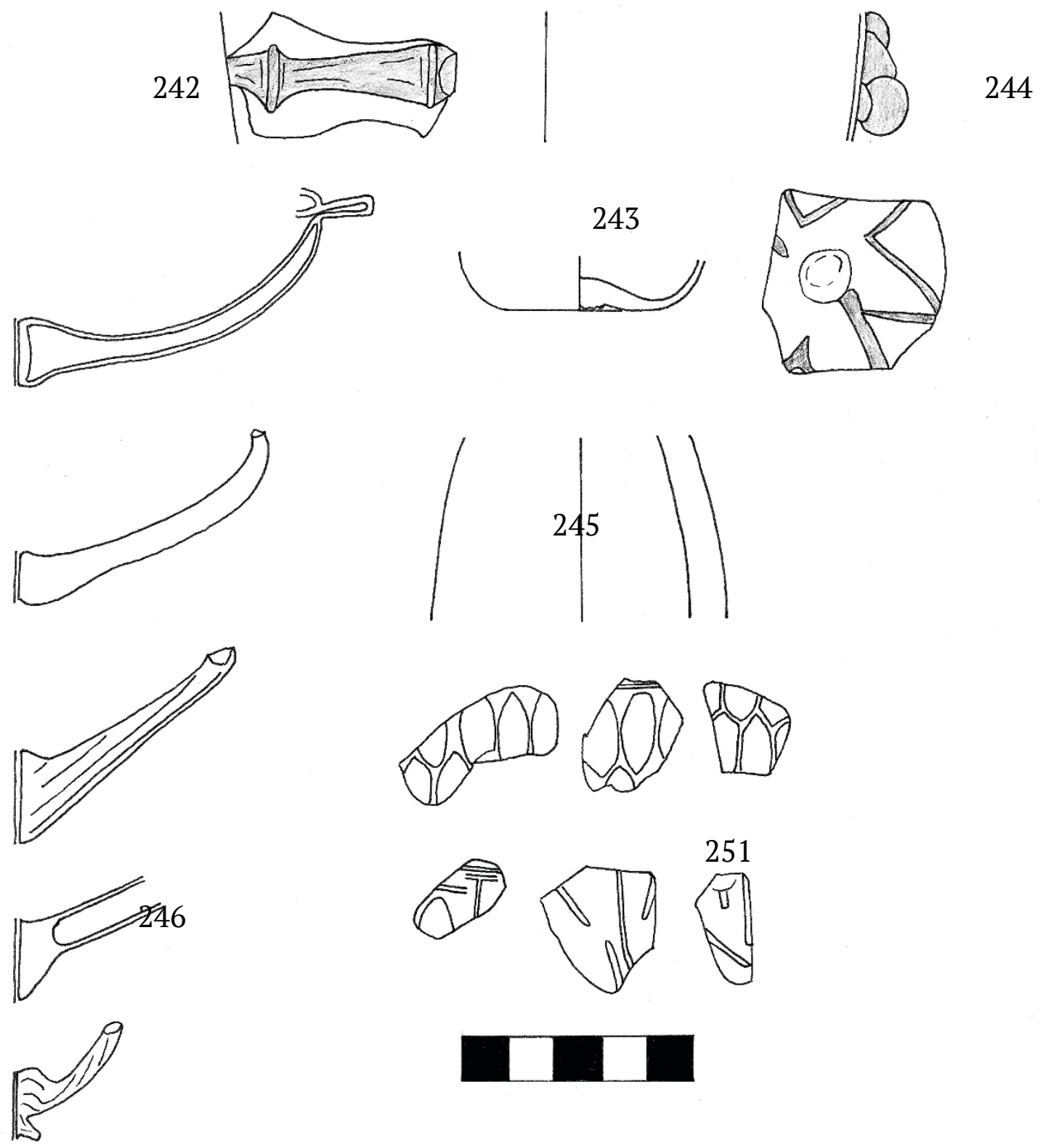
Illustration 21
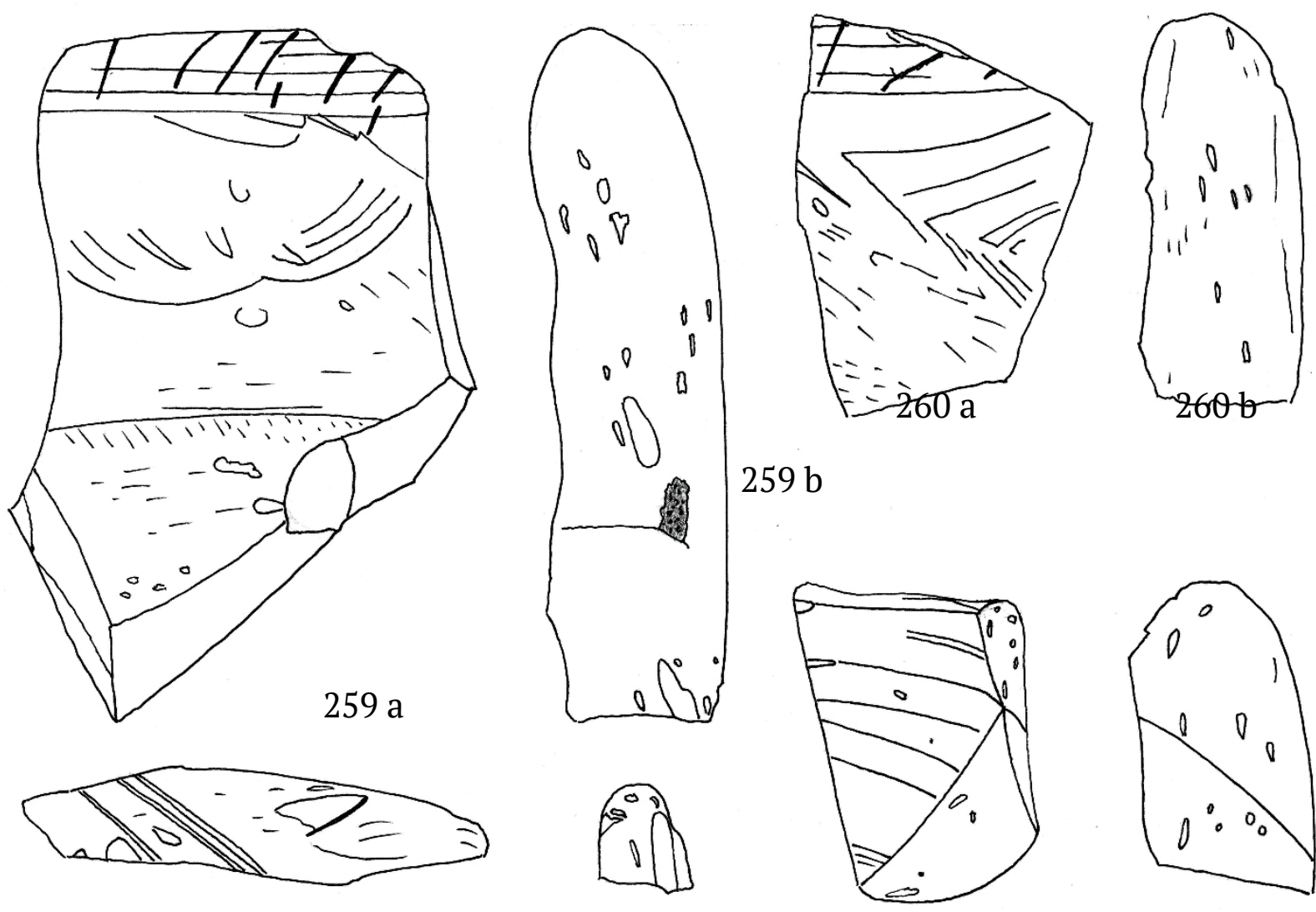

$259 \mathrm{~b}$
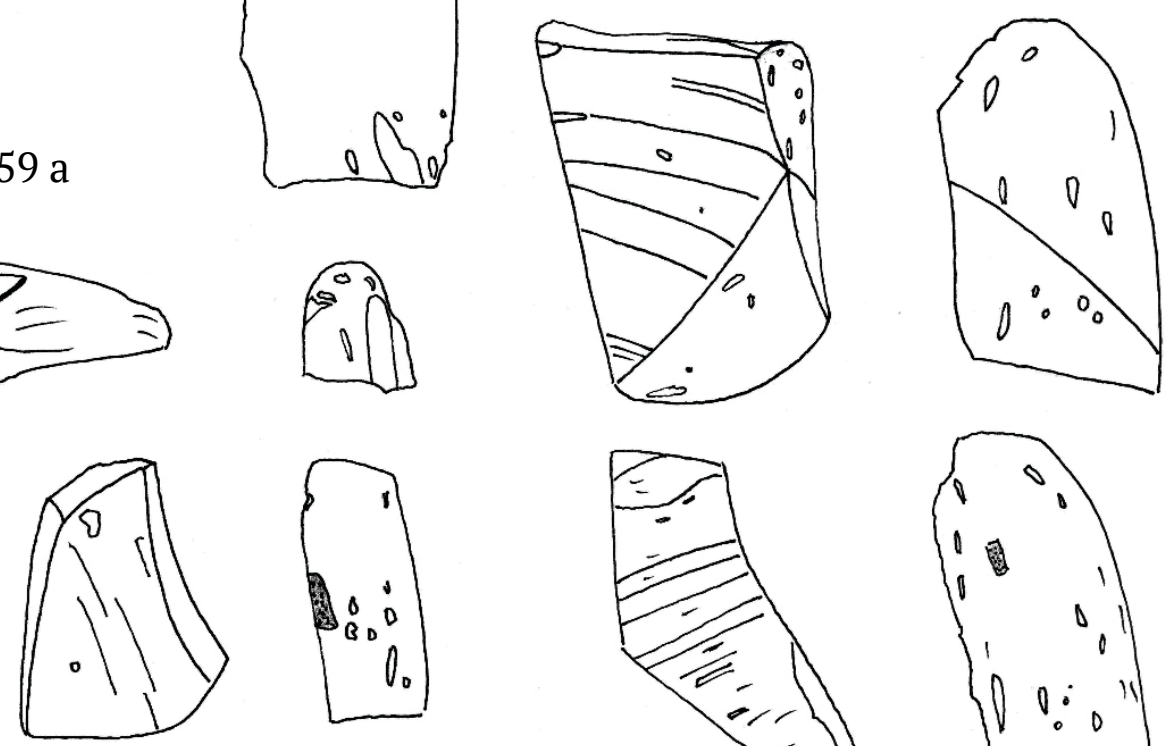

$261 \mathrm{a}$

$261 \mathrm{~b}$
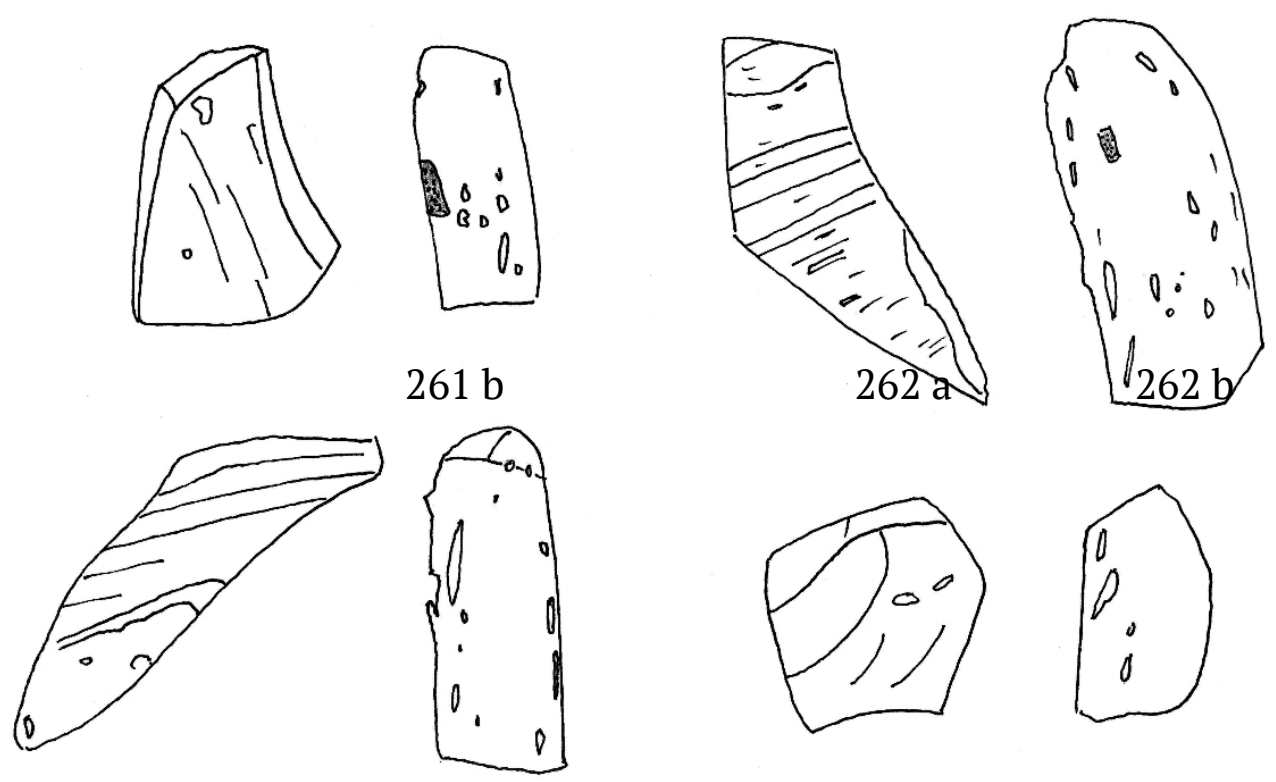


\section{Illustration 22}
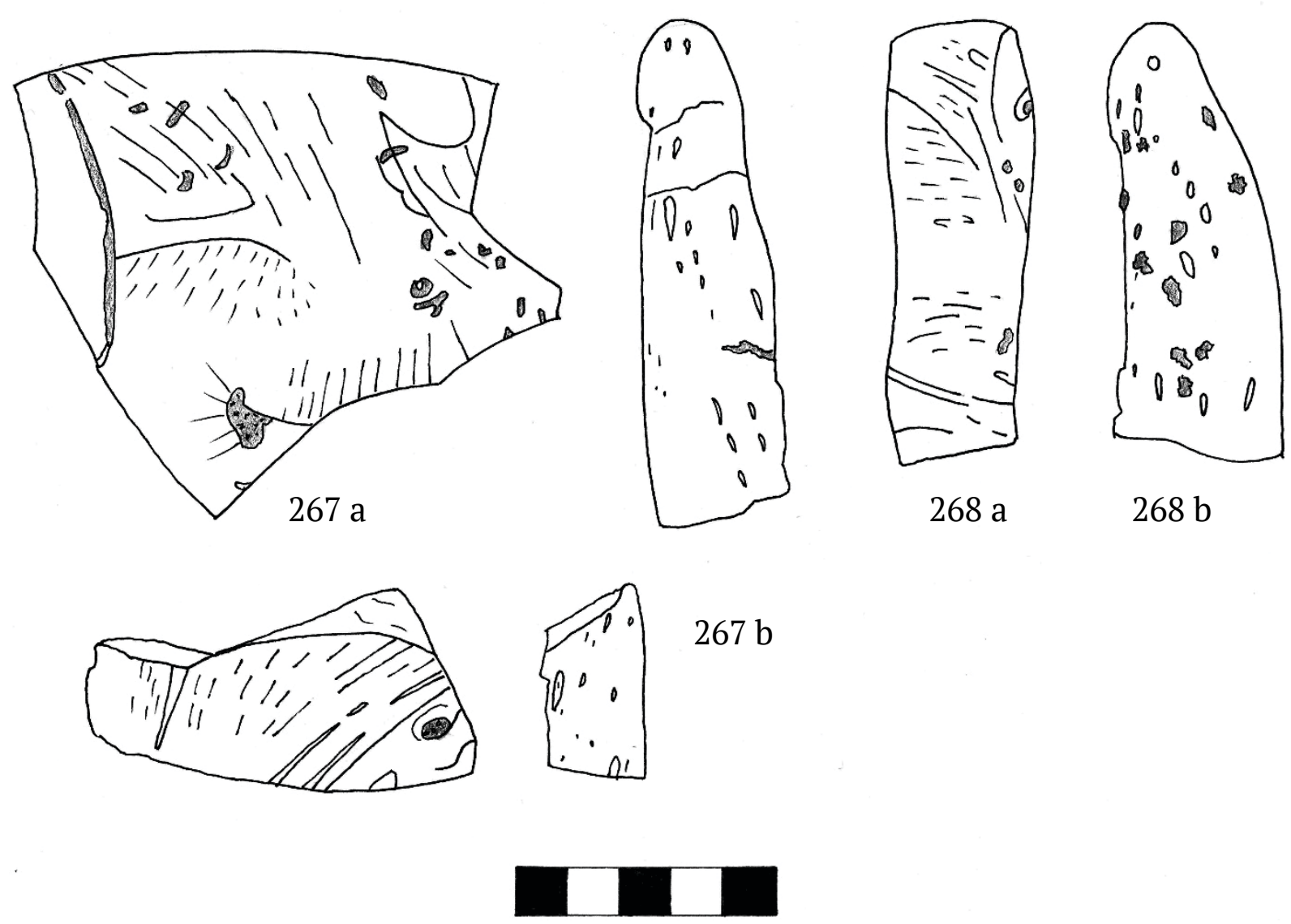


\section{0.}

\section{URBAN MONASTERY HYPOTHESIS}

$\mathrm{M}$ onasticism in Late Antique Palaestina is well-known. Judean wilderness monasticism has received significant scholarly attention. ${ }^{381}$ Jerusalem is a special case to which both literary and inscriptional sources point. ${ }^{382}$

Fewer are the references to monasticism in urban sites such as Hippos Palaistinēs. Cyril of Scythopolis describes his Decapolis city as so steeped in monastic influence that Sabas visited it twice (Lives 162.20 and 165.1). In Madaba, "a monk named John undertook the paving with mosaics of a chapel on the north wall of the church of the Apostles" (Piccirillo 2015; IGLSyr 21,2 144). The Supplementum epigraphicum graecum (SEG) catalog has at least ten additional inscriptions from urban contexts in and around Palaestina mentioning the term

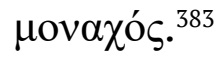

Archaeological evidence for urban monasticism is also relatively meager. At Scythopolis, churches and monasteries are close to one another along the northern city wall. At Tiberias, a monastery at the peak of Mt. Berenike is within the city walls. ${ }^{384}$ In Sepphoris' civic center

\footnotetext{
${ }^{381}$ Derwas J. Chitty, The Desert a City: An Introduction to the Study of Egyptian and Palestinian Monasticism under the Christian Empire (Oxford: Blackwell, 1966); Hirschfeld, The Judean Desert Monasteries in the Byzantine Period; Joseph Patrich, Sabas, Leader of Palestinian Monasticism: A Comparative Study in Eastern Monasticism, Fourth to Seventh Centuries, Dumbarton Oaks studies 32 (Washington, D.C: Dumbarton Oaks Research Library and Collection, 1995).

382 Chitty, The Desert a City, 48-49; Palladius and A Lucot, Historia Lausiaca: Vies d'ascètes et de pères du désert = Histoire Lausiaque (Paris: Picard, 1912), 44; Ezio Franceschini and Robert Weber, eds., Itinerarium Egeriae, Corpus Christianorum 1 (Turnholti: Brepols, 1958), 24.1, 24.12; Theodore Constantine Papaloizos, "Gerontius's Sanctae Melanie Junioris Vita: A Translation with Introduction, Notes, and Commentary" (Ph.D. dissertation, Catholic University of America, 1977); Frederick Jones Bliss and Archibald Campbell Dickie, Excavations at Jerusalem, $1894-1897$ (London: Committee of the Palestine Exploration Fund, 1898); Supplementum Epigraphicum Graecum, 8:177.

383 At Antioch of Syria: Louis Jalabert and René Mouterde, eds., Inscriptions grecques et latines de la Syrie (Paris: P. Geuthner, 1977), 3.1, 3.814, and 3.185; Emessa: ibid., 5.2207, 5.2208, and 5.2211; Kissufim: Supplementum Epigraphicum Graecum, 30.1688 and 30.1689; Bostra: Jalabert and Mouterde, Inscriptions grecques et latines de la Syrie, 13.1 and 13.9040; Philadelphia: ibid., 22.2 and 22.43; Supplementum Epigraphicum Graecum, 38.1661.

384 Yizhar Hirschfeld, "The Monasteries of Palestine in the Byzantine Period," in Christians and Christianity in the Holy Land (Turnhout: Brepols, 2006), 401-419.
} 
are the remains of a small church surrounded by rooms. Identified as an "urban pilgrim monastery," 385 only the foundations of the rooms' walls were found.

Complicating the study of urban monasticism is the very definition of "urban." For example, Rubin in his study of the Negev concludes that monasticism in the Negev was, to a large extent, an urban phenomenon. ${ }^{386}$ From the perspective of the desert monasteries, those in Rehovot-in-the-Negev, 'Avdat, Nessana, and Shivta are more urban. However, when such Negev sites are compared to the Roman cities of Palaestina, the Decapolis, or the special case of Jerusalem, the Negev sites are quite different in terms of the extent of the urban surroundings.

Second, archaeologists tend to excavate churches in urban areas without carefully examining or even excavating surrounding or related structures. ${ }^{387}$ Monastic complexes may stay hidden while the prayer hall is exposed. Third, unlike rural areas where the monasteries were isolated in self-contained facilities, an urban monastery might not display all the functions of a rural monastery, relying instead on resources from the community within which it is located. Similarly, monastic boundaries may not be demarked by a substantial wall, as was necessary for rural areas.

To enable a closer scrutiny of urban monasticism, Haim Goldfus has proposed criteria "by which one can, intelligibly, characterize urban monasticism and monastic complexes." 388 "The first guideline defining an urban monastery would be its location in relation to the city." ${ }^{389}$ A second guideline identifies the particular function of the monastery within the urban context. Asking whether the monastery served men or women or an ethnic group, whether it was a "desert in the city" or served pilgrims or treated the ill, such questions might help "to comprehend the shape and infrastructure of an unknown monastery." 390 Third, Goldfus suggests paying attention to the "size, dimension, and spatial plan" of the monastery, noting that an urban monastery would not need all the facilities to be self-sustaining, as would a rural monastery. ${ }^{391}$ Later in the article, Goldfus writes, "The existence of tombs in these specific churches, as well as in other churches of Byzantine Palaestina,

\footnotetext{
${ }^{385}$ Mordechai Aviam, "Late Antique Pilgrim Monasteries in Galilean Loca Sancta," Studium Biblicum Franciscanum 64 (2014): 561.

ריכב רובין, הנגב כארץ נושבת: עיור והתיישבות במדבר בתקופה הביזנטית (ירושלים: יד יצחק בן־צבי : החברה לחקירת 386

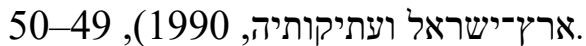

${ }^{387}$ Anne Michel, Les Eglises d'Epoque Byzantine et Umayyade de La Jordanie V-VIII Siecle (Turnhout: Brepols, 2001), xi.

${ }^{388}$ Haim Goldfus, "Urban Monasticism and Monasteries of Early Byzantine Palestine - Preliminary Observations," ARAM Periodical, no. 15 (2003): 73.

${ }^{389}$ Ibid.

${ }^{390}$ Ibid., 74.

${ }^{391}$ Ibid. 
might be used also as a preliminary indicator for identifying monastic complexes." ${ }^{392}$ Burials could then be a fourth indicator.

This chapter examines the hypothesis that the Late Antique remains in the northeast insulae at Hippos Palaistinēs was an urban monastery. We assert that the compound of interrelated structures in the northeast insulae at Hippos Palaistinēs conforms with all four indicators and so may be an example of the varied practice of urban monasticism in Late Antique Palaestina.

The first indicator: "defining an urban monastery would be its location in relation to the city." " is located within the city limits and thus an urban compound. However, in contrast to nearby monastic sites at Tiberius and Scythopolis, this compound, in the northeast insulae, is in the urban core, less than $100 \mathrm{~m}$ from the forum. In what may have been a neighborhood of wealthy homes, a small church, of similar footprint to a neighboring house, is positioned within the earlier Roman street grid, interrupting the eastern street (Cardo 3 North) with its apse and using the western cardo (Cardo 2 North) as its via sacra and portico. It incorporated walls of an earlier building, set some of its walls over foundations of other buildings, and has an irregular configuration of entrances resulting from the reuse of a part of an earlier peristyle court. The Northeast Church replaced an urban peristyle house. Paul Magdalino has argued that "many, if not most, urban and suburban churches and monasteries were converted lay oî́kou." ${ }^{394}$ Interestingly, Cyril of Scythopolis uses the word oĩ scribe both the monastery of Procopius at Scythopolis and the monastery of St. Stephen in Jerusalem. ${ }^{395}$ The compound in the northeast insulae at Hippos Palaistinēs is consistent with the first indicator proposed by Goldfus.

Goldfus attends to the "size, dimension, and spatial plan" as a second indicator of a monastery. ${ }^{396}$ As we have noted above, the Northeast Church is part of a larger interconnected compound. Five distinct components make up this complex: the Northeast Church; a small complex to the south sharing the southern wall of the domus and the west wall of the diakonikon; a two-room structure to the west; a two storied building to the north; and the rebuilt and repurposed House of Tyche to the east.

The interconnection of these five units is demonstrated by the passageways among them. That interconnection is further confirmed by the intentional decommissioning of all the interrelated buildings of the complex, seemly at the same time. Prior to the earthquake of 749 CE, liturgical rites ceased in the Northeast Church. Burials stopped. Reliquaries were

\footnotetext{
392 Ibid., 78.

${ }^{393}$ Ibid., 73.

${ }^{394}$ Paul Magdalino, "The Byzantine Aristocratic Oikos," in The Byzantine Aristocracy, IX-XIII Centuries, ed. Michael Angold, BAR International Series 221 (Oxford, 1984), 94.

${ }^{395}$ Cyril, Lives of the Monks of Palestine, Cistercian studies series ; no. 114 (Kalamazoo, Mich: Cistercian Publications, 1991), 180.6-8 and 151.12, 19.

${ }^{396}$ Goldfus, "Urban Monasticism and Monasteries of Early Byzantine Palestine - Preliminary Observations," 74.
} 
removed. All doors to the domus were intentionally sealed, except the entrance to the south aisle that gave access to the tomb of the elderly woman.

The southern structure had its doorways closed. The northerly building was sealed off at the north medial chamber, and Cardo 3 North was blocked south of the two easterly entrances of the northerly building. Similarly, in the House of Tyche, the principal doorway from the south portico of the peristyle court to Cardo 3 North and the west doorway from the southwest room were blocked. Such comprehensive and systematic blockages affirm the hypothesis that the structures were an interrelated complex in the late antique period. What remained accessible after the decommissioning became a mausoleum and was little used or abandoned by the earthquake of $749 \mathrm{CE}$.

We have argued that the four structures surrounding the Northeast Church and together with it were an interconnected complex in the Late Antique period. However, a complex involving a church in an urban context is not conclusively a monastery, unless further indicators to that end are present.

The third indicator, following Goldfus, is the presence of burials in the church. At the south end of the chancel, a single limestone slab covers a sarcophagus containing the bones of a single, small, elderly woman gathered under the anointing hole. The example resembles that of a chapel in a monastery at Scythopolis which reserves a tomb for "Lady Mary who founded this church." ${ }^{397}$ The burial in the Northeast Church has the additional distinctions of demarcating the tomb within the chancel, providing for ongoing veneration, and according a degree of anonymity appropriate for a foundress/abbess. We should expect a considerable number of monasteries for women in urban contexts, as the environment is safer than the desert and as pious and wealthy Christian widows often took up monastic life.

To the north of the central axis of the chancel is a second burial site, a masonry tomb constructed of four courses of basalt ashlars. At about $75 \mathrm{~cm}$ below floor is the limestone box of a sarcophagus perched on irregular stones above the limestone floor of the masonry tomb. Recovered from the accessible fill at the bottom of the masonry tomb were twentysix fragments of iron nails and a lead corner bracket like those from Late Antique burial sites in the Hefer Valley and Rammun and likely belonged to a wooden coffin. ${ }^{398}$

Human remains were uncovered in two main areas of the tomb: the interior of the sarcophagus held the remains of at least nine individuals, while the second area under the sarcophagus yielded three individuals. The pattern is like the so-called "family tombs" at Rehovot-

\footnotetext{
${ }^{397}$ FitzGerald, A Sixth Century Monastery at Beth-Shan (Scythopolis), 27.

${ }^{398}$ Rahmani, "A Lead Coffin from the Hefer Valley," 124; Taha, "A Byzantine Tomb at the Village of Rammun," 432, plate 5 .
} 
in-the-Negev, Khirbet Karkur, `Avdat, and Nesanna. In discussing the multiple-burial phenomenon, Goldfus writes:

In many churches - evidently private foundations, whether of a single family or several families - the tombs were used as a family burial receptacle. The 'family' could have consisted of members of consecutive generations or of several members of the same generation, as we have observed in churches of the Negev region such as Rehovot-in-the-Negev, Nessana, and 'Avdat.... [In monasteries,] this 'family' was not necessarily based on blood ties but rather on ecclesiastical kinship or monastic brotherhood. 399

All the individuals found in the masonry tomb were adults, except for one infant represented only by teeth and pelvis fragments. As for the genders, at least three were men and three women. All the skeletons were disarticulated, with some individuals represented by only a few pieces. The mix of ages and genders might also suggest an idea of celibacy in urban monastic contexts different from that of the monks of the desert. ${ }^{400}$

These two burial locations, both in the chancel, and both venerating those there interred are significant indicators for identifying the complex in the northeast insulae at Hippos Palaistinēs as an urban monastic complex. ${ }^{401}$

If the complex is monastic in some form, an identifiable function for the complex would further the case. It is the fourth indicator for our consideration.

Certainly, the veneration of the elderly woman was part of the function of this complex, even after it was decommissioned. A well-paved street gave access to the gate of the compound. The only unblocked door after the decommissioning allowed continuing access to her tomb. A crude wall was built around the exposed sarcophagus of the woman, and a bench was installed inside the remaining southwest entrance. However, the cult of the elderly woman may have involved more than a memorial.

Next to the chancel and the tomb of the elderly woman is an arched diakonikon, oversized compared to the church. Its only entrance is adjacent to the tomb of the elderly woman. Three high benches line the south, west and north walls. In the northeast corner of the diakonikon is a cistern head. This cistern is in direct proximity to the tomb, prominently placed in the room, and is an unprecedented feature of a diakonikon. Behind it, a small hoard of gold jewelry was found, including a magical amulet for somatic diseases.

We suggest that the room was a monastic infirmary and the locus of a healing cult that grew from the veneration of the elderly woman. Christians in late antiquity searched for healing

\footnotetext{
${ }^{399}$ Goldfus, "Tombs and Burials in Churches and Monasteries of Byzantine Palestine (324--628 AD)," 240.

${ }^{400}$ Goldfus, "Urban Monasticism and Monasteries of Early Byzantine Palestine - Preliminary Observations," 79.

401 Ibid., 78.
} 
at the shrines of saints, usually their tombs, or another place where their relics were preserved. Examples from comparable times periods include the tomb of the martyr St. Menas in Egypt in the fifth century; Sts. Abbakyros and John also in Egypt in the fifth and seventh centuries; the shrine of St. Thekla in Anatolia, attested between the fourth and sixth centuries; and the pilgrimage site at the column of St. Simon the Stylite the Elder, active in the late fifth and sixth centuries. "These shrines are known through their extensive archaeological remains, through accounts of the posthumous miracles performed by the saints, and through pilgrimage artifacts or 'souvenirs,' such as ampullae, designed as containers for holy oil or water, and clay tokens made from the dust of a holy site." ${ }^{402}$

Binns posits a similar monastic healing site at neighboring Scythopolis, by drawing on references in Cyril to the monastery of Euthemane that Cyril calls the "well of eight," to the Piacenza Pilgrim describing Scythopolis as a place where St. John the Baptist performed many miracles, and to a Russian abbot, Daniel, who visited Scythopolis in the twelfth century and was shown a miraculous pool. ${ }^{403}$

Although ampullae were not found in the diakonikon, the presence of the cistern suggests a healing function. The discovery of the healing amulet nearby, although pagan, supports this hypothesis, for Alexander of Tralles advocated the use of any means in the interests of the sick. ${ }^{404} \mathrm{~A}$ third piece of evidence is the ancient pollen signature left on the plaster surfaces of the diakonikon indicating that as many as fourteen ancient herbal plants were utilized for the purposes of healing within its confines. ${ }^{405}$

A healing cult, a cistern adjoining a revered tomb, a magical healing amulet and a pollen signature of healing herbals together build a strong case that the monastery served as an infirmary for the community. The need for such a facility may have been precipitated by the Plague of Justinian, the outbreak of infectious disease that occurred in the Egyptian port of Pelusium, spread quickly to Palaistina, and remained virulent in the east for two centuries.

The sixth century pharmacopoeia was of negligible use in treating the plague. Understandably, in such recurring crises, the practice of medicine used charms and folk remedies, and clinician would try anything that might alleviate the discomfort of his patients ... even magic amulets. ${ }^{406}$ Somewhat more effective, because more widely available, was the one

\footnotetext{
402 Talbot, "Pilgrimage to Healing Shrines: The Evidence of Miracle Accounts," 154.

403 John Binns, Ascetics and Ambassadors of Christ: The Monasteries of Palestine, 314-631, Oxford early Christian studies (Oxford : New York: Clarendon Press ; Oxford University Press, 1994), 146-147.

404 Alexander of Trailles and Félix Louis Émile Brunet, Euvres médicales d'Alexandre de Tralles, le dernier auteur classique des grandes médecins grecs de l'antiquité. (Paris: P. Geuthner, 1933), 319, 475.

${ }^{405}$ See a full discussion of the materia medica later in this work.

${ }^{406}$ William Rosen, Justinian's Flea: Plague, Empire, and the Birth of Europe (New York: Viking, 2007$), 212$.
} 
great medical innovation of Late Antiquity: the hospital, which developed in monastic contexts and spread from their original locations in Judaea during the late fourth century to Rome, Ephesus, and Constantinople. ${ }^{407}$

In the monastic infirmary at Hippos, we find pharmacological resources, the use of stomatic amulets, and a monastic infirmary/hospital. Seemingly, faith and pharmacology brought some relief and hope in the context of the revered memory of a now unknown woman.

\section{Conclusion}

A compound comprising four interconnected buildings surrounding the Northeast Church at Hippos Palaistinēs may have been an urban monastery. The compound is in the urban core of the city. In its interconnectivity and in its decommissioning, the compound was treated as a unit. Its prominent burials in the chancel including a revered tomb of an elderly woman strongly suggest a monastic community. The compound also provided a significant function to the Late Antique workings of Hippos Palaistinēs, as the tomb of the elderly woman became and to a degree continued to be a site of healing. While the lack of specific literary or inscriptional evidence requires that the identification of this monastic compound be at best tentative, the material remains from the northeast insulae at Hippos Palaistinēs ought to be part of any study of urban monasticism and monasteries in Palaestina.

The case of the northeast insulae at Hippos Palaistinēs demonstrates the possibility of using key indicators to identify monastic compounds in ancient cities with concentrations of churches. Such identification has the potential to reveal more about urban monastic practice in Late Antique Palaestina as a complement to the practice in the desert.

${ }^{407}$ Ibid., 214. 
The Northeast Insulae Project 


\section{1.}

\section{MATERIA MEDICA OF MONASTIC HEALTH CARE AT HIPPOS PALAISTINĒS}

Chapter co-authored with Patrick Scott Geyer, University of San Diego and the Zinman Institute of Archaeology, University of Haifa

In a previous publication, ${ }^{408}$ we stated that the discovery of a healing charm in the diakonikon raises the question of the function of the room in which the horde was hidden. The room is oversized in comparison to the small size of the church. It is wrapped around the corner of the church that houses the tomb of a revered woman. The only entrance to the room is immediately adjacent to the tomb. The cistern in its northeast corner is in direct proximity to the tomb, prominently placed in the room, and at the same time is an unprecedented feature of a diakonikon. The combination of high benches that could allow reclining, the healing amulet, and the proximity of the cistern to the tomb of a revered woman suggest that the room may have served some sort of cultic function in the veneration of the sacred woman.

Subsequent excavation of structures surrounding the Northeast Church suggest that the complex functioned as an urban monastery centered on the cult of a revered woman and healings associated with her veneration. Pollen analysis from archaeological plasters points to a concentration of herbals in the diakonikon supportive of such a function.

In Part 1of this chapter advances the theory by presenting evidence for the use of materia medica in this facility. Specifically, we discuss preliminary pollen analysis of diakonikon herbals. In Part 2, these findings are compared with literary references to the use of herbals in early monastic health care. Part 3 posits situations that may have created a need for such health care.

\footnotetext{
${ }^{408}$ Mark Schuler, "Oĩ̄o to Monastery: An Interpretative Possibility for the Northeast Insulae at Antiochia Hippos," in Between Sea and Desert: On Kings, Nomads, Cities and Monks, Essays in Honor of Joseph Patrich, ed. Jacob Ashkenazi Orit Peleg-Barkat Uzi Leibner, Mordechai Aviam, Rina Talgam (Jerusalem: Kinneret Academic College and Ostracon, Tzemach, 2019), 75-85.
} 


\section{Part 1: Preliminary Pollen Analysis of Diakonikon Herbals}

Archaeological plasters are ideal repositories of ancient pollen. ${ }^{409}$ The plasters from the diakonikon of the Northeast Church have recoverable fossil pollen and provide a ready resource for data relating to anthropogenic activity at the site.

\section{Methodology}

Samples from level depths of between two and five centimeters were taken from the plasters of the diakonikon: two from the base of the niche and ten from the plaster floor.

\section{Pollen analysis of herbals recovered from the diakonikon}

The plant species from the pollen recovered from this structure are divided into herbal and non-herbal categories. We begin with the herbals. We will restrict our analysis to herbal species with recovered fossil pollen occurring in concentrations of $2 \%$ or greater. This confines our analysis to fourteen herbals out of the total pollen signature. Finally, we will examine the non-herbal pollens to shed further light on the characteristically anthropogenic activities occurring in this structure.

\section{Cyclamen sp. $($ pollen count = 171) common name "Sow Bread"}

... is native to the Golan Heights and occurs in significant percentages in eleven of the diakonikon samples. Since it registers both on the niche and floor plaster surfaces, it was, in all probability, gathered in bulk and heaped upon the floor prior to processing. Sow bread or Cyclamen pollen registers in all twelve samples but occurs in aggregates (clusters of pollen) in just one of the niche samples (H48) and just one of the floor samples (H47). Significantly, this floor sample is located directly in front of the niche and, besides being an aggregate, registers at $26.5 \%$ of the total sample count. Theophrastus tells us that the root of Cyclamen is beneficial for running wounds and that mixed with honey is a good wound dressing. Both Cyclamen and honey are known in modern medicine for their antibacterial properties. ${ }^{410}$

\footnotetext{
${ }^{409}$ Examples of the recovery of pollen from archaeological plasters include work with the temple and granary at Bethsaida/Julias: Schoenwetter and Scott-Geyer, "Implications of Archaeological Palynology, at Bethsaida, Israel"; the basilica at Gamla Geyer et al., "Pollen Analysis"; the winery complex of the North-West Church Patrick Scott Geyer, "Pollen Analysis of the Winery Complex Adjacent to the North-West Church," in Hippos-Sussita: Tenth Season of Excavations (July and September 2009), ed. Arthur Segal (Haifa, Israel: Zinman Institute of Archaeology, University of Haifa, 2009), 93-103; the industrial complex at Hippos Geyer, "Pollen Analysis of the Hippos-Sussita Industrial Complex"; other related complexes at Hippos including the Roman basilica Patrick Scott Geyer, "Pollen Analysis," in Hippos-Sussita of the Decapolis: The First Twelve Seasons of Excavations 2000-2011, Vol. II, ed. Michael Eisenberg, 2018, 370-373.

410 John Scarborough, "Theophrastus on Herbals and Herbal Remedies," Journal of the History of Biology 11, no. 2 (1978): 365-366.
} 
Glaucium sp. (pollen count = 168) common name Red Horned Poppy

... occurs in high concentration in both niche samples and in six floor samples. Aggregates (clusters of pollen) occur in the niche and in a sample from the floor close to the niche. These suggest both a local source and stockpiling within the structure. Dioscorides prescribes a poultice of the juice of the Red Horned Poppy for sore eyes. ${ }^{411}$

Veratrum sp. (pollen count $=159)$ common name White Hellaboras

... shows concentrations in the niche samples and five floor samples, three of which include aggregates. It was gathered locally. Theophrastus mentions that Hellaboras "grows in the vineyards of Elea" and Hippos, with multiple wine presses, must have had extensive vineyards of its own. Theophrastus identifies the root and the fruit of White Hellaboras as a useful purge. ${ }^{412}$ It is mixed with wine prior to being drunk.

Hyroscyamus sp. (pollen count = 146) common name Henbane, Hen Bill or Hyoscyamus

... appears in both niche samples, but only registers a high concentration in one of them (11.5\%). It occurs in high concentrations within some of the floor samples, suggesting that it is not an imported herb. Dioscorides prescribes an aromatic concoction of Henbane as a suppository treatment for earaches and constipation. ${ }^{413}$

Artemisia herba-alba sp. (pollen count = 143) common name White Wormwood ... occurs in high concentrations in both niche samples and several places in the room. It also was seen in aggregate form in four samples. It was gathered locally and is thus the local species Artemisia herba-alba. Dioscorides prescribes mixing the leaves with almond oil and applying it as a compress for stomach aches and as an invigorating body rub for weakness. ${ }^{414}$

Crocus sp. (pollen count $=141$ ) common name Saffron

... appears in both niche samples, and in two floor samples. One floor sample is a very high percentage suggesting both stockpiling of the plant and a local source for it. Dioscorides prescribes a concoction of Crocus as an aromatic that when rubbed on the head or nostrils serves as both a warming agent and sleep inducer. He also recommends it for boils and the hardening of the uterus. ${ }^{415}$

Taraxacum sp. (pollen count $=120)$ common name dandelion ... occurs in five floor samples, three of which with aggregates. Dandelion is another local plant and its pollen also appears in aggregate form in three of the ten floor samples, which is a strong indicator that it was gathered and hung to dry from the roof of the Diakonikon. Dioscorides tells us that Dandelion mixed in wine is an antidote against snake bite and

\footnotetext{
411 Pedanius Dioscorides, De Materia Medica 3.100.

412 Scarborough, "Theophrastus on Herbals and Herbal Remedies," 361-362.

${ }^{413}$ Dioscorides, De Materia Medica, 1.42.

${ }^{414}$ Dioscorides, De Materia Medica 3.128.

415 Ibid. 1.64.
} 
boiled in wine or even ingested whole is a cure for bowel ailments like dysentery. The stalk and the leaves of another kind of Dandelion are digestive. ${ }^{416}$

Atropa sp. (pollen count $=96$ ) common name Belladonna

... occurs in a high concentration (18\%) in one of the two niche samples and in two locations on the floor. It also was seen in aggregate form in three samples. Theophrastus describes putting a small portion of the Belladonna leaf into wine for use as a "sleep inducer."

Conium sp. (pollen count $=94)$ common name Poison Hemlock

... occurs in the diakonikon niche samples. Both percentages are low (3.5\% and $2.5 \%)$, but statistically still significant. Conium is also present in five floor samples at $5 \%$ or above concentration. However, like the opium poppy, it is in all plausibility an imported herb. The floor samples may denote processing or spilage. Theophastrus lists the classic symptoms that an increased dosage of Hemlock produces: weakness, sleepiness, nausea, vomiting, difficult respiration, paralysis, asphyxia and death. ${ }^{418}$ In small amounts, conium can be used beneficially as both a sedative and as an antispasmodic. In large amounts it can be used for euthanasia.

Mandragorus sp. (pollen count $=91)$ common name Mandrake

... has the highest concentration (38.5\%) of pollen taken from the recessed niche of the diakonikon. Mandrake also occurs into the second niche sample (5\%), but strikingly does not occur is a statistically significant amount in any floor sample. Crocus (Saffron) is the only herb with a single higher concentration than Mandrake (42.5\% versus $38.5 \%$ ); but that concentration occurs within a floor sample. Crocus is therefore a local plant; Mandrake is an import.

According to Theophrastus, the leaf of Mandrake is mixed with barley to make a poultice for wounds. Also, the root scraped into vinegar is useful as a lotion treatment for erysipelas (bacterial inflammation of the skin) and when ingested is a treatment for gout and a sleep inducer. Dioscorides, Galen and Oribasius concur that Mandrake is a sleep inducer, and Galen claims it reduces pain. ${ }^{419}$

Ephedra sp. (pollen count $=61$ )

... is likely the hippuris of Dioscorides and does not appear in either consistent or significant amounts in the two niche samples. It does register throughout the ten floor samples, ranging from a low of $1 \%$ (H76) to a high of $8 \%$ (H78). Ephedra is a locally gathered herb, as evidenced by its pollen being spread throughout the floor samples, which denotes its being hung from the rafters of the diakonikon for drying. The juice of it stops discharges of blood

\footnotetext{
${ }^{416}$ Ibid. 2.161.

${ }^{417}$ Scarborough, "Theophrastus on Herbals and Herbal Remedies," 367.

${ }^{418}$ Ibid., 379-380.

${ }^{419}$ Ibid., 360.
} 
from the nostrils. Mixed with wine, it helps dysentery and induces urine. Pounded into small pieces (and sprinkled on) it closes bleeding wounds. Both root and top were reputed to be useful in the treatment of cough and internal rupture. ${ }^{420}$

Polypodium sp. (pollen count $=49$ ) common name Shield Fern

... with a high of $2.5 \%$ in the niche samples, and $6 \%$ in the floor samples, overall registers quite low in concentration of the fourteen herbs recovered from the diakonikon. According to Dioscorides, the leaves are added to vinegar to cure wounds and remove inflammation. ${ }^{421}$

Papaver sp. (pollen count $=42$ ) common name Poppy

... occurs only in small amounts within the two niche samples and four floor samples. $\mathrm{Pa}$ paver is native to the area. Theophrastus mentions the common Poppy (Papaver rhoeas) and lists it as another purgative. He also claims that the juice of the common Poppy (Papaver rhoeas), when ingested, induces sleep and relieves pain in the limbs. ${ }^{422}$

Lawsonia sp. (pollen count = 26) common name Henna, Cyprus or Egyptian Privet.

... exhibits the lowest concentrations throughout all twelve samples. It reaches the statistical benchmark of $2 \%$ in only three of the floor samples and one of the niche samples. Dioscorides prescribes a concoction of Henna as an aromatic and an ointment to treat a variety of circulatory problems. ${ }^{423}$ Elsewhere he states that the leaves are chewed to treat mouth ulcers and applied to the forehead with vinegar for headaches. ${ }^{424}$

\section{Cultivar (agricultural) pollens}

Three of the major agricultural cultivars were recovered from the diakonikon plasters: grain, olive, and flax. The fourth, grape, was not recovered. Two agricultural cultivars are utilized in the preparation of five of the herbals covered above. Barley grain is used in preparing Mandrake (Mandragoras), as is vinegar. Wine or vinegar is used in the preparation of herbal concoctions of Belladonna, White Helleboras, Henna and Shield Fern. Thus, the absence of grape or wine pollen may either denote the absence of spillage or it may be written down to the scarcity of samples.

\section{Indicator (anthropogenic) pollens}

Of the six recovered indicator pollens, Chenoam and Umbelliferae, found only in the floor samples, are strong indicators for pastures. Liguliferae and Tubiliflorae, which are found throughout the samplings, are strong indicators of both foot paths and pastureland, along

\footnotetext{
${ }^{420}$ Dioscorides, De Materia Medica 4.46.

421 Ibid. 3.162.

422 Scarborough, "Theophrastus on Herbals and Herbal Remedies," 371.

${ }^{423}$ Dioscorides, De Materia Medica 1.65.

${ }^{424}$ Ibid. 1.124.
} 
which they opportunistically grow. ${ }^{425}$ Thus, their presence within the confines of the diakonikon reinforces the interpretation that most of the herbals were gathered locally from the surrounding fields.

\section{Hydrophyll (aquatic) pollens}

As in most of the structures sampled at Hippos, the strong presence of water born pollens attests to the presence of a ready supply of water. Three of the main aquatic plants are present: papyrus, lake rush and willow.

\section{Arboreal (tree) pollens}

Arboreal or tree pollens meet the $2 \%$ threshold in only three samples.

\section{Conclusion}

The ancient pollen signature left within the diakonikon tells us that as many as fourteen ancient herbal plants were utilized for the purposes of healing within its confines. An examination of differences between the floor and shelf samples further indicates that some of the herbs were gathered locally, while the remaining plants were probably exotic imports. The Indicator category reinforces this interpretation. In addition, double-digit concentrations of at least seven of the local herbal pollens within the floor samplings suggests a practice of stockpiling plants within the precincts of the diakonikon. This stockpiling could have taken the form of baskets or bundles of fresh herbs being placed directly upon the floor or, more likely, fresh bundles of herbal plants were hung from the ceiling of the diakonikon to dry them prior to their utilization in medicinal concoctions.

\section{Part 2: the use of herbals in early Christian/monastic health care}

Having proposed that the northeast insulae at Hippos functioned as a monastic infirmary/healing site, we thirdly argue from a survey of literary sources that the material remains at the site are consistent with the use of herbals in monastic health care of that era.

From the beginnings of Christianity, healing was a focal practice. Mighty deeds were attributed to the words and hands of Jesus. An increasing stream of recent Gospel scholarship designates Jesus a healer. ${ }^{426}$ "Jesus should be put in the general category of being a healer,

\footnotetext{
${ }^{425}$ Karl-Ernst Behre, "The Interpretation of Anthropogenic Indicators in Pollen Diagrams," Pollen et spores 23, no. 2 (1981): 225-245.

${ }^{426}$ James D. G. 1939- Dunn, Jesus Remembered, Christianity in the making ; volume 1 (Grand Rapids, Michigan: W.B. Eerdmans, 2003), 677; Justin Meggitt, "The Historical Jesus and Healing: Jesus' Miracles in Psychosocial Context," in Spiritual Healing : Scientific and Religious Perspectives, ed. Fraser N. Watts (Cambridge, UK ; Cambridge University Press, 2011), 17.
} 
even though an equivalent noun is not actually used of him in the Gospels. " ${ }^{427}$ His first followers did signs, wonders, and healings "by the name of Jesus Christ of Nazareth" (Acts $4: 10 ; 8: 7 ; 9: 40 ; 14: 3,10 ; 15: 12)$; and Christians were instructed to call the elders if they are sick, for "the prayer of faithful will save the sick, and the Lord will raise them up" (James $5: 14-15)$. "The concern of Jesus and the early Christians with illness and healing was not unique in the ancient world. The growth of the Asklepios cult, the development of the Greek medical tradition and many of the magical papyri illustrate the fact that these were matters of deep concern." ${ }^{428}$ But, the therapeutic strategy of Christians was quite simple in comparison to other practitioners. Christians did not perceive a need for pharmaceuticals ${ }^{429}$ and did not charge for their services.

Tatian, the noted Christian polemicist of the second century, portrays of the whole pharmaceutical enterprise as a Satanic artifice: "Pharmacy in all its forms is due to the same artificial devising. If anyone is healed by matter because he trusts in it, all the more will he be healed if in himself he relies on the power of God." 430 Thus, for Tatian, faith in the power of God precluded pharmaceuticals. Moreover, according to Tatian, such remedies are as dangerous as poisons because they share the same material constitution. ${ }^{431} \mathrm{~A}$ similar antipharmaceutical sentiment appears in Justin Martyr, who praises Christians able to heal patients who could not be cured by "those who used incantations and drugs." ${ }^{232}$

Irenaeus treats at length the biblical traditions about healing in the Hebrew and Christian scriptures in Adversus haereses. Although he discusses physical healings, he sees them as "an integral feature of the work of redemption and the renewal of society." 433 Healing is both physical and spiritual. Irenaeus asserts that physical healings and raising of the dead have occurred frequently in the church ${ }^{434}$ and is distinguished from the Greek medical tradition of Dioscorides and Galen, from magic, and from Gnostic practice.

In the fourth century, similar themes are still asserted. Barrett-Lennard finds in private letters among the papyri from Christians that writers use the phrases "body, soul and spirit" or "soul and body" to suggest that "their concept of health is much broader than merely physical health." ${ }^{435}$ In other letters, "writers conceived of illness to be a matter that was

\footnotetext{
${ }^{427}$ Maurice. Casey, Jesus of Nazareth : An Independent Historian's Account of His Life and Teaching (London; T \& T Clark, 2010), 245.

${ }^{428}$ R. J. S. Barrett-Lennard, Christian Healing after the New Testament: Some Approaches to Illness in the Second, Third, and Fourth Centuries (Lanham: University Press of America, 1994), 3.

${ }^{429}$ Hector. Avalos, Health Care and the Rise of Christianity (Peabody, Mass.: Hendrickson, 1999), 83.

${ }^{430}$ Tatian, Oratio Ad Graecos 18.

${ }^{431}$ Ibid. 18.

432 Justin, Apologia ii 6.

${ }^{433}$ Barrett-Lennard, Christian Healing after the New Testament, 100.

${ }^{434}$ Irenaeus, Adversus Haereses 11.31.2.63.

${ }^{435}$ Barrett-Lennard, Christian Healing after the New Testament, 86.
} 
related to their Christian faith and belief. Christ (or God) is specifically mentioned as having, or having had, a part to play in the healing that they (or their family members) are seeking or have already obtained." ${ }^{\prime 36}$

Moreover, by the fourth century, care for the sick was "a distinctive and remarkable characteristic of early Christian missionary outreach." ${ }^{37}$ Polycarp of Smyrna had identified care of the sick as one of the chief tasks for which church elders were responsible. A guidebook for Christian communities written in Rome around 215 instructed bishops to pay house calls on sick members. ${ }^{438}$ Hector Avalos argued that earliest Christianity won adherents because its health care system was cheaper, and more accessible and accommodating, than what other groups provided. . $^{49}$

Christian care for the sick was particularly notable in times of epidemics. Dionysius, bishop of Alexandria, described the dedication to the sick and dead displayed by Christians during an epidemic and their fearlessness in the face of sickness and death. "Most of our brethren showed love and loyalty in not sparing themselves while helping one another," Dionysius reported, "tending to the sick with no thought of danger and gladly departing this life with them after becoming infected with their disease." "Similarly, Eusebius of Caesarea, wrote of the response of Christians at a time when the city was fraught with disease and famine, "The zeal and piety of the Christians were obvious to all the heathen" as they "tended to the dying and to their burial, countless numbers with no one to care for them." Christians also "gathered together from all parts of the city a multitude of those withered from famine and distributed bread to them all, so that that their deeds were on everyone's lips, and they glorified the God of the Christians." ${ }^{411}$

Such practices were consistent with earliest Christianity, but new factors were emerging in the healing practices of Christianity. Greek medical theory was dominated by Galen's theory of four primary opposites (hot, cold, wet, dry). Athanasius in Contra gentes embraces this understanding.

[He] explain[s] that these elements exist in combination and that the isolation or separation of them causes their mutual destruction by the dominance of the stronger element.... [H]e accepts that ill-health represents a disturbance of the basic bodily elements.... It is the theory of contemporary Greek medical "science' and indicates

\footnotetext{
436 Ibid.

${ }^{437}$ Andrew T. Crislip, From Monastery to Hospital: Christian Monasticism \& the Transformation of Health Care in Late Antiquity (Ann Arbor: University of Michigan Press, 2005), 47.

${ }^{438}$ Ibid.

439 Avalos, Health Care and the Rise of Christianity, 21.

${ }^{440}$ Eusebius, Eusebius--the Church History: A New Translation with Commentary, trans. Paul L. Maier (Grand Rapids, MI: Kregel Publications, 1999), 269.

${ }^{441}$ Ibid., 328-329.
} 
that Athanasius was able to both hold to this theory and yet accept ... that Christianity offered a distinctive approach to obtaining healing and health. ${ }^{42}$

Along with a rapprochement with the Greek medical tradition, letters from the fourth century note a second new factor: certain ascetics who "acquired a reputation for both personal holiness and a special effectiveness in relation to prayer to God for the healing of people's illnesses." 443 The prayers of these monks were sought by many from across ancient society and were thought to play a significant part in healing. Athanasius, in the Vita Antonii, reports that Antony of Egypt had a particularly efficacious gift of healing. ${ }^{444}$

But the monastics did more than pray. Stanley Harakas has noted that holy men, when they performed more mundane healings for people, employed a wide variety of material means in these endeavors. "Aided and abetted by their holiness," Harakas wrote, holy men "used the panoply of prayer together with their medical skills, folk wisdom, and herbal lore to cure the ills of others," in effect affirming that outreach to the sick was an essential aspect of their holiness. ${ }^{445}$

Andrew Crislip notes, "In the early Egyptian coenobia, the traditions of Egyptian medicine were observed, both in classification of diseases and in pharmaceutical therapy" 446 citing Shenoute as an example. "Medical manuscripts [such as the handbook recovered from the coenobium of Apa Jeremias in Saqqara] and inscriptions from late antique coenobia, as well as testimonia from monastic writers, ... [show] pharmaceutical techniques advised, and maladies treated." ${ }^{447}$

In the monasticism of the Greek east, with only a few exceptions, monastics used the Greek medical tradition in monastic infirmaries. ${ }^{48}$ The Cappadocian Fathers provide a theological foundation for these activities. Gregory of Nyssa referred to Christ as "the true doctor of the soul's suffering." ${ }^{449}$ Gregory of Nazianzus elaborated on the metaphor of healing to conceptualize the incarnation of Christ and his saving power. In his biography of Basil of Caesarea, Gregory of Nazianzus asserted that Basil based his approach to pastoral work on his understanding of medicine, noting that Basil had studied Hippocratic texts as part of his upperclass education in Greek philosophy and that he had considerable knowledge of herbal remedies as well. Basil personally visited the sick in his hospital, greeting them with a kiss and

\footnotetext{
${ }^{442}$ Barrett-Lennard, Christian Healing after the New Testament, 181-182.

443 Ibid., 86.

444 Ibid.

${ }^{445}$ Stanley Samuel Harakas, "The Eastern Orthodox Tradition," in Caring and Curing: Health and Medicine in the Western Religious Traditions, ed. Ronald L. Numbers and Darrel W. Amundsen (New York: Macmillan, 1986$), 151$.

${ }^{446}$ Crislip, From Monastery to Hospital, 31.

447 Ibid., 32.

448 Ibid., 34.

449 Amanda Porterfield, Healing in the History of Christianity, 53, accessed April 14, 2021, https://www.academia.edu/35883319/Healing_in_the_History_of_Christianity.
} 
attending to their wounds and aliments, and for centuries afterward, monks emulated his humility and friendship for the sick..$^{450}$

Basil writes of the divine gift of the medical art:

Just as each of the arts has been given us by God as a help to supplement the deficiencies of nature--so it is with the medical art. Since our body, so subject to disease, is liable to various kinds of harm, ... the medical art--a type in this respect of the healing of the soul--has been given us by God Who directs all our life to advise the removal of what is in excess or the addition of what is wanting. ${ }^{451}$

Basil further points to the use of pharmaceutical approaches:

For the herbs which are appropriate to each disease did not grow out of the ground automatically, but to be sure, were produced by the will of the Creator with the object of benefiting us. So, the natural forces which reside in roots, flowers, leaves, fruits, or juices, or whatever is found in metals or in the sea to have properties beneficial to the body, fall into line with the things to eat and drink which we find. ${ }^{452}$

Indeed, monastic practitioners were expected to use the best that the Greek medical tradition advised. Cassiodorus, writing to monasteries of the sixth century, is most specific:

Learn, therefore, the properties of herbs and perform the compounding of drugs punctiliously .... But if the eloquence of Greek letters is un-known to you, you have first of all the Herb Book of Dioscorides, who has treated and portrayed the herbs of the fields with remarkable accuracy. After this read the Latin translation of Hippocrates and Galen (that is the Therapeutics of Galen, addressed to the philosopher Glauco) and a certain anonymous work, which has been compiled from various authors. Finally, read Caelius Aurelius' On Medicine, and Hippocrates' On Herbs and Cures, and various other works written on the art of medicine; with God's help, I have left you these books, stored away in the recesses of our library. ${ }^{453}$

The healing practice of Christianity of the second century, which imitated the practice of Jesus and distinguished itself from those of the Greek medical tradition and other practice of Graeco-Roman society, underwent a major change by the sixth century when the monastic infirmary at Hippos Palaistinēs began to serve its community. Christian practice in the

450 Timothy S. Miller, The Birth of the Hospital in the Byzantine Empire, Johns Hopkins pbk. ed. (Baltimore: Johns Hopkins University Press, 1997), 52-61, 86.

${ }^{451}$ Saint Basil Bishop of Caesarea, ca. 329-379, The Ascetic Works of Saint Basil (England: England: Society for Promoting Knowledge, 1925), 55.

${ }^{452}$ Ibid.

${ }^{453}$ Cassiodorus, “An Introduction to Divine and Human Readings," electronic resource, trans. Leslie Webber Jones, $A C L S$ Humanities E-Book, Records of civilization, sources and studies no. 40 (1969): 136, accessed April 14, 2021, http://proxy.libraries.uc.edu/login?url=http://hdl.handle.net/2027/heb.05980. 
sixth century had embraced the Greek medical tradition, especially under the influence of monastic practices. A monastic infirmary serving a community by invoking the holiness of a revered woman, providing space in her presence to rest and recover, employing pharmaceutical approaches reliant on Galen and Dioscorides, and even allowing the use of healing amulets is consistent with the literary sources of the time and the emergence of such facilities in Constantinople and cities of the Greek east.

\section{Part 3: Function of the Infirmary}

Urban monasteries typically served a larger purpose in the community. My co-author initially suggested that the infirmary may have served the military needs of this fortress city.

However, after the earthquake of $363 \mathrm{CE}$, the significance and fortifications of the city waned. Its aqueduct system was no longer fully functional.

A more likely and longer-term need was precipitated by the Plague of Justinian, the outbreak of infectious disease that occurred in the Egyptian port of Pelusium in the summer of 541, spread quickly to Palaistina, and remained virulent in the east for two centuries until it disappeared in the mid eighth century even as the area was devastated by the major earthquake in $749 \mathrm{CE}$. Substantive stagnation and decline of urban centers in the Greek east beginning in the mid-sixth century ${ }^{454}$ testify to the long-term impact of the plague that caused massive loss of life on repeated occasions. At Hippos, the city shrank within its fortifications. One mass burial has been discovered of victims lacking signs of physical trauma as could occur in battle or a natural disaster. ${ }^{455}$

Procopius describes the symptoms ...

They had a sudden fever, a bubonic swelling developed ... Then ensued with some a deep coma, with others a violent delirium.... They had also great difficulty in the matter of eating.... And in those cases where neither coma nor delirium came on, the bubonic swelling became mortified.... Death came in some cases immediately, in others after many days; and with some the body broke out with black pustules.... With many a vomiting of blood ensued without visible cause and straightway brought death..$^{456}$

\footnotetext{
${ }^{454}$ Hugh N. Kennedy, "Justinianic Plague in Syria and the Archaeological Evidence," in Plague and the End of Antiquity: The Pandemic of 541-750, ed. Lester K. Little (Cambridge: Cambridge University Press, 2009), 95.

${ }^{455}$ Segal et al., Hippos-Sussita : Eighth Season of Excavations : July 2007, 98-103.

${ }^{456}$ Procopius, History of the Wars, Books I and II The Persian War, trans. H. B. (Henry Bronson) Dewing, 2005, accessed April 14, 2021, http://www.gutenberg.org/ebooks/16764 2.22.
} 
The sixth century pharmacopoeia was of negligible use in treating plague. Understandably, in such recurring crises, the practice of medicine used charms and folk remedies, and clinician would try anything that might alleviate the discomfort of his patients, even magic amulets. $^{457}$

Somewhat more effective, because more widely available, was the one great medical innovation of late antiquity: the hospital, which developed in monastic contexts and spread from their original locations in Judaea during the late fourth century to Rome, Ephesus, and Constantinople. ${ }^{458}$

In the monastic infirmary at Hippos, we find pharmacological resources, the use of stomatic amulets, and a monastic infirmary/hospital. Hippos had ways of responding to the plague, even though limited in effectiveness.

\section{Diakonikon Pollen Counts in Percentages}

* indicates aggregates (grape like clusters of the same pollen)

\begin{tabular}{|c|c|c|c|c|}
\hline Season & \multicolumn{4}{|c|}{ Samples gathered in 2010} \\
\hline Sample \# & $\begin{array}{c}\mathrm{H} \# 43 \\
\text { No } 1\end{array}$ & $\begin{array}{c}\mathrm{H} \# 48 \\
\text { No } 2\end{array}$ & $\begin{array}{c}\mathrm{H} \# 46 \\
\text { No } 3\end{array}$ & $\begin{array}{c}\mathrm{H} \# 47 \\
\text { No } 4\end{array}$ \\
\hline Location: & Shelf east & Shelf west & $\begin{array}{c}\text { Floor } .5 \mathrm{~m} \\
\text { from south } \\
\text { bench (row } 2 \\
\# 1 \text { ) }\end{array}$ & $\begin{array}{c}\text { Floor } 1.5 \mathrm{~m} \\
\text { from south } \\
\text { bench (row } 4 \\
\# 1 \text { ) }\end{array}$ \\
\hline \multicolumn{5}{|l|}{ Type/species/common name } \\
\hline \multicolumn{5}{|c|}{ Herbal (medicinal) listed in order of concentration high to low: } \\
\hline Cyclamen & 4 & $4.5^{*}$ & 5.5 & $26.5^{*}$ \\
\hline Glaucium (poppy) & $12 *$ & $9.5^{*}$ & $12.5^{*}$ & 7* \\
\hline Veratrum (white helleboras) & 3.5 & $4^{*}$ & & \\
\hline Hyroscyamus (henbane) & $11.5^{*}$ & 1 & & .5 \\
\hline Artemisia (wormwood) & $6.5^{*}$ & $13^{*}$ & 15 & $25^{*}$ \\
\hline Crocus (saffron) & 3 & $4^{*}$ & $42.5^{*}$ & \\
\hline \multicolumn{5}{|l|}{ Taraxacum (dandelion) } \\
\hline Atropa (belladonna) & 1.5 & $18^{*}$ & & .5 \\
\hline
\end{tabular}

${ }^{457}$ Rosen, Justinian's Flea, 212.

${ }^{458}$ Ibid., 214. 


\begin{tabular}{|c|c|c|c|c|}
\hline Conium (hemlock) & 3.5 & 2.5 & & \\
\hline Mandragorus (mandrake) & $38.5^{*}$ & 5 & & \\
\hline Ephedra (herb) & .5 & & & \\
\hline Polypodium (fern) & 1 & 2.5 & 1 & \\
\hline Papaver (opium poppy) & 1.5 & 4.5 & & \\
\hline Lawsonia (henna) & 2 & 1 & 1 & $2^{*}$ \\
\hline \multicolumn{5}{|l|}{ Cultivar (crop): } \\
\hline Cerealis (wheat and Barley) & 2 & 4 & & \\
\hline Olea (olive) & .5 & $4^{*}$ & & $2.5^{*}$ \\
\hline \multicolumn{5}{|l|}{ Linum (flax) } \\
\hline \multicolumn{5}{|l|}{ Arboreal (tree): } \\
\hline \multicolumn{5}{|l|}{ Juglans (walnut) } \\
\hline \multicolumn{5}{|l|}{ Pistacia (terebinth) } \\
\hline Pinus (pine) & & .5 & & \\
\hline \multicolumn{5}{|l|}{ Quercus (oak) } \\
\hline \multicolumn{5}{|l|}{ Lacustrine/hydrophil (aquatic): } \\
\hline Papyrus & 1 & 1.5 & 3 & $24^{*}$ \\
\hline Salix (willow) & 3.5 & $4.5^{*}$ & & \\
\hline Scirpus (reed) & 3 & 3 & 1 & $4.5^{*}$ \\
\hline \multicolumn{5}{|l|}{ Typha (cattail) } \\
\hline \multicolumn{5}{|l|}{ Other species/types: } \\
\hline Chenoam (chenopodium, goose foot) & & & 2.5 & .5 \\
\hline \multicolumn{5}{|l|}{ Dipsacus (fullers brush) } \\
\hline \multicolumn{5}{|l|}{ Echinops (globe thistle) } \\
\hline Liguliflorae (low-spine) & .5 & $8.5^{*}$ & & $4.5^{*}$ \\
\hline Tubuliflorae (hi-spine) & .5 & $4.5^{*}$ & $15.5^{*}$ & $2 *$ \\
\hline Umbelliflorae (umbrella plant) & & & .5 & .5 \\
\hline POLLEN COUNT: & 200 & 200 & 200 & 200 \\
\hline
\end{tabular}

\begin{tabular}{|l|c|c|c|c|}
\hline Season & \multicolumn{4}{|c|}{ Samples Gathered in 2017} \\
\hline Sample \# & $\mathrm{H} \# 71$ & $\mathrm{H} \# 72$ & $\mathrm{H} \# 73$ & $\mathrm{H} \# 74$ \\
\hline
\end{tabular}




\begin{tabular}{|c|c|c|c|c|}
\hline & No 5 & No 6 & No 7 & No 8 \\
\hline Location: & $\begin{array}{c}\text { Floor by } \\
\text { east end south } \\
\text { bench (row } 1 \\
\# 1 \text { ) }\end{array}$ & $\begin{array}{c}\text { Floor by west } \\
\text { end south } \\
\text { bench (row } 1 \\
\# 2 \text { ) }\end{array}$ & $\begin{array}{l}\text { Floor } 1 \mathrm{~m} \text { from } \\
\text { south bench } \\
\text { (row } 3 \# 2 \text { ) }\end{array}$ & $\begin{array}{c}\text { Floor } 1 \mathrm{~m} \text { from } \\
\text { east pilaster } \\
(\text { row } 3 \# 1)\end{array}$ \\
\hline \multicolumn{5}{|l|}{ Type/species/common name } \\
\hline Cyclamen & 6 & 5 & 9 & 6 \\
\hline Glaucium (poppy) & $8 *$ & $7 *$ & 4 & 10 \\
\hline Veratrum (white helleboras) & $13 *$ & 3 & 10 & 11 \\
\hline Hyroscyamus (henbane) & 6 & 4 & 5 & 6 \\
\hline Artemisia (wormwood) & & 2 & & 1 \\
\hline Crocus (saffron) & 3 & 2 & 2 & \\
\hline Taraxacum (dandelion) & $19^{*}$ & 13 & & \\
\hline Atropa (belladonna) & 1 & $8 *$ & 3 & 4 \\
\hline Conium (hemlock) & 4 & 1 & 7 & 6 \\
\hline Mandragorus (mandrake) & 1 & 1 & & \\
\hline Ephedra (herb) & 5 & 2 & 5 & 4 \\
\hline Polypodium (fern) & 6 & 2 & 3 & 1 \\
\hline Papaver (opium poppy) & 2 & 4 & 2 & 1 \\
\hline Lawsonia (henna) & & 2 & 1 & \\
\hline \multicolumn{5}{|l|}{ Cultivar (crop): } \\
\hline Cerealis (wheat and Barley) & 2 & 6 & 6 & 4 \\
\hline Olea (olive) & & & & 1 \\
\hline Linum (flax) & & 6 & 1 & 3 \\
\hline \multicolumn{5}{|l|}{ Arboreal (tree): } \\
\hline Juglans (walnut) & & & 1 & 2 \\
\hline Pistacia (terebinth) & 1 & 1 & 3 & \\
\hline Pinus (pine) & & & 2 & 1 \\
\hline \multicolumn{5}{|l|}{ Quercus (oak) } \\
\hline \multicolumn{5}{|c|}{ Lacustrine/hydrophil (aquatic): } \\
\hline Papyrus & 2 & 4 & 9 & 12 \\
\hline Salix (willow) & $12 *$ & 1 & 6 & 3 \\
\hline
\end{tabular}




\begin{tabular}{|l|c|c|c|c|}
\hline Scirpus (reed) & 6 & 5 & $15^{*}$ & 19 \\
\hline Typha (cattail) & & & & \\
\hline Other species/types: & & & & \\
\hline Chenoam (chenopodium, goose foot) & & & & \\
\hline Dipsacus (fullers brush) & & $15^{*}$ & 2 & 2 \\
\hline Echinops (globe thistle) & 2 & 3 & 1 & 200 \\
\hline Liguliflorae (low-spine) & 1 & 1 & 2 & \\
\hline Tubuliflorae (hi-spine) & & 200 & 200 & \\
\hline Umbelliflorae (umbrella plant) & & & & \\
\hline POLLEN COUNT: & 200 & & & \\
\hline
\end{tabular}

\begin{tabular}{|c|c|c|c|c|}
\hline \multirow{2}{*}{$\begin{array}{l}\text { Season } \\
\text { Sample \# }\end{array}$} & \multicolumn{4}{|c|}{ Samples Gathered in 2017} \\
\hline & $\begin{array}{c}\mathrm{H} \# 75 \\
\text { No } 9\end{array}$ & $\begin{array}{l}\mathrm{H} \# 76 \\
\text { No } 10\end{array}$ & $\begin{array}{l}\mathrm{H} \# 77 \\
\text { No } 11\end{array}$ & $\begin{array}{l}\mathrm{H} \# 78 \\
\text { No } 12\end{array}$ \\
\hline Location: & $\begin{array}{c}\text { Floor } .5 \mathrm{~m} \\
\text { from south } \\
\text { bench (row } 2 \\
\# 2)\end{array}$ & $\begin{array}{c}\text { Floor } 1 \mathrm{~m} \\
\text { from south } \\
\text { bench (row } 3 \\
\# 3 \text { ) }\end{array}$ & $\begin{array}{c}\text { Floor } \\
1.5 \mathrm{~m} \text { from } \\
\text { west pilaster } \\
\text { bench (row } 4 \\
\# 2 \text { ) }\end{array}$ & $\begin{array}{c}\text { Floor } .5 \mathrm{~m} \\
\text { from south } \\
\text { bench (row } 2 \\
\# 3 \text { ) }\end{array}$ \\
\hline \multicolumn{5}{|l|}{ Type/species/common name } \\
\hline Cyclamen - 171 & 3 & 5 & 5 & 6 \\
\hline Glaucium (рорру) - 168 & 3 & 1 & 6 & 4 \\
\hline Veratrum (white helleboras) -- 159 & 2 & & $25 *$ & $8 *$ \\
\hline Hyroscyamus (henbane) -- 146 & $17 *$ & 8 & 7 & 7 \\
\hline Artemisia (wormwood) - 143 & 1 & $6 *$ & & 2 \\
\hline Crocus (saffron) -- 141 & $8 *$ & & 3 & 3 \\
\hline Taraxacum (dandelion) -- 120 & $15 *$ & $6 *$ & 5 & 2 \\
\hline Atropa (belladonna) - 96 & 1 & $8 *$ & 1 & 2 \\
\hline Conium (hemlock) -- 94 & 5 & $9 *$ & 2 & 7 \\
\hline \multicolumn{5}{|l|}{ Mandragorus (mandrake) -- 91} \\
\hline Ephedra (herb) -- 61 & 3 & 1 & 2 & 8 \\
\hline Polypodium (fern) -- 49 & 3 & 1 & 2 & 2 \\
\hline Papaver (opium poppy) -- 42 & 1 & 3 & 1 & 1 \\
\hline
\end{tabular}




\begin{tabular}{|c|c|c|c|c|}
\hline Lawsonia (henna) -- 26 & 1 & & 1 & 2 \\
\hline \multicolumn{5}{|l|}{ Cultivar (crop): } \\
\hline Cerealis (wheat and Barley) & $8 *$ & 3 & 3 & $16 *$ \\
\hline \multicolumn{5}{|l|}{ Olea (olive) } \\
\hline Linum (flax) & 3 & 10 & 1 & 5 \\
\hline \multicolumn{5}{|l|}{ Arboreal (tree): } \\
\hline \multicolumn{5}{|l|}{ Juglans (walnut) } \\
\hline \multicolumn{5}{|l|}{ Pistacia (terebinth) } \\
\hline Pinus (pine) & & 1 & & \\
\hline Quercus (oak) & & 3 & & \\
\hline \multicolumn{5}{|l|}{ Lacustrine/hydrophil (aquatic): } \\
\hline Papyrus & 3 & $8 *$ & 3 & 4 \\
\hline Salix (willow) & & 4 & & 2 \\
\hline Scirpus (reed) & $16 *$ & $8 *$ & 8 & 8 \\
\hline Typha (cattail) & & & & 2 \\
\hline \multicolumn{5}{|l|}{ Other species/types: } \\
\hline Chenoam (chenopodium, goose foot) & & & & $6 *$ \\
\hline Dipsacus (fullers brush) & 1 & 5 & $23 *$ & 2 \\
\hline Echinops (globe thistle) & 2 & 10 * & & \\
\hline Liguliflorae (low-spine) & 1 & & 1 & \\
\hline Tubuliflorae (hi-spine) & 3 & & 1 & \\
\hline Umbelliflorae (umbrella plant) & & & & 1 \\
\hline POLLEN COUNT: & 200 & 200 & 200 & 200 \\
\hline
\end{tabular}

\section{Conclusion}

The preliminary pollen analysis of diakonikon herbals presented in this chapter is an additional line of support for the thesis that the diakonikon of the Northeast Church at Hippos served as a monastic infirmary as part a larger veneration of a revered woman at the site. The practice at the site is consistent with developing Christian approaches to healing in the Greek east in the sixth and seventh centuries, especially in view of the ongoing trauma of 
the plague of Justinian. In the infirmary at Hippos, faith and pharmacology brought some relief and hope in the context of the revered memory of a now unknown woman. 
The Northeast Insulae Project 


\section{2.}

\section{A CHRONOLOGY OF THE NORTHEAST INSULAE}

$\boldsymbol{T}$ his chapter summarizes the archaeological evidence for a chronology of the northeast 1 insulae in two major phases. We propose that the first phase comes from the Roman Imperial period with Hellenistic antecedents, roughly from the $1^{\text {st }}$ century BCE through the fourth century CE. The great earthquake of $363^{459}$ that destroyed the basilica of Hippos and damaged heavily the northeast insulae was followed by rapid decline and a fifth century from which comes little identifiable evidence. ${ }^{460}$ Then, in the late fifth or early sixth century $\mathrm{CE}$ a second phase begins and continues in the Late Antique period with abandonment of the area by the early eighth century. That abandonment happened prior to the earthquake of $749 \mathrm{CE}$ that ended any substantive occupation of Hippos.

Our discussion of the Roman Imperial period will identify remains of some structures from that period and note the role of the Roman-era street grid in giving shape to the insulae within which was constructed at least one peristyle house. As most of the surviving evidence is from the Late Antique period and centers around the Northeast Church, we shall show that the street grid was intentionally interrupted in the Late Antique period for a memorial chapel and related buildings constructed within the original grid and using elements of previous structures. We shall suggest at least three phases in the life of the church as demonstrated by changes in architecture and decoration.

\section{Primary Evidence from the probes}

In representative locations throughout the excavation area, probes were dug to bedrock under the last surviving floor layer. These probes give evidence for what is preceded the Late Antique remains.

\footnotetext{
${ }^{459}$ Segal et al., Hippos-Sussita of the Decapolis: The First Twelve Seasons of Excavations (2000-2011) Vol 1, 180; Wechsler and Marco, "Historical Earthquakes in the North of Israel and Their Influence on Hippos-Sussita (Hebrew)."

${ }^{460}$ Safrai, The Missing Century.
} 


\section{Probes in the central zone}

Probes in an around the Northeast Church attest that the church was constructed in the late fifth or early sixth century CE, along with providing some glimpse of earlier remains.

Probe in the nave

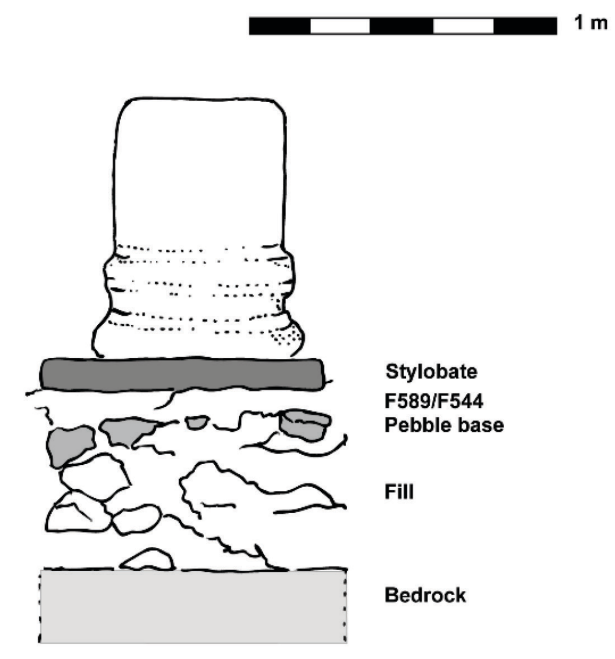

Figure 239 Cross section of probe in the nave

A probe $(1 \times 2 \mathrm{~m})$ was opened south of the north stylobate and next to the chancel screen base. Under the layer of cobbles was heavier fill, and within about $45 \mathrm{~cm}$ came limestone bedrock. The bedrock is about $52 \mathrm{~cm}$ below the top of the stylobate. There is no indication of a previously existing structure. The latest datable material from the pottery assemblage is a Khan bowl form $1 \mathrm{E}$ (not later than the early fifth century).

Probe in the portico of the church

We removed the cobble base for the floor of a northern segment of the portico next to the stylobate and excavated to bedrock, which at its lowest point was $76 \mathrm{~cm}$ below the surface. We found no evidence of a previously paved surface for this small cardo. However, we did find a line of stones running parallel with the stylobate and sitting on the bedrock with a possible perpendicular pattern as well. We presume these stones were so positioned to help stabilize the fill over the bedrock to provide a stable surface for the portico. Of the meager pottery materials recovered from this probe, nothing could be dated later than the third century CE. 


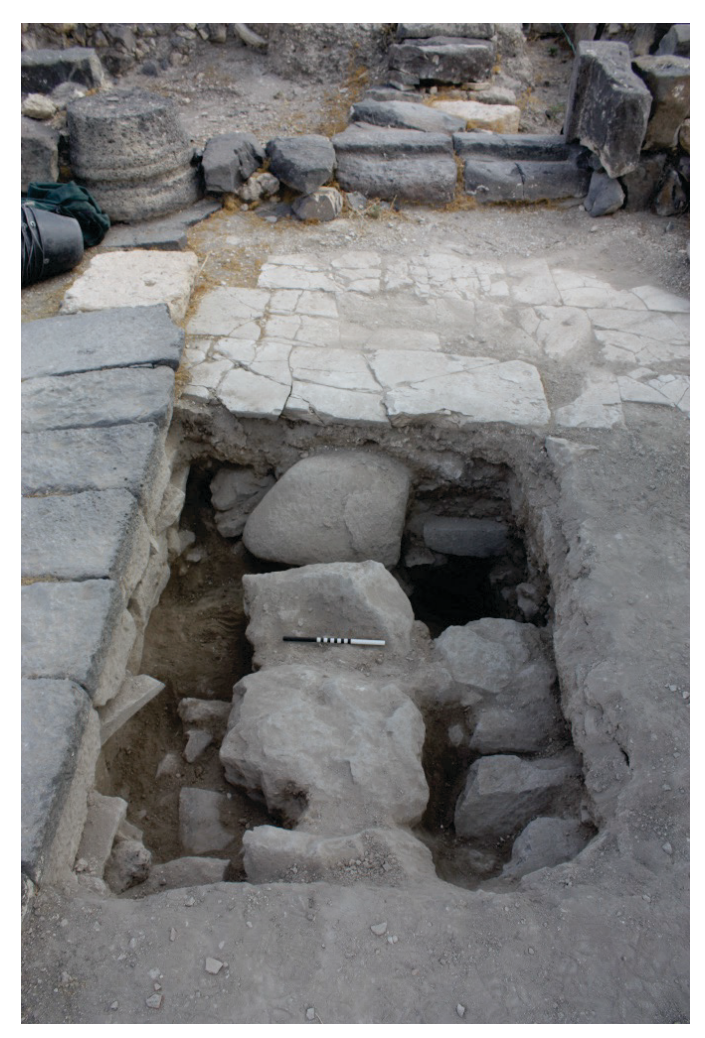

Figure 240 Probe of the Portico (looking north)

Probes in the North Building

In the western section of the North Building, we excavated to bedrock north of W2156, east of W2153 and west of wall 2154. Indicative wares as we approached bedrock included a Kfar Hananya cooking pot 4E1 from the early fourth to early fifth $\mathrm{CE}$, a neckless cooking pot parallel to Hamat Gader (plate III:21) dated late Roman-Byzantine, a cooking bowl parallel to Hamat Gader (plate I:15-18) from the mid fifth CE-Umayyad, a Kfar Hananya cooking bowl $1 \mathrm{E}$ from the third-early fifth CE, a cooking bowl parallel to Hamat Gader (plate I:1518) from mid fifth CE-Umayyad, a Byzantine casserole, a neckless cooking pot parallel to Hamat Gader (plate III:21) from late Roman-Byzantine, a high-neck cooking pot parallel to Hamat Gader (plate III:18) from 300-450 CE, and jars parallel to Sussita 2010 (plate IV:54) from third-fourth CE. The main dating of all material above bedrock was fourth and fifth centuries CE.

In the same western section, we excavated below the level of the foundation trench of W2156 south of the wall to bedrock $(40-90 \mathrm{~cm})$. Sitting on bedrock under the W2156 was the foundation course of an early wall (W2168), 4.3 m east of W2153. It runs under W2156, through the southwest quadrant, and under the north wall of the church building (W540).

Similarly, when exposing the floor level in the eastern portion of the North Building, only a few of the brick pavers remain next to the northeast doorway. In the rest of the room we exposed smooth bedrock, with the exception of a threshold (W2163) oriented east to west set in the bedrock $1 \mathrm{~m}$ east of W2154 and $4 \mathrm{~m}$ north of W540. Ceramics from the locus above 
the floor date primarily to the sixth and seventh centuries CE with indicative wares including Baysan jars parallel to Sussita 2008 (fig.11:212) dated Byzantine, a Baysan jar parallel to Sussita 2009 (fig. 13:240) from the seventh CE; and Kfar Hananya 1B from the early second to mid-fourth CE.

\section{Probe in the South Building}

In a small anteroom west of W559 and south of W1201, we reached bedrock and rough stones resting on bedrock within $20 \mathrm{~cm}$ of the surface. A $50 \mathrm{~cm}$ section of a corroded lead drainpipe rested on the bedrock.

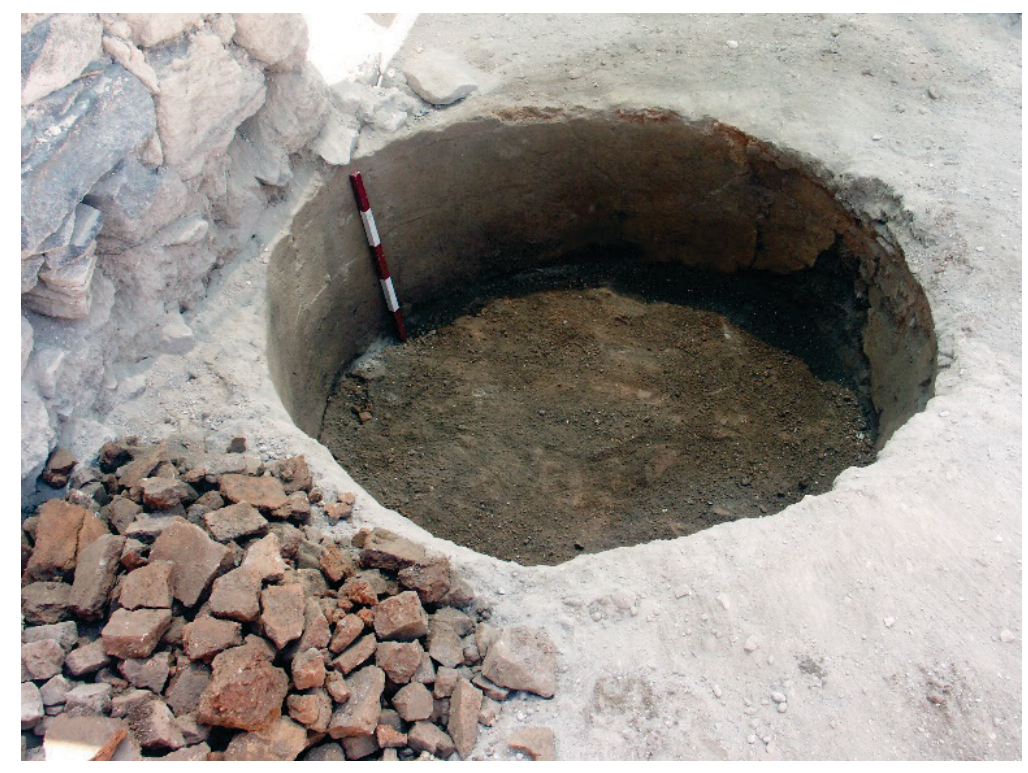

Figure 241 Oven

While digging a probe south of W1201 and east of W585, we discovered the remains of a large round oven. Its inside diameter is $1.45 \mathrm{~m}$ and it was preserved to a height of about 50 $\mathrm{cm}$. The fill within it was mostly soft ceramic chunks from the top of the oven, although two nail fragments, a pestle, and a button were retrieved from the fill. The oven is similar in dimension to those from the "oven room" east of the Hellenistic Compound. ${ }^{461}$ However, the latest shards were from the fifth century. The surviving top edge of the oven is about 40 $\mathrm{cm}$ below the level of the street to the west.

\section{Probes in the eastern zone}

Probe in the northerly sections of Cardo 3 North

We opened $4.4 \mathrm{~m}$ section of the cardo north of the apse of the church and dug to bedrock some $80 \mathrm{~cm}$ below and dropping off rapidly to the north. We did expose a plastered drainage

${ }^{461}$ Segal et al., Hippos-Sussita : Eighth Season of Excavations : July 2007, 20-22. 
channel covered with crude stones $45 \mathrm{~cm}$ from the west wall of the house and running parallel with it.

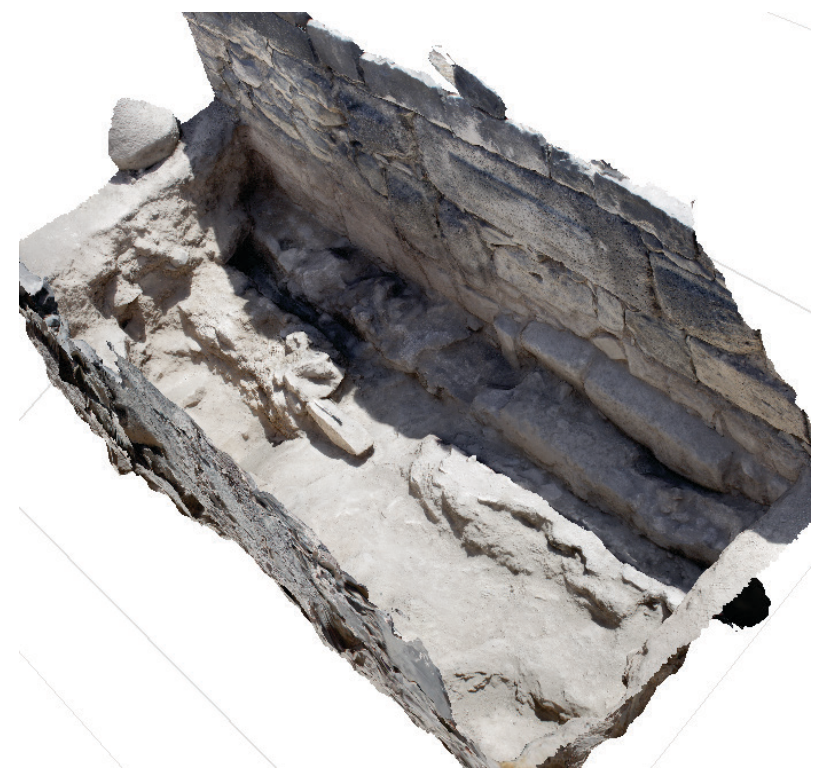

Figure 242 Photogrammetry of the drainage channel

Field readings of pottery identified Late Antique fragments in the drain including a fragment of a sixth century oil lamp. The fill at the level of bedrock was exclusively Roman including a fragment of an early Roman oil lamp. We surmise that the foundations set on bedrock date from Roman times with the drain having been added in the Late Antique period.

Probe in the eastern room of the peristyle house

We opened a $1 \times 2 \mathrm{~m}$ probe in the northeast corner of the room, but we shortly reached bedrock. There were almost no remains in the plaster floor. Elsewhere in the room, no plaster remained on top of the bedrock. The ceramic assemblages near the floor level were mostly from the sixth and seventh centuries. Nothing distinctly Umayyad was found.

Probe to bedrock east of the apse

A probe was opened in the small room directly east of the apse of the church. There was little pottery in the probe except from a fragment of a Hellenistic drinking bowl. We encountered bedrock from $15-49 \mathrm{~cm}$ below the surface, a depth comparable to the probes dug in the central zone. 

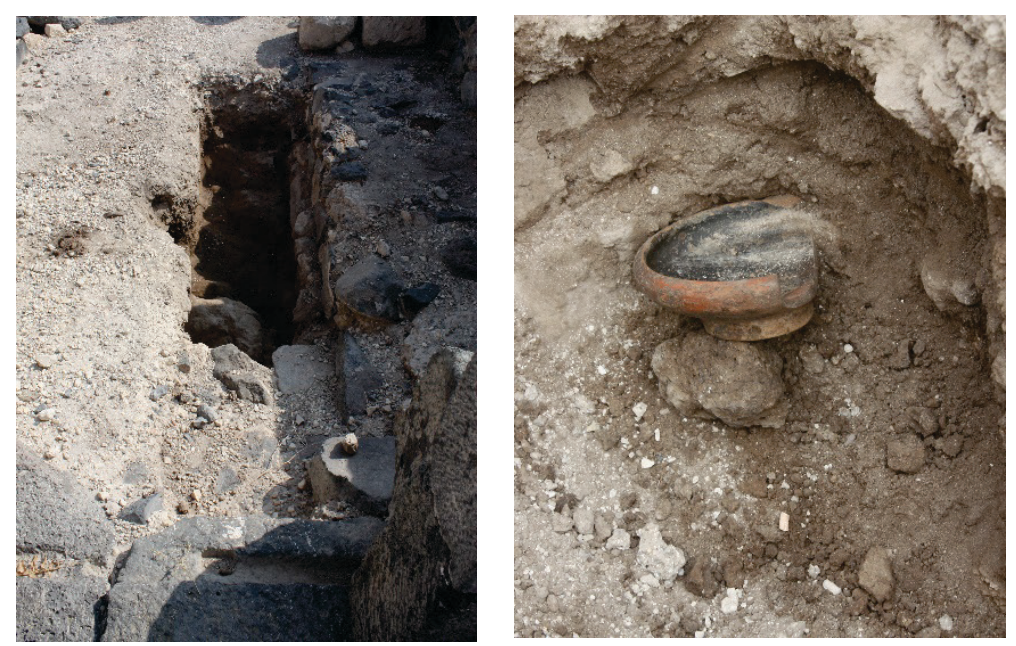

Figure 243 Probe (looking north) and bowl fragment

\section{Probes in the western zone}

Probe west of the portico of the church

A $1 \mathrm{~m}$ trench was opened perpendicular to and west of the stylobate. The top $35-50 \mathrm{~cm}$ of the trench were the mud/plaster layer identified as F1214.

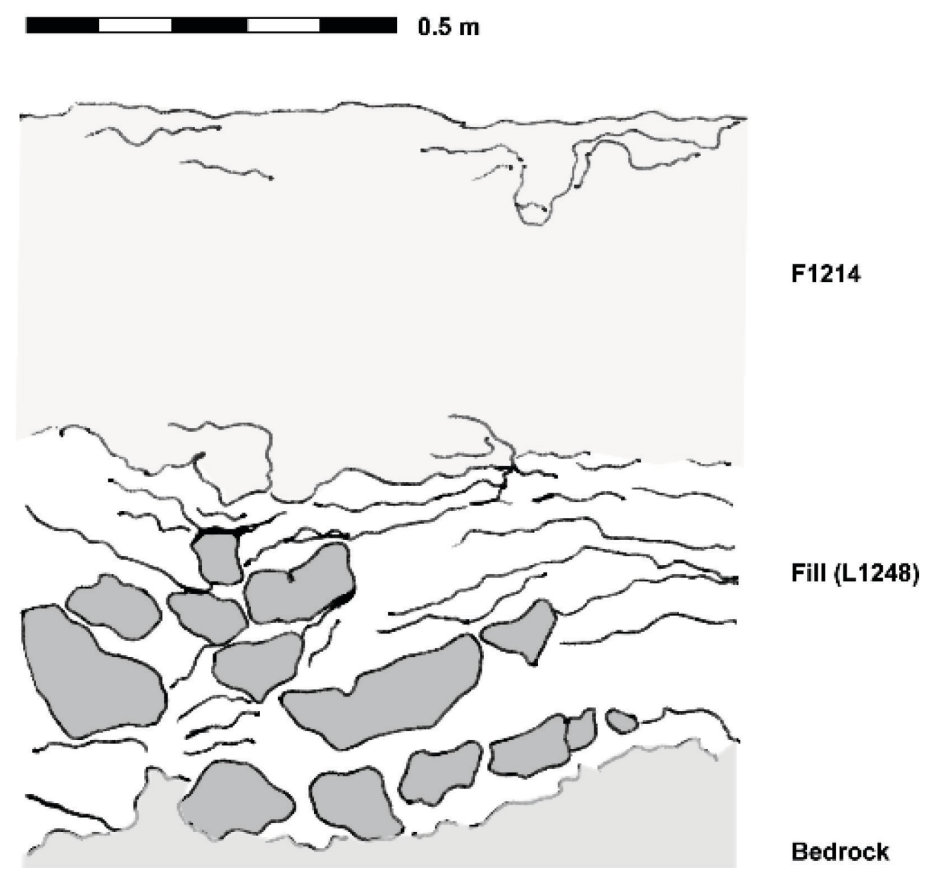

Figure 244 Cross section of probe

A level of cobbles appeared about $50 \mathrm{~cm}$ below the top of the floor. Below the cobbles, the soil was softer and contained heavy destruction fill. A coin from the reign of Constantius II 
(355-361 CE) was retrieved from the sifted fill. The decades immediately following the earthquake of $361 \mathrm{CE}$ were the last period of activity at Hippos before the "lost" fifth century. ${ }^{462}$

At about $1.1 \mathrm{~m}$ below the surface of F1214, bedrock was exposed through the length of the trench. A second trench to bedrock was dug north of W553 perpendicular with W1246.

The pottery collection from these probes is helpful in dating construction. Shards sealed in the plaster floor are late fifth to mid-sixth century material, including Phocaean Red Slip form 3C (ca. 460-490 CE) and Phocaean Red Slip form 3H (ca. mid-sixth century). From beneath the floor came common wares of the third to fourth century. From the base of the foundation trench came common wares of the fifth century and an African Red Slip Ware form 91 flanged bowl, probably variant B and dated to 450-530 CE. We conclude that the Delta Building was constructed in the fifth century to be replaced by the church complex (or at least F1214 and W553) in the late fifth or early sixth centuries.

\section{Probe between Building Alpha and Building Beta}

We dug a $1.5 \times 2.75 \mathrm{~m}$ probe in the east end of the gap between the Building Alpha and Building Beta to a level of cobbles, which were identified as the base for the stylobate previously seen as running to the north in Building Alpha. The stylobate is clearly visible in W2007 but has been robbed out to the north. There is no evidence of the stylobate in situ in south wall (W1945) of Beta Building, although at least two stones of similar shape were used in the wall as well as multiples in the south wall (W2108) of the northeast room. We conclude that Building Beta was built after removal of the stylobate for the purpose of getting building stones for constructing the building. We infer that Building Beta was constructed after Building Alpha. The ceramic assemblage was mostly seventh and eighth CE. We recovered cooking pots, lids, and casseroles, made from black or brown material, dating to Byzantine/Umayyad periods. Indicative wares included a lamp molded fragment with concentric dots decoration from the $7^{\text {th }}$-8th century (Hadad, type 35 in Beth Shean which was in use until 749), Baysan jars from 6th-7th CE, two fragments of different lamps (Hadad type 32, from the Umayyad period), Fine Byzantine Ware bowl (6th-late 7/8th CE), lid from the end of Byzantine/Umayyad (6th to mid-8th CE), and African Red Slip (7th CE).

Probe in the northeast corner of the northeast room of Building Beta

A probe was dug in the northeast corner of the room. The probe reached bedrock at a depth of approximately $1 \mathrm{~m}$ below the floor. There was little pottery in the probe beyond some non-indicative Byzantine body shards of jars and cooking vessels. The probe also revealed that the lower three courses of W1244 were of earlier and better construction (ashlars). The lowest course rests on bedrock and runs into the line of W1239 and possibly under the

${ }^{462}$ Safrai, The Missing Century. 
street. The north section of Building Beta was constructed on the ruins of a previous structure.

\section{Observations on the probes}

As the Late Antique remains of the northeast insulae center on the Northeast Church, these probes consistently show ceramic assemblages dating no later than the late fifth or early sixth centuries. In every case, bedrock was reached less than a meter under the floor. Remains under the church are meager and demonstrate that the church and its related North and South Buildings were constructed no earlier than the late fifth or early sixth centuries CE. Fortuitous as we probed bedrock were some indicators of previous structure and usage.

Probes in the eastern zone were of similar depth and contents. Although the probes did not reveal any new antecedent architectural features, they did confirm that the Late Antique remains were built on and reused foundational courses from the Roman Imperial period.

In the western zone, probes revealed the foundations of the Delta Building and gave addition glimpses of a Roman public building that was overbuilt by Building Alpha and Building Beta.

Emerging from the probes is a chronological assessment of the northeast insulae that identifies an occupational phase in the Roman Imperial period and a second phase in the Late Antique period with a century of dramatic decline and possible disuse in the fifth century CE.

\section{Roman era structures}

Shaping the northeast insulae is the street plan which comes from the Roman Imperial period. As with other poleis in the east, Antiochia Hippos was organized on an orthogonal plan. The topography of the site made the decumanus the major street. It was bisected by small cardines. The forum and east gate of the city are dated to the late first or early second century CE. The decumanus dates similarly with the western half being somewhat later. The cardines would likewise be later additions.

In the southwest part of the project area, we discovered the remains of two stylobates forming a corner, still visible in the floor of the surviving Umayyad structures. The western stylobate runs parallel to and about 4 meters from the east wall of the Roman basilica. $18 \mathrm{~m}$ north of the stylobate corner is the remains of an ashlar wall in three surviving courses upon which a later wall (W1244) was constructed. This ashlar wall sits on bedrock and may run under the Cardo 2 North to the east. If that wall is the remains of a northern wall of an earlier structure, it might be plausible to suggest that a building bounded by a stylobate sat 
north of the Decumanus and east of the entrance to the Roman basilica prior to the full development of the street grid. As the basalt surface of F2116 in the south room of Building Beta preceded its construction, this surface may have been part of an earlier temenos or courtyard of that earlier Roman building.

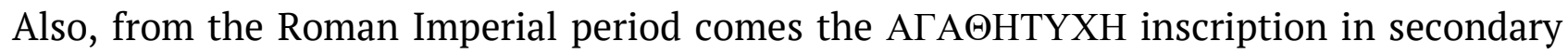
used in the paved plaza west of Cardo 2 North. It was originally part of an honorific inscription for Tarius Titianus, governor of Syria Palaestinae in the late second or early third century. ${ }^{463}$ Whether his monument stood in the northeast insulae or was part of the building referenced above is unknown.

In the eastern zone during the Roman Imperial period, a peristyle house stood at the north end of an insula between Cardo 3 North and Cardo 4 North. From the ruins of the house came a fragmentary fresco of the goddess Tyche. As discussed earlier, the fresco is very similar to the third Roman style of villa painting frozen at Pompeii and Herculaneum--the Architectural Style. This style was common throughout the Roman Empire. But the realistic aesthetics of the Roman Empire gave way to the stylization of the Late Antique by the fifth century. The fresco places the original peristyle house into the Roman Imperial period.

More significant in dating the house to the Roman Imperial period is the three-sided peristyle courtyard. "The peristyle house has a long tradition in the East going back at least to the fourth century B.C.E." ${ }^{464}$ Nevertheless, "the known distribution of the peristyle house in Palestine is quite limited." ${ }^{655}$ Yizhar Hirschfeld lists four sites from the late Roman and early Byzantine periods (Umm el-Jimal, Sepphoris, Aphek and Jerusalem). ${ }^{466}$ At least two others have been subsequently published (Sepphoris ${ }^{467}$ and 'Ein ez-Zeituna ${ }^{468}$ ). A threesided peristyle is particularly characteristic of the evolution of the peristyle house in Roman North Africa, ${ }^{469}$ although both the House of the Tragic Poet ${ }^{470}$ and the House of Sallust ${ }^{471}$ at Pompeii have three-sided peristyle courts. Simon Ellis has argued that the latest peristyle houses were constructed in the mid-sixth century. ${ }^{472}$ Although we cannot yet date the foundation of the house with certainty, modifications to the house by the construction of the church to the west and its possible connection to this structure suggest a foundation in the third or fourth century, which fits within Ellis' timeframe.

\footnotetext{
${ }^{463}$ Segal et al., Hippos-Sussita of the Decapolis: The First Twelve Seasons of Excavations (2000-2011) Vol 1, 251-253.

${ }^{464}$ Trümper, "Material and Social Environment of Graeco-Roman Houses in the East: The Case of Hellenistic Delos," 37.

${ }^{465}$ Hirschfeld, The Palestinian Dwelling in the Roman-Byzantine Period, 86.

${ }^{466}$ Ibid.

${ }^{467}$ Sion and Sa'id, "A Mansion House from the Late Byzantine-Umayyad Period in Beth Shean-Scythopolis.," 353-366.

${ }^{468}$ Milson, "Design Analysis of the Peristyle Building from 'Ein Ez-Zeituna," 71-75.

${ }^{469}$ Thébert, "Private Life and Domestic Architecture in Roman Africa," 357-364.

${ }^{470}$ In this case the peristyle court is against the outside wall of the house. Bergmann, "The Roman House as Memory Theater," 225-256.

${ }^{471}$ Zanker, Pompeii, 43.

${ }^{472}$ Simon P. Ellis, 'The End of the Roman House,' American Journal of Archaeology, 92 (1988), 565.
} 
There are minor indicators of a Roman-era timeframe for the original construction of the house. At the eastern entrance to the compound, an inscription in tabula ansata was discovered just inside the threshold facing those entering through the threshold. The Greek is EYTYX $\Omega \Sigma / T \Omega$ KTH $\Sigma T H$. A parallel for this inscription comes from the hall of a bath complex at Pelusium from the third century. ${ }^{473} \mathrm{~A}$ second inscription from inside the entrance

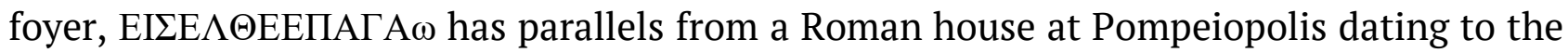
third century ${ }^{474}$ and a Late Antique mosaic inscription at Krokodeilon Polis near Caesarea. ${ }^{475}$ The survival of some opus quadratum at the west end of W1266 adds to the minor indicators.

Indirect evidence may also be cited for a foundation of the original House of Tyche in the Roman Imperial period. While the Late Antique structure reused walls and the peristyle courtyard of the original house in the northern part of the house, the reconstruction over the southern portion of the house deviated from the original footprint in the southeast corner, with southern wall segments W1288 and W1917 built $3 \mathrm{~m}$ to the north of the south wall of the house where a threshold of a southern door survives in situ.

The House of Tyche was likely founded in the second or third century CE along with much other Roman construction at Antiochia Hippos.

In the central zone of the site and west of the portico of the church, there are indicators of antecedent usage. In the building south of the church, the taboun below floor level and the courtyard south of W1231 point to occupation prior to the Late Antique construction of the church. In the building north of the church, the single surviving course of W2168 and the threshold set in bedrock east of W2154 point to earlier structures. West of the church and south of W569, there are remnants of earlier small structures (W1272, W1274, W1278, W1280, W1281). And in the northwest corner of the site W1246 and W2179 of Building Delta are overbuilt by W553. All of these are antecedent, but none are distinctly Roman.

It is in the Northeast Church that we may find indicators of previous Roman construction. First of all, the church is bounded on the east and the west by earlier cardines of the city, with the apse of the church blocking Cardo 3 North. Moreover, the church is of comparable size $\left(371 \mathrm{~m}^{2}\right)$ to the house of Tyche $\left(350 \mathrm{~m}^{2}\right)$. Secondly, the cistern in the south aisle of the church is surrounded by rectangular pavers like to the pavers of the peristyle courtyard of the House of Tyche with its cistern. The odd configuration of the entrances to the church (two from the west and one from the north rather than three from the west) argues that the cistern was present before the church was built. It may have been part of a peristyle courtyard of a similar house the footprint of which was later occupied by the Northeast Church. Thirdly, the blocked door hidden behind the wall plaster in W512 of the diakonikon points

\footnotetext{
473 Supplementum Epigraphicum Graecum, 37.1639.

${ }^{474}$ Ibid., 40:1177.

${ }^{475}$ Ibid., 56:1891.
} 
to the reuse of a previous wall in the construction of the church-a wall that may have been part of the footprint of the posited house.

A transition from the Roman Imperial period was inaugurated by the earthquake of 363 . As we noted earlier, an earthquake in $363 \mathrm{CE}$ devastated the Roman province of Palaistina. ${ }^{476}$ Coins at floor level under the destruction fill of the Roman basilica at Hippos date its destruction to this event. ${ }^{477}$ Such destruction would also have occurred in the northeast insulae. The earthquake was followed by rapid decline and a fifth century from which comes little identifiable evidence. ${ }^{478}$

\section{The Late Antique Period}

In the late fifth or more likely early sixth century, a religious compound was constructed in the ruins of this former domestic area. The compound consisted of a support facility built into the ruins of the House of Tyche, a building to the north, a building to the south, and Building Gamma spanning the south gate to the compound from the via sacra. But central was a small mono-apsidal church with a bar-shaped chancel. It was a memorial chapel. At the east end of the south aisle was a prominent burial exposed above the floor and marked with crosses. It held the fragmentary remains of a revered woman of significant age. Just north of the central axis of the chancel was a masonry tomb in two layers holding the remains of 12 individuals. The apse of the domus protruded into the line of the easterly street. The western portico for the church used the line of the western cardo. Ceramic from all five structures point to their contemporaneous usage. But the church is the primary source for the chronology of the Late Antique period in the northeast insulae.

There are three major phases to the Late Antique period that can be surmised from the remains of the church. In both the chancel and the nave, a second floor was laid over the top of the first floor. In the chancel, the original floor (F517) was mosaic, a fragment of which survives south of the tomb of a revered woman. This floor was laid around the tomb of the woman and the masonry tomb in the center of the chancel. Subsequently, a crude opus sectile floor (F516) was installed over a base of $12 \mathrm{~cm}$ of plaster. This second floor accommodated the insertion of reliquaries in the floor in the center of the chancel and it the chancel at the head of the north aisle. This second floor was also necessary in view of additional burials in the masonry tomb and the installation of a lead pipe with which to venerate the dead with oil/wine.

The nave of the church has a fragmentary mosaic floor (F544). The original floor was overlaid by 3-4 cm of plaster and a second mosaic floor (F589). The second floor seems to have

\footnotetext{
${ }^{476}$ Segal et al., Hippos-Sussita of the Decapolis: The First Twelve Seasons of Excavations (2000-2011) Vol 1, 180; Wechsler and Marco, "Historical Earthquakes in the North of Israel and Their Influence on Hippos-Sussita (Hebrew)."

${ }^{477}$ Segal et al., Hippos-Sussita : Tenth Season of Excavations : July and September 2009, 31.

${ }^{478}$ Safrai, The Missing Century.
} 
been entirely geometric in design (Avi-Yonah patterns F4 and F9 ${ }^{479}$ ). A square-in-square pattern is like the one observed in intercolumnar panel 2 at Kursi. ${ }^{480}$ The late sixth-century date of the mosaics at Kursi suggests a similar date for the geometric floor (F589) of the Northeast Church. As Karen Britt has discussed, geometric compositions and uniform carpet patterns are part of a "stylistic shift in the pavements .... The compositional arrangement of fifth century mosaics displays a degree of spontaneity and liveliness that gave way to predictability and repetitiveness during the sixth century." ${ }^{481}$ The geometric patterns of the later floor (F589) covered over the complexity and beauty of first floor (F544). Surviving from the first floor (F544) are a series of borders surrounding two rows of six overlapping medallions.

Also, of some significance for dating are crosses in the floor (F538) at the head of the north aisle and large crosses on the floor at the entrance from the skeuophylakion into the chancel. Crosses in mosaic floors are important due to the prohibition against their use after $427 \mathrm{CE}$ by the Theodosian code. ${ }^{482}$ However, as noted earlier, crosses continue to appear on mosaic floors into the sixth century. ${ }^{483}$

Two phases are also suggested by the architecture of the church. The architecture of Late Antique basilical churches is as a rule symmetrical. The Northeast Church is not. Each aisle is separated from the nave by a row of columns, but the intercolumniation is irregular: six columns in a systyle pattern to the north and four columns in an areostyle pattern on the south side. Further, the bench against the north wall sits on top of the mosaic floor and is made of identical corbels, some of which are also used in the north wall of the church. These features of the second phase of the church suggest a major repair was necessary, perhaps after an earthquake such as that of $551 \mathrm{CE}^{484}$ or other substantial of damage to the church.

In addition to the floors and the architecture, radiocarbon dating of the outer layer of plaster from the wall of the apse indicates the Northeast Church complex was still in use into the late seventh or early eighth centuries. ${ }^{485}$

The material remains of the Northeast Church point to a foundation in the late fifth or more likely early sixth century CE. Toward the end of the sixth century, a second phase was inaugurated when a mosaic floor with only geometric decoration was laid in the nave. This

\footnotetext{
${ }^{479}$ Avi-Yonah, "Mosaic Pavements in Palestine," 139.

${ }^{480}$ Tzafaris, Kessin, and Urman, "The Excavations of Kursi-Gergesa," Plate 8.5.

${ }^{481}$ Britt, "Mosaics in the Byzantine Churches of Palestine," 251.

${ }^{482}$ Nimini locere signum salvatoris Christi vel in silice vel in marmore aut sculpere aut pingere. Codex Theodosianus, 1.8.0.

${ }^{483}$ The prohibition was reaffirmed in the Code of Justinian and was even included in the canons of the Council of Trullo in 692 CE. Mansi et al., Sacrorum conciliorum nova et amplissima collectio vol. 11, col. 975, no. 73.

${ }^{484}$ Russell, "The Earthquake Chronology of Palestine and Northwest Arabia from the 2nd through the Mid-8th Century AD," 44-46.

${ }^{485}$ Segal et al., Hippos-Sussita : Seventh Season of Excavations : July 2006, 84.
} 
second phase continued at least until the late seventh century. Most plausibly, at the beginning of this second phase or perhaps sometime during it major damage was done to the church necessitating reconstruction of the north part of the church with systyle intercolumniation using six columns. We also suggest that the insertion of the sarcophagus into the masonry tomb and the opus sectile floor of the chancel are from this same period.

Two phases are also present in the portico of the church. The first floor is geometric. On stylistic grounds it may be aligned with the second geometric floor in the chancel and may be dated to the late sixth century. The second floor is flagstone and reuses the top of a reliquary. We suggest it was installed later in the second phase when the monastic community and its practices were in serious decline. Notably, this flagstone floor reused the cover of a reliquary for one of its pavers. This decline is also witnessed by the narrowing of the doorways from the skeuophylakion to the chancel, from the skeuophylakion to alley north of the apse, and from the same alley into the support compound to the east (built into the ruins of the house of Tyche).

There is a third phase in the chronology of the Northeast Church. The complex and the domus seem to have been intentionally abandoned prior to the destructive earthquake of 749. We suspected such abandonment because throughout the project area only rarely did we find concentrations of ceramic shards at the floor level. But there is also direct evidence for abandonment. Reliquaries were removed from the chancel. A protective wall was constructed around the tomb of the elderly woman. And almost all the doorways to the various parts of a compound were intentionally sealed. One door remained open to the church providing access to the south aisle. Such would allow continued veneration of tomb of the elderly woman. The doorway to the north lateral chambers was also left open and the two westerly chambers may have functioned as primitive domestic space, as was indicated by the presence of cooking pots and grinding tools. Even the via sacra to the church compound was blocked some $18 \mathrm{~m}$ to the south of the gate to the compound. The third phase aligned with the decline and shrinkage of Hippos Palaistinēs.

\section{The Umayyad Period and later}

In 637/8 CE, Jerusalem surrendered to Caliph Umar. Tiberias was conquered earlier in 634 and by 636 CE, Tabariya served as the regional capital. The Umayyad Caliphate (661-750 $\mathrm{CE})$ controlled Palestine subsequently. We have noted above some material remains pointing to increased Muslim/Arab influence and corresponding decline at the Hippos. In the northeast insulae, although Christian practice continued it also declined dramatically.

Toward the end of the Umayyad period in the decades preceding the earthquake of $749 \mathrm{CE}$, three structures show activity after the Northeast Church complex was abandoned. 
In the western zone, Building Beta was constructed after Building Alpha. Entrance to it was south of the intentional blockage in Cardo 2 North, so access to it was not hindered after the church complex was closed. But few shards were found at floor level and stone vessels in the interior courtyard were pushed against the east wall. Seemingly, Building Beta went out of use prior to the earthquake.

Building Alpha, standing on the decumanus, may have continued in use. While we discovered no crushed ceramics at floor level, the east niche in the northwest room contained two nearly complete pots dated to the late seventh or early eighth centuries. The proximity of the building to the center of the city makes continued usage until the earthquake plausible.

A third structure on the east side of Cardo 3 North, the north wall of which was laid over remains of the south wall of the House of Tyche, may also come from the Umayyad period. Although it was not excavated to floor level, pottery readings of the material from inside the later structure shows Umayyad shards. The latest pottery from the fill in the structure to the north and the last levels of Cardo 3 North is Late Antique. Consequently, we identify the building created by W1221 and W1236 as a Umayyad structure, perhaps a farmhouse. But it is equally possible that this structure is associated with other floating walls and intrusions around the northeast insulae and comes from a time after 749 CE.

Over the years excavating in the northeast insulae, we frequently encountered portions of poorly constructed walls "floating" over earlier ruins. Sometimes these walls used earlier walls as foundations. At other times a single course of stone survives. Survival is so fragmentary that few discernable patterns can be identified.

Also, certain finds in Late Antique levels seem to be intrusions from later times. For example, we discovered the bell of a cistern (Cistern F) in the small room east of the apse. But at the floor level, no neck survived and there was no means for water to flow into the cistern. The cistern is an intrusion from a later time and higher level.

Taken together, these ruins suggest that well after the $749 \mathrm{CE}$ earthquake and the final collapse of remaining structures from the Later Antique period, agricultural and minor domestic usage occurred on the site in the ruins, as still occurs today in places such as Umm Qais on Jordan or Bosra in Syria. We also note that a Turkish pipe was recovered at the base level of one of these floating walls above the northern chambers of the church.

\section{Confirmation from coins}

The major occupational phases of the northeast insulae are confirmed by coin findings. Fifty-five coins were recovered during the excavations of the northeast insulae. Of these, forty-five were identifiable. 
The earliest coin is from the reign of John Hyrcanus I. The latest coin is Umayyad from the mid-eighth century. The coins span the period typically identified with the occupation of the site from its founding after the Battle of Paneion (ca. 199 BCE) either by Antiochus III the Great (222-187 BCE) or by Antiochus IV Epiphanes (175-164 BCE). No coin dates from after the earthquake of $749 \mathrm{CE}$, when Hippos was abandoned.

A cluster of the coins are from the third and fourth centuries, a period of significant Roman activity and prosperity in the Galilee and surrounding areas. It is during this period that the northeast insulae contained one or more wealthy peristyle homes of which the House of Tyche is the primary example. The late Roman coins along with a worn $\operatorname{coin}^{486}$ sealed into a mud floor of the North Building confirm this period of occupation. This period was disrupted by a major earthquake in $363 \mathrm{CE}$ that destroyed the Roman basilica immediately to the west. As with other sites, economic activity continued for several decades. But the project area has no coins datable to the fifth century. As with other sites, Hippos experienced decline, if not collapse. ${ }^{487}$

Coin finds also support the proposed chronology of the Late Antique period. The Northeast Church and its related compound were constructed into the ruins of the Roman Imperial period in the late fifth or early sixth century and were intentionally abandoned prior to the earthquake of $749 \mathrm{CE}$. Several sixth and seventh century coins were recovered at or near floor level in the southern part of the compound that was the House of Tyche in the Roman Imperial period. The triclinium to the east of the peristyle court was rebuilt into two rooms separated by a window wall. The southern of those two spaces yielded a late sixth century coin from the reign of Maurice and an early eighth-century coin from the Umayyad period during the reign of Al-Walid I. ${ }^{488}$ Immediately to the south is a large, vaulted room with two windows walls separating off spaces to the west and east. We discovered in the east space a coin from 572/3 CE of Justin II. ${ }^{489}$ Fill from the same locus had three coins from the second half of the fourth century $\mathrm{CE},{ }^{490}$ attesting to the two major periods of occupation of the northeast insulae.

\footnotetext{
${ }^{486}$ Basket 3474.

${ }^{487}$ Safrai, The Missing Century, 129.

488 Baskets 2489 and 2499.

489 Basket 3195.

${ }^{490}$ Baskets 3444 and 3449.
} 


\section{Coin chart}

\begin{tabular}{|c|c|c|c|c|c|c|c|c|c|c|}
\hline Year & Cat. & Bas. & Loc. & $\begin{array}{l}\text { Wt. } \\
\text { (Gm.) }\end{array}$ & Diam. & Obverse & Reverse & $\begin{array}{l}\text { Date } \\
\text { (CE) }\end{array}$ & Mint & Biblio \\
\hline 2002 & none & & & & & & & & & \\
\hline 2003 & none & & & & & & & & & \\
\hline \multicolumn{11}{|l|}{2004} \\
\hline & 4 & 1902 & 501 & 9.5 & 25 & $\begin{array}{l}\text { AVT KAIC M AVP } \\
\text { ANTWN Bust r., } \\
\text { laur., wearing palu- } \\
\text { damentum And cui- } \\
\text { rass, shown from the } \\
\text { rear }\end{array}$ & \begin{tabular}{|l|} 
ANTIOC PRIP \\
IERACVL Tyche \\
wearing turreted \\
crown, and long chi- \\
ton, stg. l., holding \\
horse by Bridle, in 1. \\
cornucopia. In ex. \\
$\Theta K \Sigma$
\end{tabular} & $165 / 166$ & Hippos & $\begin{array}{l}\text { Spijkerman } \\
\text { 1978: } 172 \text {, No. } \\
8\end{array}$ \\
\hline & 16 & 1909 & 501 & 3.8 & 17 & & & $\begin{array}{l}\text { Undated, } \\
\text { mid } \\
\text { eighth } \\
\text { century }\end{array}$ & Tabariya & $\begin{array}{l}\text { Walker 1956: } \\
\text { 269, No. 898; } \\
\text { SNAT 1993: } 32 . \\
\text { Nos. 339-344 }\end{array}$ \\
\hline 2005 & none & & & & & & & & & \\
\hline \multicolumn{11}{|l|}{2006} \\
\hline & 11 & $2089 / 177$ & 563 & 6.5 & 20 & $\begin{array}{l}\text { Head of Tyche } \mathrm{r} \text {. } \\
\text { Wearing turreted } \\
\text { crown }\end{array}$ & $\begin{array}{l}\text { War-galley l., stem } \\
\text { terminating for- } \\
\text { wards in volute, aph- } \\
\text { laston at stern, } \\
\text { above: IEPAS [---] }\end{array}$ & $\begin{array}{l}\text { 1st cen- } \\
\text { tury CE }\end{array}$ & Tyre & $\begin{array}{l}\text { Cf. BMC } \\
\text { Phoen: p. 256, } \\
\text { Nos.260-65 }\end{array}$ \\
\hline & 12 & $2089 / 176$ & 563 & 5.2 & 21 & Same & Same & Same & Same & \\
\hline & 30 & {$[2107] / 202$} & Surf. & 2.5 & 19 & Bust to r. & $\begin{array}{l}\text { FEL TEMP REPARA- } \\
\text { TIO Falling horse- } \\
\text { man } 1 .\end{array}$ & $355-361$ & & $\begin{array}{l}\text { Cf. LRBC II: p. } \\
97, \text { No. } 2498\end{array}$ \\
\hline & 50 & $2094 / 181$ & Surf. & 11.85 & 32 & $\begin{array}{l}\text { DNIVSTINI ANVSP- } \\
\text { PAVG Bust to r., } \\
\text { cuir. in palud. }\end{array}$ & $\begin{array}{l}\text { Large M Above cross. } \\
\text { To l. and r., * Be- } \\
\text { neath B, in exergue: } \\
\text { THEUP+ }\end{array}$ & 533-537 & Antioch & $\begin{array}{l}\text { Cf. DOC I: p. } \\
\text { 138, No.210b }\end{array}$ \\
\hline & 51 & $2094 / 182$ & Surf. & 10.7 & 28 & $\begin{array}{l}\text { DNIVSTINVS [---] } \\
\text { Justin and Sophia } \\
\text { facing enthroned }\end{array}$ & $\begin{array}{l}\text { Large M Above cross. } \\
\text { To l., A/N/N/O To r., } \\
\text { X, beneath A, in ex- } \\
\text { ergue: KYZ }\end{array}$ & $574 / 5$ & Cyzicus & $\begin{array}{l}\text { Cf. DOC I: p. } \\
\text { 236, No.123a }\end{array}$ \\
\hline & & $2053 / 153$ & & $\begin{array}{l}\text { not } \\
\text { identi- } \\
\text { fied }\end{array}$ & & & & & & \\
\hline & & $2076 / 169$ & & $\begin{array}{l}\text { not } \\
\text { identi- } \\
\text { fied }\end{array}$ & & & & & & \\
\hline & & & & & & & & & & \\
\hline
\end{tabular}




\begin{tabular}{|c|c|c|c|c|c|c|c|c|c|c|}
\hline 2007 & & & & & & & & & & \\
\hline & 13 & 2136 & 563 & 3.6 & 21 & $\begin{array}{l}\text { GALLIENVS AVG } \\
\text { Bust radiate r. } \\
\text { draped }\end{array}$ & $\begin{array}{l}\text { IOVIS STATOR Jupi- } \\
\text { ter stg. facing, hold- } \\
\text { ing scepter and } \\
\text { thunderbolt }\end{array}$ & 263 & Antioch & $\begin{array}{l}\text { RIC } 5 \text { (1): 188, } \\
\text { No. } 645\end{array}$ \\
\hline & & 2136 & & $\begin{array}{l}\text { not } \\
\text { identi- } \\
\text { fied }\end{array}$ & & & & & & \\
\hline & & 2122 & & $\begin{array}{l}\text { not } \\
\text { identi- } \\
\text { fied }\end{array}$ & & & & & & \\
\hline & & 4 coins & surface & not ides & tified & & & & & \\
\hline 2008 & & & & & & & & & & \\
\hline & 7 & 2192 & 563 & 6.75 & 21 & $\begin{array}{l}\text { IMP MAVR ANTO- } \\
\text { NINVS Bust r., un- } \\
\text { draped, laureate }\end{array}$ & $\begin{array}{l}\text { SEP TVRVS METRO } \\
\text { COLONI Temple (of } \\
\text { the Phoenician Koi- } \\
\text { non) seen in per- } \\
\text { spective; in ex., mu- } \\
\text { rex shell between } \\
\text { two palm-branches }\end{array}$ & $198-217$ & Tyre & $\begin{array}{l}\text { BMC Phoen.: } \\
\text { 271, No. } 376\end{array}$ \\
\hline & 22 & 5438 & 1248 & 1.8 & 16 & Bust to $r$. & \begin{tabular}{|l|} 
SPES REI PVBLICE \\
Virtus helmeted to \\
r., holding globe and \\
spear
\end{tabular} & $355-361$ & & $\begin{array}{l}\text { Cf. LBRC 2:0 } \\
100 \text {, Nos. 2638- } \\
39\end{array}$ \\
\hline 2009 & & & & & & & & & & \\
\hline & $1 *$ & $2260 / 363$ & 1277 & 2.4 & 14 & $\begin{array}{l}\text { Double cornucopias } \\
\text { with a pomegranate } \\
\text { set between horns }\end{array}$ & $\begin{array}{l}\text { Inscription sur- } \\
\text { rounded by a wreath }\end{array}$ & $\begin{array}{l}127-104 \\
\text { BCE }\end{array}$ & Jerusalem & $\begin{array}{l}\text { Meshorer 1997: } \\
\text { 176, No. } 2\end{array}$ \\
\hline & 31 & $2244 / 345$ & 1243 & 3.55 & 21 & $\begin{array}{l}\text { Bust r. laureate, } \\
\text { wearing palud. and } \\
\text { cuir. }\end{array}$ & $\begin{array}{l}\text { Bust of city-goddess } \\
\text { l., draped and tur- } \\
\text { reted; cornucopiae } \\
\text { at shoulder }\end{array}$ & $222-235$ & Bostra & $\begin{array}{l}\text { Spijkerman: 80, } \\
\text { No. } 50\end{array}$ \\
\hline & 93 & $2254 / 351$ & 1275 & 3.2 & 17 & $\begin{array}{l}\text { [---] VS AVG Bust to } \\
\text { r. diademed }\end{array}$ & \begin{tabular}{|l|} 
VIRTVS EXERCITI \\
Emperor stg.,in hand \\
spear, l. rests on \\
shield. Victory to l. \\
crowns him with \\
wreath and holds \\
palm in 1. hand, In \\
ex. ANTA
\end{tabular} & $395-408$ & Antioch & $\begin{array}{l}\text { LRBC (2): 101, } \\
\text { No. } 2791\end{array}$ \\
\hline & 94 & $2286 / 389$ & 1226 & 1.4 & 13 & Effaced & Standing figure to $l$. & $\begin{array}{l}\text { fourth } \\
\text { century }\end{array}$ & & \\
\hline & 95 & $2253 / 355$ & 1243 & 0.5 & 10 & & & 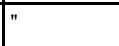 & & \\
\hline & 96 & $2262 / 360$ & 1243 & 1.65 & 12 & Worn & Worn & " & & \\
\hline & 97 & $2260 / 362$ & 1277 & 1.25 & 14 & Effaced & Effaced & |" & & \\
\hline & 103 & $2297 / 341$ & surface & 5.8 & $19 X 22$ & Bust facing & $\begin{array}{l}\text { Large K Above } \\
\text { cross. To l. A/N/N/O, } \\
\text { to r. II, beneath TES }\end{array}$ & $583 / 4$ & $\begin{array}{l}\text { Thessalo- } \\
\text { nica }\end{array}$ & DOC I: 320,72 \\
\hline
\end{tabular}




\begin{tabular}{|c|c|c|c|c|c|c|c|c|c|c|}
\hline & 106 & $2297 / 342$ & 1 & 2.05 & $17 \times 18$ & $\begin{array}{l}\text { Imperial figure stg. } \\
\text { facing }\end{array}$ & $\begin{array}{l}\mathrm{m} \text {, to r. illegible leg- } \\
\text { end downwards }\end{array}$ & $\begin{array}{l}\text { c. sev- } \\
\text { enth } \\
\text { cent. }\end{array}$ & & \\
\hline \multicolumn{11}{|l|}{2010} \\
\hline & 22 & 2346 & 1906 & 3.65 & 22 & $\begin{array}{l}\text { IMP C DIOCLE- } \\
\text { TIANVS AVG Bust } \\
\text { radiate, draped to r. }\end{array}$ & $\begin{array}{l}\text { CONCORDIA MILI- } \\
\text { TVM Caesar r. re- } \\
\text { ceiving Victory on } \\
\text { globe from Jupiter } 1 . \\
\text { Between B, in ex. } \\
\text { XXI }\end{array}$ & $293-295$ & Antioch & $\begin{array}{l}\text { RIC 5.1: 256, } \\
\text { No. 322. }\end{array}$ \\
\hline & $41 *$ & 2313 & 1219 & 12.9 & $28 \times 32$ & $\begin{array}{l}\text { CK 0 n HC Two im- } \\
\text { perial figures facing } \\
\text { seated on double } \\
\text { throne, both nim- } \\
\text { bate, holding in their } \\
\text { hands cruciform } \\
\text { scepter, cross be- } \\
\text { tween their heads }\end{array}$ & $\begin{array}{l}\text { Large M, above } \\
\text { cross, to l., A/N/N/O } \\
\text { to r., 1/II; beneath, } \\
\text { A; in ex. NIKO } \\
\end{array}$ & $\begin{array}{l}\text { Mid sev- } \\
\text { enth cen- } \\
\text { tury }\end{array}$ & \begin{tabular}{|l|} 
Scythopo- \\
lis/ \\
Baysan
\end{tabular} & $\begin{array}{l}\text { INJ 13: 141, No. } \\
\text { A1. }\end{array}$ \\
\hline \multicolumn{11}{|l|}{2011} \\
\hline & 7 & 2447 & 1930 & 4.35 & 17 & Bust r., laur. & $\begin{array}{l}\text { Eagle displayed, sup- } \\
\text { porting wreath, with } \\
\text { SPQR }\end{array}$ & $\begin{array}{l}\text { Undated } \\
(198- \\
217)\end{array}$ & Caesarea & $\begin{array}{l}\text { Kadman 1957: } \\
\text { 112, No. } 72\end{array}$ \\
\hline & 8 & 2386 & 1219 & 7.95 & 22 & Bust r., laur. & $\begin{array}{l}\text { Pegasos, stg., l., } \\
\text { head turned back, } \\
\text { wings open }\end{array}$ & $218 / 19$ & Hippum & $\begin{array}{l}\text { Spijkerman } \\
\text { 1978: } 178, \text { No. } \\
37-38\end{array}$ \\
\hline & 12 & 2442 & 1930 & 6.9 & 23 & Bust r. (effaced) & Effaced & $\begin{array}{l}\text { third } \\
\text { century }\end{array}$ & & \\
\hline & 35 & 2468 & $\begin{array}{l}1938 \\
\text { (floor) }\end{array}$ & 1.05 & 12 & Bust r. & $\begin{array}{l}\text { Within wreath: VOT/ } \\
\text { X/ MVLT/ XX mint } \\
\text { missing }\end{array}$ & 382 & & $\begin{array}{l}\text { LRBC (2): 101, } \\
\text { No. 2731. }\end{array}$ \\
\hline \multicolumn{11}{|l|}{2012} \\
\hline & 28 & 2497 & 1948 & 1.35 & 20 & Head & Worn & third? & & \\
\hline & 67 & $2489 / 2$ & 2101 & 8.5 & $28 \times 29$ & Bust r., diad. & $\begin{array}{l}\text { Large M, above } \\
\text { cross, to l. and r., } \\
\text { stars, beneath: } \Gamma \text {. in } \\
\text { ex. [CON] }\end{array}$ & \begin{tabular}{|l}
$527-538$ \\
\end{tabular} & $\begin{array}{l}\text { Constan- } \\
\text { tinople }\end{array}$ & $\begin{array}{l}\text { DOC I: 80, No. } \\
\text { 30e }\end{array}$ \\
\hline & 71 & $2489 / 1$ & 2101 & 6.9 & $26 \times 32$ & $\begin{array}{l}\text { DNTIbERm AVRCP- } \\
\text { PAVI Bust facing, in } \\
\text { cuirass and crown } \\
\text { with cross, holding } \\
\text { gl. cr. }\end{array}$ & $\begin{array}{l}\text { Large } \mathrm{M}, \text { above } \\
\text { cross, to } 1 . \mathrm{A} / \mathrm{N} / \mathrm{N} / \mathrm{O}, \\
\text { to r., II/II, beneath: } \\
\Delta . \text { in ex. CON }\end{array}$ & $585 / 6$ & $\begin{array}{l}\text { Constan- } \\
\text { tinople }\end{array}$ & $\begin{array}{l}\text { DOC I: 304, No. } \\
27 d\end{array}$ \\
\hline & 72 & 3129 & 1238 & 3.1 & $24 \times 25$ & $\begin{array}{l}\text { Three standing fig- } \\
\text { ures, each holding a } \\
\text { globus cruciger, } \\
\text { crosses on crown }\end{array}$ & $\begin{array}{l}\text { Large M, above de- } \\
\text { formed cross, to l. } \\
\text { THBEPIA } \triangle O \text {, to r., } \\
\text { طبرية, beneath: C. }\end{array}$ & $660-680$ & Tabariya & $\begin{array}{l}\text { Walker 1956: } \\
15-16 \text { Nos. } 43- \\
51\end{array}$ \\
\hline
\end{tabular}




\begin{tabular}{|c|c|c|c|c|c|c|c|c|c|c|}
\hline & 73 & 2499 & 2101 & 2.1 & 16 & 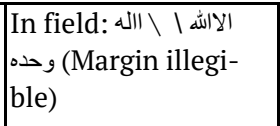 & $\begin{array}{l}\text { In field: محمد ارسول } 1 \text { الش Lion couchant to } \\
\text { l., (margin illegible) }\end{array}$ & 705-714 & Tabariya & $\begin{array}{l}\text { Walker 1956: } \\
\text { 269-270, No. } \\
\text { ANS 42 }\end{array}$ \\
\hline \multicolumn{11}{|l|}{2013} \\
\hline & 18 & 3174 & 545 & 4.99 & \begin{tabular}{|l|}
$20 \mathrm{x}$ \\
19.17 \\
\end{tabular} & $\begin{array}{l}\text { IMP CM AVR ANTO- } \\
\text { NINVS Bust r. laure- } \\
\text { ate and draped }\end{array}$ & \begin{tabular}{|l|} 
CP LC CAESAREA \\
Eagle supporting \\
wreath, with SPQR
\end{tabular} & $218-222$ & Caesarea & $\begin{array}{l}\text { Kadman 1957: } \\
\text { 114, No. 85 }\end{array}$ \\
\hline & 46 & 3145 & 2115 & 2.31 & $\begin{array}{l}17.02 \mathrm{x} \\
17.43 \\
\end{array}$ & $\begin{array}{l}\text { CONSTANTINVS } \\
\text { MAX AVG Bust r., } \\
\text { laureate, cuir. In } \\
\text { palud. }\end{array}$ & $\begin{array}{l}\text { GLORIA EXERCITVS } \\
\text { Two soldiers stg., } \\
\text { each holding spear } \\
\text { and leaning on } \\
\text { shield; between } \\
\text { them two standards, } \\
\text { in ex.: CONS }\end{array}$ & $330-335$ & $\begin{array}{l}\text { Constan- } \\
\text { tinople }\end{array}$ & $\begin{array}{l}\text { LRBC (1): 24, } \\
\text { No. } 1005\end{array}$ \\
\hline & $50 *$ & $3170 / 778$ & F1213 & 1.65 & $\begin{array}{l}14.80 \mathrm{x} \\
15.87 \\
\end{array}$ & $\begin{array}{l}\text { CONSTAN SPFAVG } \\
\text { Bust r., laureate, } \\
\text { (and rosettes) cuir. } \\
\text { in palud. }\end{array}$ & \begin{tabular}{|l|} 
VICTORIAE DD \\
AVGGQ NN Two \\
Victories vis-a-vis, \\
each holding wreath
\end{tabular} & $341-346$ & Rome & $\begin{array}{l}\text { LRBC (1): 16, } \\
\text { No. 637 }\end{array}$ \\
\hline & 53 & 3170/777 & 1206 & 1.61 & \begin{tabular}{|l|}
$15.31 \mathrm{x}$ \\
17.31
\end{tabular} & $\begin{array}{l}\text { DN THEODOSIVS PF } \\
\text { AVG Bust r., dia- } \\
\text { demed }\end{array}$ & \begin{tabular}{|l|} 
GLORIA ROMA- \\
NORVM Emperor \\
draped, with r. hand \\
dragging captive and \\
holding labarum in 1.
\end{tabular} & $367-375$ & $\begin{array}{l}\text { Thessalo- } \\
\text { nica }\end{array}$ & $\begin{array}{l}\text { LRBC (2): 79, } \\
\text { No. } 1728\end{array}$ \\
\hline & 61 & $3155 / 764$ & W1949 & 1.18 & \begin{tabular}{|l|}
$10.90 \mathrm{x}$ \\
11.54 \\
\end{tabular} & $\begin{array}{l}\text { DN THEODOSIVS PF } \\
\text { AVG Bust r., dia- } \\
\text { demed }\end{array}$ & $\begin{array}{l}\text { SALVS REIPVBLI- } \\
\text { CAE Victory drag- } \\
\text { ging captive to l., } \\
\text { trophy on shoulder, } \\
\text { in field l., Christo- } \\
\text { gram } \\
\end{array}$ & 393-395 & & $\begin{array}{l}\text { LRBC (2): 102, } \\
\text { No. } 2776\end{array}$ \\
\hline & 62 & $3167 / 775$ & 2124 & 0.88 & $\begin{array}{l}11.86 \mathrm{x} \\
12.89 \\
\end{array}$ & $\begin{array}{l}\text { DN THEODOSIVS PF } \\
\text { AVG Bust r., dia- } \\
\text { demed }\end{array}$ & $\begin{array}{l}\text { SALVS REIPVBLI- } \\
\text { CAE Victory drag- } \\
\text { ging captive to l., } \\
\text { trophy on shoulder, } \\
\text { in field l., Christo- } \\
\text { gram }\end{array}$ & 393-396 & & $\begin{array}{l}\text { LRBC (2): 102, } \\
\text { No. } 2777\end{array}$ \\
\hline & 63 & $3170 / 779$ & F597 & 1.22 & $\begin{array}{l}12.89 \mathrm{x} \\
14.34 \\
\end{array}$ & $\begin{array}{l}\text { DN THEODOSIVS PF } \\
\text { AVG Bust r., dia- } \\
\text { demed }\end{array}$ & $\begin{array}{l}\text { SALVS REIPVBLI- } \\
\text { CAE Victory drag- } \\
\text { ging captive to l., } \\
\text { trophy on shoulder, } \\
\text { in field l., Christo- } \\
\text { gram }\end{array}$ & 393-397 & & $\begin{array}{l}\text { LRBC (2): 102, } \\
\text { No. } 2778\end{array}$ \\
\hline & 66 & 3167 & 2124 & 0.91 & $\left|\begin{array}{l}12.38 \mathrm{x} \\
13.92\end{array}\right|$ & & & $\begin{array}{l}\text { End } \\
\text { fourth- } \\
\text { fifth cen- } \\
\text { tury }\end{array}$ & & \\
\hline 2014 & \multicolumn{4}{|c|}{ none (maintenance season) } & & & & & & \\
\hline & & & & & & & & & & \\
\hline 2015 & & & & & & & & & & \\
\hline
\end{tabular}




\begin{tabular}{|c|c|c|c|c|c|c|c|c|c|c|}
\hline & & 3195 & 2135 & 13.27 & 30 & $\begin{array}{l}\text { DN IVSTI NVS PP } \\
\text { AVG Justin and So- } \\
\text { phia facing, en- } \\
\text { throned }\end{array}$ & $\begin{array}{l}\text { Large M. Above } \\
\text { cross. To l.: ANNO. } \\
\text { To r.: y II. Beneath } \\
\text { A. In exergue: NIKO }\end{array}$ & $572 / 3$ & $\begin{array}{l}\text { Nikome- } \\
\text { dia }\end{array}$ & DOC I: $229,98 \mathrm{a}$ \\
\hline & & 3196 & 2136 & 0.97 & 15 & $\begin{array}{l}{[---]-\text { TIVS PF AVG }} \\
\text { Bust to r. diademed } \\
\text { and draped }\end{array}$ & $\begin{array}{l}\text { Virtus spearing } \\
\text { fallen horseman }\end{array}$ & $350-361$ & & \\
\hline & & 3406 & 2136 & 3.36 & 19 & Bust $\mathrm{r}$ & $\begin{array}{l}\text { Virtus spearing } \\
\text { fallen horseman. In } \\
\text { ex., [C]O[N-] }\end{array}$ & $341-361$ & $\begin{array}{l}\text { Constan- } \\
\text { tinople }\end{array}$ & \\
\hline & & 3422 & 2139 & 1.57 & 12 & PF AVG Head to r. ... & $\begin{array}{l}\text { Victory dragging } \\
\text { capture to r. }\end{array}$ & fourth CE & & \\
\hline & & & & & & & & & & \\
\hline \multicolumn{11}{|l|}{2016} \\
\hline & & $3444 / 821$ & 2135 & 1.3 & $\begin{array}{l}12-- \\
14\end{array}$ & [---] Bust r. & $\begin{array}{l}\text { FEL TEMP[---] Vir- } \\
\text { tus spearing fallen } \\
\text { horseman }\end{array}$ & $\begin{array}{l}350-361 \\
\text { CE }\end{array}$ & & \\
\hline & & $3444 / 824$ & 2135 & 1.19 & 13 & $\begin{array}{l}\text { DN THEODO-SIVS } \\
\text { PF AVG Bust r., pearl } \\
\text { diademed }\end{array}$ & $\begin{array}{l}\text { SALVS REI-PVBLI- } \\
\text { CAE Victory advanc- } \\
\text { ing l., dragging cap- } \\
\text { tive. In l. field, In } \\
\text { ex., ANT } \Delta\end{array}$ & $\begin{array}{l}\text { 383-392 } \\
\text { CE }\end{array}$ & Antioch & $\begin{array}{l}\text { RIC 9: Antioch } \\
\text { 67b/70a }\end{array}$ \\
\hline & & $3449 / 827$ & 2135 & 1.51 & 15 & $\begin{array}{l}\text { DN CONSTA-NS PF } \\
\text { AVG Bust r., pearl } \\
\text { diademed }\end{array}$ & $\begin{array}{l}\text { GLOR-IA EXERC- } \\
\text { ITVS Two soldiers } \\
\text { with one standard }\end{array}$ & $\begin{array}{l}346-348 \\
\text { CE }\end{array}$ & Kyzikos & $\begin{array}{l}\text { RIC 8: Cyzicus } \\
18\end{array}$ \\
\hline & & $3474 / 860$ & 2165 & 0.38 & 10 & Traces of bust & & $\begin{array}{l}\text { Late } \\
\text { fourth c. } \\
\text { CE }\end{array}$ & & \\
\hline & & $3474 / 861$ & 2165 & 0.96 & 14 & & & & & \\
\hline & & & & & & & & & & \\
\hline 2019 & none & & & & & & & & & \\
\hline
\end{tabular}

\section{Summary}

This brief overview of our work suggests three major phases: The Roman Imperial period to 363 when the area was the site of one or more residences. The Late Antique period when a memorial church and monastic compound were constructed in and reused the remains of that domestic quarter. The third phase aligned with the decline and shrinkage of Hippos Palaistinēs. The compound was closed and blocked, although some access remained to the revered tomb. Light agricultural and/or domestic usage occurred over the centuries following the earthquake. 


\section{3.}

\section{AFTERWORD}

The Northeast Insulae Project began with an invitation from Arthur Segal in 2001 to excavate a small Late Antique church northeast of the forum at Antiochia Hippos. During the first season, we discovered the tomb of a revered woman. The work expanded over fifteen seasons to expose structures around the church and the route to the church up a small cardo. We believe we have exposed an urban monastic compound centered the memorial church at which a healing cult and infirmary adjacent to the tomb of a revered woman served the larger community. That community continued to venerate the tomb even after the complex was closed in the decades before the earthquake of $749 \mathrm{CE}$.

But our work also revealed that this compound was constructed within and reused elements of a wealthy domestic area from the Roman Imperial period. We exposed a peristyle house which we called the House of Tyche for a fragmentary fresco of the face of the goddess recovered from its north terrace. The street grid that defines the area comes from this era. There are also hints of other Roman structures, including a public building with a colonnade next to the decumanus maximus.

The Northeast Insulae Project contributes to an understanding of Christianity in Late Antique Hippos Palaistinēs. As one of some seven church structures at the site, it attests to the diversity of practice and ritual characteristic of this largest center of Christianity on the Sea of Galilee in the Late Antique period. As excavation continues, a comprehensive telling of this story must emerge. 
The Northeast Insulae Project calls for further research into the characteristics and practices of urban monasticism in Palaestina outside of Jerusalem and the Negev. The identification, definition of, and practices within such communities merit further synthetic work. ${ }^{491}$ Even the composition of such communities may be open to discussion in view of the remains from the masonry tomb in the Northeast Church.

Lastly, healing cults, the rise of monastic infirmaries, and the use of herbals within them merit additional synthesis. ${ }^{492}$

As with any archaeological project, the work has only begun. And as to theories posited, "Ask me again in twenty minutes."

Mark Schuler

2021

\footnotetext{
${ }^{491}$ Karel J. H. Vriezen, "Churches in Urban Context in the Fifth-Eighth Centuries in Jordan and Palestine.," Studies in the History and Archaeology of Jordan 8 (2004): 469-476; Goldfus, "Urban Monasticism and Monasteries of Early Byzantine Palestine - Preliminary Observations"; Mordechai Aviam, "Christian Galilee in the Byzantine Period.," in Galilee through the Centuries, ed. Eric M. Meyers (Winona Lake, IN: Eisenbrauns, 1999), 281-300.

492 Cp., Crislip, From Monastery to Hospital; Ronald L. Numbers and Darrel W. Amundsen, eds., Caring and Curing: Health and Medicine in the Western Religious Traditions (New York: Macmillan, 1986).
} 


\section{TABLE OF FIGURES}

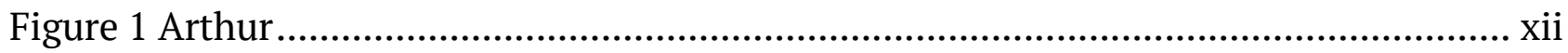

Figure 2 Arleta, Michael, and Nofar .......................................................................... xii

Figure 3 Churches of Hippos (Courtesy of the Hippos-Sussita Excavations. Used with permission.)

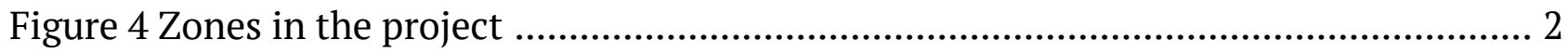

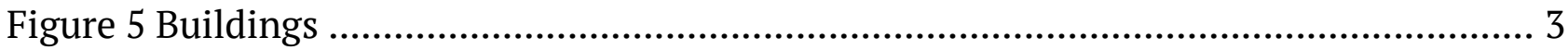

Figure 6 Ortho and DEM of NIP (Courtesy of the Hippos-Sussita Excavations. Used with permission.) .....

Figure 7 Orthographic of the insulae in 2016 (Courtesy of the Hippos-Sussita Excavations.

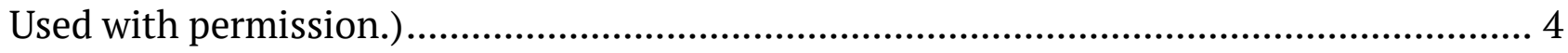

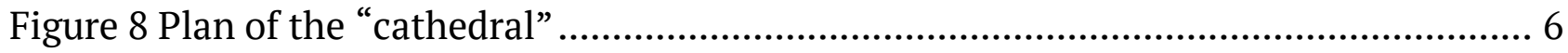

Figure 9 Northeast Church (Courtesy of the Hippos-Sussita Excavations. Used with permission.)

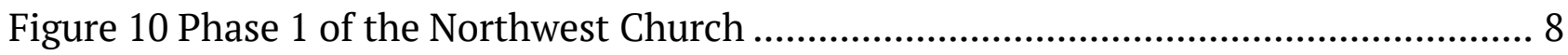

Figure 11 Phase 2 of the Northwest Church ....................................................................... 9

Figure 12 Southwest Church (Courtesy of the Hippos-Sussita Excavations. Used with permission.)

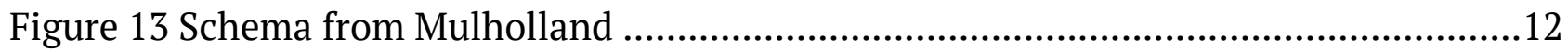

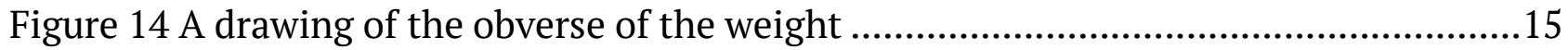

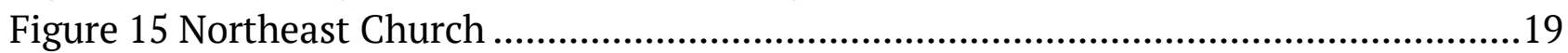

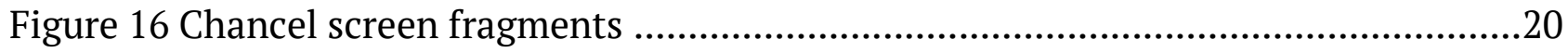

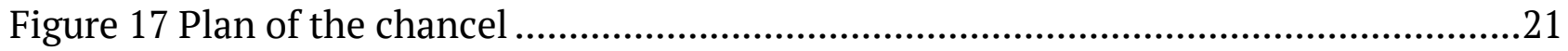

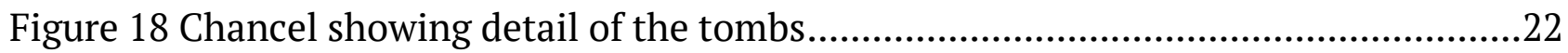

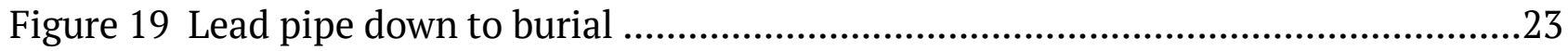

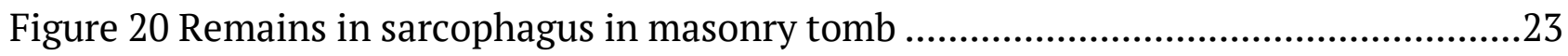

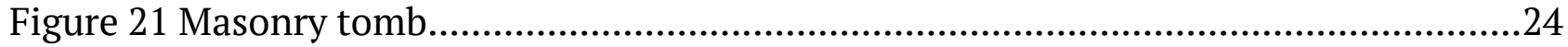

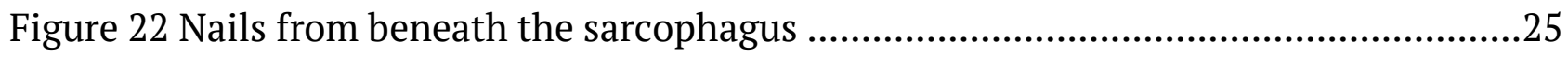

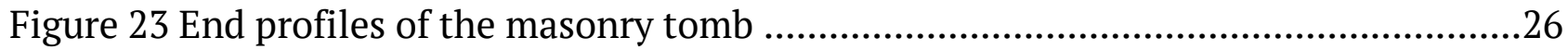

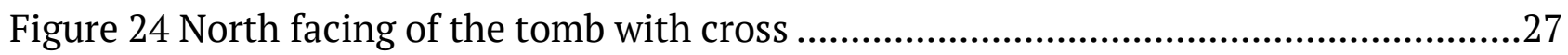

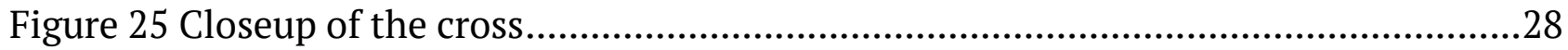

Figure 26 Basin and hole bored into the lid of the sarcophagus ....................................28

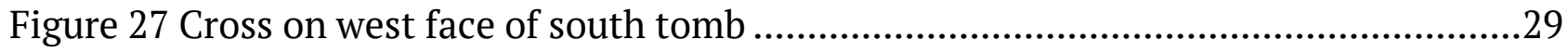

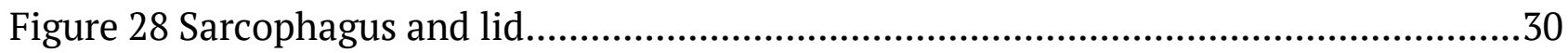

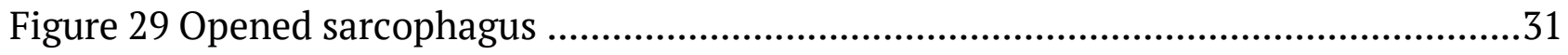

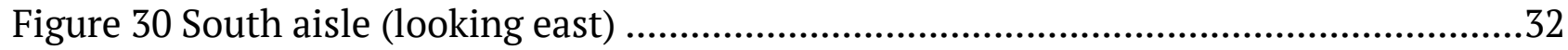

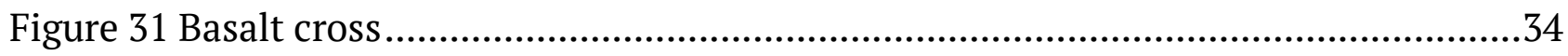

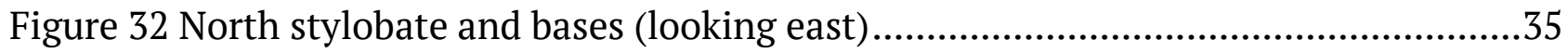

Figure 33 Aqueduct pipe segment over a cistern............................................................... 


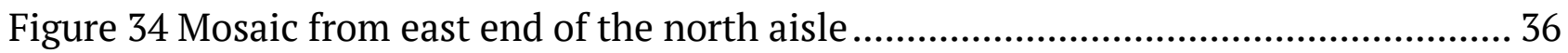

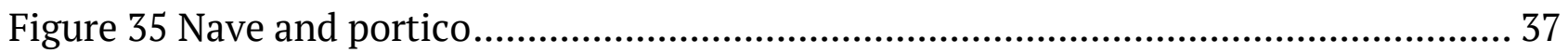

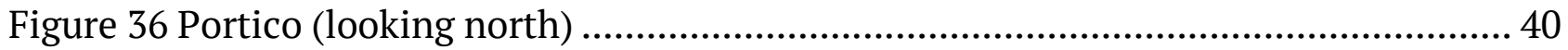

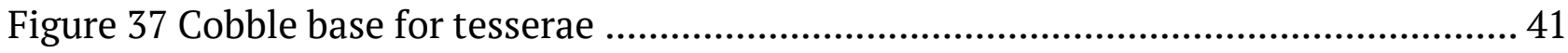

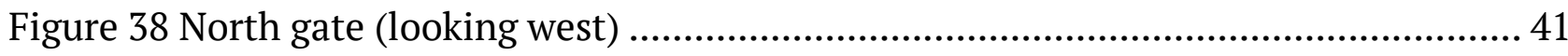

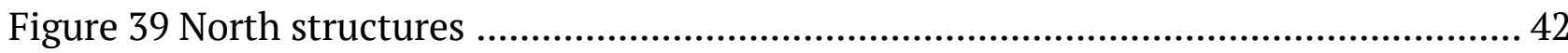

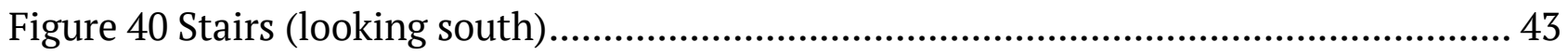

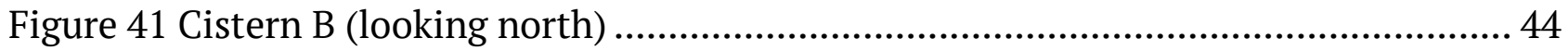

Figure 42 Skeuophylakion (looking east) ......................................................................... 45

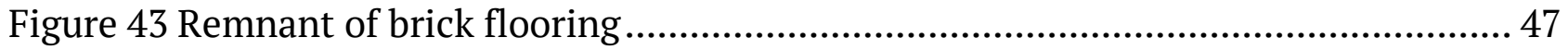

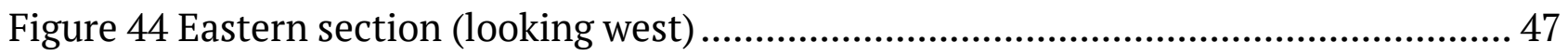

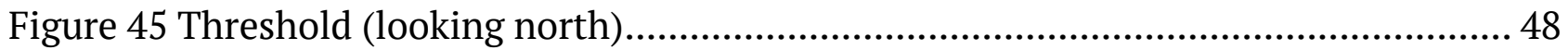

Figure 46 Buff ware storage jar (Late Antique/Umayyad) ............................................. 49

Figure 47 Southwest quadrant of the northern building.....................................................49

Figure 48 Blocked doorway from the Northern Building to the North Lateral Chamber

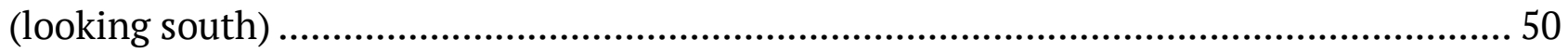

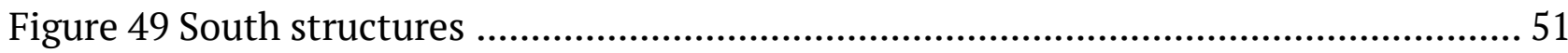

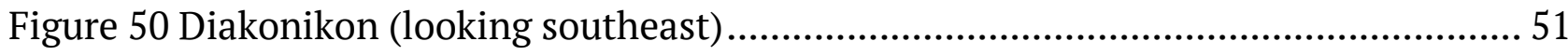

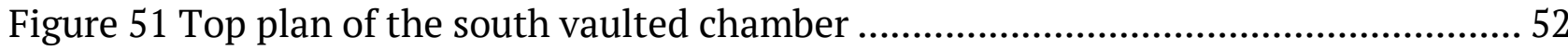

Figure 52 Cistern D (looking northeast) ….................................................................... 53

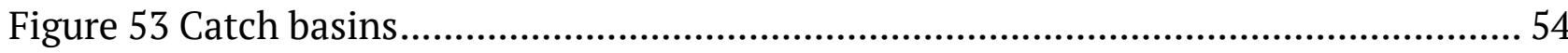

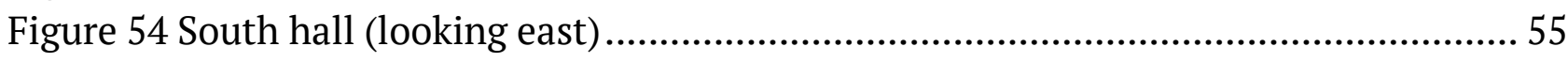

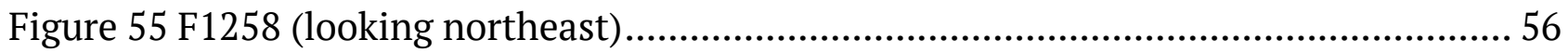

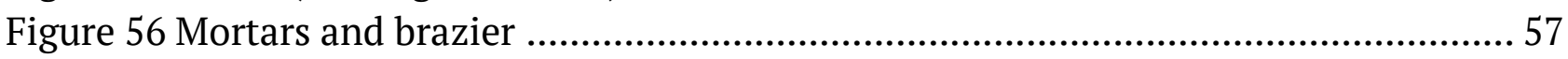

Figure 57 Tripodic mortar..................................................................................... 58

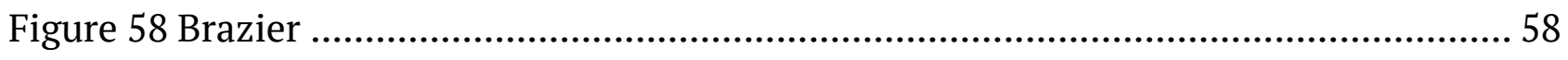

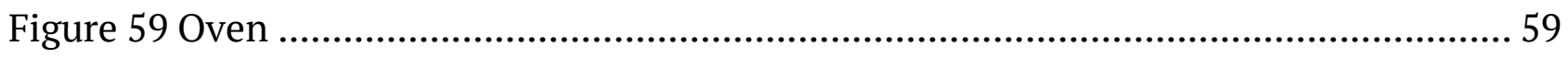

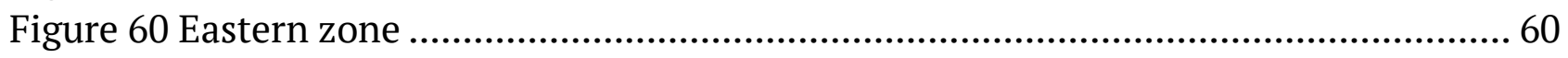

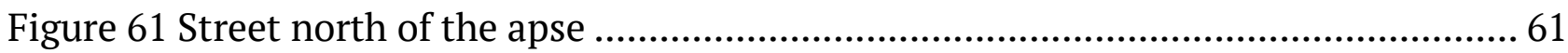

Figure 62 Doorframe incorporated into the wall of the apse (looking south) .....................61

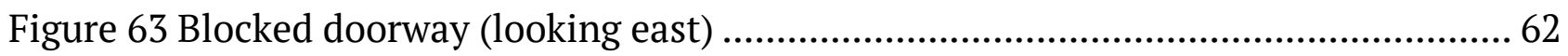

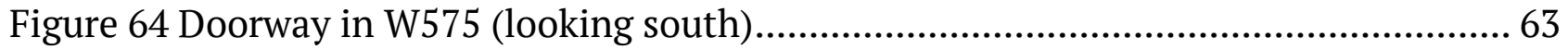

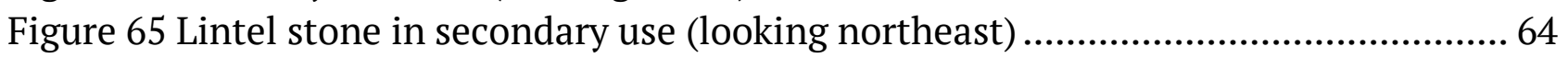

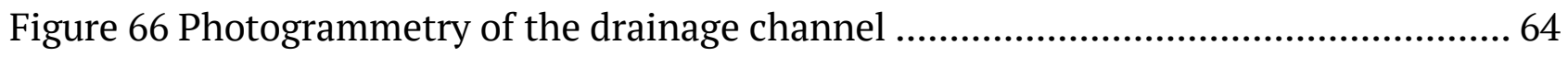

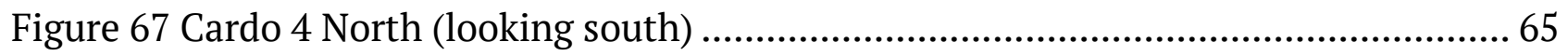

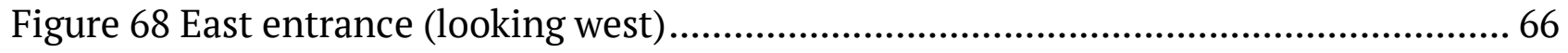

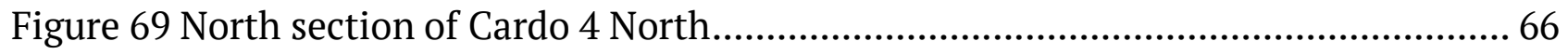

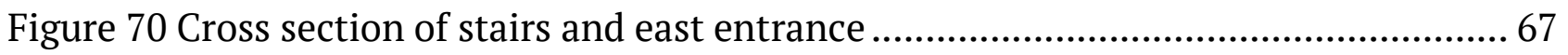

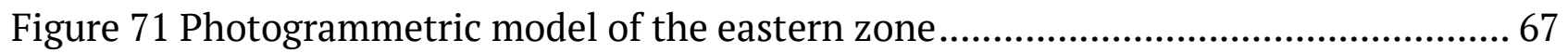

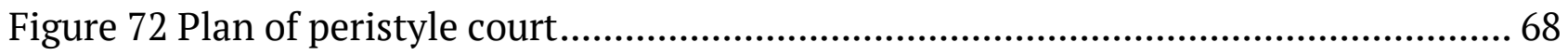




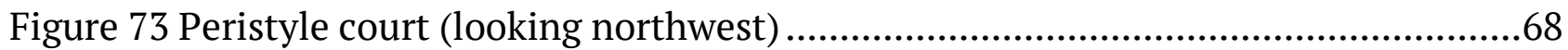

Figure 74 Pilaster and blocked doorway (looking south) ..................................................69

Figure 75 Entrances to the south portico (looking south) …............................................70

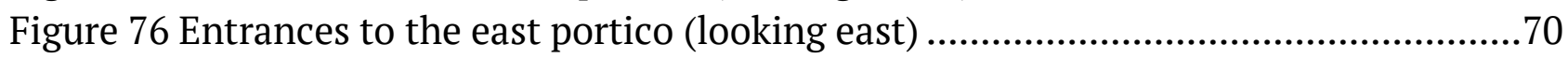

Figure 77 Shelf with lamps (looking east) ........................................................................71

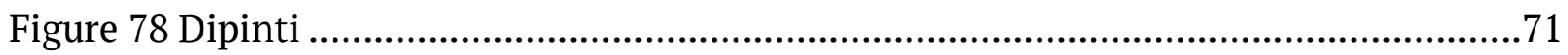

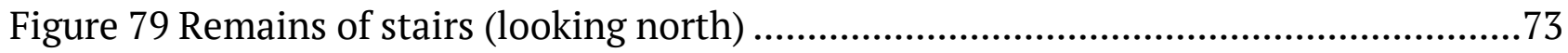

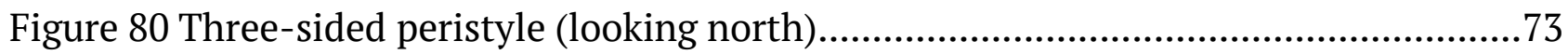

Figure 81 Stairs up to paved courtyard from the north (looking south) ............................74

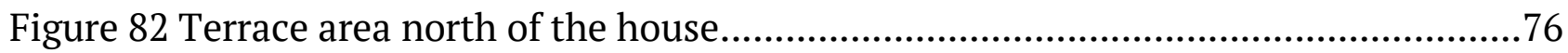

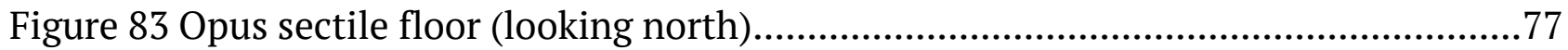

Figure 84 Portico with opus sectile floor (looking north) ..................................................78

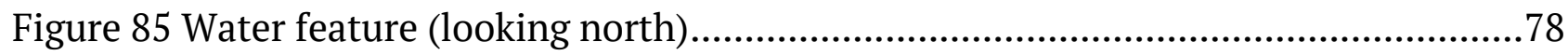

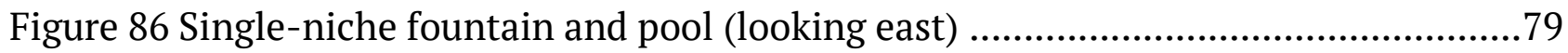

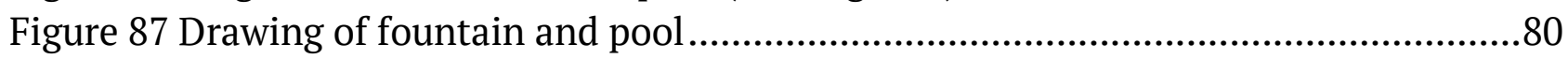

Figure 88 Upper portion of the secondary channel (looking southeast) ..............................81

Figure 89 Lower portion of the secondary channel (looking east) ......................................82

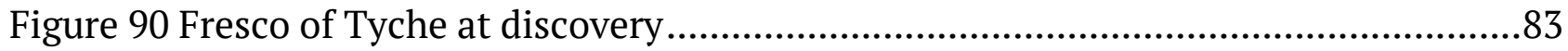

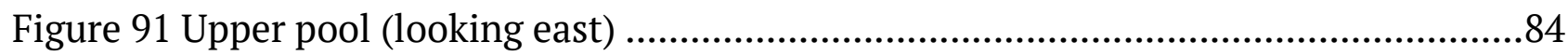

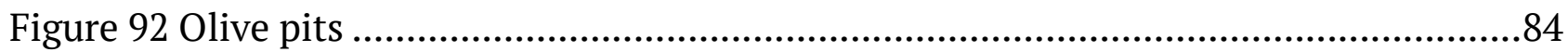

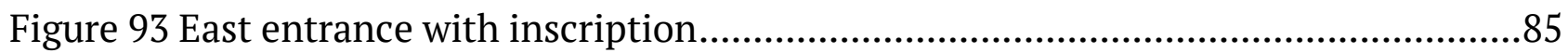

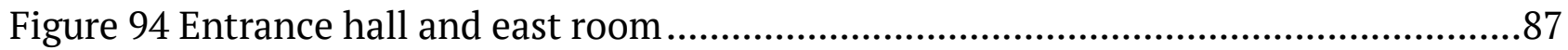

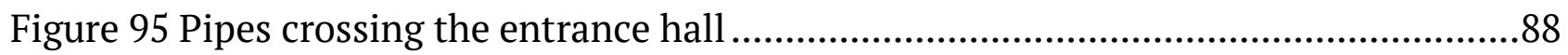

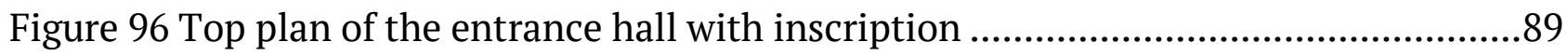

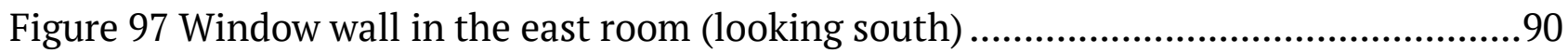

Figure 98 Bench and fixture in eastern room (looking west) ............................................91

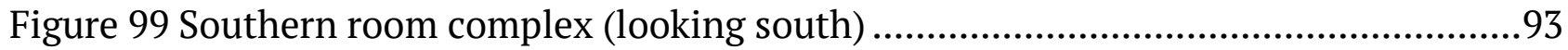

Figure 100 Extent of the southern room complex ............................................................93

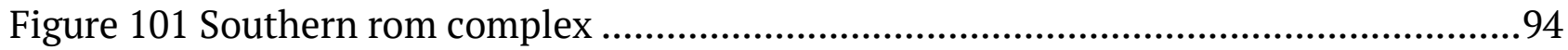

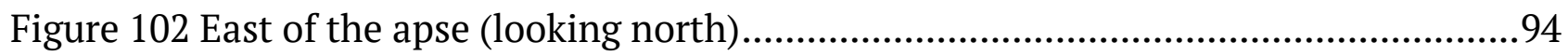

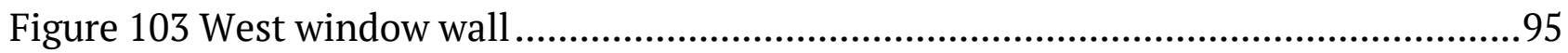

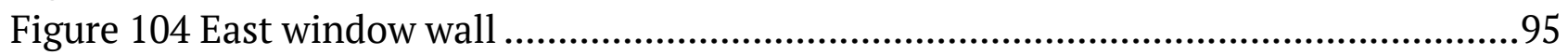

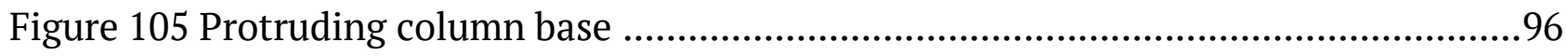

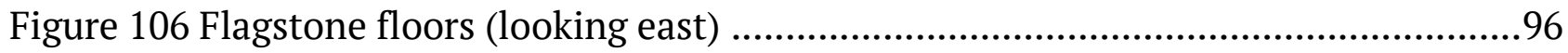

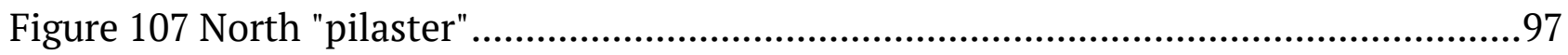

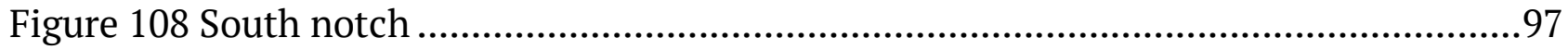

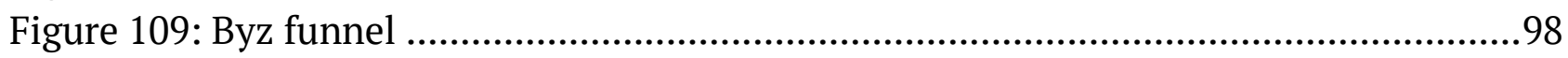

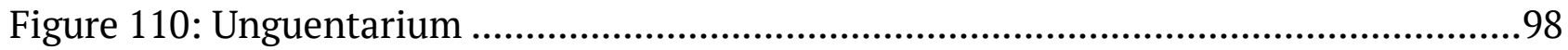

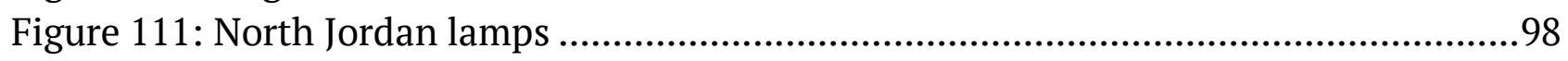

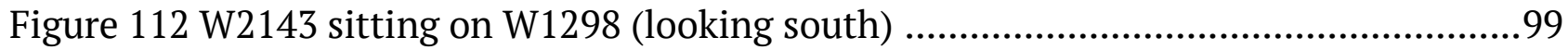

Figure 113 W1917 collapsing (looking southeast) .............................................................99 


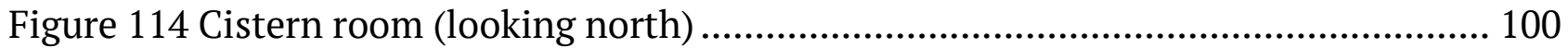

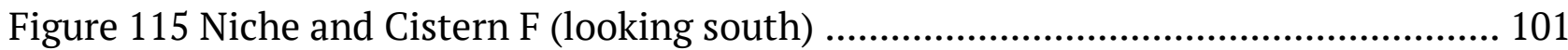

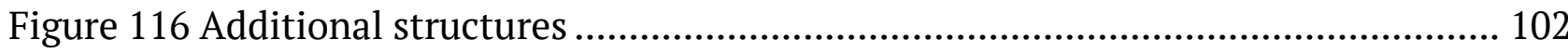

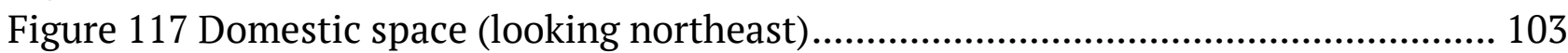

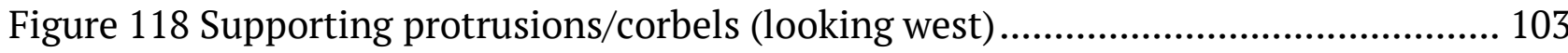

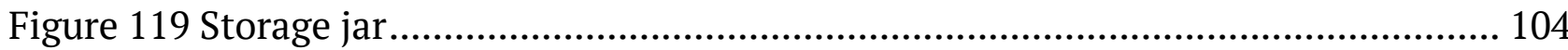

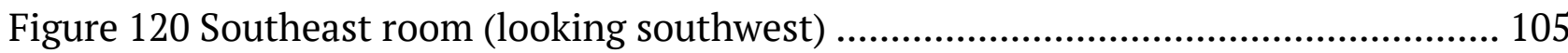

Figure 121 Items from southeast corner of House of Tyche .......................................... 105

Figure 122 Southwest corner and bench (looking northwest) ......................................... 106

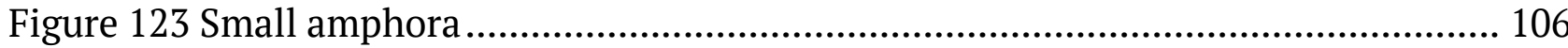

Figure 124 Umayyad structure on the corner of W1230 (looking north).......................... 107

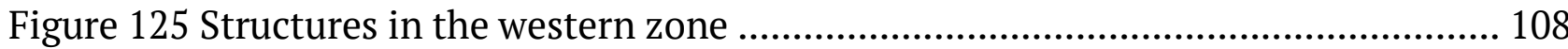

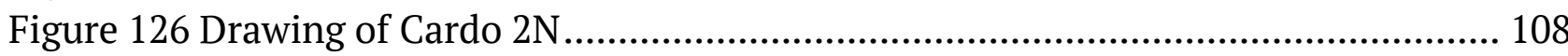

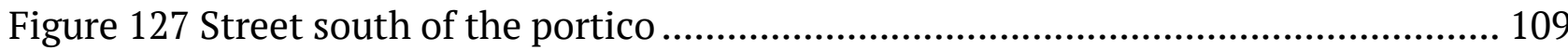

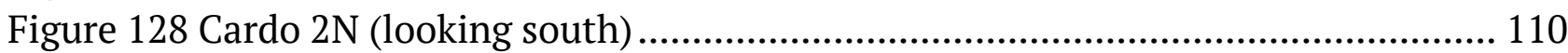

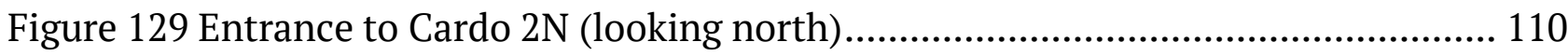

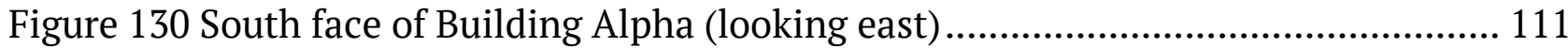

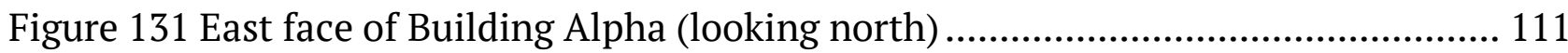

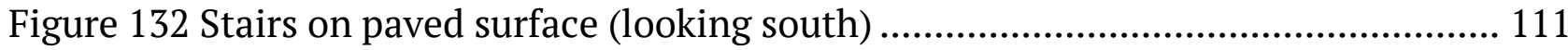

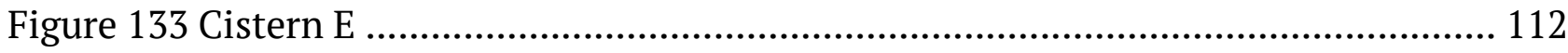

Figure 134 Paved plaza west of Cardo 2 North (looking southwest) ................................ 113

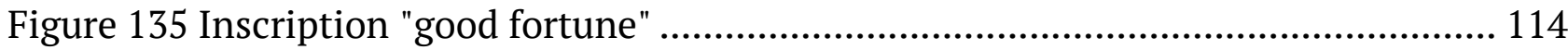

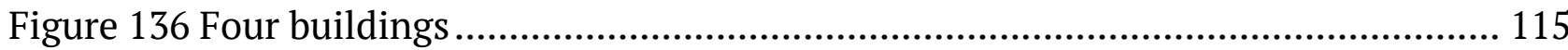

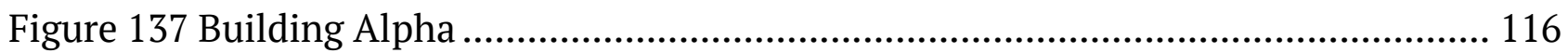

Figure 138 East face of window wall (1926) .................................................................... 116

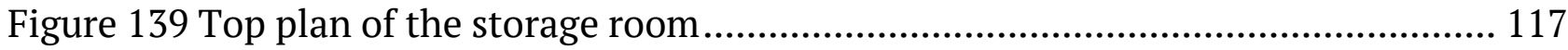

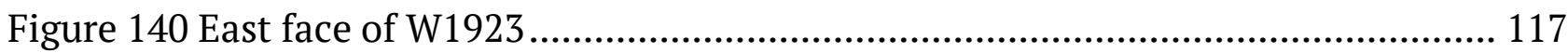

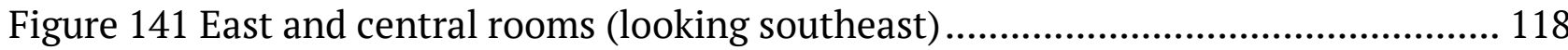

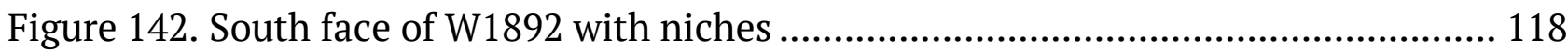

Figure 143 Southwest room (looking southeast) ............................................................. 119

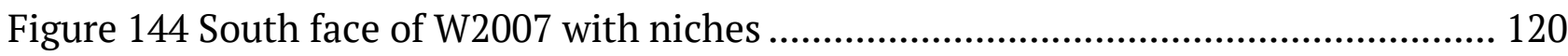

Figure 145 Northwest room (looking southeast) ............................................................ 120

Figure 146 Stylobates in floor of the Building Alpha (looking south) ............................. 121

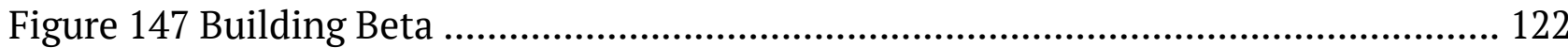

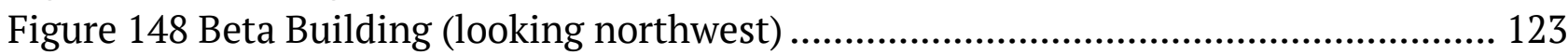

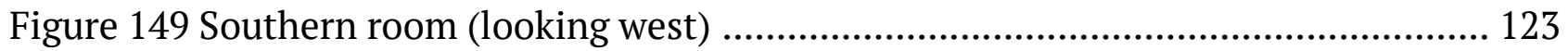

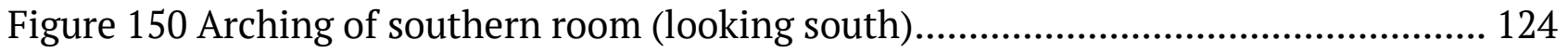

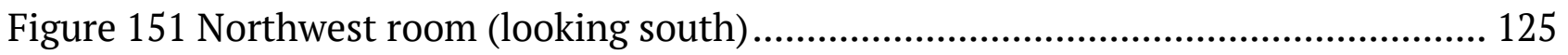

Figure 152 Northeast room and probe (looking northwest)......................................... 126

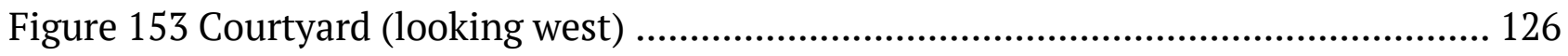


Figure 154 Staircase in the interior courtyard of Building Beta......................................127

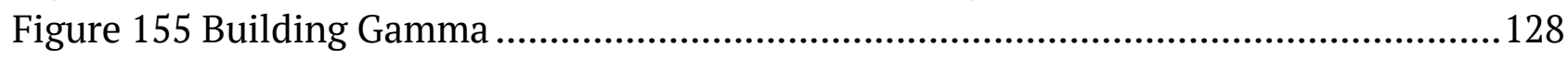

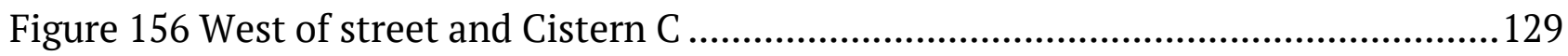

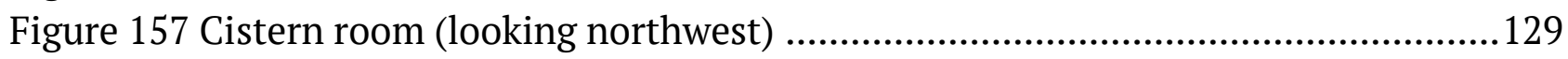

Figure 158 Incubatio with bench (looking west) ……...................................................129

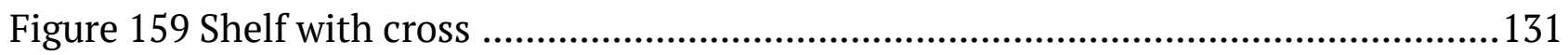

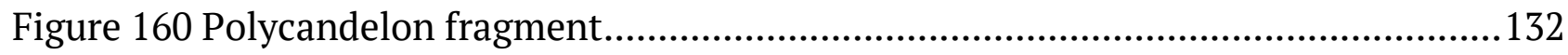

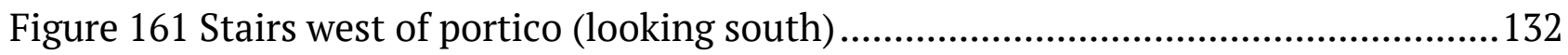

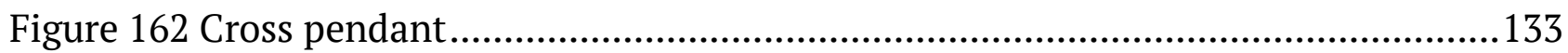

Figure 163 South of Building Gamma west of Cardo 2 North (looking northeast)............134

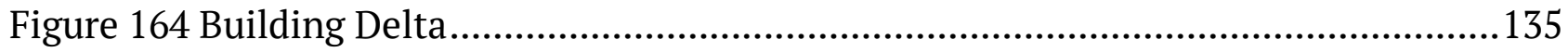

Figure 165 Probe perpendicular to the stylobate (looking west) .....................................135

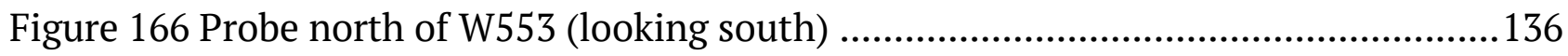

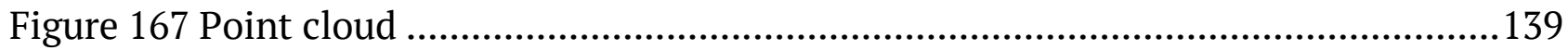

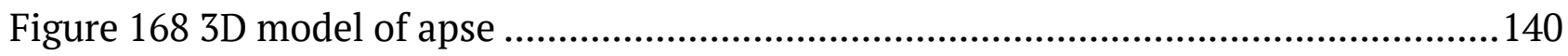

Figure 169 Photogrammetric Model of the Northeast Church (Courtesy of the HipposSussita Excavations. Used with permission.) .................................................................. 141

Figure 170 Photogrammetic model of the northeast insulae (Courtesy of the Hippos-Sussita

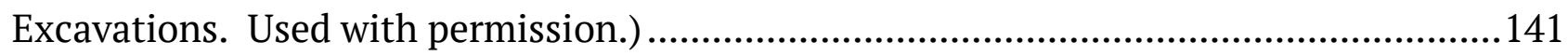

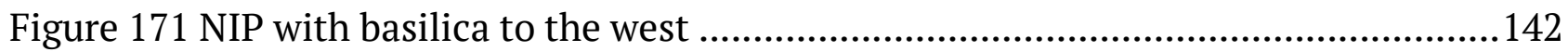

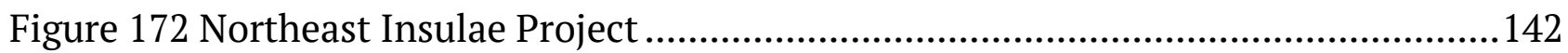

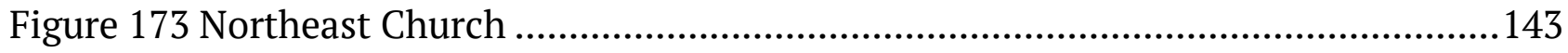

Figure 174 South wall and niche from the diakonikon ....................................................143

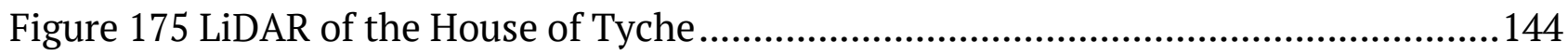

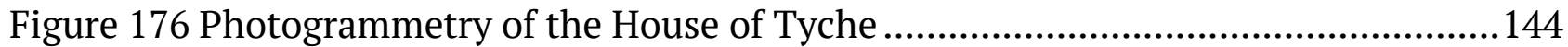

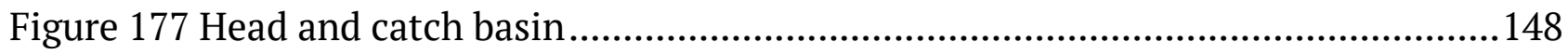

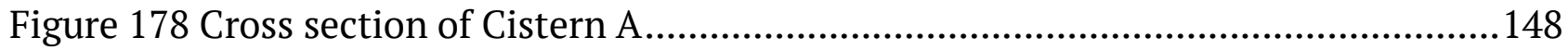

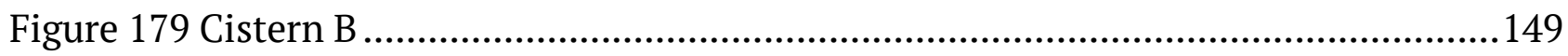

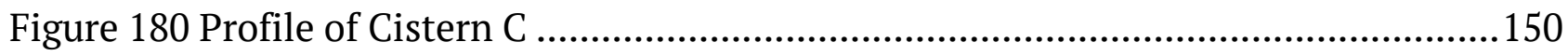

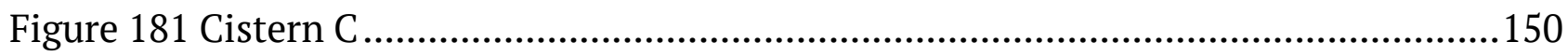

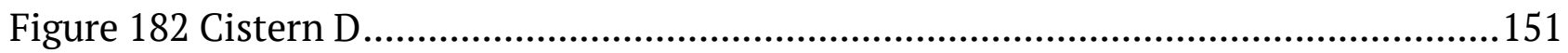

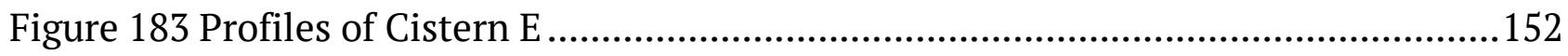

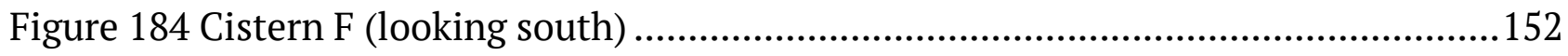

Figure 185 Head, Cistern G, and catch basin (looking east) ...........................................153

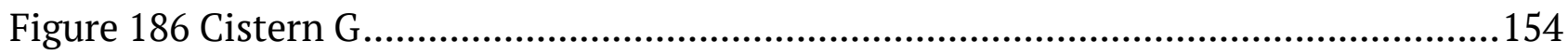

Figure 187 Profile of Cistern $\mathrm{H}$ under the peristyle court .................................................155

Figure 188 Chancel showing the location of the tombs..................................................156

Figure 189 Remains in sarcophagus in masonry tomb ....................................................156

Figure 190 Fresco of hand from masonry tomb .............................................................157

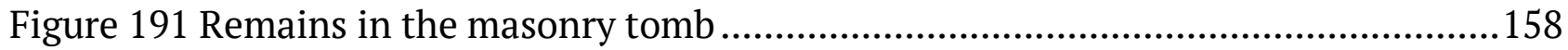

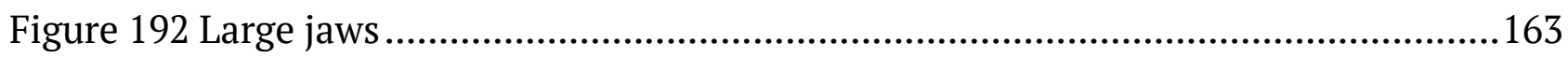




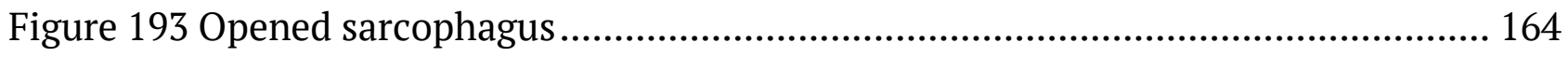

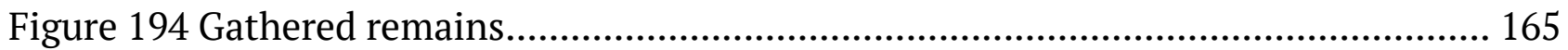

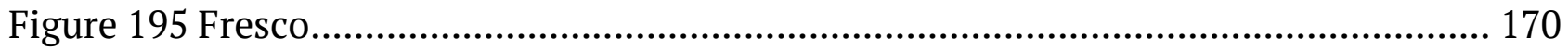

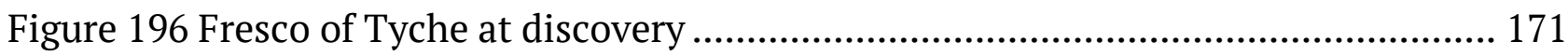

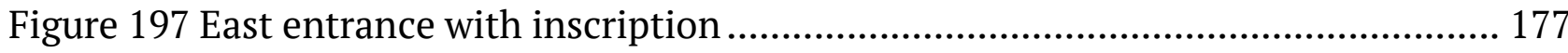

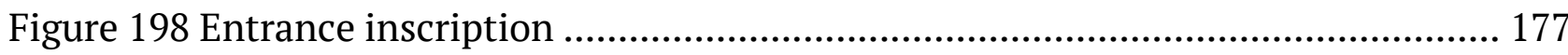

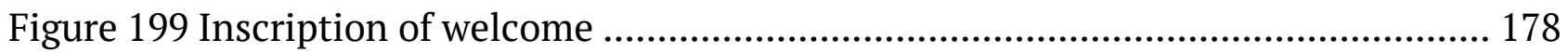

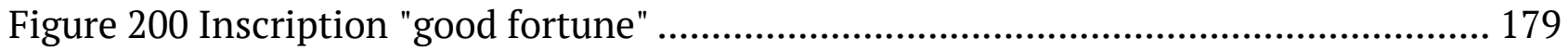

Figure 201 Portion of Tarius Titianus inscription............................................................ 180

Figure 202 Fragment of F517 next to the south wall of the chancel ............................... 181

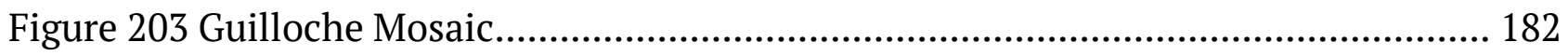

Figure 204 Mosaic from east end of the north aisle (looking south) ................................ 183

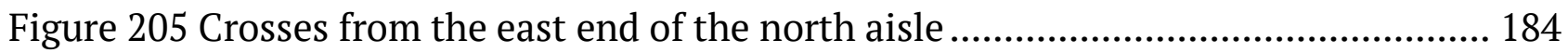

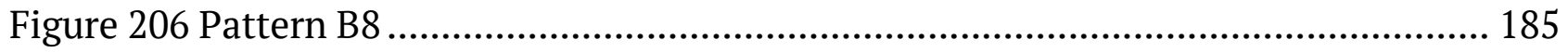

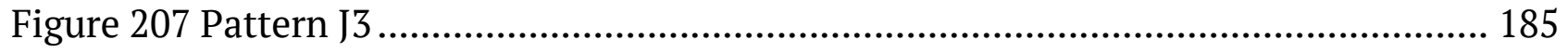

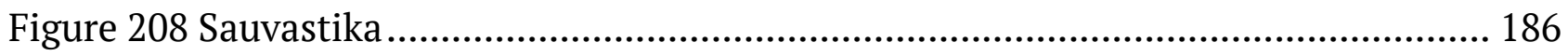

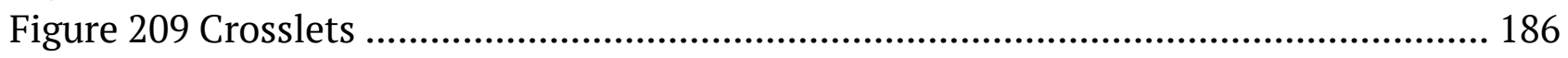

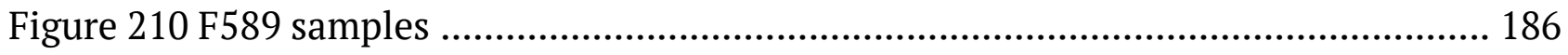

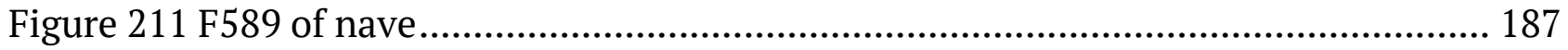

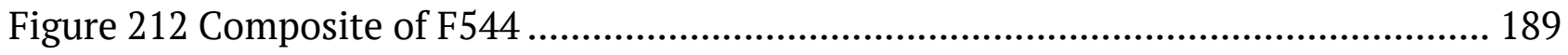

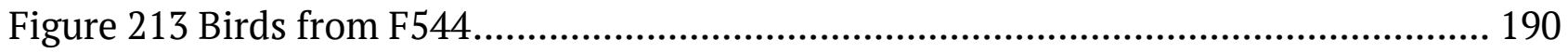

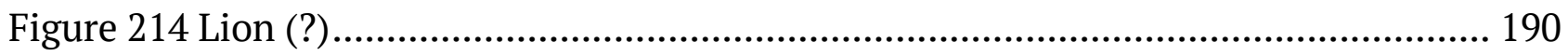

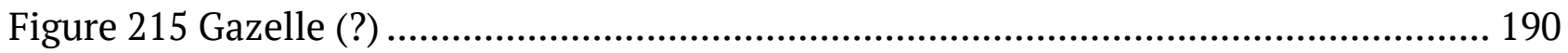

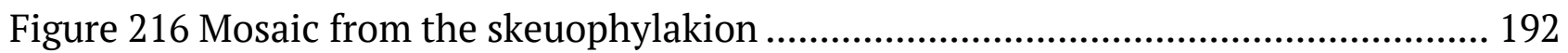

Figure 217 Avi Yonah pattern B9................................................................................. 193

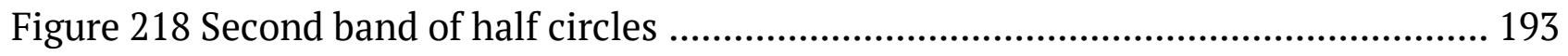

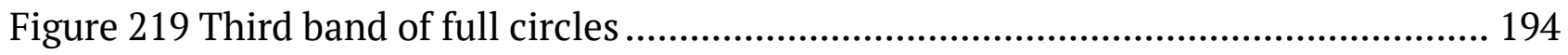

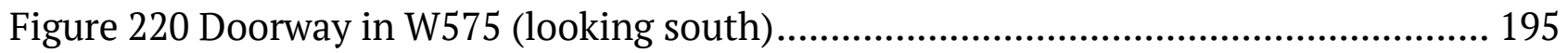

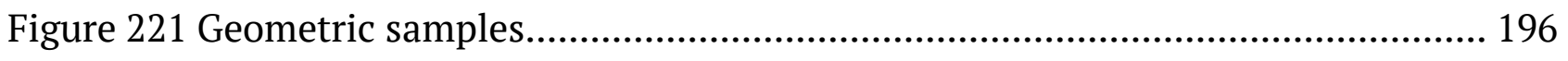

Figure 222 Guilloche from floor the church aisles .......................................................... 196

Figure 223 Fragments of an inscription....................................................................... 197

Figure 224 Mosaic floor next to the fountain (looking north) ......................................... 198

Figure 225 Decoration with inscription in the entrance hall ........................................... 199

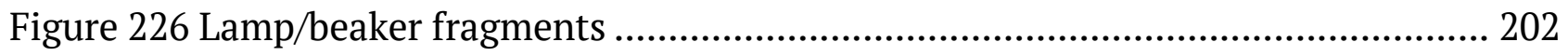

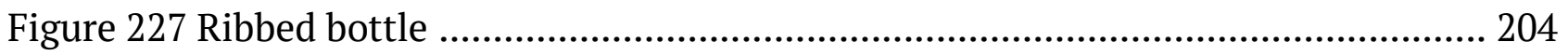

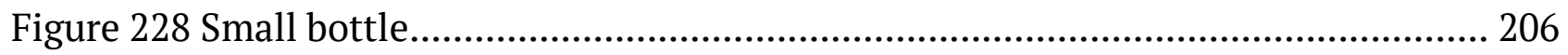

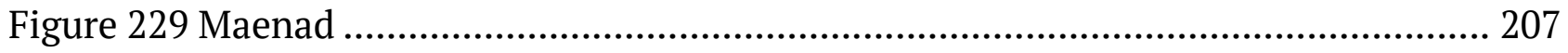

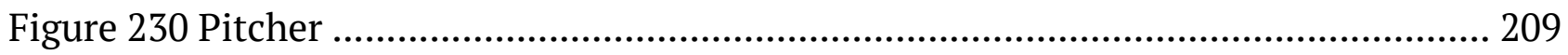

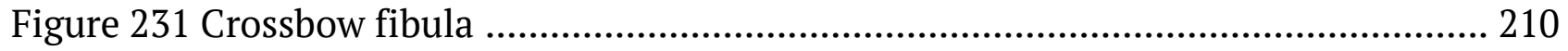


Figure 232 Belt elements (Courtesy of the Hippos-Sussita Excavations. Used with

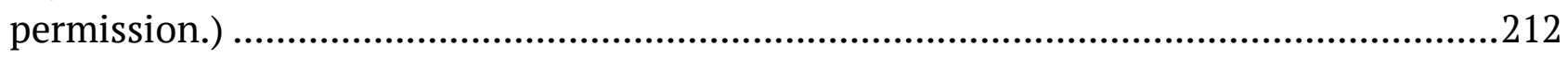

Figure 233 Belt tab .....................................................................................................213

Figure 234 Healing amulet (Courtesy of the Hippos-Sussita Excavations. Used with

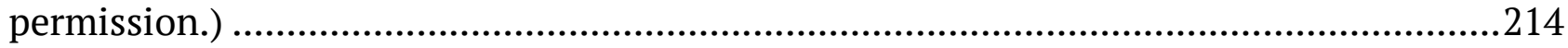

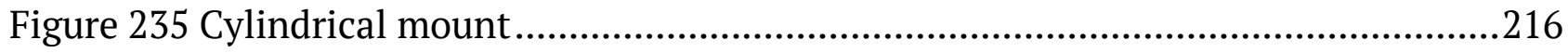

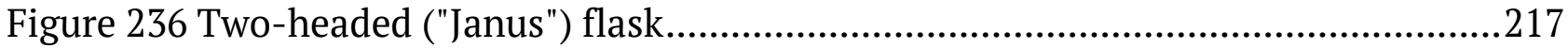

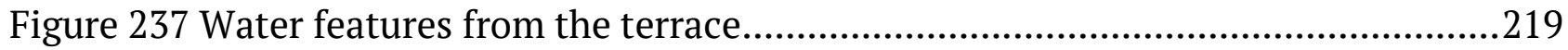

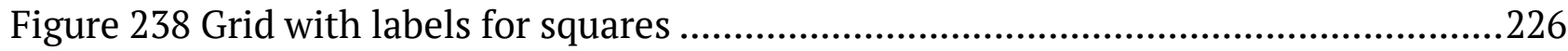

Figure 239 Cross section of probe in the nave ...............................................................354

Figure 240 Probe of the Portico (looking north) .............................................................355

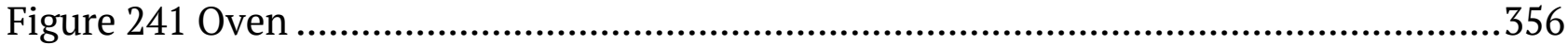

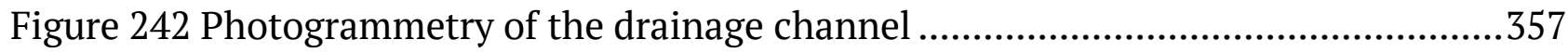

Figure 243 Probe (looking north) and bowl fragment.......................................................358

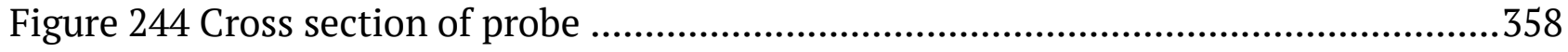


$-382-$ 


\section{BIBLIOGRAPHY}

Albright, William Foxwell. The Excavation of Tell Beit Mirsim. Vol. XVII. Annual of the American Schools of Oriental Research. New Haven: American Schools of Oriental Research, under the Jane Dows Nies Publication Fund, 1937.

Alexander of Trailles, and Félix Louis Émile Brunet. Euvres médicales d'Alexandre de Tralles, le dernier auteur classique des grandes médecins grecs de l'antiquité. Paris: P. Geuthner, 1933.

Angel, J. Lawrence. "Health as a Crucial Factor in the Changes from Hunting to Developed Farming in the Eastern Mediterranean." In Paleopathology at the Origins of Agriculture, edited by M. Cohen and G. Armelagos, 51-74. Orlando, FL: Academic Press, 1984.

Arensburg, Baruch. "A Short Review of Paleopathology in the Middle East." Mitekufat Haeven 18 (1985): 21-36.

---. "The People in the Land of Israel from the Epipaleolithic to Present Times." Ph.D., Tel Aviv University, 1973.

Arveiller-Dulong, Véronique, and Jacques Arveiller. Le Verre d'époque Romaine Au Musée Archéologique de Strasbourg. Notes et documents des musées de France 10. Paris: Ministère de la culture, Editions de la Réunion des musées nationaux, 1985.

Aufderheide, Arthur C., Conrado Rodriguez-Martin, and Odin Langsjoen. The Cambridge Encyclopedia of Human Paleopathology. Cambridge, UK ; New York, NY, USA: Cambridge University Press, 1998.

Avalos, Hector. Health Care and the Rise of Christianity. Peabody, Mass.: Hendrickson, 1999.

Aviam, Mordechai. "Christian Galilee in the Byzantine Period." In Galilee through the Centuries, edited by Eric M. Meyers, 281-300. Winona Lake, IN: Eisenbrauns, 1999.

---. "Late Antique Pilgrim Monasteries in Galilean Loca Sancta." Studium Biblicum Franciscanum 64 (2014): 559-573.

Avigad, Nahman. Beth She'arim: Report On The Excavations During 1953-1958. Vol III: Catacombs 12-23. Edited by Benjamin Mazar. New Brunswick, N.J: Rutgers University Press on behalf of the Israel Exploration Society and the Institute of Archaeology, Hebrew University, 1973. 
Avi-Yonah, Michael. "Mosaic Pavements in Palestine." Quarterly of the Department of Antiquities of Palestine 2 (1932): 136-181.

Bar-Nathan, Rachel, and Gabriel Mazor. "City Center (South) and Tel Iztabba Area Excavations of the Antiquities Authority Expedition." Excavations and Surveys in Israel 11 (1993): 33-51.

Barrett-Lennard, R. J. S. Christian Healing after the New Testament: Some Approaches to Illness in the Second, Third, and Fourth Centuries. Lanham: University Press of America, 1994.

Basil, Saint, Bishop of Caesarea, ca. 329-379. The Ascetic Works of Saint Basil. England: England: Society for Promoting Knowledge, 1925.

Basile, Joseph J. "A Head of the Goddess Tyche from Petra, Jordan. The Seventh Season.” Annual of the Department of Antiquities of Jordan 41 (1997): 255-266.

Bass, George Fletcher, and Frederick H. Van Doorninck. Yassl Ada. 1st ed. The Nautical archaeology series no. 1. College Station: Published with the cooperation of the Institute of Nautical Archaeology by Texas A\&M University Press, 1982.

Bass, William M. Human Osteology: A Laboratory and Field Manual. 4th ed. Special publication no. 2 of the Missouri Archaeological Society. Columbia, Mo: Missouri Archaeological Society, 1995.

Baur, Paul Victor Christopher. "Glassware.” In Gerasa, City of the Decapolis, edited by Carl H. Kraeling, 505-546. New Haven, Conn.: American Schools of Oriental Research, 1938.

Beckwith, John. Early Christian and Byzantine Art. The Pelican history of art. Harmondsworth: Penguin, 1970.

Behre, Karl-Ernst. "The Interpretation of Anthropogenic Indicators in Pollen Diagrams.” Pollen et spores 23, no. 2 (1981): 225-245.

Belayche, Nicole. “Tychè et la 'Tychè' dans les cités de la Palestine romaine.” Syria; revue d'art oriental et d'archéologie 80 (2003): 111-138.

Ben-Arieh, Roni. “The Roman, Byzantine and Umayyad Pottery.” In The Roman Baths of Hammat Gader, edited by Yizhar Hirschfeld, 347-381. Jerusalem: Israel Exploration Society, 1997. 
Bergmann, Bettina. "The Roman House as Memory Theater: The House of the Tragic Poet in Pompeii.” The Art Bulletin 76, no. 2 (June 1, 1994): 225-256.

Binns, John. Ascetics and Ambassadors of Christ: The Monasteries of Palestine, 314-631. Oxford early Christian studies. Oxford : New York: Clarendon Press ; Oxford University Press, 1994.

Bliss, Frederick Jones, and Archibald Campbell Dickie. Excavations at Jerusalem, 1894-1897. London: Committee of the Palestine Exploration Fund, 1898.

Bonner, Campbell. Studies in Magical Amulets: Chiefly Graeco-Egyptian. University of Michigan studies Humanistic series,. Ann Arbor London: University of Michigan Press; Geoffrey Cumberlege, Oxford University Press, 1950.

Braun, Eliot. “Soundings under a Sixth Century Monastery at Beth Shean.” Atiqot 17 (1985): 201-204.

Brill, Robert H. "Scientific Investigations of the Jalame Glass and Related Finds.” In Excavations at Jalame, Site of a Glass Factory in Late Roman Palestine, edited by Gladys Davidson Weinberg, 257-294. Columbia, MO: University of Missouri Press, 1988.

Britt, Karen Christina. "Mosaics in the Byzantine Churches of Palestine: Innovation or Replication?” Ph.D., Indiana University, 2003.

Brooks, Sheilagh, and Judy M Suchey. "Skeletal Age Determination Based on the Os Pubis: A Comparison of the Acsádi-Nemeskéri and Suchey-Brooks Methods." Human evolution 5, no. 3 (1990): 227-238.

Broucke, Pieter BFJ. "Tyche and the Fortune of Cities in the Greek and Roman World.” In An Obsession with Fortune: Tyche in Greek and Roman Art, edited by Susan Matheson, 34-49. New Haven, Conn.: Yale University Art Gallery, 1994.

Brox, Norbert. "Magie Und Aberglaube an Den Anfängen Des Christentums.” Trierer Theologische Zeitschrift 83 (1974): 157-80.

Burdajewicz, Mariusz. "Glass Finds from the North-West Church Complex.” In Hippos-Sussita : Seventh Season of Excavations : July 2006, edited by Arthur Segal, Jolanta Mlynarczyk, Mariusz Burdajewicz, Mark Schuler, and Michael Eisenberg, 127-143. Haifa: Zinman Institute of Archaeology, University of Haifa, 2006.

Butler, Howard Crosby, and E. Baldwin Smith. Early Churches in Syria. Princeton: Department of Art and Archaeology of Princeton University, 1929. 
Casey, Maurice. Jesus of Nazareth : An Independent Historian's Account of His Life and Teaching. London; T \& T Clark, 2010.

Cassiodorus. "An Introduction to Divine and Human Readings.” Electronic resource. Translated by Leslie Webber Jones. ACLS Humanities E-Book. Records of civilization, sources and studies no. 40 (1969). Accessed April 14, 2021. http://proxy.libraries.uc.edu/login?url=http://hdl.handle.net/2027/heb.05980.

Chambers, Stephen. "Window Glass Finds in the Northeast Church '” In Hippos-Sussita of the Decapolis: The First Twelve Seasons of Excavations (2000-2011) Vol 1, edited by Arthur Segal, 242-249. Haifa, Israel: The Zinman Inst of Archaeology, 2013.

Chestnut, Glenn. "The Pagan Background.” In The Christian and Judaic Invention of History, edited by Jacob Neusner. Studies in religion / American Academy of Religion no. 55. Atlanta, Ga: Scholars Press, 1990.

Chitty, Derwas J. The Desert a City: An Introduction to the Study of Egyptian and Palestian Monasticism under the Christian Empire. Crestwood, NY: St. Vladimir's Seminary Press, 1995.

-- . The Desert a City: An Introduction to the Study of Egyptian and Palestinian Monasticism under the Christian Empire. Oxford: Blackwell, 1966.

Christern, Jürgen, and Eckhart Müller. Das frühchristliche Pilgerheiligtum von Tebessa: Architektur u. Ornamentik e. spätantiken Bauhütte in Nordafrika. Wiesbaden: Steiner, 1976.

Chrysostom, John. In Epistulam I Ad Corinthios.

---. In Epistulam I Ad Timotheum.

Ciancio Rossetto, Paola. Il Sepolcro Del Fornaio Marco Virgilio Eurisace a Porta Maggiore. I Monumenti romani 5. Roma: Istituto di studi romani, 1973.

Cohen, Einat. "Roman, Byzantine and Umayyad Glass.” In The Roman Baths of Hammat Gader, edited by Yizhar Hirschfeld, 396-431. Jerusalem: Israel Exploration Society, 1997.

Codex Theodosianus

Cotsonis, John A. Byzantine Figural Processional Crosses. Dumbarton Oaks Byzantine Collection publications no. 10. Washington, D.C: Dumbarton Oaks Research Library and Collection, 1994. 
Cox, M. “Aging Adults from the Skeleton.” In Human Osteology in Archaeology and Forensic Science, edited by M. Cox and S. Mays, 61-82. London: Greenwich Medical Media, 2000.

Crislip, Andrew T. From Monastery to Hospital: Christian Monasticism \& the Transformation of Health Care in Late Antiquity. Ann Arbor: University of Michigan Press, 2005.

Crowfoot, Grace M, and Donald B Harden. "Early Byzantine and Later Glass Lamps.” The Journal of Egyptian Archaeology 17, no. 1 (1931): 196-208.

Crowfoot, John Winter, Grace Mary Crowfoot, and Kathleen M. Kenyon. The Objects from Samaria. Samaria-Sebaste; reports of the work of the Joint expedition in 1931-1933 and of the British expedition in 1935 ; no. 3. London: Palestine Exploration Fund, 1957.

Cutler, Anthony. The Craft of Ivory: Sources, Techniques, and Uses in TheMediterranean World, A.D. 200-1400. Publications / Dumbarton Oaks, Byzantine Collection no. 8. Washington, D.C.: Dumbarton Oaks, Research Library and Collection, 1985.

Cyril. Lives of the Monks of Palestine. Cistercian studies series ; no. 114. Kalamazoo, Mich: Cistercian Publications, 1991.

Dagron, Gilbert. “The Urban Economy, Seventh-Twelfth Centuries.” In The Economic History of Byzantium: From the Seventh through the Fifteenth Century, edited by A. E. Laiou, 393-461. Washington, D.C.: Dumbarton Oaks Research Library and Collection, 2002.

Dahari, Uzi. “The Church of St. Bacchus near Horvat Tinshemet.” Christ Is Here! (2012): $105-124$.

Dahari, Uzi, and Yoram Tsafrir. "Remote Monasteries in Southern Sinai and Their Economic Base.” In Anceint Churches Revealed, 341-350. Jerusalem: Israel Exploration Society, 1993.

Dandridge, Pete. “Idiomatic and Mainstream: The Technical Vocabulary of a Late Roman Crossbow Fibula.” Metropolitan Museum Journal 35 (2000): 71-77.

Dauphin, Claudine. "Carpets of Stone: The Graeco-Roman Legacy in the Levant.” Classics Ireland 4 (1997): 1-32.

- - . "On the Pilgrim's Way to the Holy City of Jerusalem. The Basilica of Dor in Israel." In Archaeology and Biblical Interpretation, edited by John R Bartlett, 145-165. New York: Routledge, 1997. 
Davidson, Gladys R. “A Mediaeval Glass-Factory at Corinth.” American Journal of Archaeology 44, no. 3 (1940): 297-324.

Delougaz, Pinhas, and Richard C. Haines. A Byzantine Church at Khirbat Al-Karak. University of Chicago. Oriental Institute Publications v. 85. Chicago: University of Chicago Press, 1960.

Deppert-Lippitz, Barbara. "A Late Antique Crossbow Fibula in the Metropolitan Museum of Art.” Metropolitan Museum Journal 35 (2000): 39-70.

Descoeudres, Georges. Die Pastophorien Im Syro-Byzantinischen Osten: Eine Untersuchung Zu Architektur- Und Liturgiegeschichtlichen Problemen. Schriften zur Geistesgeschichte des östlichen Europa Bd. 16. Wiesbaden: O. Harrassowitz, 1983.

Dioscorides, Pedanius. De Materia Medica.

Dunn, James D. G. 1939-. Jesus Remembered. Christianity in the making ; volume 1. Grand Rapids, Michigan: W.B. Eerdmans, 2003.

Dussart, Odile. Le verre en Jordanie et en Syrie du Sud. Bibliothèque archéologique et historique t. 152. Beyrouth: Institut français d'archéologie du Proche-Orient, 1998.

Eisenberg, Michael, Alexander Iermolin, and Sariel Shalev. "Archaeological and XRF Analysis of a Byzantine Weight from Hippos Sheds New Light on the Transition from Christian to the Islamic Rule." Israel Exploration Journal 68, no. 1 (2018): 77-99.

Elad, Amikam. "The Southern Golan in the Early Muslim Period: The Significance of Two Newly Discovered Milestones of Abd al-Malik.” Der Islam; Zeitschrift für Geschichte und Kultur des islamischen Orients 76, no. 1 (1999): 33-88.

Ellis, Simon P. “The End of the Roman House.” American Journal of Archaeology 92 (1988): 565-576.

Epiphanius of Salamis. Panarion (Adversus Haereses).

Epstein, Claire. “Hippos (Sussita).” In The New Encyclopedia of Archaeological Excavations in the Holy Land, edited by Ephraim Stern, Ayelet Leviinzon-Gilbo'a, and J. Aviram, 2:634-636. Jerusalem : New York: Israel Exploration Society \& Carta; Simon \& Schuster, 1993.

Eusebius. Eusebius--the Church History: A New Translation with Commentary. Translated by Paul L. Maier. Grand Rapids, MI: Kregel Publications, 1999. 
Ferguson, John. The Religions of the Roman Empire. Aspects of Greek and Roman life. Ithaca, N.Y: Cornell University Press, 1970.

Fiema, Zbigniew. "The Early Byzantine Christian Church: An Archaeological Re-Assessment of Forty-Seven Early Byzantine Basilical Church Excavations Primarily in Israel and Jordan, and Their Historical and Liturgical Context." Bulletin of the American Schools of Oriental Research 376 (November 2016): 246-249.

FitzGerald, Gerald M. A Sixth Century Monastery at Beth-Shan (Scythopolis). Philadelphia: Published for the University museum by the University of Pennsylvania press, 1939.

Fortescue, Adrian. “Jerusalem (A.D. 71-1099).” In The Catholic Encyclopedia. Vol. 8. New York: Robert Appleton Company, 1910. Accessed July 9, 2021. https://www.newadvent.org/cathen/08355a.htm.

Franceschini, Ezio, and Robert Weber, eds. Itinerarium Egeriae. Corpus Christianorum 1. Turnholti: Brepols, 1958.

Freestone, Ian C, Ruth E Jackson-Tal, and Oren Tal. "Raw Glass and the Production of Glass Vessels at Late Byzantine Apollonia-Arsuf, Israel.” Journal of glass studies 50 (2008): 67-80.

Galen. De Simplicium Medicamentorum Temperamentis et Facultatibus.

Galor, Katharina. "Domestic Architecture in Roman and Byzantine Galilee and Golan.” Near Eastern Archaeology 66, no. 1-2 (March 2003): 44-57.

Gams, Pius Bonifacius. Series episcoporum Ecclesiae catholicae. Graz: Akademische Drucku. Verlagsanstalt, 1857.

Gersht, Rivka. “The Tyche of Caesarea Maritima.” Palestine Exploration Quarterly 116, no. 2 (1984): 110-114.

Geyer, Patrick Scott. "Pollen Analysis.” In Hippos-Sussita of the Decapolis: The First Twelve Seasons of Excavations 2000-2011, Vol. II, edited by Michael Eisenberg, 370-373, 2018.

- - . "Pollen Analysis of the Hippos-Sussita Industrial Complex." In Hippos-Sussita : eleventh season of excavations, July 2010, edited by Arthur Segal, 83-88. Haifa: University of Haifa, 2010. 
---. "Pollen Analysis of the Winery Complex Adjacent to the North-West Church." In Hippos-Sussita: Tenth Season of Excavations (July and September 2009), edited by Arthur Segal, 93-103. Haifa, Israel: Zinman Institute of Archaeology, University of Haifa, 2009.

Geyer, Patrick Scott, Danny Syon, Shua Amorai-Stark, Yoav Arbel, Chaim Ben-David, Baruch Brandl, Deborah Cassuto, et al. "Pollen Analysis." In Gamla III Part 2, 59:351362. The Shmarya Gutmann excavations 1976-1989, finds and studies: part 2. Israel Antiquities Authority, 2016. Accessed April 13, 2021. http://www.jstor.org/stable/j.ctt1m3p1w7.22.

Goldfus, Haim. "Tombs and Burials in Churches and Monasteries of Byzantine Palestine (324--628 AD).” Ph.D. dissertation, Princeton University, 1997.

- - . "Urban Monasticism and Monasteries of Early Byzantine Palestine - Preliminary Observations.” ARAM Periodical, no. 15 (2003): 71-79.

Goldfus, Haim, and Kimberly Diane Bowes. "New Late Roman Bone Carvings from Halusa and the Problem of Regional Bone Carving Workshops in Palestine." Israel Exploration Journal 50, no. 3-4 (2000): 185-202.

Gorin-Rosen, Yael. “Glass Vessels from Area A.” In Jewish Quarter Excavations in the Old City of Jerusalem Conducted by Nahman Avigad 1969-1982, Volume II The Finds from Areas $A$, $W$, and $X$-2, edited by Hillel Geva, 364-386. Jerusalem: Israel Exploration Society, 2003.

Grabar, André. Martyrium: Recherches Sur Le Culte Des Reliques et l'artchrétien Antique. Vol. 2. London: Variorum Reprints, 1972.

Gygax, Marc Domingo, and Arjan Zuiderhoek. Benefactors and the Polis: The Public Gift in the Greek Cities from the Homeric World to Late Antiquity. Cambridge University Press, 2021.

Haas, Jonathan, Jane E. Buikstra, Douglas H. Ubelaker, David Aftandilian, and Field Museum of Natural History, eds. Standards for Data Collection from Human Skeletal Remains: Proceedings of a Seminar at the Field Museum of Natural History, Organized by Jonathan Haas. Arkansas Archeological Survey research series no. 44. Fayetteville, Ark: Arkansas Archeological Survey, 1994.

Harakas, Stanley Samuel. “The Eastern Orthodox Tradition.” In Caring and Curing: Health and Medicine in the Western Religious Traditions, edited by Ronald L. Numbers and Darrel W. Amundsen, 146-172. New York: Macmillan, 1986. 
Harden, Donald B. “Roman Window-Panes from Jerash, and Later Parallels.” Iraq 6, no. 1 (1939): 91.

---. “Tomb-Groups of Glass of Roman Date from Syria and Palestine.” Iraq 11, no. 2 (1949): 151-159.

Hayes, John W. Roman and Pre-Roman Glass in the Royal Ontario Museum: A Catalogue. Toronto: Royal Ontario Museum, 1975.

Hershkovitz, Israel. "Skeletal Remains from the Northern Church.” Qedem (1988).

---. "The Human Remains from the Byzantine Monastery at Khan El-Ahmar." Liber Annuus 43 (1994): 373-385.

Hirschfeld, Yizhar. The Early Byzantine Monastery at Khirbet Ed-Deir in the Judean Desert: The Excavations in 1981-1987. Qedem 38. Jerusalem, Israel: Institute of Archaeology, the Hebrew University of Jerusalem, 1999.

---. The Judean Desert Monasteries in the Byzantine Period. New Haven: Yale University Press, 1992.

---. "The Monasteries of Palestine in the Byzantine Period." In Christians and Christianity in the Holy Land, 401-419. Turnhout: Brepols, 2006.

---. The Palestinian Dwelling in the Roman-Byzantine Period. Collectio minor n. 34. Jerusalem: Franciscan Printing Press ; Israel Exploration Society, 1995.

Hutter, Irmgard. Early Christian and Byzantine. The Universe history of art and architecture. New York: Universe Books, 1988.

Irenaeus. Adversus Haereses.

Iscan, Mehmet Yasar, and Susan R Loth. "Osteological Manifestations of Age in the Adult.” In Reconstruction of Life from the Skeleton, edited by M. Yaşar İşcan and Kenneth A. R. Kennedy, 23-40. New York: Wiley-Liss, 1989.

Isings, C. Roman Glass from Dated Finds. Archaeologica traiectina 2. Groningen: J. B. Wolters, 1957.

Jackson-Tal, Ruth E. "The Late Hellenistic Glass Industry in Syro-Palestine: A Reappraisal.” Journal of Glass Studies 46 (2004): 11-32.

Jalabert, Louis, and René Mouterde, eds. Inscriptions grecques et latines de la Syrie. Paris: P. Geuthner, 1977. 
Justin. Apologia II.

Kennedy, Hugh N. "Justinianic Plague in Syria and the Archaeological Evidence." In Plague and the End of Antiquity: The Pandemic of 541-750, edited by Lester K. Little, 87-95. Cambridge: Cambridge University Press, 2009.

Killebrew, Ann E, and Steven Fine. "Qatzrin: Reconstructing Village Life in Talmudic Times." Biblical Archaeology Review 17, no. 3 (May 1991): 44-56.

Killebrew, Ann E., Billy J. Grantham, and Steven Fine. “A' Talmudic' House at Qasrin: On the Use of Domestic Space and Daily Life during the Byzantine Period." Near Eastern Archaeology 66, no. 1-2 (March 2003): 59-72.

Kitzinger, Ernst. "The Threshold of the Holy Shrine: Observations on the Floor Mosaics at Antioch and Bethlehem." In Kyriakon: Festschrift Johannes Quasten, edited by Patrick Granfield and Josef A. Jungmann, 2:639-647. Münster/Westf: Aschendorff, 1970.

Kraeling, Carl H. Gerasa, City of the Decapolis. New Haven, Conn: American school of oriental research, 1938.

Łajtar, Adam. "Greek Inscriptions." In Hippos-Sussita of the Decapolis: The First Twelve Seasons of Excavations (2000-2011) Vol 1, edited by Arthur Segal, 250-277. Haifa, Israel: The Zinman Inst of Archaeology, 2013.

---. "Mosaic Fragments from the Northern Building,” July 9, 2016.

---. "Mosaic Inscription from the South-West Church." In Hippos-Sussita : Eighth Season of Excavations : July 2007, edited by Arthur Segal, 57-59. Haifa: Zinman Institute of Archaeology, University of Haifa, 2007.

---. "Two Honorific Monuments for Governors of Syria Palaestinae in Hippos." Palamedes: A Journal of Ancient History 5 (2010): 177-186.

Lassus, Jean. Sanctuaires Chrétiens de Syrie: Essai Sur La Genèse, La Forme et l'usage Liturgique Des Édifices Du Culte Chrétien En Syrie, Du IIIe Siècle à La Conquête Musulmane. Paris: P. Geuthner, 1947.

Le Strange, G. Palestine under the Moslems: A Description of Syria and the Holy Land from A.D. 650 to 1500. Khayats oriental reprints no. 14. Beirut: Khayats, 1965.

Lester, Ayala. "Islamic Glass Finds.” In The Roman Baths of Hammat Gader: Final Report, edited by Yizhar Hirschfeld, 432-441. Jerusalem: Israel Exploration Society, 1997. 
---. "The Glass." In Excavations at Tiberias, 1973-1974: The Early Islamic Periods, edited by David Allen Stacey, 167-220. Jerusalem: Israel Antiquities Authority, 2004.

Levi, Doro. Antioch Mosaic Pavements. Roma: L’Erma di Bretschneider, 1971.

Liebowitz, Harold. “A Unique Worked Stone Mortar from Tel Yin’am.” Levant 32 (2000): 129-134.

Ling, Roger. Roman Painting. Cambridge [England]; New York: Cambridge University Press, 1991.

Livy. History of Rome.

Loth, Susan. "Morphological Assessment of Age in the Adult: The Thoracic Region." In Age Markers in the Human Skeleton, edited by M. Y. Iscan, 105-136. Springfield, IL: Charles C. Thomas, 1989.

Lovejoy, C Owen, Richard S Meindl, Thomas R Pryzbeck, and Robert P Mensforth. "Chronological Metamorphosis of the Auricular Surface of the Ilium: A New Method for the Determination of Adult Skeletal Age at Death.” American journal of physical anthropology 68, no. 1 (1985): 15-28.

Lovell, Nancy C. “Paleopathological Description and Diagnosis.” In Biological Anthropology of the Human Skeleton, edited by S. R. Saunders and M. A. Katzenberg, 217-248. New York: Wiley-Liss, 2000.

Magdalino, Paul. “The Byzantine Aristocratic Oikos.” In The Byzantine Aristocracy, IX-XIII Centuries, edited by Michael Angold, 92-111. BAR International Series 221. Oxford, 1984.

Magen, Izchak, and Rina Talgam. "The Monastery of Martyrius at Maale Adummim (Khirbet El-Murassas) and Its Mosaics." In Christian Archaeology in the Holy Land, edited by G.C. Bottini, 91-152. Jerusalem: Franciscan Printing Press, 1990.

Magen, Yitzhak. “The Monastery of St Martyrius of Ma'ale Adummim.” In Ancient Churches Revealed, edited by Yoram Tsafrir, 170-196. Jerusalem: Israel Exploration Society, 1993.

Mansi, Giovan Domenico, Philippe Labbe, Gabriel Cossart, Nicolò Coleti, Jean Baptiste Martin, and Louis Petit. Sacrorum conciliorum nova et amplissima collectio: in qua praeter ea quae Phil. Labbeus et Gabr. Cossartius ... et novissime Nicolaus Coleti in lucem edidere ea omnia insuper suis in locis optime disposita exhibentur. Edito novissima ab eodem patre Mansi ... curata; Accedunt etiam notae, et Dissertationes quamplurimae quae in ceteris editionibus desiderantur. Paris: H. Welter, 1901. 
Margalit, Shlomo. "The North Church of Shivta: The Discovery of the First Church.” Palestine Exploration Quarterly 119 (1987): 106-121.

Matheson, Susan. "The Goddess Tyche.” In An Obsession with Fortune: Tyche in Greek and Roman Art, edited by Susan B. Matheson and J. J. Pollitt, 19-33. Yale University Art Gallery Bulletin 1994. New Haven, Conn: Yale University Art Gallery, 1994.

Mays, S., and M. Cox. “Sex Determination in Skeletal Remains.” In Human Osteology in Archaeology and Forensic Science, edited by S. Mays and M. Cox, 117-130. London: Greenwich Medical Media, 2000.

Meggitt, Justin. “The Historical Jesus and Healing: Jesus' Miracles in Psychosocial Context.” In Spiritual Healing: Scientific and Religious Perspectives, edited by Fraser N. Watts. Cambridge, UK ; Cambridge University Press, 2011.

Meshel, Zeev, Tsvika Tsuk, Henning Fahlbusch, and Yehuda Peleg. The Water-Supply System of Susita. Tel Aviv: Tel Aviv Univ. Pr., 1998.

Meyendorff, John. Imperial Unity and Christian Divisions: The Church, 450-680 AD. Church history 2. Crestwood, N.Y: St. Vladimir’s Seminary Press, 1989.

Meyer, Carol. "Glass from the North Theater Byzantine Church, and Soundings at Jerash, Jordan, 1982-1983." Bulletin of the American Schools of Oriental Research. Supplementary Studies (1988): 175-222.

Michel, Anne. Les Eglises d'Epoque Byzantine et Umayyade de La Jordanie V-VIII Siecle. Turnhout: Brepols, 2001.

Michel, Simone, Peter Zazoff, Hilde Zazoff, and British Museum. Die Magischen Gemmen Im Britischen Museum. 2 vols. London: British Museum Press, 2001.

Miller, Timothy S. The Birth of the Hospital in the Byzantine Empire. Johns Hopkins pbk. ed. Baltimore: Johns Hopkins University Press, 1997.

Milner, George R. Determination of Skeletal Age and Sex: A Manual Prepared for the Dickson Mounds Reburial Team. Lewiston, Illinois: Dickson Mound Museum, 1992.

Milson, David. “Design Analysis of the Peristyle Building from 'Ein Ez-Zeituna.” Atiqot 51 (2006): 71-75.

Mlynarczyk, Jolanta. "Churches and Society in Byzantine and Umayyad-Period Hippos." ARAM 23 (2011): 253-284. 
Moritz, L. A. Grain-Mills and Flour in Classical Antiquity. Oxford: Clarendon Press, 1958.

Mulholland, Bernard. The Early Byzantine Christian Church: An Archaeological Re-Assessment of Forty-Seven Early Byzantine Basilical Church Excavations Primarily in Israel and Jordan, and Their Historical and Liturgical Context. Byzantine and neohellenic studies Vol. 9. Oxford ; New York: Peter Lang, 2014.

Negev, Avraham. The Greek Inscriptions from the Negev. Studium Biblicum Franciscanum. Collectio minor N. 25. Jerusalem: Franciscan Printing Press, 1981.

Nemesius of Emesa. De Natura Hominis.

Neumann, Kristina. "The Dipinti of the North-East Church Complex." In Hippos-Sussita : Tenth Season of Excavations: July and September 2009, edited by Arthur Segal, 80-83. Haifa, Israel: Zinman Institute of Archaeology, University of Haifa, 2009.

Numbers, Ronald L., and Darrel W. Amundsen, eds. Caring and Curing: Health and Medicine in the Western Religious Traditions. New York: Macmillan, 1986.

Oren, Eliezer. "A Christian Settlement at Ostrakine in North Sinai.” In Ancient Churches Revealed, edited by Yoram Tsafrir, 305-314. Jerusalem: Israel Exploration Society, 1993.

Osiek, Carolyn, and David L. Balch. Families in the New Testament World: Households and House Churches. 1st ed. The family, religion, and culture. Louisville, Ky: Westminster John Knox Press, 1997.

Ousterhout, Robert G. “Justinian's Building Program and Sixth-Century Developments.” In Eastern Medieval Architecture: The Building Traditions of Byzantium and Neighboring Lands, 219-242. New York: Oxford University Press, 2019.

Ovadiah, Ruth, and Asher Ovadiah. Mosaic Pavements in Israel: Hellenistic, Roman, and Early Byzantine. Bibliotheca archaeologica 6. Roma: “L’Erma” di Bretschneider, 1987.

Page, Charles R. "Kursi Excavations Resumed: Two New Seasons (2001, 2002)” Presented at the Annual Meeting of the Society of Biblical Literature, Toronto, Canada, November 23, 2002.

Palladius, and A Lucot. Historia Lausiaca: Vies d'ascètes et de pères du désert = Histoire Lausiaque. Paris: Picard, 1912.

Papaloizos, Theodore Constantine. “Gerontius's Sanctae Melanie Junioris Vita: A Translation with Introduction, Notes, and Commentary." Ph.D. dissertation, Catholic University of America, 1977. 
Patrich, Joseph. Sabas, Leader of Palestinian Monasticism: A Comparative Study in Eastern Monasticism, Fourth to Seventh Centuries. Dumbarton Oaks studies 32. Washington, D.C: Dumbarton Oaks Research Library and Collection, 1995.

Pernice, Erich. Gefässe Und Geräte Aus Bronze. Die hellenistische Kunst in Pompeji Bd. 4. Berlin: W. de Gruyter, 1925.

Pfann, Stephen J., K. R. Dark, René Salm, Yehudah Rapuano, and Ross Voss. "Surveys and Excavations at the Nazareth Village Farm (1997-2002): Final Report." Bulletin of the Anglo-Israel Archaeological Society 25 (2007): 19-79.

Phenice, Terrell W. "A Newly Developed Visual Method of Sexing the Os Pubis.” American journal of physical anthropology 30, no. 2 (1969): 297-301.

Piccirillo, Michele, and Eugenio Alliata, eds. The Madaba Map Centenary, 1897-1997: Travelling through the Byzantine Umayyad Period. Collectio maior 40. Jerusalem: Studium Biblicum Franciscanum, 1999.

Piccirillo, Michele, Patricia Maynor Bikai, and Thomas A. Dailey. The Mosaics of Jordan. American Center of Oriental Research publications no. 1. Amman, Jordan: American Center of Oriental Research, 1993.

Pitarakis, Brigitte. Les Croix-Reliquaires Pectorales Byzantines En Bronze. Bibliothèque des cahiers archéologiques 16. Paris: Picard, 2006.

Plautus, Titus Maccius. Captivi.

---.Persa.

Pollak, Rachel. “The Glass.” In Tel Tanninim: Excavations at Krokodeilon Polis, 1996-1999, edited by R. Raphael Stieglitz and Ya'el D Arnon, 155-192. Boston MA: American Schools of Oriental Research, 2006.

Pollitt, J. J. “An Obsession with Fortune." In An Obsession with Fortune: Tyche in Greek and Roman Art, edited by Susan B. Matheson and J. J. Pollitt, 12-17. Yale University Art Gallery Bulletin 1994. New Haven, Conn: Yale University Art Gallery, 1994.

Porterfield, Amanda. Healing in the History of Christianity, n.d. Accessed April 14, 2021. https://www.academia.edu/35883319/Healing_in_the_History_of_Christianity.

Prausnitz, Moshe W., and Michael Avi-Yonah. Excavations at Shavei Zion: The Early Christian Church; Report of the Excavations Carried out by the Israel Department of Antiquities and Museums (in Cooperation with the Hebrew University of Jerusalem). Monografie 
di archeologia e d'arte 2. Roma: Centro per le antichita e la storia dell'arte del Vicino Oriente, 1967.

Procopius. History of the Wars, Books I and II The Persian War. Translated by H. B. (Henry Bronson) Dewing, 2005. Accessed April 14, 2021. http://www.gutenberg.org/ebooks/16764.

Prottel, P. M. “Zur Chronologie Der Zwiebelknopffibeln.” Jahrbuch des Römisch-Germanischen Zentralmuseums Mainz 35, no. 1 (1988): 347-372.

Puschmann, Theodor. Alexander von Tralles: Originaltext Und Übersetzung Nebst Einer Einleitenden Abhandlung: Ein Beitrag Zur Geschichte Der Medicin; Zwei Bände. Vol. 2. Braumüller, 1879.

Rahmani, Levi Itshaq. “A Christian Lead Coffin from Caesarea.” Israel Exploration Journal 38, no. 4 (1988): 246-248.

---. “A Lead Coffin from the Hefer Valley.” Israel Exploration Journal, no. 24 (1974): 124127.

--_. “Five Lead Coffins from Israel.” Israel Exploration Journal 42, no. 1-2 (1992): 81-102.

Richardson, Lawrence. Pompeii: An Architectural History. Baltimore: Johns Hopkins University Press, 1988.

Rosen, William. Justinian's Flea: Plague, Empire, and the Birth of Europe. New York: Viking, 2007.

Rosenthal-Heginbottom, Renate. "Late Roman and Byzantine Bone Carvings from Palestine.” Israel Exploration Journal 26 (1976): 96-103.

Ross, Marvin C. "A Small Byzantine Treasure Found at Antioch-on-the-Orontes.” Archaeology 5, no. 1 (1952): 30-32.

Ross, Marvin C., and Kurt Weitzmann. Catalogue of the Byzantine and Early Mediaeval Antiquities in the Dumbarton Oaks Collection. Vol. 2. 3 vols. Dumbarton Oaks catalogues. Washington DC: Dumbarton Oaks Research Library and Collection, 1962.

Russell, James. “Archaeological Context of Magic.” In Byzantine Magic: [Papers... Originally Delivered at a Colloquium... at Dumbarton Oaks Feb. 27-28, 1993], edited by Henry Maguire. Dumbarton Oaks Res. Library and Collection, 1995. 
Russell, Kenneth W. "The Earthquake Chronology of Palestine and Northwest Arabia from the 2nd through the Mid-8th Century AD." Bulletin of the American Schools of Oriental Research 260, no. 1 (1985): 37-59.

Safrai, Zeev. The Economy of Roman Palestine. London ; New York: Routledge, 1994.

---. The Missing Century: Palestine in the Fifth Century: Growth and Decline. Leuven: Peeters, 1998.

Saldern, Axel von. Ancient and Byzantine Glass from Sardis. Monograph - Archaeological Exploration of Sardis ; 6. Cambridge, Mass: Harvard University Press, 1980.

---. Ancient Glass in the Museum of Fine Arts, Boston. Greenwich, Conn: New York Graphic Society, 1968.

Saller, Sylvester John, and Hilary Schneider. The Memorial of Moses on Mount Nebo. Jerusalem: Franciscan Press, 1941.

Saradi, Helen. "Privatization and Subdivision of Urban Properties in the Early Byzantine Centuries: Social and Cultural Implications." The Bulletin of the American Society of Papyrologists 35, no. 1/2 (1998): 17-43.

Saxer, V. "Cult of Martyrs, Saints, and Relics.” Edited by Angelo Di Berardino. Encyclopedia of the Early Church. Istituto patristico Augustinianum. New York: Oxford University Press, 1992.

Scarborough, John. "Theophrastus on Herbals and Herbal Remedies." Journal of the History of Biology 11, no. 2 (1978): 353-385.

Schellewald, Barbara. "Zur Typologie, Entwicklung Und Funktion von Oberräumen in Syrien, Armenien Und Byzanz." Jahrbuch für Antike und Christentum 27 (1984): 171218.

Schoenwetter, James, and Patrick Scott-Geyer. "Implications of Archaeological Palynology, at Bethsaida, Israel.” Journal of field archaeology 27, no. 1 (2000): 63-73.

Schuler, Mark. "Oĩ at Antiochia Hippos." In Between Sea and Desert: On Kings, Nomads, Cities and Monks, Essays in Honor of Joseph Patrich, edited by Jacob Ashkenazi Orit Peleg-Barkat Uzi Leibner, Mordechai Aviam, Rina Talgam, 75-85. Jerusalem: Kinneret Academic College and Ostracon, Tzemach, 2019. 
Schumacher, Gottlieb. “Beschreibung Des Dscholan.” Zeitschrift d. Deutschen Palastine-Veriens 9 (1886): 267-268.

Segal, Arthur, Michael Eisenberg, Jolanta Młynarczyk, Mariusz Burdajewicz, and Mark T Schuler. Hippos-Sussita of the Decapolis: The First Twelve Seasons of Excavations (2000-2011) Vol 1. Haifa, Israel: The Zinman Inst of Archaeology, 2013.

Segal, Arthur, Jolanta Mlynarczyk, Mariusz Burdajewicz, Mark Schuler, and Michael Eisenberg. Hippos-Sussita : Eighth Season of Excavations : July 2007. Haifa: Zinman Institute of Archaeology, University of Haifa, 2007.

---. Hippos-Sussita : Fifth Season of Excavations : September-October 2004 ; and Summary of All Five Seasons : 2000-2004. Haifa, Israel: Zinman Institute of Archaeology, University of Haifa, 2004.

---. Hippos-Sussita: Fourth Season of Excavations : June-July 2003. Haifa: Zinman Institute of Archaeology, University of Haifa, 2003.

---. Hippos-Sussita: Ninth Season of Excavations : June-July 2008. 1 vols. Haifa: Zinman Institute of Archaeology, University of Haifa, 2008.

-- - Hippos-Sussita : Seventh Season of Excavations : July 2006. Haifa: Zinman Institute of Archaeology, University of Haifa, 2006.

---. Hippos-Sussita : Tenth Season of Excavations : July and September 2009. Haifa, Israel: Zinman Institute of Archaeology, University of Haifa, 2009.

Segal, Arthur, Mark Schuler, and Michael Eisenberg. Hippos-Sussita : eleventh season of excavations : July 2010. Haifa: University of Haifa, 2010.

Sheridan, Susan Guise. "Biocultural Reconstruction of Byzantine St. Stephen's.” ASOR Newsletter 50.1 (2000): 14.

---. "Sex Determination.” Byzantine St. Stephens: A Biocultural Reconstruction of Urban Monastic Life. Accessed June 7, 2021. https://www3.nd.edu/ stephens/sex.html.

---. "Statue Reconstruction." Byzantine St. Stephens: A Biocultural Reconstruction of Urban Monastic Life. Accessed June 7, 2021. https://www3.nd.edu/ stephens/sex.html.

Sion, Ofer, and 'Abd al-Salam Sa'id. "A Mansion House from the Late Byzantine-Umayyad Period in Beth Shean-Scythopolis.” Liber Annuus 52 (2002): 353-366.

Sperber, Daniel. The City in Roman Palestine. New York: Oxford University Press, 1998.

Spier, Jeffrey. “Belt Tabs and Healing Amulet,” July 18, 2005. 
Spijkerman, Augustus. The Coins of the Decapolis and Provincia Arabia. Studii biblici franciscani collectio maior 25. Jerusalem : Franciscan Printing Press, 1978.

St. Clair, Archer. Carving as Craft: Palatine East and the Greco-Roman Bone and Ivory Carving Tradition. Baltimore: Johns Hopkins University Press, 2003.

Staab, Gregor, and Michael Eisenberg. "Building Inscriptions from the Martyrion of Theodoros at the 'Burnt Church' in Hippos above the Sea of Galilee.” Zeitschrift für Papyrologie und Epigraphik 2014 (2020): 203-214.

Stager, Lawrence E. “The Archaeology of the Family in Ancient Israel.” Bulletin of the American Schools of Oriental Research 260 (1985): 1-35.

Stansbury-O'Donnell, Mark. "Reflections of the Tyche of Antioch in Literary Sources and on Coins." In An Obsession with Fortune: Tyche in Greek and Roman Art, edited by Susan B. Matheson and J. J. Pollitt, 50-63. Yale University Art Gallery Bulletin 1994. New Haven, Conn: Yale University Art Gallery, 1994.

Stewart, Columba. Cassian the Monk. Oxford studies in historical theology. New York: Oxford University Press, 1998.

Supplementum Epigraphicum Graecum. Alphen aan den Rijn, the Netherlands: Sijthoff \& Noordhoff, $1923 \mathrm{ff}$.

Syon, Danny. “Bet She'an.” Hadashot Arkheologiyot: Excavations and Surveys in Israel 116 (2004): 12-16.

Taft, Robert F. The Great Entrance: A History of the Transfer of Gifts and Other Pre-Anaphoral Rites. 2nd ed. Orientalia Christiana analecta 200. Roma: Pontificium Institutum Studiorum Orientalium, 1978.

Taha, Hamdan. “A Byzantine Tomb at the Village of Rammun.” Liber Annuus 48 (1998): $335-344$.

Tal, Oren, Ruth E Jackson-Tal, and Ian C Freestone. "Glass from a Late Byzantine Secondary Workshop at Ramla (South), Israel.” Journal of Glass Studies 50 (2008): 81-95.

---. "New Evidence of the Production of Raw Glass at Late Byzantine Apollonia-Arsuf, Israel.” Journal of Glass Studies 46 (2004): 51-66.

Talbot, Alice-Mary. "Pilgrimage to Healing Shrines: The Evidence of Miracle Accounts." Dumbarton Oaks Papers 56 (2002): 153-173. 
Tatian. Oratio Ad Graecos.

Taxel, Itamar. "Late Antique Ionic Column Capitals in the Countryside of Central Palestine between Provincial Trends and Classical Traditions." Studies in Late Antiquity 2, no. 1 (2018): 84-125.

Tchalenko, Georges, E. Baccache, and Institut français d'archéologie du Proche-Orient, eds. Eglises de Village de La Syrie Du Nord. Bibliothèque archéologique et historique / Institut français d'archéologie du Proche-Orient t. 105. Paris: Librairie orientaliste P. Geuthner, 1979.

Thébert, Yvon. "Private Life and Domestic Architecture in Roman Africa." In A History of Private Life, 1: From pagan Rome to Byzantium:357-364. Cambridge: Harvard University Press, 1987.

Thee, Francis CR. Julius Africanus and the Early Christian View of Magic. Vol. 19. Mohr Siebeck, 1984.

Toth, E. “Zur Datierung Der Zwiebelknopffibeln.” Folia Archaeologica 31 (1980): 146-154.

Trombly, Frank Richard. "Destruction of Pagan Statuary and Christianization (Fourth-Sixth Century C.E.).” In The Sculptural Environment of the Roman Near East: Reflections on Culture, Ideology, and Power, edited by Yaron Z. Eliav, Elise A. Friedland, and Sharon Herbert, 143-164. Interdisciplinary studies in ancient culture and religion 9. Leuven ; Dudley, MA: Peeters, 2008.

Trümper, Monika. "Material and Social Environment of Graeco-Roman Houses in the East: The Case of Hellenistic Delos." In Early Christian Families in Context: An Interdisciplinary Dialogue, edited by David L. Balch and Carolyn Osiek, 19-43. Grand Rapids, Mich: W.B. Eerdmans Pub. Co, 2003.

Tsafrir, Yoram. "The Classical Heritage in Late Antique Palestine: The Fate of Freestanding Sculptures." In The Sculptural Environment of the Roman Near East, edited by Yaron Z. Eliav, Elise A. Friedland, and Sharon Herbert, 117-142. Lueven: Peeters, 2008.

Tsuk, Tsvika. "The Water Supply System of Shivta in the Byzantine Period." Cura Aquarum in Israel (2002): 65-80.

Tzafaris, Vassilios, E. Kessin, and D. Urman. "The Excavations of Kursi-Gergesa." Antiqot 16 (1983): I-X.

Vriezen, Karel J. H. "Churches in Urban Context in the Fifth-Eighth Centuries in Jordan and Palestine." Studies in the History and Archaeology of Jordan 8 (2004): 469-476. 
Waagé, Frederick O. “Bronze Objects from Old Corinth, Greece.” American Journal of Archaeology 39, no. 1 (1935): 79-91.

Wechsler, N, and Samuel Marco. "Historical Earthquakes in the North of Israel and Their Influence on Hippos-Sussita (Hebrew).” Michmanim 27 (2017): 35-46.

Weinberg, Gladys Davidson. “Hellenistic Glass from Tel Anafa in Upper Galilee.” Journal of Glass Studies 12 (1970): 17-27.

-_-. “Notes on Glass from Upper Galilee.” Journal of Glass Studies 15 (1973): 35-51.

Weinberg, Gladys Davidson, and Sidney M. Goldstein. “The Glass Vessels.” In Excavations at Jalame, Site of a Glass Factory in Late Roman Palestine, edited by Gladys Davidson Weinberg, 38-102. Columbia, MO: University of Missouri Press, 1988.

White, T. D., and Pieter A. Folkens. Human Osteology. San Diego: Academic Press, 1991.

Whittaker, David. “Ageing from the Dentition.” In Human Osteology in Archaeology and Forensic Science, edited by M. Cox and S. Mays, 83-99. London: Greenwich Medical Media, 2000.

Williams, Keith, September 2, 2021.

Wright, GRH. “Some Byzantine Bronze Objects from Beycesultan.” Anatolian Studies 50 (2000): 159-170.

Yasin, Ann Marie. Saints and Church Spaces in the Late Antique Mediterranean: Architecture, Cult, and Community. Greek culture in the Roman world. Cambridge, UK ; New York: Cambridge Univ Press, 2009.

Zanker, Paul. Pompeii: Public and Private Life. Revealing antiquity 11. Cambridge, Mass: Harvard University Press, 1998.

רובין, ריכב. הנגב כארץ נושבת: עיור והתיישבות במדבר בתקופה הביזנטית. ירושלים: יד יצחק בן־צבי: החברה ועריה לחקירת ארץ-ישראל ועתיקותיה, 1990. 

